\title{
Assessment of Undiscovered Copper Resources of the World, 2015
}

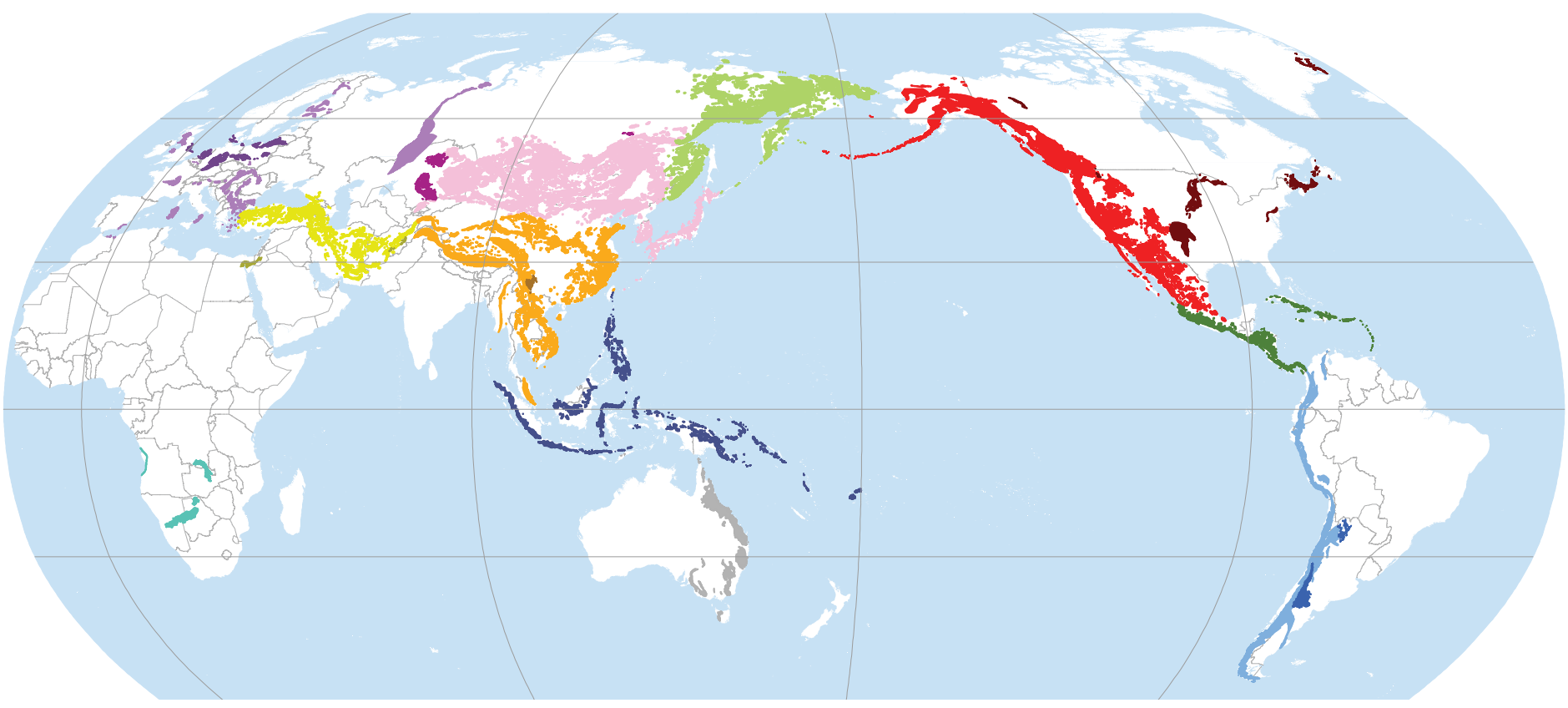

Scientific Investigations Report 2018-5160

Version 1.2, December 2021 
Cover: Map showing permissive tracts for porphyry copper and sediment-hosted stratabound copper deposits color coded by world region. For more information, see chapter A, figure A3. 


\section{Assessment of Undiscovered Copper Resources of the World, 2015}

By Jane M. Hammarstrom, Michael L. Zientek, Heather L. Parks, Connie L. Dicken, and the U.S. Geological Survey Global Copper

Mineral Resource Assessment Team

Scientific Investigations Report 2018-5160

Version 1.2, December 2021 


\title{
U.S. Department of the Interior \\ DAVID BERNHARDT, Secretary
}

\author{
U.S. Geological Survey \\ James F. Reilly II, Director
}

\author{
U.S. Geological Survey, Reston, Virginia \\ First release: May 10, 2019, online \\ Revised: May 24, 2019 (ver. 1.1), online and in print \\ Revised: December 2021 (ver. 1.2), online
}

For more information on the USGS - the Federal source for science about the Earth, its natural and living resources, natural hazards, and the environment—visit https://www.usgs.gov or call 1-888-ASK-USGS (1-888-275-8747).

For an overview of USGS information products, including maps, imagery, and publications,

visit https://store.usgs.gov.

\begin{abstract}
Any use of trade, firm, or product names is for descriptive purposes only and does not imply endorsement by the U.S. Government.

Although this information product, for the most part, is in the public domain, it also may contain copyrighted materials as noted in the text. Permission to reproduce copyrighted items must be secured from the copyright owner.
\end{abstract}

Suggested citation:

Hammarstrom, J.M., Zientek, M.L., Parks, H.L., Dicken, C.L., and the U.S. Geological Survey Global Copper Mineral Resource Assessment Team, 2019, Assessment of undiscovered copper resources of the world, 2015 (ver. 1.2, December 2021): U.S. Geological Survey Scientific Investigations Report 2018-5160, 619 p. (including 3 chap., 3 app., glossary, and atlas of 236 page-size pls.), https://doi.org/10.3133/sir20185160. 


\section{Preface}

Most of the world's population relies on copper. The physical and chemical qualities of copper make it the material of choice for a variety of industrial and high-technology applications.

Copper is used in building construction, power generation and transmission, electronic product manufacturing, and the production of industrial machinery. Copper wiring and plumbing are integral to appliances, heating and cooling systems, and telecommunications links used every day in homes and businesses. It is an essential component in cars and trucks, mobile phones, renewable energy systems, and green technologies.

As global population rises and more countries improve standards of living, demand for copper increases. The U.S. Geological Survey led a cooperative international study from 2002 to 2012 to address questions about the global distribution of current and potential future copper supplies. This first-ever global assessment of undiscovered copper resources used a geology-based methodology to assess undiscovered copper resources in the two types of mineral deposits that provide more than 70 percent of mined copper: porphyry copper deposits and sediment-hosted stratabound copper deposits. This report presents assessment results (1) in chapters including tables summarizing how much copper is estimated to be contained in undiscovered deposits and (2) in an atlas of 2-page plates presenting summary results, graphs, and maps that show where copper deposits are known to exist and where undiscovered copper resources may exist.

Chapter A summarizes the methods used in the assessment, reports the results, and explains the format of the 236 plates that compose the atlas. Chapter B provides detailed technical information on the assessment of undiscovered copper resources associated with porphyry copper deposits. The application of a simple economic filter to undiscovered mineral resource assessment results is reported for the first time in this chapter. The economic filter indicates how much undiscovered copper is likely to be economic in the reasonably foreseeable future. Chapter $C$ describes varieties of sediment-hosted stratabound copper deposits, explains approaches used for their assessment, and summarizes assessment results. The data summarized in this report are derived from a series of regional and topical publications that are available online at https://minerals.usgs.gov/global/. 


\section{Acknowledgments}

The cooperation and contributions of many individuals and institutions throughout the world made it possible to complete this first-ever global assessment of undiscovered copper resources (see appendix 1 of this volume). As Program Coordinator of the U.S. Geological Survey (USGS) Mineral Resources Program, Kathleen M. Johnson formulated the idea for the project, provided unwavering support for it throughout her tenure, and saw the project to completion as a series editor after she retired. We thank her successor, Larry Meinert, and Associate Program Coordinator Jeff Doebrich for their continued support and enthusiasm for this massive undertaking. USGS colleagues Klaus Schulz and Joseph Briskey provided leadership and established contacts with international collaborators during the first years of the project. The staff of the USGS Office of International Programs provided invaluable assistance and logistical support.

The authors of this summary report are grateful for helpful and constructive technical reviews provided by USGS colleagues Jeff Doebrich and Sharon Swanson. Ruth Schulte of the USGS and student interns Shyla A. Hatch, Cassandra Hennings, and M. Christopher Jenkins of Eastern Washington University, Cheney, Wash., assisted with figures for the text and plates in this report. The USGS Science Publishing Network staff guided publication of the global assessment products. We are especially grateful to Carolyn Donlin, Sarah Nagorsen, Jim Hendley, and Peter Stauffer in Menlo Park, Calif., and Kate Schindler, Elizabeth Good, D. Paul Mathieux, and Jeannette Foltz in Reston, Va. We appreciate the support of Bruce Taggart, USGS Bureau Approving Official. We also thank Dave Frank (USGS) for creating and maintaining the global mineral resource assessment project's website. 


\section{Contents}

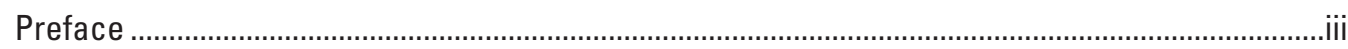

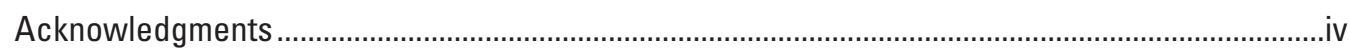

Abstract-Assessment of Undiscovered Copper Resources of the World, 2015............................1

Chapter A. Assessment of Undiscovered Copper Resources of the World, 2015-

Summary of Methods and Results ................................................................................

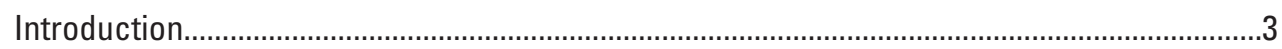

Types of Copper Deposits—Why Does It Matter? ..............................................................

Porphyry Copper Deposits ..........................................................................................

Sediment-Hosted Stratabound Copper Deposits ............................................................7

Mineral Resources_-Identified Versus Undiscovered ..........................................................

Deposits Versus Prospects ...................................................................................................

Assessment Methods—An Overview .............................................................................

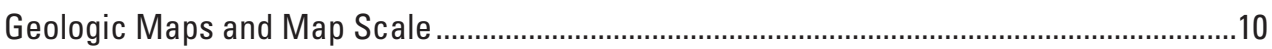

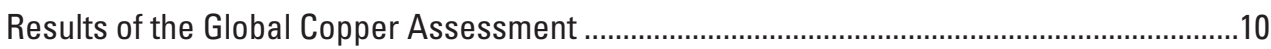

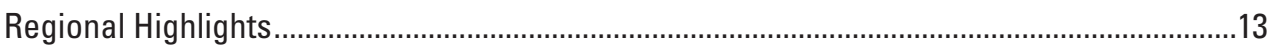

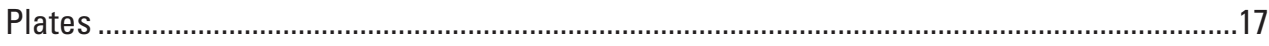

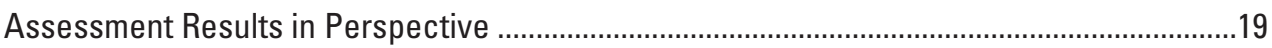

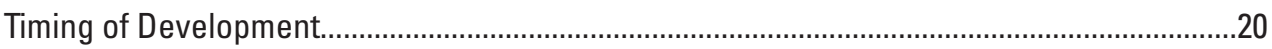

Will We Face a Copper Supply Crisis in the 21st Century? ......................................................22

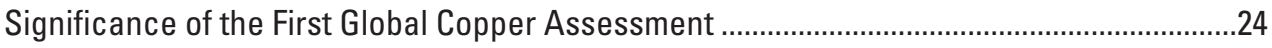

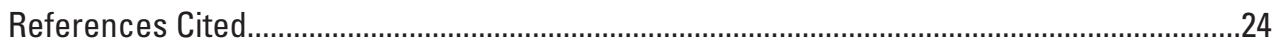

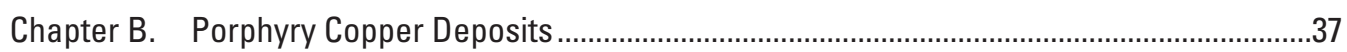

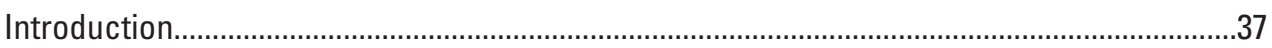

Formation of Porphyry Copper Deposits .....................................................................38

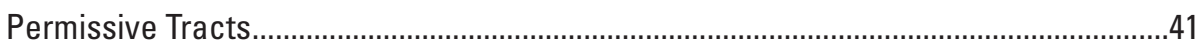

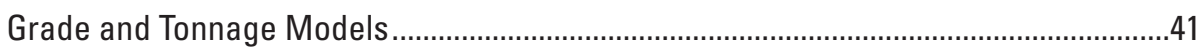

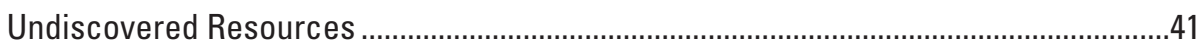

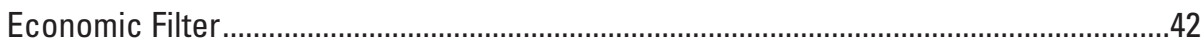

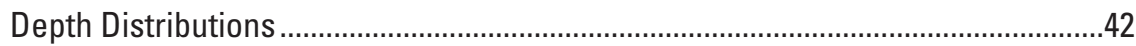

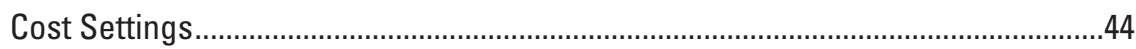

Understanding the Results .............................................................................................4

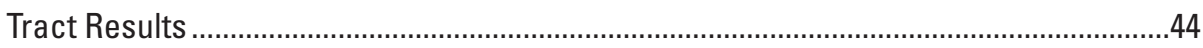

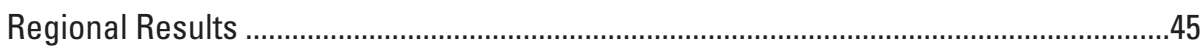

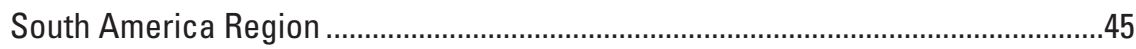

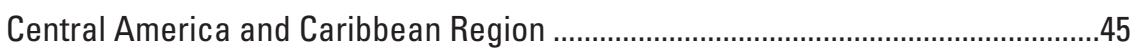

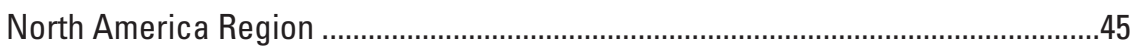

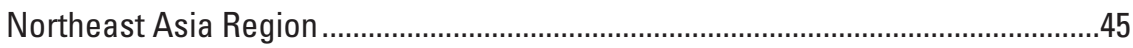

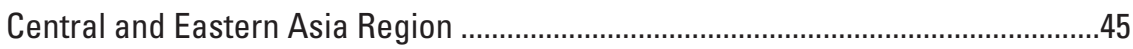

Southeast Asia Region .......................................................................................46

Southeast Asia Archipelagos Region....................................................................46

Eastern Australia Region .......................................................................................

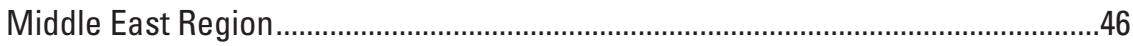

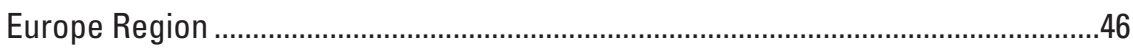

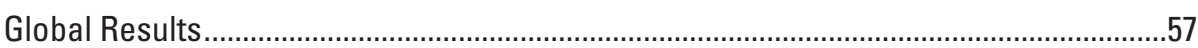




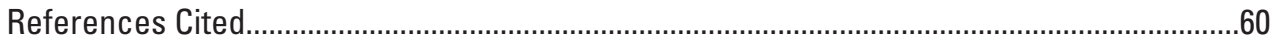

Chapter C. Sediment-Hosted Stratabound Copper Deposits .....................................................79

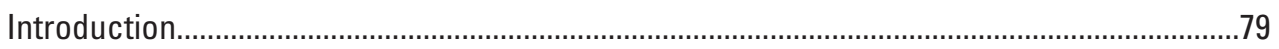

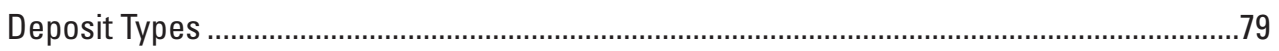

Deposit Type Assessed —Sediment-Hosted Stratabound Copper Deposits ............................79

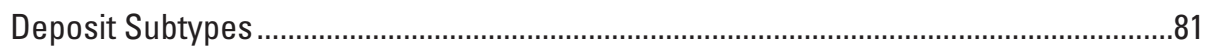

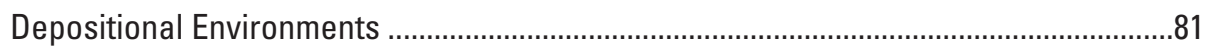

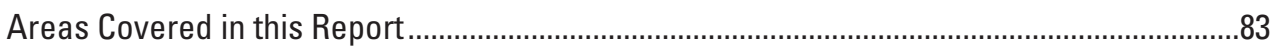

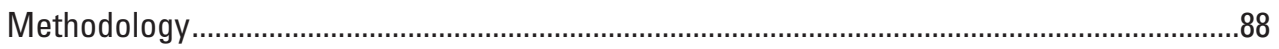

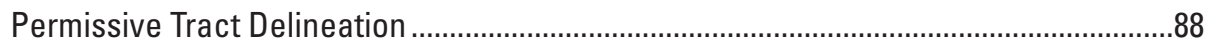

Probabilistic Estimation ...................................................................................... 89

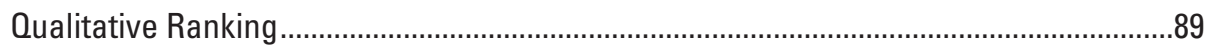

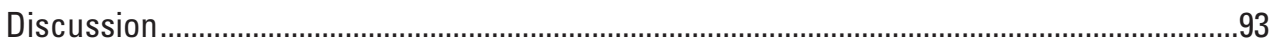

The "Look" of Permissive Tracts on Maps ……..........................................................93

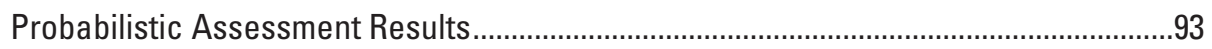

Qualitative Assessment Results .............................................................................97

Lessons Learned and Future Research Opportunities .....................................................97

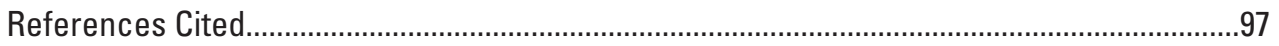

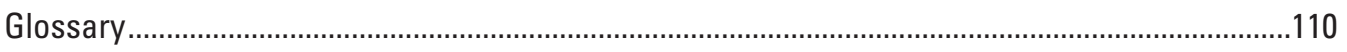

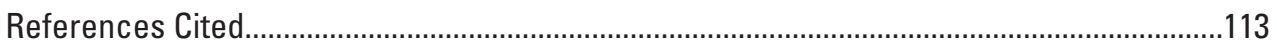

Appendix 1. Individuals and Institutions Who Contributed to the Studies

Summarized in this Volume, the "Assessment of Undiscovered Copper

Resources of the World, 2015".

U.S. Geological Survey Scientists and Contractors $\left(^{*}\right)$ on the U.S. Geological

Survey Global Copper Mineral Resource Assessment Team ......................................116

Scientific Collaborators ...............................................................................................117

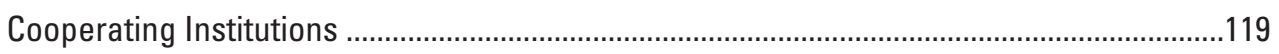

Appendix 2. Mineral Resource Assessment Methods and Procedures Used in

the U.S. Geological Survey Global Mineral Resource Assessment ...................................121

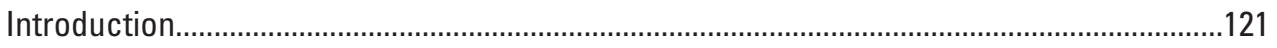

Technical Language and the Assessment Process .........................................................121

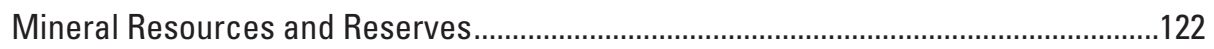

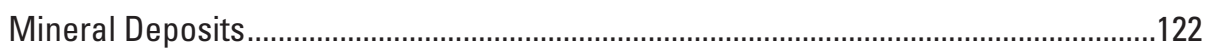

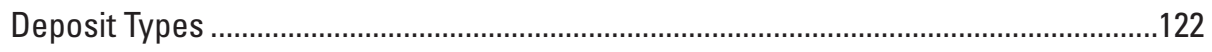

Undiscovered Mineral Resources and Mineral Deposits...............................................123

Assessment Methodology—Parts and Procedures ...........................................................123

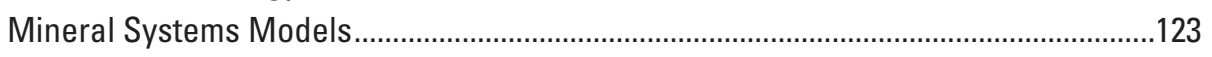

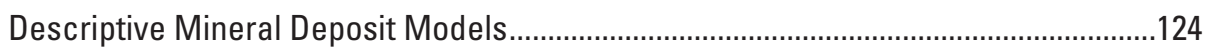

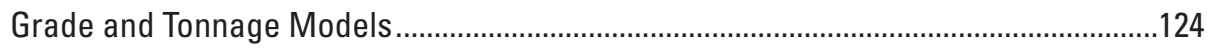

Assessing Location (Mineral Resource Potential Maps) ............................................125

Assessing Probable Amounts of Undiscovered Metal.................................................125

Estimating Undiscovered Resources by Estimating Numbers of

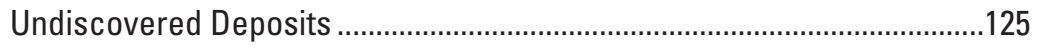

Number of Undiscovered Deposits................................................................125

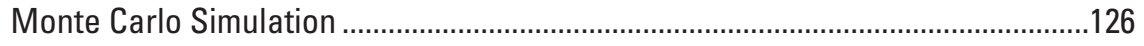

Estimating Undiscovered Resources Using Geostatistical Methods ...................126 
Metal Surface Density .................................................................................126

Interpolation and Simulation Techniques ....................................................127

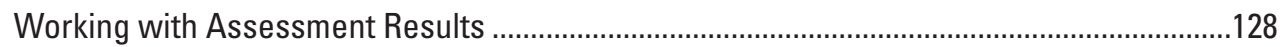

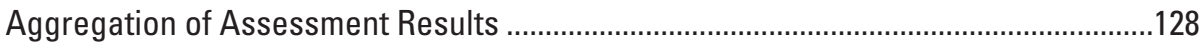

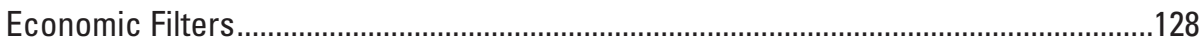

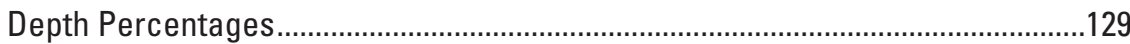

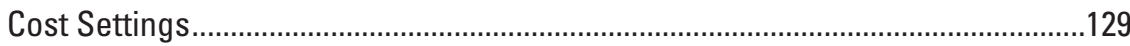

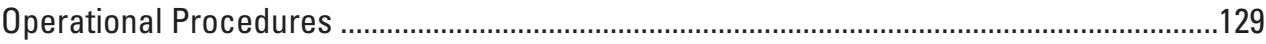

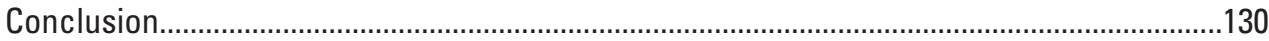

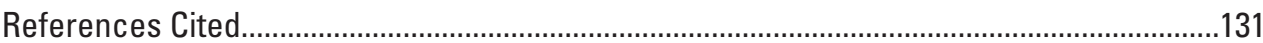

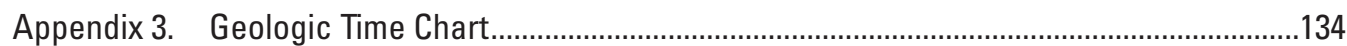

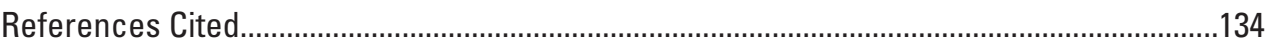

\section{Plates}

[Plates 1-236 follow appendix 3]

1-188. Porphyry copper assessment for-

1. Tract 005pCu1020, Cretaceous Turbio-Chile and Argentina............................138

2. Tract 005pCu1019, Late Triassic to Middle Jurassic Bajo de la Leona-

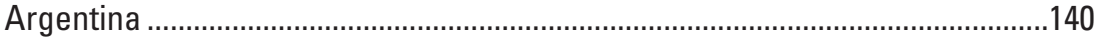

3. Tract 005pCu1013d, Miocene Coastal—Chile and Argentina............................142

4. Tract 005pCu1015, Late Cretaceous-Middle Eocene Campana Mahuida_Argentina and Chile .......................................................................144

5. Tract 005pCu1014b, Miocene-Pliocene El Teniente-Chile ...............................146

6. Tract 005pCu1013b, Miocene-Pliocene Los Pelambres-Argentina

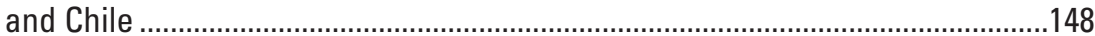

7. Tract 005pCu1016ab, Permian San Jorge-Argentina and Chile .....................150

8. Tract 005pCu1014a, Miocene Paramillos_-Argentina ……………....................152

9. Tract 005pCu1012, Eocene-Oligocene La Fortuna-Chile and Argentina ........154

10. Tract 005pCu1013c, Miocene-Pliocene-Argentina and Chile .......................156

11. Tract 005pCu1014d, Miocene-Pliocene Nevados de Famatina-

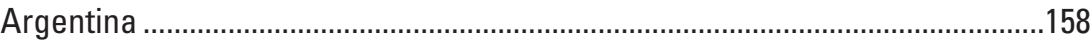

12. Tract 005pCu1017, Cretaceous Antucoya-Chile ..............................................160

13. Tract 005pCu1008, Paleocene-Eocene Toquepala-Chile and Peru ................162

14. Tract 005pCu1013a, Miocene-Pliocene Cerro Casale-Argentina

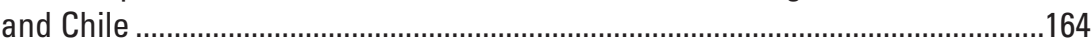

15. Tract 005pCu1014c, Miocene-Pliocene Bajo de la Alumbrera-

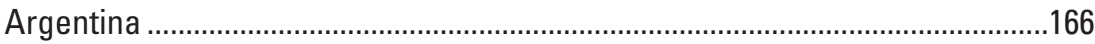

16. Tract 005pCu1011, Eocene-Oligocene Taca Taca Bajo—Argentina...................168

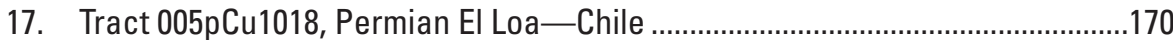

18. Tract 005pCu1010ab, Eocene-Oligocene Chuquicamata_Chile .......................172

19. Tract 005pCu1009, Eocene-Oligocene Antapaccay-Peru................................174

20. Tract 005pCu1007, Cretaceous Almacen—Peru and Ecuador ...........................176

21. Tract 005pCu1006, Miocene La Granja_Peru and Ecuador................................178

22. Tract 005pCu1005, Miocene Chaucha-Colombia and Ecuador .......................180 
23. Tract 005pCu1003, Jurassic San Carlos_Colombia, Ecuador, and Peru ..........182

24. Tract 005pCu1001, Paleocene-Eocene Acandi-Colombia, Ecuador,

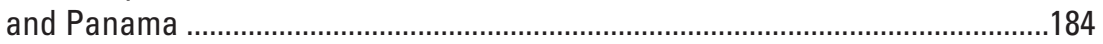

25. Tract 005pCu1004, Cretaceous Infierno-Chilí-Colombia .................................186

26. Tract 005pCu1002, Jurassic California—Colombia and Venezuela ....................188

27. Tract 003pCu4002, Darién Region—Panama .................................................190

28. Tract 003pCu4004, Cocos Region—Central America .........................................192

29. Tract 003pCu4003, Chortis Region —Central America.......................................194

30. Tract 003pCu4005, Lesser Antilles_Caribbean Basin........................................196

31. Tract 003pCu4001, Santiago Region—Caribbean Basin .....................................198

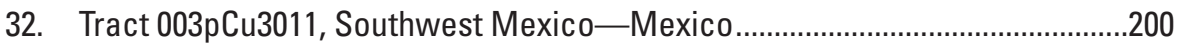

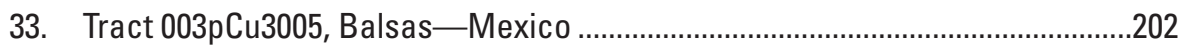

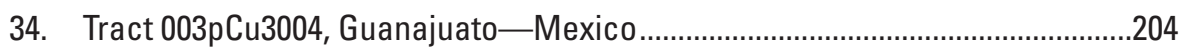

35. Tract 003pCu3002, Coastal Baja California-Mexico.........................................206

36. Tract 003pCu3007x, Western Sierra Madre 0ccidental and Laramide

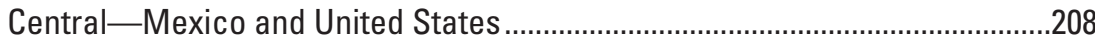

37. Tract 003pCu3008, Laramide Central Plateau—Mexico .....................................210

38. Tract 003pCu3009x, Tertiary Central Plateau and Rocky MountainsMexico and United States ............................................................................212

39. Tract 003pCu3010x, Eastern Alkalic Province-Mexico and United States .....214

40. Tract 003pCu3001x, Southern California Batholith—Mexico and United States

41. Tract 003pCu3006x, Western Mexican Basin and Range and Laramide Southwest-Mexico and United States.............................................................218

42. Tract 003pCu9008, Southwest Laramide East—United States ...........................220

43. Tract 003pCu9006x, Western U.S. and Sonoran Desert Jurassic Arc-

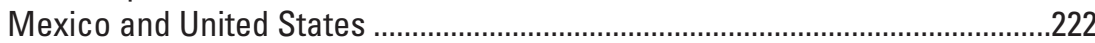

44. Tract 003pCu9007, Sierran Arc_United States .............................................224

45. Tract 003pCu9013, Great Basin Tertiary—United States...................................226

46. Tract 003pCu9014, Cascade Arc—United States.............................................228

47. Tract 003pCu9004, Northern Rocky Mountains_-United States ........................230

48. Tract 003pCu2003, Insular Island and Continental Arcs-British Columbia and Yukon Territory, Canada..

49. Tract 003pCu2002x, Intermontane Island Arc Cu-Au, Western Cordillera-Canada and United States

50. Tract 003pCu2004x, Cordilleran Continental Arc, Western CordilleraCanada and United States

51. Tract 003pCu2001x, Intermontane Island Arc, Western CordilleraCanada and United States

52. Tract 003pCu2005, Late Continental Arc-British Columbia and Yukon Territory, Canada

53. Tract 003pCu5005, Southeast Alaska Tertiary—Alaska, United States .............242

54. Tract 003pCu5001, Skolai Arc-Eastern Alaska, United States ........................244

55. Tract 003pCu5002, Eastern Alaska Range and Wrangell MountainsAlaska, United States

56. Tract 003pCu5003, Yukon-Tanana Upland-Alaska, United States ...................248

57. Tract 003pCu5004, Western Alaska Range-Alaska, United States .................250 
58. Tract 003pCu5006, Alaska Peninsula and Aleutian IslandsAlaska, United States 252

59. Tract 003pCu5007, Koyukuk Arc-Alaska, United States....................................254

60. Tract 003pCu5008, Brooks Range_-Alaska, United States .................................256

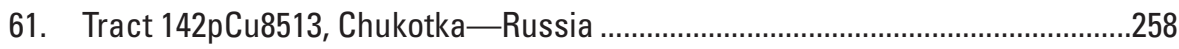

62. Tract 142pCu8514, Pacific Margin-Russia and China.........................................260

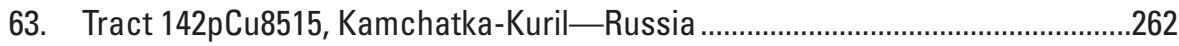

64. Tract 142pCu8510, Kedon-Russia..................................................................264

65. Tract 142pCu8512, Kolyma-Russia....................................................................266

66. Tract 142pCu7315, Subaerial Neogene Arcs of Western Japan-Japan ........268

67. Tract 142pCu7314, Western Honshu Area-Japan ..............................................270

68. Tract 142pCu7313, Gyeongsang Basin-South Korea ........................................272

69. Tract 142pCu8509, Manchuride_China, North Korea, Mongolia,

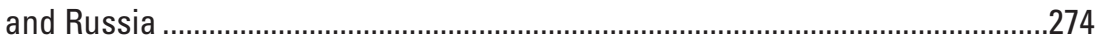

70. Tract 142pCu8503, Gobi-Amur-Mongolia, China, and Russia.............................276

71. Tract 142pCu8508b, Erdenet (Northeast) — Russia ............................................278

72. Tract 142pCu8507, Mongol-Altai-Mongolia, Russia, Kazakhstan,

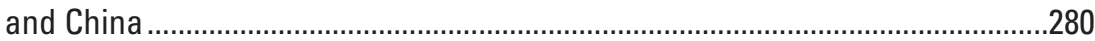

73. Tract 142pCu8504, Mongol-Sayan-Mongolia, China, and Russia ....................282

74. Tract 142pCu8508a, Erdenet-Mongolia............................................................284

75. Tract 142pCu8506, Oyu Tolgoi-China and Mongolia .........................................286

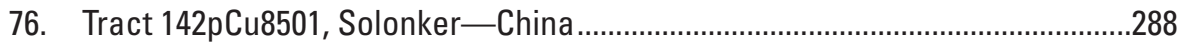

77. Tract 142pCu8505, Kazakh-Tarim-Kazakhstan and China ...............................290

78. Tract 142pCu8502, Kazakh-Tianshan-Kazakhstan and China............................292

79. Tract 142pCu8003a, Late Paleozoic Balkhash-Ili Magmatic Arc (East)—

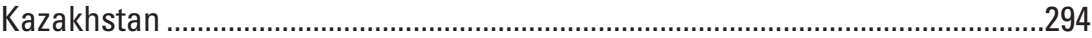

80. Tract 142pCu8003b, Late Paleozoic Balkhash-Ili Magmatic Arc (North)—

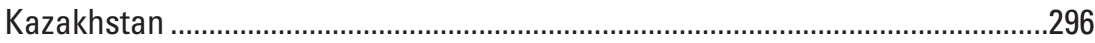

81. Tract 142pCu8004, Late Paleozoic Central Balkhash-Ili Magmatic ArcKazakhstan .298

82. Tract 142pCu8003d, Late Paleozoic Balkhash-Ili Magmatic Arc (Northwest) - Kazakhstan and Kyrgyzstan. 300

83. Tract 142pCu8003c, Late Paleozoic Balkhash-Ili Magmatic Arc (West) -

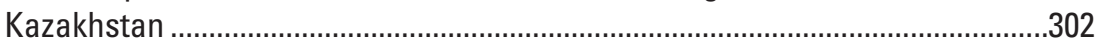

84. Tract 142pCu8002, Ordovician North Tian Shan Magmatic ArcKazakhstan and Kyrgyzstan.

85. Tract 142pCu8001, Chatkal and Kurama Ranges-Kazakhstan, Kyrgyzstan, Tajikistan, and Uzbekistan...............................................................306

86. Tract 142pCu8704, Coastal Pacific_China, Taiwan, and Vietnam .....................308

87. Tract 142pCu8705, East Qinling-China................................................................310

88. Tract 142pCu8701, Qinling-Dabie-China and Tajikistan.....................................312

89. Tract 142pCu8706, Tethyan Gangdese-China, India, and Pakistan ..................314

90. Tract 142pCu8712, Gangdese-China................................................................316

91. Tract 142pCu8702, Jinsajiang —China .................................................................318

92. Tract 142pCu8710, Yulong —China......................................................................320

93. Tract 142pCu8711, Dali-China and Vietnam ......................................................322

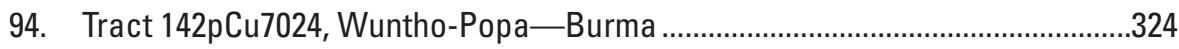


95. Tract 142pCu7021, Sukhothai-Cambodia, China, Laos, Burma,

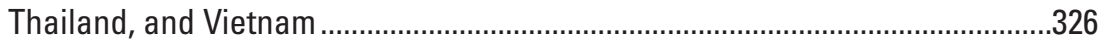

96. Tract 142pCu7023, Mekong Delta-Cambodia, Laos, and Vietnam.....................328

97. Tract 142pCu7022, Malaysia-Indonesia, Malaysia, Singapore, and Thailand ......................................................................................................3

98. Tract 142pCu7301abcd, Luzon Arc_-Philippines and Taiwan..............................332

99. Tract 142pCu7304ab, Sierra Madre Arc_-Philippines .......................................338

100. Tract 142pCu7302, Cordon Alkalic Complex —Philippines..................................342

101. Tract 142pCu7309, Philippine Arc_-Philippines ..................................................344

102. Tract 142pCu7311, Mindoro-Tablas-West Panay Area-Philippines .................346

103. Tract 142pCu7305, Masbate-Negros Arc System_-Philippines..........................348

104. Tract 142pCu7306, Bohol-Cebu Area-Philippines ..............................................350

105. Tract 142pCu7307, Sulu-Zamboanga Arc_-Philippines ........................................352

106. Tract 142pCu7308, Central Mindanao Volcanic Province-Philippines ............354

107. Tract 142pCu7312, Cotabato Arc_-Philippines.....................................................356

108. Tract 142pCu7019, Central Kalimantan_-Indonesia and Malaysia.....................358

109. Tract 142pCu7020, Sumatra Island_-Indonesia ..................................................360

110. Tract 142pCu7025a, Sunda Banda Arc (West) —Indonesia ..................................362

111. Tract 142pCu7025b, Sunda Banda Arc (Central) —Indonesia...............................364

112. Tract 142pCu7025c, Sunda Banda Arc (East) _-Indonesia .................................366

113. Tract 142pCu7026, West Sulawesi-Indonesia ..................................................368

114. Tract 142pCu7027, North Sulawesi-Sangihe-Indonesia ...................................370

115. Tract 142pCu7202, Halmahera Arc, North Molucca Islands_-Indonesia..........372

116. Tract 142pCu7201, Ambon Arc, Central Molucca Islands_-Indonesia ..............374

117. Tract 142pCu7208, Inner Melanesian Arc Terranes I_Indonesia .......................376

118. Tract 142pCu7205, Moon-Utawa-Ular Merah Areas_-Indonesia........................378

119. Tract 142pCu7203, Western Medial New Guinea Magmatic BeltIndonesia .380

120. Tract 142pCu7204, Rotanburg-Taratatua Area-Indonesia and Papua New Guinea 382

121. Tract 009pCu7203a, Eastern Medial New Guinea Magmatic Belt (West)_Papua New Guinea and Indonesia .384

122. Tract 009pCu7203b, Eastern Medial New Guinea Magmatic Belt (East)_Papua New Guinea 386

123. Tract 009pCu7208, Inner Melanesian Arc Terranes IIPapua New Guinea and Indonesia... 388

124. Tract 009pCu7205, Maramuni Arc_Papua New Guinea .....................................390

125. Tract 009pCu7206, Miocene Alkalic Rocks, Southeastern New Guinea Island-Papua New Guinea.

126. Tract 009pCu7209, Inner Melanesian Arc (New Britain)Papua New Guinea

127. Tract 009pCu7207, Outer Melanesian Arc I-Papua New Guinea .....................396

128. Tract 009pCu7210, Outer Melanesian Arc-Solomon Islands, Vanuatu, and Fiji .398

129. Tract 009pCu8004d, East Tasmanide (North)_Australia.....................................400

130. Tract 009pCu8004b, East Tasmanide (Central)—Australia ...................................402

131. Tract 009pCu8004a, East Tasmanide (Island Arc)—Australia .............................404 
132. Tract 009pCu8004c, East Tasmanide (South)—Australia ......................................406

133. Tract 009pCu8002, Macquarie-Australia ...........................................................408

134. Tract 009pCu8003, Yeoval-Australia ................................................................ 410

135. Tract 009pCu8001b, Delamerian (Victoria)—Australia ........................................412

136. Tract 009pCu8001c, Delamerian (Tasmania)—Australia .....................................414

137. Tract 009pCu8001a, Delamerian (Adelaide)—Australia ........................................416

138. Tract 142pCu8901, Darra Alasang_Afghanistan ..............................................418

139. Tract 142pCu8902, Kundalyan—Afghanistan ..................................................420

140. Tract 142pCu8903, Oruzgan—Afghanistan ..................................................422

141. Tract 142pCu8904, Spin Boldak_Afghanistan and Pakistan ...........................424

142. Tract 142pCu9013, Chagai-Afghanistan, Pakistan, and Iran ..........................426

143. Tract 142pCu9017c, Pliocene-Quaternary (Bazman)—Afghanistan, Pakistan, and Iran ...........................................................................................428

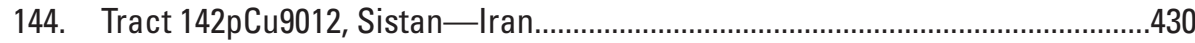

145. Tract 142pCu9010, Lut Tertiary—Iran.............................................................432

146. Tract 142pCu9000, Lut Jurassic —Iran ............................................................434

147. Tract 142pCu9006, Lut Cretaceous_-Iran.............................................................436

148. Tract 142pCu9011, Makran—Iran..................................................................438

149. Tract 142pCu9009, Khorasan—Afghanistan and Iran ........................................440

150. Tract 142pCu9016, Kerman_Iran ....................................................................442

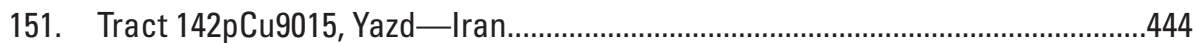

152. Tract 142pCu9008, Esfahan —Iran, Iraq, and Turkey ………..............................446

153. Tract 142pCu9014c, Azerbaijan (Caucasus) —Iran, Azerbaijan, and

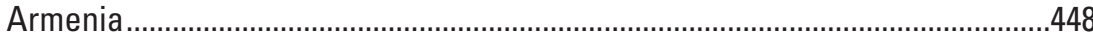

154. Tract 142pCu9003, Sanandaj-Sirjan—Iran, Iraq, and Turkey...........................450

155. Tract 142pCu9004c, Pontide (Asia)-Caucasus-Iran, Azerbaijan,

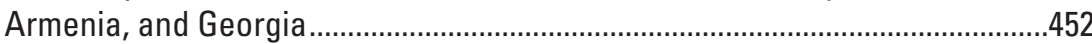

156. Tract 142pCu9001, Cimmeride Lesser Caucasus-Armenia,

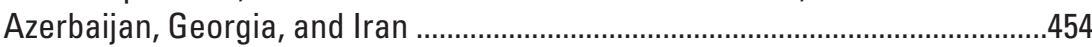

157. Tract 142pCu9002, Cimmeride Greater Caucasus-Azerbaijan, Georgia, and Russia

158. Tract 142pCu9017b, Pliocene-Quaternary (Postcollisional)Iran, Armenia, Azerbaijan, Georgia, Turkey, and Russia ...................................458

159. Tract 142pCu9007, Border Folds_-Iran, Iraq, and Turkey.................................460

160. Tract 142pCu9004b, Pontide (Asia, Northeastern) - Turkey and Georgia..........462

161. Tract 142pCu9014b, Azerbaijan (East) —Turkey .................................................464

162. Tract 142pCu9005c, Anatolide-Tauride (Eastern Turkey-Caucasus)Iran, Azerbaijan, Armenia, and Turkey..............................................................466

163. Tract 142pCu9005b, Anatolide-Tauride (Central) —Turkey ................................468

164. Tract 142pCu9017a, Pliocene-Quaternary (Konya) - Turkey................................470

165. Tract 142pCu9004a, Pontide (Asia, Northwestern) - Turkey...............................472

166. Tract 142pCu9005a, Anatolide-Tauride (West)—Turkey....................................474

167. Tract 142pCu9014a, Azerbaijan (West)—Turkey..................................................476

168. Tract 150pCu6001, Transylvania-Balkan Mountains-Bulgaria,

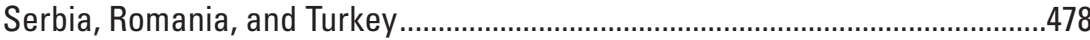

169. Tract 150pCu6003, Apuseni Mountains_-Romania .............................................480 
170. Tract 150pCu6004, Northern Carpathians-Hungary, Romania, Slovakia, and Ukraine .482

171. Tract 150pCu6002, Dinaride-Aegean Region-Eastern Europe …….................484

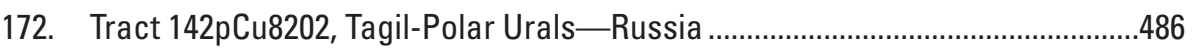

173. Tract 142pCu8201, Magnitogorsk—Russia and Kazakhstan..............................488

174. Tract 142pCu8203, East Uralian—Russia and Kazakhstan...............................490

175. Tract 142pCu8204, Transuralian—Kazakhstan and Russia .................................492

176. Tract 150pCu6006, Southern and Central European VariscanFrance, Italy, and Poland..............................................................................494

177. Tract 150pCu6005, Western Peri-Mediterranean RegionItaly, Morocco, Algeria, and Spain ..................................................................496

178. Tract 150pCu6007, Western European Caledonian-Belgium and United Kingdom .498

179. Tract 150pCu6108, Southern Ostrobothnia—Finland ........................................500

180. Tract 150pCu6104, Häme-Finland..............................................................502

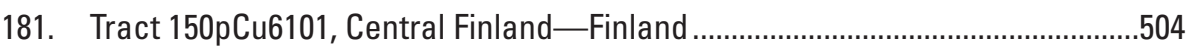

182. Tract 150pCu6105, Mäntsälä_Finland .............................................................506

183. Tract 150pCu6107, Ruokolahti-Finland .........................................................50

184. Tract 150pCu6110, Tampere-Finland ………….........................................

185. Tract 150pCu6109, Southern Savo—Finland...................................................512

186. Tract 150pCu6102, Central Ostrobothnia_Finland............................................514

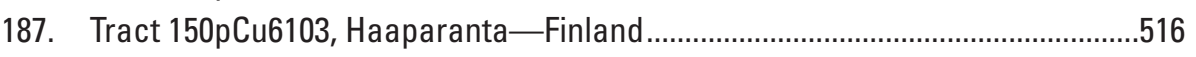

188. Tract 150pCu6106, Nilipää_Finland ..................................................................

189-236. Sediment-hosted stratabound copper assessment for-

189. Tract 005ssCu5100, Neuquén Basin—Argentina and Chile ................................522

190. Tract 005rfCu5101, Salta Rift System —Argentina ..........................................524

191. Tract 003rfnbCu3002, Great Plains (GP04), Anadarko-Palo Duro-Midland Permian Basin-United States.

192. Tract 003rfnbCu3003, Lake Superior (LS07), Midcontinent Rift-

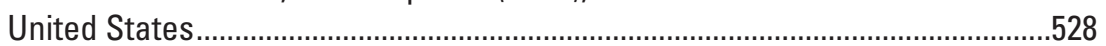

193. Tract 003ssCu3100, Belt-Purcell Basin—United States and Canada.................530

194. Tract 003rfCu3000, Redstone Copperbelt-Canada .........................................534

195. Tract 003rfnbCu3004, Southern Appalachian Mountains (SA18), Culpeper Basin—United States.......................................................................536

196. Tract 003shCu1000, Maritimes Basin—Canada...............................................538

197. Tract 003rfnbCu0004, Ravnefjeld Formation (CE 2 and CE 4-15), Central European Basin System—Greenland ...................................................540

198. Tract 003rfnbCu0001, Pingel Dal Beds (CE 1B), Jameson Land BasinGreenland

199. Tract 003rfnbCu0005, Pingel Dal Beds (CE 1A), Jameson Land BasinGreenland

200. Tract 003ssCu0001, Huledal Formation (CE 15), Jameson Land BasinGreenland

201. Tract 003ssCu0002, Huledal Formation (CE 13-14), Jameson Land BasinGreenland

202. Tract 003ssCu0003, Huledal Formation (CE 2), Jameson Land BasinGreenland 
203. Tract 003ssCu0004, Huledal Formation (CE 8-12), Jameson Land BasinGreenland

204. Tract 003ssCu0005, Huledal Formation (CE 4-7), Jameson Land BasinGreenland .554

205. Tract 003rfnbCu0002, Eleonore Bay Supergroup (CE 7-8), Eleonore Bay Basin-Greenland .556

206. Tract 003rfnbCu0003, Eleonore Bay Supergroup (CE 1-6 and CE 9-16), Eleonore Bay Basin-Greenland ...................................................................558

207. Tract 150ssCu0001, Sulban, Kodar-Udokan Trough-Russia...............................560

208. Tract 150ssCu0002, Saku, Kodar-Udokan Trough-Russia ..................................562

209. Tract 150ssCu0003, Ingamakit, Kodar-Udokan Trough-Russia ..........................564

210. Tract 150ssCu0004, Unkur, Kodar-Udokan Trough-Russia.................................566

211. Tract 150ssCu0005, Krasnoe, Kodar-Udokan Trough-Russia ............................568

212. Tract 150ssCu0006, Burpala, Kodar-Udokan Trough-Russia .............................570

213. Tract 142ssCu8001, Dzhezkazgan Subbasin, Chu-Sarysu BasinKazakhstan 572

214. Tract 142ssCu8002, Tesbulak Subbasin, Chu-Sarysu BasinKazakhstan

215. Tract 142ssCu8003, Kokpansor Subbasin, Chu-Sarysu Basin-

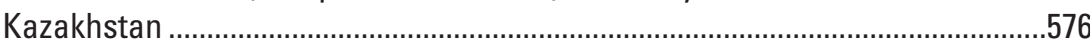

216. Tract 142ssCu8004, Muyunkum Subbasin, Chu-Sarysu BasinKazakhstan and Kyrgyzstan.............................................................................5.5

217. Tract 142ssCu8050, Teniz Basin-Kazakhstan .................................................580

218. Tract 142rfCu4000, Dongchuan Group Rocks, Yangtze Block, South China Craton-China ............................................................................582

219. Tract 142ssCu6000, Chuxiong Basin-China .......................................................584

220. Tract 150rfnbCu0001, Hercynian-Thüringian Basin, Southern Permian Basin-Germany.............................................................................586

221. Tract 150rfnbCu0002, Hessian Depression, Southern Permian

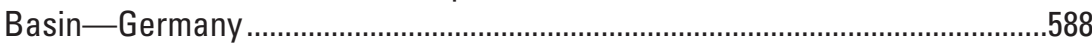

222. Tract 150rfnbCu0003, North Sea, Southern Permian BasinNetherlands and United Kingdom

223. Tract 150rfnbCu0004, Dolny Śląsk (Lower Silesia), Southern Permian Basin-Poland and Germany

224. Tract 150rfnbCu0005, Spremberg-Wittenberg, Southern Permian Basin-Germany

225. Tract 150rfnbCu0006, Baltic Basin, Southern Permian BasinLithuania, Poland, and Russia .596

226. Tract 150rfnbCu0007, Jutland Peninsula, Southern Permian BasinDenmark and Germany..... .598

227. Tract 142rfCu4001, Aynak (sedcu01), Kabul Block-Afghanistan.......................600

228. Tract 142rfCu4002, Kundalyan (sedcu02), Kundalyan Area-Afghanistan .......602

229. Tract 002rfCu2001, Egypt-Israel-Jordan Rift-Egypt, Israel, and Jordan..........604

230. Tract 002rfceCu1000a, Southern Carbonate Écaille, Katanga BasinDemocratic Republic of the Congo .606

231. Tract 002rfceCu1000b, Central Carbonate Écaille, Katanga BasinDemocratic Republic of the Congo and Zambia 
232. Tract 002rfceCu1000c, Northern Carbonate Écaille, Katanga BasinDemocratic Republic of the Congo

233. Tract 002rfnbCu1001, Ore Shale, Katanga Basin—Democratic Republic of the Congo and Zambia

234. Tract 002ssCu1002, Roan Arenite, Katanga Basin-Democratic Republic of the Congo and Zambia

235. Tract 002rfCu2002, Northwest Botswana Rift—Botswana and Namibia .........616

236. Tract 002rfCu2000, Benguela and Cuanza Basins-Angola

\section{Figures}

[Figures A3, A5, A6, A8, and A9 follow the References Cited for chapter A]

A1. Pie chart showing the distribution of identified copper resources by deposit type in selected recently active mining projects

A2. Schematic cross section of the uppermost layers of the Earth illustrating the distribution of porphyry copper deposits and sediment-hosted stratabound copper deposits in relation to the main types of tectonic plate boundaries

A3. Map showing permissive tracts for porphyry copper and sediment-hosted stratabound copper deposits color coded by world region

A4. Pie charts showing identified copper resources and mean estimates of undiscovered copper resources in both porphyry copper and sedimenthosted stratabound copper deposits in the 11 world regions defined for the U.S. Geological Survey global copper assessment

A5. Map showing the global distribution of world-class porphyry copper deposits along with permissive tracts color coded by world region

A6. Map showing the global distribution of world-class sediment-hosted stratabound copper deposits along with permissive tracts color coded by world region

A7. Diagram identifying the types of information presented on the left halves of plates $1-236$ in this volume

A8. Map showing permissive tracts assigned to three size classes on the basis of mean undiscovered copper resources

A9. Map showing the expected economic value categories of permissive tracts for two types of copper deposits based on the grade and tonnage and depth distribution characteristics of the deposits and the remoteness and cost settings of the locations

A10. Bar graph showing the years from discovery of porphyry copper deposits to mine startup for mines brought on stream between 1989 and 2008.

A11. Graph of primary global copper mine production and world population from 1850 to 2050 (estimate)

A12. Bar graph summarizing global copper assessment results by category and region

B1. Map showing permissive tracts for porphyry copper deposits, color coded by world region, and locations of known Precambrian porphyry copper deposits

B2. Generalized model of a porphyry copper system.

B3. Illustration of depth distributions for undiscovered porphyry copper deposits used in the economic filter. 
B4. Map showing locations of 26 permissive tracts for porphyry copper deposits in the South America region (pls. 1-26).

B5. Map showing locations of seven permissive tracts for porphyry copper deposits in the Central America and Caribbean region (pls. 27-33).

B6. Map showing locations of 27 permissive tracts for porphyry copper deposits in the North America region (pls. 34-60)

B7. Map showing locations of five permissive tracts for porphyry copper deposits in the Northeast Asia region (pls. 61-65)

B8. Map showing locations of 20 permissive tracts for porphyry copper deposits in the Central and Eastern Asia region (pls. 66-85)

B9. Map showing locations of 12 permissive tracts for porphyry copper deposits in the Southeast Asia region (pls. 86-97).

B10. Map showing locations of 31 permissive tracts for porphyry copper deposits in the Southeast Asia Archipelagos region (pls. 98-128).

B11. Map showing locations of nine permissive tracts for porphyry copper deposits in the Eastern Australia region (pls. 129-137)...

B12. Map showing locations of 30 permissive tracts for porphyry copper deposits in the Middle East region (pls. 138-167).

B13. Map showing locations of 21 permissive tracts for porphyry copper deposits in the Europe region (pls. 168-188)

B14. Bar chart showing amounts of identified copper resources and mean estimates of undiscovered copper resources in porphyry copper deposits by world region and selected data on U.S. and world copper resources in all deposit types.....

B15. Pie charts comparing the relative percentages of identified porphyry copper resources and mean estimates of undiscovered porphyry copper resources by world region

C1. Map showing 23 basins containing permissive tracts for sediment-hosted stratabound copper deposits, color coded for 7 world regions

C2. Schematic section of a sedimentary basin showing the local geologic settings and essential ore-system components required to form the reduced-facies copper subtype and sandstone copper subtype of sediment-hosted stratabound copper deposits

C3. Map showing permissive tracts in the Chu-Sarysu Basin, Kazakhstan, that were defined for quantitative assessments of sediment-hosted stratabound copper deposits

C4. Map showing permissive tracts in the Katanga Basin, Democratic Republic of the Congo and Zambia, that were defined for quantitative assessments of sediment-hosted stratabound copper deposits

C5. Map showing permissive tracts in the Kodar-Udokan Trough, Russia, that were defined for quantitative assessments of sediment-hosted stratabound copper deposits

C6. Map showing permissive tracts in the Southern Permian Basin in Europe that were defined for quantitative and qualitative assessments of sedimenthosted stratabound copper deposits

C7. Chart showing criteria hierarchy used for the analytic hierarchy process (AHP) analysis for 10 areas containing sediment-hosted stratabound copper deposits throughout the world

C8. Bar graph showing qualitative ranking of 10 basins determined by the analytic hierarchy process (AHP) 
C9. Graphs showing for each permissive tract mean estimates of undiscovered copper resources plotted on a logarithmic scale, probabilities of the mean estimated amount of copper existing, and probabilities of zero undiscovered copper resources existing

C10. Boxplots showing results of Monte Carlo simulations for sediment-hosted stratabound copper deposits aggregated by sedimentary basin and plotted on a logarithmic scale.

3-1. Reproduction of version 2013/01 of the "International Chronostratigraphic Chart"

\section{Tables}

[Tables B2-B11 follow the References Cited for chapter B. Tables C3 and C4 follow the References Cited for chapter C]

A1. Source reports for the global copper assessment

A2. Typical characteristics of porphyry copper deposits and sediment-hosted stratabound copper deposits.

A3. Aggregated assessment results for identified and undiscovered copper resources in porphyry copper and sediment-hosted stratabound copper deposits by world region

A4. World-class porphyry copper deposits by world region

A5. World-class sediment-hosted stratabound copper deposits by world region

A6. Global copper assessment results from this study compared with other measures of global and U.S. copper endowment, production, and consumption

B1. Aggregated assessment results for identified and undiscovered copper resources in porphyry copper deposits by world regions.

B2. Summary of assessment results for identified and undiscovered copper resources in porphyry copper deposits in the South America region

B3. Summary of assessment results for identified and undiscovered copper resources in porphyry copper deposits in the Central America and Caribbean region

B4. Summary of assessment results for identified and undiscovered copper resources in porphyry copper deposits in the North America region.

B5. Summary of assessment results for identified and undiscovered copper resources in porphyry copper deposits in the Northeast Asia region

B6. Summary of assessment results for identified and undiscovered copper resources in porphyry copper deposits in the Central and Eastern Asia region

B7. Summary of assessment results for identified and undiscovered copper resources in porphyry copper deposits in the Southeast Asia region

B8. Summary of assessment results for identified and undiscovered copper resources in porphyry copper deposits in the Southeast Asia Archipelagos region

B9. Summary of assessment results for identified and undiscovered copper resources in porphyry copper deposits in the Eastern Australia region

B10. Summary of assessment results for identified and undiscovered copper resources in porphyry copper deposits in the Middle East region 
B11. Summary of assessment results for identified and undiscovered copper resources in porphyry copper deposits in the Europe region.

C1. Aggregated assessment results for identified copper resources and estimates of undiscovered copper resources in sediment-hosted stratabound copper deposits by world regions.

C2. Aggregated assessment results for identified copper resources and estimates of undiscovered copper resources in sediment-hosted stratabound copper deposits by sedimentary basins for 13 basins that were quantitatively assessed.

C3. Summary of assessment results for identified copper resources and mean estimates of undiscovered in-place copper resources in sediment-hosted stratabound copper deposits in the Western Hemisphere by permissive tract.

C4. Summary of assessment results for identified copper resources and mean estimates of undiscovered in-place copper resources in sediment-hosted stratabound copper deposits in the Eastern Hemisphere by permissive tract. 106 


\section{Conversion Factors}

\begin{tabular}{|c|c|c|}
\hline Multiply & By & To obtain \\
\hline \multicolumn{3}{|c|}{ Length } \\
\hline centimeter $(\mathrm{cm})$ & 0.3937 & inch (in.) \\
\hline meter $(\mathrm{m})$ & 3.281 & foot (ft) \\
\hline kilometer (km) & 0.6214 & mile (mi) \\
\hline mile (mi) & 1.609 & kilometer $(\mathrm{km})$ \\
\hline \multicolumn{3}{|c|}{ Area } \\
\hline square meter $\left(\mathrm{m}^{2}\right)$ & 10.76 & square foot $\left(\mathrm{ft}^{2}\right)$ \\
\hline square kilometer $\left(\mathrm{km}^{2}\right)$ & 0.3861 & square mile $\left(\mathrm{mi}^{2}\right)$ \\
\hline \multicolumn{3}{|c|}{ Volume } \\
\hline cubic meter $\left(\mathrm{m}^{3}\right)$ & 35.31 & cubic foot $\left(\mathrm{ft}^{3}\right)$ \\
\hline \multicolumn{3}{|c|}{ Mass } \\
\hline gram (g) & 0.03215 & ounce, troy (troy oz) \\
\hline kilogram (kg) & 2.205 & pound avoirdupois (lb) \\
\hline megagram $(\mathrm{Mg})$ & 1.102 & ton, short $(2,000$ pounds, $1 b)$ \\
\hline megagram (Mg) & 0.9842 & ton, long $(2,240 \mathrm{lb})$ \\
\hline metric ton $(\mathrm{t})$ & 1 & megagram $(\mathrm{Mg})$ \\
\hline million metric tons $(\mathrm{Mt})$ & 1.102 & million short tons \\
\hline \multicolumn{3}{|c|}{ Bulk density of ore } \\
\hline metric ton per cubic meter $\left(\mathrm{t} / \mathrm{m}^{3}\right)$ & 0.03613 & pound per cubic inch $\left(\mathrm{lb} / \mathrm{in}^{3}\right)$ \\
\hline \multicolumn{3}{|c|}{ Grade } \\
\hline gram per metric ton $(\mathrm{g} / \mathrm{t})$ & 0.02917 & troy ounce per short ton \\
\hline \multicolumn{3}{|c|}{ Other conversions used in this report } \\
\hline percent $(\%)$ & 000 & $\begin{array}{l}\text { part per million }(\mathrm{ppm}) \text { or } \\
\text { gram per metric ton }(\mathrm{g} / \mathrm{t})\end{array}$ \\
\hline
\end{tabular}

Temperature in degrees Celsius $\left({ }^{\circ} \mathrm{C}\right)$ may be converted to degrees Fahrenheit $\left({ }^{\circ} \mathrm{F}\right)$ as follows:

$$
{ }^{\circ} \mathrm{F}=\left(1.8 \times{ }^{\circ} \mathrm{C}\right)+32 .
$$




\section{Abbreviations}

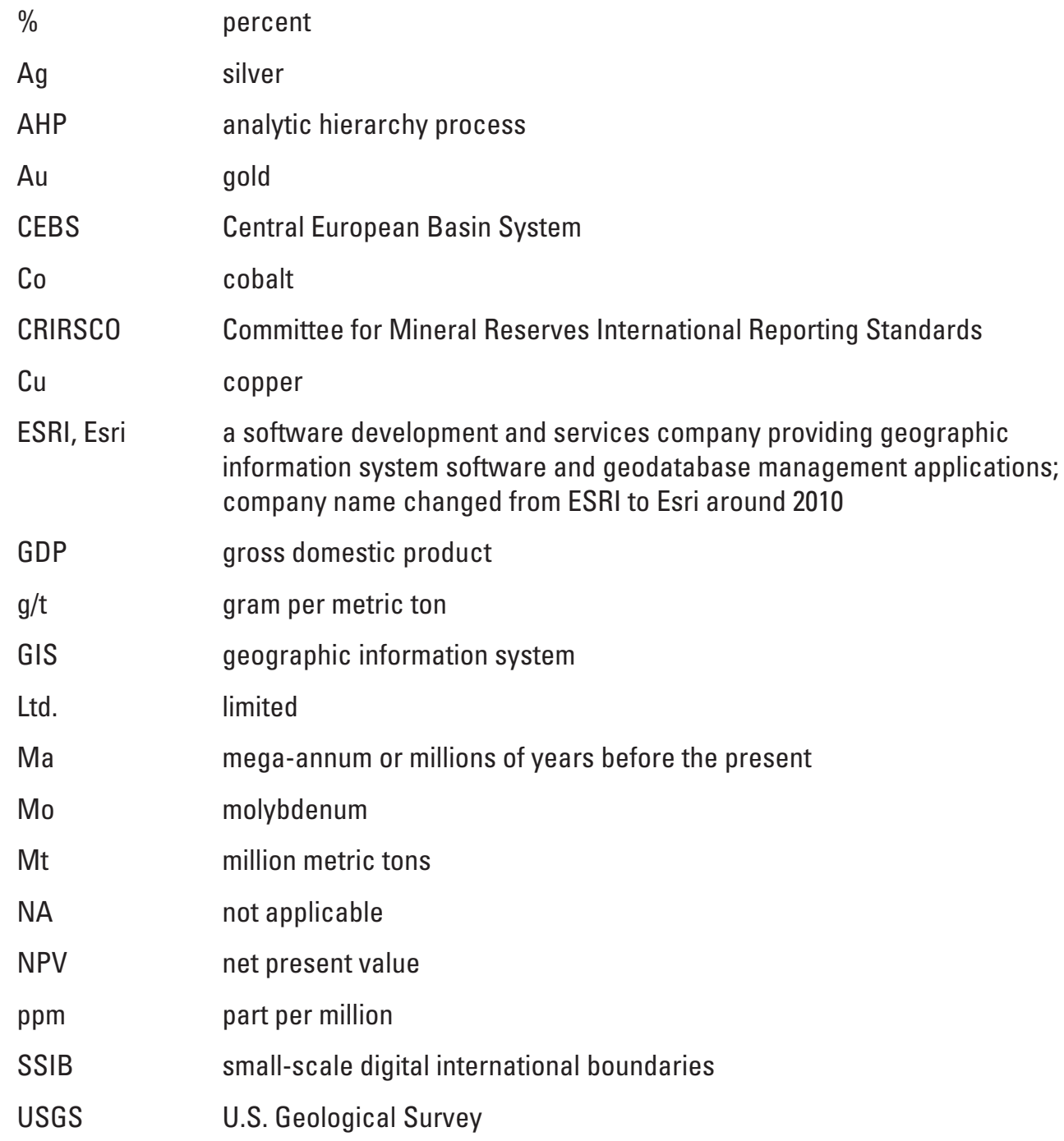

USGS U.S. Geological Survey

\section{Country Names}

[For ease in labeling maps, this report uses short-form names for the countries listed below]

\begin{tabular}{ll}
\hline \multicolumn{1}{c}{ Short form } & \multicolumn{1}{c}{ Long form } \\
\hline China & People's Republic of China \\
Laos & Lao People's Democratic Republic \\
North Korea & Democratic People's Republic of Korea \\
Russia & Russian Federation \\
South Korea & Republic of Korea \\
\hline
\end{tabular}





\title{
Abstract-Assessment of Undiscovered Copper Resources of the World, 2015
}

\author{
By Jane M. Hammarstrom, Michael L. Zientek, Heather L. Parks, Connie L. Dicken, and the \\ U.S. Geological Survey Global Copper Mineral Resource Assessment Team
}

The U.S. Geological Survey completed the first-ever global assessment of undiscovered copper resources for the two most significant sources of global copper supply: porphyry copper deposits and sediment-hosted stratabound copper deposits. The geology-based study identified 236 areas for undiscovered copper in 11 regions of the world. Estimated amounts of undiscovered copper resources are reported at different levels of probability. The results of the assessment indicate that a mean of at least 3,500 million metric tons (Mt) of undiscovered copper associated with these deposit types may exist worldwide, exceeding the 2,100 Mt of identified copper resources tabulated for these deposit types.

Porphyry copper deposits contain 1,800 Mt of identified copper resources and are estimated to contain a mean of at least 3,100 Mt of undiscovered copper resources. South America is the dominant source for both identified and undiscovered porphyry copper resources. However, several regions of Asia, including China, have significant potential for undiscovered porphyry copper resources. The amount of mean undiscovered porphyry copper resources that may be economic to extract varies as a function of likely depth to a deposit and quality of local infrastructure that could support mining.

Sediment-hosted stratabound copper deposits contain 310 Mt of identified copper resources and are estimated to contain a mean of at least $420 \mathrm{Mt}$ of undiscovered copper resources.
The sedimentary basins that may contain significant undiscovered copper resources are the Katanga Basin in central Africa, the Southern Permian Basin of Poland and Germany, the Chu-Sarysu Basin of Kazakhstan, and the Kodar-Udokan area of Russia. Sedimentary basins in the Northwest Botswana Rift in Botswana and Namibia, the Benguela and Cuanza Basins of Angola, and the Cambrian rocks of Egypt, Israel, and Jordan are recognized as having significant potential for undiscovered copper resources in sediment-hosted stratabound copper deposits; however, these areas require additional research, analysis, and evaluation before quantitative resource estimates can be made.

The estimate of at least 3,500 Mt of undiscovered copper in two deposit types provides a basis for long-range planning for this important commodity. U.S. copper consumption is 2 Mt per year, world consumption is about $20 \mathrm{Mt}$ per year, and global production from these two deposit types is about $12 \mathrm{Mt}$ per year. Total global copper production from all deposit types from 1879 to 2012 was about 600 Mt. The world's use of mineral resources, such as copper, will continue to increase in the foreseeable future to support a growing world population and increasing standards of living. The world has sufficient copper to last for decades. However, increases in exploration and growth in mining capacity will be necessary to identify and develop undiscovered resources to supply projected demand. 



\title{
Chapter A. Assessment of Undiscovered Copper Resources of the World, 2015-Summary of Methods and Results
}

\author{
By Jane M. Hammarstrom, Gilpin R. Robinson, Jr., and Michael L. Zientek
}

\section{Introduction}

Production and consumption of minerals create wealth and jobs, improve the quality of life for many people, and sustain prosperity. A nation's economic security depends on access to adequate mineral supplies from many domestic and international sources. The demand for minerals poses obvious questions. What is the current inventory of mineral resources available to society? Where will new mineral resources be found? How much of a particular mineral commodity is likely to be present in a given area? What will be the benefit of developing these resources? How soon can they be developed? Mineral resource assessment studies are done to begin to answer these questions.

In 2015, the first geologic assessment of global undiscovered copper resources was completed by the U.S. Geological Survey (USGS). Copper was one of the first metals used by people, and it continues to be a major industrial metal because of its high ductility, malleability, thermal and electrical conductivity, and resistance to corrosion. Copper ranks third in global metal consumption after iron and aluminum (U.S. Geological Survey, 2017).

The global copper assessment was coordinated by the USGS as part of a cooperative international project to estimate the regional locations and probable quantity and quality of the world's undiscovered nonfuel mineral resources (Briskey and others, 2001, 2007; Schulz and Briskey, 2003; Johnson and others, 2014). This assessment was the first globally consistent and comprehensive analysis of copper from the two types of copper deposits (porphyry copper deposits and sediment-hosted stratabound copper deposits) that together account for more than 70 percent of the world's copper supply. Its results provide a regional and global context for evaluating copper resources; planning for future sources of copper; anticipating the economic, environmental, and social effects of copper mine development; and making land-use decisions. The assessment process included compilation of geologic data and characterization of identified deposits for each area considered, delineation of geographic areas (permissive tracts) in which the geology is permissive for specific types of copper deposits, consideration of the amounts of metal in typical deposits, and quantitative or qualitative evaluations of undiscovered copper resources within each delineated permissive tract. For some geographic areas, where data were sufficient, a simple economic filter was applied to evaluate the amount of undiscovered copper resources that might be economic.

This chapter is a general overview of the assessment, with an explanation of plates 1-236, which summarize the assessment results for 236 geographic areas in maps, graphs, and tables. More details on the assessment of the porphyry copper deposits and sediment-hosted stratabound copper deposits are presented in chapters B and C, respectively. The assessment is based on geology rather than geography. Therefore, some permissive tracts cross country and regional boundaries. Table A1 lists the 11 regions adopted for this report along with the principal countries included in each region.

The assessment was done by USGS scientists working with mineral resource experts from government geological surveys, the exploration and mining industry, and academia throughout the world. Appendix 1 of this volume lists the USGS participants, the international contributors, and the cooperating institutions. The assessment results summarized here are derived from multiple sources (table A1):

1. A series of regional reports published as separate chapters of USGS Scientific Investigations Report 2010-5090 (Zientek and others, 2010-16)

2. A 1998 assessment of undiscovered deposits of gold, silver, copper, lead, and zinc in the United States (U.S. Geological Survey National Mineral Resource Assessment Team, 2002); permissive tracts that border Mexico and Canada were updated for the global assessment and the identifier ends with an " $x$ " to indicate tracts extended across country borders

3. A quantitative assessment of copper, molybdenum, gold, and silver in undiscovered porphyry copper deposits in the Andes Mountains of South America (Cunningham and others, 2008)

4. A preliminary mineral resource assessment of Afghanistan (Ludington and others, 2007; Peters and others, 2007)

5. Reports by cooperators

6. Spatial databases for the global copper assessment (Dicken and others, 2016). Global copper assessment results are available as files that can be used in a geographic information system (Esri format), including the permissive tract outlines (polygons) and attributes as well as point data for deposits and prospects (Dicken and others, 2016). 
Table A1. Source reports for the global copper assessment.

[The 11 regions adopted for this report are listed according to the order of plate numbering for the porphyry copper tracts. The last part of the table lists a global source. The main countries and other geographic entities included in each region are listed in the headnote for that region. Some source reports discuss multiple regions and are cited under several regions in the table. Some permissive tracts extend into adjacent regions. Different parts of China are discussed in source reports for three regions: Northeast Asia region, Central and Eastern Asia region, and Southeast Asia region. Greenland is included in the North America region. Parts of Mexico are included in the North America region and parts are in the Central America and Caribbean region. Afghanistan is included in the Middle East region. Colors are those used in figure A3]

\begin{tabular}{|c|c|}
\hline Source report & Reference \\
\hline \multicolumn{2}{|c|}{$\begin{array}{c}\text { South America region (pls. 1-26, 189-190) } \\
\text { [Argentina, Chile, Colombia, Ecuador, Peru, and Venezuela] }\end{array}$} \\
\hline $\begin{array}{l}\text { Quantitative mineral resource assessment of copper, molybdenum, gold, and silver in } \\
\text { undiscovered porphyry copper deposits in the Andes Mountains of South America }\end{array}$ & Cunningham and others (2008) \\
\hline \multicolumn{2}{|c|}{$\begin{array}{l}\text { Central America and Caribbean region (pls. 27-33) } \\
\text { [Cuba, Dominican Republic, El Salvador, Guatemala, Haiti, Honduras, Jamaica, } \\
\text { Lesser Antilles, Mexico, Nicaragua, Panama, Puerto Rico, and Virgin Islands] }\end{array}$} \\
\hline
\end{tabular}

Porphyry copper assessment of Central America and the Caribbean Basin

Porphyry copper assessment of Mexico

Gray and others (2014)

North America region (pls. 34-60, 191-206)
[Canada, Greenland, Mexico, and United States]

\section{Porphyry copper assessment of British Columbia and Yukon Territory, Canada}

Porphyry copper assessment of Mexico

Assessment of undiscovered deposits of gold, silver, copper, lead, and zinc in the United States

Sediment-hosted copper in Greenland-Assessment of potential and undiscovered $\mathrm{Cu}$ deposits

Quantitative mineral resource assessment-Sedimentary-hosted copper in Greenland

Qualitative assessment of selected areas of the world for undiscovered sediment-hosted stratabound copper deposits
Mihalasky, Bookstrom, and others (2013)
Hammarstrom, Robinson, and others (2010)

U.S. Geological Survey National Mineral Resource Assessment Team (2002)

Stensgaard (2011)

Stensgaard and others (2011)

Zientek, Wintzer, and others (2015)

\begin{tabular}{c}
$\begin{array}{c}\text { Northeast Asia region (pls. 61-65) } \\
\text { [China and Russia] }\end{array}$ \\
\hline Porphyry copper assessment of northeast Asia_-Far East Russia and northeasternmost China \\
[China, Japan, Kazakhstan, Kyrgyzstan, Mongolia, North Korea, Russia, and South Korea] \\
Central and Eastern Asia region (pls. 66-85, 207-217)
\end{tabular}

Porphyry copper assessment of the Central Asian Orogenic Belt and eastern TethysidesChina, Mongolia, Russia, Pakistan, Kazakhstan, Tajikistan, and India

Porphyry copper assessment of East and Southeast Asia—Philippines, Taiwan (Republic of China), Republic of Korea (South Korea), and Japan

Porphyry copper assessment of western Central Asia

Porphyry copper assessment of the Mesozoic of East Asia-China, Vietnam, North Korea, Mongolia, and Russia

Assessment of undiscovered sandstone copper deposits of the Kodar-Udokan area, Russia

Sandstone copper assessment of the Chu-Sarysu Basin, central Kazakhstan

Sandstone copper assessment of the Teniz Basin, Kazakhstan
Mihalasky, Ludington, Hammarstrom, and others (2015)

Hammarstrom, Bookstrom, DeMarr, and others (2014)

Berger and others (2014)

Ludington, Mihalasky, and others (2012)

Zientek, Chechetkin, and others (2014)

Box and others (2012)

Cossette and others (2014) 
Table A1. Source reports for the global copper assessment.-Continued

\begin{tabular}{c} 
Source report \\
Reference \\
$\begin{array}{c}\text { Southeast Asia region (pls. 86-97, 218-219) } \\
\text { [Burma, Cambodia, China, India, Laos, Tajikistan, Thailand, and Vietnam] }\end{array}$ \\
\hline
\end{tabular}

Porphyry copper assessment of the Tibetan Plateau, China

Ludington, Hammarstrom, and others (2012)

Porphyry copper assessment of the Mesozoic of East Asia - China, Vietnam, North Korea, Mongolia, and Russia

Porphyry copper assessment of Southeast Asia and Melanesia

Ludington, Mihalasky, and others (2012)

Porphyry copper assessment of the Central Asian Orogenic Belt and eastern TethysidesChina, Mongolia, Russia, Pakistan, Kazakhstan, Tajikistan, and India

Hammarstrom, Bookstrom, Dicken, and others (2013)

Qualitative assessment of selected areas of the world for undiscovered sediment-hosted

Mihalasky, Ludington, Hammarstrom, and others stratabound copper deposits

Zientek, Wintzer, and others (2015)

Southeast Asia Archipelagos region (pls. 98-128)

[Fiji, Indonesia, Malaysia, Papua New Guinea, Philippines, Solomon Islands, Taiwan, and Vanuatu]

Porphyry copper assessment of East and Southeast Asia-Philippines, Taiwan (Republic of China), Republic of Korea (South Korea), and Japan

Porphyry copper assessment of Southeast Asia and Melanesia
Hammarstrom, Bookstrom, DeMarr, and others (2014)

Hammarstrom, Bookstrom, Dicken, and others (2013)

Eastern Australia region (pls. 129-137)
[Australia]

Porphyry copper assessment of eastern Australia

Bookstrom and others (2014)

Middle East region (pls. 138-167, 227-229)
[Afghanistan, Armenia, Azerbaijan, Egypt, Georgia, Iran,
Iraq, Israel, Jordan, Pakistan, Russia, and Turkey]

Preliminary mineral resource assessment of selected mineral deposit types in Afghanistan

Ludington and others (2007)

Porphyry copper assessment of the Tethys region of western and southern Asia

Zürcher and others (2015)

Qualitative assessment of selected areas of the world for undiscovered sediment-hosted

Zientek, Wintzer, and others (2015) stratabound copper deposits

Preliminary non-fuel mineral resource assessment of Afghanistan

Peters and others (2007)

Europe region (pls. 168-188, 220-226)
[Belgium, Bulgaria, Denmark, Finland, France, Germany, Italy, Kazakhstan,
Lithuania, Netherlands, Poland, Romania, Russia, Serbia, and United Kingdom]

Porphyry copper assessment of Europe, exclusive of the Fennoscandian Shield

Sutphin and others (2013)

Quantitative assessment of undiscovered resources in volcanogenic massive sulphide deposits,

Rasilainen and others (2014) porphyry copper deposits and Outokumpu-type deposits in Finland

Undiscovered porphyry copper resources in the Urals-A probabilistic mineral resource assessment

Hammarstrom, Mihalasky, and others (2017)

Assessment of undiscovered copper resources associated with the Permian Kupferschiefer, Southern Permian Basin, Europe

\section{Africa region (pls. 230-236)}

[Angola, Botswana, Democratic Republic of the Congo, Namibia, and Zambia]

Sediment-hosted stratabound copper assessment of the Neoproterozoic Roan Group, Central African Copperbelt, Katanga Basin, Democratic Republic of the Congo and Zambia

Qualitative assessment of selected areas of the world for undiscovered sediment-hosted stratabound copper deposits
Zientek, Bliss, and others (2014)

Zientek, Wintzer, and others (2015)

Global 
This volume also includes a glossary of terms used and a concise summary of the assessment methodology (appendix 2). Divisions of geologic time and boundaries of age assignments are based on the International Stratigraphic Chart (International Commission on Stratigraphy, 2010, 2013). The 2013 chart is reproduced in appendix 3.

\section{Types of Copper Deposits-Why Does It Matter?}

Copper is the major commodity in several types of mineral deposits (Singer, 1995). Porphyry copper deposits and sediment-hosted stratabound copper deposits are the focus of the USGS global assessment because they are the sources of most of the world's copper (Singer and Menzie, 2010; Mudd and others, 2013) (fig. A1). These two deposit types occur in different kinds of rocks that were formed by different geologic processes. Each deposit type has characteristic ore tonnages, copper grades, and associated metals (table A2). The following features of the two deposit types are distinct: locations and geologic settings, deposit geometries and sizes, copper contents, guidelines for exploration and development, mining and processing methods, and environmental signatures.

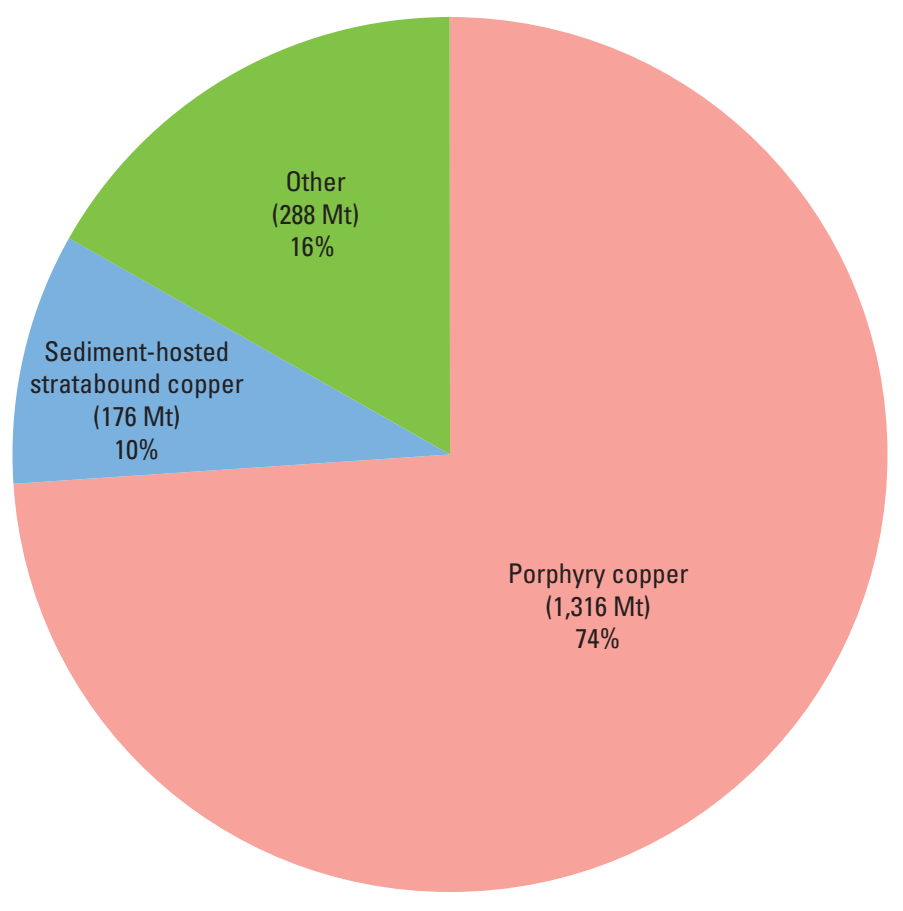

Figure A1. Pie chart showing the distribution of identified copper resources by deposit type in selected recently active mining projects. Information is based on 730 mining projects around the world as of 2010 and is based on data compiled by Mudd and others (2013). Mt, millions of metric tons; \%, percent.

Table A2. Typical characteristics of porphyry copper deposits and sediment-hosted stratabound copper deposits.

[Porphyry copper characteristics from John and others (2010); sediment-hosted stratabound copper characteristics from Zientek, Hayes, and Hammarstrom (2013) and Zientek, Hayes, and Taylor (2013). km, kilometer; m, meter]

\begin{tabular}{|c|c|c|}
\hline Characteristic & Porphyry copper & Sediment-hosted stratabound copper \\
\hline Tonnage & 100 million metric tons or more & 100 million metric tons or less \\
\hline Copper grade & 0.3 to 2.0 percent copper & 0.5 to 5 percent copper \\
\hline Orebody shape & Circular, pipelike & Sheetlike or tabular \\
\hline Orebody dimensions & 0.1 to $1 \mathrm{~km}$ in diameter & $\begin{array}{l}\text { Thousands of meters long, widths from } 500 \text { to } 2,000 \mathrm{~m} \text {, } \\
\text { a few to } 50 \mathrm{~m} \text { thick }\end{array}$ \\
\hline $\begin{array}{l}\text { Ore minerals (listed from most } \\
\text { common to least common) }\end{array}$ & Chalcopyrite, bornite & Chalcocite, bornite, chalcopyrite \\
\hline
\end{tabular}




\section{Porphyry Copper Deposits}

Porphyry copper deposits consist of copper minerals in disseminations and veins that are distributed throughout large volumes of igneous rock that range from less than 1 to $10 \mathrm{~s}$ of cubic kilometers (John and others, 2010). Copper ore minerals, typically chalcopyrite $\left(\mathrm{CuFeS}_{2}\right)$ or bornite $\left(\mathrm{Cu}_{5} \mathrm{FeS}_{4}\right)$, were deposited from high-temperature fluids associated with magmas as they cooled. The fluids that carried copper in solution interacted with and altered rocks, forming new assemblages of alteration minerals and depositing copper. Porphyry copper deposits are large-tonnage, low-grade deposits that typically are mined in large open pits. Tonnages are on the order of $10 \mathrm{~s}$ to 10,000 s of millions of metric tons of ore; copper grades typically are less than 1 percent. Molybdenum, gold, and silver are also recovered from many porphyry copper deposits.

Deposits mainly formed in island or continental magmatic arcs along active or ancient tectonic plate margins (fig. A2). The huge porphyry copper deposits in the Andes of South America formed in a continental arc setting. Deposits in the islands of the Philippine archipelago formed in an island arc setting.

Although porphyry copper deposits probably formed throughout Earth's history, most known deposits are Mesozoic or Cenozoic in age (John and others, 2010). Paleozoic deposits are preserved in parts of Europe, Asia, Australia, and the Americas. The deposits formed in the upper crust at depths less than 5 kilometers $(\mathrm{km})$ below the surface; therefore, older deposits are more likely to be eroded away than younger deposits in many parts of the world. A few Precambrian (older than about 540 million years) porphyry copper deposits are known in the following areas, listed by continent: Namibia and Zambia in Africa, China and India in Asia, western Australia, Finland and Sweden in Europe, Canada in North America, and
Brazil in South America (see this volume, chap. B, fig. B1). These ancient deposits are difficult to characterize and assess because of their complex geologic histories. Therefore, the assessment focused on areas of the world that are most likely to contain undiscovered Phanerozoic porphyry copper deposits (younger than about 540 million years), with the exception of the assessment for Finland provided by Geological Survey of Finland (Rasilainen and others, 2014).

\section{Sediment-Hosted Stratabound Copper Deposits}

Sediment-hosted stratabound copper deposits are bodies of disseminated, cementing, and lesser veinlet-hosted copper minerals that are peneconformable (nearly conformable) with their sedimentary or metasedimentary host rocks (Hayes and others, 2015). Chalcocite $\left(\mathrm{Cu}_{2} \mathrm{~S}\right)$ and bornite $\left(\mathrm{Cu}_{5} \mathrm{FeS}_{4}\right)$ are the typical ore zone minerals. The deposits contain laterally extensive (several kilometers), relatively thin ( $<50$ meters) orebodies that form layers in rocks such as sandstone, shale, and dolomite in sedimentary basins (fig. A2). Sedimenthosted stratabound deposits are mined by using both surface (open-pit) and underground methods, depending on deposit depth and geometry. Tonnages are on the order of 10 s to 100s of millions of metric tons of ore (smaller than typical porphyry copper deposits); copper grades typically are about 1-3 percent (that is, higher than typical grades for porphyry copper deposits). The deposits formed in sedimentary basins that contained saltwater (brines) that dissolved and transported copper; interaction of the copper-bearing brines with organic matter in the host rocks caused precipitation of the ore minerals. Sedimentary basins in Europe and central Africa host the largest known sediment-hosted stratabound copper deposits.

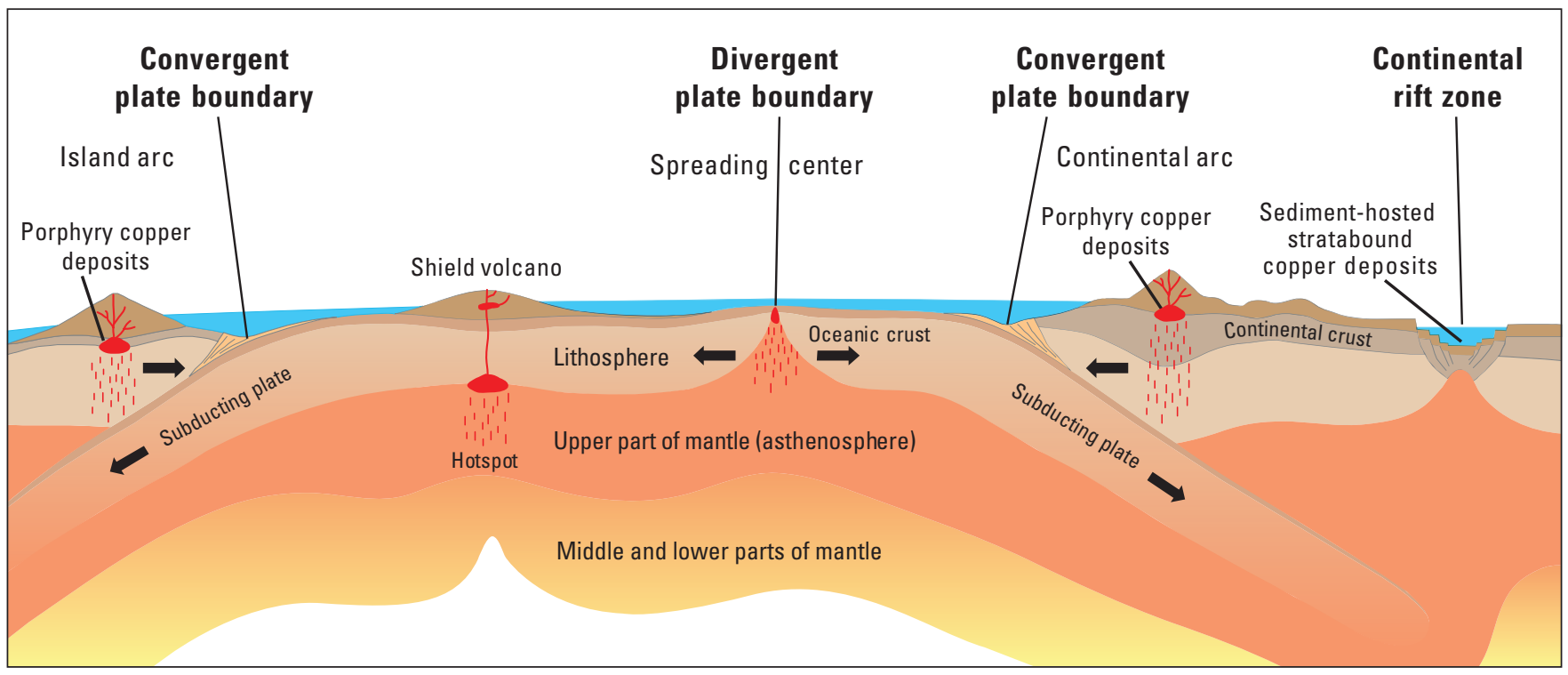

Figure A2. Schematic cross section of the uppermost layers of the Earth illustrating the distribution of porphyry copper deposits and sediment-hosted stratabound copper deposits in relation to the main types of tectonic plate boundaries. Arrows indicate plate movement. Simplified from Zientek and Orris (2005, fig. 3). 
The global distribution of sediment-hosted stratabound copper deposits is mainly controlled by paleolatitude; the host sedimentary rocks were deposited within 20-30 degrees of the paleo-equator (Hayes and others, 2015). The formation and location of sedimentary basins at these latitudes varied over geologic time with changes in plate tectonic activity. Most sediment-hosted stratabound copper deposits formed in Proterozoic, Permian, Carboniferous, and Tertiary time (Hitzman and others, 2005).

\section{Mineral Resources—Identified Versus Undiscovered}

Mineral resources are concentrations of naturally occurring mineral material of economic interest in or on the Earth's crust in such form, quality, and quantity that economic extraction of a mineral commodity is currently or potentially feasible. Identified resources refer to mineral resources for which the location, grade, quality, and quantity are known or can be estimated from specific geologic evidence (U.S. Bureau of Mines and U.S. Geological Survey, 1980, p. 1). In order for material to be designated a mineral resource, the location, quantity, grade, continuity, and other geological characteristics of a mineral resource must be known, estimated, or interpreted from specific geological evidence, sampling, and other knowledge (Committee for Mineral Reserves International Reporting Standards, 2006). Identified resources include deposits that have been mined as well as deposits that are well characterized but not developed. Identified resources are sufficiently characterized to estimate mineral resources using industry-standard practices. ${ }^{1}$

Undiscovered resources refer to resources in undiscovered or incompletely characterized mineral deposits. The existence of undiscovered resources is postulated on the basis of indirect geologic evidence (U.S. Geological Survey National Mineral Resource Assessment Team, 2000, p. 4). In USGS assessments, "undiscovered mineral resources" refers to mineral resources that may be present but for which location, grade, quality, and quantity of mineralized material are not specifically constrained by geologic evidence.

\section{Deposits Versus Prospects}

We reserve the term "deposit" for those sites that have identified mineral resources, such as a formally defined mineral-resource estimate based on drilling, as described above. Deposits are not necessarily economic, and deposits include sites with resources as well as reserves. The data for the total endowment of a deposit or a group of closely spaced

\footnotetext{
${ }^{1}$ See the Committee for Mineral Reserves International Reporting Standards website for information on national reporting standards used throughout the world (http://www.crirsco.com/national.asp).
}

deposits include the total measured, indicated, and inferred resources at the lowest cutoff grade reported, as well as past production. Spatial rules are adopted to aggregate resource information to define the endowment of a deposit. For porphyry copper deposits, the spatial rule typically used aggregates all sites within $2 \mathrm{~km}$ of each other that have reported resources as a group. The name and location of the group are based on the name and location of the largest or best known deposit in the group. For example, the Reko Diq Group in Iran refers to several closely spaced sites that are considered parts of the same deposit.

The term "prospect" is used for sites that do not have identified resources reported but that fit the descriptive mineral deposit models for porphyry copper or sediment-hosted stratabound copper deposits. These include significant exploration sites, sites that have been partially drilled, and sites described as prospects in the geologic literature and in mineral occurrence databases. The geographic information system (GIS) for the global copper assessment identifies locations and data for deposits, prospects, and deposit groups as well as for individual group members (Dicken and others, 2016).

\section{Assessment Methods-An Overview}

U.S. Geological Survey mineral resource assessments address two basic questions: (1) where are undiscovered mineral resources likely to exist? and (2) how much of the undiscovered mineral resource may be present? Geographic areas that may contain undiscovered resources are shown on maps. The areas are selected by identifying geologic features that are known to be associated with a particular type of mineral deposit, as described in mineral deposit models. For this assessment, members of the team identified 236 areas of the world that are likely to contain one of the two types of copper deposits that were considered. They addressed the "how much" question by making a quantitative mineral resource assessment for 198 of these areas.

Mineral deposits are classified into types based on their physical characteristics and systematic differences in oreforming processes. Models summarize essential attributes of the deposit type and are used to distinguish areas that are permissive for the deposit type from those that are not, as indicated by the available geologic data. The recognition that mineral deposits can be systematically classified into types allows scientists to use geoscience information to predict where deposits of a given type could occur. In addition, each ore deposit type has characteristic geometries, distributions of tonnage and grade, and rock and mineral properties that determine the potential value of the deposit and how the mineral resource is delimited and developed. These characteristics allow scientists to predict how much resource may be associated with undiscovered deposit types. Each deposit type also has a characteristic impact on the environment, whether through natural weathering processes or mining. 
Mineral-systems models provide criteria based on theories of regional ore genesis that can be used in mineral resource assessment and exploration targeting (Wyborn and others, 1994; Knox-Robinson and Wyborn, 1997). Descriptive models and mineral-systems models are used to identify and map geographic areas that are permissive for the occurrence of each type.

Mineral resource maps are created by delineating geographic areas that are permissive for the occurrence of a particular type of mineral deposit; these areas are referred to as "permissive tracts." The delineated area represents the surface projection of a volume of rock that corresponds to a geologic environment described in a published deposit model; consequently, depth from the surface is an essential part of a tract definition. Descriptive mineral deposit models provide the criteria to select the permissive volume of rock. Locations and characteristics of any known deposits and mineral occurrences are also examined. Permissive tracts are based on geologic characteristics as portrayed on modern geologic maps. Permissive tracts are delineated without regard for political boundaries, land use, or land status. The likelihood of occurrence of a deposit outside of the permissive tract is considered negligible. Specific criteria used to delineate the permissive tracts for the porphyry and sediment-hosted stratabound copper deposits are described in chapters $B$ and $C$, respectively.

Several strategies are used by the USGS to assess the amount of undiscovered mineral resources (see appendix 2 for details). The first is to estimate the number of undiscovered deposits; this approach has been widely used in USGS mineral resource assessments since the 1970s. The global porphyry copper assessment used this geology-based form of mineral resource assessment (Singer, 1993; Singer and Menzie, 2010). A different approach was adopted for some sediment-hosted stratabound copper assessments; geostatistical methods were used to estimate undiscovered mineral resources (appendix 2). Results of quantitative assessments by both approaches are reported as probability distributions of amounts of in-place, undiscovered metal.

Quantitative mineral resource assessment results can be further evaluated by using economic filters and cash flow models for economic and policy analysis, and they can be applied to mineral supply, economic, environmental, and land-use planning. A simple economic filter developed by Robinson and Menzie (2014) for the global porphyry copper assessment was applied to the quantitative assessment results for undiscovered resources associated with porphyry copper deposits (see chapter B). Although economic filters are not yet available for sediment-hosted stratabound copper deposits, about 55 percent of the mean undiscovered resources are considered to be economic, and about 55 percent of those results are likely to be economic in the reasonably foreseeable future (G.R. Robinson, Jr., USGS, written commun., 2016).

Qualitative assessments made for areas that had insufficient information for a complete quantitative assessment include permissive tracts and compilations of any associated deposits and prospects. For qualitative porphyry copper assessments, evidence for the existence of the deposit type was compiled, along with descriptions of any known deposits and prospects. For the sediment-hosted stratabound copper qualitative assessment, a decision support tool called the analytic hierarchy process (AHP) was applied to rank 10 areas of the world for their potential to contain undiscovered deposits (see chapter C). Four other tracts were assessed qualitatively for sediment-hosted stratabound copper.

Mineral resource assessments are done by teams of experts who are knowledgeable about the deposit type, region of interest, and assessment methodology. Each team compiles and evaluates available geologic information such as geologic maps at a variety of scales, mineral deposit and occurrence databases, geological literature on tectonic setting, and exploration history. For some areas of the world, geochemical and (or) geophysical data are available. The data are compiled and analyzed by using a geographic information system to develop the permissive tracts. In a series of workshops, the team finalizes the permissive tract boundaries and decides whether a quantitative or qualitative assessment is warranted. The team then determines which strategy to use.

For most study areas, forecasts of undiscovered resources were made by estimating the number of undiscovered deposits. In this approach, the team discusses the data and appropriate grade and tonnage models and then makes estimates of numbers of undiscovered deposits. The estimates are combined with grade and tonnage models to estimate amounts of contained metal. Information on the tonnages and grades of well-explored deposits of a given type is used as a model for tonnages and grades of undiscovered deposits of the same type in similar geologic settings. Grade and tonnage models are constructed from data for known deposits that fit the criteria for each deposit type (Singer and Menzie, 2010). These models are used as analogs for the copper resources that could be present in undiscovered deposits of the same type. Grade and tonnage models are compiled from the grades and sizes of thoroughly explored and (or) completely mined out individual mineral deposits. The data include the average grades of metals of economic interest and the associated tonnage based on the total production, reserves, and resources at the lowest reported cutoff grade, which is the lowest grade of ore material that can be included in a resource estimate that has reasonable prospects for application of a feasible mining method. Grades and tonnages of any known deposits within a permissive tract are compared with data in the models to ensure that the most appropriate model is selected for the assessment of the undiscovered resources. If deposits are already identified within a tract, statistical tests are used to guide model selection. In some cases where global models failed statistical tests, regional models were constructed (for example, Frost and others, 2013). If no deposits are known, general global models can be used as a default.

The assessment team reviews the geologic framework, the characteristics and distribution of the known deposits and prospects, the grade and tonnage models, evidence of oreforming processes in the tract area, and any available information about the thoroughness of past mineral exploration. The 
grade and tonnage model is an integral part of a quantitative assessment because the estimates of numbers of undiscovered deposits must be consistent with the selected model. The team members make estimates of numbers of undiscovered deposits at different confidence levels on the basis of expert judgment and guidelines for estimation. A number of guidelines are used, such as consideration of ore-forming process constraints, deposit density models, and ranking prospects (see Singer and Menzie, 2010, for a discussion of this topic). Estimates typically are elicited in a quantile form, by asking for a minimum number of deposits at a given probability. For example, there could be a 90-percent chance of 1 or more undiscovered deposits, a 50-percent chance of 5 or more, and a 10-percent chance of 10 undiscovered deposits. The estimates express the degree of belief that some fixed but unknown number of deposits exists within the tract. A probability distribution that is consistent with the estimates is computed (Root and others, 1992; Singer and Menzie, 2010) to obtain an estimate of the mean number of deposits and a standard deviation. The estimates represent a measure of the favorability of the permissive tract and the spread of the estimates captures the estimator's uncertainty about what may exist (Singer and Menzie, 2010).

Monte Carlo computer simulation methods are used to combine three probability distributions to produce a probabilistic estimate of amounts of in-place undiscovered resources (Root and others, 1992; Bawiec and Spanski, 2012; Duval, 2012). The three distributions are the distribution of undiscovered deposits, a grade model, and a tonnage model. Results are reported as another probability distribution showing the amount of metal at different levels of confidence and as a mean amount of metal in undiscovered deposits in each permissive tract.

Following the completion of the assessment, results are presented to an internal review committee for approval. The committee's comments are addressed prior to finalizing the report for formal technical review and publication. This report is a summary of selected results of regional porphyry copper and sediment-hosted stratabound copper assessments that were done with this methodology (table A1).

\section{Geologic Maps and Map Scale}

One goal of the assessment was a globally consistent compilation of permissive tracts that could be used at a scale of 1:1,000,000. The size and shape of the resulting permissive tracts reflect the type, quality, and resolution of the available geologic maps. A geologic map is a special purpose map made to show geologic features, including rock units, structural features, mineral deposits, and (or) fossil localities. Geologic maps provide the basic data for identifying geographic areas that fit a descriptive mineral deposit model as the starting point of a mineral resource assessment. The map scale defines the resolution of the geologic features that are depicted on the map. For example, at a scale of 1:1,000,000, the detectable size of a map feature is 1,000 meters $(\mathrm{m})$ according to Tobler's rule, which states that the detectable size of a map feature is obtained by dividing the denominator of the map scale by 1,000 (Tobler, 1987). Ideally, one would use the most detailed geologic map available for an assessment. For a global-scale assessment, however, it was difficult to acquire and interpret the most detailed geologic maps that exist throughout the world. Generalized regional maps were used to identify gross geologic features such as basins, magmatic arcs, and terranes. Detailed maps were used to select permissive map units that define permissive tracts for porphyry copper deposits based on rock type and age. Other types of geologic maps, such as structure contour maps, lithofacies maps, and alteration and diagenetic mineral zoning maps, were used to define permissive tracts for sediment-hosted stratabound copper deposits.

The data used for each permissive tract are described in the source reports (table A1). These tracts should not be used at a scale larger than 1:1,000,000 and should be considered a starting point for future refinement of tract boundaries as new and more detailed data, including higher resolution and richly attributed maps, topical studies, and new age determinations, become available. Permissive tract areas reported in square kilometers $\left(\mathrm{km}^{2}\right)$ in tables throughout this report were computed in GIS using an equal-area projection appropriate to the tract location.

\section{Results of the Global Copper Assessment}

The global copper assessment teams considered the potential for exposed and concealed undiscovered deposits within $1 \mathrm{~km}$ of the surface for porphyry deposits and within up to $2.5 \mathrm{~km}$ of the surface for sediment-hosted stratabound deposits. These depths are based on current practical limits to conventional mining techniques. For porphyry deposits, 188 permissive tracts were delineated; 115 tracts contain at least 1 identified deposit. Forty-eight permissive tracts were delineated for sediment-hosted stratabound copper deposits; 26 contain at least 1 identified deposit.

The results of this assessment show that a mean of 3,500 million metric tons (Mt) of undiscovered copper may be present globally, with 3,100 Mt of copper associated with porphyry deposits and $420 \mathrm{Mt}$ of copper associated with sediment-hosted deposits (table A3). This undiscovered copper is in addition to identified copper resources of 2,100 Mt of copper (table A3).

The results were aggregated for 11 world regions (fig. A3, which follows the "References Cited" for this chapter A) to allow comparison of identified copper resources with mean estimates of undiscovered copper resources (fig. A4). The mean estimates indicate that almost two-thirds of the undiscovered copper resources are in South America, Southeast Asia, North America, and Central and Eastern Asia. Note that some large countries, such as Russia and China, are split between several world regions. The Urals area of western Russia is included with Europe, whereas other parts of Russia are in the Northeast Asia and Central and Eastern Asia regions. China, for example, is split among the Northeast Asia, Central and Eastern Asia, and Southeast Asia regions. 
Table A3. Aggregated assessment results for identified and undiscovered copper resources in porphyry copper and sediment-hosted stratabound copper deposits by world region.

[Results of probabilistic estimates of undiscovered copper resources are reported as means and selected percentiles $(90,50,10)$ for aggregated results by region, assuming statistical independence; 90 represents a 90-percent chance of at least the amount indicated. Tract area and identified copper resources refer to all tracts within the region; mean and percentiles apply to tracts that were assessed quantitatively. See tables in chapters B and C and plates for results for individual tracts. Resources are reported to two significant figures. $\mathrm{km}^{2}$, square kilometer; Mt, millions of metric tons; NA, not applicable, as no quantitative assessment was done; *, percentiles are not additive for the two deposit types]

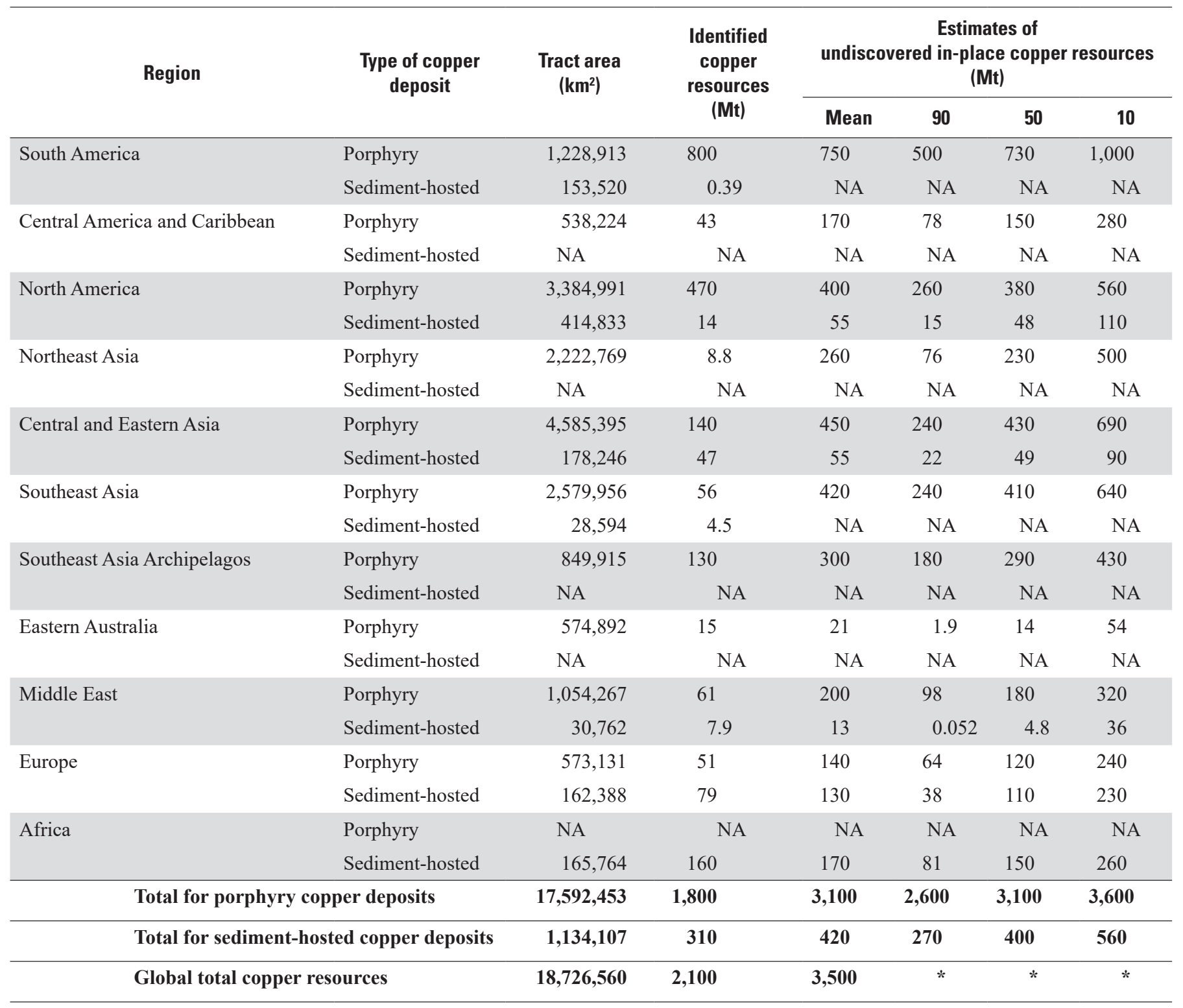


A. Identified copper resources, world total $=2,100 \mathrm{Mt}$

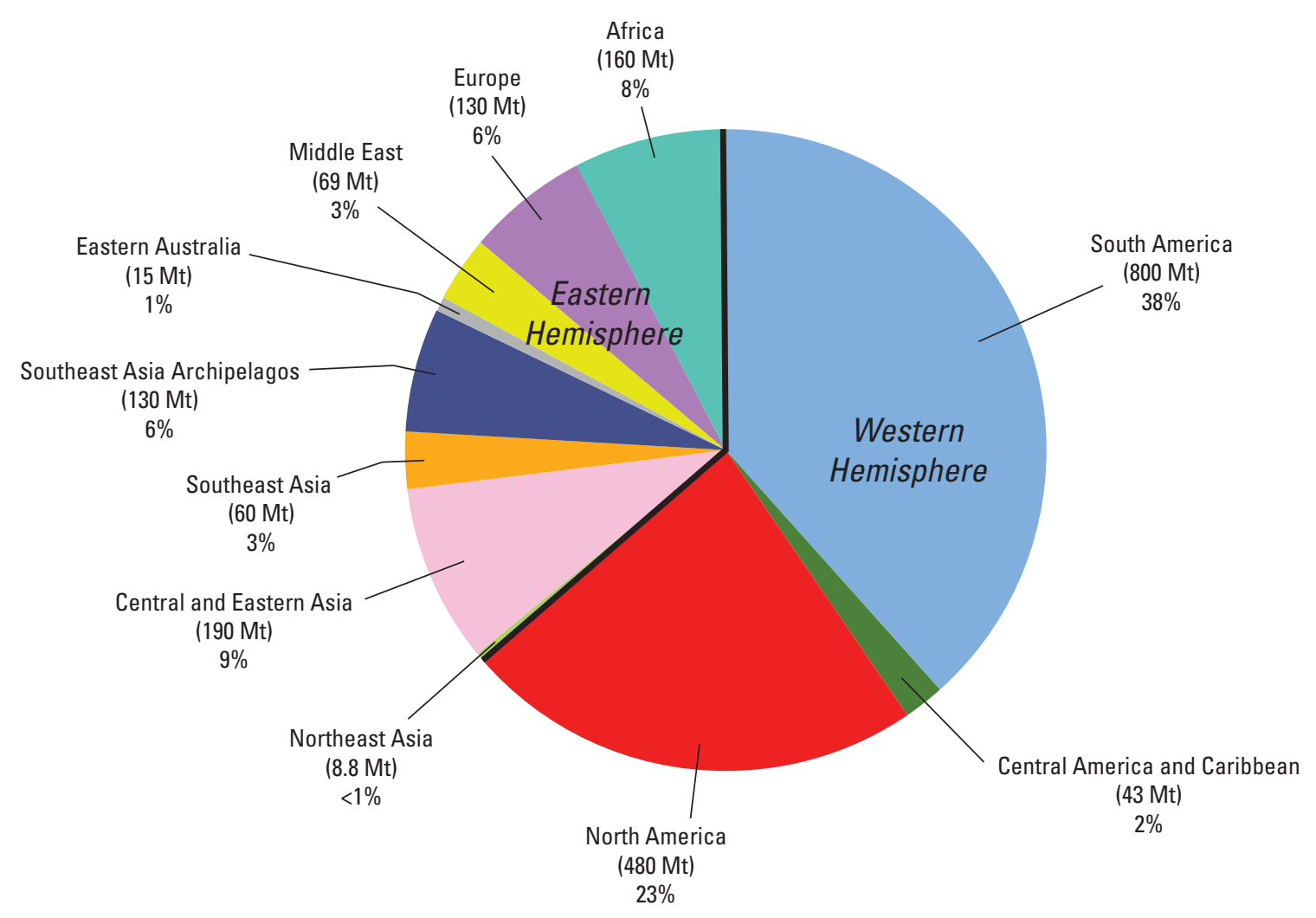

B. Mean estimates of undiscovered copper resources, world total $=3,500 \mathrm{Mt}$

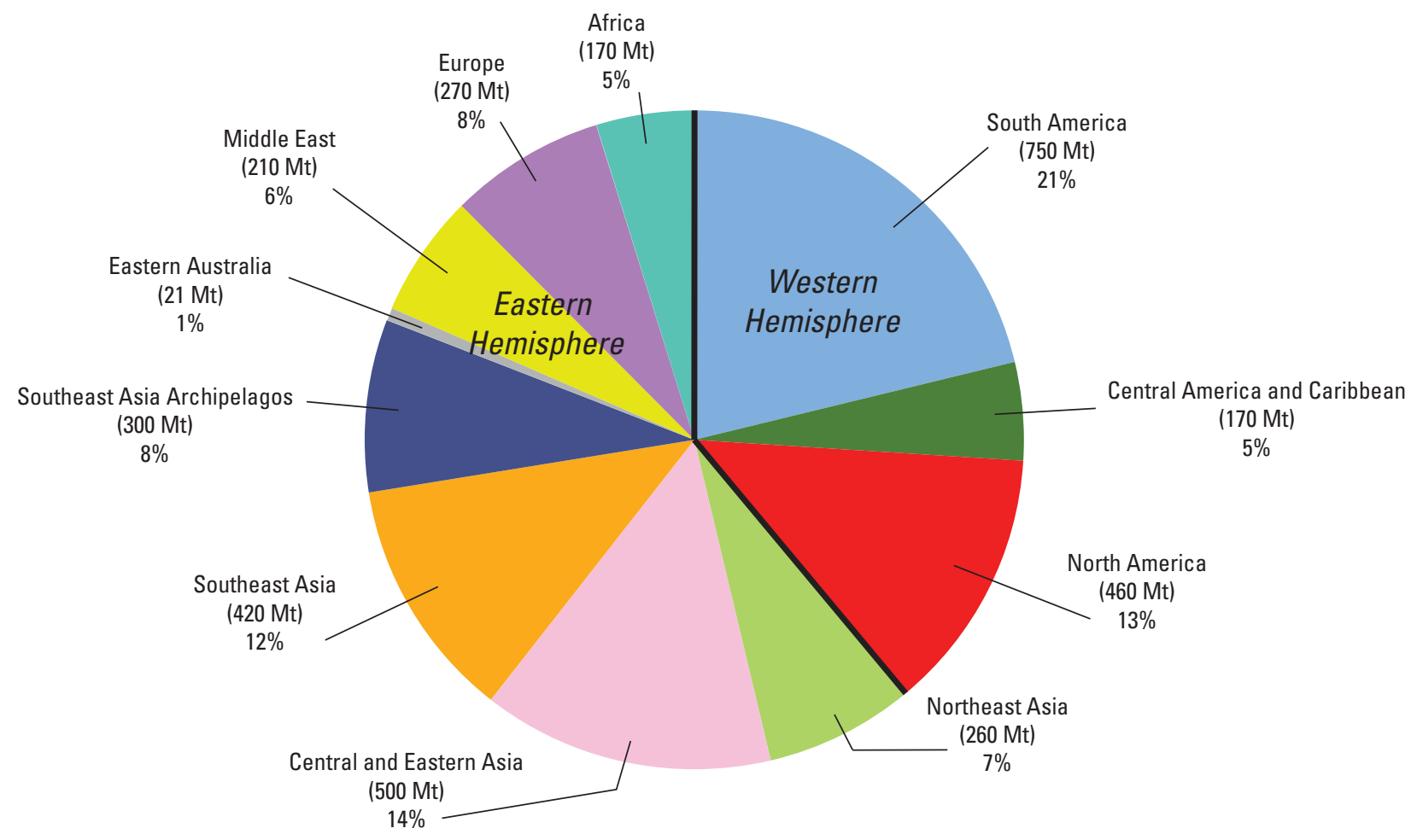

Figure A4. Pie charts showing $(A)$ identified copper resources and $(B)$ mean estimates of undiscovered copper resources in both porphyry copper and sediment-hosted stratabound copper deposits in the 11 world regions defined for the U.S. Geological Survey global copper assessment. Mt, millions of metric tons; \%, percent. 
The regional assessment results were aggregated by using a method based on an assumption of complete independence between tracts, a statistical approach that implies no correlation from tract to tract (Schuenemeyer and others, 2011). The ranges of resource estimates (between the 90th and 10th percentiles) listed in table $\mathrm{A} 3$ reflect a measure of geologic uncertainty in the assessment process and results. Simulation input and results for each permissive tract are included in the source reports (table A1) and in the GIS (Dicken and others, 2016). For data and results of aggregating simulation data by region, see Hammarstrom and others (2018).

The distributions of permissive tracts for porphyry copper and sediment-hosted stratabound copper deposits, along with the locations of already identified world-class deposits of these types, are shown in figures A5 and A6, respectively (these figures follow the "References Cited" for this chapter A). World-class deposits represent the upper 10 percent of all deposits in terms of their contained copper content. Among the world-class copper deposits, those that contain $2 \mathrm{Mt}$ or more of copper are considered giants and those that contain more than $24 \mathrm{Mt}$ of copper are referred to as supergiants (Singer, 1995, p. 103). Identified porphyry copper deposits are concentrated around the Pacific rim in the Andes Mountains of western South America, western North America, and the Southeast Asia Archipelagos region that includes the Philippines, Indonesia, and Papua New Guinea (fig. A5, table A4). The largest copper deposits of any type in the world are porphyry copper deposits in Chile. Other porphyry copper deposits that are among the world's largest known copper deposits include the Grasberg Group deposit $(37 \mathrm{Mt})^{2}$ in Indonesia, the Oyu Tolgoi deposit (37 Mt) in Mongolia, the undeveloped Pebble deposit (37 Mt) in Alaska, the Continental/Butte deposit (35 Mt) in Montana, the Morenci-Metcalf (34 Mt) and Safford (32 Mt) deposits in Arizona, the Cananea deposit (30 Mt) in Mexico, the Bingham deposit (28 Mt) in Utah, and the Reko Diq Group (23 Mt) in Pakistan (table A4).

The global distribution of sediment-hosted stratabound copper deposits is different from that of the porphyry copper deposits because they form in different geologic environments (see fig. A2). The largest known sediment-hosted stratabound copper deposits are found in central Africa, Europe, and the Central and Eastern Asia region (fig. A6, table A5). The largest sediment-hosted stratabound copper deposits have contained metal amounts that are similar to amounts in the largest porphyry copper deposits. Examples include Lubin-Sieroszowice (72 Mt) in Poland, Dzhezkazgan (22 Mt) in Kazakhstan, and Konkola-Musoshi (22 Mt) in Zambia.

\footnotetext{
${ }^{2}$ The Grasberg Group resources were reported as $24 \mathrm{Mt}$ of contained copper (Singer and others, 2008), and that number was used in the assessment of the region (Hammarstrom, Bookstrom, Dicken, and others, 2013). Total resources and reserves as of December 31, 2016, were $37 \mathrm{Mt}$ (Rio Tinto, 2017, p. 224, 229).
}

\section{Regional Highlights}

The South America region has the largest percentage of both identified and undiscovered copper resources (fig. A4), almost all in porphyry copper deposits. However, the undiscovered resources represent 21 percent of the total global undiscovered resources, whereas the identified resources in South America represent 39 percent of the total identified copper resources compiled for this study. This observation suggests that although South America is likely to continue to be a significant source of global copper supply, other regions that are less thoroughly explored and developed could become increasingly important contributors to global copper supply.

The Central America and Caribbean region hosts two undeveloped giant porphyry copper deposits in Panama: Cerro Colorado and Cobre Panama (fig. A5, table A4). Most of the undiscovered resources in the region are in a belt that extends from Panama to southwestern Mexico. No permissive tracts for sediment-hosted stratabound copper deposits are delineated in this region. Some identified porphyry copper resources in this region, including those in Puerto Rico, are unavailable for development because of political decisions to ban mining.

The North America region hosts highly mineralized porphyry copper tracts that include supergiant deposits such as the Cananea deposit in northern Mexico, the Bingham deposit in the southwestern United States, and the Pebble deposit in Alaska, as well as giant deposits in western Canada. The estimated undiscovered porphyry copper resources $(400 \mathrm{Mt})$ are approximately equal to the identified resources (470 Mt; see table A3). In the United States, undiscovered sediment-hosted stratabound copper deposits in Michigan, Montana, and Texas are estimated to contain about three times as much copper (mean estimate of $44 \mathrm{Mt}$ ) as has been identified (13 Mt) in deposits of this type in these areas (pls. 191-193). World-class sediment-hosted stratabound copper deposits in North America include White Pine in Michigan in the United States and Boleo in Mexico (fig. A6, table A5). As described above for South America, the relative percentage of undiscovered copper resources in the North America region for these two types of deposits (13 percent) is less than the relative percentage of identified global copper resources (23 percent) (fig. A4).

The Northeast Asia region is relatively underexplored, with modest identified porphyry copper resources $(8.8 \mathrm{Mt})$ and only one identified world-class porphyry copper deposit, the Peschanka deposit in Russia (figs. A4 and A5, tables A3 and A4). However, the undiscovered resources are estimated to be quite large $(260 \mathrm{Mt})$, representing 7 percent of the total undiscovered copper resources compared to less than 1 percent of the identified copper resources (fig. A4). This region has the largest ratio of undiscovered to identified resources in the study, and all of those resources are associated with porphyry copper type deposits. 
Table A4. World-class porphyry copper deposits by world region.

[World-class deposits are giant and supergiant deposits that contain at least 2 and 24 million metric tons of copper, respectively (Singer, 1995, p. 103). In column 1, "Map number" refers to site numbers in figure A5, which follows the "References Cited" for this chapter A. In column 5, "Plate number" refers to plates in this volume. Contained copper data are from the compilation by Dicken and others (2016), reported in millions of metric tons (Mt). On the basis of spatial rules adopted for this study, the reported contained copper data may include resources for groups of closely spaced deposits. Resource data for a number of worldclass porphyry deposits became available after the assessments were completed; these deposits are identified with an asterisk (*) in the table and are plotted for reference on figure A5 and on the plates in this volume. However, contained copper data for these deposits are not included as identified resources on the plates because these resources were undiscovered when the assessment of the region was done]

\begin{tabular}{|c|c|c|c|c|}
\hline $\begin{array}{c}\text { Map } \\
\text { number } \\
\text { (fig. A5) }\end{array}$ & Deposit name & Country & $\begin{array}{l}\text { Contained } \\
\text { copper } \\
\text { (Mt) }\end{array}$ & $\begin{array}{l}\text { Plate } \\
\text { number }\end{array}$ \\
\hline
\end{tabular}

\begin{tabular}{|c|c|c|c|c|}
\hline \multicolumn{5}{|c|}{ South America region } \\
\hline 1 & El Teniente & Chile & 130 & 5 \\
\hline 2 & Los Sulfatos* & Chile & 18 & 5 \\
\hline 3 & $\begin{array}{l}\text { Los Bronces/Rio Blanco } \\
\text { Group (Andina) }\end{array}$ & Chile & 100 & 5 \\
\hline 4 & Vizcachitas & Chile & 4.4 & 6 \\
\hline 5 & Los Pelambres/El Pachon & Chile & 46 & 6 \\
\hline 6 & Andacollo* & Chile & 2.3 & 12 \\
\hline 7 & La Fortuna & Chile & 5.1 & 9 \\
\hline 8 & Relincho & Chile & 2.5 & 13 \\
\hline 9 & Regalito (Caserones)* & Chile & 4.3 & 14 \\
\hline 10 & Cerro Casale & Chile & 4.5 & 14 \\
\hline 11 & Agua Rica & Argentina & 7.4 & 15 \\
\hline 12 & Bajo de la Alumbrera & Argentina & 4.3 & 15 \\
\hline 13 & Potrerillos & Chile & 10 & 18 \\
\hline 14 & El Salvador & Chile & 17 & 18 \\
\hline 15 & Taca Taca Bajo & Argentina & 3.0 & 16 \\
\hline 16 & Escondida & Chile & 86 & 18 \\
\hline 17 & Lomas Bayas Group & Chile & 3.4 & 13 \\
\hline 18 & Gaby & Chile & 12 & 18 \\
\hline 19 & El Telégrafo* & Chile & 4.0 & 18 \\
\hline 20 & Esperanza* & Chile & 7.3 & 18 \\
\hline 21 & Sierra Gorda & Chile & 10 & 13 \\
\hline 22 & Spence & Chile & 4.6 & 13 \\
\hline 23 & Toki* & Chile & 12 & 18 \\
\hline 24 & Mansa Mina & Chile & 13 & 18 \\
\hline 25 & Chuquicamata & Chile & 130 & 18 \\
\hline 26 & Conchi* & Chile & 3.7 & 18 \\
\hline 27 & El Abra & Chile & 8.8 & 18 \\
\hline 28 & Quebrada Blanca & Chile & 7.8 & 18 \\
\hline 29 & Ujina & Chile & 9.2 & 18 \\
\hline 30 & Collahuasi & Chile & 27 & 18 \\
\hline 31 & Cerro Colorado & Chile & 4.9 & 13 \\
\hline 32 & Cerro Colorado & Peru & 2.2 & 13 \\
\hline 33 & Toquepala & Peru & 13 & 13 \\
\hline
\end{tabular}

\begin{tabular}{ccccc}
\hline $\begin{array}{c}\text { Map } \\
\text { number } \\
\text { (fig. A5) }\end{array}$ & Deposit name & Country & $\begin{array}{c}\text { Contained } \\
\text { copper } \\
\text { (Mt) }\end{array}$ & $\begin{array}{c}\text { Plate } \\
\text { number }\end{array}$ \\
\hline
\end{tabular}

\begin{tabular}{lllll}
\hline \multicolumn{5}{c}{ South America region-Continued } \\
\hline 34 & Quellaveco & Peru & 6.3 & 13 \\
35 & Cuajone & Peru & 11 & 13 \\
36 & Cerro Verde & Peru & 13 & 13 \\
37 & Quechua & Peru & 2.0 & 19 \\
38 & Antapaccay & Peru & 3.5 & 19 \\
39 & Coroccohuayco & Peru & 2.4 & 19 \\
40 & Los Chancas & Peru & 2.0 & 19 \\
41 & Las Bambas & Peru & 10 & 19 \\
42 & Toromocho & Peru & 9.9 & 21 \\
43 & Michiquillay & Peru & 4.6 & 21 \\
44 & El Galeno & Peru & 4.1 & 21 \\
45 & Tantahuatay & Peru & 3.0 & 21 \\
46 & La Granja & Peru & 17 & 21 \\
47 & Cañariaco & Peru & 3.7 & 21 \\
48 & Rio Blanco & Peru & 7.2 & 21 \\
49 & Mirador & Ecuador & 5.0 & 23 \\
50 & San Carlos & Ecuador & 4.2 & 23 \\
51 & Panantza & Ecuador & 3.1 & 23 \\
52 & Junin & Ecuador & 2.3 & 22 \\
\hline
\end{tabular}

\begin{tabular}{lllll}
52 & Junin & Ecuador & 2.3 & 22 \\
\hline \multicolumn{5}{c}{ Central America and Caribbean region } \\
\hline 53 & Cerro Colorado & Panama & 15 & 28 \\
54 & Cobre Panama & Panama & 19 & 27 \\
\hline
\end{tabular}

\begin{tabular}{llccc}
\hline \multicolumn{5}{c}{ North America region } \\
\hline 55 & Tiámaro & Mexico & 3.0 & 33
\end{tabular}

56 Bahuerachi Group $\quad$ Mexico $\quad 2.4 \quad 36$

$57 \quad$ El Arco

$58 \quad$ La Caridad

59 Cananea

$60 \quad$ Milpillas

$61 \quad$ Bisbee

62 Red Mountain

63 Rosemont-Helvetia

64 Group

Mexico

Mexico

$5.3 \quad 40$

Mexico

$8.1 \quad 36$

Mexico

30

United States

$2.0 \quad 36$

United States $\quad 5.3 \quad 36$
United States

36
40
36
36
36
43
36
36
36


Table A4. World-class porphyry copper deposits by world region.-Continued

\begin{tabular}{ccccc}
\hline $\begin{array}{c}\text { Map } \\
\text { number } \\
\text { (fig. A5) }\end{array}$ & Deposit name & Country & $\begin{array}{c}\text { Contained } \\
\text { copper } \\
\text { (Mt) }\end{array}$ & $\begin{array}{c}\text { Plate } \\
\text { number }\end{array}$ \\
\hline
\end{tabular}

\begin{tabular}{|c|c|c|c|c|}
\hline $\begin{array}{c}\text { Map } \\
\text { number } \\
\text { (fig. A5) }\end{array}$ & Deposit name & Country & $\begin{array}{c}\text { Contained } \\
\text { copper } \\
\text { (Mt) }\end{array}$ & $\begin{array}{c}\text { Plate } \\
\text { number }\end{array}$ \\
\hline
\end{tabular}

\begin{tabular}{lllll}
\hline \multicolumn{5}{c}{ North America region-Continued } \\
\hline 65 & Twin Buttes & United States & 4.7 & 36
\end{tabular}

\begin{tabular}{lllll}
\hline \multicolumn{4}{c}{ North America region-Continued } \\
\hline 97 & Schaft Creek Group & Canada & 3.9 & 51 \\
98 & Red Chris & Canada & 2.5 & 49 \\
99 & Casino & Canada & 2.1 & 50 \\
100 & Taurus & United States & 2.2 & 56 \\
101 & Pebble & United States & 37 & 57
\end{tabular}

66 Mission-Pima

$67 \quad$ Ajo

$68 \quad$ Lakeshore

Tyrone

United States

$4.7 \quad 36$

San Manuel-Kalamazoo

United States

United States

$4.4 \quad 41$

United States

$4.7 \quad 36$

Chino

United States

$\begin{array}{ll}5.1 & 42 \\ 8.0 & 36\end{array}$

United States

Hanover Mountain Group

United States

Casa Grande West

United States

Safford

Poston Butte

United States

United States

Morenci-Metcalf

United States

Ray

Superior East

United States

United States

Miami-Inspiration Group

Castle Dome Group

United States

United States

Sheep Mountain

United States

United States

United States

United States

United States

United States

United States

United States

United States

United States

Canada

Canada

Canada

Canada

Canada

Canada
Afton-Ajax Group

Fish Lake

Gibraltar Group

Sulphurets Group

Galore Creek Group

$\begin{array}{ll}5.1 & 42 \\ 8.0 & 36\end{array}$

$\begin{array}{ll}5.1 & 42 \\ 8.0 & 36\end{array}$

14

$14 \quad 42$

$4.8 \quad 42$

$8.5 \quad 36$

$32 \quad 42$

$2.8 \quad 36$

$34 \quad 42$

$11 \quad 36$

$10 \quad 36$

$4.7 \quad 36$

$3.1 \quad 36$

$6.0 \quad 36$

$3.8 \quad 43$

$4.8 \quad 43$

$2.0 \quad 43$

$4.6 \quad 44$

$28 \quad 45$

$35 \quad 47$

$2.2 \quad 50$

$5.7 \quad 46$

$13 \quad 51$

$2.9 \quad 49$

$2.5 \quad 50$

$3.8 \quad 51$

$3.8 \quad 49$

$9.3 \quad 49$

$5.0 \quad 36$

\begin{tabular}{|c|c|c|c|c|}
\hline \multicolumn{5}{|c|}{ Northeast Asia region } \\
\hline 102 & Peschanka & Russia & 7.9 & 65 \\
\hline \multicolumn{5}{|c|}{ Central and Eastern Asia region } \\
\hline 103 & Duobaoshan & China & 3.3 & 70 \\
\hline 104 & Bystrinskoe & Russia & 2.4 & 69 \\
\hline 105 & Shaktama & Russia & 2.9 & 69 \\
\hline 106 & Wunugetushan & China & 2.2 & 69 \\
\hline 107 & Oyu Tolgoi & Mongolia & 37 & 75 \\
\hline 108 & Erdenet & Mongolia & 9.0 & 74 \\
\hline 109 & Aksug & Russia & 4.2 & 73 \\
\hline 110 & Tuwu-Yandong-Yanxi & China & 4.0 & 77 \\
\hline 111 & Agaskyr & Russia & 9.9 & 73 \\
\hline 112 & Aktogai-Aidarly & Kazakhstan & 10 & 79 \\
\hline 113 & Kounrad & Kazakhstan & 3.8 & 80 \\
\hline 114 & Bozshakol & Kazakhstan & 6.7 & 78 \\
\hline 115 & Kyzata & Uzbekistan & 6.0 & 85 \\
\hline 116 & Almalyk Group & Uzbekistan & 24 & 85 \\
\hline
\end{tabular}

\begin{tabular}{lcccc}
\multicolumn{9}{c}{ A } & Uzbekistan & 24 & 85 \\
\hline 117 & Southeast Asia region & & \\
\hline & Dexing & China & 8.4 & 86
\end{tabular}

118 Chengmenshan

119 Pulang

$120 \quad$ Yulong

121 Monywa Group

122 Jiama

123 Qulong

124 XietongmenNewtongmen Group

$\begin{array}{lll}\text { China } & 3.1 & 86\end{array}$

$\begin{array}{lll}\text { China } & 4.2 \quad 91\end{array}$

$\begin{array}{lll}\text { China } & 7.1 & 92\end{array}$

$\begin{array}{lll}\text { Burma } & 6.3 \quad 94\end{array}$

$\begin{array}{lll}\text { China } & 3.9 & 90\end{array}$

$\begin{array}{lll}\text { China } & 8.0 \quad 90\end{array}$

$\begin{array}{lll}\text { China } & 3.3 & 90\end{array}$


Table A4. World-class porphyry copper deposits by world region.-Continued

\begin{tabular}{|c|c|c|c|c|}
\hline $\begin{array}{c}\text { Map } \\
\text { number } \\
\text { (fig. A5) }\end{array}$ & Deposit name & Country & $\begin{array}{l}\text { Contained } \\
\text { copper } \\
\text { (Mt) }\end{array}$ & $\begin{array}{l}\text { Plate } \\
\text { number }\end{array}$ \\
\hline \multicolumn{5}{|c|}{ Southeast Asia Archipelagos region } \\
\hline 125 & Namosi Group & Fiji & 6.6 & 128 \\
\hline 126 & Panguna & $\begin{array}{l}\text { Papua New } \\
\text { Guinea }\end{array}$ & 6.6 & 127 \\
\hline 127 & Wafi-Golpu Group & $\begin{array}{c}\text { Papua New } \\
\text { Guinea }\end{array}$ & 4.9 & 122 \\
\hline 128 & Yandera & $\begin{array}{l}\text { Papua New } \\
\text { Guinea }\end{array}$ & 5.7 & 122 \\
\hline 129 & Frieda River Group & $\begin{array}{l}\text { Papua New } \\
\text { Guinea }\end{array}$ & 8.6 & 124 \\
\hline 130 & Ok Tedi & $\begin{array}{l}\text { Papua New } \\
\text { Guinea }\end{array}$ & 5.5 & 121 \\
\hline 131 & Grasberg Group $^{1}$ & Indonesia & 24 & 119 \\
\hline 132 & Kingking & Philippines & 2.9 & 101 \\
\hline 133 & $\begin{array}{l}\text { Boyongan-Bayugo } \\
\text { Group }\end{array}$ & Philippines & 2.0 & 101 \\
\hline 134 & Tampakan & Philippines & 15 & 107 \\
\hline 135 & Atlas Group & Philippines & 6.4 & 104 \\
\hline 136 & Sipalay Group & Philippines & 3.8 & 103 \\
\hline 137 & Marcopper Group & Philippines & 2.0 & 98 \\
\hline 138 & Taysan & Philippines & 2.1 & 98 \\
\hline 139 & Far Southeast-Bato Tabio & Philippines & 4.3 & 98 \\
\hline 140 & Batu Hijau & Indonesia & 7.2 & 111 \\
\hline 141 & Tujuh-Bukit* & Indonesia & 4.1 & 110 \\
\hline \multicolumn{5}{|c|}{ Eastern Australia region } \\
\hline 142 & Cadia Group & Australia & 10 & 133 \\
\hline \multicolumn{5}{|c|}{ Middle East region } \\
\hline 143 & Reko Diq Group & Pakistan & 23 & 142 \\
\hline 144 & Sar Cheshmeh Group & Iran & 10 & 150 \\
\hline 145 & Sungun & Iran & 5.0 & 153 \\
\hline 146 & Kadjaran & Armenia & 4.6 & 153 \\
\hline \multicolumn{5}{|c|}{ Europe region } \\
\hline 147 & Mikheevskoe & Russia & 2.1 & 175 \\
\hline 148 & Skouries Group & Greece & 2.0 & 171 \\
\hline 149 & Bor Group & Serbia & 14 & 168 \\
\hline 150 & Majdanpek & Serbia & 6.0 & 168 \\
\hline 151 & Rosia Poieni & Romania & 2.4 & 169 \\
\hline 152 & Recsk & Hungary & 4.6 & 171 \\
\hline
\end{tabular}

${ }^{1}$ The Grasberg Group resources were reported as $24 \mathrm{Mt}$ of contained copper (Singer and others, 2008), and that number was used in the assessment of the region (Hammarstrom, Bookstrom, Dicken, and others, 2013). Total resources and reserves as of December 31, 2016, were $37 \mathrm{Mt}$ (Rio Tinto, 2017, p. 224, 229).
Table A5. World-class sediment-hosted stratabound copper deposits by world region.

[World-class deposits are giant and supergiant deposits that contain at least 2 and 24 million metric tons of copper, respectively (Singer, 1995, p. 103). In column 1, "Map number" refers to site numbers in figure A6, which follows the "References Cited" for this chapter A. In column 5, "Plate number" refers to the plates in this volume. Contained copper data are from the compilation by Dicken and others (2016), reported in millions of metric tons (Mt). On the basis of spatial rules adopted for this study, the reported contained copper data may include resources for groups of closely spaced deposits. NA, not applicable, as no plate shows the Boleo deposit because Mexico was not assessed for this deposit type; the contained copper value of $2.8 \mathrm{Mt}$ is from Baja Mining Corporation (2010)]

\begin{tabular}{|c|c|c|c|c|}
\hline $\begin{array}{c}\text { Map } \\
\text { number } \\
\text { (fig. A6) }\end{array}$ & Deposit name & Country & $\begin{array}{l}\text { Contained } \\
\text { copper } \\
\text { (Mt) }\end{array}$ & $\begin{array}{c}\text { Plate } \\
\text { number }\end{array}$ \\
\hline \multicolumn{5}{|c|}{ North America region } \\
\hline 1 & Boleo & Mexico & 2.8 & NA \\
\hline 2 & White Pine & United States & 8.3 & 192 \\
\hline 3 & Rock Creek and Montanore & United States & 2.4 & 193 \\
\hline \multicolumn{5}{|c|}{ Middle East region } \\
\hline 4 & Aynak & Afghanistan & 5.5 & 227 \\
\hline \multicolumn{5}{|c|}{ Central and Eastern Asia region } \\
\hline 5 & Dzhezkazgan & Kazakhstan & 22 & 213 \\
\hline 6 & Zhaman-Aibat & Kazakhstan & 2.7 & 214 \\
\hline 7 & Udokan & Russia & 19 & 208 \\
\hline \multicolumn{5}{|c|}{ Europe region } \\
\hline 8 & Mansfeld & Germany & 2.0 & 220 \\
\hline 9 & Lubin-Sieroszowice & Poland & 72 & 223 \\
\hline \multicolumn{5}{|c|}{ Africa region } \\
\hline 10 & Baluba-Muliashi-Luanshya & Zambia & 10 & 233 \\
\hline 11 & Mindola-Nkana N-S & Zambia & 15 & 233 \\
\hline 12 & Chambishi Southeast & Zambia & 3.8 & 233 \\
\hline 13 & Chambishi Main and West & Zambia & 2.9 & 233 \\
\hline 14 & Mufulira & Zambia & 8.9 & 234 \\
\hline 15 & Chingola-Nchanga & Zambia & 16 & 233 \\
\hline 16 & Konkola-Musoshi & Zambia & 22 & 233 \\
\hline 17 & Kinsevere & $\begin{array}{l}\text { Democratic } \\
\text { Republic of } \\
\text { the Congo } \\
\text { (DRC) }\end{array}$ & 2.1 & 232 \\
\hline 18 & Kimbwe & DRC & 2.0 & 232 \\
\hline 19 & $\begin{array}{c}\text { Kambove Principal- } \\
\text { Kambove West }\end{array}$ & DRC & 3.1 & 231 \\
\hline 20 & Fungurume & DRC & 2.8 & 231 \\
\hline 21 & Kansalawile-Mambilima & DRC & 2.8 & 231 \\
\hline 22 & Kwatebala & DRC & 2.2 & 231 \\
\hline 23 & Tenke & DRC & 2.5 & 231 \\
\hline 24 & Mutanda-Ya-Mukonkota & DRC & 3.7 & 231 \\
\hline 25 & $\begin{array}{l}\text { Kamoto-KOV-Musonie- } \\
\text { Mupine }\end{array}$ & DRC & 19 & 231 \\
\hline 26 & DIMA & DRC & 7.8 & 231 \\
\hline
\end{tabular}


The Central and Eastern Asia region has 38 identified porphyry copper deposits (this volume, chap. B, table B6), including the supergiant Oyu Tolgoi deposit in Mongolia, the Almalyk Group deposit in Uzbekistan, and several other world-class deposits in Kazakhstan (fig. A5, table A4). The region is estimated to contain about three times as much undiscovered porphyry copper $(450 \mathrm{Mt})$ as has been identified to date (140 Mt) (table A3). This region also hosts giant sediment-hosted stratabound copper deposits, such as the Dzhezkazgan deposit in Kazakhstan and the Udokan deposit in Russia (fig. A6, table A5). The USGS estimates that as much undiscovered sediment-hosted stratabound copper (55 Mt) as has already been discovered (47 Mt) may be present (table A3).

The Southeast Asia region is less thoroughly explored than many other parts of the world; however, four giant porphyry copper deposits have been identified to date in the Tibetan Plateau: Qulong, Yulong, Jiama, and XietongmenNewtongmen Group (fig. A5, table A4). Undiscovered porphyry copper deposits may contain eight times the identified amount of copper (table A3). Known sediment-hosted stratabound copper deposits are also located in southwestern China, with identified resources of $4.5 \mathrm{Mt}$ (pls. 218, 219).

The Southeast Asia Archipelagos region (including Melanesia) hosts world-class, gold-rich porphyry copper deposits such as the supergiant Grasberg Group in Indonesia and at least 16 giant deposits in Fiji, Indonesia, Papua New Guinea, and the Philippines (fig. A5, table A4). Although parts of the region are well explored, undiscovered porphyry resources $(300 \mathrm{Mt})$ are likely to exceed identified resources (130 Mt) (table A3).

The Eastern Australia region has one giant Phanerozoic porphyry copper deposit, the Cadia Group (fig. A5, table A4), and several small porphyry deposits. Modest undiscovered resources are expected, and those are likely to be at some depth under cover rock.

The Middle East region has been mined for copper since ancient times, and giant porphyry copper deposits, such as the Reko Diq Group in Pakistan, have recently been identified (fig. A5, table A4). Undiscovered copper (200 Mt) is predicted to be about three times the identified resources $(61 \mathrm{Mt})$ for porphyry deposits along a belt including Turkey, Iran, Azerbaijan, and Armenia (fig. A5, table A3). Sediment-hosted stratabound copper deposits are associated with a rift setting in Egypt, Israel, and Jordan. Mean undiscovered copper resources in sediment-hosted stratabound copper deposits in the Kabul Block tract (pl. 227) in eastern Afghanistan (13 Mt) exceed identified resources (6.4 Mt). Most of the identified resources are associated with the giant Aynak deposit (table A5).

The Europe region has the largest sediment-hosted stratabound copper deposit in the world, the Lubin-Sieroszowice deposit in Poland, which contains $72 \mathrm{Mt}$ of copper (fig. A6, table A5). Undiscovered sediment-hosted stratabound copper resources in southwestern Poland (96 Mt) are estimated to exceed identified resources ( $74 \mathrm{Mt}$ ) by about 30 percent (pl. 223). Eastern Europe hosts six world-class Phanerozoic porphyry copper deposits (table A4), including the only porphyry copper deposit that has been developed in the Urals at Mikheevskoe. The most prospective areas for porphyry copper deposits in northern Europe are Precambrian deposits in Sweden and Finland (chap. B, fig. B1).

The Africa region has the world's largest accumulation of sediment-hosted stratabound copper deposits, with 17 giant deposits in the Central African Copperbelt in the Democratic Republic of the Congo and Zambia (fig. A6, table A5). A mean estimate of $170 \mathrm{Mt}$ of undiscovered copper resources in sediment-hosted stratabound copper deposits in this region is slightly more than the $160 \mathrm{Mt}$ of copper that has already been identified (table A3). Phanerozoic porphyry copper deposits are not known in this region, and available information indicates that the near-surface geology of the region is not permissive for their occurrence.

\section{Plates}

The 236 plates in this volume each summarize assessment results for one permissive tract. Each plate consists of two facing pages. Figure A7 explains the elements that are common to the left pages of all plates; chapters B and C describe additional information on plates for porphyry copper and sediment-hosted stratabound copper deposits, respectively. The left page of each plate has the plate number and title, identifies the descriptive models and grade and tonnage models used for the assessment of the tract, has a brief statement of the geologic basis for delineating the tract, and gives the source(s) of data. A brief table presents the assessment results numerically. The left page also includes a graph of results for quantitative assessments. For qualitative assessments of sediment-hosted stratabound copper potential, a graph showing the relative ranking of a sedimentary basin analyzed by the AHP method is provided for 10 tracts. For qualitative assessments of porphyry copper deposits and of four sediment-hosted stratabound copper tracts, a summary paragraph describes the qualitative assessment. The right side of each plate includes an index map and a main map showing the extent of the assessed tract on a shaded-relief base, locations and names of deposits, and locations of prospects.

The plate title includes the tract identifier, a geographic/ geologic tract name, and the region or countries in which the tract is present. Titles of some plates for sediment-hosted stratabound deposits include a basin name. Each tract has a unique identifier based on a three-digit United Nations world region number (United Nations Statistics Division, 2016), a deposit type or subtype abbreviation, and a four-digit identification number. The deposit type abbreviation for porphyry copper deposits is "pCu." Deposit type abbreviations for sediment-hosted stratabound deposits vary by subtype; these include " $\mathrm{ssCu}$ " for the sandstone copper subtype, "shCu" for general sediment-hosted copper that includes all subtypes, "rfCu" for the reduced-facies copper subtype, "rfceCu" for the reduced-facies-carbonate-écaille copper subtype, and "rfnbCu" for the reduced-facies-nonbrecciated copper subtype. 


\section{Plate Number. Plate Title}

[The plate title contains a tract identifier, a basin name for some sediment-hosted stratabound copper tracts, a tract name, and a list of countries in which the tract is present. Each tract identifier is a unique code composed of a three-digit United Nations world region number (003 for North America) (United Nations Statistics Division, 2016), a deposit type abbreviation (such as pCu for porphyry copper) or a subtype abbreviation (such as the following for sediment-hosted stratabound copper: rfCu, general reduced-facies copper subtype; rfceCu, reduced-facies-carbonate-écaille copper subtype; rfnbCu, reduced-facies-nonbrecciated copper subtype; shCu, general sediment-hosted copper that includes all subtypes; ssCu, sandstone copper subtype), and a four-digit number (for some tracts, followed by a letter a, b, ab, c, d, or x, explained in the text)]

Descriptive model: Model name and reference

Grade and tonnage model: Model name and reference (for quantitative assessments)

Economic filter depth percentages: Depth distribution applied to quantitative assessment results for porphyry copper deposits

Economic filter cost setting: Cost setting applied to quantitative assessment results for porphyry copper deposits

Geologic feature assessed: Brief statement describing the geologic feature that forms the basis for delineating the tract

Number of known deposits: Number of deposits that have well-defined tonnages and grades in the tract

\section{Selected Resource Assessment Results}

[Assessment depth, 1 kilometer $(\mathrm{km})$ for porphyry copper, 0 to $2.5 \mathrm{~km}$ for sediment-hosted stratabound copper; $\mathrm{km}^{2}$, square kilometer; Mt, millions of metric tons]

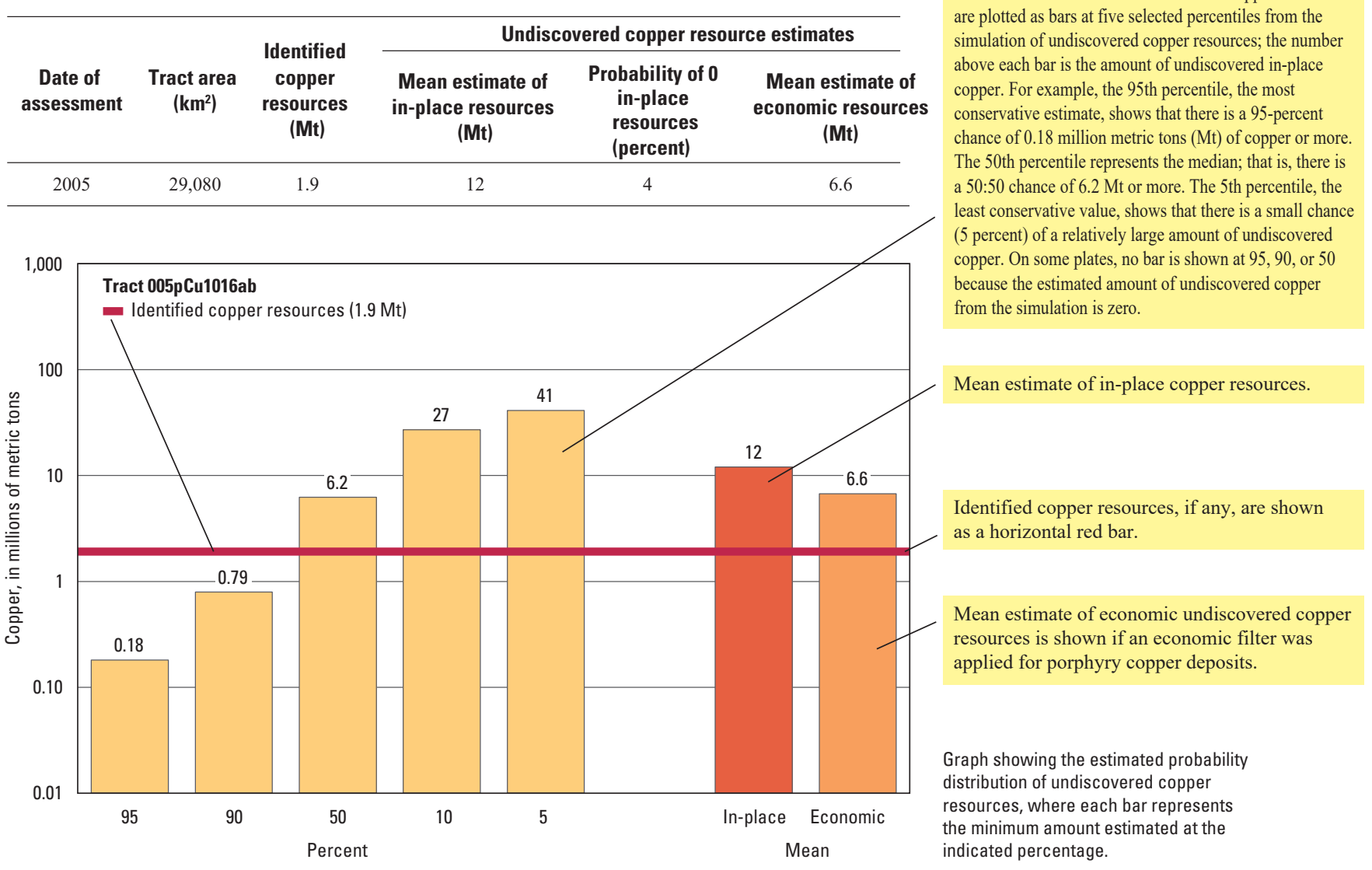

[For tracts assessed qualitatively, the section above includes text and (or) graphs indicating the likelihood for undiscovered copper resources in the tract.]

\section{Source}

Shortened reference to the source of the data for the tract. The full reference is in the "References Cited" list of chapter A.

Figure A7. Diagram identifying the types of information presented on the left halves of plates 1-236 in this volume. 
The use of an "x" (for extended) at the end of a tract identifier indicates tracts that were modified to extend across borders of the United States, Mexico, and Canada. For example, plate 36 describes tract $003 \mathrm{pCu} 3007 \mathrm{x}$, which is based on a tract covering the western Sierra Madre Occidental of northern Mexico that extends into the Laramide Central tract in the southwestern United States. These extended tracts are each based on two source reports, as noted on the plates.

Some border issues were not resolved; therefore, some tracts appear truncated at country borders. In addition, some tracts overlap parts of other tracts because of age differences in the permissive rocks. For example, the map on plate 87 depicts a permissive tract (East Qinling) for Jurassic and Cretaceous porphyry copper deposits in China; that tract overlaps parts of the older Paleozoic through Triassic tract shown on plate 88.

Some tract identifiers end in letters such as "a," "b," "ab," "c," or "d." These letters indicate sub-tracts. For example, plates $79,80,82$, and 83 show parts a, b, d, and c, respectively, of tract $142 \mathrm{pCu} 8003$.

Selected assessment results for each tract are summarized in a table and a graph on the plate. Each graph is shown at the same scale, so results for tracts on different plates can be compared.

See table A1 and the "References Cited" at the end of this chapter for all references noted on plates, including references to descriptive models and grade and tonnage models. Interested readers are directed to the source reports for more information on the rationale for delineating each tract. Base map sources for tract maps include ESRI (2008), de Ferranti and Hormann (2009), Danielson and Gesch (2011), Earth Resources Observation and Science (EROS) Center (2011), and Howat and others (2014). Country boundaries are from the U.S. Department of State (2009).

\section{Assessment Results in Perspective}

Every country in the world uses copper. Actual world copper mine production from all types of copper deposits was 17.0 Mt in 2012, 17.9 Mt in 2013, and 18.7 Mt in 2014 (table A6). Global production from porphyry and sedimenthosted stratabound copper deposits is about $12 \mathrm{Mt}$ per year (Johnson and others, 2014). According to the International Copper Study Group (2015a), global consumption of refined copper increased from 20.4 Mt in 2012 to $22.9 \mathrm{Mt}$ in 2014 (table A6). From 2002 to 2012, global consumption of refined copper increased an average of about 3 percent per year (Brininstool, 2015). U.S. copper consumption is about $2 \mathrm{Mt}$ per year (Brininstool, 2015). The mean estimated in-place copper resource in undiscovered porphyry and sediment-hosted stratabound copper deposits is 3,500 Mt and represents about 200 times the amount of copper produced globally in recent years. In addition, much of the copper that has already been identified is in deposits that have not yet gone into production.

How do these estimates of undiscovered copper compare with what has already been discovered? The mean estimate of undiscovered copper, 3,500 Mt, is about six times the amount of copper $(600 \mathrm{Mt})$ produced from all types of deposits over a span of more than 100 years (table A6). Identified in-place world copper resources that could be developed for the 730 mining projects of all types reported by Mudd and others (2013) total 1,860 Mt. Identified world copper reserves (the portion of resources that are economic) are on the order of 680-700 Mt (table A6).

The map of area-averaged estimates of undiscovered porphyry copper and sediment-hosted stratabound copper resources portrays where future copper resources are most likely to occur (fig. A8, which follows the "References Cited" for this chapter A). However, this portrayal does not consider costs of discovery, development, and mining or potential return based on tonnage and grade characteristics of the likely undiscovered deposits.

A simple economic filter was applied to the quantitative porphyry copper assessment results to address the question of what portion of in-place undiscovered porphyry copper resources might be economic (see this volume, chap. B). The economic filter for porphyry copper deposits applies assumptions about metal prices, mining methods, capital costs, recovery rates, mining depth, and availability of infrastructure (Robinson and Menzie, 2014). Estimates of the amount of undiscovered in-place porphyry copper resources that may be economic based on these assumptions range from none for some tracts to about 80 percent for other tracts, with an average of 50 percent. Results of the Monte Carlo simulation and economic filter analysis provide an estimate of undiscovered resources, potential economic resources, net-present-value (NPV), the probability of failure (probability of no economic resource), and the probability associated with the mean for each porphyry copper tract (chap. B).

The potential economic copper resources in sedimenthosted stratabound copper deposits were not evaluated on a tract-by-tract basis but were estimated to be similar to the economic percentages calculated for porphyry copper deposits on a regional basis. Economic resources were not estimated for tracts of either type that were qualitatively assessed.

The mean NPV of undiscovered deposits was discounted by the probability of failure and normalized by areal extent to rank the relative economic potential of each porphyry copper tract, shown in high, medium, and low expected value categories. Sediment-hosted stratabound copper tracts that were assessed quantitatively with mean undiscovered copper greater than $20 \mathrm{Mt}$ were classified as having a high expected economic value; those with 2 to $20 \mathrm{Mt}$ of copper were classified as having a medium expected economic value, and those with less than $2 \mathrm{Mt}$ were classified as having a low expected economic value. The map shown in figure A9 (which follows the "References Cited" for this chapter A) categorizes the economic characteristics of areas likely to contain undiscovered copper resources based on the grade and tonnage and depth distribution characteristics of the deposits, and the remoteness and cost settings of the locations. Note that this analysis applies to the area evaluated, not individual prospects or deposits located in these areas. 
Table A6. Global copper assessment results from this study compared with other measures of global and U.S. copper endowment, production, and consumption.

[Reserves are identified resources that could be economically extracted at the time of determination. Theoretical porphyry copper resources were estimated by Kesler and Wilkinson (2008) from a time-space model for the tectonic migration of porphyry copper deposits vertically through the entire Earth's crust and for all copper deposit types in the upper 3.3 kilometers $(\mathrm{km})$. Mt, millions of metric tons]

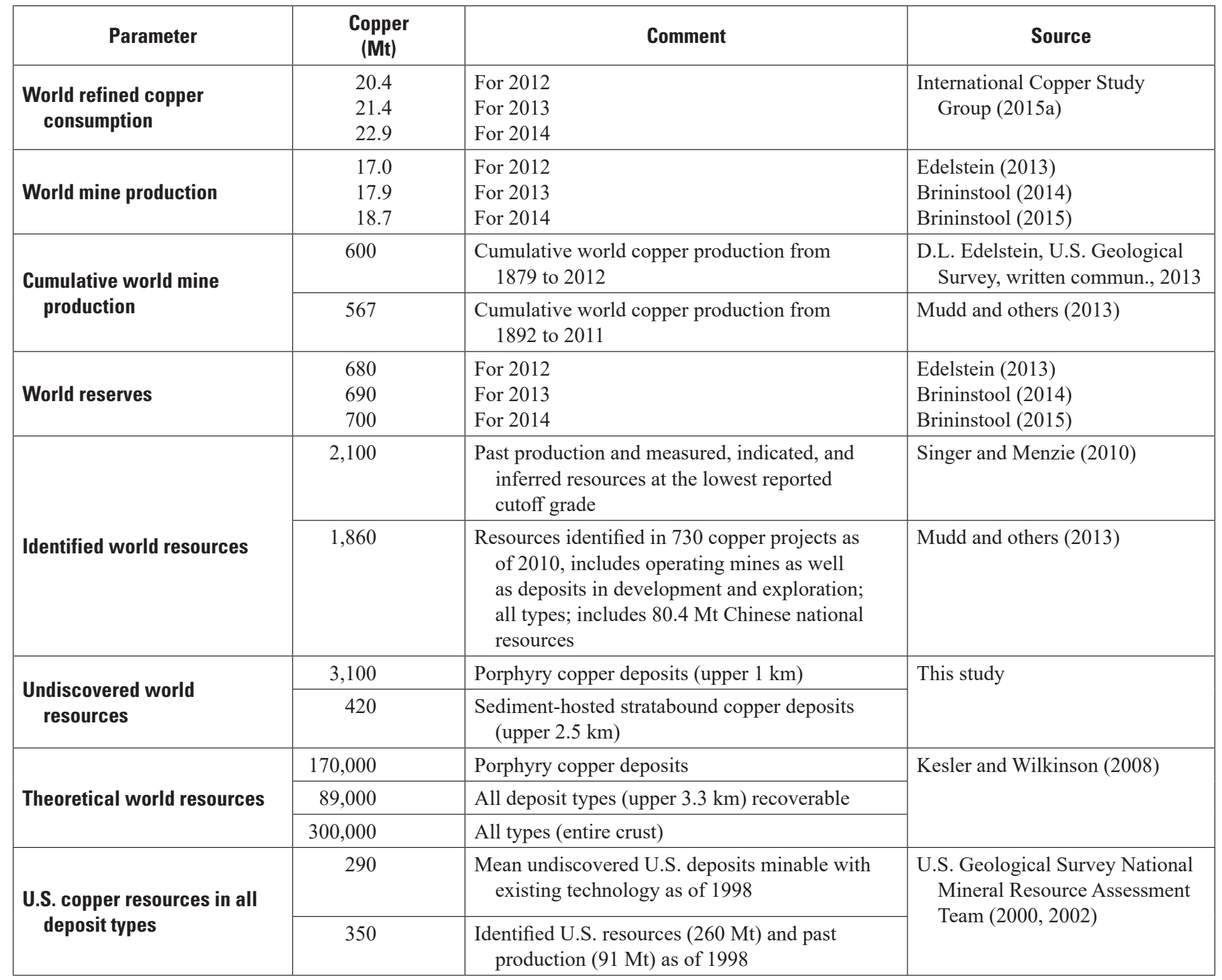

\section{Timing of Development}

The global assessment of undiscovered copper resources addresses geologic endowment. Undiscovered resources do not represent an immediate source of supply or wealth. Finding the postulated undiscovered resources requires exploration and exploration success. Exploration is a lengthy and expensive process beginning with area selection, and moving through target selection involving sitespecific mapping, utilization of geophysical, geochemical, and (or) remote-sensing techniques, to drilling, evaluating resources, and defining reserves. Studies of exploration success rates suggest that fewer than 10 percent of reconnaissance exploration sites might be mineral deposits consistent with grade and tonnage models (Anderson, 1982; Singer and Menzie, 2010).

Furthermore, many already identified copper resources have not yet been developed and may never be developed because of social, environmental, political, or economic reasons. Examples include the supergiant Pebble porphyry copper deposit in Alaska and the giant Tampakan porphyry copper deposit in the Philippines (table A4). 


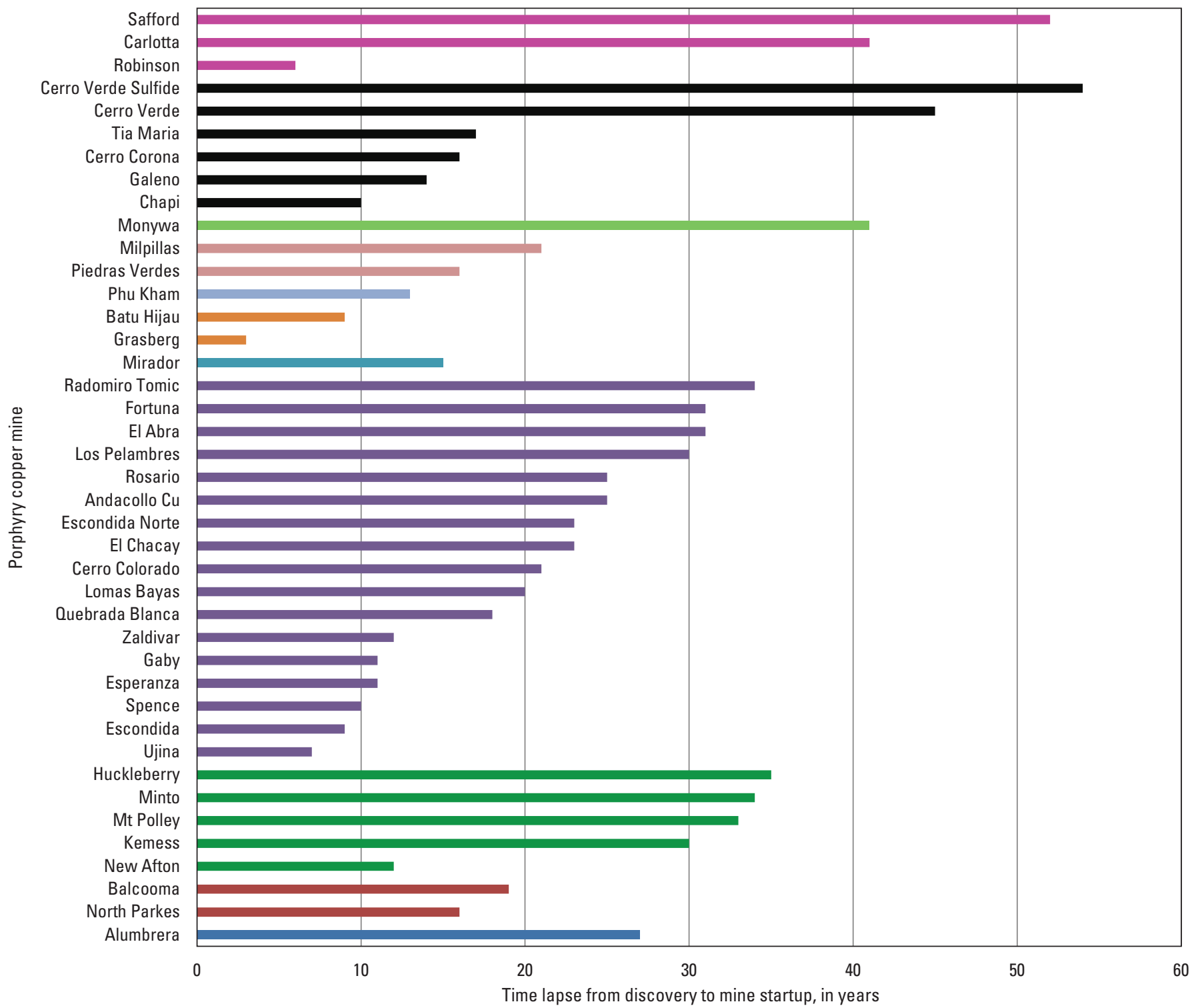

EXPLANATION

\begin{tabular}{|l|l|l|l|}
\hline United States & Mexico & Ecuador & Australia \\
\hline Peru & Laos & Chile & Argentina \\
\hline Burma & Indonesia & Canada & \\
\hline
\end{tabular}

Figure A10. Bar graph showing the years from discovery of porphyry copper deposits to mine startup for mines brought on stream between 1989 and 2008. Data from Doggett and Leveille (2010, table 1).

In planning for future resource availability, the long lag times between discovery and production must be considered (fig. A10). Most viable projects take 10-30 years to go from discovery to production, even in countries with well-developed copper mining industries such as Chile or Peru (fig. A10). The unusually short time from discovery to production in 3 years at the supergiant Grasberg porphyry copper-gold deposit in Indonesia was possible because other deposit types (skarns) had been mined in the area since 1972 and mineralized rock was first recognized in the area in the 1930s. In most cases, mine development proceeds at a much slower pace. In order for copper production to keep up with increases in consumption, the mining industry must plan far ahead to replenish depleted reserves. 
Will We Face a Copper Supply Crisis in the 21st Century?

World copper production has increased over time, as shown by a graph of annual copper production from the 1880s to the present in figure A11. Cumulative production from 1879 to 2012 was $600 \mathrm{Mt}$ (table A6); 45 percent of this has been produced during the past 20 years, and 26 percent has been produced during the past 10 years. These percentages relative to total production by time periods are nearly identical to those estimated in 2000 (Doggett, 2007), suggesting that copper mine production approximately doubles every 30 years to accommodate trends in global copper consumption. Can new copper resources continue to meet this increasing consumption trend into the future?

Copper consumption in developed countries becomes relatively stable over time, whereas copper consumption in developing countries and those with increasing populations tends to increase as living standards improve (DeYoung and Menzie, 1999; Menzie and others, 2003). World consumption of minerals is influenced by a number of factors, including geologic scarcity, uses for mineral commodities, the number of people using the minerals, and the standard of living of the population. Of these factors, geologic scarcity influences the ultimate resource base available for extraction and the costs required for discovery and extraction. Changes in population and standard of living appear to be the dominant drivers of global consumption trends over time.

In 2014, the U.S. Census Bureau estimated that world population would grow from 7 billion in 2012 to 9.4 billion in 2050 (U.S. Census Bureau, 2014). At current rates of global per capita consumption of copper, estimated at about 2.94 kilograms (kg) per year in 2012 (International Copper Study Group, 2015a), the demand for copper satisfied by mine production $^{3}$ would grow from the 2012 level of $16.9 \mathrm{Mt} / \mathrm{year}$ to $22.6 \mathrm{Mt} /$ year in 2050 (low mine curve in fig. A11). However, the global per capita consumption value of $2.94 \mathrm{~kg} / \mathrm{year}$ reflects very different levels of per capita consumption around the globe. Studies of per capita copper consumption in various countries show a consistent pattern of per capita consumption relative to level of economic development, with per capita consumption increasing with increasing per capita income (Menzie and others, 2003). Per capita consumption of copper

${ }^{3}$ Excludes the 20 percent of produced copper supplied by recycled and recovered processed metal per year (International Copper Study Group, 2015a).

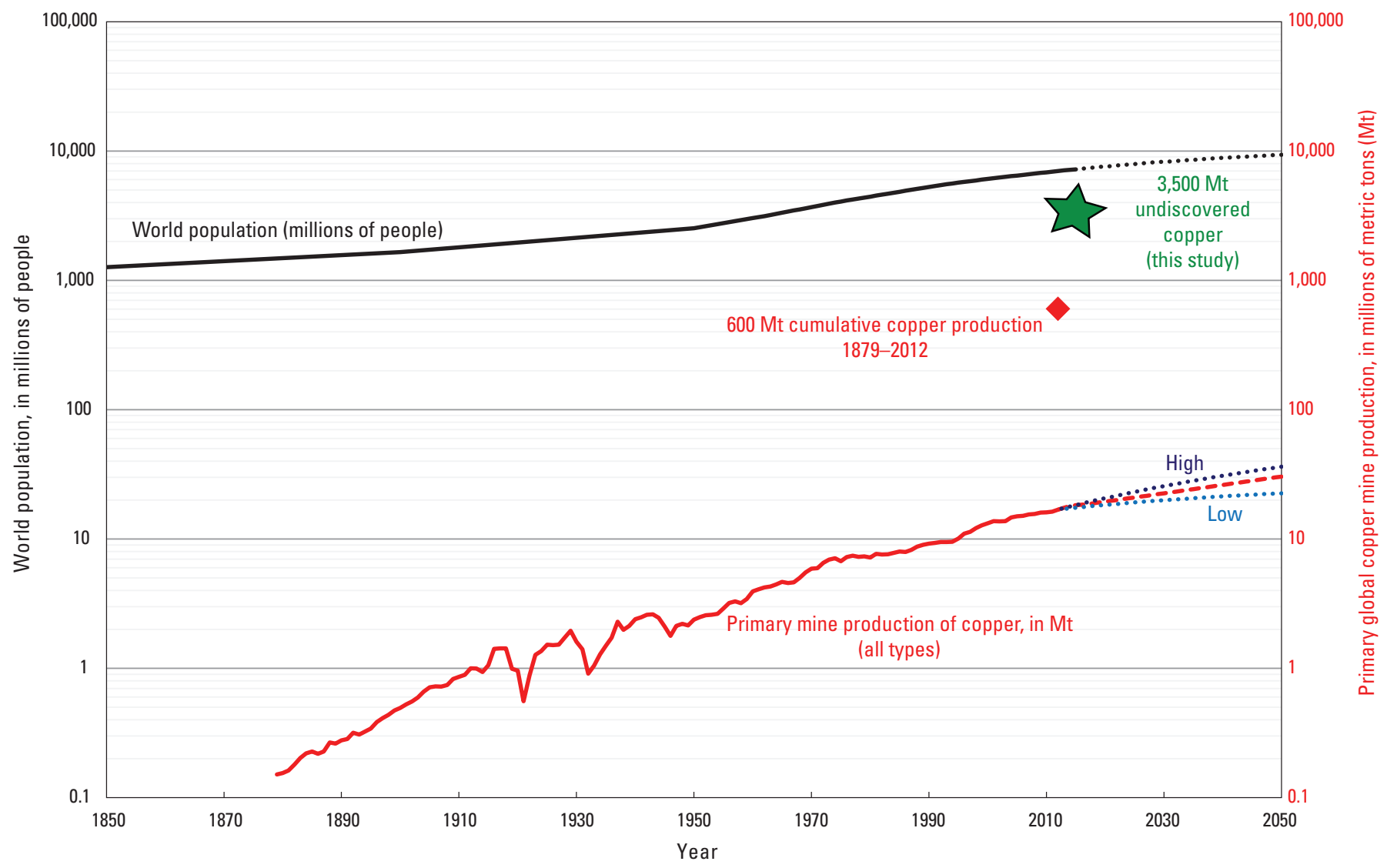

Figure A11. Graph of primary global copper mine production and world population from 1850 to 2050 (estimate). Census data from U.S. Census Bureau (2014). Copper production data in line graph and cumulative copper production from 1879 to 2012 from D.L. Edelstein (U.S. Geological Survey, written commun., 2013). 
is relatively stable over time in developed countries with high gross domestic products (GDPs), such as the United States and Japan, at values of $8.5-10 \mathrm{~kg} / \mathrm{year}$ (Menzie and others, 2003). Very low levels of consumption occur in countries with low economic activity and low income levels, such as some of the African nations. Rapidly increasing levels of per capita consumption are observed in rapidly developing countries such as South Korea and China. Factoring in projected growth in population and global per capita GDP to 2050 provides a forecast of copper consumption satisfied by primary mine production of 30-36 Mt of produced copper per year (mine and high mine trends in fig. A11). These projections estimate that between 750 and $990 \mathrm{Mt}$ of produced copper by mine production will be required to satisfy projected global demand for copper from 2012 to 2050. Are estimates of identified but undeveloped and undiscovered resources sufficient to meet this anticipated demand?
More than 2,000 Mt of copper resources is identified in, or has already been produced from, major copper deposits worldwide. South America, North America, and Asia contain the largest identified copper resources (fig. A12). Members of the USGS Global Copper Mineral Resource Assessment Team estimated that more than 3,500 Mt of copper is present in undiscovered deposits; most of these resources are located in Asia, followed by the Americas. Of this 3,500-Mt estimate of in-place copper resources, approximately $2,000 \mathrm{Mt}$ is predicted by the economic filter to be economic under current economic conditions and by use of current mining technology.

A significant fraction of the undiscovered resources is estimated to occur in deposits located in remote areas and (or) concealed deep beneath covering rock and sediments. These deposits will be difficult and time consuming to discover, and it is likely that many of these may not be discovered and developed in the next few decades. An estimate of potentially

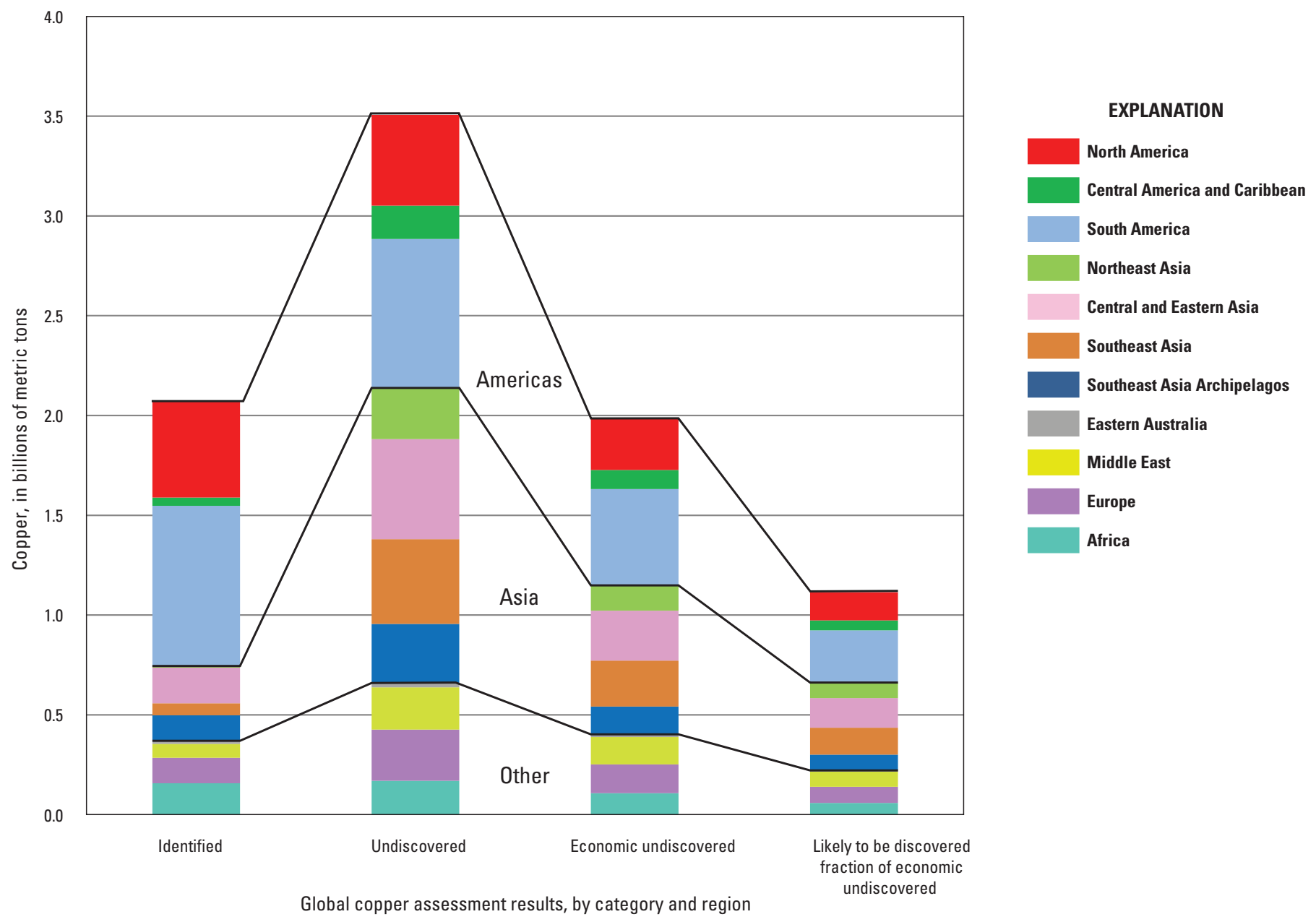

Figure A12. Bar graph summarizing global copper assessment results by category and region. The amounts in porphyry copper and sediment-hosted stratabound copper deposits (table A3) are combined for each region. For each color-coded region, the graph summarizes the identified copper resources, the mean estimates of undiscovered copper resources, the mean estimates of economic undiscovered copper resources, and the amounts of economic undiscovered copper resources that are likely to be discovered and developed before 2050. Heavy black lines group the data for the Americas, Asia, and other parts of the world. 
economic undiscovered resources that are most likely to be discovered and characterized by 2050 is approximately $1,100 \mathrm{Mt}$. This estimate of the fraction of economic resources likely to be discovered by 2050 is based on the discovery and characterization rates of gold deposits discovered worldwide from 1980 to 2010, as a function of discovery depth, reported by Schodde (2010). In our analysis, the 1,100 Mt of economic copper resources likely to be discovered by 2050 is derived by using the following assumptions for a 30 -year timeframe: nearly 100 percent of economic deposits at depths of less than $250 \mathrm{~m}$ will be discovered, 45 percent of economic deposits in the depth range of $>250-500 \mathrm{~m}$ will be discovered, and 32 percent of economic deposits in the depth range of $>500-1,000 \mathrm{~m}$ will be discovered. These resource estimates exceed or equal the projected global demand for primary copper production by 2050 and are in addition to identified copper resources. However, extensive mineral exploration will be required to meet this future resource demand, as many of these deposits will be harder to find and more costly to mine than near-surface deposits located in more accessible areas. The resource issue for the future likely will be the development of capacity to discover, develop, and mine additional resources.

\section{Significance of the First Global Copper Assessment}

This first global copper assessment identified areas of the world where undiscovered copper resources are likely to exist. This information provides decision makers with a scientific basis for including mineral potential in land-use and other policy decisions. This assessment provides answers to the questions about how much of the world's copper endowment is left, where it is, and what kinds of deposits contain it. A variety of factors including economics, political stability, social license, sustainable development policies, environmental concerns, availability of land, and technology will determine the extent of exploration and development of these undiscovered resources. Applications of simplified economic filters suggest that although copper is not an infinite resource, the amount of copper that is projected to be needed by 2050 is likely to be discovered from the two major geologic sources of global copper supply considered in this assessment-porphyry copper and sediment-hosted stratabound copper. Other types of copper deposits, such as volcanogenic massive sulfide deposits and iron-oxide-copper-gold deposits, also contribute to the global copper supply. In addition, almost 20 percent of world copper refinery production is from copper scrap, including used products and residuals from manufacturing (International Copper Study Group, 2015b). Because copper retains its properties when reprocessed, nearly all of the primary copper extracted during mining can be reused again and again by society, thereby contributing to sustainability (Papp, 2015).
Areas that have not been significant sources of copper in the past, such as the Tibetan Plateau; the Pacific margin of Russia and China; and Turkey, Iran, and Pakistan, may become more important in the future. An exploration focus on permissive tracts for undiscovered sediment-hosted stratabound copper deposits in Africa potentially could contribute to the economic well-being of developing countries as well as contribute to global copper and cobalt supply.

This study is the first application of USGS mineral resource assessment methods for nonfuel commodities on a global scale. A vast amount of geologic information was compiled and evaluated in doing the assessment. These data and methods are applicable to assessments for other commodities. In addition, this assessment provides a framework that can be refined and updated as new data become available in the future. The assessment results and maps presented here can be used by governments, nongovernmental groups, the mineral industry, economists, land-use planners, and students to address societal issues associated with copper availability.

\section{References Cited}

Anderson, J.A., 1982, Gold-Its history and role in the U.S. economy and the U.S. exploration program of Homestake Mining Co.: American Mining Congress Journal, v. 68, no. 1 (January), p. 51-58.

Baja Mining Corporation, 2010, El Boleo (Boleo) Project, technical report update, Baja California South, Mexico: Baja Mining Corporation, 206 p.

Bawiec, W.J., and Spanski, G.T., 2012, Quick-start guide for version 3.0 of EMINERS-Economic Mineral Resource Simulator: U.S. Geological Survey Open-File Report 2009-1057, 26 p., accessed June 30, 2012, at http://pubs.usgs.gov/of/2009/1057. [This report supplements USGS OFR 2004-1344; see Duval (2012).]

Berger, B.R., Mars, J.C., Denning, P.D., Phillips, J.D., Hammarstrom, J.M., Zientek, M.L, Dicken, C.L., and Drew, L.J., 2014, Porphyry copper assessment of western Central Asia: U.S. Geological Survey Scientific Investigations Report 2010-5090-N, 219 p., 8 pls., and spatial data, accessed June 1, 2015, at http://dx.doi.org/10.3133/ sir20105090N.

Bookstrom, A.A., Glen, R.A., Hammarstrom, J.M., Robinson, G.R., Jr., Zientek, M.L., Drenth, B.J., Jaireth, Subhash, Cossette, P.M., and Wallis, J.C., 2014, Porphyry copper assessment of eastern Australia: U.S. Geological Survey Scientific Investigations Report 2010-5090-L, 160 p. and GIS data, accessed June 1, 2015, at http://dx.doi.org/10.3133/ sir20105090L. 
Box, S.E., Syusyura, Boris, Hayes, T.S., Taylor, C.D., Zientek, M.L., Hitzman, M.W., Seltmann, Reimar, Chechetkin, Vladimir, Dolgopolova, Alla, Cossette, P.M., and Wallis, J.C., 2012, Sandstone copper assessment of the Chu-Sarysu Basin, central Kazakhstan (ver. 1.1, November 2012): U.S. Geological Survey Scientific Investigations Report 2010-5090-E, 63 p. and spatial data tables, accessed June 1, 2015, at http://pubs.usgs.gov/sir/2010/5090/e/.

Brininstool, Mark, 2014, Copper: U.S. Geological Survey Mineral Commodity Summaries 2014, p. 48-49, accessed June 1, 2015, at http://minerals.usgs.gov/minerals/pubs/ commodity/copper/mcs-2014-coppe.pdf.

Brininstool, Mark, 2015, Copper: U.S. Geological Survey Mineral Commodity Summaries 2015, p. 48-49, accessed June 1, 2015, at http://minerals.usgs.gov/minerals/pubs/ commodity/copper/mcs-2015-coppe.pdf.

Briskey, J.A., Schulz, K.J., Mosesso, J.P., Horwitz, L.R., and Cunningham, C.G., 2001, It's time to know the planet's mineral resources: Geotimes, v. 46, no. 3, p. 14-19, accessed October 10, 2011, at http://www.geotimes.org/ mar01/.

Briskey, J.A., Schulz, K.J., Mosesso, J.P., Horwitz, L.R., and Cunningham, C.G., 2007, Environmental planning issues and a conceptual global assessment of undiscovered nonfuel mineral resources, in Briskey, J.A., and Schulz, K.J., eds., Proceedings for a Workshop on Deposit Modeling, Mineral Resource Assessment, and Their Role in Sustainable Development: U.S. Geological Survey Circular 1294, p. 19-28, accessed June 1, 2015, at http://pubs.usgs.gov/ circ/2007/1294/.

Committee for Mineral Reserves International Reporting Standards, 2006, International reporting template for the public reporting of exploration results, mineral resources and mineral reserves: Committee for Mineral Reserves International Reporting Standards, 33 p., accessed July 15, 2007, at http://www.crirsco.com/crirsco_template_first_ed_0806.pdf.

Cossette, P.M., Bookstrom, A.A., Hayes, T.S., Robinson, G.R., Jr., Wallis, J.C., and Zientek, M.L., 2014, Sandstone copper assessment of the Teniz Basin, Kazakhstan: U.S. Geological Survey Scientific Investigations Report 2010-5090-R, 42 p. and spatial data, accessed June 1, 2015, at http://dx.doi. org/10.3133/sir20105090R.
Cunningham, C.G.; Zappettini, E.O.; Vivallo S., Waldo; Celada, C.M.; Quispe, Jorge; Singer, D.A.; Briskey, J.A.; Sutphin, D.M.; Gajardo M., Mariano; Diaz, Alejandro; Portigliati, Carlos; Berger, V.I.; Carrasco, Rodrigo; and Schulz, K.J., 2008, Quantitative mineral resource assessment of copper, molybdenum, gold, and silver in undiscovered porphyry copper deposits in the Andes Mountains of South America: U.S. Geological Survey Open-File Report 2008-1253, 282 p., accessed June 1, 2015, at http://pubs.usgs.gov/of/2008/1253.

Danielson, J.J., and Gesch, D.B., 2011, Global multiresolution terrain elevation data 2010 (GMTED2010): U.S. Geological Survey Open-File Report 2011-1073, 26 p., accessed June 1, 2015, at http://pubs.usgs.gov/ of $/ 2011 / 1073 /$.

de Ferranti, Jonathan, and Hormann, Christoph, 2009, Digital elevation data - North Eurasia: Viewfinder Panoramas, accessed August 24, 2015, at http://www.viewfinderpanoramas.org/ Coverage\%20map\%20viewfinderpanoramas_org3.htm.

DeYoung, J.H., Jr., and Menzie, W.D., 1999, The changing uses of minerals information-A government perspective, in Otto, James, and Kim, H.-S., eds., Proceedings of the Workshop on the Sustainable Development of Non-Renewable Resources, Towards the 21st Century-New York, United States, October 15-16, 1998: New York, United Nations Revolving Fund for Natural Resources Exploration, p. 111-127.

Dicken, C.L., Dunlap, Pamela, Parks, H.L., Hammarstrom, J.M., and Zientek, M.L., 2016, Spatial database for a global assessment of undiscovered copper resources: U.S. Geological Survey Scientific Investigations Report 2010-5090-Z, 29 p. and GIS data, accessed July 21, 2016, at http://dx.doi.org/10.3133/sir20105090Z.

Doggett, M.D., 2007, Global mineral exploration and production-The impact of technology, in Briskey, J.A., and Schulz, K.J., eds., Proceedings for a Workshop on Deposit Modeling, Mineral Resource Assessment, and Their Role in Sustainable Development: U.S. Geological Survey Circular 1294, p. 63-68, accessed June 1, 2015, at http://pubs.usgs.gov/ circ/2007/1294/.

Doggett, M.D., and Leveille, R.A., 2010, Assessing the returns to copper exploration, 1989-2008: Exploration and Mining Geology, v. 19, nos. 1-2, p. 23-33.

Duval, J.S., 2012, Version 3.0 of EMINERS-Economic Mineral Resource Simulator: U.S. Geological Survey Open-File Report 2004-1344, accessed July 15, 2012, at http://pubs.usgs.gov/of/2004/1344. 
Earth Resources Observation and Science (EROS) Center, 2011, HYDRO1k elevation derivative database: U.S. Geological Survey web page, accessed May 29, 2013, at http:// eros.usgs.gov/\#Find_Data/Products_and_Data_Available/ gtopo30/hydro.

Edelstein, D.L, 2013, Copper: U.S. Geological Survey Mineral Commodity Summaries 2013, p. 48-49, accessed June 1, 2015, at http://minerals.usgs.gov/minerals/pubs/mcs/ mcs2013.pdf.

ESRI, 2008, Global shaded relief derived from the Shuttle Radar Topography Mission (SRTM): Redlands, Calif., ESRI Data \& Maps, release 9.3-Global Imagery and Shaded Relief, DVD.

Frost, T.P., Bookstrom, A.A., and Mihalasky, M.J., 2013, Grade and tonnage model for calc-alkalic porphyry $\mathrm{Cu} \pm \mathrm{Mo} \pm \mathrm{Au}$ deposits of the Canadian Cordillera, app. G of Mihalasky, M.J., Bookstrom, A.A., Frost, T.P., and Ludington, Steve, Porphyry copper assessment of British Columbia and Yukon Territory, Canada (ver. 1.1, February 2013): U.S. Geological Survey Scientific Investigations Report 2010-5090-C, p. 118-125, accessed June 1, 2015, at http://pubs.usgs.gov/sir/2010/5090/c/.

Gray, Floyd, Hammarstrom, J.M., Ludington, Steve, Zürcher, Lukas, Nelson, C.E., Robinson, G.R., Jr., Miller, R.J., and Moring, B.C., 2014, Porphyry copper assessment of Central America and the Caribbean Basin: U.S. Geological Survey Scientific Investigations Report 2010-5090-I, 81 p. and GIS data, accessed June 1, 2015, at http://dx.doi.org/ 10.3133/sir20105090I.

Hammarstrom, J.M., Bookstrom, A.A., DeMarr, M.W., Dicken, C.L., Ludington, Steve, Robinson, G.R., Jr., and Zientek, M.L., 2014, Porphyry copper assessment of East and Southeast Asia - Philippines, Taiwan (Republic of China), Republic of Korea (South Korea), and Japan: U.S. Geological Survey Scientific Investigations Report 2010-5090-P, 243 p. and spatial data, accessed June 1, 2015, at http://dx.doi.org/10.3133/sir20105090P.

Hammarstrom, J.M., Bookstrom, A.A., Dicken, C.L., Drenth, B.J., Ludington, Steve, Robinson, G.R., Jr., Setiabudi, B.T., Sukserm, Wudihikarn, Sunuhadi, D.N., Wah, A.Y.S., and Zientek, M.L., 2013, Porphyry copper assessment of Southeast Asia and Melanesia: U.S. Geological Survey Scientific Investigations Report 2010-5090-D, 332 p. and GIS data, accessed June 1, 2015, at http://pubs.usgs.gov/ $\operatorname{sir} / 2010 / 5090 / \mathrm{d} /$.
Hammarstrom, J.M., Mihalasky, M.J., Ludington, Steve, Phillips, J.D., Berger, B.R., Denning, P.D., Dicken, C.L., Mars, J.C., Zientek, M.L., Herrington, R.J., and Seltmann, Reimar, 2017, Undiscovered porphyry copper resources in the Urals-A probabilistic mineral resource assessment: Ore Geology Reviews, v. 85 (May 2017), p. 181-203, accessed May 16, 2017, at https://doi.org/10.1016/ j.oregeorev.2016.09.007.

Hammarstrom, J.M., Robinson, G.R., Jr., Ludington, Steve, Gray, Floyd, Drenth, B.J., Cendejas-Cruz, Francisco, Espinosa, Enrique, Pérez-Segura, Efrén, Valencia-Moreno, Martín, Rodríguez-Castañeda, J.L., Vásquez-Mendoza, Rigoberto, and Zürcher, Lukas, 2010, Porphyry copper assessment of Mexico: U.S. Geological Survey Scientific Investigations Report 2010-5090-A, 176 p. and GIS package, accessed October 10, 2011, at http://pubs.usgs.gov/ sir/2010/5090/a/.

Hammarstrom, J.M., Zientek, M.L., and Parks, H.L., 2018, Global mineral resource assessment—Summary simulation results for estimates of amounts of copper in undiscovered porphyry copper deposits: U.S. Geological Survey data release, accessed February 1, 2018, at https://doi.org/10.5066/ F70K26Q4.

Hayes, T.S., Cox, D.P., Piatak, N.M., and Seal, R.R., II, 2015, Sediment-hosted stratabound copper deposit model: U.S. Geological Survey Scientific Investigations Report 2010-5070-M, 147 p., accessed July 7, 2015, at http://dx.doi.org/10.3133/sir20105070M.

Hitzman, Murray, Kirkham, Rodney, Broughton, David, Thorson, Jon, and Selley, David, 2005, The sedimenthosted stratiform copper ore system, in Hedenquist, J.W., Thompson, J.F.H., Goldfarb, R.J., and Richards, J.P., eds., Economic Geology - One hundredth anniversary volume 1905-2005: Littleton, Colo., Society of Economic Geologists, Inc., p. 609-642.

Howat, I.M., Negrete, A., and Smith, B.E., 2014, The Greenland Ice Mapping Project (GIMP) land classification and surface elevation data sets: Cryosphere, v. 8, p. 1509-1518, accessed September 15, 2015, at http://www.the-cryosphere. net/8/1509/2014/tc-8-1509-2014.html.

International Commission on Stratigraphy, 2010, International stratigraphic chart: International Commission on Stratigraphy chart, accessed October 1, 2016, at http://www.stratigraphy.org/index.php/ics-chart-timescale.

International Commission on Stratigraphy, 2013, International chronostratigraphic chart, version 2013/01: International Commission on Stratigraphy chart, accessed October 1, 2016, at http://www.stratigraphy.org/index.php/ics-charttimescale.

International Copper Study Group, 2015a, Copper bulletin: International Copper Study Group, v. 22, no. 7, July, 53 p. 
International Copper Study Group, 2015b, The world copper factbook 2015: accessed August 20, 2016, at http://www.icsg.org/index.php/component/jdownloads/ finish/170-publications-press-releases/2092-2015-10-03icsg-factbook-2015?Itemid=0.

John, D.A., Ayuso, R.A., Barton, M.D., Blakely, R.J., Bodnar, R.J., Dilles, J.H., Gray, Floyd, Graybeal, F.T., Mars, J.C., McPhee, D.K., Seal, R.R., Taylor, R.D., and Vikre, P.G., 2010, Porphyry copper deposit model: U.S. Geological Survey Scientific Investigations Report 2010-5070-B, 169 p., accessed June 1, 2015, at http://pubs.usgs.gov/ $\operatorname{sir} / 2010 / 5070 / b /$.

Johnson, K.M., Hammarstrom, J.M., Zientek, M.L., and Dicken, C.L., 2014, Estimate of undiscovered copper resources of the world, 2013: U.S. Geological Survey Fact Sheet 2014-3004, 3 p., accessed June 1, 2016, at http://dx.doi.org/10.3133/fs20143004.

Kesler, S.E., and Wilkinson, B.H., 2008, Earth's copper resources estimated from tectonic diffusion of porphyry copper deposits: Geology, v. 36, no. 3, p. 255-258.

Knox-Robinson, C.M., and Wyborn, L.A.I., 1997, Towards a holistic exploration strategy-Using geographic information systems as a tool to enhanced exploration: Australian Journal of Earth Sciences, v. 44, no. 4, p. 453-463.

Ludington, Steve, Hammarstrom, J.M., Robinson, G.R., Jr., Mars, J.C., and Miller, R.J., 2012, Porphyry copper assessment of the Tibetan Plateau, China: U.S. Geological Survey Scientific Investigations Report 2010-5090-F, 63 p. and GIS data, accessed June 1, 2015, at http://pubs.usgs.gov/ $\operatorname{sir} / 2010 / 5090 / \mathrm{f} /$.

Ludington, Steve, Mihalasky, M.J., Hammarstrom, J.M., Robinson, G.R., Jr., Frost, T.P., Gans, K.D., Light, T.D., Miller, R.J., and Alexeiev, Dmitriy, 2012, Porphyry copper assessment of the Mesozoic of East Asia — China, Vietnam, North Korea, Mongolia, and Russia: U.S. Geological Survey Scientific Investigations Report 2010-5090-G, 53 p. and GIS data, accessed June 1, 2015, at http://pubs.usgs.gov/ $\operatorname{sir} / 2010 / 5090 / \mathrm{g} /$.

Ludington, Steve, Orris, G.J., Bolm, K.S., Peters, S.G., and the U.S. Geological Survey-Afghanistan Ministry of Mines and Industry Joint Mineral Resource Assessment Team, 2007, Preliminary mineral resource assessment of selected mineral deposit types in Afghanistan: U.S. Geological Survey Open-File Report 2007-1005, 44 p., accessed July 7, 2014, at http://pubs.usgs.gov/of/2007/1005/.

Menzie, W.D., DeYoung, J.H., Jr., and Steblez, W.G., 2003, Some implications of changing patterns of mineral consumption: U.S. Geological Survey OpenFile Report 03-382, 35 p., accessed June 1, 2015, at http://pubs.usgs.gov/of/2003/of03-382/.
Mihalasky, M.J., Bookstrom, A.A., Frost, T.P., and Ludington, Steve, 2013, Porphyry copper assessment of British Columbia and Yukon Territory, Canada (ver. 1.1, February 2013): U.S. Geological Survey Scientific Investigations Report 2010-5090-C, 128 p. and data tables, accessed June 1, 2015, at http://pubs.usgs.gov/sir/2010/5090/c/.

Mihalasky, M.J., Ludington, Steve, Alexeiev, D.V., Frost, T.P., Light, T.D., Briggs, D.A., Hammarstrom, J.M., and Wallis, J.C., 2015, Porphyry copper assessment of northeast Asia-Far East Russia and northeasternmost China: U.S. Geological Survey Scientific Investigations Report 2010 5090-W, 104 p. and spatial data, accessed June 1, 2015, at http://dx.doi.org/10.3133/sir20105090W.

Mihalasky, M.J., Ludington, Steve, Hammarstrom, J.M., Alexeiev, D.V., Frost, T.P., Light, T.D., Robinson, G.R., Jr., Briggs, D.A., Wallis, John, and Miller, R.J., 2015, Porphyry copper assessment of the Central Asian Orogenic Belt and eastern Tethysides - China, Mongolia, Russia, Pakistan, Kazakhstan, Tajikistan, and India: U.S. Geological Survey Scientific Investigations Report 2010-5090-X, 106 p. and spatial data, accessed June 1, 2016, at http://dx.doi.org/ 10.3133/sir20105090X.

Mudd, G.M., Weng, Zhehan, and Jowitt, S.M., 2013, A detailed assessment of global $\mathrm{Cu}$ resource trends and endowments: Economic Geology, v. 108, no. 5, p. $1163-$ 1183 .

Papp, J.F., 2015, Recycling-Metals [advance release] in Metals and minerals: U.S. Geological Survey Minerals Yearbook 2013, v. I, p. 61.1-61.5, accessed September 1, 2015, at http://minerals.usgs.gov/minerals/pubs/commodity/myb/.

Peters, S.G., Ludington, S.D., Orris, G.J., Sutphin, D.M., Bliss, J.D., and Rytuba, J.J., eds., and the U.S. Geological Survey-Afghanistan Ministry of Mines Joint Mineral Resource Assessment Team, 2007, Preliminary non-fuel mineral resource assessment of Afghanistan: U.S. Geological Survey Open-File Report 2007-1214, 810 p. and data files, accessed August 15, 2014, at http://pubs.usgs.gov/ of $/ 2007 / 1214 /$.

Rasilainen, K., Eilu, P., Halkoaho, T., Karvinen, A., Kontinen, A., Kousa, J., Lauri, L., Luukas, J., Niiranen, T., Nikander, J., Sipilä, P., Sorjonen-Ward, P., Tiainen, M., Törmänen, T., and Västi, K., 2014, Quantitative assessment of undiscovered resources in volcanogenic massive sulphide deposits, porphyry copper deposits and Outokumpu-type deposits in Finland: Geological Survey of Finland Report of Investigation 208, 393 p., accessed July 30, 2015, at http://tupa.gtk.fi/ julkaisu/tutkimusraportti/tr_208.pdf.

Rio Tinto, 2017, 2016 annual report: Rio Tinto, 252 p., accessed August 23, 2017, at http://www.riotinto.com/ documents/RT_2016_Annual_report.pdf. 
Robinson, G.R., Jr., and Menzie, W.D., 2014, Economic filters for evaluating porphyry copper deposit resource assessments using grade-tonnage deposit models, with examples from the U.S. Geological Survey global mineral resource assessment (ver. 1.2, March 2014): U.S. Geological Survey Scientific Investigations Report 2010-5090-H, 21 p. and separate file for tables 7 and 8, accessed June 1, 2015, at http://pubs.usgs.gov/sir/2010/5090/h/.

Root, D.H., Menzie, W.D., and Scott, W.A., 1992, Computer Monte Carlo simulation in quantitative resource estimation: Nonrenewable Resources, v. 1, no. 2, p. 125-138.

Schodde, Richard, 2010, Giant ore deposits-Why they are important! - transcript of talk given at Theo Murphy High Flyers Think Tank 2010, Searching the deep Earth-The future of Australian resource discovery and utilisation [sic], the Shine Dome, Canberra, 19-20 August 2010: transcript, 19 p., accessed July 15, 2015, at http://www.minexconsulting.com/ publications/aug2010.html.

Schuenemeyer, J.H., Zientek, M.L, and Box, S.E., 2011, Aggregation of estimated numbers of undiscovered mineral deposits-An R-script with an example from the Chu Sarysu Basin, Kazakhstan: U.S. Geological Survey Scientific Investigations Report 2010-5090-B, 13 p. and code package, accessed June 1, 2015, at http://pubs.usgs.gov/ $\operatorname{sir} / 2010 / 5090 / b /$.

Schulz, K.J., and Briskey, J.A., 2003, The global mineral resource assessment project: U.S. Geological Survey Fact Sheet FS-053-03, 4 p., accessed October 10, 2011, at http://pubs.usgs.gov/fs/fs053-03/.

Singer, D.A., 1993, Basic concepts in three-part quantitative assessments of undiscovered mineral resources: Nonrenewable Resources, v. 2, no. 2, p. 69-81.

Singer, D.A., 1995, World class base and precious metal deposits-A quantitative analysis: Economic Geology, v. 90 , no. 1 , p. $88-104$.

Singer, D.A., and Menzie, W.D., 2010, Quantitative mineral resource assessments - An integrated approach: New York, Oxford University Press, 219 p.

Singer, D.A., Berger, V.I., and Moring, B.C., 2008, Porphyry copper deposits of the world-Database and grade and tonnage models, 2008: U.S. Geological Survey Open-File Report 2008-1155, 45 p., accessed November 15, 2010, at http://pubs.usgs.gov/of/2008/1155/.

Stensgaard, B.M., 2011, Sediment-hosted copper in Greenland-Assessment of potential and undiscovered $\mathrm{Cu}$ deposits: Geology and Ore, no. 18 (January 2011), 12 p., accessed October 18, 2011, at http://www.geus.dk/minex/go18.pdf.
Stensgaard, B.M., Kalvig, Per, and Stendal, Henrik, 2011, Quantitative mineral resource assessment-Sedimentaryhosted copper in Greenland-Reporting the copper assessment workshop, GEUS, Copenhagen, March 2009: Geological Survey of Denmark and Greenland (GEUS) Report 2011/104, 104 p., 1 CD-ROM.

Sutphin, D.M., Hammarstrom, J.M., Drew, L.J., Large, D.E., Berger, B.R., Dicken, C.L., and DeMarr, M.W., 2013, Porphyry copper assessment of Europe, exclusive of the Fennoscandian Shield: U.S. Geological Survey Scientific Investigations Report 2010-5090-K, 197 p. and GIS data, accessed June 1, 2015, at http://pubs.usgs.gov/ $\operatorname{sir} / 2010 / 5090 / \mathrm{k} /$.

Tobler, Waldo, 1987, Measuring spatial resolution, in Land Resources Information Systems Conference, Proceedings: Beijing, p. 12-16.

United Nations Statistics Division, 2016, Composition of macro geographical (continental) regions, geographical sub-regions, and selected economic and other groupings: United Nations website, accessed October 4, 2016, at http://unstats.un.org/unsd/methods/m49/m49regin.htm.

U.S. Bureau of Mines and U.S. Geological Survey, 1980, Principles of a resource/reserve classification for minerals: U.S. Geological Survey Circular 831, 5 p. [Also available at https://pubs.er.usgs.gov/publication/cir831.]

U.S. Census Bureau, 2014, International Data Base: U.S. Census Bureau database, accessed May 20, 2014, at http://www.census.gov/population/international/data/idb/ informationGateway.php.

U.S. Department of State, 2009, Small-scale digital international land boundaries (SSIB) - Lines, edition 10, and polygons, beta edition 1, in Boundaries and sovereignty encyclopedia (B.A.S.E.): U.S. Department of State, Office of the Geographer and Global Issues.

U.S. Geological Survey, 2017, Copper-Statistics and information: U.S. Geological Survey web page, accessed August 17, 2017, at https://minerals.usgs.gov/minerals/pubs/ commodity/copper.

U.S. Geological Survey National Mineral Resource Assessment Team, 2000, 1998 assessment of undiscovered deposits of gold, silver, copper, lead, and zinc in the United States: U.S. Geological Survey Circular 1178, 21 p., 1 CD-ROM in pocket. [Also available at http://pubs.usgs.gov/circ/c1178/. Recompiled in USGS Open-File Report 02-198.] 
U.S. Geological Survey National Mineral Resource Assessment Team, 2002, Assessment of undiscovered deposits of gold, silver, copper, lead, and zinc in the United States-A Portable Document Format (PDF) recompilation of USGS Open-File Report 96-96 and Circular 1178: U.S. Geological Survey Open-File Report 02-198, accessed October 1, 2015, at http://pubs.usgs.gov/of/2002/of02-198/. [Recompilation by Paul Schruben.]

Wyborn, L.A.I., Heinrich, C.A., and Jaques, A.L., 1994, Australian Proterozoic mineral systems-Essential ingredients and mappable criteria, in Hallenstein, C.P., ed., Australian mining looks north-The challenges and choices-1994 AusIMM Annual Conference, Darwin, 5-9 August 1994, technical program proceedings: Australasian Institute of Mining and Metallurgy Publication 5/94, p. 109-115, accessed May 24, 2012, at http://www.ga.gov.au/image cache/GA5228.pdf.

Zientek, M.L. and Orris, G.J., 2005, Geology and nonfuel mineral deposits of the United States, chap. A of Schulz, K.J., and Briskey, J.A., eds., Reviews of the geology and nonfuel mineral deposits of the world: U.S. Geological Survey Open-File Report 2005-1294, 172 p., accessed April 15, 2014, at http://pubs.usgs.gov/of/2005/1294/a/ index.html.

Zientek, M.L., Bliss, J.D., Broughton, D.W., Christie, Michael, Denning, P.D., Hayes, T.S., Hitzman, M.W., Horton, J.D., Frost-Killian, Susan, Jack, D.J., Master, Sharad, Parks, H.L., Taylor, C.D., Wilson, A.B., Wintzer, N.E., and Woodhead, Jon, 2014, Sediment-hosted stratabound copper assessment of the Neoproterozoic Roan Group, Central African Copperbelt, Katanga Basin, Democratic Republic of the Congo and Zambia: U.S. Geological Survey Scientific Investigations Report 2010-5090-T, 162 p. and spatial data, accessed June 1, 2015, at http://dx.doi.org/10.3133/ sir20105090T.

Zientek, M.L., Chechetkin, V.S., Parks, H.L., Box, S.E., Briggs, D.A., Cossette, P.M., Dolgopolova, Alla, Hayes, T.S., Seltmann, Reimar, Syusyura, Boris, Taylor, C.D., and Wintzer, N.E., 2014, Assessment of undiscovered sandstone copper deposits of the Kodar-Udokan area, Russia: U.S. Geological Survey Scientific Investigations Report 2010-5090-M, 129 p. and GIS data, accessed August 22, 2016, at http://dx.doi.org/10.3133/sir20105090M.

Zientek, M.L., Hammarstrom, J.M., Johnson, K.M., and Pierce, F.W., eds., 2010-16, Global mineral resource assessment: U.S. Geological Survey Scientific Investigations Report 2010-5090-A-Z, accessed August 22, 2016, at http://pubs.usgs.gov/sir/2010/5090/index.html. [Chapters are variously paged and are published separately online.]
Zientek, M.L., Hayes, T.S., and Hammarstrom, J.M., 2013, Overview of a new descriptive model for sediment-hosted stratabound copper deposits, chap. 1 of Taylor, C.D., Causey, J.D., Denning, P.D., Hammarstrom, J.M., Hayes, T.S., Horton, J.D., Kirschbaum, M.J., Parks, H.L., Wilson, A.B., Wintzer, N.E., and Zientek, M.L., Descriptive models, grade-tonnage relations, and databases for the assessment of sediment-hosted copper deposits-With emphasis on deposits in the Central African Copperbelt, Democratic Republic of the Congo and Zambia: U.S. Geological Survey Scientific Investigations Report 2010-5090-J, p. 2-16, accessed April 24, 2014, at http://pubs.usgs.gov/sir/2010/5090/j/.

Zientek, M.L., Hayes, T.S., and Taylor, C.D., 2013, Grade and tonnage relations for sediment-hosted stratabound copper deposits, chap. 2 of Taylor, C.D., Causey, J.D., Denning, P.D., Hammarstrom, J.M., Hayes, T.S., Horton, J.D., Kirschbaum, M.J., Parks, H.L., Wilson, A.B., Wintzer, N.E., and Zientek, M.L., Descriptive models, grade-tonnage relations, and databases for the assessment of sediment-hosted copper deposits-With emphasis on deposits in the Central African Copperbelt, Democratic Republic of the Congo and Zambia: U.S. Geological Survey Scientific Investigations Report 2010-5090-J, p. 17-59, accessed April 24, 2014, at http://pubs.usgs.gov/sir/2010/5090/j/.

Zientek, M.L., Oszczepalski, Sławomir, Parks, H.L., Bliss, J.D., Borg, Gregor, Box, S.E., Denning, P.D., Hayes, T.S., Spieth, Volker, and Taylor, C.D., 2015, Assessment of undiscovered copper resources associated with the Permian Kupferschiefer, Southern Permian Basin, Europe: U.S. Geological Survey Scientific Investigations Report 2010-5090-U, 94 p. and spatial data, http://dx.doi.org/ 10.3133/sir20105090U.

Zientek, M.L., Wintzer, N.E., Hayes, T.S., Parks, H.L., Briggs, D.A., Causey, J.D., Hatch, S.A., Jenkins, M.C., and Williams, D.J., 2015, Qualitative assessment of selected areas of the world for undiscovered sediment-hosted stratabound copper deposits: U.S. Geological Survey Scientific Investigations Report 2010-5090-Y, 143 p. and spatial data, accessed December 30, 2015, at http://dx.doi.org/10.3133/ sir20105090Y.

Zürcher, Lukas, Bookstrom A.A., Hammarstrom, J.M., Mars, J.C., Ludington, Steve, Zientek, M.L., Dunlap, Pamela, and Wallis, J.C., 2015, Porphyry copper assessment of the Tethys region of western and southern Asia: U.S. Geological Survey Scientific Investigations Report 2010-5090-V, 232 p. and spatial data, accessed December 30, 2015, at http://dx.doi.org/10.3133/sir20105090V. 

Figures $A 3, A 5, A 6, A 8$, and $A 9$ 


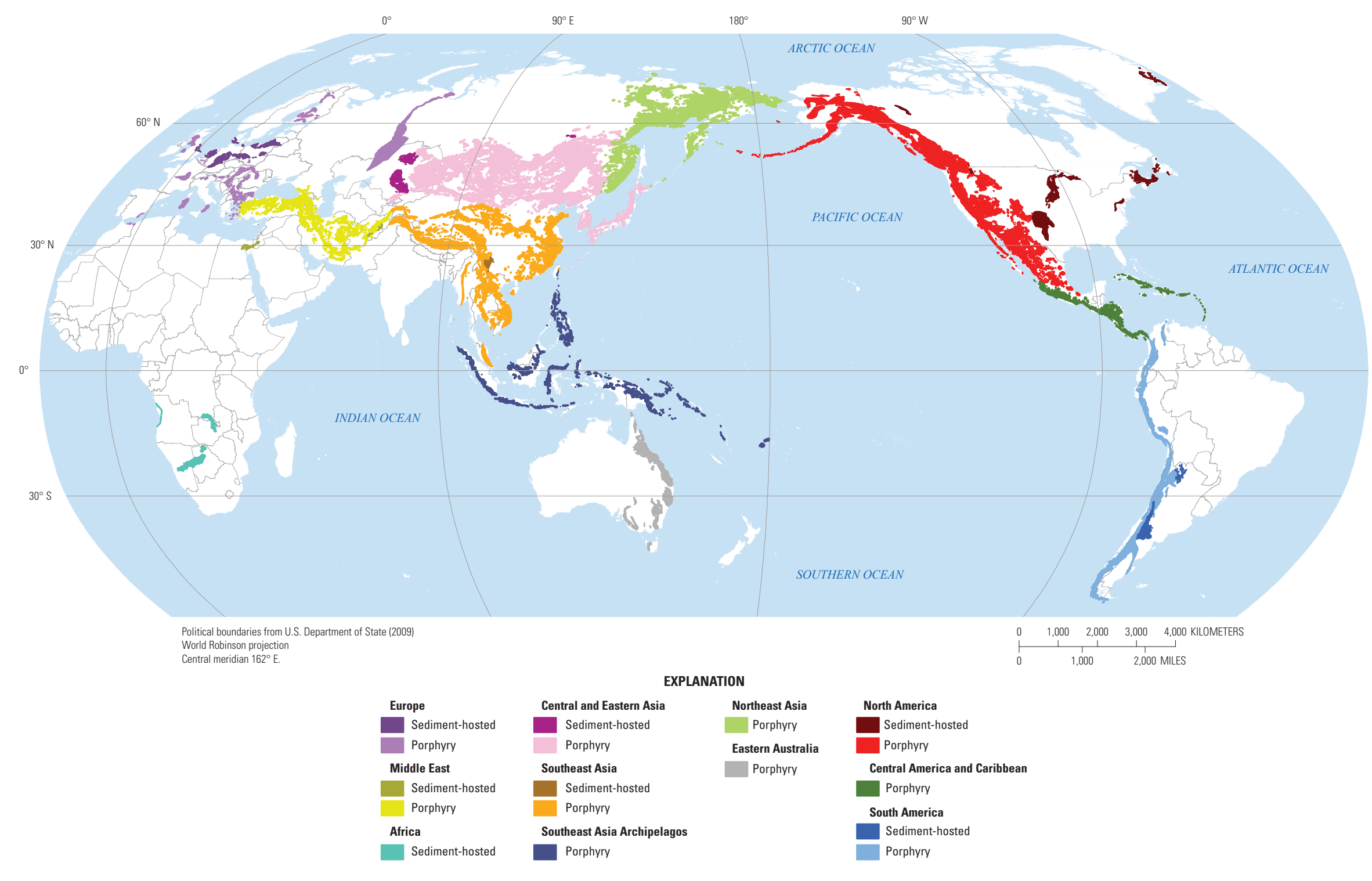

Figure A3. Map showing permissive tracts for porphyry copper and sediment-hosted stratabound copper deposits color coded by world region. 


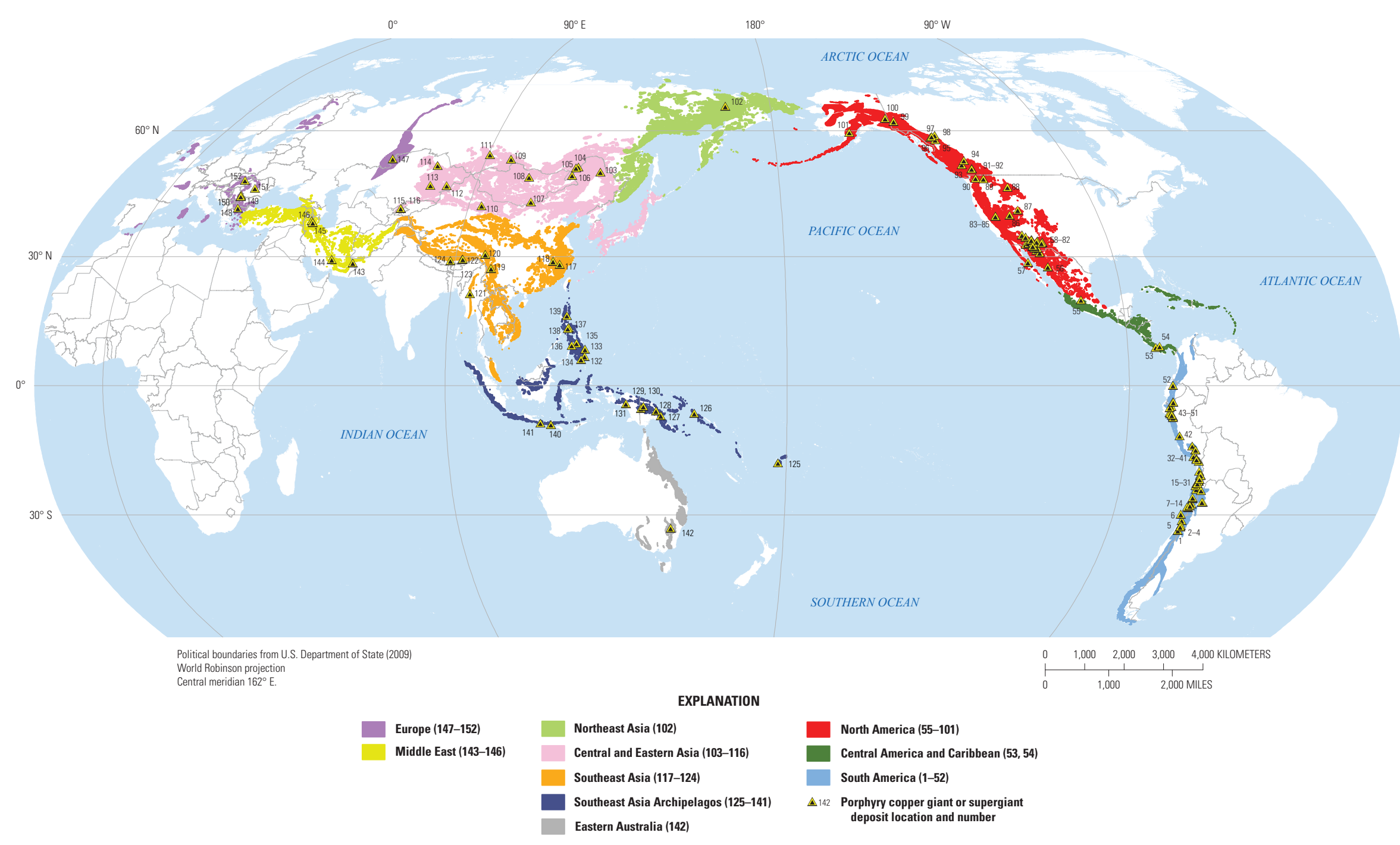

Figure A5. Map showing the global distribution of world-class porphyry copper deposits along with permissive tracts color coded by world region. World-class deposits are giant and supergiant deposits that contain at least 2 and 24 million metric tons of copper, respectively (Singer, 1995, p. 103). See table A4 for deposit key. 


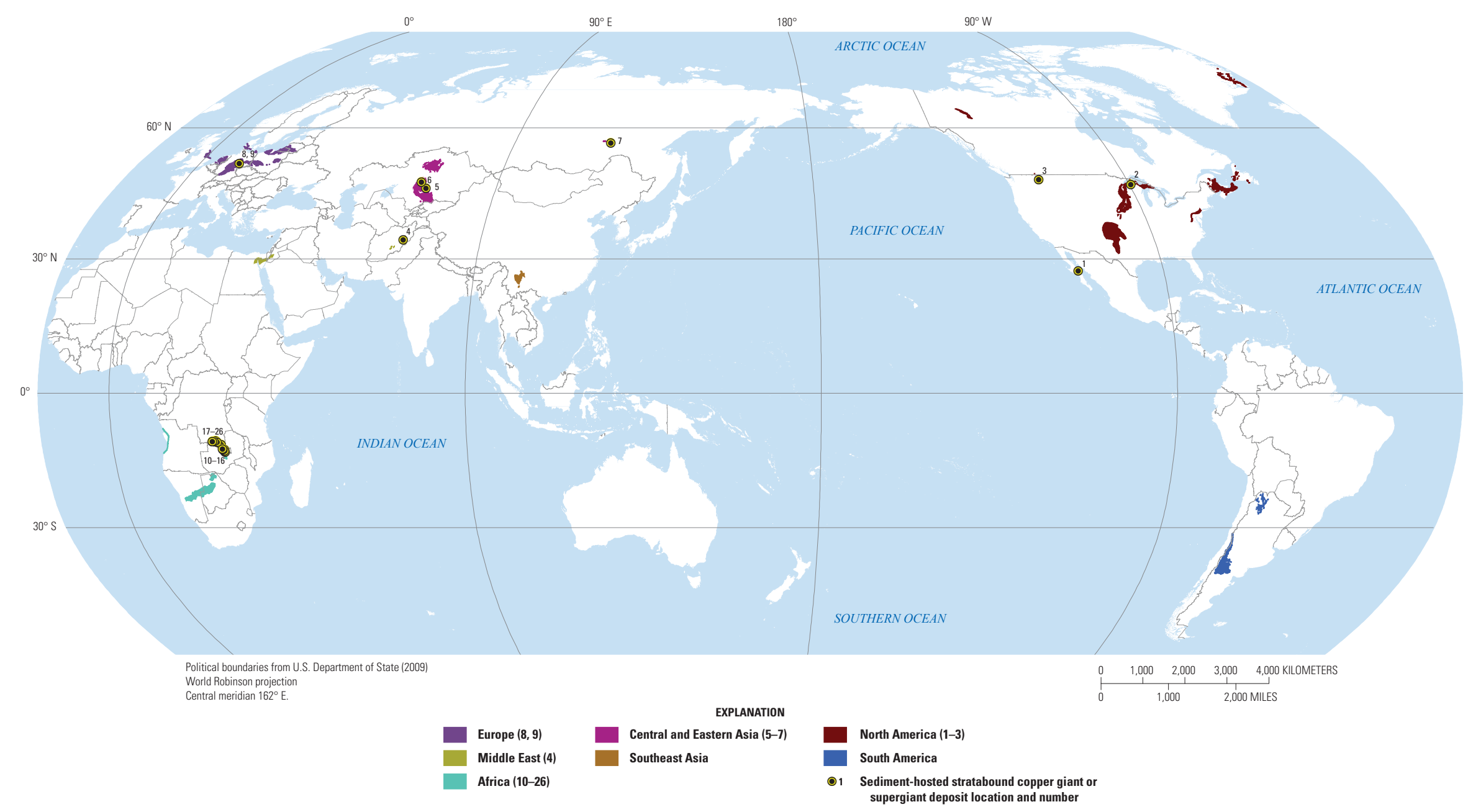

Figure A6. Map showing the global distribution of world-class sediment-hosted stratabound copper deposits along with permissive tracts color coded by world region. Worldclass deposits are giant and supergiant deposits that contain at least 2 and 24 million metric tons of copper, respectively (Singer, 1995, p. 103). See table A5 for deposit key. 


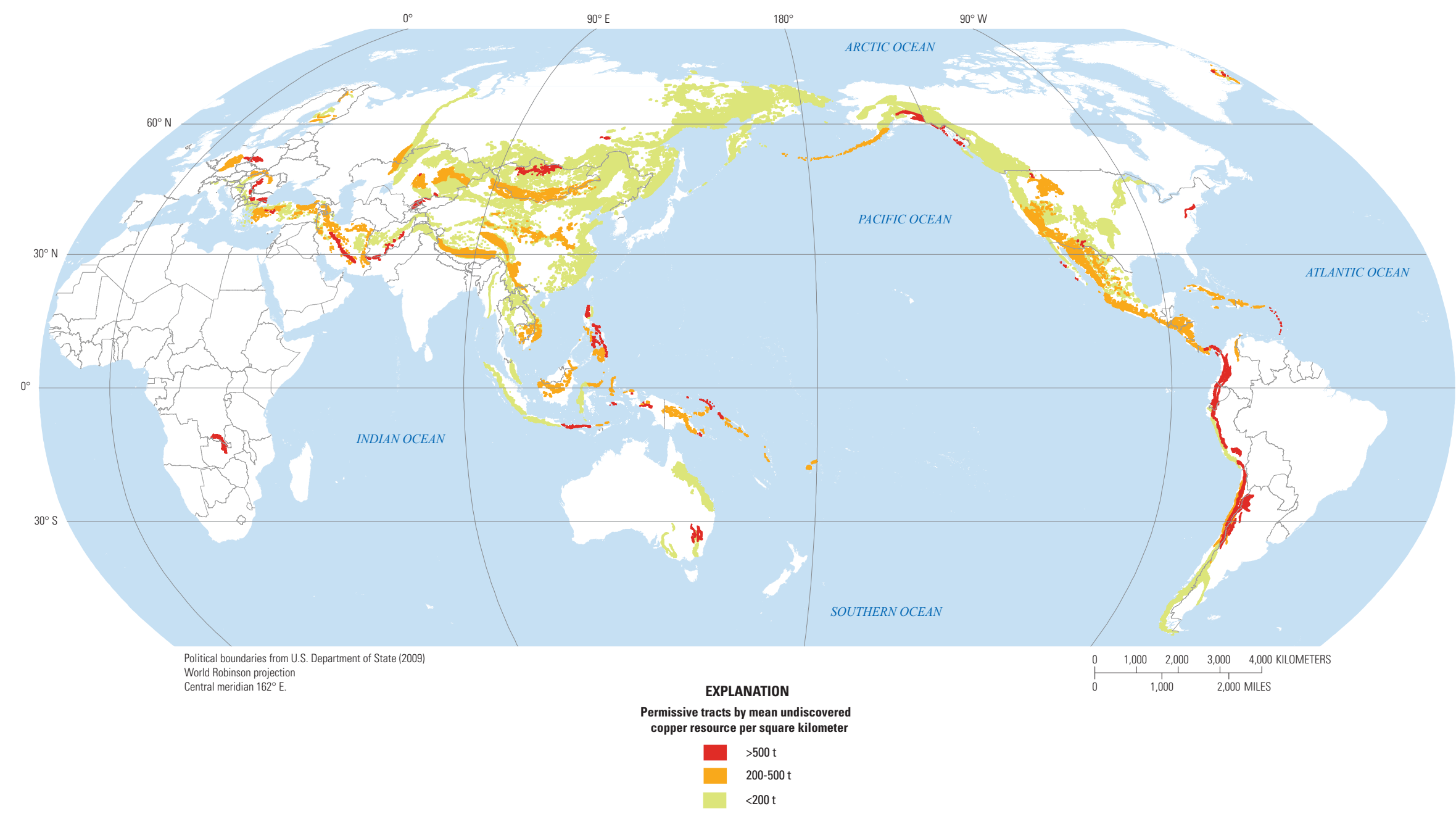

Figure A8. Map showing permissive tracts assigned to three size classes on the basis of mean undiscovered copper resources. Size classes represent metric tons (t) of copper per square kilometer, normalized by permissive tract area. Quantitatively assessed tracts for porphyry copper and sediment-hosted stratabound copper deposits are shown. 


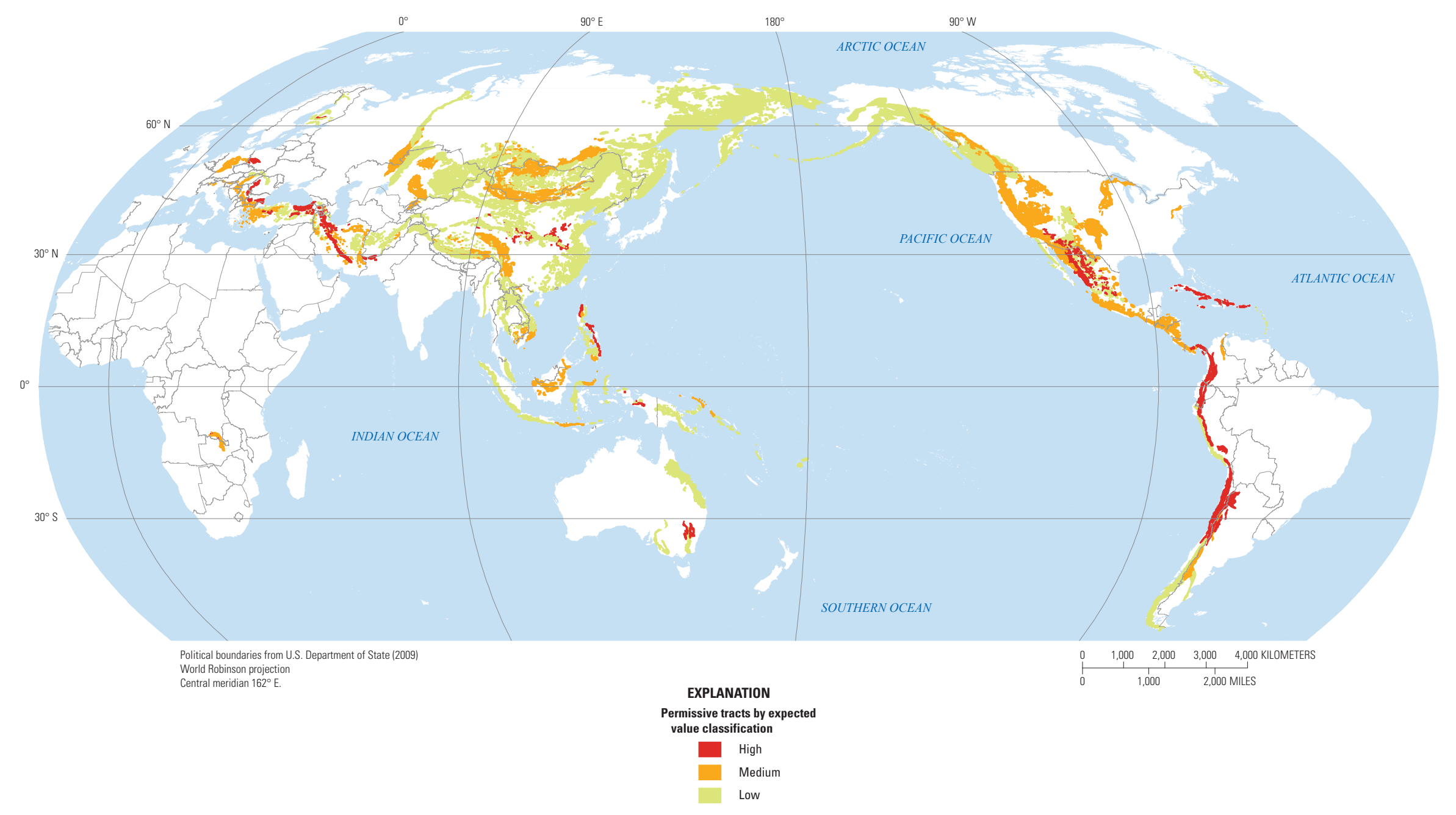

Figure A9. Map showing the expected economic value categories of permissive tracts for two types of copper deposits based on the grade and tonnage and depth distribution characteristics of the deposits and the remoteness and cost settings of the locations. Porphyry copper tracts that were assessed quantitatively with mean expected economic values of undiscovered copper in three value ranges (in U.S. dollars) were classified as follows: greater than $\$ 43$ million, high; between $\$ 15$ million and $\$ 43$ million, medium; and less than $\$ 15$ million, low. Sediment-hosted stratabound copper tracts that were assessed quantitatively with mean undiscovered copper in three size ranges were classified as having the following expected economic values: greater than 20 million metric tons (Mt), high; 2 to $20 \mathrm{Mt}$, medium; and less than $2 \mathrm{Mt}$, low. Tracts that were assessed qualitatively are not shown. 


\title{
Chapter B. Porphyry Copper Deposits
}

\author{
By Jane M. Hammarstrom for the U.S. Geological Survey Global Copper Mineral Resource Assessment Team
}

\section{Introduction}

Porphyry copper deposits are the source of most of the world's copper resources. The two largest known porphyry copper deposits are in Chile at El Teniente (pl. 5) and Chuquicamata (pl. 18); each originally contained more than 100 million metric tons (Mt) of copper. These and other large porphyry copper deposits in Chile, Indonesia, Mongolia, the United States, Mexico, Panama, and Peru were 19 of the 25 largest active copper mining projects of any type in 2013 (Mudd and others, 2013).

Results of the 2015 U.S. Geological Survey (USGS) assessment of undiscovered copper resources indicate that global undiscovered porphyry copper deposits may contain a mean of 3,100 Mt of copper, which represents almost twice the 1,800 Mt of copper in identified porphyry copper deposits (table B1). The assessors focused on undiscovered porphyry copper resources that formed during the Phanerozoic Eon (during the last 540 million years) since the end of the Precambrian (for a chronostratigraphic chart, see this volume, appendix 3). Ten of the eleven world regions defined for the global assessment of undiscovered copper resources were considered for the porphyry copper assessment and are shown in figure B1; Africa is not considered permissive for the occurrence of Phanerozoic porphyry copper deposits. For each region, the total amount of identified copper resources in porphyry copper deposits is listed in table B1, along with the mean estimate of undiscovered resources and the amounts of undiscovered copper that could be present at three different levels of probability - 90 percent, 50 percent, and 10 percent.

This chapter summarizes results of regional-scale porphyry copper assessments that were completed between 1995 and 2015 with contributions from cooperators from many countries; details are on plates $1-188$. In addition to studies done for the global mineral resource assessment, the plates include quantitative assessment results for Afghanistan (Ludington and others, 2007) and the United States. Results of the USGS assessment of U.S. undiscovered deposits of five minerals, including copper, were published in three reports. Results of the 1995 assessment of the conterminous United States were published in 1996 (U.S. Geological Survey Minerals Team, 1996). These results were combined with those for Alaska in the 1998 assessment and were released in 2000 as USGS Circular 1178 (U.S. Geological Survey National
Mineral Resource Assessment Team, 2000). Results from both the 1995 and 1998 assessments were recompiled and released in 2002 (U.S. Geological Survey National Mineral Resource Assessment Team, 2002).

The first regional porphyry copper assessment of the global assessment was prepared for the Andes region of South America (Cunningham and others, 2008). Subsequent reports have assessment results for geologic and geographic regions such as the Mesozoic of East Asia (Ludington, Mihalasky, and others, 2012) and the Tibetan Plateau (Ludington, Hammarstrom, and others, 2012). Assessments of permissive tracts that cross the borders between the United States and Canada or Mexico are based on slight revisions and updates to the data from the 1995 and 1998 U.S. assessments (U.S. Geological Survey Minerals Team, 1996; U.S. Geological Survey National Mineral Resource Assessment Team, 2000, 2002) combined with the global assessment products for Mexico (Hammarstrom and others, 2010) and for British Columbia and the Yukon Territory, Canada (Mihalasky and others, 2013). See table A1 (this volume, chap. A) for a list of all assessments summarized in this volume.

Precambrian deposits (older than 540 million years) are known in Africa and in some other parts of the world such as Brazil and eastern Canada in the Western Hemisphere and China, Finland and Sweden in northern Europe, India, and western Australia in the Eastern Hemisphere (fig. B1). Many of these deposits are difficult to classify unequivocally as porphyry copper deposits because of subsequent metamorphism and complex geological histories of Precambrian terranes. An assessment of undiscovered porphyry copper deposits in Precambrian rocks in Finland was done by the Geological Survey of Finland (Rasilainen and others, 2014), and results are included on plates 179-188 of this volume.

Cooperators provided data, local expertise in geology, and knowledge of mineral exploration history; they also participated in discussions of the likelihood of undiscovered deposits. Assessment team members and cooperating institutions are listed in appendix 1 of this volume.

The porphyry copper assessments were done by using a geology-based form of mineral resource assessment that relies on mineral deposit models (Singer, 1993, 2007a, b; Singer and Berger, 2007; Singer and Menzie, 2010), as described in chapter $A$ and in appendix 2 of this volume. Estimates of numbers of undiscovered deposits for each permissive tract 
Table B1. Aggregated assessment results for identified and undiscovered copper resources in porphyry copper deposits by world regions.

[Undiscovered resources were estimated probabilistically; "90" indicates a 90-percent chance of at least the amounts shown, and other percentiles are similarly defined. Assessment results were aggregated to report the percentiles for each region and for the world by assuming statistical independence (Hammarstrom and others, 2018). Resources are reported to two significant figures. The resources in this table are Phanerozoic except for Precambrian resources in Finland included in the Europe region. Africa is the 11th world region defined for the global assessment. Because Africa is not considered permissive for the occurrence of Phanerozoic porphyry copper deposits, it is not listed in this table. $\mathrm{km}^{2}$, square kilometer; Mt, millions of metric tons]

\begin{tabular}{|c|c|c|c|c|c|c|c|}
\hline \multirow[t]{2}{*}{ Region } & \multirow[t]{2}{*}{ Plates } & \multirow[t]{2}{*}{$\begin{array}{c}\text { Tract area } \\
\left(\mathbf{k m}^{2}\right)\end{array}$} & \multirow{2}{*}{$\begin{array}{l}\text { Identified } \\
\text { copper } \\
\text { resources } \\
\text { (Mt) }\end{array}$} & \multicolumn{4}{|c|}{$\begin{array}{c}\text { Estimates of } \\
\text { undiscovered in-place copper resources } \\
\text { (Mt) }\end{array}$} \\
\hline & & & & Mean & 90 & 50 & 10 \\
\hline South America (table B2) & $1-26$ & $1,228,913$ & 800 & 750 & 500 & 730 & 1,000 \\
\hline Central America and Caribbean (table B3) & $27-33$ & 538,224 & 43 & 170 & 78 & 150 & 280 \\
\hline North America (table B4) & $34-60$ & $3,384,991$ & 470 & 400 & 260 & 380 & 560 \\
\hline Northeast Asia (table B5) & $61-65$ & $2,222,769$ & 8.8 & 260 & 76 & 230 & 500 \\
\hline Central and Eastern Asia (table B6) & $66-85$ & $4,585,395$ & 140 & 450 & 240 & 430 & 690 \\
\hline Southeast Asia (table B7) & $86-97$ & $2,579,956$ & 56 & 420 & 240 & 410 & 640 \\
\hline Southeast Asia Archipelagos (table B8) & $98-128$ & 849,915 & 130 & 300 & 180 & 290 & 430 \\
\hline Eastern Australia (table B9) & $129-137$ & 574,892 & 15 & 21 & 1.9 & 14 & 54 \\
\hline Middle East (table B10) & $138-167$ & $1,054,267$ & 61 & 200 & 98 & 180 & 320 \\
\hline Europe (table B11) & $168-188$ & 573,131 & 51 & 140 & 64 & 120 & 240 \\
\hline World total & & $17,592,453$ & 1,800 & 3,100 & 2,600 & 3,100 & 3,600 \\
\hline
\end{tabular}

were combined with grade and tonnage models in a Monte Carlo simulation to provide a probabilistic estimate of the amounts of resources that could be contained in undiscovered deposits (Root and others, 1992). The results are reported as a mean amount of in-place copper that could be contained in undiscovered deposits within each permissive tract, as well as estimates of the minimum amount of copper associated with different probabilities. The probability distribution gives a range of values that conveys the uncertainty associated with the estimate. Simulation results for each permissive tract are included in the source reports (table A1) and in the geographic information system data (Dicken and others, 2016). For methods and results of aggregating simulation data by region (table B1), see Hammarstrom and others (2018).

An analysis of the potential economic viability of the undiscovered copper is important for assessing the long-term adequacy and availability of mineral supplies. To address this question, an economic filter based on simplified engineering cost models was applied to the assessment results to estimate how much, if any, of the in-place undiscovered copper in each permissive tract might be economic (Robinson and Menzie, 2014).

\section{Formation of Porphyry Copper Deposits}

Porphyry copper deposits represent the largest source of global copper supply, as well as significant sources of molybdenum, gold, and silver. Porphyry copper deposits occur in subduction-related magmatic arcs, in volcanic island arcs, and in belts of magmatic rocks that formed in postconvergent tectonic settings (this volume, chap. A, fig. A2). They formed at shallow depths, typically less than 4 kilometers $(\mathrm{km})$, and mainly in association with calc-alkalic igneous rocks. Descriptive mineral deposit models that summarize the characteristics of the deposit type were used for the global assessment (Cox, 1986a, b, c; Panteleyev, 1995a, b; 2005a, b; Cooke and others, 1998; Jaireth and Miezitis, 2004; Berger and others, 2008; John and others, 2010; Eilu, 2014).

Porphyry copper deposits typically are centered on small, upright, cylindrical porphyry stocks, sometimes referred to as "pencil porphyries" because of their shape (fig. B2). Chalcopyrite $\left(\mathrm{CuFeS}_{2}\right)$ and bornite $\left(\mathrm{Cu}_{5} \mathrm{FeS}_{4}\right)$ are the main hypogene ore minerals; in some climates, high-grade supergene ore zones rich in copper oxide minerals develop above the hypogene ore. Associated deposit types such as skarns, epithermal veins, 

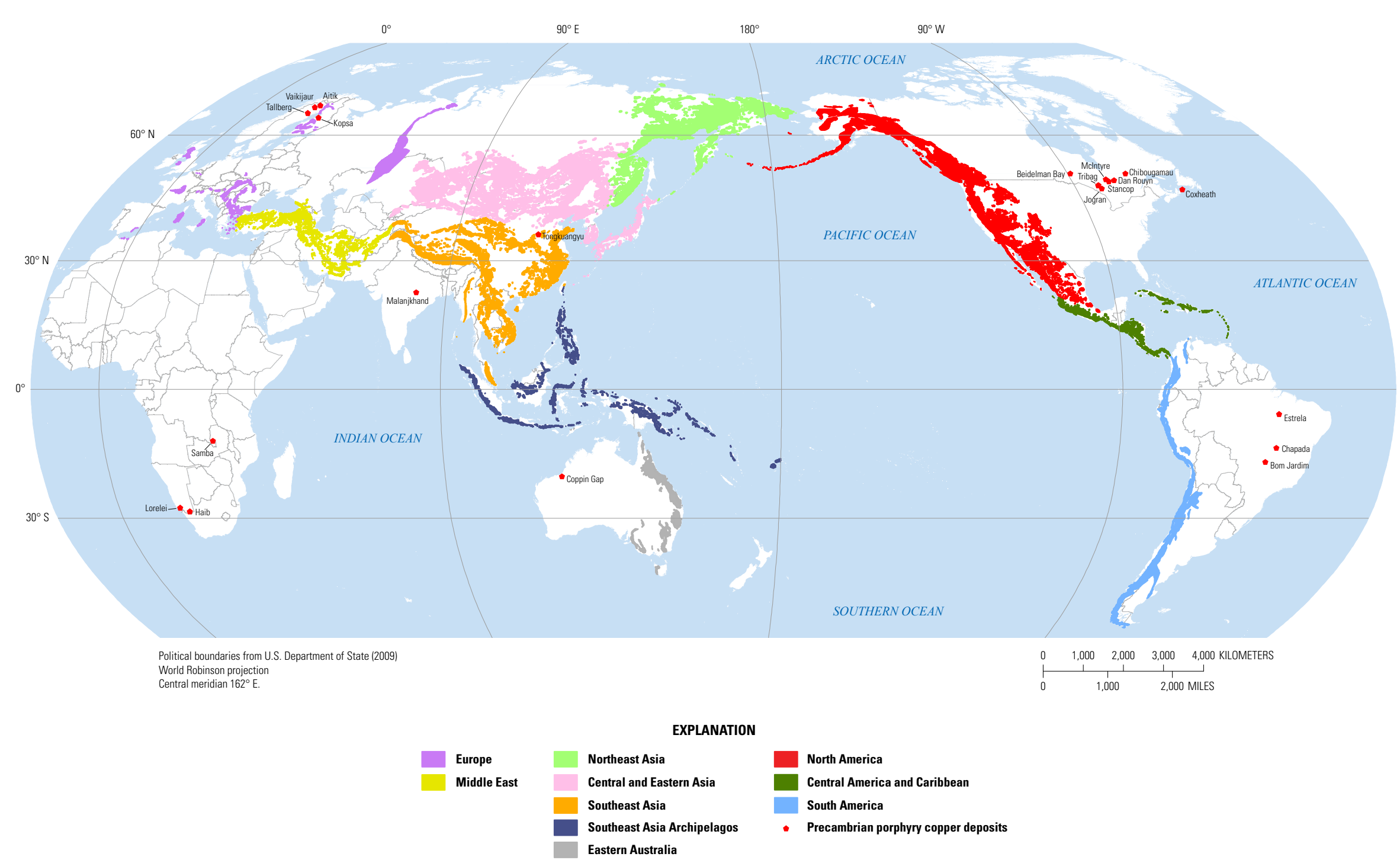

Figure B1. Map showing permissive tracts for porphyry copper deposits, color coded by world region, and locations of known Precambrian porphyry copper deposits. More detailed maps of each region (except Africa) are in figures B4-B13. Precambrian porphyry copper deposits are from Dicken and others (2016) and Rasilainen and others (2014). 


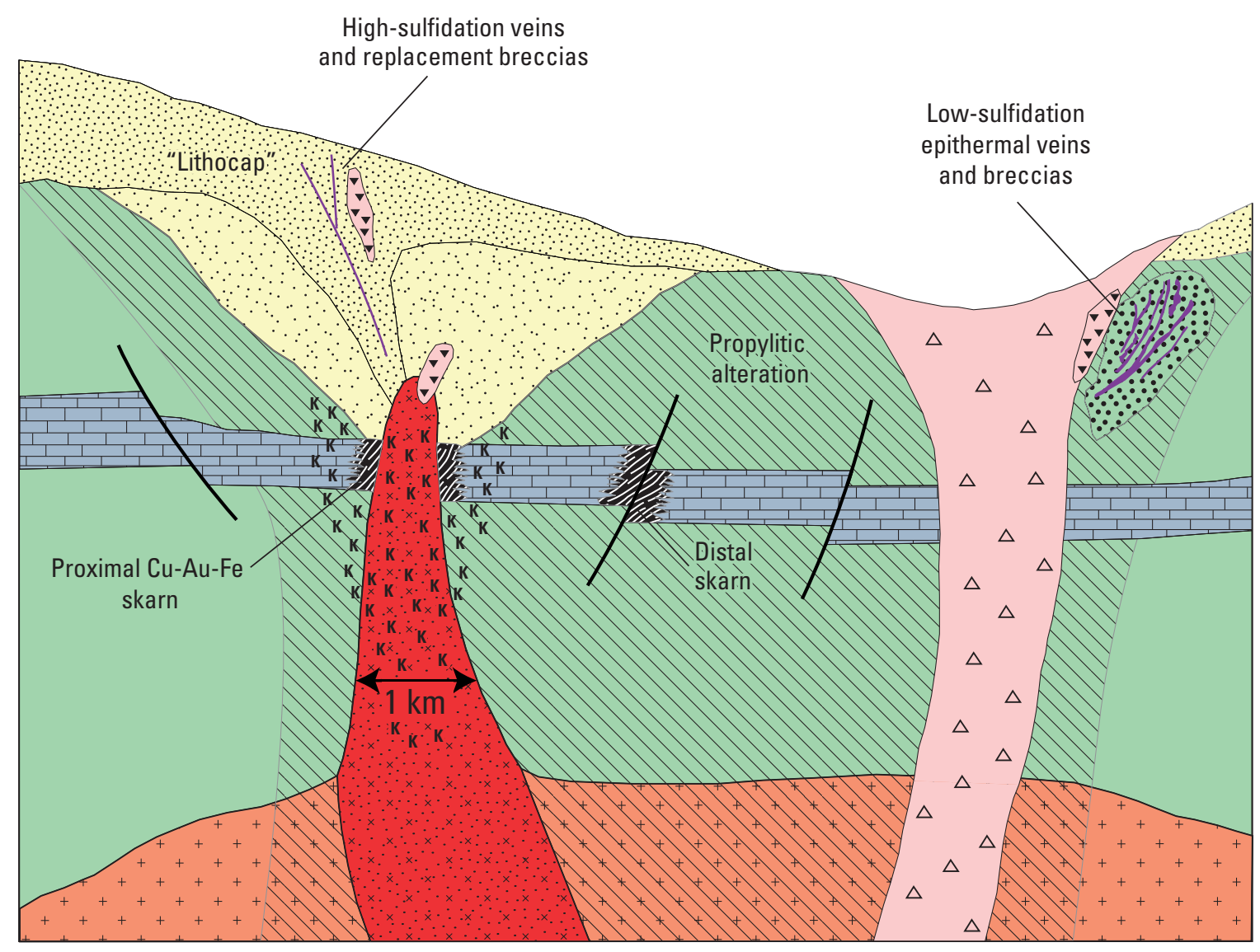

EXPLANATION

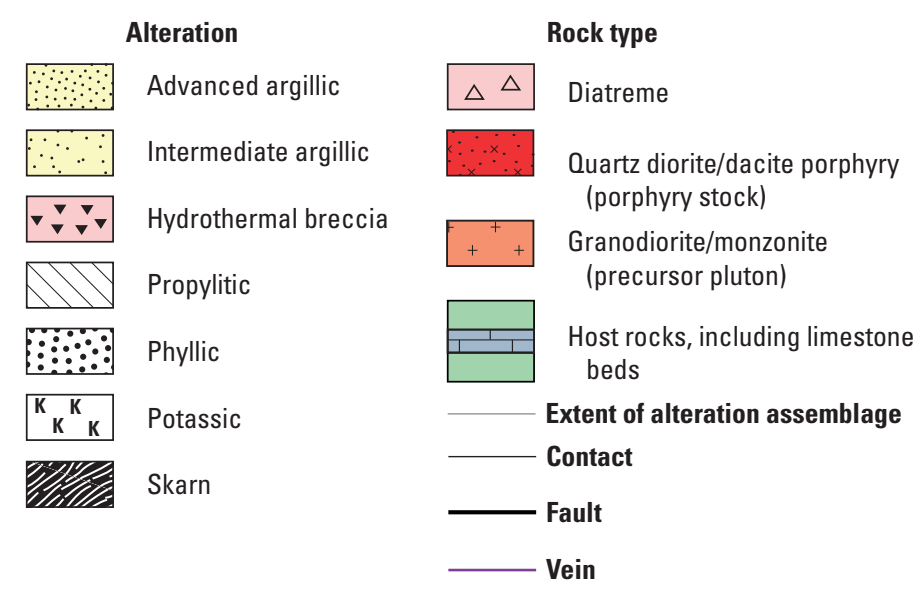

Figure B2. Generalized model of a porphyry copper system. Cu-Au-Fe, copper-gold-iron; km, kilometer. Modified from Cooke and others (1998, fig. 2). 
and polymetallic replacement and (or) vein deposits may be genetically related (fig. B2). Distinctive, zoned hydrothermal alteration assemblages form in wall rocks upward and outward from porphyry copper centers over distances of up to several kilometers (potassic, phyllic, intermediate and advanced argillic, and propylitic in fig. B2). Ore minerals occur as disseminations and veins or veinlets, typically in the potassic and phyllic (also known as sericitic) alteration zones. Veins typically are less than 10 centimeters $(\mathrm{cm})$ wide and make up less than 5 volume percent of the mineralized rock. Mapping alteration by doing fieldwork or by using remote-sensing techniques can provide guides to undiscovered deposits.

\section{Permissive Tracts}

Permissive tracts for porphyry copper deposits are geographic areas that include volcanic and intrusive rocks of specified compositions and age ranges, as shown on geologic maps, and that can be related to the types of geologic settings illustrated in figure A2 (this volume, chap. A). The permissive tracts include areas where permissive rocks are assumed to lie within the upper kilometer of the crust (fig. B3A). Porphyry copper deposits are known to occur deeper, but mining costs may prohibit development unless the deposits are very large and rich in copper.

The first step in delineating a permissive tract for porphyry copper deposits is identifying the magmatic arcs and belts and their age ranges within a study region. Then, on the basis of characteristics described in mineral deposit models, the igneous rock units that define the terrestrial extent of the arcs are selected from geologic maps. Geologic maps are processed in a geographic information system to select appropriate rock units to include in a permissive tract. Permissive rocks include calc-alkalic and alkalic plutonic and volcanic rocks. Types of igneous rocks that are unlikely to be associated with porphyry copper deposits are classified as nonpermissive. Examples of nonpermissive lithologies for porphyry copper deposits include ultramafic rocks, ophiolite complexes, highly evolved granites, peraluminous granites, rhyolites, and pillow basalts.

For the global assessment, available data on mineral deposits and occurrences, locations of dated igneous rock samples, and structural, geophysical, and geochemical information were examined to ensure that the tract included permissive rocks and evidence of hydrothermal systems. Volcanic centers and other areas of volcanic cover where the thickness of cover was known to exceed $1 \mathrm{~km}$ were excluded from tracts. Volcanic rocks younger than the designated tract age but inferred to be less than $1 \mathrm{~km}$ thick that may be present as cover were included in permissive tracts. Deep-seated porphyry copper deposits are known, such as the undeveloped Resolution deposit (not shown on a figure in this volume) that lies more than $1.5 \mathrm{~km}$ below the surface near Superior, Ariz. (Manska and Paul, 2002). However, the detailed threedimensional information from drilling or geophysical studies that is needed to extend mineral assessments for porphyry copper deposits to greater depths typically is not available. Most porphyry copper deposits are developed, at least initially, as open-pit mines. Mining at depth requires very rich ores to justify expensive underground mining methods; in addition, high temperatures at depth pose technical challenges.

Data were compiled in a geographic information system to define the tract boundaries. Final tract boundaries were clipped to shorelines to eliminate undersea areas by using small-scale digital international land boundaries and polygon files from the U.S. Department of State (2009).

\section{Grade and Tonnage Models}

The global porphyry copper grade and tonnage models of Singer, Berger, and Moring (2008), were used for the simulation of undiscovered resources in many of the areas studied. These models include a copper-gold subtype model based on data for 115 deposits, a copper-molybdenum subtype model based on data for 51 deposits, a copper subtype model based on data for 256 deposits, and a general porphyry copper-goldmolybdenum-silver model based on all 422 deposits. The subtypes are based on grade criteria defined by Singer, Berger, and Moring (2008). Deposits are classified as the copper-gold subtype if (1) the ratio of gold (in grams per metric ton, $\mathrm{g} / \mathrm{t}$ ) to molybdenum (in percent) is greater than or equal to 30 or (2) no molybdenum grade is reported and the gold grade is greater than $0.2 \mathrm{~g} / \mathrm{t}$. Deposits are classified as the coppermolybdenum subtype if (1) the ratio of gold (in grams per metric ton) to molybdenum (in percent) is less than or equal to 3 or (2) no gold grade is reported and the molybdenum grade is greater than 0.03 percent. Otherwise, the deposits are classified as the porphyry copper subtype.

For some study areas, custom models were developed. The grade and tonnage model used for each tract is indicated on plates $1-188$ of this volume.

\section{Undiscovered Resources}

The assessment teams evaluated all available data and made individual, subjective estimates of the numbers of undiscovered porphyry copper deposits in each tract. This form of assessment relies on expert judgment based on the individual's geologic understanding of porphyry copper deposits. The distribution of known deposits, prospects, and related deposit types; types of alteration; depth of erosion; thickness of cover; and level of exploration were factors considered in making estimates. Deposit density models (Singer, Berger, and others, 2005; Singer and Berger, 2007; Singer, 2008) and consideration of map scales (Singer and Menzie, 2008) facilitated estimates of numbers of undiscovered deposits in some studies. Prospects were ranked with regard to the likelihood that if fully explored, they would fit the grade and tonnage models. The location, number, deposit type, and relative importance of other prospects, such as skarns and epithermal deposits, were also considered. 
Estimates were expressed in terms of different levels of certainty. The individual estimates were tabulated and then discussed by the assessment team. As a result of the discussion, a single team consensus estimate was agreed upon for each tract. The estimates were converted to a mean number of deposits and a standard deviation based on an algorithm developed by Singer and Menzie (2005). See appendix 2 of this volume for details. The mean number of deposits for the permissive tract reflects both the uncertainty in what may exist and the favorability of the tract (Singer, 1993).

The undiscovered resources for each permissive tract were estimated as follows:

undiscovered metal

$=$ number of undiscovered deposits $\times$ tonnage $\times$ grade,

where number of deposits, tonnage, and grade are each described by probability distributions and modeled by using a Monte Carlo simulation that combines the estimates with the selected grade and tonnage model (Singer and Menzie, 2010).

\section{Economic Filter}

The economic filter developed by Robinson and Menzie (2014) modified and updated mining engineering cost models from the former U.S. Bureau of Mines (Taylor, 1978, 1986). These models use data on mine capacity, mine life, capital and operating costs needed to build and operate a mine and mill, metallurgical recovery rates, and 20-year average metal prices. To apply the economic filter for each permissive porphyry copper tract, a depth distribution of undiscovered deposits within the upper $1 \mathrm{~km}$ of the Earth's crust was specified along with an estimate of the cost setting determined by the country or countries containing the tract.

Simplified engineering cost models, updated with a cost index, were used to estimate the economic fraction of resources contained in undiscovered porphyry copper deposits as predicted in the USGS assessment of global copper resources (Robinson and Menzie, 2014). The economic resource was estimated as follows:

$$
\text { economic resource }=\text { resource } \times \text { economic filter, }
$$

where resource is the mean undiscovered resource estimated by simulation and the economic filter is the fraction of the resource estimated to be economic on the basis of the grade and tonnage model used in the simulation, the depth distribution for the undiscovered deposits, and adjustments for cost settings. The economic filters were computed by using an Excel workbook developed by Robinson and Menzie (2014). The 20-year (1989-2008) average metal prices and metallurgical recovery rates were used in the filter calculations. The depth distribution and cost setting parameters in the economic filter were varied, as described below.

\section{Depth Distributions}

The depth distribution affects the amount of material that would have to be removed to develop a mine and determines the mining method (open-pit mining or underground mining by block caving). Porphyry systems typically form within 1-4 km of the Earth's surface. Some deposits are exposed at the surface, but many are not. The cost of removing cover material to access the ore adds to the cost of developing a mine.

For each tract, an estimate of a hypothetical depth distribution for undiscovered deposits was made. These estimates refer to the part of the upper kilometer of the Earth's crust that may contain the tops of any undiscovered porphyry copper deposits. Some tracts were delineated with knowledge of the thickness of cover, which could be volcanic or sedimentary rock, or rocks of any type that have been moved over permissive rocks by faulting (cover shown in fig. B3A). For other tracts, the relative amounts of mapped volcanic and intrusive rock were considered in estimating depth distributions. In areas where the areal extent of volcanic rocks greatly exceeds the amount of exposed intrusive rock, it is likely that porphyry systems may be covered by tens to thousands of meters of volcanic rock. In regions where intrusive rocks that formed at some depth have been uplifted or exposed through erosion, much of the material that originally covered a porphyry system may have been removed, and remaining deposits may be located closer to the modern surface.

Three common depth distribution categories were developed, as illustrated schematically in figure B3B. Depth distributions for a few tracts (pls. 4, 11, 27, 45, 57, 65, 76, 156 , and 165) varied from the standard three categories, and these custom distributions were estimated on the basis of the background knowledge of the assessors. Tracts that could not be quantitatively assessed lack estimated depth distributions.

In the absence of specific data that could indicate an appropriate depth distribution of undiscovered deposits to use for the economic filter, a default depth distribution was adopted. In the default, 25 percent of the undiscovered deposits were considered to be accessible above 250 meters (m) depth in the crust; 25 percent were considered to be accessible between 250 and $500 \mathrm{~m}$; and 50 percent were assumed to lie below $500 \mathrm{~m}$ but above $1 \mathrm{~km}$ (fig. B3B).

For permissive tracts having significant amounts of volcanic rocks or other cover, it was assumed that a larger percentage of the undiscovered deposits would lie at greater depths than the default depths. The distribution for these areas was skewed to be deeper than the default depth distribution, and 10 percent of the undiscovered deposits were estimated to be in the upper $250 \mathrm{~m}$ of the crust; 30 percent were estimated to be between 250 and $500 \mathrm{~m}$; and 60 percent were estimated to be below $500 \mathrm{~m}$ but above $1 \mathrm{~km}$.

For areas that were uplifted and eroded, as indicated by the tectonic history and relative amounts of volcanic and intrusive permissive rocks, it was assumed that any undiscovered deposits that were preserved would be found closer to the present surface than the default depth distribution. The depth distribution 


\section{A. Porphyry copper deposits at different depths}

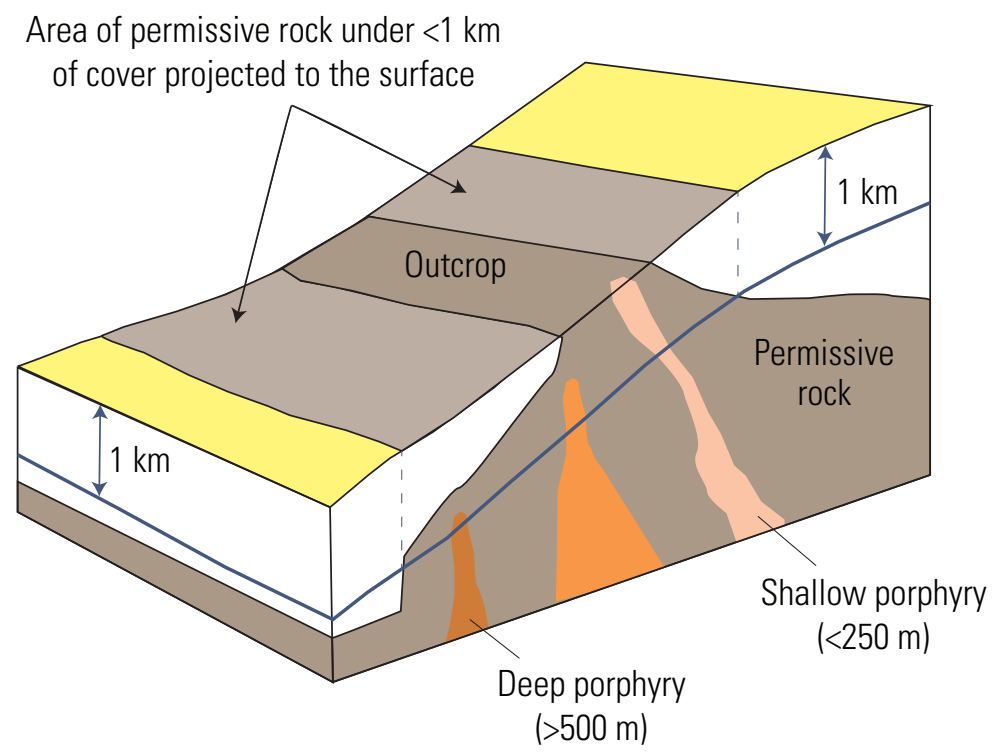

\section{B. Percentages of undiscovered deposits in each tract assigned to} each of three depth ranges for economic filter calculation

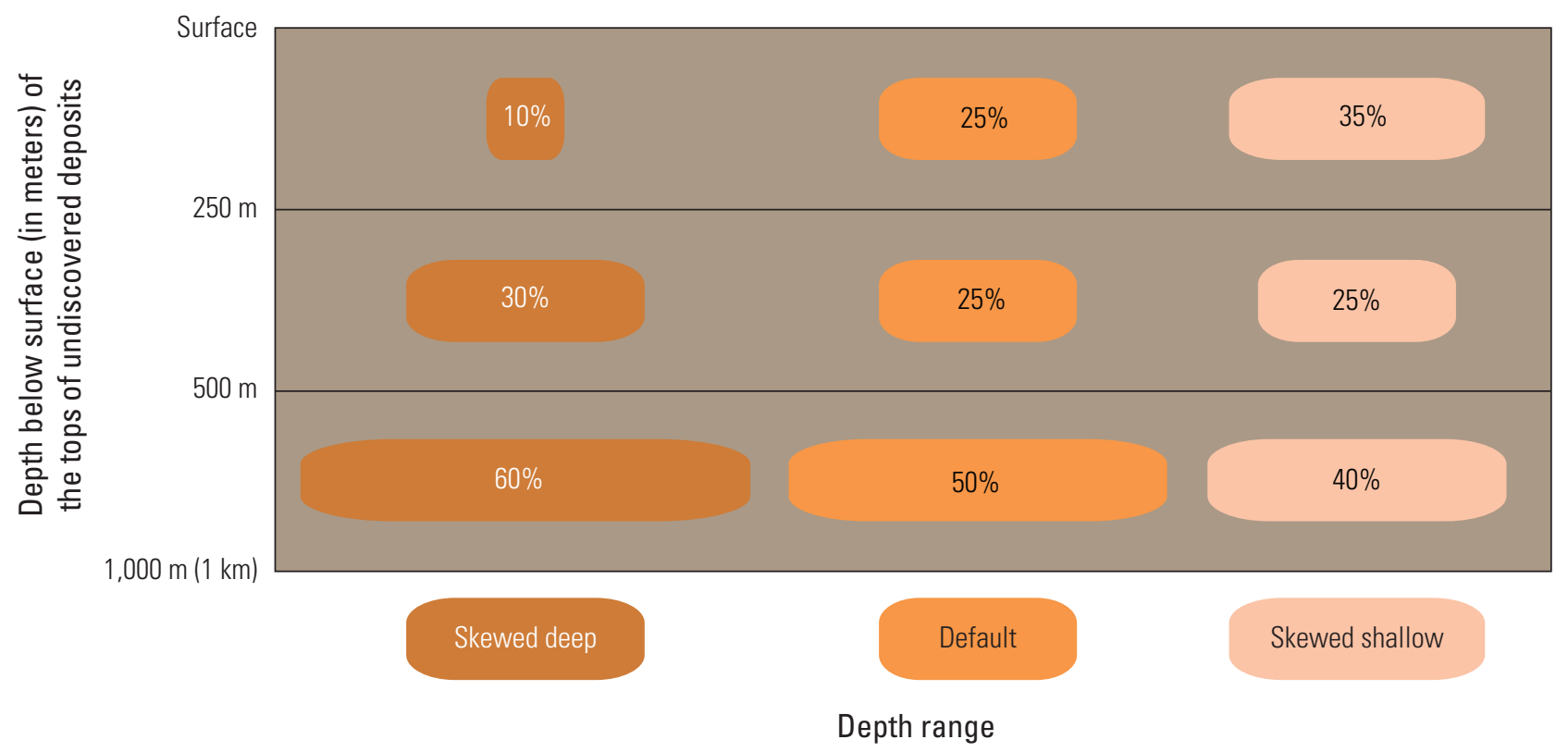

Figure B3. Illustration of depth distributions for undiscovered porphyry copper deposits used in the economic filter.

$A$, Diagram showing that permissive rock for hosting porphyry copper deposits may be exposed at the surface in outcrop or may be hidden beneath cover composed of nonpermissive rock. $B$, Diagram in which oblongs show the percentages of undiscovered deposits that would have the tops of the deposits within the illustrated depth interval for the three common depth categories: default, skewed shallow, and skewed deep. Depth distributions for a few tracts (pls. 4, $11,27,45,57,65,76,156,165)$ varied from the standard three categories, and these custom distributions were estimated on the basis of the background knowledge of the assessors. $\mathrm{km}$, kilometer; $\mathrm{m}$, meter. 
adopted for the economic filter for these areas was skewed to be shallower than the default depth distribution, and 35 percent of the deposits were estimated to be at depths less than $250 \mathrm{~m}$; 25 percent of the deposits were estimated to be in the interval between 250 and $500 \mathrm{~m}$; and 40 percent of the deposits were estimated to be at depths below $500 \mathrm{~m}$ but above $1 \mathrm{~km}$.

\section{Cost Settings}

The economic viability of a deposit also depends on the existence of infrastructure. For example, are there roads, power, water, and nearby towns for logistical support or must these be provided as part of the cost of developing a mine? The economic filter incorporates a parameter for cost setting to capture information about infrastructure for each permissive tract (Robinson and Menzie, 2014). A “typical-cost" setting applies to a region that has existing regional infrastructure to support mining (for example, northern Mexico and southwestern United States or established mining areas in Chile). A "high-cost" setting refers to remote areas that lack existing infrastructure to support mining (for example, the Tibetan Plateau or Mongolia).

The country-by-country infrastructure rankings compiled by the Fraser Institute (McMahon and Cervantes, 2012) were used as an independent guide to select appropriate cost settings for mining for each tract. The Fraser Institute conducts annual surveys of exploration, development, and mining-related companies to assess and rank global jurisdictions in terms of their attractiveness for investment in mining on the basis of government policies (such as regulations, land-use requirements, taxation, political stability), available geological database, infrastructure, supply of labor, mineral potential, and other factors. The quality of infrastructure rankings reflects the mining community's evaluation of access to roads, availability of power, and other infrastructure considerations that encourage or deter investment in mining. The data from the 2011-12 quality of infrastructure table (table A10 of McMahon and Cervantes, 2012) are expressed in terms of five categories of response: (1) encourages investment, (2) not a deterrent to investment, (3) mild deterrent, (4) strong deterrent, and (5) would not pursue investment due to this factor. The category scores were used to classify cost settings as typical cost where categories 1 and 2 represent more than 50 percent of the response, as high cost where categories 3,4 , and 5 represent more than 50 percent of the response, and as mixed cost otherwise.

Many tracts cross jurisdictions, and some tract areas are in jurisdictions that were not evaluated by the Fraser Institute. For these tracts, we used the jurisdiction most closely associated with the tract as a proxy. For example, the rankings for Turkey (typical-cost setting, for example pls. 160, 161, 162) were applied to tracts within Iran (pls. 145, 146, 151), and rankings for Vietnam (high-cost setting) were used for tracts mainly in Burma.

\section{Understanding the Results}

\section{Tract Results}

Quantitative assessments were made for 163 of the 188 porphyry copper tracts. The other tracts were delineated on the basis of broadly permissive geology. For the 25 tracts assessed qualitatively, some areas had been thoroughly explored, and no definitive evidence had been found for porphyry copper deposits within the upper kilometer of the Earth's crust (for example, in Japan); for other areas, the assessment team had insufficient reliable information to make estimates of numbers of undiscovered deposits. The plates for these tracts include a brief discussion of the likelihood of undiscovered porphyry copper resources in the tract.

Plates 1-60 summarize assessment results for porphyry copper tracts in the Americas (which are primarily in the Western Hemisphere), from south to north. Plates 61-188 depict tracts that are primarily in the Eastern Hemisphere, starting in northeast Asia, extending south to eastern Australia, and then through the Middle East to Europe.

The arithmetic mean estimate of undiscovered in-place copper resources is reported in millions of metric tons (Mt), along with the probability of zero in-place copper resources expressed in percent. The results of applying the economic filter are reported as the mean estimate of economically recoverable resources (in millions of metric tons), along with the probability of zero economically recoverable resources. Note that for some tracts such as tract $142 \mathrm{pCu} 8510$, KedonRussia (pl. 64), the probability of zero in-place resources may be relatively low (31 percent), yet the probability of zero economic resources may be relatively high (90 percent). This difference for tract $142 \mathrm{pCu} 8510$ is explained by the effect of the economic filter because this tract is in a high-cost setting. Permissive tracts that have depth percentages skewed deep (more material to remove to develop a mine) and that occur in high-cost settings, where infrastructure is poor to nonexistent, may have in-place undiscovered resources that are unlikely to be economic in the foreseeable future.

The range of amounts of undiscovered copper estimated at different confidence levels is shown in graphs on each plate. Assessment results for a permissive tract are a probability distribution of in-place copper metal, and values may vary over an order of magnitude depending on the level of certainty. For example, the results for permissive tract $005 \mathrm{pCu} 1020$ (pl. 1) show that at the most certain confidence levels (95 and 90 percent), no undiscovered copper is expected. The median (50 percent) estimate is $3.0 \mathrm{Mt}$ of copper or more. The less certain, or higher risk, estimates at 10 and 5 percent are 20 and $31 \mathrm{Mt}$ of copper, respectively. The mean estimate of in-place copper $(7.8 \mathrm{Mt})$ is greater than the median estimate, and about half of that $(3.9 \mathrm{Mt})$ is expected to be economic. 


\section{Regional Results}

\section{South America Region}

The assessors of the Andes region of South America delineated 26 permissive tracts for porphyry copper deposits (fig. B4, table B2, pls. 1-26). Individual tracts range in areal extent from about 2,000 to 200,000 square kilometers $\left(\mathrm{km}^{2}\right)$. In places, the tracts overlap each other because tracts are based on the distribution of permissive rocks of particular age ranges, and rocks of different age groups may occur in the same geographic area.

Nineteen permissive tracts have one or more known deposits; 16 deposits are known in the tract that includes the supergiant Chuquicamata deposit in Chile (pl. 18). The mean estimate of $750 \mathrm{Mt}$ of in-place undiscovered copper resources for the region is slightly less than the $800 \mathrm{Mt}$ of identified resources (table B2). More than half of the undiscovered resources may be economic, according to the parameters applied in the economic filter (table B2).

The Andes assessment work was done in 2005-2007 (Cunningham and others, 2008). Since that time, new exploration has identified additional deposits in the region, such as the world-class Los Sulfatos deposit in Chile, discovered in 2007, with identified resources of $18 \mathrm{Mt}$ of copper (this volume, chap. A, table A4). Los Sulfatos falls within the permissive tract shown on plate 5 .

\section{Central America and Caribbean Region}

The Central America and Caribbean region includes three tracts in Central America, two tracts in the Caribbean Basin, and two tracts in southern Mexico (fig. B5, table B3, pls. 27-33). Five tracts include one or more known deposits, including two world-class deposits in Panama. Estimated undiscovered copper resources for the region are about four times the identified resources, and about half of those undiscovered resources are deemed economic. The Darién Region permissive tract (pl. 27), which contains the world-class Cobre Panama deposit, is estimated to contain less undiscovered copper (14 Mt) than the amount of copper that has already been identified (19 Mt). Similarly, identified copper in the Balsas tract in Mexico (3.0 Mt) exceeds the mean undiscovered copper estimate (1.2 Mt; table B3, pl. 33).

\section{North America Region}

The North America region includes 27 permissive tracts that extend from Mexico through the western conterminous United States to British Columbia and the Yukon Territory in western Canada and northwestward through Alaska (fig. B6, table B4, pls. 34-60). Although Mexico is part of North America, two tracts in southern Mexico were grouped with the Central America and Caribbean region for geologic continuity.
The mean estimate of in-place undiscovered resources for the North America region, $400 \mathrm{Mt}$ of contained copper, is slightly less than the $470 \mathrm{Mt}$ of identified resources. About half of the in-place undiscovered resources $(230 \mathrm{Mt})$ may be economic according to economic filter results (table B4). Seven of the tracts have no identified porphyry copper resources.

The permissive tracts within the United States were assessed in previous studies (U.S. Geological Survey Minerals Team, 1996; U.S. Geological Survey National Mineral Resource Assessment Team, 2000, 2002). Two poorly known tracts in Alaska (pls. 59 and 60) are included from the later studies (U.S. Geological Survey National Mineral Resource Assessment Team, 2000, 2002) as qualitatively assessed tracts because insufficient information was available to complete a quantitative assessment.

To address permissive tracts that cross country boundaries between the United States and Canada or Mexico, permissive tracts constructed for the global assessment were combined with those made for the U.S. national assessments, and estimates of numbers of undiscovered deposits were revised to provide a single estimate for the combined tract that honors the original estimates. Differences in assessment approaches and data availability over time led to some odd cross-border matches, especially at northwestern United States-Canadian borders. These areas would benefit from future, more detailed studies, especially as new data for Alaska become available.

\section{Northeast Asia Region}

The Northeast Asia region has five permissive tracts in eastern Russia and parts of northeastern China (fig. B7, table B5, pls. 61-65). Northeastern Russia contains two known porphyry copper deposits, including the world-class Peschanka deposit with 7.9 Mt of contained copper (table A4). Results of this assessment indicate that considerable undiscovered resources $(260 \mathrm{Mt})$, on the order of 10 to 60 times the identified resources (8.8 Mt), could exist in this region (table B5). Some permissive tracts on the Asian mainland in this region are quite large because the limited amount of available geologic data precluded more detailed delineation of permissive areas.

\section{Central and Eastern Asia Region}

Twenty permissive tracts are delimited in the Central and Eastern Asia region, which includes parts of Russia, China, Mongolia, Japan, South Korea, and North Korea and extends westward into Kazakhstan and parts of Kyrgyzstan, Tajikistan, and Uzbekistan (fig. B8, table B6, pls. 66-85). Fourteen world-class porphyry copper deposits (table A4), including the Oyu Tolgoi deposit (37 Mt of copper) in Mongolia and the Almalyk Group deposit in Uzbekistan (24 Mt of copper), occur in the region. Six tracts lack known porphyry copper deposits (table B6). The mean estimate of in-place undiscovered copper resources in the region (450 Mt) exceeds the identified resources $(140 \mathrm{Mt}$ ). Some $270 \mathrm{Mt}$ of undiscovered in-place resources may be economic. 
A quantitative assessment was not done for permissive tracts in Japan and South Korea. Although high-quality geologic information was available for both countries and exploration has been conducted for near-surface porphyry copper deposits, there have been no discoveries of porphyry copper deposits. Possible reasons for the lack of porphyry systems in this part of the world include lack of thick crust, insufficient erosion to expose porphyry deposits, abundance of ilmenite- versus magnetite-series igneous rocks, and low oxidation state of magnetite-series rocks (Qin and Ishihara, 1998; Takagi, 2004).

\section{Southeast Asia Region}

The Southeast Asia region extends across southern China eastward and southward through the Indochina Peninsula; it includes 12 permissive tracts (fig. B9, table B7, pls. 86-97). The region has eight world-class porphyry copper deposits, including the two largest deposits of this type known in China: Dexing (8.4 Mt) and Qulong (8.0 Mt; table A4). The mean estimate of in-place undiscovered resources (420 Mt of copper) greatly exceeds the identified resources ( $56 \mathrm{Mt}$ ); about half of the undiscovered copper resources (230 Mt) may be economic (table B7).

\section{Southeast Asia Archipelagos Region}

The Southeast Asia Archipelagos region is a large area that includes the Philippines, Taiwan, Malaysia, Indonesia, and the Melanesian nations of Papua New Guinea, the Solomon Islands, Vanuatu, and Fiji (fig. B10, table B8, pls. 98-128). Of the 53 porphyry copper deposits known in the region, 17 are world class (table A4), including the largest developed porphyry copper-gold deposit in the world, the Grasberg Group ${ }^{1}$ in Indonesia (24 Mt). More than half (33) of the 53 known deposits are in the Philippines. Three tracts with scant information in remote areas of Indonesia and Papua New Guinea were assessed qualitatively (pls. 117, 120, 123). The mean estimate of in-place undiscovered resources (300 Mt of copper) exceeds the identified resources $(130 \mathrm{Mt})$, and the potential economic undiscovered resources (140 Mt of copper) are comparable to the amount of copper that has already been identified in the region (130 Mt; table B8).

\section{Eastern Australia Region}

With the exception of the Macquarie tract (pl. 133), which includes the world-class Cadia Group deposit (table A4), the Eastern Australia region has not been particularly

\footnotetext{
${ }^{1}$ The Grasberg Group resources were reported as $24 \mathrm{Mt}$ of contained copper (Singer, Berger, and Moring, 2008), and that number was used in the assessment of the region (Hammarstrom, Bookstrom, Dicken, and others, 2013). Total resources and reserves as of December 31, 2016, were $37 \mathrm{Mt}$ (Rio Tinto, 2017, p. 224, 229).
}

prospective for porphyry copper deposits (fig. B11, table B9, pls. 129-137). Deposits that have been found to date in two (pls. 130,134) of the other eight tracts are small and low grade compared to porphyry copper deposits in most other parts of the world. The mean estimate of in-place undiscovered copper resources for the Macquarie tract $(21 \mathrm{Mt})$ is larger than the amount of identified copper resources of $13 \mathrm{Mt}$ for the tract; potential economic undiscovered resources (14 Mt) are comparable to identified resources.

\section{Middle East Region}

The geology of a vast area that extends from western Pakistan and Afghanistan westward through Iran, Iraq, and Turkey to eastern Europe records the history of the opening and closing of an ancient ocean known as the Tethys. Of the 30 permissive tracts in this Middle East region (fig. B12, table B10, pls. 138-167), 12 tracts include 42 known porphyry copper deposits. Some of the very young (Pliocene and Quaternary) permissive tracts in the region were assessed qualitatively, along with some older tracts that are extensively overlapped by younger permissive rocks (for example, the Lut Jurassic, Lut Cretaceous, and Makran tracts in Iran shown on pls. 146, 147, and 148). The mean estimate of undiscovered copper resources of $200 \mathrm{Mt}$ exceeds the $61 \mathrm{Mt}$ of identified resources. A little more than half $(130 \mathrm{Mt})$ of the in-place undiscovered resources may be economic.

\section{Europe Region}

Tracts permissive for porphyry copper resources in the Europe region are shown on plates 168-188. Western Europe has been relatively well explored for porphyry copper deposits, and no significant discoveries have been found. Three permissive tracts in western Europe were delineated and qualitatively assessed (fig. B13, ${ }^{2}$ table B11, pls. 176-178). Three small Paleozoic-age porphyry copper deposits are known with combined identified resources of 1.5 Mt of copper (pls. 176 and 178). The very small Calabona deposit in Sardinia (0.13 Mt identified copper resources) is Cenozoic (pl. 177).

More than 25 porphyry copper deposits have been identified in four permissive tracts for eastern Europe (table B11, pls. 168-171), including 15 deposits within the Balkan Mountains (pl. 168). Four tracts are in the Ural Mountains of Russia and westernmost Kazakhstan (pls. 172-175). Although several porphyry copper deposits have been discovered in the Ural Mountains, only the 2.1-Mt Mikheevskoe deposit has been developed (pl. 175, table A4). In northern Europe, all of the known porphyry copper occurrences are Precambrian in age. Ten permissive tracts for Precambrian porphyry copper deposits in Finland include one known deposit (pl. 186), the small (0.045-Mt copper) Kopsa deposit (Rasilainen and others, 2014).

\footnotetext{
${ }^{2}$ Text continues on page 57 .
} 

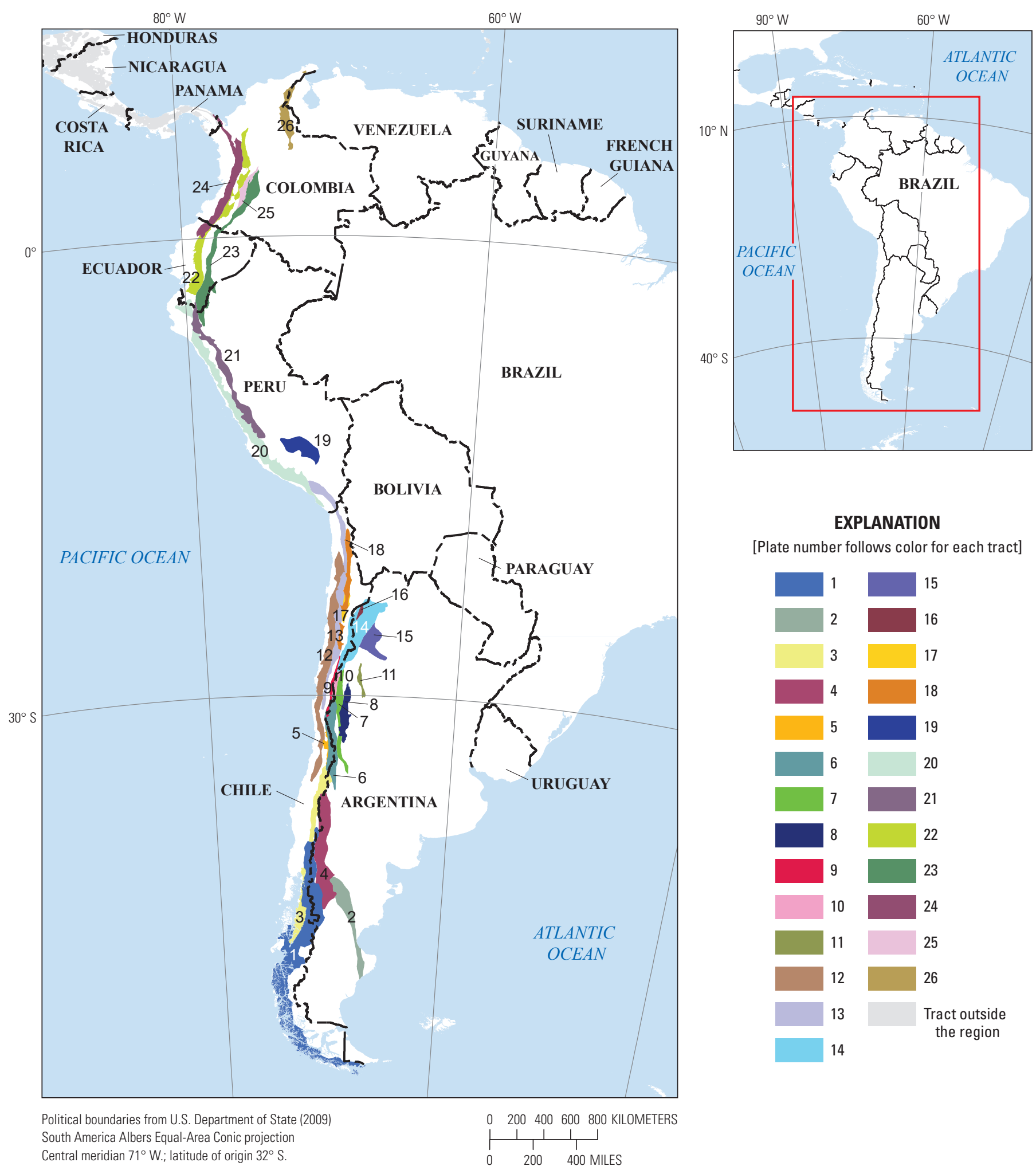

[Plate number follows color for each tract]

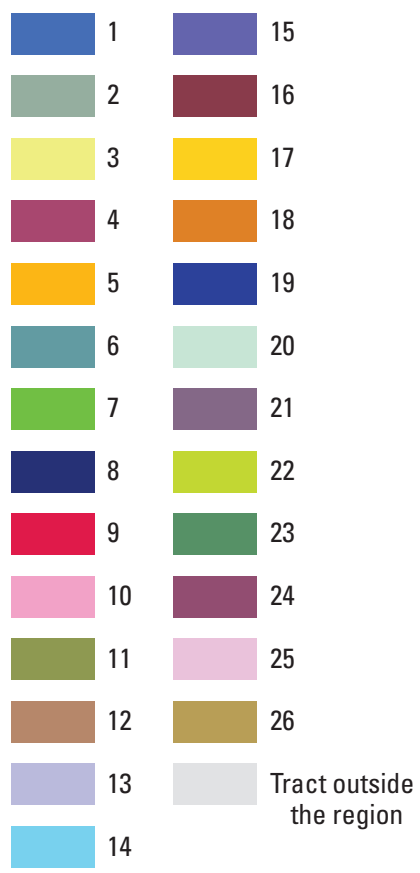

Figure B4. Map showing locations of 26 permissive tracts for porphyry copper deposits in the South America region (pls. 1-26). See table B2 for tract names and a summary of assessment results. 


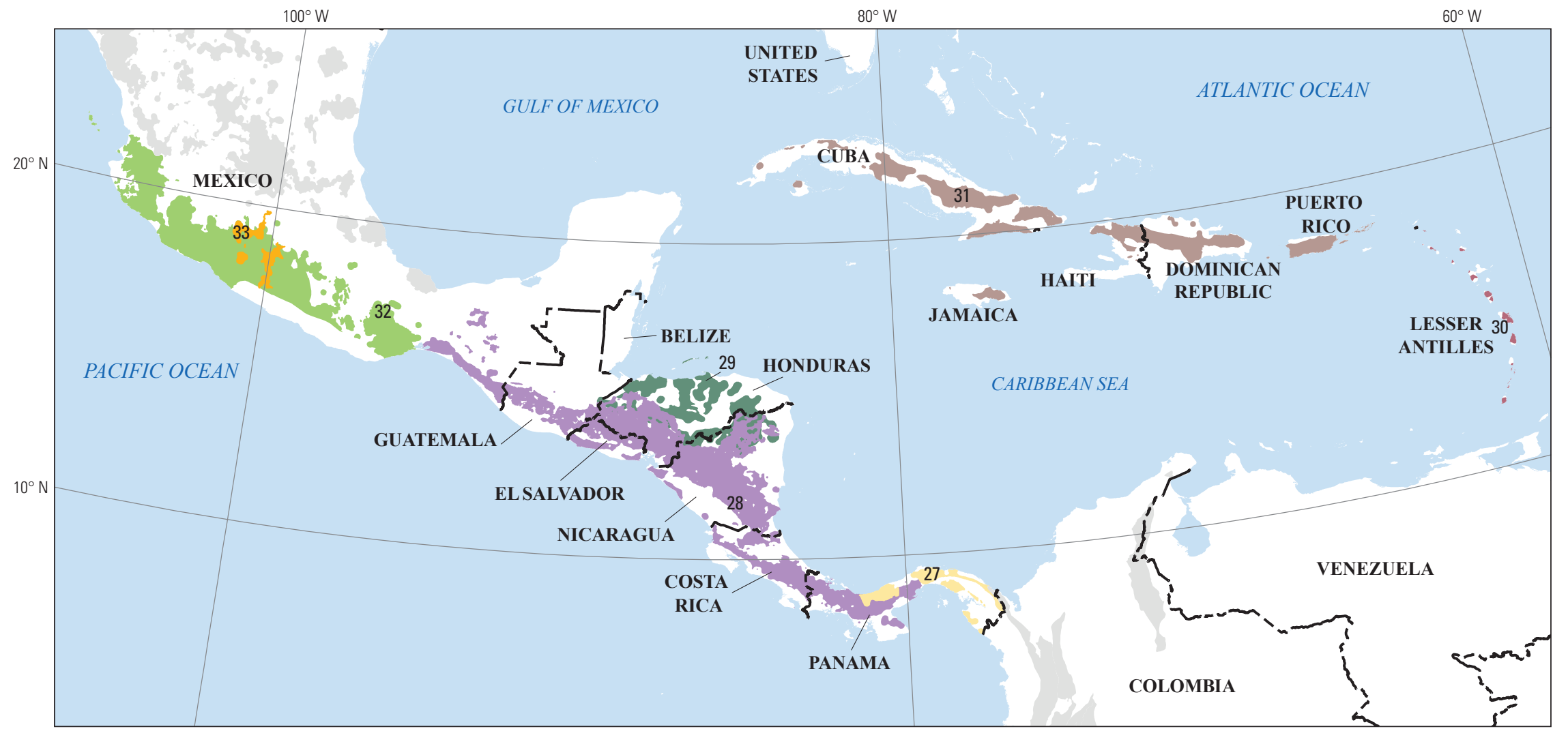

Political boundaries from U.S. Department of State (2009) North America Albers Equal-Area Conic projection Central meridian $85^{\circ} \mathrm{W}$.; latitude of origin $40^{\circ} \mathrm{N}$

\begin{tabular}{|c|c|c|c|c|}
\hline & 200 & 400 & 600 & 800 KILOMETERS \\
\hline & & & & IILES \\
\hline
\end{tabular}

\section{EXPLANATION}

[Plate number follows color for each tract]
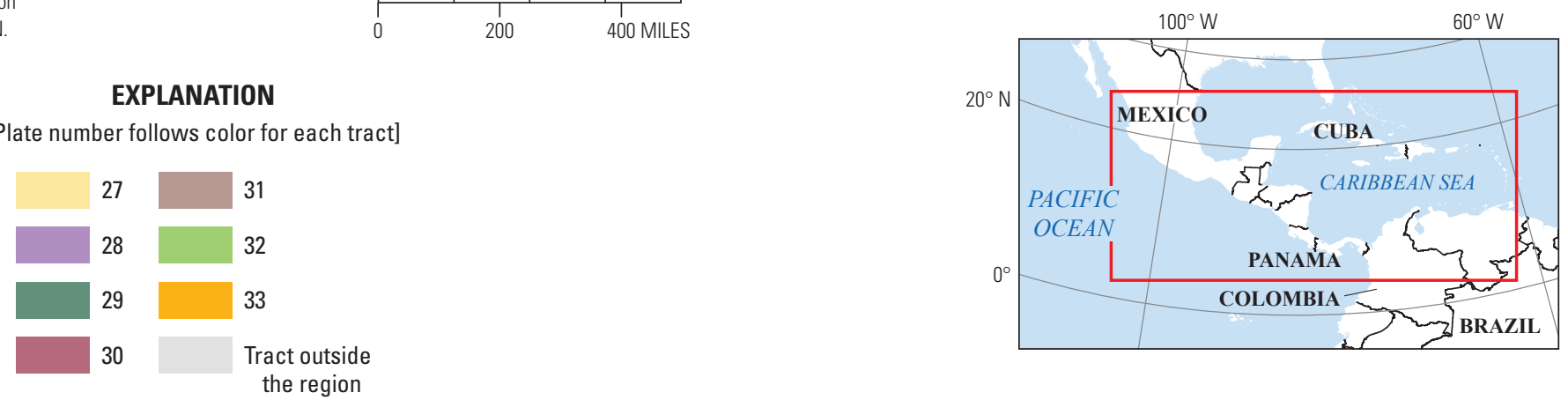
the region

Figure B5. Map showing locations of seven permissive tracts for porphyry copper deposits in the Central America and Caribbean region (pls. 27-33). See table B3 for tract names and a summary of assessment results. 


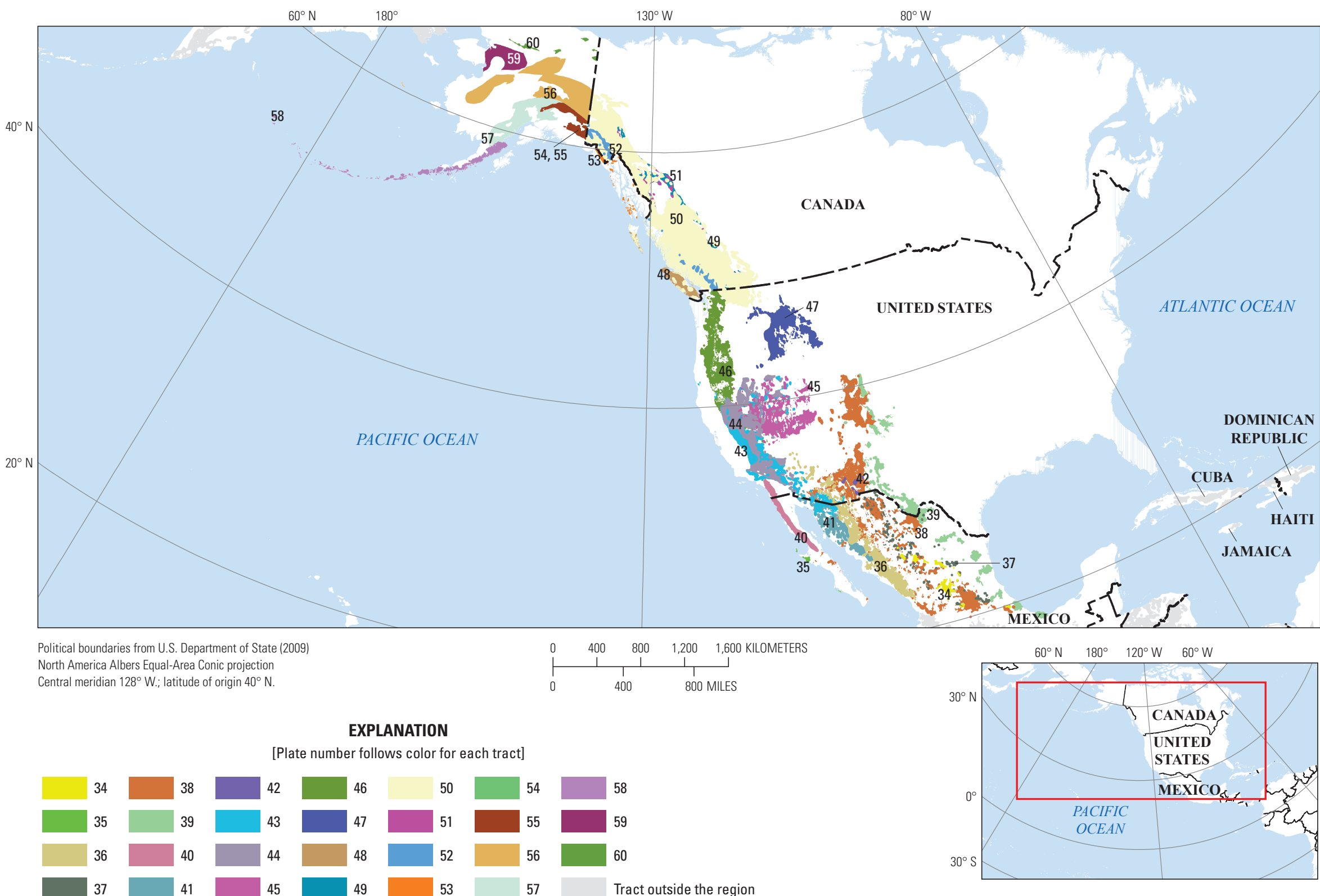

Figure B6. Map showing locations of 27 permissive tracts for porphyry copper deposits in the North America region (pls. 34-60). See table B4 for tract names and a summary of assessment results. On this map, tract 54 is completely covered by tract 55. 

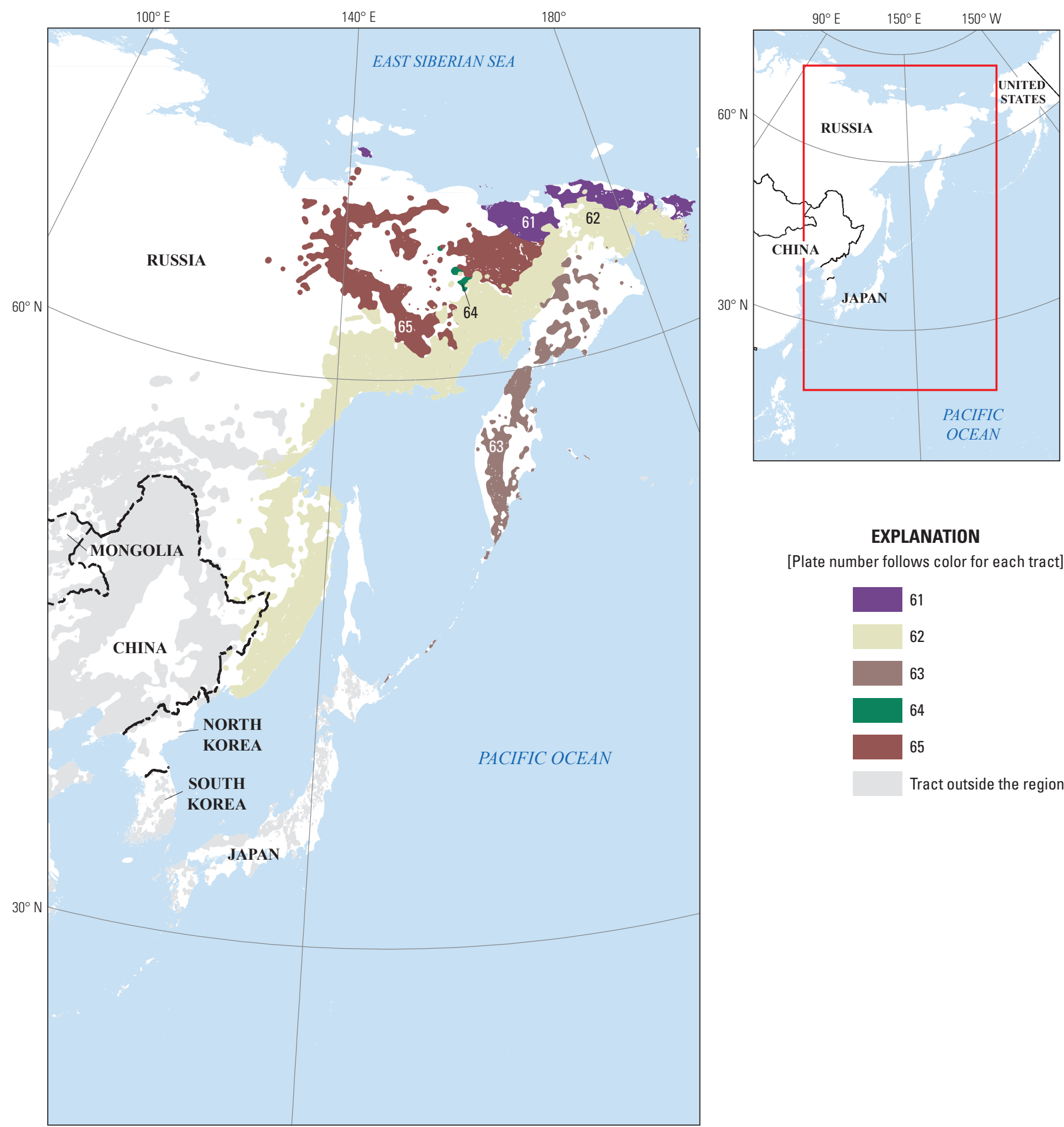

\section{EXPLANATION}

[Plate number follows color for each tract]

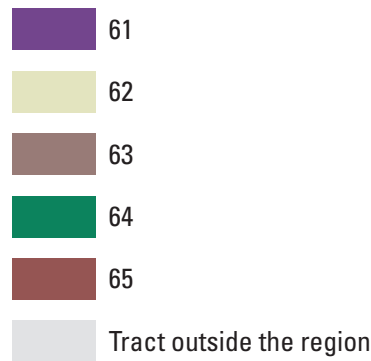

Political boundaries from U.S. Department of State (2009)

Asia North Albers Equal-Area Conic projection

Central meridian $146^{\circ} \mathrm{E}$.; latitude of origin $30^{\circ} \mathrm{N}$

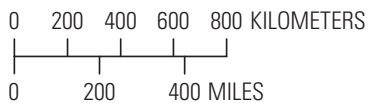

Figure B7. Map showing locations of five permissive tracts for porphyry copper deposits in the Northeast Asia region (pls. 61-65). See table B5 for tract names and a summary of assessment results. 


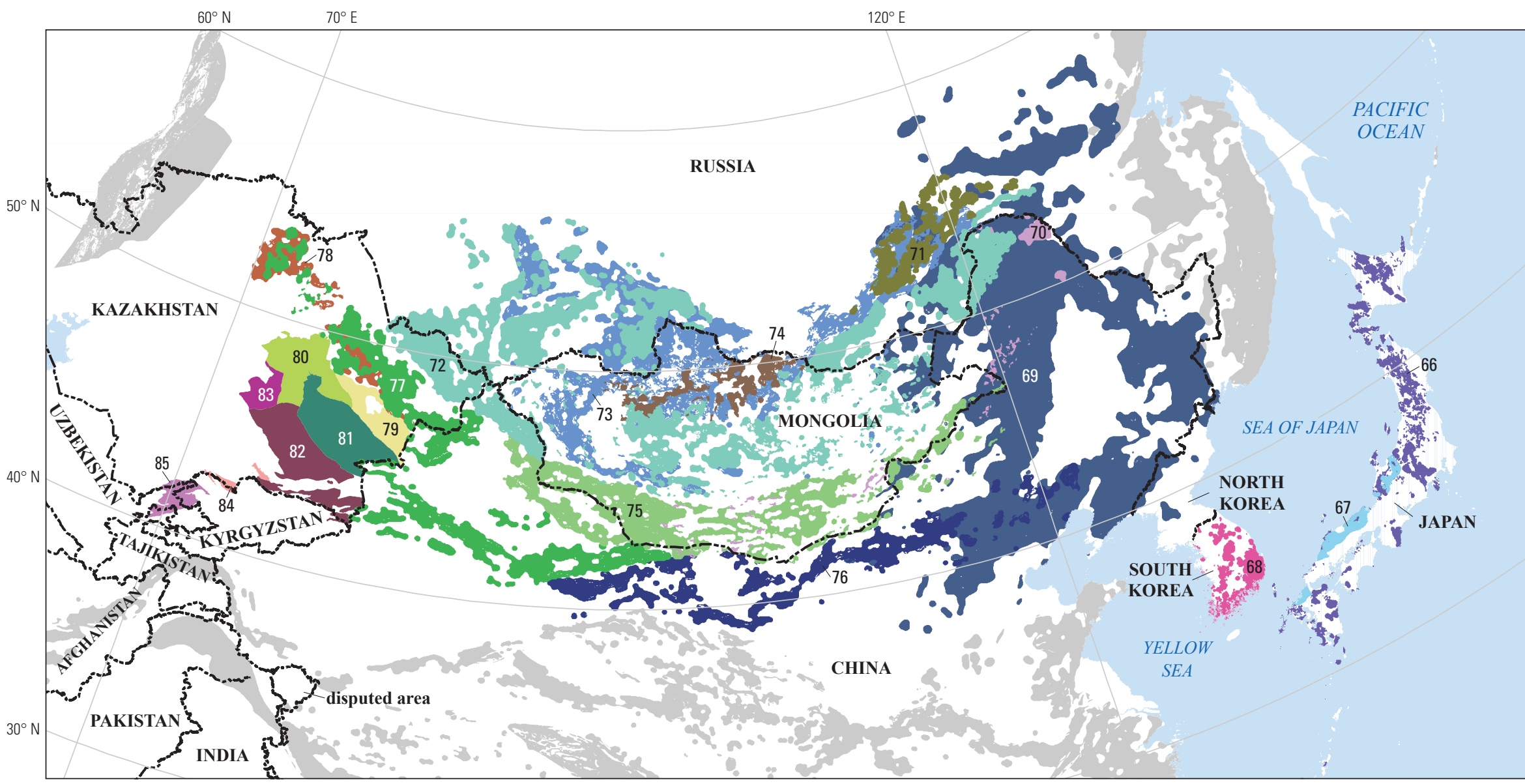

Political boundaries from U.S. Department of State (2009) Europe Albers Equal-Area Conic projection Central meridian $96^{\circ} \mathrm{E} . ;$ latitude of origin $30^{\circ} \mathrm{N}$

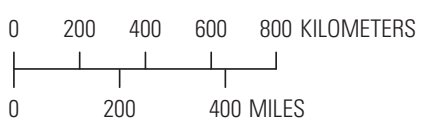

\section{EXPLANATION}

[Plate number follows color for each tract]

\begin{tabular}{|l|l|l|l|l|l|l|l|}
\hline 66 & & 69 & 72 & 75 & 78 & 81 & 84 \\
\hline 67 & 70 & 73 & 76 & 79 & 82 & 85 \\
\hline 68 & 71 & 74 & 77 & 80 & 83 & Tract outside the region \\
\hline
\end{tabular}

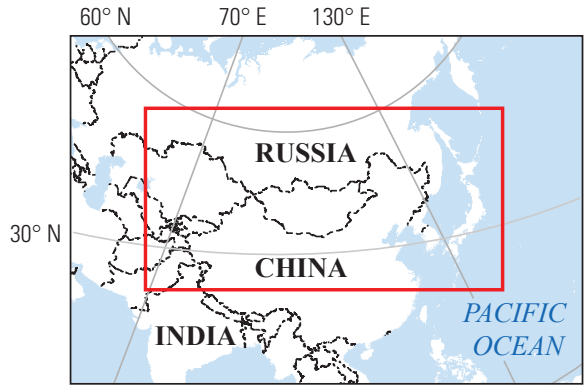

Figure B8. Map showing locations of 20 permissive tracts for porphyry copper deposits in the Central and Eastern Asia region (pls. 66-85). See table B6 for tract names and a summary of assessment results. 


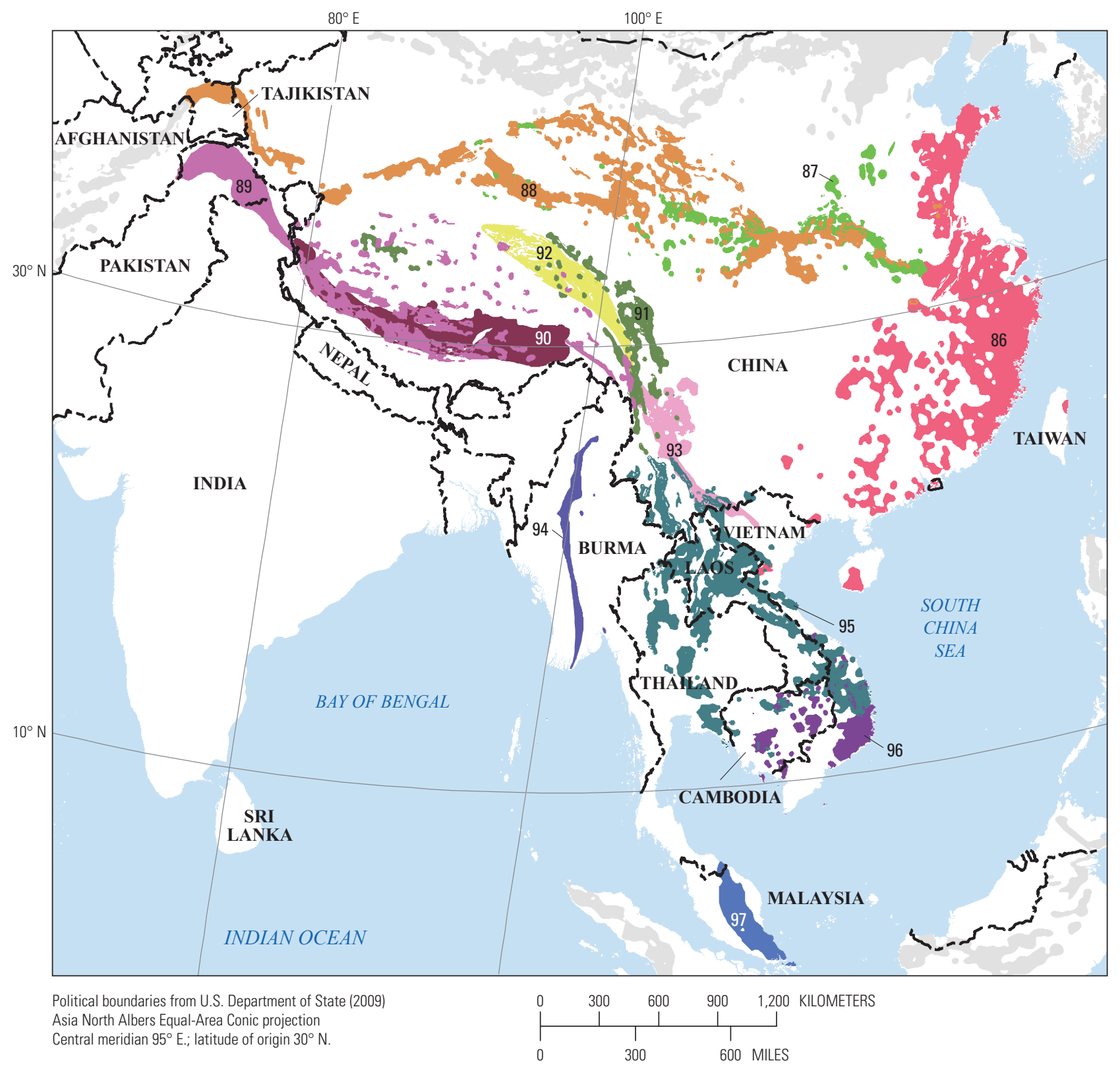

\section{EXPLANATION}

[Plate number follows color for each tract]

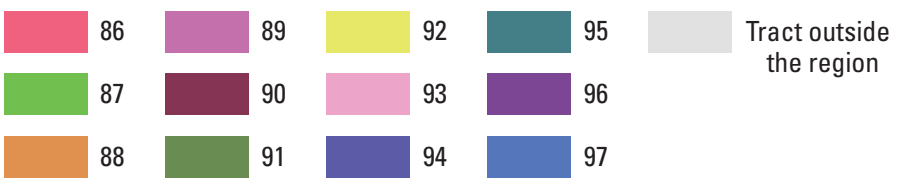

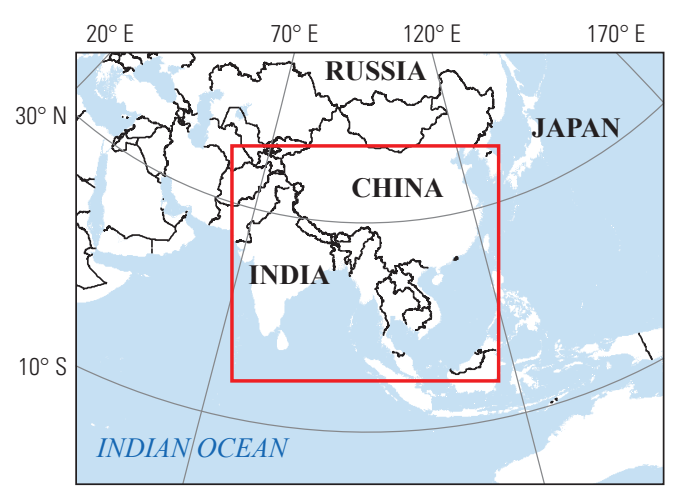

Figure B9. Map showing locations of 12 permissive tracts for porphyry copper deposits in the Southeast Asia region (pls. 86-97). See table B7 for tract names and a summary of assessment results. 


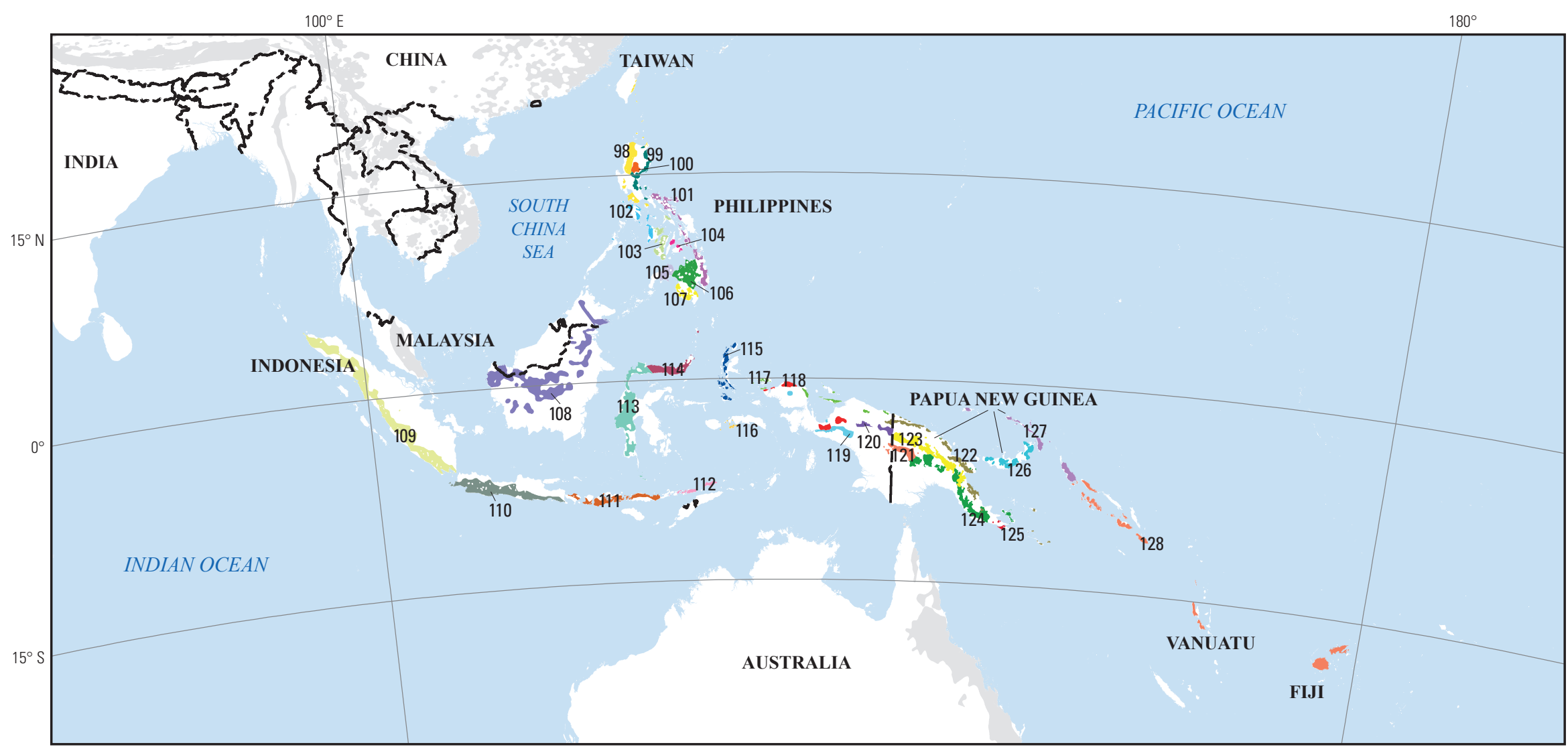

Political boundaries from U.S. Department of State (2009)
Asia South Albers Equal-Area Conic projection

EXPLANATION

[Plate number follows color for each tract]

\begin{tabular}{|l|l|l|l|l|l|l|l|l|l|}
\hline 98 & 102 & 106 & 110 & 114 & 118 & 122 & 126 \\
\hline 99 & 103 & 107 & 111 & 115 & 119 & 123 & 127 \\
\hline 100 & 104 & 108 & 112 & 116 & 120 & 124 & 128 \\
\hline 101 & 105 & 109 & 113 & 117 & 121 & 125 & Tract outside the region \\
\hline
\end{tabular}

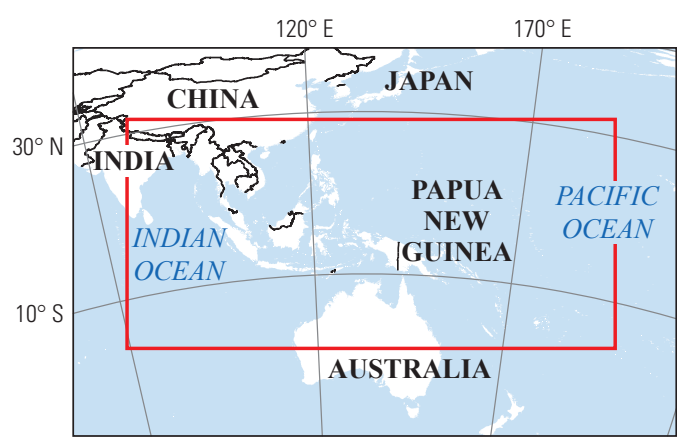

Figure B10. Map showing locations of 31 permissive tracts for porphyry copper deposits in the Southeast Asia Archipelagos region (pls. 98-128). See table B8 for tract names and a summary of assessment results. 

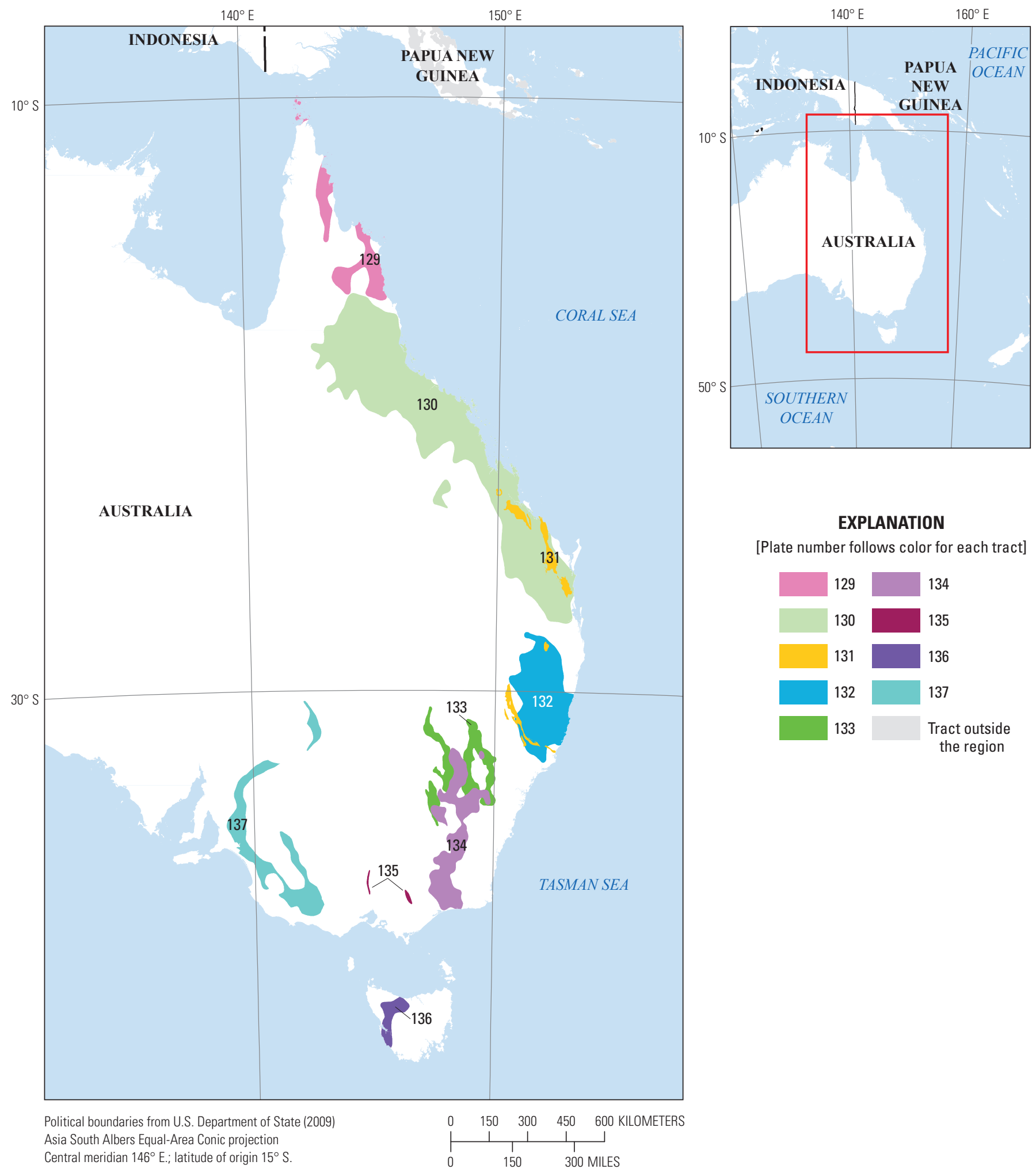

[Plate number follows color for each tract]

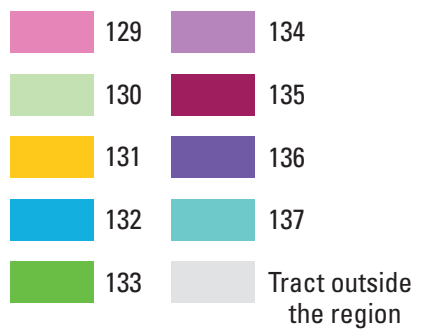

Figure B11. Map showing locations of nine permissive tracts for porphyry copper deposits in the Eastern Australia region (pls. 129-137). See table B9 for tract names and a summary of assessment results. 


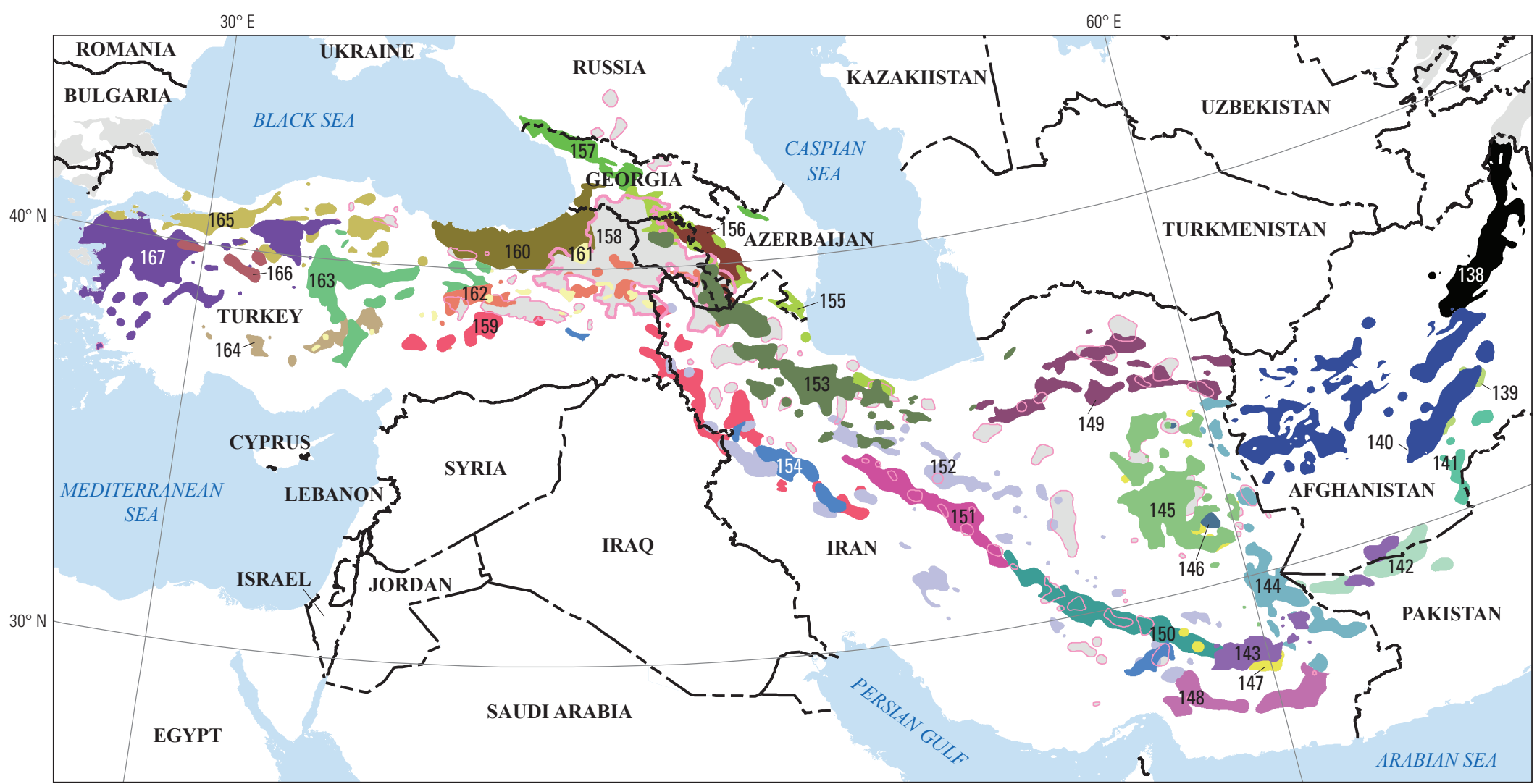

Political boundaries from U.S. Department of State (2009) Europe Albers Equal-Area Conic projection Central meridian $41^{\circ} \mathrm{E}$.; latitude of origin $30^{\circ} \mathrm{N}$.

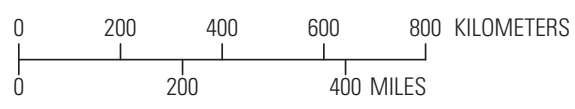

\section{EXPLANATION}

[Plate number follows color for each tract]

\begin{tabular}{|l|l|l|l|l|l|l|l|l|}
\hline 138 & 142 & 146 & 150 & 154 & $\square$ & 158 & 162 & 166 \\
139 & 143 & 147 & 151 & 155 & 159 & 163 & 167 \\
\hline 140 & 144 & 148 & 152 & 156 & 160 & 164 & Tract outside \\
141 & 145 & 149 & 153 & 157 & 161 & 165 & the region \\
\hline
\end{tabular}

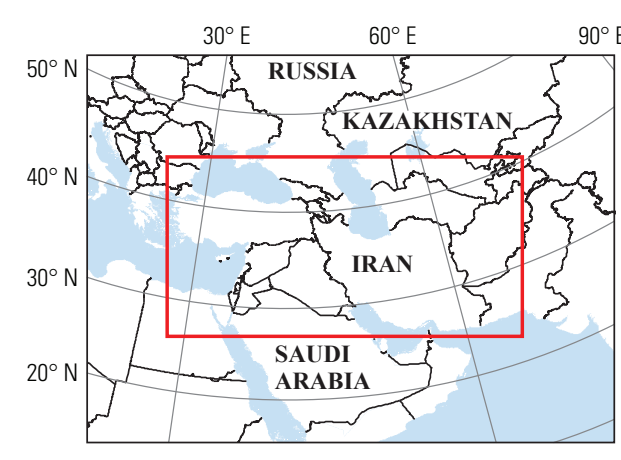

Figure B12. Map showing locations of 30 permissive tracts for porphyry copper deposits in the Middle East region (pls. 138-167). See table B10 for tract names and a summary of assessment results. 


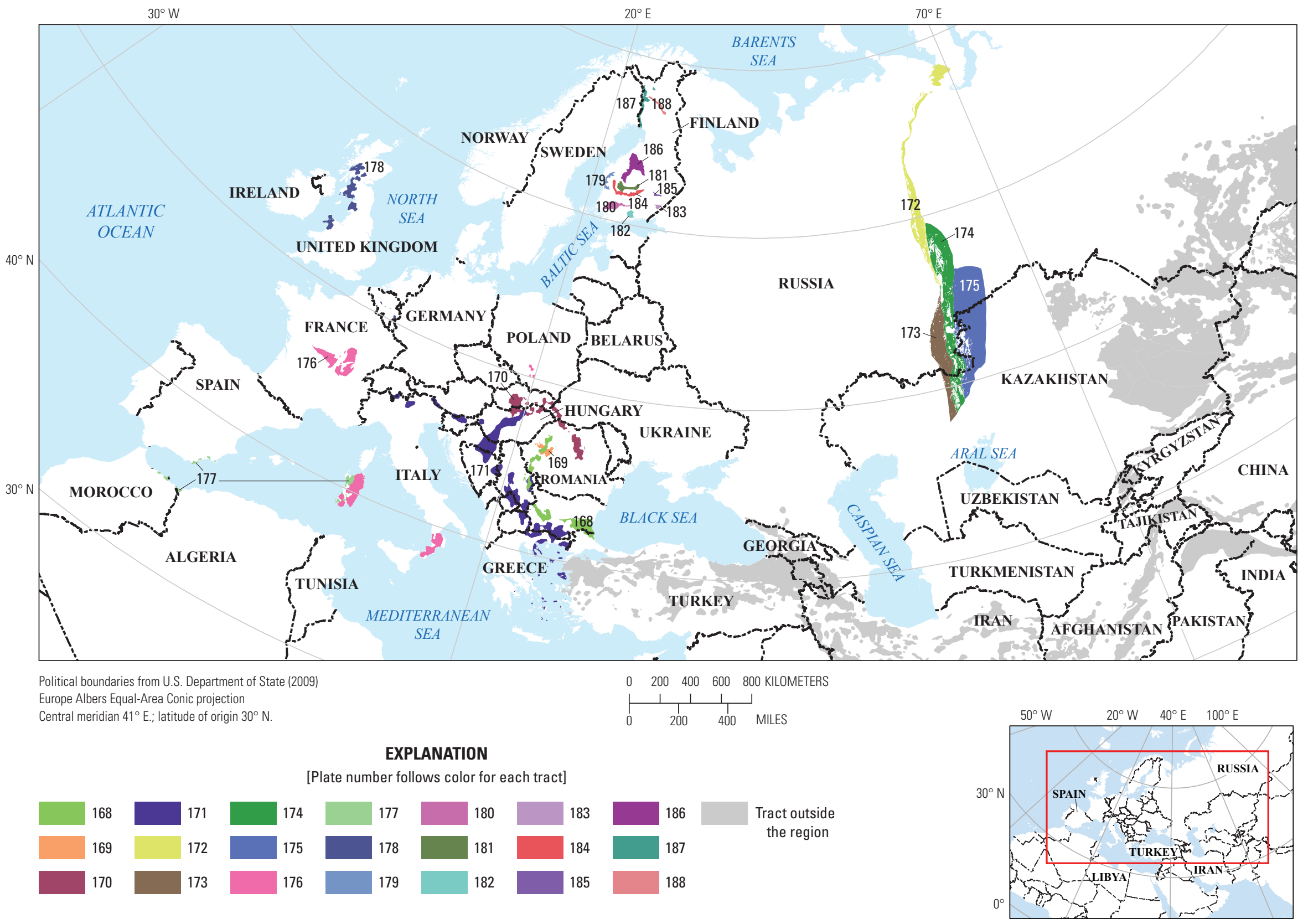

Figure B13. Map showing locations of 21 permissive tracts for porphyry copper deposits in the Europe region (pls. 168-188). See table B11 for tract names and a summary of assessment results. 
The strongly deformed and metamorphosed Aitik coppergold-silver deposit in northern Sweden (fig. B1) has also been classified as a Precambrian porphyry copper deposit (Wanhainen and others, 2003). The Aitik mine is one of the largest copper producers in Europe; however, the Precambrian rocks of Sweden were not assessed because of the complex geologic history of the area and uncertainties about the deposit type.

\section{Global Results}

The global porphyry copper assessment provides answers to three main questions: (1) How much copper may be present in undiscovered porphyry copper deposits? (2) How much of the mean undiscovered copper is likely to be economic? and

(3) Where are the undiscovered porphyry copper deposits most likely to be?

In response to the first question, the mean estimate of in-place undiscovered copper resources is 3,100 Mt (table B1). This is nearly twice the $1,800 \mathrm{Mt}$ of copper resources that have already been identified in porphyry copper deposits. Identified resources include past production and well-documented resources reported for deposits that have not yet been developed. The distribution of identified and mean undiscovered copper resources associated with porphyry copper deposits by world region is plotted in figure B14. Information on identified and mean undiscovered copper reported for all deposit types in the United States from the 1995 and 1998 assessments (U.S. Geological Survey Minerals Team, 1996; U.S. Geological Survey National Mineral Resource Assessment Team, 2000, 2002) is also presented, along with world copper production and world copper reserves for 2014.

The amount of in-place undiscovered copper in porphyry copper deposits varies from region to region. The mean undiscovered copper estimate for each world region exceeds the total amount of copper produced worldwide in 2014 (18.7 Mt of copper) from all deposit types (fig. B14). With the exception of the Eastern Australia region, both the most certain (90-percent) and median (50-percent) estimates also exceed the 2014 global copper production (this volume, tables A6, B1).

The second question, which is about the economic value of undiscovered resources, is addressed by applying an economic filter. The economic value of the in-place undiscovered copper varies greatly depending on the depth setting and the degree of infrastructure associated with each permissive tract; tables B2-B11 summarize the mean estimates of amounts of economic resources in the regions. Some of the already identified resources may never be developed for a variety of reasons related to economic conditions, land-use issues, environmental issues, or political and societal concerns. These issues also may restrict exploration for future copper resources. The global porphyry copper assessment indicates that many regions of the world that do not have significant identified resources may contain $100 \mathrm{Mt}$ or more of undiscovered copper resources. Although South America is the largest source of identified copper resources associated with porphyry copper $(800 \mathrm{Mt})$ and has the largest mean undiscovered porphyry copper resource estimate $(750 \mathrm{Mt}$ ), other regions may contribute a larger relative portion of the global copper resources in the future than they have in the past (fig. B15, table B1). The regions in Asia are especially likely to contribute a larger relative portion. For example, identified copper resources in Northeast Asia (8.8 Mt) represent less than 1 percent of the global identified porphyry copper resources $(1,800 \mathrm{Mt})$, whereas the undiscovered porphyry copper resources for that region $(260 \mathrm{Mt})$ represent about 8 percent of the global undiscovered resources (3,100 Mt) (fig. B15, table B1).

Lastly, the question about the most likely locations of undiscovered porphyry copper resources is answered by the permissive tract maps (pls. 1-188) and the distribution of tracts around the world (fig. B1). Ten of the eleven world regions considered in the global copper assessment are likely to contain undiscovered Phanerozoic porphyry copper deposits (fig. B14); only Africa is not considered likely for discovery of deposits of this age and type. South America and North America are estimated to contain undiscovered resources that are roughly comparable to the amounts that have already been identified. On the basis of the assessment results, the real future frontier areas for undiscovered porphyry copper deposits are in the Eastern Hemisphere (fig. B15).

Porphyry copper deposits are likely to continue to provide much of the world's copper. Exploration, discovery, and development of future copper sources could provide data that could be used to refine and test the geology-based assessment results presented here. In addition to recognizing geologically permissive areas of the world for porphyry copper deposits, however, a variety of other factors (economic, political, social, and environmental) determine what resources may become available in the future. 


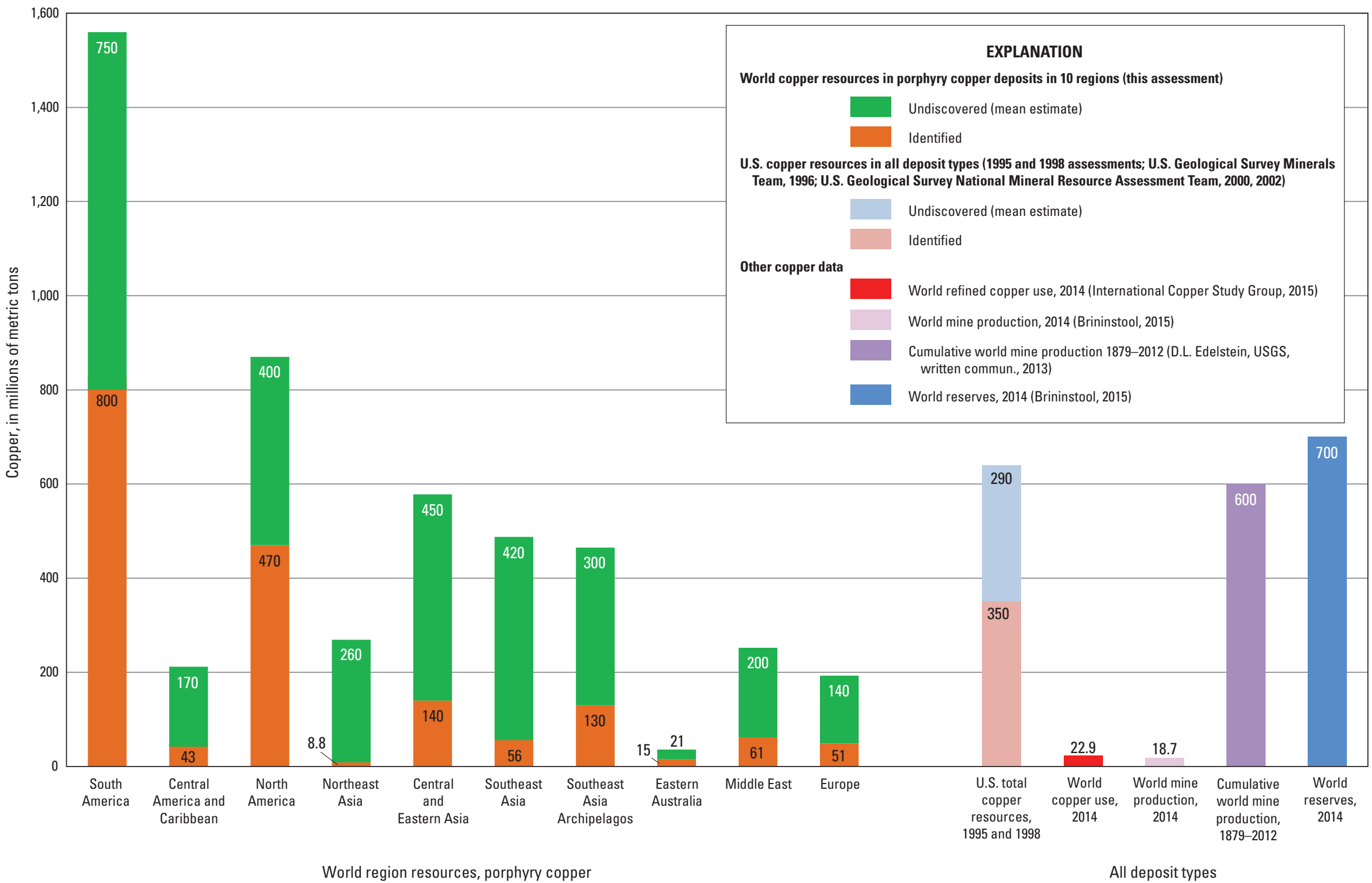

Figure B14. Bar chart showing amounts of identified copper resources and mean estimates of undiscovered copper resources in porphyry copper deposits by world region and selected data on U.S. and world copper resources in all deposit types. Data plotted from the U.S. Geological Survey (USGS) global assessment of porphyry copper resources (left part of chart) are summarized in tables B1-B11. Sources of other data are indicated in the explanation and table A6 (this volume, chap. A). 
A. Identified porphyry copper resources, world total $=1,800 \mathrm{Mt}$

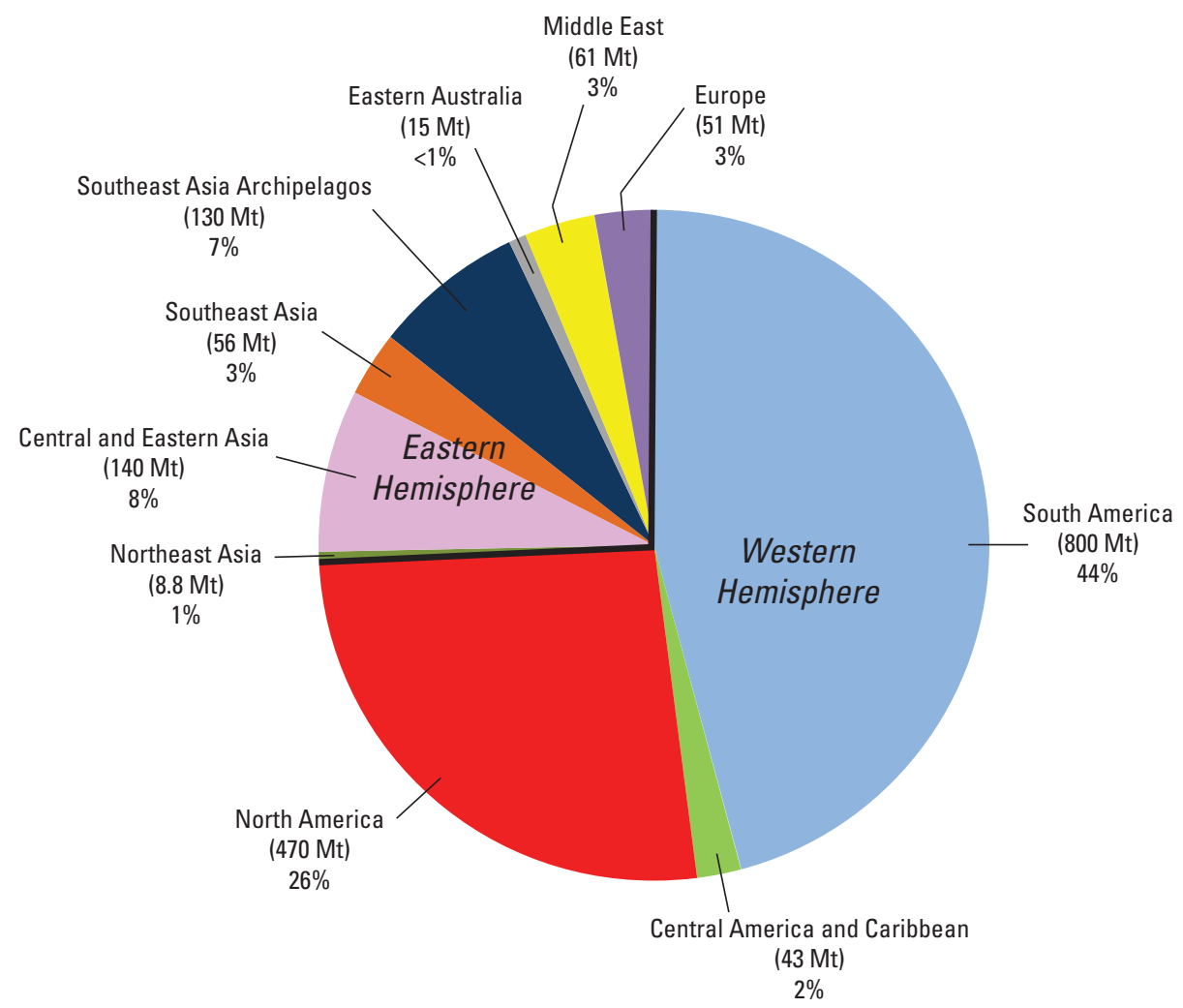

B. Mean estimates of undiscovered porphyry copper resources, world total $=3,100 \mathrm{Mt}$

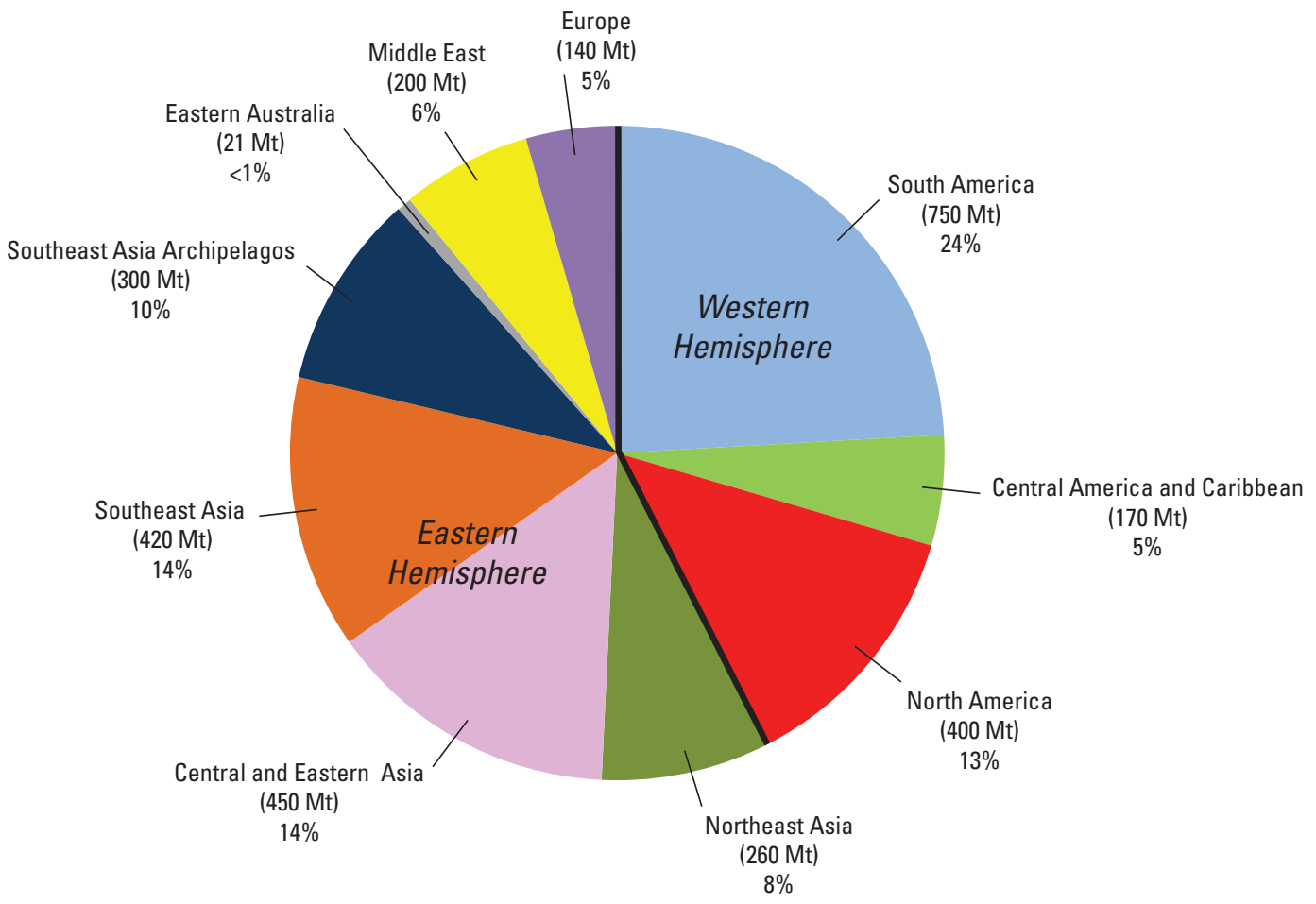

Figure B15. Pie charts comparing the relative percentages of $(A)$ identified porphyry copper resources and $(B)$ mean estimates of undiscovered porphyry copper resources by world region. The data are summarized from tables B1-B11. Because Africa is not considered permissive for the occurrence of Phanerozoic porphyry copper deposits, it is not included in the charts. Mt, millions of metric tons; \%, percent. 


\section{References Cited}

Chapter B describes the undiscovered porphyry copper resources for which data are provided in plates 1-188. This list of references cited includes sources cited in chapter B and in plates 1-188.

Berger, B.R., Ayuso, R.A., Wynn, J.C., and Seal, R.R., 2008, Preliminary model of porphyry copper deposits: U.S. Geological Survey Open-File Report 2008-1321, 55 p., accessed May 15, 2009, at http://pubs.usgs.gov/ of $/ 2008 / 1321$

Berger, B.R., Mars, J.C., Denning, P.D., Phillips, J.D., Hammarstrom, J.M., Zientek, M.L, Dicken, C.L., and Drew, L.J., 2014, Porphyry copper assessment of western Central Asia: U.S. Geological Survey Scientific Investigations Report 2010-5090-N, 219 p., 8 pls., and spatial data, accessed October 15, 2015, at http://dx.doi.org/10.3133/ sir20105090N.

Bookstrom, A.A., Glen, R.A., Hammarstrom, J.M., Robinson, G.R., Jr., Zientek, M.L., Drenth, B.J., Jaireth, Subhash, Cossette, P.M., and Wallis, J.C., 2014, Porphyry copper assessment of eastern Australia: U.S. Geological Survey Scientific Investigations Report 2010-5090-L, 160 p. and GIS data, accessed November 15, 2015, at https://doi.org/10.3133/ sir20105090L.

Brininstool, Mark, 2015, Copper: U.S. Geological Survey Mineral Commodity Summaries 2015, p. 48-49, accessed November 25, 2016, at http://minerals.usgs.gov/minerals/ pubs/mcs/2015/mcs2015.pdf.

Cooke, D.R., Heithersay, P.S., Wolfe, Rohan, and Calderon, A.L., 1998, Australian and western Pacific porphyry $\mathrm{Cu}-\mathrm{Au}$ deposits: Journal of Australian Geology and Geophysics, v. 17, no. 4, p. 97-104. [Also available at http://www.southernarcminerals.com/upload/presentations/ WesternPacificPorpheries.pdf.]

Cox, D.P., 1986a, Descriptive model of porphyry $\mathrm{Cu}$ (model 17), in Cox, D.P., and Singer, D.A., eds., Mineral deposit models: U.S. Geological Survey Bulletin 1693, p. 76, accessed June 1, 2015, at http://pubs.usgs.gov/bul/b1693/.

Cox, D.P., 1986b, Descriptive model of porphyry $\mathrm{Cu}-\mathrm{Au}$ (model 20c), in Cox, D.P., and Singer, D.A., eds., Mineral deposit models: U.S. Geological Survey Bulletin 1693, p. 110, accessed June 1, 2015, at http://pubs.usgs.gov/bul/ b1693/.

Cox, D.P., 1986c, Descriptive model of porphyry Cu-Mo (model 21a), in Cox, D.P., and Singer, D.A., eds., Mineral deposit models: U.S. Geological Survey Bulletin 1693, p. 115, accessed June 1, 2015, at http://pubs.usgs.gov/bul/ b1693/.
Cunningham, C.G.; Zappettini, E.O.; Vivallo S., Waldo; Celada, C.M.; Quispe, Jorge; Singer, D.A.; Briskey, J.A.; Sutphin, D.M.; Gajardo M., Mariano; Diaz, Alejandro; Portigliati, Carlos; Berger, V.I.; Carrasco, Rodrigo; and Schulz, K.J., 2008, Quantitative mineral resource assessment of copper, molybdenum, gold, and silver in undiscovered porphyry copper deposits in the Andes Mountains of South America: U.S. Geological Survey Open-File Report 2008-1253, 282 p., accessed May 15, 2012, at http://pubs.usgs.gov/of/2008/1253/.

de Ferranti, Jonathan, and Hormann, Christoph, 2009, Digital elevation data-North Eurasia: Viewfinder Panoramas, accessed August 24, 2015, at http://www.viewfinderpanoramas.org/Coverage $\% 20$ map\%20viewfinderpanoramas_org3. htm.

Dicken, C.L., Dunlap, Pamela, Parks, H.L., Hammarstrom, J.M., and Zientek, M.L., 2016, Spatial database for a global assessment of undiscovered copper resources: U.S. Geological Survey Scientific Investigations Report 20105090-Z, 29 p. and GIS data, accessed July 21, 2016, at http://dx.doi.org/10.3133/sir20105090Z.

Earth Resources Observation and Science (EROS) Center, 2011, HYDRO1k elevation derivative database: U.S. Geological Survey web page, accessed May 29, 2013, at http:// eros.usgs.gov/\#Find_Data/Products_and_Data_Available/ gtopo30/hydro.

Eilu, P., 2014, Descriptive model of porphyry copper (gold, molybdenum), app. 3 of Rasilainen, K., Eilu, P., Halkoaho, T., Karvinen, A., Kontinen, A., Kousa, J., Lauri, L., Luukas, J., Niiranen, T., Nikander, J., Sipilä, P., Sorjonen-Ward, P., Tiainen, M., Törmänen, T., and Västi, K., Quantitative assessment of undiscovered resources in volcanogenic massive sulphide deposits, porphyry copper deposits and Outokumpu-type deposits in Finland: Geological Survey of Finland Report of Investigation 208, p. 76-78, accessed July 30, 2015, at http://tupa.gtk.fi/julkaisu/tutkimusraportti/ tr_208.pdf.

ESRI, 2008, Global shaded relief derived from the Shuttle Radar Topography Mission (SRTM): Redlands, Calif., ESRI Data \& Maps, release 9.3-Global Imagery and Shaded Relief, DVD.

Frost, T.P., Bookstrom, A.A., and Mihalasky, M.J., 2013, Grade and tonnage model for calc-alkalic porphyry $\mathrm{Cu} \pm \mathrm{Mo} \pm \mathrm{Au}$ deposits of the Canadian Cordillera, app. $\mathrm{G}$ of Mihalasky, M.J., Bookstrom, A.A., Frost, T.P., and Ludington, Steve, Porphyry copper assessment of British Columbia and Yukon Territory, Canada (ver. 1.1, February 2013): U.S. Geological Survey Scientific Investigations Report 20105090-C, p. 118-125, accessed June 1, 2015, at http://pubs. usgs.gov/sir/2010/5090/c/. 
Gray, Floyd, Hammarstrom, J.M., Ludington, Steve, Zürcher, Lukas, Nelson, C.E., Robinson, G.R., Jr., Miller, R.J., and Moring, B.C., 2014, Porphyry copper assessment of Central America and the Caribbean Basin: U.S. Geological Survey Scientific Investigations Report 2010-5090-I, 81 p. and GIS data, accessed June 1, 2015, at http://dx.doi.org/10.3133/ sir20105090I.

Hammarstrom, J.M., Bookstrom, A.A., DeMarr, M.W., Dicken, C.L., Ludington, Steve, Robinson, G.R., Jr., and Zientek, M.L., 2014, Porphyry copper assessment of East and Southeast Asia-Philippines, Taiwan (Republic of China), Republic of Korea (South Korea), and Japan: U.S. Geological Survey Scientific Investigations Report 2010 5090-P, 243 p. and spatial data, accessed June 1, 2015, at http://dx.doi.org/10.3133/sir20105090P.

Hammarstrom, J.M., Bookstrom, A.A., Dicken, C.L., Drenth, B.J., Ludington, Steve, Robinson, G.R., Jr., Setiabudi, B.T., Sukserm, Wudihikarn, Sunuhadi, D.N., Wah, A.Y.S., and Zientek, M.L., 2013, Porphyry copper assessment of Southeast Asia and Melanesia: U.S. Geological Survey Scientific Investigations Report 2010-5090-D, 332 p. and GIS data, accessed September 16, 2014, at http://pubs.usgs. gov/sir/2010/5090/d/.

Hammarstrom, J.M., Mihalasky, M.J., Ludington, Steve, Phillips, J.D., Berger, B.R., Denning, P.D., Dicken, C.L., Mars, J.C., Zientek, M.L., Herrington, R.J., and Seltmann, Reimar, 2017, Undiscovered porphyry copper resources in the Urals - A probabilistic mineral resource assessment: Ore Geology Reviews, v. 85 (May 2017), p. 181-203, accessed May 16, 2017, at https://doi.org/10.1016/ j.oregeorev.2016.09.007.

Hammarstrom, J.M., Robinson, G.R., Jr., Ludington, Steve, Gray, Floyd, Drenth, B.J., Cendejas-Cruz, Francisco, Espinosa, Enrique, Pérez-Segura, Efrén, Valencia-Moreno, Martín, Rodríguez-Castañeda, J.L., Vásquez-Mendoza, Rigoberto, and Zürcher, Lukas, 2010, Porphyry copper assessment of Mexico: U.S. Geological Survey Scientific Investigations Report 2010-5090-A, 176 p. and GIS package, accessed October 10, 2011, at http://pubs.usgs.gov/ sir/2010/5090/a/.

Hammarstrom, J.M., Zientek, M.L., and Parks, H.L., 2018, Global mineral resource assessment-Summary simulation results for estimates of amounts of copper in undiscovered porphyry copper deposits: U.S. Geological Survey data release, accessed February 1, 2018, at https://doi.org/10.5066/ F70K26Q4.

International Copper Study Group, 2015, Copper bulletin: International Copper Study Group, v. 22, no. 7, July, 53 p.
Jaireth, S., and Miezitis, Y., 2004, OZPOT geoprovince-scale assessment of mineral potential of Australia [1:2,500,000 scale GIS]: Canberra, Geoscience Australia, web page, accessed June 21, 2010, to December 27, 2010, at http://www.australianminesatlas.gov.au/build/common/ minpot.html.

John, D.A., Ayuso, R.A., Barton, M.D., Blakely, R.J., Bodnar, R.J., Dilles, J.H., Gray, Floyd, Graybeal, F.T., Mars, J.C., McPhee, D.K., Seal, R.R., Taylor, R.D., and Vikre, P.G., 2010, Porphyry copper deposit model: U.S. Geological Survey Scientific Investigations Report 2010-5070-B, 169 p., accessed September 8, 2010, at http://pubs.usgs.gov/ $\operatorname{sir} / 2010 / 5070 / b /$.

Ludington, Steve, Hammarstrom, J.M., Robinson, G.R., Jr., Mars, J.C., and Miller, R.J., 2012, Porphyry copper assessment of the Tibetan Plateau, China: U.S. Geological Survey Scientific Investigations Report 2010-5090-F, 63 p. and GIS data, accessed July 7, 2014, at http://pubs.usgs.gov/ $\operatorname{sir} / 2010 / 5090 / f /$.

Ludington, Steve, Mihalasky, M.J., Hammarstrom, J.M., Robinson, G.R., Jr., Frost, T.P., Gans, K.D., Light, T.D., Miller, R.J., and Alexeiev, Dmitriy, 2012, Porphyry copper assessment of the Mesozoic of East Asia - China, Vietnam, North Korea, Mongolia, and Russia: U.S. Geological Survey Scientific Investigations Report 2010-5090-G, 53 p. and GIS data, accessed July 7, 2014, at http://pubs.usgs.gov/ $\operatorname{sir} / 2010 / 5090 / g /$.

Ludington, Steve, Orris, G.J., Bolm, K.S., Peters, S.G., and the U.S. Geological Survey-Afghanistan Ministry of Mines and Industry Joint Mineral Resource Assessment Team, 2007, Preliminary mineral resource assessment of selected mineral deposit types in Afghanistan: U.S. Geological Survey Open-File Report 2007-1005, 44 p., accessed July 7, 2014, at http://pubs.usgs.gov/of/2007/1005/.

Manska, S.L., and Paul, A.H., 2002, Geology of a major new porphyry copper center in the Superior (Pioneer) district, Arizona: Economic Geology, v. 97, no. 2, p. 197-220.

McMahon, Fred, and Cervantes, Miguel, 2012, Fraser Institute annual survey of mining companies 2011/2012: Vancouver, Canada, Fraser Institute, 131 p.

Mihalasky, M.J., Bookstrom, A.A., Frost, T.P., and Ludington, Steve, 2013, Porphyry copper assessment of British Columbia and Yukon Territory, Canada (ver. 1.1, February 2013): U.S. Geological Survey Scientific Investigations Report 2010-5090-C, 128 p. and data tables, accessed June 1, 2015, at http:/pubs.usgs.gov/sir/2010/5090/c/. 
Mihalasky, M.J., Ludington, Steve, Alexeiev, D.V., Frost, T.P., Light, T.D., Briggs, D.A., Hammarstrom, J.M., and Wallis, J.C., 2015, Porphyry copper assessment of northeast AsiaFar East Russia and northeasternmost China: U.S. Geological Survey Scientific Investigations Report 2010-5090-W, 104 p. and spatial data, accessed July 15, 2015, at http:// dx.doi.org/10.3133/sir20105090W.

Mihalasky, M.J., Ludington, Steve, Hammarstrom, J.M., Alexeiev, D.V., Frost, T.P., Light, T.D., Robinson, G.R., Jr., Briggs, D.A., Wallis, John, and Miller, R.J., 2015, Porphyry copper assessment of the Central Asian Orogenic Belt and eastern Tethysides - China, Mongolia, Russia, Pakistan, Kazakhstan, Tajikistan, and India: U.S. Geological Survey Scientific Investigations Report 2010-5090-X, 106 p. and spatial data, accessed June 2, 2016, at http://dx.doi. org/10.3133/sir20105090X.

Mudd, G.M., Weng, Zhehan, and Jowitt, S.M., 2013, A detailed assessment of global $\mathrm{Cu}$ resource trends and endowments: Economic Geology, v. 108, no. 5, p. $1163-1183$.

Panteleyev, Andre, 1995a, Porphyry $\mathrm{Cu} \pm \mathrm{Mo} \pm \mathrm{Au}$ [profile] L04, in Lefebure, D.V., and Ray, G.E., eds., Selected British Columbia mineral deposit profiles, Volume 1-Metallics and coal: British Columbia Ministry of Employment and Investment Open File 1995-20, p. 87-92, accessed April 15, 2016, at http://www.empr.gov.bc.ca/Mining/ Geoscience/MineralDepositProfiles/ListbyDepositGroup/ Pages/LPorphyry.aspx\#103.

Panteleyev, Andre, 1995b, Porphyry Cu-Au-Alkalic [profile] L03, in Lefebure, D.V., and Ray, G.E., eds., Selected British Columbia mineral deposit profiles, Volume 1-Metallics and coal: British Columbia Ministry of Employment and Investment Open File 1995-20, p. 83-86, accessed April 15, 2016, at http://www.empr.gov.bc.ca/Mining/ Geoscience/MineralDepositProfiles/ListbyDepositGroup/ Pages/LPorphyry.aspx\#103.

Panteleyev, Andre, 2005a, Porphyry $\mathrm{Cu} \pm \mathrm{Mo} \pm \mathrm{Au}$ [profile] L04 (modified for Yukon by A. Fonseca), in Fonseca, A., and Bradshaw, G., comps., Yukon mineral deposit profiles: Yukon Geological Survey Open File 2005-5, 9 p. [unpaginated, about p. 136-144], accessed July 28, 2009, at http:// www.geology.gov.yk.ca/mineral_deposit_profiles.html.

Panteleyev, Andre, 2005b, Porphyry $\mathrm{Cu}-\mathrm{Au}$-Alkalic [profile] L03 (modified for Yukon by A. Fonseca), in Fonseca, A., and Bradshaw, G., comps., Yukon mineral deposit profiles: Yukon Geological Survey Open File 2005-5, 7 p. [unpaginated, about p. 129-135], accessed July 28, 2009, at http:// www.geology.gov.yk.ca/pdf/103_alkalic_porphyry_cu_ au.pdf.
Qin, Kezhang, and Ishihara, Shunso, 1998, On the possibility of porphyry copper mineralization in Japan: International Geology Review, v. 40, no. 6, p. 539-551.

Rasilainen, K., 2014, Grade-tonnage model of Precambrian porphyry copper, in Rasilainen, K., Eilu, P., Halkoaho, T., Karvinen, A., Kontinen, A., Kousa, J., Lauri, L., Luukas, J., Niiranen, T., Nikander, J., Sipilä, P., Sorjonen-Ward, P., Tiainen, M., Törmänen, T., and Västi, K., Quantitative assessment of undiscovered resources in volcanogenic massive sulphide deposits, porphyry copper deposits and Outokumpu-type deposits in Finland: Geological Survey of Finland Report of Investigation 208, p. 79-82, accessed July 30, 2015, at http://tupa.gtk.fi/julkaisu/tutkimusraportti/ tr_208.pdf.

Rasilainen, K., Eilu, P., Halkoaho, T., Karvinen, A., Kontinen, A., Kousa, J., Lauri, L., Luukas, J., Niiranen, T., Nikander, J., Sipilä, P., Sorjonen-Ward, P., Tiainen, M., Törmänen, T., and Västi, K., 2014, Quantitative assessment of undiscovered resources in volcanogenic massive sulphide deposits, porphyry copper deposits and Outokumpu-type deposits in Finland: Geological Survey of Finland Report of Investigation 208, 393 p., accessed July 30, 2015, at http://tupa.gtk.fi/ julkaisu/tutkimusraportti/tr_208.pdf.

Rio Tinto, 2017, 2016 annual report: Rio Tinto, 252 p., accessed August 23, 2017, at http://www.riotinto.com/ documents/RT_2016_Annual_report.pdf.

Robinson, G.R., Jr., and Menzie, W.D., 2014, Economic filters for evaluating porphyry copper deposit resource assessments using grade-tonnage deposit models, with examples from the U.S. Geological Survey global mineral resource assessment (ver. 1.2, March 2014): U.S. Geological Survey Scientific Investigations Report 2010-5090-H, 21 p. and separate file for tables 7 and 8, accessed June 1, 2015, at http://pubs.usgs.gov/sir/2010/5090/h/.

Root, D.H., Menzie, W.D., and Scott, W.A., 1992, Computer Monte Carlo simulation in quantitative resource estimation: Nonrenewable Resources, v. 1, no. 2, p. 125-138.

Singer, D.A., 1993, Basic concepts in three-part quantitative assessments of undiscovered mineral resources: Nonrenewable Resources, v. 2, no. 2, p. 69-81.

Singer, D.A., 2007a, Estimating amounts of undiscovered mineral resources, in Briskey, J.A., and Schulz, K.J., eds., Proceedings for a Workshop on Deposit Modeling, Mineral Resource Assessment, and Their Role in Sustainable Development: U.S. Geological Survey Circular 1294, p. 79-84, accessed June 1, 2015, at http://pubs.usgs.gov/ circ/2007/1294/. 
Singer, D.A., 2007b, Short course introduction to quantitative mineral resource assessments: U.S. Geological Survey Open-File Report 2007-1434, 13 p. and 3 slide sets, accessed November 15, 2010, at http://pubs.usgs.gov/ of/2007/1434/.

Singer, D.A., 2008, Mineral deposit densities for estimating mineral resources: Mathematical Geosciences, v. 40, no. 1, p. 33-46.

Singer, D.A., and Berger, V.I., 2007, Deposit models and their application in mineral resource assessments, in Briskey, J.A., and Schulz, K.J., eds., Proceedings for a Workshop on Deposit Modeling, Mineral Resource Assessment, and Their Role in Sustainable Development: U.S. Geological Survey Circular 1294, p. 71-78, accessed June 1, 2015, at http://pubs.usgs.gov/circ/2007/1294/.

Singer, D.A., Berger, V.I., Menzie, W.D., and Berger, B.R., 2005, Porphyry copper deposit density: Economic Geology, v. 100 , no. 3 , p. 491-514.

Singer, D.A., Berger, V.I., and Moring, B.C., 2005, Porphyry copper deposits of the world-Database, map, and grade and tonnage models; U.S. Geological Survey Open-File Report 2005-1060, 9 p., accessed October 31, 2011, at http://pubs.usgs.gov/of/2005/1060/.

Singer, D.A., Berger, V.I., and Moring, B.C., 2008, Porphyry copper deposits of the world-Database and grade and tonnage models, 2008: U.S. Geological Survey Open-File Report 2008-1155, 45 p., accessed November 15, 2010, at http://pubs.usgs.gov/of/2008/1155/.

Singer, D.A., Briskey, J.A., and Cunningham, C.G., 2008, Grade and tonnage model of giant porphyry copper deposits, app. I of Cunningham, C.G.; Zappettini, E.O.; Vivallo S., Waldo; Celada, C.M.; Quispe, Jorge; Singer, D.A.; Briskey, J.A.; Sutphin, D.M.; Gajardo M., Mariano; Diaz, Alejandro; Portigliati, Carlos; Berger, V.I.; Carrasco, Rodrigo; and Schulz, K.J., Quantitative mineral resource assessment of copper, molybdenum, gold, and silver in undiscovered porphyry copper deposits in the Andes Mountains of South America: U.S. Geological Survey Open-File Report 2008-1253, p. 64-67. [Also available at http://pubs.usgs.gov/of/2008/1253/.]

Singer, D.A., and Menzie, W.D., 2005, Statistical guides to estimating the number of undiscovered mineral depositsAn example with porphyry copper deposits, in Cheng, Qiuming, and Bonham-Carter, Graeme, eds., Proceedings of IAMG '05-The annual conference of the International Association for Mathematical Geology - GIS and spatial analysis: Toronto, Canada, York University, Geomatics Research Laboratory, v. 2, p. 1028-1033.

Singer, D.A., and Menzie, W.D., 2008, Map scale effects on estimating the number of undiscovered mineral deposits: Natural Resources Research, v. 17, no. 2, p. 79-86.
Singer, D.A., and Menzie, W.D., 2010, Quantitative mineral resource assessments-An integrated approach: New York, Oxford University Press, 219 p.

Sutphin, D.M., Hammarstrom, J.M., Drew, L.J., Large, D.E., Berger, B.R., Dicken, C.L., and DeMarr, M.W., 2013, Porphyry copper assessment of Europe, exclusive of the Fennoscandian Shield: U.S. Geological Survey Scientific Investigations Report 2010-5090-K, 197 p. and GIS data, accessed March 7, 2014, at http://pubs.usgs.gov/ $\operatorname{sir} / 2010 / 5090 / \mathrm{k} /$.

Takagi, Tetsuichi, 2004, Origin of magnetite- and ilmeniteseries granitic rocks in the Japan Arc: American Journal of Science, v. 304, p. 169-202.

Taylor, H.K., 1978, Mine valuation and feasibility studies, in Hoskins, J.R., and Green, W.R., eds., Mineral industry costs (2d ed., revised): Spokane, Wash., Northwest Mining Association, p. 1-17.

Taylor, H.K., 1986, Rates of working of mines - A simple rule of thumb: Transactions of the Institution of Mining and Metallurgy, Section A, Mining Industry, v. 95, p. A203-A204.

U.S. Department of State, 2009, Small-scale digital international land boundaries (SSIB)_Lines, edition 10, and polygons, beta edition 1, in Boundaries and sovereignty encyclopedia (B.A.S.E.): U.S. Department of State, Office of the Geographer and Global Issues.

U.S. Geological Survey Minerals Team, 1996, Data base for a national mineral-resource assessment of undiscovered deposits of gold, silver, copper, lead, and zinc in the conterminous United States (edited by Steve Ludington and Dennis Cox): U.S. Geological Survey Open-File Report 96-96, 1 CD-ROM. [Also available at http://pubs.usgs.gov/ of/1996/of96-096/. Recompiled in USGS Open-File Report 02-198.]

U.S. Geological Survey National Mineral Resource Assessment Team, 2000, 1998 assessment of undiscovered deposits of gold, silver, copper, lead, and zinc in the United States: U.S. Geological Survey Circular 1178, 21 p., 1 CDROM in pocket. [Also available at http://pubs.usgs.gov/circ/ c1178/. Recompiled in USGS Open-File Report 02-198.]

U.S. Geological Survey National Mineral Resource Assessment Team, 2002, Assessment of undiscovered deposits of gold, silver, copper, lead, and zinc in the United States; A Portable Document Format (PDF) recompilation of USGS Open-File Report 96-96 and Circular 1178: U.S. Geological Survey Open-File Report 02-198, 1 CD-ROM. [Recompilation by Paul Schruben. Also available at http://pubs.usgs.gov/of/2002/of02-198/.] 
Wanhainen, Christina, Broman, Curt, and Martinsson, Olof, 2003, The Aitik Cu-Au-Ag deposit in northern Sweden-A product of high salinity fluids: Mineralium Deposita, v. 38, p. 715-726.

Zürcher, Lukas, Bookstrom A.A., Hammarstrom, J.M., Mars, J.C., Ludington, Steve, Zientek, M.L., Dunlap, Pamela, and Wallis, J.C., 2015, Porphyry copper assessment of the Tethys region of western and southern Asia: U.S. Geological Survey Scientific Investigations Report 2010-5090-V, 232 p. and spatial data, accessed October 8, 2016, at http://dx.doi.org/10.3133/sir20105090V. 
Tables B2-B11 
Table B2. Summary of assessment results for identified and undiscovered copper resources in porphyry copper deposits in the South America region.

[Resources are reported to two significant figures and reflect information available when the assessment was done. In column 5, numbers of deposits known at the time of the tract assessment are followed in parentheses by the numbers of new deposits known as of 2015. Deposits that were not included at the time of the assessments are plotted as solid diamonds on maps on the plates. Coded_ID, unique identifier for each tract; an identifier that ends in a letter (a, b, c, d) represents a sub-tract of a larger tract of the same age range, and an identifier that ends in "ab" represents a tract consisting of several sub-tracts. km², square kilometer; Mt, millions of metric tons]

\begin{tabular}{|c|c|c|c|c|c|c|c|}
\hline \multirow{2}{*}{$\begin{array}{l}\text { Plate } \\
\text { number }\end{array}$} & \multirow[t]{2}{*}{ Tract name } & \multirow[t]{2}{*}{ Coded_ID } & \multirow{2}{*}{$\begin{array}{l}\text { Tract area } \\
\quad\left(\mathbf{k m}^{2}\right)\end{array}$} & \multirow{2}{*}{$\begin{array}{l}\text { Number } \\
\text { of known } \\
\text { deposits }\end{array}$} & \multirow{2}{*}{$\begin{array}{l}\text { Identified } \\
\text { copper } \\
\text { resources } \\
\text { (Mt) }\end{array}$} & \multicolumn{2}{|c|}{$\begin{array}{c}\text { Undiscovered copper } \\
\text { resource estimates } \\
\text { (Mt) }\end{array}$} \\
\hline & & & & & & $\begin{array}{l}\text { Mean } \\
\text { in-place }\end{array}$ & $\begin{array}{c}\text { Mean } \\
\text { economic }\end{array}$ \\
\hline 1 & Cretaceous Turbio - Chile and Argentina & $005 \mathrm{pCu} 1020$ & 223,010 & 0 & 0 & 7.8 & 3.9 \\
\hline 2 & $\begin{array}{l}\text { Late Triassic to Middle Jurassic Bajo de la } \\
\text { Leona-Argentina }\end{array}$ & $005 \mathrm{pCu} 1019$ & 45,642 & 0 & 0 & 5.9 & 2.8 \\
\hline 3 & Miocene Coastal_Chile and Argentina & 005pCu1013d & 63,233 & 0 & 0 & 4.5 & 2.5 \\
\hline 4 & $\begin{array}{l}\text { Late Cretaceous-Middle Eocene Campana } \\
\text { Mahuida-Argentina and Chile }\end{array}$ & $005 \mathrm{pCu} 1015$ & 83,204 & 1 & 0.95 & 15 & 8.6 \\
\hline 5 & Miocene-Pliocene El Teniente-Chile & $005 \mathrm{pCu} 1014 \mathrm{~b}$ & 9,284 & $2(1)$ & 230 & 69 & 56 \\
\hline 7 & Permian San Jorge-Argentina and Chile & 005pCu1016ab & 29,080 & 2 & 1.9 & 12 & 6.6 \\
\hline 8 & Miocene Paramillos-Argentina & $005 \mathrm{pCu} 1014 \mathrm{a}$ & 21,721 & 2 & 2.1 & 21 & 11 \\
\hline 9 & $\begin{array}{l}\text { Eocene-Oligocene La Fortuna-Chile and } \\
\text { Argentina }\end{array}$ & $005 \mathrm{pCu} 1012$ & 6,913 & 1 & 5.1 & 15 & 10 \\
\hline 10 & Miocene-Pliocene-Argentina and Chile & $005 \mathrm{pCu} 1013 \mathrm{c}$ & 5,767 & 0 & 0 & 7.7 & 4.0 \\
\hline 11 & $\begin{array}{l}\text { Miocene-Pliocene Nevados de } \\
\text { Famatina-Argentina }\end{array}$ & 005pCu1014d & 5,770 & 1 & 1.1 & 12 & 6.3 \\
\hline 12 & Cretaceous Antucoya-Chile & $005 \mathrm{pCu} 1017$ & 77,511 & $0(2)$ & 0 & 23 & 15 \\
\hline 16 & $\begin{array}{l}\text { Eocene-Oligocene Taca Taca Bajo-- } \\
\text { Argentina }\end{array}$ & $005 \mathrm{pCu} 1011$ & 2,429 & 1 & 3.0 & 4.2 & 2.6 \\
\hline 17 & Permian El Loa-Chile & $005 \mathrm{pCu} 1018$ & 17,765 & 0 & 0 & 7.5 & 4.8 \\
\hline 18 & Eocene-Oligocene Chuquicamata-Chile & $005 \mathrm{pCu} 1010 \mathrm{ab}$ & 25,690 & $10(6)$ & 320 & 210 & 170 \\
\hline 19 & Eocene-Oligocene Antapaccay_-Peru & $005 \mathrm{pCu} 1009$ & 30,154 & $5(1)$ & 13 & 19 & 9.9 \\
\hline 20 & Cretaceous Almacen-Peru and Ecuador & $005 \mathrm{pCu} 1007$ & 107,297 & 2 & 0.67 & 14 & 7.7 \\
\hline 21 & Miocene La Granja_-Peru and Ecuador & $005 \mathrm{pCu} 1006$ & 53,186 & 12 & 54 & 49 & 24 \\
\hline 22 & $\begin{array}{l}\text { Miocene Chaucha-Colombia and } \\
\text { Ecuador }\end{array}$ & $005 \mathrm{pCu} 1005$ & 58,797 & 4 & 4.0 & 39 & 21 \\
\hline
\end{tabular}


Table B2. Summary of assessment results for identified and undiscovered copper resources in porphyry copper deposits in the South America region.-Continued

[Resources are reported to two significant figures and reflect information available when the assessment was done. In column 5, numbers of deposits known at the time of the tract assessment are followed in parentheses by the numbers of new deposits known as of 2015. Deposits that were not included at the time of the assessments are plotted as solid diamonds on maps on the plates. Coded_ID, unique identifier for each tract; an identifier that ends in a letter (a, b, c, d) represents a sub-tract of a larger tract of the same age range, and an identifier that ends in "ab" represents a tract consisting of several sub-tracts. $\mathrm{km}^{2}$, square kilometer; Mt, millions of metric tons]

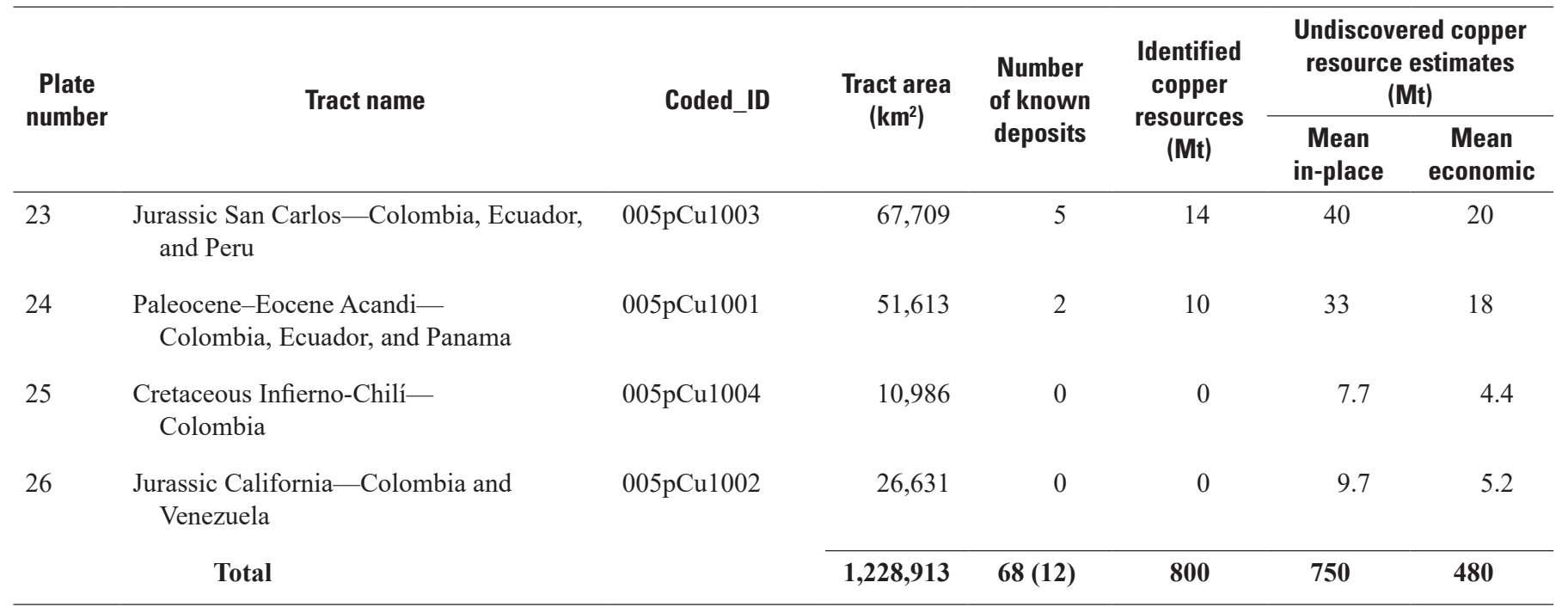

Table B3. Summary of assessment results for identified and undiscovered copper resources in porphyry copper deposits in the Central America and Caribbean region.

[Resources are reported to two significant figures. Resources and numbers of known deposits reflect information available at the time of the tract assessment. Coded_ID, unique identifier for each tract; $\mathrm{km}^{2}$, square kilometer; Mt, millions of metric tons]

\begin{tabular}{|c|c|c|c|c|c|c|c|}
\hline \multirow{2}{*}{$\begin{array}{c}\text { Plate } \\
\text { number }\end{array}$} & \multirow{2}{*}{ Tract name } & \multirow{2}{*}{ Coded_ID } & \multirow{2}{*}{$\begin{array}{c}\text { Tract area } \\
\left(\mathrm{km}^{2}\right)\end{array}$} & \multirow{2}{*}{$\begin{array}{l}\text { Number } \\
\text { of known } \\
\text { deposits }\end{array}$} & \multirow{2}{*}{$\begin{array}{l}\text { Identified } \\
\text { copper } \\
\text { resources } \\
\text { (Mt) }\end{array}$} & \multicolumn{2}{|c|}{$\begin{array}{c}\text { Undiscovered copper } \\
\text { resource estimates } \\
\text { (Mt) }\end{array}$} \\
\hline & & & & & & $\begin{array}{c}\text { Mean } \\
\text { in-place }\end{array}$ & $\begin{array}{c}\text { Mean } \\
\text { economic }\end{array}$ \\
\hline 27 & Darién Region-Panama & $003 \mathrm{pCu} 4002$ & 16,475 & 1 & 19 & 14 & 8.6 \\
\hline 28 & Cocos Region-Central America & $003 \mathrm{pCu} 4004$ & 203,634 & 2 & 16 & 53 & 29 \\
\hline 30 & Lesser Antilles-Caribbean Basin & $003 \mathrm{pCu} 4005$ & 2,982 & 0 & 0 & 3.3 & 1.4 \\
\hline 31 & Santiago Region-Caribbean Basin & $003 \mathrm{pCu} 4001$ & 78,775 & 4 & 4.1 & 36 & 19 \\
\hline 32 & Southwest Mexico-Mexico & $003 \mathrm{pCu} 3011$ & 156,976 & 3 & 1.0 & 37 & 25 \\
\hline
\end{tabular}


Table B4. Summary of assessment results for identified and undiscovered copper resources in porphyry copper deposits in the North America region.

[Resources are reported to two significant figures. Resources and numbers of known deposits reflect information available at the time of the tract assessment. Coded_ID, unique identifier for each tract; an identifier that ends in the letter " $\mathrm{x}$ " represents a tract combined from tracts in two source reports, as indicated on the plate. $\mathrm{km}^{2}$, square kilometer; Mt, millions of metric tons; NA, not applicable, as a quantitative assessment was not done]

\begin{tabular}{|c|c|c|c|c|c|c|c|}
\hline \multirow{2}{*}{$\begin{array}{l}\text { Plate } \\
\text { number }\end{array}$} & \multirow{2}{*}{ Tract name } & \multirow[t]{2}{*}{ Coded_ID } & \multirow{2}{*}{$\begin{array}{l}\text { Tract area } \\
\quad\left(\mathbf{k m}^{2}\right)\end{array}$} & \multirow{2}{*}{$\begin{array}{l}\text { Number } \\
\text { of known } \\
\text { deposits }\end{array}$} & \multirow{2}{*}{$\begin{array}{l}\text { Identified } \\
\text { copper } \\
\text { resources } \\
\text { (Mt) }\end{array}$} & \multicolumn{2}{|c|}{$\begin{array}{l}\text { Undiscovered copper } \\
\text { resource estimates } \\
\text { (Mt) }\end{array}$} \\
\hline & & & & & & $\begin{array}{c}\text { Mean } \\
\text { in-place }\end{array}$ & $\begin{array}{c}\text { Mean } \\
\text { economic }\end{array}$ \\
\hline 34 & Guanajuato-Mexico & $003 \mathrm{pCu} 3004$ & 26,080 & 0 & 0 & 1.5 & 0.97 \\
\hline 37 & Laramide Central Plateau-Mexico & $003 \mathrm{pCu} 3008$ & 58,724 & 0 & 0 & 20 & 13 \\
\hline 38 & $\begin{array}{l}\text { Tertiary Central Plateau and Rocky } \\
\text { Mountains - Mexico and United States }\end{array}$ & 003pCu3009x & 374,235 & 0 & 0 & 22 & 15 \\
\hline 40 & $\begin{array}{l}\text { Southern California Batholith-Mexico } \\
\text { and United States }\end{array}$ & 003pCu3001x & 40,228 & 1 & 5.3 & 3.3 & 2.3 \\
\hline 41 & $\begin{array}{l}\text { Western Mexican Basin and Range and } \\
\text { Laramide Southwest-Mexico and } \\
\text { United States }\end{array}$ & 003pCu3006x & 82,624 & 2 & 5.4 & 20 & 13 \\
\hline 42 & Southwest Laramide East_-United States & 003pCu9008 & 7,076 & 7 & 90 & 11 & 7.4 \\
\hline 43 & $\begin{array}{l}\text { Western U.S. and Sonoran Desert Jurassic } \\
\text { Arc-Mexico and United States }\end{array}$ & 003pCu9006x & 255,631 & 6 & 13 & 23 & 15 \\
\hline 48 & $\begin{array}{l}\text { Insular Island and Continental Arcs- } \\
\text { British Columbia and Yukon Territory, } \\
\text { Canada }\end{array}$ & $003 \mathrm{pCu} 2003$ & 58,361 & 2 & 3.2 & 3.0 & 0.87 \\
\hline 49 & $\begin{array}{l}\text { Intermontane Island Arc } \mathrm{Cu}-\mathrm{Au} \text {, Western } \\
\text { Cordillera - Canada and United States }\end{array}$ & 003pCu2002x & 109,903 & 13 & 24 & 22 & 14 \\
\hline 50 & $\begin{array}{l}\text { Cordilleran Continental Arc, Western } \\
\text { Cordillera - Canada and United States }\end{array}$ & 003pCu2004x & 684,535 & 25 & 23 & 13 & 3.8 \\
\hline 51 & $\begin{array}{l}\text { Intermontane Island Arc, Western } \\
\text { Cordillera - Canada and United States }\end{array}$ & 003pCu2001x & 181,190 & 12 & 25 & 9.3 & 2.7 \\
\hline 52 & $\begin{array}{l}\text { Late Continental Arc-British Columbia } \\
\text { and Yukon Territory, Canada }\end{array}$ & $003 \mathrm{pCu} 2005$ & 32,843 & 1 & 0.22 & 1.8 & 0.40 \\
\hline
\end{tabular}


Table B4. Summary of assessment results for identified and undiscovered copper resources in porphyry copper deposits in the North America region.-Continued

[Resources are reported to two significant figures. Resources and numbers of known deposits reflect information available at the time of the tract assessment. Coded_ID, unique identifier for each tract; an identifier that ends in the letter " $\mathrm{x}$ " represents a tract combined from tracts in two source reports, as indicated on the plate. $\mathrm{km}^{2}$, square kilometer; Mt, millions of metric tons; NA, not applicable, as a quantitative assessment was not done]

\begin{tabular}{|c|c|c|c|c|c|c|c|}
\hline \multirow{2}{*}{$\begin{array}{l}\text { Plate } \\
\text { number }\end{array}$} & \multirow{2}{*}{ Tract name } & \multirow{2}{*}{ Coded_ID } & \multirow{2}{*}{$\begin{array}{l}\text { Tract area } \\
\left(\mathbf{k m}^{2}\right)\end{array}$} & \multirow{2}{*}{$\begin{array}{l}\text { Number } \\
\text { of known } \\
\text { deposits }\end{array}$} & \multirow{2}{*}{$\begin{array}{l}\text { Identified } \\
\text { copper } \\
\text { resources } \\
\text { (Mt) }\end{array}$} & \multicolumn{2}{|c|}{$\begin{array}{l}\text { Undiscovered copper } \\
\text { resource estimates } \\
\text { (Mt) }\end{array}$} \\
\hline & & & & & & $\begin{array}{l}\text { Mean } \\
\text { in-place }\end{array}$ & $\begin{array}{c}\text { Mean } \\
\text { economic }\end{array}$ \\
\hline 53 & $\begin{array}{l}\text { Southeast Alaska Tertiary-Alaska, } \\
\text { United States }\end{array}$ & 003pCu5005 & 9,970 & 2 & 0.51 & 6.1 & 3.2 \\
\hline 54 & Skolai Arc_-Eastern Alaska, United States & 003pCu5001 & 17,154 & 0 & 0 & 1.7 & 0.76 \\
\hline 55 & $\begin{array}{l}\text { Eastern Alaska Range and Wrangell } \\
\text { Mountains-Alaska, United States }\end{array}$ & 003pCu5002 & 37,675 & 5 & 3.0 & 21 & 0.48 \\
\hline 56 & $\begin{array}{l}\text { Yukon-Tanana Upland-Alaska, } \\
\text { United States }\end{array}$ & $003 \mathrm{pCu} 5003$ & 200,514 & 2 & 2.4 & 9.1 & 0.21 \\
\hline 57 & $\begin{array}{l}\text { Western Alaska Range—Alaska, } \\
\text { United States }\end{array}$ & 003pCu5004 & 125,078 & 1 & 37 & 23 & 11 \\
\hline 58 & $\begin{array}{l}\text { Alaska Peninsula and Aleutian Islands- } \\
\text { Alaska, United States }\end{array}$ & $003 \mathrm{pCu} 5006$ & 49,222 & 1 & 0.59 & 12 & 5.9 \\
\hline 59 & Koyukuk Arc_-Alaska, United States & 003pCu5007 & 57,122 & 0 & 0 & NA & NA \\
\hline \multirow[t]{2}{*}{60} & Brooks Range_-Alaska, United States & 003pCu5008 & 9,782 & 0 & 0 & NA & NA \\
\hline & Total & & $3,384,991$ & 148 & 470 & 400 & 230 \\
\hline
\end{tabular}

Table B5. Summary of assessment results for identified and undiscovered copper resources in porphyry copper deposits in the Northeast Asia region.

[Resources are reported to two significant figures. Coded_ID, unique identifier for each tract; $\mathrm{km}^{2}$, square kilometer; Mt, millions of metric tons]

\begin{tabular}{|c|c|c|c|c|c|c|c|}
\hline \multirow{2}{*}{$\begin{array}{c}\text { Plate } \\
\text { number }\end{array}$} & \multirow{2}{*}{ Tract name } & \multirow{2}{*}{ Coded_ID } & \multirow{2}{*}{$\begin{array}{c}\text { Tract area } \\
\quad\left(\mathbf{k m}^{2}\right)\end{array}$} & \multirow{2}{*}{$\begin{array}{l}\text { Number } \\
\text { of known } \\
\text { deposits }\end{array}$} & \multirow{2}{*}{$\begin{array}{l}\text { Identified } \\
\text { copper } \\
\text { resources } \\
\text { (Mt) }\end{array}$} & \multicolumn{2}{|c|}{$\begin{array}{l}\text { Undiscovered copper } \\
\text { resource estimates } \\
\text { (Mt) }\end{array}$} \\
\hline & & & & & & $\begin{array}{c}\text { Mean } \\
\text { in-place }\end{array}$ & $\begin{array}{c}\text { Mean } \\
\text { economic }\end{array}$ \\
\hline 61 & Chukotka-Russia & $142 \mathrm{pCu} 8513$ & 196,564 & 0 & 0 & 12 & 6.3 \\
\hline 62 & Pacific Margin_-Russia and China & $142 \mathrm{pCu} 8514$ & $1,238,565$ & 1 & 0.89 & 150 & 73 \\
\hline 64 & Kedon-Russia & $142 \mathrm{pCu} 8510$ & 30,927 & 0 & 0 & 4.5 & 2.2 \\
\hline \multirow[t]{2}{*}{65} & Kolyma-Russia & $142 \mathrm{pCu} 8512$ & 541,829 & 1 & 7.9 & 56 & 28 \\
\hline & Total & & $2,222,769$ & 2 & 8.8 & 260 & 130 \\
\hline
\end{tabular}


Table B6. Summary of assessment results for identified and undiscovered copper resources in porphyry copper deposits in the Central and Eastern Asia region.

[Resources are reported to two significant figures. Coded_ID, unique identifier for each tract; an identifier that ends in a letter (a, b, c, d) represents a sub-tract of a larger tract of the same age range. $\mathrm{km}^{2}$, square kilometer; $\mathrm{Mt}$, millions of metric tons; NA, not applicable, as a quantitative assessment was not done]

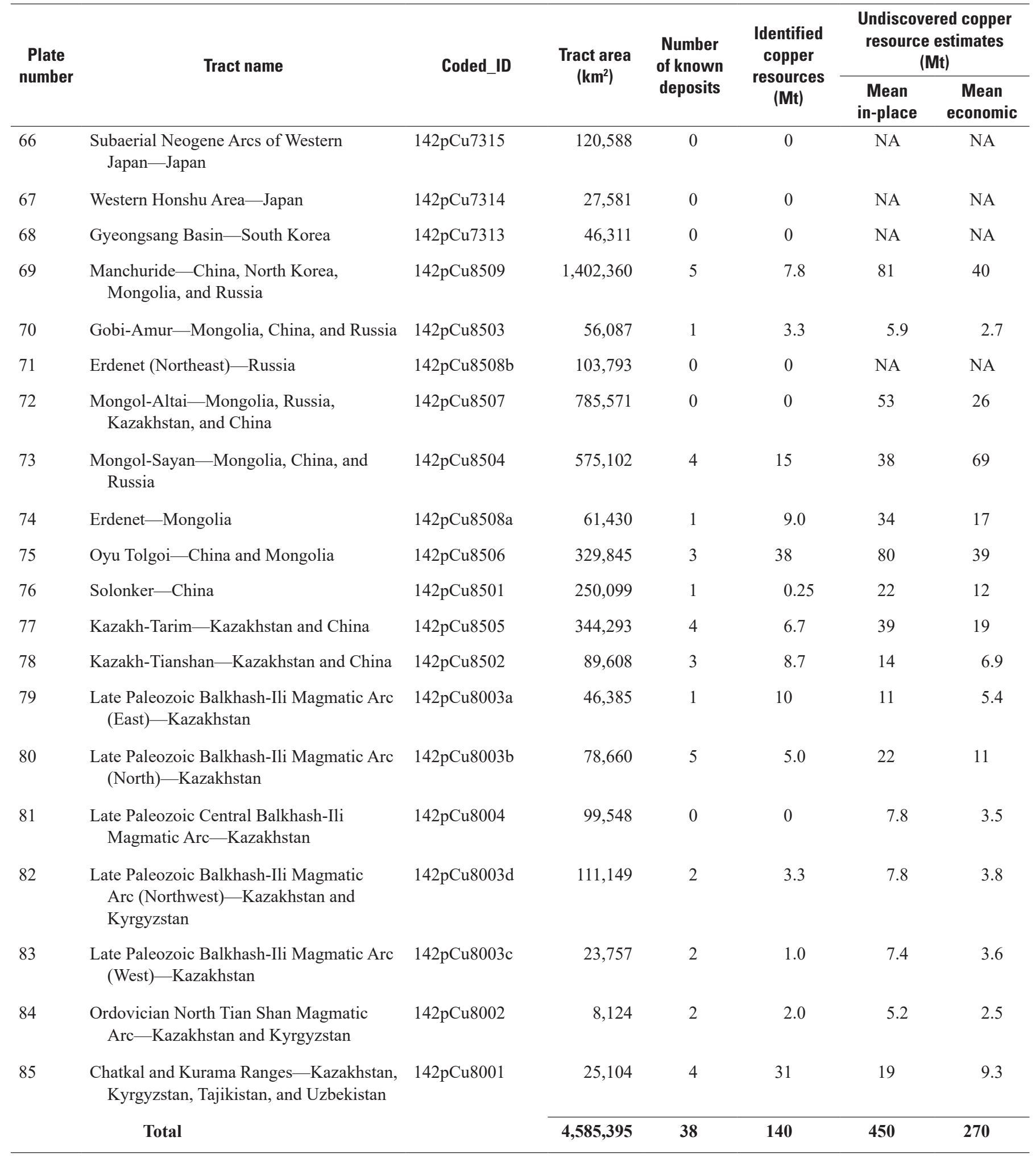


Table B7. Summary of assessment results for identified and undiscovered copper resources in porphyry copper deposits in the Southeast Asia region.

[Resources are reported to two significant figures. Coded_ID, unique identifier for each tract; $\mathrm{km}^{2}$, square kilometer; Mt, millions of metric tons]

\begin{tabular}{|c|c|c|c|c|c|c|c|}
\hline \multirow{2}{*}{$\begin{array}{l}\text { Plate } \\
\text { number }\end{array}$} & \multirow{2}{*}{ Tract name } & \multirow{2}{*}{ Coded_ID } & \multirow{2}{*}{$\begin{array}{l}\text { Tract area } \\
\qquad\left(\mathrm{km}^{2}\right)\end{array}$} & \multirow{2}{*}{$\begin{array}{l}\text { Number } \\
\text { of known } \\
\text { deposits }\end{array}$} & \multirow{2}{*}{$\begin{array}{l}\text { Identified } \\
\text { copper } \\
\text { resources } \\
\text { (Mt) }\end{array}$} & \multicolumn{2}{|c|}{$\begin{array}{l}\text { Undiscovered copper } \\
\text { resource estimates } \\
\text { (Mt) }\end{array}$} \\
\hline & & & & & & $\begin{array}{c}\text { Mean } \\
\text { in-place }\end{array}$ & $\begin{array}{c}\text { Mean } \\
\text { economic }\end{array}$ \\
\hline 86 & $\begin{array}{l}\text { Coastal Pacific - China, Taiwan, and } \\
\text { Vietnam }\end{array}$ & $142 \mathrm{pCu} 8704$ & 604,560 & 6 & 15 & 65 & 38 \\
\hline 88 & Qinling-Dabie-China and Tajikistan & $142 \mathrm{pCu} 8701$ & 403,215 & 1 & 1.4 & 32 & 17 \\
\hline 89 & $\begin{array}{l}\text { Tethyan Gangdese - China, India, and } \\
\text { Pakistan }\end{array}$ & $142 \mathrm{pCu} 8706$ & 289,647 & 0 & 0 & 28 & 14 \\
\hline 90 & Gangdese - China & $142 \mathrm{pCu} 8712$ & 239,860 & 3 & 15 & 87 & 43 \\
\hline 93 & Dali_-China and Vietnam & $142 \mathrm{pCu} 8711$ & 96,670 & 2 & 0.49 & 26 & 12 \\
\hline 94 & Wuntho-Popa-Burma & $142 \mathrm{pCu} 7024$ & 45,257 & 1 & 6.3 & 8.8 & 4.0 \\
\hline 95 & $\begin{array}{l}\text { Sukhothai-Cambodia, China, Laos, } \\
\text { Burma, Thailand, and Vietnam }\end{array}$ & $142 \mathrm{pCu} 7021$ & 354,260 & 1 & 1.2 & 37 & 18 \\
\hline 96 & $\begin{array}{l}\text { Mekong Delta-Cambodia, Laos, and } \\
\text { Vietnam }\end{array}$ & $142 \mathrm{pCu} 7023$ & 91,216 & 0 & 0 & 28 & 14 \\
\hline 97 & $\begin{array}{l}\text { Malaysia-Indonesia, Malaysia, } \\
\text { Singapore, and Thailand }\end{array}$ & $142 \mathrm{pCu} 7022$ & 60,010 & 1 & 0.81 & 8.9 & 4.3 \\
\hline
\end{tabular}


Table B8. Summary of assessment results for identified and undiscovered copper resources in porphyry copper deposits in the Southeast Asia Archipelagos region.

[Resources are reported to two significant figures. Resources and numbers of known deposits reflect information available at the time of the tract assessment. Coded_ID, unique identifier for each tract; an identifier than ends in a letter $(a, b, c)$ represents a sub-tract of a larger tract of the same age range, and an identifier that ends in several letters (abcd, ab) indicates a tract consisting of several sub-tracts. $\mathrm{km}^{2}$, square kilometer; Mt, millions of metric tons; NA, not applicable, as a quantitative assessment was not done]

\begin{tabular}{|c|c|c|c|c|c|c|c|}
\hline \multirow{2}{*}{$\begin{array}{l}\text { Plate } \\
\text { number }\end{array}$} & \multirow[t]{2}{*}{ Tract name } & \multirow[t]{2}{*}{ Coded_ID } & \multirow{2}{*}{$\begin{array}{l}\text { Tract area } \\
\left(\mathbf{k m}^{2}\right)\end{array}$} & \multirow{2}{*}{$\begin{array}{l}\text { Number } \\
\text { of known } \\
\text { deposits }\end{array}$} & \multirow{2}{*}{$\begin{array}{c}\text { Identified } \\
\text { copper } \\
\text { resources } \\
\text { (Mt) }\end{array}$} & \multicolumn{2}{|c|}{$\begin{array}{c}\text { Undiscovered copper } \\
\text { resource estimates } \\
\text { (Mt) }\end{array}$} \\
\hline & & & & & & $\begin{array}{c}\text { Mean } \\
\text { in-place }\end{array}$ & $\begin{array}{c}\text { Mean } \\
\text { economic }\end{array}$ \\
\hline 98 & Luzon Arc—Philippines and Taiwan & 142pCu7301abcd & 23,698 & 16 & 16 & 31 & 15 \\
\hline 99 & Sierra Madre Arc_Philippines & $142 \mathrm{pCu} 7304 \mathrm{ab}$ & 13,966 & 1 & 0.31 & 1.4 & 0.69 \\
\hline 100 & Cordon Alkalic Complex-Philippines & $142 \mathrm{pCu} 7302$ & 4,860 & 3 & 1.4 & 4.9 & 2.4 \\
\hline 101 & Philippine Arc_-Philippines & $142 \mathrm{pCu} 7309$ & 20,650 & 5 & 5.7 & 24 & 12 \\
\hline 102 & $\begin{array}{l}\text { Mindoro-Tablas-West Panay Area- } \\
\text { Philippines }\end{array}$ & $142 \mathrm{pCu} 7311$ & 9,168 & 0 & 0 & 3.2 & 1.5 \\
\hline 103 & Masbate-Negros Arc System—Philippines & $142 \mathrm{pCu} 7305$ & 12,226 & 5 & 6.8 & 7.8 & 3.5 \\
\hline 104 & Bohol-Cebu Area-Philippines & $142 \mathrm{pCu} 7306$ & 2,601 & 2 & 6.4 & 5.0 & 2.6 \\
\hline 105 & Sulu-Zamboanga Arc—Philippines & $142 \mathrm{pCu} 7307$ & 10,179 & 0 & 0 & 2.5 & 1.1 \\
\hline 106 & $\begin{array}{l}\text { Central Mindanao Volcanic Province-- } \\
\text { Philippines }\end{array}$ & $142 \mathrm{pCu} 7308$ & 29,324 & 0 & 0 & 5.9 & 2.6 \\
\hline 107 & Cotabato Arc—Philippines & $142 \mathrm{pCu} 7312$ & 9,699 & 1 & 15 & 4.6 & 2.3 \\
\hline 108 & $\begin{array}{l}\text { Central Kalimantan-Indonesia and } \\
\text { Malaysia }\end{array}$ & $142 \mathrm{pCu} 7019$ & 144,580 & 1 & 0.94 & 40 & 19 \\
\hline 109 & Sumatra Island—Indonesia & $142 \mathrm{pCu} 7020$ & 131,027 & 1 & 0.90 & 23 & 11 \\
\hline 110 & Sunda Banda Arc (West) - Indonesia & $142 \mathrm{pCu} 7025 \mathrm{a}$ & 61,201 & 0 & 0 & 10 & 4.8 \\
\hline 111 & Sunda Banda Arc (Central) - Indonesia & $142 \mathrm{pCu} 7025 \mathrm{~b}$ & 22,553 & 1 & 7.2 & 15 & 6.5 \\
\hline 112 & Sunda Banda Arc (East)—Indonesia & $142 \mathrm{pCu} 7025 \mathrm{c}$ & 5,665 & 0 & 0 & 2.1 & 0.91 \\
\hline 113 & West Sulawesi-Indonesia & $142 \mathrm{pCu} 7026$ & 60,272 & 0 & 0 & 3.4 & 1.6 \\
\hline 114 & North Sulawesi-Sangihe-Indonesia & $142 \mathrm{pCu} 7027$ & 20,325 & 2 & 2.0 & 8.9 & 4.3 \\
\hline 115 & $\begin{array}{l}\text { Halmahera Arc, North Molucca Islands- } \\
\text { Indonesia }\end{array}$ & $142 \mathrm{pCu} 7202$ & 12,245 & 1 & 0.25 & 4.8 & 2.1 \\
\hline 116 & $\begin{array}{l}\text { Ambon Arc, Central Molucca Islands- } \\
\text { Indonesia }\end{array}$ & $142 \mathrm{pCu} 7201$ & 1,537 & 0 & 0 & 3.1 & 1.3 \\
\hline 117 & $\begin{array}{l}\text { Inner Melanesian Arc Terranes I- } \\
\text { Indonesia }\end{array}$ & $142 \mathrm{pCu} 7208$ & 7,717 & 0 & 0 & NA & NA \\
\hline 118 & $\begin{array}{l}\text { Moon-Utawa-Ular Merah Areas- } \\
\text { Indonesia }\end{array}$ & $142 \mathrm{pCu} 7205$ & 13,577 & 0 & 0 & 3.2 & 1.5 \\
\hline 119 & $\begin{array}{l}\text { Western Medial New Guinea Magmatic } \\
\text { Belt-Indonesia }\end{array}$ & $142 \mathrm{pCu} 7203$ & 13,268 & 1 & 24 & 14 & 6.7 \\
\hline 120 & Rotanburg-Taratatua Area-Indonesia & $142 \mathrm{pCu} 7204$ & 9,371 & 0 & 0 & NA & NA \\
\hline
\end{tabular}


Table B8. Summary of assessment results for identified and undiscovered copper resources in porphyry copper deposits in the Southeast Asia Archipelagos region.-Continued

[Resources are reported to two significant figures. Resources and numbers of known deposits reflect information available at the time of the tract assessment. Coded ID, unique identifier for each tract; an identifier than ends in a letter (a, b, c) represents a sub-tract of a larger tract of the same age range, and an identifier that ends in several letters (abcd, ab) indicates a tract consisting of several sub-tracts. km², square kilometer; Mt, millions of metric tons; NA, not applicable, as a quantitative assessment was not done]

\begin{tabular}{|c|c|c|c|c|c|c|c|}
\hline \multirow{2}{*}{$\begin{array}{l}\text { Plate } \\
\text { number }\end{array}$} & \multirow{2}{*}{ Tract name } & \multirow{2}{*}{ Coded_ID } & \multirow{2}{*}{$\begin{array}{l}\text { Tract area } \\
\left(\mathbf{k m}^{2}\right)\end{array}$} & \multirow{2}{*}{$\begin{array}{l}\text { Number } \\
\text { of known } \\
\text { deposits }\end{array}$} & \multirow{2}{*}{$\begin{array}{l}\text { Identified } \\
\text { copper } \\
\text { resources } \\
\text { (Mt) }\end{array}$} & \multicolumn{2}{|c|}{$\begin{array}{l}\text { Undiscovered copper } \\
\text { resource estimates } \\
\text { (Mt) }\end{array}$} \\
\hline & & & & & & $\begin{array}{l}\text { Mean } \\
\text { in-place }\end{array}$ & $\begin{array}{c}\text { Mean } \\
\text { economic }\end{array}$ \\
\hline 121 & $\begin{array}{l}\text { Eastern Medial New Guinea Magmatic } \\
\text { Belt (West)—Papua New Guinea and } \\
\text { Indonesia }\end{array}$ & 009pCu7203a & 14,229 & 3 & 6.1 & 5.1 & 2.5 \\
\hline 122 & $\begin{array}{l}\text { Eastern Medial New Guinea Magmatic } \\
\text { Belt (East)_Papua New Guinea }\end{array}$ & 009pCu7203b & 53,222 & 3 & 11 & 20 & 8.7 \\
\hline 123 & $\begin{array}{l}\text { Inner Melanesian Arc Terranes II—Papua } \\
\text { New Guinea and Indonesia }\end{array}$ & 009pCu7208 & 29,141 & 0 & 0 & NA & NA \\
\hline 124 & Maramuni Arc—Papua New Guinea & 009pCu7205 & 38,975 & 1 & 8.6 & 9.9 & 5.1 \\
\hline 125 & $\begin{array}{l}\text { Miocene Alkalic Rocks, Southeastern New } \\
\text { Guinea Island_-Papua New Guinea }\end{array}$ & 009pCu7206 & 1,638 & 0 & 0 & 1.2 & 0.58 \\
\hline 126 & $\begin{array}{l}\text { Inner Melanesian Arc (New Britain)- } \\
\text { Papua New Guinea }\end{array}$ & 009pCu7209 & 17,987 & 1 & 0.72 & 8.5 & 3.8 \\
\hline 127 & $\begin{array}{l}\text { Outer Melanesian Arc I-Papua New } \\
\text { Guinea }\end{array}$ & 009pCu7207 & 16,834 & 2 & 7.2 & 17 & 7.4 \\
\hline \multirow[t]{2}{*}{128} & $\begin{array}{l}\text { Outer Melanesian Arc-Solomon Islands, } \\
\text { Vanuatu, and Fiji }\end{array}$ & $009 \mathrm{pCu} 7210$ & 38,180 & 3 & 6.9 & 16 & 7.0 \\
\hline & Total & & 849,915 & 53 & 130 & 300 & 140 \\
\hline
\end{tabular}




\section{Assessment of Undiscovered Copper Resources of the World, 2015}

Table B9. Summary of assessment results for identified and undiscovered copper resources in porphyry copper deposits in the Eastern Australia region.

[Resources are reported to two significant figures. Coded_ID, unique identifier for each tract; an identifier than ends in a letter (a, b, c, d) represents a sub-tract of a larger tract of the same age range. $\mathrm{km}^{2}$, square kilometer; Mt, millions of metric tons; NA, not applicable, as a quantitative assessment was not done]

\begin{tabular}{|c|c|c|c|c|c|c|c|}
\hline \multirow{2}{*}{$\begin{array}{l}\text { Plate } \\
\text { number }\end{array}$} & \multirow[t]{2}{*}{ Tract name } & \multirow[t]{2}{*}{ Coded_ID } & \multirow{2}{*}{$\begin{array}{c}\text { Tract area } \\
\left(\mathbf{k m}^{2}\right)\end{array}$} & \multirow{2}{*}{$\begin{array}{l}\text { Number } \\
\text { of known } \\
\text { deposits }\end{array}$} & \multirow{2}{*}{$\begin{array}{l}\text { Identified } \\
\text { copper } \\
\text { resources } \\
\text { (Mt) }\end{array}$} & \multicolumn{2}{|c|}{$\begin{array}{l}\text { Undiscovered copper } \\
\text { resource estimates } \\
\text { (Mt) }\end{array}$} \\
\hline & & & & & & $\begin{array}{c}\text { Mean } \\
\text { in-place }\end{array}$ & $\begin{array}{c}\text { Mean } \\
\text { economic }\end{array}$ \\
\hline 129 & East Tasmanide (North) - Australia & 009pCu8004d & 34,759 & 0 & 0 & NA & NA \\
\hline 130 & East Tasmanide (Central)—Australia & 009pCu8004b & 290,646 & 14 & 2.3 & 0.28 & 0 \\
\hline 131 & East Tasmanide (Island Arc) —Australia & 009pCu8004a & 16,741 & 0 & 0 & NA & NA \\
\hline 132 & East Tasmanide (South)—Australia & 009pCu8004c & 76,737 & 0 & 0 & NA & NA \\
\hline 133 & Macquarie-Australia & 009pCu8002 & 41,463 & 9 & 13 & 21 & 14 \\
\hline 134 & Yeoval-Australia & $009 \mathrm{pCu} 8003$ & 53,157 & 1 & 0.049 & 0.071 & 0 \\
\hline 135 & Delamerian (Victoria)—Australia & 009pCu8001b & 1,314 & 0 & 0 & NA & NA \\
\hline 136 & Delamerian (Tasmania)—Australia & 009pCu8001c & 9,328 & 0 & 0 & NA & NA \\
\hline \multirow[t]{2}{*}{137} & Delamerian (Adelaide)—Australia & 009pCu8001a & 50,747 & 0 & 0 & 0.14 & 0 \\
\hline & Total & & 574,892 & 24 & 15 & 21 & 14 \\
\hline
\end{tabular}


Table B10. Summary of assessment results for identified and undiscovered copper resources in porphyry copper deposits in the Middle East region.

[In this report, for geologic continuity, the Middle East region includes Afghanistan, Iran, Iraq, Pakistan, Turkey, and parts of Armenia, Georgia, and Russia. Resources are reported to two significant figures. Coded_ID, unique identifier for each tract; an identifier than ends in a letter (a, b, c) represents a sub-tract of a larger tract of the same age range. $\mathrm{km}^{2}$, square kilometer; Mt, millions of metric tons; NA, not applicable, as a quantitative assessment was not done]

\begin{tabular}{|c|c|c|c|c|c|c|c|}
\hline \multirow{2}{*}{$\begin{array}{l}\text { Plate } \\
\text { number }\end{array}$} & \multirow[t]{2}{*}{ Tract name } & \multirow[t]{2}{*}{ Coded_ID } & \multirow{2}{*}{$\begin{array}{l}\text { Tract area } \\
\left(\mathbf{k m}^{2}\right)\end{array}$} & \multirow{2}{*}{$\begin{array}{l}\text { Number } \\
\text { of known } \\
\text { deposits }\end{array}$} & \multirow{2}{*}{$\begin{array}{l}\text { Identified } \\
\text { copper } \\
\text { resources } \\
\text { (Mt) }\end{array}$} & \multicolumn{2}{|c|}{$\begin{array}{l}\text { Undiscovered copper } \\
\text { resource estimates } \\
\text { (Mt) }\end{array}$} \\
\hline & & & & & & $\begin{array}{l}\text { Mean } \\
\text { in-place }\end{array}$ & $\begin{array}{c}\text { Mean } \\
\text { economic }\end{array}$ \\
\hline 138 & Darra Alasang_Afghanistan & $142 \mathrm{pCu} 8901$ & 35,088 & 0 & 0 & 4.0 & 2.1 \\
\hline 139 & Kundalyan_Afghanistan & $142 \mathrm{pCu} 8902$ & 4,446 & 0 & 0 & 4.0 & 2.1 \\
\hline 140 & Oruzgan-Afghanistan & $142 \mathrm{pCu} 8903$ & 82,464 & 0 & 0 & 10 & 4.9 \\
\hline 141 & Spin Boldak —Afghanistan and Pakistan & $142 \mathrm{pCu} 8904$ & 7,452 & 0 & 0 & 4.4 & 2.3 \\
\hline 142 & Chagai_-Afghanistan, Pakistan, and Iran & $142 \mathrm{pCu} 9013$ & 19,075 & 4 & 26 & 12 & 8.0 \\
\hline 143 & $\begin{array}{l}\text { Pliocene-Quaternary (Bazman)- } \\
\text { Afghanistan, Pakistan, and Iran }\end{array}$ & 142pCu9017c & 21,298 & 0 & 0 & NA & NA \\
\hline 144 & Sistan-Iran & $142 \mathrm{pCu} 9012$ & 32,820 & 0 & 0 & 9.8 & 6.6 \\
\hline 145 & Lut Tertiary—Iran & $142 \mathrm{pCu} 9010$ & 56,256 & 0 & 0 & 7.5 & 5.0 \\
\hline 146 & Lut Jurassic_-Iran & $142 \mathrm{pCu} 9000$ & 2,965 & 0 & 0 & NA & NA \\
\hline 147 & Lut Cretaceous-Iran & $142 \mathrm{pCu} 9006$ & 12,030 & 0 & 0 & NA & NA \\
\hline 148 & Makran-Iran & $142 \mathrm{pCu} 9011$ & 24,117 & 0 & 0 & NA & NA \\
\hline 149 & Khorasan-Afghanistan and Iran & $142 \mathrm{pCu} 9009$ & 38,311 & 0 & 0 & 8.1 & 5.5 \\
\hline 150 & Kerman-Iran & $142 \mathrm{pCu} 9016$ & 32,800 & 12 & 15 & 22 & 15 \\
\hline 151 & Yazd-Iran & $142 \mathrm{pCu} 9015$ & 25,711 & 2 & 0.27 & 13 & 8.7 \\
\hline 152 & Esfahan-Iran, Iraq, and Turkey & $142 \mathrm{pCu} 9008$ & 56,857 & 1 & 0.64 & 15 & 10 \\
\hline 153 & $\begin{array}{l}\text { Azerbaijan (Caucasus)-Iran, Azerbaijan, } \\
\text { and Armenia }\end{array}$ & 142pCu9014c & 58,270 & 5 & 11 & 27 & 18 \\
\hline 154 & Sanandaj-Sirjan —Iran, Iraq, and Turkey & $142 \mathrm{pCu} 9003$ & 20,160 & 0 & 0 & NA & NA \\
\hline 155 & $\begin{array}{l}\text { Pontide (Asia)-Caucasus-Iran, } \\
\text { Azerbaijan, Armenia, and Georgia }\end{array}$ & $142 \mathrm{pCu} 9004 \mathrm{c}$ & 24,289 & 0 & 0 & 3.3 & 2.1 \\
\hline 156 & $\begin{array}{l}\text { Cimmeride Lesser Caucasus-Armenia, } \\
\text { Azerbaijan, Georgia, and Iran }\end{array}$ & $142 \mathrm{pCu} 9001$ & 17,369 & 3 & 2.3 & 7.1 & 4.7 \\
\hline 157 & $\begin{array}{l}\text { Cimmeride Greater Caucasus-- } \\
\text { Azerbaijan, Georgia, and Russia }\end{array}$ & $142 \mathrm{pCu} 9002$ & 16,688 & 0 & 0 & NA & NA \\
\hline 158 & $\begin{array}{l}\text { Pliocene-Quaternary (Postcollisional)- } \\
\text { Iran, Armenia, Azerbaijan, Georgia, } \\
\text { Turkey, and Russia }\end{array}$ & 142pCu9017b & 193,763 & 0 & 0 & NA & NA \\
\hline 159 & Border Folds - Iran, Iraq, and Turkey & $142 \mathrm{pCu} 9007$ & 45,285 & 0 & 0 & 4.6 & 3.2 \\
\hline 160 & $\begin{array}{l}\text { Pontide (Asia, Northeastern) - Turkey and } \\
\text { Georgia }\end{array}$ & $142 \mathrm{pCu} 9004 \mathrm{~b}$ & 45,539 & 4 & 1.5 & 15 & 10 \\
\hline 161 & Azerbaijan (East)—Turkey & 142pCu9014b & 7,754 & 1 & 1.7 & 1.5 & 0.97 \\
\hline
\end{tabular}


Table B10. Summary of assessment results for identified and undiscovered copper resources in porphyry copper deposits in the Middle East region.-Continued

[In this report, for geologic continuity, the Middle East region includes Afghanistan, Iran, Iraq, Pakistan, Turkey, and parts of Armenia, Georgia, and Russia. Resources are reported to two significant figures. Coded ID, unique identifier for each tract; an identifier than ends in a letter (a, b, c) represents a sub-tract of a larger tract of the same age range. $\mathrm{km}^{2}$, square kilometer; Mt, millions of metric tons; NA, not applicable, as a quantitative assessment was not done]

\begin{tabular}{|c|c|c|c|c|c|c|c|}
\hline \multirow{2}{*}{$\begin{array}{c}\text { Plate } \\
\text { number }\end{array}$} & \multirow[t]{2}{*}{ Tract name } & \multirow[t]{2}{*}{ Coded_ID } & \multirow{2}{*}{$\begin{array}{l}\text { Tract area } \\
\qquad\left(\mathrm{km}^{2}\right)\end{array}$} & \multirow{2}{*}{$\begin{array}{l}\text { Number } \\
\text { of known } \\
\text { deposits }\end{array}$} & \multirow{2}{*}{$\begin{array}{l}\text { Identified } \\
\text { copper } \\
\text { resources } \\
\text { (Mt) }\end{array}$} & \multicolumn{2}{|c|}{$\begin{array}{l}\text { Undiscovered copper } \\
\text { resource estimates } \\
\text { (Mt) }\end{array}$} \\
\hline & & & & & & $\begin{array}{c}\text { Mean } \\
\text { in-place }\end{array}$ & $\begin{array}{c}\text { Mean } \\
\text { economic }\end{array}$ \\
\hline 162 & $\begin{array}{l}\text { Anatolide-Tauride (Eastern Turkey- } \\
\text { Caucasus)-Iran, Azerbaijan, Armenia, } \\
\text { and Turkey }\end{array}$ & $142 \mathrm{pCu} 9005 \mathrm{c}$ & 21,675 & 4 & 1.2 & 8.2 & 5.5 \\
\hline 163 & Anatolide-Tauride (Central) — Turkey & $142 \mathrm{pCu} 9005 \mathrm{~b}$ & 36,208 & 0 & 0 & 1.3 & 0.90 \\
\hline 164 & Pliocene-Quaternary (Konya)_-Turkey & $142 \mathrm{pCu} 9017 \mathrm{a}$ & 11,788 & 0 & 0 & NA & NA \\
\hline 165 & Pontide (Asia, Northwestern)_-Turkey & $142 \mathrm{pCu} 9004 \mathrm{a}$ & 32,671 & 1 & 0.40 & 4.1 & 2.7 \\
\hline 166 & Anatolide-Tauride (West)—Turkey & $142 \mathrm{pCu} 9005 \mathrm{a}$ & 5,940 & 2 & 0.38 & 3.0 & 2.1 \\
\hline
\end{tabular}


Table B11. Summary of assessment results for identified and undiscovered copper resources in porphyry copper deposits in the Europe region.

[Resources are reported to two significant figures. Coded_ID, unique identifier for each tract; $\mathrm{km}^{2}$, square kilometer; Mt, millions of metric tons; NA, not applicable, as a quantitative assessment was not done]

\begin{tabular}{|c|c|c|c|c|c|c|c|}
\hline \multirow{2}{*}{$\begin{array}{l}\text { Plate } \\
\text { number }\end{array}$} & \multirow[t]{2}{*}{ Tract name } & \multirow[t]{2}{*}{ Coded_ID } & \multirow{2}{*}{$\begin{array}{l}\text { Tract area } \\
\quad\left(\mathrm{km}^{2}\right)\end{array}$} & \multirow{2}{*}{$\begin{array}{l}\text { Number } \\
\text { of known } \\
\text { deposits }\end{array}$} & \multirow{2}{*}{$\begin{array}{l}\text { Identified } \\
\text { copper } \\
\text { resources } \\
\text { (Mt) }\end{array}$} & \multicolumn{2}{|c|}{$\begin{array}{l}\text { Undiscovered copper } \\
\text { resource estimates } \\
\text { (Mt) }\end{array}$} \\
\hline & & & & & & $\begin{array}{l}\text { Mean } \\
\text { in-place }\end{array}$ & $\begin{array}{c}\text { Mean } \\
\text { economic }\end{array}$ \\
\hline 168 & $\begin{array}{l}\text { Transylvania-Balkan Mountains- } \\
\text { Bulgaria, Serbia, Romania, and Turkey }\end{array}$ & $150 \mathrm{pCu} 6001$ & 28,469 & 15 & 30 & 16 & 10 \\
\hline 170 & $\begin{array}{l}\text { Northern Carpathians-Hungary, } \\
\text { Romania, Slovakia, and Ukraine }\end{array}$ & $150 \mathrm{pCu} 6004$ & 28,846 & 1 & 0.73 & 7.9 & 3.9 \\
\hline 171 & Dinaride-Aegean Region-Eastern Europe & $150 \mathrm{pCu} 6002$ & 92,723 & 4 & 7.2 & 12 & 7.7 \\
\hline 172 & Tagil-Polar Urals_-Russia & $142 \mathrm{pCu} 8202$ & 49,605 & 0 & 0 & 17 & 8.3 \\
\hline 175 & Transuralian —Kazakhstan and Russia & $142 \mathrm{pCu} 8204$ & 128,788 & 4 & 4.3 & 24 & 11 \\
\hline 176 & $\begin{array}{l}\text { Southern and Central European Variscan- } \\
\text { France, Italy, and Poland }\end{array}$ & $150 \mathrm{pCu} 6006$ & 45,963 & 1 & 0.88 & NA & NA \\
\hline 177 & $\begin{array}{l}\text { Western Peri-Mediterranean Region- } \\
\text { Italy, Morocco, Algeria, and Spain }\end{array}$ & $150 \mathrm{pCu} 6005$ & 9,461 & 1 & 0.13 & NA & NA \\
\hline 178 & $\begin{array}{l}\text { Western European Caledonian-Belgium } \\
\text { and United Kingdom }\end{array}$ & $150 \mathrm{pCu} 6007$ & 17,471 & 2 & 0.63 & NA & NA \\
\hline 179 & Southern Ostrobothnia-Finland & $150 \mathrm{pCu} 6108$ & 2,317 & 0 & 0 & 0.31 & 0.052 \\
\hline 185 & Southern Savo-Finland & $150 \mathrm{pCu} 6109$ & 603 & 0 & 0 & 0.28 & 0.047 \\
\hline 186 & Central Ostrobothnia-Finland & $150 \mathrm{pCu} 6102$ & 11,155 & 1 & 0.045 & 1.9 & 0.32 \\
\hline 187 & Haaparanta_Finland & $150 \mathrm{pCu} 6103$ & 5,823 & 0 & 0 & 1.5 & 0.25 \\
\hline \multirow[t]{2}{*}{188} & Nilipää_Finland & $150 \mathrm{pCu} 6106$ & 2,035 & 0 & 0 & 0.21 & 0.035 \\
\hline & Total & & 573,131 & 39 & 51 & 140 & 72 \\
\hline
\end{tabular}





\title{
Chapter C. Sediment-Hosted Stratabound Copper Deposits
}

\author{
By Michael L. Zientek for the U.S. Geological Survey Global Copper Mineral Resource Assessment Team
}

\section{Introduction}

Sediment-hosted stratabound copper deposits are the second largest source of global copper supply after porphyry copper deposits. The largest known deposits of this type occur in the Central African Copperbelt, where deposits in the Katanga Basin of the Democratic Republic of the Congo and Zambia (fig. C1) contain about 150 million metric tons (Mt) of copper. Other areas of the world that are important for these deposits are the Southern Permian Basin in Europe and the Chu-Sarysu Basin in Kazakhstan and Kyrgyzstan (fig. C1).

Characteristics of subtypes of sediment-hosted stratabound copper deposits and assessment methods are described in this chapter, and quantitative and qualitative assessment results are summarized for 23 sedimentary basins (fig. C1). Quantitative assessments show where undiscovered copper resources may be present and provide probabilistic estimates of amounts of in-place undiscovered copper resources. Quantitative assessments of sediment-hosted stratabound copper deposits were made for five sedimentary basins by the U.S. Geological Survey (USGS) Global Copper Mineral Resource Assessment Team. Quantitative assessments for seven basins and a qualitative assessment for one basin are included from other studies in Afghanistan (Peters and others, 2007), Greenland (Stensgaard and others, 2011), and the United States (U.S. Geological Survey National Mineral Resource Assessment Team, 2002). Ten other areas were selected for cursory study and qualitative assessment. These qualitative assessments show where deposits and prospects are known, show where undiscovered resources may be present, and provide a relative ranking of the study areas according to the amount of undiscovered copper that may be present. The results of this study are discussed in terms of what we learned while conducting the assessment, developing directions for future research, and understanding the implications for the future supply of copper from sediment-hosted stratabound copper deposits.

Comprehensive regional assessment reports were prepared for each of the assessed areas (see this volume, chap. A, table A1). Databases of sediment-hosted stratabound copper deposits and prospects were updated for all study areas in regional reports. In all, 48 permissive tracts were delineated within the 23 basins. Selected resource assessment results and mineral resource maps are shown on plates 189-236. Quantitative assessment results are summarized in tables $\mathrm{C} 1-\mathrm{C} 4$, and probability distributions of undiscovered copper resources are shown in bar charts on the plates. Qualitative assessment results are presented as bar charts on 10 plates. The entire database of deposits and prospects and permissive tracts is included in a richly attributed geographic information system (GIS) compiled by Dicken and others (2016).

\section{Deposit Types}

Mineral deposits can be classified into types defined by shared characteristics that result from similar ore-forming processes. The recognition that mineral deposits can be systematically classified into types allows scientists to use geoscience information to predict where deposits of a given type could occur. In addition, each ore deposit type has characteristic geometries, distributions of tonnage and grade, and rock and mineral properties that determine the potential value of the deposit and how the mineral resource is delimited and developed. These characteristics allow scientists to predict how much resource may be associated with undiscovered deposit types. Descriptive mineral deposit models summarize the characteristics of each deposit type and provide a basis for using geology to classify mineral deposits by type (Singer and Menzie, 2010). Mineral-systems models provide criteria based on theories of regional ore genesis that can be used in mineral resource assessment and exploration targeting (Wyborn and others, 1994; Knox-Robinson and Wyborn, 1997). Descriptive models and mineral-systems models are used to identify and map geographic areas that are permissive for the occurrence of each type. The range of deposit size (tonnages) and commodity grades (expressed in percentage of metal for copper) are described in grade and tonnage models that are constructed from data for known deposits that fit the criteria for each deposit type (Singer and Menzie, 2010). These models are used as analogs for the copper resources that could be present in undiscovered deposits of the same type.

\section{Deposit Type Assessed-Sediment- Hosted Stratabound Copper Deposits}

Sediment-hosted stratabound copper deposits consist of fine-grained, copper-sulfide and copper-iron-sulfide minerals that form stratabound to stratiform disseminations in sedimentary rocks (Hitzman and others, 2005; Cox and others, 2007; 


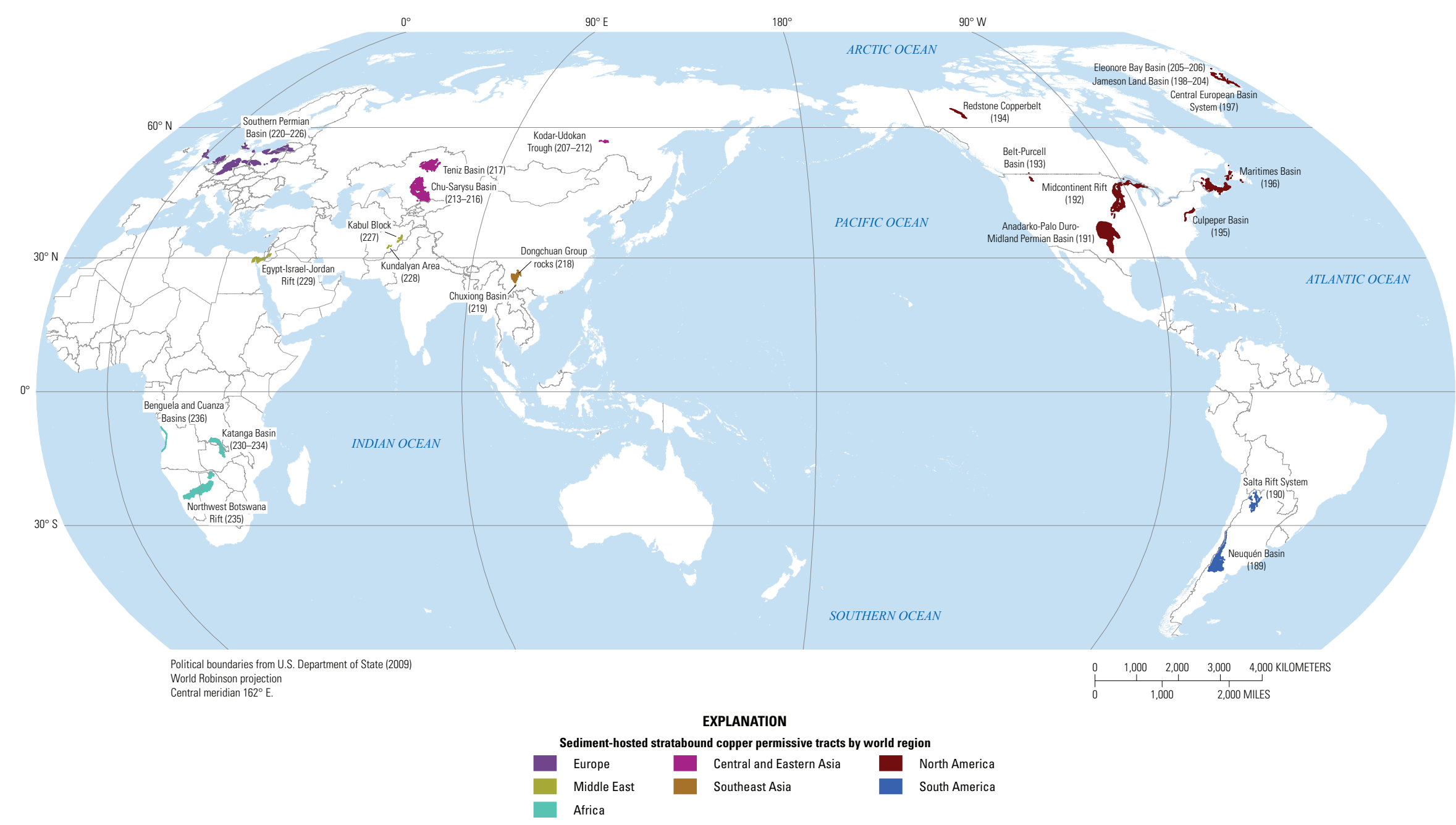

Figure C1. Map showing 23 basins containing permissive tracts for sediment-hosted stratabound copper deposits, color coded for 7 world regions. Plate numbers for each basin are given in parentheses. See table $\mathrm{C} 1$ for summary results by world region, table $\mathrm{C} 2$ for summary results for 13 basins that were quantitatively assessed, and tables $\mathrm{C} 3$ and $\mathrm{C} 4$ for summary results by permissive tract. 
Zientek, Hayes, and Hammarstrom, 2013). Ore minerals, such as chalcocite and bornite, occur as cements and replacements in the matrix of the sedimentary rocks and, less commonly, as veinlets. The concentration of sulfide minerals is broadly conformable with stratification in the host rocks. In more detail, though, deposits are characterized by systematic changes (zonation) in ore mineralogy along and across bedding from pyrite $\left(\mathrm{FeS}_{2}\right)$ to chalcopyrite $\left(\mathrm{CuFeS}_{2}\right)$ to bornite $\left(\mathrm{Cu}_{5} \mathrm{FeS}_{4}\right)$, to chalcocite $\left(\mathrm{Cu}_{2} \mathrm{~S}\right)$ to hematite $\left(\mathrm{Fe}_{2} \mathrm{O}_{3}\right)$.

\section{Deposit Subtypes}

Three main subtypes of sediment-hosted stratabound copper deposits are distinguished by host rock composition (lithology) and by the nature of organic material in the sedimentary strata (Kirkham, 1989; Hitzman and others, 2005; Cox and others, 2007; Zientek, Hayes, and Hammarstrom, 2013; Hayes and others, 2015). The three subtypes described below are (1) reduced-facies copper subtype, (2) sandstone copper subtype, and (3) red bed copper subtype.

Reduced-facies copper subtype.- - Host rocks for deposits of the reduced-facies copper subtype (fig. C2) include black shale, dark-gray to black siltstone, dark-gray dolo-siltstone, gray shale, and, locally, green shale or siltstone, all of which contain varying amounts of solid organic material. Host beds for many reduced-facies copper deposits occur adjacent to a flooding surface that marks the extension of marine deposits over nonmarine red beds (fig. C2). Red beds are sedimentary rocks (mainly sandstone, siltstone, shale, and conglomerate) that are predominantly red because of the iron oxide mineral hematite, which occurs as coatings on mineral grains. The host rocks of reduced-facies subtype deposits contain organic matter and finely disseminated pyrite. These host rocks overlie, or are locally interbedded with, red to brown or purple, hematitebearing sandstone, siltstone, and (or) conglomerate (red beds) that were deposited in an arid climate (Davidson, 1965; Rose, 1976; Kirkham, 1989). Variants of the reduced-facies copper subtype in the Central African Copperbelt include the reducedfacies carbonate écaille deposits that occur in giant breccia fragments (longest dimension $=1$ to 10 kilometers) in some carbonate lithologies and reduced-facies nonbrecciated deposits (Cox and others, 2007; Zientek, Hayes, and Hammarstrom, 2013; Zientek, Hayes, and Taylor, 2013). Other names for the reduced-facies subtype are "paralic marine," "Mansfeld-type," and "Kupferschiefer-type."

Sandstone copper subtype.- - Host rocks for deposits of the sandstone copper subtype (fig. C2) are well-sorted ${ }^{1}$ quartzrich sandstones characteristic of deposition in a delta setting. The occurrence of petroleum-bearing fluid inclusions and solid hydrocarbons that coat detrital grains, stain minerals, and

\footnotetext{
${ }^{1}$ Sorting refers to the uniformity of grain sizes in the rock; well-sorted deposits have grains that are approximately the same size, whereas poorly sorted deposits have a mixture of different grain sizes.
}

locally form cements indicates that the mineralized strata once contained liquid or gaseous hydrocarbon accumulations. For many sandstone copper deposits, the hydrocarbons could have been sour gas - natural gas containing significant amounts of hydrogen sulfide (Hayes and others, 2012). Sandstone copper deposits in the Central African Copperbelt have higher average copper grades than deposits elsewhere in the world. Therefore, a custom grade and tonnage model (Roan arenite subtype) was developed for assessing that area (Zientek, Hayes, and Taylor, 2013). Cox and others (2007) referred to the sandstone copper subtype as "Revett-type."

Red bed copper subtype.- - Host rocks for deposits of the red bed copper subtype are poorly to moderately sorted, commonly conglomeratic sandstone (red beds) containing carbonized plant fragments. The depositional setting for the host rocks is fluvial or, rarely, deltaic. The plant fragments range in size from silt to whole logs that are replaced by copper minerals. Kirkham (1989), Kirkham and others (1994), and Hitzman and others (2005) did not distinguish between sandstone and red bed subtype deposits and referred to them as "Continental redbed type" or "Redbed-type." The red bed deposit type of Cox and others (2007) was not considered for the global assessment study; deposit sizes are too small to be important on a global basis.

\section{Depositional Environments}

Sediment-hosted stratabound copper deposits are associated with red bed sequences and evaporites (Davidson, 1965; Rose, 1976; Kirkham, 1989). This type of mineralization is found only in sedimentary rocks that formed after 2,300 Ma (million years ago), when free oxygen first appeared in the Earth's atmosphere, allowing the formation of the earliest red beds (Chandler, 1988; Bekker and others, 2004; Canfield, 2005; Hitzman and others, 2010). Sediment-hosted stratabound copper deposits are found only in red beds that formed in arid climates in depositional environments that included aeolian dunes, sabkhas (saline marshes), playas, and sand sheets, together with minor alluvial fans, ephemeral rivers, and inland lakes. Evaporite deposits commonly are present within these types of red beds. Sedimentary deposits characteristic of arid environments form between 20 to 30 degrees of latitude on either side of the Equator in continental areas (Kirkham, 1989).

The association of red beds and evaporites with sedimenthosted stratabound copper deposits implies that this style of mineralization should be widespread. There are about 700 to 800 Phanerozoic sedimentary basins in the world (U.S. Geological Survey World Energy Assessment Team, 2000; Fugro Robertson, Ltd., 2008). Of these, 124 basins have been affected by salt tectonism (Jackson, 2005); additional basins probably contain salt (and red beds) because Jackson's 2005 compilation excluded evaporite basins lacking major salt tectonism, such as most intracratonic basins. 
Sediment-hosted stratabound copper deposits that contain significant copper (more than 50,000 metric tons [t]) are known from only about 20 basins despite the widespread distribution of sedimentary basins with appropriate host rocks. World-class deposits (Singer, 1995) are limited to eight basins (Kirkham and others, 1994; Kirkham and Broughton, 2005; Cox and others, 2007; Zientek, Hayes, and Hammarstrom, 2013). Hitzman and others (2010) emphasized that basins formed during the Cryogenian Period (720-635 Ma) of the Proterozoic Eon and the Permian Period (299-252 Ma) of the Paleozoic Era contain most of the world's known sedimenthosted copper mineralization. They suggested that global-scale secular processes may have some role in the genesis of these deposits, such as periods of Earth history during which oceans were rich in sulfate and host sedimentary rocks formed near the paleoequator.

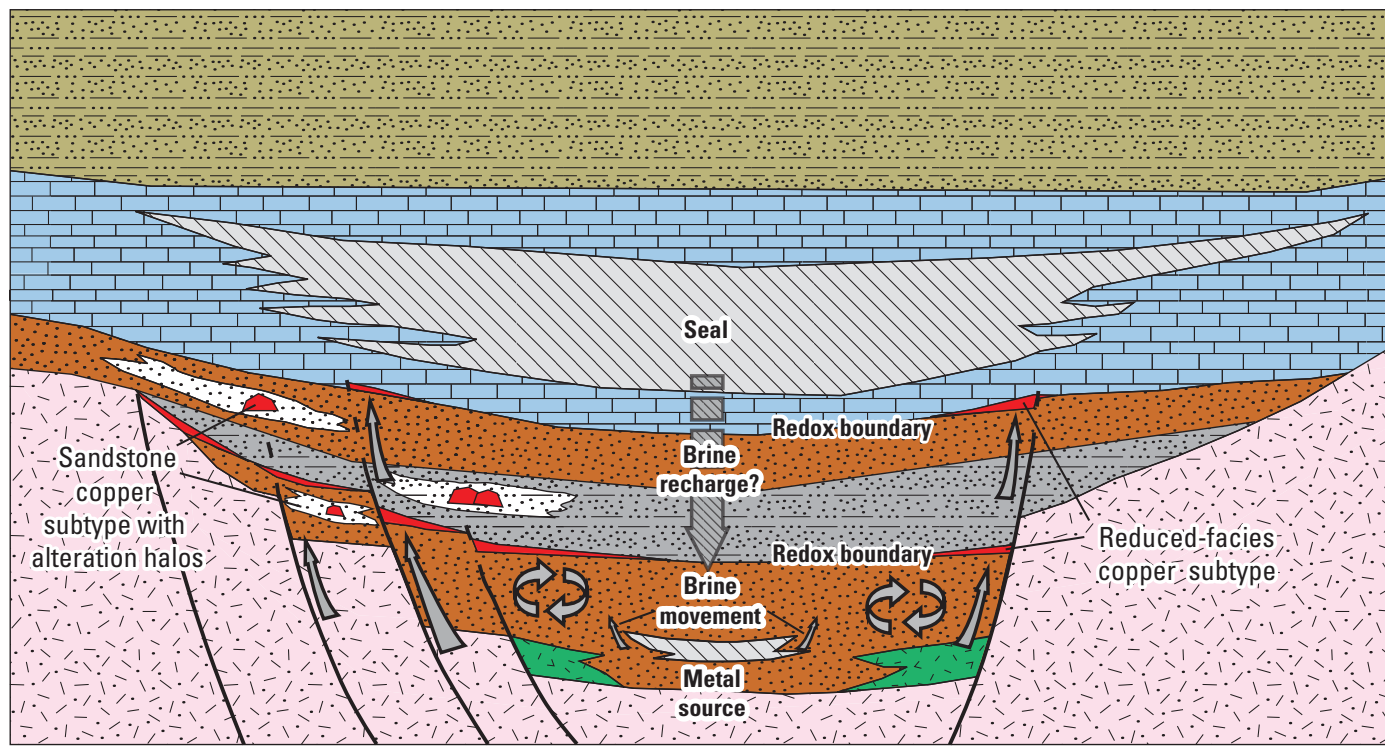

EXPLANATION
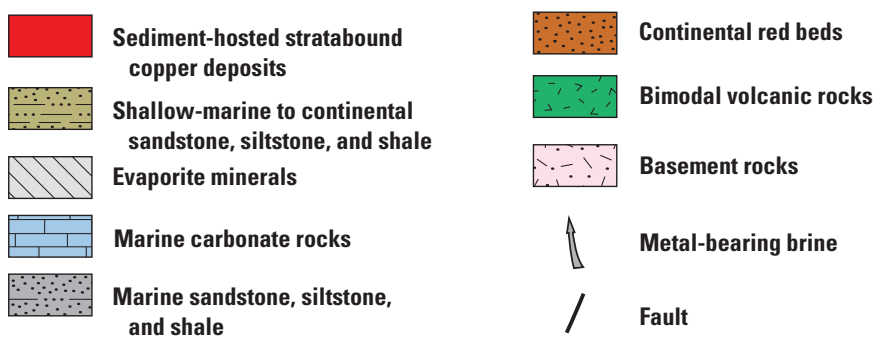

Figure C2. Schematic section of a sedimentary basin showing the local geologic settings and essential ore-system components required to form the reduced-facies copper subtype and sandstone copper subtype of sediment-hosted stratabound copper deposits (modified from figure 1-2 of Zientek, Wintzer, and others, 2015). 


\section{Areas Covered in this Report}

This chapter summarizes (1) quantitative assessments of sediment-hosted stratabound copper deposits in five basins in Europe, Asia, and Africa that were studied by the USGS as part of the global mineral resource assessment, (2) quantitative assessments of three basins in Greenland by the Geological Survey of Denmark and Greenland (GEUS), (3) quantitative assessments of four basins that were done as part of an assessment by the USGS of the United States, (4) a quantitative assessment of one basin in Afghanistan, (5) a qualitative assessment of one area in Afghanistan, and (6) qualitative assessments of 10 other basins throughout the world that were also studied by the USGS Global Copper Mineral Resource Assessment Team (fig. C1).

Some basins, such as the Neuquén Basin of Argentina (pl. 189) are represented by a single permissive tract. Others, such as the Kodar-Udokan Trough of Russia (pls. 207-212), are represented by multiple permissive tracts. Permissive tracts are primarily named for the basin in which they occur; in cases where a specific name within a basin was used in the source report and in the GIS, the tract name is listed along with the basin name in tables C3 and C4 and on the plates. Each permissive tract is assigned a unique identifier that includes a term that designates the deposit subtype (such as "ssCu" for sandstone copper subtype, "rfCu" for general reduced-facies copper subtype, and "shCu" for general sediment-hosted stratabound copper that includes all subtypes). Plates are numbered in order of the world regions shown in figure $\mathrm{C} 1$, starting with plates 189 and 190 (South America region), continuing through 191-206 (North America region, including Greenland), 207-217 (Central and Eastern Asia region), 218-219 (Southeast Asia region), 220-226 (Europe region), and 227-229 (Middle East region), and ending with plates 230-236 (Africa region).

The five sedimentary basins that were quantitatively assessed by the USGS in the global copper mineral resource assessment are the Chu-Sarysu Basin, Kazakhstan, shown in figure C3 and plates 213-216 (Box and others, 2012); the Katanga Basin, Democratic Republic of the Congo and Zambia, shown in figure C4 and plates 230-234 (Zientek, Bliss, and others, 2014); the Kodar-Udokan Trough, Russia, shown in figure C5 and plates 207-212 (Zientek, Chechetkin, and others, 2014); the Southern Permian Basin in Europe shown in figure C6 and plates 220, 221, 223, and 224 (Zientek, Oszczepalski, and others, 2015); and the Teniz Basin, Kazakhstan, shown in plate 217 (Cossette and others, 2014).

In addition, the Geological Survey of Denmark and Greenland (GEUS) provided quantitative assessments of the Central European Basin System (pl. 197), Jameson Land Basin (pls. 198-204), and Eleonore Bay Basin (pls. 205, 206) in Greenland (fig. C1) as part of the global copper assessment
(Stensgaard, 2011; Stensgaard and others, 2011). The assessment also incorporates results from previous USGS quantitative mineral resource assessments of the United States (U.S. Geological Survey Minerals Team, 1996; U.S. Geological Survey National Mineral Resource Assessment Team, 2000, 2002), which included sediment-hosted stratabound copper assessments for four basins - the Anadarko-Palo DuroMidland Permian Basin (pl. 191), the Midcontinent Rift (pl. 192), the Belt-Purcell Basin (pl. 193), and the Culpeper Basin (pl. 195). The Kabul Block and the Kundalyan area (pls. 227, 228) were assessed as part of a mineral resource assessment of Afghanistan (Ludington and others, 2007; Peters and others, 2007).

Also as part of the USGS global mineral resource assessment study, 10 basins were qualitatively assessed by using a decision support tool that provided a relative ranking of each basin according to the amount of undiscovered copper that may be present in sediment-hosted stratabound copper deposits (Zientek, Wintzer, and others, 2015). This tool, the analytic hierarchy process (AHP), is described below in the section, "Qualitative Ranking." The 10 basins are ordered by plate number in the list below:

- Neuquén Basin in Argentina and Chile (pl. 189)

- Salta Rift System in Argentina (pl. 190)

- Belt-Purcell Basin in the United States and Canada (pl. 193). The Belt-Purcell Basin was assessed as part of the quantitative assessment of the United States and was also included in the qualitative AHP analysis. It is the only basin for which results from two methods are provided in this report.

- Neoproterozoic rocks that host the Redstone Copperbelt in the Mackenzie Mountains in Canada (pl. 194)

- Maritimes Basin in Canada (pl. 196)

- The basin that contains the Dongchuan Group rocks in the Yangtze Block of the South China Craton in China (pl. 218)

- Chuxiong Basin in China (pl. 219)

- A rift-related basin containing Cambrian rocks in Egypt, Israel, and Jordan (pl. 229)

- Northwest Botswana Rift in Botswana and Namibia, which includes the Kalahari Copperbelt (pl. 235)

- Benguela and Cuanza Basins in Angola (pl. 236)

The Belt-Purcell Basin (pl. 193) was assessed as part of the quantitative assessment of the United States and was also included in the qualitative analytic hierarchy process (AHP) analysis. 


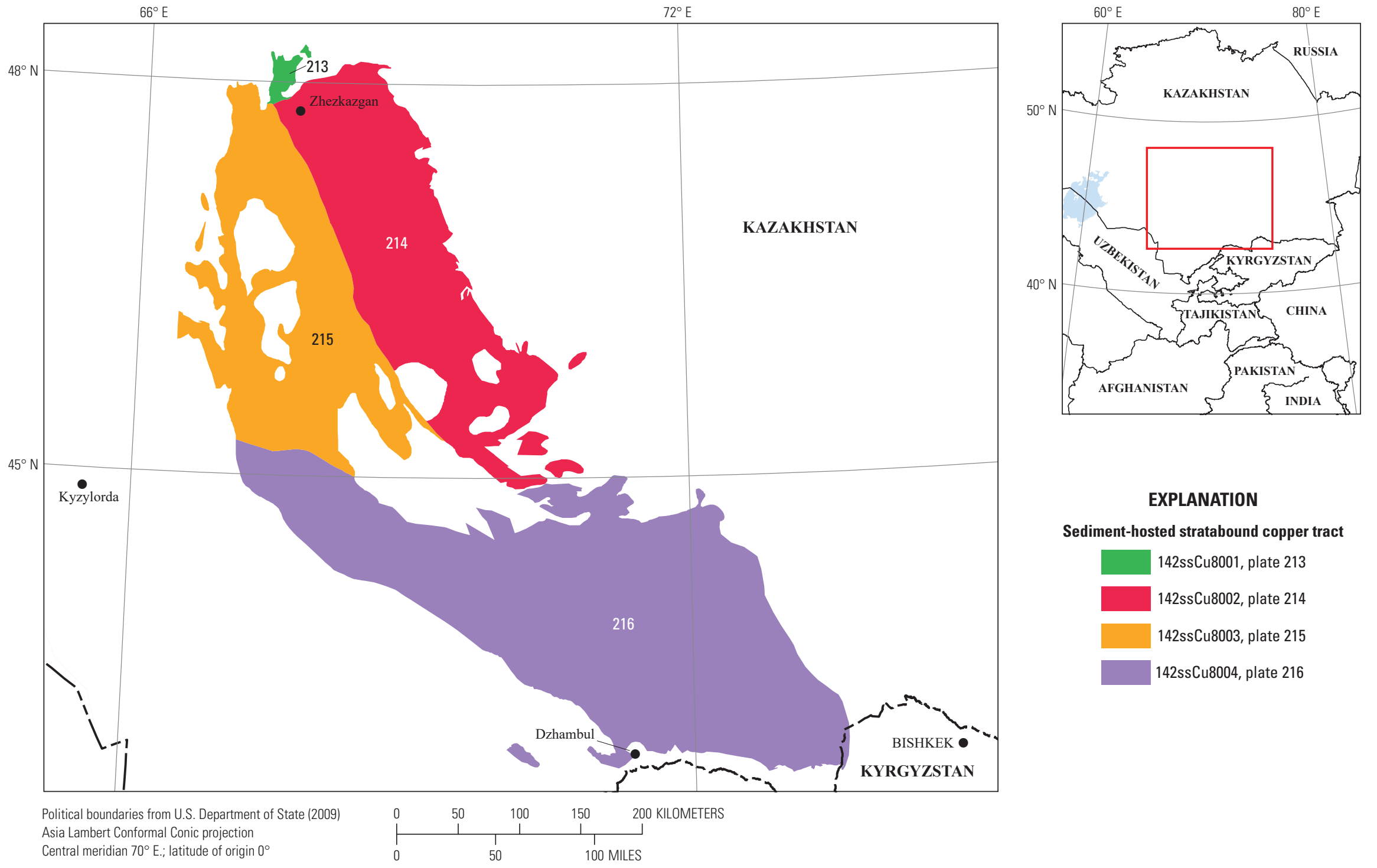

Figure C3. Map showing permissive tracts in the Chu-Sarysu Basin, Kazakhstan and Kyrgyzstan, that were defined for quantitative assessments of sediment-hosted stratabound copper deposits (Box and others, 2012). 

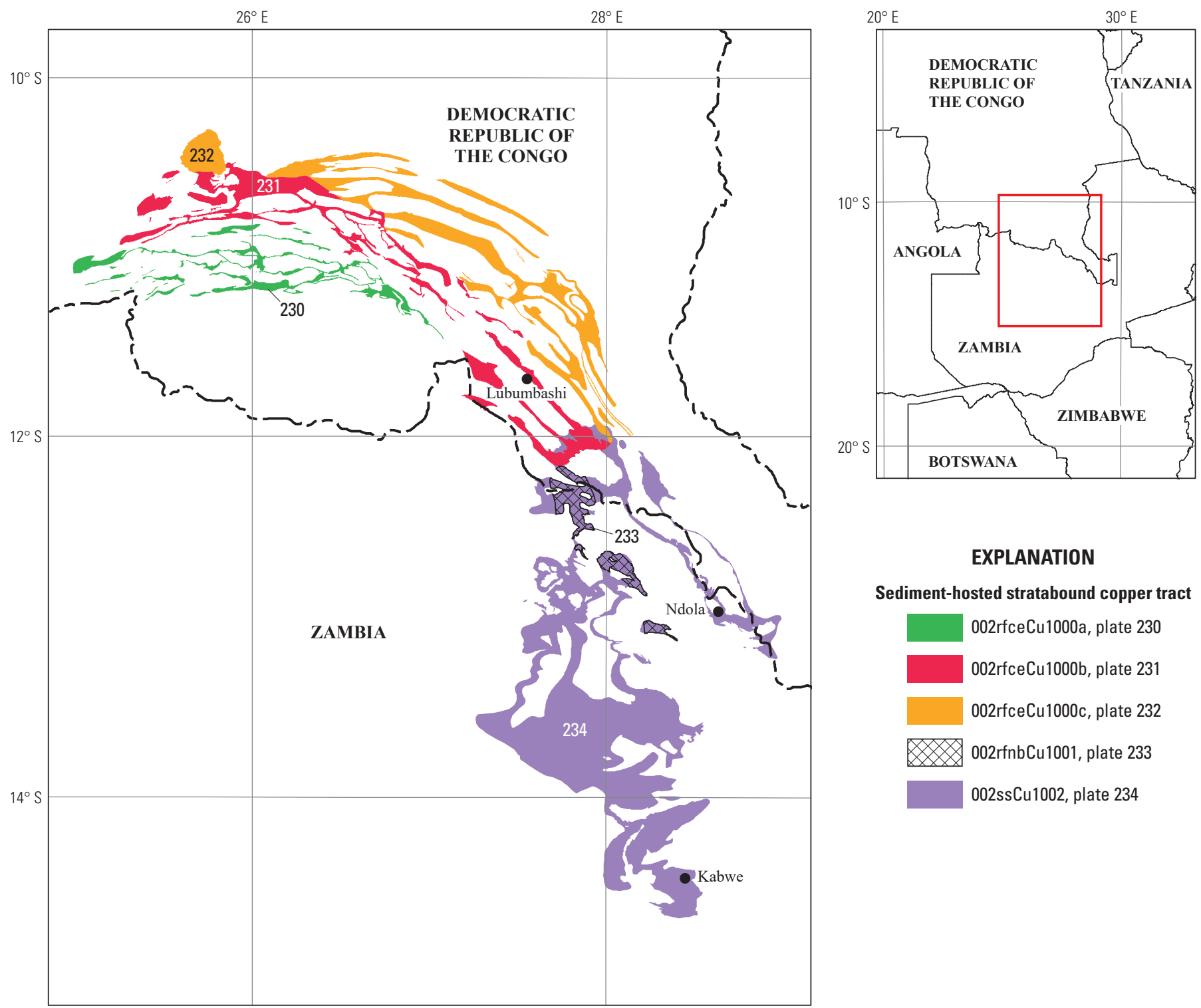

Political boundaries from U.S. Department of State (2009) Africa Lambert Conformal Conic projection Central meridian $25^{\circ} \mathrm{E}$; latitude of origin $0^{\circ}$

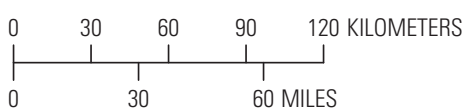

\section{EXPLANATION}

Sediment-hosted stratabound copper tract

002rfceCu1000a, plate 230

002rfceCu1000b, plate 231

002 rfceCu1000c, plate 232

002rfnbCu1001, plate 233

002ssCu1002, plate 234

Figure C4. Map showing permissive tracts in the Katanga Basin, Democratic Republic of the Congo and Zambia, that were defined for quantitative assessments of sediment-hosted stratabound copper deposits (Zientek, Bliss, and others, 2014). 


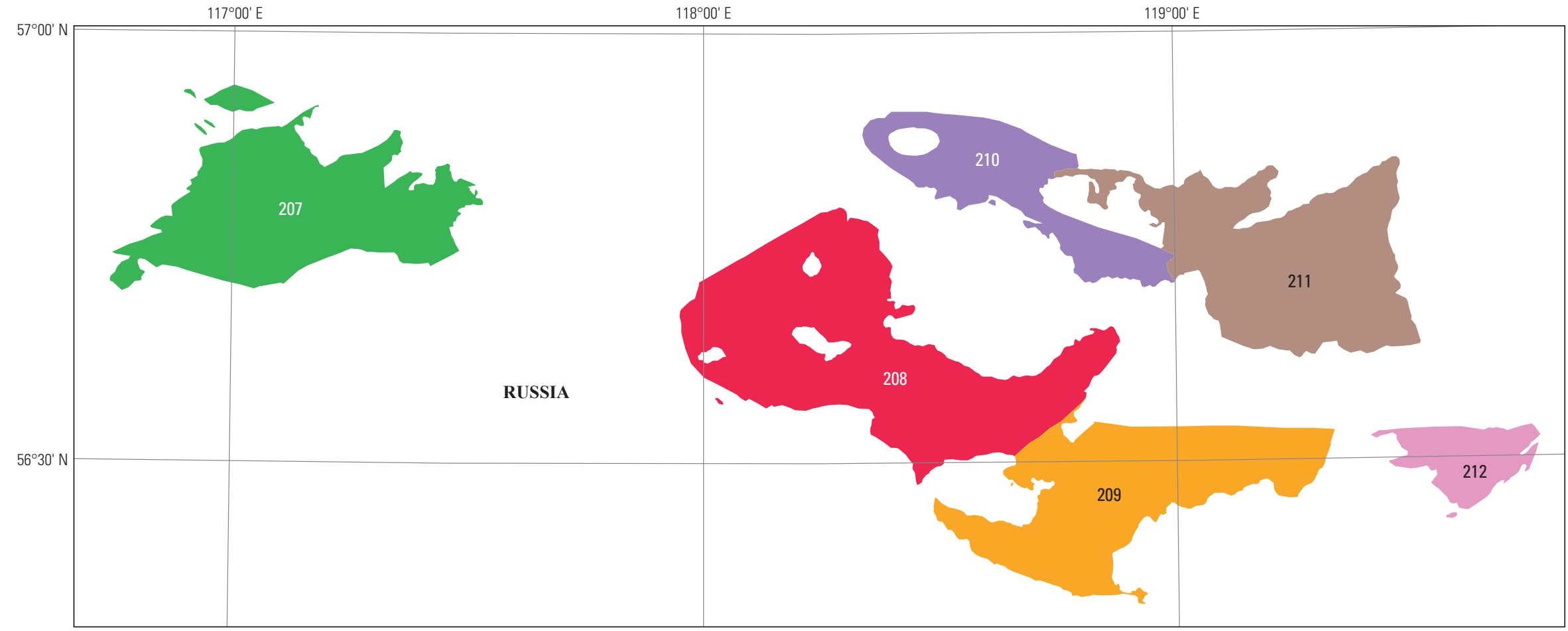

Political boundaries from U.S. Department of State (2009)

Asia Lambert Conformal Conic projection

Central meridian $118^{\circ} \mathrm{E}$.; latitude of origin $0^{\circ}$
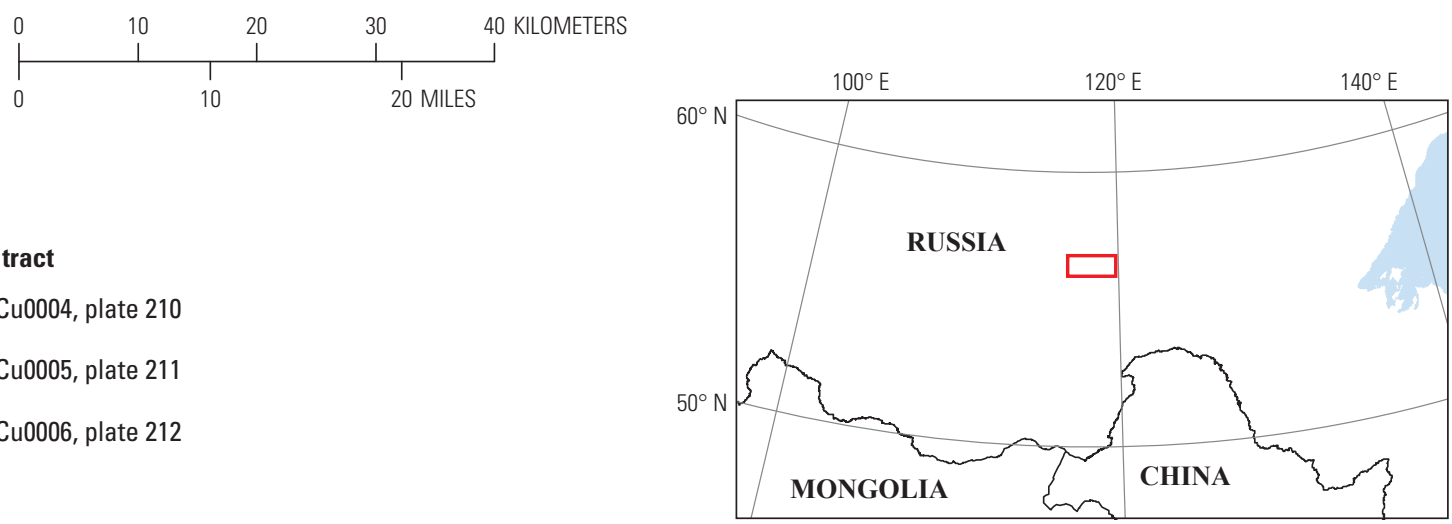

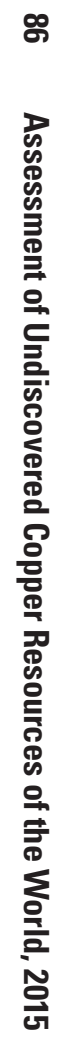

EXPLANATION

Sediment-hosted stratabound copper tract

\begin{tabular}{|l|l|}
\hline 150ssCu0001, plate 207 & 150ssCu0004, plate 210 \\
\hline 150ssCu0002, plate 208 & 150ssCu0005, plate 211 \\
\hline 150ssCu0003, plate 209 & 150ssCu0006, plate 212 \\
\hline
\end{tabular}

Figure C5. Map showing permissive tracts in the Kodar-Udokan Trough, Russia, that were defined for quantitative assessments of sediment-hosted stratabound copper deposits (Zientek, Chechetkin, and others, 2014). 


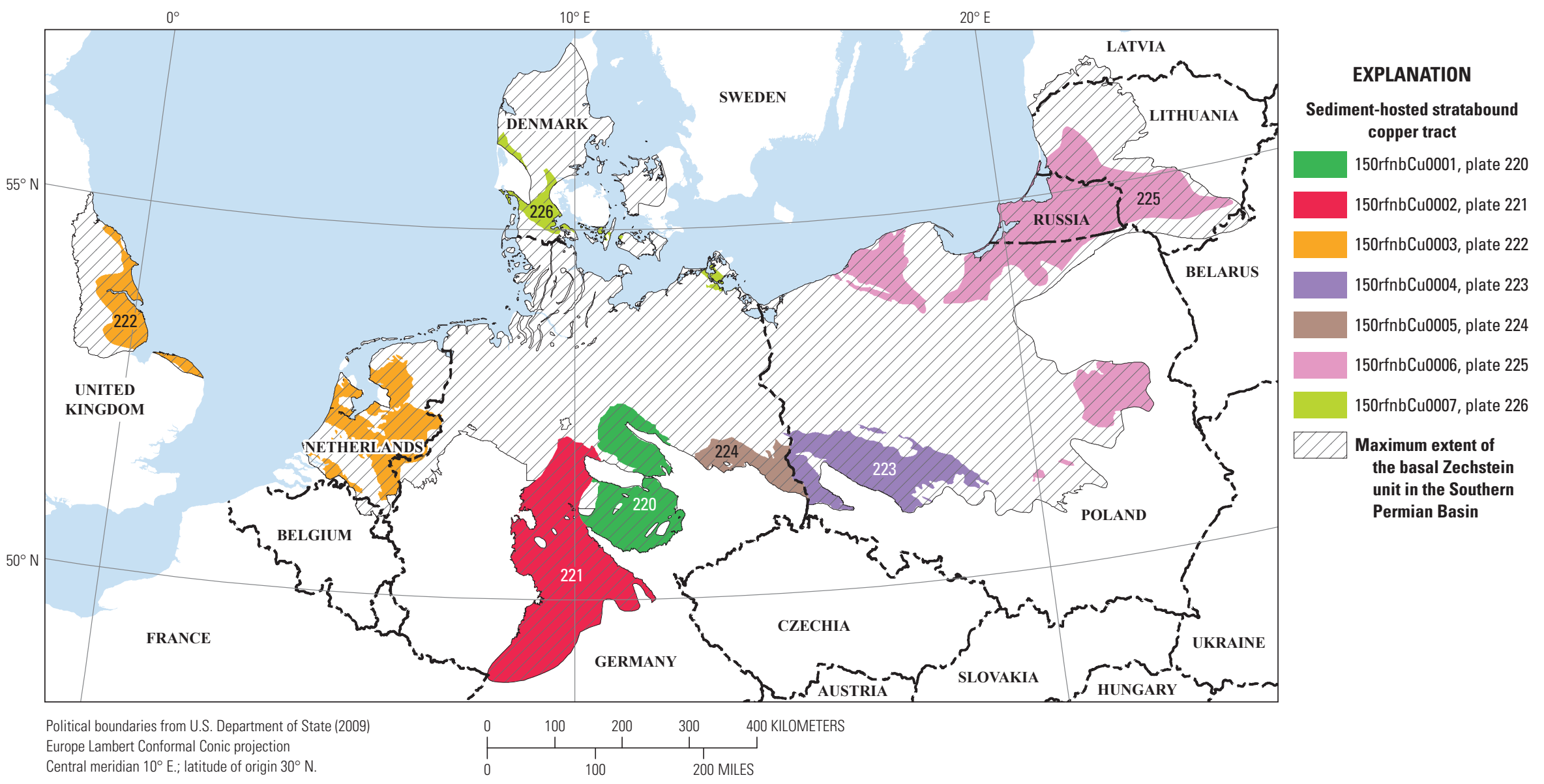

Figure C6. Map showing permissive tracts in the Southern Permian Basin in Europe that were defined for quantitative and qualitative assessments of sediment-hosted stratabound copper deposits (Zientek, Oszczepalski, and others, 2015). Tracts 220, 221, 223, and 224 were assessed quantitatively (table C4). 


\section{Methodology}

The quantitative mineral resource assessment of sedimenthosted stratabound copper deposits utilized the three-part form of assessment (Singer, 1993; Singer and Menzie, 2010; this volume, appendix 2). This form of assessment (also used for the porphyry copper assessment) is applicable to any type of mineral deposit provided that descriptive models and grade and tonnage models are available. In depicting results of this approach, maps show "permissive tracts," where the geology permits the existence of deposits of one or more types. Probabilistic distributions of the amount of metal in place are used to express the potential amount of undiscovered mineral resource for quantitative assessments. Qualitative assessment results allow basins to be ranked according to the amount of undiscovered copper that may be present.

\section{Permissive Tract Delineation}

Permissive tracts represent the surface projection of part of the Earth's crust and overlying surficial materials to a predetermined depth where undiscovered mineral resources may be present. The criteria for selecting the permissive volume of rock, or assessment unit, are provided by descriptive mineral deposit models and mineral systems models. Boundaries of the rock volume are defined such that the occurrence of deposits of the type being assessed outside the volume is negligible. In assessment reports and in the plates that accompany this report, maps show the permissive tracts along with locations of mineral deposits and prospects of the deposit type being assessed.

The assessment geologist creates maps that show where deposits of the type being sought may exist; in the process, areas that are thought to be barren of the deposit type are excluded. Specifically, area selection defines permissive regions where the existence of mineral deposits of the type sought is plausible on the basis of knowledge of environments at or near the surface of the Earth's crust where the geological processes are or were favorable for mineral deposit formation (Singer, 1993).

Models guide assessment geologists as they use empirical information to discriminate between areas that may be mineralized and those that are likely to be barren. The methods and models used should allow people with similar experience and information to create consistent and comparable maps for different study areas and different deposit types. In most USGS studies, the "Geological Environment" section of the descriptive mineral deposit models is used to guide permissive tract delineation (Singer, 1993; Singer and Menzie, 2010). Tract delineation for sediment-hosted stratabound copper deposits for the global mineral resource assessment also relied on mineral systems models (Wyborn and others, 1994; Hitzman and others, 2005; Hayes and others, 2015). Specifically, the part of the mineral system where ore deposits are localized was used to define the assessment unit, which, in turn, was used to delineate the permissive tract on a map. Mappable indicators or proxies (measures of favorability) were used to identify a volume of rock where the geology permitted the existence of sediment-hosted stratabound copper deposits (the assessment unit or the permissive unit). Outside of the selected volume, the probability of occurrence for sediment-hosted stratabound copper deposits is negligible; that is, less than 1 in 100,000.

Sedimentary copper deposits are hydrothermal deposits formed in a sedimentary basin during diagenesis; that is, all the chemical, physical, and biologic changes that affect a sediment after its initial deposition and during and after the process of conversion to a coherent rock (lithification). The mineral system is defined by variations of the source-transporttrap paradigm (Magoon and Dow, 1994; Wyborn and others, 1994; Magoon and Schmoker, 2000; Hitzman and others, 2005, 2010; Cox and others, 2007; Hayes and others, 2015). The formation of sediment-hosted stratabound copper deposits in sedimentary basins requires a source of metals, a fluid that extracts and moves metals away from the source rocks, a pathway that allows the movement of these ore-bearing fluids, and a trap that fixes metal in an ore body (Taylor, 2000; Hitzman and others, 2005; Cox and others, 2007; Hayes and others, 2015). Previous USGS mineral resource assessment studies for sediment-hosted stratabound copper deposits emphasized the juxtaposition of red beds (with or without evaporite) with reduced strata in order to define areas where undiscovered resources could be present (Hodges and others, 1984; Spanski and McKelvey, 1990; Spanski, 1992; Box and others, 1996; U.S. Geological Survey National Mineral Resource Assessment Team, 2000).

For the purposes of this assessment, the following components of the sediment-hosted stratabound copper mineral system were considered essential when delineating permissive volumes of rock: (1) reservoir facies red bed rocks were juxtaposed against strata that contained reductants (most likely organic material), (2) these rocks had undergone diagenesis at intermediate burial depths of 1-5 kilometers $(\mathrm{km})$ and at temperatures ranging from 70 to $160{ }^{\circ} \mathrm{C}$, and (3) subsurface water that was enriched in copper must have been present. Maps, cross sections, and stratigraphic sections can be used to map hydrologically conductive sequences of rock with appropriate stratigraphic relations. Studies of the cementation history and time-stratigraphic relations can be used to constrain the burial history of the rocks. However, the information usually available for assessments does not have any proxies for the presence of copper-enriched subsurface water other than the presence of copper deposits and prospects in some portion of the basin that is being evaluated. For the global assessment, the permissive tract defined the volume of permissive rocks within 2 to $2.5 \mathrm{~km}$ of the surface, depending on the study area. This depth is based on current technological or economic limits for mining the deposit type. 


\section{Probabilistic Estimation}

In order to estimate undiscovered resources, numbers of undiscovered deposits of a given type are estimated at various quantile levels for the permissive tracts. By using Monte Carlo simulations, these undiscovered deposit estimates are combined with appropriate tonnage and grade models for the deposit type being assessed to derive a probability distribution for the amounts of commodities and rock that could be present in undiscovered deposits. For this study, about 170 wellexplored deposits were used to construct several sedimenthosted stratabound copper grade and tonnage models (Zientek, Hayes, and Taylor, 2013). Monte Carlo simulation was done by using EMINERS (Duval, 2012); the computational process was described by Root and others (1992). Simulation results are reported at selected quantile levels, together with the mean expected amount of metal, the probability of the mean, and the probability of no resources being present.

\section{Qualitative Ranking}

Qualitative assessments were conducted where information was insufficient for a complete probabilistic quantitative assessment. Ten areas were qualitatively assessed by using a decision support tool, the analytic hierarchy process (AHP), to rank them according to their potential to contain undiscovered sediment-hosted stratabound copper deposits. The AHP is a structured technique for making complex decisions that quantifies the qualitative evaluation process (Saaty, 1980; Meyer and Booker, 2001; Saaty and Vargas, 2001).

The AHP is a theory of measurement used to derive relative priorities on absolute scales from paired comparisons in multilevel hierarchic structures (Saaty, 1980; Malczewski, 1999, p. 217-223; Saaty and Vargas, 2001; Coulter and others, 2006). The AHP involves (1) decomposing the decision into a hierarchy of components that can be evaluated with pairwise comparisons, (2) creating sets of comparison matrices by evaluating the pairwise comparisons in the hierarchy, (3) calculating priorities from the comparison matrices for each element in the hierarchy, and (4) constructing a composite set of priorities for the alternatives being considered. In this study, our goal was to decide which of the 10 areas (the alternatives) have the greatest potential for undiscovered copper. The decision was decomposed into a hierarchy of pairwise comparisons that captured the essential elements of the problem (Saaty, 1980; Malczewski, 1999). In the hierarchy, the top level was the goal of the decision. The hierarchy then descended from general to more specific criteria until the set of alternatives was reached. Each element in an upper level was used to compare the elements in the level immediately below it (Saaty, 1980). The elements within a given level of the hierarchical structure were evaluated by using pairwise comparisons.
Pairwise comparisons reduce the conceptual complexity of decisionmaking because only two components are considered at any given time. Paired comparisons can be made by (1) rating items relative to each other in a qualitative evaluation or (2) using specified numerical scales (Meyer and Booker, 2001). The result is a set of pairwise comparison matrices. For each pairwise comparison matrix, the eigenvalue is used to obtain a priority weight vector (Saaty, 1980). In addition to the eigenvalue and the eigenvector, consistency tests are also computed (Saaty, 1990). A sequence of multiplications of the matrices of relative weights at each level of the hierarchy is used to produce overall scores for each alternative (called "alternative utility" in this report).

For this study, the goal (the top level of the hierarchy) was a qualitative estimate of the amount of undiscovered copper that may be present in each of the 10 prospective basins. The alternatives (the bottom of the hierarchy) were the 10 study areas (fig. C7). Three criteria were used at the second level of the hierarchy: (1) the sizes of the study areas (extent), (2) rock types and stratigraphic associations (lithostratigraphic framework), and (3) evidence for fluids capable of forming sediment-hosted stratabound copper deposits (mineralization). Figure C7 illustrates the factors that were considered in the pairwise correlations for each area.

Alternatives can be ranked by their importance in contributing to the goal of the analysis by simply sorting alternatives on the basis of their overall score. Those alternatives with the higher score receive a higher overall ranking. The most important outcome is a chart that compares alternative utility scores for the study areas (fig. C8). The Northwest Botswana Rift had the highest overall alternative utility score, which means that this area has a greater potential to contain undiscovered sediment-hosted stratabound copper deposits than the other nine areas that were considered.

All the study areas have maps showing permissive tracts; the maps also show identified deposits and prospects if any are known. Quantitatively assessed areas have a probabilistic estimate of the amount of undiscovered copper; study areas that were qualitatively assessed by the AHP were compared with a ranked list. The results for each tract are presented in the plates that accompany this report. Quantitative assessment results aggregated by world region and by sedimentary basin are presented in tables $\mathrm{C} 1$ and $\mathrm{C} 2$, respectively. Table $\mathrm{C} 3$ (Western Hemisphere) and C4 (Eastern Hemisphere) provide a key to the plates and summarize results for individual tracts. Tables C3 and C4 follow the "References Cited" for this chapter C.

Study areas were selected on the basis of previous compilations of deposits and prospects by Kirkham and others (1994), Kirkham and Broughton (2005), and Cox and others (2007). As part of the assessment process, deposit and prospect information was reviewed and revised. For the areas that were assessed, there are 284 and 388 sites in the compilations by Cox and others (2007) and Kirkham and others (1994), 


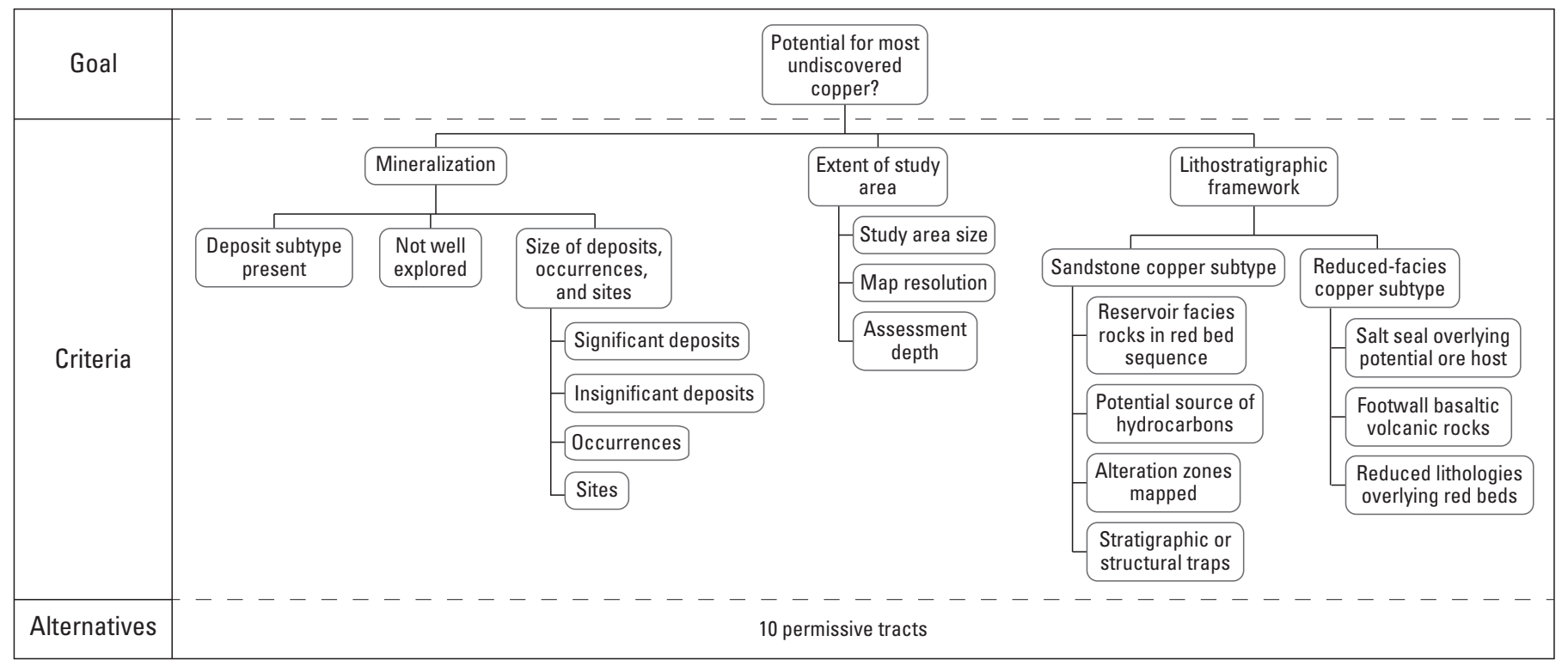

Figure C7. Chart showing criteria hierarchy used for the analytic hierarchy process (AHP) analysis for 10 areas containing sedimenthosted stratabound copper deposits throughout the world.

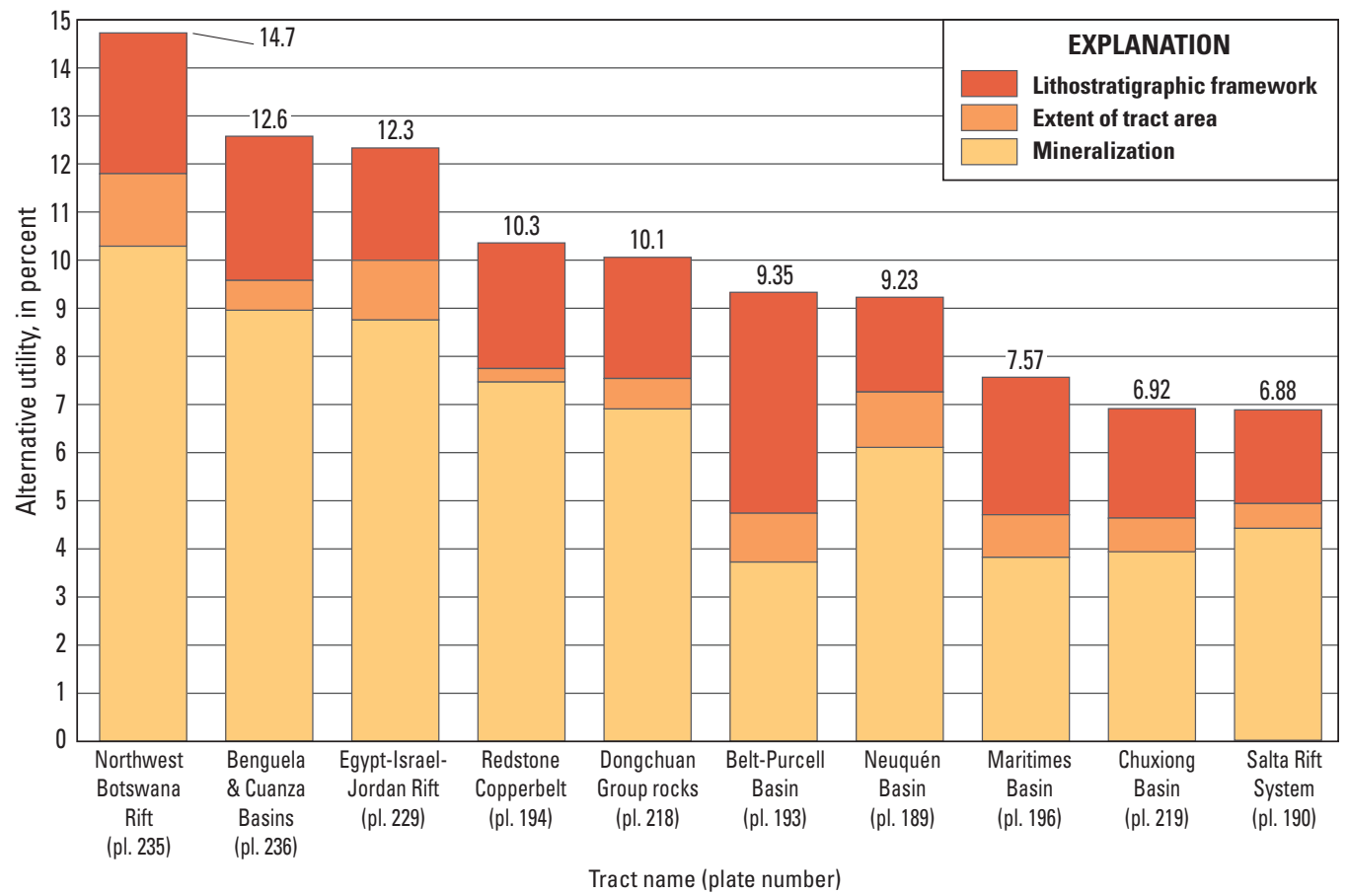

Figure C8. Bar graph showing qualitative ranking of 10 basins determined by the analytic hierarchy process (AHP). They were ranked according to their potential to contain undiscovered sediment-hosted stratabound copper deposits. Alternative utility is the overall score derived from the AHP method. 
respectively. The revised database used for the global assessment of sediment-hosted stratabound copper deposits contains 1,002 sites (Dicken and others, 2016). This revised database is significantly different in that there are more records and the site locations are more precise. The changes reflect the use of the world wide web to find and access information and GIS technology and satellite imagery to verify site locations. For some areas, scientific cooperators provided new information that previously was not in the public domain (for example, Syusyura and others, 2010).

The areas of the world that are included in the quantitative assessment of sediment-hosted stratabound copper deposits have identified copper resources of $310 \mathrm{Mt}$ and a mean of $420 \mathrm{Mt}$ of undiscovered copper (table C1). About 70 percent of the estimated undiscovered copper is in two sedimentary basins: the Katanga Basin in the Democratic Republic of the Congo and Zambia and the Southern Permian Basin in Europe (table C2). These basins contain about 75 percent of the copper identified in discovered sedimenthosted stratabound deposits. Of the 10 areas assessed qualitatively by using the AHP, the Northwest Botswana Rift in Botswana and Namibia and the Benguela and Cuanza Basins in Angola had the highest rankings (fig. C8). These were followed by Cambrian sedimentary rocks in a rift in Egypt, Israel, and Jordon, the Redstone Copperbelt in the Mackenzie Mountains in the Northwest Territories in Canada, the basin that includes the Dongchuan Group rocks, China (Yangtze Block, South China Craton), and the Belt-Purcell Basin in the United States and Canada (pl. 193), which was included in both the quantitative and qualitative assessments (fig. $\mathrm{C} 8$ and table $\mathrm{C} 2$ ).
Two basins stand out for their potential for undiscovered copper resources in sediment-hosted stratabound copper deposits - the Katanga Basin in the Democratic Republic of the Congo and Zambia (pls. 230-234) and the Southern Permian Basin in Europe (pls. 220-226). Both basins have large amounts of identified copper and a long history of mineral development.

The Katangan area was one of three primary sources of copper traded in sub-Saharan Africa up to the late 19th century (Herbert, 1984). Archeological findings suggest that malachite outcrops in the copperbelt were mined as early as the fourth century A.D. (Bisson, 2000). Indigenous peoples may have smelted at least 100,000 $\mathrm{t}$ of copper, requiring the mining of over 1,000,000 Mt of ore and waste (Ball, 1922). Western colonial enterprises began mining in the early 1900s, and exploration resulted in the discovery of about 90 deposits in what has come to be known as the Central African Copperbelt. The mean estimate of undiscovered copper in the Katanga Basin, $170 \mathrm{Mt}$, is slightly greater than the known resources of $150 \mathrm{Mt}$ (table C2). Significant value can be expected from associated metals, particularly cobalt. The three tracts (002rfceCu1000a, b, c shown on pls. 230-232) that contain most of the mean undiscovered copper in the Katanga Basin (table $\mathrm{C} 4$ ) also have the potential for near-surface, undiscovered deposits. The significant prospects in these tracts were ranked and assigned probabilities to estimate the amount of undiscovered metal that might be present at or near the surface. Simulation results indicate a mean value of $37 \mathrm{Mt}$ of undiscovered copper may be within these significant prospects. Sites similar to these are most likely to be developed in the near future.

Table C1. Aggregated assessment results for identified copper resources and estimates of undiscovered copper resources in sediment-hosted stratabound copper deposits by world regions.

[Results of probabilistic estimates of undiscovered copper resources are reported as means and selected percentiles $(90,50,10)$ for aggregated results by region, assuming statistical independence; 90 represents a 90 -percent chance of at least the amount indicated. Tract extent and identified copper resources refer to all tracts within the region; mean and percentiles apply to tracts that were assessed quantitatively. See tables C3 and C4 and plates for results for individual tracts. Resources are reported to two significant figures. Four of the 11 world regions defined for the global assessment did not contain significant sedimenthosted copper deposits and are not listed in this table: the Central America and Caribbean, Northeast Asia, Southeast Asia Archipelagos, and Eastern Australia regions. $\mathrm{km}^{2}$, square kilometer; Mt, millions of metric tons; NA, not applicable, as a quantitative assessment was not done]

\begin{tabular}{|c|c|c|c|c|c|c|c|}
\hline \multirow[t]{2}{*}{ Region } & \multirow[t]{2}{*}{ Plates } & \multirow[t]{2}{*}{$\begin{array}{c}\text { Tract area } \\
\quad\left(\mathbf{k m}^{2}\right)\end{array}$} & \multirow{2}{*}{$\begin{array}{l}\text { Identified } \\
\text { copper } \\
\text { resources } \\
\text { (Mt) }\end{array}$} & \multicolumn{4}{|c|}{$\begin{array}{l}\text { Estimates of } \\
\text { undiscovered in-place copper resources } \\
\text { (Mt) }\end{array}$} \\
\hline & & & & Mean & 90 & 50 & 10 \\
\hline South America & 189-190 & 153,520 & 0.39 & NA & NA & NA & NA \\
\hline North America & $191-206$ & 414,833 & 14 & 55 & 15 & 48 & 110 \\
\hline Southeast Asia & 218-219 & 28,594 & 4.5 & NA & NA & NA & NA \\
\hline Europe & $220-226$ & 162,388 & 79 & 130 & 38 & 110 & 230 \\
\hline Middle East & $227-229$ & 30,762 & 7.9 & 13 & 0.052 & 4.8 & 36 \\
\hline Africa & $230-236$ & 165,764 & 160 & 170 & 81 & 150 & 260 \\
\hline
\end{tabular}


Table C2. Aggregated assessment results for identified copper resources and estimates of undiscovered copper resources in sediment-hosted stratabound copper deposits by sedimentary basins for 13 basins that were quantitatively assessed.

[Undiscovered resources were estimated probabilistically as described in table $\mathrm{C} 1 ; 90$ represents a 90-percent chance of at least the amount shown, and other percentiles are similarly defined. Resources are reported to two significant figures. $\mathrm{km}^{2}$, square kilometer; $\mathrm{Mt}$, millions of metric tons]

\begin{tabular}{|c|c|c|c|c|c|c|c|c|}
\hline \multirow[t]{2}{*}{ Basin } & \multirow[t]{2}{*}{$\begin{array}{l}\text { Tract area } \\
\quad\left(\mathrm{km}^{2}\right)\end{array}$} & \multirow[t]{2}{*}{ Plates } & \multirow{2}{*}{$\begin{array}{l}\text { Number } \\
\text { of known } \\
\text { deposits }\end{array}$} & \multirow{2}{*}{$\begin{array}{l}\text { Identified } \\
\text { copper } \\
\text { resources } \\
\text { (Mt) }\end{array}$} & \multicolumn{4}{|c|}{$\begin{array}{c}\text { Estimates of } \\
\text { undiscovered in-place copper resources } \\
\text { (Mt) }\end{array}$} \\
\hline & & & & & Mean & 90 & 50 & 10 \\
\hline \multicolumn{9}{|c|}{ North America region } \\
\hline $\begin{array}{l}\text { Anadarko-Palo Duro-Midland Permian } \\
\text { Basin-United States }\end{array}$ & 186,791 & 191 & 3 & 0.046 & 16 & 0.060 & 5.8 & 46 \\
\hline Midcontinent Rift_-United States & 123,147 & 192 & 2 & 9.4 & 18 & 0.59 & 10 & 47 \\
\hline $\begin{array}{l}\text { Belt-Purcell Basin-United States and } \\
\text { Canada }\end{array}$ & 1,633 & 193 & 11 & 3.2 & 10 & 1.4 & 5.2 & 26 \\
\hline Culpeper Basin-United States & 11,566 & 195 & 0 & 0 & 6.6 & 0.037 & 1.4 & 19 \\
\hline Eleonore Bay Basin-Greenland & 3,055 & $205-206$ & 0 & 0 & 1.3 & 0 & 0 & 0.96 \\
\hline \multicolumn{9}{|c|}{ Central and Eastern Asia region } \\
\hline Kodar-Udokan Trough-Russia & 3,015 & $207-212$ & 2 & 20 & 21 & 4.6 & 16 & 42 \\
\hline $\begin{array}{l}\text { Chu-Sarysu Basin-Kazakhstan and } \\
\text { Kyrgyzstan }\end{array}$ & 125,517 & $213-216$ & 8 & 28 & 25 & 5.6 & 20 & 49 \\
\hline Teniz Basin-Kazakhstan & 49,714 & 217 & 0 & 0 & 8.9 & 0.33 & 3.7 & 25 \\
\hline \multicolumn{9}{|c|}{ Europe region } \\
\hline \multicolumn{9}{|c|}{ Africa region } \\
\hline $\begin{array}{l}\text { Katanga Basin-Democratic Republic } \\
\text { of the Congo and Zambia }\end{array}$ & 23,133 & $230-234$ & 85 & 150 & 170 & 81 & 150 & 260 \\
\hline
\end{tabular}


The assessment of the Katanga Basin focused on the stratigraphic interval where most of the copper mineralization has been found. Recently, the world-class Kamoa deposit in the Democratic Republic of the Congo has been found in a different stratigraphic interval, upsection from the part of the section that historically has been explored for large sedimenthosted stratabound copper deposits in the Central African Copperbelt (Broughton and Rogers, 2010a, b). This discovery raises the possibility that additional undiscovered deposits are present in areas not considered in this study.

Copper mining in the Southern Permian Basin of Europe likely began in the High Middle Ages (approximately A.D. 1000-1299). Ore production significantly increased during the industrial revolution; however, the largest identified deposit in the basin (pl. 223) was not discovered until 1957 in southwestern Poland at a depth of 600 meters (m). Since 1958, about $15 \mathrm{Mt}$ of copper has been produced, leaving about $30 \mathrm{Mt}$ of copper in remaining resources. Drilling in southwestern Poland clearly shows that ore-grade, mineralized rocks extend at depth. Mean estimates of the amount of undiscovered copper to depths of $2.5 \mathrm{~km}$ are about $110 \mathrm{Mt}$. Most of the undiscovered resource in southwestern Poland will be below depths of $1.5 \mathrm{~km}$ where virgin rock temperatures will exceed $50{ }^{\circ} \mathrm{C}$. There is enough drilling information to use geostatistical methods to estimate the amount of undiscovered metal that may be present (see this volume, appendix 2). The mean values to a depth of 2,500 m were 62 and $97 \mathrm{Mt}$ and were obtained by the USGS by using Gaussian geostatistical simulation and the three-part form of assessment, respectively. See Zientek, Oszczepalski, and others (2015) for more information.

\section{Discussion}

The USGS mineral resource assessment methodology outlines the process to discriminate areas with mineral potential from those that are nonpermissive and to place value on the resources that may be present. The actual outcomes reflect the quality of information that is available for the assessment and the knowledge and skill of the assessment team. These factors affect the areas and shapes defined for the permissive tracts and the uncertainty associated with the undiscovered resource estimates.

\section{The "Look" of Permissive Tracts on Maps}

Permissive tracts are defined by geology. Therefore, they should have shapes consistent with the volumes of permissive rock projected to the Earth's surface. For a sediment-hosted stratabound copper deposit, a thin tabular concave sheet is a simple geometric approximation for the permissive volume of rock. Depending on the orientation of the tabular layer with respect to the surface, permissive tract shapes range from linear arcs to ellipses. One edge of the permissive tract usually corresponds to the lower geologic contact of the permissive unit.

For the sediment-hosted stratabound copper assessment, available information strongly affected the assessment unit used to delineate the permissive rock volume and corresponding tract. For most areas, the assessment unit ended up being defined by general lithostratigraphic associations (such as the presence of red beds) where sediment-hosted stratabound copper deposits and prospects were known. For some of our study areas, two limitations affected the assessment: (1) geologic maps showed the distribution of map units but did not illustrate the orientation of rock units, and (2) subsurface information in the form of cross sections, seismic data, or drilling data that would constrain the subsurface geometry of rocks was not available. Without information on the orientation of rock layers, it was not possible to accurately project the surface geology to depth to generate a rock volume for the permissive tract. In these situations, the permissive tracts essentially show the surface extent of the stratigraphic unit known to host sediment-hosted stratabound copper deposits and prospects (for example, the Benguela and Cuanza Basins in Angola, pl. 236). For other areas, subsurface information allowed a stratigraphic unit to be traced into the subsurface; however, the subsurface extent of the unit was found to be above the assessment depth limit of $2.5 \mathrm{~km}$ below the Earth's surface. In this situation, an entire sedimentary basin makes up the permissive tract extent because no other data were available to reduce the tract area (for example, the Teniz Basin, Kazakhstan, pl. 217). In other situations, depth constraints and a sedimentary-facies boundary were available to constrain the tract (for example, Cambrian rocks of the Egypt-Israel-Jordan Rift, pl. 229). Three study areas had enough information on the subsurface extent of permissive rocks and on the distribution of critical mineral systems components to restrict the permissive tract extent within the basin: the Katanga Basin in the Democratic Republic of the Congo and Zambia (fig. C4), the Southern Permian Basin in Europe (fig. C6), and the Belt-Purcell Basin in the United States and Canada (pl. 193). In summary, when looking at the tracts, the reader should be aware that the tract outlines vary according to the geometry of rock layers and the quality of available information.

\section{Probabilistic Assessment Results}

For the quantitative assessments, Monte Carlo methods were used to combine the estimates of undiscovered deposits with the appropriate tonnage and grade distributions to estimate the amount of contained metal that may be present in undiscovered deposits. Each simulation trial in the Monte Carlo computation yields a possible value of contained metal in place that is based upon randomly sampling values from the input distributions. The results of all the simulation trials can be summarized by using various statistical measures such as the mean (or average value) and illustrated in graphs. 
$\boldsymbol{A}$

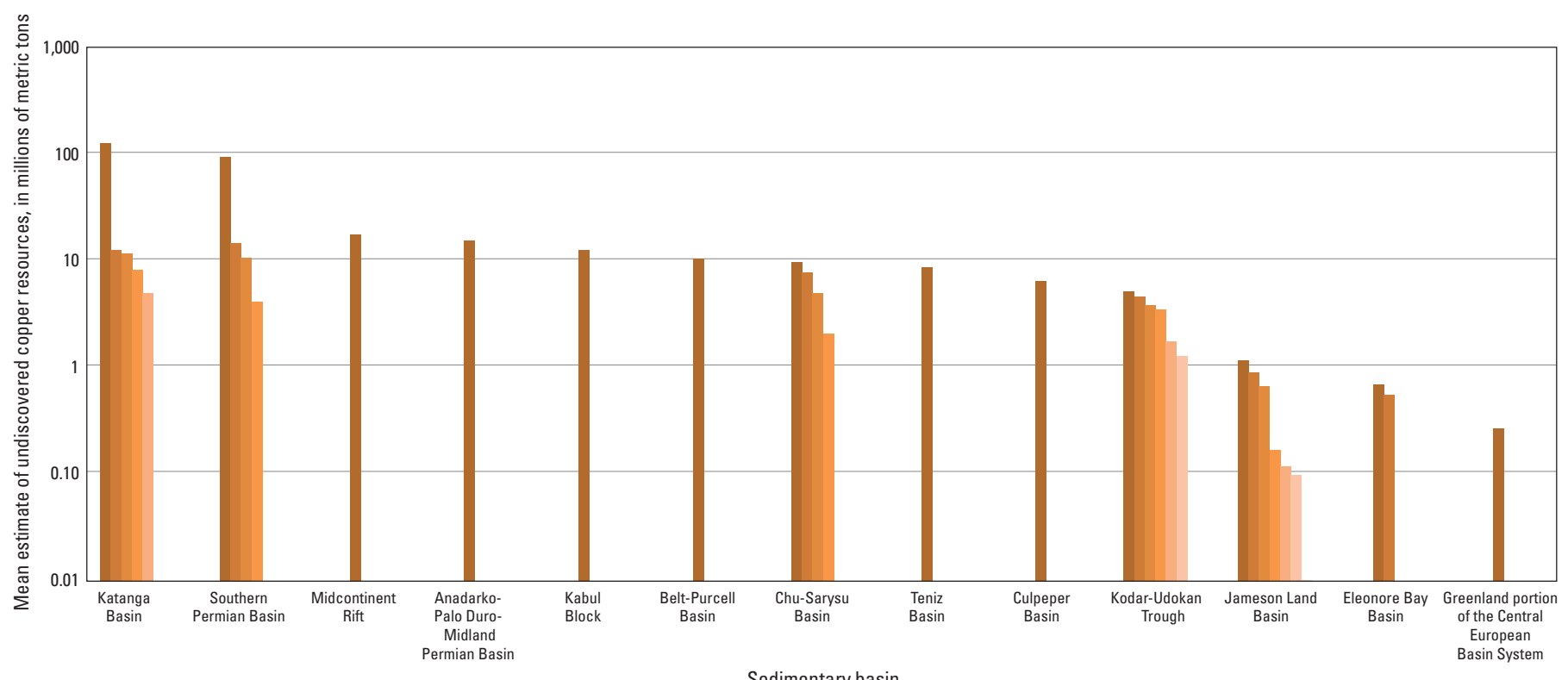

B

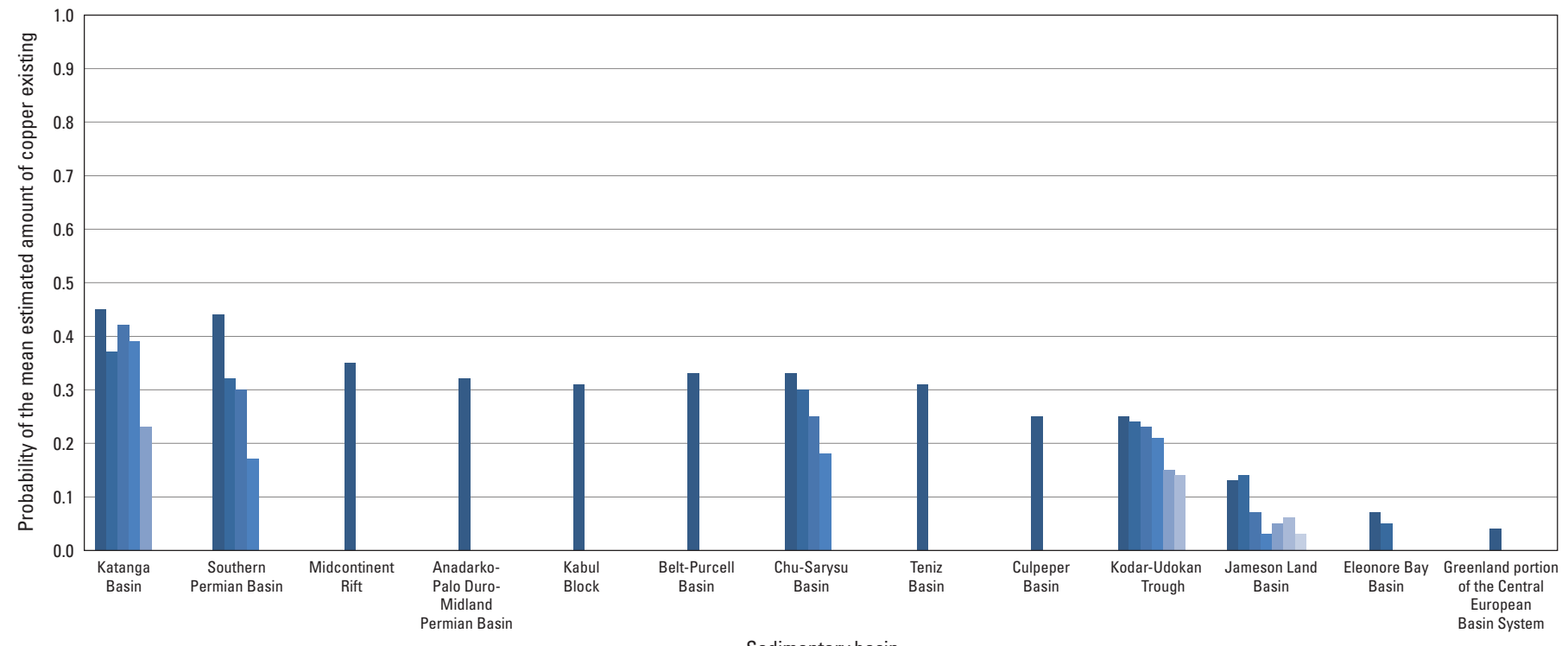

Figure C9. Graphs showing for each permissive tract $(A)$ mean estimates of undiscovered copper resources plotted on a logarithmic scale, $(B)$ probabilities of the mean estimated amount of copper existing, and $(C)$ probabilities of zero undiscovered copper resources existing. Tracts are grouped by sedimentary basin and are shown in the same order in parts $A, B$, and $C$. Each bar represents data for an individual tract within a basin, arranged in order of decreasing mean copper within the basin. The basins are ordered from left to right in terms of decreasing maximum mean estimates of undiscovered copper in tracts within each basin (tables C3 and C4). 


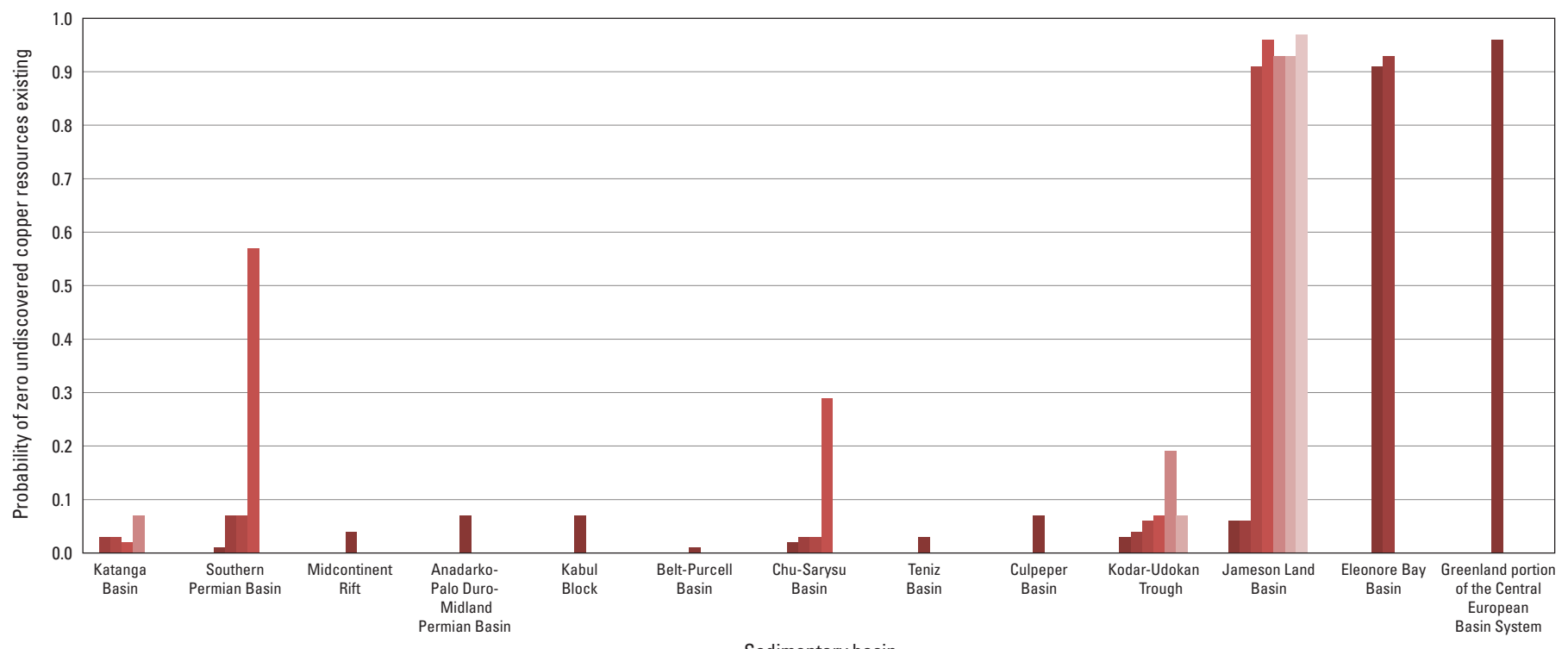

Figure C9. Continued.

There is a tendency to focus on the mean values of the simulation results when discussing assessment outcomes. This metric is easy for most people to understand and it is mathematically correct to add mean values when aggregating assessment results. However, when discussing mean values from assessment studies, it is equally important to consider the probability of the mean. Mean values for undiscovered copper resources and their corresponding probabilities are shown in figure C9. These graphs show the variability of assessment results within a basin and from basin to basin. The tracts are ordered by basin from left to right in terms of decreasing maximum mean estimates of undiscovered copper in the basin. Some basins (Midcontinent Rift, United States, pl. 192) are represented by a single tract. Other basins are represented by multiple tracts (Kodar-Udokan Trough, Russia, pls. 207-212). Mean values for individual tracts within a basin are shown by bars in different shades of orange in figure $\mathrm{C} 9 A$. The graph in figure $\mathrm{C} 9 A$ has a logarithmic scale and shows that the mean estimates of undiscovered copper for two tracts-130 Mt for Katanga Basin tract 002rfceCu1000b (pl. 231) and $96 \mathrm{Mt}$ for Southern Permian Basin tract 150rfnbCu0004 (pl. 223) - are about an order of magnitude higher than estimates for all other tracts. However, the graph of the probability associated with the mean shows that the chance that the amount of undiscovered copper is equal to the mean is less than 50 percent for all tracts (fig. C9B) and that chance decreases to 10 percent (probability $=0.1$ ) or less for the tracts with the lowest estimates of undiscovered copper (fig. C9B).

The probability of zero copper resources is another important metric to consider (fig. $\mathrm{C} 9 \mathrm{C}$ ); for most tracts, there is less than a 10-percent chance that no undiscovered copper may be present. However, the chance of no undiscovered copper does vary and is over 90 percent for some tracts in the Jameson Land Basin and Eleonore Bay Basin in Greenland and the Greenland portion of the Central European Basin System. 


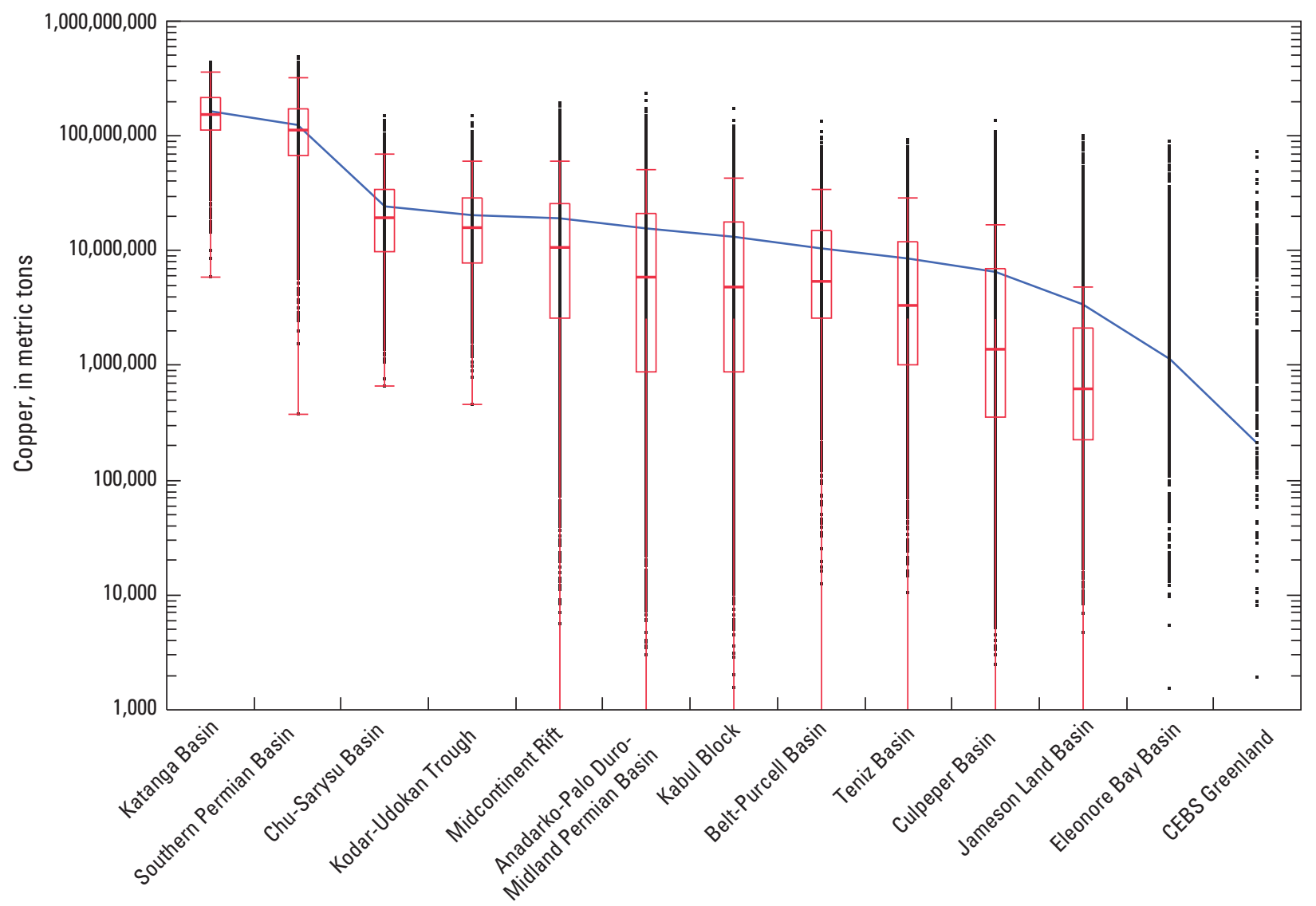

Sedimentary basin

Figure C10. Boxplots showing results of Monte Carlo simulations for sediment-hosted stratabound copper deposits aggregated by sedimentary basin and plotted on a logarithmic scale. Each boxplot shows the median value (red horizontal line) and the interquartile range between the 25th percentile (bottom of box) and the 75th percentile (top of box). The median of the probability distribution is the 50th percentile; that is, the value between the 50 percent of the data that are higher than the median and the 50 percent that are lower. The whiskers extend to the 10th and 90th percentiles. The blue line connects the mean values (table $\mathrm{C} 2$ ). The basins are ordered by decreasing mean estimates of undiscovered copper in each basin from left to right. CEBS Greenland, Greenland portion of the Central European Basin System.

By assuming complete independence between tracts, simulation results were aggregated for basins (table C2). Figure $\mathrm{C} 10$ graphs the actual simulation results aggregated for each basin as points and illustrates population percentiles with boxplots. Mean values are connected by a line between study areas; the copper axis is shown using a logarithmic scale in figure $\mathrm{C} 10$. Basins are ordered by decreasing mean estimates of undiscovered copper in each basin from left to right.

Figure $\mathrm{C} 10$ shows several interesting relations. The basins with tracts 002 rfceCu1000b and $150 \mathrm{rfnbCu0004-}$ Katanga Basin (fig. C4) and Southern Permian Basin (fig. C6) - have mean and median estimates of undiscovered copper that are about an order of magnitude higher than other basins. Mean values are higher than median values for all the basins; however, the disparity between the values increases as the mean copper value decreases (that is, the distance between the median red bar and the blue line in figure $\mathrm{C} 10$ increases from left to right across the graph). The assessment results indicate that at the most confident percentile (lowest red bar in figure $\mathrm{C} 10$ ), four basins will have undiscovered sedimenthosted stratabound copper resources (Katanga, Southern Permian, Chu-Sarysu, and Kodar-Udokan). If someone were risk adverse, these would be the places to explore for undiscovered copper resources of this deposit type. The most confident percentile indicates a resource of less than 1,000 $t$ of copper for seven basins. The chances for little or no copper for the Eleonore Bay Basin in Greenland and the Greenland portion of the Central European Basin System are quite high. 


\section{Qualitative Assessment Results}

The AHP analysis identifies the Northwest Botswana Rift, the Benguela and Cuanza Basins, and the Cambrian rocks of Egypt-Israel-Jordan Rift as having the highest potential for undiscovered copper in sediment-hosted stratabound copper deposits relative to the seven other basins that were evaluated by using this approach (fig. C8). These study areas are candidates for more in-depth analysis, research, and evaluation.

\section{Lessons Learned and Future Research Opportunities}

The AHP tool may be an effective screening tool to decide which areas to quantitatively assess. Assessment projects usually have limited time and resources, and this technique could be used to select those areas with the greatest potential for undiscovered resource endowment.

Mineral systems models will become useful elements of future mineral resource assessments. Use of the models helped clarify logic and reasoning in the tract delineation and resource estimation process. At the same time, the exercise showed areas where further research is required to understand the ore-forming process and demonstrated the type of information that would be required to conduct an assessment using the models. For the most part, the areas we assessed had insufficient information to fully benefit from a mineral systems assessment approach. However, with sufficient information, assessment results were robust, reproducible, and consistent.

The lack of sufficient information in part stems from competing genetic concepts about the origin of sedimenthosted stratabound copper deposits that have been discussed in scientific literature: (1) syngenesis, in which the mineralization developed simultaneously with the deposition of the sediments, and (2) diagenesis, in which the mineralization formed later than the deposition of the sediments, from processes occurring at low temperatures and pressures during compaction and lithification. The diagenetic model of ore formation is now widely accepted. Field and laboratory evidence indicates that sediment-hosted stratabound copper deposits formed from late diagenetic fluids generated during the compaction and lithification of sedimentary basins containing successions of red beds and evaporites. A quote attributed to Albert Einstein says: "Whether you can observe a thing or not depends on the theory which you use. ... It is the theory which decides what can be observed" (Salam, 1990, p. 99). We found that hypotheses of ore formation affected what information scientists chose to observe and report for sediment-hosted stratabound copper deposits; their selective observations ultimately limited the ability to conduct mineral assessments in some areas.

Prior to this study, there was no consensus on how to identify permissive rock units for sediment-hosted stratabound copper deposits. From the deposit and mineral system models, an association of red bed and evaporite sequences with a hydrocarbon-bearing ore trap would seem to define the assessment unit for sediment-hosted stratabound copper deposits. However, this definition excludes rocks that host some important deposits (those that are in basins with no known evaporites) and would identify large volumes of rock as permissive that appear to be barren. The ignorance of conditions under which an oxidized brine is developed and preserved in a sedimentary basin is a key obstacle to understanding how and where sediment-hosted stratabound deposits form.

The concentration of most of the identified resources of sediment-hosted stratabound copper into two sedimentary basins (the Neoproterozoic Katanga and the Southern Permian) invites additional research on the role of secular variation in the formation of this deposit type. In particular, the links to the eruption of mafic lavas related to large igneous provinces and to global glaciation events (with associated changes in seawater chemistry and the possibility of catastrophic flooding of continental basins) are two areas for investigation.

\section{References Cited}

Chapter $\mathrm{C}$ describes the undiscovered sediment-hosted stratabound copper resources for which data are provided in plates 189-236. This list of references cited includes sources cited in chapter $\mathrm{C}$ and in plates 189-236.

Ball, S.H., 1922, Copper smelting by central African natives: Engineering and Mining Journal, v. 113, no. 16, p. 680.

Bekker, A., Holland, H.D., Wang, P.L., Rumble, D., III, Stein, H.J., Hannah, J.L., Coetzee, L.L., and Beukes, N.J., 2004, Dating the rise of atmospheric oxygen: Nature, v. 427, p. $117-120$.

Bisson, M.S., 2000, Precolonial copper metallurgy-Sociopolitical context, chap. 2 of Vogel, J.O., ed., Ancient African metallurgy-The sociocultural context: Walnut Creek, Calif., AltaMira Press, p. 83-146.

Box, S.E., Bookstrom, A.A., Zientek, M.L., Derkey, P.D., Ashley, R.P., Elliott, J.E., and Peters, S.G., eds., 1996, Assessment of undiscovered mineral resources in the Pacific Northwest-A contribution to the Interior Columbia Basin Ecosystem Management Project: U.S. Geological Survey Open-File Report 95-682, variously paged text and appendixes plus data files. [Also available at http://pubs.usgs.gov/ of/1995/of95-682/.]

Box, S.E., Syusyura, Boris, Hayes, T.S., Taylor, C.D., Zientek, M.L., Hitzman, M.W., Seltmann, Reimar, Chechetkin, Vladimir, Dolgopolova, Alla, Cossette, P.M., and Wallis, J.C., 2012, Sandstone copper assessment of the Chu-Sarysu Basin, central Kazakhstan (ver. 1.1, November 2012): U.S. Geological Survey Scientific Investigations Report 2010-5090-E, 63 p. and spatial data tables, accessed June 1, 2015, at http://pubs.usgs.gov/sir/2010/5090/e/. 
Broughton, D., and Rogers, T., 2010a, Discovery of the Kamoa $\mathrm{Cu}$ deposit, Central African Copperbelt, Democratic Republic of the Congo: Littleton, Colo., Society of Economic Geologists, PowerPoint and PDF slide presentations, SEG 2010 Conference at Keystone, Colo., Oct. 2-5, 2010, 19Broughton.pdf, CD-ROM.

Broughton, D.W., and Rogers, T., 2010b, Discovery of the Kamoa $\mathrm{Cu}$ deposit, Central African Copperbelt, D.R.C., in Goldfarb, R.J., Marsh, E.E., and Monecke, Thomas, eds., The challenge of finding new mineral resources - Global metallogeny, innovative exploration, and new discoveries, Volume I-Gold, silver, and copper-molybdenum: Society of Economic Geologists Special Publication no. 15, p. 287-297.

Canfield, D.E., 2005, The early history of atmospheric oxygen-Homage to Robert M. Garrels: Annual Review of Earth and Planetary Sciences, v. 33, p. 1-36.

Chandler, F.W., 1988, Diagenesis of sabkha-related, sulphate nodules in the Early Proterozoic Gordon Lake Formation, Ontario, Canada: Carbonates and Evaporites v. 3, no. 1, p. 75-94.

Cossette, P.M., Bookstrom, A.A., Hayes, T.S., Robinson, G.R., Jr., Wallis, J.C., and Zientek, M.L., 2014, Sandstone copper assessment of the Teniz Basin, Kazakhstan: U.S. Geological Survey Scientific Investigations Report 2010-5090-R, 42 p. and spatial data, accessed June 1, 2015, at http://dx.doi.org/ 10.3133/sir20105090R.

Coulter, E.D., Coakley, James, and Sessions, John, 2006, The analytic hierarchy process - A tutorial for use in prioritizing forest road investments to minimize environmental effects: International Journal of Forest Engineering, v. 17, no. 2, p. 51-69. [Also available at https://journals.lib.unb.ca/ index.php/IJFE/article/view/5696.]

Cox, D.P., Lindsey, D.A., Singer, D.A., Moring, B.C., and Diggles, M.F., 2007, Sediment-hosted copper deposits of the world-Deposit models and database (ver. 1.3, 2007): U.S. Geological Survey Open-File Report 03-107, variously paged text plus plot and data files, accessed July 15, 2010, at http://pubs.usgs.gov/of/2003/of03-107/.

Davidson, C.F., 1965, A possible mode of origin of stratabound copper ores: Economic Geology, v. 60, no. 5, p. $942-954$.

Dicken, C.L., Dunlap, Pamela, Parks, H.L., Hammarstrom, J.M., and Zientek, M.L., 2016, Spatial database for a global assessment of undiscovered copper resources: U.S. Geological Survey Scientific Investigations Report 2010 5090-Z, 29 p. and GIS data, accessed July 21, 2016, at http://dx.doi.org/10.3133/sir20105090Z.
Duval, J.S., 2012, Version 3.0 of EMINERS-Economic Mineral Resource Simulator: U.S. Geological Survey Open-File Report 2004-1344, accessed July 15, 2012, at http://pubs.usgs.gov/of/2004/1344/.

Earth Resources Observation and Science (EROS) Center, 2011, HYDRO1k elevation derivative database: U.S. Geological Survey web page, accessed May 29, 2013, at http://eros.usgs.gov/\#Find_Data/Products_and_Data_ Available/gtopo30/hydro.

ESRI, 2008, Global shaded relief derived from the Shuttle Radar Topography Mission (SRTM): Redlands, Calif., ESRI Data \& Maps, release 9.3- Global imagery and Shaded Relief, DVD.

Fugro Robertson, Ltd., 2008, Fugro Tellus sedimentary basins of the world map: AAPG Datapages, accessed November 6, 2009, at http://www.datapages.com/AssociatedWebsites/ GISOpenFiles/FugroTellusSedimentaryBasinsoftheWorldMap.aspx.

Hayes, T.S., Cox, D.P., Piatak, N.M., and Seal, R.R., II, 2015, Sediment-hosted stratabound copper deposit model: U.S. Geological Survey Scientific Investigations Report 2010-5070-M, 147 p., accessed July 7, 2015, at http://dx.doi.org/10.3133/sir20105070M.

Hayes, T.S., Landis, G.P., Whelan, J.F., Rye, R.O., and Moscati, R.J., 2012, The Spar Lake strata-bound $\mathrm{Cu}-\mathrm{Ag}$ deposit formed across a mixing zone between trapped natural gas and metals-bearing brine: Economic Geology, v. 107 , no. 6 , p. $1223-1249$.

Herbert, E.W., 1984, Red gold of Africa-Copper in precolonial history and culture: Madison, Wis., University of Wisconsin Press, 413 p.

Hitzman, M.W., Selley, David, and Bull, Stuart, 2010, Formation of sedimentary rock-hosted stratiform copper deposits through Earth history: Economic Geology, v. 105, no. 3, p. $627-640$.

Hitzman, Murray, Kirkham, Rodney, Broughton, David, Thorson, Jon, and Selley, David, 2005, The sedimenthosted stratiform copper ore system, in Hedenquist, J.W., Thompson, J.F.H., Goldfarb, R.J., and Richards, J.P., eds., Economic Geology - One hundredth anniversary volume, 1905-2005: Littleton, Colo., Society of Economic Geologists, Inc., p. 609-642. 
Hodges, C.A.; Cox, D.P.; Singer, D.A.; Case, J.E.; Berger, B.R.; Albers, J.P.; Zambrano-Ortiz, Francisco; Etayo-Serna, Fernando; Barrero Lozano, Dario; Lozano Quiroga, Hernando; Espinosa Baquero, Armando; Gonzalez Iregui, Humberto; Orrego Lopez, Abigail; Arias Tauta, Alfonso; Cedeno Ochoa, Carlos; Pulido Ulloa, Oscar; Murillo Rodriquez, Alvaro; Jose Diaz, Manuel; Duque-Caro, Hermann; Vargas Higuera, Rodrigo; Nunez Tello, Alberto; Alvarez Agudelo, Jairo; Ropain Ulloa, Clemente; Buenaventura Arango, Joaquin; Mendoza Forero, Hernando; Rodriquez Sierra, Gloria; and Jaramillo Cortes, Luis, 1984, U.S. Geological SurveyINGEOMINAS mineral resource assessment of Colombia: U.S. Geological Survey Open-File Report 84-345, 337 p., 2 sheets, scale 1:1,000,000, accessed June 1, 2015, at http://pubs.usgs.gov/of/1984/0345/.

Howat, I.M., Negrete, A., and Smith, B.E., 2014, The Greenland Ice Mapping Project (GIMP) land classification and surface elevation data sets: Cryosphere, v. 8, p. 1509-1518, accessed September 15, 2015, at http://www.the-cryosphere. net/8/1509/2014/tc-8-1509-2014.html.

Jackson, Martin, 2005, Global distribution of salt tectonics in space and time: PowerPoint presentation, accessed December 6, 2013, at http://www.docstoc.com/docs/ 93376856/16-Global_Salt.

Kirkham, R.V., 1989, Distribution, settings, and genesis of sediment-hosted stratiform copper deposits, in Boyle, R.W., Brown, A.C., Jefferson, C.W., Jowett, E.C., and Kirkham, R.V., eds., Sediment-hosted stratiform copper deposits: Geological Association of Canada Special Paper 36, p. 3-38.

Kirkham, Rodney, and Broughton, David, 2005, Supplementary appendix for "The sediment-hosted stratiform copper ore system" by Murray Hitzman and others, in Hedenquist, J.W., Thompson, J.F.H., Goldfarb, R.J., and Richards, J.P., eds., Economic Geology — One hundredth anniversary volume, 1905-2005: Littleton, Colo., Society of Economic Geologists, Inc., file named "Hitzman" on CD-ROM in pocket.

Kirkham, R.V., Carrière, J.J., Laramée, R.M., and Garson, D.F., comps., 1994, Global distribution of sediment-hosted stratiform copper deposits and occurrences: Geological Survey of Canada Open File 2915b, 256 p., 1 oversize map, scale 1:36,000,000. [Map is also available at $\mathrm{ftp} / / / \mathrm{ftp} . g e o g r a t i s . g c . c a / p u b /$ nrcan_rncan/publications/ ess_sst/207/207806/gscof_2915b_e_1994_mn01.pdf.]

Knox-Robinson, C.M., and Wyborn, L.A.I., 1997, Towards a holistic exploration strategy-Using geographic information systems as a tool to enhanced exploration: Australian Journal of Earth Sciences, v. 44, no. 4, p. 453-463.
Ludington, Steve, Orris, G.J., Bolm, K.S., Peters, S.G., and the U.S. Geological Survey-Afghanistan Ministry of Mines and Industry Joint Mineral Resource Assessment Team, 2007, Preliminary mineral resource assessment of selected mineral deposit types in Afghanistan: U.S. Geological Survey OpenFile Report 2007-1005, 44 p., accessed June 1, 2015, at http://pubs.usgs.gov/of/2007/1005/.

Magoon, L.B., and Dow, W.G., 1994, The petroleum system, in Magoon, L.B., and Dow, W.G., eds., The petroleum system-From source to trap: American Association of Petroleum Geologists Memoir 60, p. 3-24.

Magoon, L.B., and Schmoker, J.W., 2000, The total petroleum system-The natural fluid network that constrains the assessment unit, chap. PS of U.S. Geological Survey World Energy Assessment Team, U.S. Geological Survey world petroleum assessment 2000-Description and results: U.S. Geological Survey Digital Data Series DDS-60, p. PS-1 to PS-20 plus 3 figures and 1 table, on a CD-ROM. [Also available at http://pubs.usgs.gov/dds/dds-060/.]

Malczewski, Jacek, 1999, GIS and multicriteria decision analysis: New York, John Wiley \& Sons, Inc., 408 p.

Meyer, M.A., and Booker, J.M., 2001, Eliciting and analyzing expert judgment-A practical guide: Philadelphia, Pa., Society for Industrial and Applied Mathematics and American Statistical Association, 459 p. [This SIAM edition is an unabridged republication of the work first published by Academic Press Limited, London, 1991.]

Peters, S.G., Ludington, S.D., Orris, G.J., Sutphin, D.M., Bliss, J.D., and Rytuba, J.J., eds., and the U.S. Geological Survey-Afghanistan Ministry of Mines Joint Mineral Resource Assessment Team, 2007, Preliminary non-fuel mineral resource assessment of Afghanistan: U.S. Geological Survey Open-File Report 2007-1214, $810 \mathrm{p}$. and data files, accessed August 15, 2014, at http://pubs.usgs.gov/of/2007/1214/.

Root, D.H., Menzie, W.D., and Scott, W.A., 1992, Computer Monte Carlo simulation in quantitative resource estimation: Nonrenewable Resources, v. 1, no. 2, p. 125-138.

Rose, A.W., 1976, The effect of cuprous chloride complexes in the origin of red-bed copper and related deposits: Economic Geology, v. 71, no. 6, p. 1036-1048.

Saaty, T.L., 1980, The analytic hierarchy process-Planning, priority setting, resource allocation: New York, McGrawHill, $287 \mathrm{p}$.

Saaty, T.L., 1990, How to make a decision-The analytic hierarchy process: European Journal of Operational Research, v. 48 , no. 1 , p. $9-26$. 
Saaty, T.L., and Vargas, L.G., 2001, Models, methods, concepts and applications of the analytic hierarchy process: Norwell, Mass., Kluwer Academic Publishers, 333 p.

Salam, Abdus, 1990, Unification of fundamental forces: New York, Cambridge University Press, 153 p., accessed December 9, 2016, at https:/www.scribd.com/ document/329034606/SALAM-unification-of-fundamentalforces-pdf.

Singer, D.A., 1993, Basic concepts in three-part quantitative assessments of undiscovered mineral resources: Nonrenewable Resources, v. 2, no. 2, p. 69-81.

Singer, D.A., 1995, World class base and precious metal deposits - A quantitative analysis: Economic Geology, v. 90, no. 1, p. 88-104. [Also available at http:dx.doi.org/ 10.2113/gsecongeo.90.1.88.]

Singer, D.A., and Menzie, W.D., 2010, Quantitative mineral resource assessments - An integrated approach: New York, Oxford University Press, 219 p.

Spanski, G.T., 1992, Quantitative assessment of future development of copper/silver resources in the Kootenai National Forest, Idaho/Montana. Part I-Estimation of the copper and silver endowments: Nonrenewable Resources, v. 1, no. 2, p. 163-183.

Spanski, G.T., and McKelvey, G.E., 1990, An assessment of metal endowments in Revett-type sediment hosted $\mathrm{Cu}$ deposits in the Kootenai National Forest, Montana and Idaho: U.S. Geological Survey Open-File Report 90-470, 44 p. [Also available at http://pubs.usgs.gov/of/1990/0470/ report.pdf.]

Stensgaard, B.M., 2011, Sediment-hosted copper in Greenland-Assessment of potential and undiscovered $\mathrm{Cu}$ deposits: Geology and Ore, no. 18 (January 2011), 12 p., accessed October 18, 2011, at http://www.geus.dk/minex/go18.pdf.

Stensgaard, B.M., Kalvig, Per, and Stendal, Henrik, 2011, Quantitative mineral resource assessment-Sedimentaryhosted copper in Greenland-Reporting the copper assessment workshop, GEUS, Copenhagen, March 2009: Geological Survey of Denmark and Greenland (GEUS) Report 2011/104, 104 p., 1 CD-ROM.

Syusyura, Boris, Box, S.E., and Wallis, J.C., 2010, Spatial databases of geological, geophysical, and mineral resource data relevant to sandstone-hosted copper deposits in central Kazakhstan: U.S. Geological Survey Open-File Report 2010-1124, 4 p., 4 appendixes, and databases, accessed October 10, 2011, at http://pubs.usgs.gov/of/2010/1124/.
Taylor, D., 2000, 'Soft-rock' petroleum-type approach to exploration for 'hard-rock' minerals in sedimentary basins, in Glikson, M., and Mastalerz, M., eds., Organic matter and mineralisation - Thermal alteration, hydrocarbon generation, and role in metallogenesis: Dordrecht, The Netherlands, Kluwer Academic Publishers, p. 1-12.

U.S. Department of State, 2009, Small-scale digital international land boundaries (SSIB)—Lines, edition 10, and polygons, beta edition 1, in Boundaries and sovereignty encyclopedia (B.A.S.E.): U.S. Department of State, Office of the Geographer and Global Issues.

U.S. Geological Survey Minerals Team, 1996, Data base for a national mineral-resource assessment of undiscovered deposits of gold, silver, copper, lead, and zinc in the conterminous United States (edited by Steve Ludington and Dennis Cox): U.S. Geological Survey Open-File Report 96-96, 1 CD-ROM. [Also available at http://pubs.usgs.gov/ of/1996/of96-096/. Recompiled in USGS Open-File Report 02-198.]

U.S. Geological Survey National Mineral Resource Assessment Team, 2000, 1998 assessment of undiscovered deposits of gold, silver, copper, lead, and zinc in the United States: U.S. Geological Survey Circular 1178, 21 p., 1 CDROM in pocket. [Also available at http://pubs.usgs.gov/circ/ c1178/. Recompiled in USGS Open-File Report 02-198.]

U.S. Geological Survey National Mineral Resource Assessment Team, 2002, Assessment of undiscovered deposits of gold, silver, copper, lead, and zinc in the United States; A Portable Document Format (PDF) recompilation of USGS Open-File Report 96-96 and Circular 1178: U.S. Geological Survey Open-File Report 02-198, 1 CD-ROM. [Recompilation by Paul Schruben. Also available at http://pubs.usgs. gov/of/2002/of02-198/.]

U.S. Geological Survey World Energy Assessment Team, 2000, U.S. Geological Survey world petroleum assessment 2000-Description and results: U.S. Geological Survey Digital Data Series DDS-60, accessed December 6, 2013, at http://pubs.usgs.gov/dds/dds-060/.

Wyborn, L.A.I., Heinrich, C.A., and Jaques, A.L., 1994, Australian Proterozoic mineral systems-Essential ingredients and mappable criteria, in Hallenstein, C.P., ed., Australian mining looks north — The challenges and choices - 1994 AusIMM Annual Conference, Darwin, 5-9 August 1994, technical program proceedings: Australasian Institute of Mining and Metallurgy Publication 5/94, p. 109-115, accessed May 24, 2012, at http://www.ga.gov.au/image_ cache/GA5228.pdf. 
Zientek, M.L., Bliss, J.D., Broughton, D.W., Christie, Michael, Denning, P.D., Hayes, T.S., Hitzman, M.W., Horton, J.D., Frost-Killian, Susan, Jack, D.J., Master, Sharad, Parks, H.L., Taylor, C.D., Wilson, A.B., Wintzer, N.E., and Woodhead, Jon, 2014, Sediment-hosted stratabound copper assessment of the Neoproterozoic Roan Group, Central African Copperbelt, Katanga Basin, Democratic Republic of the Congo and Zambia: U.S. Geological Survey Scientific Investigations Report 2010-5090-T, 162 p. and spatial data, accessed June 1, 2015, at http://dx.doi.org/10.3133/ sir20105090T.

Zientek, M.L., Chechetkin, V.S., Parks, H.L., Box, S.E., Briggs, D.A., Cossette, P.M., Dolgopolova, Alla, Hayes, T.S., Seltmann, Reimar, Syusyura, Boris, Taylor, C.D., and Wintzer, N.E., 2014, Assessment of undiscovered sandstone copper deposits of the Kodar-Udokan area, Russia: U.S. Geological Survey Scientific Investigations Report 2010-5090-M, 129 p. and GIS data, accessed June 1, 2015, at http://dx.doi.org/10.3133/sir20105090M.

Zientek, M.L., Hayes, T.S., and Hammarstrom, J.M., 2013, Overview of a new descriptive model for sediment-hosted stratabound copper deposits, chap. 1 of Taylor, C.D., Causey, J.D., Denning, P.D., Hammarstrom, J.M., Hayes, T.S., Horton, J.D., Kirschbaum, M.J., Parks, H.L., Wilson, A.B., Wintzer, N.E., and Zientek, M.L., Descriptive models, grade-tonnage relations, and databases for the assessment of sediment-hosted copper deposits - With emphasis on deposits in the Central African Copperbelt, Democratic Republic of the Congo and Zambia: U.S. Geological Survey Scientific Investigations Report 2010-5090-J, p. 2-16, accessed July 7, 2014, at http://pubs.usgs.gov/sir/2010/5090/j/.
Zientek, M.L., Hayes, T.S., and Taylor, C.D., 2013, Grade and tonnage relations for sediment-hosted stratabound copper deposits, chap. 2 of Taylor, C.D., Causey, J.D., Denning, P.D., Hammarstrom, J.M., Hayes, T.S., Horton, J.D., Kirschbaum, M.J., Parks, H.L., Wilson, A.B., Wintzer, N.E., and Zientek, M.L., Descriptive models, grade-tonnage relations, and databases for the assessment of sediment-hosted copper deposits - With emphasis on deposits in the Central African Copperbelt, Democratic Republic of the Congo and Zambia: U.S. Geological Survey Scientific Investigations Report 2010-5090-J, p. 17-59, accessed July 7, 2014, at http://pubs.usgs.gov/sir/2010/5090/j/.

Zientek, M.L., Oszczepalski, Sławomir, Parks, H.L., Bliss, J.D., Borg, Gregor, Box, S.E., Denning, P.D., Hayes, T.S., Spieth, Volker, and Taylor, C.D., 2015, Assessment of undiscovered copper resources associated with the Permian Kupferschiefer, Southern Permian Basin, Europe: U.S. Geological Survey Scientific Investigations Report 20105090-U, 94 p. and spatial data, http://dx.doi.org/10.3133/ sir20105090U.

Zientek, M.L., Wintzer, N.E., Hayes, T.S., Parks, H.L., Briggs, D.A., Causey, J.D., Hatch, S.A., Jenkins, M.C., and Williams, D.J., 2015, Qualitative assessment of selected areas of the world for undiscovered sediment-hosted stratabound copper deposits: U.S. Geological Survey Scientific Investigations Report 2010-5090-Y, 143 p. and spatial data, accessed December 30, 2015, at http://dx.doi.org/10.3133/ sir20105090Y. 

Tables C3, C4 
Table C3. Summary of assessment results for identified copper resources and mean estimates of undiscovered in-place copper resources in sediment-hosted stratabound copper deposits in the Western Hemisphere by permissive tract.

[Resources are reported to two significant figures. Coded_ID, a unique identifier for each tract, where $\mathrm{rfCu}=$ reduced-facies copper subtype, rfnbCu $=$ reducedfacies-nonbrecciated copper subtype, $\mathrm{shCu}=$ general sediment-hosted copper that includes all subtypes, and $\mathrm{ssCu}=$ sandstone copper subtype. $\mathrm{km}^{2}$, square kilometer; Mt, millions of metric tons; NA, not applicable, as a quantitative assessment was not done. For North American tract names, terms in parentheses are model numbers from source reports cited in the plates]

\begin{tabular}{|c|c|c|c|c|c|c|c|}
\hline $\begin{array}{c}\text { Plate } \\
\text { number }\end{array}$ & Basin name & Tract name & Coded_ID & $\begin{array}{l}\text { Tract } \\
\text { area } \\
\left(\mathrm{km}^{2}\right)\end{array}$ & $\begin{array}{l}\text { Number } \\
\text { of known } \\
\text { deposits }\end{array}$ & $\begin{array}{l}\text { Identified } \\
\text { copper } \\
\text { resources } \\
\text { (Mt) }\end{array}$ & $\begin{array}{c}\text { Mean } \\
\text { estimate of } \\
\text { undiscovered } \\
\text { in-place } \\
\text { copper } \\
\text { resources } \\
\text { (Mt) }\end{array}$ \\
\hline \multicolumn{8}{|c|}{ South America region } \\
\hline \multirow[t]{2}{*}{190} & Salta Rift System —Argentina & Salta Rift System & $005 \mathrm{rfCu} 5101$ & 27,345 & 2 & 0.21 & NA \\
\hline & \multicolumn{2}{|c|}{ South America region total } & & 153,520 & 11 & 0.39 & NA \\
\hline \multicolumn{8}{|c|}{ North America region } \\
\hline 192 & $\begin{array}{l}\text { Midcontinent Rift- } \\
\text { United States }\end{array}$ & Lake Superior (LS07) & $003 \mathrm{rfnbCu} 3003$ & 123,147 & 2 & 9.4 & 18 \\
\hline 193 & $\begin{array}{l}\text { Belt-Purcell Basin-United } \\
\text { States and Canada }\end{array}$ & Belt-Purcell Basin & $003 \mathrm{ssCu} 3100$ & 1,633 & 11 & 3.2 & 10 \\
\hline 194 & $\begin{array}{l}\text { Redstone Copperbelt- } \\
\text { Canada }\end{array}$ & Redstone Copperbelt & $003 \mathrm{rfCu} 3000$ & 8,923 & 3 & 1.4 & NA \\
\hline 195 & $\begin{array}{l}\text { Culpeper Basin- } \\
\text { United States }\end{array}$ & $\begin{array}{l}\text { Southern Appalachian } \\
\text { Mountains (SA18) }\end{array}$ & $003 \mathrm{rfnbCu} 3004$ & 11,566 & 0 & 0 & 6.6 \\
\hline
\end{tabular}


Table C3. Summary of assessment results for identified copper resources and mean estimates of undiscovered in-place copper resources in sediment-hosted stratabound copper deposits in the Western Hemisphere by permissive tract.-Continued

\begin{tabular}{|c|c|c|c|c|c|c|c|}
\hline $\begin{array}{l}\text { Plate } \\
\text { number }\end{array}$ & Basin name & Tract name & Coded_ID & $\begin{array}{l}\text { Tract } \\
\text { area } \\
\left(\mathbf{k m}^{2}\right)\end{array}$ & $\begin{array}{l}\text { Number } \\
\text { of known } \\
\text { deposits }\end{array}$ & $\begin{array}{l}\text { Identified } \\
\text { copper } \\
\text { resources } \\
\text { (Mt) }\end{array}$ & $\begin{array}{c}\text { Mean } \\
\text { estimate of } \\
\text { undiscovered } \\
\text { in-place } \\
\text { copper } \\
\text { resources } \\
\text { (Mt) }\end{array}$ \\
\hline 199 & $\begin{array}{l}\text { Jameson Land Basin- } \\
\text { Greenland }\end{array}$ & $\begin{array}{l}\text { Pingel Dal Beds } \\
\text { (CE 1A) }\end{array}$ & $003 \mathrm{rfnbCu} 0005$ & 2,507 & 0 & 0 & 0.68 \\
\hline 200 & $\begin{array}{l}\text { Jameson Land Basin- } \\
\text { Greenland }\end{array}$ & $\begin{array}{l}\text { Huledal Formation } \\
\text { (CE 15) }\end{array}$ & $003 \mathrm{ssCu} 0001$ & 154 & 0 & 0 & 0.012 \\
\hline 202 & $\begin{array}{l}\text { Jameson Land Basin- } \\
\text { Greenland }\end{array}$ & $\begin{array}{l}\text { Huledal Formation } \\
\text { (CE 2) }\end{array}$ & $003 \mathrm{ssCu} 0003$ & 395 & 0 & 0 & 0.12 \\
\hline 203 & $\begin{array}{l}\text { Jameson Land Basin- } \\
\text { Greenland }\end{array}$ & $\begin{array}{l}\text { Huledal Formation } \\
\text { (CE 8-12) }\end{array}$ & $003 \mathrm{ssCu} 0004$ & 445 & 0 & 0 & 1.2 \\
\hline 204 & $\begin{array}{l}\text { Jameson Land Basin- } \\
\text { Greenland }\end{array}$ & $\begin{array}{l}\text { Huledal Formation } \\
\quad(\mathrm{CE} 4-7)\end{array}$ & $003 \mathrm{ssCu} 0005$ & 821 & 0 & 0 & 0.099 \\
\hline 205 & $\begin{array}{l}\text { Eleonore Bay Basin- } \\
\text { Greenland }\end{array}$ & $\begin{array}{l}\text { Eleonore Bay Supergroup } \\
\quad(\mathrm{CE} 7-8)\end{array}$ & $003 \mathrm{rfnbCu} 0002$ & 998 & 0 & 0 & 0.70 \\
\hline
\end{tabular}


Table C4. Summary of assessment results for identified copper resources and mean estimates of undiscovered in-place copper resources in sediment-hosted stratabound copper deposits in the Eastern Hemisphere by permissive tract.

[Resources are reported to two significant figures. Coded_ID, a unique identifier for each tract, where rfceCu $=$ reduced-facies-carbonate-écaille copper subtype, $\mathrm{rfCu}=$ reduced-facies copper subtype, $\mathrm{rfnbu}=$ reduced-facies-nonbrecciated copper subtype, and $\mathrm{ssCu}=$ sandstone copper subtype. $\mathrm{km}^{2}$, square kilometer; Mt, millions of metric tons; NA, not applicable, as a quantitative assessment was not done. For Middle East tract names, terms in parentheses are model numbers from source reports cited in plates]

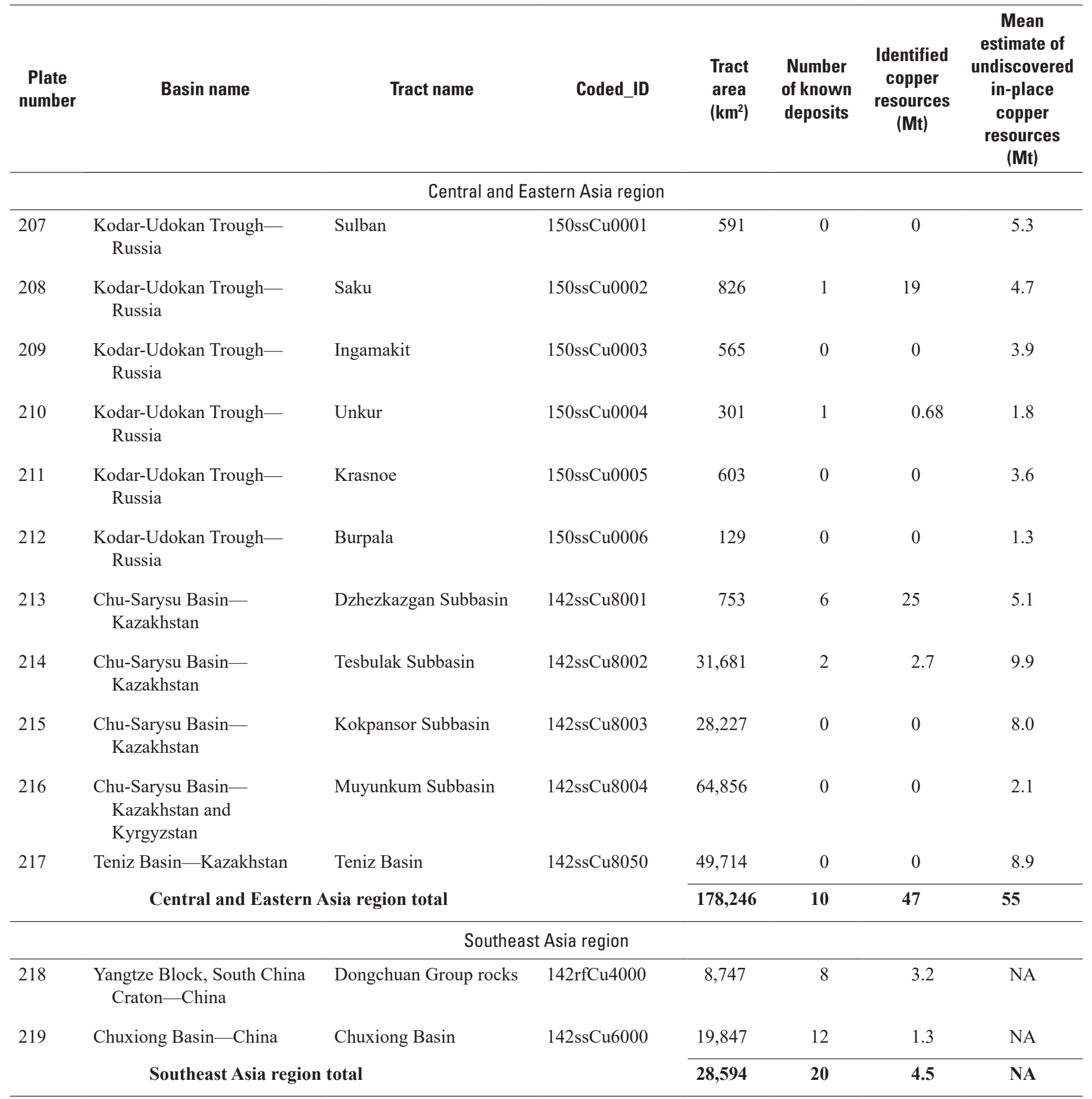


Table C4. Summary of assessment results for identified copper resources and mean estimates of undiscovered in-place copper resources in sediment-hosted stratabound copper deposits in the Eastern Hemisphere by permissive tract.-Continued

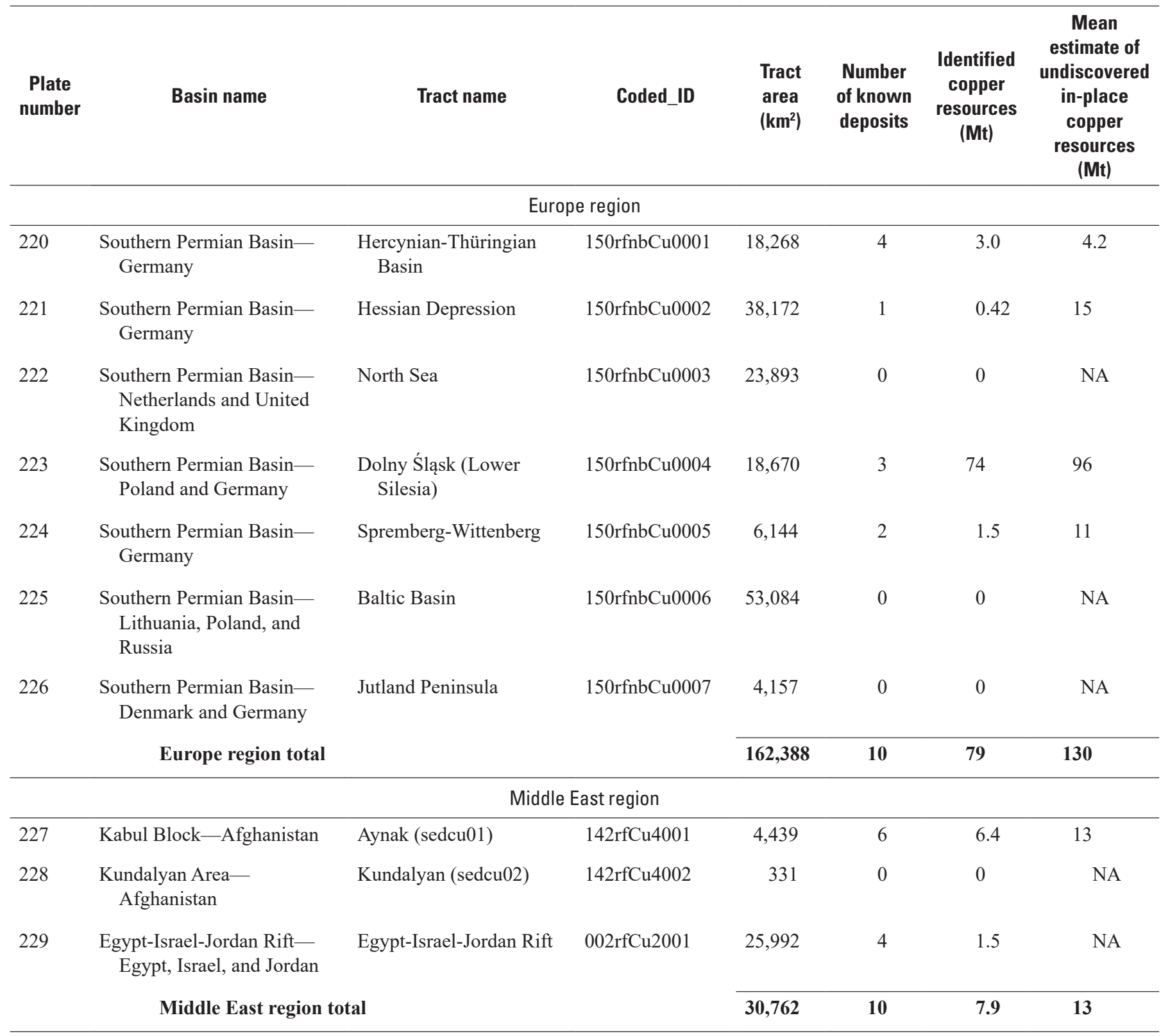


Table C4. Summary of assessment results for identified copper resources and mean estimates of undiscovered in-place copper resources in sediment-hosted stratabound copper deposits in the Eastern Hemisphere by permissive tract.-Continued

[Resources are reported to two significant figures. Coded_ID, a unique identifier for each tract, where rfceCu $=$ reduced-facies-carbonate-écaille copper subtype, $\mathrm{rfCu}=$ reduced-facies copper subtype, $\mathrm{rnbCu}=$ reduced-facies-nonbrecciated copper subtype, and $\mathrm{ssCu}=$ sandstone copper subtype. $\mathrm{km}^{2}$, square kilometer; Mt, millions of metric tons; NA, not applicable, as a quantitative assessment was not done. For Middle East tract names, terms in parentheses are model numbers from source reports cited in plates]

\begin{tabular}{|c|c|c|c|c|c|c|c|}
\hline $\begin{array}{l}\text { Plate } \\
\text { number }\end{array}$ & Basin name & Tract name & Coded_ID & $\begin{array}{l}\text { Tract } \\
\text { area } \\
\left(\mathbf{k m}^{2}\right)\end{array}$ & $\begin{array}{l}\text { Number } \\
\text { of known } \\
\text { deposits }\end{array}$ & $\begin{array}{l}\text { Identified } \\
\text { copper } \\
\text { resources } \\
\text { (Mt) }\end{array}$ & $\begin{array}{c}\text { Mean } \\
\text { estimate of } \\
\text { undiscovered } \\
\text { in-place } \\
\text { copper } \\
\text { resources } \\
\text { (Mt) }\end{array}$ \\
\hline \multicolumn{8}{|c|}{ Africa region } \\
\hline 230 & $\begin{array}{l}\text { Katanga Basin-Democratic } \\
\text { Republic of the Congo }\end{array}$ & $\begin{array}{l}\text { Southern Carbonate } \\
\text { Écaille }\end{array}$ & 002rfceCu1000a & 1,334 & 2 & 0.15 & 13 \\
\hline 231 & $\begin{array}{l}\text { Katanga Basin-Democratic } \\
\text { Republic of the Congo and } \\
\text { Zambia }\end{array}$ & $\begin{array}{l}\text { Central Carbonate } \\
\text { Écaille }\end{array}$ & $002 \mathrm{rfceCu} 1000 \mathrm{~b}$ & 3,538 & 52 & 61 & 130 \\
\hline 232 & $\begin{array}{l}\text { Katanga Basin-Democratic } \\
\text { Republic of the Congo }\end{array}$ & $\begin{array}{l}\text { Northern Carbonate } \\
\text { Écaille }\end{array}$ & $002 \mathrm{rfceCu} 1000 \mathrm{c}$ & 4,311 & 2 & 4.1 & 12 \\
\hline 233 & $\begin{array}{l}\text { Katanga Basin-Democratic } \\
\text { Republic of the Congo and } \\
\text { Zambia }\end{array}$ & Ore Shale & $002 \mathrm{rfnbCu} 1001$ & 890 & 9 & 71 & 5.1 \\
\hline 234 & $\begin{array}{l}\text { Katanga Basin-Democratic } \\
\text { Republic of the Congo and } \\
\text { Zambia }\end{array}$ & Roan Arenite & 002ssCu1002 & 13,060 & 20 & 16 & 8.4 \\
\hline 235 & $\begin{array}{l}\text { Northwest Botswana Rift- } \\
\text { Botswana and Namibia }\end{array}$ & Northwest Botswana Rift & $002 \mathrm{rfCu} 2002$ & 135,005 & 18 & 4.2 & NA \\
\hline \multirow[t]{3}{*}{236} & $\begin{array}{l}\text { Benguela and Cuanza } \\
\text { Basins-Angola }\end{array}$ & $\begin{array}{l}\text { Benguela and Cuanza } \\
\text { Basins }\end{array}$ & $002 \mathrm{rfCu} 2000$ & 7,626 & 2 & 0.15 & NA \\
\hline & Africa region total & & & 165,764 & 105 & 160 & 170 \\
\hline & Eastern Hemisphere & otal & & 565,754 & 155 & 290 & 360 \\
\hline
\end{tabular}


Glossary 


\section{Glossary}

The terminology used in the U.S. Geological Survey Global Mineral Resource Assessment is adapted from definitions established for mineral resource assessments conducted by the U.S. Geological Survey using the three-part form of mineral resource assessment (Singer, 1993), fundamental definitions for descriptive mineral deposit models and grade and tonnage mineral deposit models (Cox and Singer, 1986), and definitions for a mineral resource classification established by the U.S. Bureau of Mines and U.S. Geological Survey (1980). Other sources of definitions in this glossary are noted below.

craton A part of the Earth's crust that has attained stability and has been little deformed for a prolonged period. The term is now restricted to continental areas that have not been pervasively metamorphosed and deformed for at least about one billion years. Cratons include shield areas, where Precambrian rocks are exposed, and platform areas, where Precambrian rocks are overlain by a thin layer of Phanerozoic strata (Neuendorf and others, 2011).

descriptive mineral deposit model A set of data and information in a convenient form that describes a group of mineral deposits having similar characteristics (U.S. Geological Survey National Mineral Resource Assessment Team, 2000, 2002). The model identifies the geologic environments in which the deposit type is found and gives identifying characteristics of the type.

discovered resources The total amount of identified resources and cumulative past production (U.S. Geological Survey National Mineral Resource Assessment Team, 2000, 2002).

giant deposit A world-class mineral deposit having a contained metal content that ranks in the upper 10 percent of all known deposits. Accordingly, giant gold deposits contain at least 100 metric tons (t) of gold, giant silver deposits contain at least 2,400 $\mathrm{t}$ of silver, and giant copper, zinc, and lead deposits contain at least 2, 1.7, and 1 million metric tons (Mt) of their respective metals (Singer, 1995, p. 88, 103). See also supergiant deposit.

grade Average metal content measured as a percentage of weight of a given volume of mineralized rock. It is estimated by taking and analyzing samples of the deposit (Singer, 2007). grade and tonnage mineral deposit model Frequency distributions of premining tonnages and average grades of well-explored deposits of a given type that are used as models for grades and tonnages of undiscovered deposits of the same type in geologically similar settings. Models are constructed on the basis of average grades of each commodity of possible economic interest and the associated tonnage based on the total production, reserves, and resources at the lowest possible cutoff grade (Singer and Berger, 2007). Mineral deposits in grade and tonnage models should be completely characterized in terms of location, tonnage, and grade.

hypogene Said of a geologic process, and of its resultant features, occurring within and below the crust of the Earth. Said of a mineral deposit formed by ascending solutions; also, said of those solutions and of that environment (Neuendorf and others, 2011).

identified resources Resources whose location, grade, quality, and quantity are known or are estimated from specific geologic evidence (U.S. Bureau of Mines and U.S. Geological Survey, 1980, p. 1).

metal endowment The sum of metal in all occurrences with specified characteristics, such as concentration, size, and depth (Harris, 1984).

mineral deposit (a) A mineral occurrence of sufficient tonnage and grade that it might, under the most favorable of circumstances, be considered to have economic potential (Cox and Singer, 1986). (b) A mass of naturally occurring mineral materials, such as metal ores or nonmetallic minerals, usually of economic value, without regard to mode of origin (Neuendorf and others, 2011). 
(c) An "accumulation of associated mineralized bodies that constitute [the products of] a single mineralizing event, including subsequent processes (e.g., oxidation and supergene enrichment) affecting part or all of the accumulation" (Barton and others, 1995, p. 81).

mineral deposit type (a) Deposits sharing a relatively wide variety and large number of attributes (Cox and Singer, 1986). (b) A "class representing all the recognized mineral deposits that are defined by physical and genetic factors that can be consistently differentiated from those of other classes or deposit types" (Barton and others, 1995, p. 80).

mineral occurrence (a) A concentration of a mineral that is considered valuable by someone somewhere, or that is of scientific or technical interest (Cox and Singer, 1986). (b) Any ore or economic mineral in any concentration found in bedrock or as float; especially a valuable mineral in a concentration sufficient to suggest further exploration (Neuendorf and others, 2011).

mineral prospect (a) An area that is a potential site of mineral deposits, as indicated by preliminary exploration. (b) Sometimes, an area that has been explored in a preliminary way but has not given evidence of economic value. (c) An area to be searched by some investigative technique, for example, geophysical prospecting. (d) A geologic or geophysical anomaly, especially one recommended for additional exploration. A prospect is distinct from a mine in that it is nonproducing (Neuendorf and others, 2011). (e) A mineral property whose value has not been proved by exploration (Bureau of Land Management, 1999).

mineral resource (a) A concentration of naturally occurring mineral material in or on the Earth's crust in such form and amount that economic extraction of a commodity from the concentration is currently or potentially feasible (modified from U.S. Bureau of Mines and U.S. Geological Survey, 1980, p. 1, by adding the word "mineral"). (b) A concentration or occurrence of material of economic interest in or on the Earth's crust in such form, quality, and quantity that there are reasonable prospects for eventual economic extraction. The location, quantity, grade, continuity, and other geological characteristics of a mineral resource are known, estimated, or interpreted from specific geological evidence, sampling, and knowledge (Committee for Mineral Reserves International Reporting Standards, 2006). Please be aware that a growing consortium of the minerals industry now uses the second, more restricted definition of this term.

mineral resource assessment A study that evaluates the likelihood of occurrence of mineral deposits (resources) in terms of mineral resource potential. For qualitative assessment, the product is presented as labels or names. For quantitative assessment, the product is presented as numerical values (Singer and Menzie, 2010).

mineralization (a) Any single mineral or combination of minerals occurring in a mass, or deposit, of economic interest. The term is intended to cover all forms in which mineralization might occur, whether by class of deposit, mode of occurrence, genesis, or composition (Committee for Mineral Reserves International Reporting Standards, 2006). (b) The process or processes by which a mineral or minerals are introduced into a rock, resulting in a valuable or potentially valuable deposit (Neuendorf and others, 2011).

\section{number of undiscovered mineral deposits} estimate The probability, or degree of belief, that a fixed but unknown number of deposits like those in the grade and tonnage model exist in the delineated tracts (Singer, 2007).

ore The naturally occurring material from which a mineral or minerals of economic value can be extracted at a reasonable profit. Also, the mineral(s) thus extracted (Neuendorf and others, 2011).

ore deposit (a) A mineral deposit that has been tested and is known to be of sufficient size, grade, and accessibility to be producible and to yield a profit (Cox and Singer, 1986). (b) A mineral deposit of high enough quality to be mined at a profit (Bureau of Land Management, 1999).

oxidation (a) The chemical combination of a substance with oxygen. (b) A chemical reaction in which an atom or ion loses electrons, thus undergoing an increase in valence; for example, removing an electron from an iron atom having a valence of +2 changes the valence to +3 (American Heritage Dictionaries, 2014). 
permissive tract A geographic area delineated such that the probability of deposits of the type delineated occurring outside the boundary is negligible (that is, less than 1 in $100,000$ to $1,000,000)$ (Singer, 1993). The delineated area represents the surface projection of a portion of the Earth's crust and overlying surficial materials that corresponds to a geologic environment described in a published deposit model; consequently, depth from surface is an essential part of a tract definition. A permissive tract can be subdivided into two or more parts that have different kinds of information or possibly different numbers of undiscovered deposits.

prospect See mineral prospect.

quantitative assessment of undiscovered resources A study that presents a numerical estimate of the amount and quality of undiscovered mineral resources present within a specific volume of the Earth's crust; because of the uncertainty inherent in assessment of unknown resources, the results are presented probabilistically (Singer and Menzie, 2010).

reserve That part of a mineral deposit which could be economically and legally extracted or produced at the time of the reserve determination (Neuendorf and others, 2011).

resource A concentration of naturally occurring solid, liquid, or gaseous material in or on the Earth's crust in such form and amount that economic extraction of a commodity from the concentration is currently or potentially feasible (U.S. Bureau of Mines and U.S. Geological Survey, 1980, p. 1).

significant deposit A mineral deposit having a contained metal content that ranks in the upper 99 percent of all known deposits. Accordingly, significant gold deposits contain at least $2 \mathrm{t}$ of gold, significant silver deposits contain at least $85 \mathrm{t}$ of silver, and significant copper, lead, and zinc deposits contain at least $50,000,30,000$, and 50,000 t of their respective metals (Singer, 1995).

stratabound deposit A mineral deposit that is confined to a single stratigraphic unit.

stratiform deposit A special type of stratabound deposit in which the desired rock or ore constitutes, or is strictly coextensive with, one or more sedimentary, metamorphic, or igneous layers. supergene enrichment The supergene processes of mineral deposition. Near-surface oxidation produces acidic solutions that leach metals, carry them downward, and reprecipitate them, thus enriching sulfide minerals already present. Supergene enrichment has been important in upgrading porphyry copper deposits to the status of ore (Neuendorf and others, 2011).

supergiant deposit A world-class mineral deposit having a contained metal content that ranks in the upper 1 percent of all known deposits. According to Singer (1995, p. 103), supergiant gold deposits contain at least 1,200 t of gold, supergiant silver deposits contain at least 22,000 t of silver, and supergiant copper, zinc, and lead deposits contain at least 24, 12, and $7 \mathrm{Mt}$ of their respective metals. For this report, supergiant deposits are defined as those that contain more than $24 \mathrm{Mt}$ of copper (this volume, chap. A, table A4). See also giant deposit.

terrane A fault-bounded body of rock of regional extent, characterized by a geologic history different from that of contiguous terranes or bounding continents. A terrane is generally considered to be a discrete allochthonous fragment (moved from where it formed) of oceanic or continental material added to a craton at an active margin by accretion (Neuendorf and others, 2011).

three-part form of assessment An integrated approach to assessment that consists of three assessment parts and the models that support them. The first part uses models of tonnages and grades to estimate possible tonnages and grades of undiscovered deposits. The second part develops mineral resource maps that explore whether an area's geology permits the existence of one or more types of mineral deposits. The product of this part of the assessment is identification of so-called permissive tracts of land. For those areas that are permissive, the third part of the assessment develops estimates of the possible number of undiscovered deposits of different types. These estimated undiscovered deposits are consistent with the grade and tonnage models of the first part. Mineral deposit models are used to aid in construction of the three parts and to help convert the output of the parts into forms helpful to decision makers (Singer and Menzie, 2010). 
tonnage Weight of the volume of mineralized rock (Singer, 2007).

undiscovered mineral deposit (a) A mineral deposit that may exist within a specified volume of the Earth's crust (for example, 1 kilometer or less below the surface of the ground). (b) An incompletely explored mineral occurrence or prospect that could have sufficient size and grade to be classed as a deposit. (c) A mineral deposit whose location and (or) grade, quality, and quantity of mineralized material are unknown or incompletely characterized.

undiscovered resource (a) Resources in undiscovered mineral deposits whose existence is postulated on the basis of indirect geologic evidence (U.S. Geological Survey National Mineral Resource Assessment Team, 2000, p. 4). (b) Mineralized material whose location, grade, quality, and quantity are unknown or incompletely characterized.

world-class deposit World-class deposits represent the upper 10 percent of all deposits in terms of their contained copper content (Singer, 1995, p. 88, 103). Among the worldclass copper deposits, those that contain $2 \mathrm{Mt}$ or more of copper are considered giants and those that contain more than $24 \mathrm{Mt}$ of copper are referred to as supergiants.

\section{References Cited}

American Heritage Dictionaries, 2014, The American Heritage student science dictionary (2d ed.): New York, Houghton Mifflin Harcourt, 384 p.

Barton, P.B., Brew, D.A., Ludington, Steve, Lindsey, D.A., Ayuso, R.A., Force, E.R., Gamble, B.M., Goldfarb, R.J., John, D.A., and Johnson, K.M., 1995, Recommendations for assessments of undiscovered mineral resources: U.S. Geological Survey Open-File Report 95-82, variously paged. [Also available at https://pubs.er.usgs.gov/ publication/ofr9582.]

Bureau of Land Management, 1999, 3809 surface management regulations - Draft EIS glossary: Bureau of Land Management web page, accessed July 25, 2007, at http://www.blm.gov/nhp/Commercial/ SolidMineral/3809/deis/glossary.html.
Committee for Mineral Reserves International Reporting Standards, 2006, International reporting template for the public reporting of exploration results, mineral resources and mineral reserves: Committee for Mineral Reserves International Reporting Standards, 33 p., accessed July 25, 2007, at http://www.crirsco.com/crirsco_template_ first_ed_0806.pdf.

Cox, D.P., and Singer, D.A., eds., 1986, Mineral deposit models: U.S. Geological Survey Bulletin 1693, 379 p. [Also available at https://pubs.er.usgs.gov/publication/ b1693.]

Harris, D.P., 1984, Mineral resources appraisal-Mineral endowment, resources and potential supply-Concepts, methods, cases: Oxford, U.K., Oxford University Press, 464 p.

Neuendorf, K.K.E., Mehl, J.P., Jr., and Jackson, J.A., eds., 2011, Glossary of geology, fifth edition, revised: Alexandria, Va., American Geosciences Institute, 800 p.

Singer, D.A., 1993, Basic concepts in threepart quantitative assessments of undiscovered mineral resources: Nonrenewable Resources, v. 2, no. 2, p. 69-81.

Singer, D.A., 1995, World class base and precious metal deposits-A quantitative analysis: Economic Geology, v. 90, no. 1, p. 88-104.

Singer, D.A., 2007, Short course introduction to quantitative mineral resource assessments: U.S. Geological Survey OpenFile Report 2007-1434, 13 p. and slides, accessed June 1, 2015, at http://pubs.usgs. gov/of/2007/1434/ and pubs.usgs.gov/ of/2007/1434/of2007-1434.pdf.

Singer, D.A., and Berger, V.I., 2007, Deposit models and their application in mineral resource assessments, in Briskey, J.A., and Schulz, K.J., eds., Proceedings for a Workshop on Deposit Modeling, Mineral Resource Assessment, and Their Role in Sustainable Development: U.S. Geological Survey Circular 1294, p. 71-78, accessed June 1, 2015, at http://pubs.usgs.gov/ circ/2007/1294/. 
Singer, D.A., and Menzie, W.D., 2010, Quantitative mineral resource assessments-An integrated approach: New York, Oxford University Press, 219 p.

U.S. Bureau of Mines and U.S. Geological Survey, 1980, Principles of a resource/ reserve classification for minerals: U.S. Geological Survey Circular 831, 5 p. [Also available at https://pubs.er.usgs.gov/ publication/cir831.]

U.S. Geological Survey National Mineral Resource Assessment Team, 2000, 1998 assessment of undiscovered deposits of gold, silver, copper, lead, and zinc in the United States: U.S. Geological Survey Circular 1178, 21 p., 1 CD-ROM in pocket. [Also available at http://pubs.usgs.gov/circ/ c1178/. Recompiled in USGS Open-File Report 02-198.]

U.S. Geological Survey National Mineral Resource Assessment Team, 2002, Assessment of undiscovered deposits of gold, silver, copper, lead, and zinc in the United States; A Portable Document Format (PDF) recompilation of USGS Open-File Report 96-96 and Circular 1178: U.S. Geological Survey Open-File Report 02-198, 1 CDROM. [Recompilation by Paul Schruben. Also available at http://pubs.usgs.gov/ of/2002/of02-198/.] 
Appendixes 1-3 


\section{Appendix 1. Individuals and Institutions Who Contributed to the Studies Summarized in this Volume, the "Assessment of Undiscovered Copper Resources of the World, 2015"}

The cooperation and contributions of many individuals and institutions throughout the world made it possible to complete this first-ever global assessment of undiscovered copper resources. This appendix has three lists to acknowledge the contributors. The first names the U.S. Geological Survey members and contractors who made up the U.S. Geological Survey Global Copper Mineral Resource Assessment Team that prepared this volume. The second list has international and U.S. scientific collaborators who provided data, local expertise in geology, and knowledge of mineral exploration history; they also participated in discussions of the likelihood of undiscovered deposits. The third list names the cooperating institutions.

\section{U.S. Geological Survey Scientists and Contractors $\left(^{*}\right)$ on the U.S. Geological Survey Global Copper Mineral Resource Assessment Team}

\begin{tabular}{ll} 
Walter J. Bawiec & M. Christopher Jenkins* \\
Byron R. Berger & Kathleen M. Johnson \\
Vladimir I. Berger & Michael J. Kirschbaum \\
James D. Bliss & Shane Kosta* \\
Arthur A. Bookstrom & Michael Landkammer* \\
Stephen E. Box & Thomas D. Light \\
Deborah A. Briggs* & Kassandra Lindsey* \\
Joseph A. Briskey & Steve Ludington \\
Hannah Campbell* & John C. Mars \\
J. Douglas Causey & Mark J. Mihalasky \\
Pamela M. Cossette & Robert J. Miller \\
Dennis P. Cox & Warren J. Nokleberg \\
Charles G. Cunningham & Heather L. Parks \\
Michael W. DeMarr* & Stephen G. Peters \\
Paul D. Denning & Gilpin R. Robinson, Jr. \\
Connie L. Dicken & Klaus J. Schulz \\
Benjamin J. Drenth & Donald A. Singer \\
Lawrence J. Drew & David M. Sutphin \\
Pamela Dunlap & Cliff D. Taylor \\
Thomas P. Frost & John C. Wallis* \\
Kathleen D. Gans & David J. Williams* \\
Floyd Gray & Anna B. Wilson \\
Jane M. Hammarstrom & Niki E. Wintzer \\
Shyla A. Hatch* & Sewit Yenie* \\
Timothy S. Hayes & Michael L. Zientek \\
Cassandra Hennings* & Lukas Zürcher \\
John D. Horton & \\
& \\
\hline &
\end{tabular}




\title{
Scientific Collaborators
}

\author{
Grant Abbott \\ Yukon Geological Survey (YGS), Canada \\ Dmitriy Alexeiev \\ Russian Academy of Sciences, Moscow, Russia \\ Mario Billa \\ Gregor Borg \\ David W. Broughton \\ Bureau de Recherches Géologiques et Minières (BRGM), France \\ Martin Luther University Halle-Wittenberg, Germany \\ Ivanhoe Nickel and Platinum Ltd., Ottawa, Ontario, Canada \\ Rodrigo Carrasco \\ Daniel Cassard \\ Carlos Mario Celada \\ Francisco Cendejas-Cruz \\ Lian Changyun \\ Vladimir S. Chechetkin \\ Andre Chitalin \\ Michael Christie \\ Alejandro Diaz \\ Alla Dolgopolova \\ Enrique Espinosa \\ Susan Frost-Killian \\ Mariano Gajardo M. \\ Zhai Gangyi \\ Richard A. Glen \\ Yan Guangsheng \\ Richard J. Herrington \\ Murray W. Hitzman \\ Douglas J. Jack \\ Subhash Jaireth \\ Pairatt Jarnyaharn \\ Xiao Keyan \\ Gwaibo Kopi \\ Ilkay Kuşcu \\ Duncan E. Large \\ Jinyi Li \\ Andor Lips \\ James M. Logan \\ Claro J. Manipon \\ Jingwen Mao \\ Sharad Master \\ Nguyen Thi Minh Ngoc \\ Charles J. Moon \\ Servicio Nacional de Geología y Minería (SERNAGEOMIN; \\ Geological Survey of Chile) \\ Bureau de Recherches Géologiques et Minières (BRGM), France \\ Instituto Colombiano de Geología y Minería (INGEOMINAS) \\ Servicio Geológico Mexicano \\ China Geological Survey (CGS) \\ Zabaikalsky Division of the Russian Geological Society (RosGeo), \\ Chita, Russia \\ Institute of Geotechnology, Moscow, Russia \\ First Quantum Minerals Ltd., Perth, Western Australia \\ Servicio Nacional de Geología y Minería (SERNAGEOMIN; \\ Geological Survey of Chile) \\ Centre for Russian and Central EurAsian Mineral Studies \\ (CERCAMS), London, U.K. \\ Servicio Geológico Mexicano \\ South Africa Council for Geoscience, Pretoria, Republic of South \\ Africa \\ Servicio Nacional de Geología y Minería (SERNAGEOMIN; \\ Geological Survey of Chile) \\ China Geological Survey (CGS) \\ Geological Survey of New South Wales, New South Wales, Australia \\ China Geological Survey (CGS) \\ Natural History Museum, London, U.K. \\ Colorado School of Mines, U.S.A. \\ First Quantum Minerals Ltd., Lubumbashi, Democratic Republic of \\ the Congo \\ Geoscience Australia, Canberra, Australian Capital Territory, \\ Australia \\ Royal Thai Government Department of Mineral Resources, Bangkok \\ China Geological Survey (CGS) \\ Mineral Resources Authority of Papua New Guinea \\ University of Muğla, Muğla, Turkey \\ Consulting geologist, Braunschweig, Germany \\ China Geological Survey (CGS) \\ Bureau de Recherches Géologiques et Minières (BRGM), France \\ British Columbia Geological Survey (BCGS), Canada \\ Philippine Department of Environment and Natural Resources, \\ Mines and Geosciences Bureau, Quezon City, Philippines \\ China Academy of Geological Sciences, Beijing \\ University of the Witwatersrand, South Africa \\ Department of Geology and Minerals of Vietnam, Hanoi \\ Camborne School of Mines, Cornwall, England
}




\begin{tabular}{|c|c|}
\hline Carl E. Nelson & Recursos del Caribe, S.A. \\
\hline Sławomir Oszczepalski & Polish Geological Institute - National Research Institute (PGI-NRI) \\
\hline Pichai Otarawanna & Royal Thai Government Department of Mineral Resources, Bangkok \\
\hline Andre Panteleyev & XDM Geological Consultants \\
\hline Chen Shick Pei & $\begin{array}{l}\text { Coordinating Committee for Geoscience Programmes in East and } \\
\text { Southeast Asia (CCOP), Thailand }\end{array}$ \\
\hline Efrén Pérez-Segura & Universidad de Sonora, México \\
\hline Zdenĕk Pertold & Charles University, Praha, Czechia \\
\hline Ung Phany & Department of Geology and Mines, Phnom Penh, Cambodia \\
\hline Carlos Portigliati & $\begin{array}{l}\text { Servicio Nacional de Geología y Minería (SERNAGEOMIN; } \\
\text { Geological Survey of Chile) }\end{array}$ \\
\hline Ruizhao Qiu & China Geological Survey (CGS) \\
\hline Peng Qiuming & China Geological Survey (CGS) \\
\hline Jorge Quispe & $\begin{array}{l}\text { Instituto Geológico Minero y Metalúrgico (INGEMMET, Geological } \\
\text { Survey of Peru) }\end{array}$ \\
\hline Jeremy P. Richards & University of Alberta, Edmonton, Alberta, Canada \\
\hline José Luis Rodríguez-Castañeda & Universidad Autónoma de México \\
\hline Lilian A. Rollan & $\begin{array}{l}\text { Philippine Department of Environment and Natural Resources, } \\
\text { Mines and Geosciences Bureau, Quezon City, Philippines }\end{array}$ \\
\hline Emilian Roşu & Geological Institute of Romania (IGR), Bucharest, Romania \\
\hline Takehiro Sakimoto & Royal Thai Government Department of Mineral Resources, Bangkok \\
\hline Dulcie Saroa & Mineral Resources Authority of Papua New Guinea \\
\hline John H. Schuenemeyer & Southwest Statistical Consulting, Cortez, Colorado, U.S.A. \\
\hline Reimar Seltmann & $\begin{array}{l}\text { Centre for Russian and Central EurAsian Mineral Studies } \\
\text { (CERCAMS), London, U.K. }\end{array}$ \\
\hline Bambang Tjahjono Setiabudi & Geological Agency of Indonesia, Bandung, Indonesia \\
\hline Jianbao Shao & China Geological Survey (CGS) \\
\hline I.M. Sim & Department of Geology and Mines, Phnom Penh, Cambodia \\
\hline Norberta Soares da Costa & Director of Geology and Mineral Resources, Dili, Timor Leste \\
\hline Sieng Sotham & Department of Geology and Mines, Phnom Penh, Cambodia \\
\hline Volker Spieth & V.S. Globalmetal LLC, Tucson, Arizona, U.S.A. \\
\hline Wudhikarn Sukserm & Royal Thai Government Department of Mineral Resources, Bangkok \\
\hline Dwi Nugroho Sunuhadi & Geological Agency of Indonesia, Bandung, Indonesia \\
\hline Boris Syusyura & Mining and Economic Consulting, Ltd., Almaty, Kazakhstan \\
\hline Nguyen Nhu Trung & Royal Thai Government Department of Mineral Resources, Bangkok \\
\hline Martín Valencia-Moreno & Universidad Autónoma de México \\
\hline Rigoberto Vásquez-Mendoza & Servicio Geológico Mexicano \\
\hline Nguyen Vay Quy & Department of Geology and Minerals of Vietnam, Hanoi \\
\hline Waldo Vivallo S. & $\begin{array}{l}\text { Servicio Nacional de Geología y Minería (SERNAGEOMIN; } \\
\text { Geological Survey of Chile) }\end{array}$ \\
\hline Somob Wongsomasak & Royal Thai Government Department of Mineral Resources, Bangkok \\
\hline Jon Woodhead & Private consultant, Duncraig, Perth, Western Australia \\
\hline Alexander Yan Sze Wah & Mineral and Geoscience Department, Sabah, Malaysia \\
\hline Boonsong Yokarti & Royal Thai Government Department of Mineral Resources, Bangkok \\
\hline Du Yuliang & China Geological Survey (CGS) \\
\hline Eduardo O. Zappettini & Servicio Geológico Minero Argentino (SEGEMAR) \\
\hline Khin Zaw & University of Tasmania, Hobart, Australia \\
\hline
\end{tabular}




\section{Cooperating Institutions}

British Columbia Geological Survey (BCGS), Canada

Bundesanstalt für Geowissenschaften und Rohstoffe (BGR), Germany

Bureau de Recherches Géologiques et Minières (BRGM), France

Centre for Ore Deposit Research, University of Tasmania (CODES)

Centre for Russian and Central EurAsian Mineral Studies (CERCAMS), London, U.K.

Charles University, Czechia

China Academy of Geological Sciences, Beijing

China Geological Survey (CGS)

Colorado School of Mines, U.S.A.

Commonwealth Scientific and Industrial Research Organisation (CSIRO), Australia

Coordinating Committee for Geoscience Programmes in East and Southeast Asia (CCOP), Thailand

Council for Geoscience (CGS), South Africa

Department of Geology and Minerals of Vietnam, Hanoi

Department of Geology and Mines, Phnom Penh, Cambodia

Geological Agency of Indonesia, Bandung, Indonesia

Geological Institute of Romania (IGR)

Geological Survey of Canada (GSC)

Geological Survey of Denmark and Greenland (GEUS)

Geological Survey of Finland (GTK)

Geological Survey of Ireland (GSI)

Geological Survey of Japan/AIST - Institute for Geo-Resources \& Environment

Geological Survey of New South Wales, Australia

Geoscience Australia (GA)

Instituto Colombiano de Geologia y Mineria (INGEOMINAS)

Instituto Geológico Minero y Metalúrgico (INGEMMET, Geological Survey of Peru)

Korea Institute of Geoscience and Mineral Resources (KIGAM)

Martin Luther University Halle-Wittenberg, Germany

Mineral and Geoscience Department, Sabah, Malaysia

Mineral Resources Authority of Papua New Guinea

Mining and Economic Consulting, Ltd., Almaty, Kazakhstan

Mongolian Academy of Sciences (MAS)

Natural History Museum (NHM), London, U.K.

Philippine Department of Environment and Natural Resources, Mines and Geosciences Bureau, Quezon City, Philippines

Polish Geological Institute - National Research Institute (PGI-NRI)

Rhodes University, South Africa

Royal Thai Government Department of Mineral Resources, Bangkok

Russian Academy of Sciences, Moscow, Russia

Russian Geological Society (RosGeo), Chita, Russia

Servicio Geológico Mexicano (SGM)

Servicio Geológico Minero Argentino (SEGEMAR)

Servicio Nacional de Geología y Minería (SERNAGEOMIN; Geological Survey of Chile)

Serviço Geológico do Brasil (CPRM) 
University of Arizona, U.S.A.

University of Pretoria, South Africa

University of Tasmania, Hobart, Australia

University of the Free State, South Africa

University of the Witwatersrand, South Africa

University of Zambia

Yukon Geological Survey (YGS), Canada

Zabaikalsky Division of the Russian Geological Society (RosGeo), Chita, Russia 


\title{
Appendix 2. Mineral Resource Assessment Methods and Procedures Used in the U.S. Geological Survey Global Mineral Resource Assessment
}

\author{
By Michael L. Zientek and Jane M. Hammarstrom
}

\section{Introduction}

The U.S. Geological Survey (USGS) conducted a global mineral resource assessment. This multichaptered report on the first-ever global assessment of undiscovered copper resources presents results for two types of copper deposits: porphyry copper deposits and sediment-hosted stratabound copper deposits. To aid in interpreting the results, this appendix summarizes the technical language used in mineral assessments, the underlying principles, and the operational procedures used for USGS mineral resource assessments. An earlier version of this appendix was published by Zientek and Hammarstrom (2014).

When evaluating mineral potential, geologists distinguish rocks that are barren from those that could contain valuable concentrations of useful minerals or materials. Exploring for minerals is expensive; therefore, mineral potential is evaluated in a series of steps that minimize the cost of excluding barren areas while increasing knowledge about the possible existence of undiscovered mineral resources (Singer and Menzie, 2010). Initially, geologists use regional-scale datasets to discriminate geologic settings that are barren from those that may be mineralized. Next, targets or prospective areas that may contain mineralized rock are defined. If mineralization is found in a target area, then systematic sampling is conducted to determine if a volume of rock is present that might be economic. If a volume can be defined, then economic and feasibility studies are conducted to determine how much of the volume can be developed. After a mine is developed, detailed geologic information guides the application of mining technology that will be used to segregate ore from waste material in the mining process.

U.S. Geological Survey mineral resource assessments generally correspond to the early regional reconnaissance step in the process of determining mineral potential and address two basic questions: (1) where are undiscovered mineral resources likely to exist? and (2) how much undiscovered mineral resource may be present? Results are presented as mineral potential maps and as frequency distributions of in-place, undiscovered metal.

We can make inferences about undiscovered mineral resource potential because natural accumulations of useful minerals or rocks ("mineral deposits") can be classified by using common characteristics and associations into groups or "deposit types" that reflect processes of formation. Using the deposit-type paradigm, we can predict the geologic settings in which various types of deposits may be found and anticipate the distribution and concentration of ore materials at the scale of the deposit.

The USGS strives to conduct consistent and unbiased assessments by applying a methodology to identify areas having mineral resource potential and to probabilistically estimate the amount of mineral resources likely to be present. The methodology is a system of interrelated, internally consistent, and integrated models and procedures. The integration of models and procedures reduces the likelihood of introducing bias in the assessment process.

USGS mineral assessment protocols are based on science practices derived from the fields of economic geology, ${ }^{1}$ mineral inventory estimation, and undiscovered mineral resource appraisal. The assessments are based on our fundamental understanding of the geologic processes that concentrate valuable mineral materials near the surface of the Earth. The methodology extends the scientific and engineering principles that are used to establish mineral inventories. The science and mathematics of making forecasts and predictions are essential parts of the assessment process.

\section{Technical Language and the Assessment Process}

Successful assessments require consistent use of technical language in order to reduce bias. The use of technical language comes at a cost, however, because economic geologists take common terms and restrict their meaning in order to communicate precisely with each other. Mineral assessment scientists may understand each other, but the general user community may not understand the subtle distinctions between terms. So, it is necessary to discuss technical terms used in mineral resource assessment studies before considering mineral resource assessment methodology.

${ }^{1}$ Economic geology - The study and analysis of geologic bodies and materials that can be used profitably by man, including fuels, metals, nonmetallic minerals, and water; the application of geologic knowledge and theory to the search for and the understanding of mineral deposits (Neuendorf and others, 2015). 


\section{Mineral Resources and Reserves}

Bodies of mineralized rock are classified according to (1) their geological, physical, and chemical properties; (2) their profitability; and (3) the level of certainty associated with the estimates of mineral potential. For estimation and assessment studies, the words "deposit," "resource," "reserve," "discovered," and "undiscovered" have specialized meanings. "Mineral inventories" are formal quantifications of the amounts of naturally occurring materials estimated by a variety of empirically or theoretically based procedures using the spatial distribution of grade and the particular locations of volumes of mineralized rock that are above cutoff grade ${ }^{2}$ (Sinclair and Blackwell, 2002). Mineral inventories include mineral resources and mineral reserves. "Mineral resources" are defined as concentrations or occurrences of material of economic interest in or on the Earth's crust in such form, quality, and quantity that there are reasonable prospects for eventual economic extraction. The location, quantity, grade, continuity, and other geological characteristics of a mineral resource are known, estimated, or interpreted from specific geological evidence, sampling, and other knowledge (Committee for Mineral Reserves International Reporting Standards, 2006). The term "mineral reserve" is restricted to the economically minable part of a mineral resource. On the basis of the level of confidence in the estimates, mineral resources are divided into "measured," "indicated," and "inferred" categories, and mineral reserves are divided into "proven" and "probable" groupings.

\section{Mineral Deposits}

“'When I use a word,' Humpty Dumpty said, in rather a scornful tone, 'it means just what I choose it to mean-neither more nor less."

$$
\text { —Lewis Carroll (1872, p. 124) }
$$

"Deposit" has more than one meaning for most people, but "a layer or mass of accumulated matter" is close to how it is used by earth scientists. The following definitions are examples of how earth scientists may enhance the meaning of "mineral deposit":

1. "geologic bodies which consist mainly of a single useful mineral or which contain, throughout or in places, valuable minerals which can be profitably extracted" (Lindgren, 1933, p. 9).

2. "natural concentrations of useful minerals or rocks, which can be economically exploited" (Pohl, 2011, p. 1).

${ }^{2}$ Cutoff grade is the lowest grade, or quality, of mineralized material that qualifies as economically minable and available in a given deposit (Committee for Mineral Reserves International Reporting Standards, 2006, p. 31).
3. "A mass of naturally occurring mineral material, e.g. metal ores or nonmetallic minerals, usually of economic value, without regard to mode of origin" (Bates and Jackson, 1987, p. 424).

4. "a mineral occurrence of sufficient size and grade that it might, under the most favorable of circumstances, be considered to have economic potential" (Cox and others, 1986, p. 1).

5. an "accumulation of associated mineralized bodies that constitute [the products of] a single mineralizing event, including subsequent processes (e.g., oxidation and supergene enrichment) affecting part or all of the accumulation" (Barton and others, 1995, p. 81).

Almost all agree that a deposit is an accumulation of potentially economic material, but some include additional constraints on size and genesis. For USGS mineral resource assessments, "mineral deposits" refers to natural accumulations of minerals or mineral materials that (1) formed by the same mineralizing event, (2) might have economic potential, (3) have a formally defined mineral inventory based upon a sampling density that is appropriate for the deposit type, and (4) are well explored. In order to be well explored, a mineral inventory based on mapping, drilling, and sampling should encompass most of the potentially economic mineralized rock at the site. Accumulations of minerals or mineral materials that lack a mineral inventory or are incompletely explored are referred to as "prospects."

\section{Deposit Types}

The concept of deposit type underlies the geologically based mineral resource assessments conducted by the USGS. Geologists, engineers, and miners have long recognized that mineral deposits can be classified into groups or types based on common characteristics and associations (Skinner and Barton, 1973). According to Eckstrand (1984, p. 1), "a mineral deposit type is defined as a hypothetical composite of the geological characteristics common to a group of similar mineral deposits." Mineral deposit types are defined as follows:

- Characteristic orebody ${ }^{3}$ geometries

- Distributions of tonnage and grade

- Rock and mineral properties that determine the potential value of the deposit

- Amount of sampling that will be required to delimit mineral resources

- Amount of valuable material that can be mined and processed

\footnotetext{
${ }^{3}$ An orebody is a continuous, well-defined mass of material of sufficient ore content to make extraction economically feasible (Neuendorf and others, 2015). Ore is a naturally occurring solid material from which a metal or valuable mineral can be profitably extracted.
} 
Furthermore, deposits of each type have specific effects on the environment, whether through natural weathering processes or mining.

When referring to deposits that are members of a type, Eckstrand (1984, p. 1) stated, "It is implicit that such deposits, because of their similarities, are expected to have a common mode of genesis, whether or not that mode of genesis is well understood." The genetic foundation of deposit types allows a scientific approach to assessing mineral resources. Scientific investigations of mineral deposits show that they are extraordinary geologic features, formed by rare conjunctions of ordinary geologic processes. Even though mineral deposits result from rare events, the principle of uniformity allows us to make predictions about their location and potential value based on geologic observations. The allocation of deposits to types gives even greater predictive capability.

\section{Undiscovered Mineral Resources and Mineral Deposits}

"Undiscovered" is a term that also has specific usage in USGS mineral resource assessments. To most people, an undiscovered resource would refer to a quantity of material that is completely unknown. In assessments, the term "undiscovered mineral resources" refers to a variety of situations in which location, grade, quality, and quantity of mineralized material are not constrained by specific geologic evidence. The presence of mineralized rock might be recognized at a site (location is known) but the grade, quality, and quantity of mineralized material are not sufficiently characterized to estimate mineral resources by using industry-standard practices. In this example, the location of mineralized rock is discovered but the amount of mineral resource is unknown; therefore, any mineral resources that exist are undiscovered. In a similar situation, a well-characterized volume of mineralized rock with a resource estimate is surrounded by mineralized rocks for which the sample density is too low to classify the material as a mineral resource. Undiscovered mineral resources may be present in the poorly characterized material. Finally, undiscovered mineral resources may be associated with a completely unknown, undiscovered mineral deposit, in which location, grade, quality, and quantity of mineralized rocks are unknown.

\section{Assessment Methodology—Parts and Procedures}

An assessment method consists of "parts," each of which incorporates appropriate scientific theories, methods, and findings into the process. Rigorous reasoning integrates the parts into a consistent system or method that will indicate the possible location and potential value of undiscovered mineral resources in a form that can be consistently replicated and compared to other assessments. Parts of a method are usually models, such as mineral systems models, but can also be subjective information provided by experts or products, such as a geologic map or a database.

For example, for quantitative mineral resource assessments, the USGS uses the three-part form of assessment (Singer, 1993; Singer and Menzie, 2010). One part is construction of a mineral resource potential map in which areas are delineated according to the types of deposits permitted by the geology as guided by a descriptive mineral deposit models. Another part consists of models of grades and tonnages of deposits used to estimate the amount of metal. The final part of an assessment provides estimated numbers of undiscovered deposits of each type. These parts are essential for a quantitative assessment but do not completely describe an assessment method; in other words, they are not steps in an assessment method.

\section{Mineral Systems Models}

The concept of a mineral system can be used to incorporate concepts of regional ore genesis into mineral resource assessment and exploration targeting studies (Wyborn and others, 1994; Knox-Robinson and Wyborn, 1997; Hronsky, 2004; Hitzman and others, 2005; Barnicoat, 2006; Cox and others, 2007; Hronsky and Groves, 2008; Blewett and others, 2010). Mineral systems models use components and processes to organize ideas about how different mineral deposit types relate to regional-scale movements of energy and mass in the Earth. For example, hydrothermal ore deposits can be understood by considering the source of the ore-forming fluid, its physical and chemical character, the mechanisms for dissolving and transporting ore-forming components, and the causes of precipitation from it (Skinner and Barton, 1973). Sites where appropriate combinations of structural, chemical, and physical conditions force ore mineral precipitation reactions are called ore traps (Reed, 1997). Variations of the source-transporttrap paradigm are used to define both petroleum and mineral systems models (Magoon and Dow, 1994; Wyborn and others, 1994; Magoon and Schmoker, 2000). All proponents of mineral systems models agree that the deposition of ore minerals will not occur unless all the essential components are present and processes occur in the correct sequence and location (Magoon and Dow, 1994; Kreuzer and others, 2008; McCuaig and others, 2010).

Mineral systems models serve two functions in mineral resource assessments. All components and processes that relate to ore deposit type can be systematically evaluated to identify areas where a mineral-forming system could be present and to create prospectivity maps that identify target areas for exploration. Another function of these models is to use the components and processes of the mineral systems model to define the assessment unit in areas where the existence of a mineral-forming system is known from the presence of deposits and prospects. Mineral prospectivity analysis is a predictive tool used for regional- to mining-camp-scale exploration targeting (Porwal and Kreuzer, 2010). 
Mineral systems models are used to synthesize ideas about the processes related to mineralization. Critical processes act together to form mineral deposits; although processes cannot be directly observed, expressions of the processes can be mapped. The probabilities of occurrence of the critical mineralization processes can either be assigned subjectively on the basis of expert assessment of available spatial and nonspatial geoscience information (knowledge-driven approach) or be estimated empirically from the distribution of known mineral deposits (data-driven approach). From this information, resource potential maps can be generated in which each cell is attributed with a favorability value that represents the probability that the cell contains a deposit of the targeted type.

\section{Descriptive Mineral Deposit Models}

A descriptive mineral deposit model is systematically arranged information describing the essential attributes (properties) of a class of mineral deposits (Cox and others, 1986). Descriptive models used in USGS studies focus on observations and use theories of origin only to guide what to observe (Singer and Menzie, 2010). The function of the model is to provide the assessment geologists with information that they can interpret and use to discriminate (1) possible mineralized environments from barren environments and (2) types of known deposits from each other.

Descriptive models used in USGS assessments, such as those in Cox and Singer (1986), have two parts. The first lists characteristics of the geologic environments in which the deposits are found; the second gives identifying characteristics of deposits. The information in the first part can be interpreted by the assessment geologist and used to delineate tracts of land geologically permissive for the occurrence of undiscovered deposits. The second part of the descriptive model, the deposit description, includes information on host rocks, mineralogy, alteration, and geochemical and geophysical anomalies that are used by the assessment geologist to recognize the deposit type and to discriminate one deposit type from another.

The descriptive models are lists of information. Therefore, the theory of ore formation that guided what was included in the list is not explicitly stated. The models also do not provide any suggestions on how the information can be used to delineate tracts or to identify deposits by type. Information needed to assess the potential economic value of the deposit type, such as typical mining, beneficiation, and remediation methods, is not usually included.

\section{Grade and Tonnage Models}

Mineral deposits of a given type have characteristic distributions of size and grade that can be used to constrain the probable size and grade of undiscovered deposits of the same type. Frequency distributions of tonnages and average grades of well-explored deposits of each type are used as models for grades and tonnages of undiscovered deposits of the same type in geologically similar settings (Singer and Menzie, 2010). These models are based on the average grades of each metal or mineral commodity of possible economic interest and the associated tonnage, prior to mining. Data used in the models should represent an estimate of the total mineral endowment of each of the known deposits so that the final models can accurately represent the endowment of undiscovered deposits.

In order to be consistent, the deposits used to estimate tonnages and grade in a model should be selected according to the following criteria:

1. the candidate deposit for inclusion in the model should have formed by the same type of mineralizing event as other deposits used in the model and it should be the same deposit type as other deposits used in the model (Barton and others, 1995);

2. the candidate deposit should be well explored (Singer and Menzie, 2010);

3. an estimate of pre-mining, in-place mineral endowment of the candidate deposit should be available (Singer and Menzie, 2010);

4. the candidate deposit's endowment estimate should be based on sampling consistent with industry practices for defining mineral resources and reserves;

5. the candidate deposit's endowment estimate should use cutoff grades that are similar to those used to estimate endowments for other deposits that are in the model;

6. the rules for defining how orebodies are spatially grouped into a deposit should be consistent for the candidate deposit and for other deposits that are in the model (Singer and Menzie, 2010); and

7. the development plan for the candidate deposit should be based on mining and processing methods that are similar to those used for other deposits that are in the model (Bliss and others, 1987).

The stipulation that the data used in a grade and tonnage model should represent total endowment affects what is considered a deposit or a prospect for assessment purposes. In the USGS three-part form of assessment (Singer and Menzie, 2010), deposits must be (1) described in published literature (including tonnage and grades), (2) well explored in three dimensions, and (3) completely delineated (that is, the boundary is not open, or undefined, in any part). Mineral deposits that do not meet these three criteria are classified by the USGS, as recommended by Singer and Menzie (2010), as "undiscovered" for the sake of mineral resource assessment. For example, if there is any indication that an orebody is not completely delineated, the site is counted as an undiscovered deposit for assessment purposes (Singer and Menzie, 2010). 
Or, if a mineral deposit is well explored and completely delineated, but the mineral resource information is not published, then the deposit is considered undiscovered, but with a high probability for occurrence.

\section{Assessing Location (Mineral Resource Potential Maps)}

USGS mineral resource potential maps show geographic areas where undiscovered mineral resources may be present. For most USGS mineral resource assessments, mineral resource potential maps show "permissive tracts," where the geology permits the existence of deposits of one or more types. However, some studies create prospectivity maps, which delineate mineral exploration targets by combining various evidential layers in a geographic information system (GIS). Mineral resource potential maps can be represented cartographically as figures or plates in reports or digitally as files that can be incorporated into a GIS.

Permissive tracts represent the surface projection of part of the Earth's crust and overlying surficial materials to a predetermined depth where undiscovered mineral resources may be present. The criteria used to select the permissive volume of rock, or assessment unit, are provided by descriptive mineral deposit models and mineral systems models, as described below. The assessment geologist determines how to apply the criteria in the models to the specific datasets available for the assessment. Boundaries of the rock volume are defined such that deposits of the type being assessed have a negligible chance of occurring outside the volume. According to Singer and Menzie (2010), "negligible" means a chance of less than 1 in 100,000. Areas are excluded from these tracts only on the basis of geology, knowledge about unsuccessful exploration, or the presence of barren overburden exceeding some predetermined thickness (Singer and Menzie, 2010). In assessment reports, maps commonly show the permissive tracts along with mineral deposits, prospects, and occurrences of the deposit type being assessed.

\section{Assessing Probable Amounts of Undiscovered Metal}

Mineral resource assessments should be in a form that allows for comparison of potential value and benefit of mineral resource development with other socioeconomic benefits and consequences. Uncertainty of assessment results must also be indicated. Mineral potential can be expressed qualitatively with terms such as "high," "medium," and "low"; however, this form of valuation cannot be related to other types of information, such as the value of other natural resources or the integrity of ecosystem function and process. Therefore, USGS mineral resource assessments express amounts of undiscovered mineral resources using probabilistic estimates of the amount of in-place metal. This form of assessment result can then be filtered economically to give some idea of the potential value of the mineral resource.
At least two strategies are used by the USGS to assess undiscovered mineral resources. The first is to estimate the number of undiscovered deposits; this approach has been widely used in USGS mineral resource assessments since the 1970s. A second approach uses geostatistical methods to estimate undiscovered mineral resources associated with incompletely explored extensions of stratabound ore deposits.

\section{Estimating Undiscovered Resources by Estimating Numbers of Undiscovered Deposits}

Mineral resource assessments completed by the USGS during the past three decades express geologically based estimates of numbers of undiscovered mineral deposits as probability distributions. Numbers of undiscovered deposits of a given type are estimated in geologically defined regions. By using Monte Carlo simulations, these undiscovered deposit estimates are combined with grade and tonnage models to derive a probability distribution describing amounts of mineral commodities and rock that could be present in undiscovered deposits within a study area.

\section{Number of Undiscovered Deposits}

An estimate of some fixed, but unknown, number of undiscovered deposits of each type that are inferred to exist in the delineated tracts is another part of the three-part form of assessment (Singer and Menzie, 2010). Ore tonnages and metal grades of the undiscovered deposits are assumed to be distributed similarly to those of identified deposits of the same types. Expert panels estimate the number of undiscovered deposits at several confidence levels, usually the 90th, 50th, and 10th percentiles. An algorithm converts these estimates into a continuous distribution for use in the simulation of undiscovered mineral resources (Root and others, 1992). Two strategies typically are used when estimating 90th, 50th, and 10th percentiles. In one scenario, an expert chooses a "best estimate" (for example, the median) and then adjusts up or down from that estimate in order to get the extreme percentiles (Clemen, 2001). In another scenario, the expert decides on the extremes first (the 10th and 90th percentiles) and then selects the 50th.

Singer and Berger (2007) and Singer and Menzie (2010) offered guidelines for estimating numbers of undiscovered deposits. Estimates at the 90th and 50th percentile can be guided by counting and ranking prospects and mineral occurrences or by visualizing exploration targets based on data such as geochemical or geophysical anomalies or the presence of hydrothermal alteration. Probabilities can be assigned to each "target" and then combined to give an overall probability. Estimates are also guided by analogy with well-explored areas that are geologically similar to the study area. If a quantitative deposit density model is available, some estimators will use a predicted density from the model to guide their estimates (Singer and others, 2005; Singer, 2007). 
The mean number of undiscovered deposits and associated standard deviation are based on the algorithm developed by Singer and Menzie (2005) that replicates the deposit distribution originally described by Root and others (1992). The algorithm can be described by the following general equations to calculate a mean number of undiscovered deposits $(\lambda)$ and a standard deviation $\left(s_{x}\right)$ based on estimates predicted at different quantile levels ${ }^{4}\left(N_{90}=90\right.$-percent level, $N_{50}=50$-percent level, and so on):

$$
\begin{gathered}
\lambda=0.233 N_{90}+0.4 N_{50}+0.225 N_{10} \\
+0.045 N_{05}+0.03 N_{01} \\
s_{x}=0.121- \\
+0.237 N_{90}-0.093 N_{50}+0.183 N_{10} \\
+0.073 N_{05}+0.123 N_{01}
\end{gathered}
$$

For the USGS 2015 global copper assessment, these equations were programmed into a spreadsheet to allow the team members to quickly evaluate their estimates. The difference between the number of undiscovered deposits associated with the 90th percentile and the 10th percentile or 1st percentile is a measure of uncertainty; large differences suggest great uncertainty. Estimates of numbers of deposits as a probability distribution explicitly represent the probability (or degree of belief) that some fixed but unknown number of undiscovered deposits exist in the delineated tracts (Singer and Menzie, 2010). Another useful parameter for reporting uncertainty associated with an estimate is the coefficient of variation $\left(C_{v}\right)$, defined as:

$$
C_{v}=s_{x} / \lambda
$$

The coefficient of variation is often reported as percent relative variation $\left(100 \times C_{v}\right)$. The final team estimates reflect both the uncertainty $\left(C_{v}\right)$ in what may exist and the favorability $(\lambda)$ of the tract (Singer and Menzie, 2010).

\section{Monte Carlo Simulation}

The undiscovered resources for each permissive tract are estimated by the following equation:

mean undiscovered resource

$=$ number of undiscovered deposits $\times$ tonnage $\times$ grade

where number of deposits, tonnage, and grade are each described by probability distributions and modeled using

${ }^{4}$ To use equations 1 and 2 in cases where three nonzero quantiles (at 90, 50, and 10 percent) are estimated, use the $N_{10}$ values for $N_{05}$ and $N_{01}$; where four quantiles (at 90, 50, 10, and 5 percent) are estimated, use the $N_{05}$ value for $N_{01}$.
Monte Carlo simulation (Singer and Menzie, 2010). Monte Carlo simulation is used to combine grade and tonnage distributions with the probability distribution of undiscovered deposits to obtain probability distributions of undiscovered metals in each tract (Root and others, 1992; Bawiec and Spanski, 2012; Duval, 2012). USGS software such as the EMINERS program (Duval, 2012) uses a number of techniques to avoid introducing bias into Monte Carlo simulation results. For example, dependencies between grades and tonnages of deposits and between grades of different metals in the same deposit are preserved. In addition, tonnages and grades are approximated by piecewise linear distributions to avoid unrealistically large values.

Simulation results are reported at selected quantile levels, together with the mean expected amount of metal, the probability of the mean, and the probability of no deposits being present. The amount of metal reported at each quantile represents the least amount of metal expected.

\section{Estimating Undiscovered Resources Using Geostatistical Methods}

Estimating undiscovered resources for some stratabound ${ }^{5}$ and stratiform ${ }^{6}$ deposit types by estimating the number of undiscovered deposits is problematic. Examples of stratabound deposit types include iron formations; beds of halite or potash-salt; layers rich in chromitites and platinum-groupelement reefs in a layered igneous complex (Schulte and others, 2012; Zientek, 2012); and sediment-hosted stratabound copper deposits (Hitzman and others, 2005; Cox and others, 2007; Zientek, Hayes, and Hammarstrom, 2013; Zientek, Hayes, and Taylor, 2013; Hayes and others, 2015). The difficulty in making such estimates arises because valid grade and tonnage models cannot be constructed because most deposits are open at depth (that is, the lower limit of the deposit is not defined). In addition, deposit tonnage correlates with the extent of a basin or a layered igneous intrusion; a global tonnage model could have values that are geologically impossible for the size of a particular basin or intrusion.

\section{Metal Surface Density}

Probabilistic estimates can be made for undiscovered mineral resources in incompletely explored extensions of large stratabound deposits if appropriate data are available to calculate metal surface density surfaces. The justification for using metal surface density in layered orebodies follows.

\footnotetext{
${ }^{5} \mathrm{~A}$ stratabound mineral deposit is confined to a single stratigraphic unit.

${ }^{6} \mathrm{~A}$ stratiform deposit is a special type of stratabound deposit in which the desired rock or ore constitutes, or is strictly coextensive with, one or more sedimentary, metamorphic, or igneous layers.
} 

relation:

In-place contained metal in an orebody is given by this

$$
M=T \times g
$$

where

$M \quad$ is contained metal, in metric tons;

$T$ is the mass (tonnage) of the orebody, measured in metric tons; and

$g \quad$ is the average grade of the orebody, measured in grams per metric ton.

Tonnage is determined by this equation:

$$
T=V \times \rho_{b}
$$

where

$$
\begin{gathered}
V \quad \text { is the volume of the orebody, measured in } \\
\text { cubic meters; and } \\
\rho_{b} \quad \text { is the bulk density of the ore, measured in } \\
\text { metric tons per cubic meter. }
\end{gathered}
$$

For tabular orebodies, the volume can be approximated by the following equation:

$$
V=t_{t} \times S
$$

where

$t_{t} \quad$ is the average true thickness of the tabular orebody, in meters; and

$S \quad$ is the surface area, in square meters, measured in the plane of the tabular layer.

Alternatively, for a dipping layer, the volume can be estimated by the following equation:

$$
V=t_{a} \times S_{h}
$$

where

$$
\begin{gathered}
t_{a} \quad \begin{array}{c}
\text { is the apparent thickness of the tabular } \\
\text { orebody, in meters, measured } \\
\text { perpendicular to the horizon; and }
\end{array} \\
S_{h} \quad \begin{array}{l}
\text { is the surface area of the dipping orebody, in } \\
\text { square meters, projected to the surface. }
\end{array}
\end{gathered}
$$

Combining equations, the in-place contained metal content of a dipping stratiform orebody is obtained by the following equation:

$$
M=S_{h} \times\left(t_{a} \times \rho_{b} \times g\right)
$$

This estimation method is a form of the area-averaging method of mineral resource estimation described by Noble (1992), which requires only an interpretation of the shape of the orebody and the average grades within the shape. This formula can be used to estimate the metal that is undiscovered in extensions to known mineral inventory if information is available for all the parameters.

Metal surface density $(M S D)$ is calculated by dividing metal content $(M)$ for the mineral resource block by its surface area $S_{h}$ :

$$
M S D=\frac{M}{S_{h}}
$$

Metal surface density can be estimated from samples collected through the mineralized intervals in stratabound or stratiform orebodies. Mineralized intervals can be sampled in outcrop, drill hole, or underground workings. Metal surface density can also be estimated for a resource or reserve block if the tonnage, grade, and surface extent of the block are known.

\section{Interpolation and Simulation Techniques}

A single value of contained metal can be calculated from the kriged metal surface density surface for an assessment area. The spatial variation in metal surface density in the area is represented by using geostatistical interpolation techniques (kriging). This approach is used because it quantifies the spatial autocorrelation among measured points and accounts for the spatial configuration of the sample points around the prediction location. From the metal surface density surface, contained metal is calculated by multiplying the value of metal surface density for a cell by the cell area, and then summing the values for all cells.

Geostatistical simulation techniques can provide probabilistic estimates of the amount of undiscovered metal. Simulation techniques approximate solutions to uncertain and complex systems through statistical sampling. The system is represented by a model in which uncertainties in inputs, represented by probability distributions, are explicitly and quantitatively propagated into model outputs, also known as a probability distribution. For each simulation, or realization of the system, all of the uncertain parameters are sampled. In geostatistics, each simulation is the realization of a random function (surface) that has the same mean, variance, and semivariogram as the sample data used to generate it. The system is simulated many times, resulting in a large number of separate and independent realizations that represent a range of plausible possibilities, and, in this case, the contained metal that can be estimated from metal surface density relations. Gaussian geostatistical simulation is an example of a simulation technique that is available in the geostatistical tools in ArcGIS. Therefore, each metal surface realization can be processed to estimate contained metal and the results from all realizations can then be tabulated to give a probability distribution of contained metal for the model. 


\section{Working with Assessment Results}

Using deposit types, assessment geologists define areas in which undiscovered resources may be present and derive a frequency distribution of undiscovered, in-place metal. An assessment study may delineate many permissive tracts and probabilistic estimates of undiscovered resource. In order to integrate mineral assessment results with other types of information, it may be necessary to aggregate mineral assessments results into a single mineral resource theme and to indicate what proportion of the undiscovered mineral resource could potentially be economic.

\section{Aggregation of Assessment Results}

Permissive tracts are polygons that are represented with a vector model. Two classes of attributes, spatially intensive and spatially extensive, are associated with the vector model (Longley and others, 2001). These two classes of attributes represent fundamentally different types of information that are governed by different rules for spatial analysis. Spatially intensive attribute values are true for each part of an area. For a vector spatial representation of counties, county name would be an example of a spatially intensive attribute value. No matter how small a part of the county polygon is considered, the county name attribute is always true. Spatially extensive attribute values are true only for entire areas. County population is an example of a spatially extensive attribute value. If the county is subdivided into four parts, the value of county population is not true for each of the subdivisions. Spatially extensive attribute information can be aggregated but not subdivided.

Permissive tracts have spatially extensive and spatially intensive attributes. Attributes like tract name and deposit type assessed are spatially intensive. However, the undiscovered deposit estimate is a spatially extensive attribute; the estimate applies to the entire tract. The results of Monte Carlo simulation (in-place, undiscovered metal and ore [reported as percentiles and mean values], mean number of deposits, and the probability of zero deposits) are also spatially extensive attributes that apply only to an entire tract. Spatially intensive attributes can be aggregated and applied to a new tract that represents a union of the input tracts in which all the internal boundaries between overlapping areas are removed. The probability distributions of undiscovered metal from several mineral resource assessments can also be aggregated into a single result. However, the degree of association (dependencies) between geologically based assessment regions and tracts must be understood before aggregating assessment results. The mean of the aggregated distributions is the sum of the means of the individual distributions. However, aggregation does affect the spread of the functions because the variance of the combined distribution is affected by the dependency between the random variables. Quantile estimates of distributions can be added if the assumption of complete dependence among tracts can be made. Adding percentiles results in underestimating variance of the joint distribution if the distributions between assessment areas are independent or partially correlated (see, for example, Pike, 2008).

Schuenemeyer and others (2011) published a script that aggregates undiscovered deposit estimates for tracts of a given deposit type, by assuming independence, total dependence, or some degree of correlation among aggregated areas, given a user-specified correlation matrix. The aggregated undiscovered deposit estimates, along with appropriate grade and tonnage models, are then input into Monte Carlo simulation software to obtain an aggregated distribution of undiscovered metal.

\section{Economic Filters}

Mineral supply, economic, environmental, and land-use planning studies often require an estimate of the amount of undiscovered mineral resources that are likely to be economically recoverable. Economic filters based on simplified engineering cost models provide a method for estimating potential tonnages of undiscovered metals that may be economic in individual assessment areas. For example, Robinson and Menzie (2014) used this approach to perform an economic analysis of undiscovered resources estimated in porphyry copper deposits in six tracts located in North America.

The economic filter developed by Robinson and Menzie (2014) modified and updated mining engineering cost models from the former U.S. Bureau of Mines (Taylor, 1978, 1986) that used mine capacity, mine life, capital and operating costs to build and operate a mine and mill, metallurgical recovery, and 20-year average metal prices. To apply the economic filter for each permissive tract for porphyry copper deposits, a depth distribution of undiscovered deposits within the upper 1 kilometer $(\mathrm{km})$ of the Earth's crust is specified along with an estimate of the cost setting determined by the country or countries covered by the tract.

Simplified engineering cost models, updated with a cost index, were used to estimate the economic fraction of resources contained in undiscovered porphyry copper deposits as predicted in the USGS assessment of global copper resources (Robinson and Menzie, 2014).

The economic resource was estimated by the following equation:

$$
\text { economic resource }=\text { resource } \times \text { economic filter, }
$$

where the resource is the mean undiscovered resource estimated by simulation and the economic filter is the fraction of the resources estimated to be economic, based on the grade and tonnage model used in the simulation, the depth distribution for the undiscovered deposits, and adjustments for cost settings. The economic filters were computed by using an Excel workbook developed by Robinson and Menzie (2014). The 20-year (1989-2008) average metal prices and metallurgical recovery rates were used in the filter calculations. 
A number of parameters can be varied, such as grade and tonnage model, mining method, metal prices, recovery rates, use of a liner for tailings, depth settings, and cost settings. Examples of approaches to depth and cost setting estimates are described in the next two sections.

\section{Depth Percentages}

The depth distribution affects the amount of material that would have to be moved to develop a mine and determines the mining method (open pit or underground mining by block caving). Porphyry systems typically form within $1-4 \mathrm{~km}$ of the Earth's surface and are mined within the upper kilometer of the surface. Stratabound-hosted sedimentary copper deposits are mined to depths of 2.5 to $3 \mathrm{~km}$. Some deposits are exposed at the surface, but many are not. The amount of cover material that must be removed to access the ore for an open pit mine adds to the cost of developing a mine.

\section{Cost Settings}

The economic filter incorporates a parameter for cost setting to express the quality of existing regional infrastructure (Robinson and Menzie, 2014). A “typical cost" setting has existing regional infrastructure to support mining (for example, northern Mexico and southwestern United States or established mining areas in Chile). A "high cost" setting refers to remote areas that lack existing infrastructure to support mining (for example, the Tibetan Plateau or Mongolia).

The country-by-country infrastructure rankings compiled by the Fraser Institute (McMahon and Cervantes, 2012) can be used as an independent guide to selecting appropriate cost settings for mining for each tract. For example, the data from the 2011-2012 quality of infrastructure table (table A10 of McMahon and Cervantes, 2012) are expressed in terms of five categories of response: (1) encourages investment, (2) not a deterrent to investment, (3) mild deterrent, (4) strong deterrent, and (5) would not pursue investment due to this factor. The category scores can be used to classify cost settings as typical where categories 1 and 2 represent more than 50 percent of the response, as high cost where categories 3,4 , and 5 represent more than 50 percent of the response, and as mixed otherwise.

Many tracts cross jurisdictions, and some tract areas are in jurisdictions that are not evaluated by the Fraser Institute. For these tracts, the jurisdiction most closely associated with the tract can be used as a proxy.

\section{Operational Procedures}

This section of the appendix describes how a USGS mineral resource assessment is conducted. The following steps are used to conduct a mineral resource assessment by using the three-part form of assessment:

\section{- Understand the assignment}

- Identify the commodities and deposit types to assess

- Define the anticipated end use of assessment results

- Describe the scope of work, including assessment depth and nominal scale

- Identify available resources (models, procedures, personnel, and budget)

- Plan for the preparation of required products

- Set a timeframe for completion

\section{- Gather and compile data}

- Review literature

- Acquire geologic maps and databases of known mineral deposits and mineral occurrences; all datasets for the assessment should be at a scale appropriate for the study

- Acquire geochemical, geophysical, and exploration data, if available

- Acquire specialized data required to assess and delineate tracts for a particular deposit type

- Organize the data in a digital library and share the library with project staff

\section{- Enhance geologic data}

- Add attributes as needed for assessment study based on criteria in deposit and mineral system models

- Process data as needed to delineate tracts

\section{- Review and enhance mineral occurrence data}

- Classify known mineral deposits and occurrences by deposit type according to models

- Verify locations of deposits and prospects

- Update information using literature and technical reports published by exploration companies

- Review and apply spatial rules so that data will correspond to rules used to construct grade and tonnage and spatial density models

- Assess if deposits (sites with tonnage and grade) are well explored and should be classified as known deposits 


\section{- Select appropriate grade and tonnage model}

- Select published grade and tonnage models that might be appropriate for a quantitative assessment

- Use statistical tests to compare known deposits in an assessment area with published models. If all the published grade and tonnage models fail statistical tests, determine if an appropriate model can be developed for the quantitative assessment. If a unique model is developed for the quantitative assessment of an area, it must be published with the assessment.

\section{- Complete a preliminary study prior to the assess- ment meeting}

- Using descriptive mineral deposit models and mineral systems models, select the assessment unit for tract delineation

- Delineate permissive tracts

- Make preliminary estimates of undiscovered deposits

- Assemble an assessment team and identify an assessment oversight committee

- Assemble an assessment team, which should include a mix of scientists with appropriate backgrounds for the deposit type being assessed. Ideally, the team should include geologists with expertise in (1) the deposit type being assessed, (2) the regional geology of the study area, and (3) the mineral resource assessment methodology.

- Identify an assessment oversight committee

\section{- Conduct a workshop to quantitatively assess the} area

- Discuss ground rules, purpose, and goals of the workshop

- Summarize the geology of the deposit type, the geology of the study area, the characteristics of the grade and tonnage model, and the assessment method

- Present preliminary tracts and revise as needed

- If using grade and tonnage models to estimate undiscovered mineral resources, emphasize that undiscovered deposit estimates must be consistent with the models

- Estimate the number of undiscovered deposits. Each team member initially determines estimates independently. The independent estimates are then compared and discussed. Regression equations are used to calculate the mean number of undiscovered deposits and the coefficient of variation. A consensus value for the simulation value is determined.

- Document assessment information-deposit type assessed; descriptive model used; grade and tonnage model used; the geologic feature being assessed (the assessment unit); geologic criteria used for tract delineation; known deposits, prospects, and occurrences; exploration history; sources of information; estimate of the number of undiscovered deposits; and rationale for the estimate

- Estimate undiscovered mineral resources by using Monte Carlo simulation

- Run Monte Carlo simulations

- Check Monte Carlo simulation results to make sure they are consistent with the cited grade and tonnage model

- Present results of the assessment to the assessment oversight committee

- Provide all data used to the assessment oversight committee, in digital format, for review prior to the presentation

- Present the assessment results to the assessment oversight committee

- Revise the assessment in response to committee comments

\section{- Prepare a report with the assessment results}

- Prepare a template for report chapters

- Write a report draft and obtain consensus among coauthors

- Respond to reviews by project managers

- Obtain two or more technical reviews and prepare a reconciliation

- Submit the report for USGS editing, Bureau approval, and publication

\section{Conclusion}

Assessments of undiscovered mineral resources prepared according to the USGS procedures described in this appendix are internally consistent because the team members have a shared understanding of terminology, use consistent methods, and document the models and assumptions used. 


\section{References Cited}

Barnicoat, Andy, 2006, Exploration science-Linking fundamental controls on ore deposition with the exploration process: [Australia] Cooperative Research Centre Predictive Mineral Discovery Fact Sheet, 4 p., accessed June 29, 2012, at http://www.pmdcrc.com.au/pdfs/brochures_exploration science_fs.pdf.

Barton, P.B., Brew, D.A., Ludington, Steve, Lindsey, D.A., Ayuso, R.A., Force, E.R., Gamble, B.M., Goldfarb, R.J., John, D.A., and Johnson, K.M., 1995, Recommendations for assessments of undiscovered mineral resources: U.S. Geological Survey Open-File Report 95-82, variously paged. [Also available at https://pubs.er.usgs.gov/ publication/ofr9582.]

Bates, R.L., and Jackson, J.A., eds., 1987, Glossary of geology (3d ed.): Alexandria, Va., American Geological Institute, $788 \mathrm{p}$.

Bawiec, W.J., and Spanski, G.T., 2012, Quick-start guide for version 3.0 of EMINERS-Economic Mineral Resource Simulator: U.S. Geological Survey Open-File Report 2009-1057, 26 p., accessed June 30, 2012, at http://pubs. usgs.gov/of/2009/1057. [This report supplements USGS OFR 2004-1344 by J.S. Duval.]

Blewett, R.S., Henson, P.A., Roy, I.G., Champion, D.C., and Cassidy, K.F., 2010, Scale-integrated architecture of a world-class gold mineral system - The Archaean eastern Yilgarn Craton, Western Australia: Precambrian Research, v. 183, no. 2, p. 230-250. [Also available at http://dx.doi. org/10.1016/j.precamres.2010.06.004.]

Bliss, J.D., Orris, G.J., and Menzie, W.D., 1987, Changes in grade, volume and contained gold during the mining lifecycle of gold placer deposits: CIM Bulletin, v. 80, no. 903, p. 75-79.

Carroll, Lewis (Charles L. Dodgson), 1872, Through the looking-glass: London, U.K., Macmillan and Company Limited, $224 \mathrm{p}$.

Clemen, Bob, 2001, Assessing 10-50-90s-A surprise: Decision Analysis Newsletter, v. 20, no. 1, p. 2 and 15, accessed October 2, 2012, at http://faculty.fuqua.duke.edu/ clemen/ bio/Published\%20Papers/C1.Overconfidence.DAS.2001. pdf.

Committee for Mineral Reserves International Reporting Standards, 2006, International reporting template for the public reporting of exploration results, mineral resources and mineral reserves: Committee for Mineral Reserves International Reporting Standards, 33 p., accessed June 4, 2013, at http:// www.crirsco.com/crirsco_template_first_ed_0806.pdf.
Cox, D.P., and Singer, D.A., eds., 1986, Mineral deposit models: U.S. Geological Survey Bulletin 1693, 379 p. [Also available at https://pubs.er.usgs.gov/publication/b1693.]

Cox, D.P., Barton, P.B., and Singer, D.A., 1986, Introduction, in Cox, D.P., and Singer, D.A., eds., Mineral deposit models: U.S. Geological Survey Bulletin 1693, p. 1-10. [Also available at https://pubs.er.usgs.gov/publication/b1693.]

Cox, D.P., Lindsey, D.A., Singer, D.A., Moring, B.C., and Diggles, M.F., 2007, Sediment-hosted copper deposits of the world-Deposit models and database (ver. 1.3, 2007): U.S. Geological Survey Open-File Report 03-107, variously paged text plus plot and data files, accessed June 1, 2015, at http://pubs.usgs.gov/of/2003/of03-107/.

Duval, J.S., 2012, Version 3.0 of EMINERS-Economic Mineral Resource Simulator: U.S. Geological Survey Open-File Report 2004-1344, accessed July 15, 2012, at http://pubs. usgs.gov/of/2004/1344.

Eckstrand, O.R., ed., 1984, Canadian mineral deposit types-A geological synopsis: Geological Survey of Canada Economic Geology Report 36, 86 p. [Also available at http://geoscan.nrcan.gc.ca/starweb/ geoscan/servlet.starweb?path=geoscan/downloade. web\&search $1=\mathrm{R}=120000$.]

Hayes, T.S., Cox, D.P., Piatak, N.M., and Seal, R.R., II, 2015, Sediment-hosted stratabound copper deposit model: U.S. Geological Survey Scientific Investigations Report 20105070-M, 147 p., accessed July 7, 2015, at http://dx.doi. org/10.3133/sir20105070M.

Hitzman, Murray, Kirkham, Rodney, Broughton, David, Thorson, Jon, and Selley, David, 2005, The sedimenthosted stratiform copper ore system, in Hedenquist, J.W., Thompson, J.F.H., Goldfarb, R.J., and Richards, J.P., eds., Economic Geology - One hundredth anniversary volume, 1905-2005: Littleton, Colo., Society of Economic Geologists, Inc., p. 609-642.

Hronsky, J.M.A., 2004, The science of exploration targeting, in Muhling, J.R., Goldfarb, R.J., Vielreicher, N., Bierlein, F.P., Stumpfl, E.F., Groves, D.I., and Kenworthy, S., eds., SEG 2004-Predictive mineral discovery under coverExtended abstracts [for SEG Conference \& Exhibition, 27 September-1 October 2004, Perth, Western Australia]: University of Western Australia, Centre for Global Metallogeny Publication 33, p. 129-133.

Hronsky, J.M.A., and Groves, D.I., 2008, Science of targeting-Definition, strategies, targeting and performance measurement: Australian Journal of Earth Sciences, v. 55, no. 1 , p. 3-12. 
Knox-Robinson, C.M., and Wyborn, L.A.I., 1997, Towards a holistic exploration strategy_Using geographic information systems as a tool to enhanced exploration: Australian Journal of Earth Sciences, v. 44, no. 4, p. 453-463.

Kreuzer, O.P., Etheridge, M.A., Guj, Pietro, McMahon, M.E., and Holden, D.J., 2008, Linking mineral deposit models to quantitative risk analysis and decision-making in exploration: Economic Geology, v. 103, no. 4, p. 829-850.

Lindgren, Waldemar, 1933, Mineral deposits (4th ed.): New York, McGraw-Hill Book Company, Inc., 930 p.

Longley, P.A., Goodchild, M.F., Maguire, D.J., and Rhind, D.W., 2001, Geographic information systems and science (1st ed.): Chichester, U.K., John Wiley \& Sons, 454 p.

Magoon, L.B., and Dow, W.G., 1994, The petroleum system, in Magoon, L.B., and Dow, W.G., eds., The petroleum system-From source to trap: American Association of Petroleum Geologists Memoir 60, p. 3-24.

Magoon, L.B., and Schmoker, J.W., 2000, The total petroleum system - The natural fluid network that constrains the assessment unit, chap. PS of U.S. Geological Survey World Energy Assessment Team, U.S. Geological Survey world petroleum assessment 2000_Description and results: U.S. Geological Survey Digital Data Series DDS-60, p. PS-1 to PS-20 plus 3 figures and 1 table on a CD-ROM. [Also available at http://pubs.usgs.gov/dds/dds-060/.]

McCuaig, T.C., Beresford, S.W., and Hronsky, Jon, 2010, Translating the mineral systems approach into an effective exploration targeting system: Ore Geology Reviews, v. 38, no. 3 , p. 128-138.

McMahon, Fred, and Cervantes, Miguel, 2012, Fraser Institute annual survey of mining companies 2011/2012: Vancouver, Canada, Fraser Institute, 131 p.

Neuendorf, K.K.E., Mehl, J.P., Jr., and Jackson, J.A., eds., 2015, Glossary of geology: American Geosciences Institute online glossary, accessed October 1, 2015, at http://glossary. agiweb.org/dbtw-wpd/glossary/search.aspx.

Noble, A.C., 1992, Ore reserve/resource estimation, in Hartman, H.L., ed., SME Mining Engineering Handbook, vol. 1: Englewood, Colo., Society for Mining, Metallurgy, and Exploration, p. 344-359.

Pike, Richard, 2008, How much oil is really there? Making correct statistics bring reality to global planning: Significance, v. 5, no. 4, p. 149-152.

Pohl, W.L., 2011, Economic geology_Principles and practice (1st ed.): Chichester, U.K., Wiley-Blackwell, 680 p.
Porwal, A.K., and Kreuzer, O.P., 2010, Introduction to the special issue-Mineral prospectivity analysis and quantitative resource estimation: Ore Geology Reviews, v. 38, no. 3, p. $121-127$.

Reed, M.H., 1997, Hydrothermal alteration and its relationship to ore fluid composition, in Barnes, H.L., ed., Geochemistry of hydrothermal ore deposits ( $3 \mathrm{~d}$ ed.): New York, John Wiley \& Sons, p. 303-366.

Robinson, G.R., Jr., and Menzie, W.D., 2014, Economic filters for evaluating porphyry copper deposit resource assessments using grade-tonnage deposit models, with examples from the U.S. Geological Survey global mineral resource assessment (ver. 1.2, March 2014): U.S. Geological Survey Scientific Investigations Report 2010-5090-H, 21 p. and separate file for tables 7 and 8, accessed June 1, 2015, at http://pubs.usgs.gov/sir/2010/5090/h/.

Root, D.H., Menzie, W.D., and Scott, W.A., 1992, Computer Monte Carlo simulation in quantitative resource estimation: Nonrenewable Resources, v. 1, no. 2, p. 125-138.

Schuenemeyer, J.H., Zientek, M.L, and Box, S.E., 2011, Aggregation of estimated numbers of undiscovered mineral deposits-An R-script with an example from the Chu Sarysu Basin, Kazakhstan: U.S. Geological Survey Scientific Investigations Report 2010-5090-B, 13 p. and code package, accessed June 1, 2015, at http://pubs.usgs.gov/ sir/2010/5090/b/.

Schulte, R.F., Taylor, R.D., Piatak, N.M., and Seal, R.R., II, 2012, Stratiform chromite deposit model: U.S. Geological Survey Scientific Investigations Report 2010-5070-E, 131 p., accessed June 1, 2015, at http://pubs.usgs.gov/ sir/2010/5070/e/.

Sinclair, A.J., and Blackwell, G.H., 2002, Applied mineral inventory estimation: New York, Cambridge University Press, $381 \mathrm{p}$.

Singer, D.A., 1993, Basic concepts in three-part quantitative assessments of undiscovered mineral resources: Nonrenewable Resources, v. 2, no. 2, p. 69-81.

Singer, D.A., 2007, Mineral deposit densities for estimating mineral resources: Mathematical Geosciences, v. 40, no. 1, p. 33-46.

Singer, D.A., and Berger, V.I., 2007, Deposit models and their application in mineral resource assessments, in Briskey, J.A., and Schulz, K.J., eds., Proceedings for a Workshop on Deposit Modeling, Mineral Resource Assessment, and Their Role in Sustainable Development: U.S. Geological Survey Circular 1294, p. 71-78. [Also available at http://pubs.usgs. gov/circ/2007/1294/.] 
Singer, D.A., and Menzie, W.D., 2005, Statistical guides to estimating the number of undiscovered mineral deposits-An example with porphyry copper deposits, in Cheng, Qiuming, and Bonham-Carter, Graeme, eds., Proceedings of IAMG '05-The annual conference of the International Association for Mathematical Geology - GIS and spatial analysis: Toronto, Canada, York University, Geomatics Research Laboratory, v. 2, p. 1028-1033.

Singer, D.A., and Menzie, W.D., 2010, Quantitative mineral resource assessments-An integrated approach: New York, Oxford University Press, 219 p.

Singer, D.A., Berger, V.I., Menzie, W.D., and Berger, B.R., 2005, Porphyry copper deposit density: Economic Geology, v. 100 , no. 3 , p. $491-514$.

Skinner, B.J., and Barton, P.B., Jr., 1973, Genesis of mineral deposits: Annual Review of Earth and Planetary Sciences, v. 1, p. 183-211.

Taylor, H.K., 1978, Mine valuation and feasibility studies, in Hoskins, J.R., and Green, W.R., eds., Mineral industry costs (2d ed., revised): Spokane, Wash., Northwest Mining Association, p. 1-17.

Taylor, H.K., 1986, Rates of working of mines-A simple rule of thumb: Transactions of the Institution of Mining and Metallurgy, Section A, Mining Industry, v. 95, p. A203A204.

Wyborn, L.A.I., Heinrich, C.A., and Jaques, A.L., 1994, Australian Proterozoic mineral systems - Essential ingredients and mappable criteria, in Hallenstein, C.P., ed., Australian mining looks north-The challenges and choices - 1994 AusIMM Annual Conference, Darwin, 5-9 August 1994, technical program proceedings: Australasian Institute of Mining and Metallurgy Publication 5/94, p. 109-116, accessed May 24, 2012, at http://www.ga.gov.au/image_ cache/GA5228.pdf.

Zientek, M.L., 2012, Magmatic ore deposits in layered intrusions-Descriptive model for reef-type PGE and contacttype Cu-Ni-PGE deposits: U.S. Geological Survey OpenFile Report 2012-1010, 48 p., accessed June 1, 2015, at http://pubs.usgs.gov/of/2012/1010/.
Zientek, M.L., and Hammarstrom, J.M., 2014, Mineral resource assessment methods and procedures used in the global mineral resource assessment reports, app. A of Zientek, M.L., Bliss, J.D., Broughton, D.W., Christie, Michael, Denning, P.D., Hayes, T.S., Hitzman, M.W., Horton, J.D., Frost-Killian, Susan, Jack, D.J., Master, Sharad, Parks, H.L., Taylor, C.D., Wilson, A.B., Wintzer, N.E., and Woodhead, Jon, Sediment-hosted stratabound copper assessment of the Neoproterozoic Roan Group, Central African Copperbelt, Katanga Basin, Democratic Republic of the Congo and Zambia: U.S. Geological Survey Scientific Investigations Report 2010-5090-T, p. 54-64, accessed June 1, 2015, at http://dx.doi.org/10.3133/sir20105090T.

Zientek, M.L., Hayes, T.S., and Hammarstrom, J.M., 2013, Overview of a new descriptive model for sediment-hosted stratabound copper deposits, chap. 1 of Taylor, C.D., Causey, J.D., Denning, P.D., Hammarstrom, J.M., Hayes, T.S., Horton, J.D., Kirschbaum, M.J., Parks, H.L., Wilson, A.B., Wintzer, N.E., and Zientek, M.L., Descriptive models, grade-tonnage relations, and databases for the assessment of sediment-hosted copper deposits-With emphasis on deposits in the Central African Copperbelt, Democratic Republic of the Congo and Zambia: U.S. Geological Survey Scientific Investigations Report 2010-5090-J, p. 2-16, accessed July 7, 2014, at http://pubs.usgs.gov/sir/2010/5090/j/.

Zientek, M.L., Hayes, T.S., and Taylor, C.D., 2013, Grade and tonnage relations for sediment-hosted stratabound copper deposits, chap. 2 of Taylor, C.D., Causey, J.D., Denning, P.D., Hammarstrom, J.M., Hayes, T.S., Horton, J.D., Kirschbaum, M.J., Parks, H.L., Wilson, A.B., Wintzer, N.E., and Zientek, M.L., Descriptive models, grade-tonnage relations, and databases for the assessment of sediment-hosted copper deposits-With emphasis on deposits in the Central African Copperbelt, Democratic Republic of the Congo and Zambia: U.S. Geological Survey Scientific Investigations Report 2010-5090-J, p. 17-59, accessed July 7, 2014, at http://pubs.usgs.gov/sir/2010/5090/j/. 


\section{Appendix 3. Geologic Time Chart}

The "International Stratigraphic Chart" produced by the International Commission on Stratigraphy (ICS, 2010, 2013) was used throughout the U.S. Geological Survey global copper mineral resource assessment as the reference geologic time chart. A status update of the chart in 2013 was given by Cohen and others (2013). The chart is updated periodically. Old versions and translations of the chart in many languages can be accessed at http://www.stratigraphy.org/ index.php/ics-chart-timescale. For the convenience of readers of this volume, version 2013/01 is reproduced as figure $3-1$ of this appendix.

\section{References Cited}

Cohen, K.M., Finney, S.C., Gibbard, P.L., and Fan, J.-X., 2013, The ICS international chronostratigraphic chart: Episodes, v. 36, no. 3, p. 199-204.

International Commission on Stratigraphy, 2010, International stratigraphic chart, September 2010 version: International Commission on Stratigraphy chart, accessed October 1, 2016, at http://www.stratigraphy.org/index.php/ics-chart-timescale.

International Commission on Stratigraphy, 2013, International chronostratigraphic chart, version 2013/01: International Commission on Stratigraphy chart, accessed October 1, 2016, at http://www.stratigraphy.org/index.php/ics-chart-timescale. 


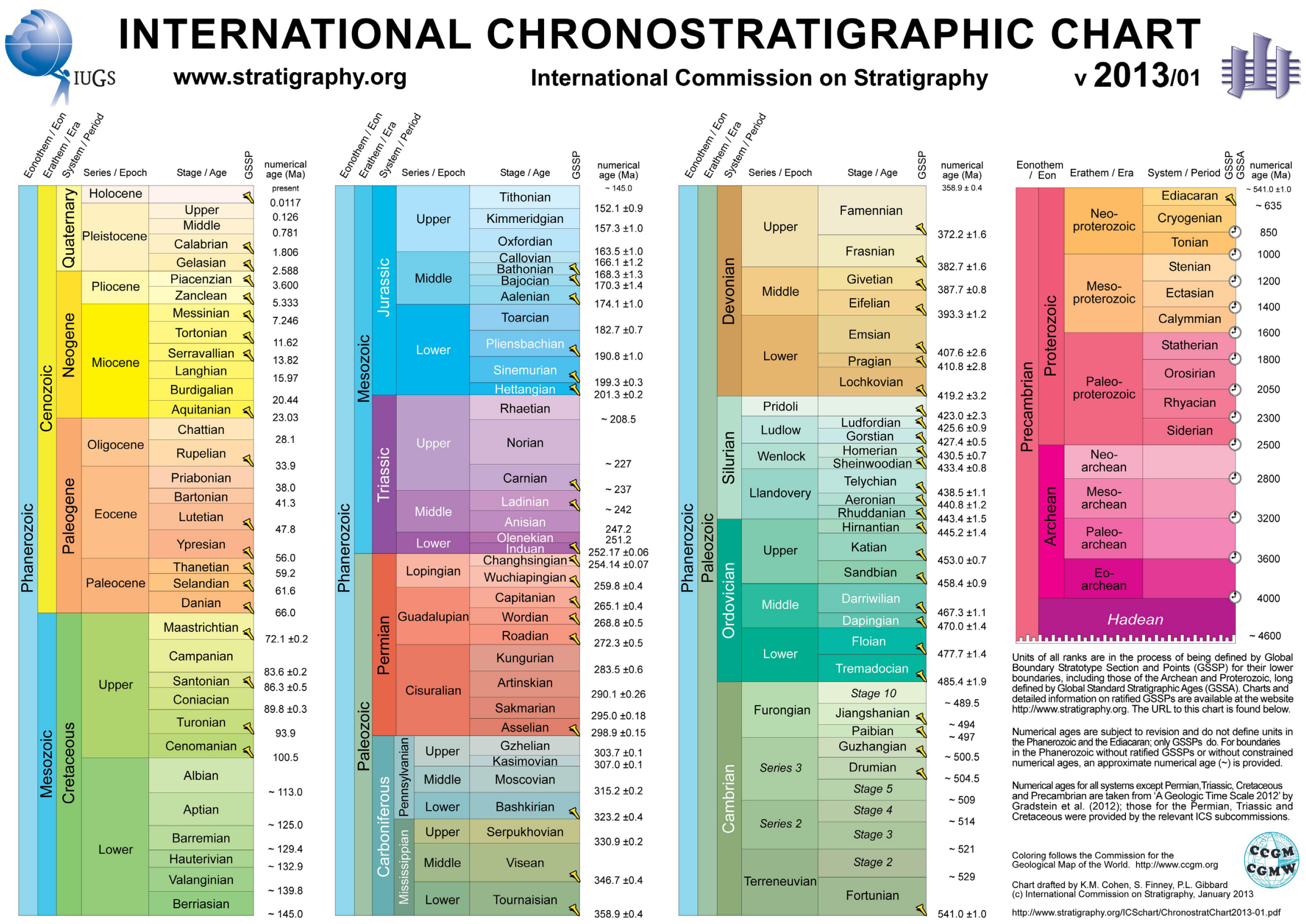

Figure 3-1. Reproduction of version 2013/01 of the "International Chronostratigraphic Chart" (International Commission on Stratigraphy, 2013). 



\section{Plates 1-188. Results of Regional-Scale Porphyry Copper Assessments}

[Plates 189-236 follow plate 188] 


\title{
Plate 1. Porphyry Copper Assessment for Tract 005pCu1020, Cretaceous Turbio - Chile and Argentina
}

\author{
Descriptive model: \\ Porphyry copper model (Cox, 1986a) \\ Grade and tonnage model: \\ General porphyry copper model (Singer, Berger, and Moring, 2005) \\ Economic filter depth percentages: \\ Economic filter cost setting: \\ Skewed shallow-0 to 250 meters (m), 35\%; > 250 to $500 \mathrm{~m}, 25 \%$; $>500 \mathrm{~m}$ to $1 \mathrm{~km}, 40 \%$ \\ High cost \\ Geologic feature assessed: \\ Cretaceous calc-alkalic batholiths and plutons composed mostly of biotite- and hornblende-bearing \\ granite, granodiorite, and tonalite \\ Number of known deposits: \\ 0
}

\section{Selected Resource Assessment Results for Porphyry Copper}

[Assessment depth, 1 kilometer ( $\mathrm{km}) ; \mathrm{km}^{2}$, square kilometer; Mt, millions of metric tons]

\begin{tabular}{ccccccc}
\hline $\begin{array}{c}\text { Date of } \\
\text { assessment }\end{array}$ & $\begin{array}{c}\text { Tract area } \\
\left(\mathbf{k m}^{2}\right)\end{array}$ & $\begin{array}{c}\text { Identified } \\
\text { copper } \\
\text { resources } \\
\text { (Mt) }\end{array}$ & $\begin{array}{c}\text { Mean estimate of } \\
\text { in-place resources } \\
(\mathbf{M t})\end{array}$ & $\begin{array}{c}\text { Probability of } \mathbf{0} \\
\text { in-place resources } \\
\text { (percent) }\end{array}$ & $\begin{array}{c}\text { Mean estimate of } \\
\text { economic resources } \\
\text { (Mt) }\end{array}$ & $\begin{array}{c}\text { Probability of 0 } \\
\text { economic resources } \\
\text { (percent) }\end{array}$ \\
\hline 2007 & 223,010 & 0 & 7.8 & 20 & 3.9 \\
\hline
\end{tabular}

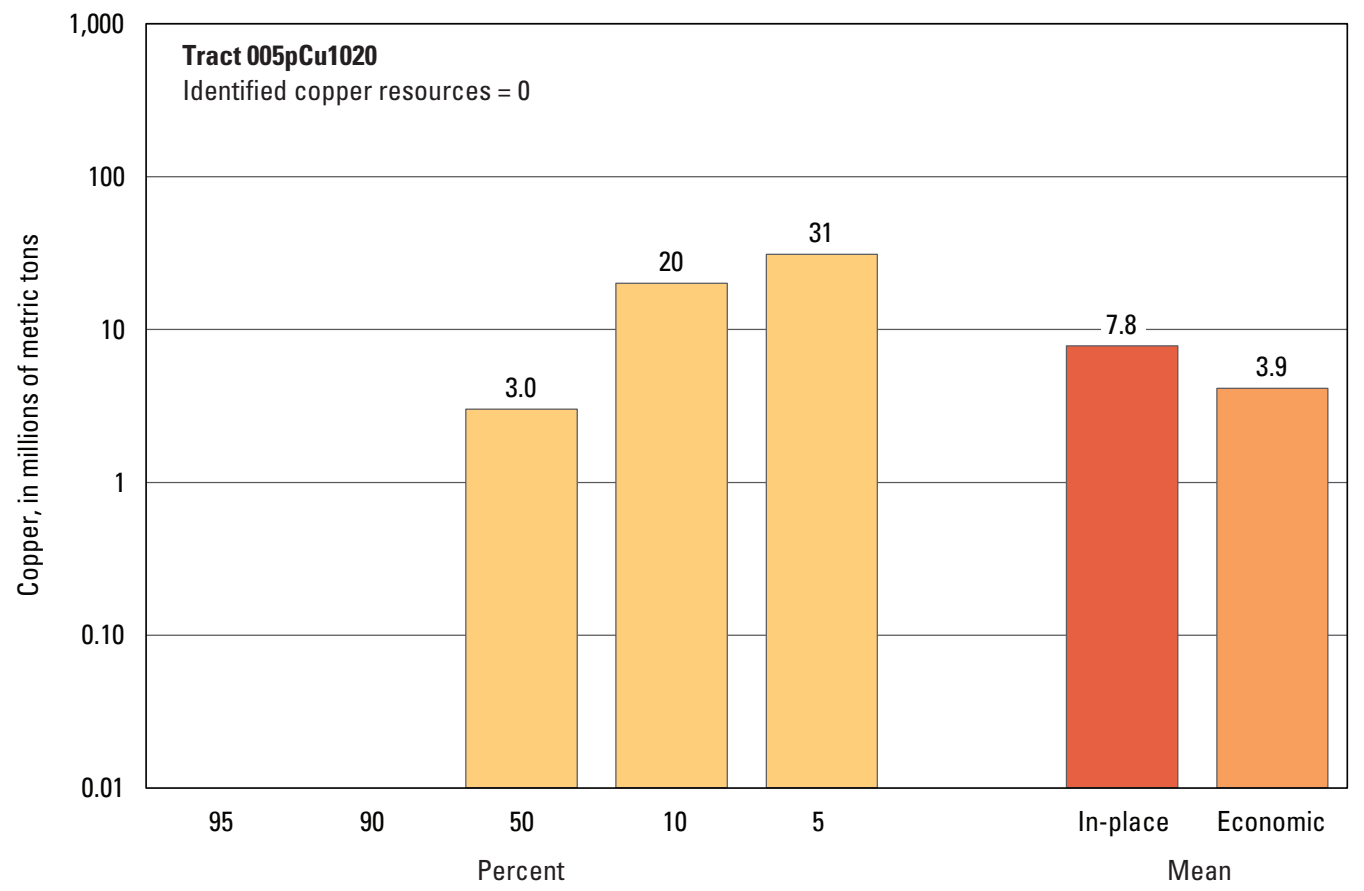

Graph showing the estimated probability distribution of undiscovered copper resources, where each bar represents the minimum amount estimated at the indicated percentage.

\section{Source}

Cunningham and others, 2008, Quantitative mineral resource assessment of copper, molybdenum, gold, and silver in undiscovered porphyry copper deposits in the Andes Mountains of South America: U.S. Geological Survey Open-File Report 2008-1253, http://pubs.usgs.gov/of/2008/1253/. 


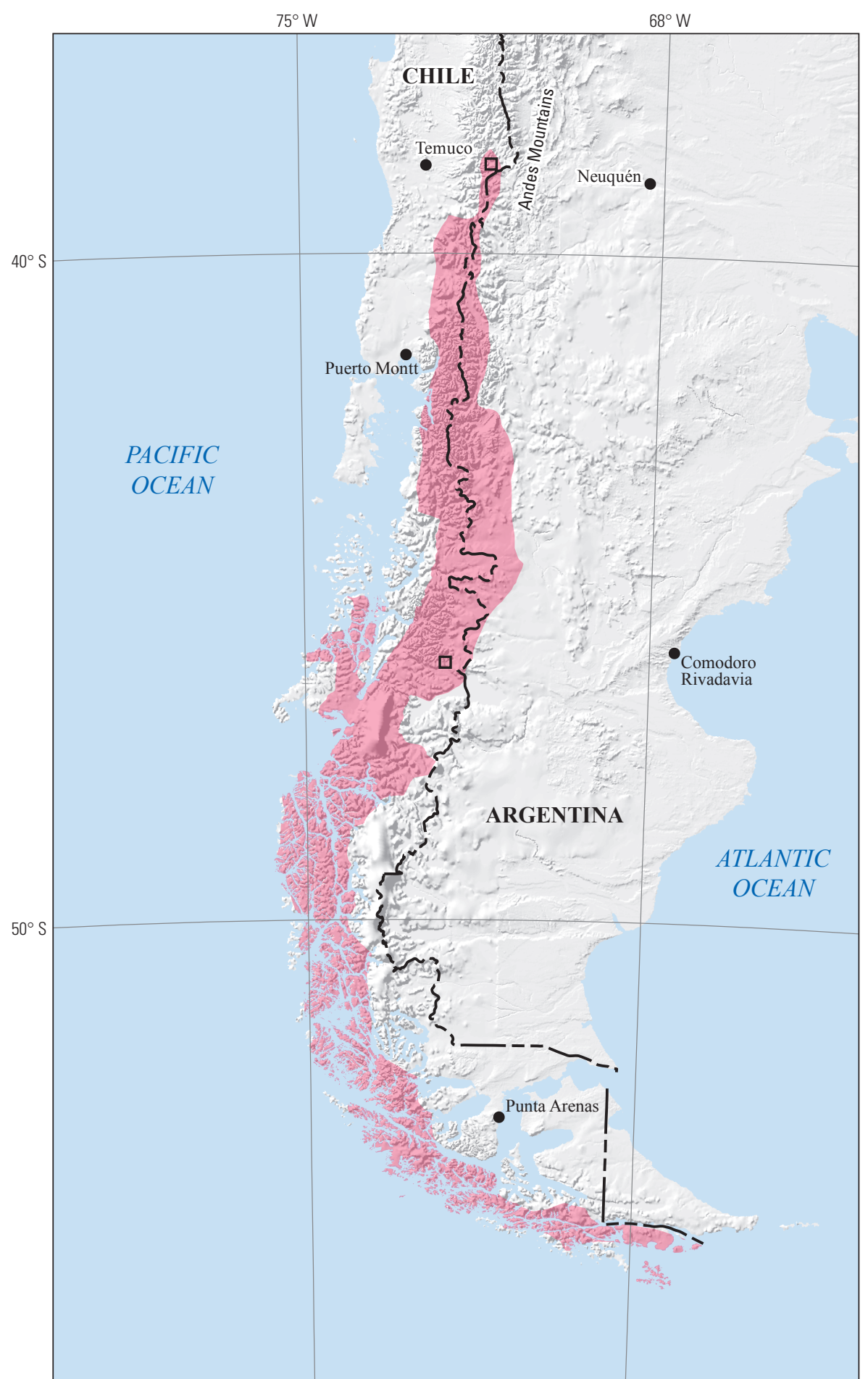

Political boundaries from U.S. Department of State (2009) Shaded relief from Earth Resources Observation and Science (EROS) Center (2011)

South America Albers Equal-Area Conic projection Central meridian $73^{\circ} \mathrm{W}$.; latitude of origin $32^{\circ} \mathrm{S}$.

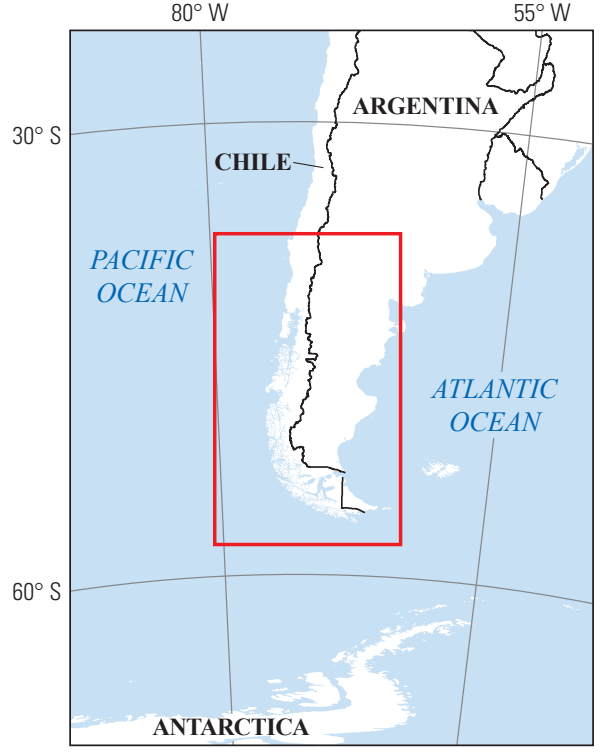

\section{EXPLANATION}

Assessed porphyry copper tract 005pCu1020

Porphyry copper prospect 


\section{Plate 2. Porphyry Copper Assessment for Tract 005pCu1019, Late Triassic to Middle Jurassic Bajo de la Leona-Argentina}

\author{
Descriptive model: \\ Grade and tonnage model: \\ Economic filter depth percentages: \\ Economic filter cost setting: \\ Geologic feature assessed:
}

Number of known deposits:

\author{
Porphyry copper model (Cox, 1986a) \\ General porphyry copper model (Singer, Berger, and Moring, 2005) \\ Default -0 to 250 meters (m), $25 \% ;>250$ to $500 \mathrm{~m}, 25 \%$; $>500 \mathrm{~m}$ to $1 \mathrm{~km}, 50 \%$ \\ High cost \\ Late Triassic to Middle Jurassic calc-alkalic plutons, including the Subcordilleran batholith and \\ the Central Patagonian batholith, which consists mostly of granodiorite, granite, and leucocratic \\ granite \\ 0
}

\section{Selected Resource Assessment Results for Porphyry Copper}

[Assessment depth, 1 kilometer $(\mathrm{km}) ; \mathrm{km}^{2}$, square kilometer; Mt, millions of metric tons]

\begin{tabular}{|c|c|c|c|c|c|c|}
\hline \multirow[b]{2}{*}{$\begin{array}{c}\text { Date of } \\
\text { assessment }\end{array}$} & \multirow[b]{2}{*}{$\begin{array}{c}\text { Tract area } \\
\quad\left(\mathrm{km}^{2}\right)\end{array}$} & \multirow{2}{*}{$\begin{array}{l}\text { Identified } \\
\text { copper } \\
\text { resources } \\
\text { (Mt) }\end{array}$} & \multicolumn{4}{|c|}{ Undiscovered copper resource estimates } \\
\hline & & & $\begin{array}{l}\text { Mean estimate of } \\
\text { in-place resources } \\
\text { (Mt) }\end{array}$ & $\begin{array}{c}\text { Probability of } 0 \\
\text { in-place resources } \\
\text { (percent) }\end{array}$ & $\begin{array}{l}\text { Mean estimate of } \\
\text { economic resources } \\
\text { (Mt) }\end{array}$ & $\begin{array}{c}\text { Probability of } 0 \\
\text { economic resources } \\
\text { (percent) }\end{array}$ \\
\hline 2006 & 45,642 & 0 & 5.9 & 30 & 2.8 & 86 \\
\hline
\end{tabular}

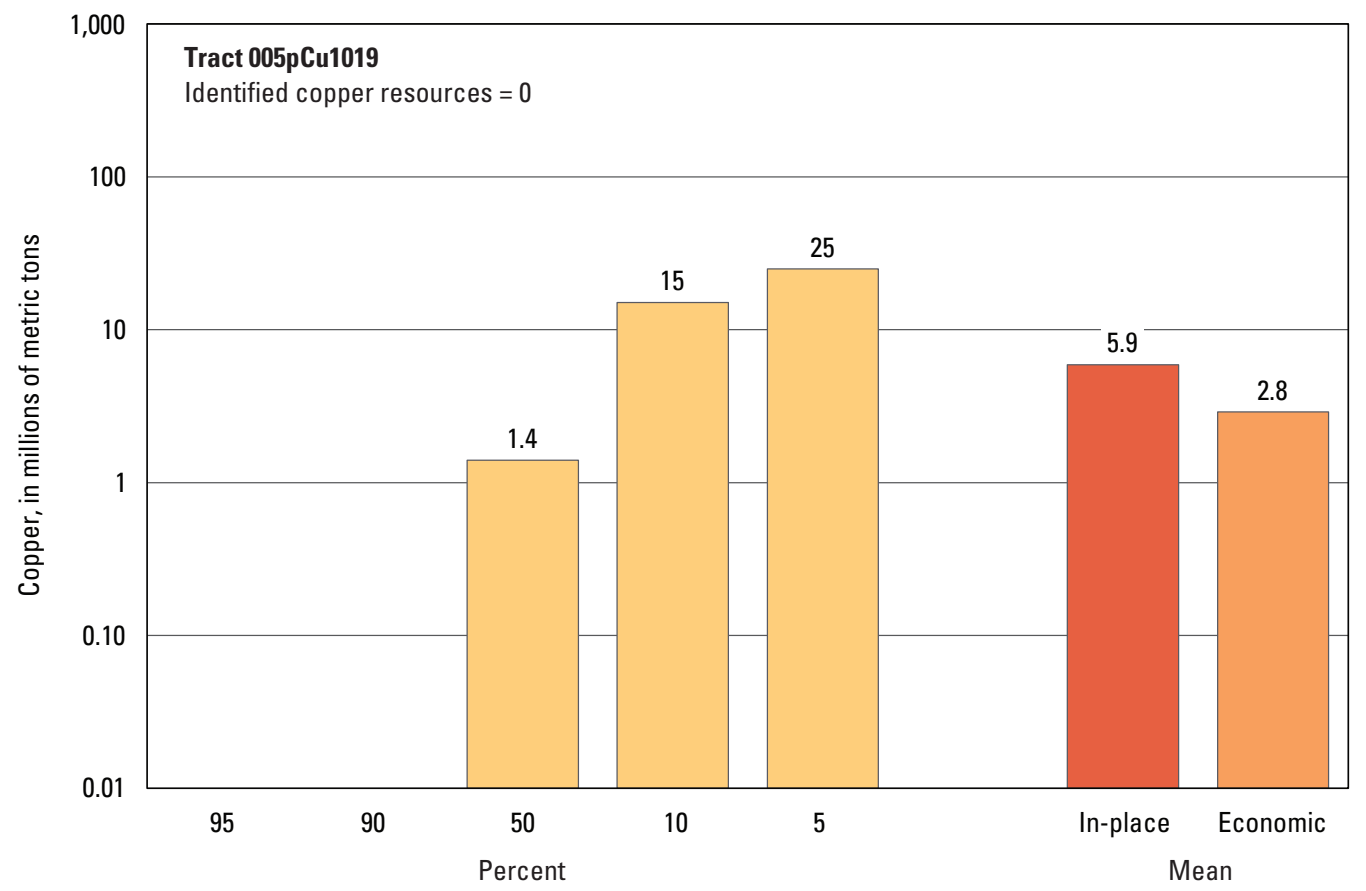

Graph showing the estimated probability distribution of undiscovered copper resources, where each bar represents the minimum amount estimated at the indicated percentage.

\section{Source}

Cunningham and others, 2008, Quantitative mineral resource assessment of copper, molybdenum, gold, and silver in undiscovered porphyry copper deposits in the Andes Mountains of South America: U.S. Geological Survey Open-File Report 2008-1253, http://pubs.usgs.gov/of/2008/1253/. 


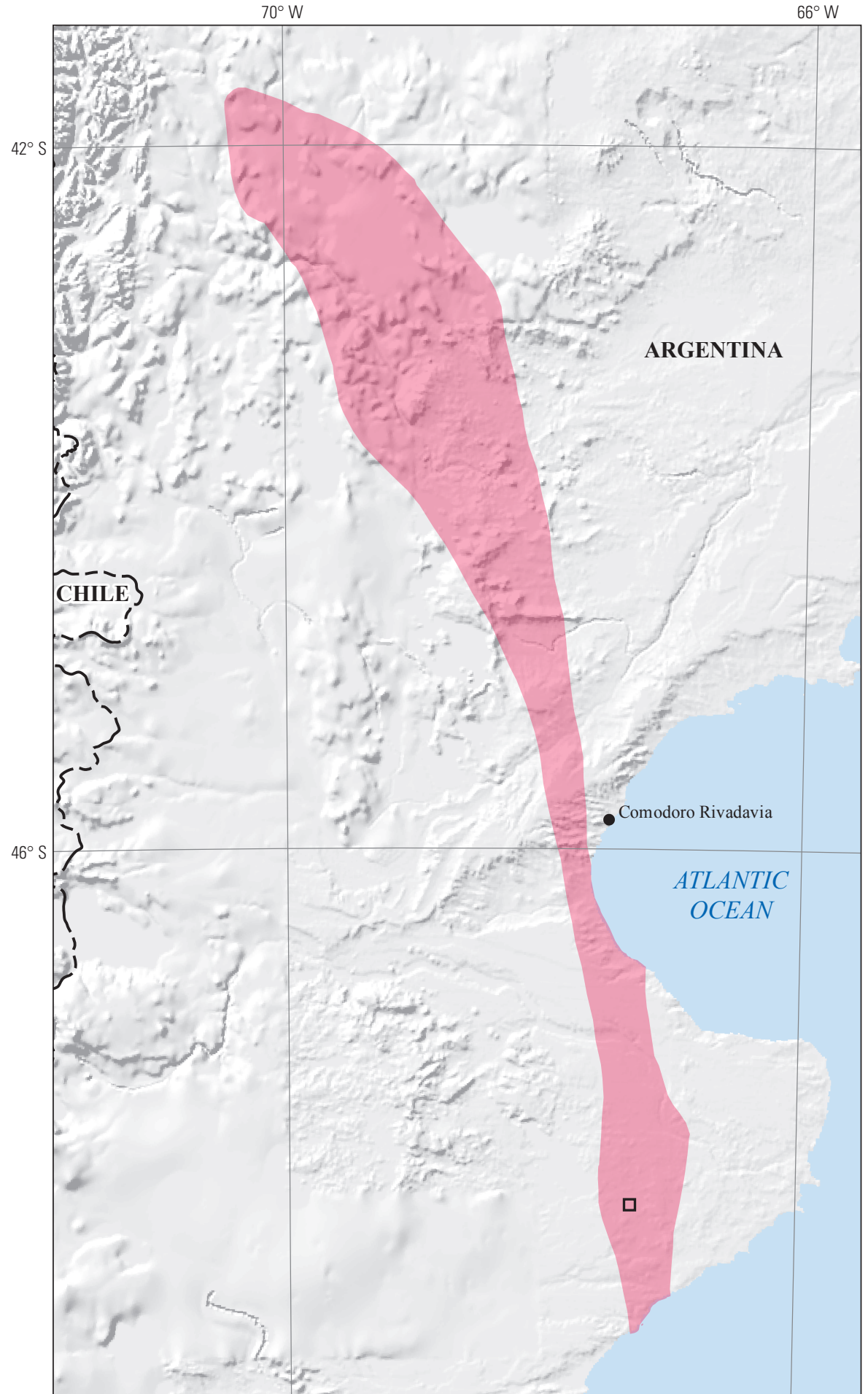

Political boundaries from U.S. Department of State (2009) Shaded relief from Earth Resources Observation and Science (EROS) Center (2011)

South America Albers Equal-Area Conic projection Central meridian $69^{\circ} \mathrm{W}$.: latitude of origin $32^{\circ} \mathrm{S}$.

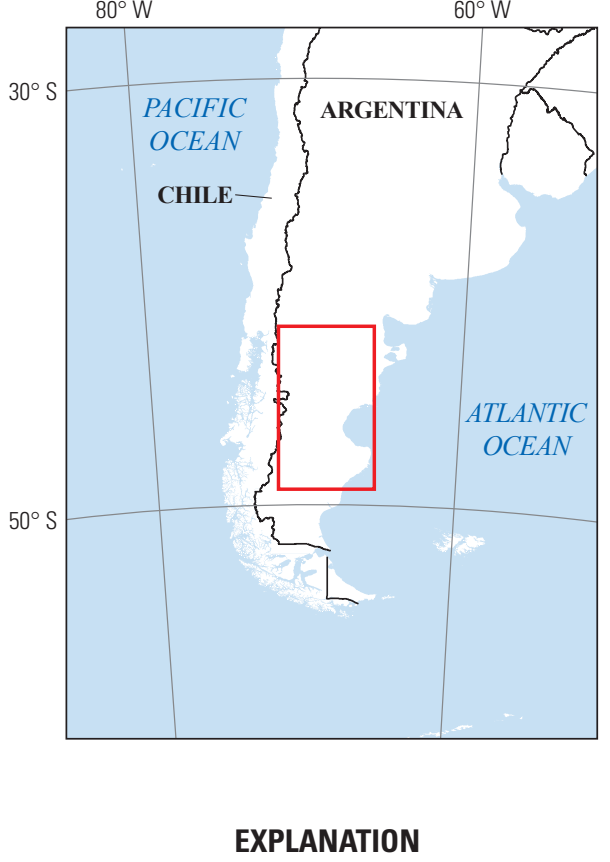

Assessed porphyry copper tract $005 p$ Cu1019

․ Porphyry copper prospect 


\section{Plate 3. Porphyry Copper Assessment for Tract 005pCu1013d, Miocene Coastal-Chile and Argentina}

\author{
Descriptive model: \\ Grade and tonnage model: \\ Economic filter depth percentages: \\ Economic filter cost setting: \\ Geologic feature assessed:
}

Number of known deposits:

\author{
Porphyry copper model (Cox, 1986a) \\ General porphyry copper model (Singer, Berger, and Moring, 2005) \\ Skewed shallow-0 to 250 meters (m), 35\%; > 250 to $500 \mathrm{~m}, 25 \%$; $>500 \mathrm{~m}$ to $1 \mathrm{~km}, 40 \%$ \\ Typical cost \\ Miocene mainly calc-alkalic granodiorite, diorite, and tonalite plutons, including batholiths; \\ plutons and batholiths apparently are consanguineous with the plutons in tracts $005 \mathrm{pCu} 1013 \mathrm{~b}$ \\ (pl. 6) and 005pCu1013c (pl. 10) \\ 0
}

\section{Selected Resource Assessment Results for Porphyry Copper}

[Assessment depth, 1 kilometer $(\mathrm{km}) ; \mathrm{km}^{2}$, square kilometer; Mt, millions of metric tons]

\begin{tabular}{ccccccc}
\hline $\begin{array}{c}\text { Date of } \\
\text { assessment }\end{array}$ & $\begin{array}{c}\text { Tract area } \\
\left(\mathbf{k m}^{2}\right)\end{array}$ & $\begin{array}{c}\text { Identified } \\
\text { copper } \\
\text { resources } \\
(\mathbf{M t})\end{array}$ & $\begin{array}{c}\text { Mean estimate of } \\
\text { in-place resources } \\
(\mathbf{M t})\end{array}$ & $\begin{array}{c}\text { Probability of } \mathbf{0} \\
\text { in-place resources } \\
\text { (percent) }\end{array}$ & $\begin{array}{c}\text { Mean estimate of } \\
\text { economic resources } \\
\text { (Mt) }\end{array}$ & $\begin{array}{c}\text { Probability of } \mathbf{0} \\
\text { economic resources } \\
\text { (percent) }\end{array}$ \\
\hline 2006 & 63,233 & 0 & 4.5 & 30 & 2.5 \\
\hline
\end{tabular}

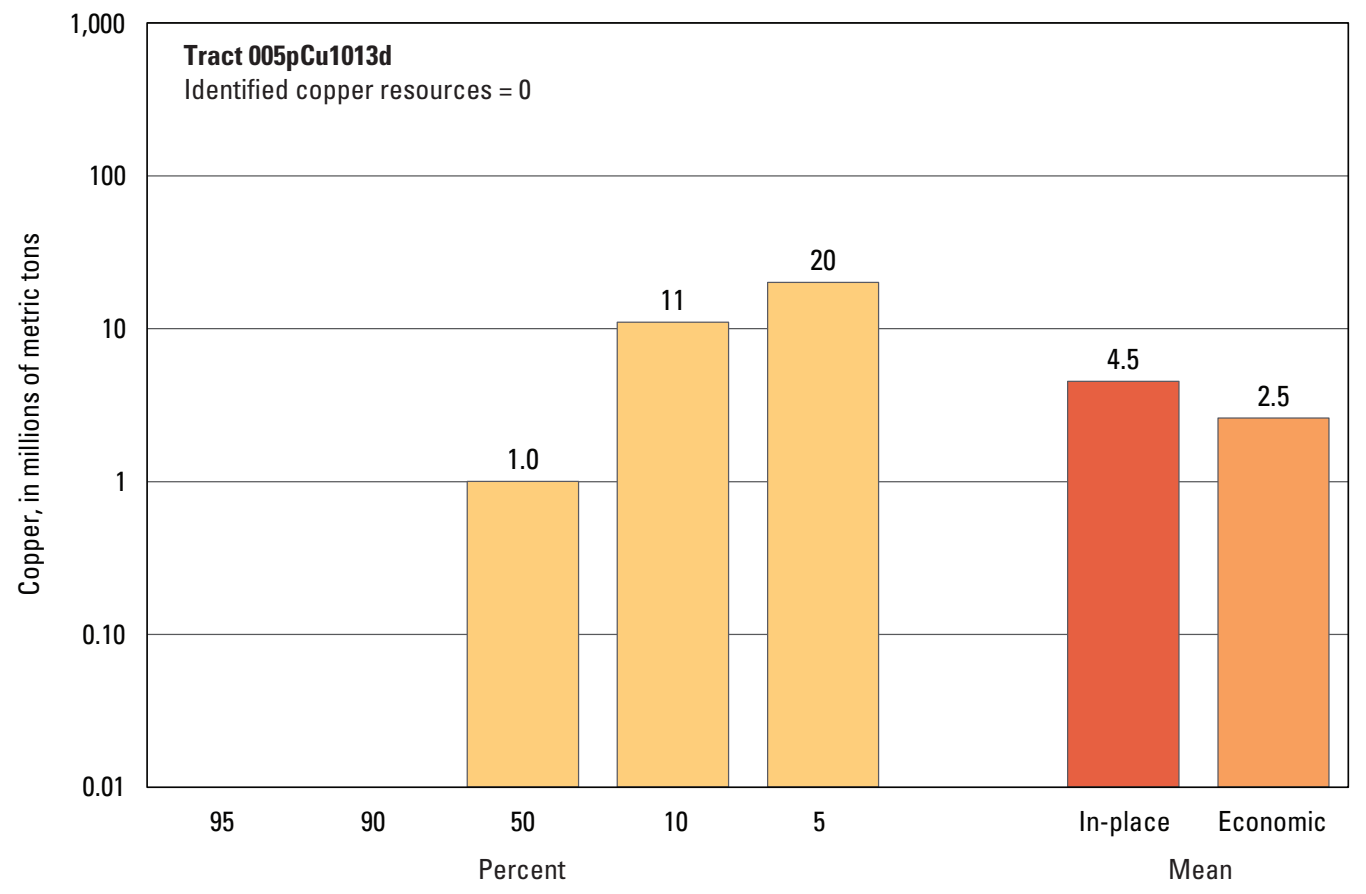

Graph showing the estimated probability distribution of undiscovered copper resources, where each bar represents the minimum amount estimated at the indicated percentage.

\section{Source}

Cunningham and others, 2008, Quantitative mineral resource assessment of copper, molybdenum, gold, and silver in undiscovered porphyry copper deposits in the Andes Mountains of South America: U.S. Geological Survey Open-File Report 2008-1253, http://pubs.usgs.gov/of/2008/1253/. 

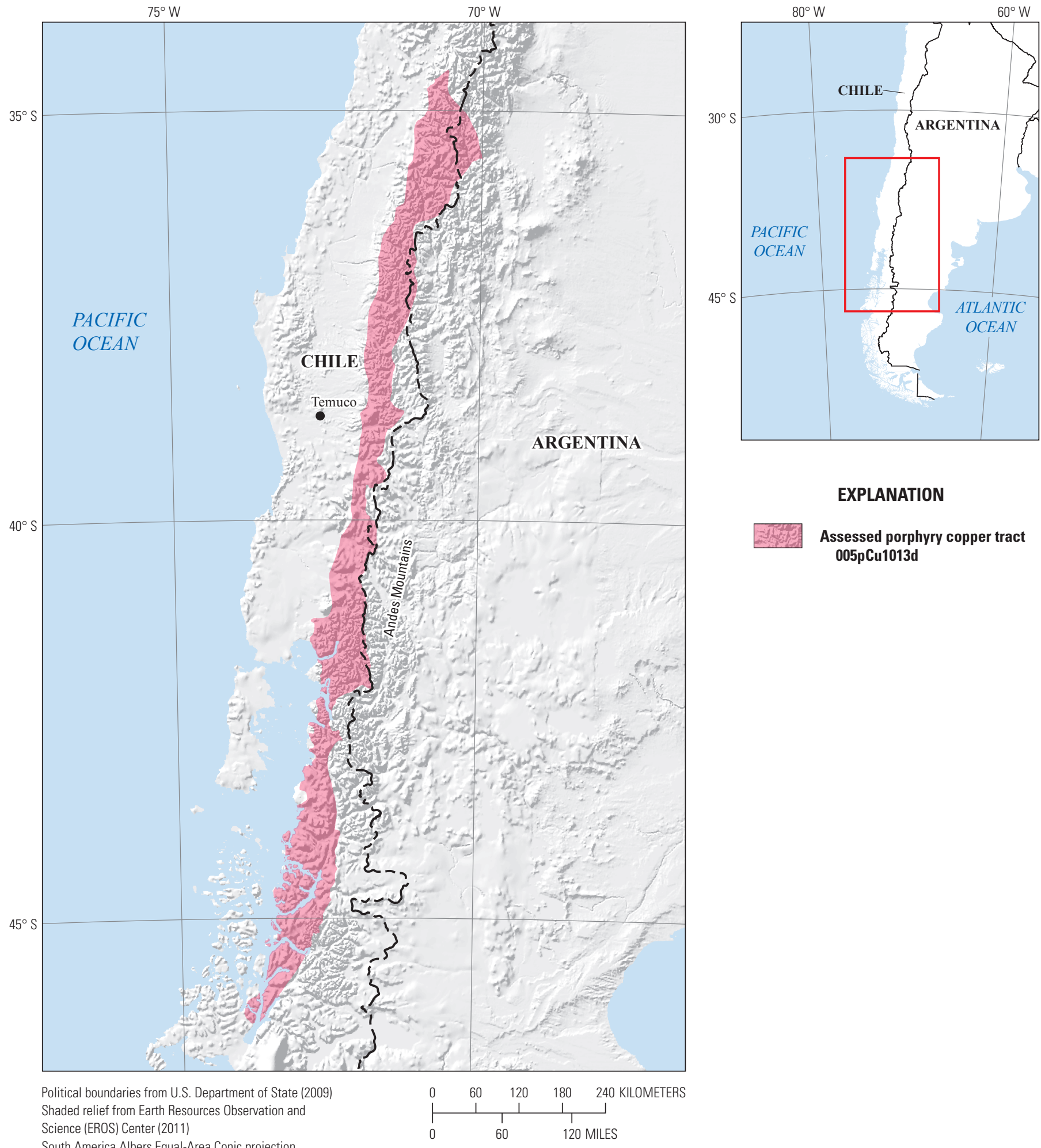

\section{EXPLANATION}

Assessed porphyry copper tract 005pCu1013d

South America Albers Equal-Area Conic projection

Central meridian $72^{\circ} \mathrm{W}$.; latitude of origin $32^{\circ} \mathrm{S}$. 


\title{
Plate 4. Porphyry Copper Assessment for Tract 005pCu1015, Late Cretaceous- Middle Eocene Campana Mahuida-Argentina and Chile
}

\author{
Descriptive model: \\ Porphyry copper model (Cox, 1986a) \\ Grade and tonnage model: \\ General porphyry copper model (Singer, Berger, and Moring, 2005) \\ Economic filter depth percentages: \\ Economic filter cost setting: \\ Geologic feature assessed: \\ Custom -0 to 250 meters (m), 20\%; >250 to $500 \mathrm{~m}, 30 \%$; $>500 \mathrm{~m}$ to $1 \mathrm{~km}, 50 \%$ \\ Mixed cost \\ Heterogeneous assemblage of Late Cretaceous, Paleocene, and middle Eocene mainly calc-alkalic \\ granite, granodiorite, andesite, diorite, and dacite plutons \\ Number of known deposits: \\ 1
}

\section{Selected Resource Assessment Results for Porphyry Copper}

[Assessment depth, 1 kilometer $(\mathrm{km}) ; \mathrm{km}^{2}$, square kilometer; Mt, millions of metric tons]

\begin{tabular}{ccccccc}
\hline $\begin{array}{c}\text { Date of } \\
\text { assessment }\end{array}$ & $\begin{array}{c}\text { Tract area } \\
\left(\mathbf{k m}^{2}\right)\end{array}$ & $\begin{array}{c}\text { Identified } \\
\text { copper } \\
\text { resources } \\
\text { (Mt) }\end{array}$ & $\begin{array}{c}\text { Mean estimate of } \\
\text { in-place resources } \\
(\mathbf{M t})\end{array}$ & $\begin{array}{c}\text { Probability of } \mathbf{0} \\
\text { in-place resources } \\
\text { (percent) }\end{array}$ & $\begin{array}{c}\text { Mean estimate of } \\
\text { economic resources } \\
\text { (Mt) }\end{array}$ & $\begin{array}{c}\text { Probability of 0 } \\
\text { economic resources } \\
\text { (percent) }\end{array}$ \\
\hline 2005 & 83,204 & 0.95 & 15 & 7 & 8.6 \\
\hline
\end{tabular}

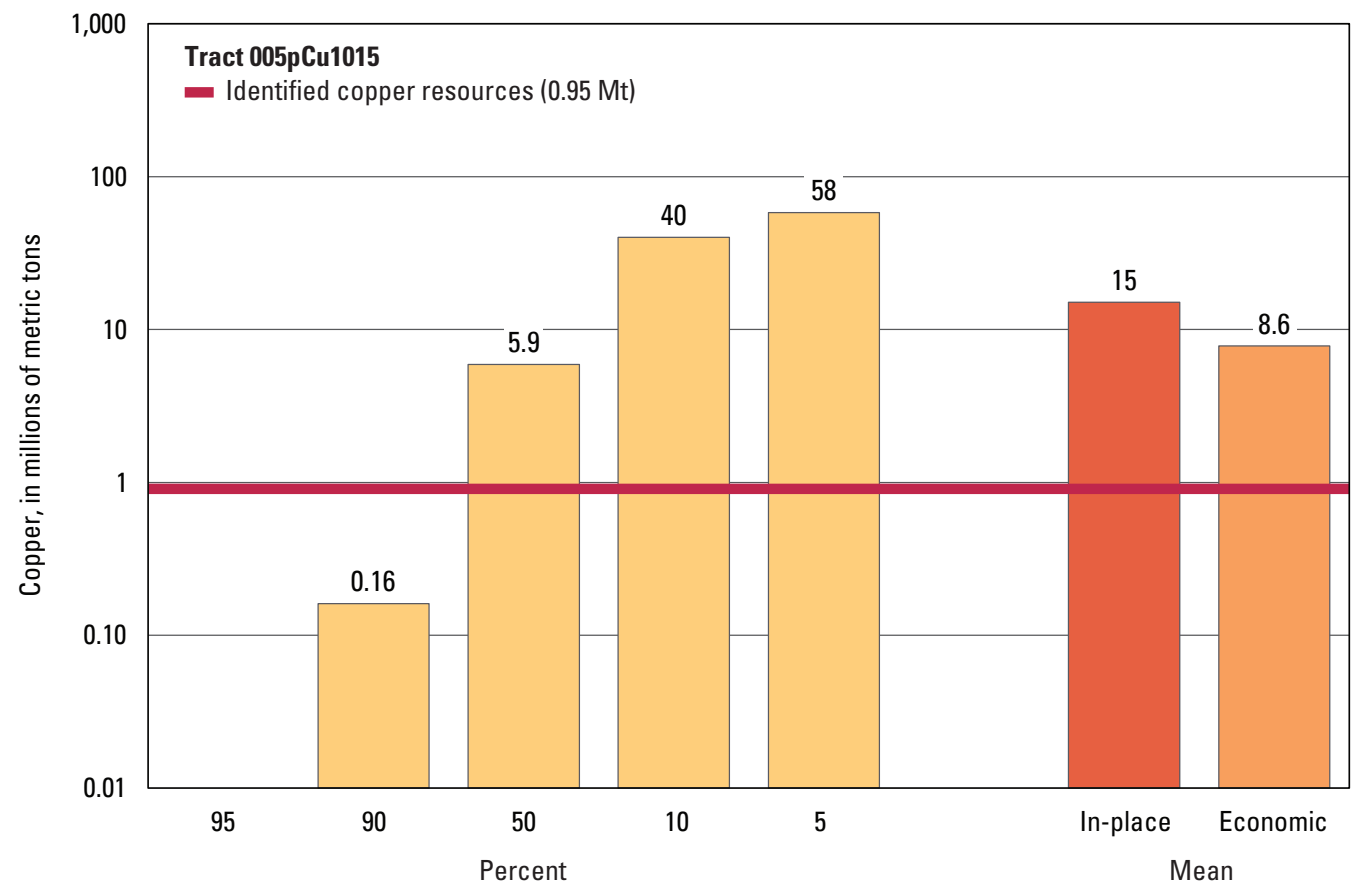

Graph showing the estimated probability distribution of undiscovered copper resources, where each bar represents the minimum amount estimated at the indicated percentage.

\section{Source}

Cunningham and others, 2008, Quantitative mineral resource assessment of copper, molybdenum, gold, and silver in undiscovered porphyry copper deposits in the Andes Mountains of South America: U.S. Geological Survey Open-File Report 2008-1253, http://pubs.usgs.gov/of/2008/1253/. 

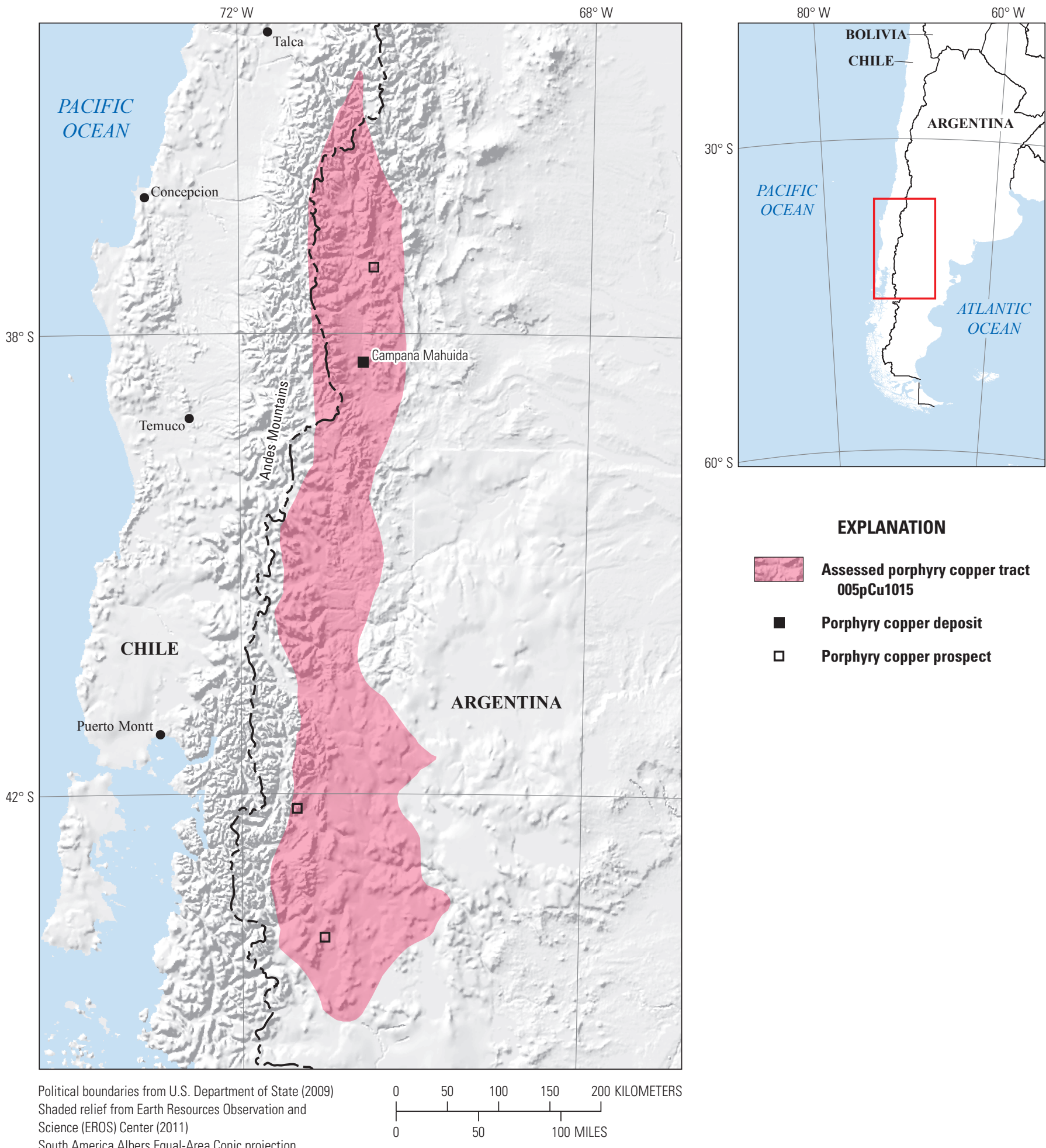

\section{EXPLANATION}

Assessed porphyry copper tract $005 p$ Cu1015

- Porphyry copper deposit

Porphyry copper prospect

South America Albers Equal-Area Conic projection

Central meridian $71^{\circ} \mathrm{W}$.; latitude of origin $32^{\circ} \mathrm{S}$ 


\title{
Plate 5. Porphyry Copper Assessment for Tract 005pCu1014b, Miocene- Pliocene El Teniente-Chile
}

\author{
Descriptive model: \\ Grade and tonnage model: \\ Economic filter depth percentages: \\ Economic filter cost setting: \\ Geologic feature assessed: \\ Number of known deposits:
}

Porphyry copper model (Cox, 1986a)

Giant porphyry copper model (Singer, Briskey, and Cunningham, 2008)

Default -0 to 250 meters (m), $25 \% ;>250$ to $500 \mathrm{~m}, 25 \% ;>500 \mathrm{~m}$ to $1 \mathrm{~km}, 50 \%$

Typical cost

Mainly late Miocene to early Pliocene calc-alkalic plutons and consanguineous coeval to slightly older lavas, breccias, pyroclastic rocks, and volcanic domes

2 (1) (As shown on the map, 1 of these deposits was found after the assessment was done; the assessment results below reflect information available in 2005 for 2 deposits.)

\section{Selected Resource Assessment Results for Porphyry Copper}

[Assessment depth, 1 kilometer $(\mathrm{km}) ; \mathrm{km}^{2}$, square kilometer; Mt, millions of metric tons]

\begin{tabular}{ccccccc}
\hline \multirow{2}{*}{$\begin{array}{c}\text { Date of } \\
\text { assessment }\end{array}$} & $\begin{array}{c}\text { Tract area } \\
\left(\mathbf{k m}^{2}\right)\end{array}$ & $\begin{array}{c}\text { Identified } \\
\text { copper } \\
\text { resources } \\
(\mathbf{M t})\end{array}$ & $\begin{array}{c}\text { Mean estimate of } \\
\text { in-place resources } \\
(\mathbf{M t})\end{array}$ & $\begin{array}{c}\text { Probability of } \mathbf{0} \\
\text { in-place resources } \\
\text { (percent) }\end{array}$ & $\begin{array}{c}\text { Mean estimate of } \\
\text { economic resources } \\
\text { (Mt) }\end{array}$ & $\begin{array}{c}\text { Probability of } \mathbf{0} \\
\text { economic resources } \\
\text { (percent) }\end{array}$ \\
\hline 2005 & 9,284 & 230 & 69 & 6 & 56 \\
\hline
\end{tabular}

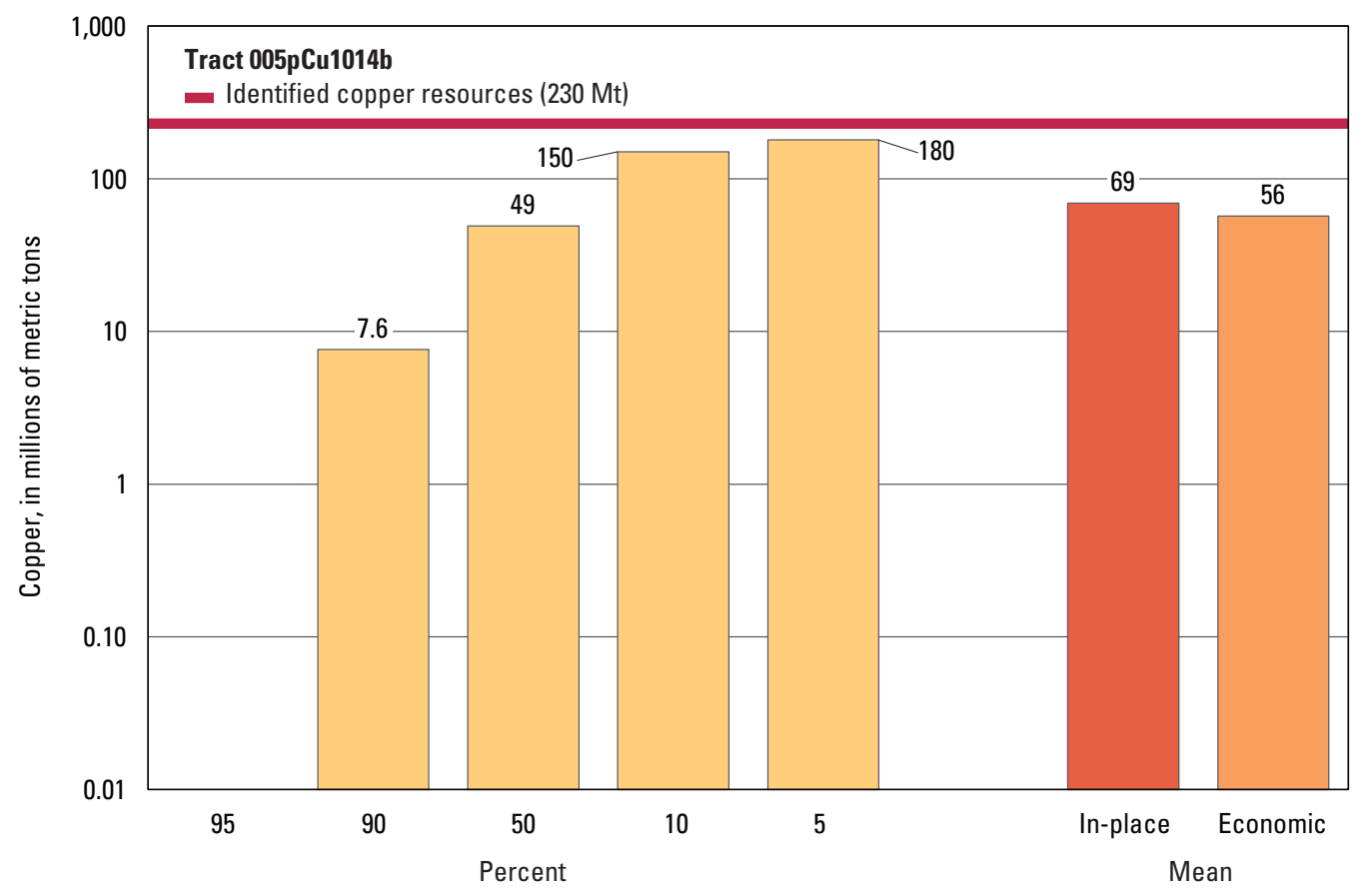

Graph showing the estimated probability distribution of undiscovered copper resources, where each bar represents the minimum amount estimated at the indicated percentage.

\section{Source}

Cunningham and others, 2008, Quantitative mineral resource assessment of copper, molybdenum, gold, and silver in undiscovered porphyry copper deposits in the Andes Mountains of South America: U.S. Geological Survey Open-File Report 2008-1253, http://pubs.usgs.gov/of/2008/1253/. 


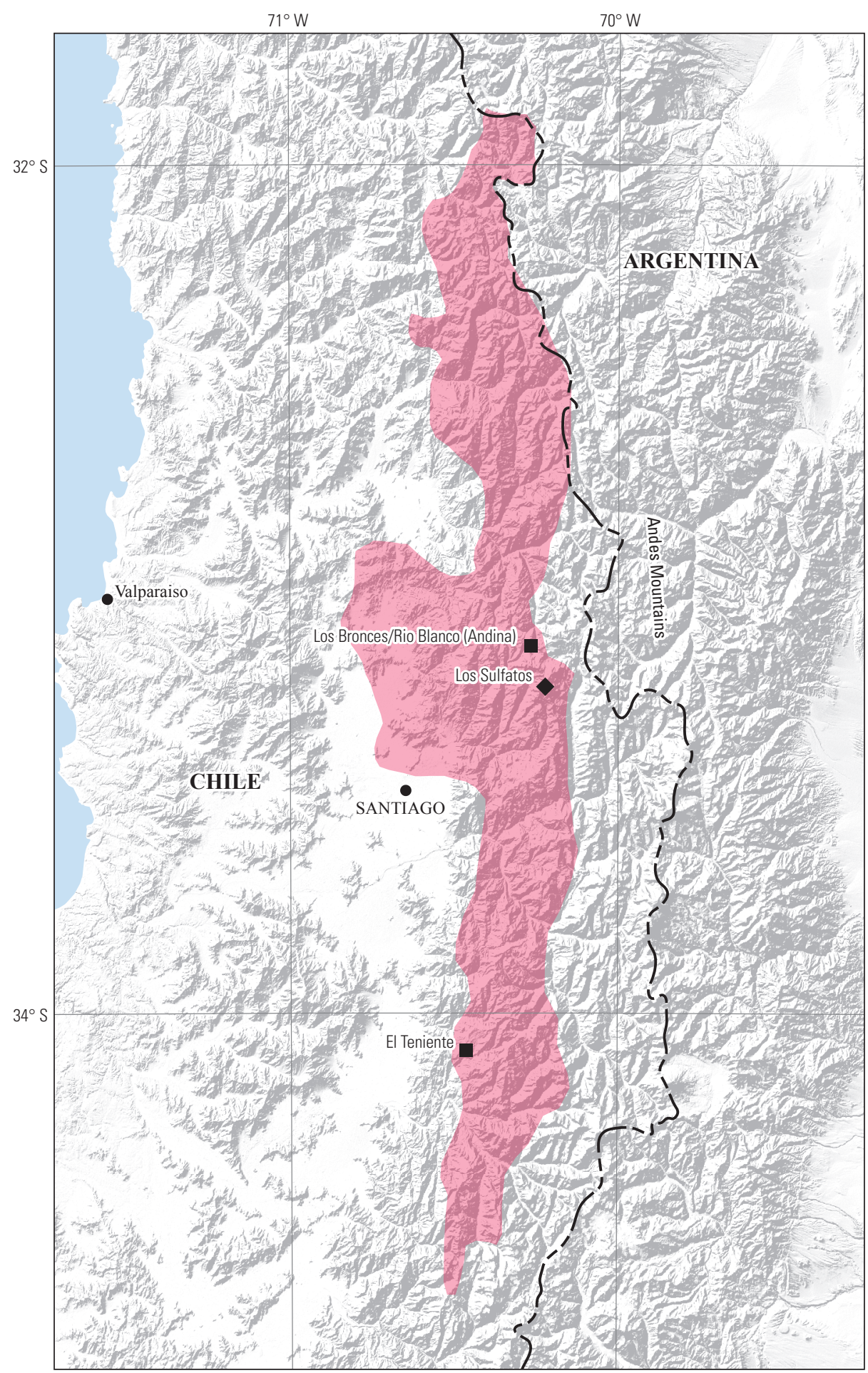

Political boundaries from U.S. Department of State (2009) Shaded relief from ESRI (2008)

South America Albers Equal-Area Conic projection

Central meridian $70^{\circ} 30^{\prime} \mathrm{W}$.; latitude of origin $32^{\circ} \mathrm{S}$.

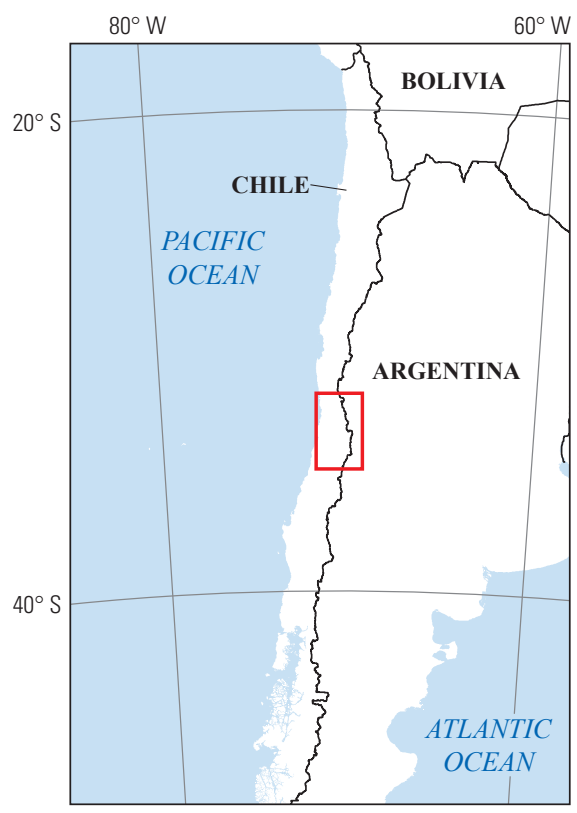

EXPLANATION

Assessed porphyry copper tract 005pCu1014b

- Porphyry copper deposit

- Porphyry copper deposit discovered after the assessment 


\section{Plate 6. Porphyry Copper Assessment for Tract 005pCu1013b, Miocene- Pliocene Los Pelambres-Argentina and Chile}

\author{
Descriptive model: \\ Grade and tonnage model: \\ Economic filter depth percentages: \\ Economic filter cost setting: \\ Geologic feature assessed:
}

Number of known deposits:
Porphyry copper model (Cox, 1986a)

General porphyry copper model (Singer, Berger, and Moring, 2005)

Default - 0 to 250 meters (m), 25\%; > 250 to $500 \mathrm{~m}, 25 \%$; >500 m to $1 \mathrm{~km}, 50 \%$

Mixed cost

Miocene to Pliocene principally calc-alkalic plutons; separated from tract $005 \mathrm{pCu} 1013 \mathrm{c}$ (pl. 10) where deeper erosion of younger cover rocks aided exploration, thereby reducing the probability of undiscovered deposits

2

\section{Selected Resource Assessment Results for Porphyry Copper}

[Assessment depth, 1 kilometer $(\mathrm{km}) ; \mathrm{km}^{2}$, square kilometer; Mt, millions of metric tons]

\begin{tabular}{|c|c|c|c|c|c|c|}
\hline \multirow[b]{2}{*}{$\begin{array}{c}\text { Date of } \\
\text { assessment }\end{array}$} & \multirow[b]{2}{*}{$\begin{array}{c}\text { Tract area } \\
\quad\left(\mathbf{k m}^{2}\right)\end{array}$} & \multirow{2}{*}{$\begin{array}{l}\text { Identified } \\
\text { copper } \\
\text { resources } \\
\text { (Mt) }\end{array}$} & \multicolumn{4}{|c|}{ Undiscovered copper resource estimates } \\
\hline & & & $\begin{array}{l}\text { Mean estimate of } \\
\text { in-place resources } \\
\text { (Mt) }\end{array}$ & $\begin{array}{c}\text { Probability of } 0 \\
\text { in-place resources } \\
\text { (percent) }\end{array}$ & $\begin{array}{l}\text { Mean estimate of } \\
\text { economic resources } \\
\text { (Mt) }\end{array}$ & $\begin{array}{c}\text { Probability of } 0 \\
\text { economic resources } \\
\text { (percent) }\end{array}$ \\
\hline 2005 & 41,799 & 51 & 22 & 3 & 12 & 29 \\
\hline
\end{tabular}

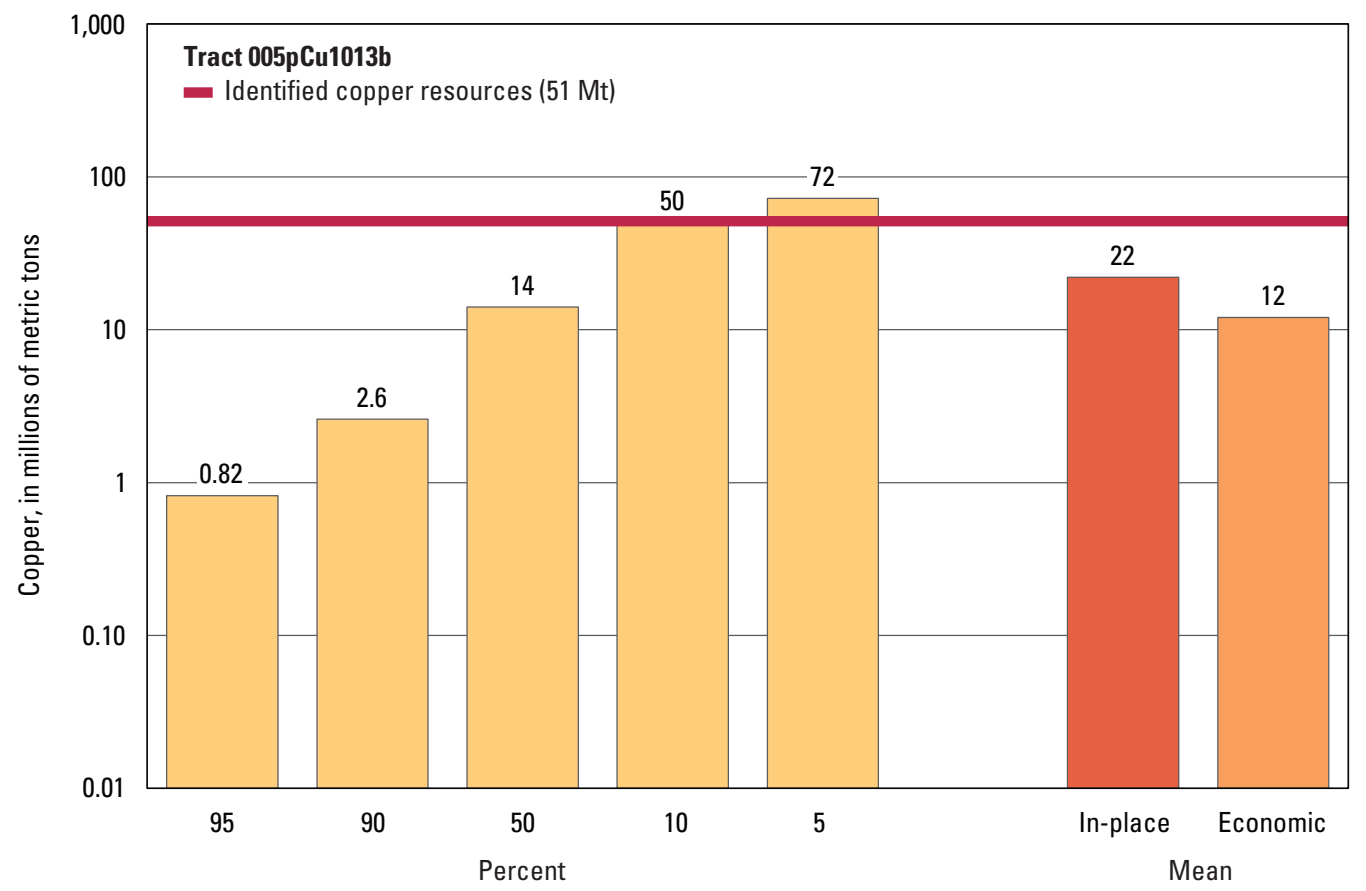

Graph showing the estimated probability distribution of undiscovered copper resources, where each bar represents the minimum amount estimated at the indicated percentage.

\section{Source}

Cunningham and others, 2008, Quantitative mineral resource assessment of copper, molybdenum, gold, and silver in undiscovered porphyry copper deposits in the Andes Mountains of South America: U.S. Geological Survey Open-File Report 2008-1253, http://pubs.usgs.gov/of/2008/1253/. 

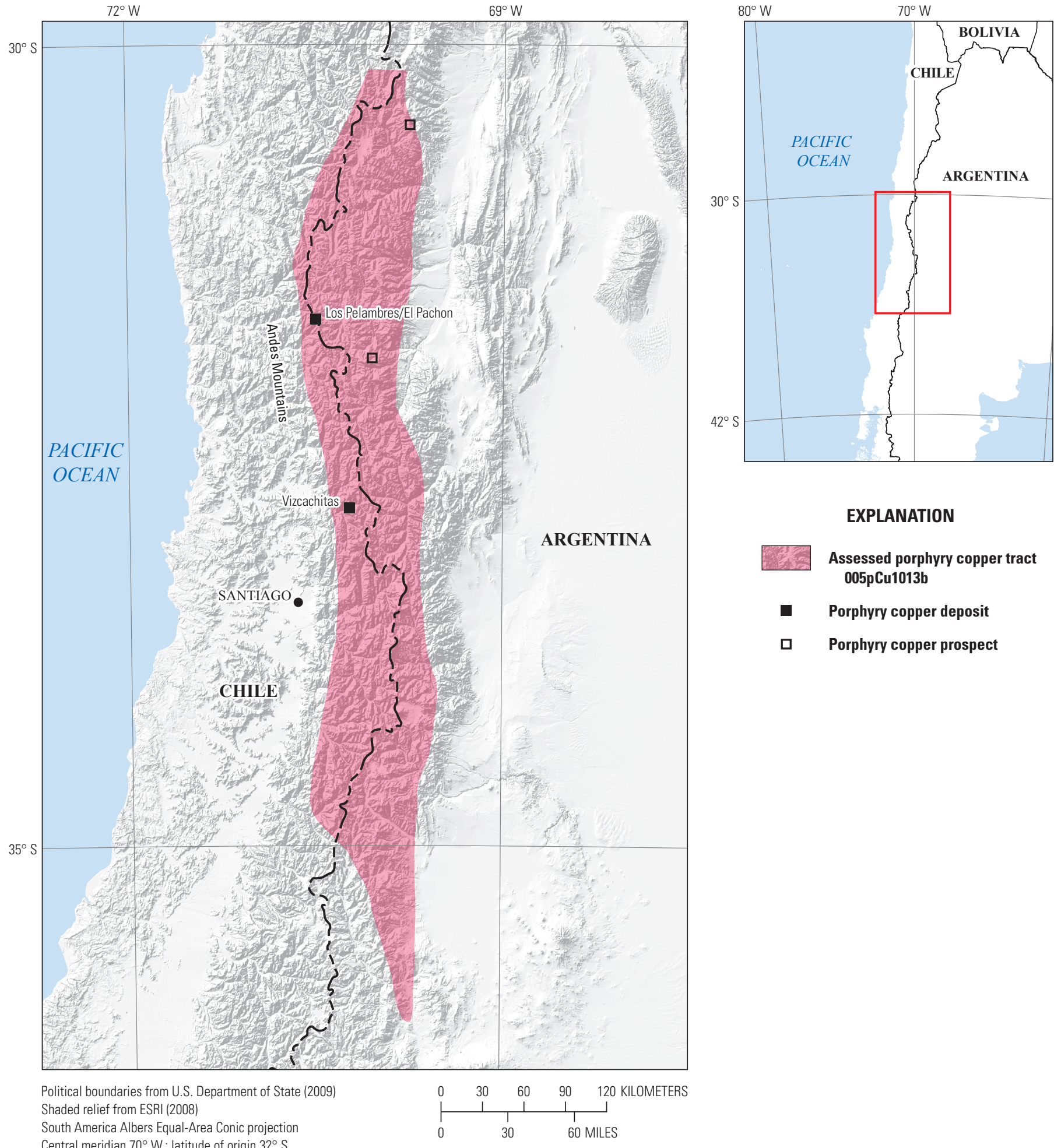

Assessed porphyry copper tract 005pCu1013b

- Porphyry copper deposit

ㅁ Porphyry copper prospect

South America Albers

Central meridian $70^{\circ} \mathrm{W}$. : latitude of origin $32^{\circ} \mathrm{S}$ 


\section{Plate 7. Porphyry Copper Assessment for Tract 005pCu1016ab, Permian San Jorge-Argentina and Chile}

\section{Descriptive model:}

Grade and tonnage model:

Economic filter depth percentages:

Economic filter cost setting:

Geologic feature assessed:

Number of known deposits:
Porphyry copper model (Cox, 1986a)

General porphyry copper model (Singer, Berger, and Moring, 2005)

Skewed deep-0 to 250 meters (m), 10\%; > 250 to $500 \mathrm{~m}, 30 \%$; >500 m to $1 \mathrm{~km}, 60 \%$

Mixed cost

Permian calc-alkalic generally dioritic to dacitic plutons in two geographically separate sub-tracts, $\mathrm{a}$ and b, which are southern continuations of Permian tract 005pCu1018 (pl. 17)

2

\section{Selected Resource Assessment Results for Porphyry Copper}

[Assessment depth, 1 kilometer (km); $\mathrm{km}^{2}$, square kilometer; Mt, millions of metric tons]

\begin{tabular}{ccccccc}
\hline $\begin{array}{c}\text { Date of } \\
\text { assessment }\end{array}$ & $\begin{array}{c}\text { Tract area } \\
\left.\mathbf{( k m}^{2}\right)\end{array}$ & $\begin{array}{c}\text { Identified } \\
\text { copper } \\
\text { resources } \\
\text { (Mt) }\end{array}$ & $\begin{array}{c}\text { Mean estimate of } \\
\text { in-place resources } \\
(\mathbf{M t})\end{array}$ & $\begin{array}{c}\text { Probability of } \mathbf{0} \\
\text { in-place resources } \\
\text { (percent) }\end{array}$ & $\begin{array}{c}\text { Mean estimate of } \\
\text { economic resources } \\
\text { (Mt) }\end{array}$ & $\begin{array}{c}\text { Probability of 0 } \\
\text { economic resources } \\
\text { (percent) }\end{array}$ \\
\hline 2005 & 29,080 & 1.9 & 12 & 4 & 6.6 \\
\hline
\end{tabular}

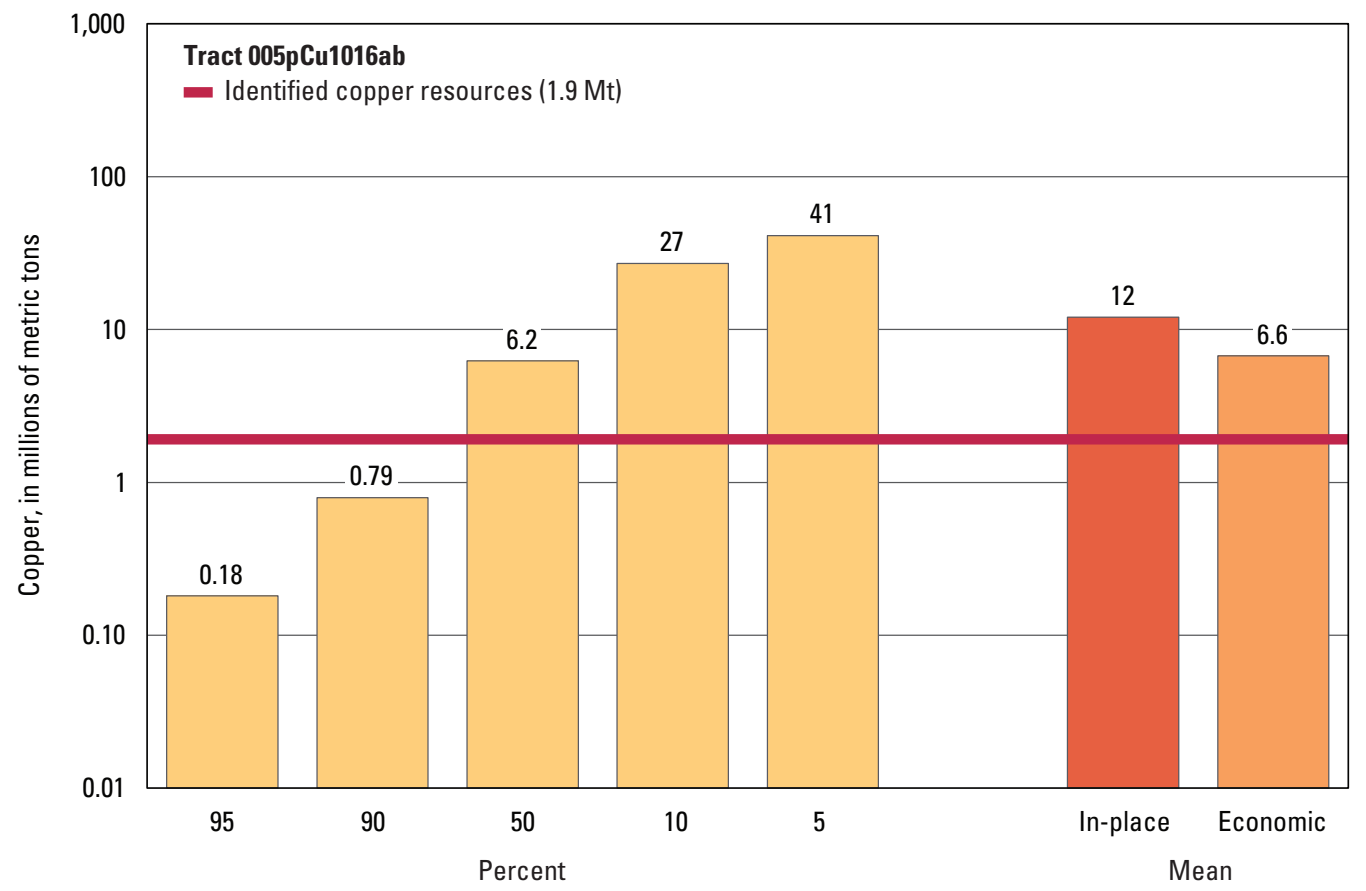

Graph showing the estimated probability distribution of undiscovered copper resources, where each bar represents the minimum amount estimated at the indicated percentage.

\section{Source}

Cunningham and others, 2008, Quantitative mineral resource assessment of copper, molybdenum, gold, and silver in undiscovered porphyry copper deposits in the Andes Mountains of South America: U.S. Geological Survey Open-File Report 2008-1253, http://pubs.usgs.gov/of/2008/1253/. 

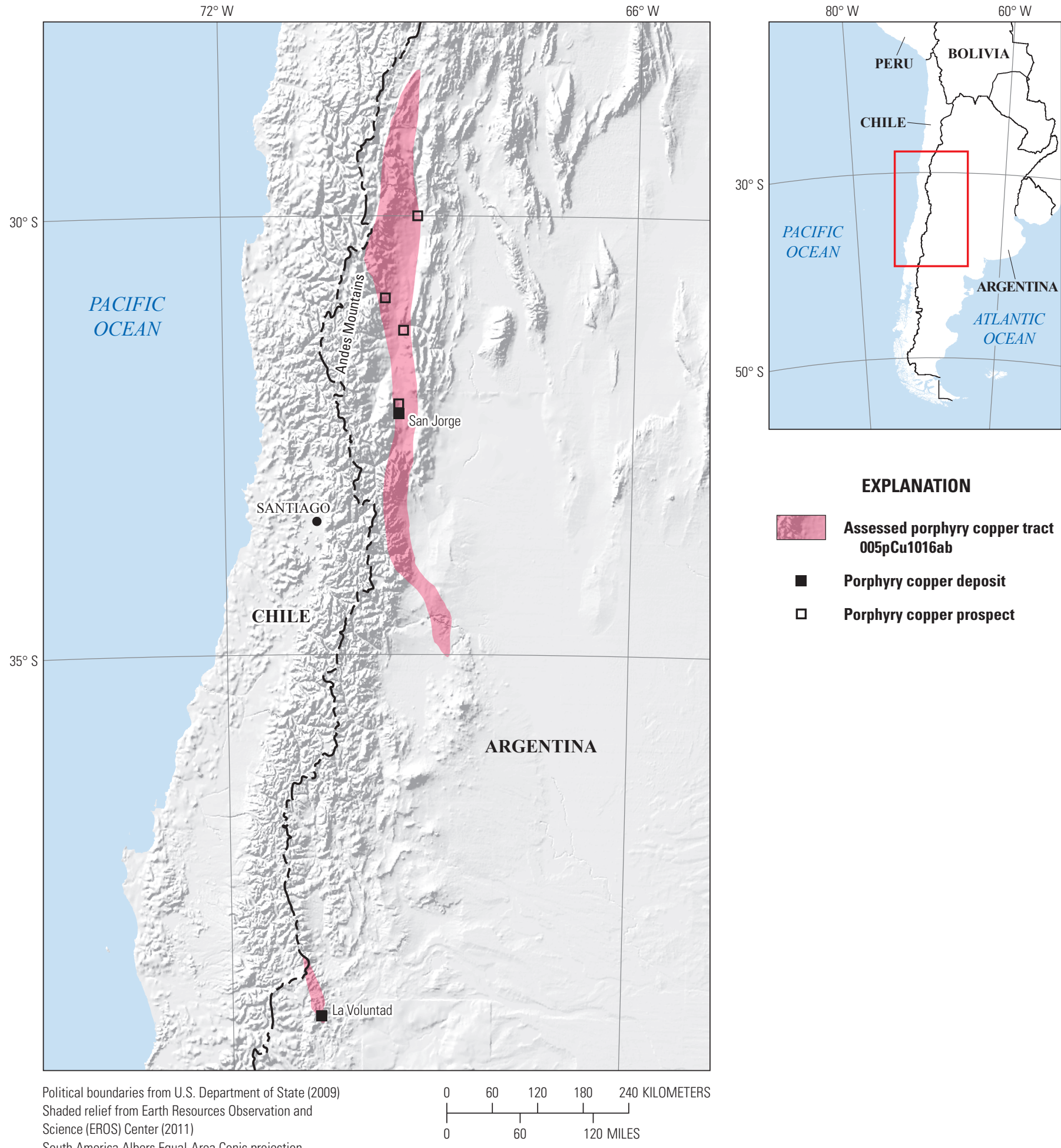

\section{EXPLANATION}

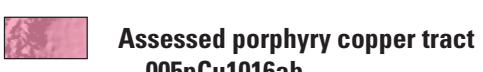
005pCu1016ab

- Porphyry copper deposit

$\square \quad$ Porphyry copper prospect

South America Albers Equal-Area Conic projection

Central meridian $69^{\circ} 30^{\prime} \mathrm{W}$.; latitude of origin $32^{\circ} \mathrm{S}$. 


\title{
Plate 8. Porphyry Copper Assessment for Tract 005pCu1014a, Miocene Paramillos-Argentina
}

\author{
Descriptive model: \\ Porphyry copper model (Cox, 1986a) \\ Grade and tonnage model: \\ General porphyry copper model (Singer, Berger, and Moring, 2005) \\ Economic filter depth percentages: \\ Economic filter cost setting: \\ Geologic feature assessed: \\ Default -0 to 250 meters (m), 25\%; > 250 to $500 \mathrm{~m}, 25 \%$; $>500 \mathrm{~m}$ to $1 \mathrm{~km}, 50 \%$ \\ Mixed cost \\ Mainly late Miocene to early Pliocene calc-alkalic plutons intruding folded and intensely thrust \\ faulted Paleozoic country rocks \\ Number of known deposits: \\ 2
}

\section{Selected Resource Assessment Results for Porphyry Copper}

[Assessment depth, 1 kilometer ( $\mathrm{km}) ; \mathrm{km}^{2}$, square kilometer; Mt, millions of metric tons]

\begin{tabular}{ccccccc}
\hline $\begin{array}{c}\text { Date of } \\
\text { assessment }\end{array}$ & $\begin{array}{c}\text { Tract area } \\
\left.\mathbf{( k m}^{2}\right)\end{array}$ & $\begin{array}{c}\text { Identified } \\
\text { copper } \\
\text { resources } \\
\text { (Mt) }\end{array}$ & $\begin{array}{c}\text { Mean estimate of } \\
\text { in-place resources } \\
\text { (Mt) }\end{array}$ & $\begin{array}{c}\text { Probability of } \mathbf{0} \\
\text { in-place resources } \\
\text { (percent) }\end{array}$ & $\begin{array}{c}\text { Mean estimate of } \\
\text { economic resources } \\
\text { (Mt) }\end{array}$ & $\begin{array}{c}\text { Probability of } \mathbf{0} \\
\text { economic resources } \\
\text { (percent) }\end{array}$ \\
\hline 2005 & 21,721 & 2.1 & 21 & 4 & 11 \\
\hline
\end{tabular}

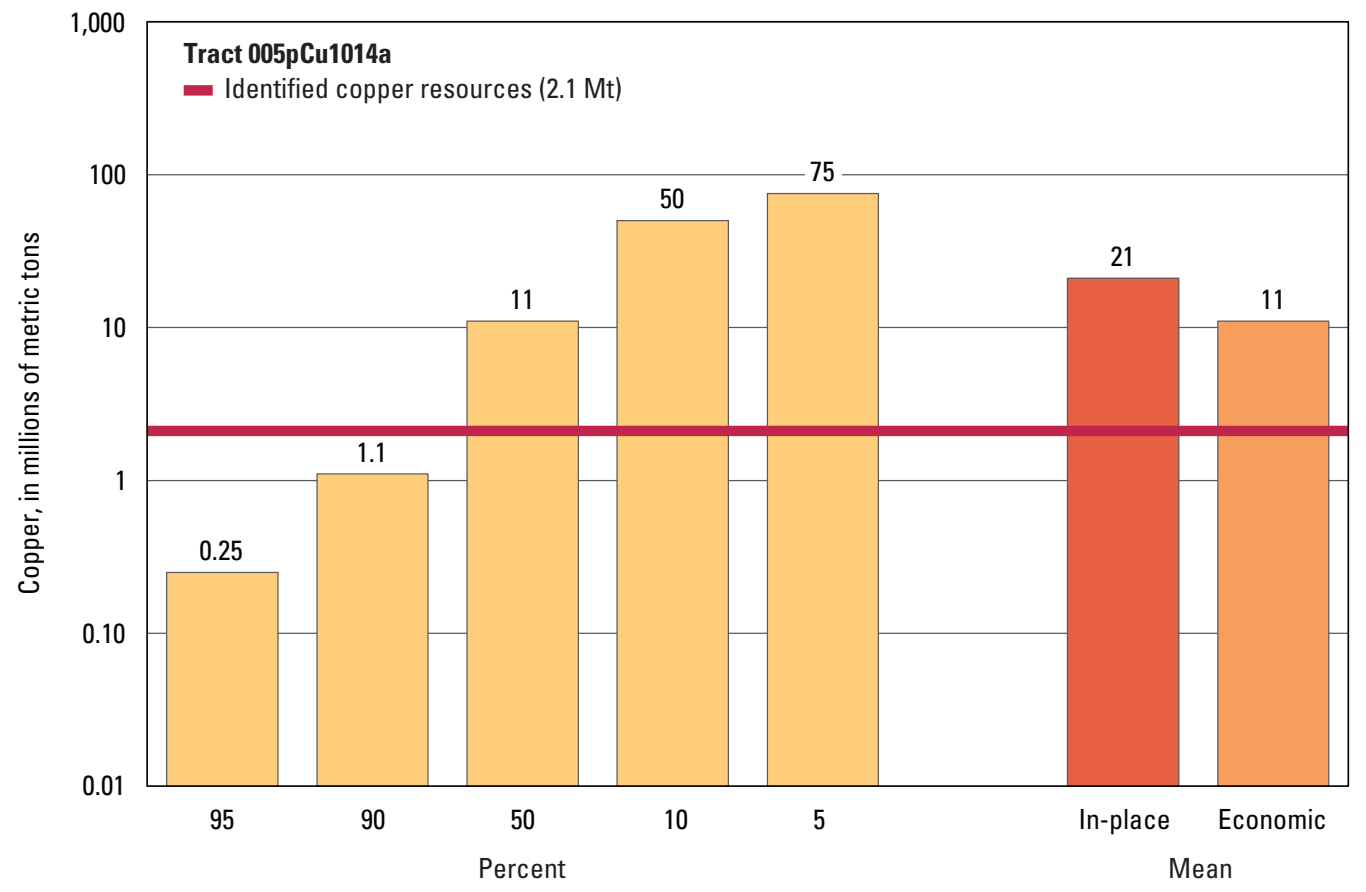

Graph showing the estimated probability distribution of undiscovered copper resources, where each bar represents the minimum amount estimated at the indicated percentage.

\section{Source}

Cunningham and others, 2008, Quantitative mineral resource assessment of copper, molybdenum, gold, and silver in undiscovered porphyry copper deposits in the Andes Mountains of South America: U.S. Geological Survey Open-File Report 2008-1253, http://pubs.usgs.gov/of/2008/1253/. 

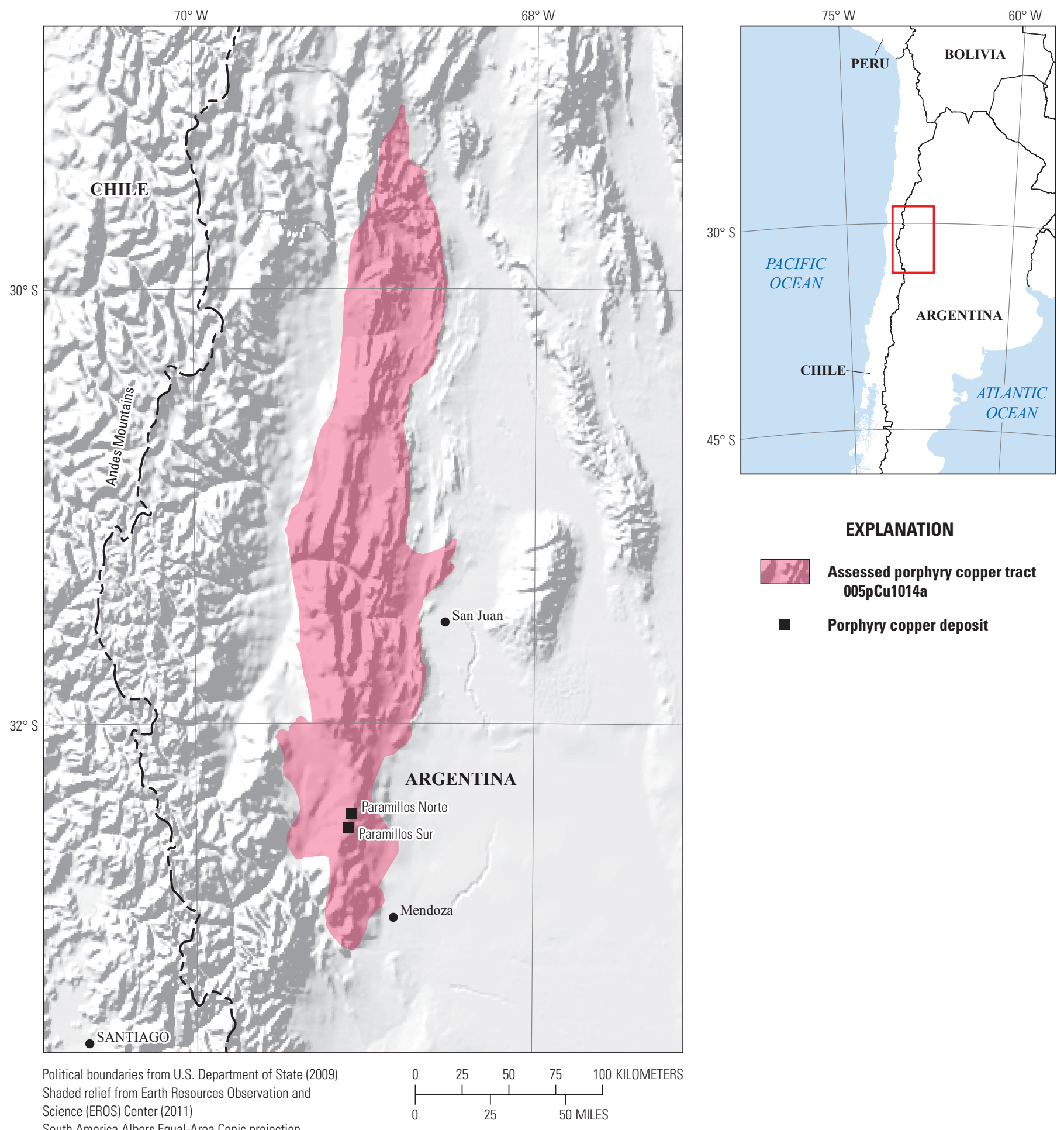

Assessed porphyry copper tract 005pCu1014a

Porphyry copper deposit

South America Albers Equal-Area Conic projection

Central meridian $69^{\circ} \mathrm{W}$; l latitude of origin $32^{\circ} \mathrm{S}$. 


\title{
Plate 9. Porphyry Copper Assessment for Tract 005pCu1012, Eocene-Oligocene La Fortuna-Chile and Argentina
}

\author{
Descriptive model: \\ Porphyry copper model (Cox, 1986a) \\ Grade and tonnage model: \\ General porphyry copper model (Singer, Berger, and Moring, 2005) \\ Economic filter depth percentages: \\ Economic filter cost setting: \\ Geologic feature assessed: \\ Default -0 to 250 meters (m), $25 \%$; $>250$ to $500 \mathrm{~m}, 25 \% ;>500 \mathrm{~m}$ to $1 \mathrm{~km}, 50 \%$ \\ Typical cost \\ Eocene to Oligocene principally calc-alkalic plutons, including epizonal plutons intruding \\ volcanic-arc lava flows and breccias; equivalent to rocks in tracts $005 \mathrm{pCu} 1009$ (pl. 19) and \\ $005 \mathrm{pCu} 1010 \mathrm{ab}(\mathrm{pl} .18)$ \\ Number of known deposits: \\ 1
}

\section{Selected Resource Assessment Results for Porphyry Copper}

[Assessment depth, 1 kilometer $(\mathrm{km}) ; \mathrm{km}^{2}$, square kilometer; Mt, millions of metric tons]

\begin{tabular}{ccccccc}
\hline $\begin{array}{c}\text { Date of } \\
\text { assessment }\end{array}$ & $\begin{array}{c}\text { Tract area } \\
\left(\mathbf{k m}^{2}\right)\end{array}$ & $\begin{array}{c}\text { Identified } \\
\text { copper } \\
\text { resources } \\
(\mathbf{M t})\end{array}$ & $\begin{array}{c}\text { Mean estimate of } \\
\text { in-place resources } \\
(\mathbf{M t})\end{array}$ & $\begin{array}{c}\text { Probability of } \mathbf{0} \\
\text { in-place resources } \\
\text { (percent) }\end{array}$ & $\begin{array}{c}\text { Mean estimate of } \\
\text { economic resources } \\
\text { (Mt) }\end{array}$ & $\begin{array}{c}\text { Probability of } \mathbf{0} \\
\text { economic resources } \\
\text { (percent) }\end{array}$ \\
\hline 2005 & 6,913 & 5.1 & 15 & 4 & 10 \\
\hline
\end{tabular}

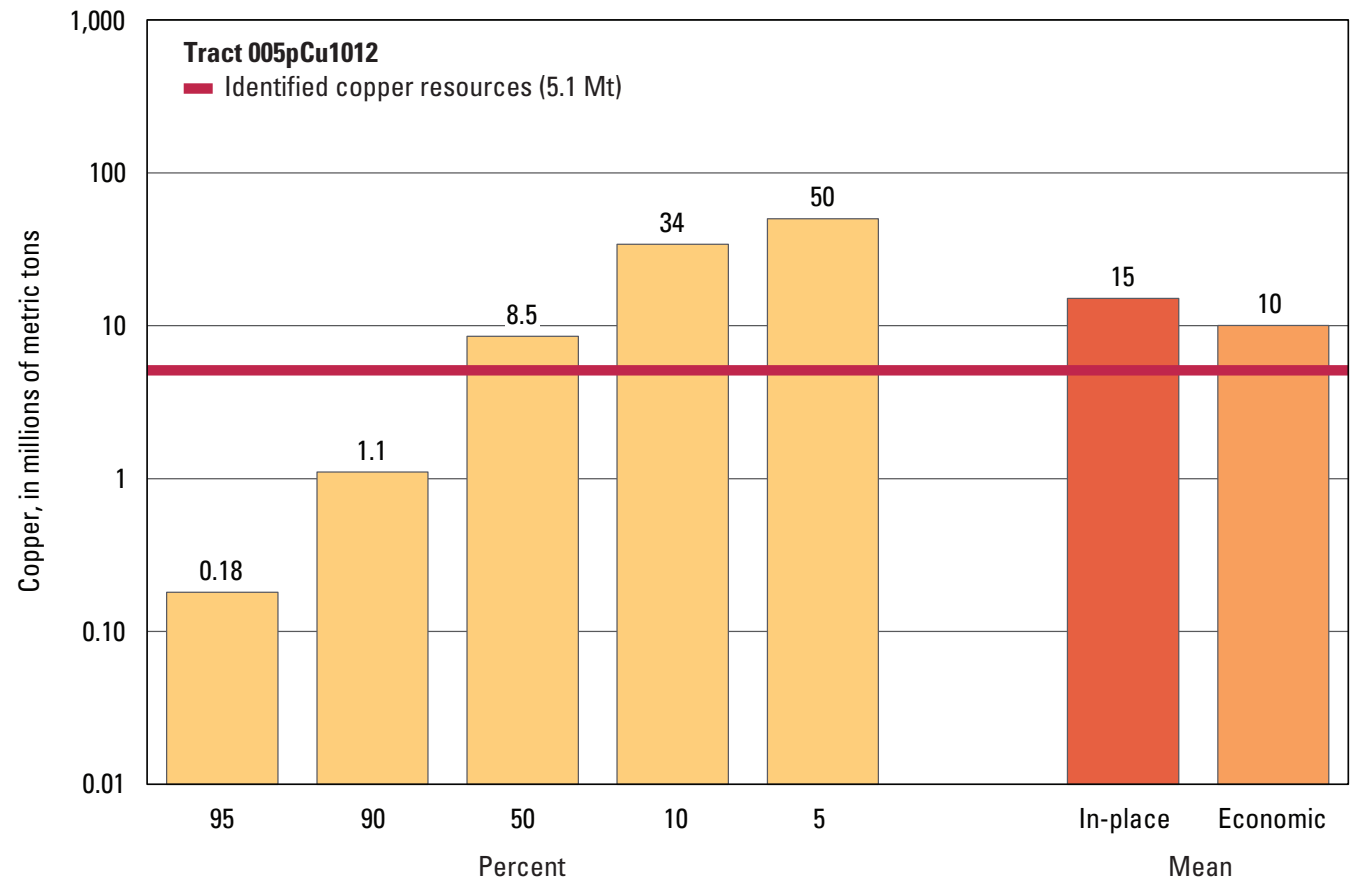

Graph showing the estimated probability distribution of undiscovered copper resources, where each bar represents the minimum amount estimated at the indicated percentage.

\section{Source}

Cunningham and others, 2008, Quantitative mineral resource assessment of copper, molybdenum, gold, and silver in undiscovered porphyry copper deposits in the Andes Mountains of South America: U.S. Geological Survey Open-File Report 2008-1253, http://pubs.usgs.gov/of/2008/1253/. 

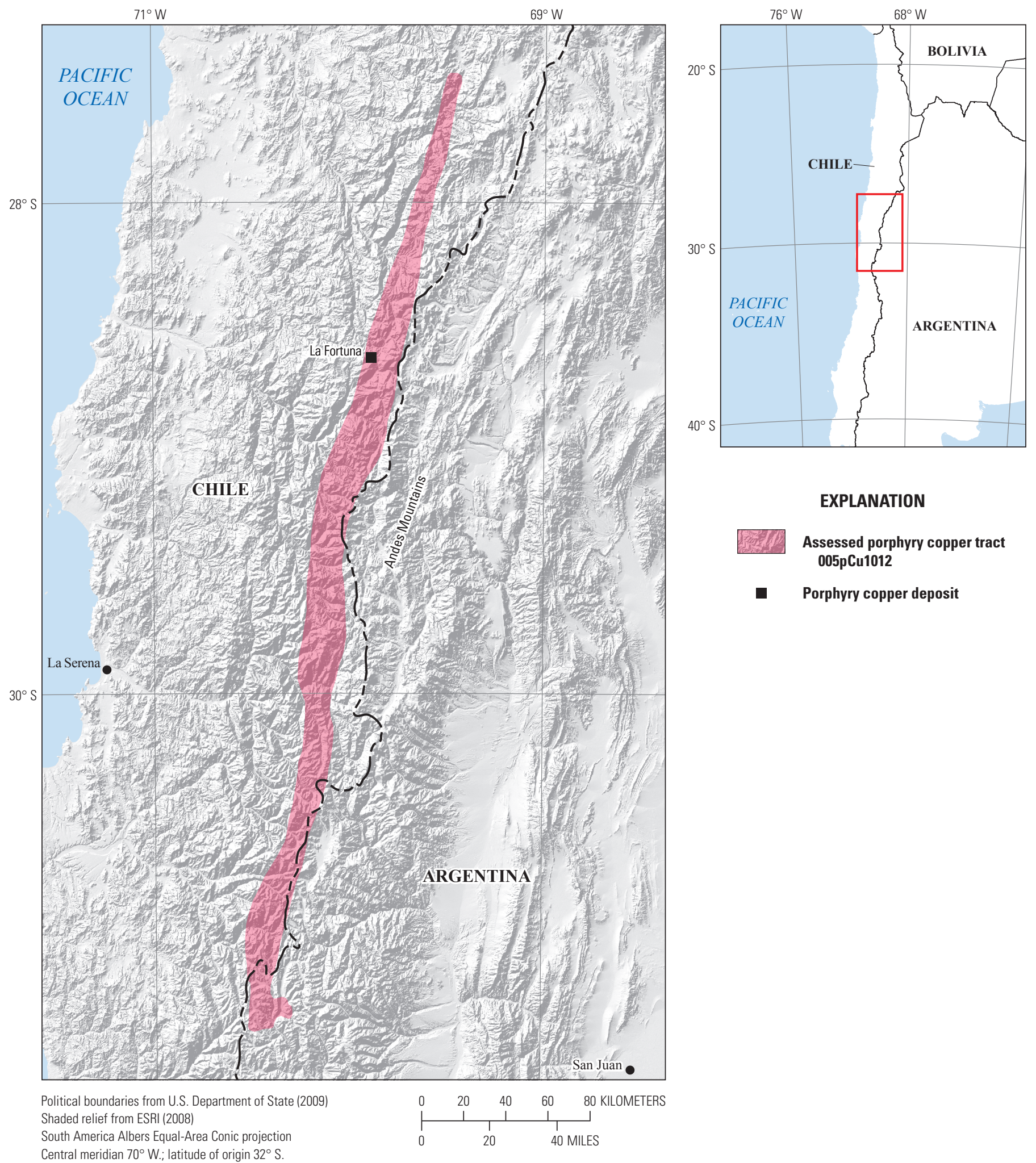

Assessed porphyry copper tract 005pCu1012

- Porphyry copper deposit 


\section{Plate 10. Porphyry Copper Assessment for Tract 005pCu1013c, Miocene- Pliocene-Argentina and Chile}

\author{
Descriptive model: \\ Grade and tonnage model: \\ Economic filter depth percentages: \\ Economic filter cost setting: \\ Geologic feature assessed:
}

Number of known deposits:

\author{
Porphyry copper model (Cox, 1986a) \\ General porphyry copper model (Singer, Berger, and Moring, 2005) \\ Default -0 to 250 meters (m), $25 \% ;>250$ to $500 \mathrm{~m}, 25 \%$; $>500 \mathrm{~m}$ to $1 \mathrm{~km}, 50 \%$ \\ Mixed cost \\ Miocene to Pliocene principally calc-alkalic plutons; separated from tract $005 \mathrm{pCu} 1013 \mathrm{~b}$ (pl. 6), \\ where more extensive cover by younger rocks hindered exploration, thereby increasing the \\ probability of undiscovered deposits
}

0

\section{Selected Resource Assessment Results for Porphyry Copper}

[Assessment depth, 1 kilometer (km); km², square kilometer; Mt, millions of metric tons]

\begin{tabular}{|c|c|c|c|c|c|c|}
\hline \multirow[b]{2}{*}{$\begin{array}{c}\text { Date of } \\
\text { assessment }\end{array}$} & \multirow[b]{2}{*}{$\begin{array}{c}\text { Tract area } \\
\qquad\left(\mathbf{k m}^{2}\right)\end{array}$} & \multirow{2}{*}{$\begin{array}{l}\text { Identified } \\
\text { copper } \\
\text { resources } \\
\text { (Mt) }\end{array}$} & \multicolumn{4}{|c|}{ Undiscovered copper resource estimates } \\
\hline & & & $\begin{array}{l}\text { Mean estimate of } \\
\text { in-place resources } \\
\text { (Mt) }\end{array}$ & $\begin{array}{c}\text { Probability of } 0 \\
\text { in-place resources } \\
\text { (percent) }\end{array}$ & $\begin{array}{l}\text { Mean estimate of } \\
\text { economic resources } \\
\text { (Mt) }\end{array}$ & $\begin{array}{c}\text { Probability of } 0 \\
\text { economic resources } \\
\text { (percent) }\end{array}$ \\
\hline 2006 & 5,767 & 0 & 7.7 & 6 & 4.0 & 66 \\
\hline
\end{tabular}

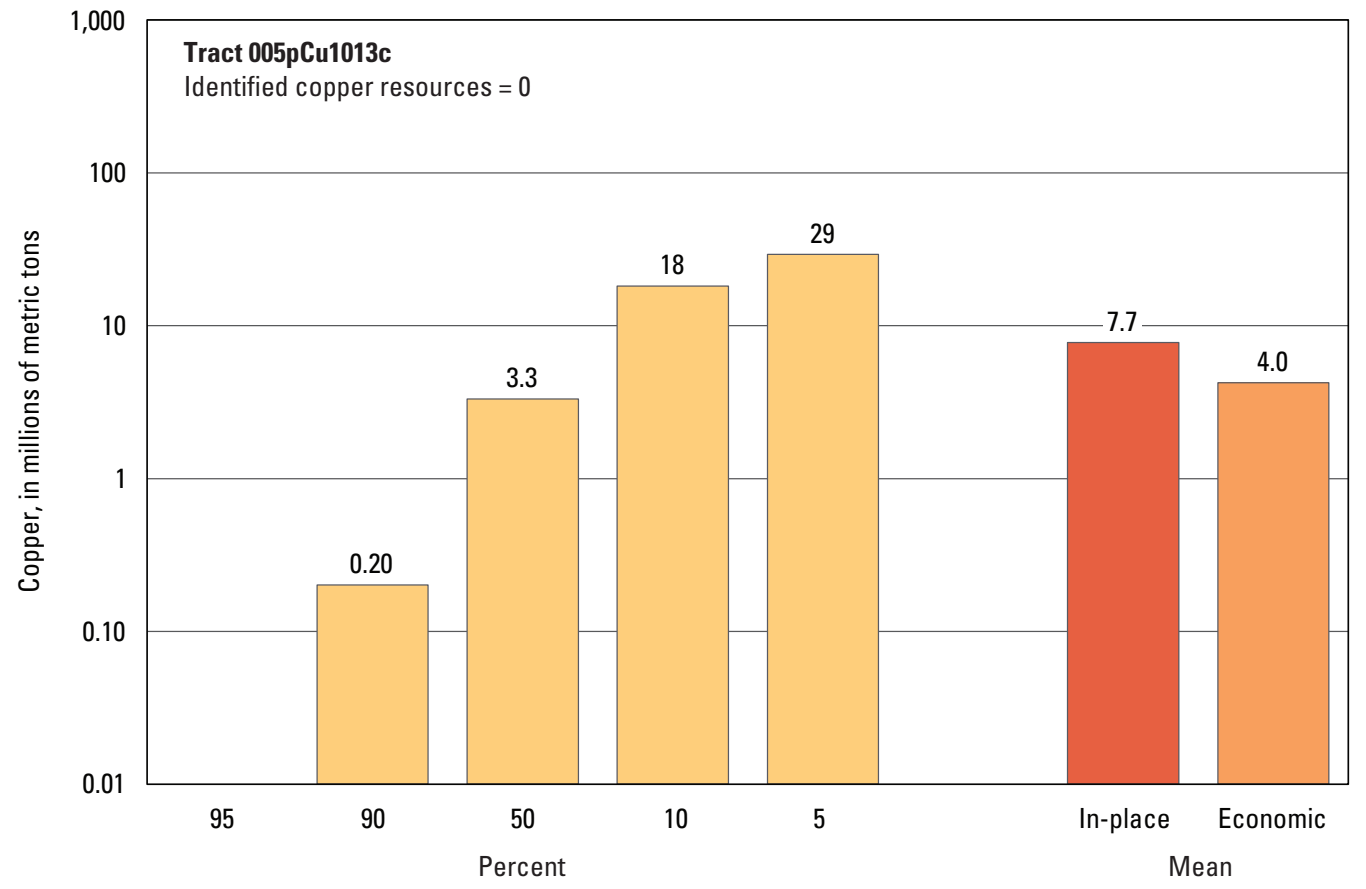

Graph showing the estimated probability distribution of undiscovered copper resources, where each bar represents the minimum amount estimated at the indicated percentage.

\section{Source}

Cunningham and others, 2008, Quantitative mineral resource assessment of copper, molybdenum, gold, and silver in undiscovered porphyry copper deposits in the Andes Mountains of South America: U.S. Geological Survey Open-File Report 2008-1253, http://pubs.usgs.gov/of/2008/1253/. 

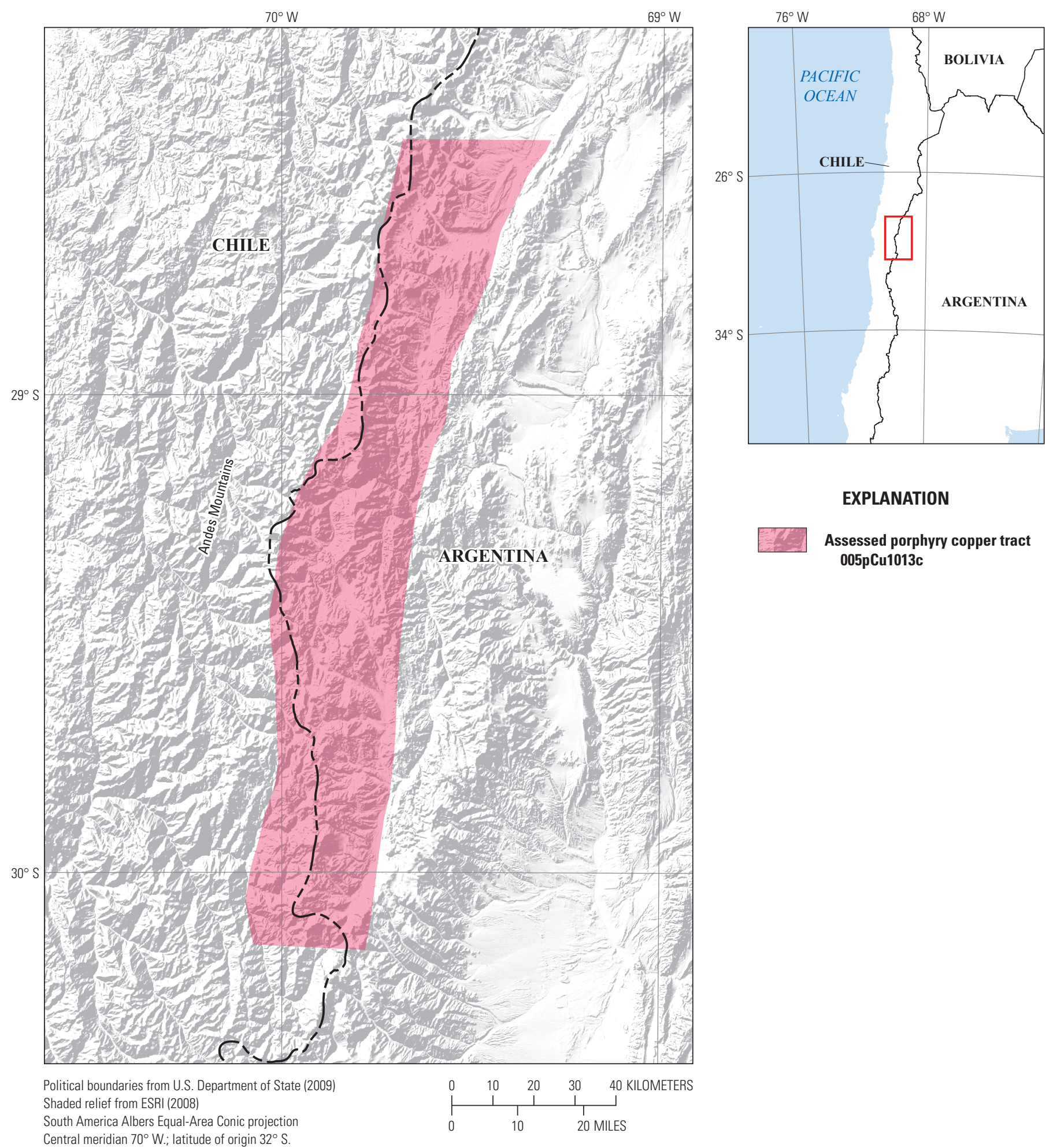

Assessed porphyry copper tract 005pCu1013c 


\title{
Plate 11. Porphyry Copper Assessment for Tract 005pCu1014d, Miocene- Pliocene Nevados de Famatina-Argentina
}

\author{
Descriptive model: \\ Porphyry copper model (Cox, 1986a) \\ Grade and tonnage model: \\ General porphyry copper model (Singer, Berger, and Moring, 2005) \\ Economic filter depth percentages: \\ Economic filter cost setting: \\ Geologic feature assessed: \\ Custom - 0 to 250 meters (m), 20\%; > 250 to $500 \mathrm{~m}, 30 \%$; $>500 \mathrm{~m}$ to $1 \mathrm{~km}, 50 \%$ \\ Mixed cost \\ Mainly late Miocene to early Pliocene calc-alkalic plutons and consanguineous coeval to slightly \\ older lavas, breccias, pyroclastic rocks, and volcanic domes \\ Number of known deposits: \\ 1
}

\section{Selected Resource Assessment Results for Porphyry Copper}

[Assessment depth, 1 kilometer ( $\mathrm{km}) ; \mathrm{km}^{2}$, square kilometer; Mt, millions of metric tons]

\begin{tabular}{ccccccc}
\hline $\begin{array}{c}\text { Date of } \\
\text { assessment }\end{array}$ & $\begin{array}{c}\text { Tract area } \\
\left(\mathbf{k m}^{2}\right)\end{array}$ & $\begin{array}{c}\text { Identified } \\
\text { copper } \\
\text { resources } \\
\text { (Mt) }\end{array}$ & $\begin{array}{c}\text { Mean estimate of } \\
\text { in-place resources } \\
(\mathbf{M t})\end{array}$ & $\begin{array}{c}\text { Probability of } \mathbf{0} \\
\text { in-place resources } \\
\text { (percent) }\end{array}$ & $\begin{array}{c}\text { Mean estimate of } \\
\text { economic resources } \\
\text { (Mt) }\end{array}$ & $\begin{array}{c}\text { Probability of 0 } \\
\text { economic resources } \\
\text { (percent) }\end{array}$ \\
\hline 2005 & 5,770 & 1.1 & 12 & 7 & 6.3 \\
\hline
\end{tabular}

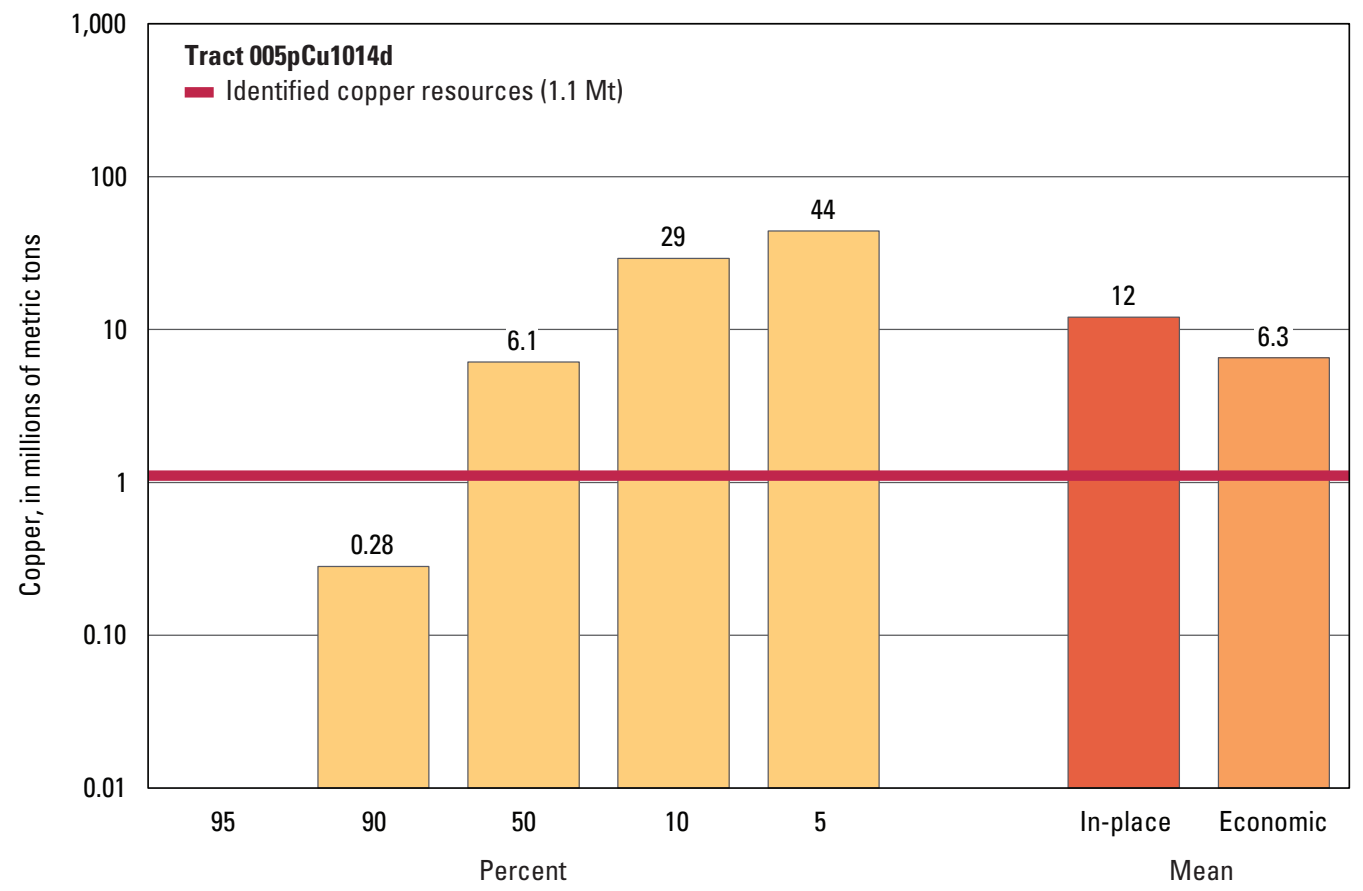

Graph showing the estimated probability distribution of undiscovered copper resources, where each bar represents the minimum amount estimated at the indicated percentage.

\section{Source}

Cunningham and others, 2008, Quantitative mineral resource assessment of copper, molybdenum, gold, and silver in undiscovered porphyry copper deposits in the Andes Mountains of South America: U.S. Geological Survey Open-File Report 2008-1253, http://pubs.usgs.gov/of/2008/1253/. 

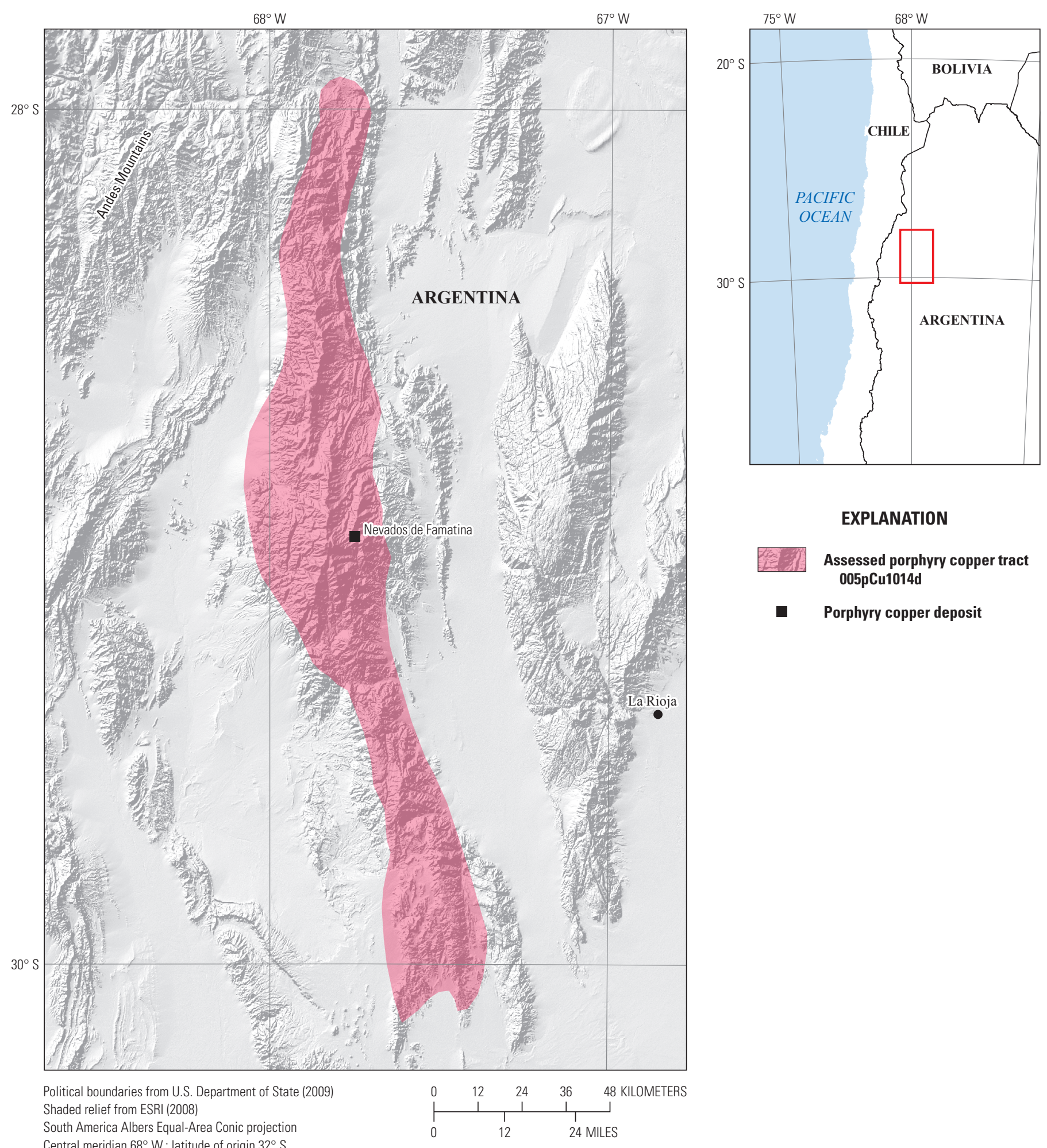

\section{pCu1014d}

Porphyry copper deposit

Central meridian $68^{\circ} \mathrm{W}$.; latitude of origin $32^{\circ} \mathrm{S}$. 


\section{Plate 12. Porphyry Copper Assessment for Tract 005pCu1017, Cretaceous Antucoya-Chile}

\author{
Descriptive model: \\ Grade and tonnage model: \\ Economic filter depth percentages: \\ Economic filter cost setting: \\ Geologic feature assessed: \\ Number of known deposits:
}

\author{
Porphyry copper model (Cox, 1986a) \\ General porphyry copper model (Singer, Berger, and Moring, 2005) \\ Default - 0 to 250 meters (m), 25\%; > 250 to $500 \mathrm{~m}, 25 \%$; > $500 \mathrm{~m}$ to $1 \mathrm{~km}, 50 \%$ \\ Typical cost \\ Cretaceous calc-alkalic plutons, including batholiths \\ 0 (2) (As shown on the map, 2 deposits were found after the assessment was done; the assessment \\ results below reflect information available in 2005 for 0 deposits.)
}

\section{Selected Resource Assessment Results for Porphyry Copper}

[Assessment depth, 1 kilometer $(\mathrm{km}) ; \mathrm{km}^{2}$, square kilometer; Mt, millions of metric tons]

\begin{tabular}{ccccccc}
\hline $\begin{array}{c}\text { Date of } \\
\text { assessment }\end{array}$ & $\begin{array}{c}\text { Tract area } \\
\left(\mathbf{k m}^{2}\right)\end{array}$ & $\begin{array}{c}\text { Identified } \\
\text { copper } \\
\text { resources } \\
\text { (Mt) }\end{array}$ & $\begin{array}{c}\text { Mean estimate of } \\
\text { in-place resources } \\
(\mathbf{M t})\end{array}$ & $\begin{array}{c}\text { Probability of } \mathbf{0} \\
\text { in-place resources } \\
\text { (percent) }\end{array}$ & $\begin{array}{c}\text { Mean estimate of } \\
\text { economic resources } \\
\text { (Mt) }\end{array}$ & $\begin{array}{c}\text { Probability of 0 } \\
\text { economic resources } \\
\text { (percent) }\end{array}$ \\
\hline 2005 & 77,511 & 0 & 23 & 3 & 15 \\
\hline
\end{tabular}

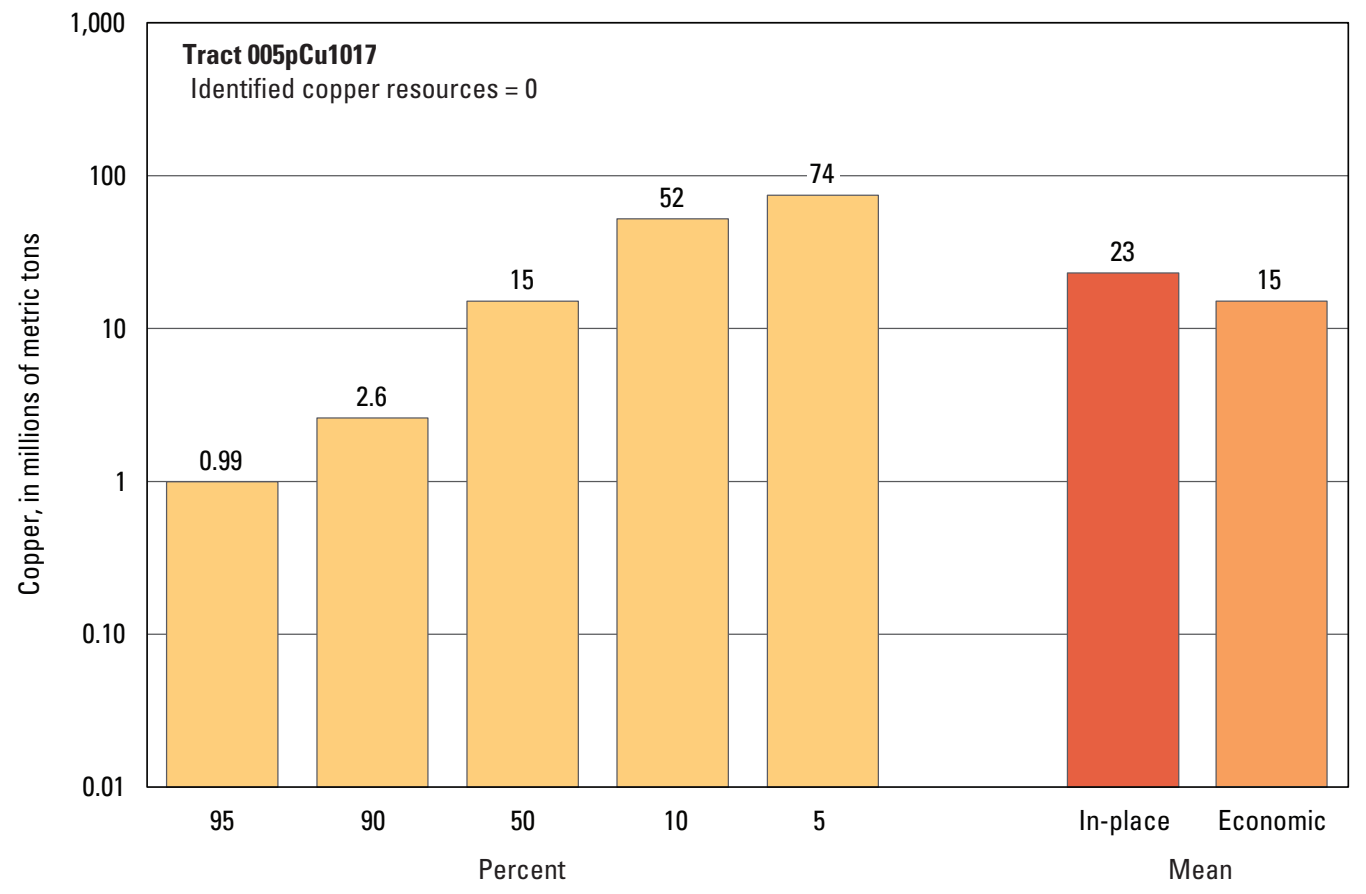

Graph showing the estimated probability distribution of undiscovered copper resources, where each bar represents the minimum amount estimated at the indicated percentage.

\section{Source}

Cunningham and others, 2008, Quantitative mineral resource assessment of copper, molybdenum, gold, and silver in undiscovered porphyry copper deposits in the Andes Mountains of South America: U.S. Geological Survey Open-File Report 2008-1253, http://pubs.usgs.gov/of/2008/1253/. 


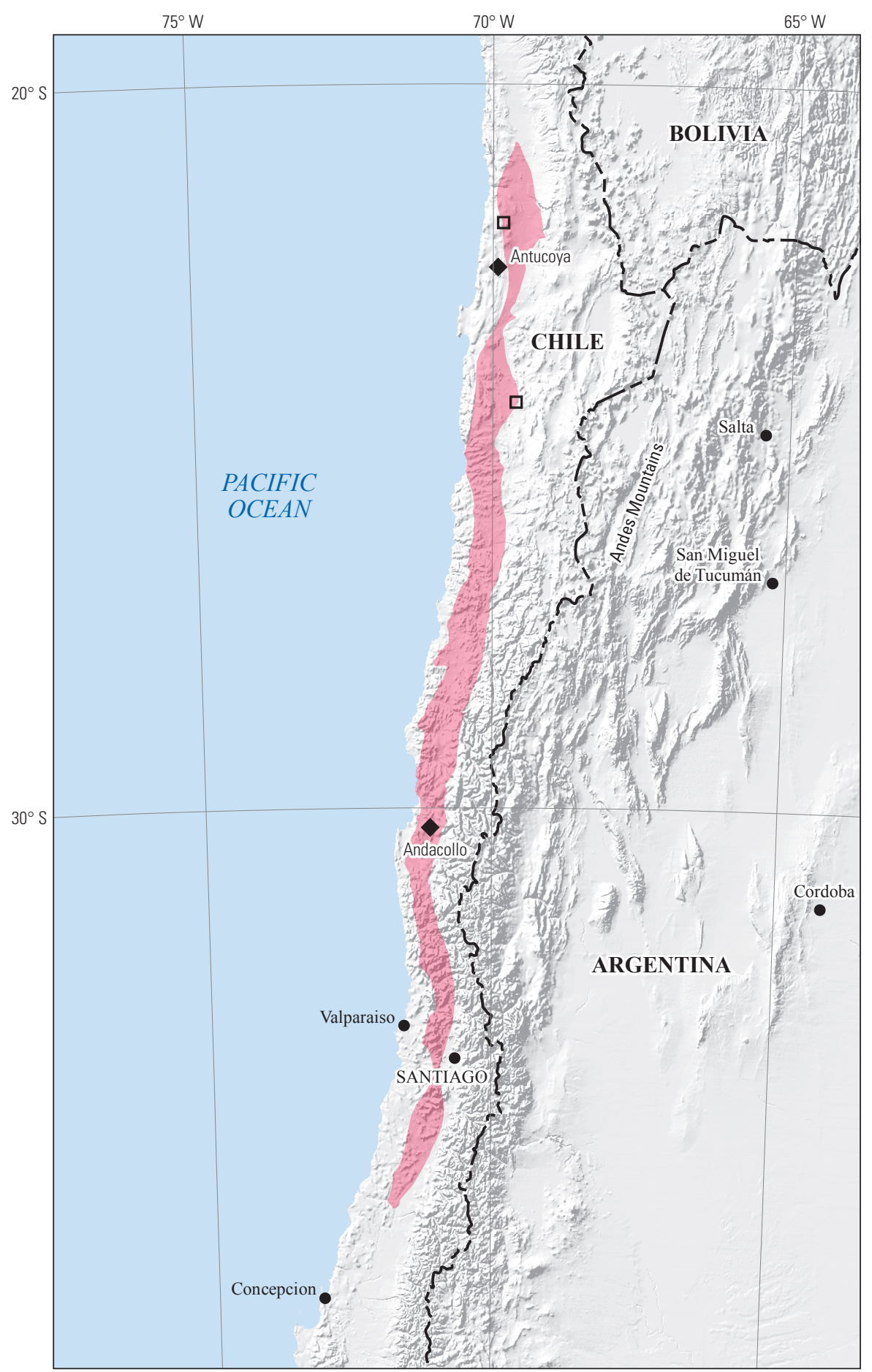

Political boundaries from U.S. Department of State (2009) Shaded relief from Earth Resources Observation and Science (EROS) Center (2011)

South America Albers Equal-Area Conic projection Central meridian $70^{\circ} 30^{\prime} \mathrm{W}$.; latitude of origin $32^{\circ} \mathrm{S}$.

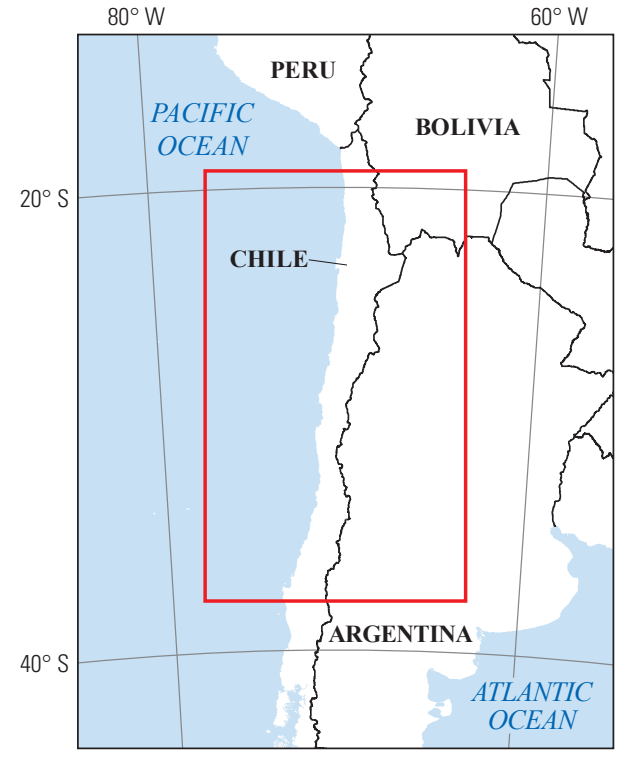

\section{EXPLANATION}

Assessed porphyry copper tract $005 p$ Cu1017

Porphyry copper deposit discovered after the assessment

$\square \quad$ Porphyry copper prospect 


\section{Plate 13. Porphyry Copper Assessment for Tract 005pCu1008, Paleocene- Eocene Toquepala-Chile and Peru}

\author{
Descriptive model: \\ Grade and tonnage model: \\ Economic filter depth percentages: \\ Economic filter cost setting: \\ Geologic feature assessed:
}

Number of known deposits:

\author{
Porphyry copper model (Cox, 1986a) \\ General porphyry copper model (Singer, Berger, and Moring, 2005) \\ Skewed deep - 0 to 250 meters (m), 10\%; > 250 to $500 \mathrm{~m}, 30 \%$; >500 m to $1 \mathrm{~km}, 60 \%$ \\ Typical cost \\ Paleocene and Eocene mostly calc-alkalic plutons; includes the Toquepala volcanic rocks and \\ coeval porphyry plutons (Peru), and rhyolite domes, dacite pyroclastics, and associated calderas \\ (Chile) \\ 12 (1) (As shown on the map, 1 of these deposits was found after the assessment was done; the \\ assessment results below reflect information available in 2005 for 12 deposits.)
}

\section{Selected Resource Assessment Results for Porphyry Copper}

[Assessment depth, 1 kilometer $(\mathrm{km}) ; \mathrm{km}^{2}$, square kilometer; Mt, millions of metric tons]

\begin{tabular}{ccccccc}
\hline \multirow{2}{*}{$\begin{array}{c}\text { Date of } \\
\text { assessment }\end{array}$} & $\begin{array}{c}\text { Tract area } \\
\left(\mathbf{k m}^{2}\right)\end{array}$ & $\begin{array}{c}\text { Identified } \\
\text { copper } \\
\text { resources } \\
(\mathbf{M t})\end{array}$ & $\begin{array}{c}\text { Mean estimate of } \\
\text { in-place resources } \\
(\mathbf{M t})\end{array}$ & $\begin{array}{c}\text { Probability of } \mathbf{2} \\
\text { in-place resources } \\
\text { (percent) }\end{array}$ & $\begin{array}{c}\text { Mean estimate of } \\
\text { economic resources } \\
\text { (Mt) }\end{array}$ & $\begin{array}{c}\text { Probability of 0 } \\
\text { economic resources } \\
\text { (percent) }\end{array}$ \\
\hline 2005 & 69,087 & 72 & 43 & 2 & 27 & 4
\end{tabular}

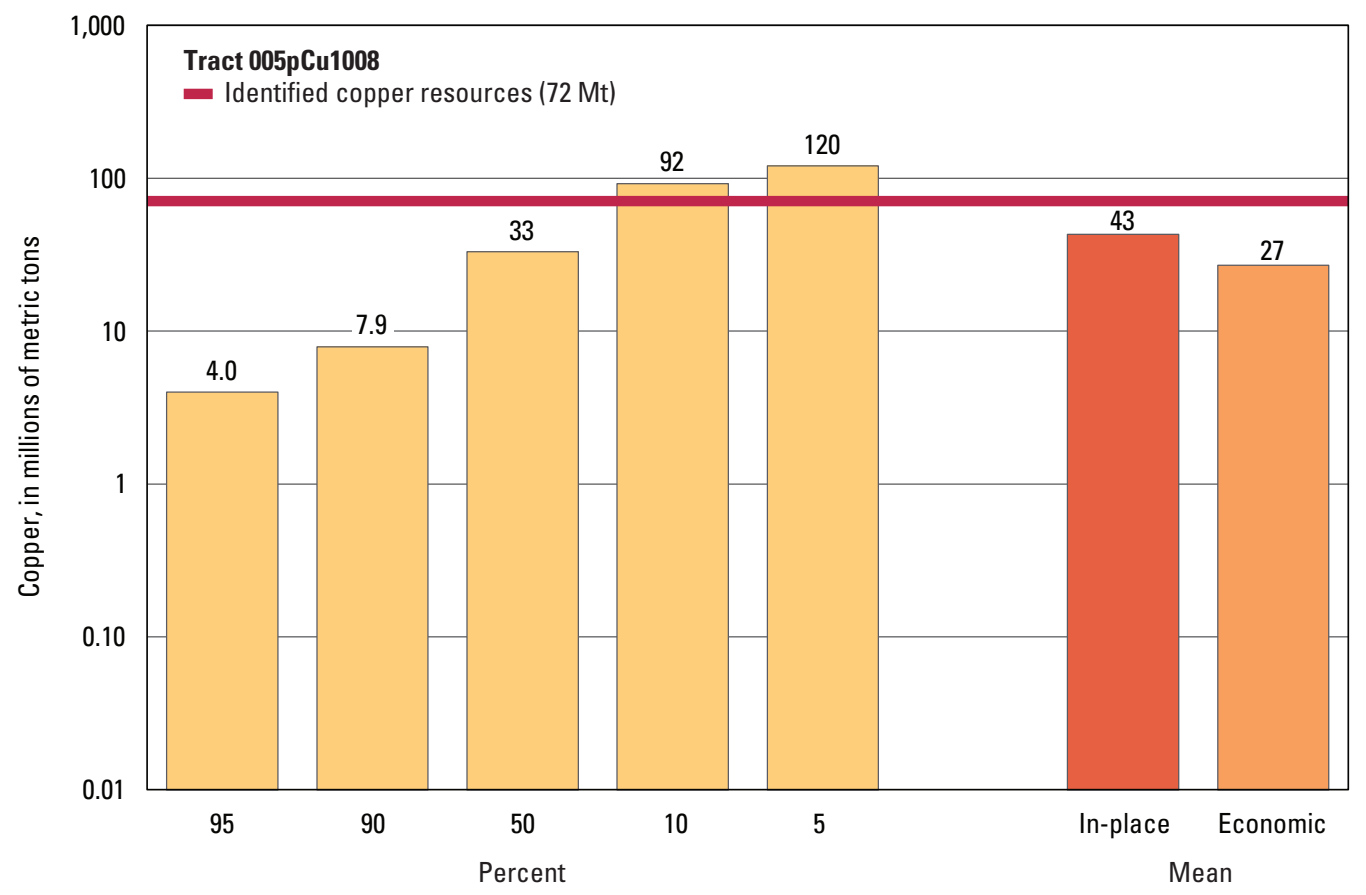

Graph showing the estimated probability distribution of undiscovered copper resources, where each bar represents the minimum amount estimated at the indicated percentage.

\section{Source}

Cunningham and others, 2008, Quantitative mineral resource assessment of copper, molybdenum, gold, and silver in undiscovered porphyry copper deposits in the Andes Mountains of South America: U.S. Geological Survey Open-File Report 2008-1253, http://pubs.usgs.gov/of/2008/1253/. 


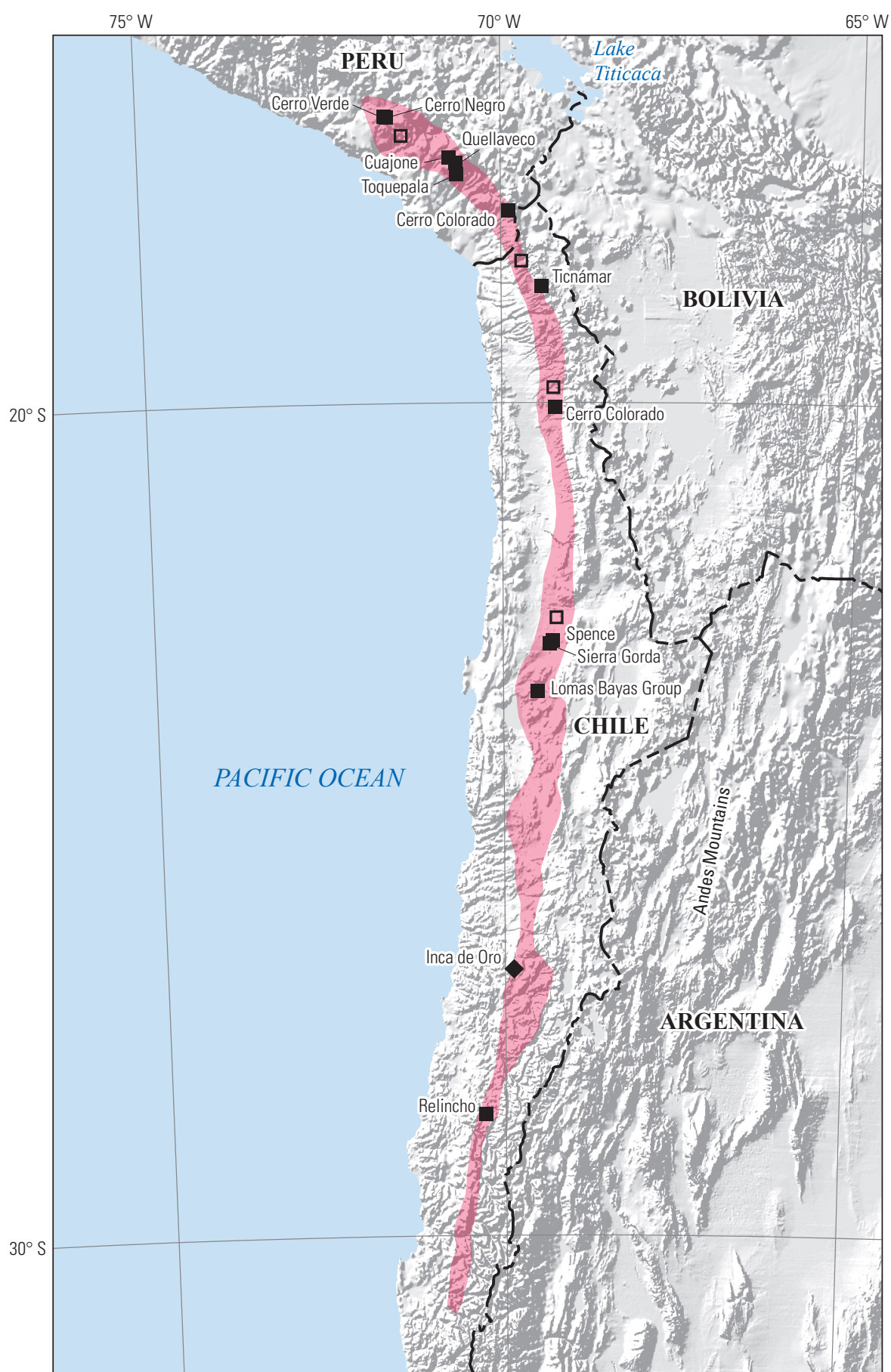

Political boundaries from U.S. Department of State (2009) Shaded relief from Earth Resources Observation and Science (EROS) Center (2011)

South America Albers Equal-Area Conic projection Central meridian $69^{\circ} \mathrm{W}$.; latitude of origin $32^{\circ} \mathrm{S}$.

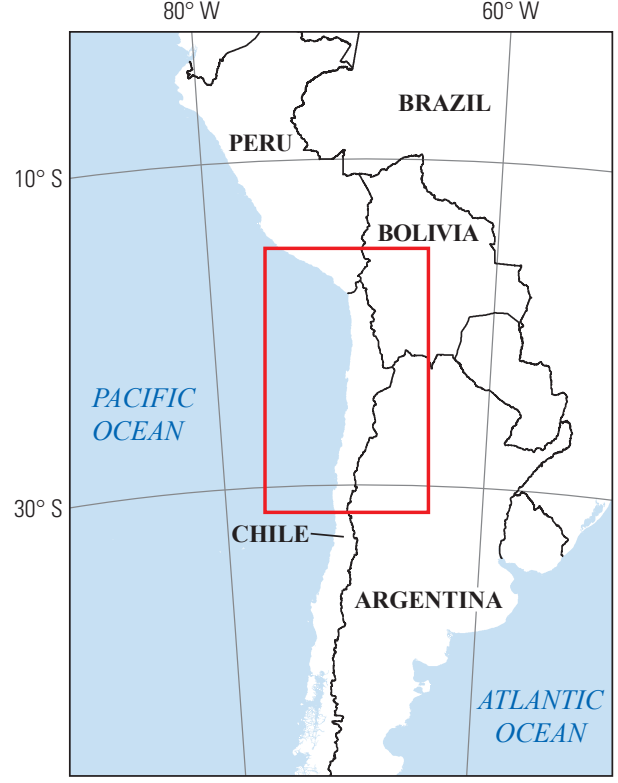

\section{EXPLANATION}

2. Assessed porphyry copper tract $005 p$ Cu1008

- Porphyry copper deposit

Porphyry copper deposit discovered after the assessment

$\square \quad$ Porphyry copper prospect 


\title{
Plate 14. Porphyry Copper Assessment for Tract 005pCu1013a, Miocene- Pliocene Cerro Casale-Argentina and Chile
}

\author{
Descriptive model: \\ Grade and tonnage model: \\ Economic filter depth percentages: \\ Economic filter cost setting: \\ Geologic feature assessed: \\ Number of known deposits:
}

Porphyry copper model (Cox, 1986a)

General porphyry copper model (Singer, Berger, and Moring, 2005)

Default -0 to 250 meters (m), $25 \% ;>250$ to $500 \mathrm{~m}, 25 \% ;>500 \mathrm{~m}$ to $1 \mathrm{~km}, 50 \%$

Mixed cost

Miocene to Pliocene plutons; including continental volcanic rocks containing lava flows, volcanic breccias, and ash-flow tuffs in three bands trending northwest across this northeast-trending tract

1 (1) (As shown on the map, 1 of these deposits was found after the assessment was done; the assessment results below reflect information available in 2006 for 1 deposit.)

\section{Selected Resource Assessment Results for Porphyry Copper}

[Assessment depth, 1 kilometer $(\mathrm{km}) ; \mathrm{km}^{2}$, square kilometer; Mt, millions of metric tons]

\begin{tabular}{ccccccc}
\hline \multirow{2}{*}{$\begin{array}{c}\text { Date of } \\
\text { assessment }\end{array}$} & $\begin{array}{c}\text { Tract area } \\
\left(\mathbf{k m}^{2}\right)\end{array}$ & $\begin{array}{c}\text { Identified } \\
\text { copper } \\
\text { resources } \\
(\mathbf{M t})\end{array}$ & $\begin{array}{c}\text { Mean estimate of } \\
\text { in-place resources } \\
(\mathbf{M t})\end{array}$ & $\begin{array}{c}\text { Probability of } \mathbf{0} \\
\text { in-place resources } \\
\text { (percent) }\end{array}$ & $\begin{array}{c}\text { Mean estimate of } \\
\text { economic resources } \\
\text { (Mt) }\end{array}$ & $\begin{array}{c}\text { Probability of } \mathbf{0} \\
\text { economic resources } \\
\text { (percent) }\end{array}$ \\
\hline 2006 & 70,587 & 4.5 & 38 & 2 & 20 \\
\hline
\end{tabular}

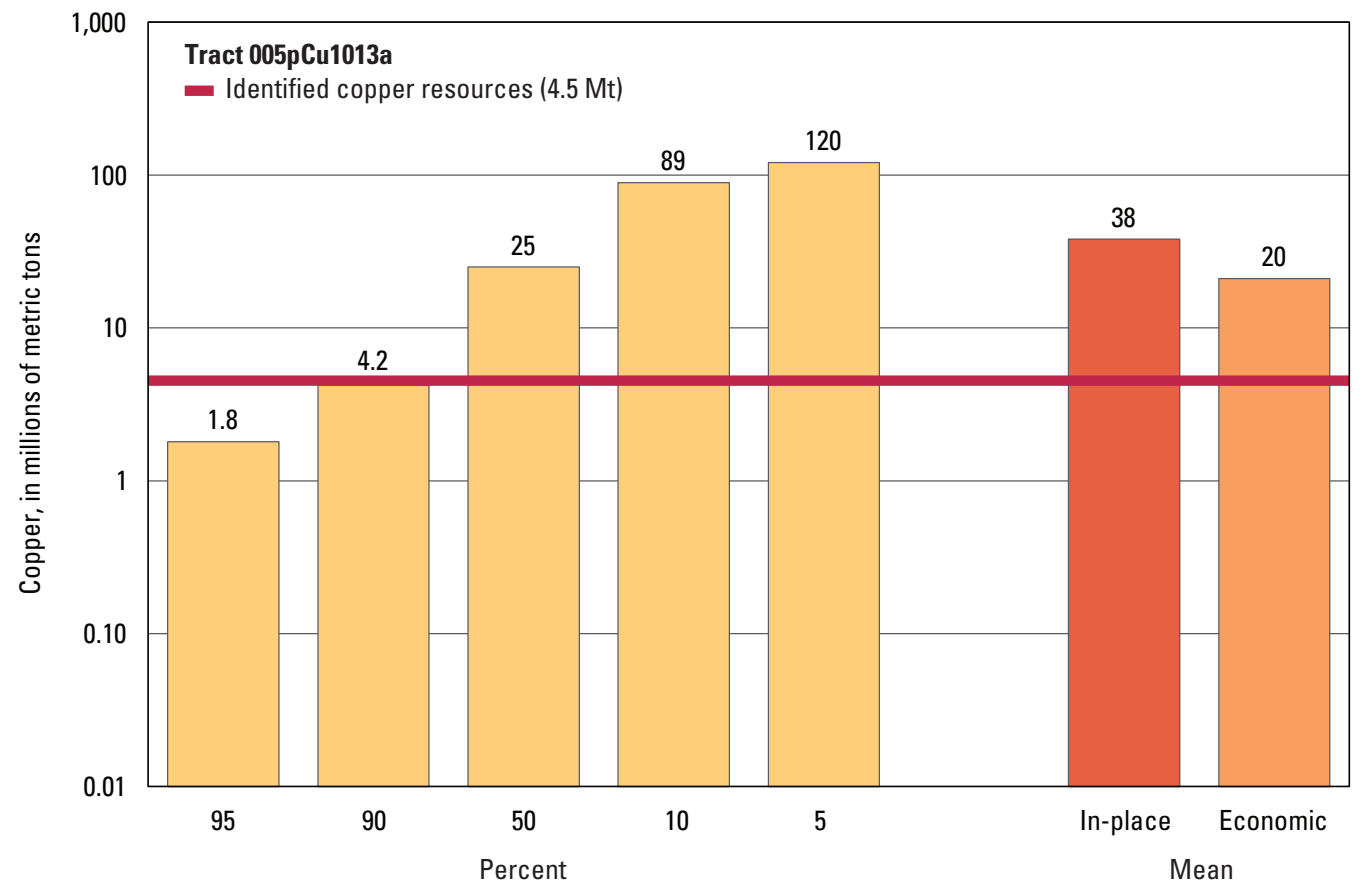

Graph showing the estimated probability distribution of undiscovered copper resources, where each bar represents the minimum amount estimated at the indicated percentage.

\section{Source}

Cunningham and others, 2008, Quantitative mineral resource assessment of copper, molybdenum, gold, and silver in undiscovered porphyry copper deposits in the Andes Mountains of South America: U.S. Geological Survey Open-File Report 2008-1253, http://pubs.usgs.gov/of/2008/1253/. 

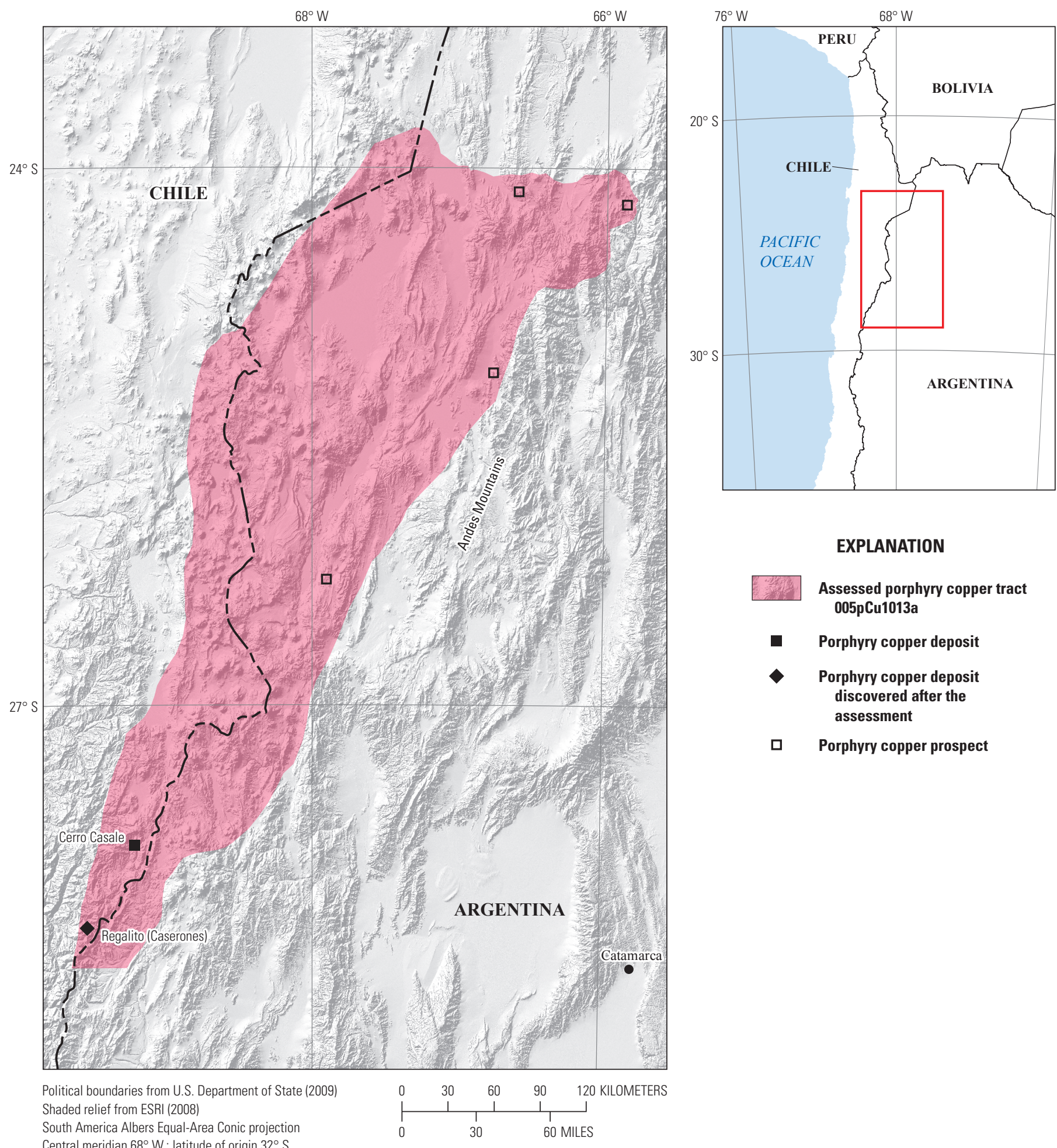

EXPLANATION

Assessed porphyry copper tract 005pCu1013a

- Porphyry copper deposit

$\checkmark \quad$ Porphyry copper deposit discovered after the assessment

Porphyry copper prospect 


\title{
Plate 15. Porphyry Copper Assessment for Tract 005pCu1014c, Miocene- Pliocene Bajo de la Alumbrera-Argentina
}

\author{
Descriptive model: \\ Porphyry copper model (Cox, 1986a) \\ Grade and tonnage model: \\ General porphyry copper model (Singer, Berger, and Moring, 2005) \\ Economic filter depth percentages: \\ Economic filter cost setting: \\ Geologic feature assessed: \\ Default -0 to 250 meters (m), $25 \% ;>250$ to $500 \mathrm{~m}, 25 \% ;>500 \mathrm{~m}$ to $1 \mathrm{~km}, 50 \%$ \\ Mixed cost \\ Mainly late Miocene to early Pliocene calc-alkalic plutons and consanguineous coeval to slightly \\ older lavas, breccias, pyroclastic rocks, and volcanic domes \\ Number of known deposits: \\ 3
}

\section{Selected Resource Assessment Results for Porphyry Copper}

[Assessment depth, 1 kilometer ( $\mathrm{km}) ; \mathrm{km}^{2}$, square kilometer; Mt, millions of metric tons]

\begin{tabular}{ccccccc}
\hline $\begin{array}{c}\text { Date of } \\
\text { assessment }\end{array}$ & $\begin{array}{c}\text { Tract area } \\
\left(\mathbf{k m}^{2}\right)\end{array}$ & $\begin{array}{c}\text { Identified } \\
\text { copper } \\
\text { resources } \\
\text { (Mt) }\end{array}$ & $\begin{array}{c}\text { Mean estimate of } \\
\text { in-place resources } \\
(\mathbf{M t})\end{array}$ & $\begin{array}{c}\text { Probability of } \mathbf{0} \\
\text { in-place resources } \\
\text { (percent) }\end{array}$ & $\begin{array}{c}\text { Mean estimate of } \\
\text { economic resources } \\
\text { (Mt) }\end{array}$ & $\begin{array}{c}\text { Probability of 0 } \\
\text { economic resources } \\
\text { (percent) }\end{array}$ \\
\hline 2005 & 24,048 & 12 & 17 & 3 & 8.9 \\
\hline
\end{tabular}

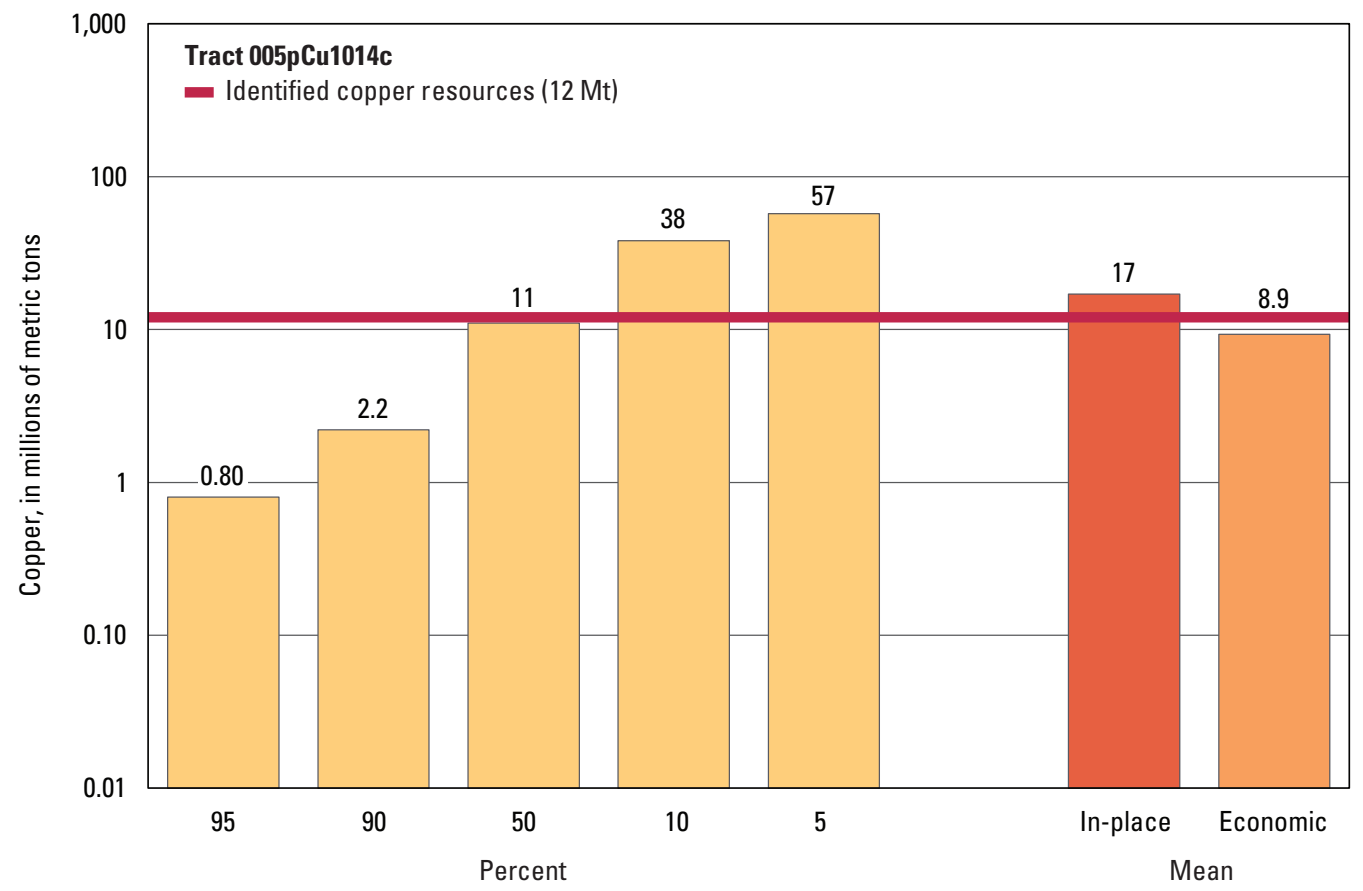

Graph showing the estimated probability distribution of undiscovered copper resources, where each bar represents the minimum amount estimated at the indicated percentage.

\section{Source}

Cunningham and others, 2008, Quantitative mineral resource assessment of copper, molybdenum, gold, and silver in undiscovered porphyry copper deposits in the Andes Mountains of South America: U.S. Geological Survey Open-File Report 2008-1253, http://pubs.usgs.gov/of/2008/1253/. 


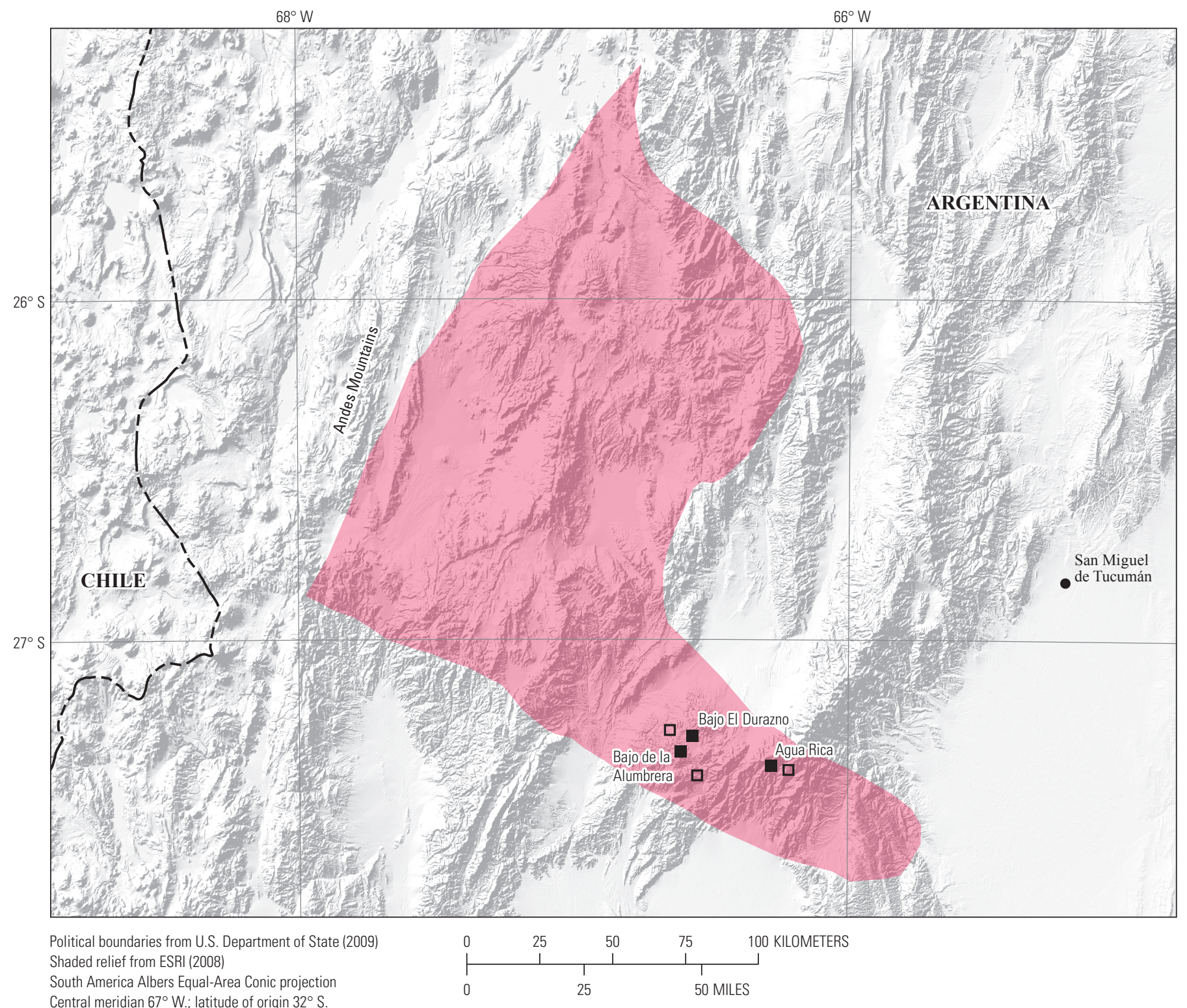

Central meridian $67^{\circ} \mathrm{W}$.; latitude of origin $32^{\circ} \mathrm{S}$.

\section{EXPLANATION}

\begin{tabular}{|c|c|}
\hline & $\begin{array}{l}\text { Assessed porphyry copper } \\
\text { 005pCu1014c }\end{array}$ \\
\hline & Porphyry copper deposit \\
\hline & Porphyry copper prospect \\
\hline
\end{tabular}

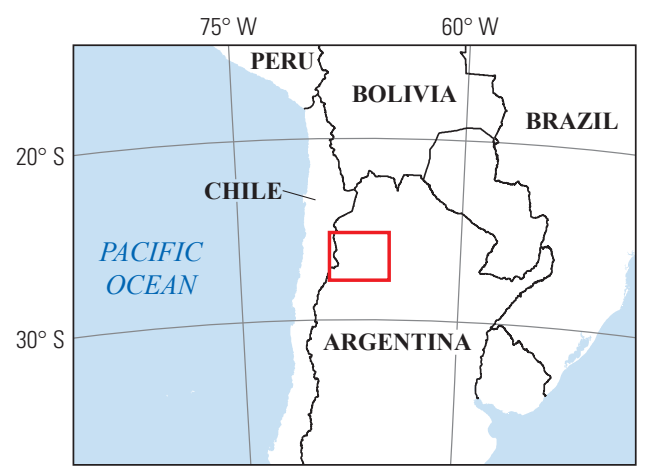




\section{Plate 16. Porphyry Copper Assessment for Tract 005pCu1011, Eocene- Oligocene Taca Taca Bajo-Argentina}

\author{
Descriptive model: \\ Grade and tonnage model: \\ Economic filter depth percentages: \\ Economic filter cost setting: \\ Geologic feature assessed: \\ Number of known deposits:
}

\author{
Porphyry copper model (Cox, 1986a) \\ General porphyry copper model (Singer, Berger, and Moring, 2005) \\ Skewed deep - 0 to 250 meters (m), 10\%; > 250 to $500 \mathrm{~m}, 30 \%$; >500 m to $1 \mathrm{~km}, 60 \%$ \\ Mixed cost \\ Assorted Eocene to Oligocene mostly calc-alkalic plutons \\ 1
}

\section{Selected Resource Assessment Results for Porphyry Copper}

[Assessment depth, 1 kilometer $(\mathrm{km}) ; \mathrm{km}^{2}$, square kilometer; Mt, millions of metric tons]

\begin{tabular}{ccccccc}
\hline \multirow{2}{*}{$\begin{array}{c}\text { Date of } \\
\text { assessment }\end{array}$} & $\begin{array}{c}\text { Tract area } \\
\left(\mathbf{k m}^{2}\right)\end{array}$ & $\begin{array}{c}\text { Identified } \\
\text { copper } \\
\text { resources } \\
(\mathbf{M t})\end{array}$ & $\begin{array}{c}\text { Mean estimate of } \\
\text { in-place resources } \\
(\mathbf{M t})\end{array}$ & $\begin{array}{c}\text { Probability of } \mathbf{0} \\
\text { in-place resources } \\
\text { (percent) }\end{array}$ & $\begin{array}{c}\text { Mean estimate of } \\
\text { economic resources } \\
\text { (Mt) }\end{array}$ & $\begin{array}{c}\text { Probability of } \mathbf{0} \\
\text { economic resources } \\
\text { (percent) }\end{array}$ \\
\hline 2005 & 2,429 & 3.0 & 4.2 & 31 & 2.6 \\
\hline
\end{tabular}

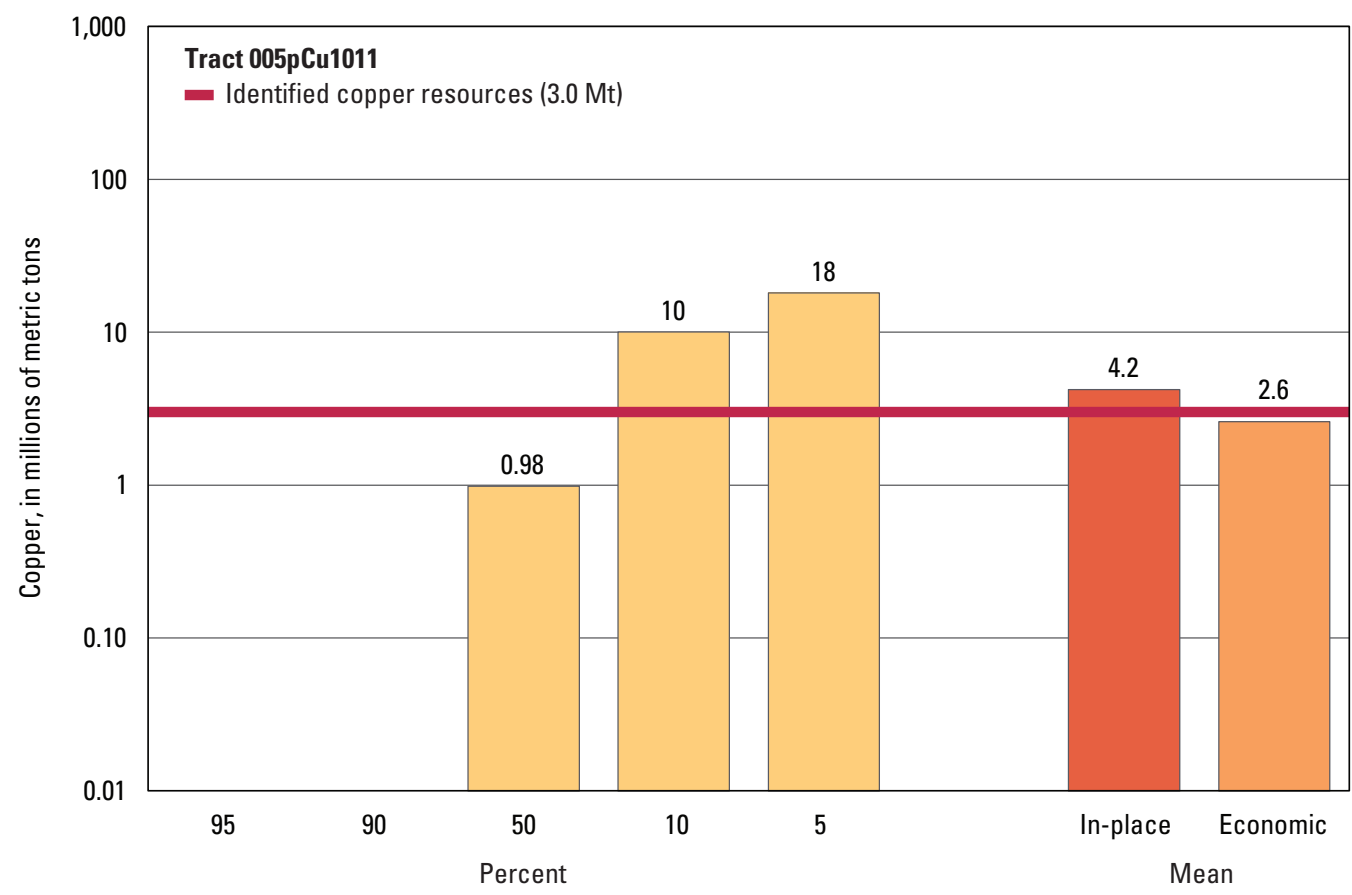

Graph showing the estimated probability distribution of undiscovered copper resources, where each bar represents the minimum amount estimated at the indicated percentage.

\section{Source}

Cunningham and others, 2008, Quantitative mineral resource assessment of copper, molybdenum, gold, and silver in undiscovered porphyry copper deposits in the Andes Mountains of South America: U.S. Geological Survey Open-File Report 2008-1253, http://pubs.usgs.gov/of/2008/1253/. 

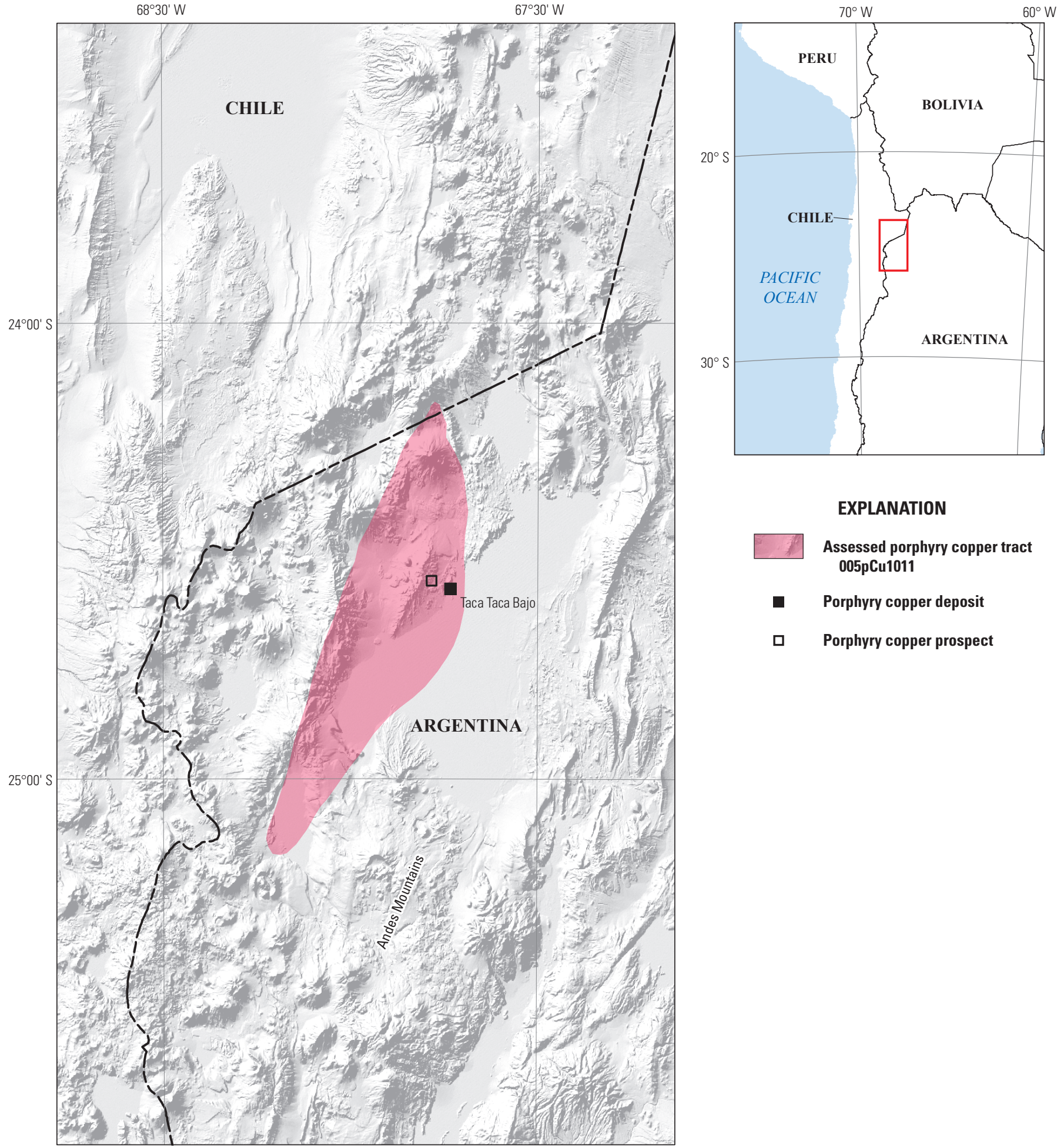

EXPLANATION

Assessed porphyry copper tract 005pCu1011

Porphyry copper deposit

ㅁ Porphyry copper prospect

Political boundaries from U.S. Department of State (2009) Shaded relief from ESRI (2008)

South America Albers Equal-Area Conic projection

Central meridian $68^{\circ} \mathrm{W}$.; latitude of origin $32^{\circ} \mathrm{S}$.

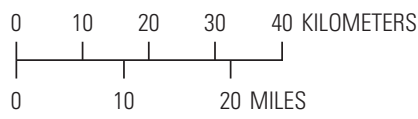




\section{Plate 17. Porphyry Copper Assessment for Tract 005pCu1018, Permian El Loa- Chile}

\section{Descriptive model:}

Grade and tonnage model:

Economic filter depth percentages:

Economic filter cost setting:

Geologic feature assessed:

Number of known deposits:

\author{
Porphyry copper model (Cox, 1986a) \\ General porphyry copper model (Singer, Berger, and Moring, 2005) \\ Skewed deep -0 to 250 meters (m), 10\%; > 250 to $500 \mathrm{~m}, 30 \%$; >500 $\mathrm{m}$ to $1 \mathrm{~km}, 60 \%$ \\ Typical cost \\ Permian calc-alkalic plutons; the southern extensions of this tract are in tract $005 \mathrm{pCu} 1016 \mathrm{ab}$ (pl. 7) \\ 0
}

\section{Selected Resource Assessment Results for Porphyry Copper}

[Assessment depth, 1 kilometer $(\mathrm{km})$; $\mathrm{km}^{2}$, square kilometer; $\mathrm{Mt}$, millions of metric tons]

\begin{tabular}{ccccccc}
\hline \multirow{2}{*}{$\begin{array}{c}\text { Date of } \\
\text { assessment }\end{array}$} & $\begin{array}{c}\text { Tract area } \\
\left(\mathbf{k m}^{2}\right)\end{array}$ & $\begin{array}{c}\text { Identified } \\
\text { copper } \\
\text { resources } \\
(\mathbf{M t})\end{array}$ & $\begin{array}{c}\text { Mean estimate of } \\
\text { in-place resources } \\
(\mathbf{M t})\end{array}$ & $\begin{array}{c}\text { Probability of } \mathbf{0} \\
\text { in-place resources } \\
\text { (percent) }\end{array}$ & $\begin{array}{c}\text { Mean estimate of } \\
\text { economic resources } \\
\text { (Mt) }\end{array}$ & $\begin{array}{c}\text { Probability of } \mathbf{0} \\
\text { economic resources } \\
\text { (percent) }\end{array}$ \\
\hline 2005 & 17,765 & 0 & 7.5 & 6 & 4.8 \\
\hline
\end{tabular}

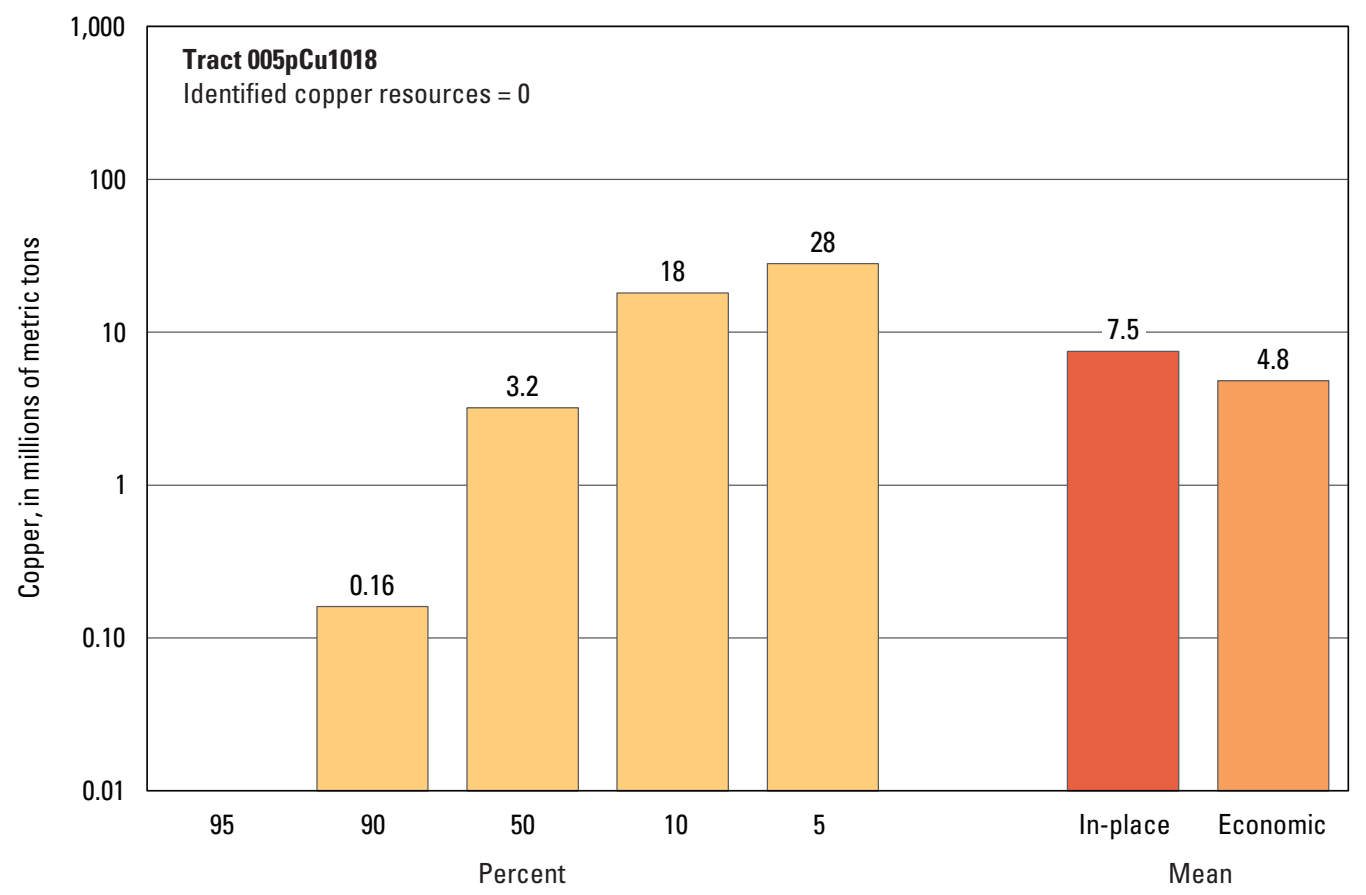

Graph showing the estimated probability distribution of undiscovered copper resources, where each bar represents the minimum amount estimated at the indicated percentage.

\section{Source}

Cunningham and others, 2008, Quantitative mineral resource assessment of copper, molybdenum, gold, and silver in undiscovered porphyry copper deposits in the Andes Mountains of South America: U.S. Geological Survey Open-File Report 2008-1253, http://pubs.usgs.gov/of/2008/1253/. 

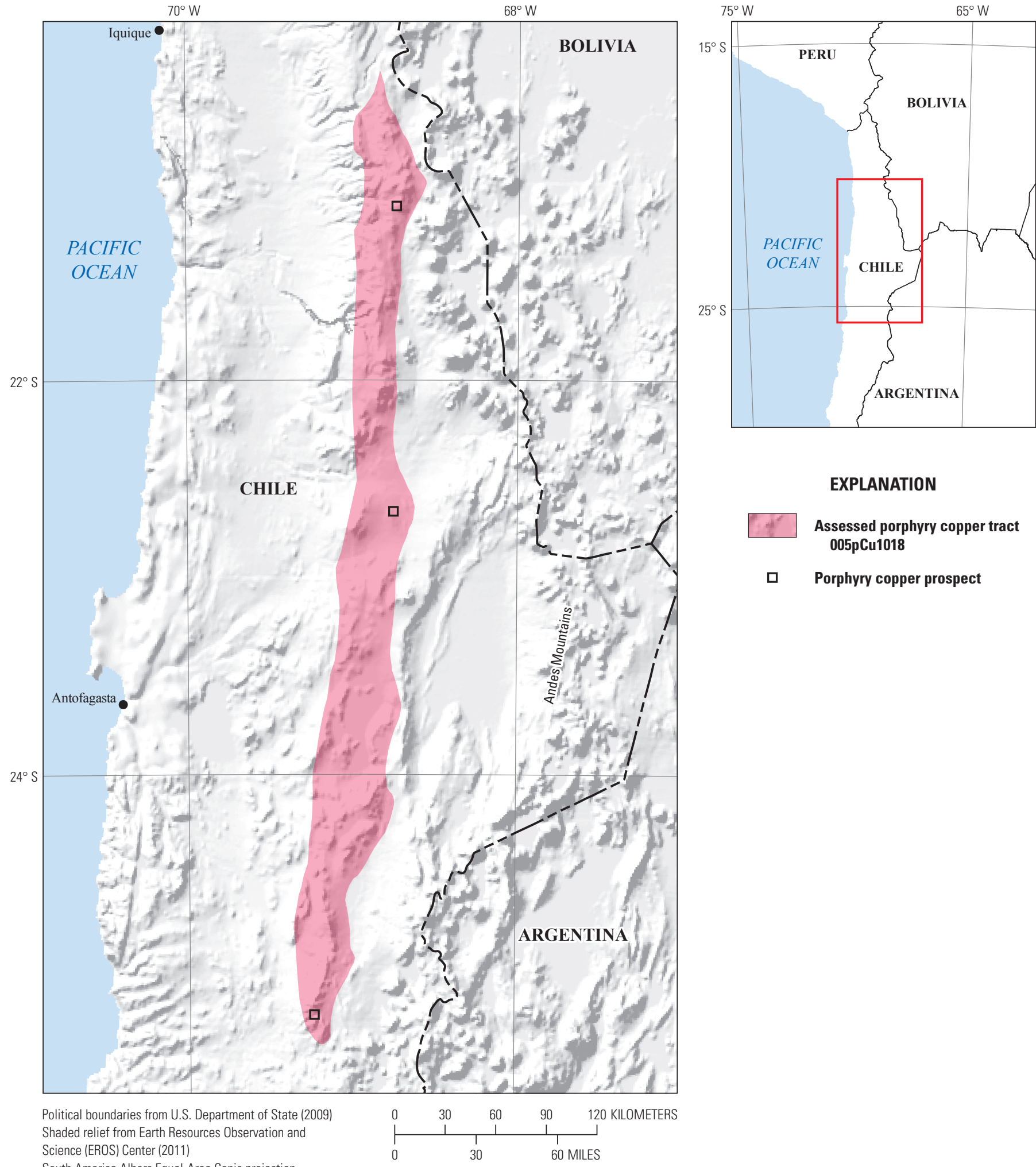

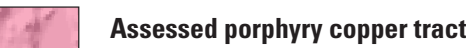
$005 p C u 1018$

ㅁ Porphyry copper prospect

South America Albers Equal-Area Conic projection

Central meridian $69^{\circ} \mathrm{W}$; l latitude of origin $32^{\circ} \mathrm{S}$. 


\section{Plate 18. Porphyry Copper Assessment for Tract 005pCu1010ab, Eocene- Oligocene Chuquicamata-Chile}

\author{
Descriptive model: \\ Grade and tonnage model: \\ Economic filter depth percentages: \\ Economic filter cost setting: \\ Geologic feature assessed:
}

Number of known deposits:

\author{
Porphyry copper model (Cox, 1986a) \\ Giant porphyry copper model (Singer, Briskey, and Cunningham, 2008) \\ Default - 0 to 250 meters (m), 25\%; > 250 to $500 \mathrm{~m}, 25 \%$; >500 m to $1 \mathrm{~km}, 50 \%$ \\ Typical cost \\ Eocene to Oligocene mainly calc-alkalic plutons, including epizonal plutons intruding \\ volcanic-arc lava flows and breccias; equivalent to rocks in tracts $005 \mathrm{pCu} 1009$ (pl. 19) \\ and $005 \mathrm{pCu} 1012$ (pl. 9) \\ 10 (6) (As shown on the map, 6 deposits were found after the assessment was done; the \\ assessment results below reflect information available in 2005 for 10 deposits.)
}

\section{Selected Resource Assessment Results for Porphyry Copper}

[Assessment depth, 1 kilometer $(\mathrm{km}) ; \mathrm{km}^{2}$, square kilometer; $\mathrm{Mt}$, millions of metric tons]

\begin{tabular}{ccccccc}
\hline \multirow{2}{*}{$\begin{array}{c}\text { Date of } \\
\text { assessment }\end{array}$} & $\begin{array}{c}\text { Tract area } \\
\left(\mathbf{k m}^{2}\right)\end{array}$ & $\begin{array}{c}\text { Identified } \\
\text { copper } \\
\text { resources } \\
(\mathbf{M t})\end{array}$ & $\begin{array}{c}\text { Mean estimate of } \\
\text { in-place resources } \\
(\mathbf{M t})\end{array}$ & $\begin{array}{c}\text { Probability of } \mathbf{0} \\
\text { in-place resources } \\
\text { (percent) }\end{array}$ & $\begin{array}{c}\text { Mean estimate of } \\
\text { economic resources } \\
\text { (Mt) }\end{array}$ & $\begin{array}{c}\text { Probability of } 0 \\
\text { economic resources } \\
\text { (percent) }\end{array}$ \\
\hline 2005 & 25,690 & 320 & 210 & 3 & 170 \\
\hline
\end{tabular}

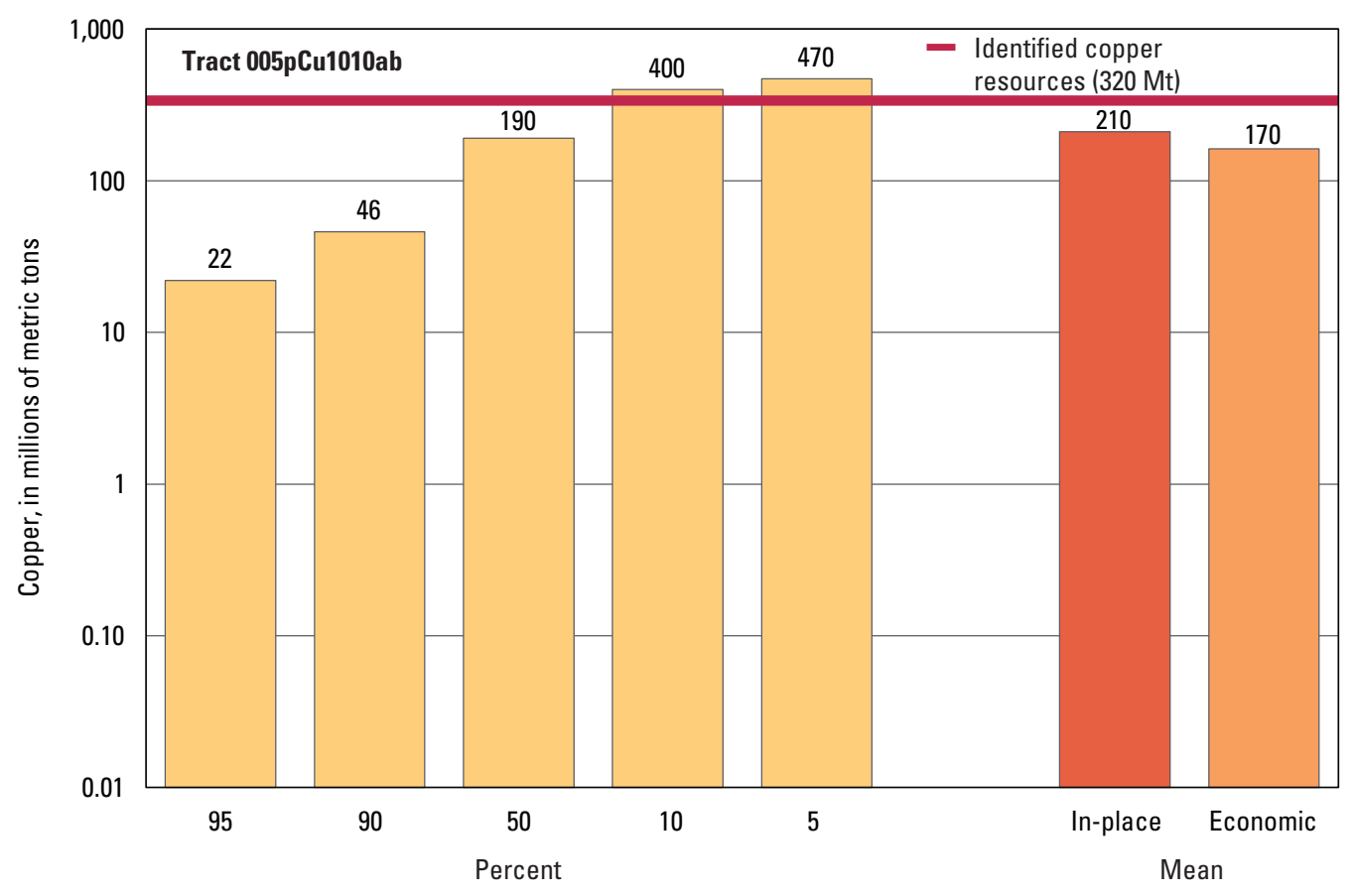

Graph showing the estimated probability distribution of undiscovered copper resources, where each bar represents the minimum amount estimated at the indicated percentage.

\section{Source}

Cunningham and others, 2008, Quantitative mineral resource assessment of copper, molybdenum, gold, and silver in undiscovered porphyry copper deposits in the Andes Mountains of South America: U.S. Geological Survey Open-File Report 2008-1253, http://pubs.usgs.gov/of/2008/1253/. 


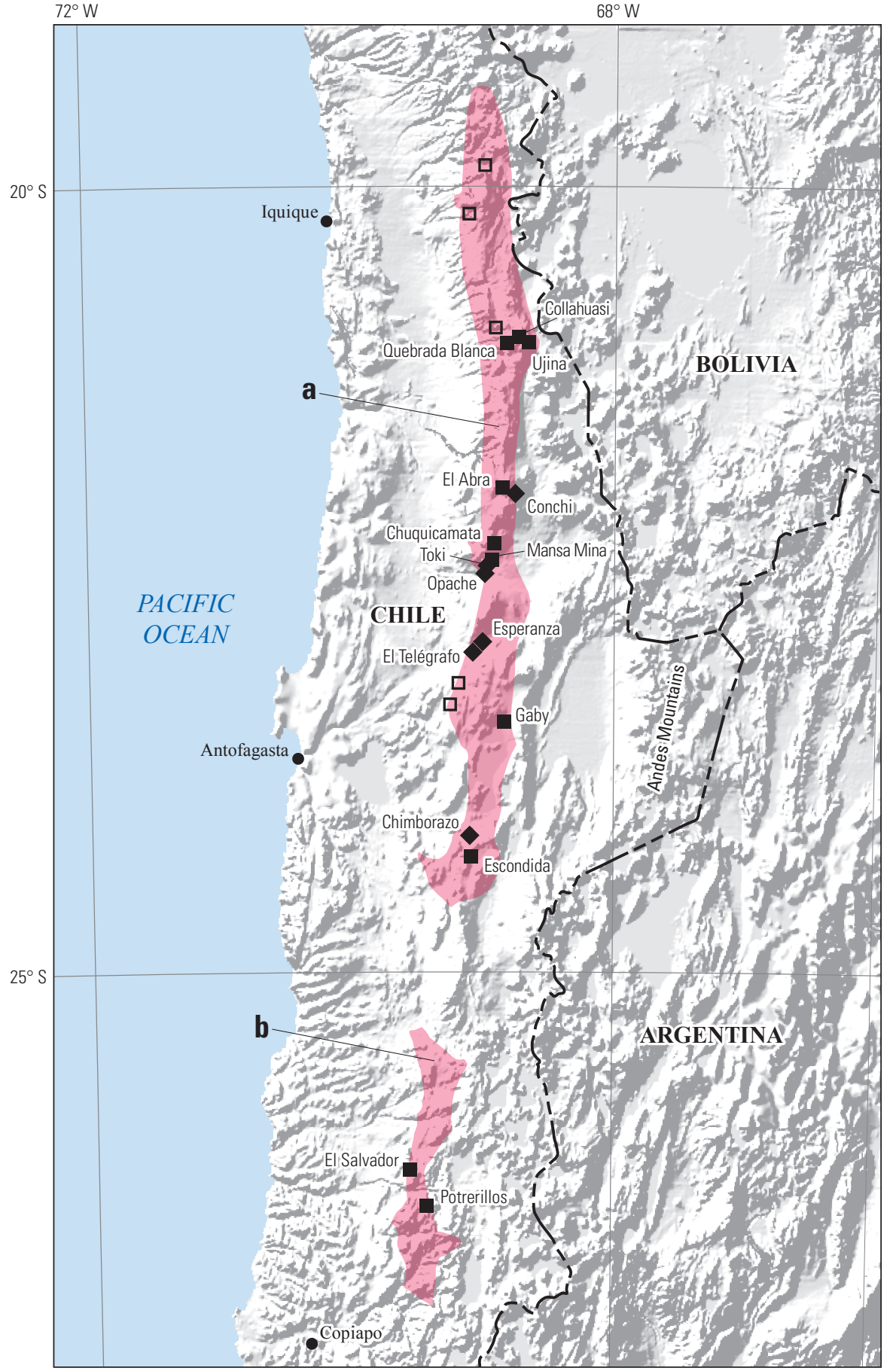

Political boundaries from U.S. Department of State (2009) Shaded relief from Earth Resources Observation and Science (EROS) Center (2011)

South America Albers Equal-Area Conic projection Central meridian $69^{\circ} \mathrm{W}$.; latitude of origin $32^{\circ} \mathrm{S}$.

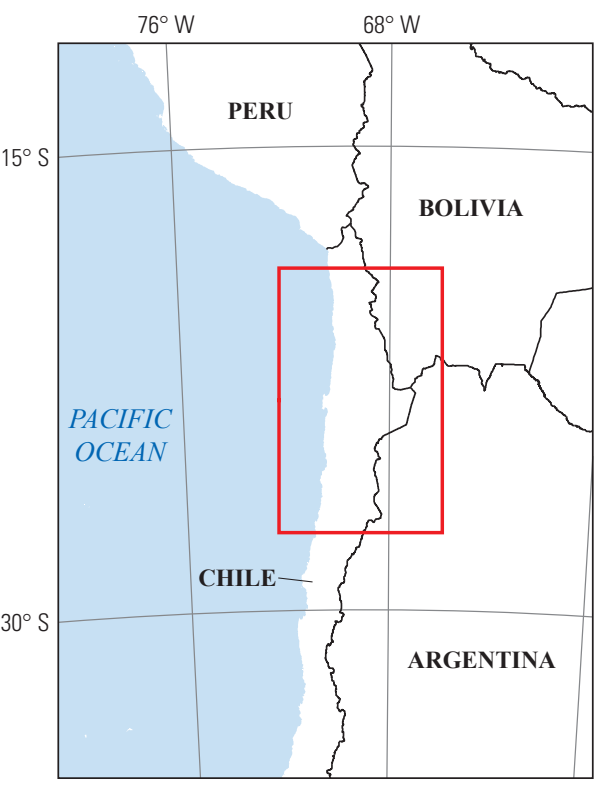

\section{EXPLANATION}

Assessed porphyry copper tracts 005pCu1010a and 005pCu1010bLetters on map indicate sub-tracts a and $b$

- Porphyry copper deposit

Porphyry copper deposit discovered after the assessment

$\square \quad$ Porphyry copper prospect 


\section{Plate 19. Porphyry Copper Assessment for Tract 005pCu1009, Eocene- Oligocene Antapaccay-Peru}

\author{
Descriptive model: \\ Grade and tonnage model: \\ Economic filter depth percentages: \\ Economic filter cost setting: \\ Geologic feature assessed:
}

Number of known deposits:

\author{
Porphyry copper model (Cox, 1986a) \\ General porphyry copper model (Singer, Berger, and Moring, 2005) \\ Default -0 to 250 meters (m), $25 \% ;>250$ to $500 \mathrm{~m}, 25 \%$; $>500 \mathrm{~m}$ to $1 \mathrm{~km}, 50 \%$ \\ Mixed cost \\ Eocene to Oligocene mostly calc-alkalic plutons, including epizonal plutons that intrude \\ voluminous volcanic-arc lava flows and breccias; equivalent to rocks in tracts $005 \mathrm{pCu} 1010 \mathrm{ab}$ \\ (pl. 18) and 005pCu1012 (pl. 9) \\ 5 (1) (As shown on the map, 1 deposit was found after the assessment was done; the assessment \\ results below reflect information available in 2005 for 5 deposits.)
}

\section{Selected Resource Assessment Results for Porphyry Copper}

[Assessment depth, 1 kilometer (km); $\mathrm{km}^{2}$, square kilometer; Mt, millions of metric tons]

\begin{tabular}{ccccccc}
\hline \multirow{2}{*}{$\begin{array}{c}\text { Date of } \\
\text { assessment }\end{array}$} & $\begin{array}{c}\text { Tract area } \\
\left(\mathbf{k m}^{2}\right)\end{array}$ & $\begin{array}{c}\text { Identified } \\
\text { copper } \\
\text { resources } \\
(\mathbf{M t})\end{array}$ & $\begin{array}{c}\text { Mean estimate of } \\
\text { in-place resources } \\
(\mathbf{M t})\end{array}$ & $\begin{array}{c}\text { Probability of } \mathbf{0} \\
\text { in-place resources } \\
\text { (percent) }\end{array}$ & $\begin{array}{c}\text { Mean estimate of } \\
\text { economic resources } \\
\text { (Mt) }\end{array}$ & $\begin{array}{c}\text { Probability of 0 } \\
\text { economic resources } \\
\text { (percent) }\end{array}$ \\
\hline 2005 & 30,154 & 13 & 19 & 3 & 9.9 \\
\hline
\end{tabular}

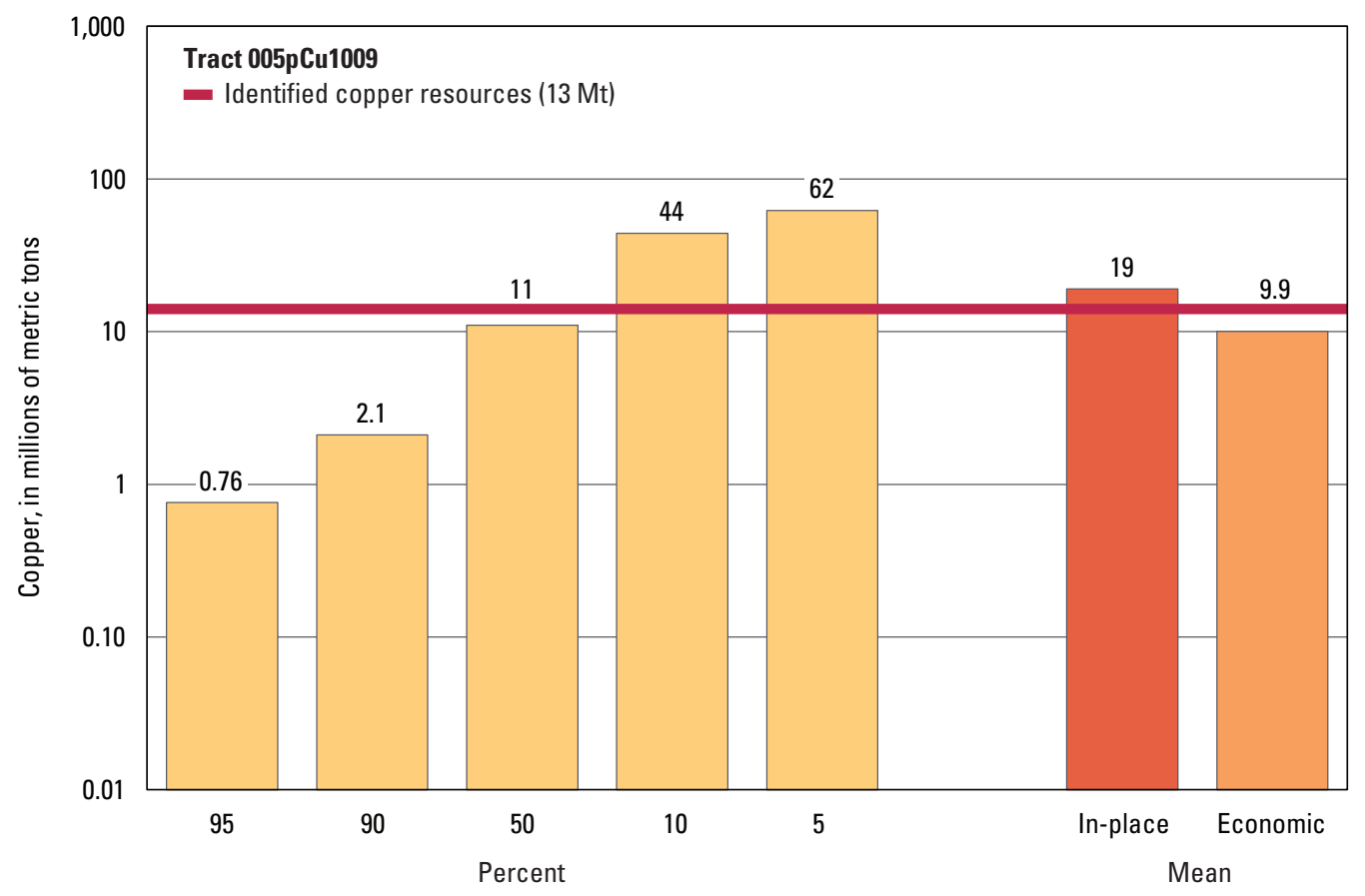

Graph showing the estimated probability distribution of undiscovered copper resources, where each bar represents the minimum amount estimated at the indicated percentage.

\section{Source}

Cunningham and others, 2008, Quantitative mineral resource assessment of copper, molybdenum, gold, and silver in undiscovered porphyry copper deposits in the Andes Mountains of South America: U.S. Geological Survey Open-File Report 2008-1253, http://pubs.usgs.gov/of/2008/1253/. 


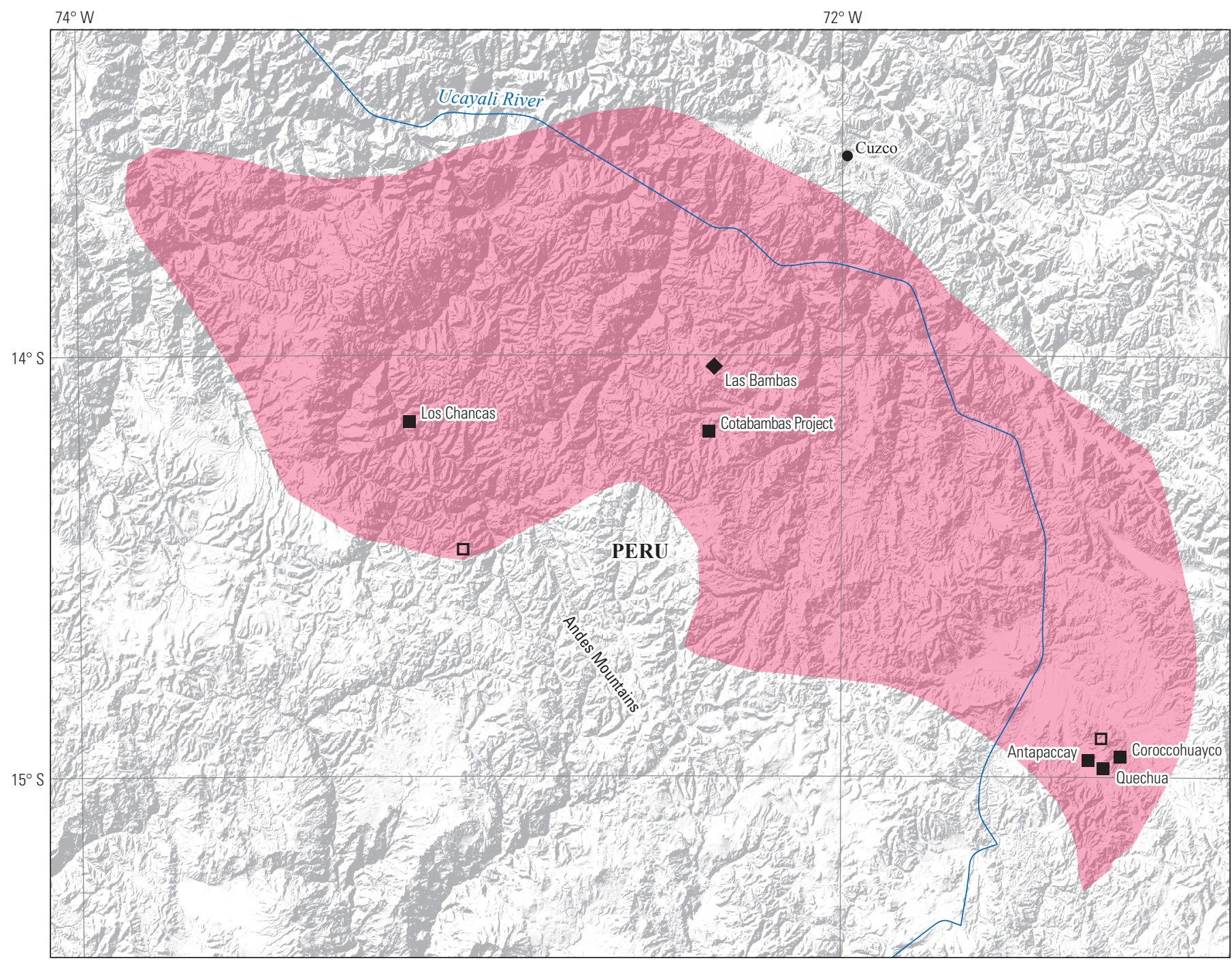

Political boundaries from U.S. Department of State (2009) Shaded relief from ESRI (2008)

South America Albers Equal-Area Conic projection

Central meridian $72^{\circ} 30^{\prime} \mathrm{W}$.; latitude of origin $32^{\circ} \mathrm{S}$.

\begin{tabular}{ccccc}
0 & 25 & 50 & 75 & 100 KILOMETERS \\
\hline & 1 & 1 & 1 & 1 \\
0 & & 25 & 50 MILES
\end{tabular}

\section{EXPLANATION}

\begin{tabular}{|c|c|}
\hline (5) & $\begin{array}{l}\text { Assessed porphyry copper tract } \\
\text { 005pCu1009 }\end{array}$ \\
\hline ש & Porphyry copper deposit \\
\hline A & $\begin{array}{l}\text { Porphyry copper deposit } \\
\text { discovered after the assessment }\end{array}$ \\
\hline 口 & Porphyry copper prospect \\
\hline
\end{tabular}

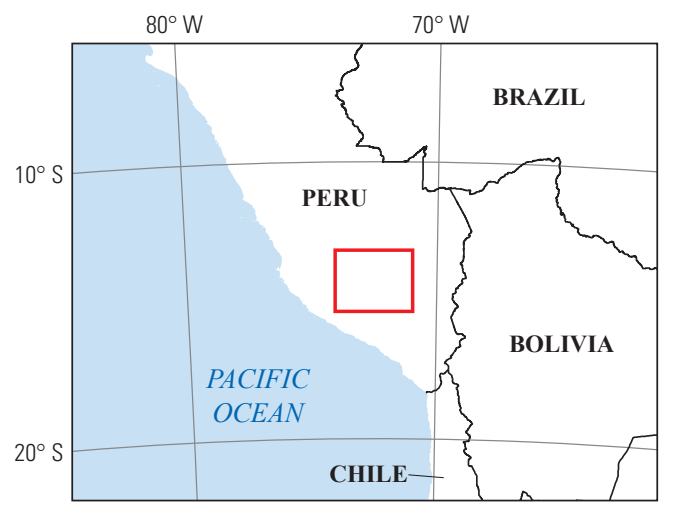




\title{
Plate 20. Porphyry Copper Assessment for Tract 005pCu1007, Cretaceous Almacen-Peru and Ecuador
}

\author{
Descriptive model: \\ Porphyry copper model (Cox, 1986a) \\ Grade and tonnage model: \\ General porphyry copper model (Singer, Berger, and Moring, 2005) \\ Economic filter depth percentages: \\ Economic filter cost setting: \\ Skewed shallow-0 to 250 meters (m), 35\%; > 250 to $500 \mathrm{~m}, 25 \%$; $>500 \mathrm{~m}$ to $1 \mathrm{~km}, 40 \%$ \\ Mixed cost \\ Geologic feature assessed: \\ Cretaceous plutons, mostly calc-alkalic diorites and tonalites, principally of the Coastal batholith \\ and smaller batholiths \\ Number of known deposits: \\ 2
}

\section{Selected Resource Assessment Results for Porphyry Copper}

[Assessment depth, 1 kilometer ( $\mathrm{km}) ; \mathrm{km}^{2}$, square kilometer; Mt, millions of metric tons]

\begin{tabular}{ccccccc}
\hline \multirow{2}{*}{$\begin{array}{c}\text { Date of } \\
\text { assessment }\end{array}$} & $\begin{array}{c}\text { Tract area } \\
\left(\mathbf{k m}^{2}\right)\end{array}$ & $\begin{array}{c}\text { Identified } \\
\text { copper } \\
\text { resources } \\
\text { (Mt) }\end{array}$ & $\begin{array}{c}\text { Mean estimate of } \\
\text { in-place resources } \\
(\mathbf{M t})\end{array}$ & $\begin{array}{c}\text { Probability of } \mathbf{0} \\
\text { in-place resources } \\
\text { (percent) }\end{array}$ & $\begin{array}{c}\text { Mean estimate of } \\
\text { economic resources } \\
\text { (Mt) }\end{array}$ & $\begin{array}{c}\text { Probability of 0 } \\
\text { economic resources } \\
\text { (percent) }\end{array}$ \\
\hline 2005 & 107,297 & 0.67 & 14 & 7 & 7.7 & 44 \\
\hline
\end{tabular}

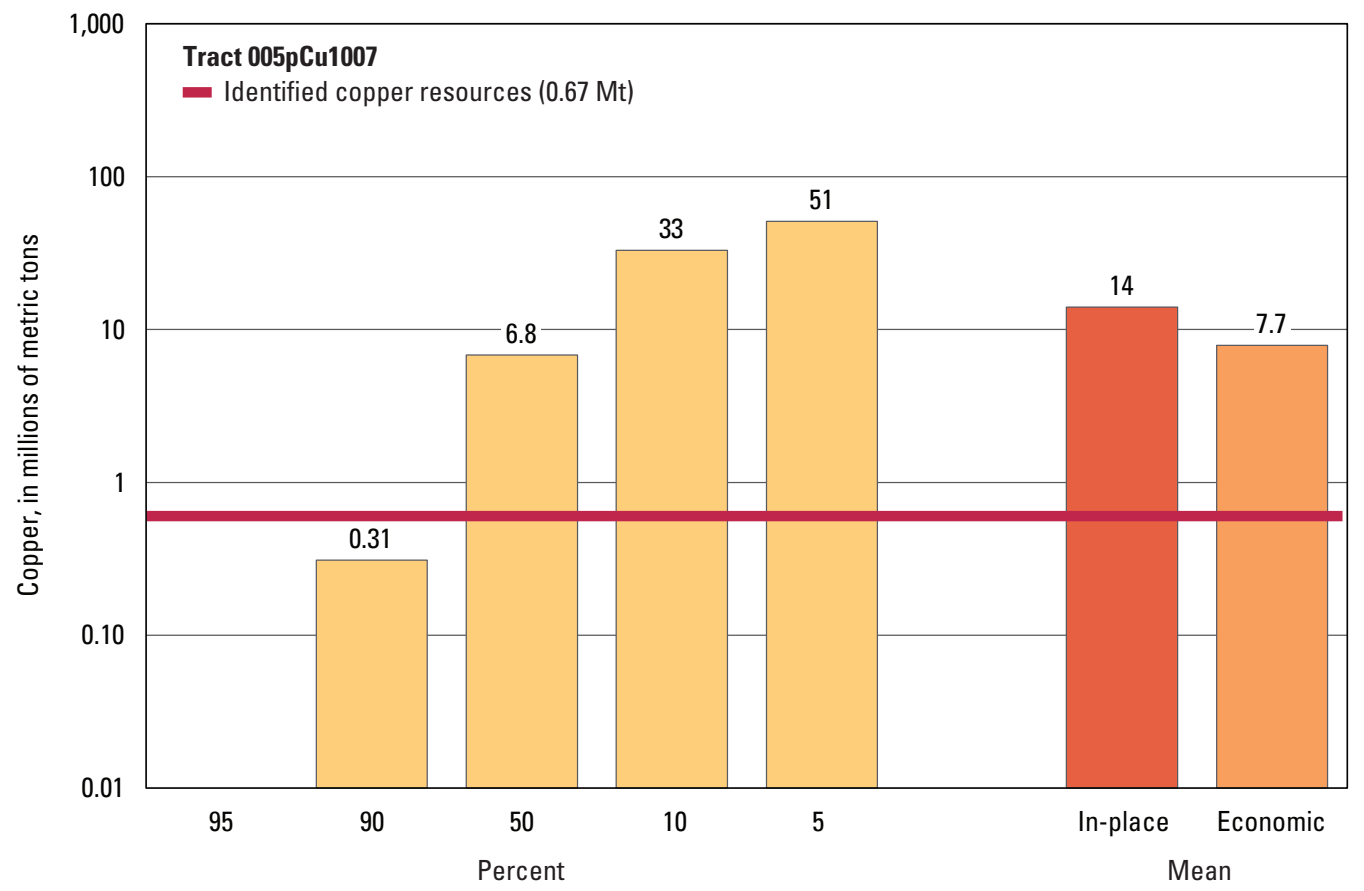

Graph showing the estimated probability distribution of undiscovered copper resources, where each bar represents the minimum amount estimated at the indicated percentage.

\section{Source}

Cunningham and others, 2008, Quantitative mineral resource assessment of copper, molybdenum, gold, and silver in undiscovered porphyry copper deposits in the Andes Mountains of South America: U.S. Geological Survey Open-File Report 2008-1253, http://pubs.usgs.gov/of/2008/1253/. 

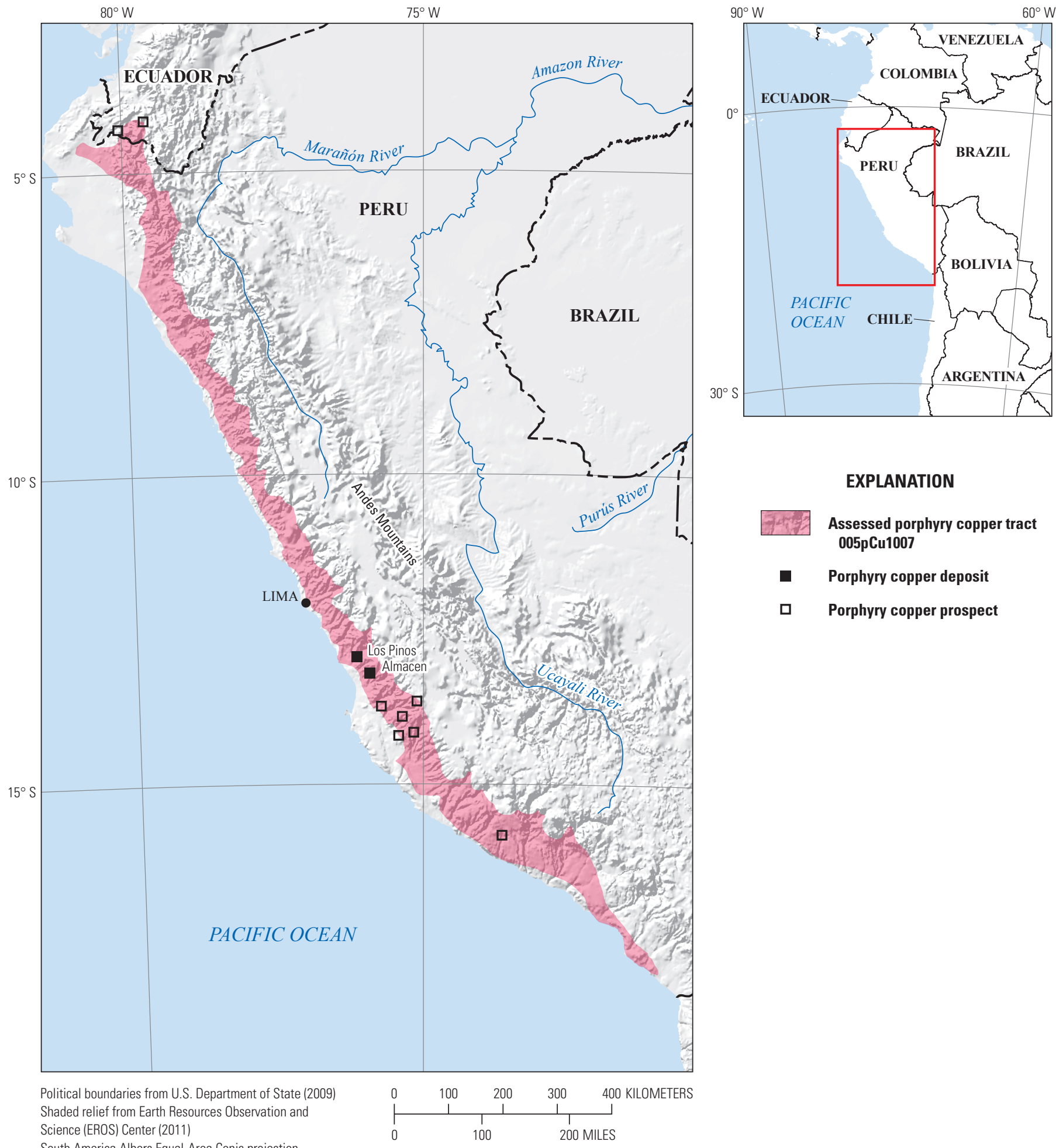

3tiny Assessed porphyry copper tract $005 \mathrm{pCu} 1007$

- Porphyry copper deposit

ㅁ Porphyry copper prospect

South America Albers Equal-Area Conic projection

Central meridian $75^{\circ} \mathrm{W}$.: latitude of origin $32^{\circ} \mathrm{S}$. 


\title{
Plate 21. Porphyry Copper Assessment for Tract 005pCu1006, Miocene La Granja-Peru and Ecuador
}

\author{
Descriptive model: \\ Porphyry copper model (Cox, 1986a) \\ Grade and tonnage model: \\ General porphyry copper model (Singer, Berger, and Moring, 2005) \\ Economic filter depth percentages: \\ Economic filter cost setting: \\ Geologic feature assessed: \\ Skewed deep — 0 to 250 meters (m), 10\%; > 250 to $500 \mathrm{~m}, 30 \%$; >500 m to $1 \mathrm{~km}, 60 \%$ \\ Mixed cost \\ Assorted middle to late Miocene mainly calc-alkalic plutons \\ Number of known deposits: \\ 12
}

\section{Selected Resource Assessment Results for Porphyry Copper}

[Assessment depth, 1 kilometer $(\mathrm{km}) ; \mathrm{km}^{2}$, square kilometer; Mt, millions of metric tons]

\begin{tabular}{ccccccc}
\hline $\begin{array}{c}\text { Date of } \\
\text { assessment }\end{array}$ & $\begin{array}{c}\text { Tract area } \\
\left(\mathbf{k m}^{2}\right)\end{array}$ & $\begin{array}{c}\text { Identified } \\
\text { copper } \\
\text { resources } \\
(\mathbf{M t})\end{array}$ & $\begin{array}{c}\text { Mean estimate of } \\
\text { in-place resources } \\
(\mathbf{M t})\end{array}$ & $\begin{array}{c}\text { Probability of } \mathbf{0} \\
\text { in-place resources } \\
\text { (percent) }\end{array}$ & $\begin{array}{c}\text { Mean estimate of } \\
\text { economic resources } \\
\text { (Mt) }\end{array}$ & $\begin{array}{c}\text { Probability of 0 } \\
\text { economic resources } \\
\text { (percent) }\end{array}$ \\
\hline 2005 & 53,186 & 54 & 49 & 1 & 24 \\
\hline
\end{tabular}

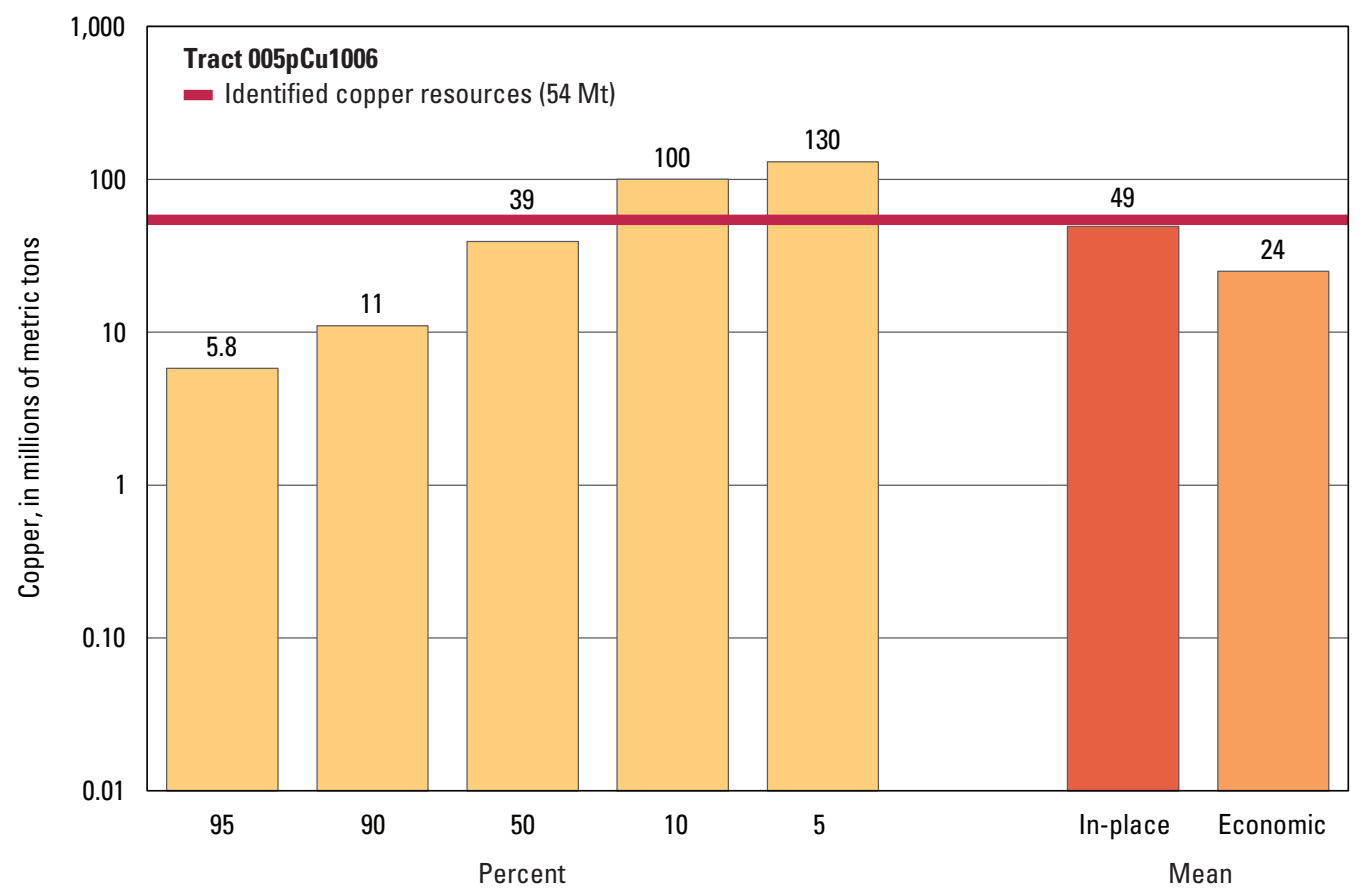

Graph showing the estimated probability distribution of undiscovered copper resources, where each bar represents the minimum amount estimated at the indicated percentage.

\section{Source}

Cunningham and others, 2008, Quantitative mineral resource assessment of copper, molybdenum, gold, and silver in undiscovered porphyry copper deposits in the Andes Mountains of South America: U.S. Geological Survey Open-File Report 2008-1253, http://pubs.usgs.gov/of/2008/1253/. 

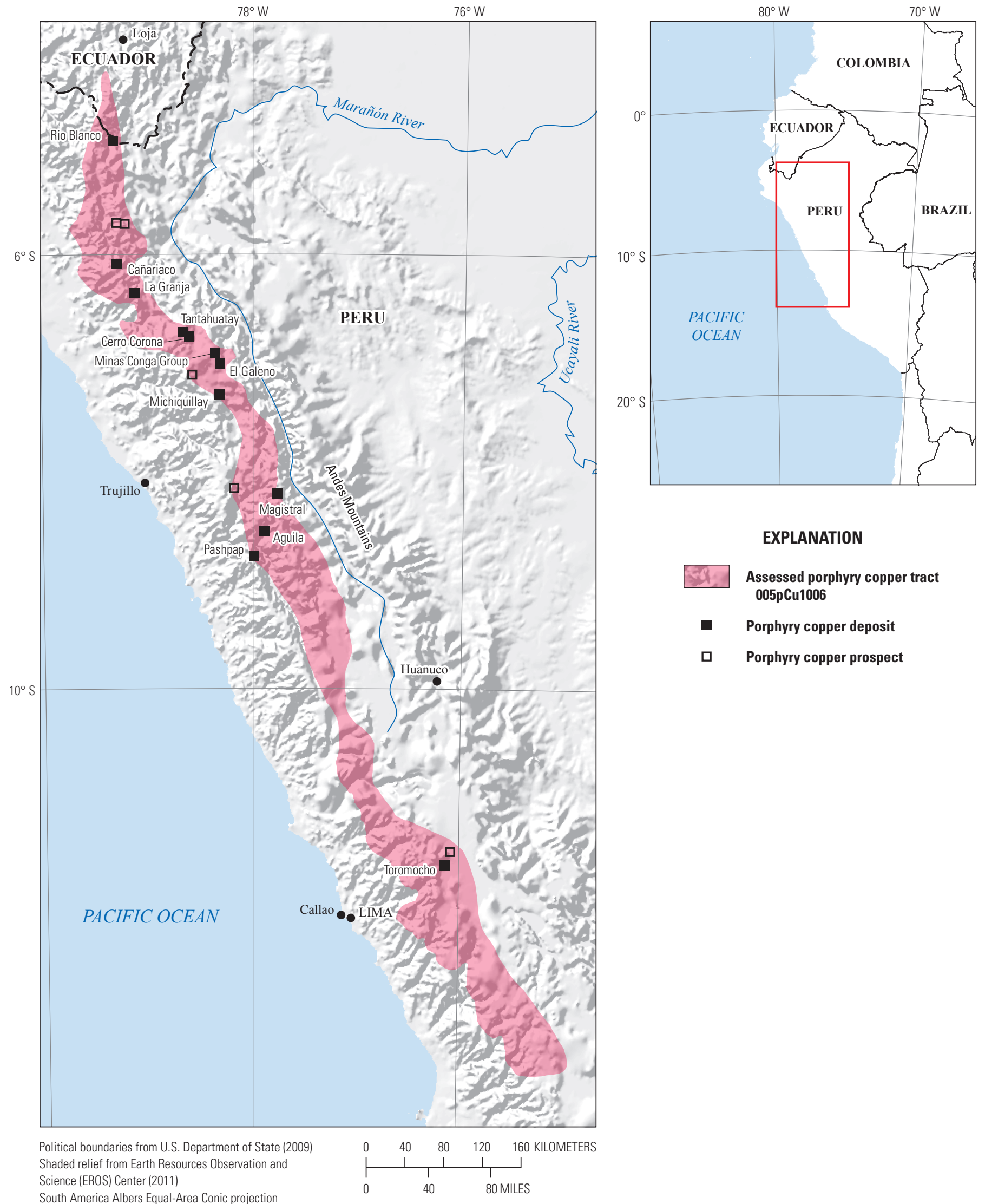

A. Assessed porphyry copper tract $005 \mathrm{pCu} 1006$

- Porphyry copper deposit

․ Porphyry copper prospect

Central meridian $78^{\circ} \mathrm{W}$.; latitude of origin $32^{\circ} \mathrm{S}$. 


\title{
Plate 22. Porphyry Copper Assessment for Tract 005pCu1005, Miocene Chaucha-Colombia and Ecuador
}

\author{
Descriptive model: \\ Porphyry copper model (Cox, 1986a) \\ Grade and tonnage model: \\ General porphyry copper model (Singer, Berger, and Moring, 2005) \\ Economic filter depth percentages: \\ Economic filter cost setting: \\ Geologic feature assessed: \\ Default -0 to 250 meters (m), $25 \% ;>250$ to $500 \mathrm{~m}, 25 \% ;>500 \mathrm{~m}$ to $1 \mathrm{~km}, 50 \%$ \\ Mixed cost \\ Miocene principally calc-alkalic plutons including granites, granodiorites, tonalites, and dacite \\ porphyries; includes parts of the Central Andes Mountains of Colombia \\ Number of known deposits: \\ 4
}

\section{Selected Resource Assessment Results for Porphyry Copper}

[Assessment depth, 1 kilometer ( $\mathrm{km}) ; \mathrm{km}^{2}$, square kilometer; Mt, millions of metric tons]

\begin{tabular}{ccccccc}
\hline $\begin{array}{c}\text { Date of } \\
\text { assessment }\end{array}$ & $\begin{array}{c}\text { Tract area } \\
\left(\mathbf{k m}^{2}\right)\end{array}$ & $\begin{array}{c}\text { Identified } \\
\text { copper } \\
\text { resources } \\
\text { (Mt) }\end{array}$ & $\begin{array}{c}\text { Mean estimate of } \\
\text { in-place resources } \\
(\mathbf{M t})\end{array}$ & $\begin{array}{c}\text { Probability of } \mathbf{0} \\
\text { in-place resources } \\
\text { (percent) }\end{array}$ & $\begin{array}{c}\text { Mean estimate of } \\
\text { economic resources } \\
\text { (Mt) }\end{array}$ & $\begin{array}{c}\text { Probability of 0 } \\
\text { economic resources } \\
\text { (percent) }\end{array}$ \\
\hline 2005 & 58,797 & 4.0 & 39 & 2 & 21 & 10 \\
\hline
\end{tabular}

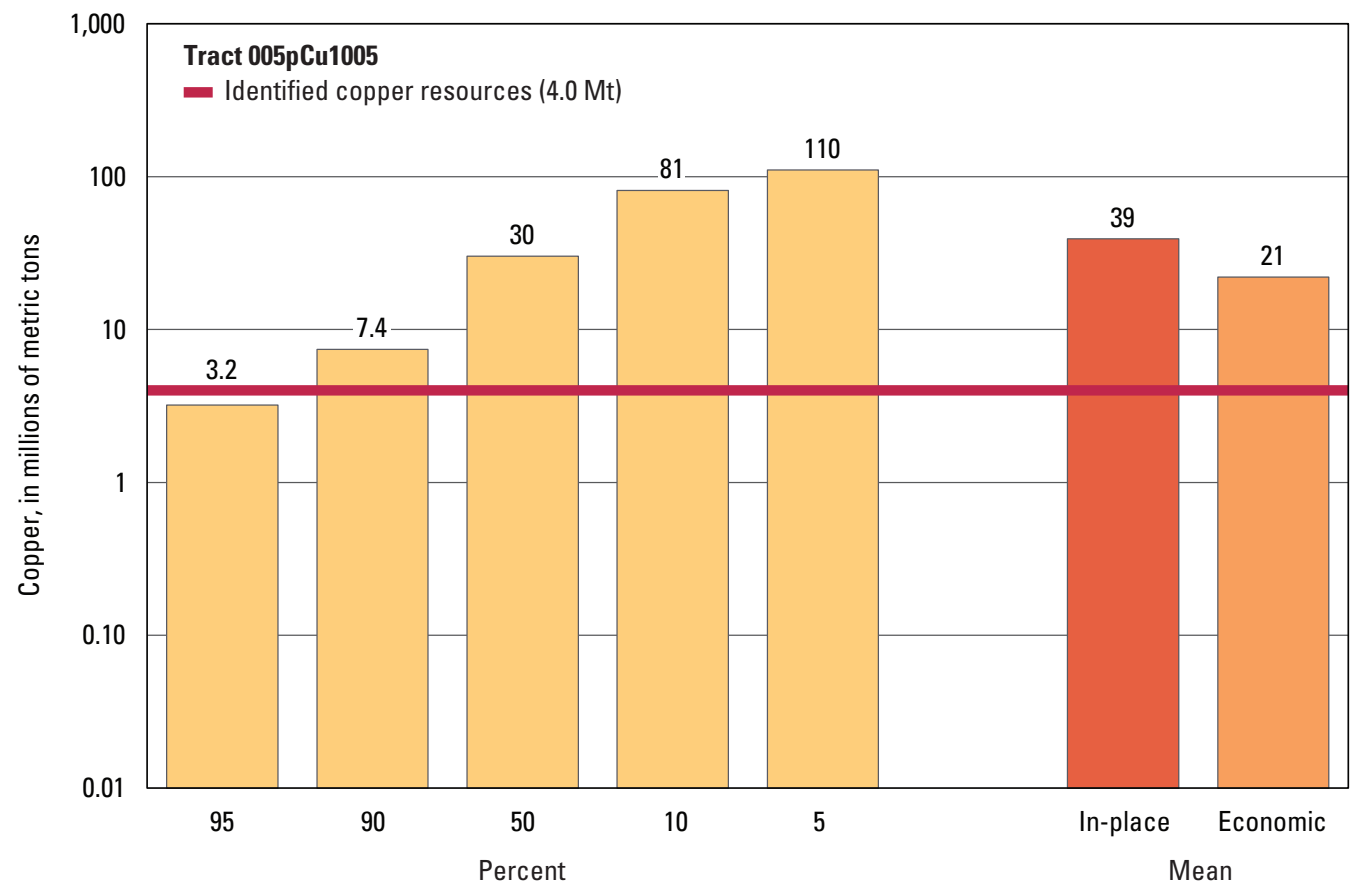

Graph showing the estimated probability distribution of undiscovered copper resources, where each bar represents the minimum amount estimated at the indicated percentage.

\section{Source}

Cunningham and others, 2008, Quantitative mineral resource assessment of copper, molybdenum, gold, and silver in undiscovered porphyry copper deposits in the Andes Mountains of South America: U.S. Geological Survey Open-File Report 2008-1253, http://pubs.usgs.gov/of/2008/1253/. 


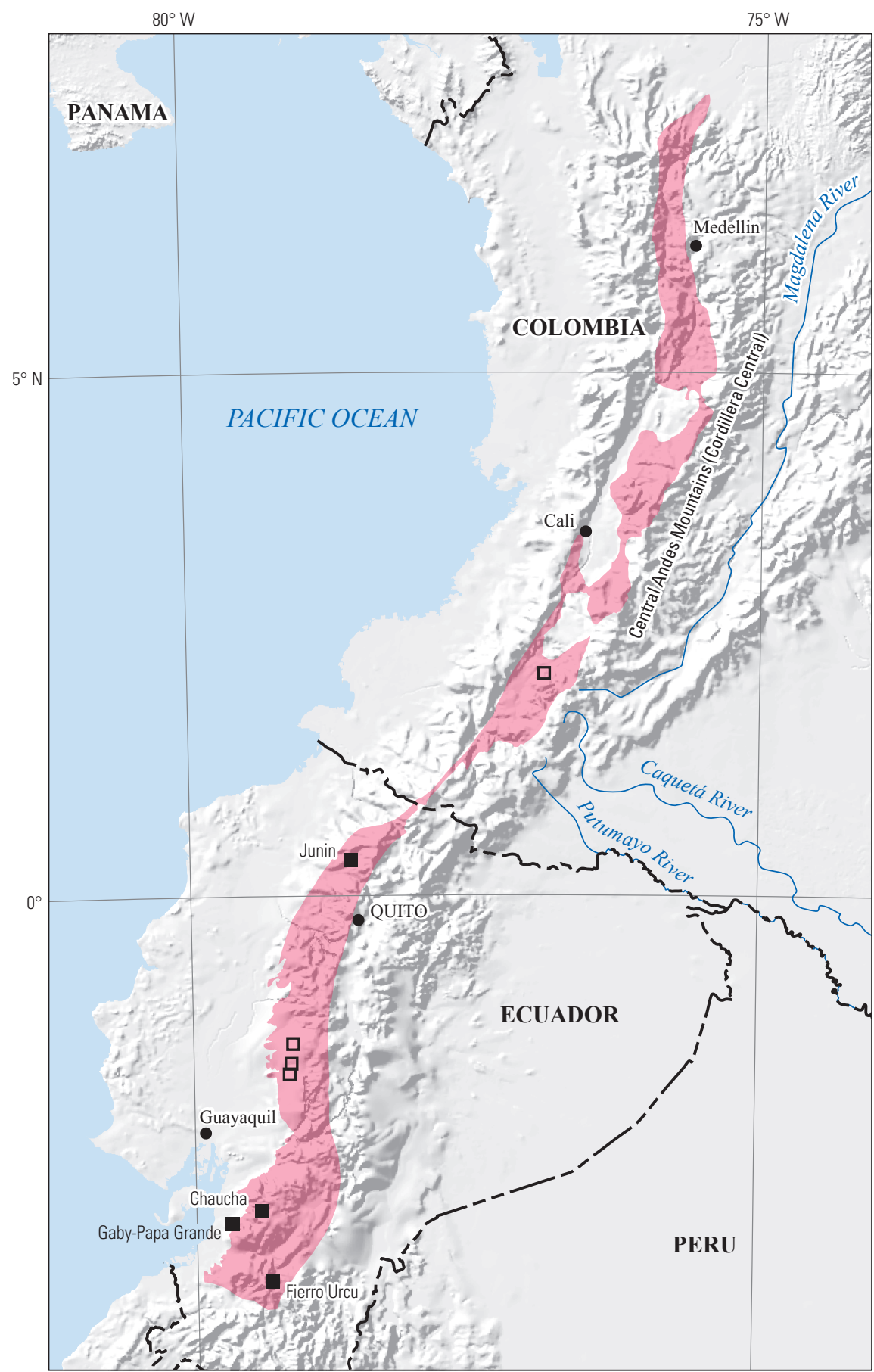

Political boundaries from U.S. Department of State (2009) Shaded relief from Earth Resources Observation and Science (EROS) Center (2011)

South America Albers Equal-Area Conic projection

Central meridian $77^{\circ} \mathrm{W}$.; latitude of origin $32^{\circ} \mathrm{S}$.

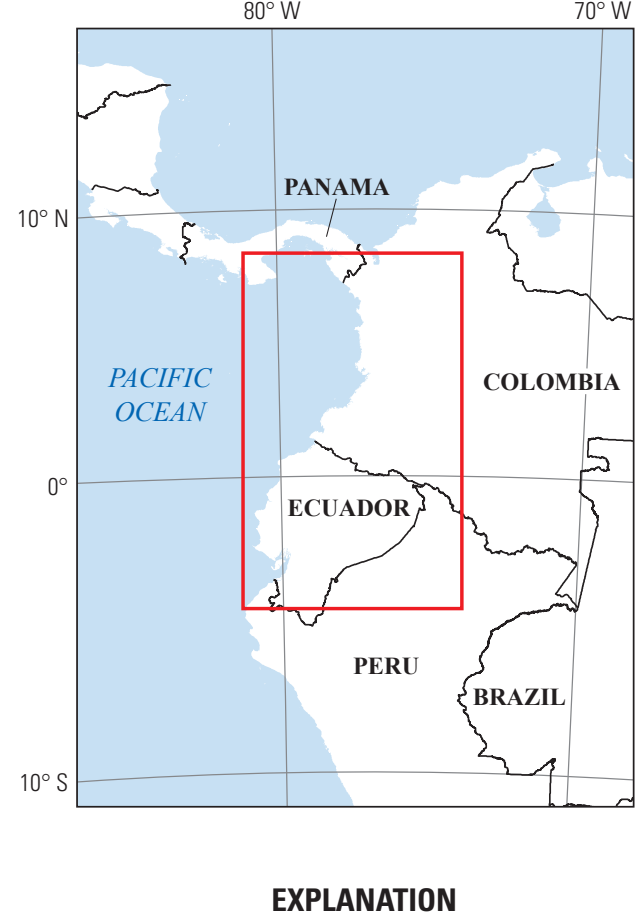

Assessed porphyry copper tract $005 \mathrm{pCu} 1005$

- Porphyry copper deposit

ㅁ Porphyry copper prospect 


\section{Plate 23. Porphyry Copper Assessment for Tract 005pCu1003, Jurassic San Carlos-Colombia, Ecuador, and Peru}

\author{
Descriptive model: \\ Grade and tonnage model: \\ Economic filter depth percentages: \\ Economic filter cost setting: \\ Geologic feature assessed:
}

Number of known deposits:

\author{
Porphyry copper model (Cox, 1986a) \\ General porphyry copper model (Singer, Berger, and Moring, 2005) \\ Default -0 to 250 meters (m), $25 \% ;>250$ to $500 \mathrm{~m}, 25 \%$; $>500 \mathrm{~m}$ to $1 \mathrm{~km}, 50 \%$ \\ Mixed cost \\ Jurassic mainly calc-alkalic granodiorite, diorite, and tonalite plutons, including the Mocoa \\ batholith (Colombia); includes intruded Jurassic basaltic and andesitic lava flows (Ecuador \\ and Peru)
}

5

\section{Selected Resource Assessment Results for Porphyry Copper}

[Assessment depth, 1 kilometer $(\mathrm{km}) ; \mathrm{km}^{2}$, square kilometer; Mt, millions of metric tons]

\begin{tabular}{|c|c|c|c|c|c|c|}
\hline \multirow[b]{2}{*}{$\begin{array}{c}\text { Date of } \\
\text { assessment }\end{array}$} & \multirow[b]{2}{*}{$\begin{array}{c}\text { Tract area } \\
\quad\left(\mathbf{k m}^{2}\right)\end{array}$} & \multirow{2}{*}{$\begin{array}{l}\text { Identified } \\
\text { copper } \\
\text { resources } \\
\text { (Mt) }\end{array}$} & \multicolumn{4}{|c|}{ Undiscovered copper resource estimates } \\
\hline & & & $\begin{array}{l}\text { Mean estimate of } \\
\text { in-place resources } \\
\text { (Mt) }\end{array}$ & $\begin{array}{c}\text { Probability of } 0 \\
\text { in-place resources } \\
\text { (percent) }\end{array}$ & $\begin{array}{l}\text { Mean estimate of } \\
\text { economic resources } \\
\text { (Mt) }\end{array}$ & $\begin{array}{c}\text { Probability of } 0 \\
\text { economic resources } \\
\text { (percent) }\end{array}$ \\
\hline 2005 & 67,709 & 14 & 40 & 2 & 20 & 15 \\
\hline
\end{tabular}

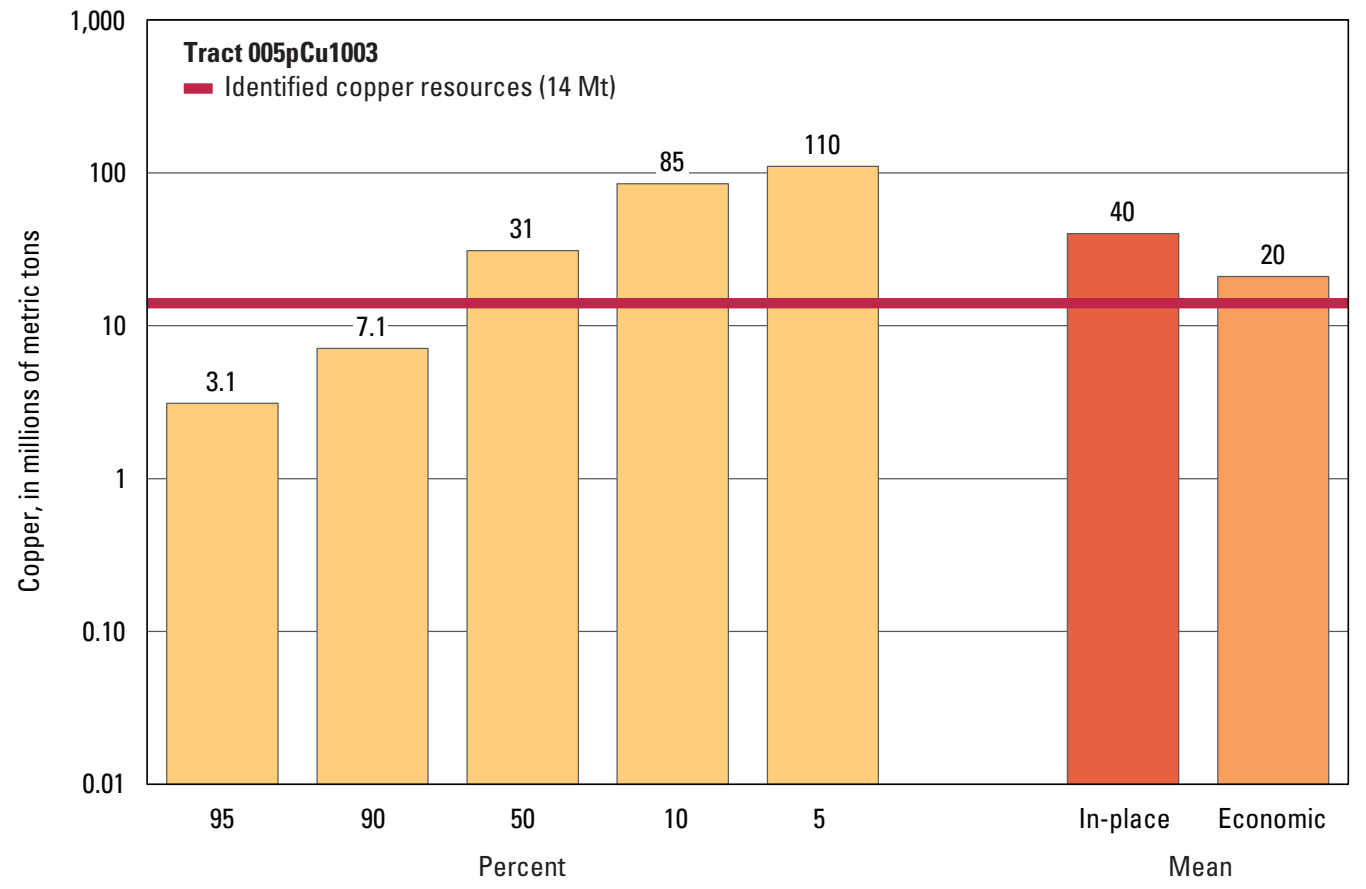

Graph showing the estimated probability distribution of undiscovered copper resources, where each bar represents the minimum amount estimated at the indicated percentage.

\section{Source}

Cunningham and others, 2008, Quantitative mineral resource assessment of copper, molybdenum, gold, and silver in undiscovered porphyry copper deposits in the Andes Mountains of South America: U.S. Geological Survey Open-File Report 2008-1253, http://pubs.usgs.gov/of/2008/1253/. 

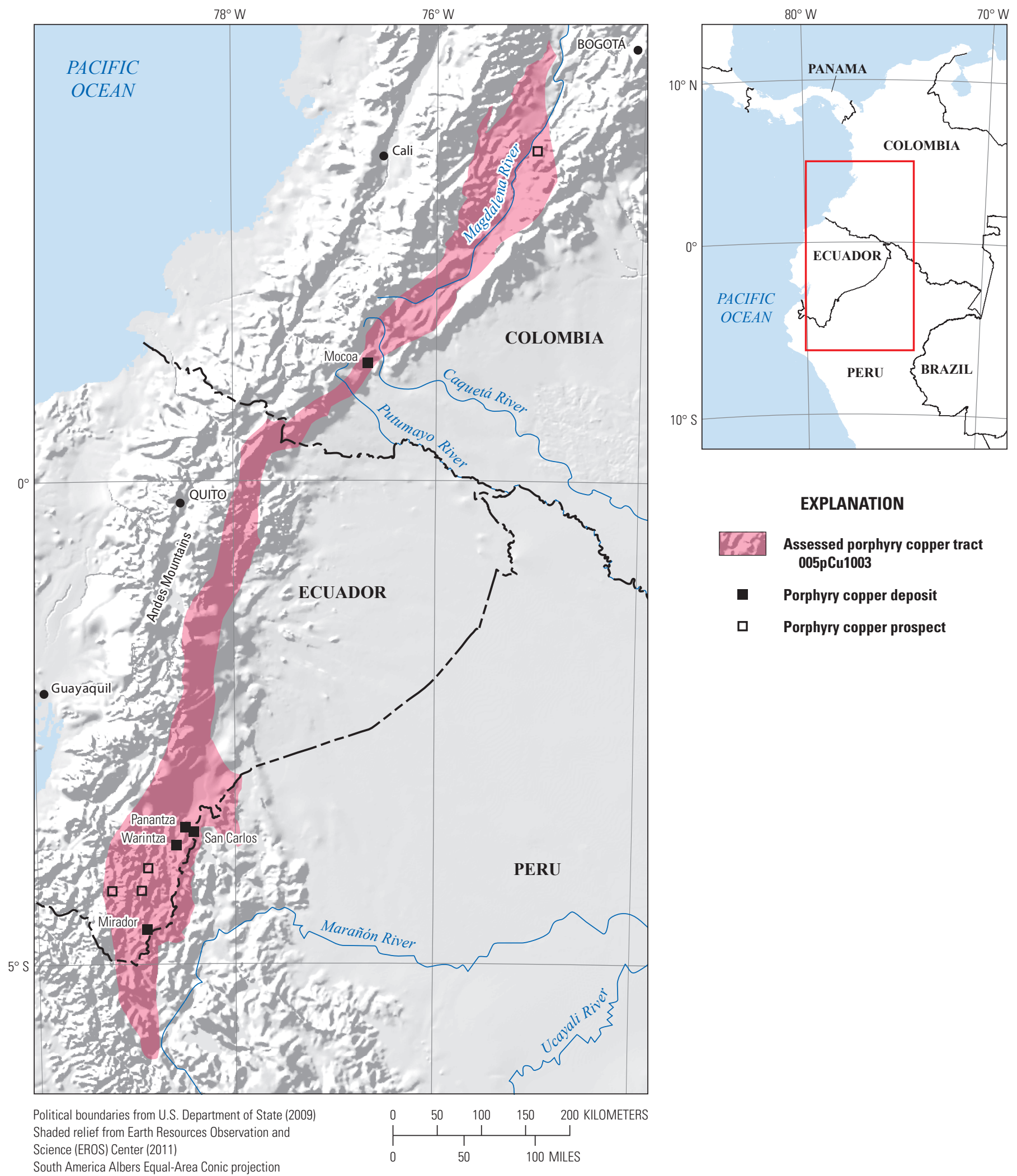

- Porphyry copper deposit

ㅁ Porphyry copper prospect

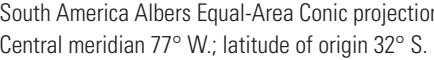




\title{
Plate 24. Porphyry Copper Assessment for Tract 005pCu1001, Paleocene- Eocene Acandi-Colombia, Ecuador, and Panama
}

\author{
Descriptive model: \\ Porphyry copper model (Cox, 1986a) \\ Grade and tonnage model: \\ General porphyry copper model (Singer, Berger, and Moring, 2005) \\ Economic filter depth percentages: \\ Economic filter cost setting: \\ Geologic feature assessed: \\ Default -0 to 250 meters (m), $25 \% ;>250$ to $500 \mathrm{~m}, 25 \% ;>500 \mathrm{~m}$ to $1 \mathrm{~km}, 50 \%$ \\ Mixed cost \\ Paleocene-Eocene mostly calc-alkalic plutons including tonalities, diorites, and granodiorites of \\ the Mande batholith (Colombia), Acandi batholith (Colombia-Panama), and some outliers \\ Number of known deposits: \\ 2
}

\section{Selected Resource Assessment Results for Porphyry Copper}

[Assessment depth, 1 kilometer $(\mathrm{km}) ; \mathrm{km}^{2}$, square kilometer; Mt, millions of metric tons]

\begin{tabular}{ccccccc}
\hline $\begin{array}{c}\text { Date of } \\
\text { assessment }\end{array}$ & $\begin{array}{c}\text { Tract area } \\
\left(\mathbf{k m}^{2}\right)\end{array}$ & $\begin{array}{c}\text { Identified } \\
\text { copper } \\
\text { resources } \\
\text { (Mt) }\end{array}$ & $\begin{array}{c}\text { Mean estimate of } \\
\text { in-place resources } \\
(\mathbf{M t})\end{array}$ & $\begin{array}{c}\text { Probability of } \mathbf{0} \\
\text { in-place resources } \\
\text { (percent) }\end{array}$ & $\begin{array}{c}\text { Mean estimate of } \\
\text { economic resources } \\
\text { (Mt) }\end{array}$ & $\begin{array}{c}\text { Probability of 0 } \\
\text { economic resources } \\
\text { (percent) }\end{array}$ \\
\hline 2005 & 51,613 & 10 & 33 & 3 & 18 \\
\hline
\end{tabular}

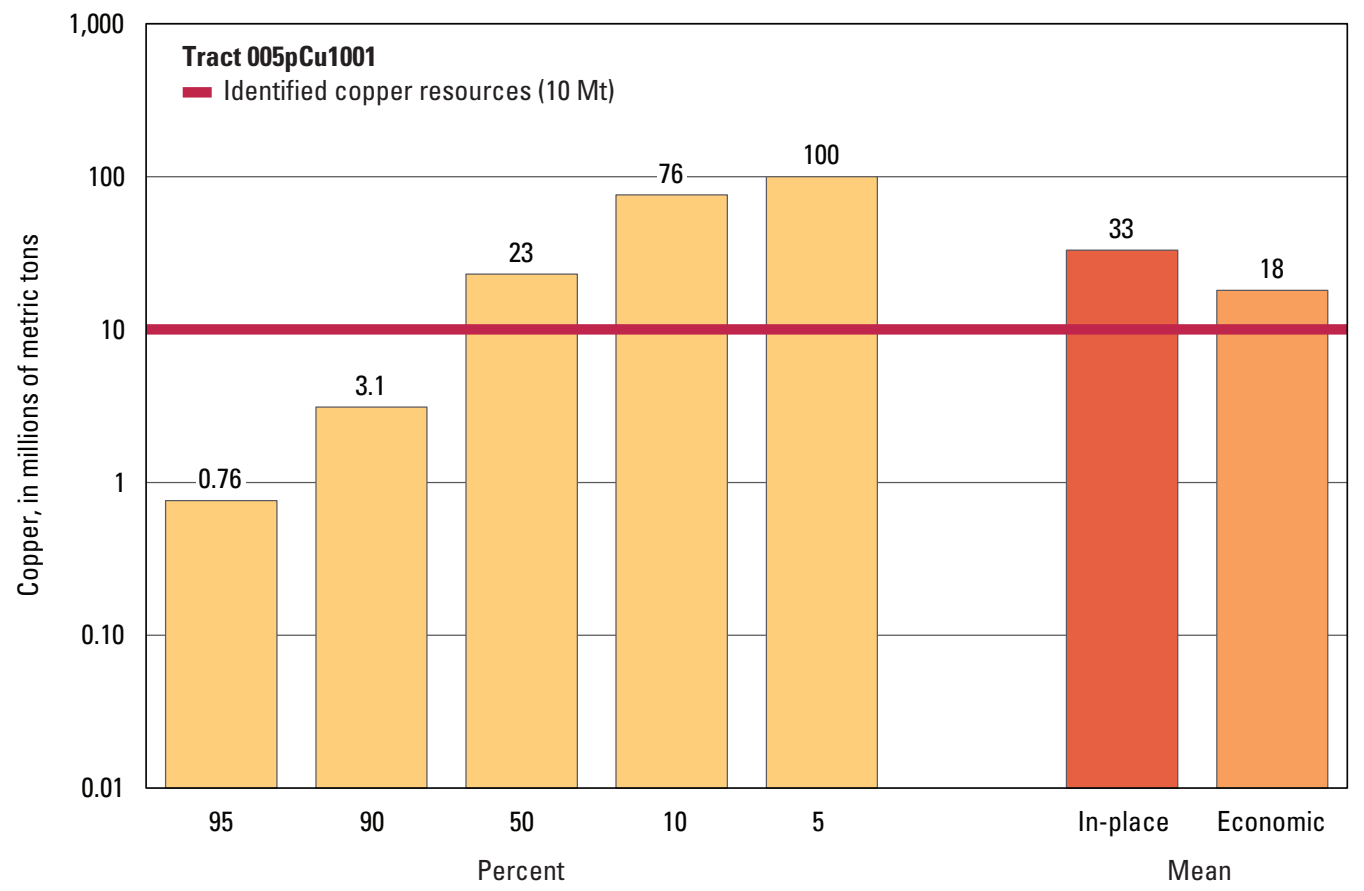

Graph showing the estimated probability distribution of undiscovered copper resources, where each bar represents the minimum amount estimated at the indicated percentage.

\section{Source}

Cunningham and others, 2008, Quantitative mineral resource assessment of copper, molybdenum, gold, and silver in undiscovered porphyry copper deposits in the Andes Mountains of South America: U.S. Geological Survey Open-File Report 2008-1253, http://pubs.usgs.gov/of/2008/1253/. 

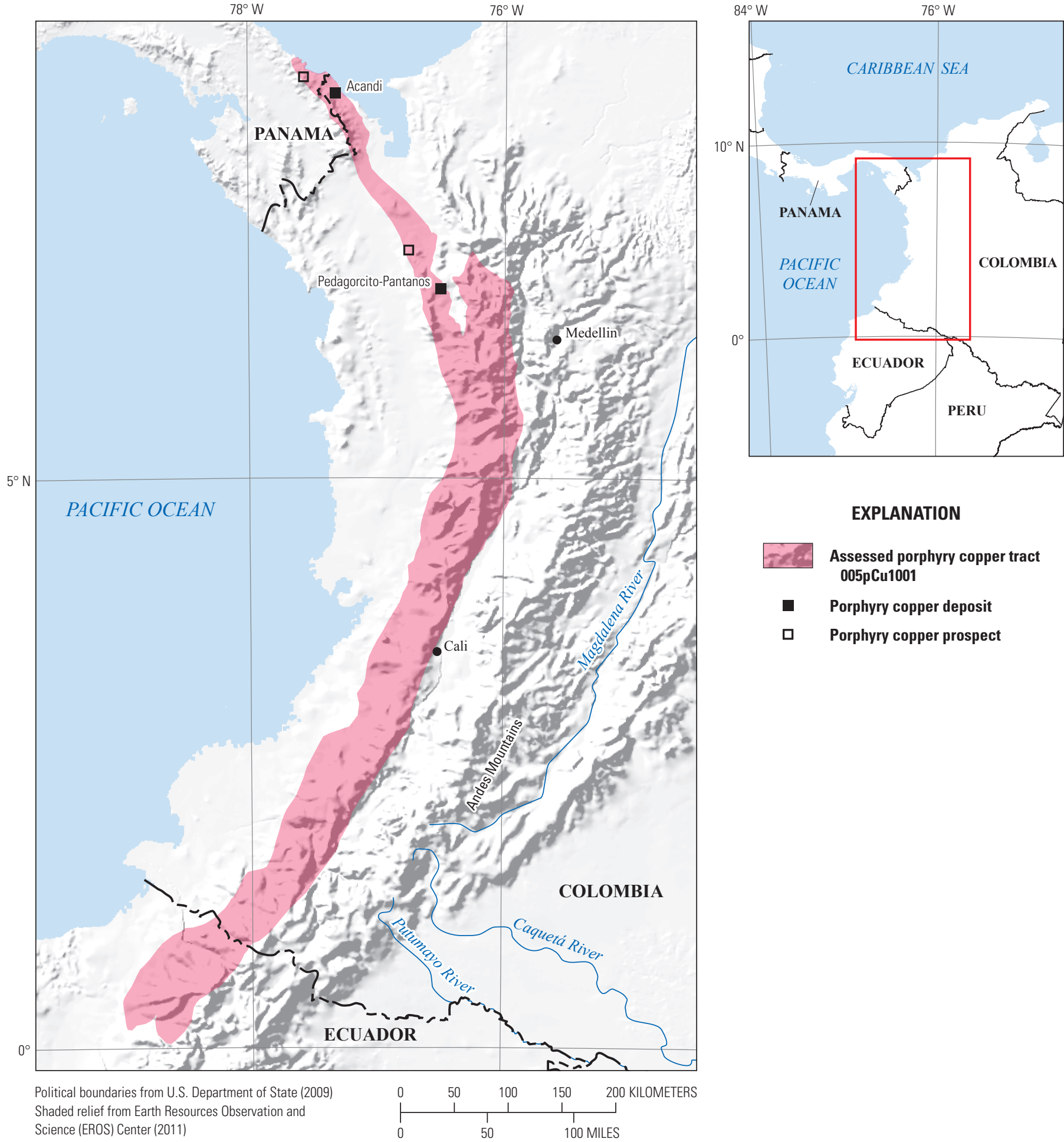

\section{EXPLANATION}

Assessed porphyry copper tract 005pCu1001

- Porphyry copper deposit

ㅁ Porphyry copper prospect

South America Albers Equal-Area Conic projection

Central meridian $77^{\circ} \mathrm{W}$.; latitude of origin $32^{\circ} \mathrm{S}$. 


\title{
Plate 25. Porphyry Copper Assessment for Tract 005pCu1004, Cretaceous Infierno-Chilí-Colombia
}

\author{
Descriptive model: \\ Porphyry copper model (Cox, 1986a) \\ Grade and tonnage model: \\ General porphyry copper model (Singer, Berger, and Moring, 2005) \\ Economic filter depth percentages: \\ Economic filter cost setting: \\ Skewed shallow-0 to 250 meters (m), 35\%; > 250 to $500 \mathrm{~m}, 25 \%$; $>500 \mathrm{~m}$ to $1 \mathrm{~km}, 40 \%$ \\ Mixed cost \\ Geologic feature assessed: \\ Cretaceous mostly calc-alkalic plutons mainly of granodioritic and tonalitic composition; large \\ batholiths to the north were excluded because they are too deeply eroded \\ Number of known deposits: \\ 0
}

\section{Selected Resource Assessment Results for Porphyry Copper}

[Assessment depth, 1 kilometer ( $\mathrm{km}) ; \mathrm{km}^{2}$, square kilometer; Mt, millions of metric tons]

\begin{tabular}{ccccccc}
\hline $\begin{array}{c}\text { Date of } \\
\text { assessment }\end{array}$ & $\begin{array}{c}\text { Tract area } \\
\left(\mathbf{k m}^{2}\right)\end{array}$ & $\begin{array}{c}\text { Identified } \\
\text { copper } \\
\text { resources } \\
(\mathbf{M t})\end{array}$ & $\begin{array}{c}\text { Mean estimate of } \\
\text { in-place resources } \\
(\mathbf{M t})\end{array}$ & $\begin{array}{c}\text { Probability of } \mathbf{0} \\
\text { in-place resources } \\
\text { (percent) }\end{array}$ & $\begin{array}{c}\text { Mean estimate of } \\
\text { economic resources } \\
\text { (Mt) }\end{array}$ & $\begin{array}{c}\text { Probability of 0 } \\
\text { economic resources } \\
\text { (percent) }\end{array}$ \\
\hline 2005 & 10,986 & 0 & 7.7 & 6 & 4.4 \\
\hline
\end{tabular}

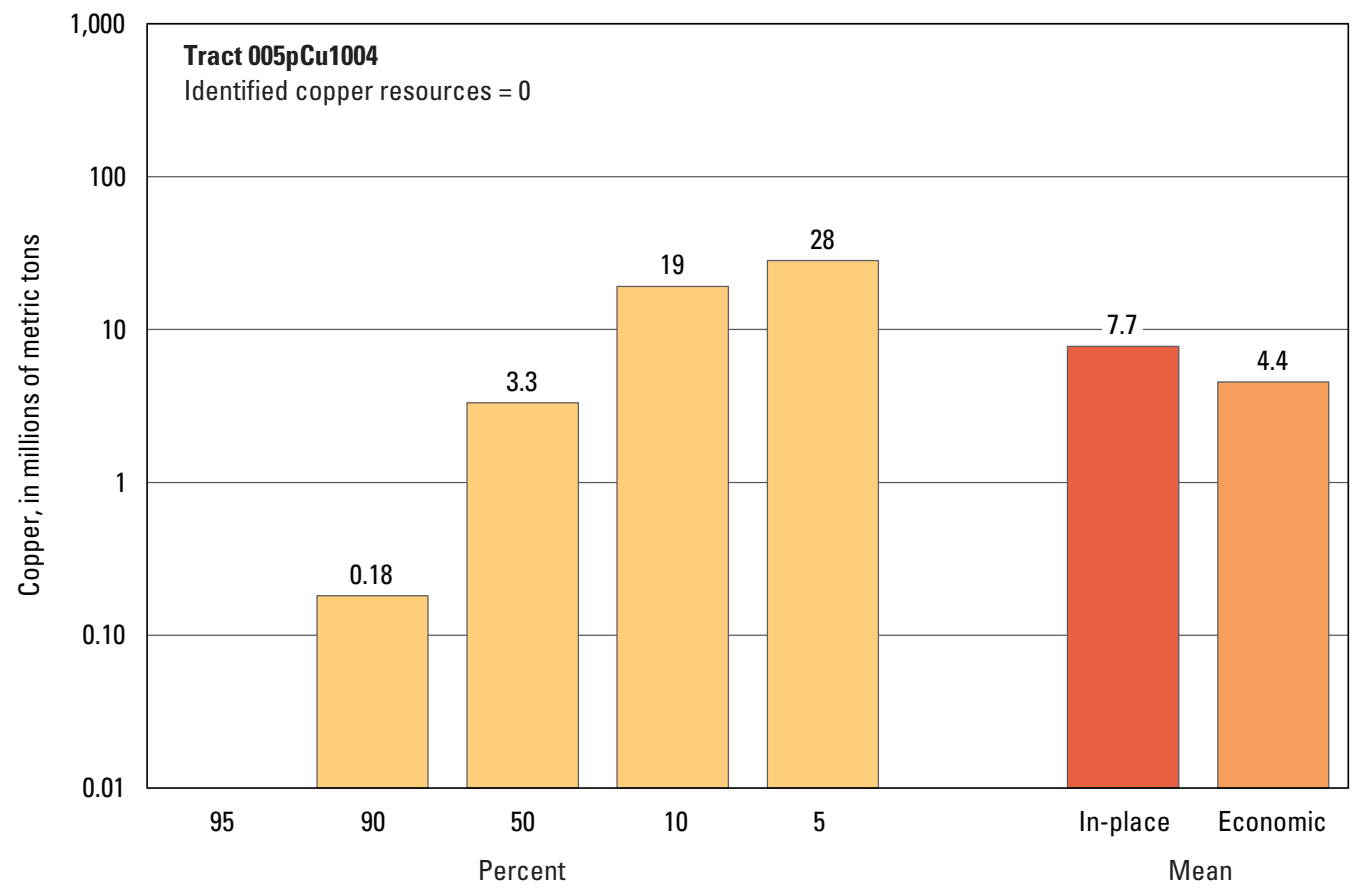

Graph showing the estimated probability distribution of undiscovered copper resources, where each bar represents the minimum amount estimated at the indicated percentage.

\section{Source}

Cunningham and others, 2008, Quantitative mineral resource assessment of copper, molybdenum, gold, and silver in undiscovered porphyry copper deposits in the Andes Mountains of South America: U.S. Geological Survey Open-File Report 2008-1253, http://pubs.usgs.gov/of/2008/1253/. 

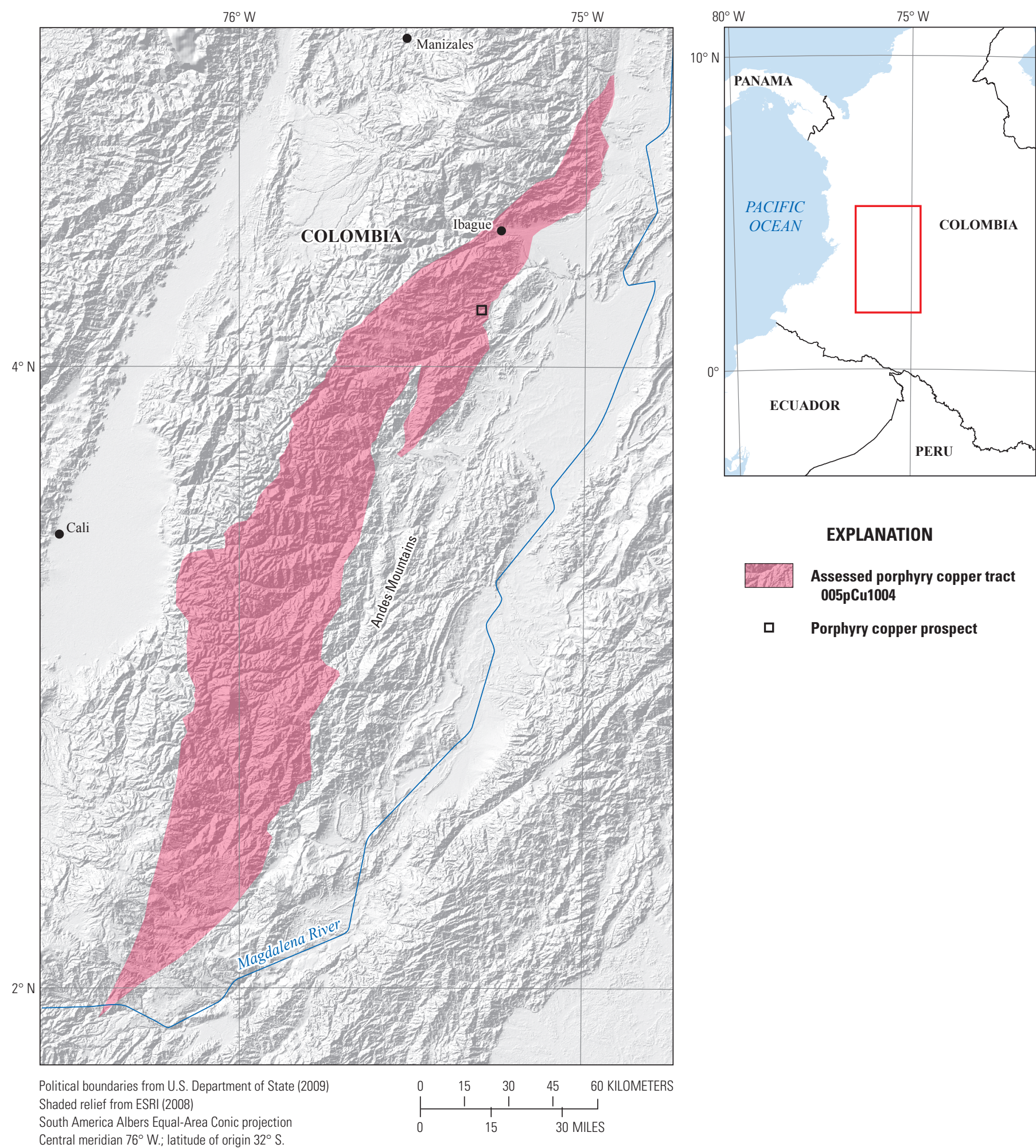

\section{EXPLANATION}

21. Assessed porphyry copper tract 005pCu1004

$\square \quad$ Porphyry copper prospect 


\title{
Plate 26. Porphyry Copper Assessment for Tract 005pCu1002, Jurassic California - Colombia and Venezuela
}

\author{
Descriptive model: \\ Porphyry copper model (Cox, 1986a) \\ Grade and tonnage model: \\ General porphyry copper model (Singer, Berger, and Moring, 2005) \\ Economic filter depth percentages: \\ Economic filter cost setting: \\ Geologic feature assessed: \\ Default -0 to 250 meters (m), $25 \% ;>250$ to $500 \mathrm{~m}, 25 \% ;>500 \mathrm{~m}$ to $1 \mathrm{~km}, 50 \%$ \\ Mixed cost \\ Late Jurassic rhyolitic to intermediate composition volcanic rocks, principally trachytes, rhyolites, \\ and andesites, and their subordinate plutonic equivalents \\ Number of known deposits: \\ 0
}

\section{Selected Resource Assessment Results for Porphyry Copper}

[Assessment depth, 1 kilometer $(\mathrm{km}) ; \mathrm{km}^{2}$, square kilometer; Mt, millions of metric tons]

\begin{tabular}{ccccccc}
\hline $\begin{array}{c}\text { Date of } \\
\text { assessment }\end{array}$ & $\begin{array}{c}\text { Tract area } \\
\left(\mathbf{k m}^{2}\right)\end{array}$ & $\begin{array}{c}\text { Identified } \\
\text { copper } \\
\text { resources } \\
\text { (Mt) }\end{array}$ & $\begin{array}{c}\text { Mean estimate of } \\
\text { in-place resources } \\
(\mathbf{M t})\end{array}$ & $\begin{array}{c}\text { Probability of } \mathbf{0} \\
\text { in-place resources } \\
\text { (percent) }\end{array}$ & $\begin{array}{c}\text { Mean estimate of } \\
\text { economic resources } \\
\text { (Mt) }\end{array}$ & $\begin{array}{c}\text { Probability of 0 } \\
\text { economic resources } \\
\text { (percent) }\end{array}$ \\
\hline 2005 & 26,631 & 0 & 9.7 & 7 & 5.2 \\
\hline
\end{tabular}

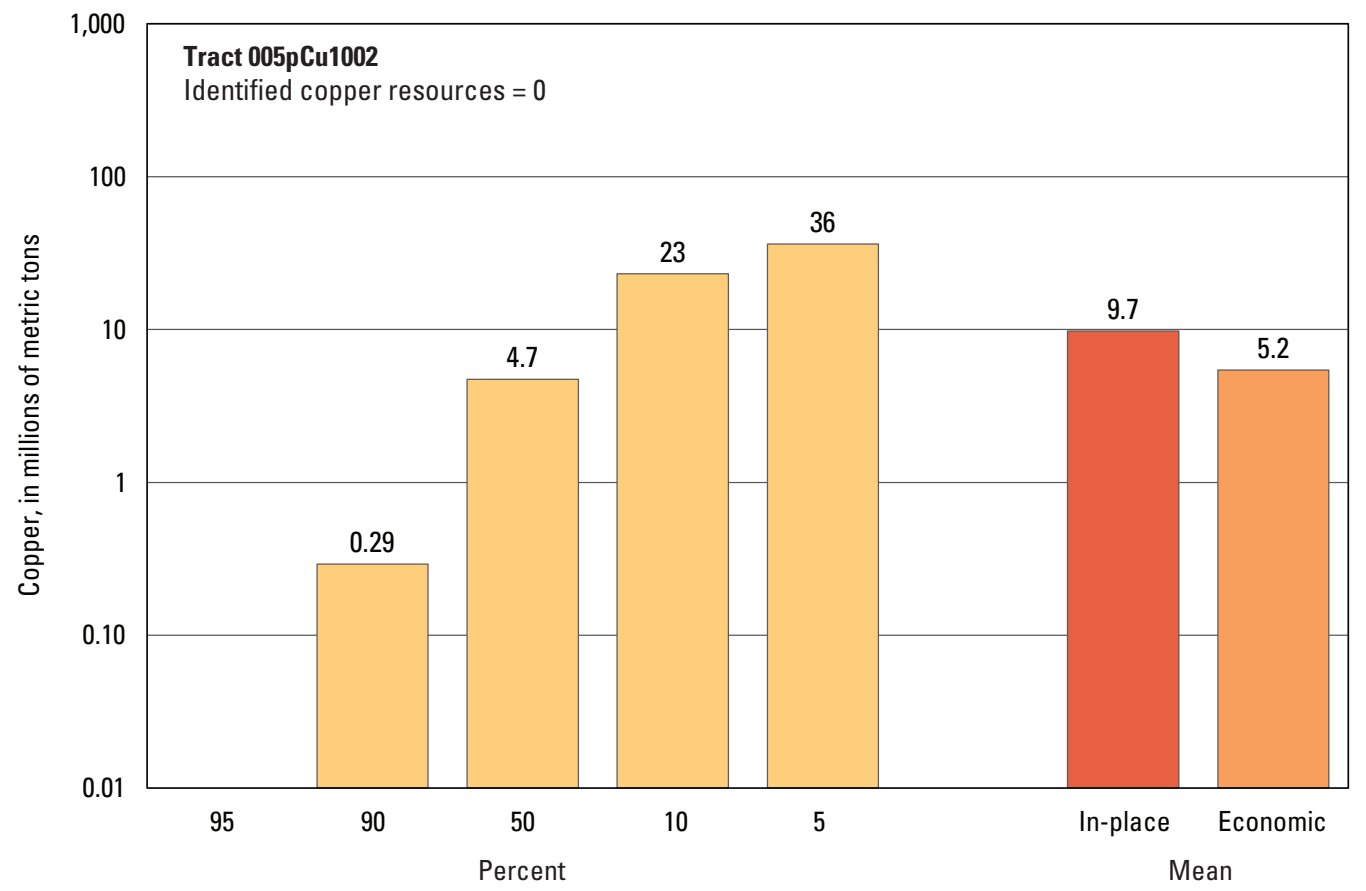

Graph showing the estimated probability distribution of undiscovered copper resources, where each bar represents the minimum amount estimated at the indicated percentage.

\section{Source}

Cunningham and others, 2008, Quantitative mineral resource assessment of copper, molybdenum, gold, and silver in undiscovered porphyry copper deposits in the Andes Mountains of South America: U.S. Geological Survey Open-File Report 2008-1253, http://pubs.usgs.gov/of/2008/1253/. 

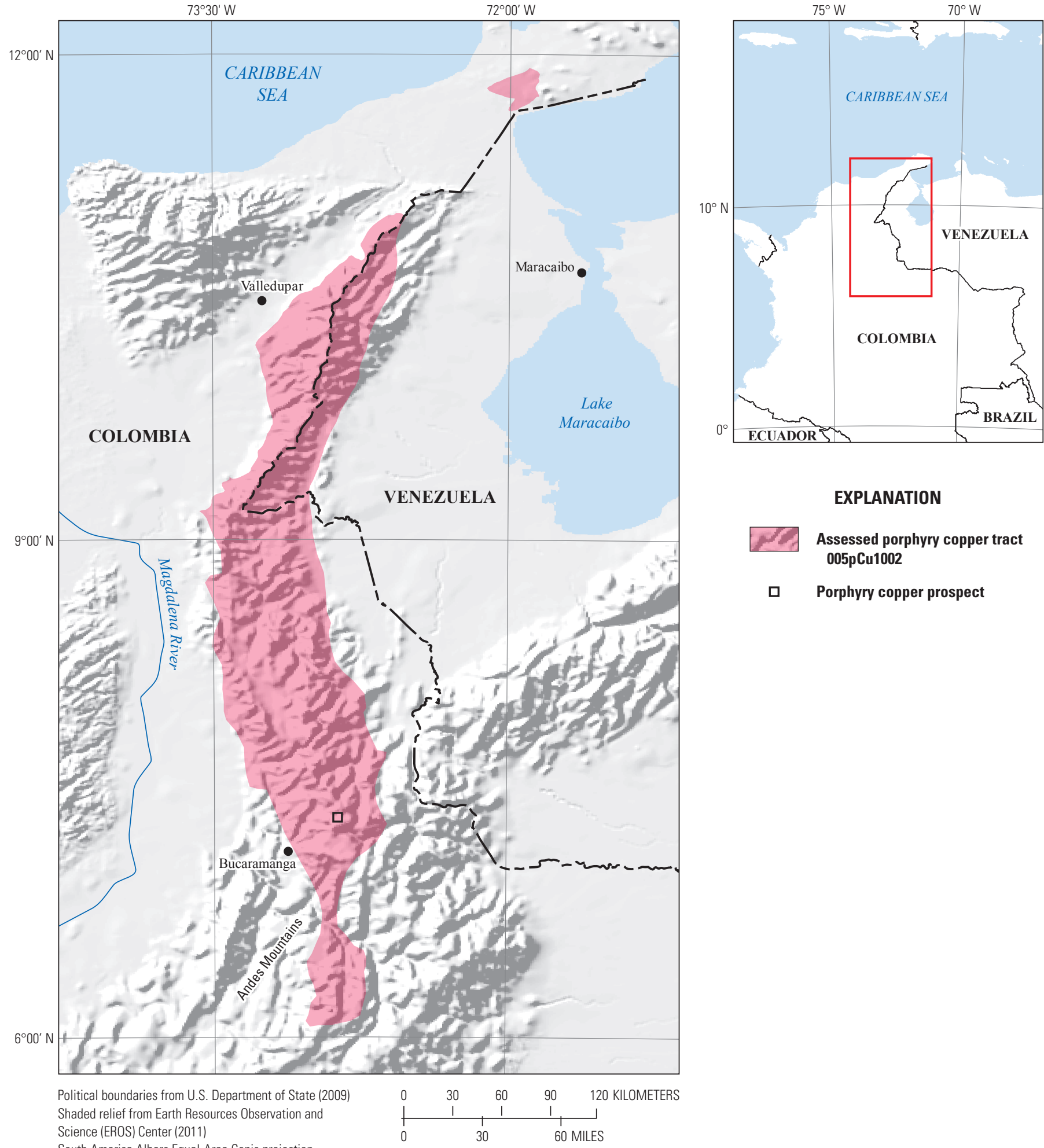

\section{EXPLANATION}

Q. Assessed porphyry copper tract 005pCu1002

․ Porphyry copper prospect 


\section{Plate 27. Porphyry Copper Assessment for Tract 003pCu4002, Darién Region- Panama}

Descriptive model:

Grade and tonnage model:

Economic filter depth percentages:

Economic filter cost setting:

Geologic feature assessed:

Number of known deposits:
Porphyry copper models (Cox, 1986a; Berger and others, 2008; John and others, 2010)

General porphyry copper model (Singer, Berger, and Moring, 2008)

Custom - 0 to 250 meters (m), 20\%; >250 to $500 \mathrm{~m}, 30 \%$; >500 m to $1 \mathrm{~km}, 50 \%$

Mixed cost

Paleocene to Oligocene island arc-related calc-alkalic igneous rocks that were formed as the Nazca Plate was subducted beneath the Caribbean Plate

1

\section{Selected Resource Assessment Results for Porphyry Copper}

[Assessment depth, 1 kilometer $(\mathrm{km}) ; \mathrm{km}^{2}$, square kilometer; Mt, millions of metric tons]

\begin{tabular}{ccccccc}
\hline $\begin{array}{c}\text { Date of } \\
\text { assessment }\end{array}$ & $\begin{array}{c}\text { Tract area } \\
\left(\mathbf{k m}^{2}\right)\end{array}$ & $\begin{array}{c}\text { Identified } \\
\text { copper } \\
\text { resources } \\
\text { (Mt) }\end{array}$ & $\begin{array}{c}\text { Mean estimate of } \\
\text { in-place resources } \\
(\mathbf{M t})\end{array}$ & $\begin{array}{c}\text { Probability of } \mathbf{0} \\
\text { in-place resources } \\
\text { (percent) }\end{array}$ & $\begin{array}{c}\text { Mean estimate of } \\
\text { economic resources } \\
\text { (Mt) }\end{array}$ & $\begin{array}{c}\text { Probability of 0 } \\
\text { economic resources } \\
\text { (percent) }\end{array}$ \\
\hline 2010 & 16,475 & 19 & 14 & 4 & 8.6 \\
\hline
\end{tabular}

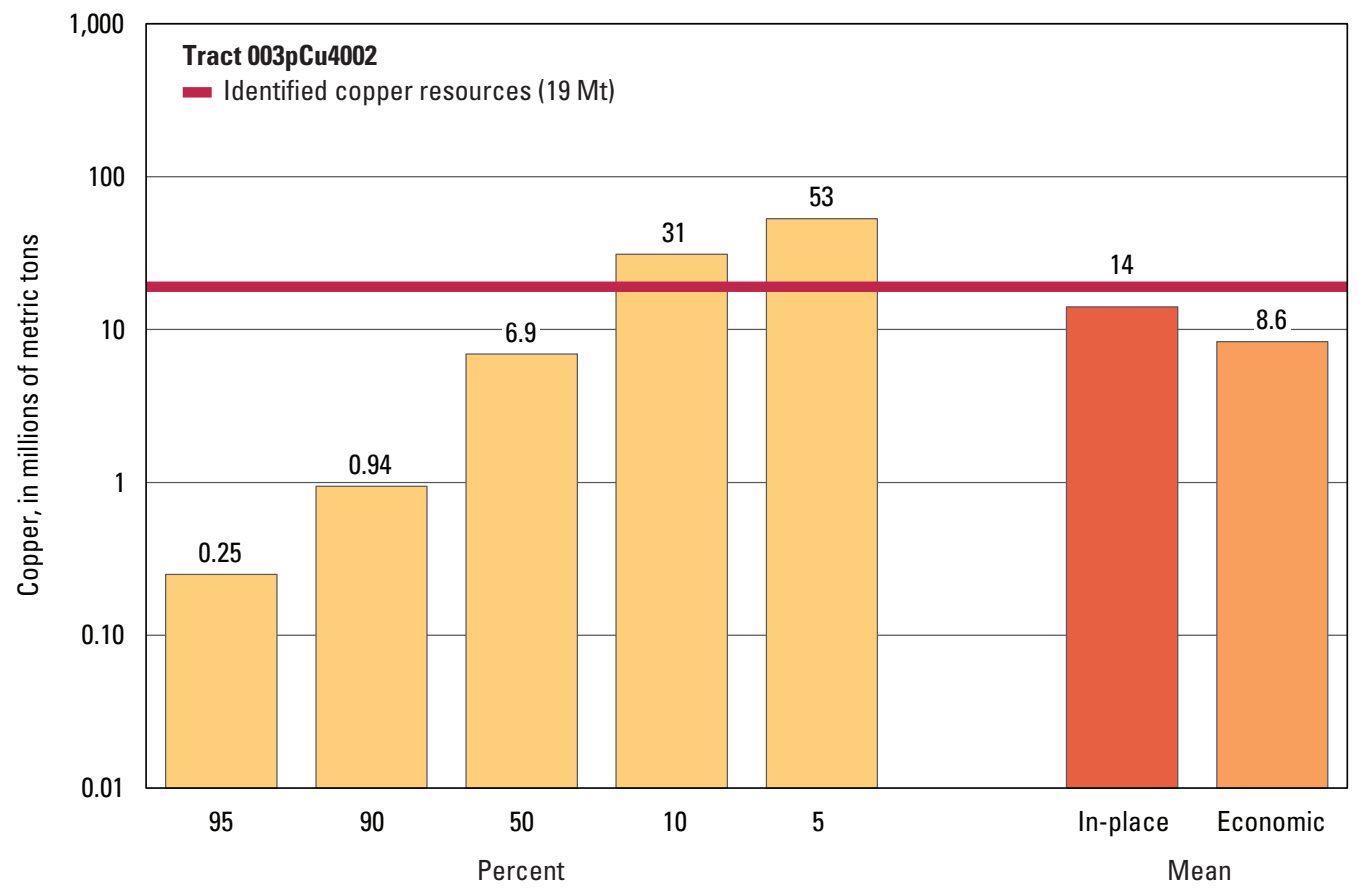

Graph showing the estimated probability distribution of undiscovered copper resources, where each bar represents the minimum amount estimated at the indicated percentage.

\section{Source}

Gray and others, 2014, Porphyry copper assessment of Central America and the Caribbean Basin: U.S. Geological Survey Scientific Investigations Report 2010-5090-I, http://dx.doi.org/10.3133/sir20105090I. 


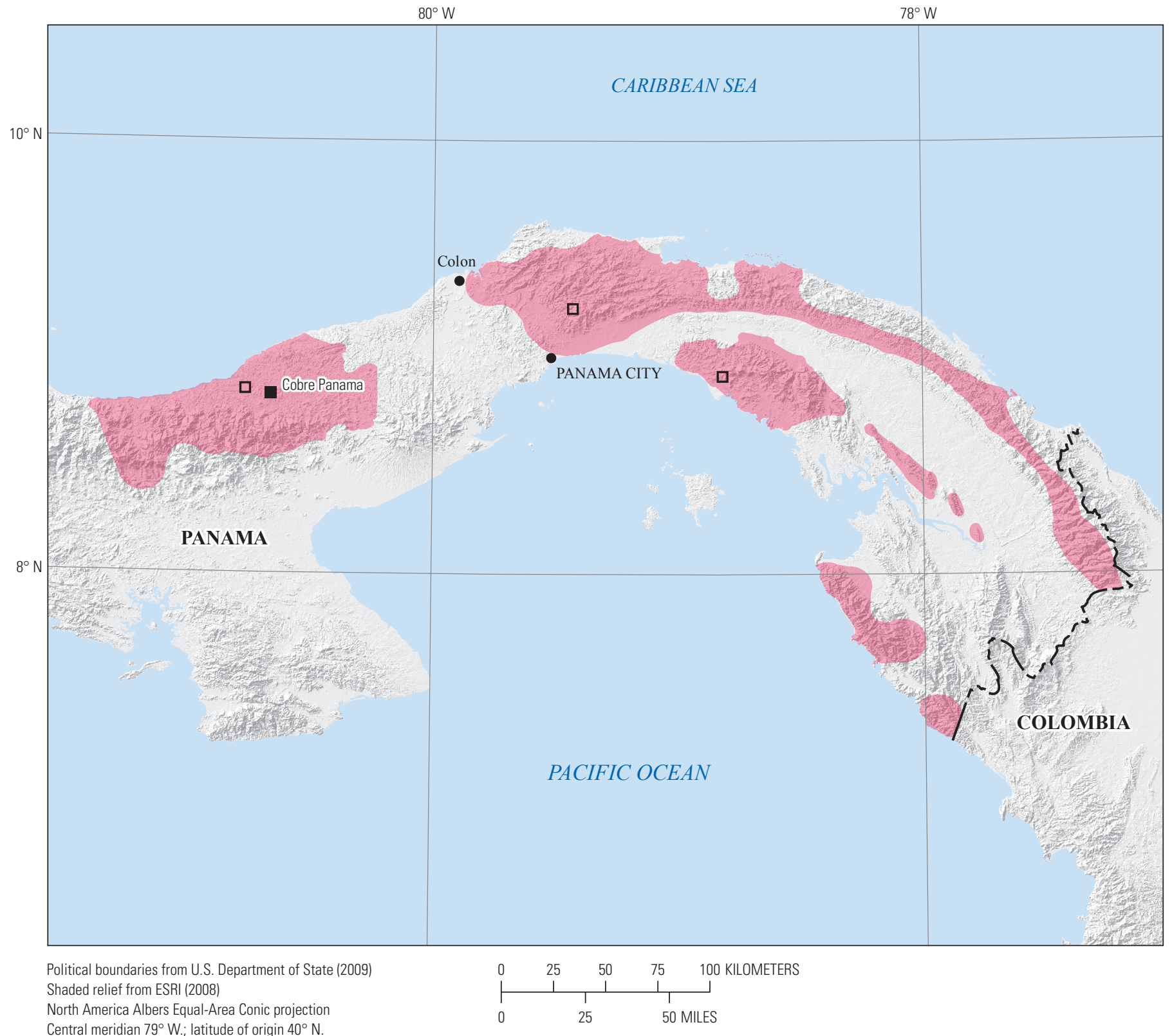

Central meridian $79^{\circ} \mathrm{W}$.; latitude of origin $40^{\circ} \mathrm{N}$.

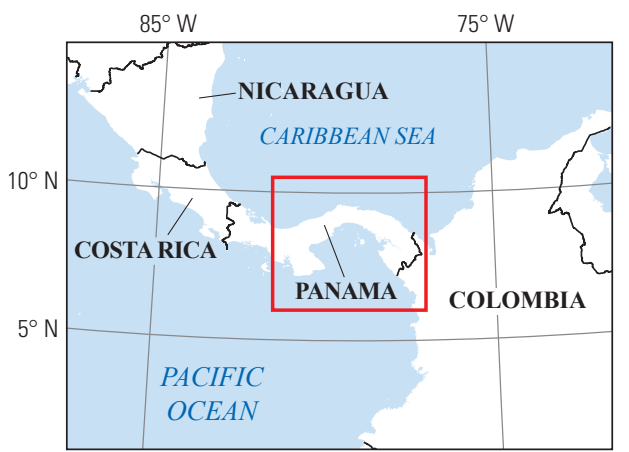




\section{Plate 28. Porphyry Copper Assessment for Tract 003pCu4004, Cocos Region- Central America}

Descriptive model:

Grade and tonnage model:

Economic filter depth percentages:

Economic filter cost setting:

Geologic feature assessed:

Number of known deposits:
Porphyry copper models (Cox, 1986a; Berger and others, 2008; John and others, 2010)

General porphyry copper model (Singer, Berger, and Moring, 2008)

Skewed deep — 0 to 250 meters (m), 10\%; > 250 to $500 \mathrm{~m}, 30 \%$; >500 m to $1 \mathrm{~km}, 60 \%$

Mixed cost

Middle to late Tertiary continental arc formed above the northern part of the Middle America Trench in a complex zone of interaction of the North American, Caribbean, Nazca, and Cocos Plates

2

\section{Selected Resource Assessment Results for Porphyry Copper}

[Assessment depth, 1 kilometer $(\mathrm{km}) ; \mathrm{km}^{2}$, square kilometer; Mt, millions of metric tons]

\begin{tabular}{ccccccc}
\hline \multirow{2}{*}{$\begin{array}{c}\text { Date of } \\
\text { assessment }\end{array}$} & $\begin{array}{c}\text { Tract area } \\
\left.\mathbf{( k m}^{2}\right)\end{array}$ & $\begin{array}{c}\text { Identified } \\
\text { copper } \\
\text { resources } \\
(\mathbf{M t})\end{array}$ & $\begin{array}{c}\text { Mean estimate of } \\
\text { in-place resources } \\
(\mathbf{M t})\end{array}$ & $\begin{array}{c}\text { Probability of } \mathbf{0} \\
\text { in-place resources } \\
\text { (percent) }\end{array}$ & $\begin{array}{c}\text { Mean estimate of } \\
\text { economic resources } \\
\text { (Mt) }\end{array}$ & $\begin{array}{c}\text { Probability of } \mathbf{0} \\
\text { economic resources } \\
\text { (percent) }\end{array}$ \\
\hline 2010 & 203,634 & 16 & 53 & 2 & 29 & 10 \\
\hline
\end{tabular}

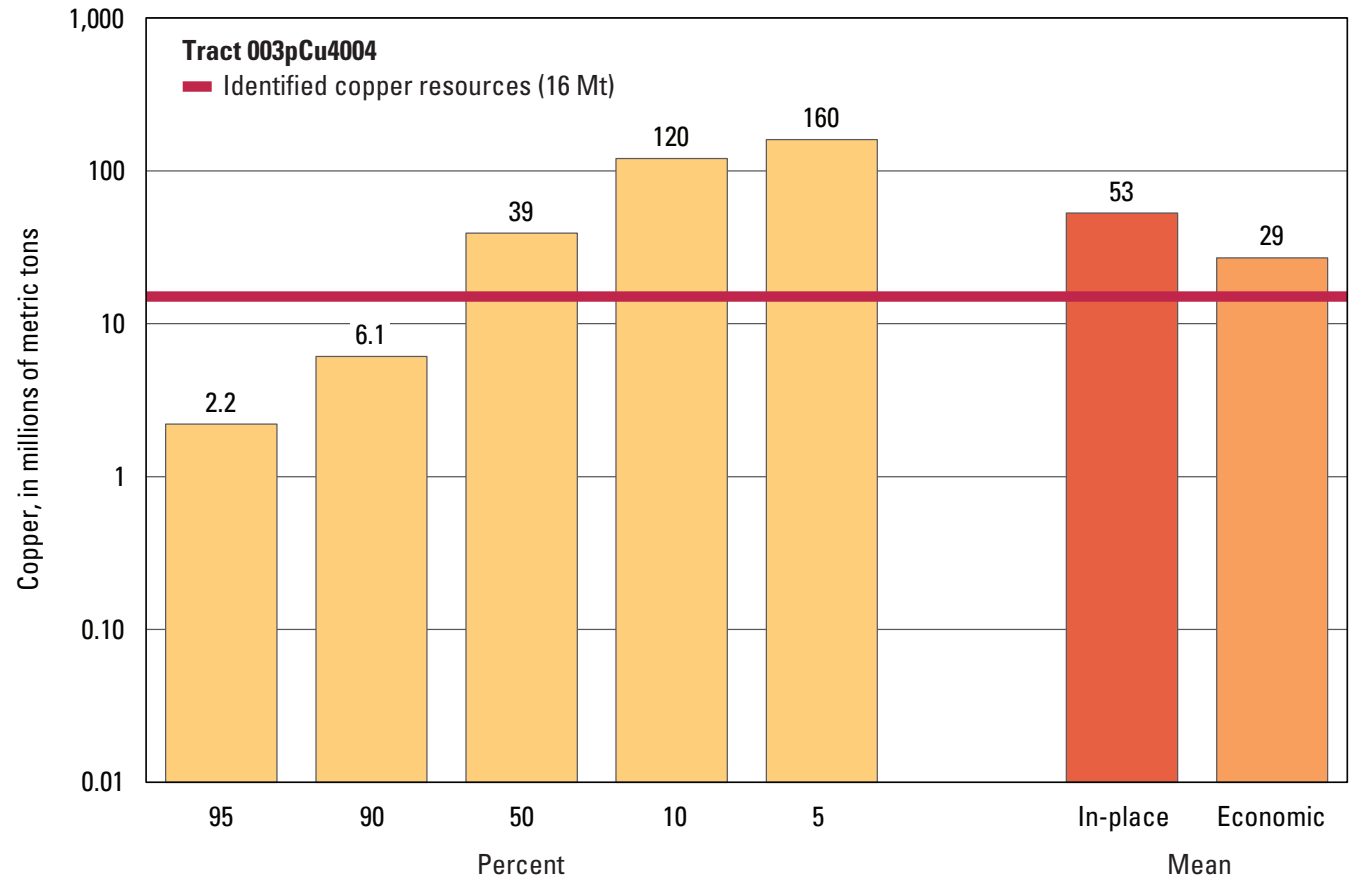

Graph showing the estimated probability distribution of undiscovered copper resources, where each bar represents the minimum amount estimated at the indicated percentage.

\section{Source}

Gray and others, 2014, Porphyry copper assessment of Central America and the Caribbean Basin: U.S. Geological Survey Scientific Investigations Report 2010-5090-I, http://dx.doi.org/10.3133/sir20105090I. 


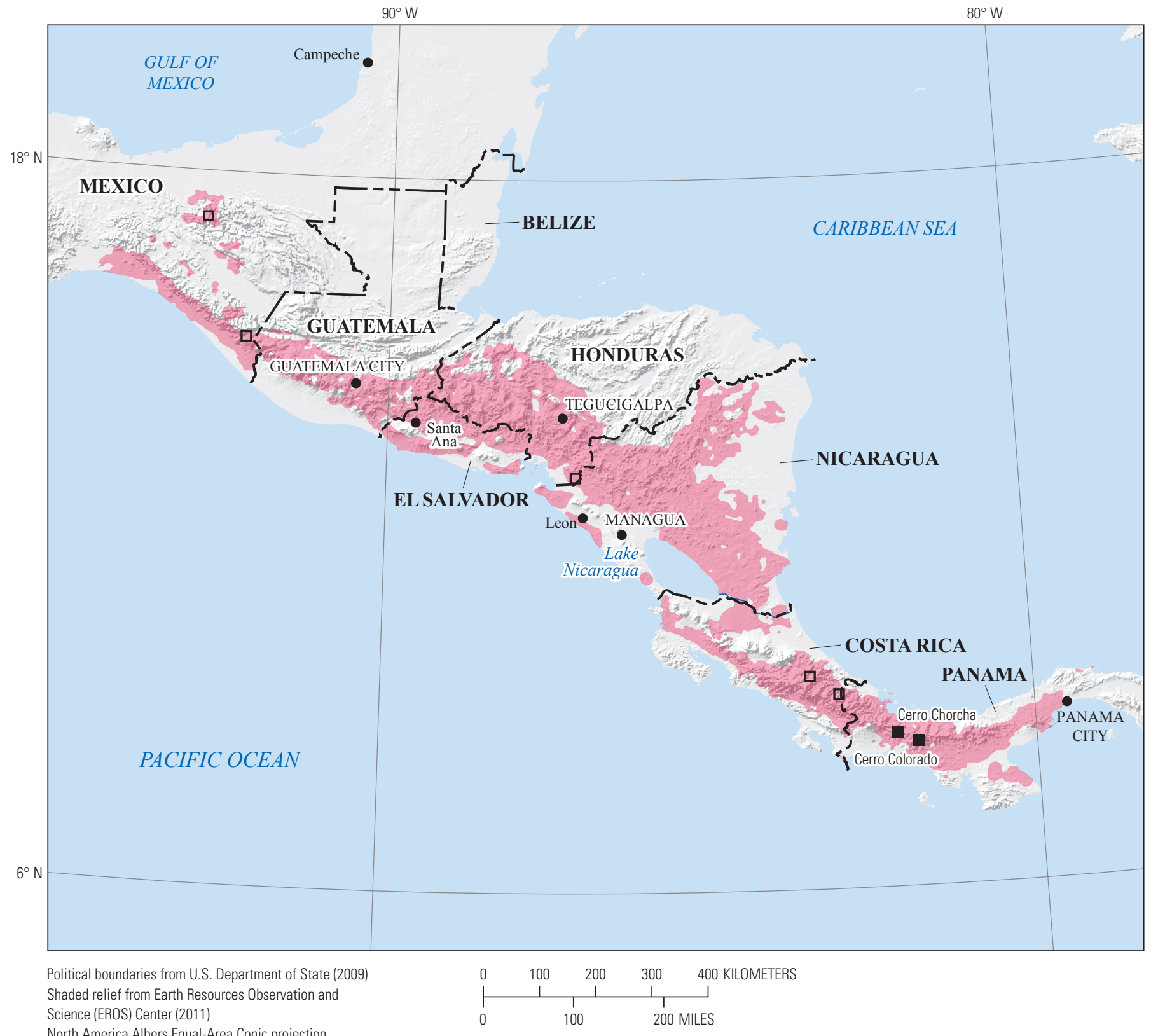

North America Albers Equal-Area Conic projection Central meridian $87^{\circ} \mathrm{W}$.; latitude of origin $40^{\circ} \mathrm{N}$.

\section{EXPLANATION}

Assessed porphyry copper tract 003pCu4004

- Porphyry copper deposit

Porphyry copper prospect

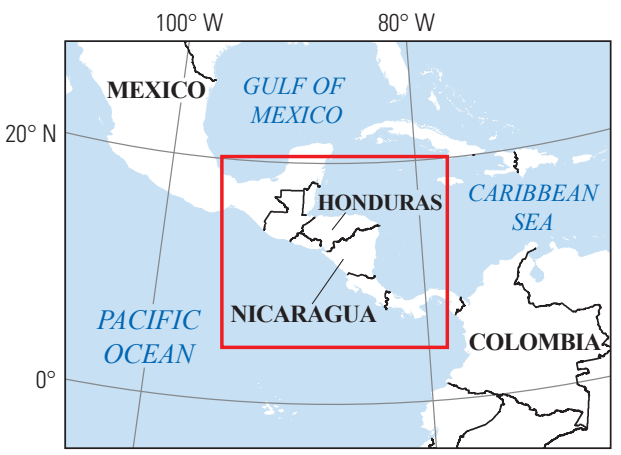




\title{
Plate 29. Porphyry Copper Assessment for Tract 003pCu4003, Chortis Region- Central America
}

\author{
Descriptive model: \\ Grade and tonnage model: \\ Porphyry copper models (Cox, 1986a; Berger and others, 2008; John and others, 2010) \\ Economic filter depth percentages: \\ Economic filter cost setting: \\ Geologic feature assessed: \\ General porphyry copper model (Singer, Berger, and Moring, 2008) \\ Default -0 to 250 meters (m), $25 \% ;>250$ to $500 \mathrm{~m}, 25 \% ;>500 \mathrm{~m}$ to $1 \mathrm{~km}, 50 \%$ \\ Mixed cost \\ Late Cretaceous to early Tertiary continental arc of dioritic-tonalitic plutons that intrude Mesozoic \\ sedimentary and older metamorphic rocks in northern Central America \\ Number of known deposits: \\ 0
}

\section{Selected Resource Assessment Results for Porphyry Copper}

[Assessment depth, 1 kilometer $(\mathrm{km}) ; \mathrm{km}^{2}$, square kilometer; Mt, millions of metric tons]

\begin{tabular}{ccccccc}
\hline $\begin{array}{c}\text { Date of } \\
\text { assessment }\end{array}$ & $\begin{array}{c}\text { Tract area } \\
\left(\mathbf{k m}^{2}\right)\end{array}$ & $\begin{array}{c}\text { Identified } \\
\text { copper } \\
\text { resources } \\
\text { (Mt) }\end{array}$ & $\begin{array}{c}\text { Mean estimate of } \\
\text { in-place resources } \\
(\mathbf{M t})\end{array}$ & $\begin{array}{c}\text { Probability of } \mathbf{0} \\
\text { in-place resources } \\
\text { (percent) }\end{array}$ & $\begin{array}{c}\text { Mean estimate of } \\
\text { economic resources } \\
\text { (Mt) }\end{array}$ & $\begin{array}{c}\text { Probability of 0 } \\
\text { economic resources } \\
\text { (percent) }\end{array}$ \\
\hline 2010 & 67,570 & 0 & 23 & 4 & 12 \\
\hline
\end{tabular}

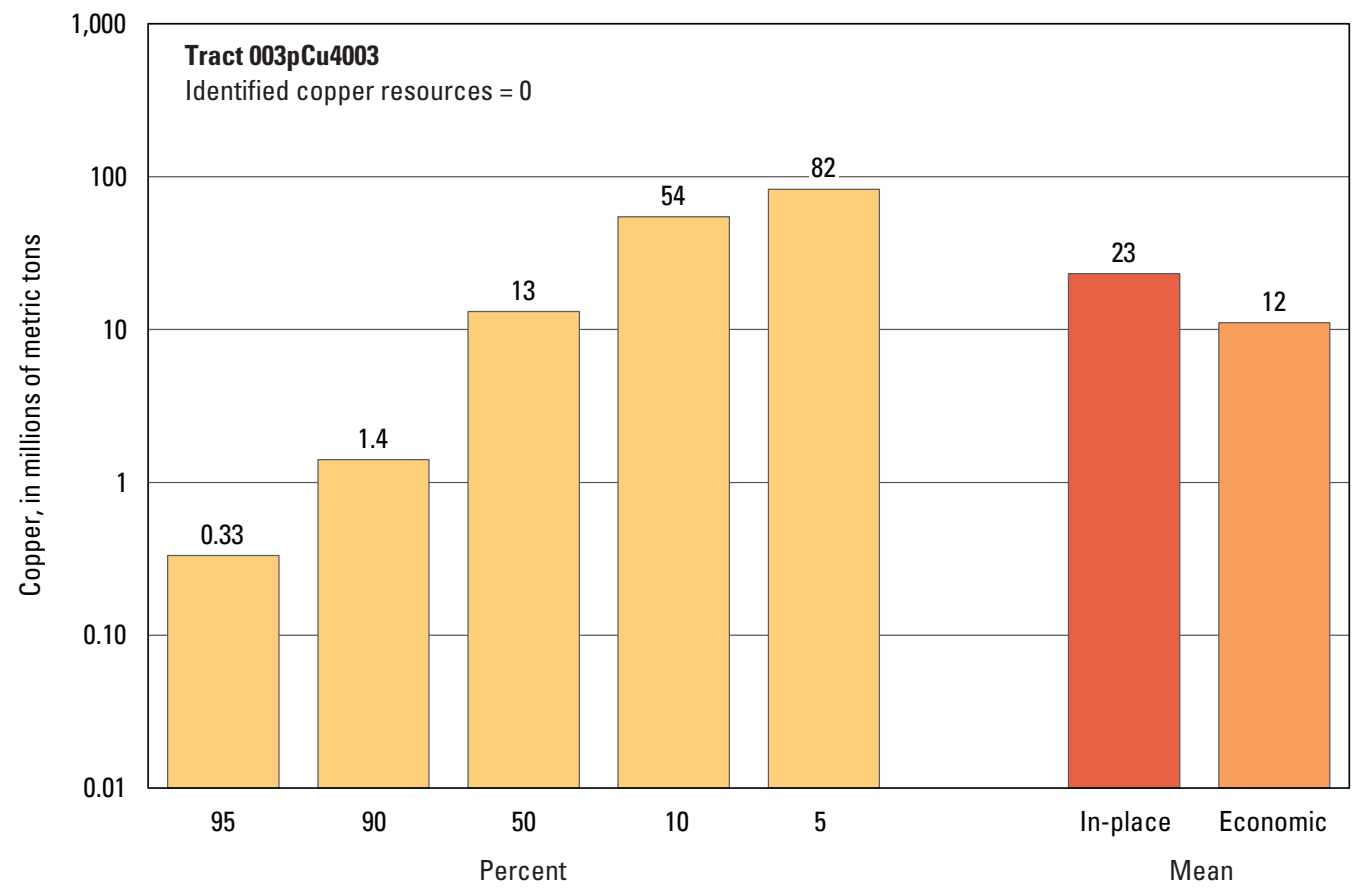

Graph showing the estimated probability distribution of undiscovered copper resources, where each bar represents the minimum amount estimated at the indicated percentage.

\section{Source}

Gray and others, 2014, Porphyry copper assessment of Central America and the Caribbean Basin: U.S. Geological Survey Scientific Investigations Report 2010-5090-I, http://dx.doi.org/10.3133/sir20105090I. 


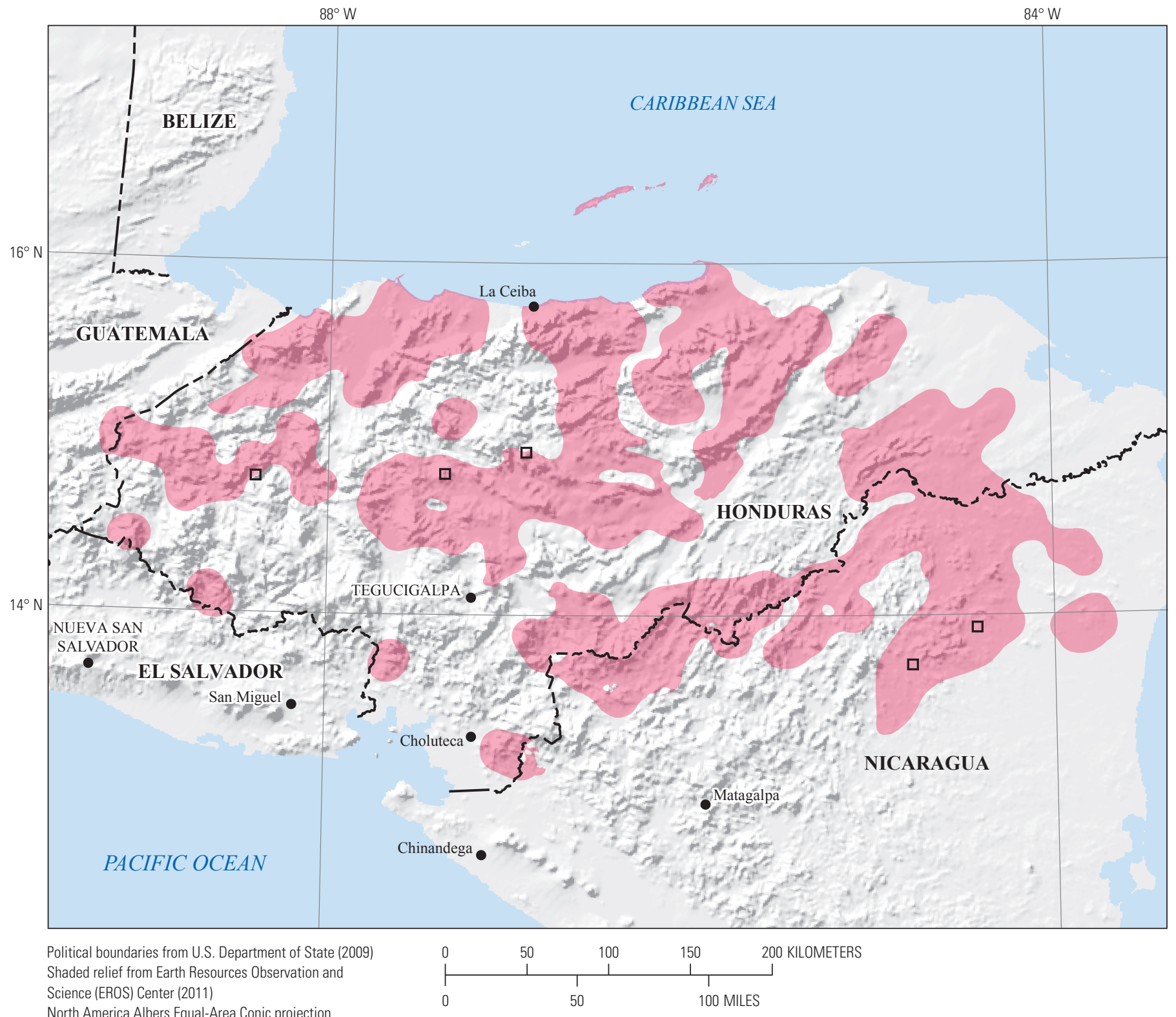

North America Albers Equal-Area Conic projection

Central meridian $86^{\circ} \mathrm{W}$.; latitude of origin $40^{\circ} \mathrm{N}$.

EXPLANATION

Assessed porphyry copper tract $003 p \mathrm{pu} 4003$

Porphyry copper prospect

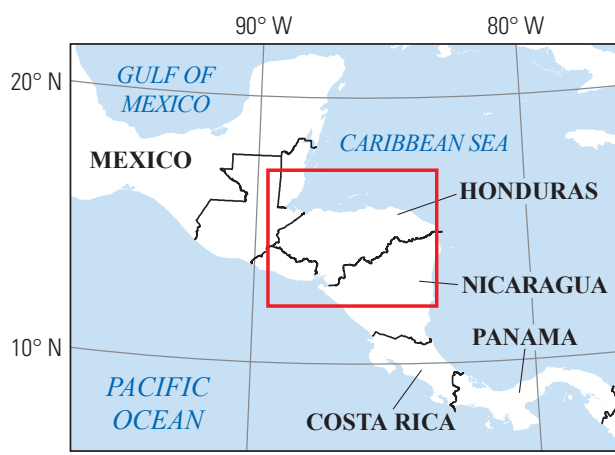




\title{
Plate 30. Porphyry Copper Assessment for Tract 003pCu4005, Lesser Antilles- Caribbean Basin
}

\author{
Descriptive model: \\ Porphyry copper-gold model (Cox, 1986b) \\ Grade and tonnage model: \\ Porphyry copper, copper-gold subtype model (Singer, Berger, and Moring, 2008) \\ Economic filter depth percentages: \\ Economic filter cost setting: \\ Geologic feature assessed: \\ Skewed deep - 0 to 250 meters (m), 10\%; > 250 to $500 \mathrm{~m}, 30 \%$; >500 m to $1 \mathrm{~km}, 60 \%$ \\ High cost \\ Eocene through Holocene Lesser Antilles composite volcanic arc \\ Number of known deposits: \\ 0
}

\section{Selected Resource Assessment Results for Porphyry Copper}

[Assessment depth, 1 kilometer $(\mathrm{km}) ; \mathrm{km}^{2}$, square kilometer; Mt, millions of metric tons]

\begin{tabular}{ccccccc}
\hline \multirow{2}{*}{$\begin{array}{c}\text { Date of } \\
\text { assessment }\end{array}$} & $\begin{array}{c}\text { Tract area } \\
\left(\mathbf{k m}^{2}\right)\end{array}$ & $\begin{array}{c}\text { Identified } \\
\text { copper } \\
\text { resources } \\
(\mathbf{M t})\end{array}$ & $\begin{array}{c}\text { Mean estimate of } \\
\text { in-place resources } \\
(\mathbf{M t})\end{array}$ & $\begin{array}{c}\text { Probability of } \mathbf{0} \\
\text { in-place resources } \\
\text { (percent) }\end{array}$ & $\begin{array}{c}\text { Mean estimate of } \\
\text { economic resources } \\
\text { (Mt) }\end{array}$ & $\begin{array}{c}\text { Probability of } \mathbf{0} \\
\text { economic resources } \\
\text { (percent) }\end{array}$ \\
\hline 2010 & 2,982 & 0 & 3.3 & 30 & 1.4 \\
\hline
\end{tabular}

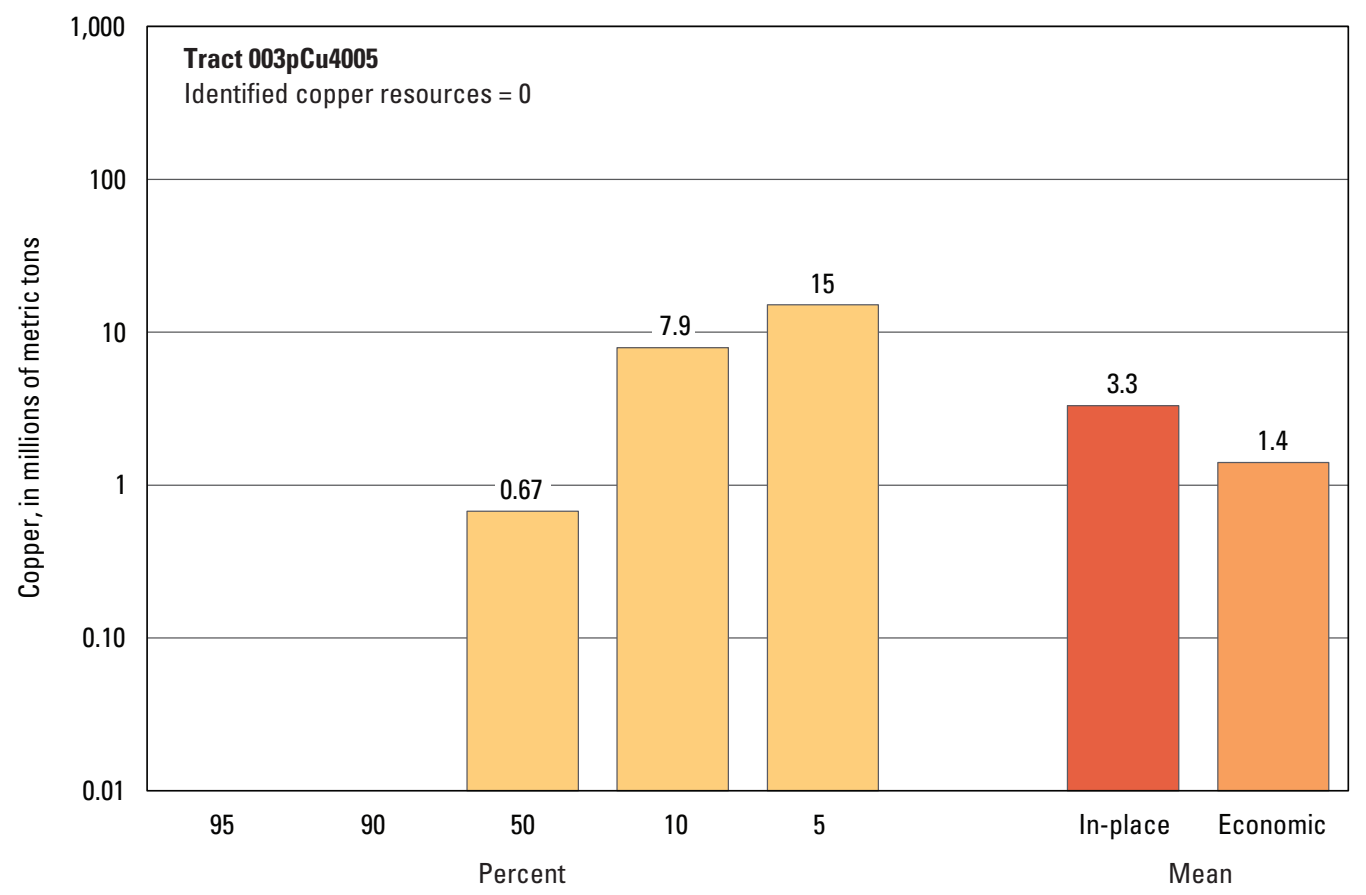

Graph showing the estimated probability distribution of undiscovered copper resources, where each bar represents the minimum amount estimated at the indicated percentage.

\section{Source}

Gray and others, 2014, Porphyry copper assessment of Central America and the Caribbean Basin: U.S. Geological Survey Scientific Investigations Report 2010-5090-I, http://dx.doi.org/10.3133/sir20105090I. 

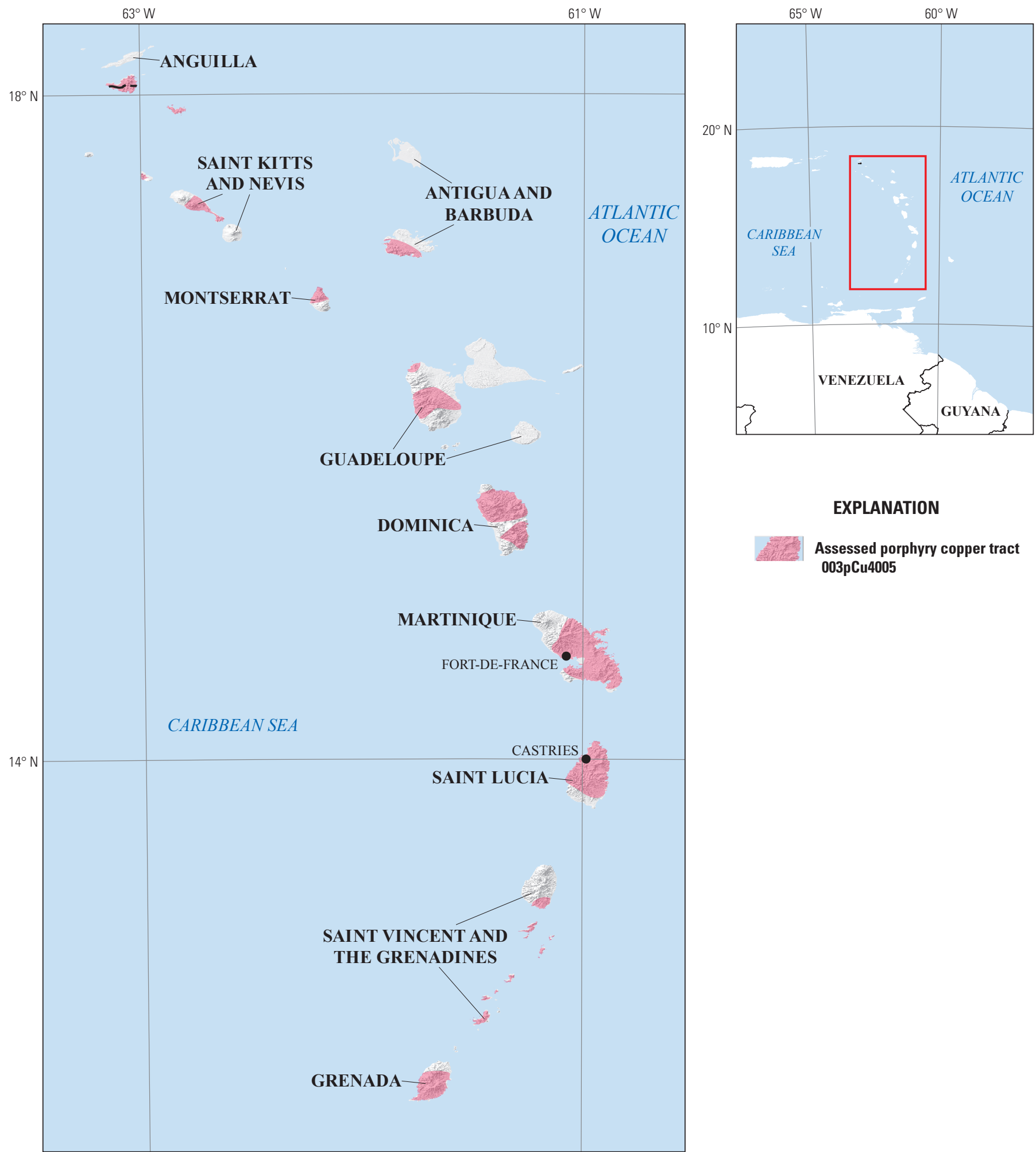

\section{EXPLANATION}

Assessed porphyry copper tract 003pCu4005

Political boundaries from U.S. Department of State (2009) Shaded relief from ESRI (2008)

South America Albers Equal-Area Conic projection

Central meridian $61^{\circ} 30^{\prime} \mathrm{W}$.; latitude of origin $32^{\circ} \mathrm{S}$.

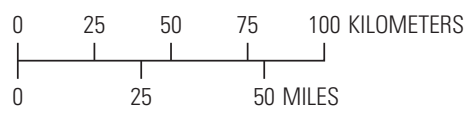




\title{
Plate 31. Porphyry Copper Assessment for Tract 003pCu4001, Santiago Region-Caribbean Basin
}

\author{
Descriptive model: \\ Porphyry copper models (Cox, 1986a; Berger and others, 2008; John and others, 2010) \\ Grade and tonnage model: \\ Porphyry copper, copper-gold subtype model (Singer, Berger, and Moring, 2008) \\ Economic filter depth percentages: \\ Economic filter cost setting: \\ Geologic feature assessed: \\ Default - 0 to 250 meters (m), 25\%; > 250 to $500 \mathrm{~m}, 25 \%$; >500 m to $1 \mathrm{~km}, 50 \%$ \\ Mixed cost \\ Cretaceous-Eocene oceanic arc associated with subduction along the northern Caribbean Plate \\ boundary, corresponding to the modern Greater Antilles arc \\ Number of known deposits: \\ 4
}

\section{Selected Resource Assessment Results for Porphyry Copper}

[Assessment depth, 1 kilometer ( $\mathrm{km}) ; \mathrm{km}^{2}$, square kilometer; Mt, millions of metric tons]

\begin{tabular}{ccccccc}
\hline $\begin{array}{c}\text { Date of } \\
\text { assessment }\end{array}$ & $\begin{array}{c}\text { Tract area } \\
\left(\mathbf{k m}^{2}\right)\end{array}$ & $\begin{array}{c}\text { Identified } \\
\text { copper } \\
\text { resources } \\
\text { (Mt) }\end{array}$ & $\begin{array}{c}\text { Mean estimate of } \\
\text { in-place resources } \\
(\mathbf{M t})\end{array}$ & $\begin{array}{c}\text { Probability of } \mathbf{0} \\
\text { in-place resources } \\
\text { (percent) }\end{array}$ & $\begin{array}{c}\text { Mean estimate of } \\
\text { economic resources } \\
\text { (Mt) }\end{array}$ & $\begin{array}{c}\text { Probability of 0 } \\
\text { economic resources } \\
\text { (percent) }\end{array}$ \\
\hline 2010 & 78,775 & 4.1 & 36 & 2 & 19 \\
\hline
\end{tabular}

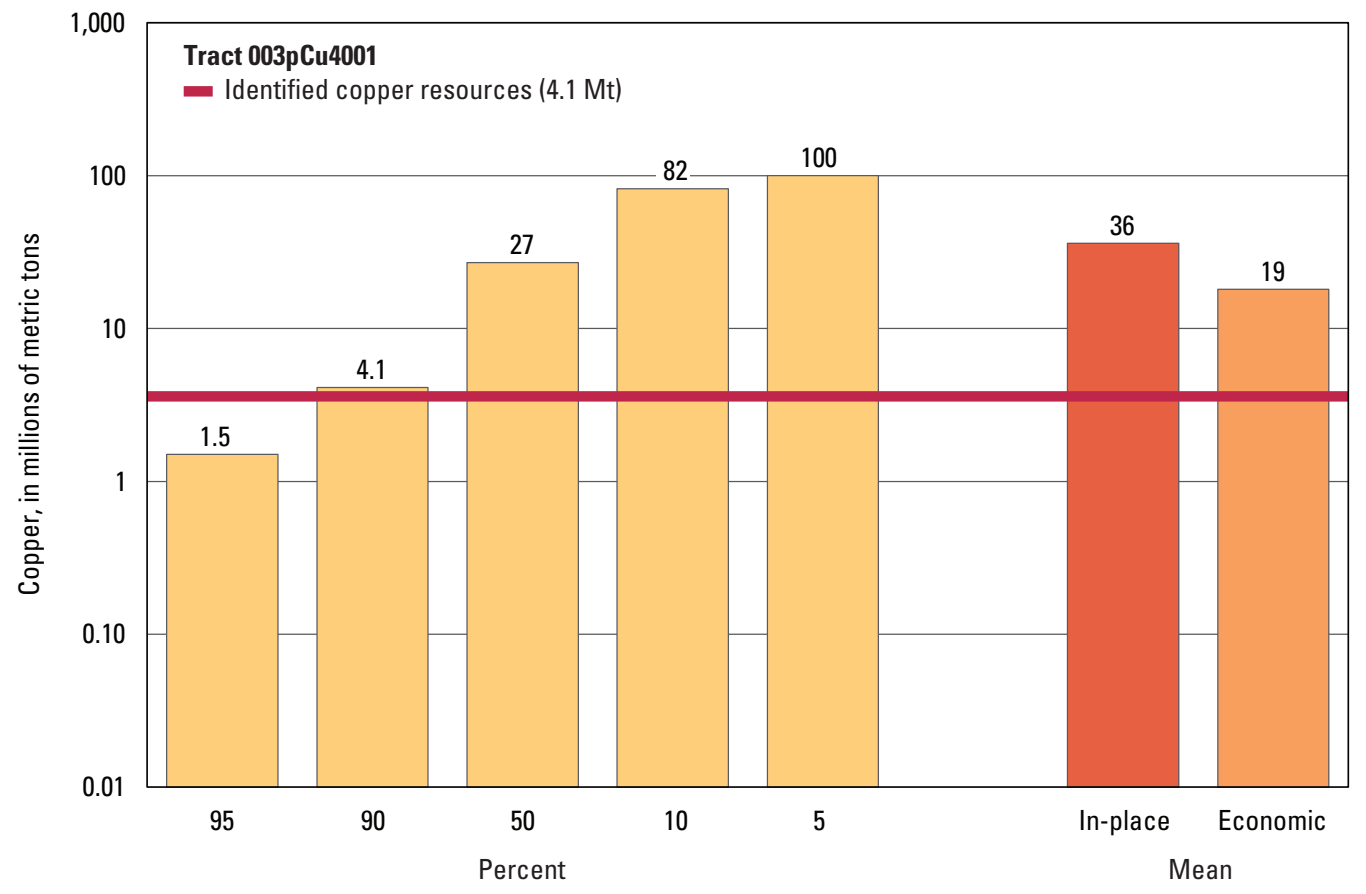

Graph showing the estimated probability distribution of undiscovered copper resources, where each bar represents the minimum amount estimated at the indicated percentage.

\section{Source}

Gray and others, 2014, Porphyry copper assessment of Central America and the Caribbean Basin: U.S. Geological Survey Scientific Investigations Report 2010-5090-I, http://dx.doi.org/10.3133/sir20105090I. 


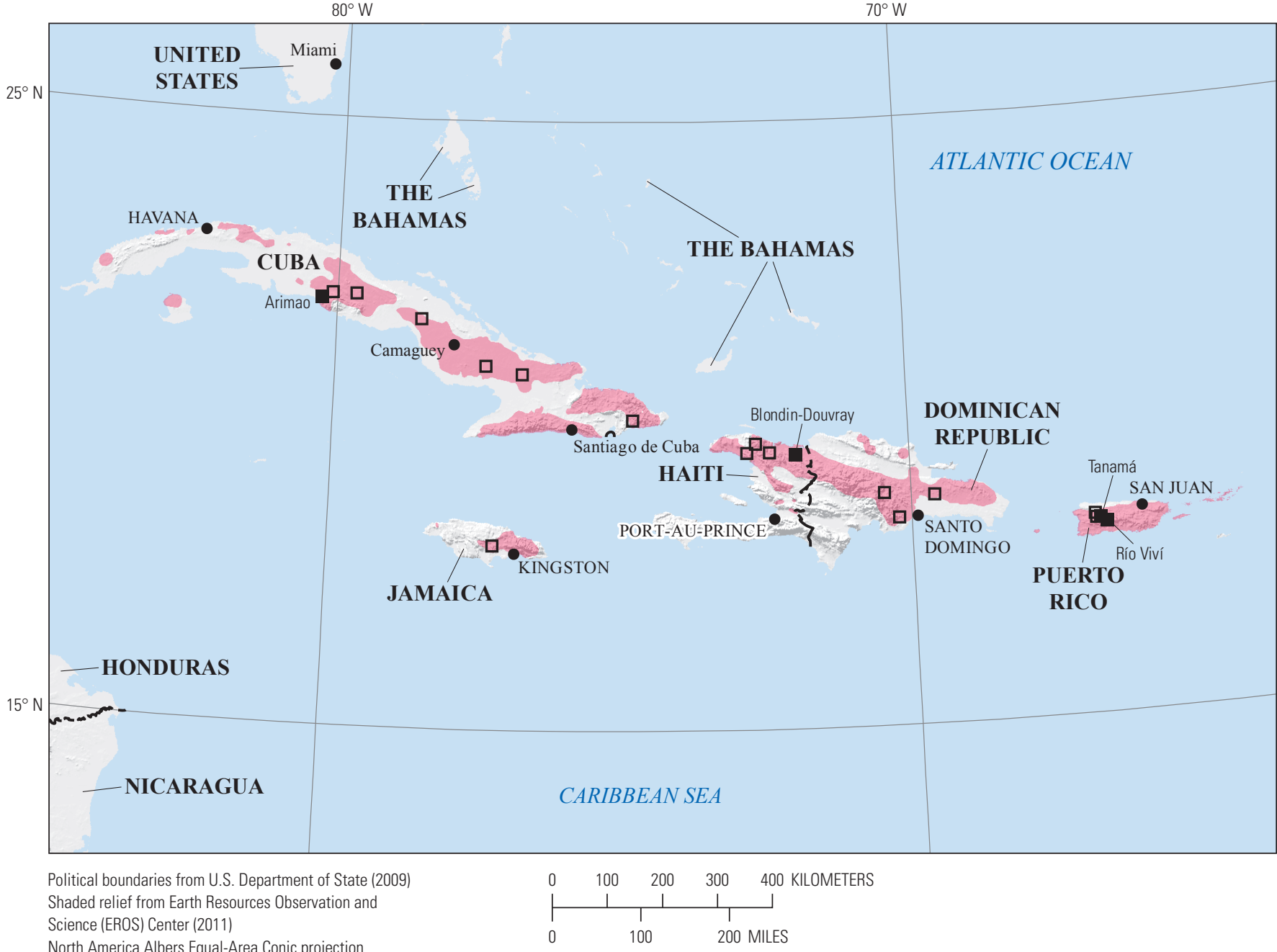

rth America Albers Equal-Area 0

Central meridian $75^{\circ} \mathrm{W}$.; latitude of origin $40^{\circ} \mathrm{N}$

\section{EXPLANATION}

\begin{tabular}{|l|l}
\hline & $\begin{array}{c}\text { Assessed porphyry copper } \\
003 p C u 4001\end{array}$ \\
& Porphyry copper deposit \\
$\square$ & Porphyry copper prospect
\end{tabular}

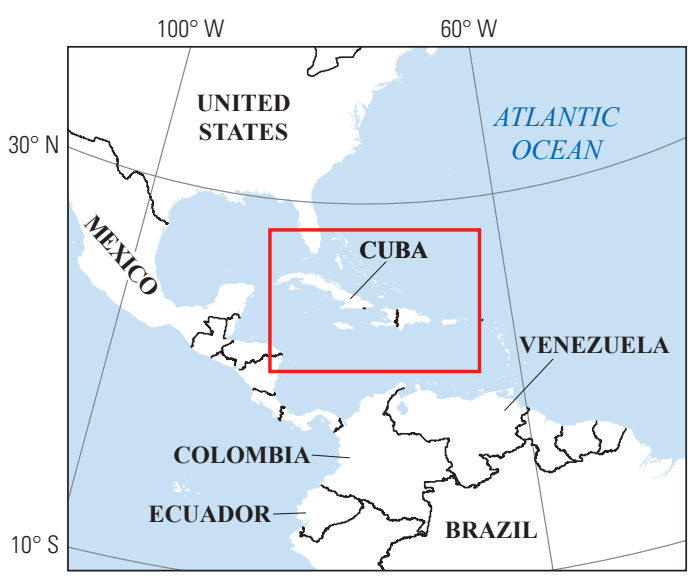




\title{
Plate 32. Porphyry Copper Assessment for Tract 003pCu3011, Southwest Mexico-Mexico
}

\author{
Descriptive model: \\ Porphyry copper models (Cox, 1986a; Berger and others, 2008) \\ Grade and tonnage model: \\ General porphyry copper model (Singer, Berger, and Moring, 2008) \\ Economic filter depth percentages: \\ Economic filter cost setting: \\ Geologic feature assessed: \\ Default -0 to 250 meters (m), $25 \%$; $>250$ to $500 \mathrm{~m}, 25 \% ;>500 \mathrm{~m}$ to $1 \mathrm{~km}, 50 \%$ \\ Typical cost \\ Paleocene to Miocene continental magmatic arc rocks along the Pacific coast of Mexico, west of \\ Mexico City, and along the Sierra Madre del Sur \\ Number of known deposits: \\ 3
}

\section{Selected Resource Assessment Results for Porphyry Copper}

[Assessment depth, 1 kilometer ( $\mathrm{km}) ; \mathrm{km}^{2}$, square kilometer; Mt, millions of metric tons]

\begin{tabular}{ccccccc}
\hline $\begin{array}{c}\text { Date of } \\
\text { assessment }\end{array}$ & $\begin{array}{c}\text { Tract area } \\
\left(\mathbf{k m}^{2}\right)\end{array}$ & $\begin{array}{c}\text { Identified } \\
\text { copper } \\
\text { resources } \\
\text { (Mt) }\end{array}$ & $\begin{array}{c}\text { Mean estimate of } \\
\text { in-place resources } \\
(\mathbf{M t})\end{array}$ & $\begin{array}{c}\text { Probability of } \mathbf{0} \\
\text { in-place resources } \\
\text { (percent) }\end{array}$ & $\begin{array}{c}\text { Mean estimate of } \\
\text { economic resources } \\
\text { (Mt) }\end{array}$ & $\begin{array}{c}\text { Probability of 0 } \\
\text { economic resources } \\
\text { (percent) }\end{array}$ \\
\hline 2008 & 156,976 & 1.0 & 37 & 2 & 25 \\
\hline
\end{tabular}

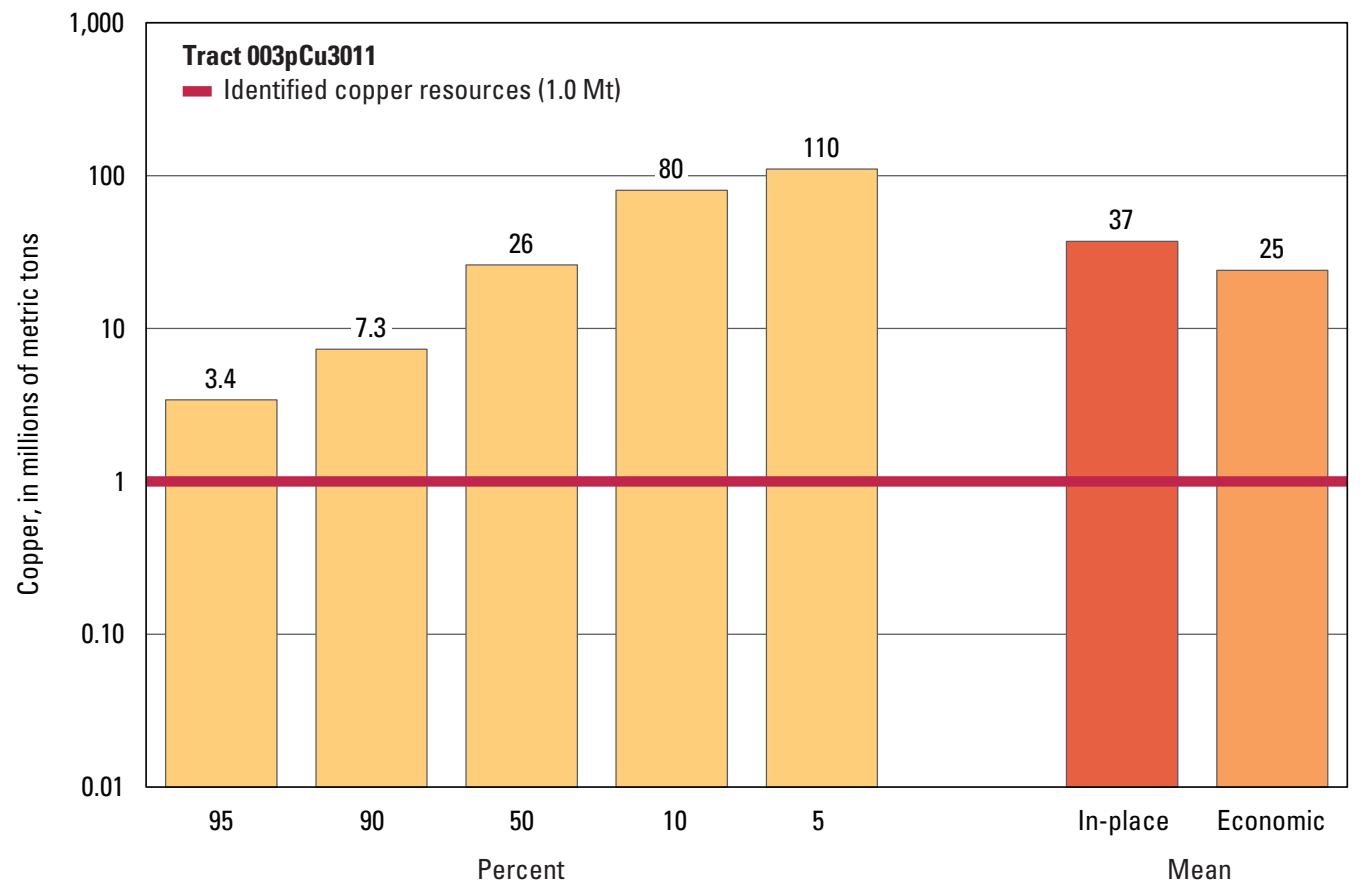

Graph showing the estimated probability distribution of undiscovered copper resources, where each bar represents the minimum amount estimated at the indicated percentage.

\section{Source}

Hammarstrom, Robinson, and others, 2010, Porphyry copper assessment of Mexico: U.S. Geological Survey Scientific Investigations Report 2010-5090-A, http://pubs.usgs.gov/sir/2010/5090/a/. 


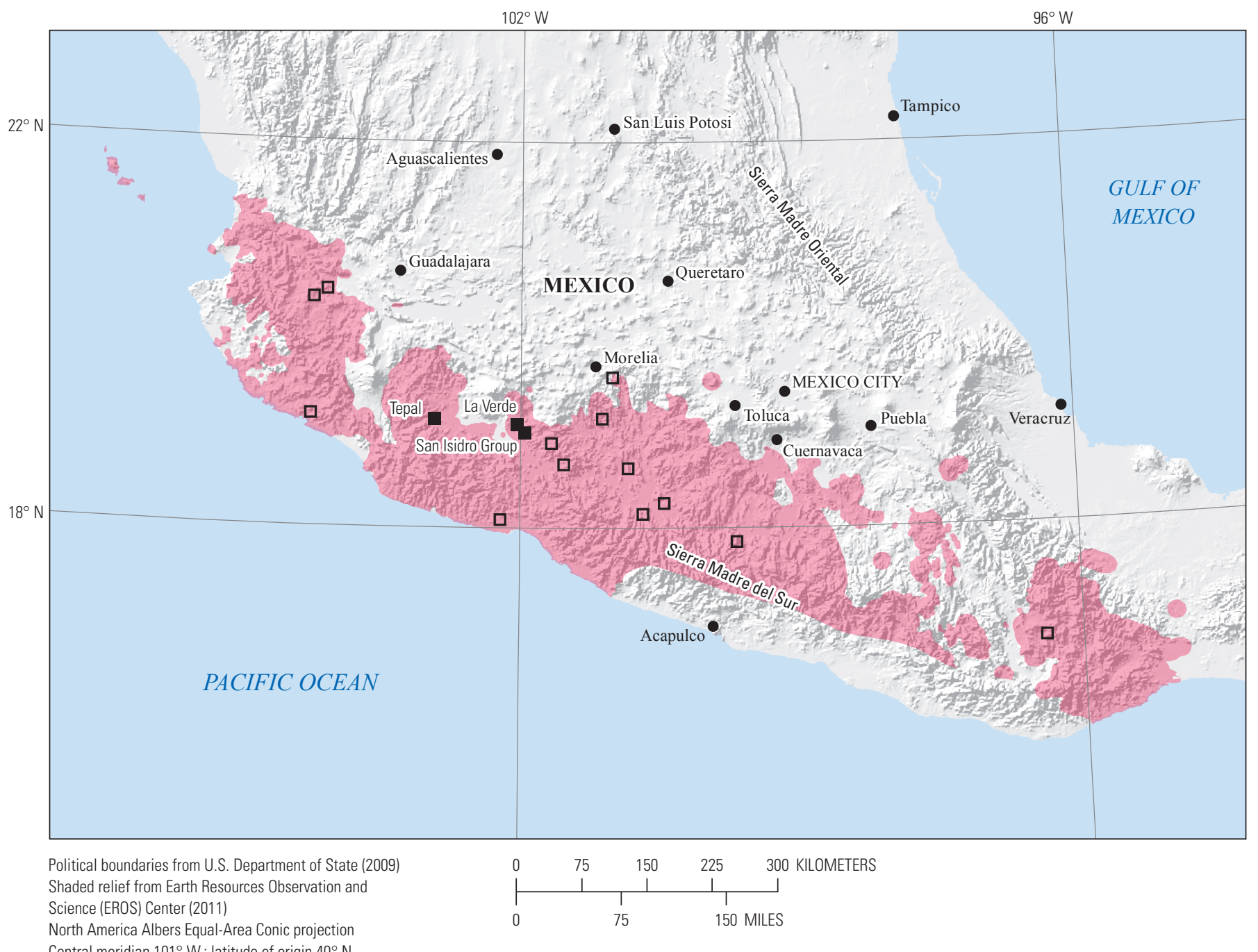

North America Albers Equal-Area Conic projection

Central meridian $101^{\circ} \mathrm{W}$.; latitude of origin $40^{\circ} \mathrm{N}$.

\section{EXPLANATION}

Assessed porphyry copper tract 003pCu3011

- Porphyry copper deposit

Porphyry copper prospect

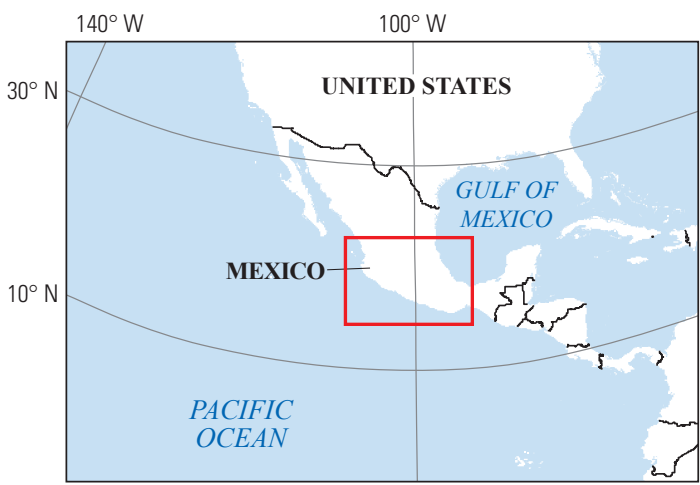




\section{Plate 33. Porphyry Copper Assessment for Tract 003pCu3005, Balsas-Mexico}

Descriptive model:

Grade and tonnage model:

Economic filter depth percentages:

Economic filter cost setting:

Geologic feature assessed:

Number of known deposits:
Porphyry copper models (Cox, 1986a; Berger and others, 2008)

General porphyry copper model (Singer, Berger, and Moring, 2008)

Default -0 to 250 meters (m), $25 \%$; $>250$ to $500 \mathrm{~m}, 25 \%$; $>500 \mathrm{~m}$ to $1 \mathrm{~km}, 50 \%$

Typical cost

Jurassic-Early Cretaceous Teloloapan volcanic-arc rocks in the Guerrero terrane of southwestern Mexico

1

\section{Selected Resource Assessment Results for Porphyry Copper}

[Assessment depth, 1 kilometer $(\mathrm{km}) ; \mathrm{km}^{2}$, square kilometer; Mt, millions of metric tons]

\begin{tabular}{ccccccc}
\hline \multirow{2}{*}{$\begin{array}{c}\text { Date of } \\
\text { assessment }\end{array}$} & $\begin{array}{c}\text { Tract area } \\
\left(\mathbf{k m}^{2}\right)\end{array}$ & $\begin{array}{c}\text { Identified } \\
\text { copper } \\
\text { resources } \\
(\mathbf{M t})\end{array}$ & $\begin{array}{c}\text { Mean estimate of } \\
\text { in-place resources } \\
(\mathbf{M t})\end{array}$ & $\begin{array}{c}\text { Probability of } \mathbf{0} \\
\text { in-place resources } \\
\text { (percent) }\end{array}$ & $\begin{array}{c}\text { Mean estimate of } \\
\text { economic resources } \\
\text { (Mt) }\end{array}$ & $\begin{array}{c}\text { Probability of 0 } \\
\text { economic resources } \\
\text { (percent) }\end{array}$ \\
\hline 2008 & 11,812 & 3.0 & 1.2 & 71 & 0.80 \\
\hline
\end{tabular}

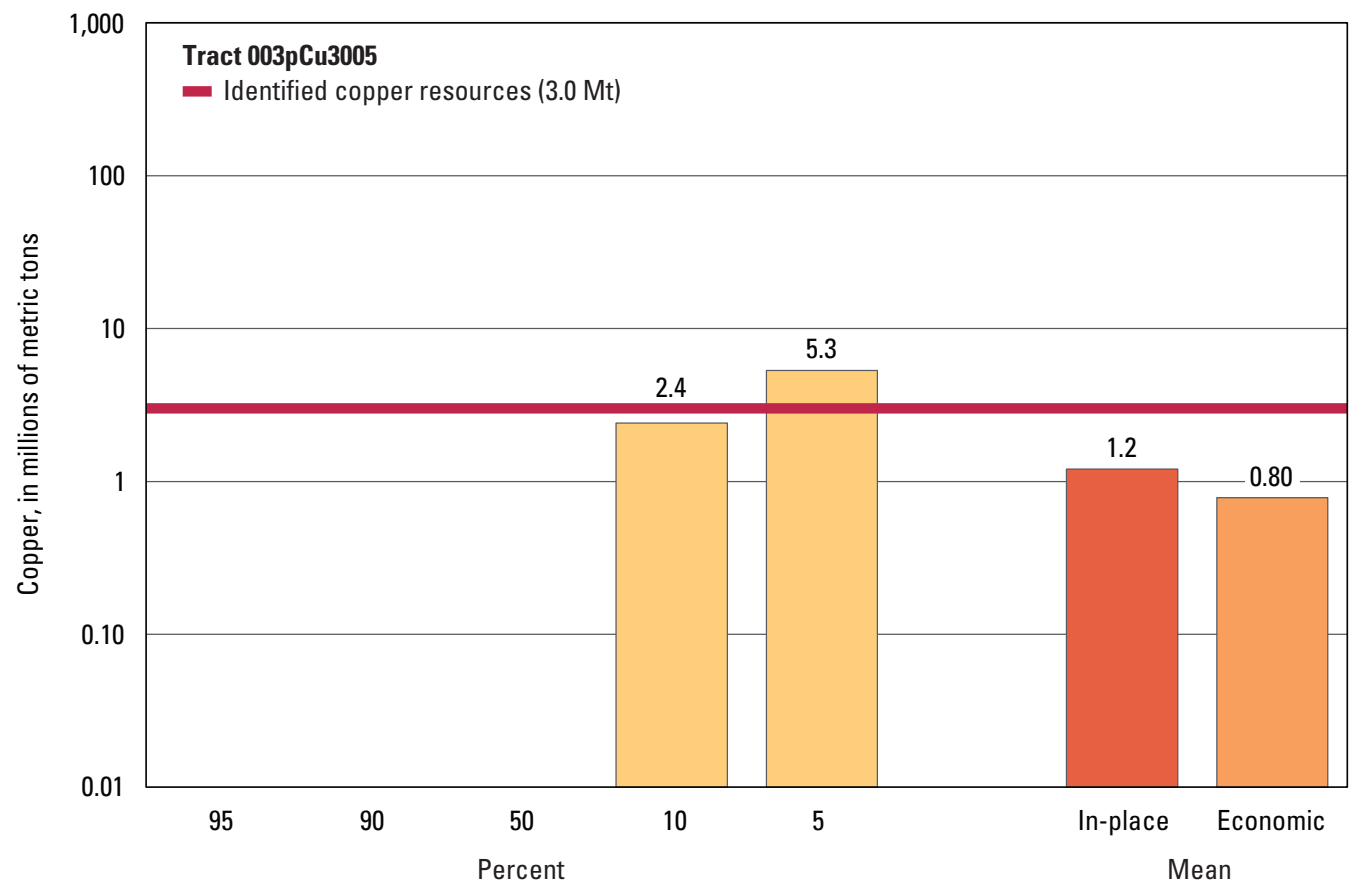

Graph showing the estimated probability distribution of undiscovered copper resources, where each bar represents the minimum amount estimated at the indicated percentage.

\section{Source}

Hammarstrom, Robinson, and others, 2010, Porphyry copper assessment of Mexico: U.S. Geological Survey Scientific Investigations Report 2010-5090-A, http://pubs.usgs.gov/sir/2010/5090/a/. 


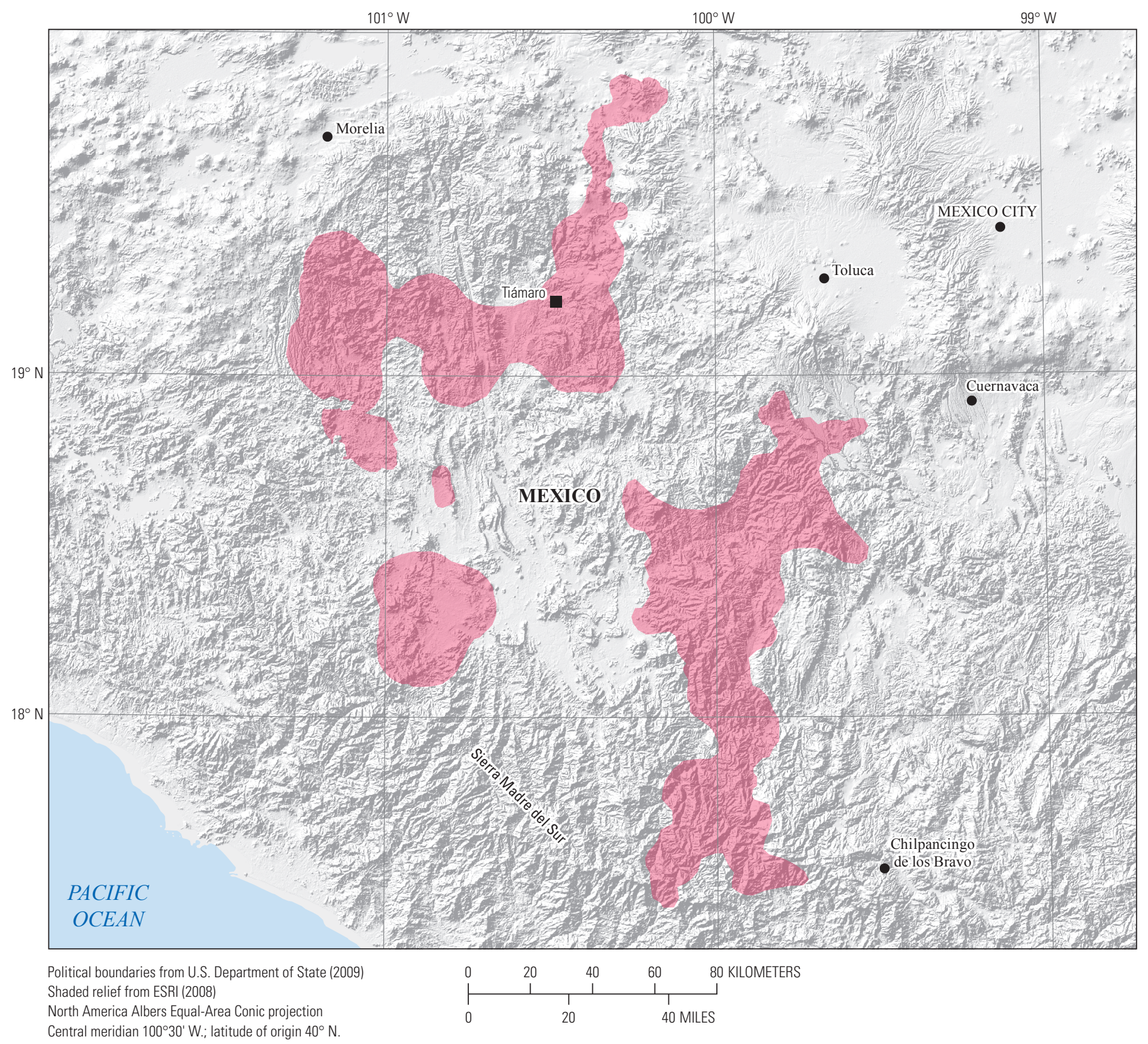

Central meridian $100^{\circ} 30^{\prime} \mathrm{W}$.; latitude of origin $40^{\circ} \mathrm{N}$.

\section{EXPLANATION}

Assessed porphyry copper tract 003pCu3005

- Porphyry copper deposit

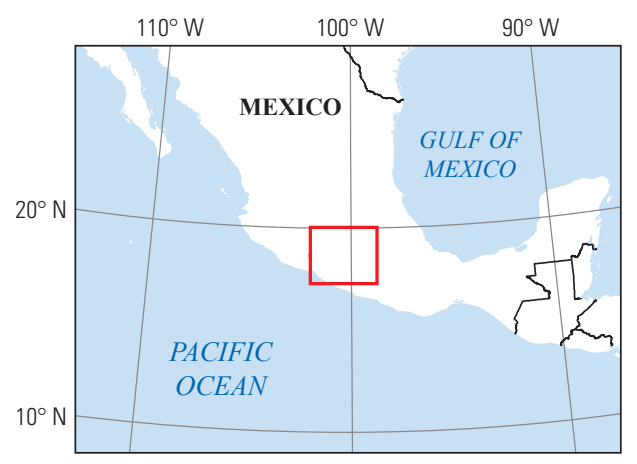




\title{
Plate 34. Porphyry Copper Assessment for Tract 003pCu3004, Guanajuato- Mexico
}

\author{
Descriptive model: \\ Porphyry copper models (Cox, 1986a; Berger and others, 2008) \\ Grade and tonnage model: \\ General porphyry copper model (Singer, Berger, and Moring, 2008) \\ Economic filter depth percentages: \\ Skewed deep — 0 to 250 meters (m), 10\%; > 250 to $500 \mathrm{~m}, 30 \%$; >500 m to $1 \mathrm{~km}, 60 \%$ \\ Economic filter cost setting: \\ Geologic feature assessed: \\ Typical cost \\ Late Triassic-Jurassic(?) Nazas magmatic arc rocks in central Mexico \\ Number of known deposits: \\ 0
}

\section{Selected Resource Assessment Results for Porphyry Copper}

[Assessment depth, 1 kilometer $(\mathrm{km}) ; \mathrm{km}^{2}$, square kilometer; Mt, millions of metric tons]

\begin{tabular}{ccccccc}
\hline \multirow{2}{*}{$\begin{array}{c}\text { Date of } \\
\text { assessment }\end{array}$} & $\begin{array}{c}\text { Tract area } \\
\left(\mathbf{k m}^{2}\right)\end{array}$ & $\begin{array}{c}\text { Identified } \\
\text { copper } \\
\text { resources } \\
(\mathbf{M t})\end{array}$ & $\begin{array}{c}\text { Mean estimate of } \\
\text { in-place resources } \\
(\mathbf{M t})\end{array}$ & $\begin{array}{c}\text { Probability of } \mathbf{0} \\
\text { in-place resources } \\
\text { (percent) }\end{array}$ & $\begin{array}{c}\text { Mean estimate of } \\
\text { economic resources } \\
\text { (Mt) }\end{array}$ & $\begin{array}{c}\text { Probability of } \mathbf{0} \\
\text { economic resources } \\
\text { (percent) }\end{array}$ \\
\hline 2008 & 26,080 & 0 & 1.5 & 69 & 0.97 \\
\hline
\end{tabular}

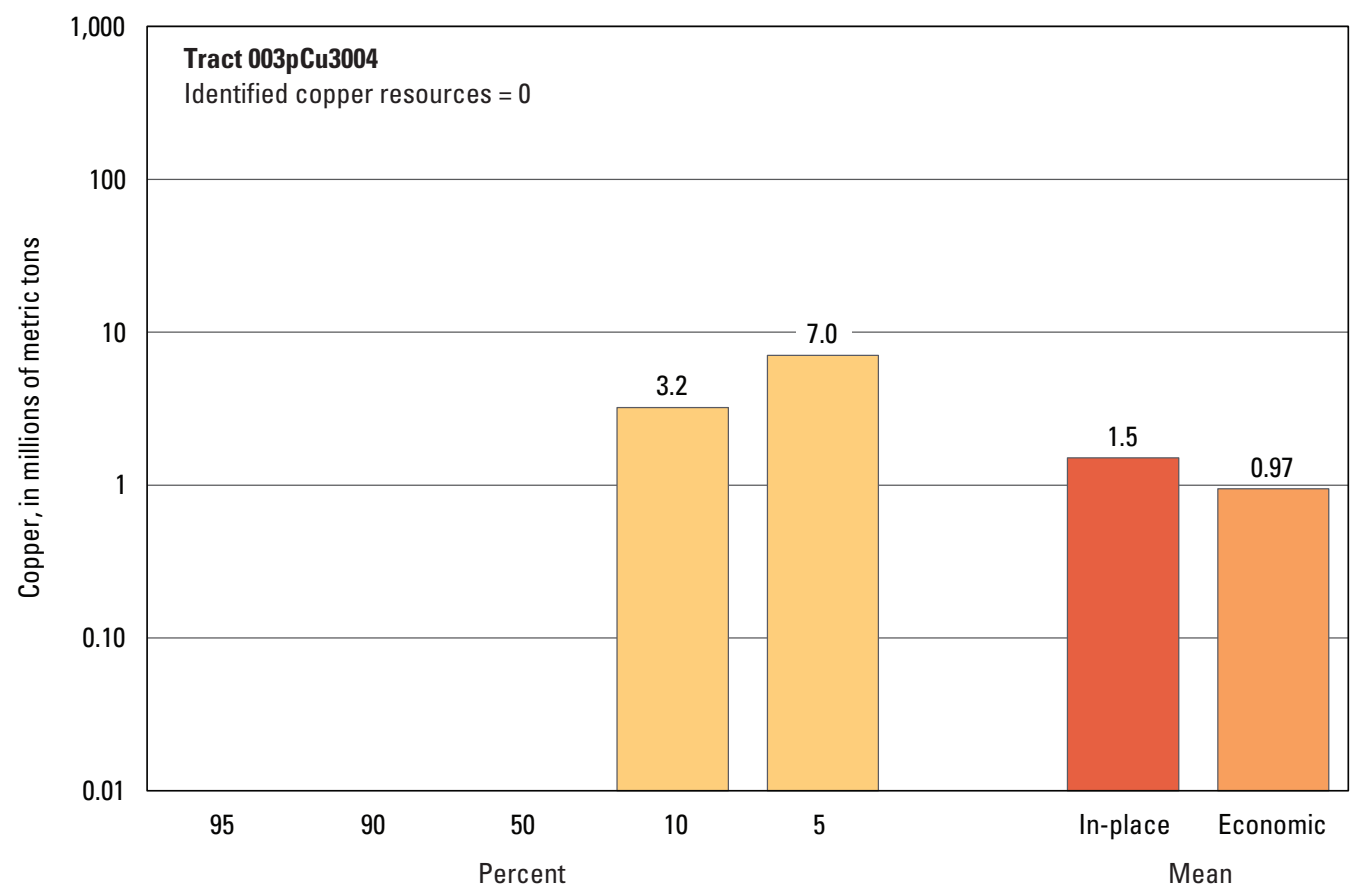

Graph showing the estimated probability distribution of undiscovered copper resources, where each bar represents the minimum amount estimated at the indicated percentage.

\section{Source}

Hammarstrom, Robinson, and others, 2010, Porphyry copper assessment of Mexico: U.S. Geological Survey Scientific Investigations Report 2010-5090-A, http://pubs.usgs.gov/sir/2010/5090/a/. 


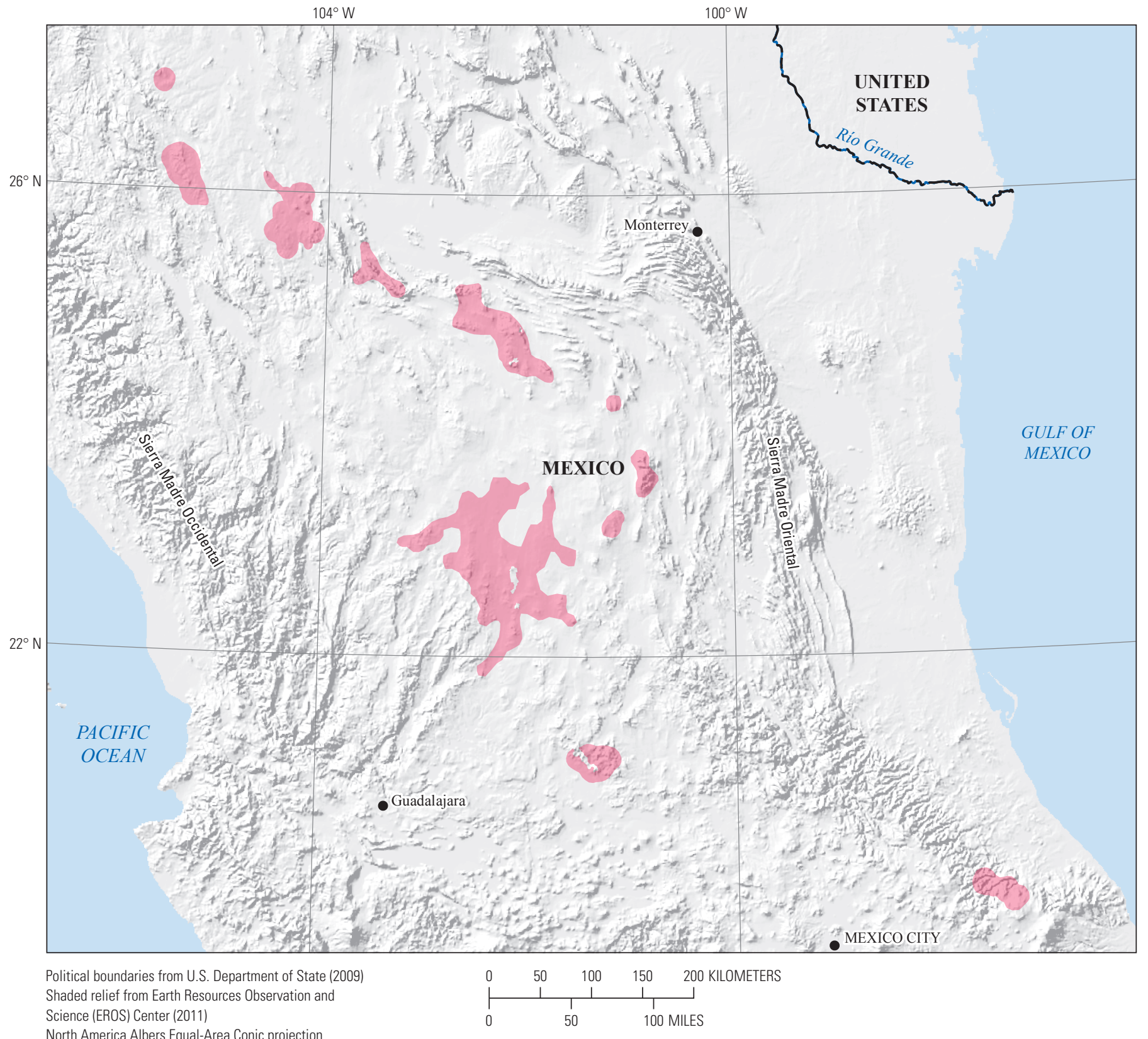

North America Albers Equal-Area Conic projection

Central meridian $101^{\circ} 30^{\prime} \mathrm{W}$.; latitude of origin $40^{\circ} \mathrm{N}$.

EXPLANATION

Assessed porphyry copper tract 003pCu3004

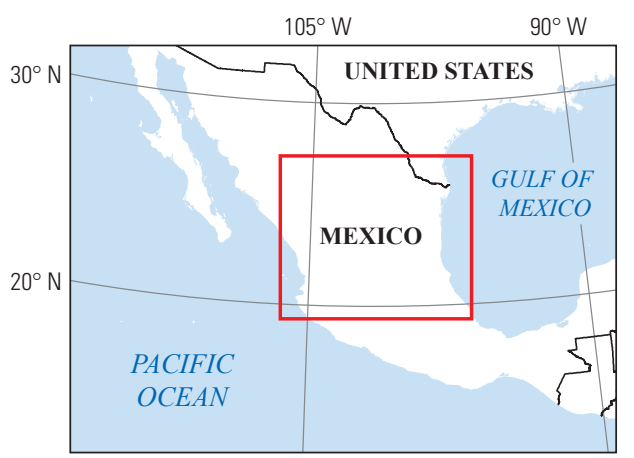




\title{
Plate 35. Porphyry Copper Assessment for Tract 003pCu3002, Coastal Baja California-Mexico
}

\author{
Descriptive model: \\ Porphyry copper models (Cox, 1986a; Berger and others, 2008) \\ Grade and tonnage model: \\ General porphyry copper model (Singer, Berger, and Moring, 2008) \\ Economic filter depth percentages: \\ Skewed deep - 0 to 250 meters (m), 10\%; > 250 to $500 \mathrm{~m}, 30 \%$; >500 m to $1 \mathrm{~km}, 60 \%$ \\ Economic filter cost setting: \\ Geologic feature assessed: \\ Typical cost \\ Jurassic-Late Cretaceous magmatic arc rocks (San Andres-Cedros Complex) along the Pacific \\ coast of Baja California Sur, Mexico \\ Number of known deposits: \\ 0
}

\section{Selected Resource Assessment Results for Porphyry Copper}

[Assessment depth, 1 kilometer ( $\mathrm{km}) ; \mathrm{km}^{2}$, square kilometer; Mt, millions of metric tons]

\begin{tabular}{ccccccc}
\hline $\begin{array}{c}\text { Date of } \\
\text { assessment }\end{array}$ & $\begin{array}{c}\text { Tract area } \\
\left(\mathbf{k m}^{2}\right)\end{array}$ & $\begin{array}{c}\text { Identified } \\
\text { copper } \\
\text { resources } \\
\text { (Mt) }\end{array}$ & $\begin{array}{c}\text { Mean estimate of } \\
\text { in-place resources } \\
(\mathbf{M t})\end{array}$ & $\begin{array}{c}\text { Probability of } \mathbf{0} \\
\text { in-place resources } \\
\text { (percent) }\end{array}$ & $\begin{array}{c}\text { Mean estimate of } \\
\text { economic resources } \\
\text { (Mt) }\end{array}$ & $\begin{array}{c}\text { Probability of 0 } \\
\text { economic resources } \\
\text { (percent) }\end{array}$ \\
\hline 2008 & 2,882 & 0 & 1.5 & 70 & 0.97 \\
\hline
\end{tabular}

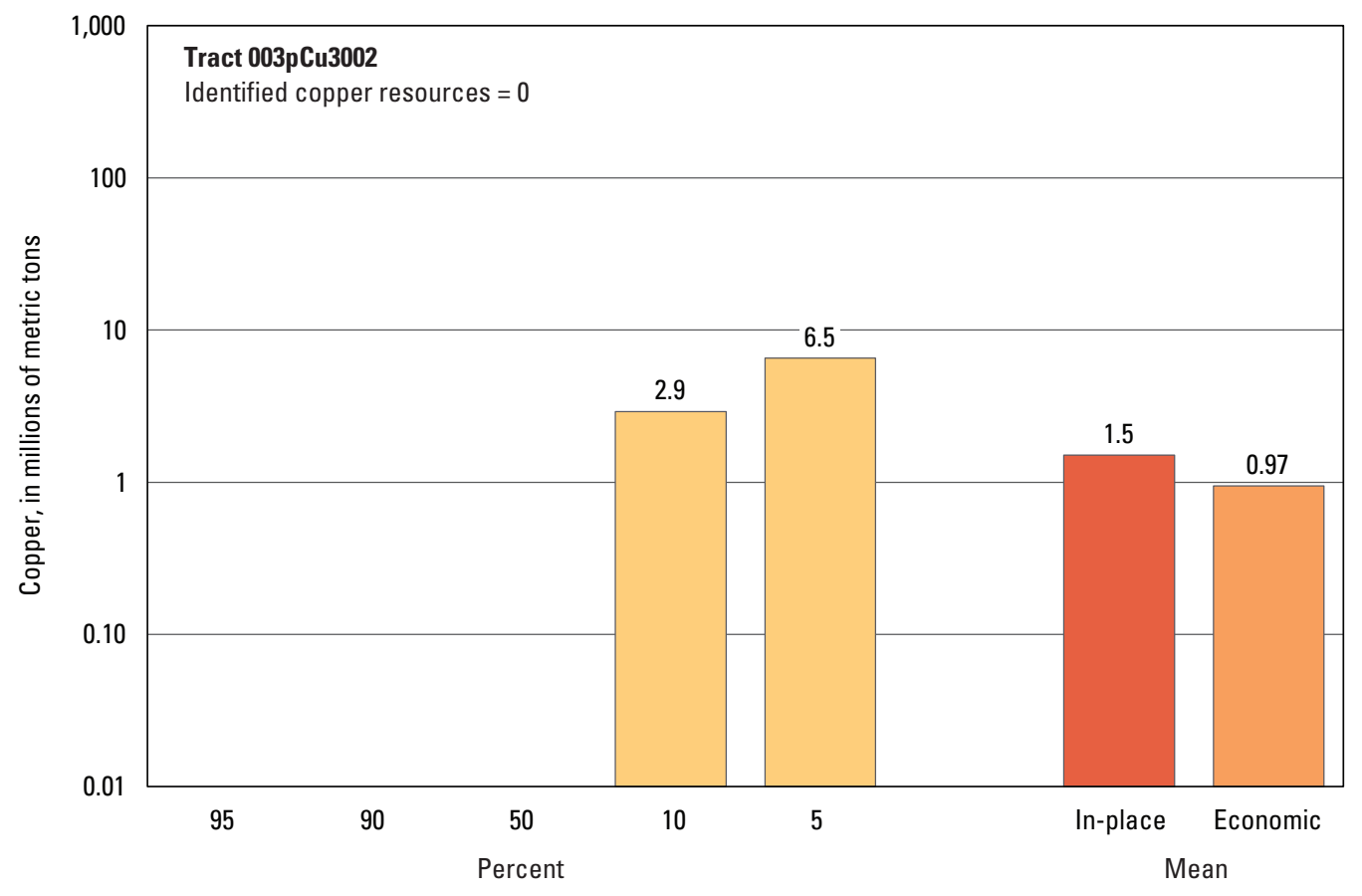

Graph showing the estimated probability distribution of undiscovered copper resources, where each bar represents the minimum amount estimated at the indicated percentage.

\section{Source}

Hammarstrom, Robinson, and others, 2010, Porphyry copper assessment of Mexico: U.S. Geological Survey Scientific Investigations Report 2010-5090-A, http://pubs.usgs.gov/sir/2010/5090/a/. 

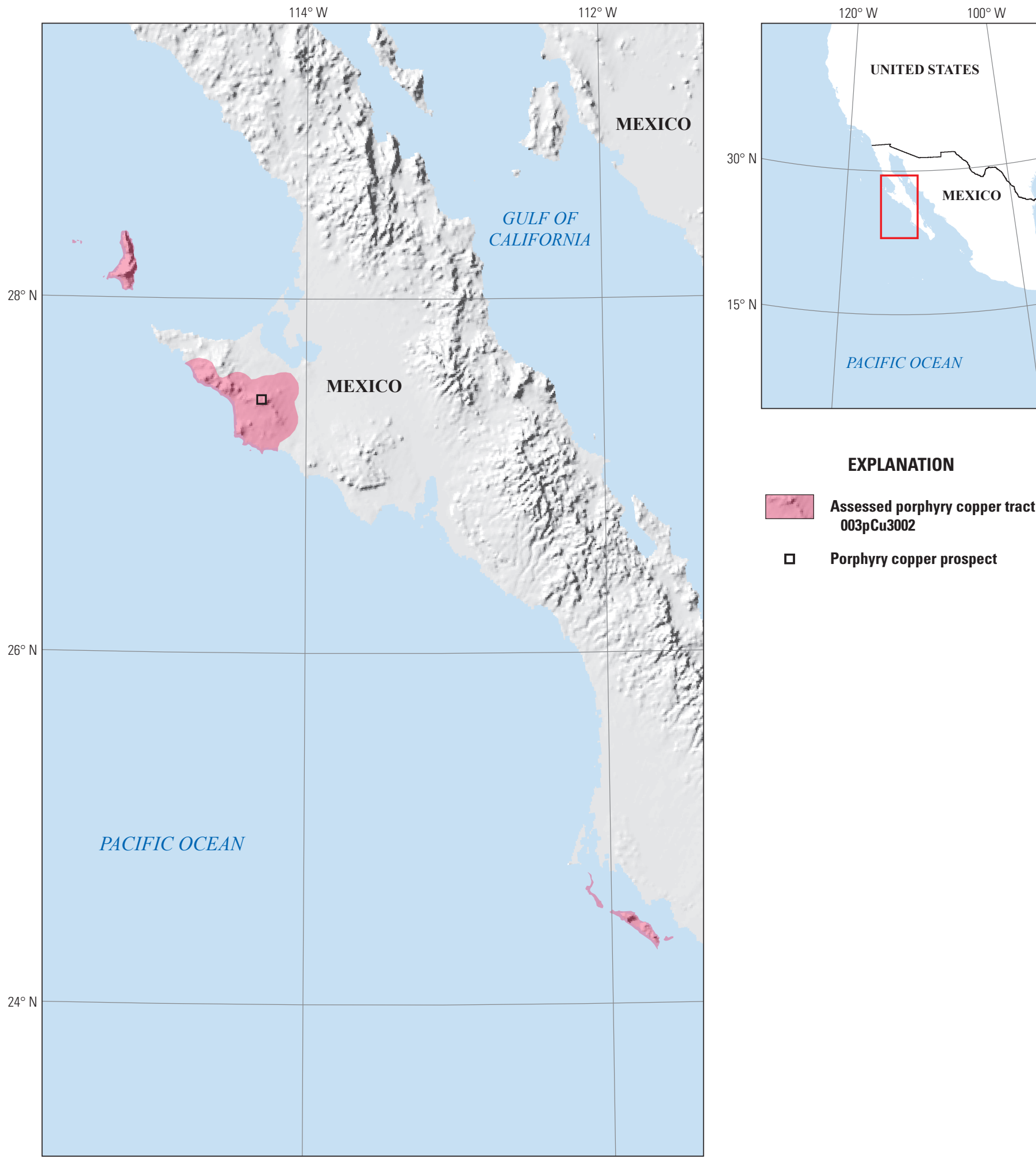

\section{EXPLANATION}

Assessed porphyry copper tract 003pCu3002

ㅁ Porphyry copper prospect

Political boundaries from U.S. Department of State (2009) Shaded relief from Earth Resources Observation and Science (EROS) Center (2011)

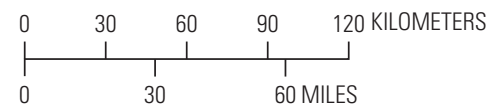

North America Albers Equal-Area Conic projection

Central meridian $113^{\circ} 30^{\prime} \mathrm{W}$.; latitude of origin $40^{\circ} \mathrm{N}$ 


\section{Plate 36. Porphyry Copper Assessment for Tract 003pCu3007x, Western Sierra Madre Occidental and Laramide Central-Mexico and United States}

\author{
Descriptive model: \\ Grade and tonnage model: \\ Economic filter depth percentages: \\ Economic filter cost setting: \\ Geologic feature assessed:
}

Number of known deposits:

\author{
Porphyry copper models (Cox, 1986a; Berger and others, 2008) \\ General porphyry copper model (Singer, Berger, and Moring, 2008) \\ Default -0 to 250 meters (m), 25\%; > 250 to $500 \mathrm{~m}, 25 \%$; $>500 \mathrm{~m}$ to $1 \mathrm{~km}, 50 \%$ \\ Typical cost \\ Belt of Late Cretaceous to middle Eocene (Laramide) magmatic arc rocks in the Sierra Madre \\ Occidental, the eastern Mexican Basin and Range, and the Mesa Central of north-central \\ Mexico and extensions north into the United States
}

46

\section{Selected Resource Assessment Results for Porphyry Copper}

[Assessment depth, 1 kilometer $(\mathrm{km}) ; \mathrm{km}^{2}$, square kilometer; Mt, millions of metric tons]

\begin{tabular}{|c|c|c|c|c|c|c|}
\hline \multirow[b]{2}{*}{$\begin{array}{c}\text { Date of } \\
\text { assessment }^{*}\end{array}$} & \multirow[b]{2}{*}{$\begin{array}{c}\text { Tract area } \\
\quad\left(\mathrm{km}^{2}\right)\end{array}$} & \multirow{2}{*}{$\begin{array}{l}\text { Identified } \\
\text { copper } \\
\text { resources } \\
\text { (Mt) }\end{array}$} & \multicolumn{4}{|c|}{ Undiscovered copper resource estimates } \\
\hline & & & $\begin{array}{l}\text { Mean estimate of } \\
\text { in-place resources } \\
\text { (Mt) }\end{array}$ & $\begin{array}{c}\text { Probability of } 0 \\
\text { in-place resources } \\
\text { (percent) }\end{array}$ & $\begin{array}{l}\text { Mean estimate of } \\
\text { economic resources } \\
\text { (Mt) }\end{array}$ & $\begin{array}{c}\text { Probability of } 0 \\
\text { economic resources } \\
\text { (percent) }\end{array}$ \\
\hline 2012 & 148,105 & 150 & 62 & 1 & 42 & 1 \\
\hline
\end{tabular}

"Updated in 2012; see text in chapter A.

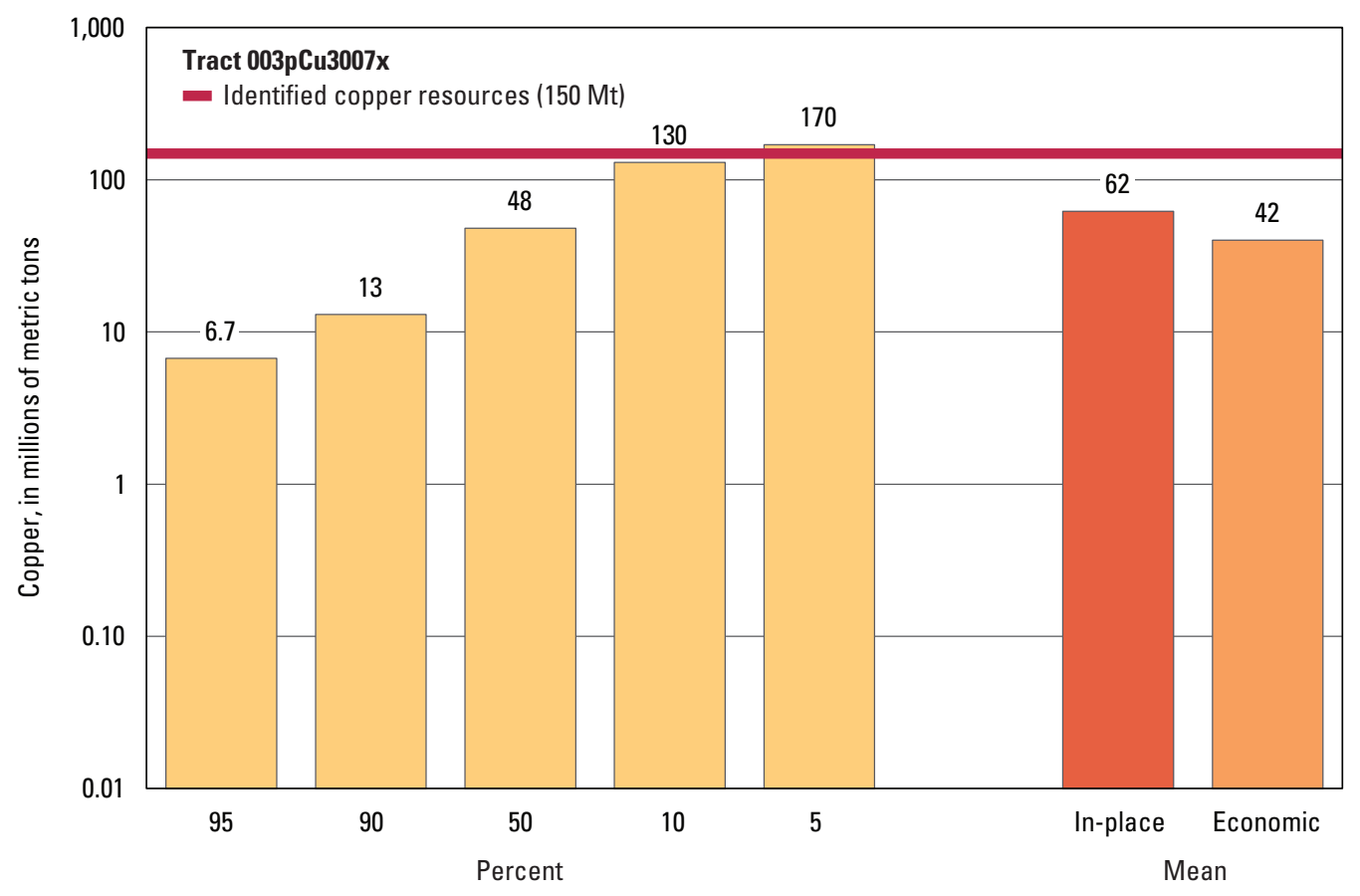

Graph showing the estimated probability distribution of undiscovered copper resources, where each bar represents the minimum amount estimated at the indicated percentage.

\section{Sources}

Hammarstrom, Robinson, and others, 2010, Porphyry copper assessment of Mexico: U.S. Geological Survey Scientific Investigations Report 2010-5090-A, http://pubs.usgs.gov/sir/2010/5090/a/.

U.S. Geological Survey National Mineral Resource Assessment Team, 2002, Assessment of undiscovered deposits of gold, silver, copper, lead, and zinc in the United States: U.S. Geological Survey Open-File Report 02-198, http://pubs.usgs.gov/of/2002/of02-198/. 


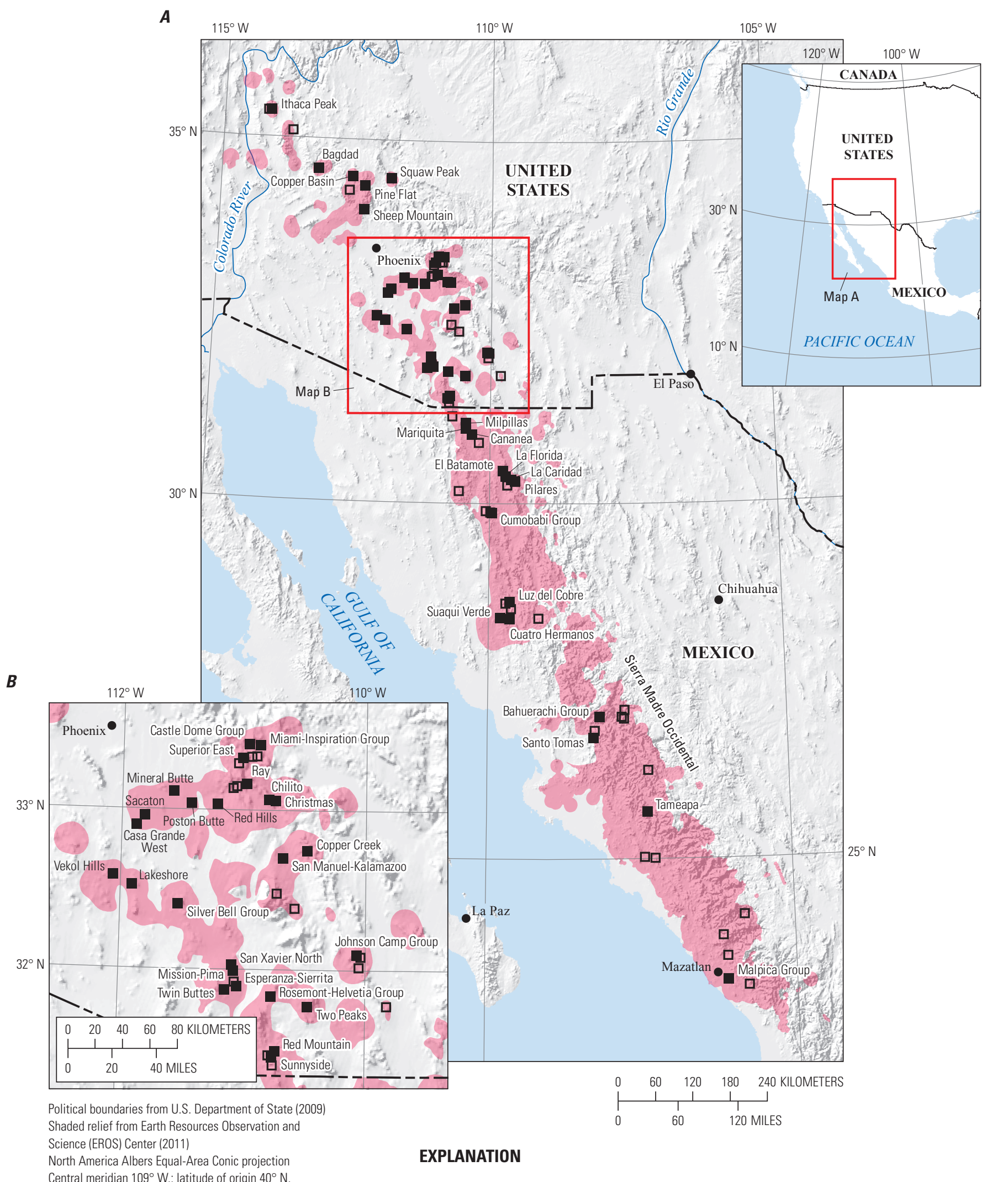

Mission-Pima San Xavier North

Ay Assessed porphyry copper tract 003pCu3007x

- Porphyry copper deposit

Porphyry copper prospect 


\section{Plate 37. Porphyry Copper Assessment for Tract 003pCu3008, Laramide Central Plateau-Mexico}

\section{Descriptive model:}

Grade and tonnage model:

Economic filter depth percentages:

Economic filter cost setting:

Geologic feature assessed:

Number of known deposits:
Porphyry copper models (Cox, 1986a; Berger and others, 2008)

General porphyry copper model (Singer, Berger, and Moring, 2008)

Skewed deep - 0 to 250 meters (m), 10\%; > 250 to $500 \mathrm{~m}, 30 \%$; >500 m to $1 \mathrm{~km}, 60 \%$

Typical cost

Belt of Late Cretaceous to middle Eocene (Laramide) magmatic arc rocks in the eastern part of the Sierra Madre Occidental, the eastern Mexican Basin and Range, and the Mesa Central of northern Mexico

0

\section{Selected Resource Assessment Results for Porphyry Copper}

[Assessment depth, 1 kilometer $(\mathrm{km}) ; \mathrm{km}^{2}$, square kilometer; Mt, millions of metric tons]

\begin{tabular}{|c|c|c|c|c|c|c|}
\hline \multirow[b]{2}{*}{$\begin{array}{c}\text { Date of } \\
\text { assessment }\end{array}$} & \multirow[b]{2}{*}{$\begin{array}{c}\text { Tract area } \\
\quad\left(\mathbf{k m}^{2}\right)\end{array}$} & \multirow{2}{*}{$\begin{array}{l}\text { Identified } \\
\text { copper } \\
\text { resources } \\
\text { (Mt) }\end{array}$} & \multicolumn{4}{|c|}{ Undiscovered copper resource estimates } \\
\hline & & & $\begin{array}{l}\text { Mean estimate of } \\
\text { in-place resources } \\
\text { (Mt) }\end{array}$ & $\begin{array}{c}\text { Probability of } 0 \\
\text { in-place resources } \\
\text { (percent) }\end{array}$ & $\begin{array}{c}\text { Mean estimate of } \\
\text { economic resources } \\
\text { (Mt) }\end{array}$ & $\begin{array}{c}\text { Probability of } 0 \\
\text { economic resources } \\
\text { (percent) }\end{array}$ \\
\hline 2008 & 58,724 & 0 & 20 & 4 & 13 & 22 \\
\hline
\end{tabular}

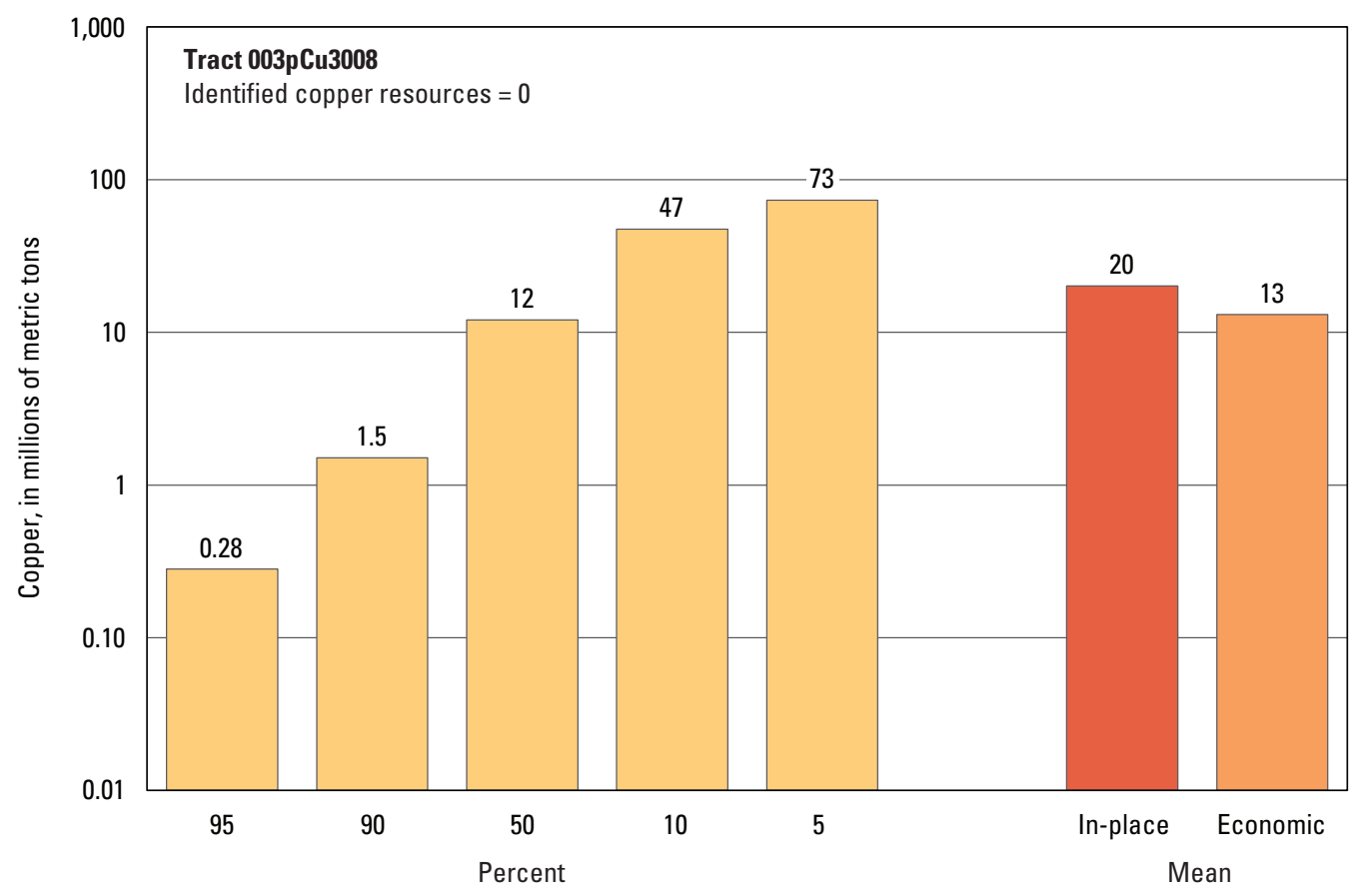

Graph showing the estimated probability distribution of undiscovered copper resources, where each bar represents the minimum amount estimated at the indicated percentage.

\section{Source}

Hammarstrom, Robinson, and others, 2010, Porphyry copper assessment of Mexico: U.S. Geological Survey Scientific Investigations Report 2010-5090-A, http://pubs.usgs.gov/sir/2010/5090/a/. 

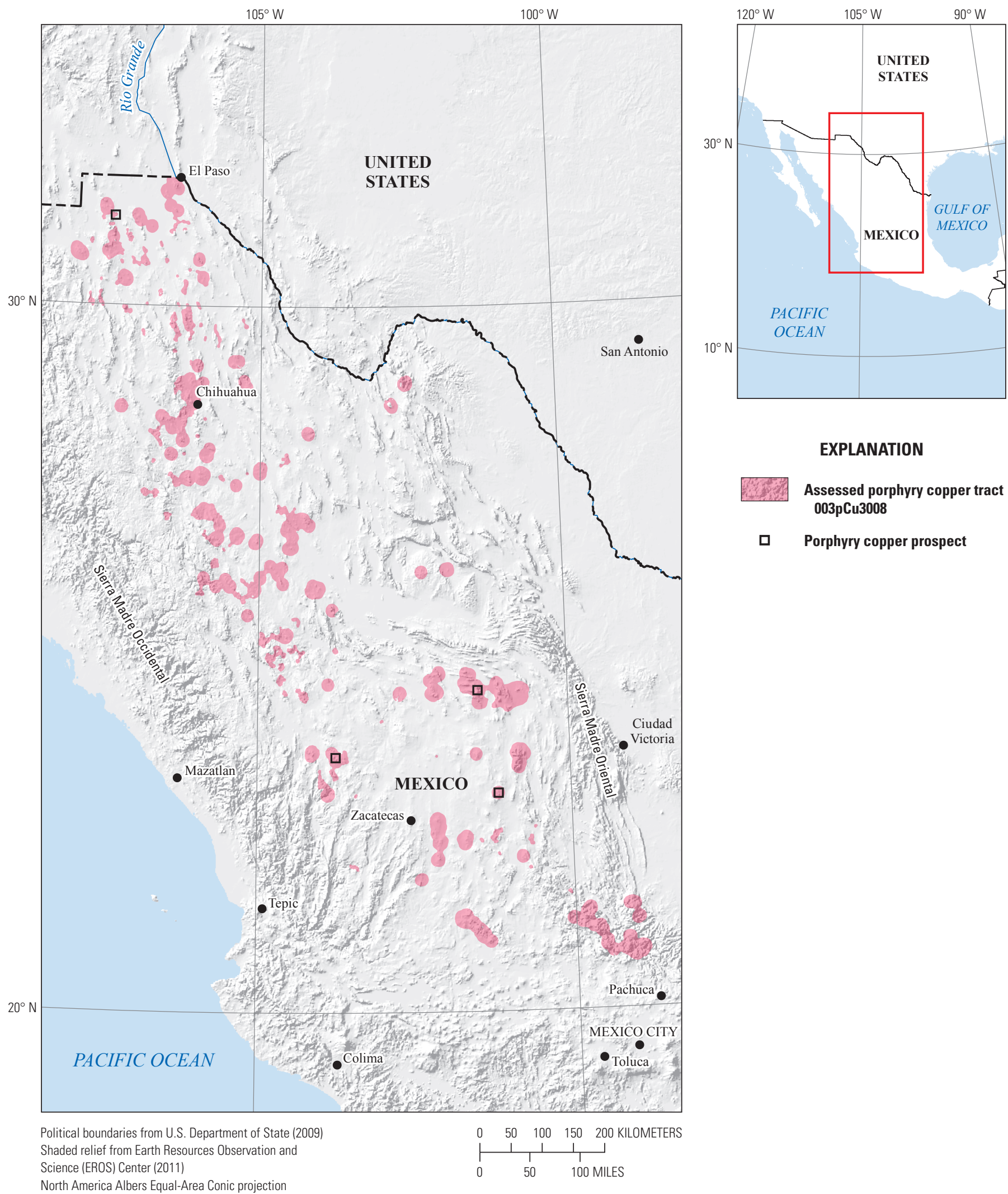

\section{EXPLANATION}

1.7 Assessed porphyry copper tract $003 p \mathrm{pu} 3008$

ㅁ Porphyry copper prospect 


\section{Plate 38. Porphyry Copper Assessment for Tract 003pCu3009x, Tertiary Central Plateau and Rocky Mountains-Mexico and United States}

\author{
Descriptive model: \\ Grade and tonnage model: \\ Economic filter depth percentages: \\ Economic filter cost setting: \\ Geologic feature assessed:
}

Number of known deposits:

\author{
Porphyry copper models (Cox, 1986a; Berger and others, 2008) \\ Porphyry copper, copper-gold subtype model (Singer, Berger, and Moring, 2008) \\ Skewed deep-0 to 250 meters (m), 10\%; > 250 to $500 \mathrm{~m}, 30 \%$; >500 m to $1 \mathrm{~km}, 60 \%$ \\ Typical cost \\ Middle Tertiary intrusive and volcanic rocks associated with the post-Laramide stage of \\ magmatism in northern Mexico and mid-Tertiary volcanic fields associated with \\ postsubduction extension in the eastern Rocky Mountains in the United States
}

0

\section{Selected Resource Assessment Results for Porphyry Copper}

[Assessment depth, 1 kilometer $(\mathrm{km}) ; \mathrm{km}^{2}$, square kilometer; Mt, millions of metric tons]

\begin{tabular}{|c|c|c|c|c|c|c|}
\hline \multirow[b]{2}{*}{$\begin{array}{c}\text { Date of } \\
\text { assessment }^{*}\end{array}$} & \multirow[b]{2}{*}{$\begin{array}{c}\text { Tract area } \\
\left(\mathbf{k m}^{2}\right)\end{array}$} & \multirow{2}{*}{$\begin{array}{l}\text { Identified } \\
\text { copper } \\
\text { resources } \\
\text { (Mt) }\end{array}$} & \multicolumn{4}{|c|}{ Undiscovered copper resource estimates } \\
\hline & & & $\begin{array}{l}\text { Mean estimate of } \\
\text { in-place resources } \\
\text { (Mt) }\end{array}$ & $\begin{array}{c}\text { Probability of } 0 \\
\text { in-place resources } \\
\text { (percent) }\end{array}$ & $\begin{array}{c}\text { Mean estimate of } \\
\text { economic resources } \\
\text { (Mt) }\end{array}$ & $\begin{array}{c}\text { Probability of } 0 \\
\text { economic resources } \\
\text { (percent) }\end{array}$ \\
\hline 2012 & 374,235 & 0 & 22 & 7 & 15 & 53 \\
\hline
\end{tabular}

"Updated in 2012; see text in chapter A.

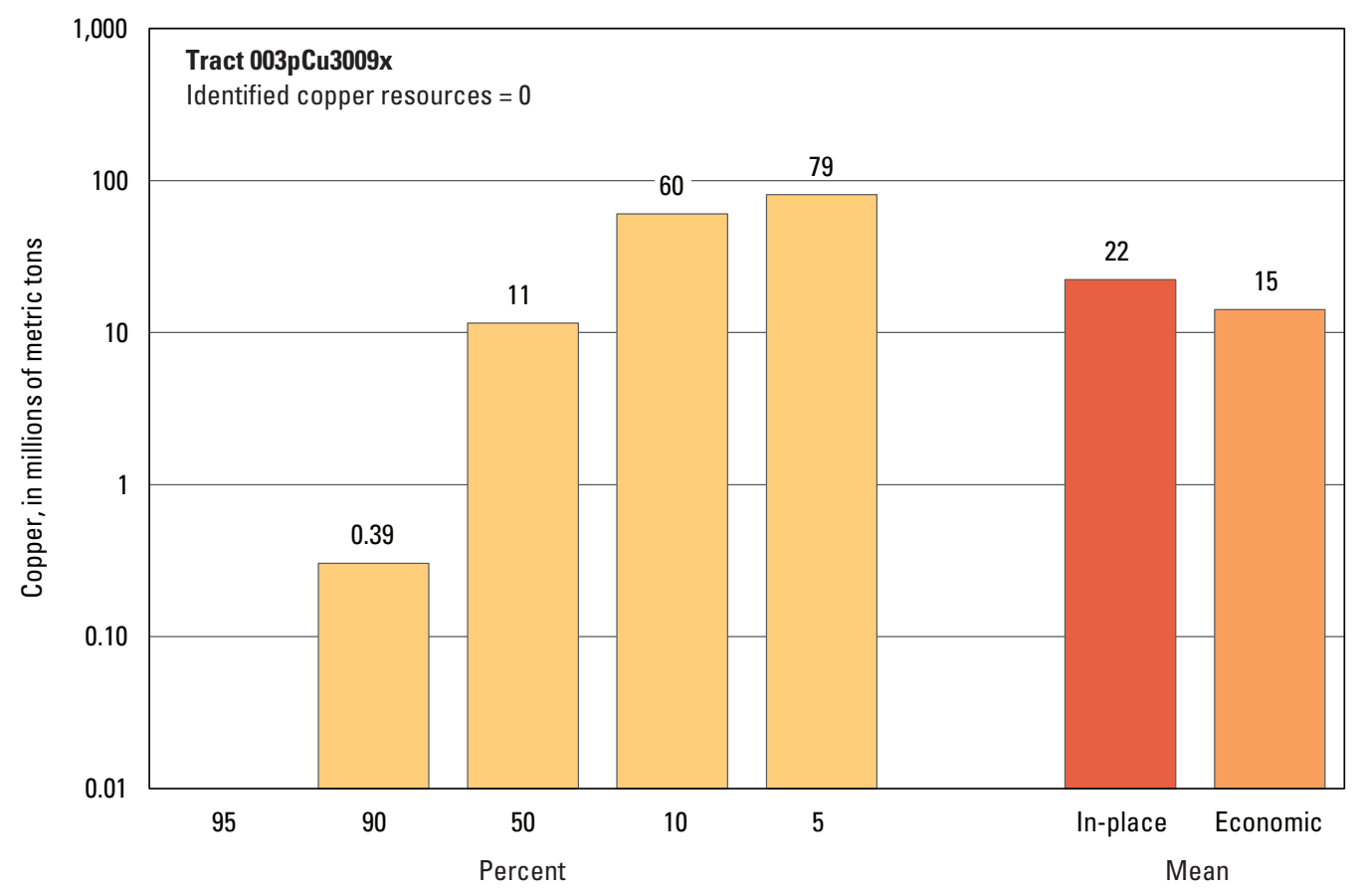

Graph showing the estimated probability distribution of undiscovered copper resources, where each bar represents the minimum amount estimated at the indicated percentage.

\section{Sources}

Hammarstrom, Robinson, and others, 2010, Porphyry copper assessment of Mexico: U.S. Geological Survey Scientific Investigations Report 2010-5090-A, http://pubs.usgs.gov/sir/2010/5090/a/.

U.S. Geological Survey National Mineral Resource Assessment Team, 2002, Assessment of undiscovered deposits of gold, silver, copper, lead, and zinc in the United States: U.S. Geological Survey Open-File Report 02-198, http://pubs.usgs.gov/of/2002/of02-198/. 

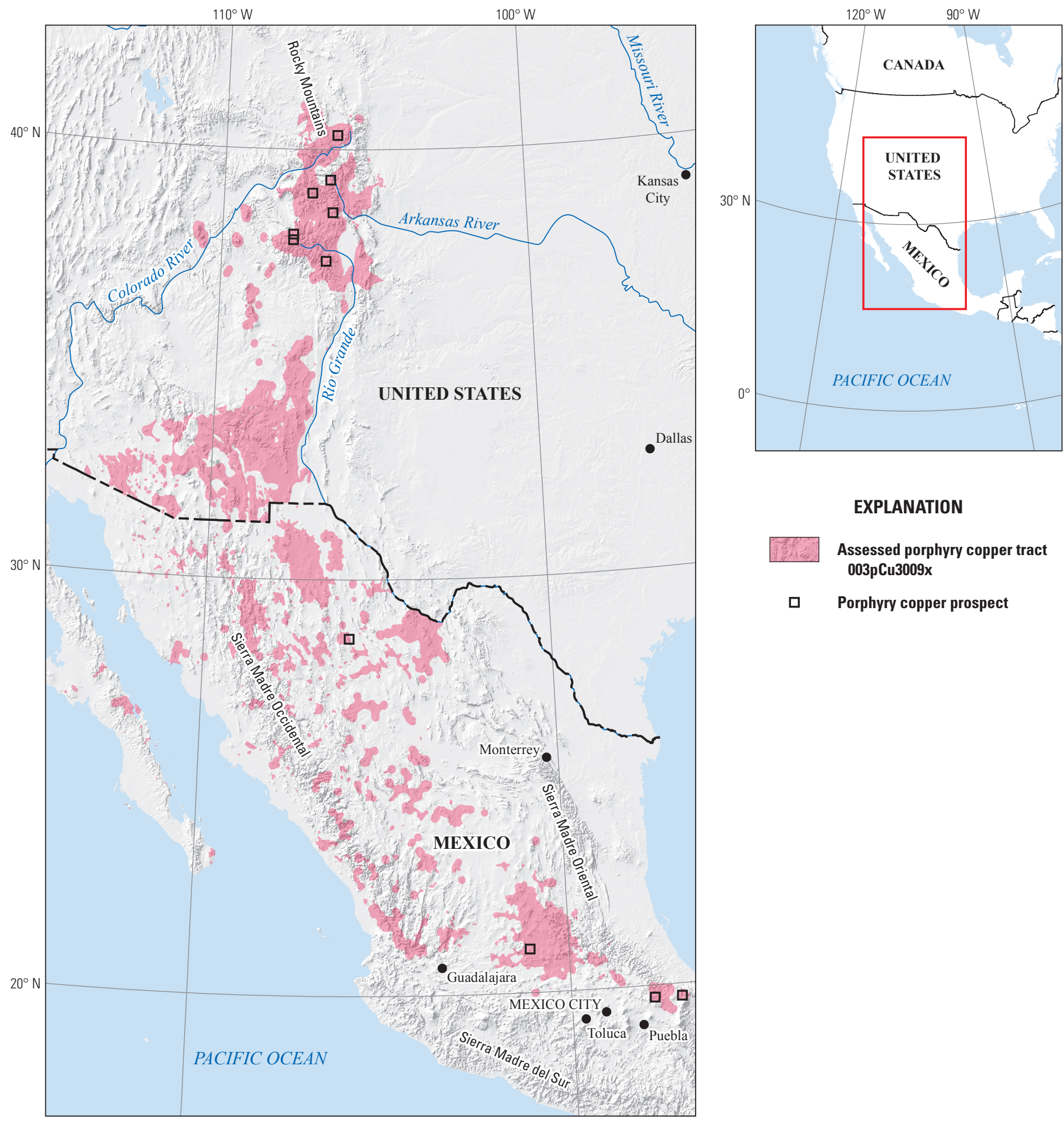

\section{Assessed porphyry copper tract 003pCu3009x}

Porphyry copper prospect

Political boundaries from U.S. Department of State (2009) Shaded relief from Earth Resources Observation and Science (EROS) Center (2011)

North America Albers Equal-Area Conic projection Central meridian $105^{\circ} 30^{\prime} \mathrm{W}$.; latitude of origin $40^{\circ} \mathrm{N}$.
$0 \quad 75 \quad 150 \quad 225 \quad 300$ KILOMETERS

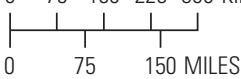




\title{
Plate 39. Porphyry Copper Assessment for Tract 003pCu3010x, Eastern Alkalic Province-Mexico and United States
}

\author{
Descriptive model: \\ Grade and tonnage model: \\ Economic filter depth percentages: \\ Economic filter cost setting: \\ Geologic feature assessed: \\ Number of known deposits:
}

\author{
Porphyry copper-gold model (Cox, 1986b) \\ Porphyry copper, copper-gold subtype model (Singer, Berger, and Moring, 2008) \\ Default -0 to 250 meters (m), $25 \%$; $>250$ to $500 \mathrm{~m}, 25 \% ;>500 \mathrm{~m}$ to $1 \mathrm{~km}, 50 \%$ \\ Typical cost \\ A belt of Tertiary alkalic granitic rocks associated with back-arc or postsubduction extension \\ 1
}

\section{Selected Resource Assessment Results for Porphyry Copper}

[Assessment depth, 1 kilometer ( $\mathrm{km}) ; \mathrm{km}^{2}$, square kilometer; Mt, millions of metric tons]

\begin{tabular}{ccccccc}
\hline \multirow{2}{*}{$\begin{array}{c}\text { Date of } \\
\text { assessment }\end{array}$} & $\begin{array}{c}\text { Tract area } \\
\left.\mathbf{( k m}^{2}\right)\end{array}$ & $\begin{array}{c}\text { Identified } \\
\text { copper } \\
\text { resources } \\
(\mathbf{M t})\end{array}$ & $\begin{array}{c}\text { Mean estimate of } \\
\text { in-place resources } \\
(\mathbf{M t})\end{array}$ & $\begin{array}{c}\text { Probability of } \mathbf{0} \\
\text { in-place resources } \\
\text { (percent) }\end{array}$ & $\begin{array}{c}\text { Mean estimate of } \\
\text { economic resources } \\
\text { (Mt) }\end{array}$ & $\begin{array}{c}\text { Probability of } 0 \\
\text { economic resources } \\
\text { (percent) }\end{array}$ \\
\hline 2012 & 137,352 & 0.80 & 15 & 7 & 10 \\
\hline
\end{tabular}

*Updated in 2012; see text in chapter A.

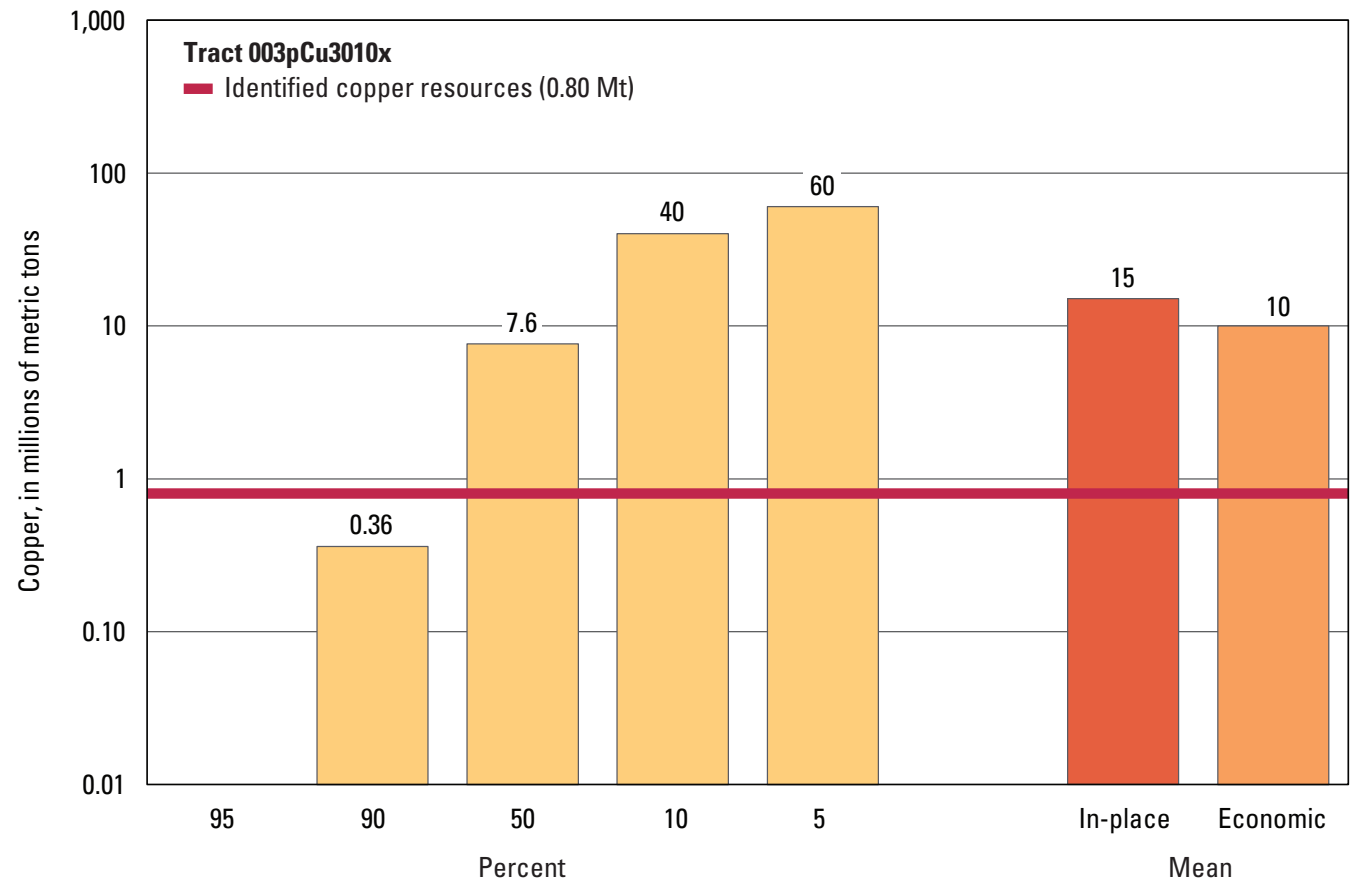

Graph showing the estimated probability distribution of undiscovered copper resources, where each bar represents the minimum amount estimated at the indicated percentage.

\section{Sources}

Hammarstrom, Robinson, and others, 2010, Porphyry copper assessment of Mexico: U.S. Geological Survey Scientific Investigations Report 2010-5090-A, http://pubs.usgs.gov/sir/2010/5090/a/.

U.S. Geological Survey National Mineral Resource Assessment Team, 2002, Assessment of undiscovered deposits of gold, silver, copper, lead, and zinc in the United States: U.S. Geological Survey Open-File Report 02-198, http://pubs.usgs.gov/of/2002/of02-198/. 


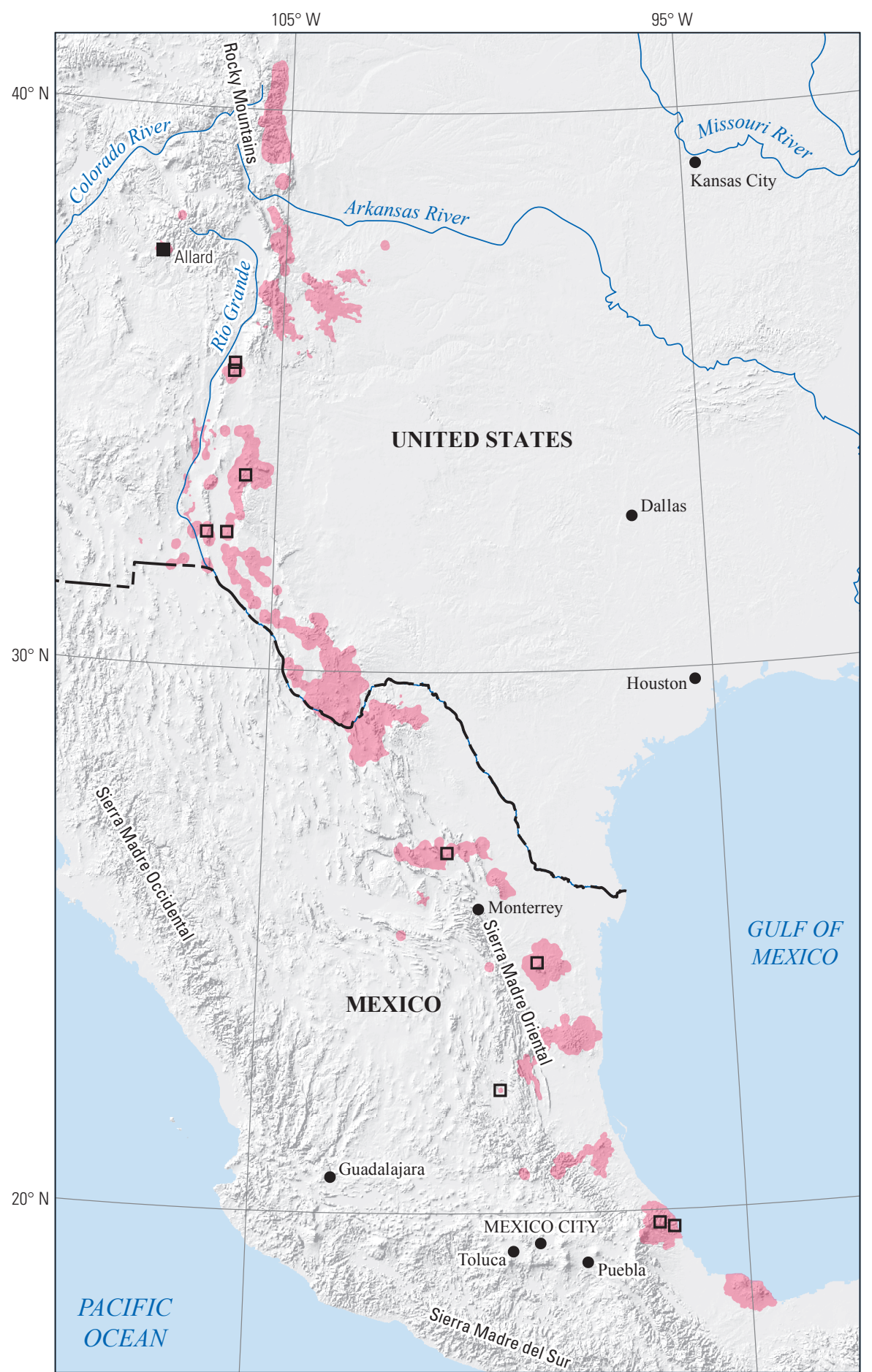

Political boundaries from U.S. Department of State (2009) Shaded relief from Earth Resources Observation and Science (EROS) Center (2011)

North America Albers Equal-Area Conic projection Central meridian $101^{\circ} \mathrm{W}$.; latitude of origin $40^{\circ} \mathrm{N}$.

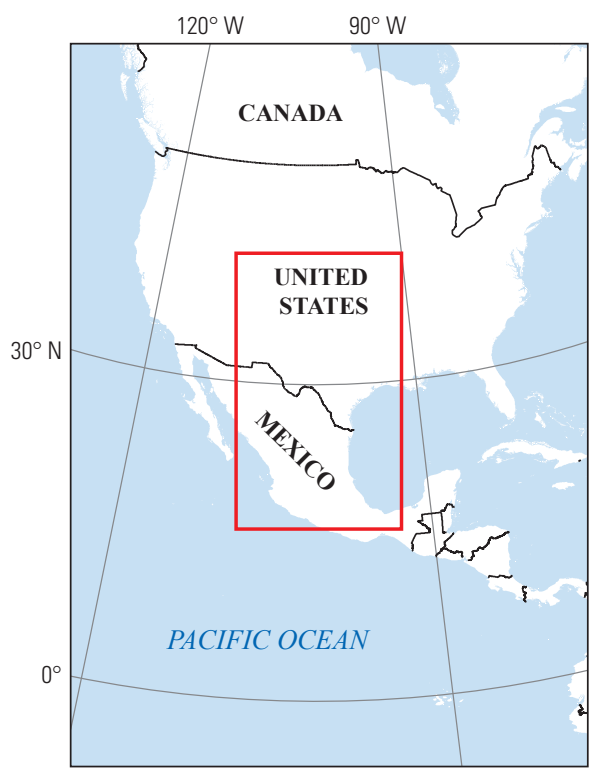

EXPLANATION

Assessed porphyry copper tract 003pCu3010x

- Porphyry copper deposit

ㅁ Porphyry copper prospect 


\title{
Plate 40. Porphyry Copper Assessment for Tract 003pCu3001x, Southern California Batholith-Mexico and United States
}

\author{
Descriptive model: \\ Porphyry copper models (Cox, 1986a; Berger and others, 2008) \\ Grade and tonnage model: \\ General porphyry copper model (Singer, Berger, and Moring, 2008) \\ Economic filter depth percentages: \\ Economic filter cost setting: \\ Geologic feature assessed: \\ Skewed shallow-0 to 250 meters (m), $35 \%$; $>250$ to $500 \mathrm{~m}, 25 \%$; $>500 \mathrm{~m}$ to $1 \mathrm{~km}, 40 \%$ \\ Typical cost \\ Jurassic-Early Cretaceous island arc(s) of western Baja California, including the western part of \\ the Cretaceous Peninsular Ranges batholith and associated volcanic rocks \\ Number of known deposits: \\ 1
}

\section{Selected Resource Assessment Results for Porphyry Copper}

[Assessment depth, 1 kilometer ( $\mathrm{km}) ; \mathrm{km}^{2}$, square kilometer; Mt, millions of metric tons]

\begin{tabular}{ccccccc}
\hline $\begin{array}{c}\text { Date of } \\
\text { assessment }\end{array}$ & $\begin{array}{c}\text { Tract area } \\
\left.\mathbf{( k m}^{2}\right)\end{array}$ & $\begin{array}{c}\text { Identified } \\
\text { copper } \\
\text { resources } \\
\text { (Mt) }\end{array}$ & $\begin{array}{c}\text { Mean estimate of } \\
\text { in-place resources } \\
\text { (Mt) }\end{array}$ & $\begin{array}{c}\text { Probability of } \mathbf{0} \\
\text { in-place resources } \\
\text { (percent) }\end{array}$ & $\begin{array}{c}\text { Mean estimate of } \\
\text { economic resources } \\
\text { (Mt) }\end{array}$ & $\begin{array}{c}\text { Probability of } \mathbf{0} \\
\text { economic resources } \\
\text { (percent) }\end{array}$ \\
\hline 2012 & 40,228 & 5.3 & 3.3 & 60 & 2.3 \\
\hline
\end{tabular}

"Updated in 2012; see text in chapter A.

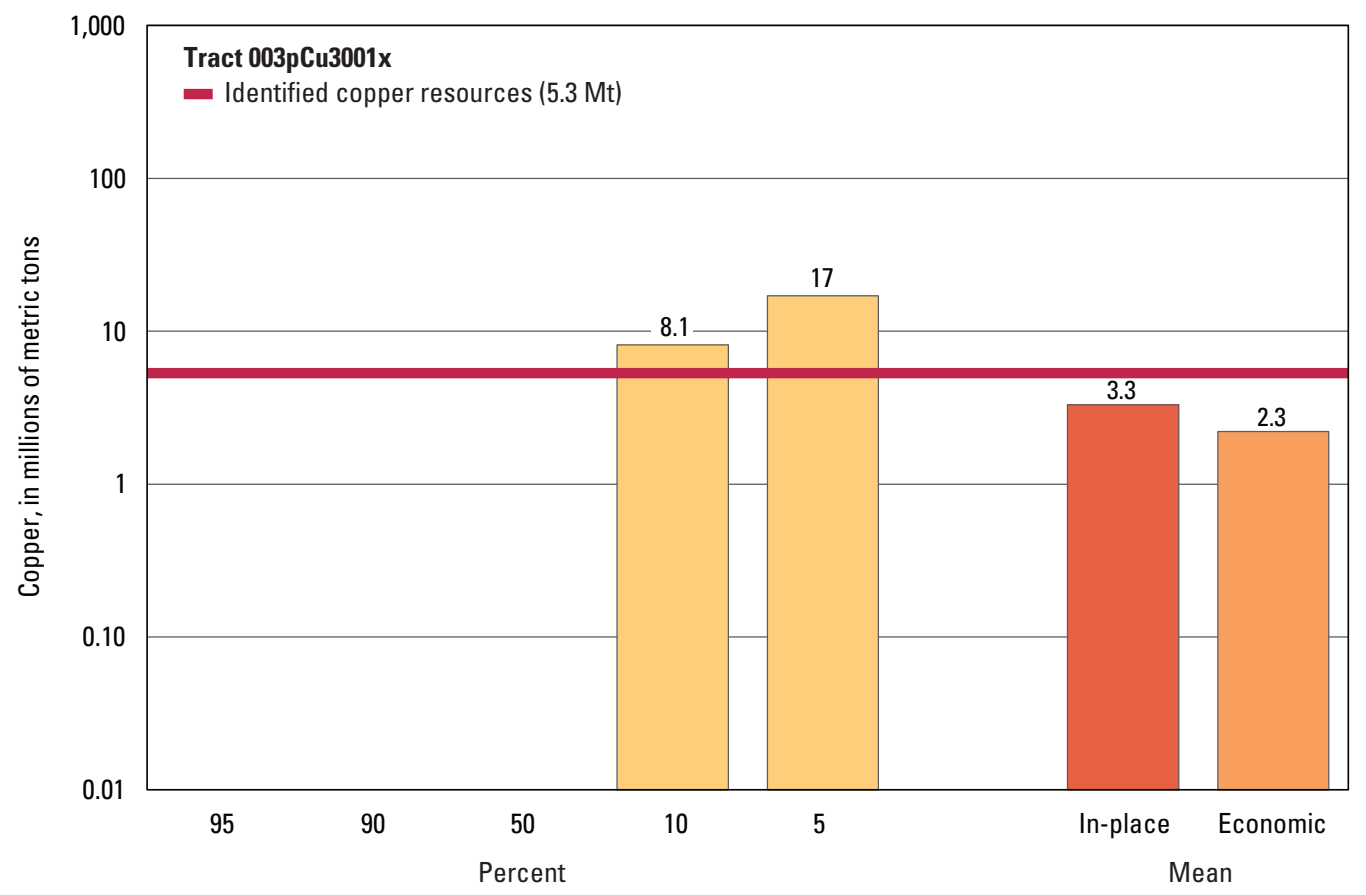

Graph showing the estimated probability distribution of undiscovered copper resources, where each bar represents the minimum amount estimated at the indicated percentage.

\section{Sources}

Hammarstrom, Robinson, and others, 2010, Porphyry copper assessment of Mexico: U.S. Geological Survey Scientific Investigations Report 2010-5090-A, http://pubs.usgs.gov/sir/2010/5090/a/.

U.S. Geological Survey National Mineral Resource Assessment Team, 2002, Assessment of undiscovered deposits of gold, silver, copper, lead, and zinc in the United States: U.S. Geological Survey Open-File Report 02-198, http://pubs.usgs.gov/of/2002/of02-198/. 

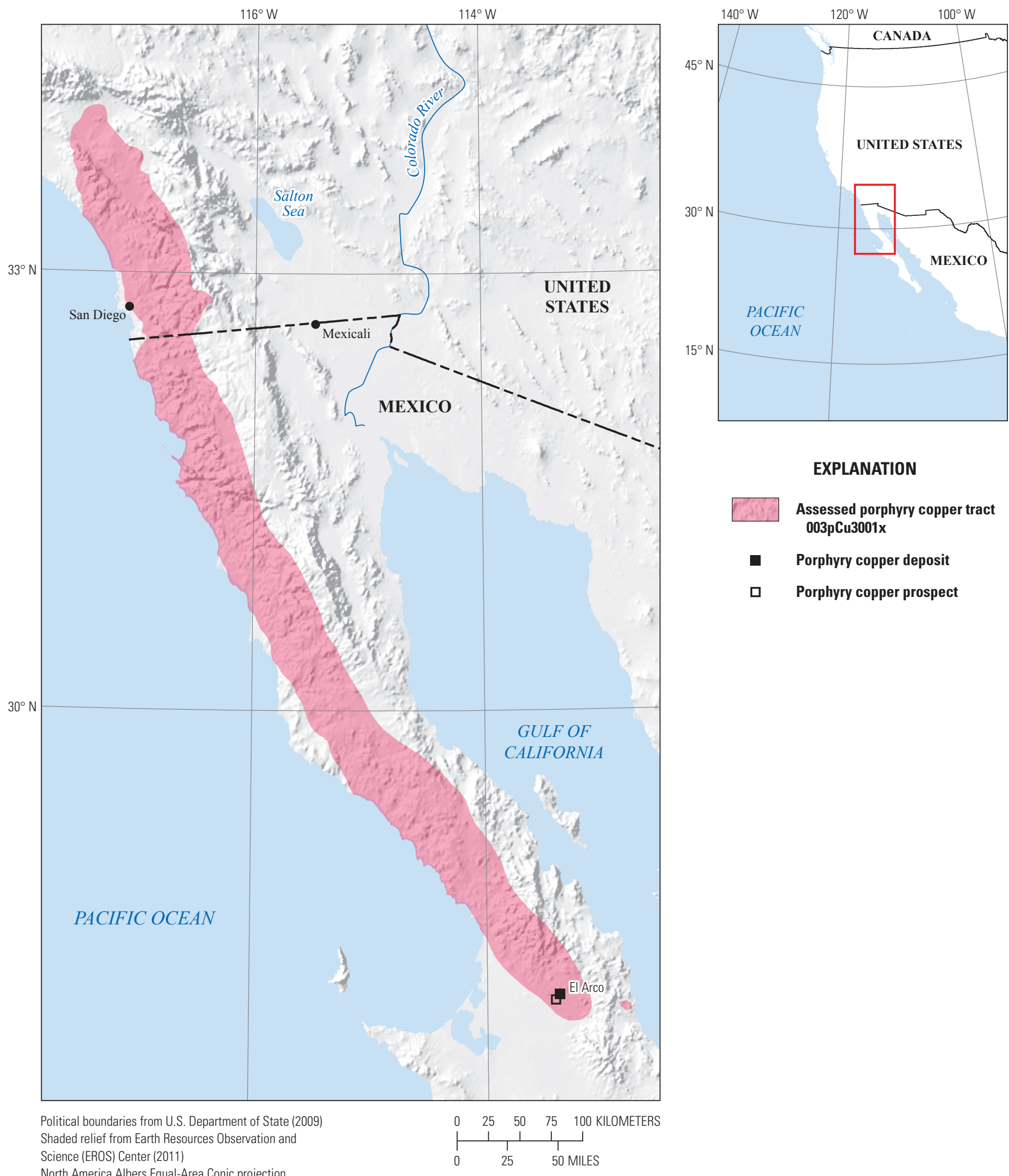

\section{EXPLANATION}

Assessed porphyry copper tract 003pCu3001x

- Porphyry copper deposit

Porphyry copper prospect

North America Albers Equal-Area Conic projection

Central meridian $115^{\circ} \mathrm{W}$; ; latitude of origin $40^{\circ} \mathrm{N}$. 


\title{
Plate 41. Porphyry Copper Assessment for Tract 003pCu3006x, Western Mexican Basin and Range and Laramide Southwest—Mexico and United States
}

\author{
Descriptive model: \\ Porphyry copper models (Cox, 1986a; Berger and others, 2008) \\ Grade and tonnage model: \\ General porphyry copper model (Singer, Berger, and Moring, 2008) \\ Economic filter depth percentages: \\ Economic filter cost setting: \\ Geologic feature assessed: \\ Skewed deep — 0 to 250 meters (m), 10\%; >250 to $500 \mathrm{~m}, 30 \%$; >500 m to $1 \mathrm{~km}, 60 \%$ \\ Typical cost \\ Late Cretaceous to middle Eocene island-arc and continental-arc rocks along the western margin of \\ Mexico and extending north into the United States \\ Number of known deposits: \\ 2
}

\section{Selected Resource Assessment Results for Porphyry Copper}

[Assessment depth, 1 kilometer ( $\mathrm{km}) ; \mathrm{km}^{2}$, square kilometer; Mt, millions of metric tons]

\begin{tabular}{ccccccc}
\hline $\begin{array}{c}\text { Date of } \\
\text { assessment }\end{array}$ & $\begin{array}{c}\text { Tract area } \\
\left.\mathbf{( k m}^{2}\right)\end{array}$ & $\begin{array}{c}\text { Identified } \\
\text { copper } \\
\text { resources } \\
\text { (Mt) }\end{array}$ & $\begin{array}{c}\text { Mean estimate of } \\
\text { in-place resources } \\
\text { (Mt) }\end{array}$ & $\begin{array}{c}\text { Pndiscovered copper resource estimates } \\
\text { in-place resources } \\
\text { (percent) }\end{array}$ & $\begin{array}{c}\text { Mean estimate of } \\
\text { economic resources } \\
\text { (Mt) }\end{array}$ & $\begin{array}{c}\text { Probability of 0 } \\
\text { economic resources } \\
\text { (percent) }\end{array}$ \\
\hline 2012 & 82,624 & 5.4 & 20 & 4 & 13 \\
\hline
\end{tabular}

"Updated in 2012; see text in chapter A.

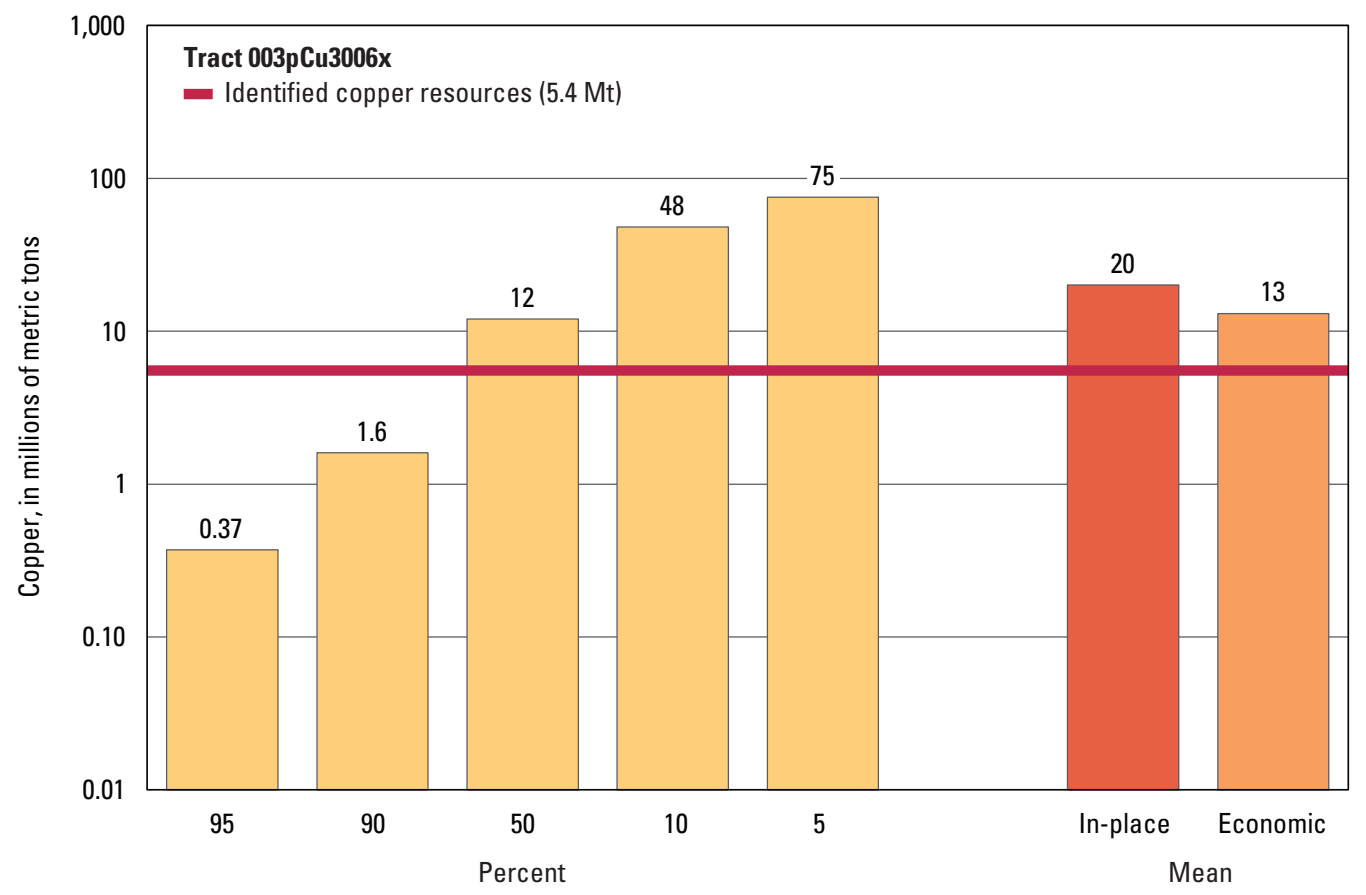

Graph showing the estimated probability distribution of undiscovered copper resources, where each bar represents the minimum amount estimated at the indicated percentage.

\section{Sources}

Hammarstrom, Robinson, and others, 2010, Porphyry copper assessment of Mexico: U.S. Geological Survey Scientific Investigations Report 2010-5090-A, http://pubs.usgs.gov/sir/2010/5090/a/.

U.S. Geological Survey National Mineral Resource Assessment Team, 2002, Assessment of undiscovered deposits of gold, silver, copper, lead, and zinc in the United States: U.S. Geological Survey Open-File Report 02-198, http://pubs.usgs.gov/of/2002/of02-198/. 


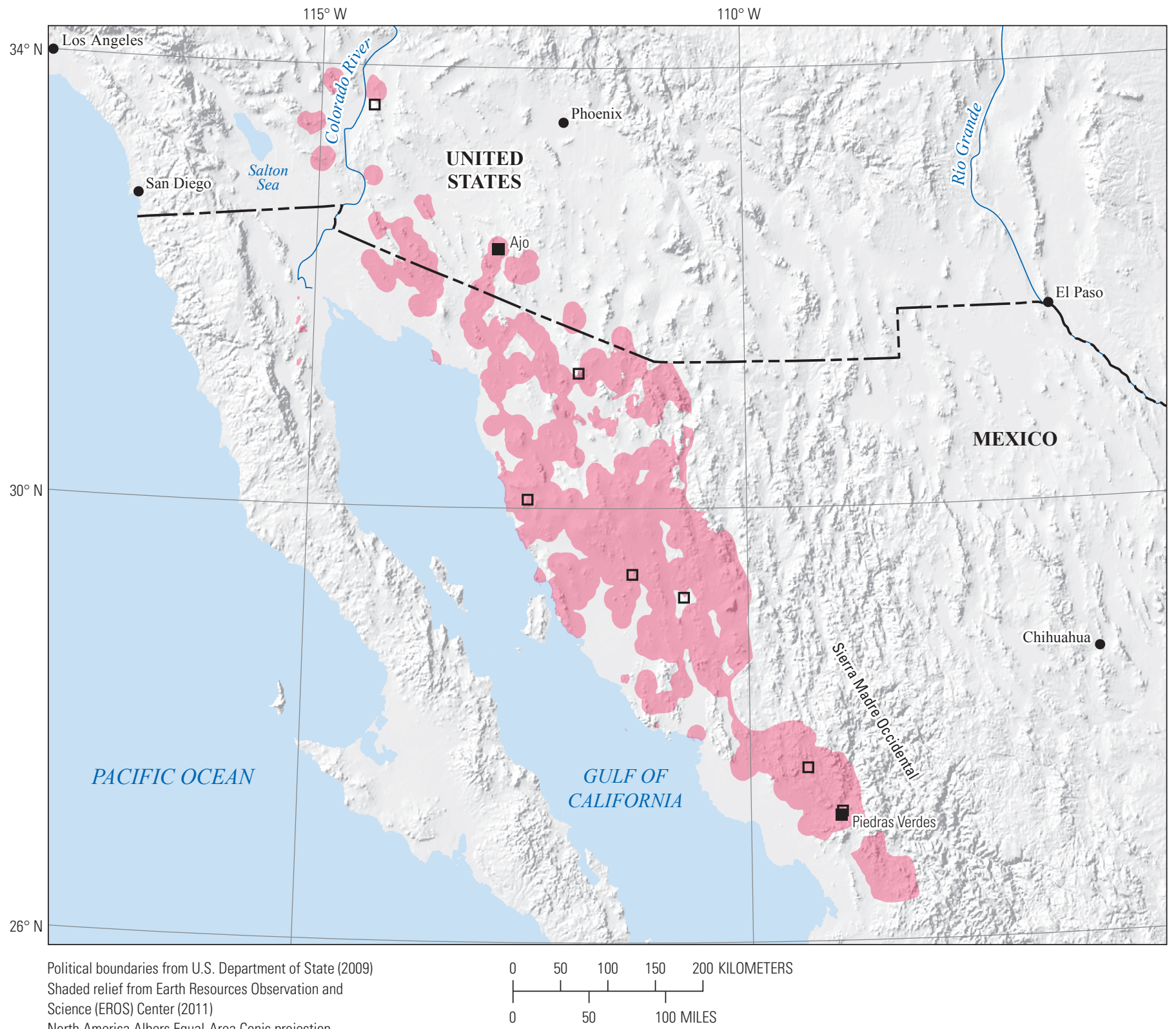

North America Albers Equal-Area Conic projection

Central meridian $111^{\circ} 30^{\prime}$ W.; latitude of origin $40^{\circ} \mathrm{N}$.

\section{EXPLANATION}

Assessed porphyry copper tract 003pCu3006x

- Porphyry copper deposit

․ Porphyry copper prospect

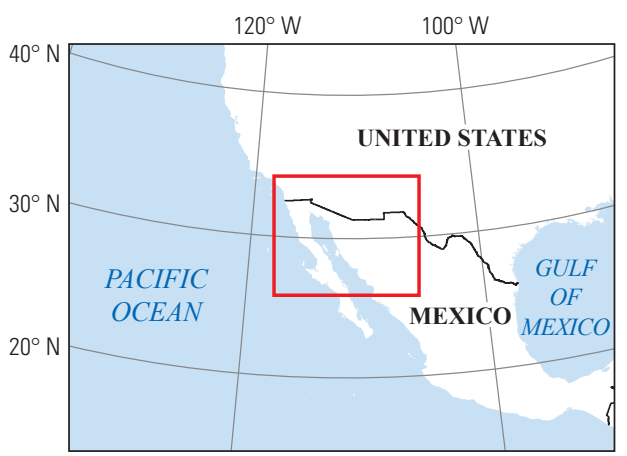




\title{
Plate 42. Porphyry Copper Assessment for Tract 003pCu9008, Southwest Laramide East-United States
}

\author{
Descriptive model: \\ Porphyry copper model (Cox, 1986a) \\ Grade and tonnage model: \\ General porphyry copper model (Singer, Berger, and Moring, 2008) \\ Economic filter depth percentages: \\ Economic filter cost setting: \\ Geologic feature assessed: \\ Default - 0 to 250 meters (m), 25\%; > 250 to $500 \mathrm{~m}, 25 \%$; >500 m to $1 \mathrm{~km}, 50 \%$ \\ Typical cost \\ A composite Laramide age (90 to $40 \mathrm{Ma}$ ) island arc and continental-margin arc that formed during \\ subduction of the Farallon Plate beneath western North America \\ Number of known deposits: \\ 7
}

\section{Selected Resource Assessment Results for Porphyry Copper}

[Assessment depth, 1 kilometer $(\mathrm{km}) ; \mathrm{km}^{2}$, square kilometer; Mt, millions of metric tons]

\begin{tabular}{ccccccc}
\hline $\begin{array}{c}\text { Date of } \\
\text { assessment }\end{array}$ & $\begin{array}{c}\text { Tract area } \\
\left.\mathbf{( k m}^{2}\right)\end{array}$ & $\begin{array}{c}\text { Identified } \\
\text { copper } \\
\text { resources } \\
\text { (Mt) }\end{array}$ & $\begin{array}{c}\text { Mean estimate of } \\
\text { in-place resources } \\
\text { (Mt) }\end{array}$ & $\begin{array}{c}\text { Probability of } 0 \\
\text { in-place resources } \\
\text { (percent) }\end{array}$ & $\begin{array}{c}\text { Mean estimate of } \\
\text { economic resources } \\
\text { (Mt) }\end{array}$ & $\begin{array}{c}\text { Probability of 0 } \\
\text { economic resources } \\
\text { (percent) }\end{array}$ \\
\hline 2012 & 7,076 & 90 & 11 & 7 & 7.4 \\
\hline
\end{tabular}

"Updated by the assessment team in 2012 to conform with project protocols and apply the 2008 grade and tonnage model; see text in chapter A.

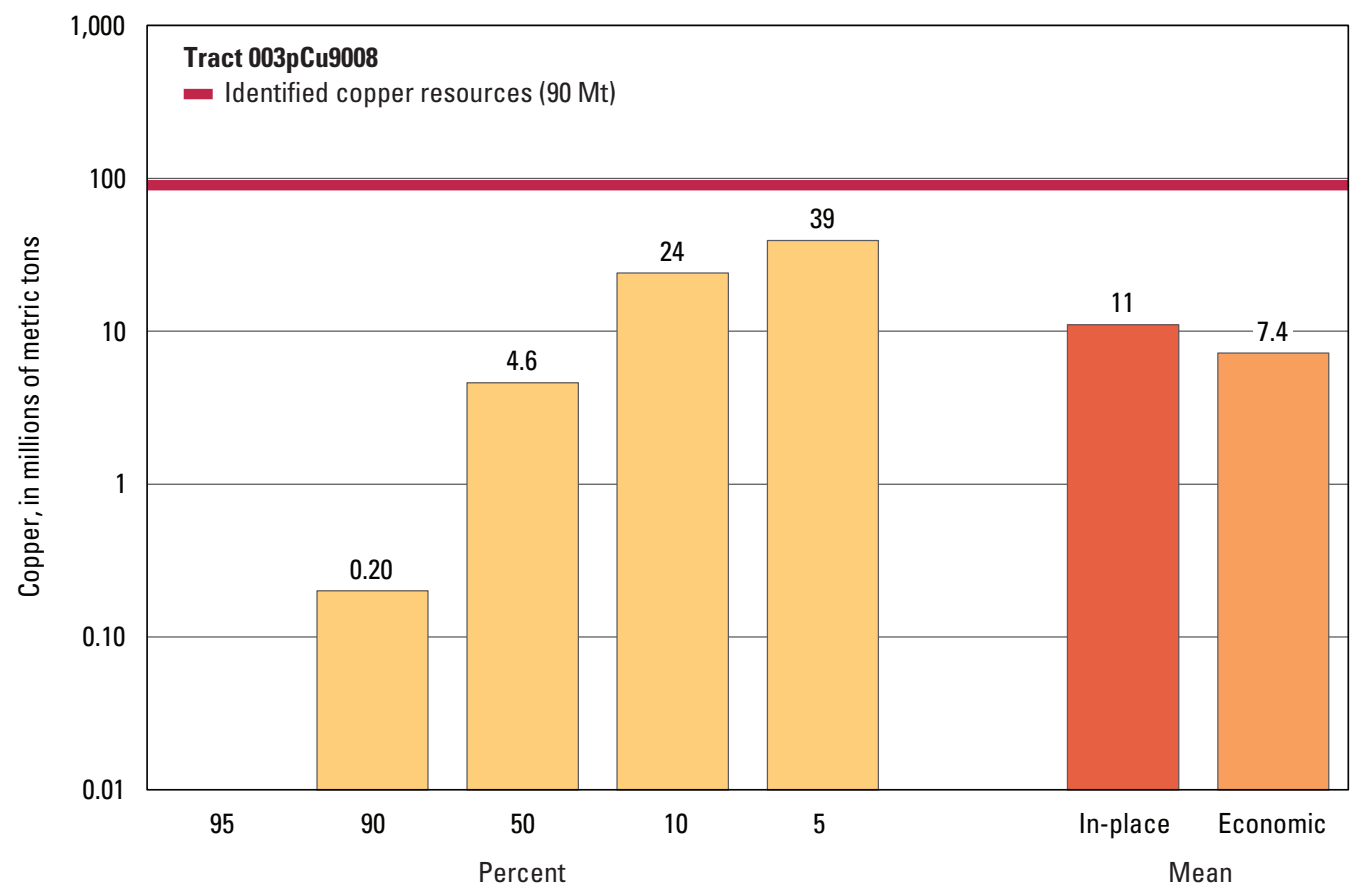

Graph showing the estimated probability distribution of undiscovered copper resources, where each bar represents the minimum amount estimated at the indicated percentage.

\section{Source}

U.S. Geological Survey National Mineral Resource Assessment Team, 2002, Assessment of undiscovered deposits of gold, silver, copper, lead, and zinc in the United States: U.S. Geological Survey Open-File Report 02-198, http://pubs.usgs.gov/of/2002/of02-198/. 


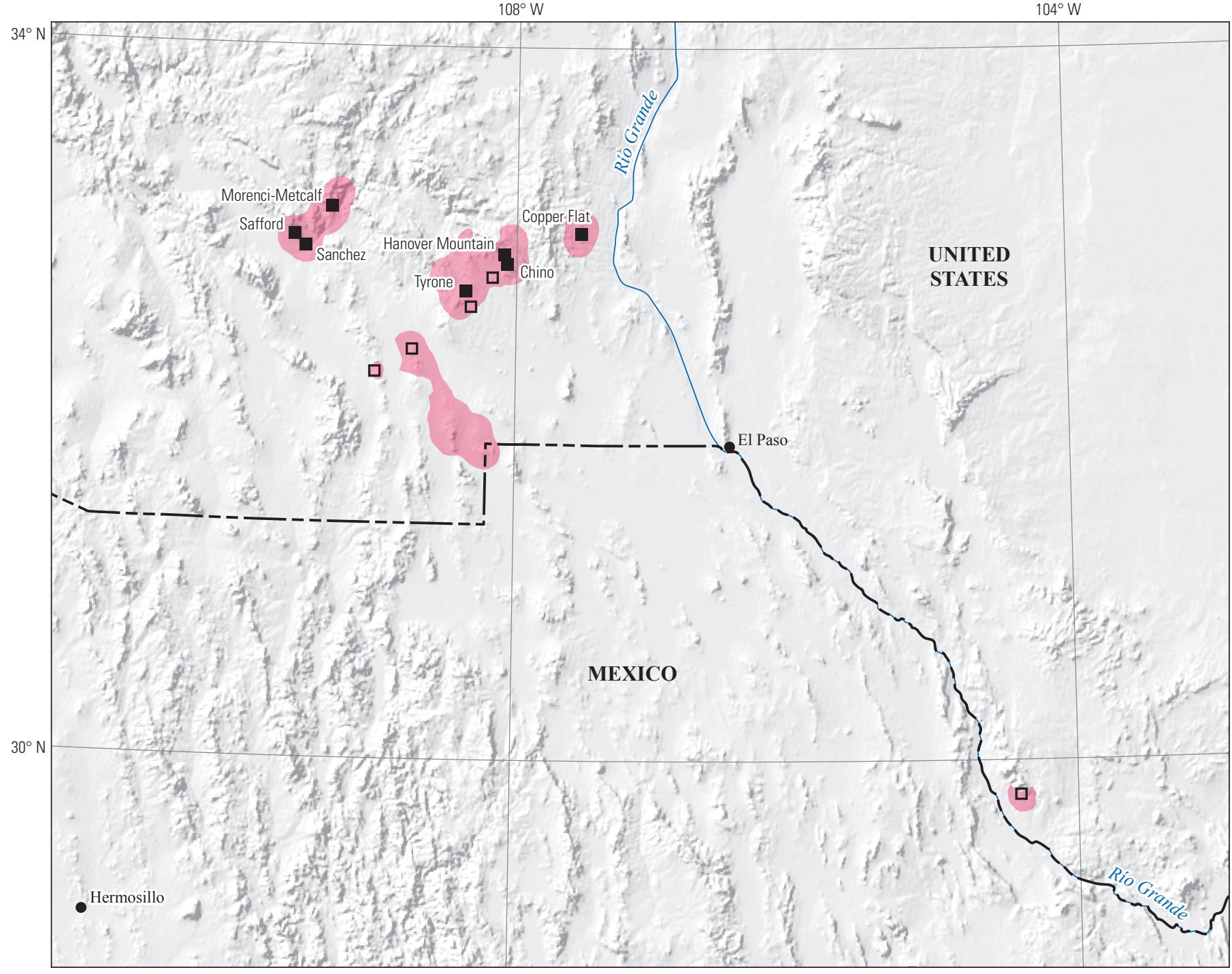

Political boundaries from U.S. Department of State (2009) Shaded relief from Earth Resources Observation and Science (EROS) Center (2011)

North America Albers Equal-Area Conic projection Central meridian $106^{\circ} 30^{\prime}$ W.; latitude of origin $40^{\circ} \mathrm{N}$.

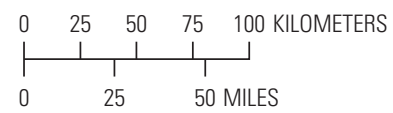

\section{EXPLANATION}

\section{Assessed porphyry copper tract} 003pCu9008

\section{- Porphyry copper deposit \\ $\square \quad$ Porphyry copper prospect}

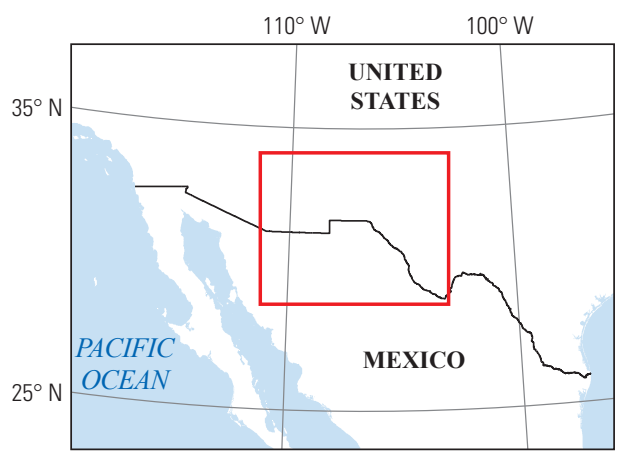




\title{
Plate 43. Porphyry Copper Assessment for Tract 003pCu9006x, Western U.S. and Sonoran Desert Jurassic Arc - Mexico and United States
}

\author{
Descriptive model: \\ Porphyry copper model (Cox, 1986a) \\ Grade and tonnage model: \\ General porphyry copper model (Singer, Berger, and Moring, 2008) \\ Economic filter depth percentages: \\ Economic filter cost setting: \\ Geologic feature assessed: \\ Default -0 to 250 meters (m), $25 \% ;>250$ to $500 \mathrm{~m}, 25 \% ;>500 \mathrm{~m}$ to $1 \mathrm{~km}, 50 \%$ \\ Typical cost \\ U.S. and Mexican parts of a Jurassic composite island arc and continental-margin arc that formed \\ during subduction of the Farallon Plate beneath western North America \\ Number of known deposits: \\ 6
}

\section{Selected Resource Assessment Results for Porphyry Copper}

[Assessment depth, 1 kilometer ( $\mathrm{km}) ; \mathrm{km}^{2}$, square kilometer; Mt, millions of metric tons]

\begin{tabular}{ccccccc}
\hline $\begin{array}{c}\text { Date of } \\
\text { assessment }\end{array}$ & $\begin{array}{c}\text { Tract area } \\
\left.\mathbf{( k m}^{2}\right)\end{array}$ & $\begin{array}{c}\text { Identified } \\
\text { copper } \\
\text { resources } \\
\text { (Mt) }\end{array}$ & $\begin{array}{c}\text { Mean estimate of } \\
\text { in-place resources } \\
\text { (Mt) }\end{array}$ & $\begin{array}{c}\text { Probability of } \mathbf{0} \\
\text { in-place resources } \\
\text { (percent) }\end{array}$ & $\begin{array}{c}\text { Mean estimate of } \\
\text { economic resources } \\
\text { (Mt) }\end{array}$ & $\begin{array}{c}\text { Probability of } \mathbf{0} \\
\text { economic resources } \\
\text { (percent) }\end{array}$ \\
\hline 2012 & 255,631 & 13 & 23 & 6 & 15 \\
\hline
\end{tabular}

"Updated in 2012; see text in chapter A.

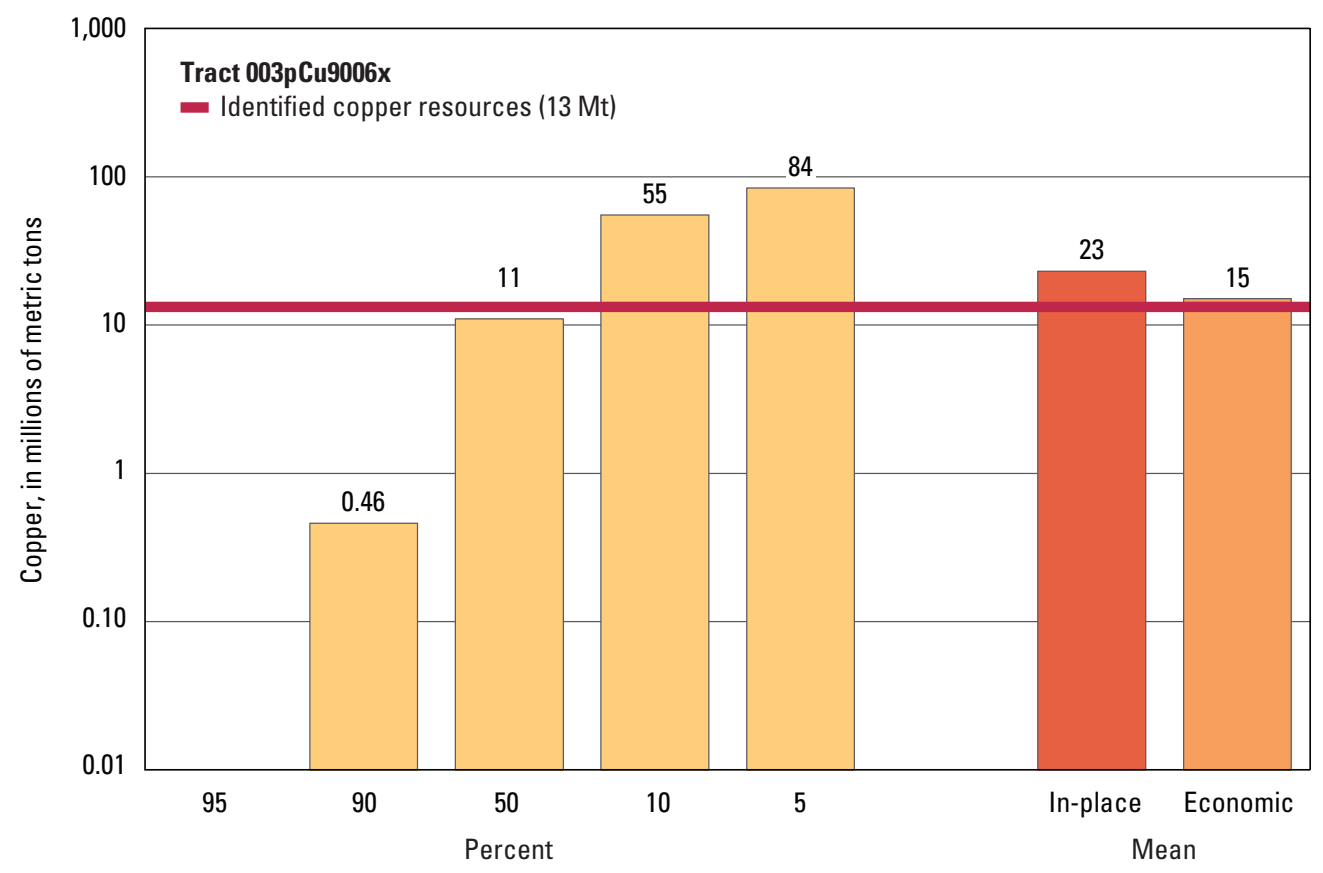

Graph showing the estimated probability distribution of undiscovered copper resources, where each bar represents the minimum amount estimated at the indicated percentage.

\section{Sources}

Hammarstrom, Robinson, and others, 2010, Porphyry copper assessment of Mexico: U.S. Geological Survey Scientific Investigations Report 2010-5090-A, http://pubs.usgs.gov/sir/2010/5090/a/.

U.S. Geological Survey National Mineral Resource Assessment Team, 2002, Assessment of undiscovered deposits of gold, silver, copper, lead, and zinc in the United States: U.S. Geological Survey Open-File Report 02-198, http://pubs.usgs.gov/of/2002/of02-198/. 

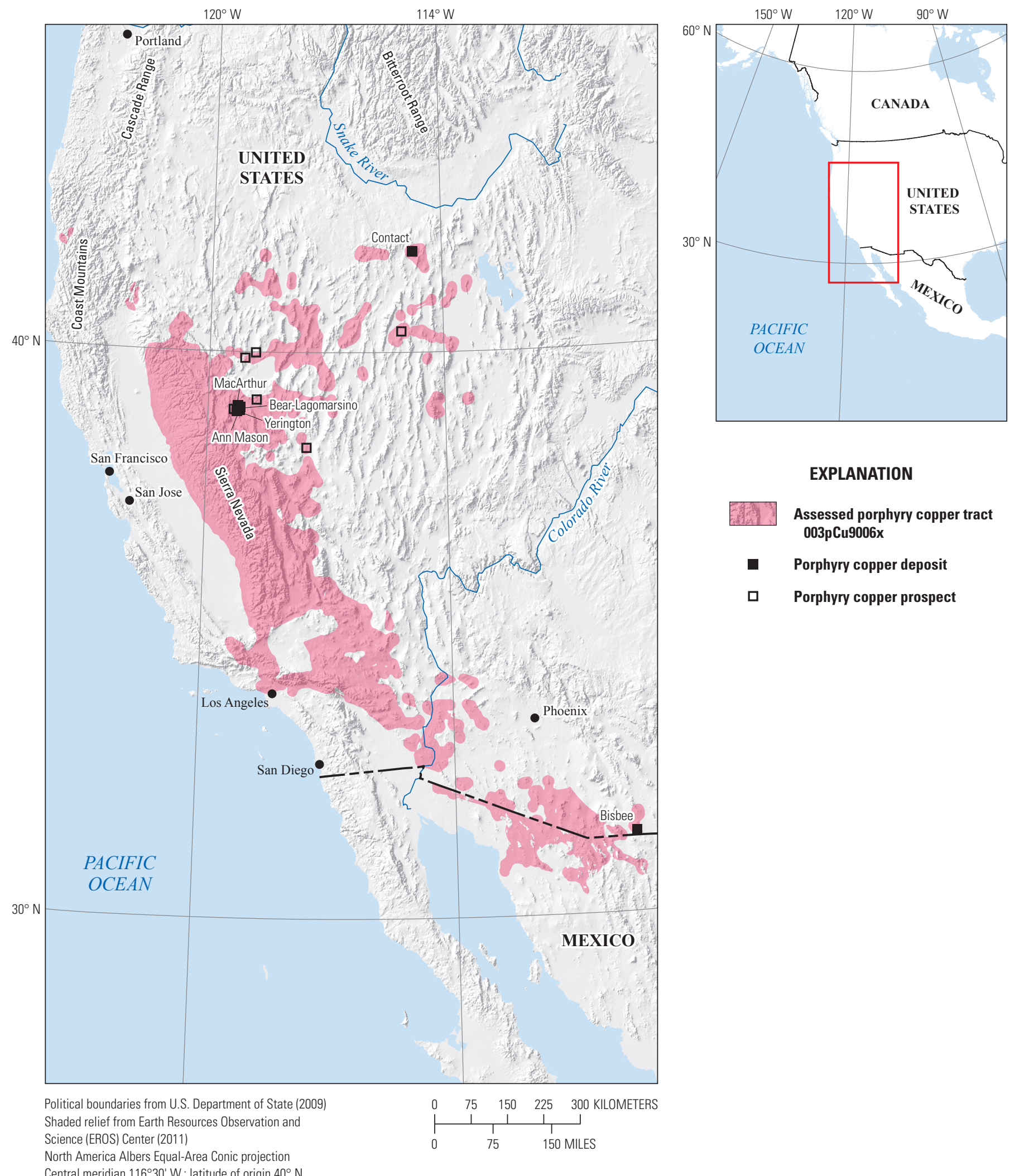

Assessed porphyry copper tract 003pCu9006x

- Porphyry copper deposit

ㅁ Porphyry copper prospect 


\title{
Plate 44. Porphyry Copper Assessment for Tract 003pCu9007, Sierran Arc- United States
}

\author{
Descriptive model: \\ Porphyry copper model (Cox, 1986a) \\ Grade and tonnage model: \\ General porphyry copper model (Singer, Berger, and Moring, 2008) \\ Economic filter depth percentages: \\ Economic filter cost setting: \\ Geologic feature assessed: \\ Skewed shallow-0 to 250 meters (m), $35 \% ;>250$ to $500 \mathrm{~m}, 25 \%$; $>500 \mathrm{~m}$ to $1 \mathrm{~km}, 40 \%$ \\ Typical cost \\ A composite Cretaceous island arc and continental-margin arc that formed during subduction of the \\ Farallon Plate beneath western North America \\ Number of known deposits: \\ 5
}

\section{Selected Resource Assessment Results for Porphyry Copper}

[Assessment depth, 1 kilometer ( $\mathrm{km}) ; \mathrm{km}^{2}$, square kilometer; Mt, millions of metric tons]

\begin{tabular}{ccccccc}
\hline $\begin{array}{c}\text { Date of } \\
\text { assessment }\end{array}$ & $\begin{array}{c}\text { Tract area } \\
\left.\mathbf{( k m}^{2}\right)\end{array}$ & $\begin{array}{c}\text { Identified } \\
\text { copper } \\
\text { resources } \\
\text { (Mt) }\end{array}$ & $\begin{array}{c}\text { Mean estimate of } \\
\text { in-place resources } \\
(\mathbf{M t})\end{array}$ & $\begin{array}{c}\text { Probability of } \mathbf{0} \\
\text { in-place resources } \\
\text { (percent) }\end{array}$ & $\begin{array}{c}\text { Mean estimate of } \\
\text { economic resources } \\
\text { (Mt) }\end{array}$ & $\begin{array}{c}\text { Probability of 0 } \\
\text { economic resources } \\
\text { (percent) }\end{array}$ \\
\hline 2012 & 175,915 & 7.0 & 18 & 17 & 12 \\
\hline
\end{tabular}

*Updated by the assessment team in 2012 to conform with project protocols and apply the 2008 grade and tonnage model; see text in chapter A.

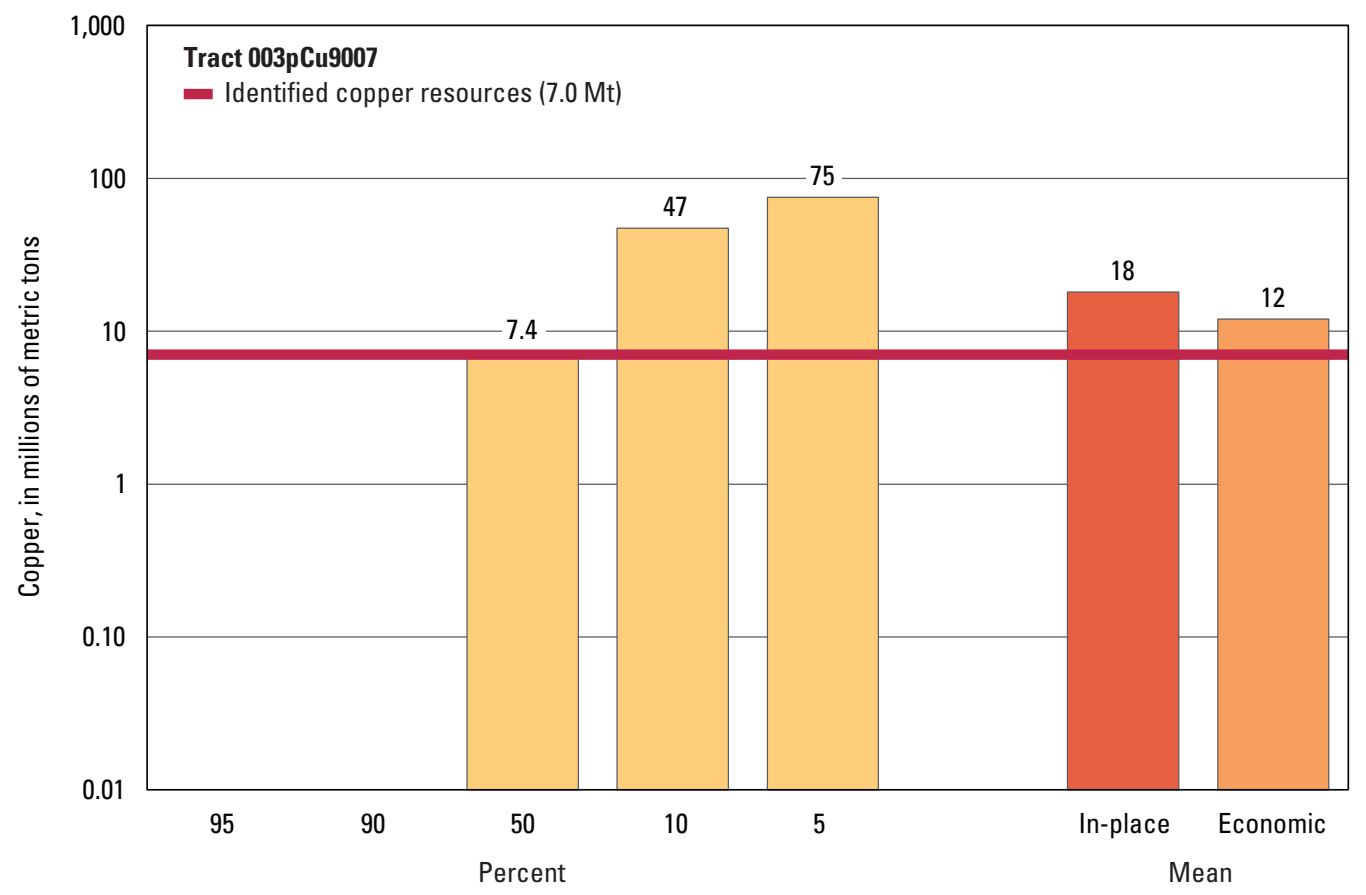

Graph showing the estimated probability distribution of undiscovered copper resources, where each bar represents the minimum amount estimated at the indicated percentage.

\section{Source}

U.S. Geological Survey National Mineral Resource Assessment Team, 2002, Assessment of undiscovered deposits of gold, silver, copper, lead, and zinc in the United States: U.S. Geological Survey Open-File Report 02-198, http://pubs.usgs.gov/of/2002/of02-198/. 


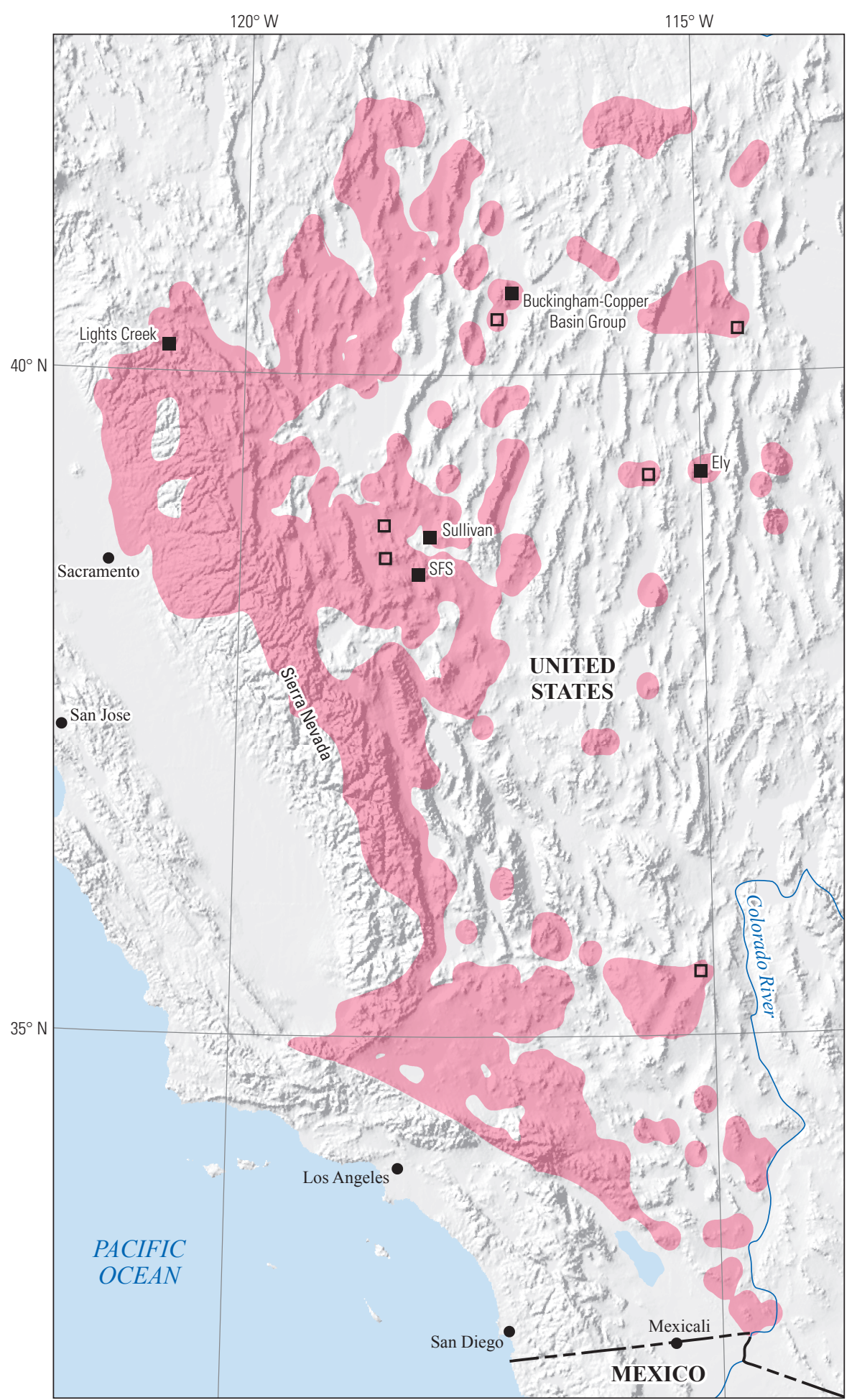

Political boundaries from U.S. Department of State (2009) Shaded relief from Earth Resources Observation and Science (EROS) Center (2011)

North America Albers Equal-Area Conic projection

Central meridian $117^{\circ} 30^{\prime} \mathrm{W}$.; latitude of origin $40^{\circ} \mathrm{N}$.

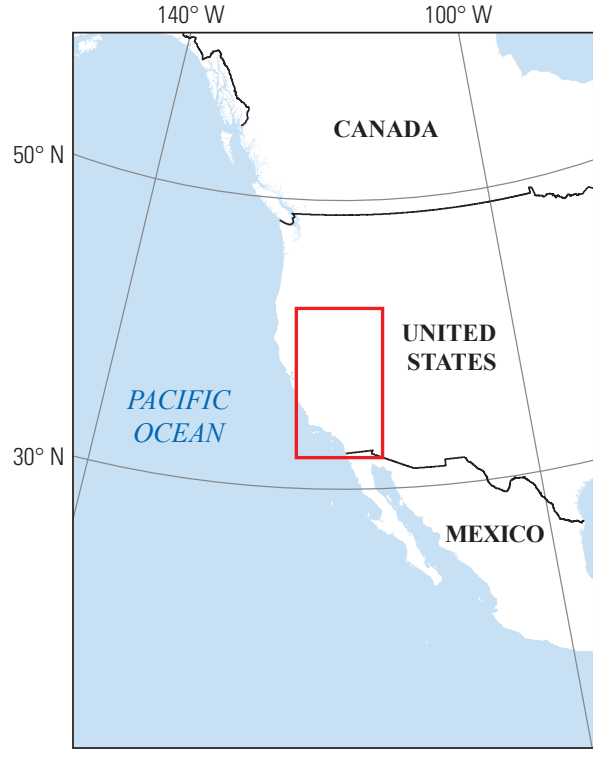

\section{EXPLANATION}

130. Assessed porphyry copper tract 003pCu9007

- Porphyry copper deposit

․ Porphyry copper prospect 


\section{Plate 45. Porphyry Copper Assessment for Tract 003pCu9013, Great Basin Tertiary-United States}

\author{
Descriptive model: \\ Grade and tonnage model: \\ Economic filter depth percentages: \\ Economic filter cost setting: \\ Geologic feature assessed: \\ Number of known deposits:
}

\author{
Porphyry copper model (Cox, 1986a) \\ General porphyry copper model (Singer, Berger, and Moring, 2008) \\ Custom - 0 to 250 meters (m), 20\%; >250 to $500 \mathrm{~m}, 30 \%$; >500 m to $1 \mathrm{~km}, 50 \%$ \\ Typical cost \\ Mid-Tertiary volcanic fields associated with postsubduction extension in the Great Basin \\ 4
}

\section{Selected Resource Assessment Results for Porphyry Copper}

[Assessment depth, 1 kilometer $(\mathrm{km})$; $\mathrm{km}^{2}$, square kilometer; $\mathrm{Mt}$, millions of metric tons]

\begin{tabular}{ccccccc}
\hline $\begin{array}{c}\text { Date of } \\
\text { assessment }\end{array}$ & $\begin{array}{c}\text { Tract area } \\
\left.\mathbf{( k m}^{2}\right)\end{array}$ & $\begin{array}{c}\text { Identified } \\
\text { copper } \\
\text { resources } \\
\text { (Mt) }\end{array}$ & $\begin{array}{c}\text { Mean estimate of } \\
\text { in-place resources } \\
(\mathbf{M t})\end{array}$ & $\begin{array}{c}\text { Probability of } \mathbf{0} \\
\text { in-place resources } \\
\text { (percent) }\end{array}$ & $\begin{array}{c}\text { Mean estimate of } \\
\text { economic resources } \\
\text { (Mt) }\end{array}$ & $\begin{array}{c}\text { Probability of 0 } \\
\text { economic resources } \\
\text { (percent) }\end{array}$ \\
\hline 2012 & 174,101 & 30 & 24 & 4 & 16 \\
\hline
\end{tabular}

*Updated by the assessment team in 2012 to conform with project protocols and apply the 2008 grade and tonnage model; see text in chapter A.

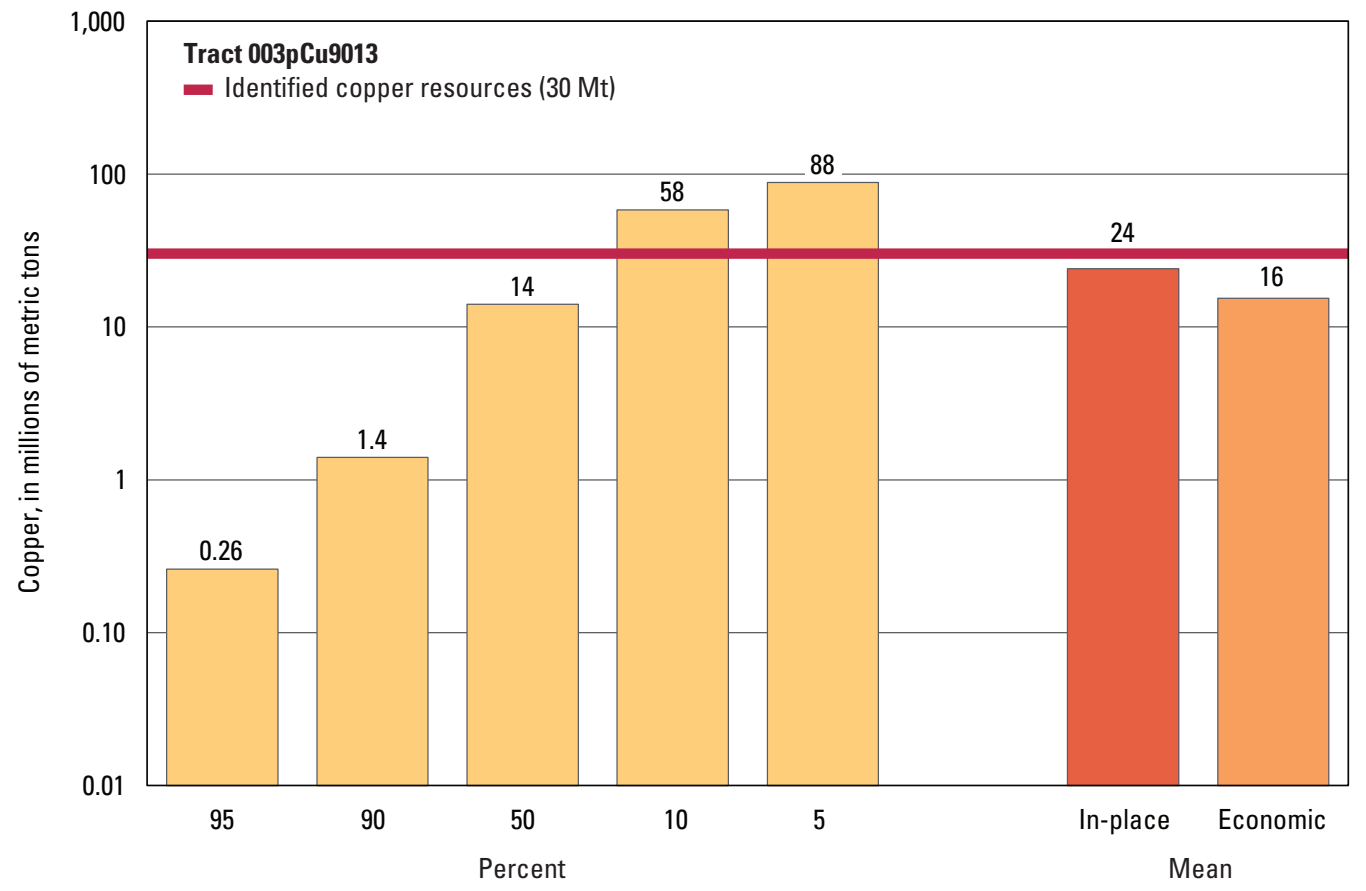

Graph showing the estimated probability distribution of undiscovered copper resources, where each bar represents the minimum amount estimated at the indicated percentage.

\section{Source}

U.S. Geological Survey National Mineral Resource Assessment Team, 2002, Assessment of undiscovered deposits of gold, silver, copper, lead, and zinc in the United States: U.S. Geological Survey Open-File Report 02-198, http://pubs.usgs.gov/of/2002/of02-198/. 


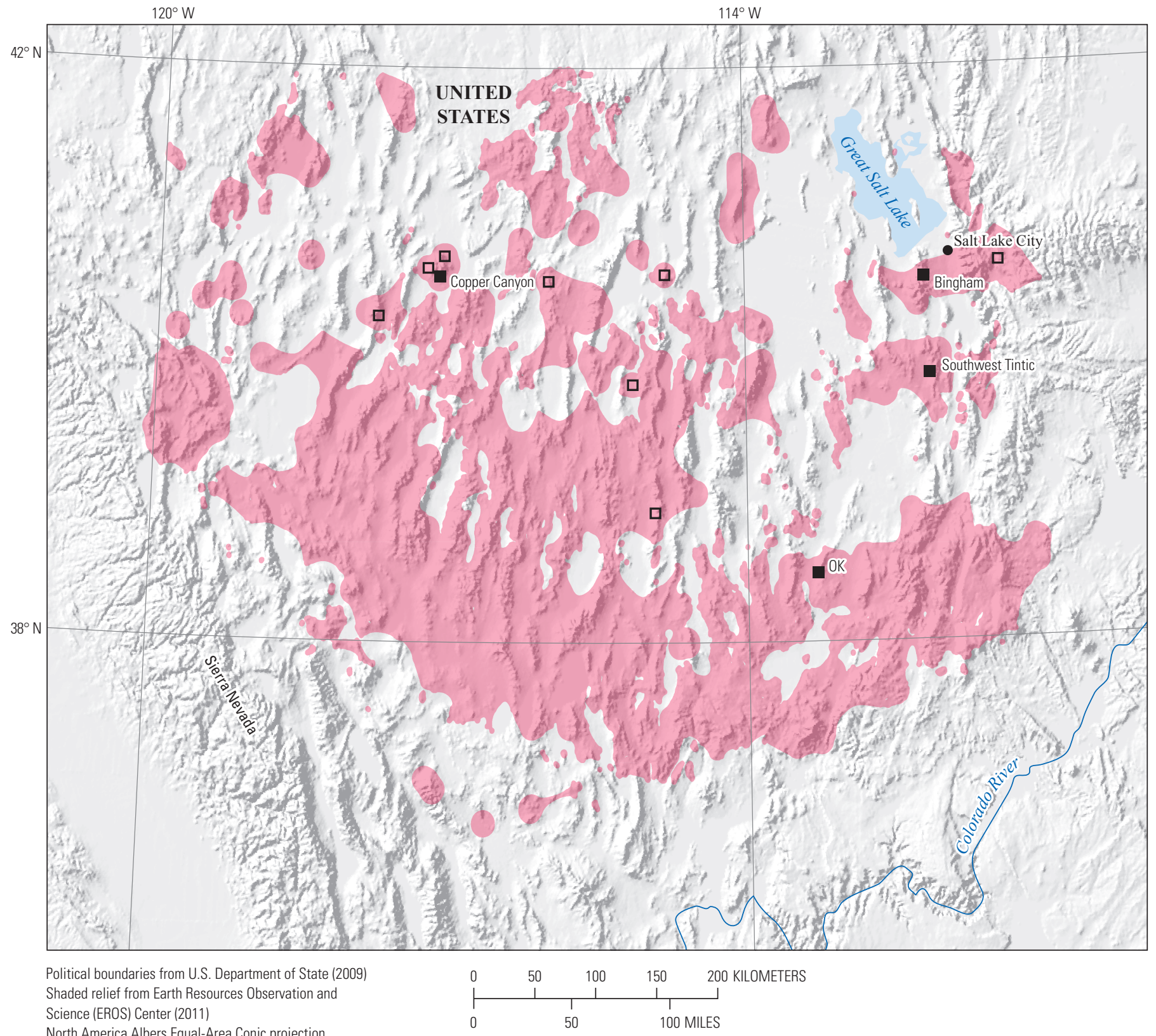

North America Albers Equal-Area Conic projection Central meridian $115^{\circ} 30^{\prime} \mathrm{W}$.; latitude of origin $40^{\circ} \mathrm{N}$.

EXPLANATION

Assessed porphyry copper tract $003 p$ Cu9013

- Porphyry copper deposit

$\square \quad$ Porphyry copper prospect

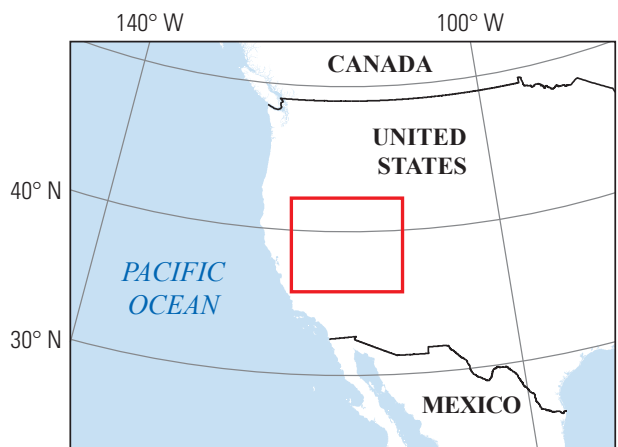




\title{
Plate 46. Porphyry Copper Assessment for Tract 003pCu9014, Cascade Arc- United States
}

\author{
Descriptive model: \\ Porphyry copper model (Cox, 1986a) \\ Grade and tonnage model: \\ General porphyry copper model (Singer, Berger, and Moring, 2008) \\ Economic filter depth percentages: \\ Default -0 to 250 meters (m), $25 \%$; $>250$ to $500 \mathrm{~m}, 25 \% ;>500 \mathrm{~m}$ to $1 \mathrm{~km}, 50 \%$ \\ Economic filter cost setting: \\ Geologic feature assessed: \\ Typical cost \\ U.S. part of a Tertiary continental-margin arc that formed during subduction of the Pacific and \\ Juan de Fuca Plates beneath western North America \\ Number of known deposits: \\ 6
}

\section{Selected Resource Assessment Results for Porphyry Copper}

[Assessment depth, 1 kilometer ( $\mathrm{km}) ; \mathrm{km}^{2}$, square kilometer; Mt, millions of metric tons]

\begin{tabular}{ccccccc}
\hline $\begin{array}{c}\text { Date of } \\
\text { assessment }\end{array}$ & $\begin{array}{c}\text { Tract area } \\
\left.\mathbf{( k m}^{2}\right)\end{array}$ & $\begin{array}{c}\text { Identified } \\
\text { copper } \\
\text { resources } \\
\text { (Mt) }\end{array}$ & $\begin{array}{c}\text { Mean estimate of } \\
\text { in-place resources } \\
\text { (Mt) }\end{array}$ & $\begin{array}{c}\text { Pndiscovered copper resource estimates } \\
\text { in-place resources } \\
\text { (percent) }\end{array}$ & $\begin{array}{c}\text { Mean estimate of } \\
\text { economic resources } \\
\text { (Mt) }\end{array}$ & $\begin{array}{c}\text { Probability of 0 } \\
\text { economic resources } \\
\text { (percent) }\end{array}$ \\
\hline 2012 & 203,703 & 9.2 & 30 & 6 & 20 \\
\hline
\end{tabular}

*Updated by the assessment team in 2012 to conform with project protocols and apply the 2008 grade and tonnage model; see text in chapter A.

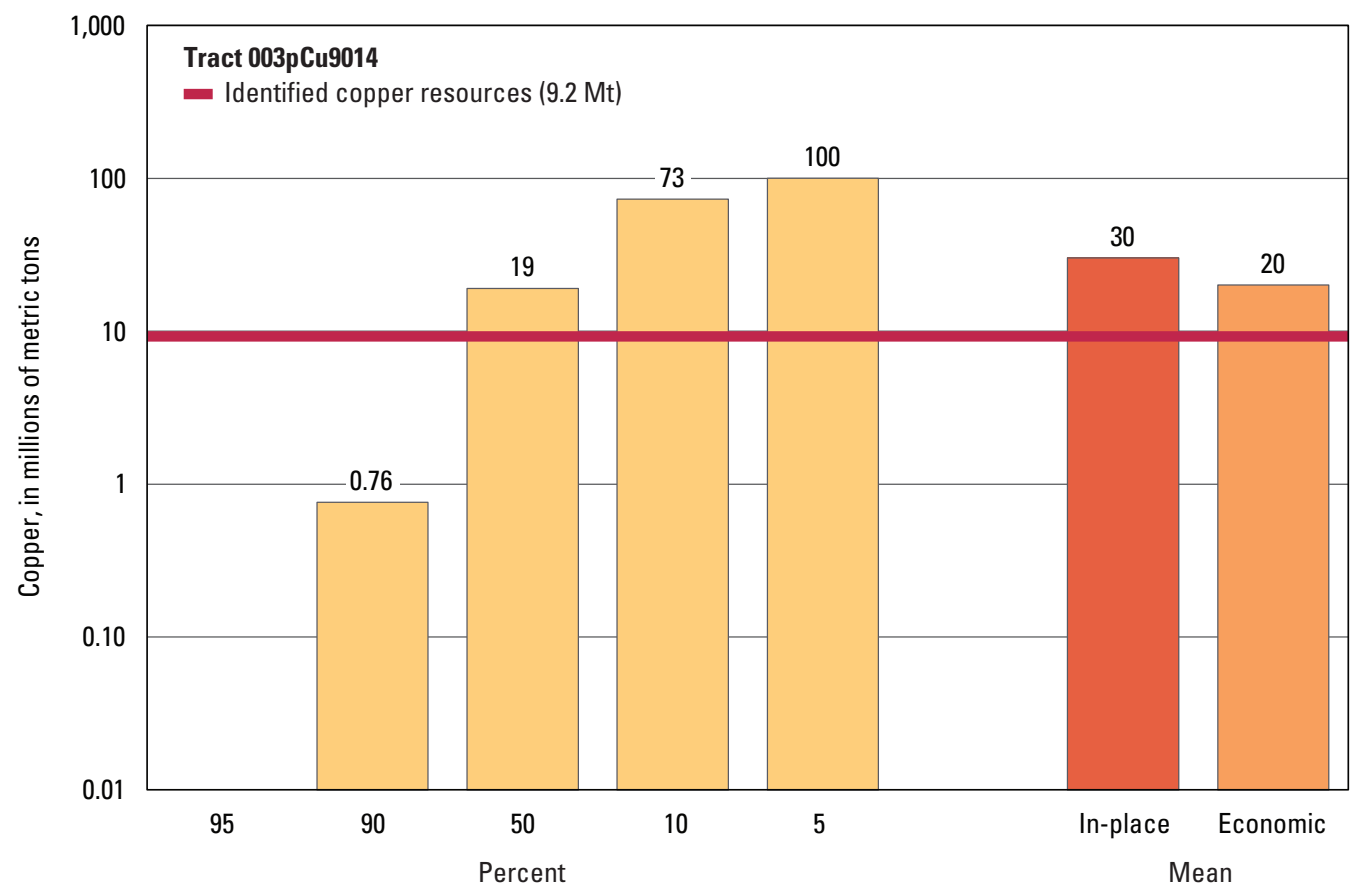

Graph showing the estimated probability distribution of undiscovered copper resources, where each bar represents the minimum amount estimated at the indicated percentage.

\section{Source}

U.S. Geological Survey National Mineral Resource Assessment Team, 2002, Assessment of undiscovered deposits of gold, silver, copper, lead, and zinc in the United States: U.S. Geological Survey Open-File Report 02-198, http://pubs.usgs.gov/of/2002/of02-198/. 


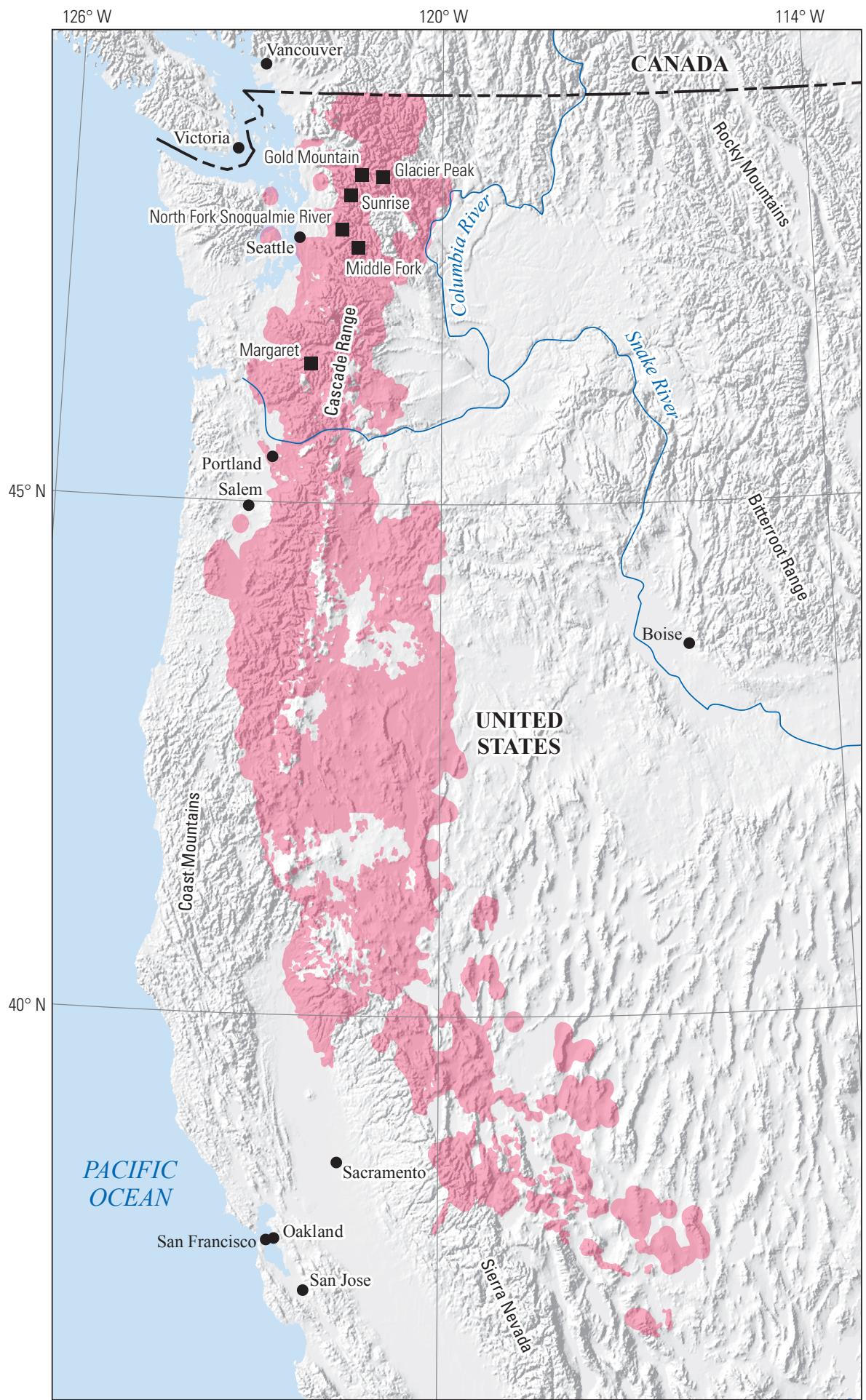

Political boundaries from U.S. Department of State (2009) Shaded relief from Earth Resources Observation and Science (EROS) Center (2011)

North America Albers Equal-Area Conic projection

Central meridian $119^{\circ} 30^{\prime} \mathrm{W}$.; latitude of origin $40^{\circ} \mathrm{N}$

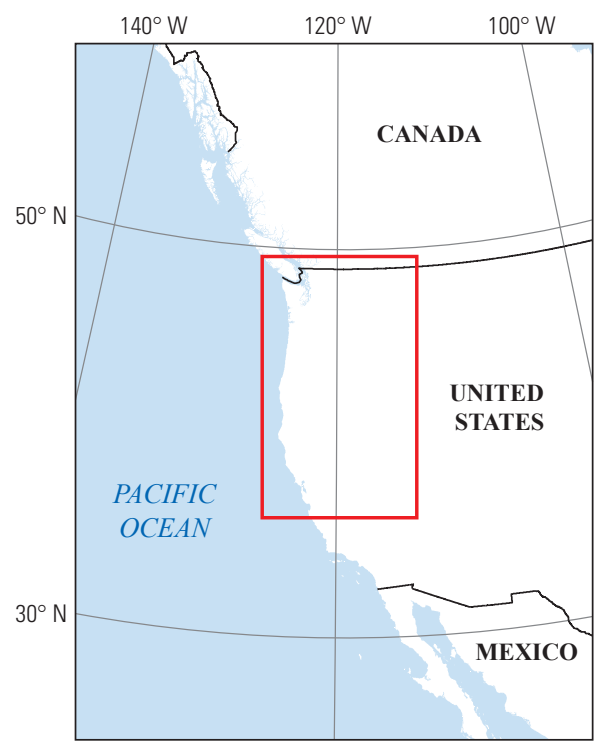

EXPLANATION

Assessed porphyry copper tract 003pCu9014

Porphyry copper deposit 


\title{
Plate 47. Porphyry Copper Assessment for Tract 003pCu9004, Northern Rocky Mountains-United States
}

\author{
Descriptive model: \\ Grade and tonnage model: \\ Economic filter depth percentages: \\ Economic filter cost setting: \\ Geologic feature assessed: \\ Number of known deposits:
}

Porphyry copper model (Cox, 1986a)

General porphyry copper model (Singer, Berger, and Moring, 2008)

Default -0 to 250 meters (m), $25 \% ;>250$ to $500 \mathrm{~m}, 25 \%$; $>500 \mathrm{~m}$ to $1 \mathrm{~km}, 50 \%$

Typical cost

Part of a Late Cretaceous through Oligocene continental-margin arc that formed along the western margin of North America

6 (1) (As shown on the map, 1 deposit was found after the assessment was done; the assessment results below reflect information available in 2012 for 6 deposits.)

\section{Selected Resource Assessment Results for Porphyry Copper}

[Assessment depth, 1 kilometer $(\mathrm{km}) ; \mathrm{km}^{2}$, square kilometer; Mt, millions of metric tons]

\begin{tabular}{ccccccc}
\hline $\begin{array}{c}\text { Date of } \\
\text { assessment }\end{array}$ & $\begin{array}{c}\text { Tract area } \\
\left(\mathbf{k m}^{2}\right)\end{array}$ & $\begin{array}{c}\text { Identified } \\
\text { copper } \\
\text { resources } \\
\text { (Mt) }\end{array}$ & $\begin{array}{c}\text { Mean estimate of } \\
\text { in-place resources } \\
(\mathbf{M t})\end{array}$ & $\begin{array}{c}\text { Probability of } \mathbf{0} \\
\text { in-place resources } \\
\text { (percent) }\end{array}$ & $\begin{array}{c}\text { Mean estimate of } \\
\text { economic resources } \\
\text { (Mt) }\end{array}$ & $\begin{array}{c}\text { Probability of } \mathbf{0} \\
\text { economic resources } \\
\text { (percent) }\end{array}$ \\
\hline 2012 & 124,986 & 38 & 26 & 4 & 17 \\
\hline
\end{tabular}

*Updated by the assessment team in 2012 to conform with project protocols and apply the 2008 grade and tonnage model; see text in chapter A.

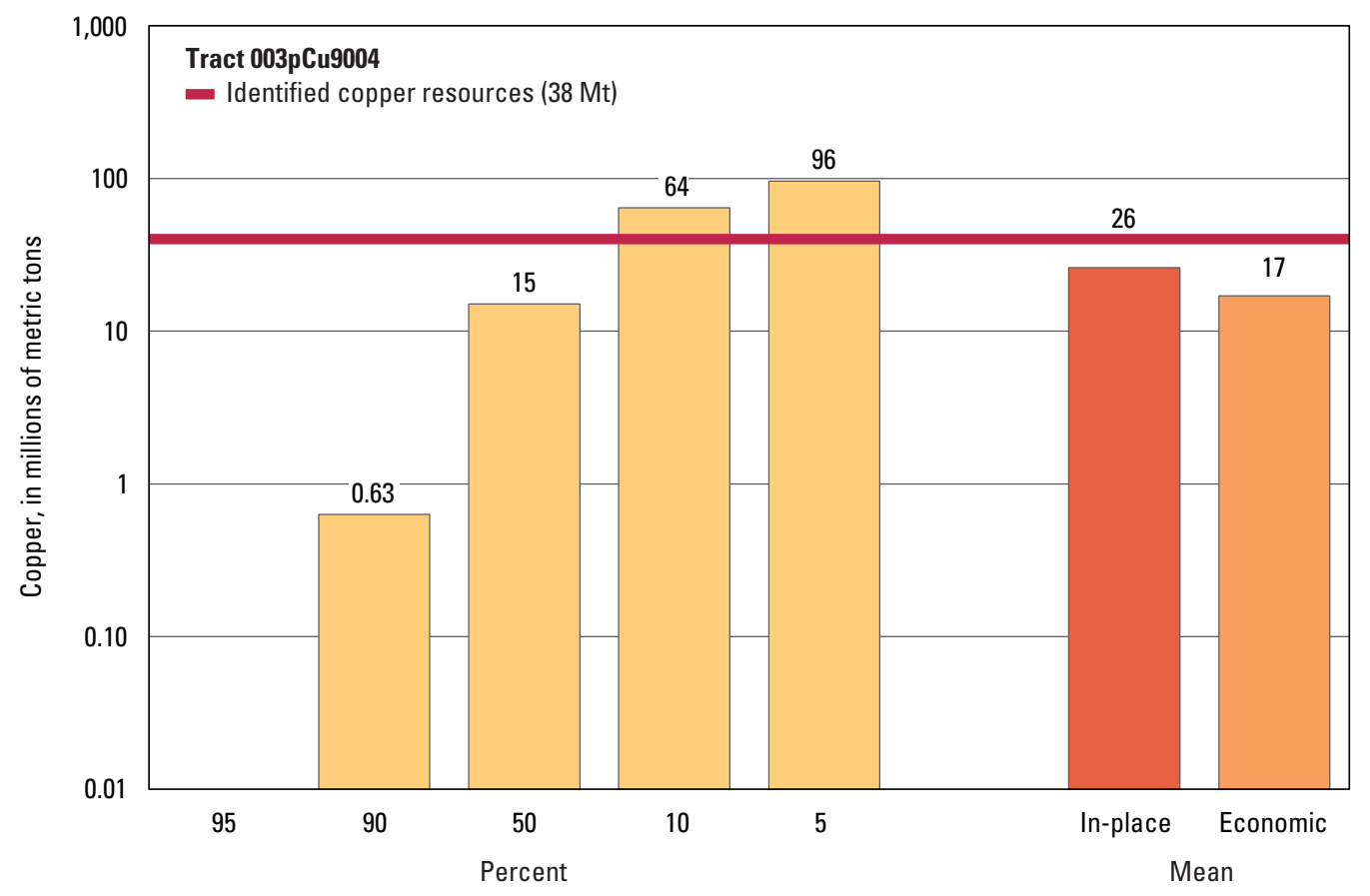

Graph showing the estimated probability distribution of undiscovered copper resources, where each bar represents the minimum amount estimated at the indicated percentage.

\section{Source}

U.S. Geological Survey National Mineral Resource Assessment Team, 2002, Assessment of undiscovered deposits of gold, silver, copper, lead, and zinc in the United States: U.S. Geological Survey Open-File Report 02-198, http://pubs.usgs.gov/of/2002/of02-198/. 


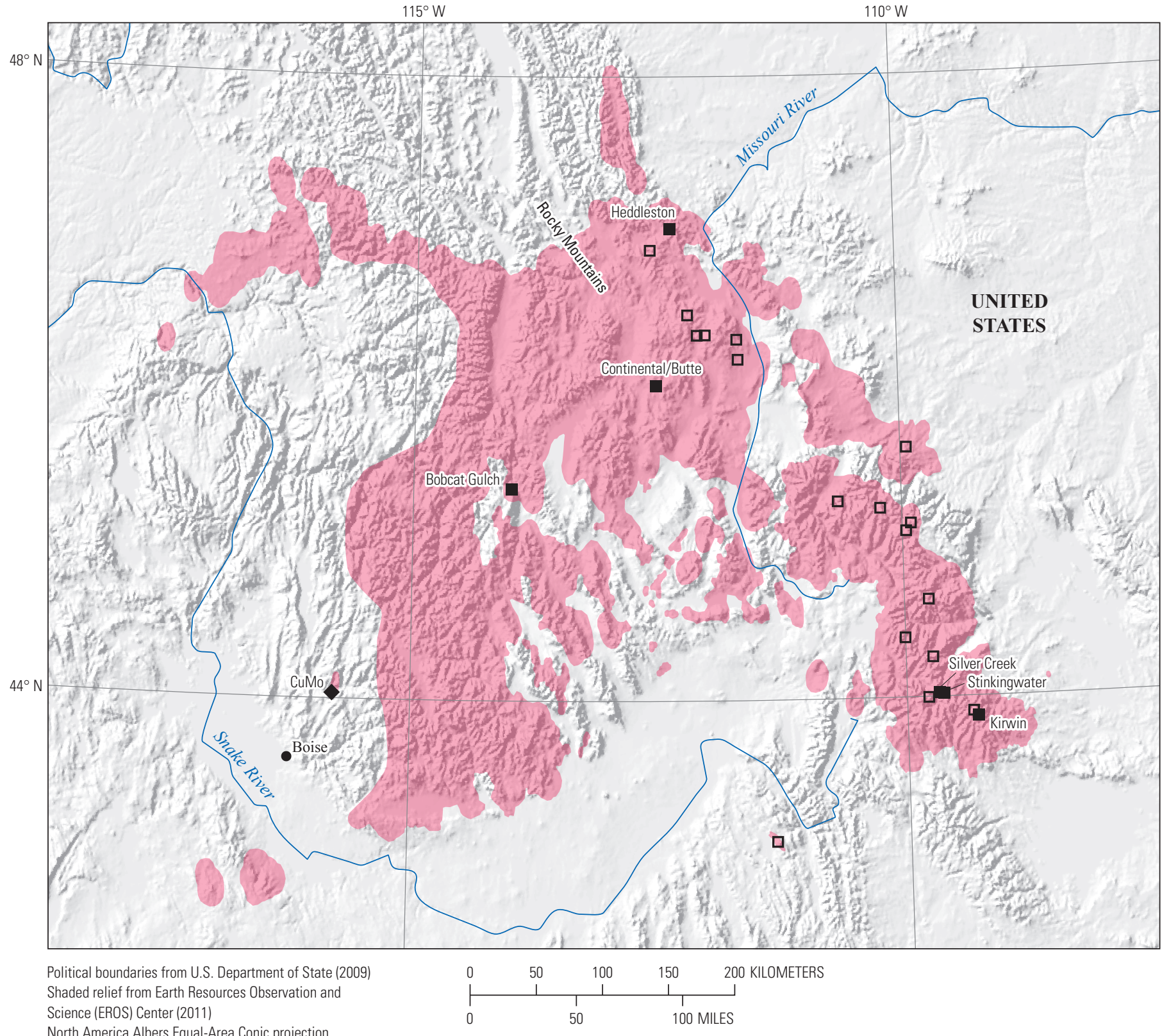

North America Albers Equal-Area Conic projection Central meridian $113^{\circ} \mathrm{W}$; ; latitude of origin $40^{\circ} \mathrm{N}$.

\section{EXPLANATION}

\section{Assessed porphyry copper tract 003pCu9004}

- Porphyry copper deposit

- Porphyry copper deposit discovered after the assessment

口 Porphyry copper prospect

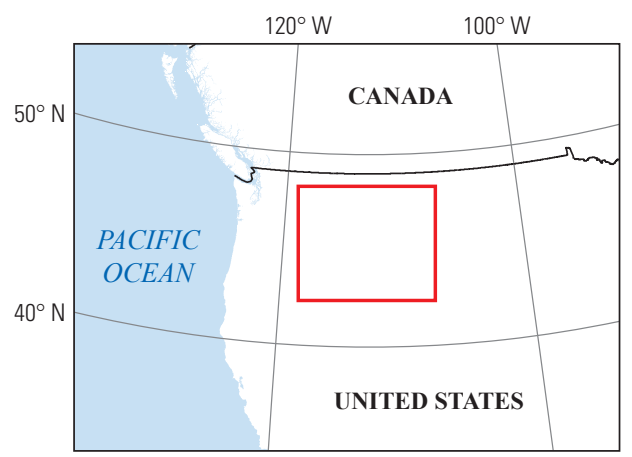




\title{
Plate 48. Porphyry Copper Assessment for Tract 003pCu2003, Insular Island and Continental Arcs-British Columbia and Yukon Territory, Canada
}

\author{
Descriptive model: \\ Grade and tonnage model: \\ Porphyry copper models (Cox, 1986a; Berger and others, 2008), porphyry copper-gold model \\ (Cox, 1986b), porphyry copper-molybdenum model (Cox, 1986c), porphyry $\mathrm{Cu} \pm \mathrm{Mo} \pm \mathrm{Au}$ model \\ (Panteleyev, 1995a) \\ Economic filter depth percentages: \\ Canadian Cordillera porphyry $\mathrm{Cu} \pm \mathrm{Mo} \pm \mathrm{Au}$ model (Frost and others, 2013) \\ Default -0 to 250 meters (m), $25 \%$; > 250 to $500 \mathrm{~m}, 25 \%$; $>500 \mathrm{~m}$ to $1 \mathrm{~km}, 50 \%$ \\ Economic filter cost setting: \\ Mixed cost \\ Geologic feature assessed: \\ Calc-alkalic igneous rocks of accreted Jurassic island-arc terranes \\ Number of known deposits: \\ 2
}

\section{Selected Resource Assessment Results for Porphyry Copper}

[Assessment depth, 1 kilometer $(\mathrm{km})$; $\mathrm{km}^{2}$, square kilometer; Mt, millions of metric tons]

\begin{tabular}{ccccccc}
\hline $\begin{array}{c}\text { Date of } \\
\text { assessment }\end{array}$ & $\begin{array}{c}\text { Tract area } \\
\left(\mathbf{k m}^{2}\right)\end{array}$ & $\begin{array}{c}\text { Identified } \\
\text { copper } \\
\text { resources } \\
(\mathbf{M t})\end{array}$ & $\begin{array}{c}\text { Mean estimate of } \\
\text { in-place resources } \\
(\mathbf{M t})\end{array}$ & $\begin{array}{c}\text { Probability of } \mathbf{0} \\
\text { in-place resources } \\
\text { (percent) }\end{array}$ & $\begin{array}{c}\text { Mean estimate of } \\
\text { economic resources } \\
\text { (Mt) }\end{array}$ & $\begin{array}{c}\text { Probability of } \mathbf{0} \\
\text { economic resources } \\
\text { (percent) }\end{array}$ \\
\hline 2013 & 58,361 & 3.2 & 3.0 & 7 & 0.87 \\
\hline
\end{tabular}

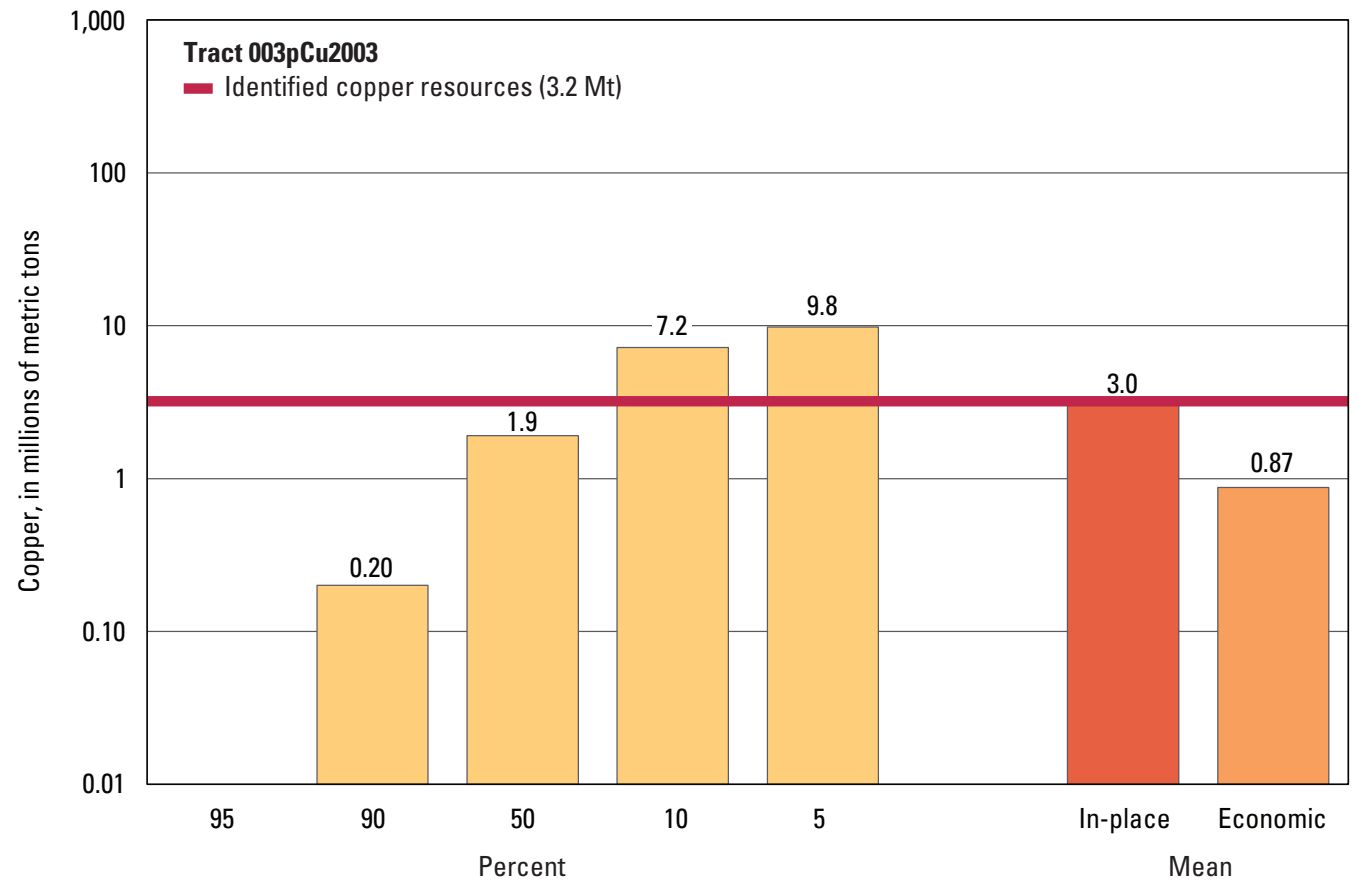

Graph showing the estimated probability distribution of undiscovered copper resources, where each bar represents the minimum amount estimated at the indicated percentage.

\section{Source}

Mihalasky, Bookstrom, and others, 2013, Porphyry copper assessment of British Columbia and Yukon Territory, Canada (ver. 1.1, February 2013): U.S. Geological Survey Scientific Investigations Report 2010-5090-C, http://pubs.usgs.gov/sir/2010/5090/c/. 

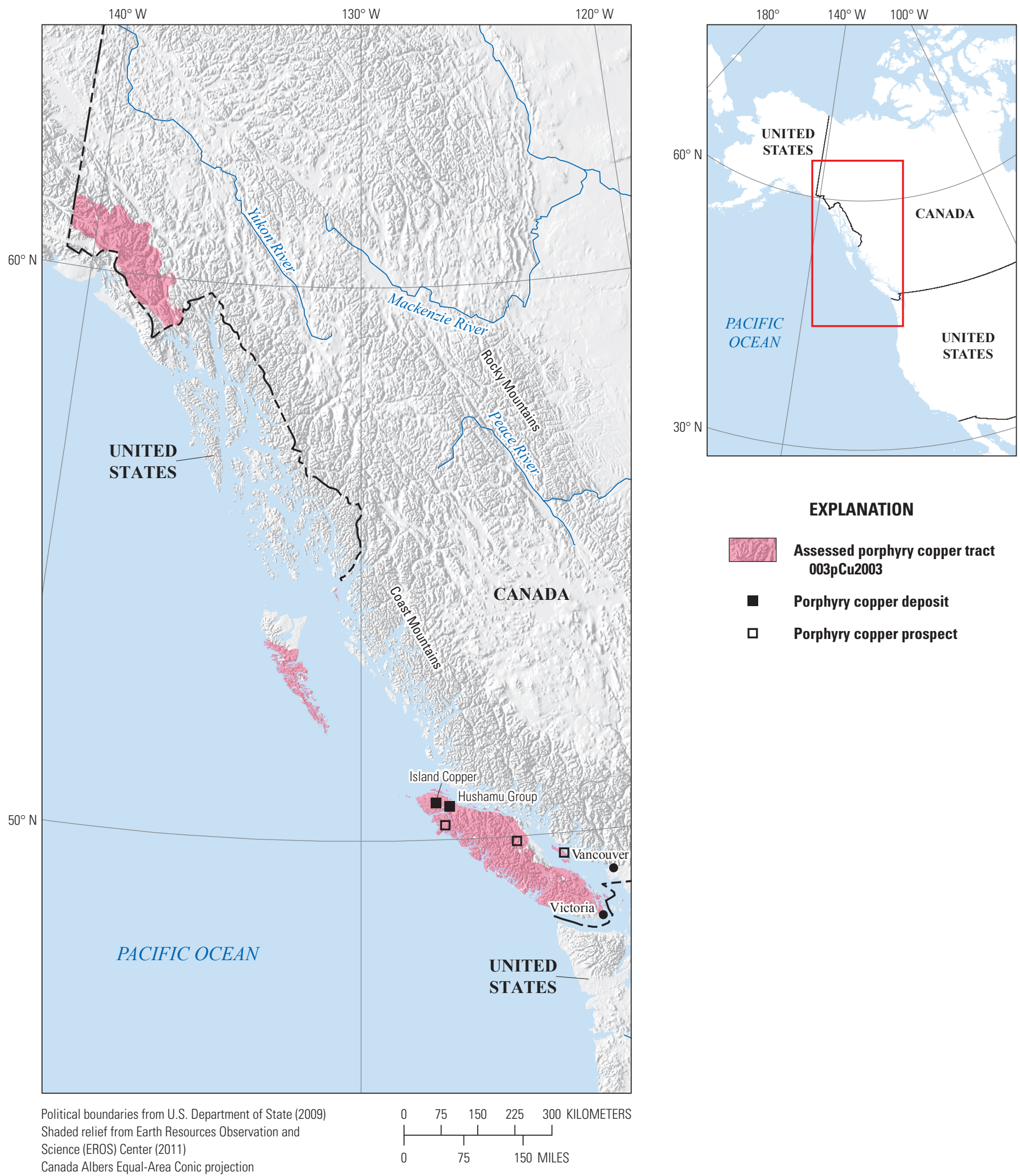

Assessed porphyry copper tract 003pCu2003

- Porphyry copper deposit

Porphyry copper prospect

Central meridian $130^{\circ} \mathrm{W}$; ; latitude of origin $40^{\circ} \mathrm{N}$. 


\title{
Plate 49. Porphyry Copper Assessment for Tract 003pCu2002x, Intermontane Island Arc Cu-Au, Western Cordillera—Canada and United States
}

\author{
Descriptive model: \\ Grade and tonnage model: \\ Porphyry copper models (Cox, 1986a; Berger and others, 2008), porphyry copper-gold model \\ (Cox, 1986b), porphyry copper-molybdenum model (Cox, 1986c), porphyry $\mathrm{Cu} \pm \mathrm{Mo} \pm \mathrm{Au}$ model \\ (Panteleyev, 1995a) \\ Economic filter depth percentages: \\ Porphyry copper, copper-gold subtype model (Singer, Berger, and Moring, 2008) \\ Economic filter cost setting: \\ Geologic feature assessed: \\ Number of known deposits: \\ Default -0 to 250 meters (m), $25 \% ;>250$ to $500 \mathrm{~m}, 25 \% ;>500 \mathrm{~m}$ to $1 \mathrm{~km}, 50 \%$ \\ Mixed cost \\ Triassic and Jurassic alkalic igneous rocks of accreted island arcs that formed offshore of western \\ North America \\ 13
}

\section{Selected Resource Assessment Results for Porphyry Copper}

[Assessment depth, 1 kilometer ( $\mathrm{km}) ; \mathrm{km}^{2}$, square kilometer; Mt, millions of metric tons]

\begin{tabular}{|c|c|c|c|c|c|c|}
\hline \multirow[b]{2}{*}{$\begin{array}{c}\text { Date of } \\
\text { assessment }\end{array}$} & \multirow[b]{2}{*}{$\begin{array}{c}\text { Tract area } \\
\quad\left(\mathbf{k m}^{2}\right)\end{array}$} & \multirow{2}{*}{$\begin{array}{l}\text { Identified } \\
\text { copper } \\
\text { resources } \\
\text { (Mt) }\end{array}$} & \multicolumn{4}{|c|}{ Undiscovered copper resource estimates } \\
\hline & & & $\begin{array}{l}\text { Mean estimate of } \\
\text { in-place resources } \\
\text { (Mt) }\end{array}$ & $\begin{array}{c}\text { Probability of } 0 \\
\text { in-place resources } \\
\text { (percent) }\end{array}$ & $\begin{array}{l}\text { Mean estimate of } \\
\text { economic resources } \\
\text { (Mt) }\end{array}$ & $\begin{array}{c}\text { Probability of } 0 \\
\text { economic resources } \\
\text { (percent) }\end{array}$ \\
\hline 2013 & 109,903 & 24 & 22 & 3 & 14 & 36 \\
\hline
\end{tabular}

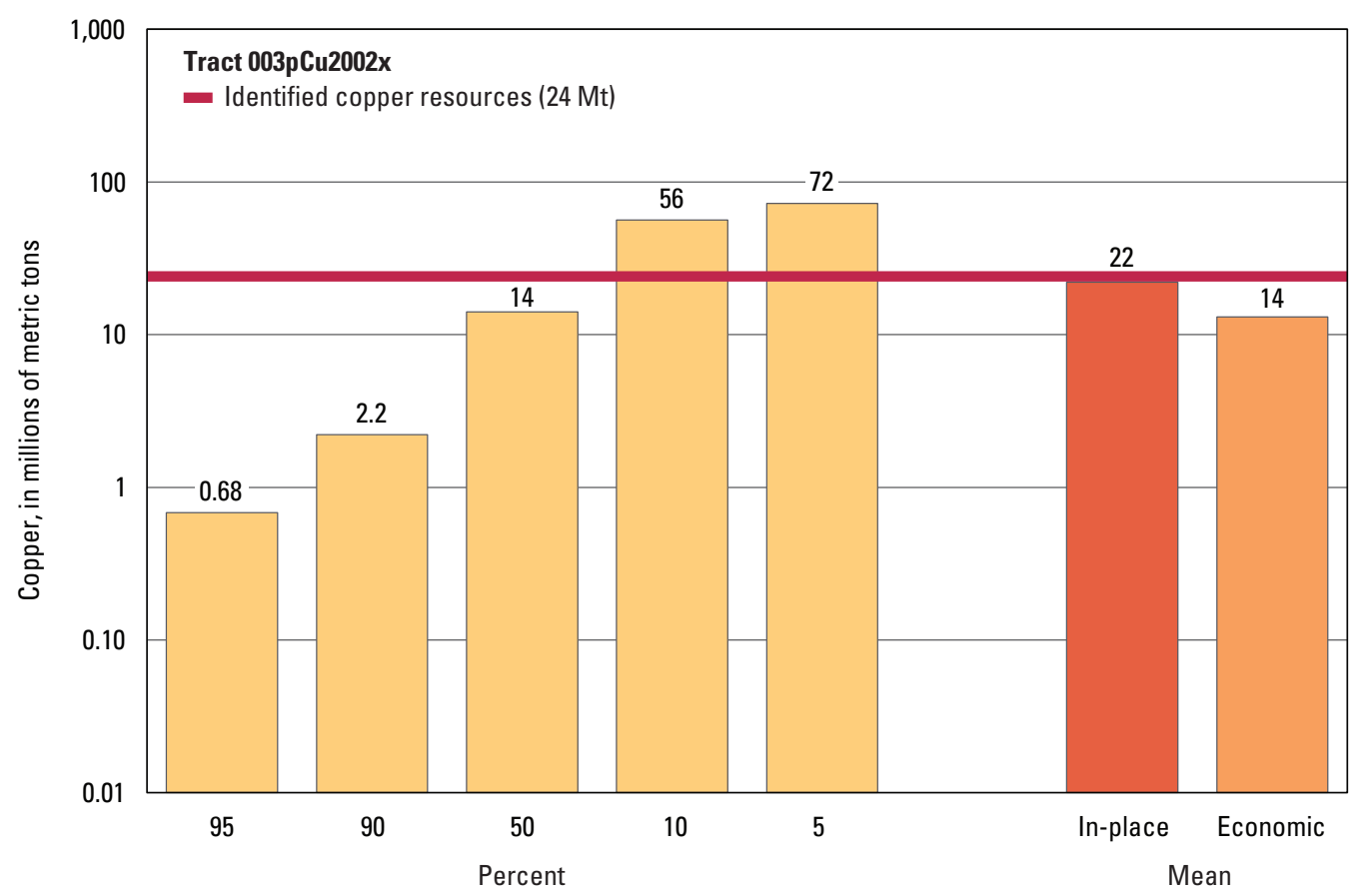

Graph showing the estimated probability distribution of undiscovered copper resources, where each bar represents the minimum amount estimated at the indicated percentage.

\section{Sources}

Mihalasky, Bookstrom, and others, 2013, Porphyry copper assessment of British Columbia and Yukon Territory, Canada (ver. 1.1, February 2013): U.S. Geological Survey Scientific Investigations Report 2010-5090-C, http://pubs.usgs.gov/sir/2010/5090/c/.

U.S. Geological Survey National Mineral Resource Assessment Team, 2002, Assessment of undiscovered deposits of gold, silver, copper, lead, and zinc in the United States: U.S. Geological Survey Open-File Report 02-198, http://pubs.usgs.gov/of/2002/of02-198/. 


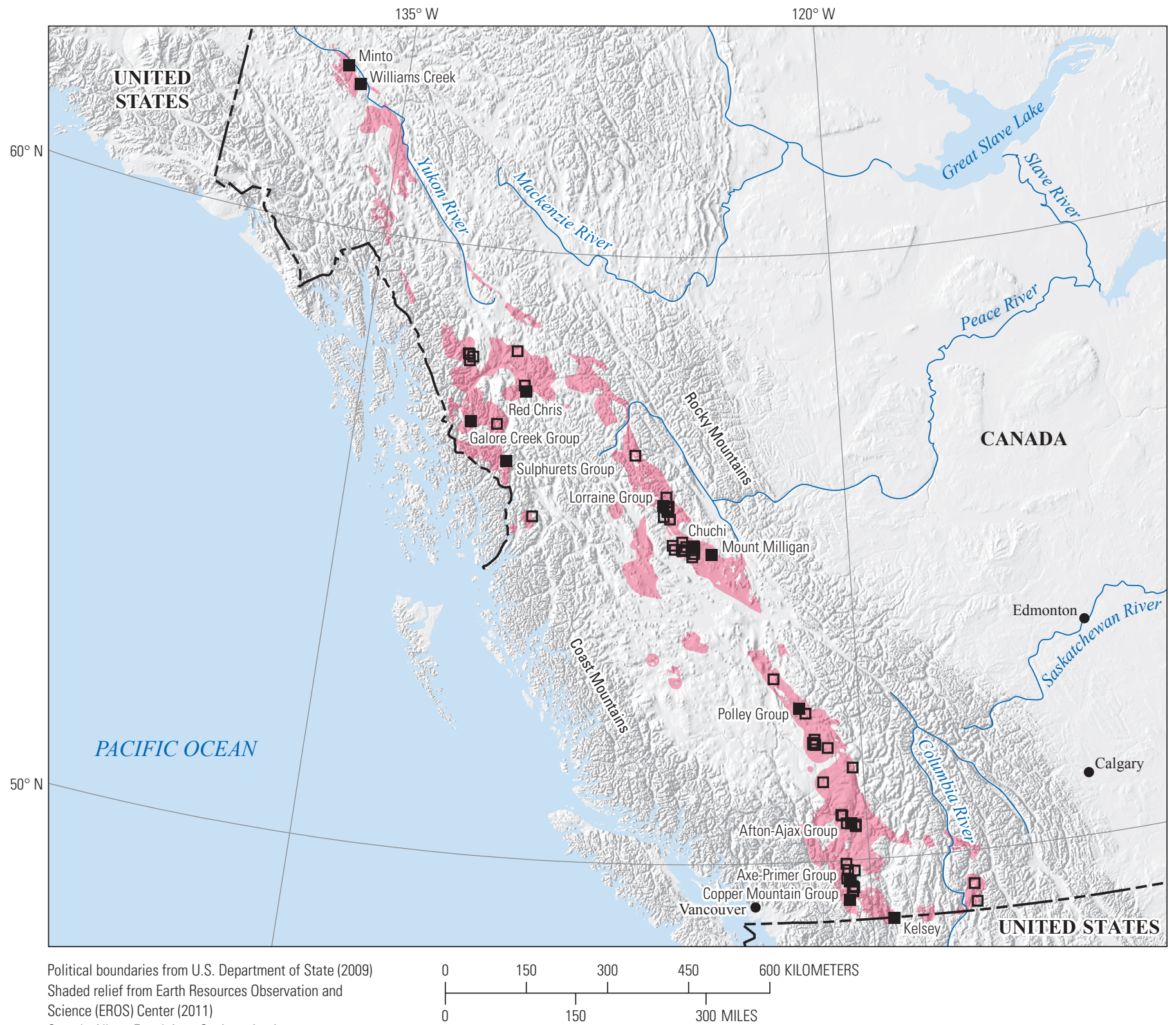

Canada Albers Equal-Area Conic projection

Central meridian $124^{\circ} 30^{\prime} \mathrm{W}$; : latitude of origin $40^{\circ} \mathrm{N}$.

EXPLANATION

Assessed porphyry copper tract 003pCu2002x

- Porphyry copper deposit

ㅁ Porphyry copper prospect

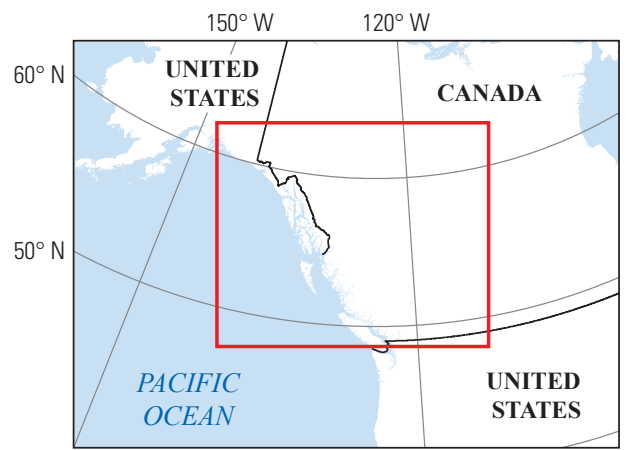




\section{Plate 50. Porphyry Copper Assessment for Tract 003pCu2004x, Cordilleran Continental Arc, Western Cordillera—Canada and United States}

\author{
Descriptive model: \\ Grade and tonnage model: \\ Economic filter depth percentages: \\ Economic filter cost setting: \\ Geologic feature assessed:
}

Number of known deposits:
Porphyry copper models (Cox, 1986a; Berger and others, 2008), porphyry copper-gold model (Cox, 1986b), porphyry copper-molybdenum model (Cox, 1986c), porphyry $\mathrm{Cu} \pm \mathrm{Mo} \pm \mathrm{Au}$ model (Panteleyev, 1995a)

Canadian Cordillera porphyry $\mathrm{Cu} \pm \mathrm{Mo} \pm \mathrm{Au}$ model (Frost and others, 2013)

Default -0 to 250 meters (m), $25 \% ;>250$ to $500 \mathrm{~m}, 25 \% ;>500 \mathrm{~m}$ to $1 \mathrm{~km}, 50 \%$

Mixed cost

Porphyry copper systems associated with predominantly calc-alkalic igneous rocks of postaccretionary continental magmatic arcs (Jurassic-Eocene); see plate 56 for adjacent area in Alaska

25

\section{Selected Resource Assessment Results for Porphyry Copper}

[Assessment depth, 1 kilometer $(\mathrm{km}) ; \mathrm{km}^{2}$, square kilometer; Mt, millions of metric tons]

\begin{tabular}{ccccccc}
\hline $\begin{array}{c}\text { Date of } \\
\text { assessment }\end{array}$ & $\begin{array}{c}\text { Tract area } \\
\left(\mathbf{k m}^{2}\right)\end{array}$ & $\begin{array}{c}\text { Identified } \\
\text { copper } \\
\text { resources } \\
(\mathbf{M t})\end{array}$ & $\begin{array}{c}\text { Mean estimate of } \\
\text { in-place resources } \\
(\mathbf{M t})\end{array}$ & $\begin{array}{c}\text { Probability of } \mathbf{0} \\
\text { in-place resources } \\
\text { (percent) }\end{array}$ & $\begin{array}{c}\text { Mean estimate of } \\
\text { economic resources } \\
\text { (Mt) }\end{array}$ & $\begin{array}{c}\text { Probability of 0 } \\
\text { economic resources } \\
\text { (percent) }\end{array}$ \\
\hline 2013 & 684,535 & 23 & 13 & 3 & 3.8 \\
\hline
\end{tabular}

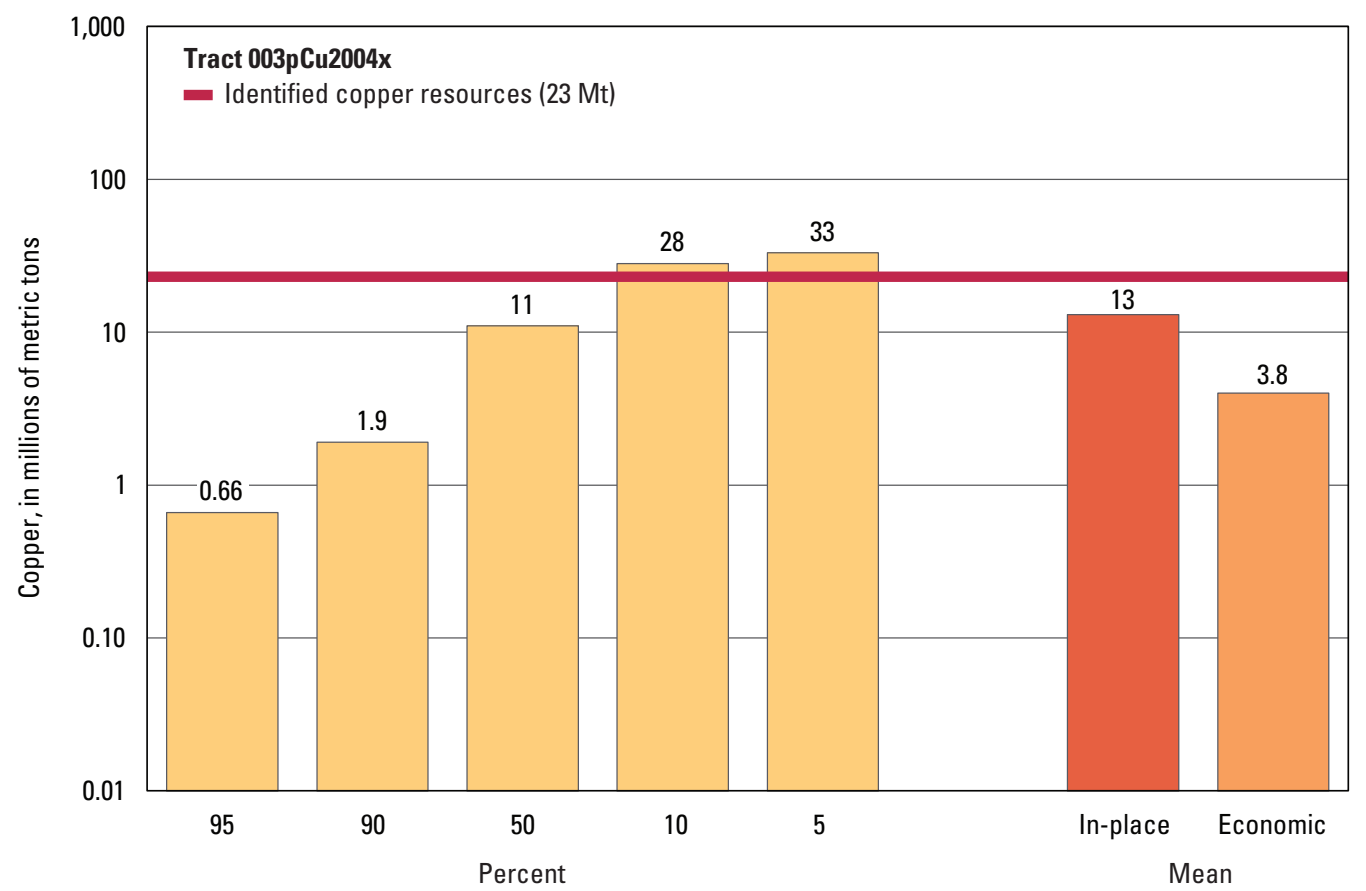

Graph showing the estimated probability distribution of undiscovered copper resources, where each bar represents the minimum amount estimated at the indicated percentage.

\section{Sources}

Mihalasky, Bookstrom, and others, 2013, Porphyry copper assessment of British Columbia and Yukon Territory, Canada (ver. 1.1, February 2013): U.S. Geological Survey Scientific Investigations Report 2010-5090-C, http://pubs.usgs.gov/sir/2010/5090/c/.

U.S. Geological Survey National Mineral Resource Assessment Team, 2002, Assessment of undiscovered deposits of gold, silver, copper, lead, and zinc in the United States: U.S. Geological Survey Open-File Report 02-198, http://pubs.usgs.gov/of/2002/of02-198/. 


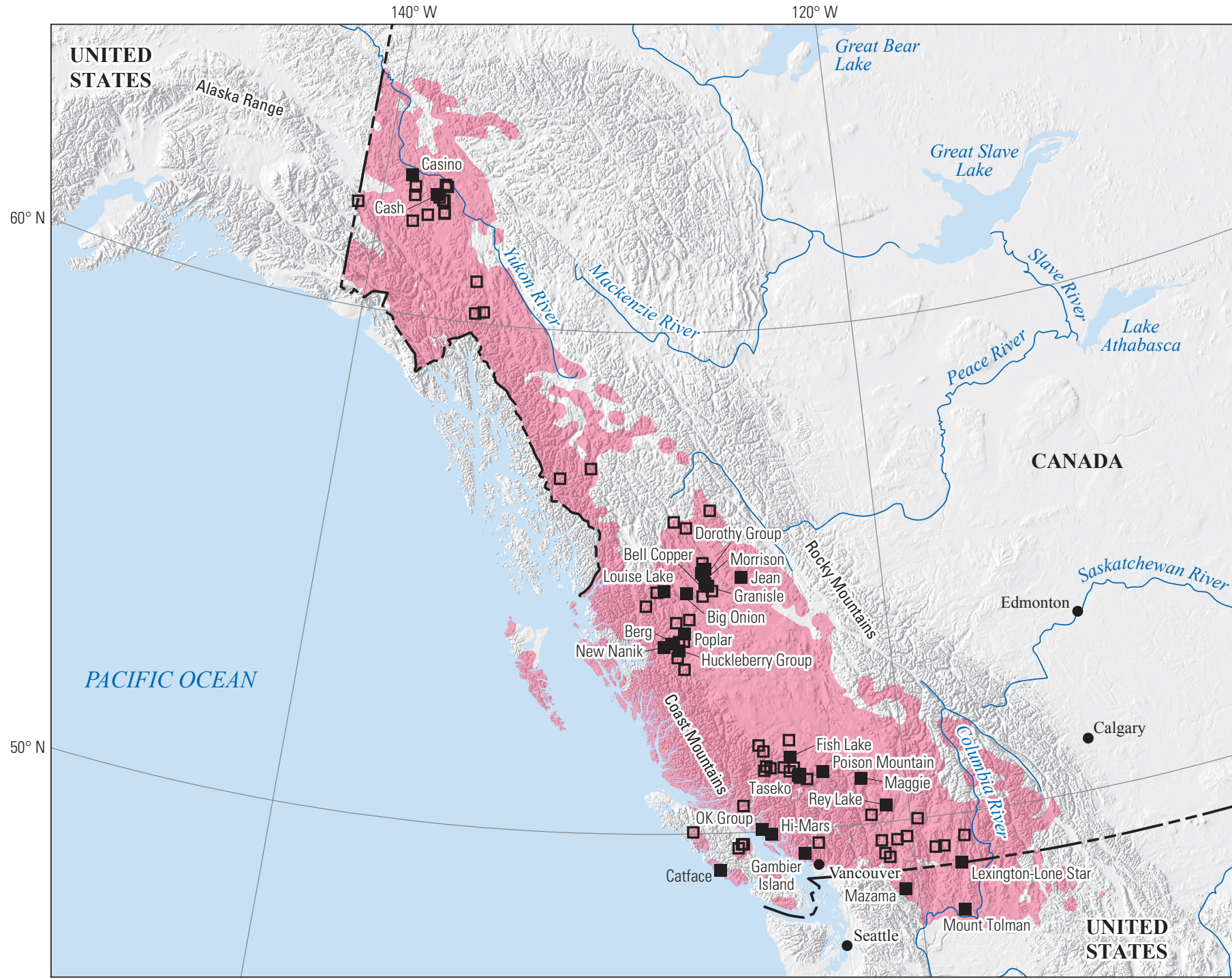

Political boundaries from U.S. Department of State (2009) Shaded relief from Earth Resources Observation and Science (EROS) Center (2011)

Canada Albers Equal-Area Conic projection

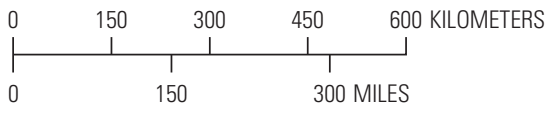

Central meridian $128^{\circ} \mathrm{W}$.; latitude of origin $40^{\circ} \mathrm{N}$.

EXPLANATION

Assessed porphyry copper tract 003pCu2004x

- Porphyry copper deposit

口 Porphyry copper prospect

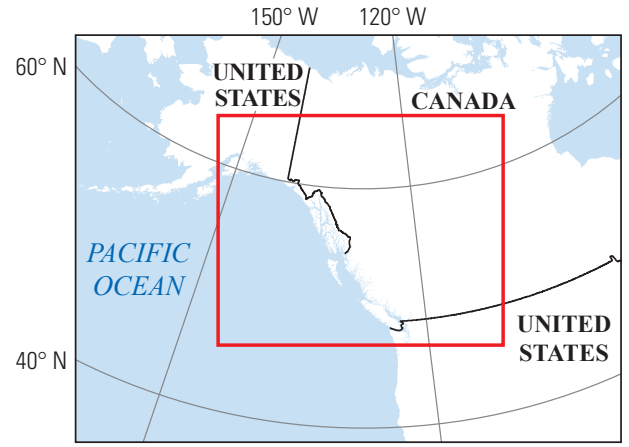




\section{Plate 51. Porphyry Copper Assessment for Tract 003pCu2001x, Intermontane Island Arc, Western Cordillera—Canada and United States}

Descriptive model:

Grade and tonnage model:

Economic filter depth percentages:

Economic filter cost setting:

Geologic feature assessed:

Number of known deposits:
Porphyry copper models (Cox, 1986a; Berger and others, 2008), porphyry copper-gold model (Cox, 1986b), porphyry copper-molybdenum model (Cox, 1986c), porphyry $\mathrm{Cu} \pm \mathrm{Mo} \pm \mathrm{Au}$ model (Panteleyev, 1995a)

Canadian Cordillera porphyry $\mathrm{Cu} \pm \mathrm{Mo} \pm \mathrm{Au}$ model (Frost and others, 2013)

Default -0 to 250 meters (m), $25 \%$; $>250$ to $500 \mathrm{~m}, 25 \%$; $>500 \mathrm{~m}$ to $1 \mathrm{~km}, 50 \%$

Mixed cost

Pre-accretionary Triassic and Jurassic calc-alkalic island arcs that formed offshore of western North America

12

\section{Selected Resource Assessment Results for Porphyry Copper}

[Assessment depth, 1 kilometer (km); $\mathrm{km}^{2}$, square kilometer; Mt, millions of metric tons]

\begin{tabular}{ccccccc}
\hline \multirow{2}{*}{$\begin{array}{c}\text { Date of } \\
\text { assessment }\end{array}$} & $\begin{array}{c}\text { Tract area } \\
\left(\mathbf{k m}^{2}\right)\end{array}$ & $\begin{array}{c}\text { Identified } \\
\text { copper } \\
\text { resources } \\
(\mathbf{M t})\end{array}$ & $\begin{array}{c}\text { Mean estimate of } \\
\text { in-place resources } \\
(\mathbf{M t})\end{array}$ & $\begin{array}{c}\text { Probability of } \mathbf{0} \\
\text { in-place resources } \\
\text { (percent) }\end{array}$ & $\begin{array}{c}\text { Mean estimate of } \\
\text { economic resources } \\
\text { (Mt) }\end{array}$ & $\begin{array}{c}\text { Probability of } \mathbf{0} \\
\text { economic resources } \\
\text { (percent) }\end{array}$ \\
\hline 2013 & 181,190 & 25 & 9.3 & 4 & 2.7 \\
\hline
\end{tabular}

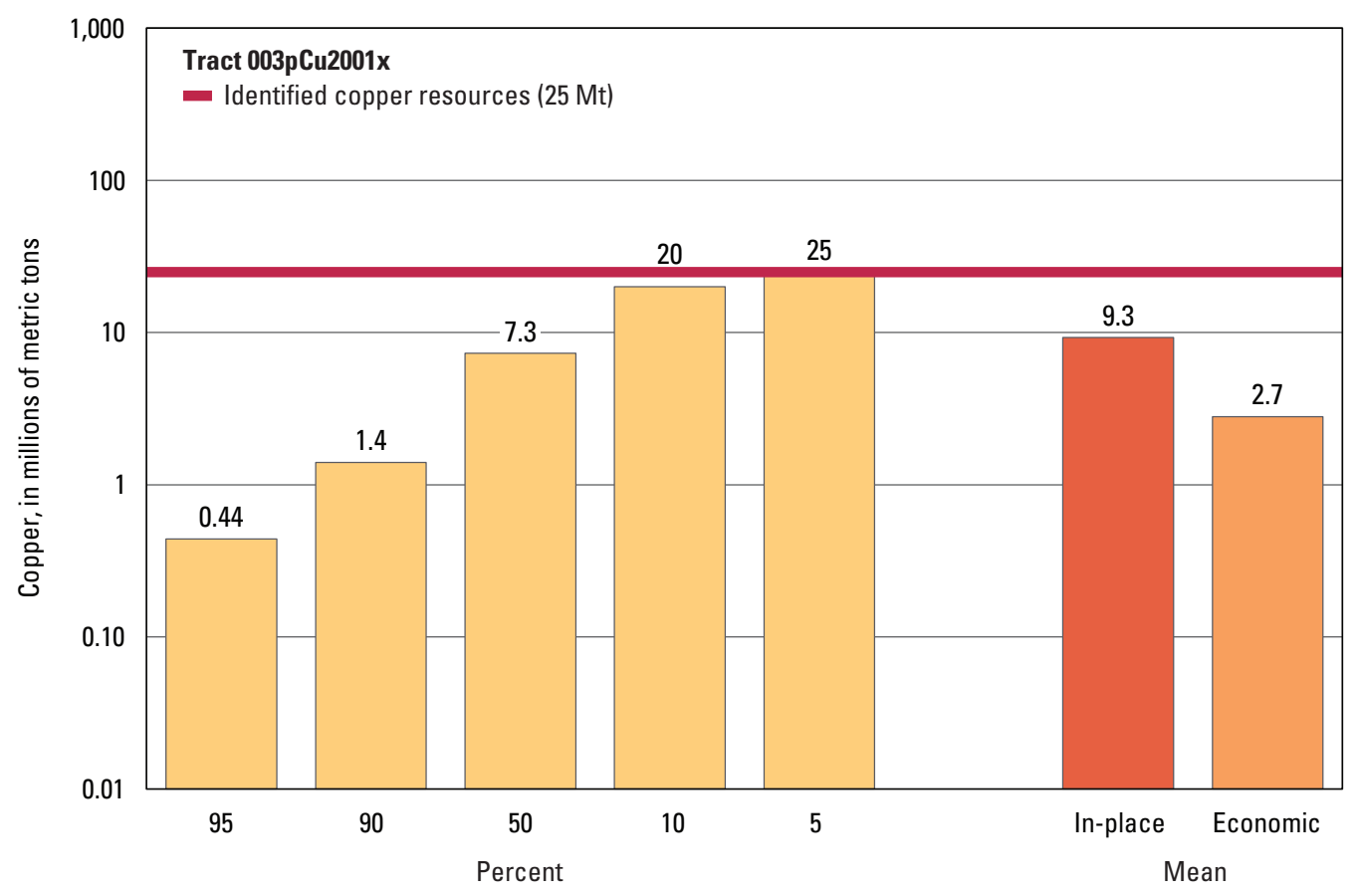

Graph showing the estimated probability distribution of undiscovered copper resources, where each bar represents the minimum amount estimated at the indicated percentage.

\section{Sources}

Mihalasky, Bookstrom, and others, 2013, Porphyry copper assessment of British Columbia and Yukon Territory, Canada (ver. 1.1, February 2013): U.S. Geological Survey Scientific Investigations Report 2010-5090-C, http://pubs.usgs.gov/sir/2010/5090/c/.

U.S. Geological Survey National Mineral Resource Assessment Team, 2002, Assessment of undiscovered deposits of gold, silver, copper, lead, and zinc in the United States: U.S. Geological Survey Open-File Report 02-198, http://pubs.usgs.gov/of/2002/of02-198/. 


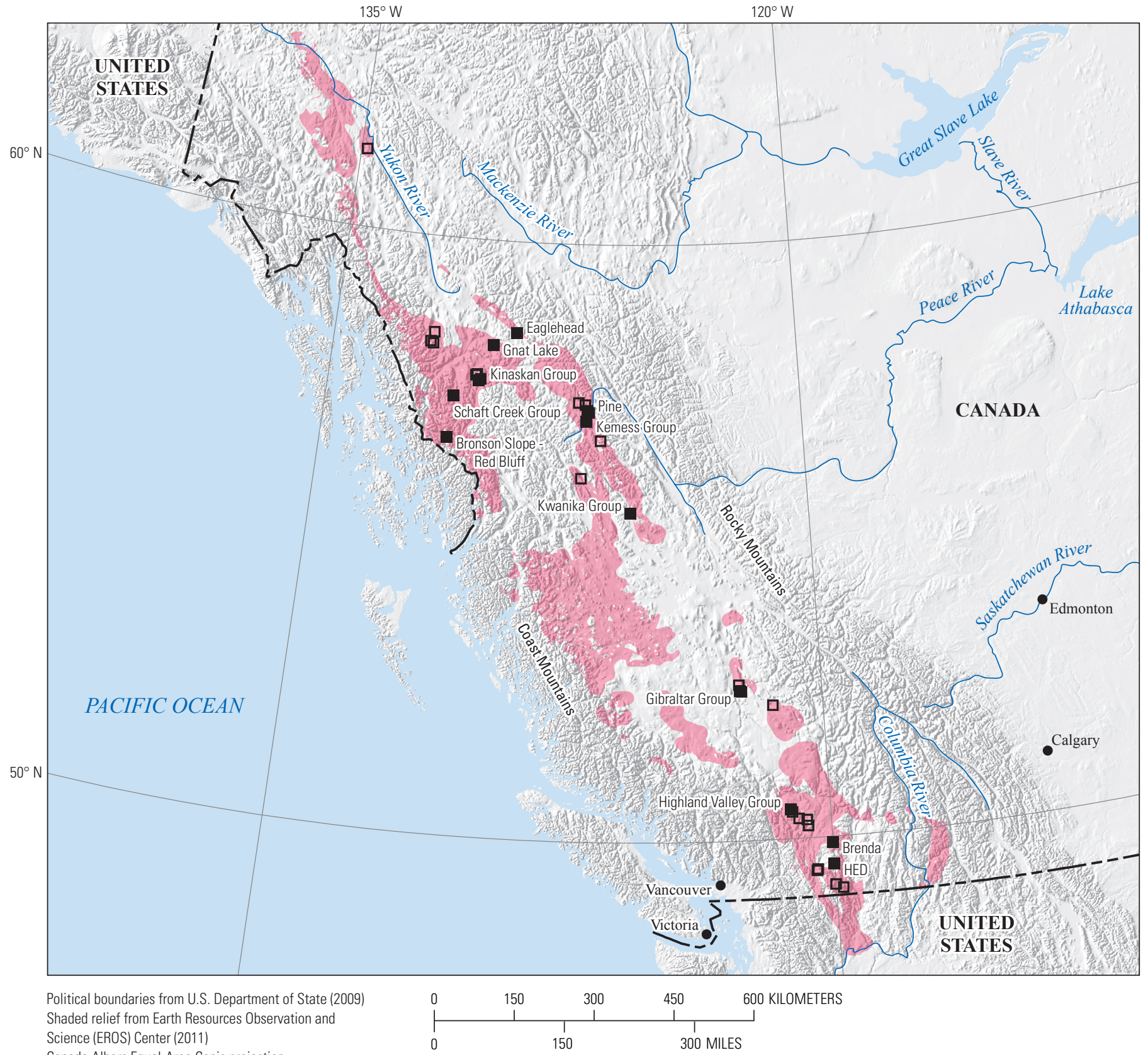

Canada Albers Equal-Area Conic projection

Central meridian $125 \mathrm{~W}$; ; latitude of origin $40^{\circ} \mathrm{N}$.

\section{EXPLANATION}

Assessed porphyry copper tract 003pCu2001x

- Porphyry copper deposit

ㅁ Porphyry copper prospect

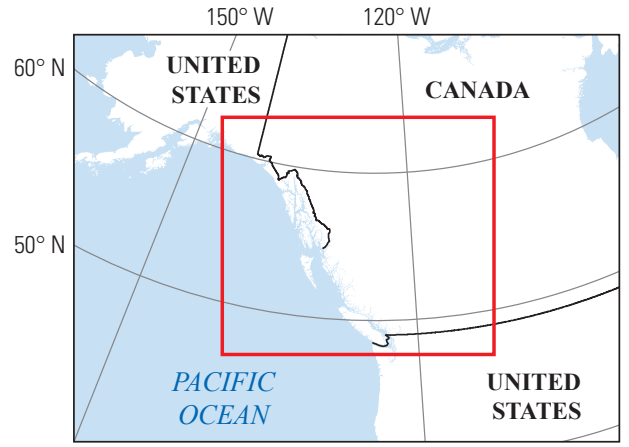




\title{
Plate 52. Porphyry Copper Assessment for Tract 003pCu2005, Late Continental Arc-British Columbia and Yukon Territory, Canada
}

\author{
Descriptive model: \\ Porphyry copper models (Cox, 1986a; Berger and others, 2008), porphyry copper-gold model \\ (Cox, 1986b), porphyry copper-molybdenum model (Cox, 1986c), porphyry $\mathrm{Cu} \pm \mathrm{Mo} \pm \mathrm{Au}$ model \\ (Panteleyev, 1995a) \\ Grade and tonnage model: \\ Canadian Cordillera porphyry $\mathrm{Cu} \pm \mathrm{Mo} \pm \mathrm{Au}$ (Frost and others, 2013) \\ Economic filter depth percentages: \\ Skewed shallow-0 to 250 meters (m), $35 \% ;>250$ to $500 \mathrm{~m}, 25 \% ;>500 \mathrm{~m}$ to $1 \mathrm{~km}, 40 \%$ \\ Economic filter cost setting: \\ Geologic feature assessed: \\ Mixed cost \\ Porphyry copper systems associated with predominantly calc-alkalic igneous rocks of \\ postaccretionary continental magmatic arcs (Oligocene-Pliocene) \\ Number of known deposits: \\ 1
}

\section{Selected Resource Assessment Results for Porphyry Copper}

[Assessment depth, 1 kilometer ( $\mathrm{km}) ; \mathrm{km}^{2}$, square kilometer; Mt, millions of metric tons]

\begin{tabular}{ccccccc}
\hline \multirow{2}{*}{$\begin{array}{c}\text { Date of } \\
\text { assessment }\end{array}$} & $\begin{array}{c}\text { Tract area } \\
\left(\mathbf{k m}^{2}\right)\end{array}$ & $\begin{array}{c}\text { Identified } \\
\text { copper } \\
\text { resources } \\
(\mathbf{M t})\end{array}$ & $\begin{array}{c}\text { Mean estimate of } \\
\text { in-place resources } \\
\text { (Mt) }\end{array}$ & $\begin{array}{c}\text { Probability of 0 } \\
\text { in-place resources } \\
\text { (percent) }\end{array}$ & $\begin{array}{c}\text { Mean estimate of } \\
\text { economic resources } \\
\text { (Mt) }\end{array}$ & $\begin{array}{c}\text { Probability of 0 } \\
\text { economic resources } \\
\text { (percent) }\end{array}$ \\
\hline 2013 & 32,843 & 0.22 & 1.8 & 29 & 0.40
\end{tabular}

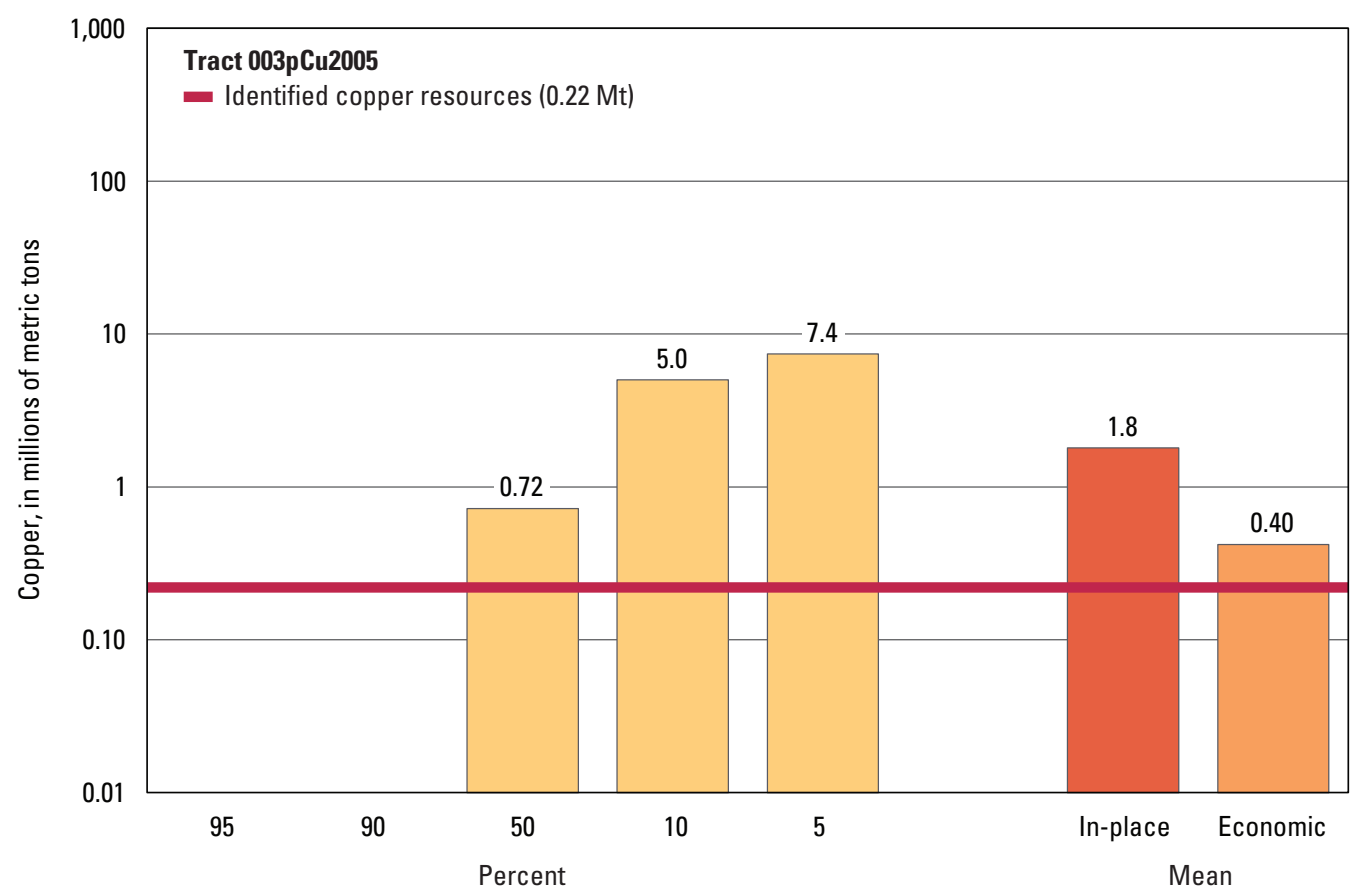

Graph showing the estimated probability distribution of undiscovered copper resources, where each bar represents the minimum amount estimated at the indicated percentage.

\section{Source}

Mihalasky, Bookstrom, and others, 2013, Porphyry copper assessment of British Columbia and Yukon Territory, Canada (ver. 1.1, February 2013): U.S. Geological Survey Scientific Investigations Report 2010-5090-C, http://pubs.usgs.gov/sir/2010/5090/c/. 


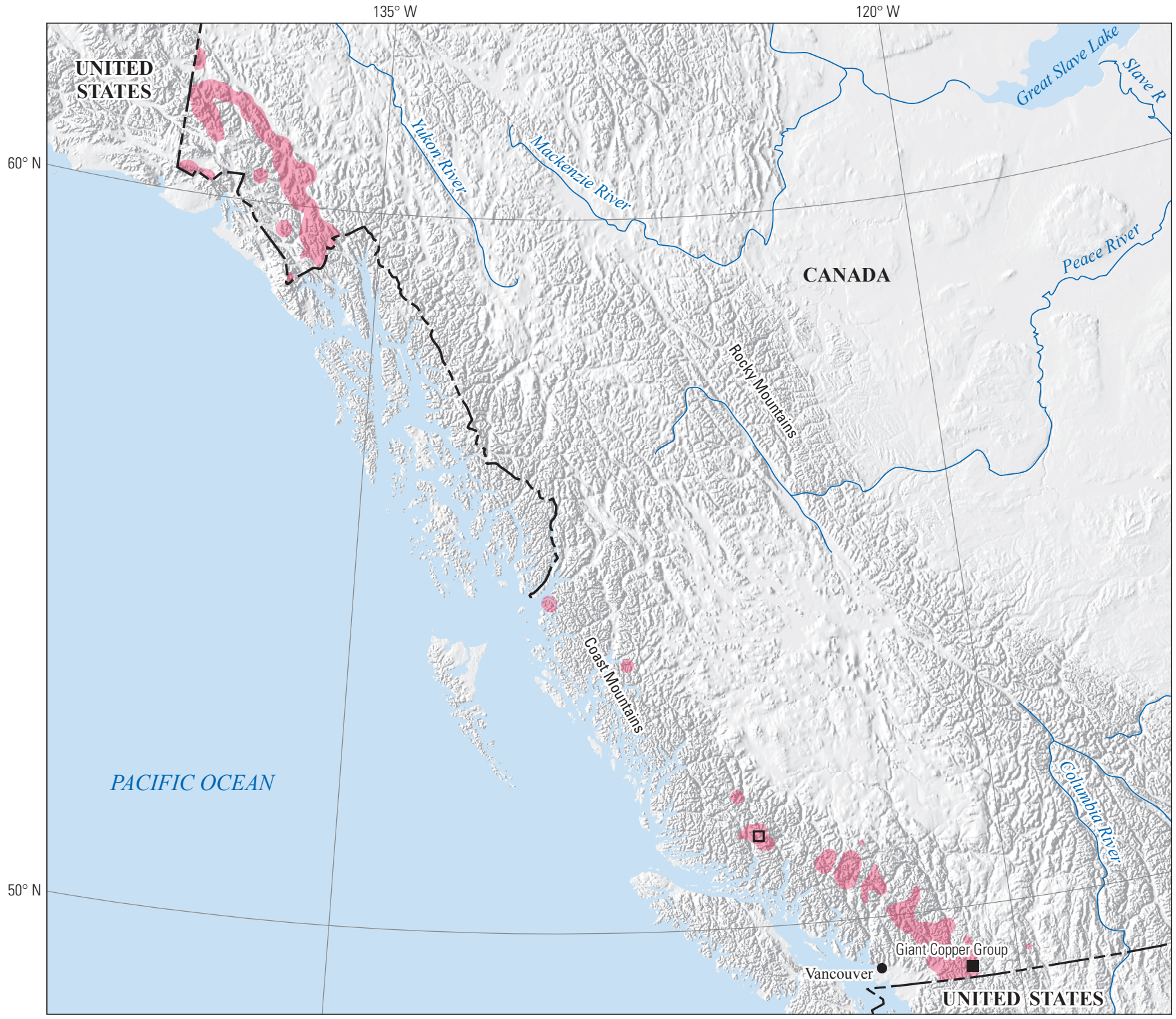

Political boundaries from U.S. Department of State (2009)

Shaded relief from Earth Resources Observation and Science (EROS) Center (2011)

Canada Albers Equal-Area Conic projection

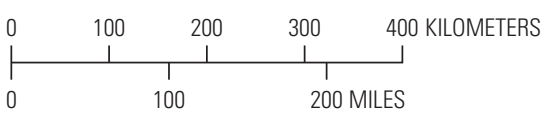

Central meridian $130^{\circ} \mathrm{W}$.; latitude of origin $40^{\circ} \mathrm{N}$.

EXPLANATION

\section{Ay Assessed porphyry copper tract $003 p C u 2005$}

- Porphyry copper deposit

․ Porphyry copper prospect

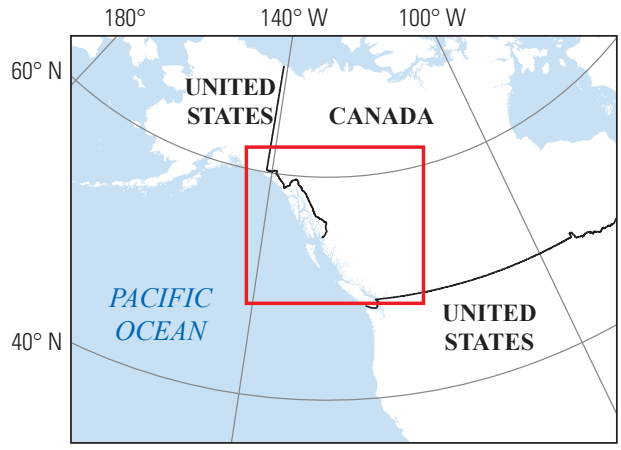




\title{
Plate 53. Porphyry Copper Assessment for Tract 003pCu5005, Southeast Alaska Tertiary-Alaska, United States
}

\author{
Descriptive model: \\ Porphyry copper model (Cox, 1986a) \\ Grade and tonnage model: \\ General porphyry copper model (Singer, Berger, and Moring, 2008) \\ Economic filter depth percentages: \\ Economic filter cost setting: \\ Geologic feature assessed: \\ Skewed shallow-0 to 250 meters (m), $35 \% ;>250$ to $500 \mathrm{~m}, 25 \% ;>500 \mathrm{~m}$ to $1 \mathrm{~km}, 40 \%$ \\ High cost \\ Tertiary subduction and postsubduction calc-alkalic plutons of southeastern Alaska \\ Number of known deposits: \\ 2
}

\section{Selected Resource Assessment Results for Porphyry Copper}

[Assessment depth, 1 kilometer $(\mathrm{km}) ; \mathrm{km}^{2}$, square kilometer; Mt, millions of metric tons]

\begin{tabular}{ccccccc}
\hline \multirow{2}{*}{$\begin{array}{c}\text { Date of } \\
\text { assessment }\end{array}$} & $\begin{array}{c}\text { Tract area } \\
\left.\mathbf{( k m}^{2}\right)\end{array}$ & $\begin{array}{c}\text { Identified } \\
\text { copper } \\
\text { resources } \\
(\mathbf{M t})\end{array}$ & $\begin{array}{c}\text { Mean estimate of } \\
\text { in-place resources } \\
(\mathbf{M t})\end{array}$ & $\begin{array}{c}\text { Probability of } \mathbf{0} \\
\text { in-place resources } \\
\text { (percent) }\end{array}$ & $\begin{array}{c}\text { Mean estimate of } \\
\text { economic resources } \\
\text { (Mt) }\end{array}$ & $\begin{array}{c}\text { Probability of 0 } \\
\text { economic resources } \\
\text { (percent) }\end{array}$ \\
\hline 2012 & 9,970 & 0.51 & 6.1 & 57 & 3.2 \\
\hline
\end{tabular}

"Updated by the assessment team in 2012 to conform with project protocols and apply the 2008 grade and tonnage model; see text in chapter A.

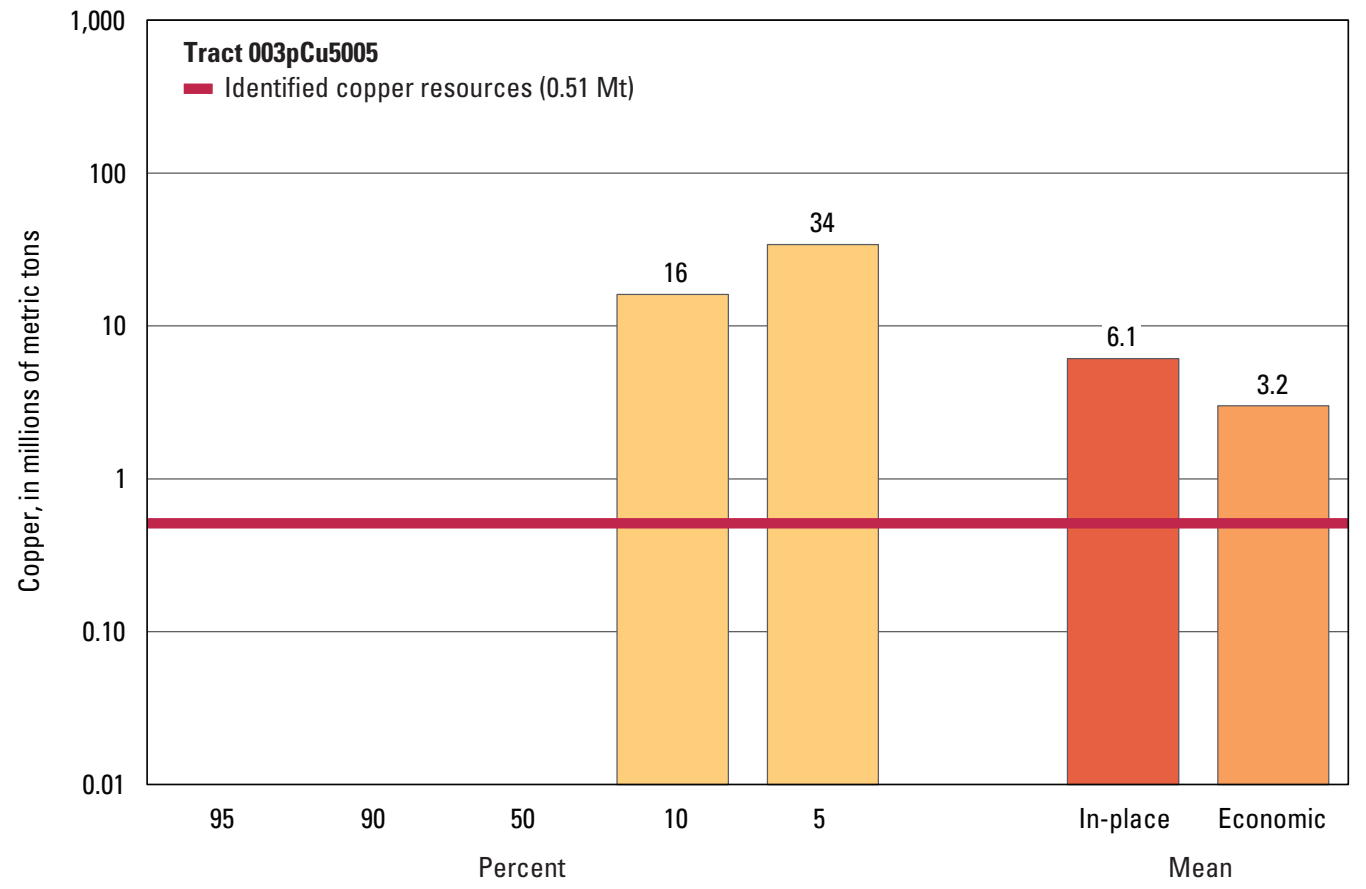

Graph showing the estimated probability distribution of undiscovered copper resources, where each bar represents the minimum amount estimated at the indicated percentage.

\section{Source}

U.S. Geological Survey National Mineral Resource Assessment Team, 2002, Assessment of undiscovered deposits of gold, silver, copper, lead, and zinc in the United States: U.S. Geological Survey Open-File Report 02-198, http://pubs.usgs.gov/of/2002/of02-198/. 

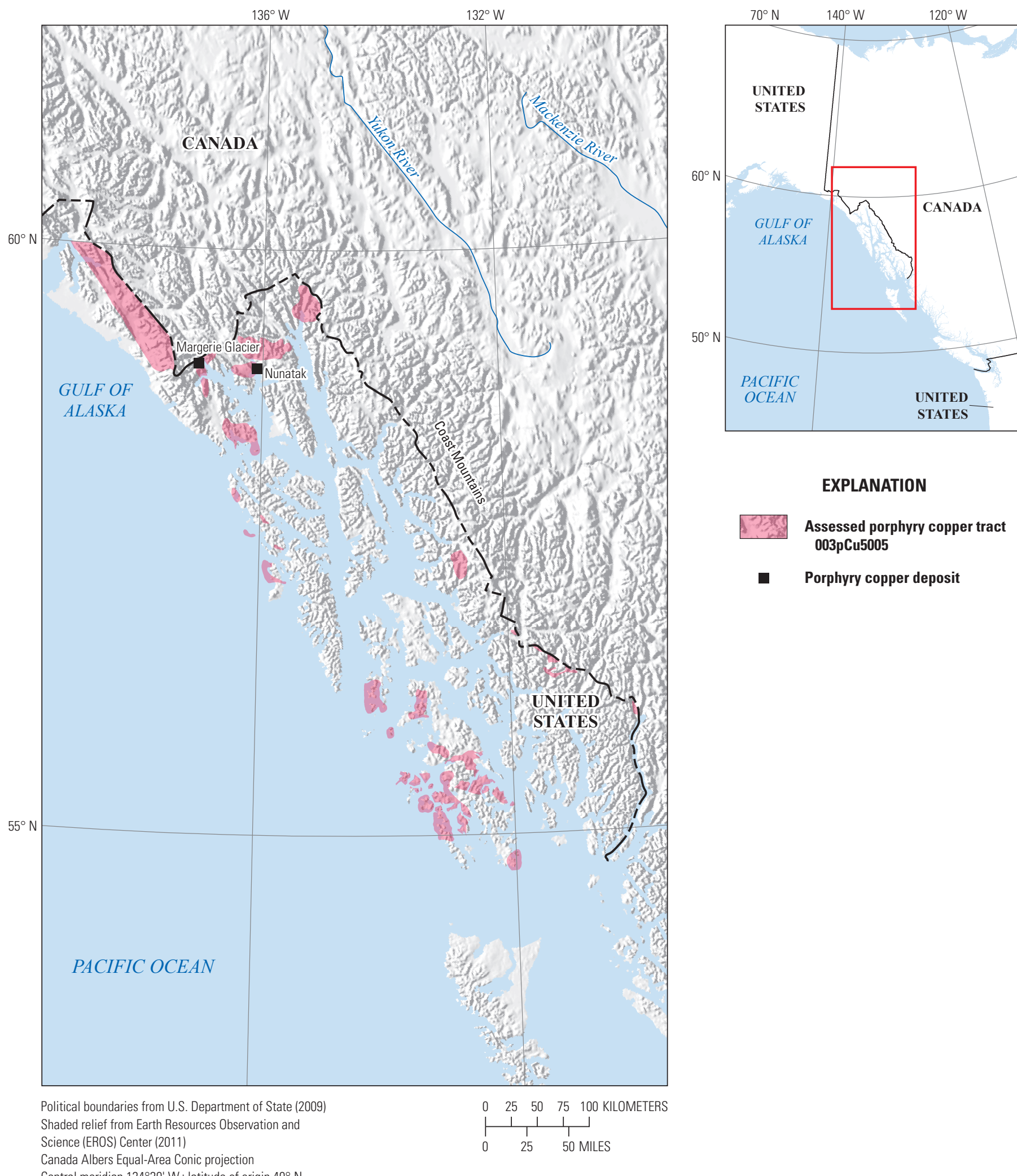

EXPLANATION

Assessed porphyry copper tract 003pCu5005

Porphyry copper deposit 


\title{
Plate 54. Porphyry Copper Assessment for Tract 003pCu5001, Skolai Arc- Eastern Alaska, United States
}

\author{
Descriptive model: \\ Porphyry copper model (Cox, 1986a) \\ Grade and tonnage model: \\ General porphyry copper model (Singer, Berger, and Moring, 2008) \\ Economic filter depth percentages: \\ Economic filter cost setting: \\ Geologic feature assessed: \\ Skewed deep - 0 to 250 meters (m), 10\%; > 250 to $500 \mathrm{~m}, 30 \%$; >500 m to $1 \mathrm{~km}, 60 \%$ \\ High cost \\ Late Paleozoic Skolai arc of the Wrangellia terrane; south of the Denali fault \\ Number of known deposits: \\ 0
}

\section{Selected Resource Assessment Results for Porphyry Copper}

[Assessment depth, 1 kilometer $(\mathrm{km}) ; \mathrm{km}^{2}$, square kilometer; Mt, millions of metric tons]

\begin{tabular}{ccccccc}
\hline \multirow{2}{*}{$\begin{array}{c}\text { Date of } \\
\text { assessment }\end{array}$} & $\begin{array}{c}\text { Tract area } \\
\left.\mathbf{( k m}^{2}\right)\end{array}$ & $\begin{array}{c}\text { Identified } \\
\text { copper } \\
\text { resources } \\
(\mathbf{M t})\end{array}$ & $\begin{array}{c}\text { Mean estimate of } \\
\text { in-place resources } \\
(\mathbf{M t})\end{array}$ & $\begin{array}{c}\text { Probability of } \mathbf{0} \\
\text { in-place resources } \\
\text { (percent) }\end{array}$ & $\begin{array}{c}\text { Mean estimate of } \\
\text { economic resources } \\
\text { (Mt) }\end{array}$ & $\begin{array}{c}\text { Probability of } 0 \\
\text { economic resources } \\
\text { (percent) }\end{array}$ \\
\hline 2012 & 17,154 & 0 & 1.7 & 71 & 0.76 \\
\hline
\end{tabular}

"Updated by the assessment team in 2012 to conform with project protocols and apply the 2008 grade and tonnage model; see text in chapter A.

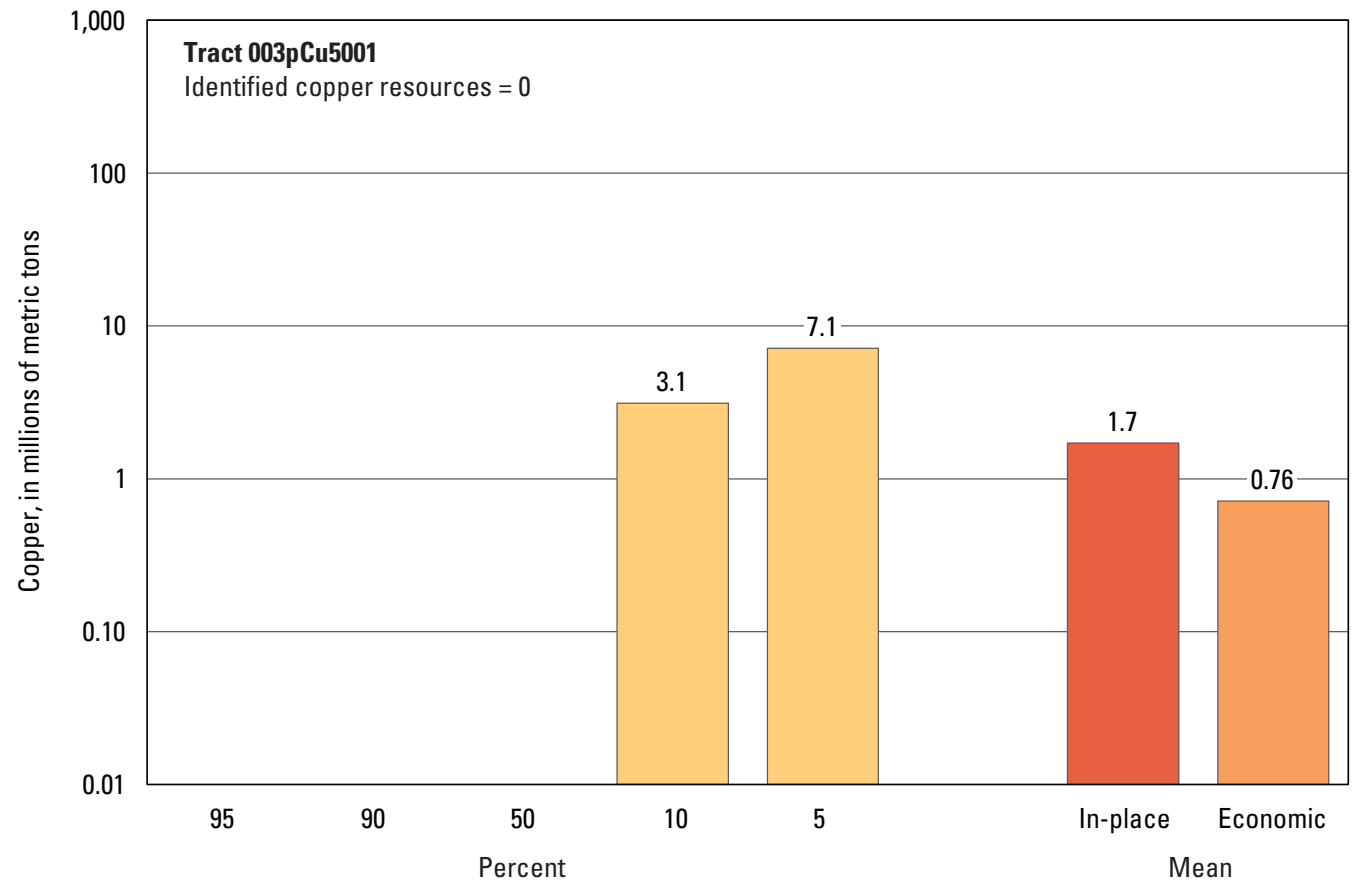

Graph showing the estimated probability distribution of undiscovered copper resources, where each bar represents the minimum amount estimated at the indicated percentage.

\section{Source}

U.S. Geological Survey National Mineral Resource Assessment Team, 2002, Assessment of undiscovered deposits of gold, silver, copper, lead, and zinc in the United States: U.S. Geological Survey Open-File Report 02-198, http://pubs.usgs.gov/of/2002/of02-198/. 


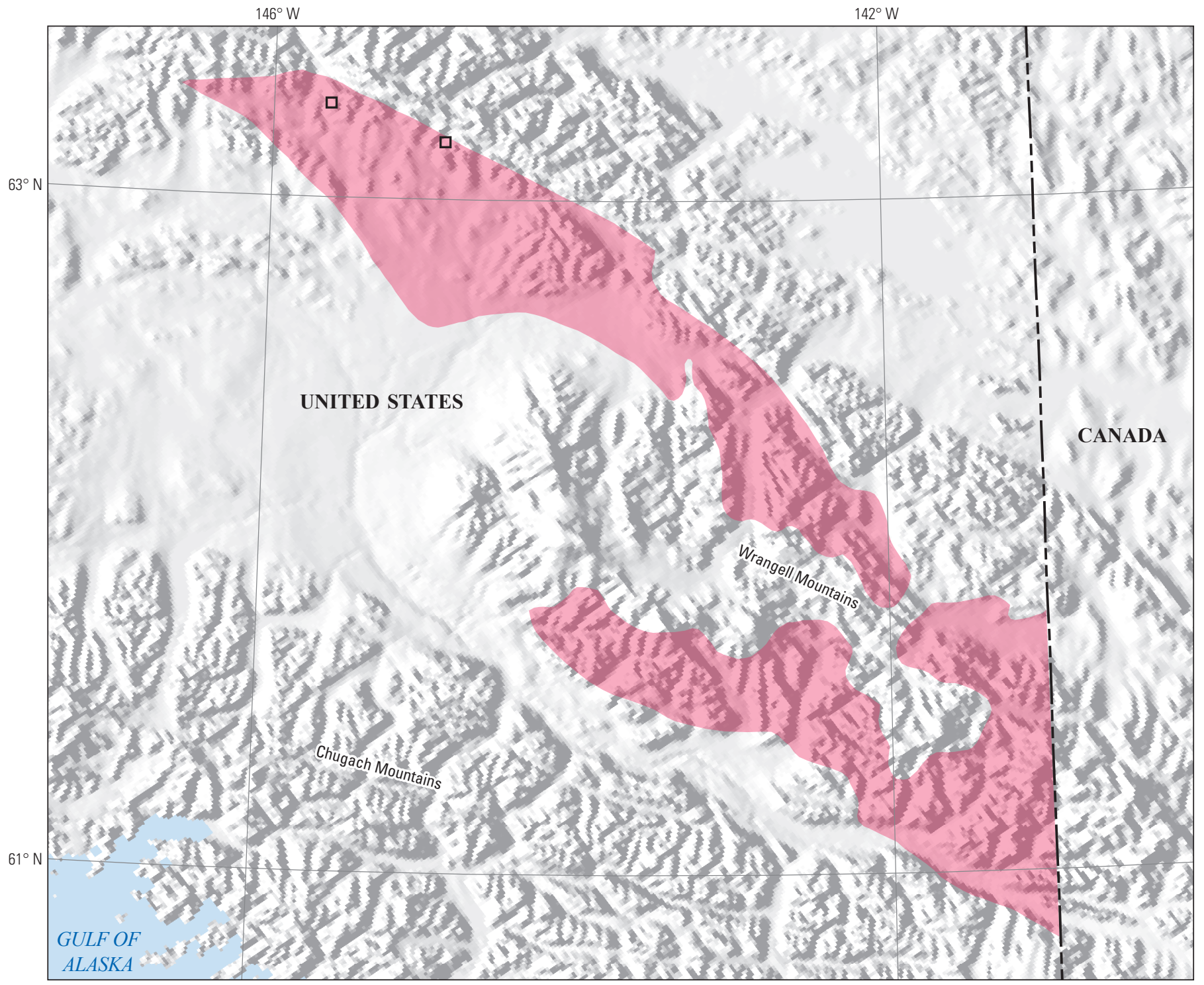

Political boundaries from U.S. Department of State (2009) Shaded relief from Earth Resources Observation and Science (EROS) Center (2011)

\begin{tabular}{ccccc}
0 & 25 & 50 & 75 & 100 KILOMETERS \\
\hline & 1 & 1 & 1 & \multicolumn{1}{|c|}{$\mid$} \\
0 & & 1 & 25 & MILES
\end{tabular}

Alaska Albers Equal-Area Conic projection

Central meridian $143^{\circ} 30^{\prime} \mathrm{W}$.; latitude of origin $50^{\circ} \mathrm{N}$.

\section{EXPLANATION}

Assessed porphyry copper tract 003pCu5001

ㅁ Porphyry copper prospect

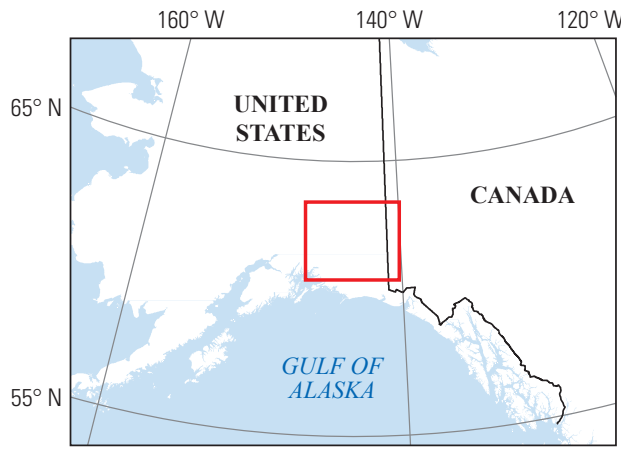




\title{
Plate 55. Porphyry Copper Assessment for Tract 003pCu5002, Eastern Alaska Range and Wrangell Mountains-Alaska, United States
}

\author{
Descriptive model: \\ Porphyry copper model (Cox, 1986a) \\ Grade and tonnage model: \\ Canadian Cordillera porphyry $\mathrm{Cu} \pm \mathrm{Mo} \pm \mathrm{Au}$ model (Frost and others, 2013) \\ Economic filter depth percentages: \\ Economic filter cost setting: \\ Skewed deep - 0 to 250 meters (m), 10\%; > 250 to $500 \mathrm{~m}, 30 \%$; >500 m to $1 \mathrm{~km}, 60 \%$ \\ High cost \\ Geologic feature assessed: \\ Cretaceous (115-105 Ma) deposits and prospects along the Nutzotin Basin-Wrangellia terrane \\ boundary; south of the Denali fault \\ Number of known deposits: \\ 5
}

\section{Selected Resource Assessment Results for Porphyry Copper}

[Assessment depth, 1 kilometer ( $\mathrm{km}) ; \mathrm{km}^{2}$, square kilometer; Mt, millions of metric tons]

\begin{tabular}{ccccccc}
\hline $\begin{array}{c}\text { Date of } \\
\text { assessment }\end{array}$ & $\begin{array}{c}\text { Tract area } \\
\left.\mathbf{( k m}^{2}\right)\end{array}$ & $\begin{array}{c}\text { Identified } \\
\text { copper } \\
\text { resources } \\
\text { (Mt) }\end{array}$ & $\begin{array}{c}\text { Mean estimate of } \\
\text { in-place resources } \\
\text { (Mt) }\end{array}$ & $\begin{array}{c}\text { Pndiscovered copper resource estimates } \\
\text { in-place resources } \\
\text { (percent) }\end{array}$ & $\begin{array}{c}\text { Mean estimate of } \\
\text { economic resources } \\
\text { (Mt) }\end{array}$ & $\begin{array}{c}\text { Probability of 0 } \\
\text { economic resources } \\
\text { (percent) }\end{array}$ \\
\hline 2013 & 37,675 & 3.0 & 21 & 2 & 0.48 \\
\hline
\end{tabular}

*Updated by the assessment team in 2013 to conform with project protocols and apply the 2013 grade and tonnage model; see text in chapter A.

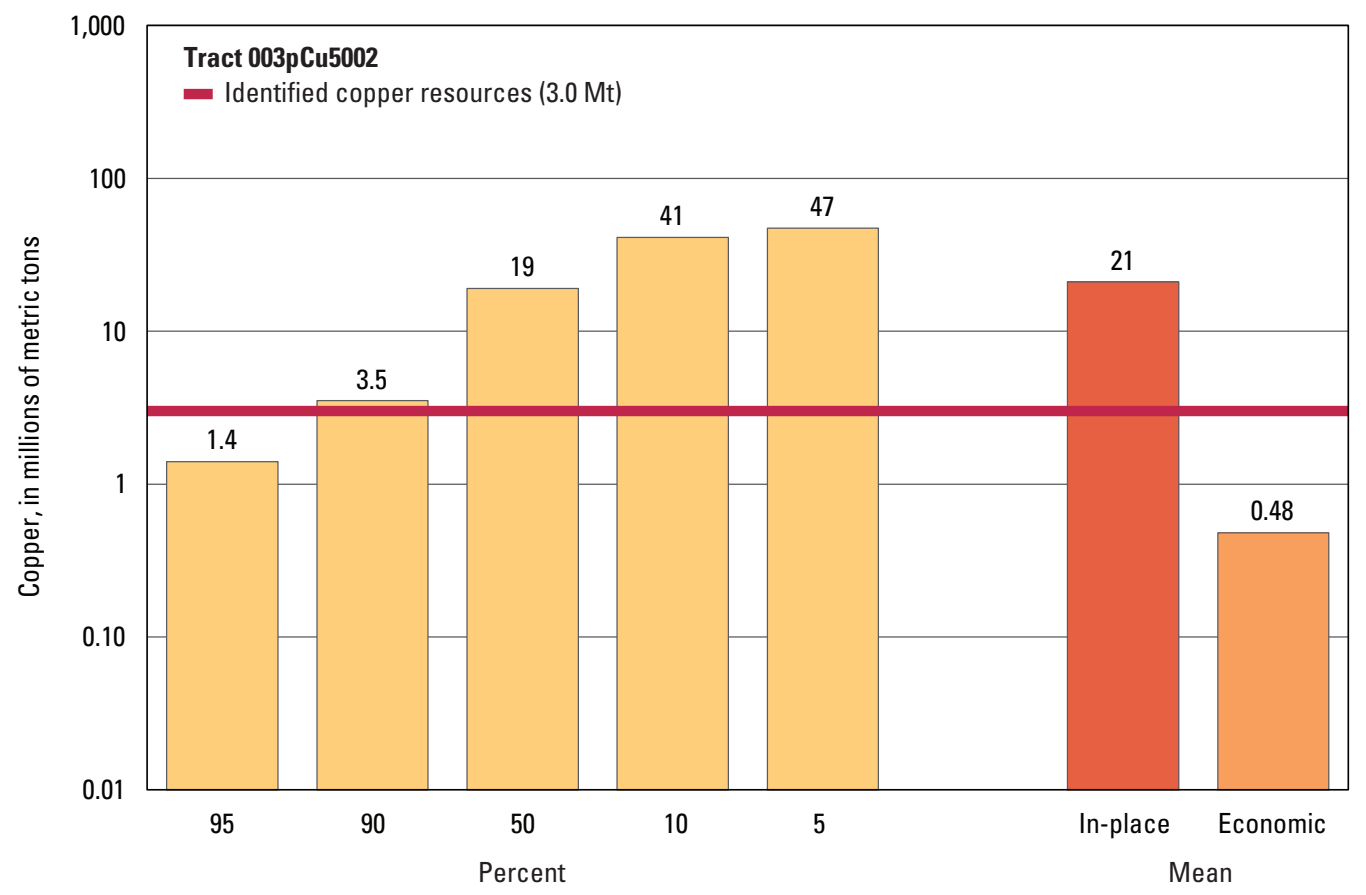

Graph showing the estimated probability distribution of undiscovered copper resources, where each bar represents the minimum amount estimated at the indicated percentage.

\section{Source}

U.S. Geological Survey National Mineral Resource Assessment Team, 2002, Assessment of undiscovered deposits of gold, silver, copper, lead, and zinc in the United States: U.S. Geological Survey Open-File Report 02-198, http://pubs.usgs.gov/of/2002/of02-198/. 


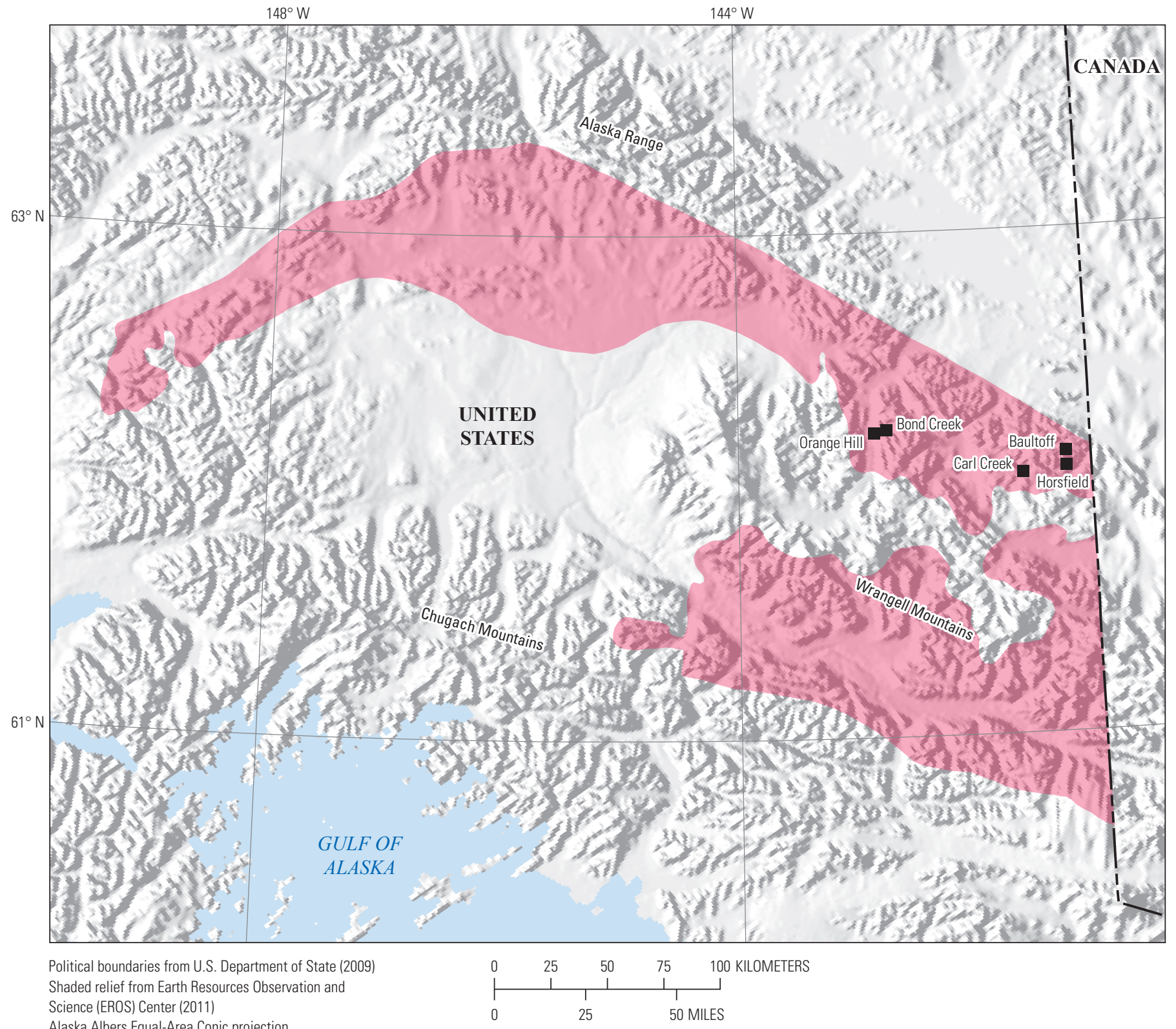

Alaska Albers Equal-Area Conic projection

Central meridian $145^{\circ} \mathrm{W}$.; latitude of origin $50^{\circ} \mathrm{N}$.

\section{EXPLANATION}

Assessed porphyry copper tract $003 p C u 5002$

Porphyry copper deposit

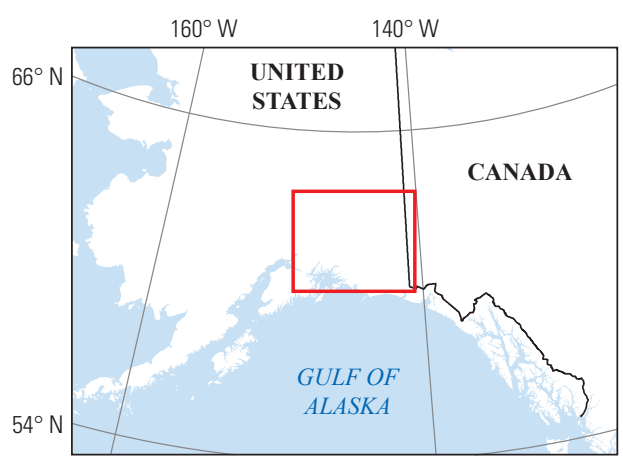




\section{Plate 56. Porphyry Copper Assessment for Tract 003pCu5003, Yukon-Tanana Upland-Alaska, United States}

\author{
Descriptive model: \\ Grade and tonnage model: \\ Economic filter depth percentages: \\ Economic filter cost setting: \\ Geologic feature assessed:
}

Number of known deposits:

\author{
Porphyry copper model (Cox, 1986a) \\ Canadian Cordillera porphyry $\mathrm{Cu} \pm \mathrm{Mo} \pm \mathrm{Au}$ model (Frost and others, 2013) \\ Skewed deep - 0 to 250 meters (m), 10\%; > 250 to $500 \mathrm{~m}, 30 \%$; >500 m to $1 \mathrm{~km}, 60 \%$ \\ High cost \\ Kluane arc and Tertiary Kuskokwim Mountains volcanic-plutonic belt (continuation of Canadian \\ Cordilleran continental arc) north of the Denali fault; see plate 50 for adjacent areas in Canada \\ and the conterminous United States
}

2

\section{Selected Resource Assessment Results for Porphyry Copper}

[Assessment depth, 1 kilometer (km); $\mathrm{km}^{2}$, square kilometer; Mt, millions of metric tons]

\begin{tabular}{|c|c|c|c|c|c|c|}
\hline \multirow[b]{2}{*}{$\begin{array}{c}\text { Date of } \\
\text { assessment }^{*}\end{array}$} & \multirow[b]{2}{*}{$\begin{array}{c}\text { Tract area } \\
\left(\mathbf{k m}^{2}\right)\end{array}$} & \multirow{2}{*}{$\begin{array}{l}\text { Identified } \\
\text { copper } \\
\text { resources } \\
\text { (Mt) }\end{array}$} & \multicolumn{4}{|c|}{ Undiscovered copper resource estimates } \\
\hline & & & $\begin{array}{l}\text { Mean estimate of } \\
\text { in-place resources } \\
\text { (Mt) }\end{array}$ & $\begin{array}{c}\text { Probability of } 0 \\
\text { in-place resources } \\
\text { (percent) }\end{array}$ & $\begin{array}{l}\text { Mean estimate of } \\
\text { economic resources } \\
\text { (Mt) }\end{array}$ & $\begin{array}{c}\text { Probability of } 0 \\
\text { economic resources } \\
\text { (percent) }\end{array}$ \\
\hline 2013 & 200,514 & 2.4 & 9.1 & 4 & 0.21 & 98 \\
\hline
\end{tabular}

${ }^{*}$ Updated by the assessment team in 2013 to conform with project protocols and apply the 2013 grade and tonnage model; see text in chapter A.

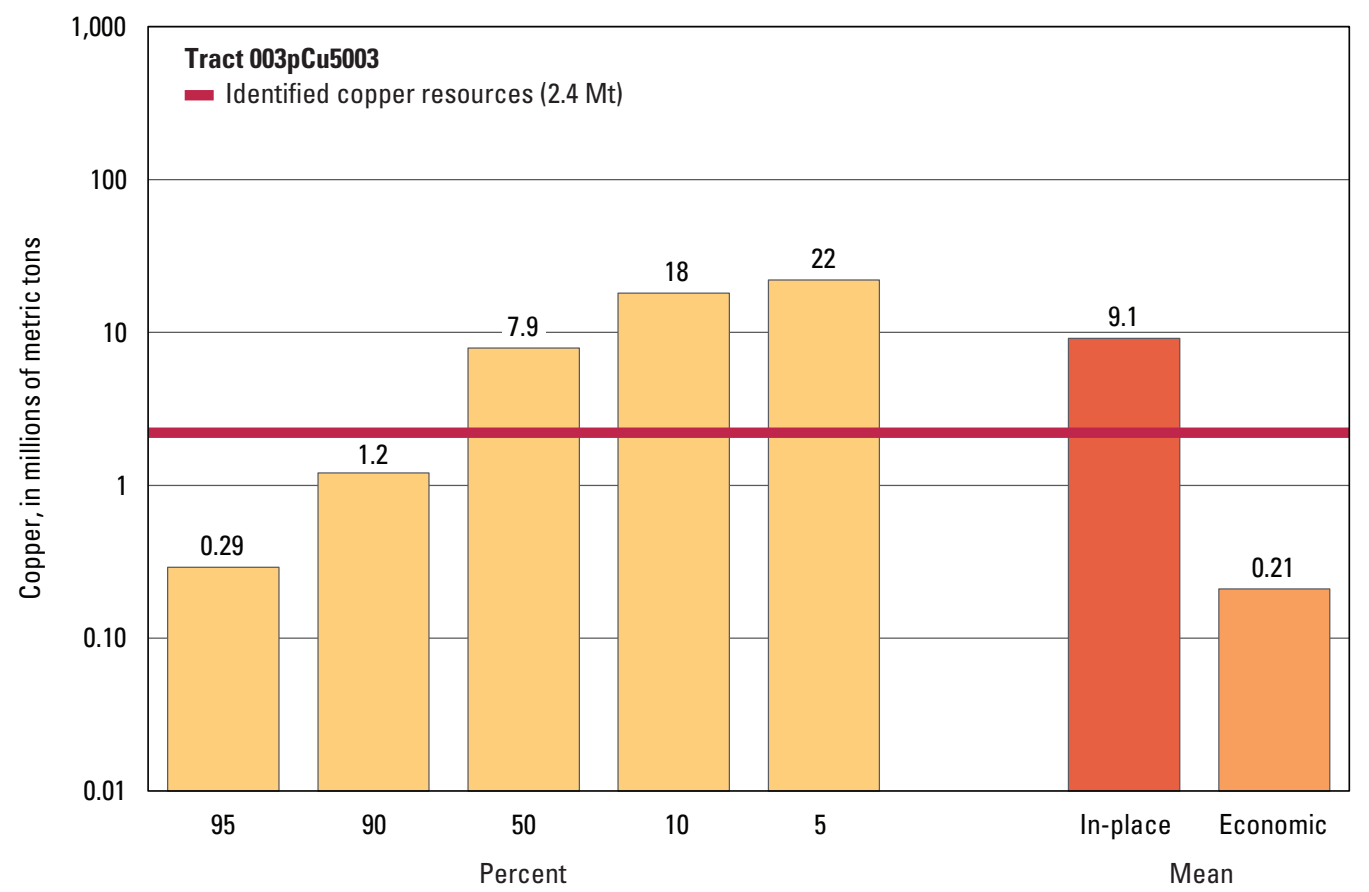

Graph showing the estimated probability distribution of undiscovered copper resources, where each bar represents the minimum amount estimated at the indicated percentage.

\section{Source}

U.S. Geological Survey National Mineral Resource Assessment Team, 2002, Assessment of undiscovered deposits of gold, silver, copper, lead, and zinc in the United States: U.S. Geological Survey Open-File Report 02-198, http://pubs.usgs.gov/of/2002/of02-198/. 


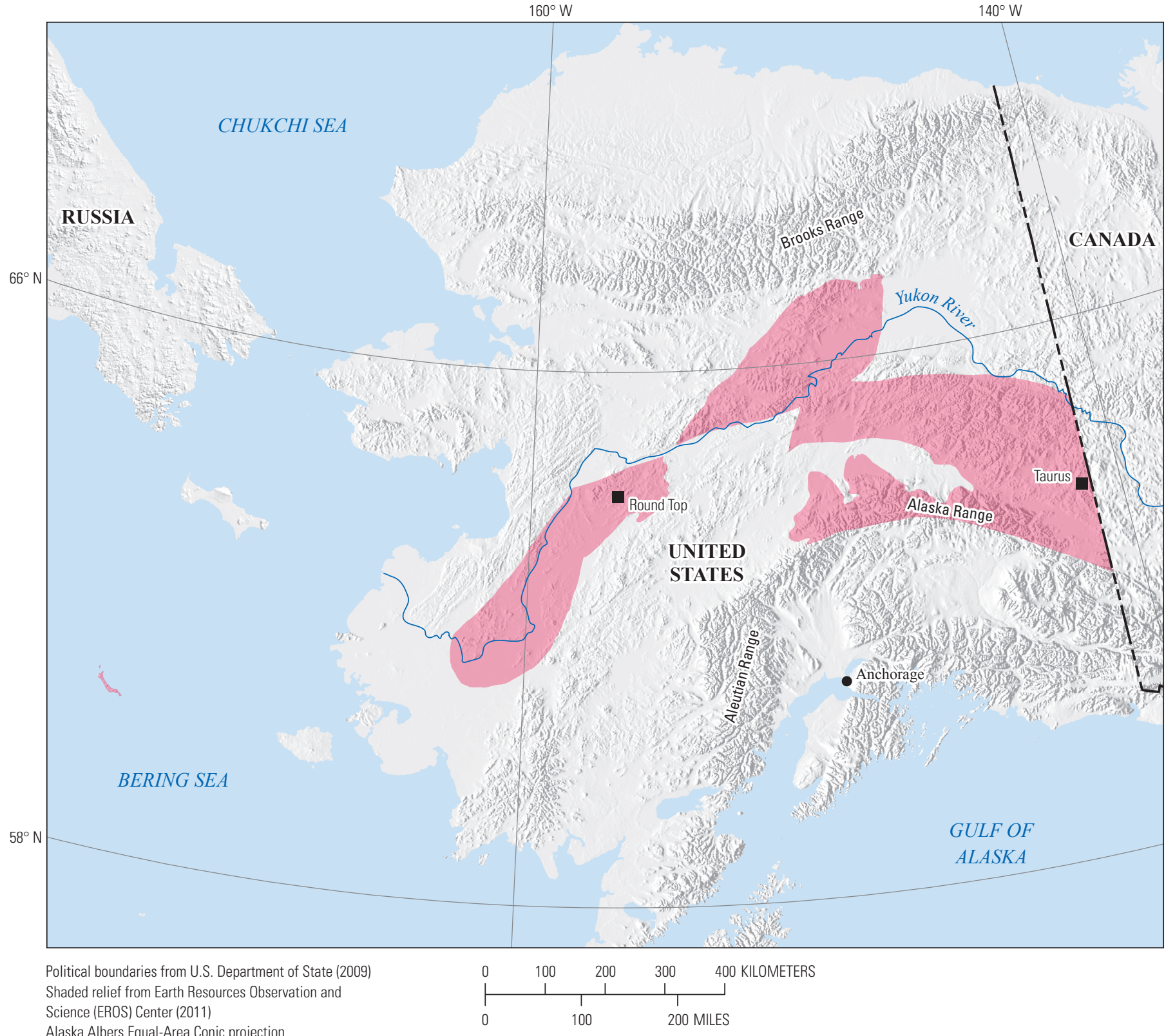

Alaska Albers Equal-Area Conic projection

Central meridian $157^{\circ} \mathrm{W}$; ; latitude of origin $50^{\circ} \mathrm{N}$.

\section{EXPLANATION}

Assessed porphyry copper tract 003pCu5003

- Porphyry copper deposit

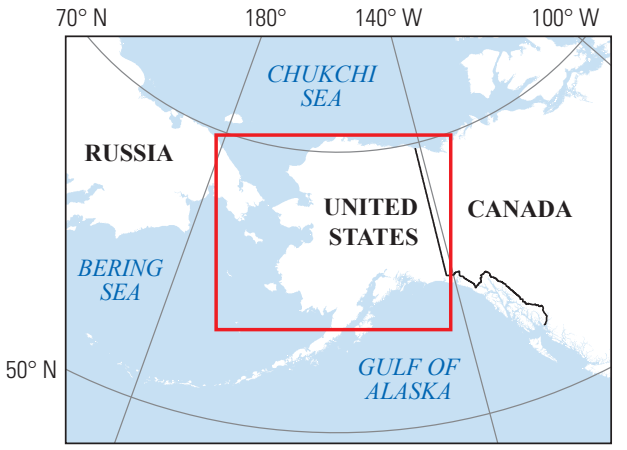




\title{
Plate 57. Porphyry Copper Assessment for Tract 003pCu5004, Western Alaska Range-Alaska, United States
}

\author{
Descriptive model: \\ Porphyry copper model (Cox, 1986a) \\ Grade and tonnage model: \\ General porphyry copper model (Singer, Berger, and Moring, 2008) \\ Economic filter depth percentages: \\ Economic filter cost setting: \\ Custom - 0 to 250 meters (m), 20\%; > 250 to $500 \mathrm{~m}, 30 \%$; >500 m to $1 \mathrm{~km}, 50 \%$ \\ Geologic feature assessed: \\ High cost \\ A belt of Cretaceous and early Tertiary calc-alkalic intrusions along the Kahiltna Basin-Peninsula \\ terrane boundary; includes the supergiant Pebble deposit \\ Number of known deposits: \\ 1
}

\section{Selected Resource Assessment Results for Porphyry Copper}

[Assessment depth, 1 kilometer (km); $\mathrm{km}^{2}$, square kilometer; Mt, millions of metric tons]

\begin{tabular}{ccccccc}
\hline $\begin{array}{c}\text { Date of } \\
\text { assessment }\end{array}$ & $\begin{array}{c}\text { Tract area } \\
\left.\mathbf{( k m}^{2}\right)\end{array}$ & $\begin{array}{c}\text { Identified } \\
\text { copper } \\
\text { resources } \\
\text { (Mt) }\end{array}$ & $\begin{array}{c}\text { Mean estimate of } \\
\text { in-place resources } \\
\text { (Mt) }\end{array}$ & $\begin{array}{c}\text { Pndiscovered copper resource estimates } \\
\text { in-place resources } \\
\text { (percent) }\end{array}$ & $\begin{array}{c}\text { Mean estimate of } \\
\text { economic resources } \\
\text { (Mt) }\end{array}$ & $\begin{array}{c}\text { Probability of 0 } \\
\text { economic resources } \\
\text { (percent) }\end{array}$ \\
\hline 2012 & 125,078 & 37 & 23 & 4 & 11 & 49 \\
\hline
\end{tabular}

"Updated by the assessment team in 2012 to conform with project protocols and apply the 2008 grade and tonnage model; see text in chapter A.

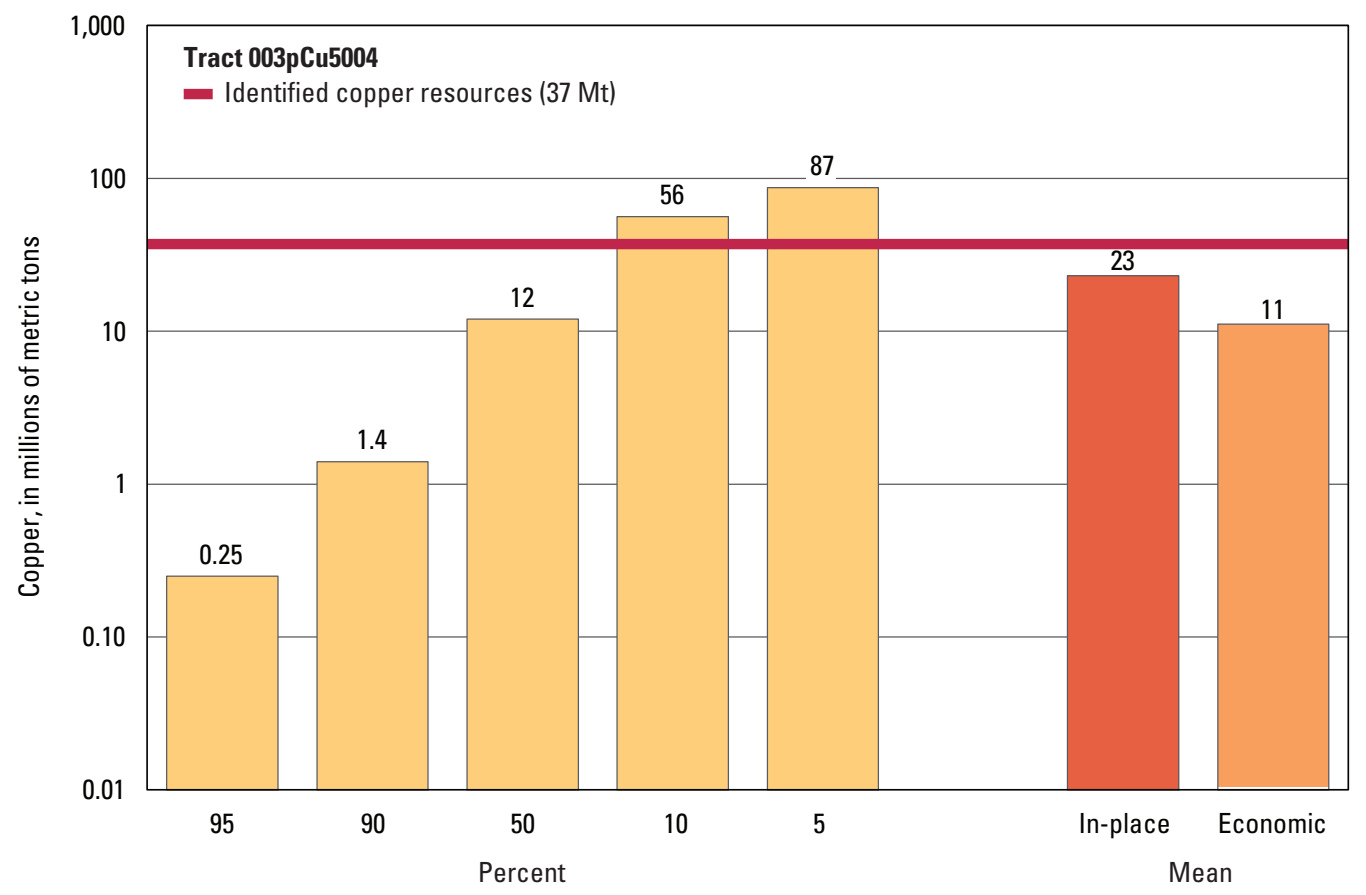

Graph showing the estimated probability distribution of undiscovered copper resources, where each bar represents the minimum amount estimated at the indicated percentage.

\section{Source}

U.S. Geological Survey National Mineral Resource Assessment Team, 2002, Assessment of undiscovered deposits of gold, silver, copper, lead, and zinc in the United States: U.S. Geological Survey Open-File Report 02-198, http://pubs.usgs.gov/of/2002/of02-198/. 


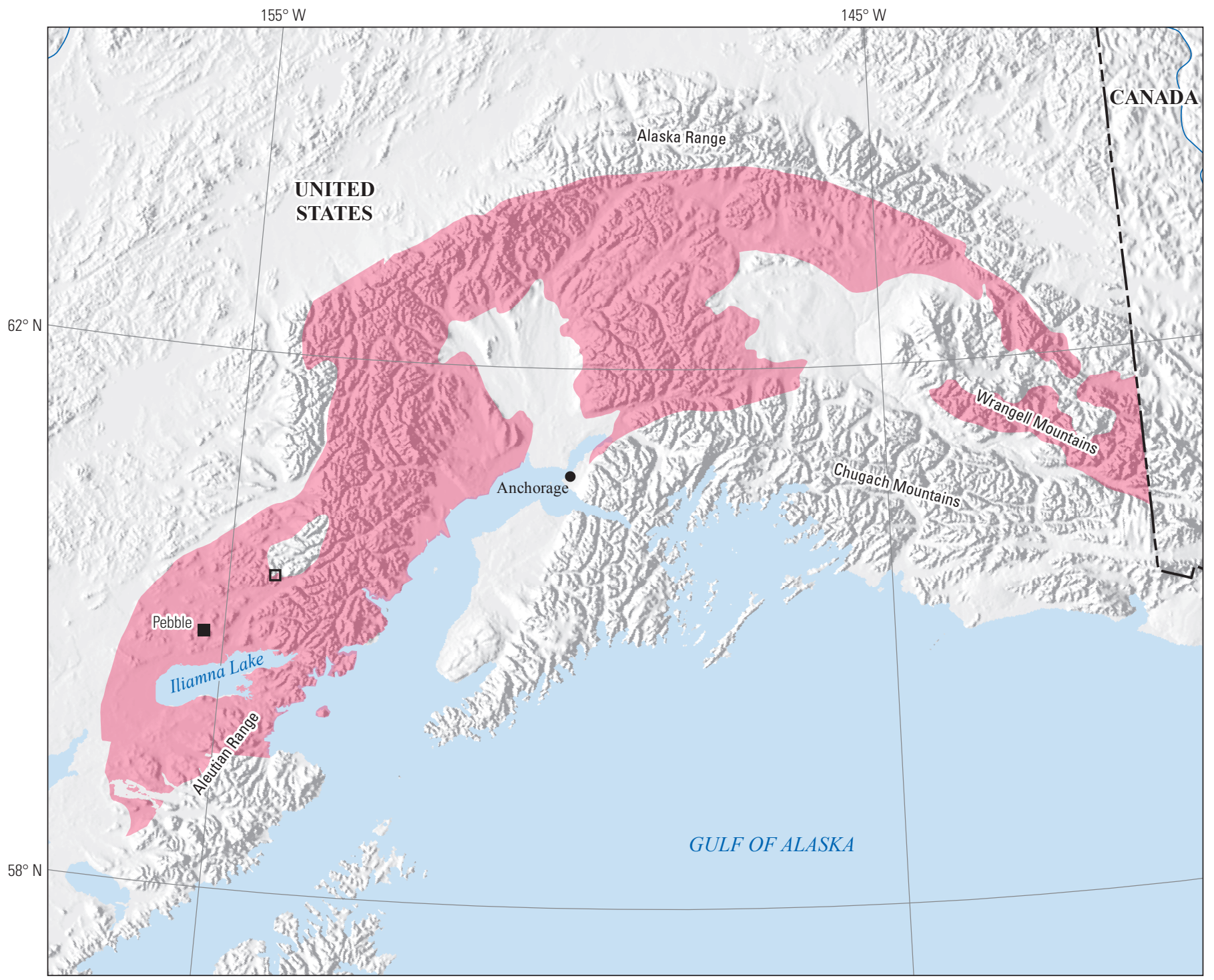

Political boundaries from U.S. Department of State (2009) Shaded relief from Earth Resources Observation and Science (EROS) Center (2011)

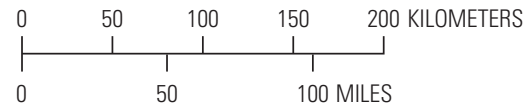

Alaska Albers Equal-Area Conic projection

Central meridian $148^{\circ} 30^{\prime} \mathrm{W}$.; latitude of origin $50^{\circ} \mathrm{N}$

EXPLANATION

14. Assessed porphyry copper tract 003pCu5004

- Porphyry copper deposit

Porphyry copper prospect

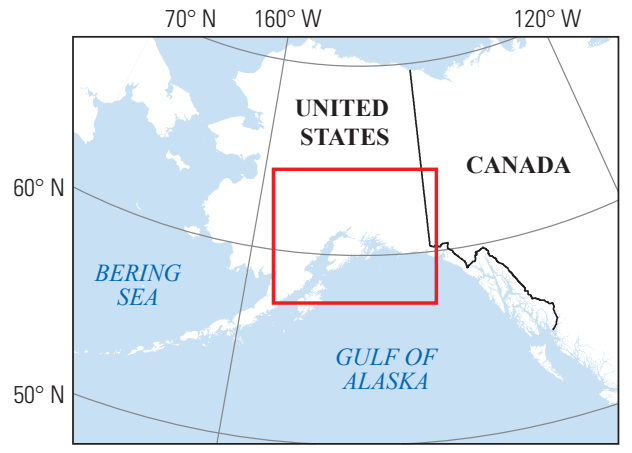




\section{Plate 58. Porphyry Copper Assessment for Tract 003pCu5006, Alaska Peninsula and Aleutian Islands-Alaska, United States}

\author{
Descriptive model: \\ Grade and tonnage model: \\ Economic filter depth percentages: \\ Economic filter cost setting: \\ Geologic feature assessed: \\ Number of known deposits:
}

\author{
Porphyry copper model (Cox, 1986a) \\ General porphyry copper model (Singer, Berger, and Moring, 2008) \\ Default - 0 to 250 meters (m), 25\%; > 250 to $500 \mathrm{~m}, 25 \%$; >500 m to $1 \mathrm{~km}, 50 \%$ \\ High cost \\ Tertiary felsic to intermediate-composition intrusions of the Alaska Peninsula and Aleutian Islands \\ 1
}

\section{Selected Resource Assessment Results for Porphyry Copper}

[Assessment depth, 1 kilometer $(\mathrm{km}) ; \mathrm{km}^{2}$, square kilometer; $\mathrm{Mt}$, millions of metric tons]

\begin{tabular}{ccccccc}
\hline $\begin{array}{c}\text { Date of } \\
\text { assessment }\end{array}$ & $\begin{array}{c}\text { Tract area } \\
\left.\mathbf{( k m}^{2}\right)\end{array}$ & $\begin{array}{c}\text { Identified } \\
\text { copper } \\
\text { resources } \\
\text { (Mt) }\end{array}$ & $\begin{array}{c}\text { Mean estimate of } \\
\text { in-place resources } \\
\text { (Mt) }\end{array}$ & $\begin{array}{c}\text { Probability of } \mathbf{0} \\
\text { in-place resources } \\
\text { (percent) }\end{array}$ & $\begin{array}{c}\text { Mean estimate of } \\
\text { economic resources } \\
\text { (Mt) }\end{array}$ & $\begin{array}{c}\text { Probability of 0 } \\
\text { economic resources } \\
\text { (percent) }\end{array}$ \\
\hline 2012 & 49,222 & 0.59 & 12 & 7 & 5.9 \\
\hline
\end{tabular}

*Updated by the assessment team in 2012 to conform with project protocols and apply the 2008 grade and tonnage model; see text in chapter A.

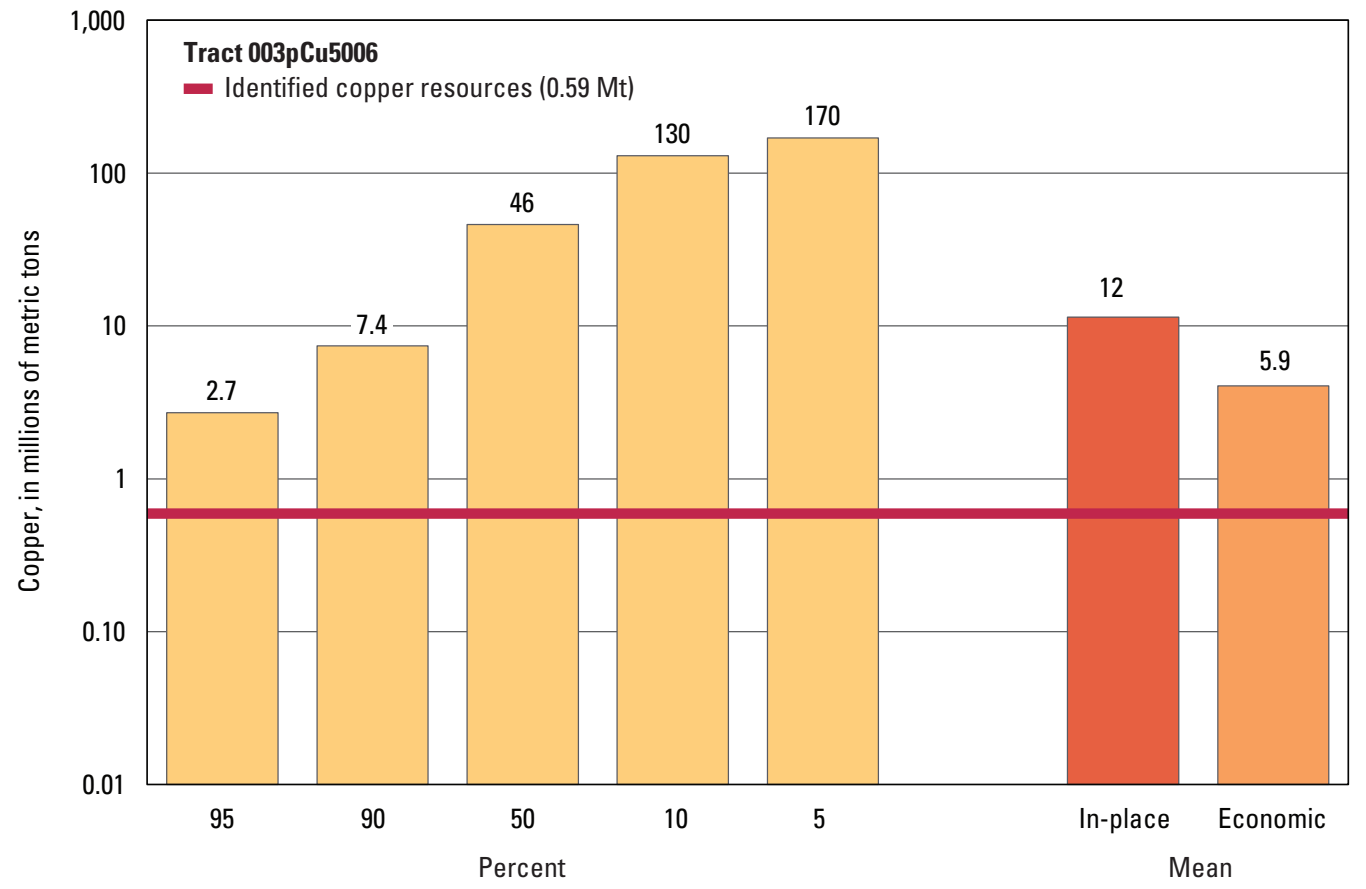

Graph showing the estimated probability distribution of undiscovered copper resources, where each bar represents the minimum amount estimated at the indicated percentage.

\section{Source}

U.S. Geological Survey National Mineral Resource Assessment Team, 2002, Assessment of undiscovered deposits of gold, silver, copper, lead, and zinc in the United States: U.S. Geological Survey Open-File Report 02-198, http://pubs.usgs.gov/of/2002/of02-198/. 


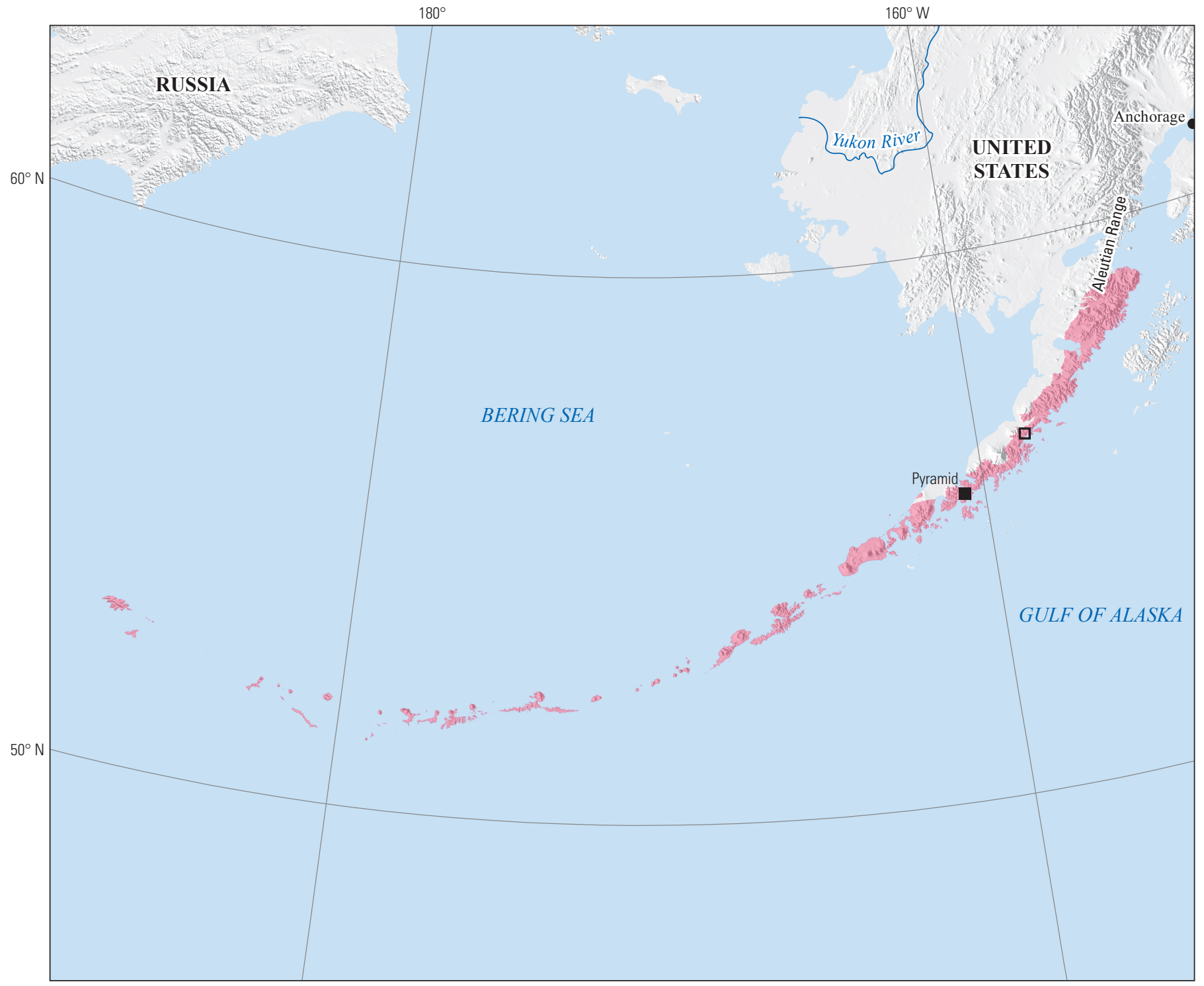

Political boundaries from U.S. Department of State (2009) Shaded relief from Earth Resources Observation and Science (EROS) Center (2011)

Alaska Albers Equal-Area Conic projection

Central meridian $171^{\circ} \mathrm{W}$.; latitude of origin $50^{\circ} \mathrm{N}$.

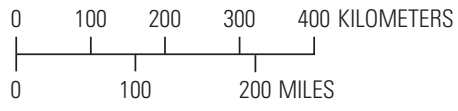

EXPLANATION

\section{Assessed porphyry copper tract $003 p$ Cu5006}

- Porphyry copper deposit

口 Porphyry copper prospect

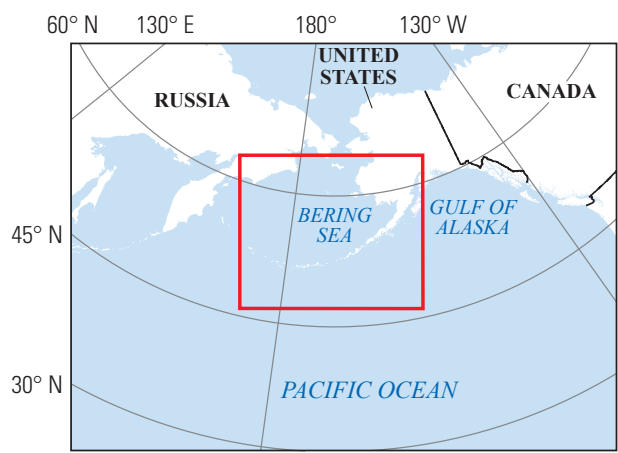




\title{
Plate 59. Porphyry Copper Assessment for Tract 003pCu5007, Koyukuk Arc- Alaska, United States
}

\author{
Descriptive model: $\quad$ Porphyry copper model (Cox, 1986a) \\ Grade and tonnage model: $\quad$ NA \\ Economic filter depth percentages: NA \\ Economic filter cost setting: NA \\ Geologic feature assessed: Late Jurassic(?) and Early Cretaceous Koyukuk island arc \\ Number of known deposits: $\quad 0$
}

\section{Selected Resource Assessment Results for Porphyry Copper}

[Assessment depth, 1 kilometer $(\mathrm{km})$; $\mathrm{km}^{2}$, square kilometer; Mt, millions of metric tons; NA, not applicable, as a quantitative assessment was not done]

\begin{tabular}{ccccccc}
\hline \multirow{2}{*}{$\begin{array}{c}\text { Date of } \\
\text { assessment }\end{array}$} & $\begin{array}{c}\text { Tract area } \\
\left(\mathbf{k m}^{2}\right)\end{array}$ & $\begin{array}{c}\text { Identified } \\
\text { copper } \\
\text { resources } \\
(\mathbf{M t})\end{array}$ & $\begin{array}{c}\text { Mean estimate of } \\
\text { in-place resources } \\
(\mathbf{M t})\end{array}$ & $\begin{array}{c}\text { Probability of } \mathbf{0} \\
\text { in-place resources } \\
\text { (percent) }\end{array}$ & $\begin{array}{c}\text { Mean estimate of } \\
\text { economic resources } \\
\text { (Mt) }\end{array}$ & $\begin{array}{c}\text { Probability of } \mathbf{0} \\
\text { economic resources } \\
\text { (percent) }\end{array}$ \\
\hline 1998 & 57,122 & 0 & NA & NA & NA \\
\hline
\end{tabular}

\section{Qualitative Assessment}

Tract 003 pCu5007 (Koyukuk Arc-Alaska, United States) is broadly permissive for the occurrence of undiscovered porphyry copper deposits on the basis of mapped intrusive igneous rocks of appropriate compositions that are interpreted to represent an island-arc setting. No porphyry copper deposits are known within the tract. At the time of the assessment (1998), one probable porphyry copper prospect with gold and molybdenum was reported in association with a monzonitic intrusion dated at $81 \mathrm{Ma}$. However, the assessment team concluded that there was insufficient geologic and mineral deposit information available to do a quantitative assessment.

Since the assessment was published in 2002, two new datasets have become available for Alaska: (1) the Alaska Resource Data File (ARDF) has been updated (https://mrdata.usgs.gov/ardf/) and (2) a digital geologic map of Alaska has been published (Wilson and others, 2015, https://doi.org/10.3133/sim3340). These sources should be consulted for more recent information about the tract area.

\section{Source}

U.S. Geological Survey National Mineral Resource Assessment Team, 2002, Assessment of undiscovered deposits of gold, silver, copper, lead, and zinc in the United States: U.S. Geological Survey Open-File Report 02-198, http://pubs.usgs.gov/of/2002/of02-198/. 


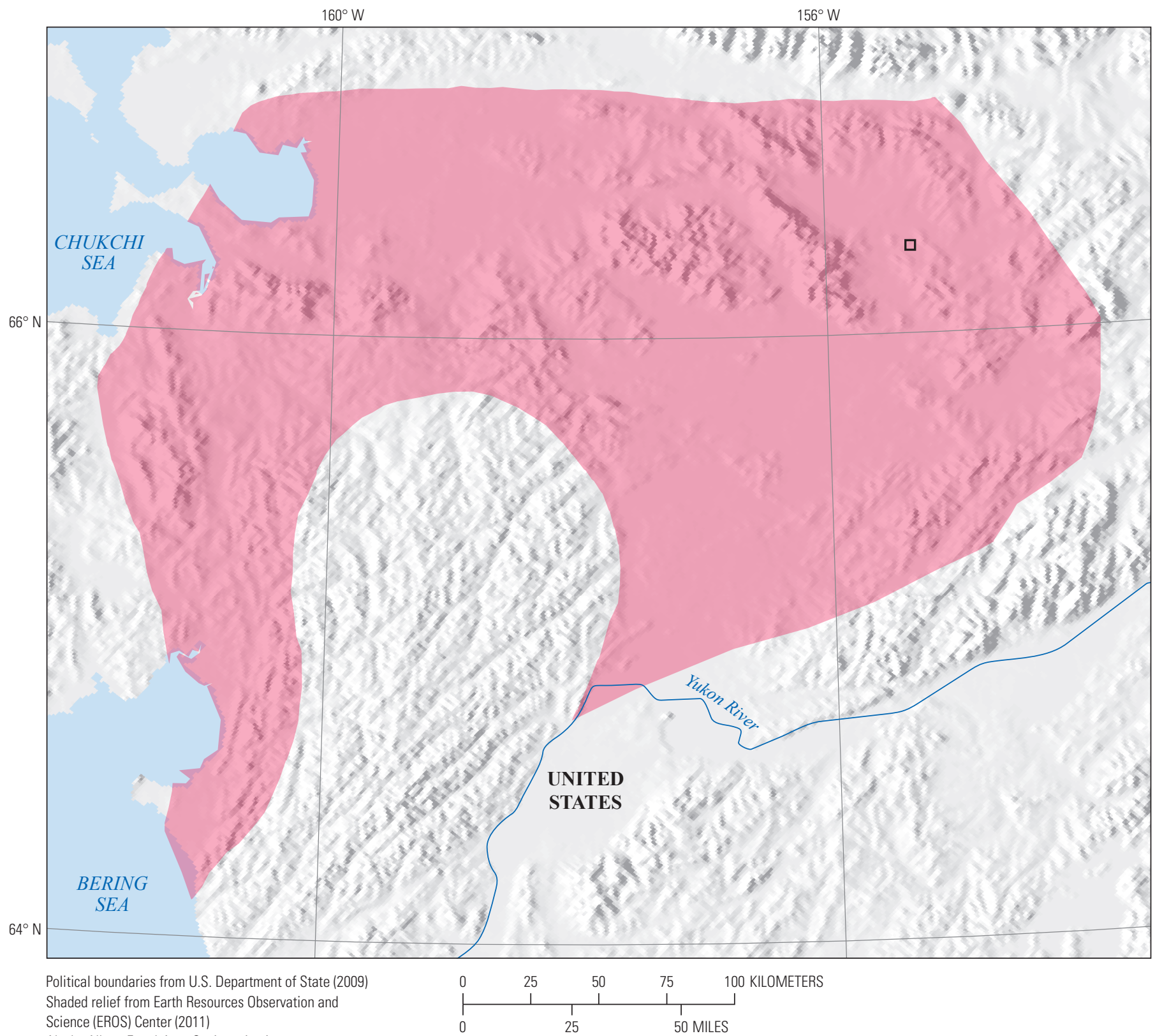

Alaska Albers Equal-Area Conic projection

Central meridian $158^{\circ} \mathrm{W}$; ; latitude of origin $50^{\circ} \mathrm{N}$.

\section{EXPLANATION}

Assessed porphyry copper tract 003pCu5007

$\square \quad$ Porphyry copper prospect

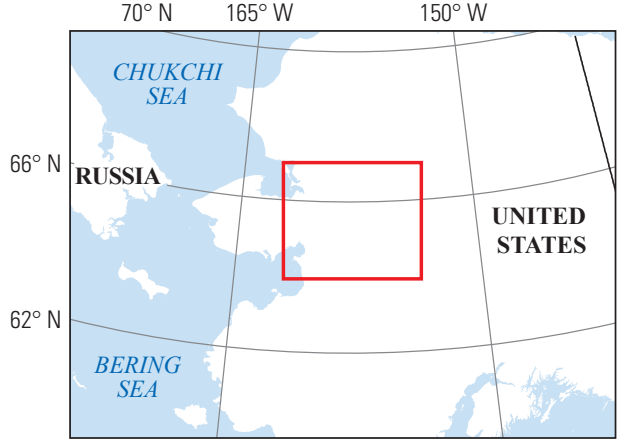




\title{
Plate 60. Porphyry Copper Assessment for Tract 003pCu5008, Brooks Range- Alaska, United States
}

\author{
Descriptive model: $\quad$ Porphyry copper model (Cox, 1986a) \\ Grade and tonnage model: $\quad$ NA \\ Economic filter depth percentages: NA \\ Economic filter cost setting: $\quad$ NA \\ Geologic feature assessed: $\quad$ Proterozoic, Devonian, or Cretaceous granitic intrusions in the Brooks Range \\ Number of known deposits: $\quad 0$
}

\section{Selected Resource Assessment Results for Porphyry Copper}

[Assessment depth, 1 kilometer $(\mathrm{km})$; $\mathrm{km}^{2}$, square kilometer; Mt, millions of metric tons; NA, not applicable, as a quantitative assessment was not done]

\begin{tabular}{ccccccc}
\hline \multirow{2}{*}{$\begin{array}{c}\text { Date of } \\
\text { assessment }\end{array}$} & $\begin{array}{c}\text { Tract area } \\
\left(\mathbf{k m}^{2}\right)\end{array}$ & $\begin{array}{c}\text { Identified } \\
\text { copper } \\
\text { resources } \\
(\mathbf{M t})\end{array}$ & $\begin{array}{c}\text { Mean estimate of } \\
\text { in-place resources } \\
(\mathbf{M t})\end{array}$ & $\begin{array}{c}\text { Probability of } \mathbf{0} \\
\text { in-place resources } \\
\text { (percent) }\end{array}$ & $\begin{array}{c}\text { Mean estimate of } \\
\text { economic resources } \\
\text { (Mt) }\end{array}$ & $\begin{array}{c}\text { Probability of } \mathbf{0} \\
\text { economic resources } \\
\text { (percent) }\end{array}$ \\
\hline 1998 & 9,782 & 0 & NA & NA & NA \\
\hline
\end{tabular}

\section{Qualitative Assessment}

Tract 003 pCu5008 (Brooks Range-Alaska, United States) is broadly permissive for undiscovered porphyry copper deposits on the basis of mapped intrusive igneous rocks of appropriate compositions. No porphyry copper deposits are known within the tract. As shown on the map, one prospect was identified. Permissive rocks, skarns, and disseminated and veinlet basemetal occurrences are present in the area. There was insufficient geologic and mineral deposit information available at the time of the assessment (1998) to do a quantitative assessment.

Since the assessment was published in 2002, two new datasets have become available for Alaska: (1) the Alaska Resource Data File (ARDF) has been updated (https://mrdata.usgs.gov/ardf/) and (2) a digital geologic map of Alaska has been published (Wilson and others, 2015, https://doi.org/10.3133/sim3340). These sources should be consulted for more recent information about the tract area.

\section{Source}

U.S. Geological Survey National Mineral Resource Assessment Team, 2002, Assessment of undiscovered deposits of gold, silver, copper, lead, and zinc in the United States: U.S. Geological Survey Open-File Report 02-198, http://pubs.usgs.gov/of/2002/of02-198/. 


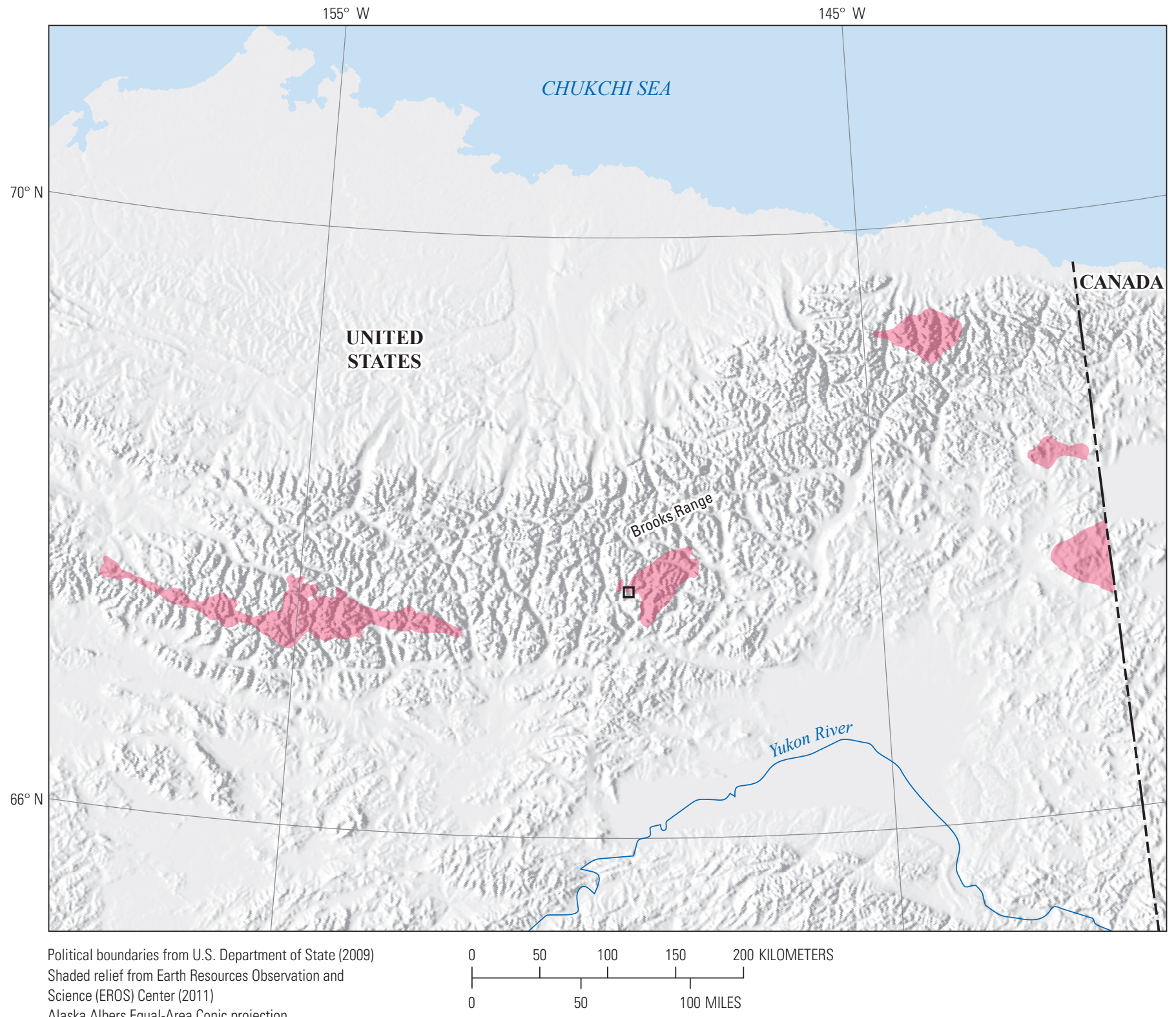

Alaska Albers Equal-Area Conic projection

Central meridian $149^{\circ} 30^{\prime} \mathrm{W}$.; latitude of origin $50^{\circ} \mathrm{N}$.

EXPLANATION

\section{C112 Assessed porphyry copper tract 003pCu5008}

$\square \quad$ Porphyry copper prospect

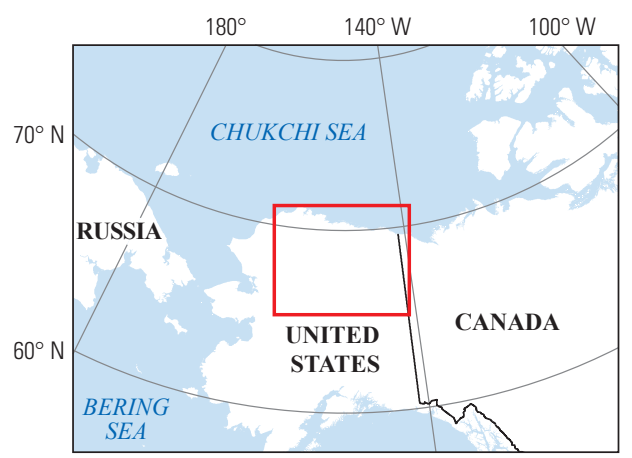




\title{
Plate 61. Porphyry Copper Assessment for Tract 142pCu8513, Chukotka- Russia
}

\author{
Descriptive model: \\ Porphyry copper models (Cox, 1986a; John and others, 2010) \\ Grade and tonnage model: \\ General porphyry copper model (Singer, Berger, and Moring, 2008) \\ Economic filter depth percentages: \\ Economic filter cost setting: \\ Skewed shallow-0 to 250 meters (m), 35\%; > 250 to $500 \mathrm{~m}, 25 \%$; $>500 \mathrm{~m}$ to $1 \mathrm{~km}, 40 \%$ \\ High cost \\ Geologic feature assessed: \\ Early to Late Cretaceous volcanic and intrusive rocks of island-arc, continental-arc, and collisional \\ magmatic belts associated with the Chukotka microcontinent \\ Number of known deposits: \\ 0
}

\section{Selected Resource Assessment Results for Porphyry Copper}

[Assessment depth, 1 kilometer $(\mathrm{km}) ; \mathrm{km}^{2}$, square kilometer; Mt, millions of metric tons]

\begin{tabular}{ccccccc}
\hline $\begin{array}{c}\text { Date of } \\
\text { assessment }\end{array}$ & $\begin{array}{c}\text { Tract area } \\
\left(\mathbf{k m}^{2}\right)\end{array}$ & $\begin{array}{c}\text { Identified } \\
\text { copper } \\
\text { resources } \\
(\mathbf{M t})\end{array}$ & $\begin{array}{c}\text { Mean estimate of } \\
\text { in-place resources } \\
(\mathbf{M t})\end{array}$ & $\begin{array}{c}\text { Probability of } \mathbf{0} \\
\text { in-place resources } \\
\text { (percent) }\end{array}$ & $\begin{array}{c}\text { Mean estimate of } \\
\text { economic resources } \\
\text { (Mt) }\end{array}$ & $\begin{array}{c}\text { Probability of 0 } \\
\text { economic resources } \\
\text { (percent) }\end{array}$ \\
\hline 2010 & 196,564 & 0 & 12 & 20 & 6.3 \\
\hline
\end{tabular}

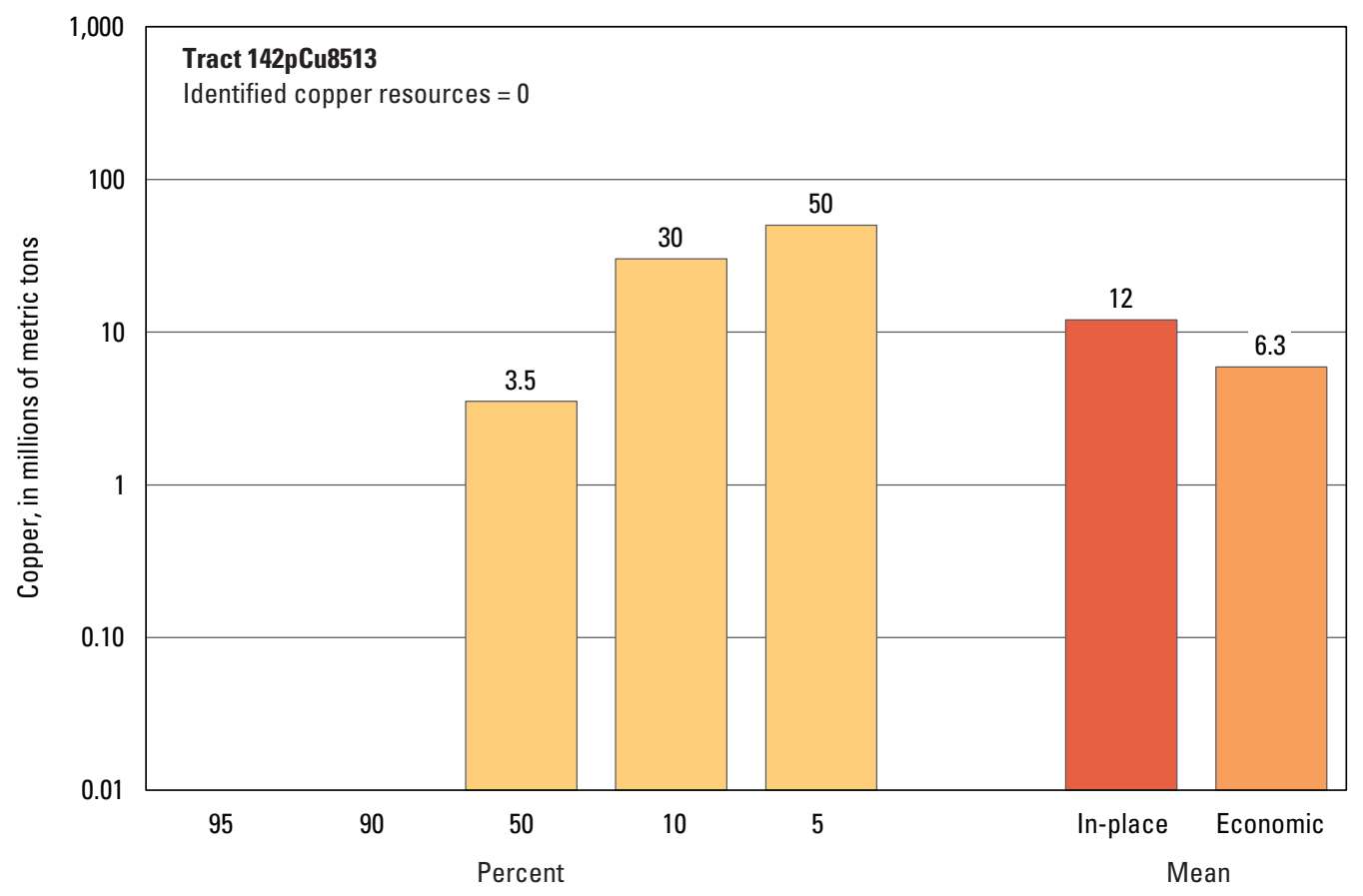

Graph showing the estimated probability distribution of undiscovered copper resources, where each bar represents the minimum amount estimated at the indicated percentage.

\section{Source}

Mihalasky, Ludington, Alexeiev, and others, 2015, Porphyry copper assessment of northeast Asia—Far East Russia and northeasternmost China: U.S. Geological Survey Scientific Investigations Report 2010-5090-W, http://dx.doi.org/10.3133/sir20105090W. 


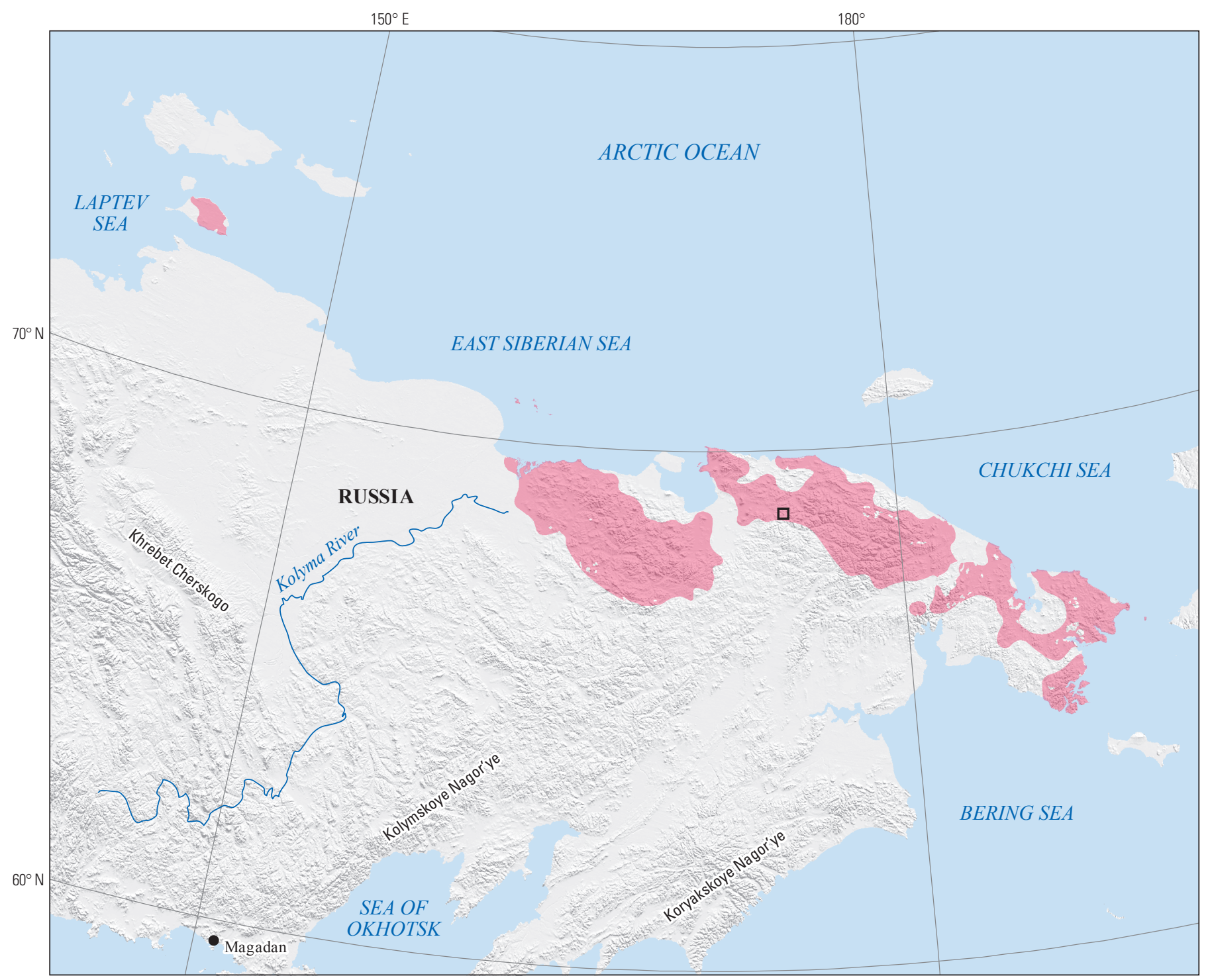

Political boundaries from U.S. Department of State (2009) Shaded relief from Earth Resources Observation and Science (EROS) Center (2011)

Asia North Albers Equal-Area Conic projection

Central meridian $171^{\circ} \mathrm{E}$.; latitude of origin $30^{\circ} \mathrm{N}$.

\section{EXPLANATION}

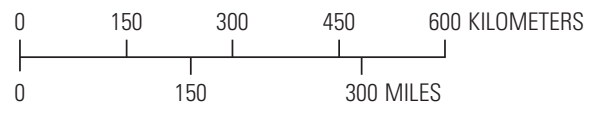

Assessed porphyry copper tract

142pCu8513

ㅁ Porphyry copper prospect

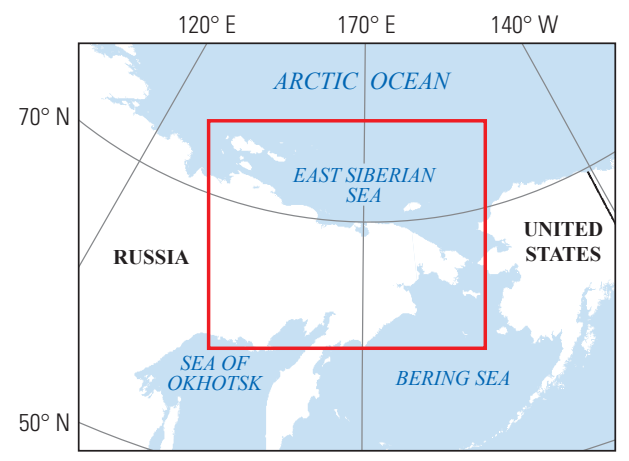




\section{Plate 62. Porphyry Copper Assessment for Tract 142pCu8514, Pacific Margin- Russia and China}

\author{
Descriptive model: \\ Grade and tonnage model: \\ Economic filter depth percentages: \\ Economic filter cost setting: \\ Geologic feature assessed:
}

Number of known deposits:

\author{
Porphyry copper models (Cox, 1986a; John and others, 2010) \\ General porphyry copper model (Singer, Berger, and Moring, 2008) \\ Default - 0 to 250 meters (m), 25\%; > 250 to $500 \mathrm{~m}, 25 \%$; >500 m to $1 \mathrm{~km}, 50 \%$ \\ High cost \\ Cretaceous through middle Tertiary volcanic and intrusive rocks representing a series of \\ continental- and island-arc systems accreted and superimposed onto the paleomargin of \\ northeastern Asia
}

1

\section{Selected Resource Assessment Results for Porphyry Copper}

[Assessment depth, 1 kilometer $(\mathrm{km}) ; \mathrm{km}^{2}$, square kilometer; Mt, millions of metric tons]

\begin{tabular}{ccccccc}
\hline \multirow{2}{*}{$\begin{array}{c}\text { Date of } \\
\text { assessment }\end{array}$} & $\begin{array}{c}\text { Tract area } \\
\left(\mathbf{k m}^{2}\right)\end{array}$ & $\begin{array}{c}\text { Identified } \\
\text { copper } \\
\text { resources } \\
(\mathbf{M t})\end{array}$ & $\begin{array}{c}\text { Mean estimate of } \\
\text { in-place resources } \\
(\mathbf{M t})\end{array}$ & $\begin{array}{c}\text { Probability of } \mathbf{0} \\
\text { in-place resources } \\
\text { (percent) }\end{array}$ & $\begin{array}{c}\text { Mean estimate of } \\
\text { economic resources } \\
\text { (Mt) }\end{array}$ & $\begin{array}{c}\text { Probability of } \mathbf{0} \\
\text { economic resources } \\
\text { (percent) }\end{array}$ \\
\hline 2010 & $1,238,565$ & 0.89 & 150 & 1 & 73 \\
\hline
\end{tabular}

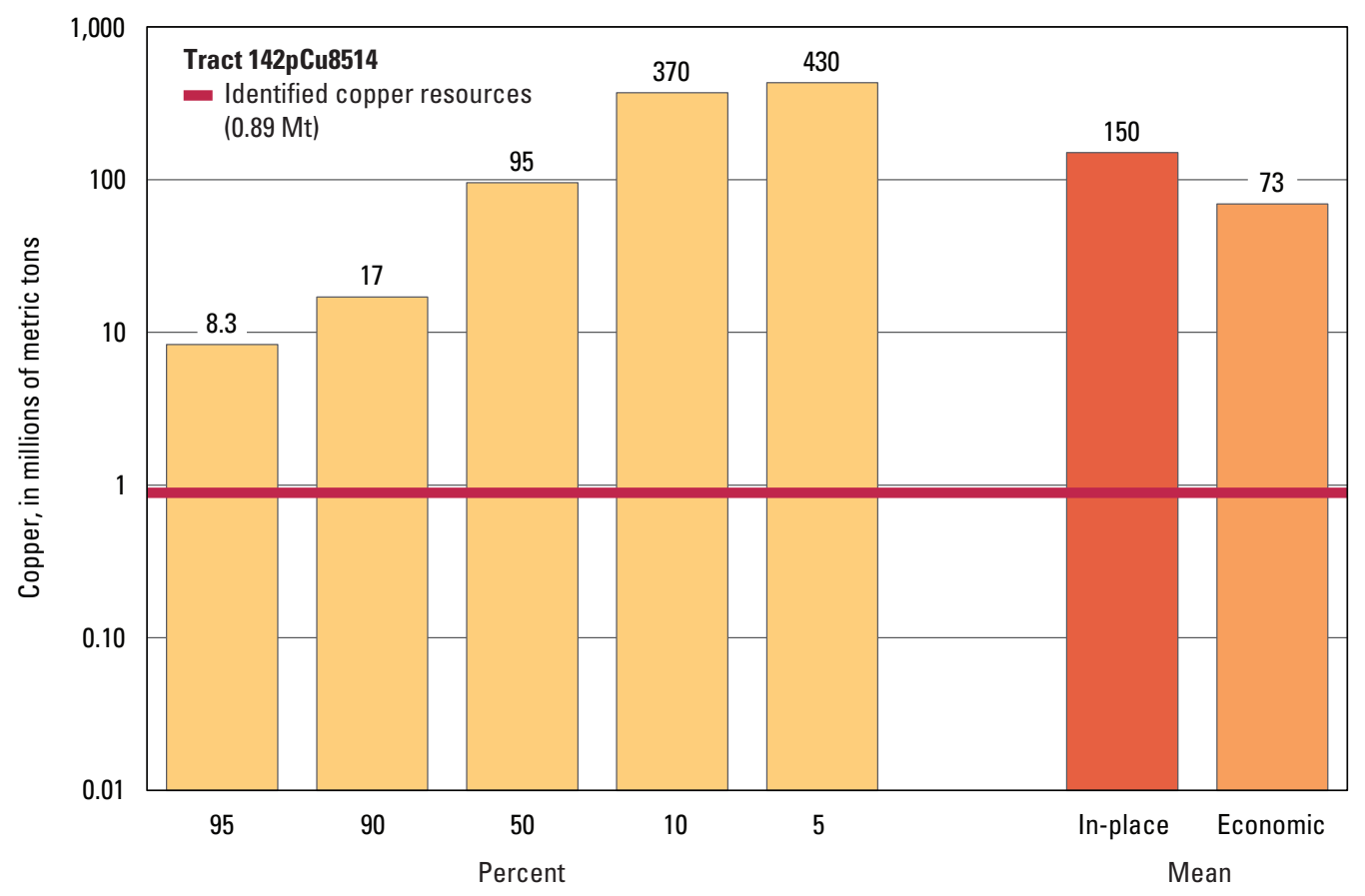

Graph showing the estimated probability distribution of undiscovered copper resources, where each bar represents the minimum amount estimated at the indicated percentage.

\section{Source}

Mihalasky, Ludington, Alexeiev, and others, 2015, Porphyry copper assessment of northeast Asia—Far East Russia and northeasternmost China: U.S. Geological Survey Scientific Investigations Report 2010-5090-W, http://dx.doi.org/10.3133/sir20105090W. 


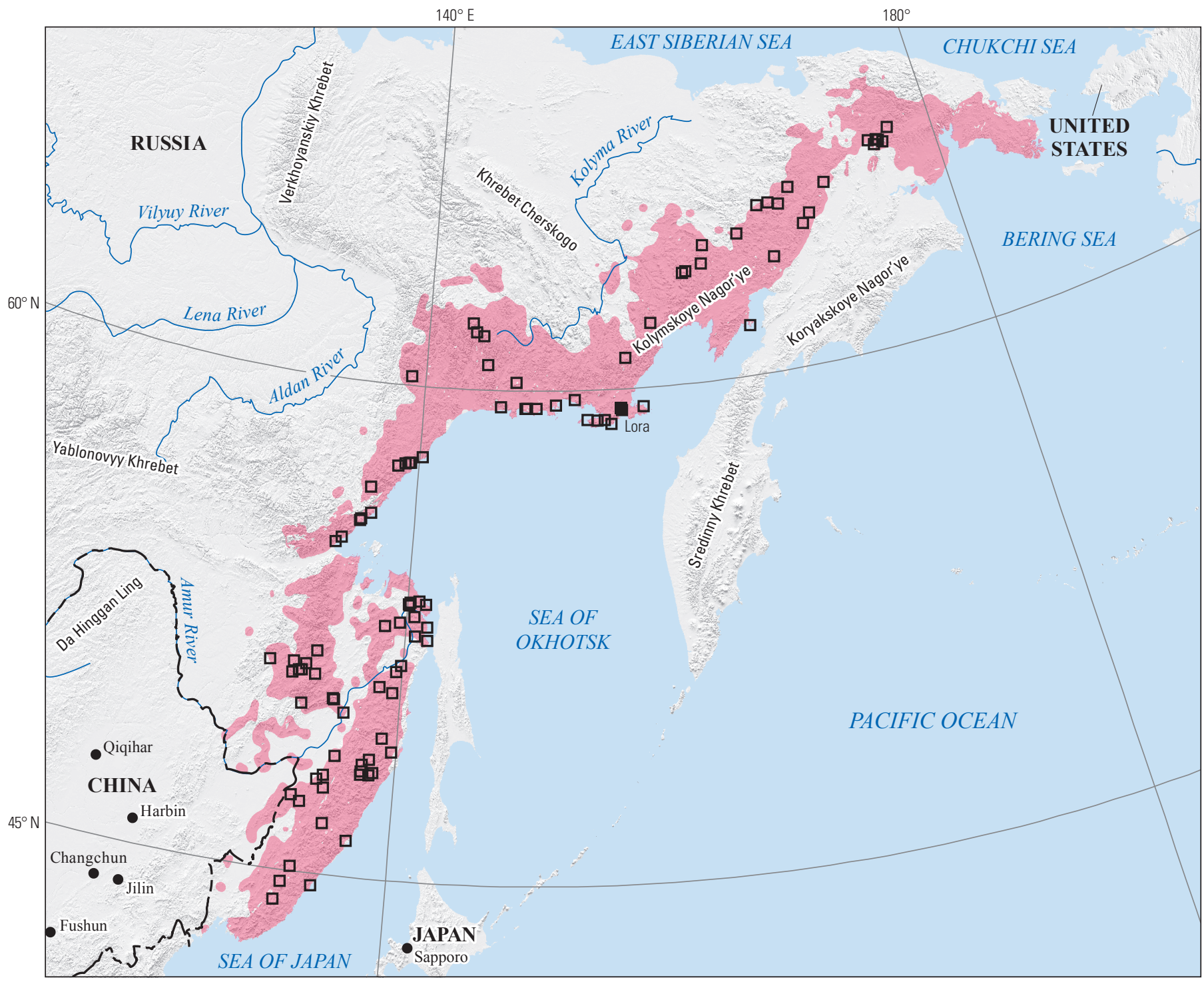

Political boundaries from U.S. Department of State (2009) Shaded relief from Earth Resources Observation and Science (EROS) Center (2011)

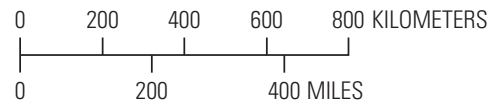

Asia North Albers Equal-Area Conic projection

Central meridian $148^{\circ} \mathrm{E}$. ; latitude of origin $30^{\circ} \mathrm{N}$

\section{EXPLANATION}

\section{Assessed porphyry copper tract 142pCu8514}

- Porphyry copper deposit

$\square \quad$ Porphyry copper prospect

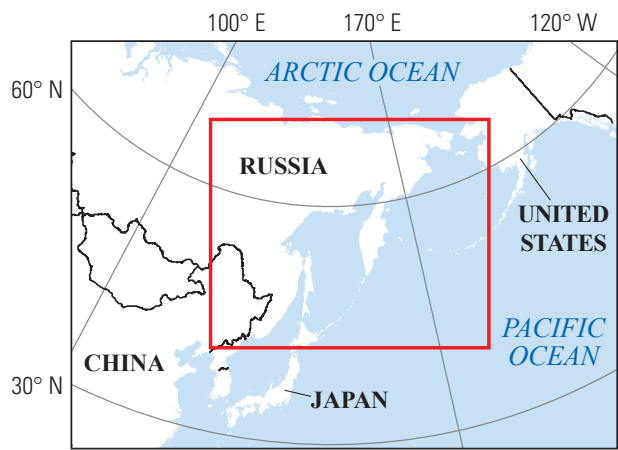




\section{Plate 63. Porphyry Copper Assessment for Tract 142pCu8515, Kamchatka- Kuril-Russia}

\author{
Descriptive model: \\ Grade and tonnage model: \\ Economic filter depth percentages: \\ Economic filter cost setting: \\ Geologic feature assessed:
}

Number of known deposits:
Porphyry copper models (Cox, 1986a; John and others, 2010)

General porphyry copper model (Singer, Berger, and Moring, 2008)

Default - 0 to 250 meters (m), 25\%; > 250 to $500 \mathrm{~m}, 25 \%$; > $500 \mathrm{~m}$ to $1 \mathrm{~km}, 50 \%$

High cost

Latest Cretaceous through Quaternary volcanic and intrusive rocks representing a series of continental- and island-arc systems accreted and superimposed onto the margin of northeastern Asia

0

\section{Selected Resource Assessment Results for Porphyry Copper}

[Assessment depth, 1 kilometer (km); $\mathrm{km}^{2}$, square kilometer; Mt, millions of metric tons]

\begin{tabular}{ccccccc}
\hline $\begin{array}{c}\text { Date of } \\
\text { assessment }\end{array}$ & $\begin{array}{c}\text { Tract area } \\
\left(\mathbf{k m}^{2}\right)\end{array}$ & $\begin{array}{c}\text { Identified } \\
\text { copper } \\
\text { resources } \\
\text { (Mt) }\end{array}$ & $\begin{array}{c}\text { Mean estimate of } \\
\text { in-place resources } \\
(\mathbf{M t})\end{array}$ & $\begin{array}{c}\text { Probability of } \mathbf{0} \\
\text { in-place resources } \\
\text { (percent) }\end{array}$ & $\begin{array}{c}\text { Mean estimate of } \\
\text { economic resources } \\
\text { (Mt) }\end{array}$ & $\begin{array}{c}\text { Probability of 0 } \\
\text { economic resources } \\
\text { (percent) }\end{array}$ \\
\hline 2010 & 214,884 & 0 & 34 & 4 & 17 \\
\hline
\end{tabular}

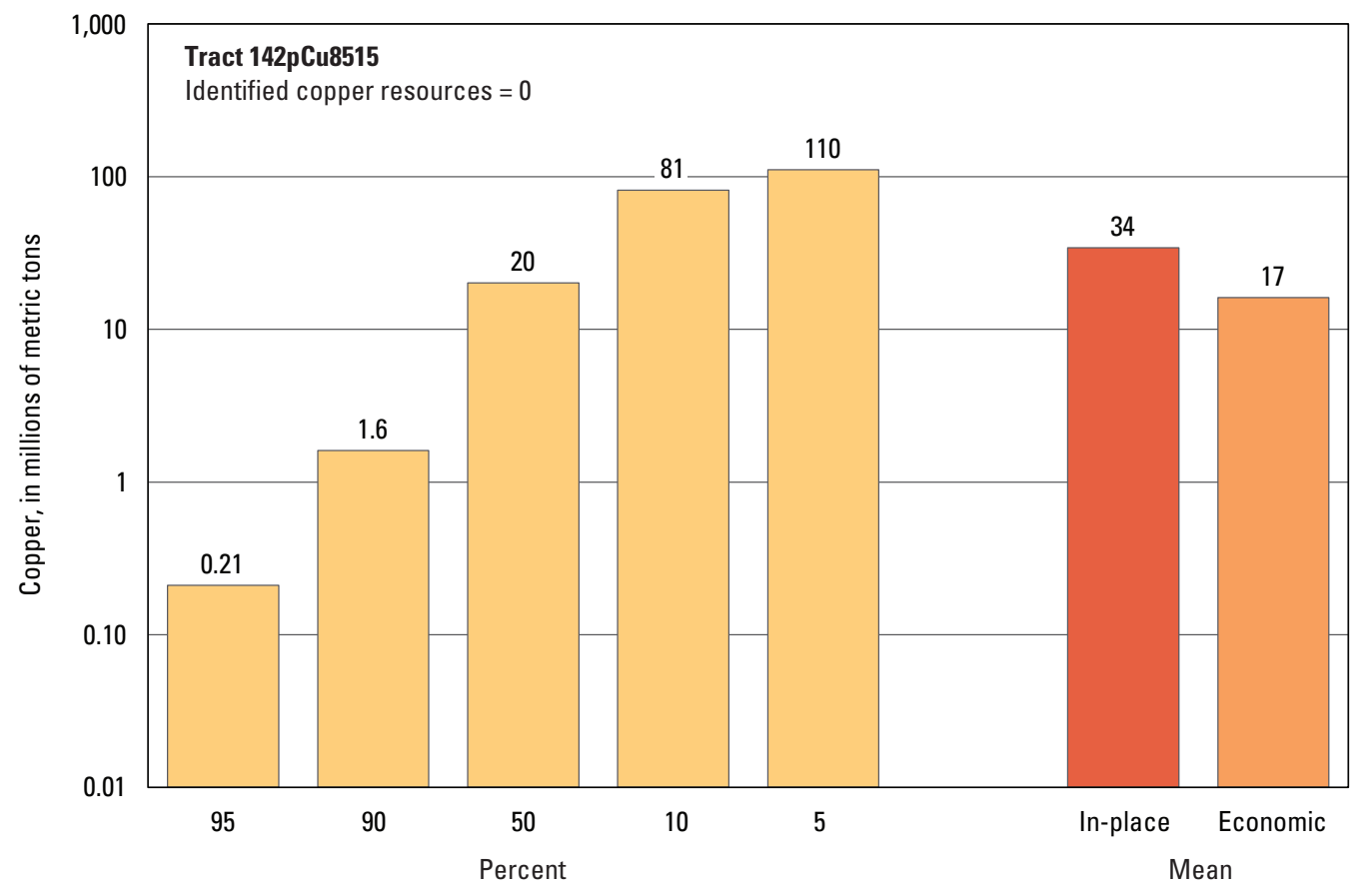

Graph showing the estimated probability distribution of undiscovered copper resources, where each bar represents the minimum amount estimated at the indicated percentage.

\section{Source}

Mihalasky, Ludington, Alexeiev, and others, 2015, Porphyry copper assessment of northeast Asia—Far East Russia and northeasternmost China: U.S. Geological Survey Scientific Investigations Report 2010-5090-W, http://dx.doi.org/10.3133/sir20105090W. 


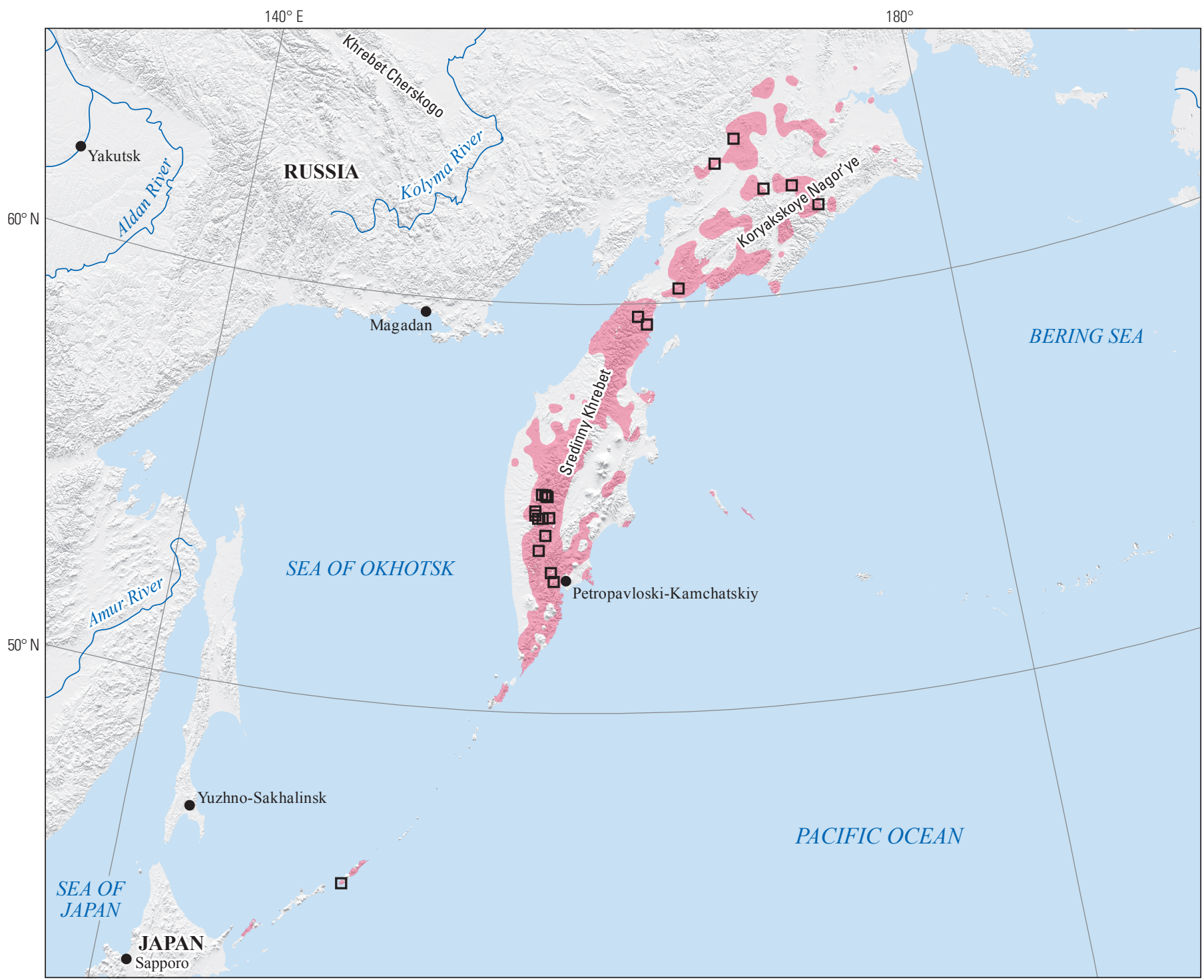

Political boundaries from U.S. Department of State (2009) Shaded relief from Earth Resources Observation and Science (EROS) Center (2011)

Asia North Albers Equal-Area Conic projection

Central meridian $160^{\circ} \mathrm{E}$.; latitude of origin $30^{\circ} \mathrm{N}$.

\section{EXPLANATION}

\section{Assessed porphyry copper tract} $142 p C u 8515$

ㅁ Porphyry copper prospect

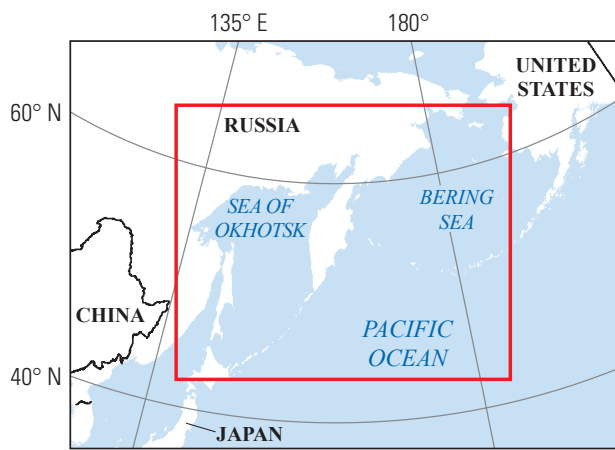




\section{Plate 64. Porphyry Copper Assessment for Tract 142pCu8510, Kedon—Russia}

Descriptive model:

Grade and tonnage model:

Economic filter depth percentages:

Economic filter cost setting:

Geologic feature assessed:

Number of known deposits:
Porphyry copper models (Cox, 1986a; John and others, 2010)

General porphyry copper model (Singer, Berger, and Moring, 2008)

Default -0 to 250 meters (m), $25 \%$; $>250$ to $500 \mathrm{~m}, 25 \%$; $>500 \mathrm{~m}$ to $1 \mathrm{~km}, 50 \%$

High cost

Middle Devonian through early Carboniferous volcanic and intrusive rocks composing a discontinuous continental-margin arc associated with the Omolon microcontinent

0

\section{Selected Resource Assessment Results for Porphyry Copper}

[Assessment depth, 1 kilometer $(\mathrm{km}) ; \mathrm{km}^{2}$, square kilometer; Mt, millions of metric tons]

\begin{tabular}{ccccccc}
\hline $\begin{array}{c}\text { Date of } \\
\text { assessment }\end{array}$ & $\begin{array}{c}\text { Tract area } \\
\left(\mathbf{k m}^{2}\right)\end{array}$ & $\begin{array}{c}\text { Identified } \\
\text { copper } \\
\text { resources } \\
(\mathbf{M t})\end{array}$ & $\begin{array}{c}\text { Mean estimate of } \\
\text { in-place resources } \\
(\mathbf{M t})\end{array}$ & $\begin{array}{c}\text { Probability of } \mathbf{0} \\
\text { in-place resources } \\
\text { (percent) }\end{array}$ & $\begin{array}{c}\text { Mean estimate of } \\
\text { economic resources } \\
\text { (Mt) }\end{array}$ & $\begin{array}{c}\text { Probability of } 0 \\
\text { economic resources } \\
\text { (percent) }\end{array}$ \\
\hline 2010 & 30,927 & 0 & 4.5 & 31 & 2.2 & 90 \\
\hline
\end{tabular}

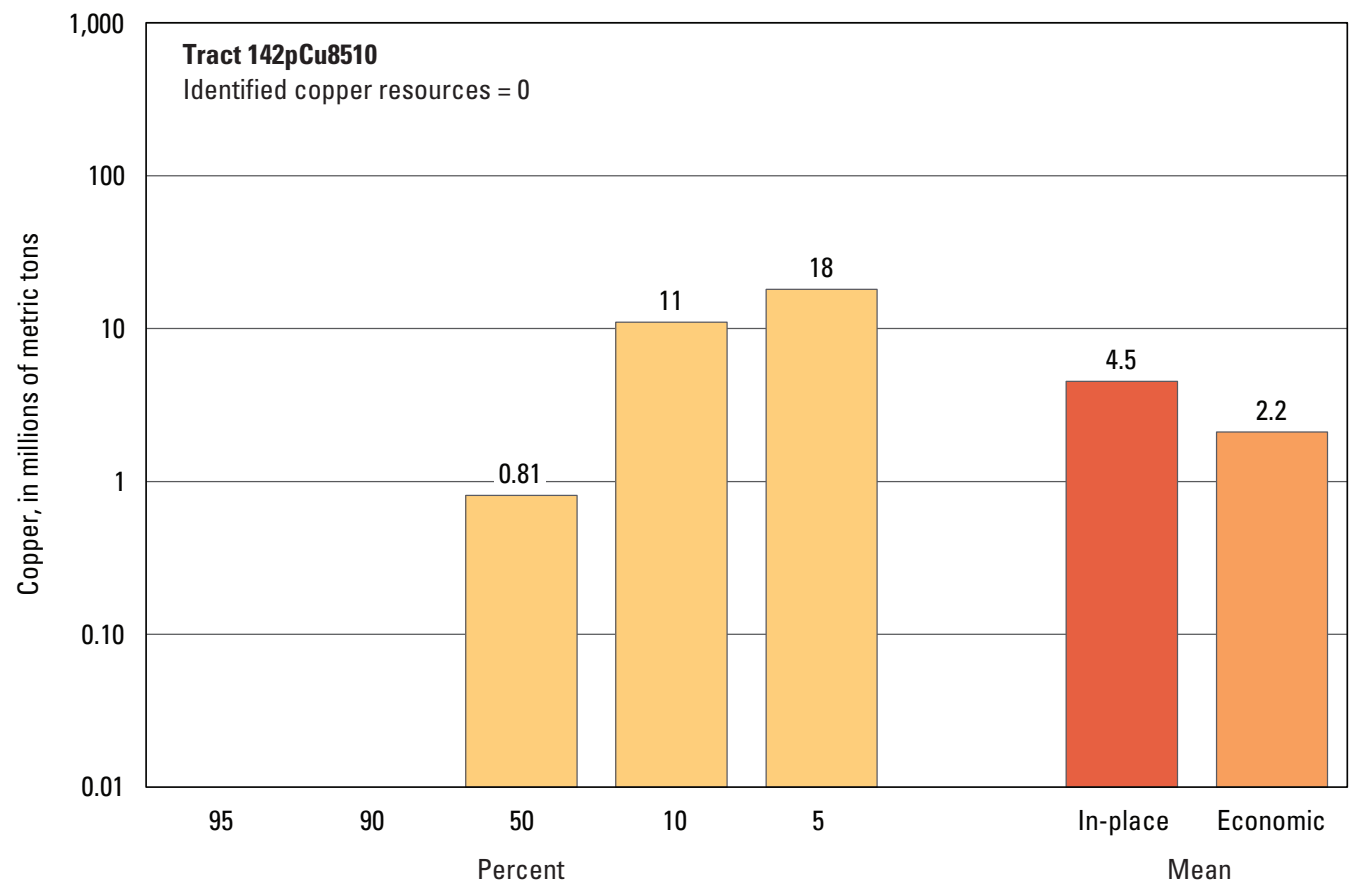

Graph showing the estimated probability distribution of undiscovered copper resources, where each bar represents the minimum amount estimated at the indicated percentage.

\section{Source}

Mihalasky, Ludington, Alexeiev, and others, 2015, Porphyry copper assessment of northeast Asia—Far East Russia and northeasternmost China: U.S. Geological Survey Scientific Investigations Report 2010-5090-W, http://dx.doi.org/10.3133/sir20105090W. 


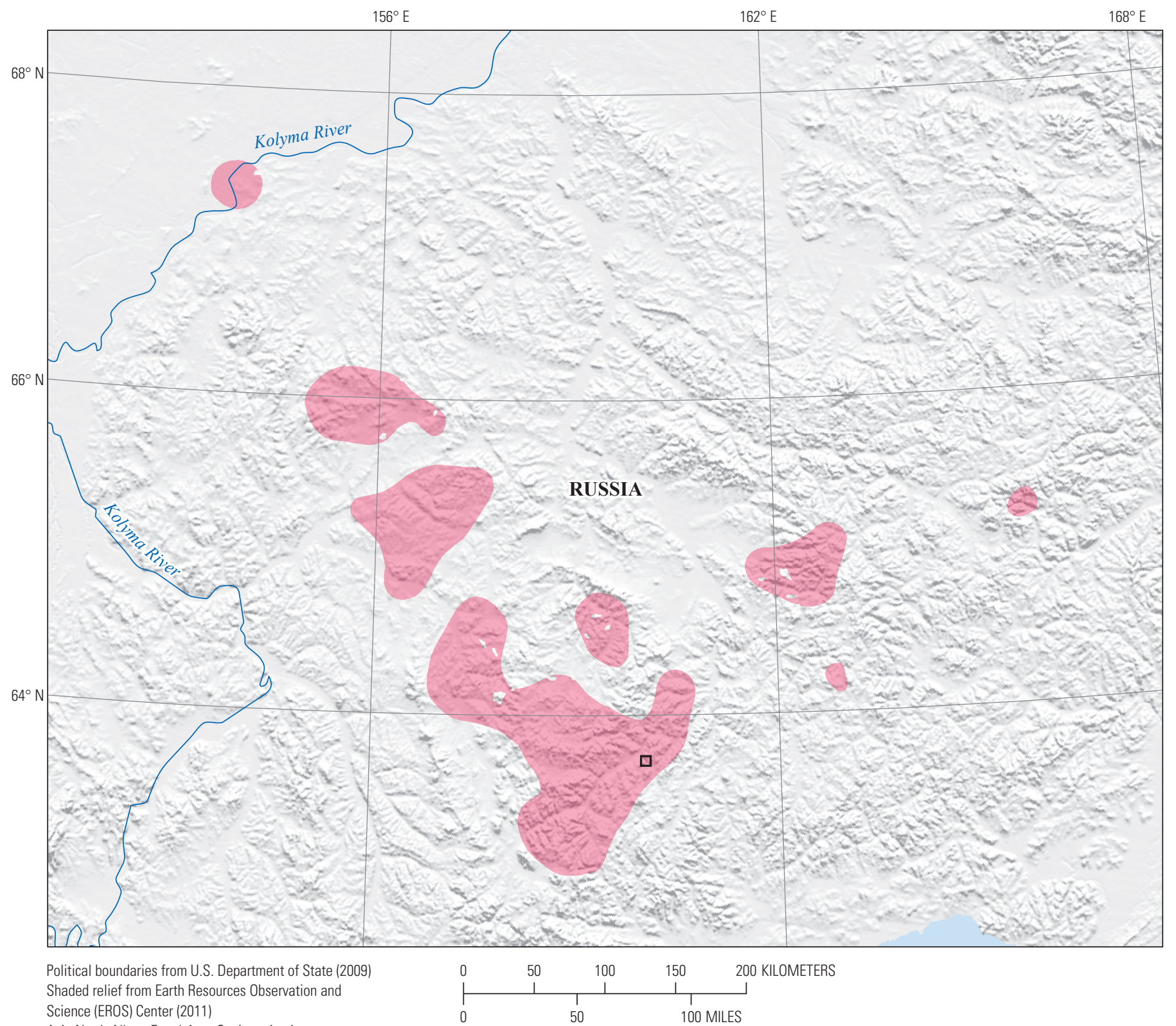

Science (EROS) Center (2011)

Asia North Albers Equal-Area Conic projection

Central meridian $159^{\circ} \mathrm{E}$.; latitude of origin $30^{\circ} \mathrm{N}$.

EXPLANATION

Assessed porphyry copper tract 142pCu8510

$\square \quad$ Porphyry copper prospect

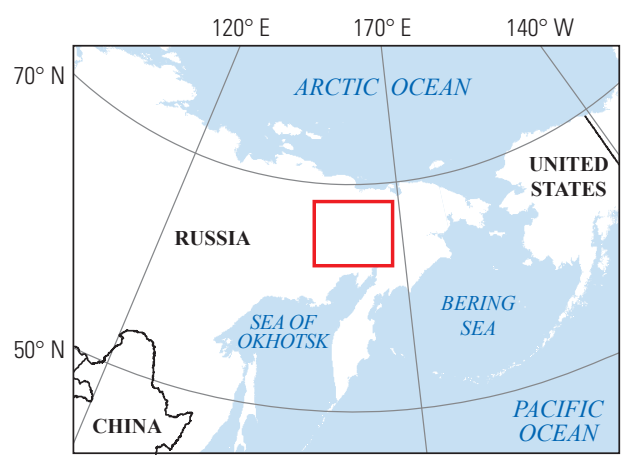




\section{Plate 65. Porphyry Copper Assessment for Tract 142pCu8512, Kolyma-Russia}

Descriptive model:

Grade and tonnage model:

Economic filter depth percentages:

Economic filter cost setting:

Geologic feature assessed:

Number of known deposits:
Porphyry copper models (Cox, 1986a; John and others, 2010)

General porphyry copper model (Singer, Berger, and Moring, 2008)

Custom-0 to 250 meters (m), 30\%; >250 to $500 \mathrm{~m}, 25 \%$; $>500 \mathrm{~m}$ to $1 \mathrm{~km}, 45 \%$

High cost

Late Jurassic to Early Cretaceous volcanic and intrusive rocks composing island-arc, continentalmargin-arc, and collisional magmatic belts associated with the Kolyma-Omolon microcontinent 1

\section{Selected Resource Assessment Results for Porphyry Copper}

[Assessment depth, 1 kilometer $(\mathrm{km}) ; \mathrm{km}^{2}$, square kilometer; Mt, millions of metric tons]

\begin{tabular}{ccccccc}
\hline $\begin{array}{c}\text { Date of } \\
\text { assessment }\end{array}$ & $\begin{array}{c}\text { Tract area } \\
\left(\mathbf{k m}^{2}\right)\end{array}$ & $\begin{array}{c}\text { Identified } \\
\text { copper } \\
\text { resources } \\
(\mathbf{M t})\end{array}$ & $\begin{array}{c}\text { Mean estimate of } \\
\text { in-place resources } \\
(\mathbf{M t})\end{array}$ & $\begin{array}{c}\text { Probability of } \mathbf{0} \\
\text { in-place resources } \\
\text { (percent) }\end{array}$ & $\begin{array}{c}\text { Mean estimate of } \\
\text { economic resources } \\
\text { (Mt) }\end{array}$ & $\begin{array}{c}\text { Probability of } \mathbf{0} \\
\text { economic resources } \\
\text { (percent) }\end{array}$ \\
\hline 2010 & 541,829 & 7.9 & 56 & 4 & 28 \\
\hline
\end{tabular}

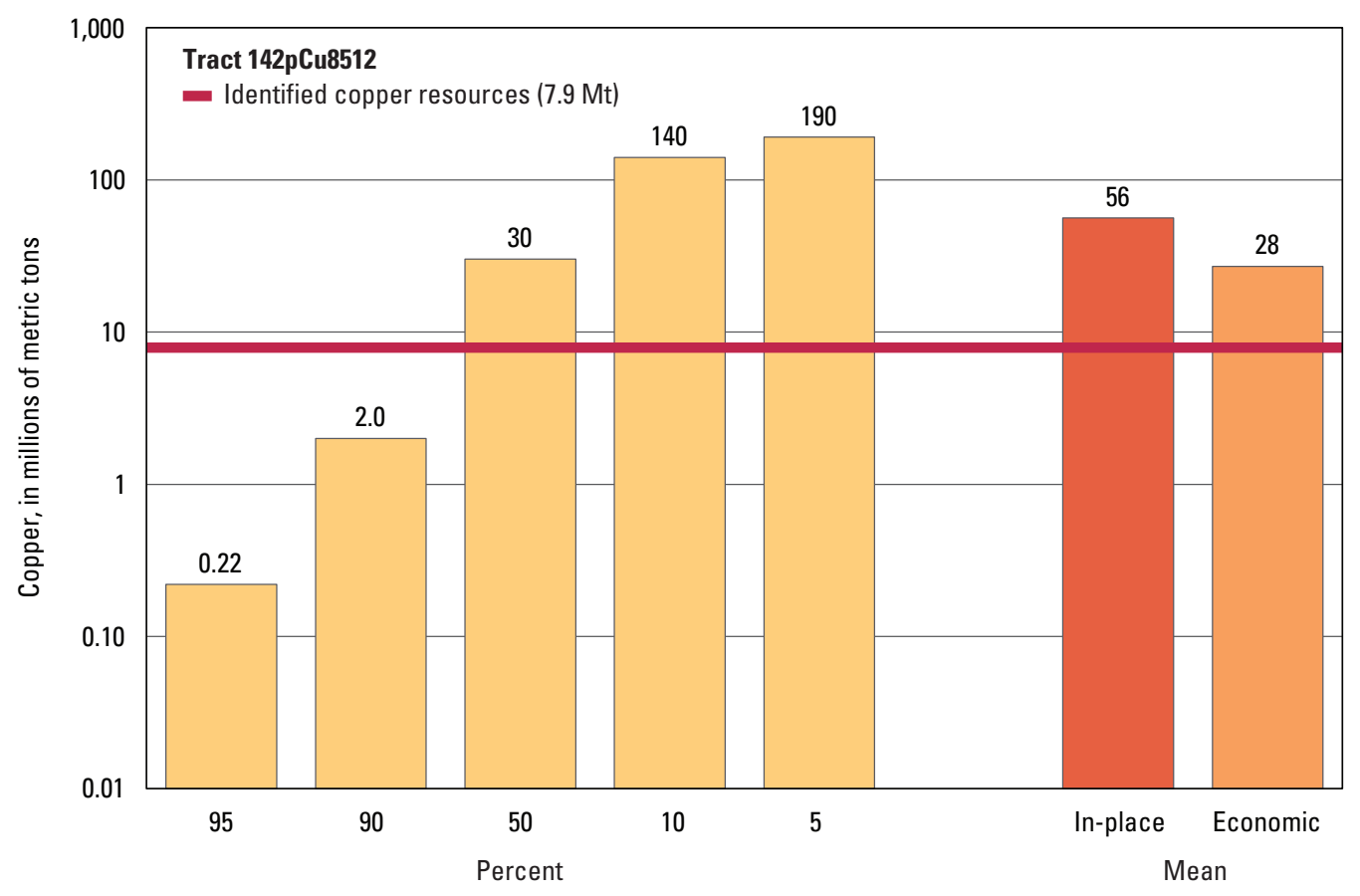

Graph showing the estimated probability distribution of undiscovered copper resources, where each bar represents the minimum amount estimated at the indicated percentage.

\section{Source}

Mihalasky, Ludington, Alexeiev, and others, 2015, Porphyry copper assessment of northeast Asia—Far East Russia and northeasternmost China: U.S. Geological Survey Scientific Investigations Report 2010-5090-W, http://dx.doi.org/10.3133/sir20105090W. 


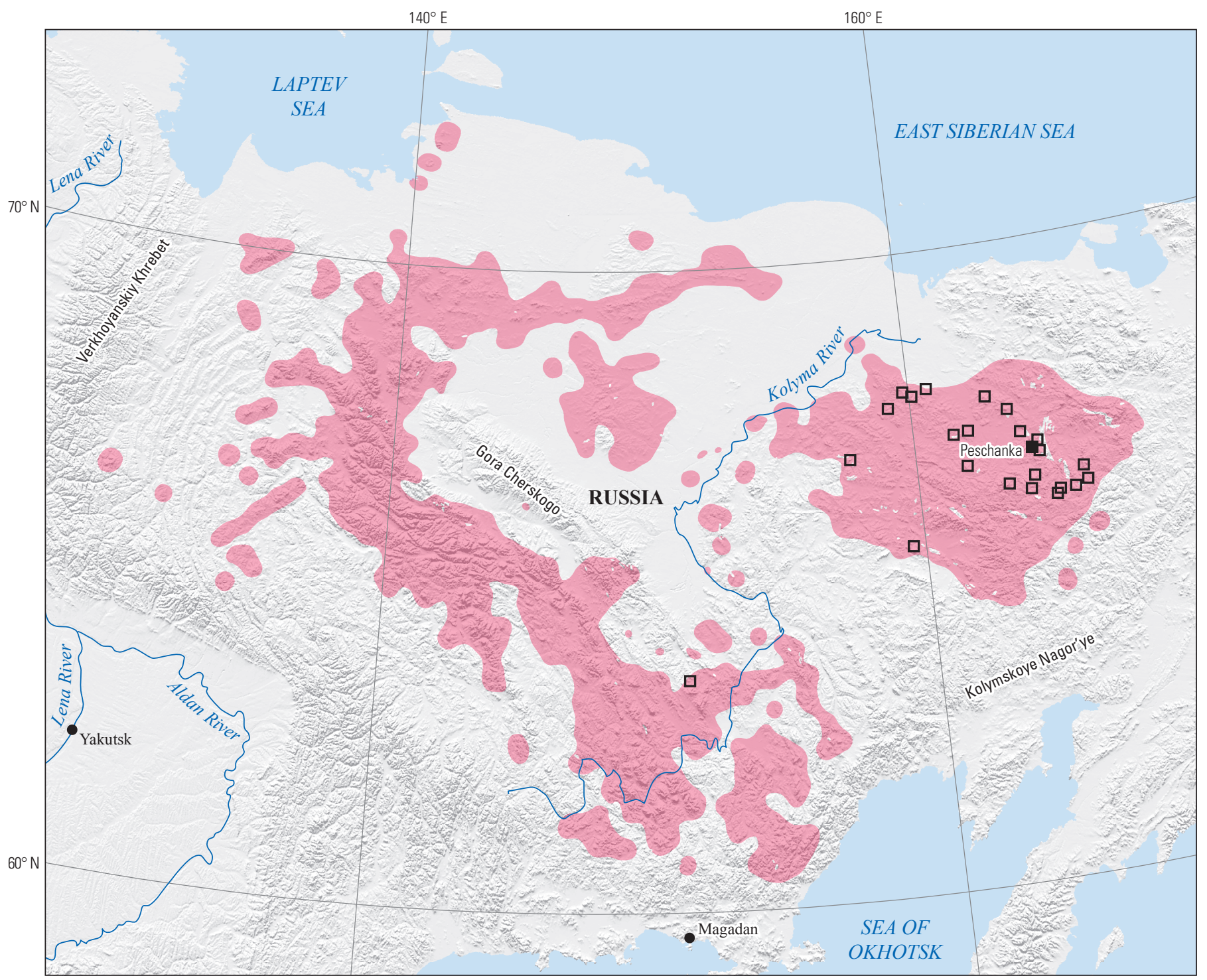

Political boundaries from U.S. Department of State (2009) Shaded relief from Earth Resources Observation and Science (EROS) Center (2011)

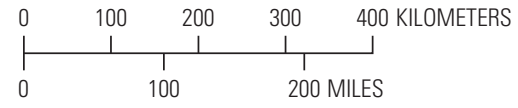

Asia North Albers Equal-Area Conic projection

Central meridian $148^{\circ} \mathrm{E}$.; latitude of origin $30^{\circ} \mathrm{N}$.

EXPLANATION

\section{Assessed porphyry copper tract 142pCu8512}

- Porphyry copper deposit

ㅁ Porphyry copper prospect

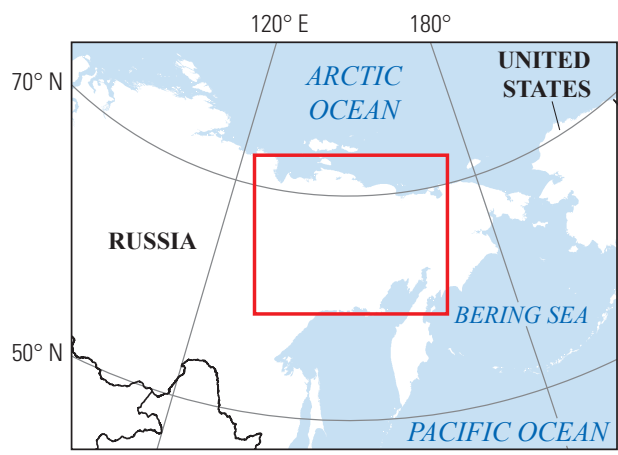




\title{
Plate 66. Porphyry Copper Assessment for Tract 142pCu7315, Subaerial Neogene Arcs of Western Japan—Japan
}

\author{
Descriptive model: $\quad$ Porphyry copper models (Cox, 1986a; John and others, 2010) \\ Grade and tonnage model: $\quad$ NA \\ Economic filter depth percentages: $\quad$ NA \\ Economic filter cost setting: NA \\ Geologic feature assessed: $\quad$ Subaerial parts of the Miocene and younger Kurile, Northeast Japan, Izu, Southwest Japan, and \\ Ryukyu volcanic arcs \\ Number of known deposits: \\ 0
}

\section{Selected Resource Assessment Results for Porphyry Copper}

[Assessment depth, 1 kilometer $(\mathrm{km})$; $\mathrm{km}^{2}$, square kilometer; Mt, millions of metric tons; NA, not applicable, as a quantitative assessment was not done]

\begin{tabular}{|c|c|c|c|c|c|c|}
\hline \multirow[b]{2}{*}{$\begin{array}{c}\text { Date of } \\
\text { assessment }\end{array}$} & \multirow[b]{2}{*}{$\begin{array}{c}\text { Tract area } \\
\quad\left(\mathbf{k m}^{2}\right)\end{array}$} & \multirow{2}{*}{$\begin{array}{l}\text { Identified } \\
\text { copper } \\
\text { resources } \\
\text { (Mt) }\end{array}$} & \multicolumn{4}{|c|}{ Undiscovered copper resource estimates } \\
\hline & & & $\begin{array}{l}\text { Mean estimate of } \\
\text { in-place resources } \\
\text { (Mt) }\end{array}$ & $\begin{array}{c}\text { Probability of } 0 \\
\text { in-place resources } \\
\text { (percent) }\end{array}$ & $\begin{array}{l}\text { Mean estimate of } \\
\text { economic resources } \\
\text { (Mt) }\end{array}$ & $\begin{array}{c}\text { Probability of } 0 \\
\text { economic resources } \\
\text { (percent) }\end{array}$ \\
\hline 2010 & 120,588 & 0 & NA & NA & NA & NA \\
\hline
\end{tabular}

\section{Qualitative Assessment}

Japan has been explored for minerals for well over 100 years, and no porphyry copper deposits have been found. Future exploration may identify deep porphyry copper deposits within areas of permissive rock. No estimates were made for Japan for this assessment.

\section{Source}

Hammarstrom, Bookstrom, DeMarr, and others, 2014, Porphyry copper assessment of East and Southeast Asia—Philippines, Taiwan (Republic of China), Republic of Korea (South Korea), and Japan: U.S. Geological Survey Scientific Investigations Report 2010-5090-P, http://dx.doi.org/10.3133/sir20105090P. 


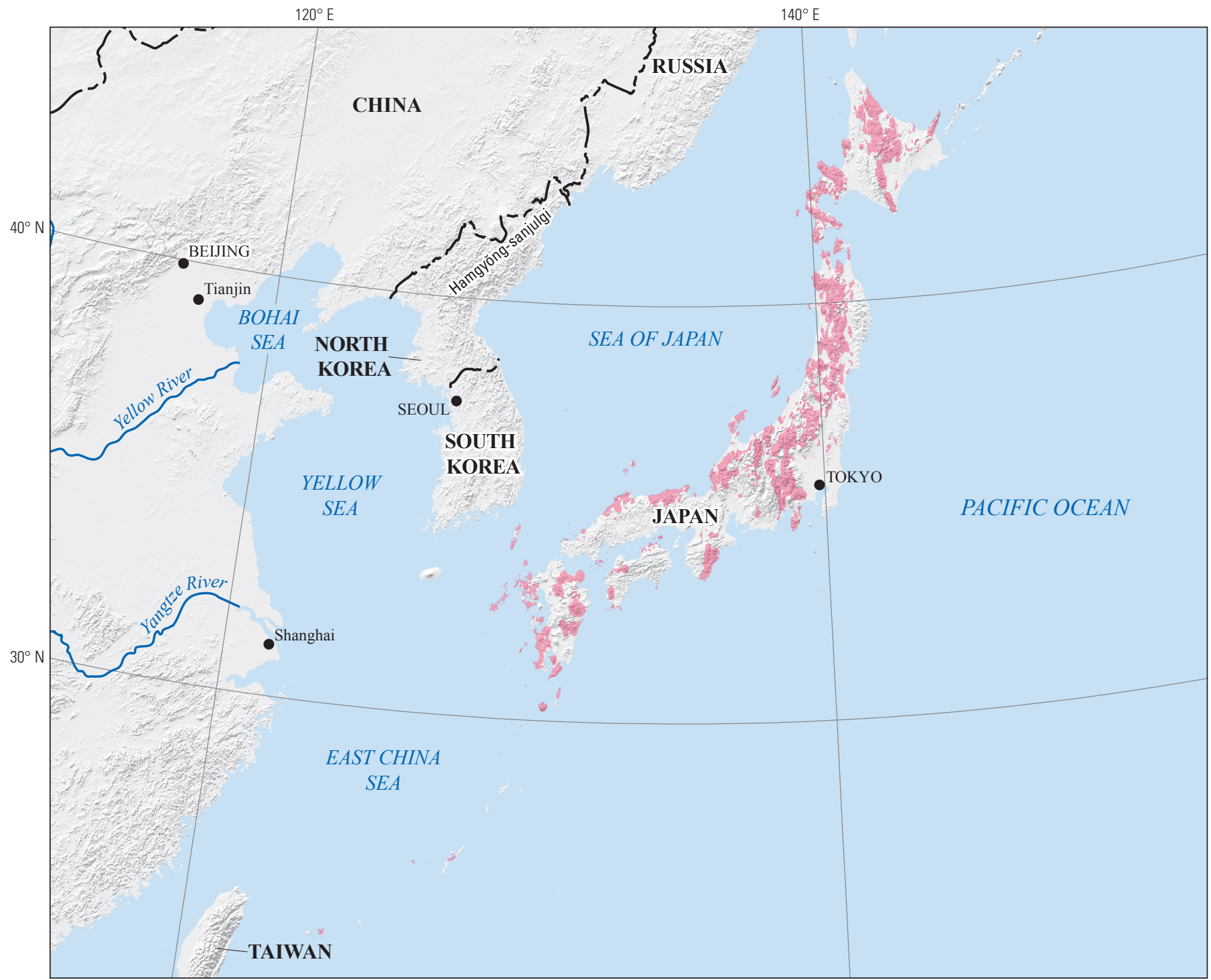

Political boundaries from U.S. Department of State (2009) Shaded relief from Earth Resources Observation and Science (EROS) Center (2011)

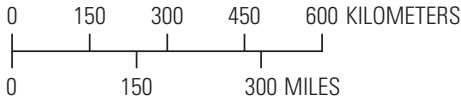

Asia North Albers Equal-Area Conic projection Central meridian $135^{\circ}$ E.; latitude of origin $30^{\circ} \mathrm{N}$.

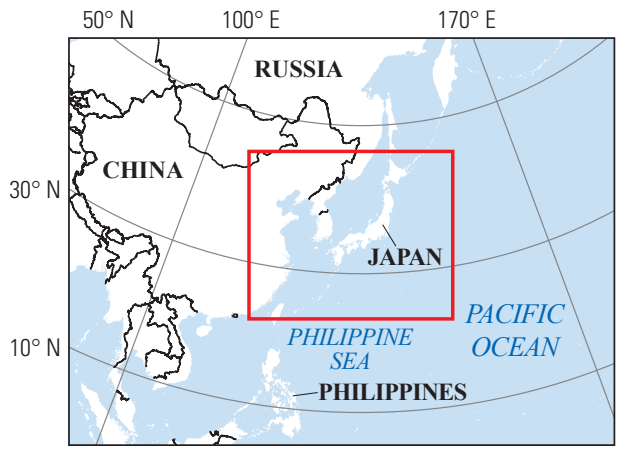




\title{
Plate 67. Porphyry Copper Assessment for Tract 142pCu7314, Western Honshu Area-Japan
}

\author{
Descriptive model: $\quad$ Porphyry copper models (Cox, 1986a; John and others, 2010) \\ Grade and tonnage model: $\quad$ NA \\ Economic filter depth percentages: $\quad$ NA \\ Economic filter cost setting: $\quad$ NA \\ Geologic feature assessed: Late Cretaceous to Paleogene magnetite-series igneous rocks of the Japan arc \\ Number of known deposits: $\quad 0$
}

\section{Selected Resource Assessment Results for Porphyry Copper}

[Assessment depth, 1 kilometer $(\mathrm{km}) ; \mathrm{km}^{2}$, square kilometer; Mt, millions of metric tons; NA, not applicable, as a quantitative assessment was not done]

\begin{tabular}{ccccccc}
\hline \multirow{2}{*}{$\begin{array}{c}\text { Date of } \\
\text { assessment }\end{array}$} & $\begin{array}{c}\text { Tract area } \\
\left(\mathbf{k m}^{2}\right)\end{array}$ & $\begin{array}{c}\text { Identified } \\
\text { copper } \\
\text { resources } \\
(\mathbf{M t})\end{array}$ & $\begin{array}{c}\text { Mean estimate of } \\
\text { in-place resources } \\
(\mathbf{M t})\end{array}$ & $\begin{array}{c}\text { Probability of } \mathbf{0} \\
\text { in-place resources } \\
\text { (percent) }\end{array}$ & $\begin{array}{c}\text { Mean estimate of } \\
\text { economic resources } \\
\text { (Mt) }\end{array}$ & $\begin{array}{c}\text { Probability of 0 } \\
\text { economic resources } \\
\text { (percent) }\end{array}$ \\
\hline 2010 & 27,581 & 0 & NA & NA & NA \\
\hline
\end{tabular}

\section{Qualitative Assessment}

Japan has been explored for minerals for well over 100 years, and no porphyry copper deposits have been found. Future exploration may identify deep porphyry copper deposits within areas of permissive rock. No estimates were made for Japan for this assessment.

\section{Source}

Hammarstrom, Bookstrom, DeMarr, and others, 2014, Porphyry copper assessment of East and Southeast Asia-Philippines, Taiwan (Republic of China), Republic of Korea (South Korea), and Japan: U.S. Geological Survey Scientific Investigations Report 2010-5090-P, http://dx.doi.org/10.3133/sir20105090P. 


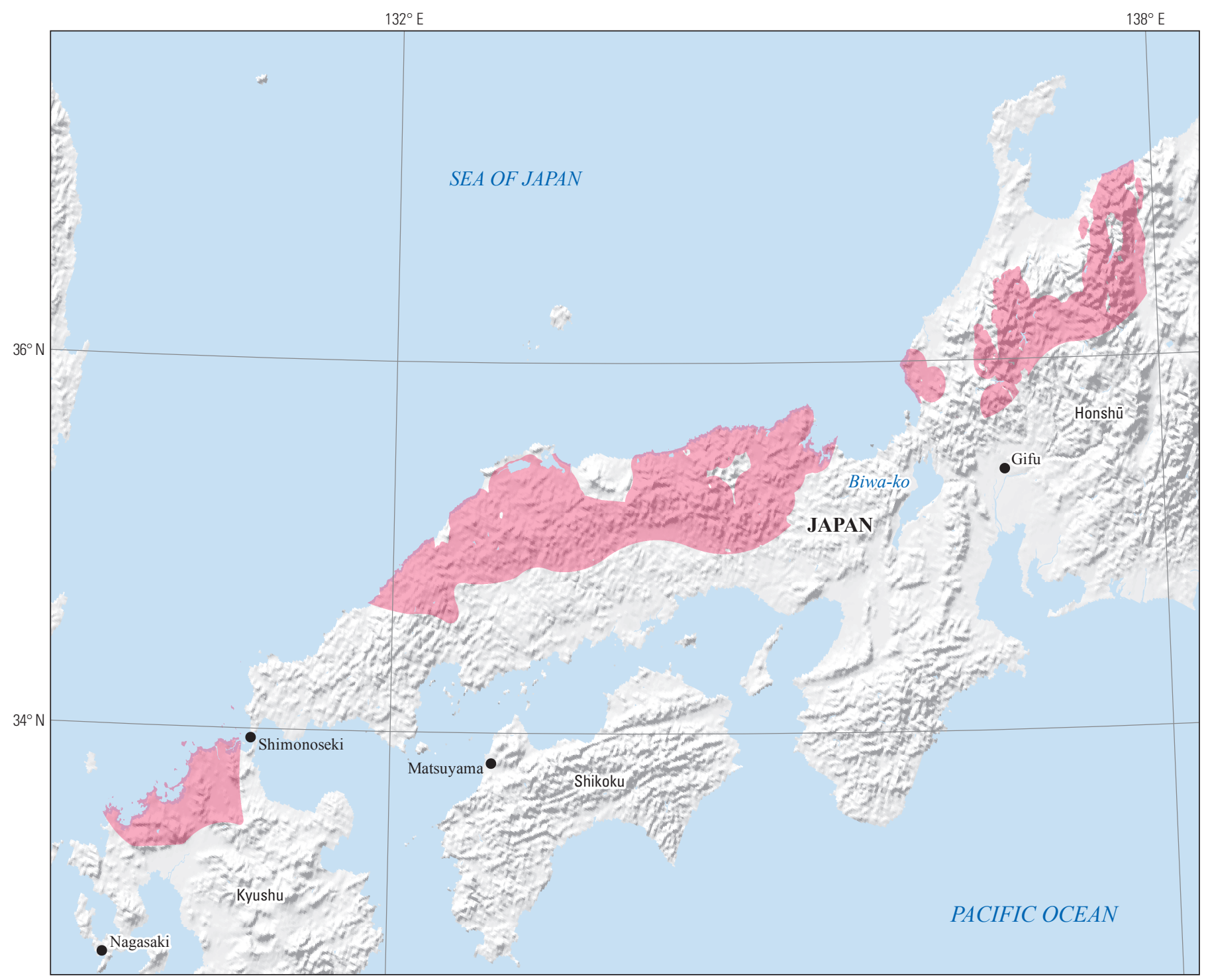

Political boundaries from U.S. Department of State (2009) Shaded relief from Earth Resources Observation and Science (EROS) Center (2011)

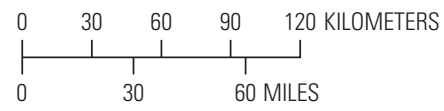

Asia North Albers Equal-Area Conic projection

Central meridian $134^{\circ} \mathrm{E}$.; latitude of origin $30^{\circ} \mathrm{N}$.

\section{EXPLANATION}

Assessed porphyry copper tract 142pCu7314

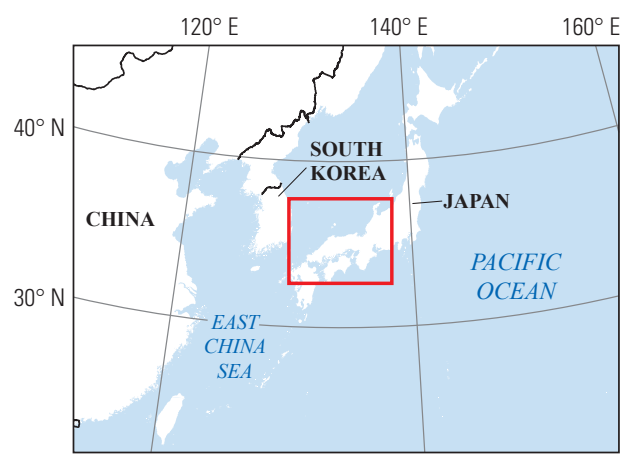




\title{
Plate 68. Porphyry Copper Assessment for Tract 142pCu7313, Gyeongsang Basin-South Korea
}

\author{
Descriptive model: $\quad$ Porphyry copper models (Cox, 1986a; John and others, 2010) \\ Grade and tonnage model: $\quad$ NA \\ Economic filter depth percentages: $\quad$ NA \\ Economic filter cost setting: $\quad$ NA \\ Geologic feature assessed: $\quad$ Late Cretaceous calc-alkalic igneous rocks of the southeastern Korean Peninsula \\ Number of known deposits: $\quad 0$
}

\section{Selected Resource Assessment Results for Porphyry Copper}

[Assessment depth, 1 kilometer $(\mathrm{km})$; $\mathrm{km}^{2}$, square kilometer; Mt, millions of metric tons; NA, not applicable, as a quantitative assessment was not done]

\begin{tabular}{ccccccc}
\hline \multirow{2}{*}{$\begin{array}{c}\text { Date of } \\
\text { assessment }\end{array}$} & $\begin{array}{c}\text { Tract area } \\
\left(\mathbf{k m}^{2}\right)\end{array}$ & $\begin{array}{c}\text { Identified } \\
\text { copper } \\
\text { resources } \\
(\mathbf{M t})\end{array}$ & $\begin{array}{c}\text { Mean estimate of } \\
\text { in-place resources } \\
(\mathbf{M t})\end{array}$ & $\begin{array}{c}\text { Probability of } \mathbf{0} \\
\text { in-place resources } \\
\text { (percent) }\end{array}$ & $\begin{array}{c}\text { Mean estimate of } \\
\text { economic resources } \\
\text { (Mt) }\end{array}$ & $\begin{array}{c}\text { Probability of } 0 \\
\text { economic resources } \\
\text { (percent) }\end{array}$ \\
\hline 2010 & 46,311 & 0 & NA & NA & NA & NA \\
\hline
\end{tabular}

\section{Qualitative Assessment}

South Korea has been explored for minerals for many years. Tract 142pCu7313 (Gyeongsang Basin-South Korea) contains significant mineral deposits of tungsten. As shown on the map, three porphyry copper prospects have been identified in tract 142pCu7313, including a low-grade copper prospect that was explored by drilling in the 1970s. Future exploration may identify deep porphyry copper deposits within areas of permissive rock. No estimates were made for South Korea for this assessment.

\section{Source}

Hammarstrom, Bookstrom, DeMarr, and others, 2014, Porphyry copper assessment of East and Southeast Asia-Philippines, Taiwan (Republic of China), Republic of Korea (South Korea), and Japan: U.S. Geological Survey Scientific Investigations Report 2010-5090-P, http://dx.doi.org/10.3133/sir20105090P. 


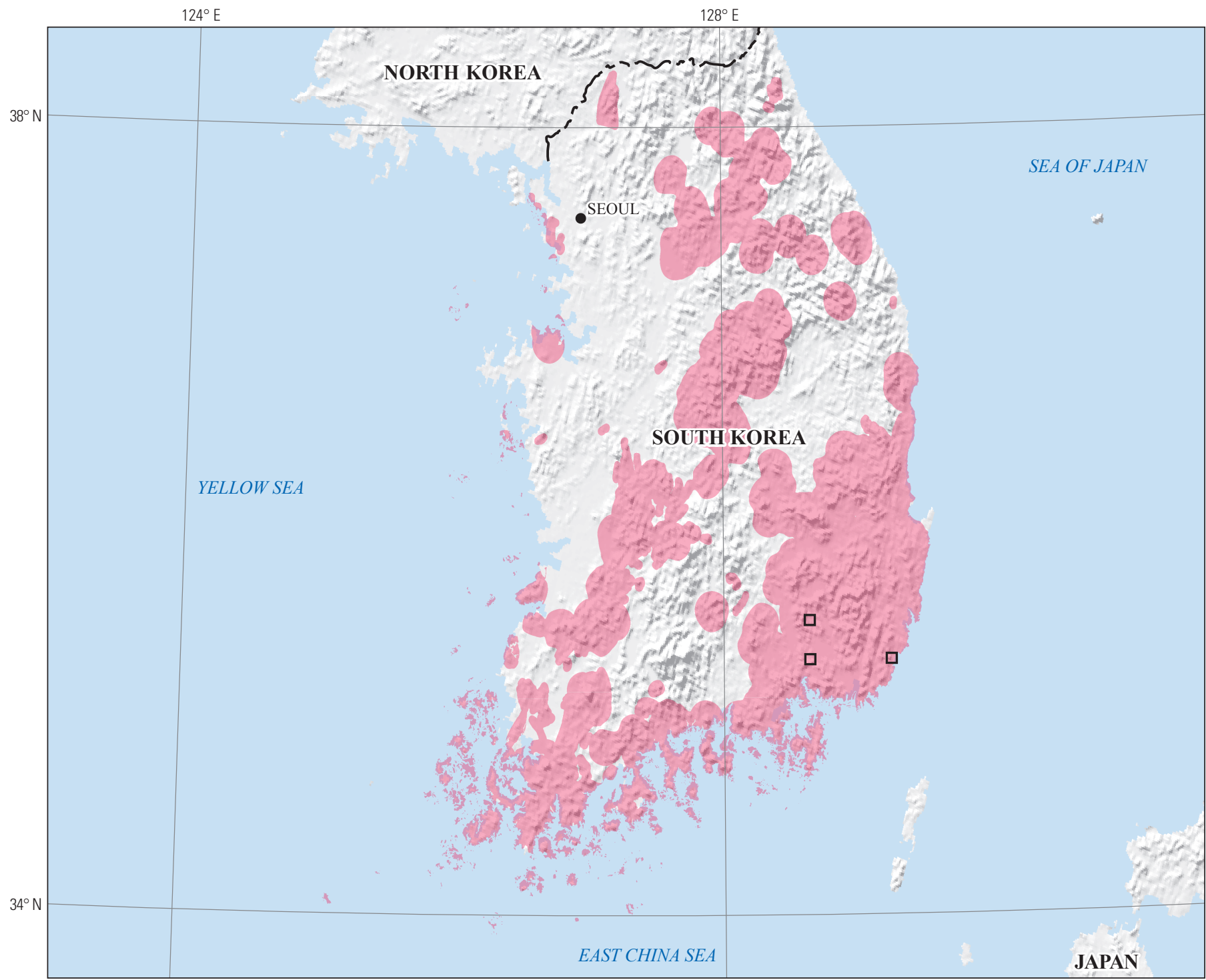

Political boundaries from U.S. Department of State (2009) Shaded relief from Earth Resources Observation and Science (EROS) Center (2011)

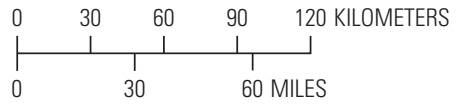

Asia North Albers Equal-Area Conic projection

Central meridian $127^{\circ} 15^{\prime} \mathrm{E}$.; latitude of origin $30^{\circ} \mathrm{N}$

\section{EXPLANATION}

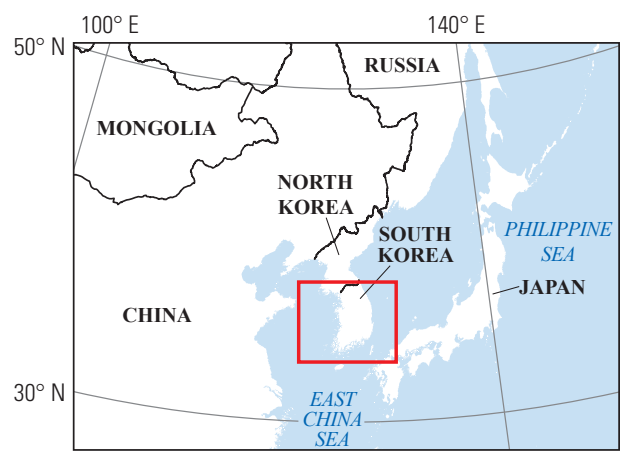

Assessed porphyry copper tract 142 Cu7313

$\square \quad$ Porphyry copper prospect 


\title{
Plate 69. Porphyry Copper Assessment for Tract 142pCu8509, Manchuride- China, North Korea, Mongolia, and Russia
}

\author{
Descriptive model: \\ Porphyry copper models (Cox, 1986a; John and others, 2010) \\ Grade and tonnage model: \\ General porphyry copper model (Singer, Berger, and Moring, 2008) \\ Economic filter depth percentages: \\ Economic filter cost setting: \\ Geologic feature assessed: \\ Default -0 to 250 meters (m), $25 \% ;>250$ to $500 \mathrm{~m}, 25 \% ;>500 \mathrm{~m}$ to $1 \mathrm{~km}, 50 \%$ \\ High cost \\ An assemblage of Jurassic and Cretaceous postsubduction volcanic and intrusive rocks in \\ northeastern China and parts of Russia, Mongolia, and North Korea \\ Number of known deposits: \\ 5
}

\section{Selected Resource Assessment Results for Porphyry Copper}

[Assessment depth, 1 kilometer ( $\mathrm{km}) ; \mathrm{km}^{2}$, square kilometer; Mt, millions of metric tons]

\begin{tabular}{ccccccc}
\hline $\begin{array}{c}\text { Date of } \\
\text { assessment }\end{array}$ & $\begin{array}{c}\text { Tract area } \\
\left(\mathbf{k m}^{2}\right)\end{array}$ & $\begin{array}{c}\text { Identified } \\
\text { copper } \\
\text { resources } \\
\text { (Mt) }\end{array}$ & $\begin{array}{c}\text { Mean estimate of } \\
\text { in-place resources } \\
(\mathbf{M t})\end{array}$ & $\begin{array}{c}\text { Probability of } \mathbf{0} \\
\text { in-place resources } \\
\text { (percent) }\end{array}$ & $\begin{array}{c}\text { Mean estimate of } \\
\text { economic resources } \\
\text { (Mt) }\end{array}$ & $\begin{array}{c}\text { Probability of 0 } \\
\text { economic resources } \\
\text { (percent) }\end{array}$ \\
\hline 2010 & $1,402,360$ & 7.8 & 81 & 4 & 40 \\
\hline
\end{tabular}

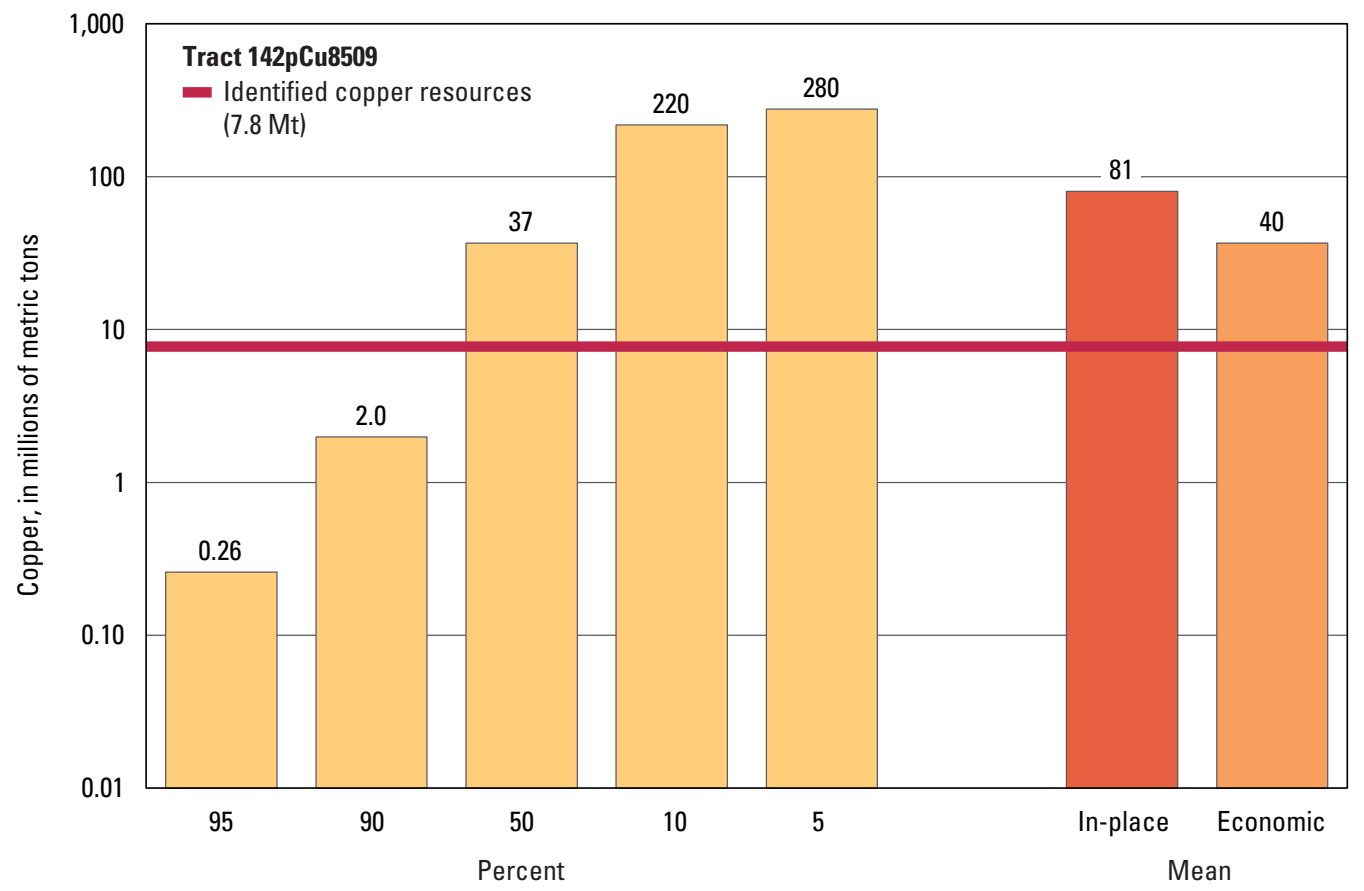

Graph showing the estimated probability distribution of undiscovered copper resources, where each bar represents the minimum amount estimated at the indicated percentage.

\section{Source}

Ludington, Mihalasky, and others, 2012, Porphyry copper assessment of the Mesozoic of East Asia—China, Vietnam, North Korea, Mongolia, and Russia: U.S. Geological Survey Scientific Investigations Report 2010-5090-G, http://pubs.usgs.gov/sir/2010/5090/g/. 


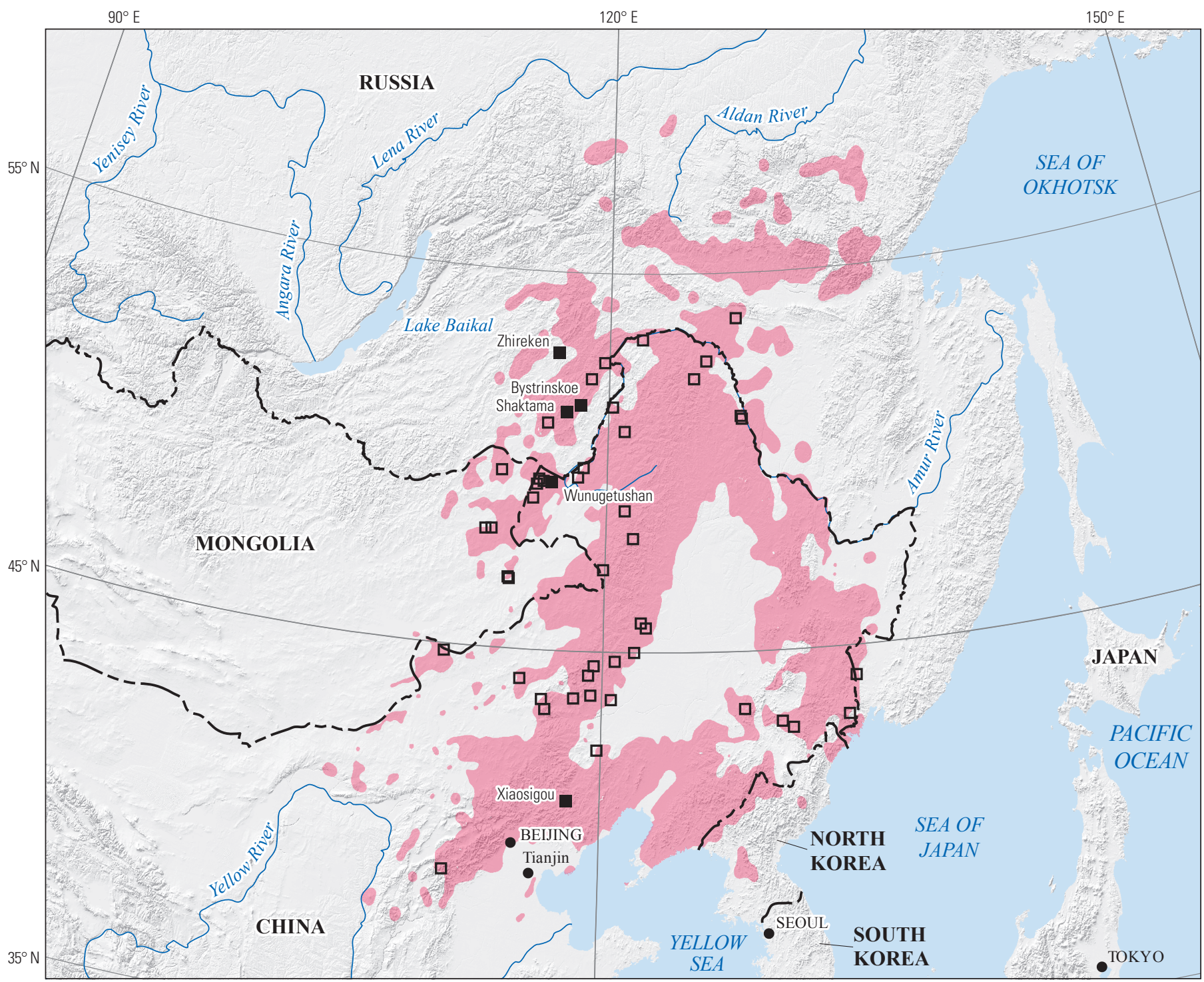

Political boundaries from U.S. Department of State (2009) Shaded relief from Earth Resources Observation and Science (EROS) Center (2011)

Asia North Albers Equal-Area Conic projection

Central meridian $122^{\circ} 30^{\prime} \mathrm{E}$.; latitude of origin $30^{\circ} \mathrm{N}$.

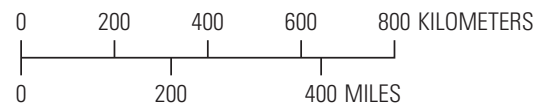

\section{EXPLANATION}

Assessed porphyry copper tract

142pCu8509

- Porphyry copper deposit

$\square \quad$ Porphyry copper prospect

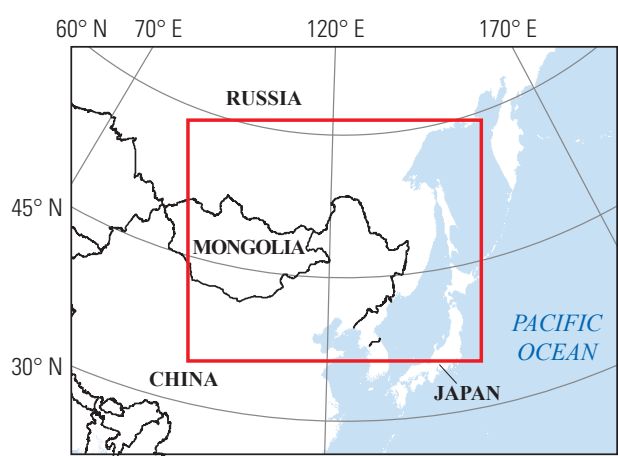




\section{Plate 70. Porphyry Copper Assessment for Tract 142pCu8503, Gobi-Amur- Mongolia, China, and Russia}

\author{
Descriptive model: \\ Grade and tonnage model: \\ Economic filter depth percentages: \\ Economic filter cost setting: \\ Geologic feature assessed:
}

Number of known deposits:

\author{
Porphyry copper models (Cox, 1986a; John and others, 2010) \\ General porphyry copper model (Singer, Berger, and Moring, 2008) \\ Skewed deep - 0 to 250 meters (m), 10\%; > 250 to $500 \mathrm{~m}, 30 \%$; >500 m to $1 \mathrm{~km}, 60 \%$ \\ High cost \\ Cambrian through Early Devonian igneous rocks that consist mostly of continental-margin-arc \\ rocks with some island-arc rocks at the eastern end; mostly covered by the late Paleozoic \\ Kazakh-Mongol arc
}

1

\section{Selected Resource Assessment Results for Porphyry Copper}

[Assessment depth, 1 kilometer $(\mathrm{km}) ; \mathrm{km}^{2}$, square kilometer; Mt, millions of metric tons]

\begin{tabular}{ccccccc}
\hline $\begin{array}{c}\text { Date of } \\
\text { assessment }\end{array}$ & $\begin{array}{c}\text { Tract area } \\
\left.\mathbf{( k m}^{2}\right)\end{array}$ & $\begin{array}{c}\text { Identified } \\
\text { copper } \\
\text { resources } \\
\text { (Mt) }\end{array}$ & $\begin{array}{c}\text { Mean estimate of } \\
\text { in-place resources } \\
(\mathbf{M t})\end{array}$ & $\begin{array}{c}\text { Probability of } \mathbf{0} \\
\text { in-place resources } \\
\text { (percent) }\end{array}$ & $\begin{array}{c}\text { Mean estimate of } \\
\text { economic resources } \\
\text { (Mt) }\end{array}$ & $\begin{array}{c}\text { Probability of 0 } \\
\text { economic resources } \\
\text { (percent) }\end{array}$ \\
\hline 2013 & 56,087 & 3.3 & 5.9 & 30 & 2.7 \\
\hline
\end{tabular}

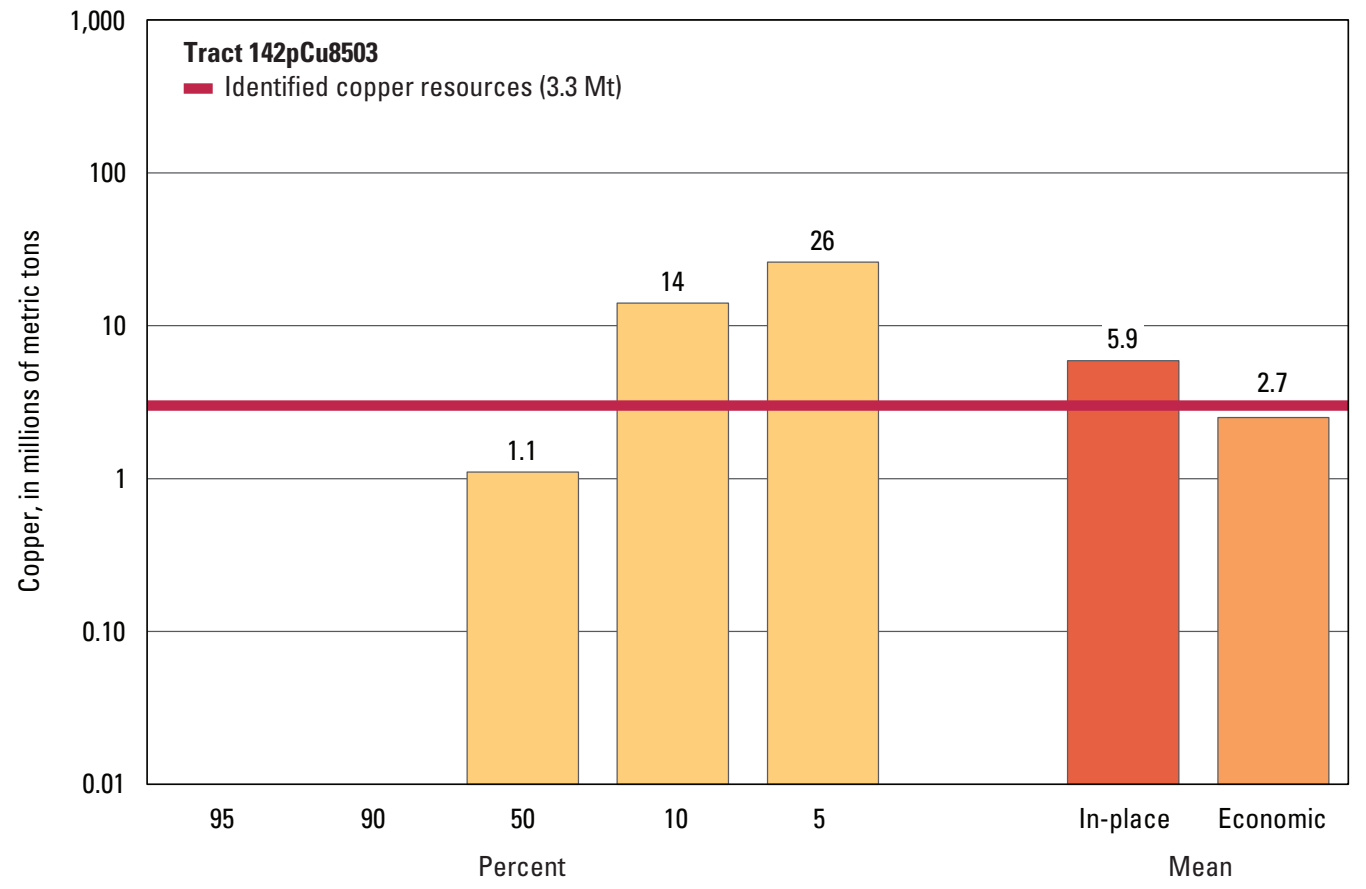

Graph showing the estimated probability distribution of undiscovered copper resources, where each bar represents the minimum amount estimated at the indicated percentage.

\section{Source}

Mihalasky, Ludington, Hammarstrom, and others, 2015, Porphyry copper assessment of the Central Asian Orogenic Belt and eastern Tethysides - China, Mongolia, Russia, Pakistan, Kazakhstan, Tajikistan, and India: U.S. Geological Survey Scientific Investigations Report 2010-5090-X, http://dx.doi.org/10.3133/sir20105090X. 


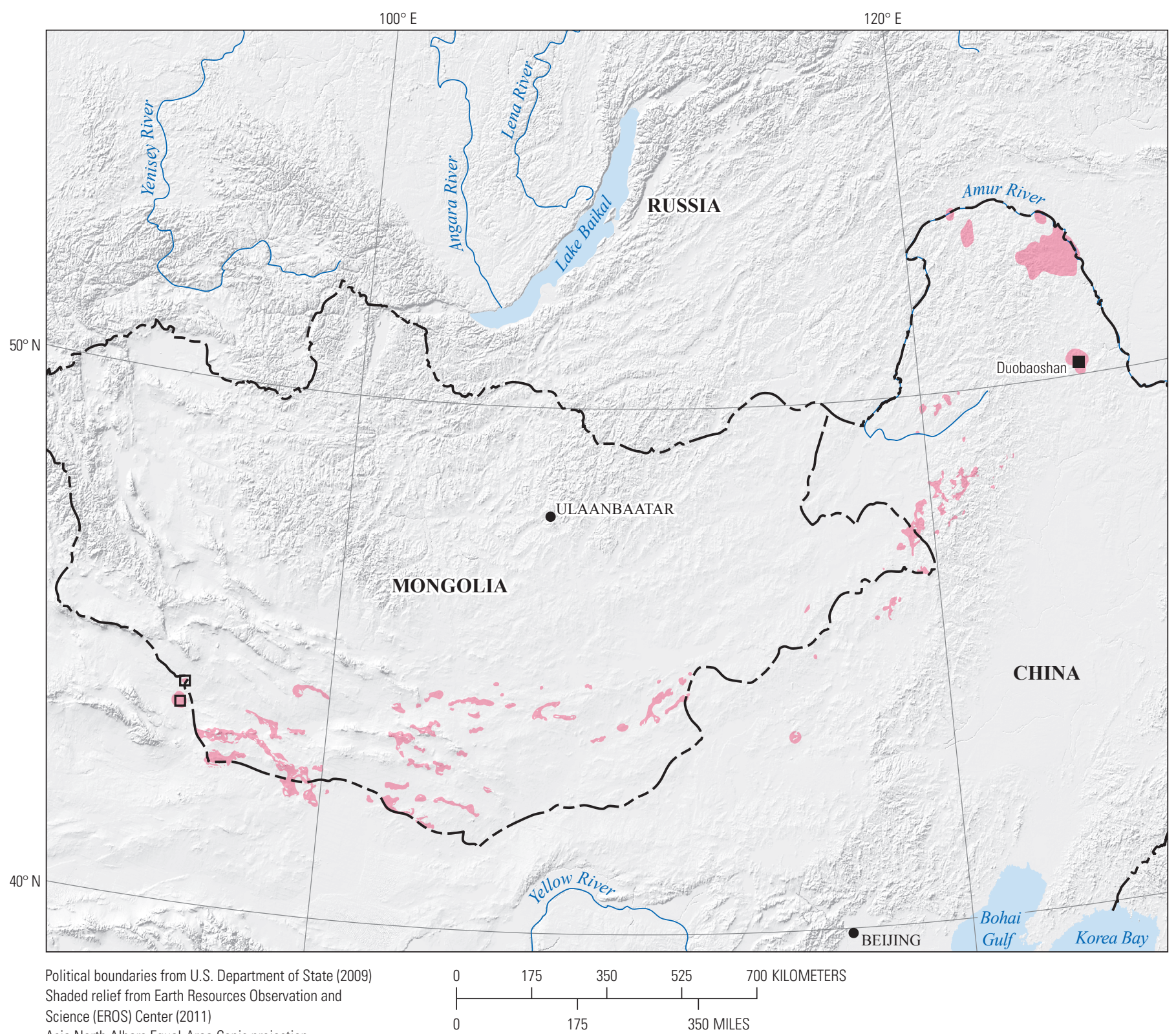

Asia North Albers Equal-Area Conic projection

Central meridian $110^{\circ} \mathrm{E}$.; latitude of origin $30^{\circ} \mathrm{N}$.

\section{EXPLANATION}

\section{Assessed porphyry copper tract 142pCu8503}

- Porphyry copper deposit

$\square \quad$ Porphyry copper prospect

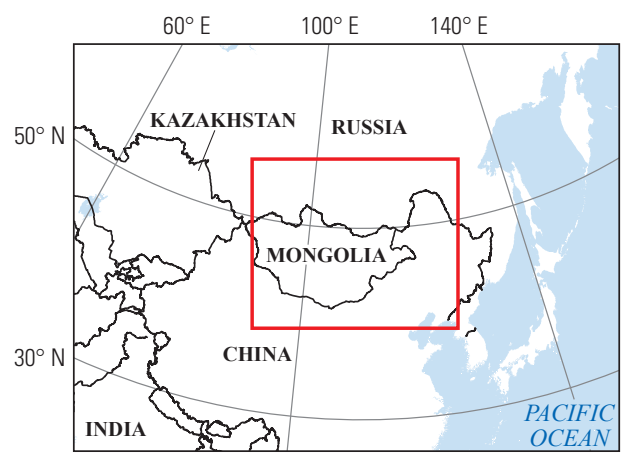




\title{
Plate 71. Porphyry Copper Assessment for Tract 142pCu8508b, Erdenet (Northeast)—Russia
}

\author{
Descriptive model: $\quad$ Porphyry copper models (Cox, 1986a; John and others, 2010) \\ Grade and tonnage model: NA \\ Economic filter depth percentages: NA \\ Economic filter cost setting: NA \\ Geologic feature assessed: $\quad$ An assemblage of Middle Permian through Triassic igneous rocks in Russia that formed during and \\ after closure of the Mongol-Okhotsk ocean, apparently in a postsubduction environment \\ Number of known deposits: \\ 0
}

\section{Selected Resource Assessment Results for Porphyry Copper}

[Assessment depth, 1 kilometer $(\mathrm{km}) ; \mathrm{km}^{2}$, square kilometer; Mt, millions of metric tons; NA, not applicable, as a quantitative assessment was not done]

\begin{tabular}{|c|c|c|c|c|c|c|}
\hline \multirow[b]{2}{*}{$\begin{array}{c}\text { Date of } \\
\text { assessment }\end{array}$} & \multirow[b]{2}{*}{$\begin{array}{c}\text { Tract area } \\
\quad\left(\mathbf{k m}^{2}\right)\end{array}$} & \multirow{2}{*}{$\begin{array}{l}\text { Identified } \\
\text { copper } \\
\text { resources } \\
\text { (Mt) }\end{array}$} & \multicolumn{4}{|c|}{ Undiscovered copper resource estimates } \\
\hline & & & $\begin{array}{l}\text { Mean estimate of } \\
\text { in-place resources } \\
\text { (Mt) }\end{array}$ & $\begin{array}{c}\text { Probability of } 0 \\
\text { in-place resources } \\
\text { (percent) }\end{array}$ & $\begin{array}{l}\text { Mean estimate of } \\
\text { economic resources } \\
\text { (Mt) }\end{array}$ & $\begin{array}{c}\text { Probability of } 0 \\
\text { economic resources } \\
\text { (percent) }\end{array}$ \\
\hline 2013 & 103,793 & 0 & NA & NA & NA & NA \\
\hline
\end{tabular}

\section{Qualitative Assessment}

The northeastern extension of the permissive rocks that host the Erdenet in tract $142 \mathrm{pCu} 8508 \mathrm{~b}$ (Erdenet (Northeast)Russia) is broadly permissive for the occurrence of porphyry copper deposits. No deposits are known, and little information was available in the public domain on the details of the geology and copper occurrences in this area. No estimates were made for this tract for this assessment.

\section{Source}

Mihalasky, Ludington, Hammarstrom, and others, 2015, Porphyry copper assessment of the Central Asian Orogenic Belt and eastern Tethysides - China, Mongolia, Russia, Pakistan, Kazakhstan, Tajikistan, and India: U.S. Geological Survey Scientific Investigations Report 2010-5090-X, http://dx.doi.org/10.3133/sir20105090X. 


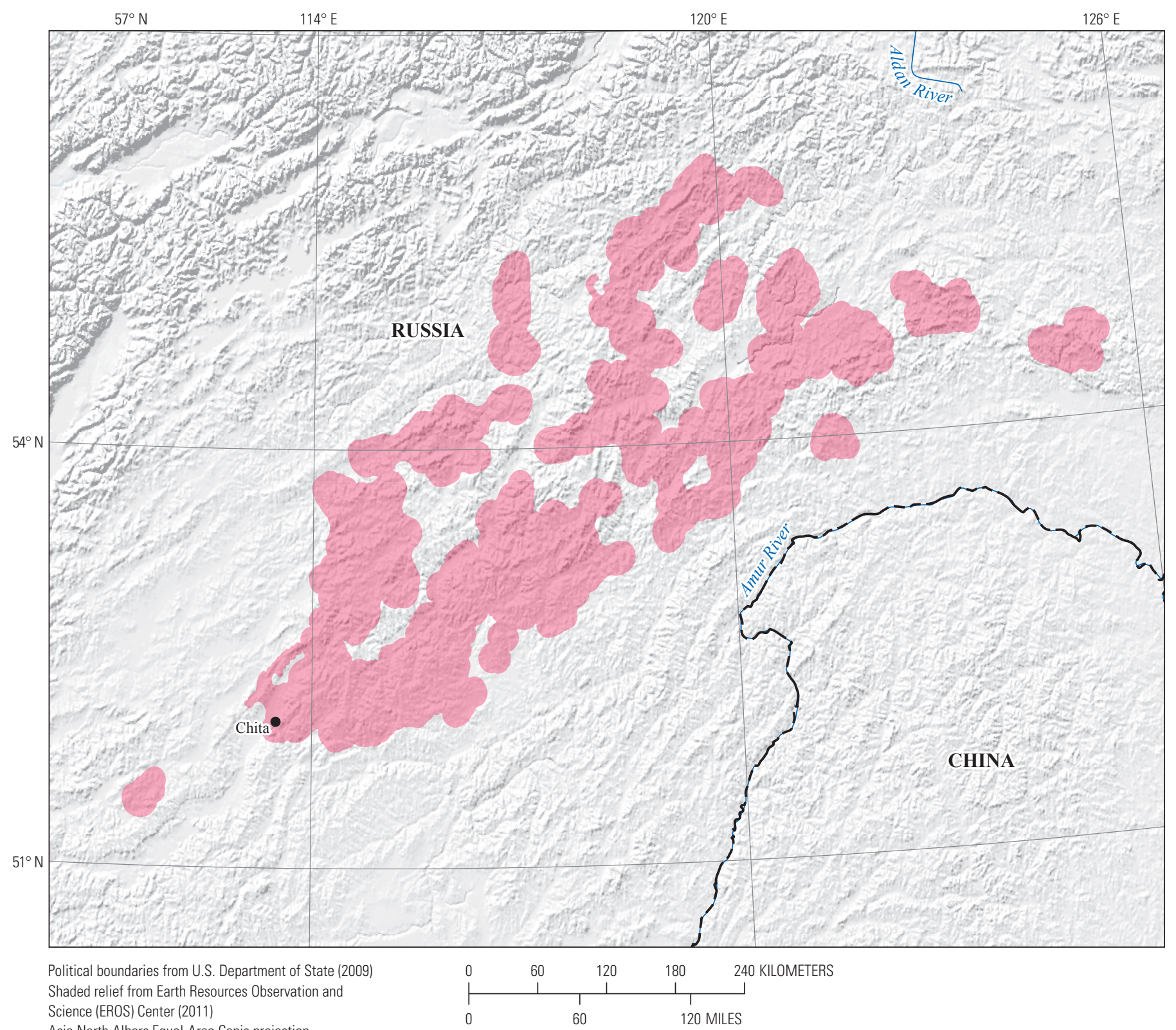

Asia North Albers Equal-Area Conic projection

Central meridian $120^{\circ} \mathrm{E}$.; latitude of origin $30^{\circ} \mathrm{N}$.

\section{EXPLANATION}

Assessed porphyry copper tract 142pCu8508b

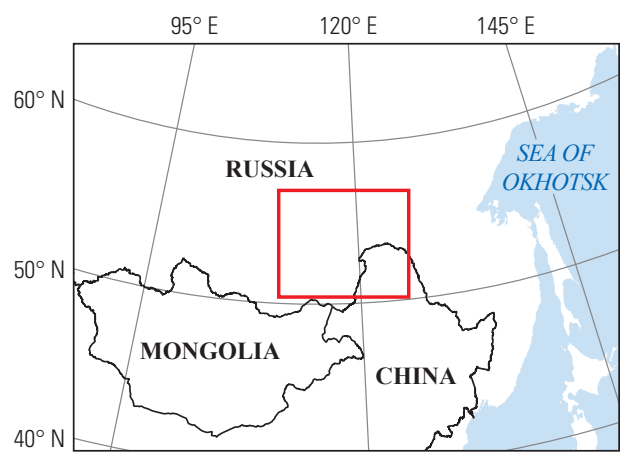




\title{
Plate 72. Porphyry Copper Assessment for Tract 142pCu8507, Mongol-Altai- Mongolia, Russia, Kazakhstan, and China
}

\author{
Descriptive model: \\ Porphyry copper models (Cox, 1986a; John and others, 2010) \\ Grade and tonnage model: \\ General porphyry copper model (Singer, Berger, and Moring, 2008) \\ Economic filter depth percentages: \\ Economic filter cost setting: \\ Geologic feature assessed: \\ Default -0 to 250 meters (m), $25 \% ;>250$ to $500 \mathrm{~m}, 25 \% ;>500 \mathrm{~m}$ to $1 \mathrm{~km}, 50 \%$ \\ High cost \\ A varied assemblage of Devonian through Early Permian igneous rocks primarily in Mongolia and \\ Russia that include primarily calc-alkalic continental-margin-arc rocks. \\ Number of known deposits: \\ 0
}

\section{Selected Resource Assessment Results for Porphyry Copper}

[Assessment depth, 1 kilometer ( $\mathrm{km}) ; \mathrm{km}^{2}$, square kilometer; Mt, millions of metric tons]

\begin{tabular}{ccccccc}
\hline $\begin{array}{c}\text { Date of } \\
\text { assessment }\end{array}$ & $\begin{array}{c}\text { Tract area } \\
\left(\mathbf{k m}^{2}\right)\end{array}$ & $\begin{array}{c}\text { Identified } \\
\text { copper } \\
\text { resources } \\
\text { (Mt) }\end{array}$ & $\begin{array}{c}\text { Mean estimate of } \\
\text { in-place resources } \\
(\mathbf{M t})\end{array}$ & $\begin{array}{c}\text { Probability of } \mathbf{0} \\
\text { in-place resources } \\
\text { (percent) }\end{array}$ & $\begin{array}{c}\text { Mean estimate of } \\
\text { economic resources } \\
\text { (Mt) }\end{array}$ & $\begin{array}{c}\text { Probability of 0 } \\
\text { economic resources } \\
\text { (percent) }\end{array}$ \\
\hline 2013 & 785,571 & 0 & 53 & 3 & 26 \\
\hline
\end{tabular}

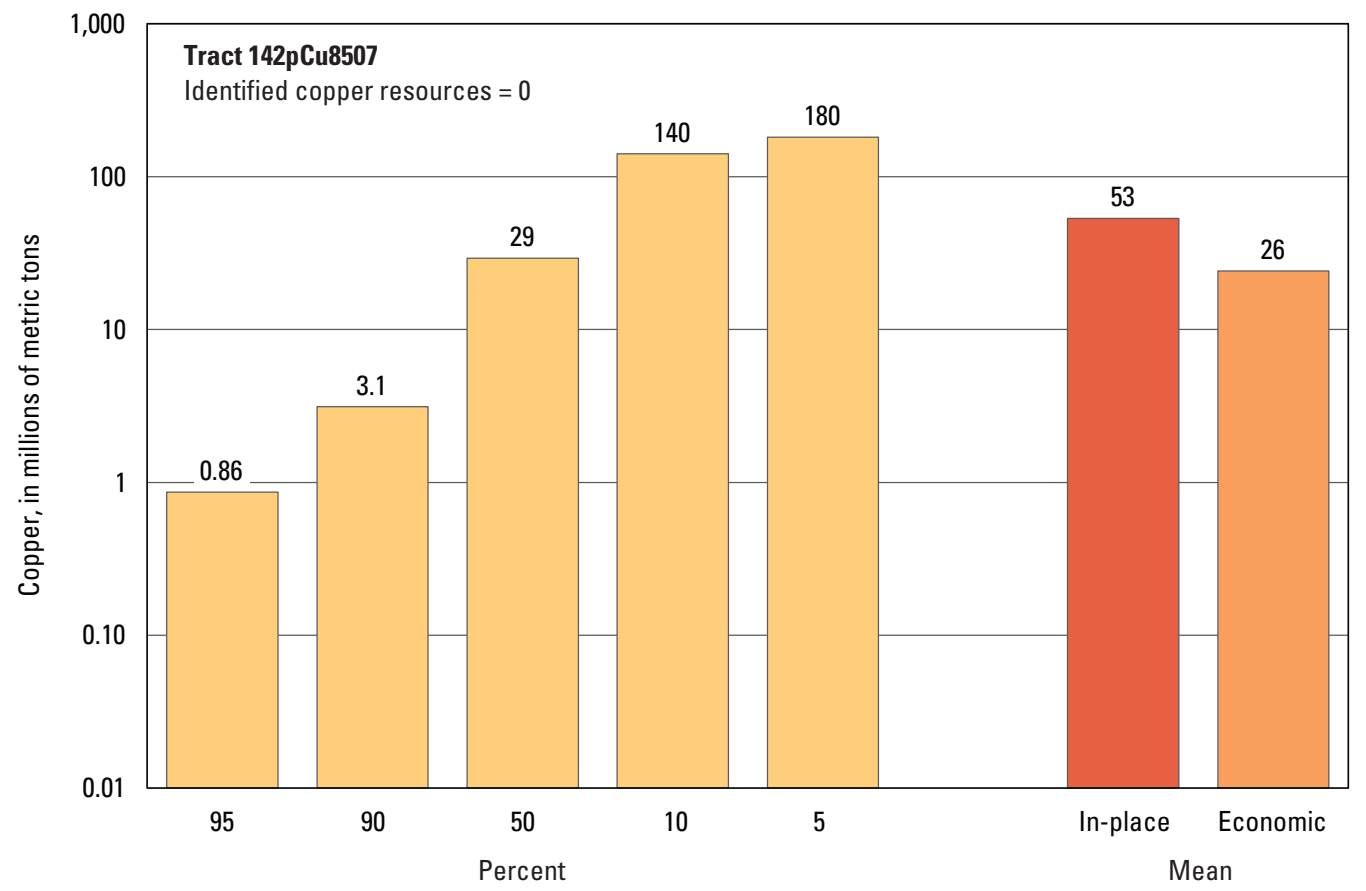

Graph showing the estimated probability distribution of undiscovered copper resources, where each bar represents the minimum amount estimated at the indicated percentage.

\section{Source}

Mihalasky, Ludington, Hammarstrom, and others, 2015, Porphyry copper assessment of the Central Asian Orogenic Belt and eastern Tethysides - China, Mongolia, Russia, Pakistan, Kazakhstan, Tajikistan, and India: U.S. Geological Survey Scientific Investigations Report 2010-5090-X, http://dx.doi.org/10.3133/sir20105090X. 


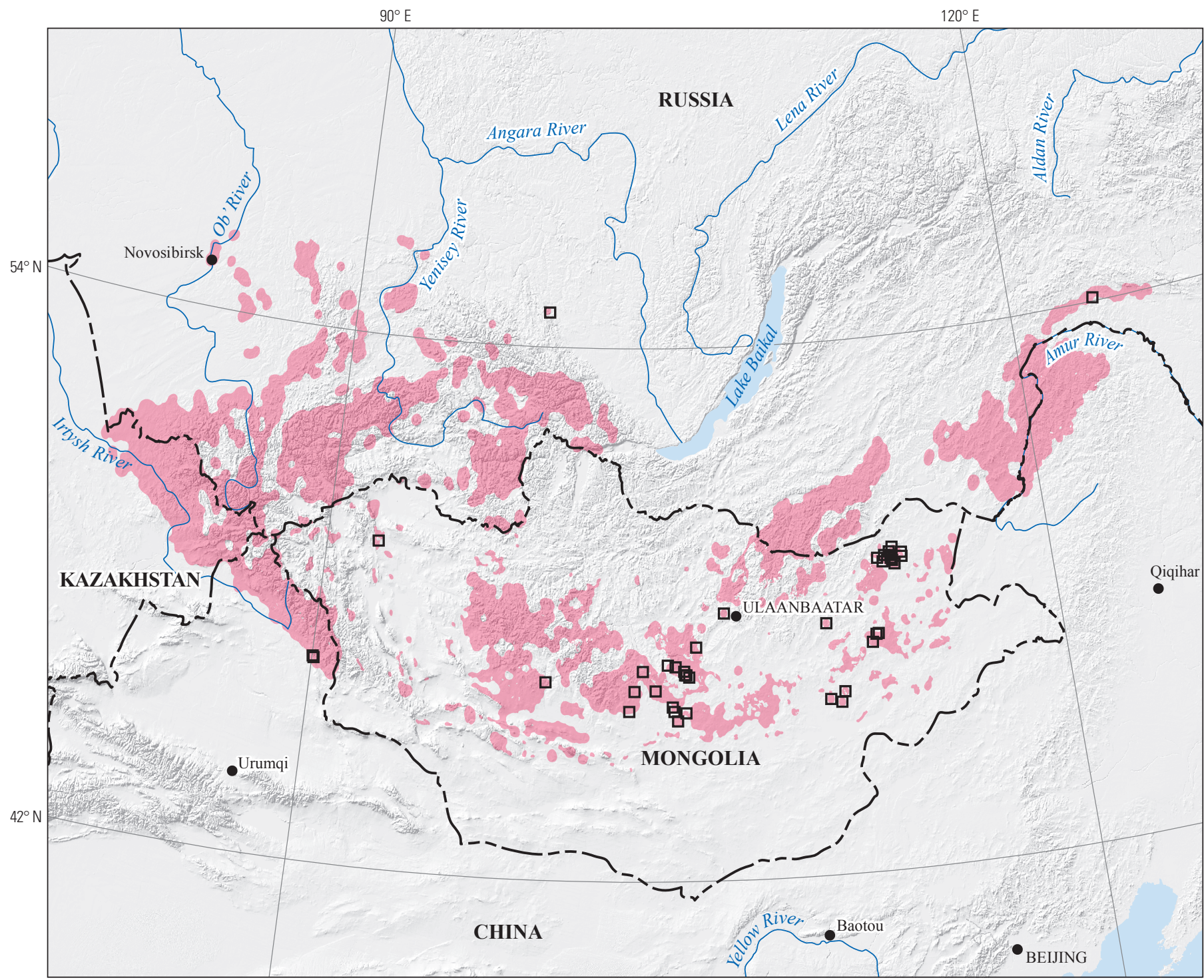

Political boundaries from U.S. Department of State (2009) Shaded relief from Earth Resources Observation and Science (EROS) Center (2011)

Asia North Albers Equal-Area Conic projection

Central meridian $103^{\circ} \mathrm{E}$.; latitude of origin $30^{\circ} \mathrm{N}$.

EXPLANATION

\section{Assessed porphyry copper tract 142pCu8507}

․ Porphyry copper prospect
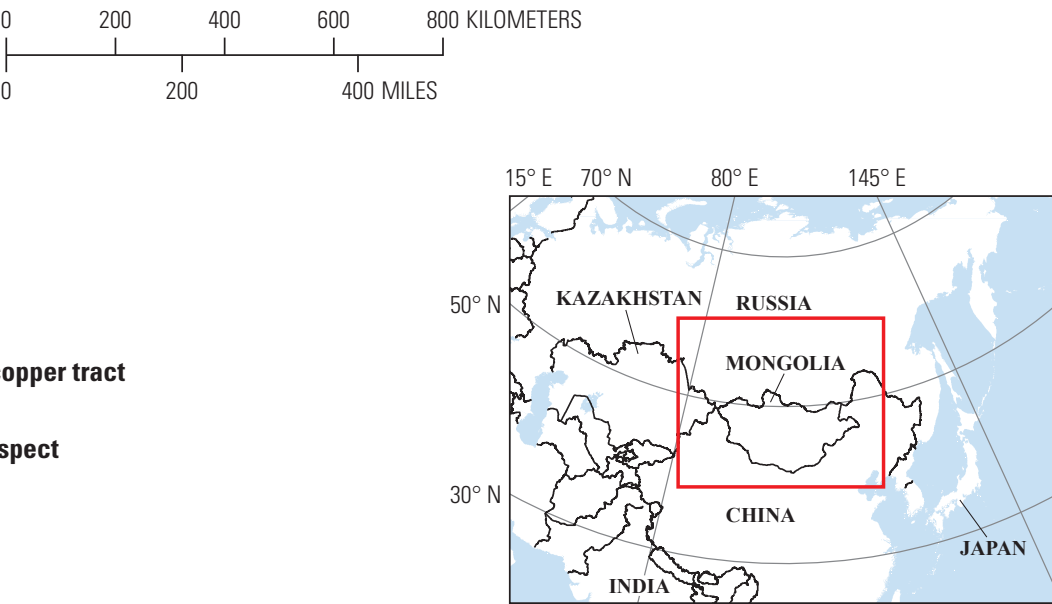


\title{
Plate 73. Porphyry Copper Assessment for Tract 142pCu8504, Mongol-Sayan- Mongolia, China, and Russia
}

\author{
Descriptive model: \\ Grade and tonnage model: \\ Porphyry copper models (Cox, 1986a; John and others, 2010) \\ Economic filter depth percentages: \\ Economic filter cost setting: \\ Geologic feature assessed: \\ Porphyry copper, copper-molybdenum subtype model (Singer, Berger, and Moring, 2008) \\ Default -0 to 250 meters (m), $25 \%$; $>250$ to $500 \mathrm{~m}, 25 \%$; $>500 \mathrm{~m}$ to $1 \mathrm{~km}, 50 \%$ \\ High cost \\ Cambrian through Silurian igneous rocks primarily in central and northern Mongolia and bordering \\ parts of Russia, including the Tuva-Mongol island arc and a variety of other calc-alkalic rocks \\ Number of known deposits: \\ 4
}

\section{Selected Resource Assessment Results for Porphyry Copper}

[Assessment depth, 1 kilometer ( $\mathrm{km}) ; \mathrm{km}^{2}$, square kilometer; Mt, millions of metric tons]

\begin{tabular}{ccccccc}
\hline $\begin{array}{c}\text { Date of } \\
\text { assessment }\end{array}$ & $\begin{array}{c}\text { Tract area } \\
\left(\mathbf{k m}^{2}\right)\end{array}$ & $\begin{array}{c}\text { Identified } \\
\text { copper } \\
\text { resources } \\
\text { (Mt) }\end{array}$ & $\begin{array}{c}\text { Mean estimate of } \\
\text { in-place resources } \\
(\mathbf{M t})\end{array}$ & $\begin{array}{c}\text { Probability of } \mathbf{0} \\
\text { in-place resources } \\
\text { (percent) }\end{array}$ & $\begin{array}{c}\text { Mean estimate of } \\
\text { economic resources } \\
\text { (Mt) }\end{array}$ & $\begin{array}{c}\text { Probability of 0 } \\
\text { economic resources } \\
\text { (percent) }\end{array}$ \\
\hline 2013 & 575,102 & 15 & 38 & 6 & 19 \\
\hline
\end{tabular}

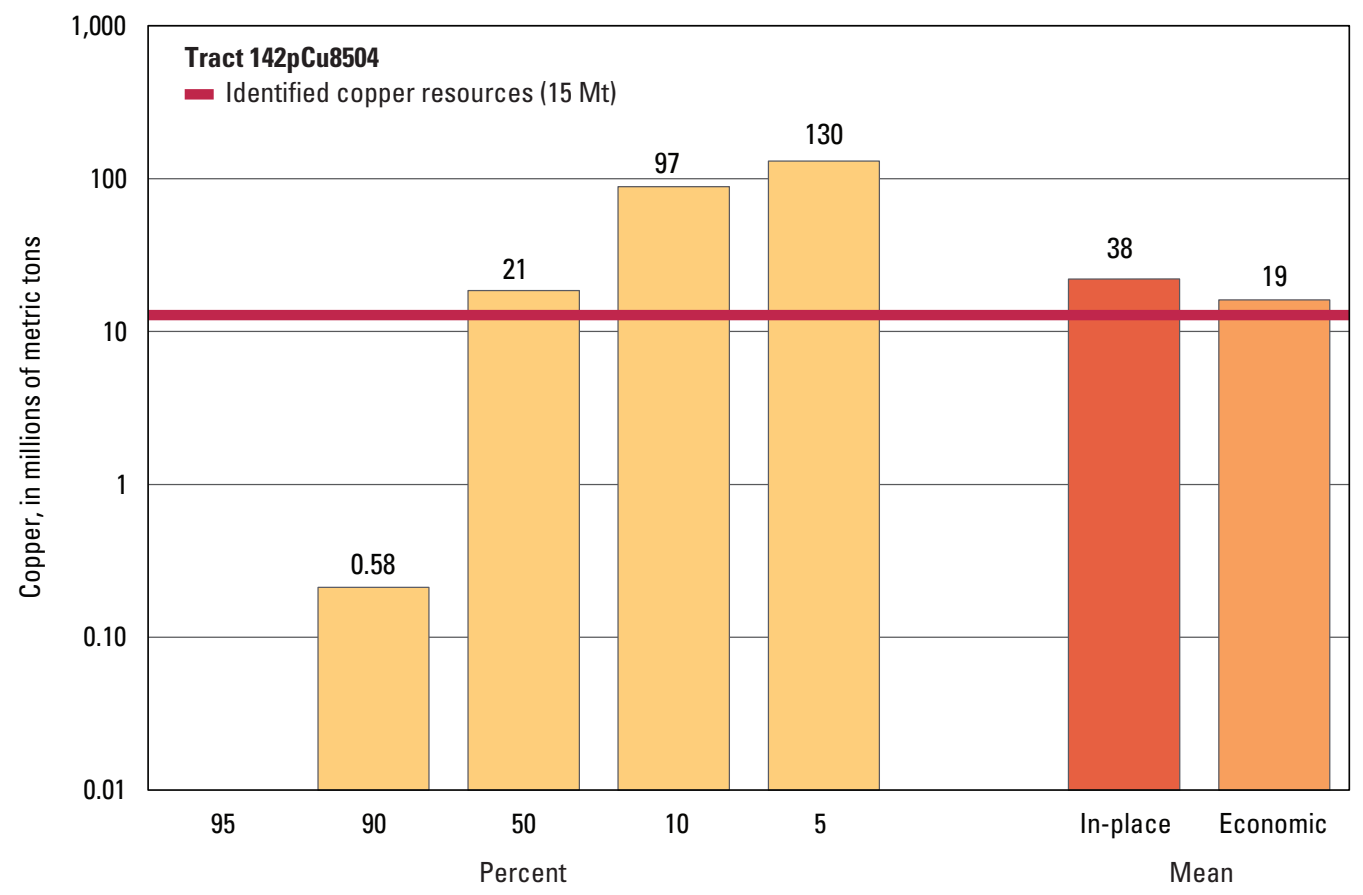

Graph showing the estimated probability distribution of undiscovered copper resources, where each bar represents the minimum amount estimated at the indicated percentage.

\section{Source}

Mihalasky, Ludington, Hammarstrom, and others, 2015, Porphyry copper assessment of the Central Asian Orogenic Belt and eastern Tethysides - China, Mongolia, Russia, Pakistan, Kazakhstan, Tajikistan, and India: U.S. Geological Survey Scientific Investigations Report 2010-5090-X, http://dx.doi.org/10.3133/sir20105090X. 


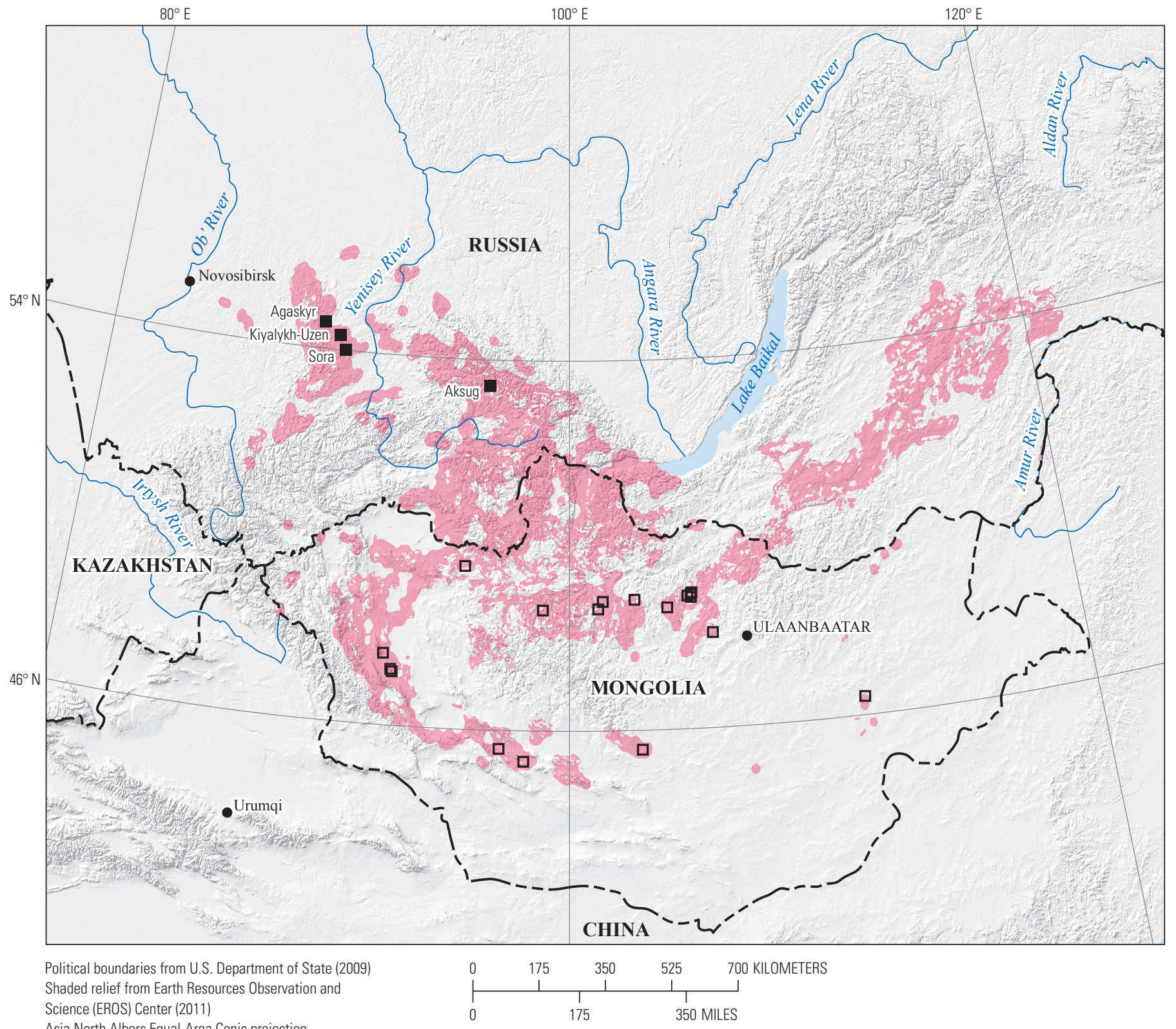

Asia North Albers Equal-Area Conic projection

Central meridian $100^{\circ} \mathrm{E}$.; latitude of origin $30^{\circ} \mathrm{N}$.

EXPLANATION

\section{Assessed porphyry copper tract 142pCu8504}

- Porphyry copper deposit

ㅁ Porphyry copper prospect

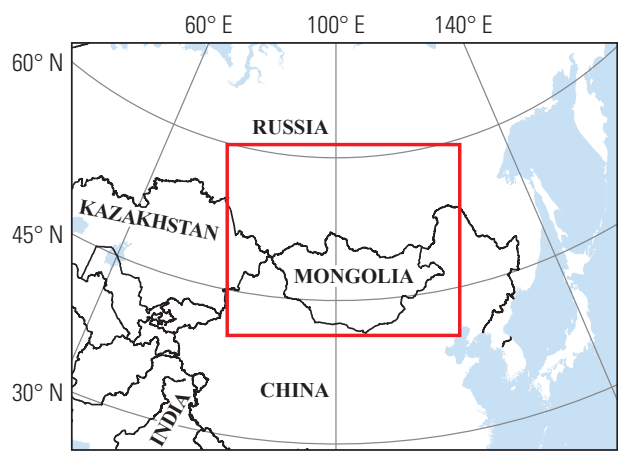




\section{Plate 74. Porphyry Copper Assessment for Tract 142pCu8508a, Erdenet- Mongolia}

\section{Descriptive model:}

Grade and tonnage model:

Economic filter depth percentages:

Economic filter cost setting:

Geologic feature assessed:

Number of known deposits:
Porphyry copper models (Cox, 1986a; John and others, 2010)

General porphyry copper model (Singer, Berger, and Moring, 2008)

Default - 0 to 250 meters (m), 25\%; > 250 to $500 \mathrm{~m}, 25 \%$; >500 m to $1 \mathrm{~km}, 50 \%$

High cost

Middle Permian through Triassic igneous rocks in Mongolia that formed during and after closure of the Mongol-Okhotsk ocean, apparently in a postsubduction environment

\section{Selected Resource Assessment Results for Porphyry Copper}

[Assessment depth, 1 kilometer (km); $\mathrm{km}^{2}$, square kilometer; Mt, millions of metric tons]

\begin{tabular}{ccccccc}
\hline $\begin{array}{c}\text { Date of } \\
\text { assessment }\end{array}$ & $\begin{array}{c}\text { Tract area } \\
\left(\mathbf{k m}^{2}\right)\end{array}$ & $\begin{array}{c}\text { Identified } \\
\text { copper } \\
\text { resources } \\
\text { (Mt) }\end{array}$ & $\begin{array}{c}\text { Mean estimate of } \\
\text { in-place resources } \\
(\mathbf{M t})\end{array}$ & $\begin{array}{c}\text { Probability of } \mathbf{0} \\
\text { in-place resources } \\
\text { (percent) }\end{array}$ & $\begin{array}{c}\text { Mean estimate of } \\
\text { economic resources } \\
\text { (Mt) }\end{array}$ & $\begin{array}{c}\text { Probability of 0 } \\
\text { economic resources } \\
\text { (percent) }\end{array}$ \\
\hline 2013 & 61,430 & 9.0 & 34 & 4 & 17 \\
\hline
\end{tabular}

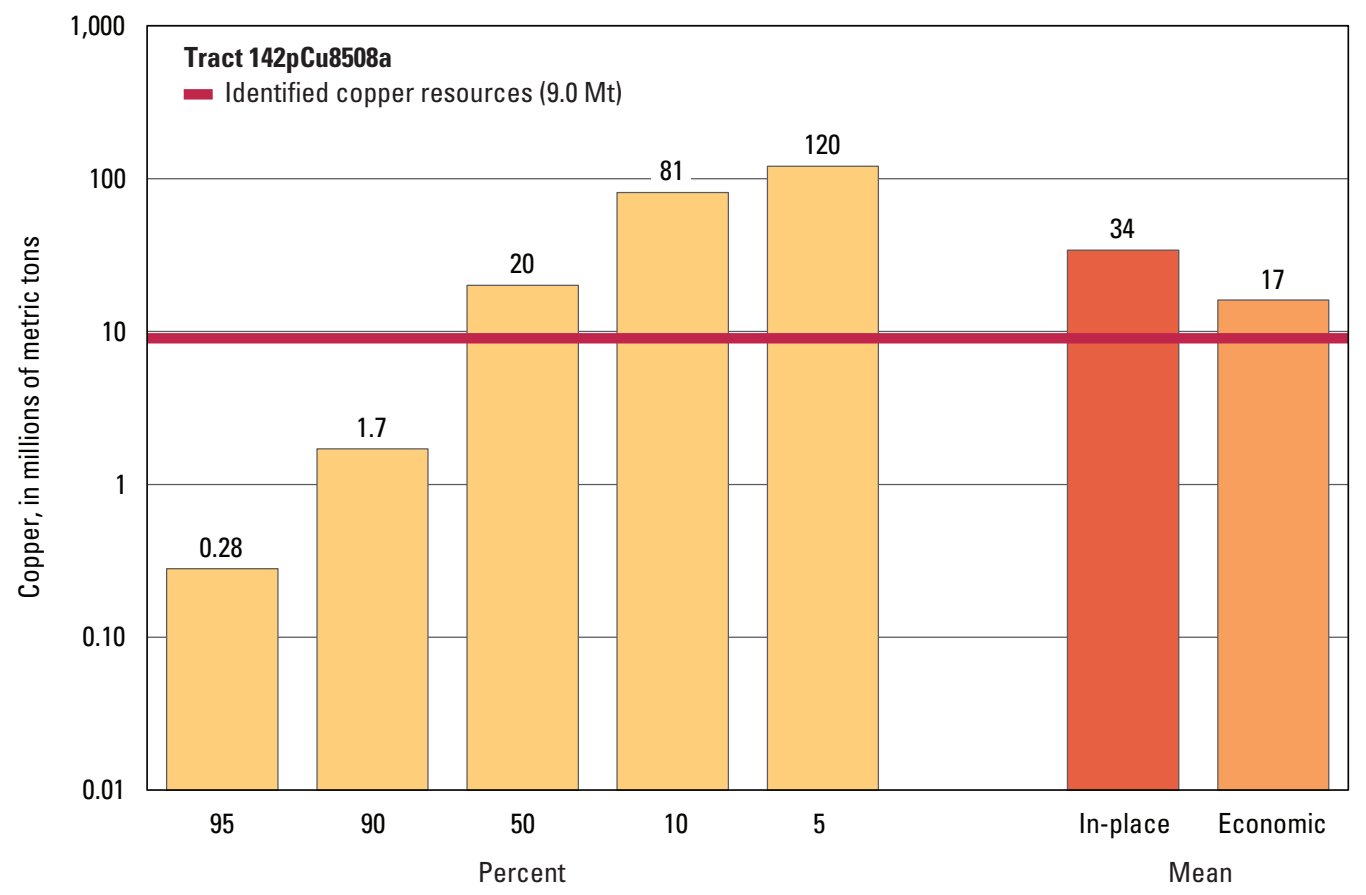

Graph showing the estimated probability distribution of undiscovered copper resources, where each bar represents the minimum amount estimated at the indicated percentage.

\section{Source}

Mihalasky, Ludington, Hammarstrom, and others, 2015, Porphyry copper assessment of the Central Asian Orogenic Belt and eastern Tethysides - China, Mongolia, Russia, Pakistan, Kazakhstan, Tajikistan, and India: U.S. Geological Survey Scientific Investigations Report 2010-5090-X, http://dx.doi.org/10.3133/sir20105090X. 


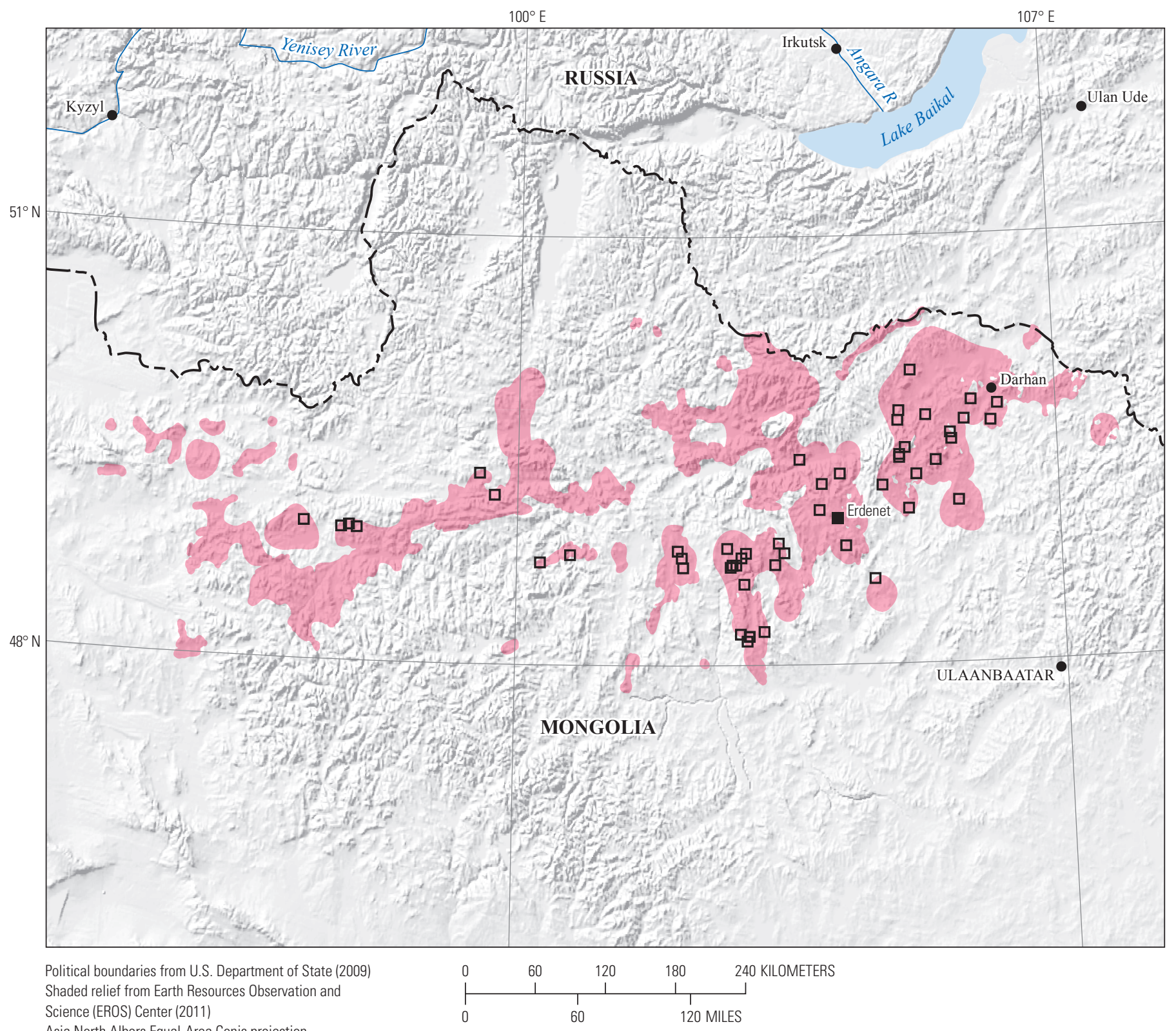

Asia North Albers Equal-Area Conic projection

Central meridian $102^{\circ} \mathrm{E}$.; latitude of origin $30^{\circ} \mathrm{N}$.

\section{EXPLANATION}

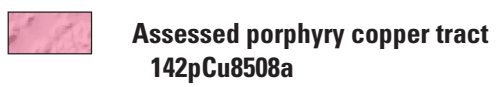

142pCu8508a

- Porphyry copper deposit

$\square \quad$ Porphyry copper prospect

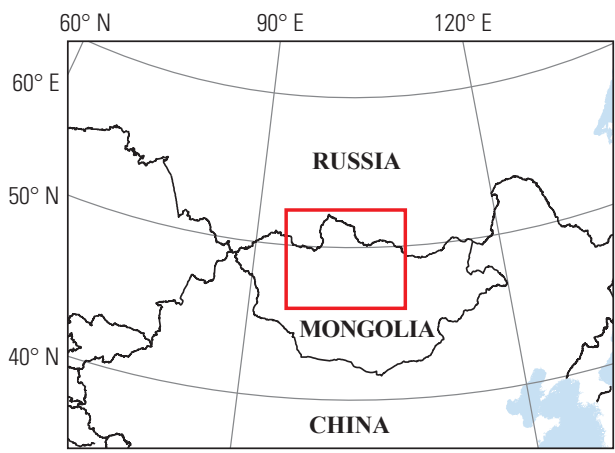




\section{Plate 75. Porphyry Copper Assessment for Tract 142pCu8506, Oyu Tolgoi- China and Mongolia}

\author{
Descriptive model: \\ Grade and tonnage model: \\ Economic filter depth percentages: \\ Economic filter cost setting: \\ Geologic feature assessed:
}

Number of known deposits:
Porphyry copper models (Cox, 1986a; John and others, 2010)

General porphyry copper model (Singer, Berger, and Moring, 2008)

Default - 0 to 250 meters (m), 25\%; > 250 to $500 \mathrm{~m}, 25 \%$; >500 m to $1 \mathrm{~km}, 50 \%$

High cost

A varied assemblage of Devonian through Triassic igneous rocks that include the Devonian Kazakh-Mongol continental-margin-arc rocks, as well as younger rocks related to the Indosinian orogeny (collision of China with Asia)

3

\section{Selected Resource Assessment Results for Porphyry Copper}

[Assessment depth, 1 kilometer $(\mathrm{km}) ; \mathrm{km}^{2}$, square kilometer; Mt, millions of metric tons]

\begin{tabular}{ccccccc}
\hline $\begin{array}{c}\text { Date of } \\
\text { assessment }\end{array}$ & $\begin{array}{c}\text { Tract area } \\
\left(\mathbf{k m}^{2}\right)\end{array}$ & $\begin{array}{c}\text { Identified } \\
\text { copper } \\
\text { resources } \\
\text { (Mt) }\end{array}$ & $\begin{array}{c}\text { Mean estimate of } \\
\text { in-place resources } \\
(\mathbf{M t})\end{array}$ & $\begin{array}{c}\text { Probability of } \mathbf{0} \\
\text { in-place resources } \\
\text { (percent) }\end{array}$ & $\begin{array}{c}\text { Mean estimate of } \\
\text { economic resources } \\
\text { (Mt) }\end{array}$ & $\begin{array}{c}\text { Probability of 0 } \\
\text { economic resources } \\
\text { (percent) }\end{array}$ \\
\hline 2013 & 329,845 & 38 & 80 & 2 & 39 \\
\hline
\end{tabular}

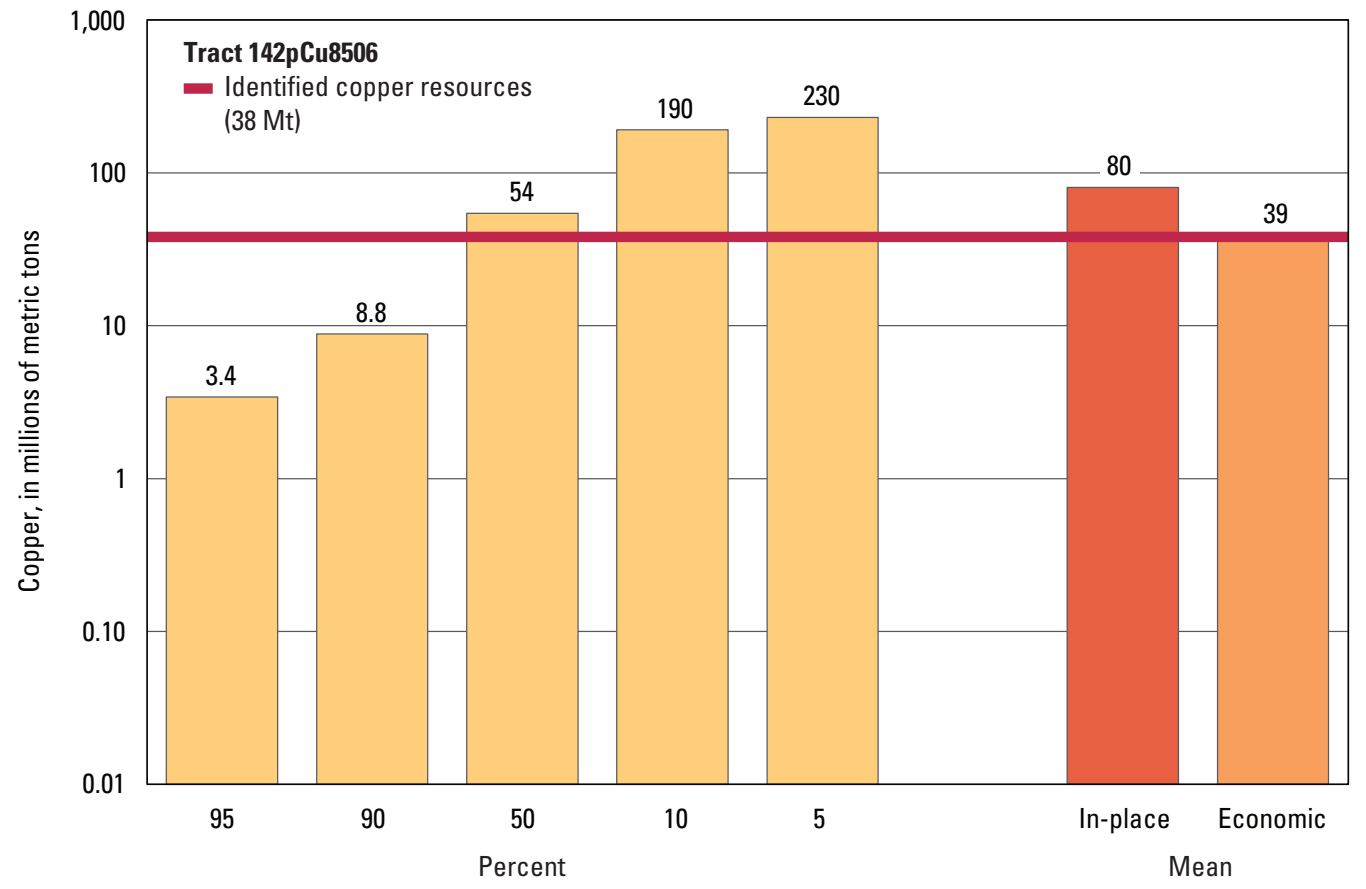

Graph showing the estimated probability distribution of undiscovered copper resources, where each bar represents the minimum amount estimated at the indicated percentage.

\section{Source}

Mihalasky, Ludington, Hammarstrom, and others, 2015, Porphyry copper assessment of the Central Asian Orogenic Belt and eastern Tethysides - China, Mongolia, Russia, Pakistan, Kazakhstan, Tajikistan, and India: U.S. Geological Survey Scientific Investigations Report 2010-5090-X, http://dx.doi.org/10.3133/sir20105090X. 


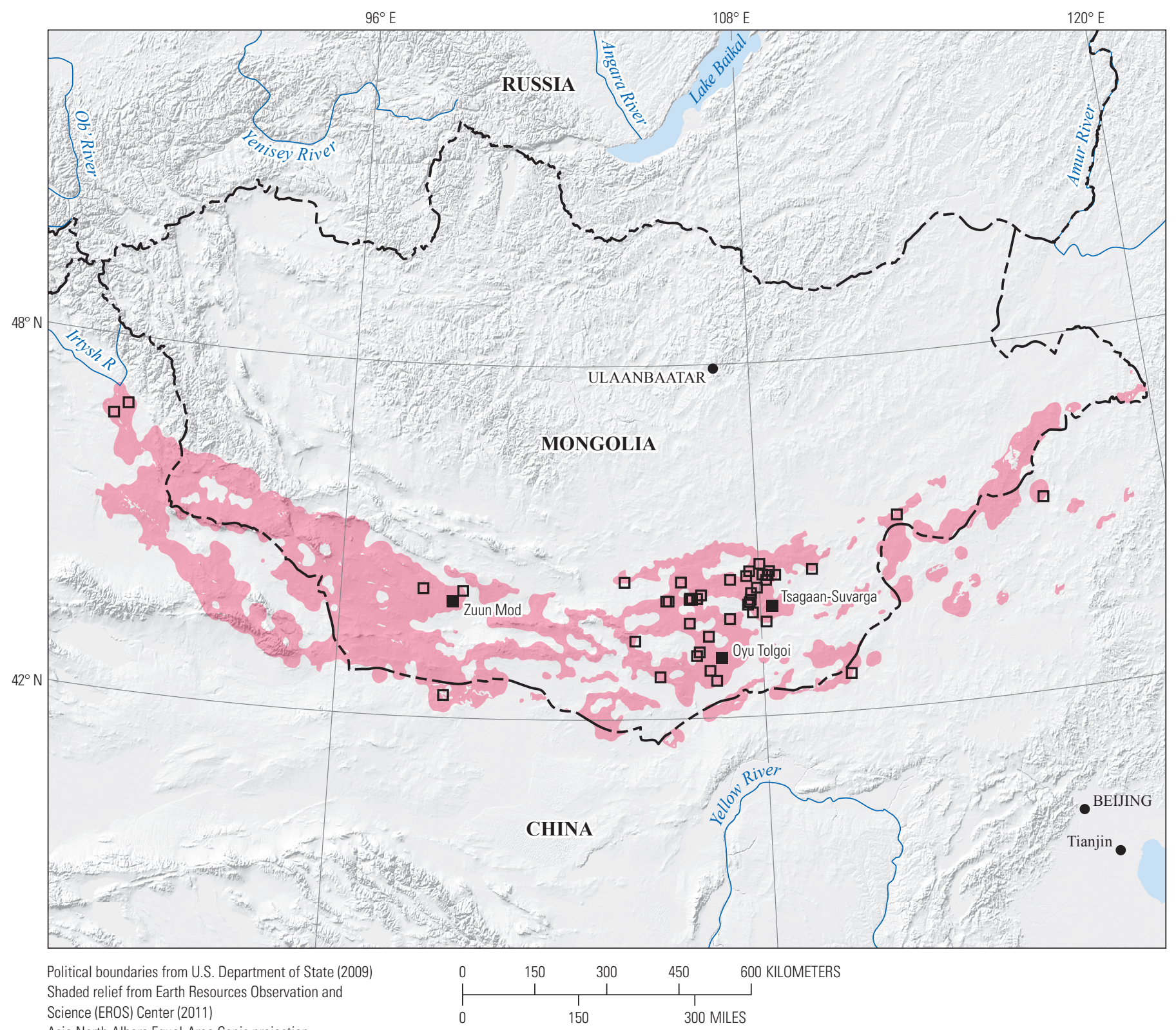

Asia North Albers Equal-Area Conic projection

Central meridian $103^{\circ} \mathrm{E}$. ; latitude of origin $30^{\circ} \mathrm{N}$.

\section{EXPLANATION}

\section{Assessed porphyry copper tract 142pCu8506}

- Porphyry copper deposit

Porphyry copper prospect

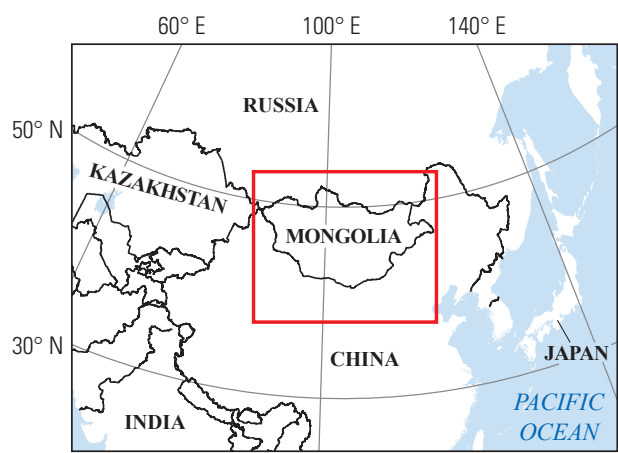




\section{Plate 76. Porphyry Copper Assessment for Tract 142pCu8501, Solonker-China}

\section{Descriptive model:}

Grade and tonnage model:

Economic filter depth percentages:

Economic filter cost setting:

Geologic feature assessed:

Number of known deposits:
Porphyry copper models (Cox, 1986a; John and others, 2010)

General porphyry copper model (Singer, Berger, and Moring, 2008)

Custom - 0 to 250 meters (m), $30 \%$; $>250$ to $500 \mathrm{~m}, 25 \%$; $>500 \mathrm{~m}$ to $1 \mathrm{~km}, 45 \%$

High cost

Paleozoic through Triassic igneous rocks (early Paleozoic Bainaimiao island arc, a late Paleozoic continental arc formed by south-directed subduction of the paleo-Asian ocean beneath the North China craton) and Permian and Triassic rocks formed by collision of the North China and Tarim cratons with Eurasia

1

\section{Selected Resource Assessment Results for Porphyry Copper}

[Assessment depth, 1 kilometer (km); $\mathrm{km}^{2}$, square kilometer; Mt, millions of metric tons]

\begin{tabular}{|c|c|c|c|c|c|c|}
\hline \multirow[b]{2}{*}{$\begin{array}{c}\text { Date of } \\
\text { assessment }\end{array}$} & \multirow[b]{2}{*}{$\begin{array}{l}\text { Tract area } \\
\quad\left(\mathbf{k m}^{2}\right)\end{array}$} & \multirow{2}{*}{$\begin{array}{l}\text { Identified } \\
\text { copper } \\
\text { resources } \\
\text { (Mt) }\end{array}$} & \multicolumn{4}{|c|}{ Undiscovered copper resource estimates } \\
\hline & & & $\begin{array}{l}\text { Mean estimate of } \\
\text { in-place resources } \\
\text { (Mt) }\end{array}$ & $\begin{array}{c}\text { Probability of } 0 \\
\text { in-place resources } \\
\text { (percent) }\end{array}$ & $\begin{array}{c}\text { Mean estimate of } \\
\text { economic resources } \\
\text { (Mt) }\end{array}$ & $\begin{array}{c}\text { Probability of } 0 \\
\text { economic resources } \\
\text { (percent) }\end{array}$ \\
\hline 2013 & 250,099 & 0.25 & 22 & 7 & 12 & 42 \\
\hline
\end{tabular}

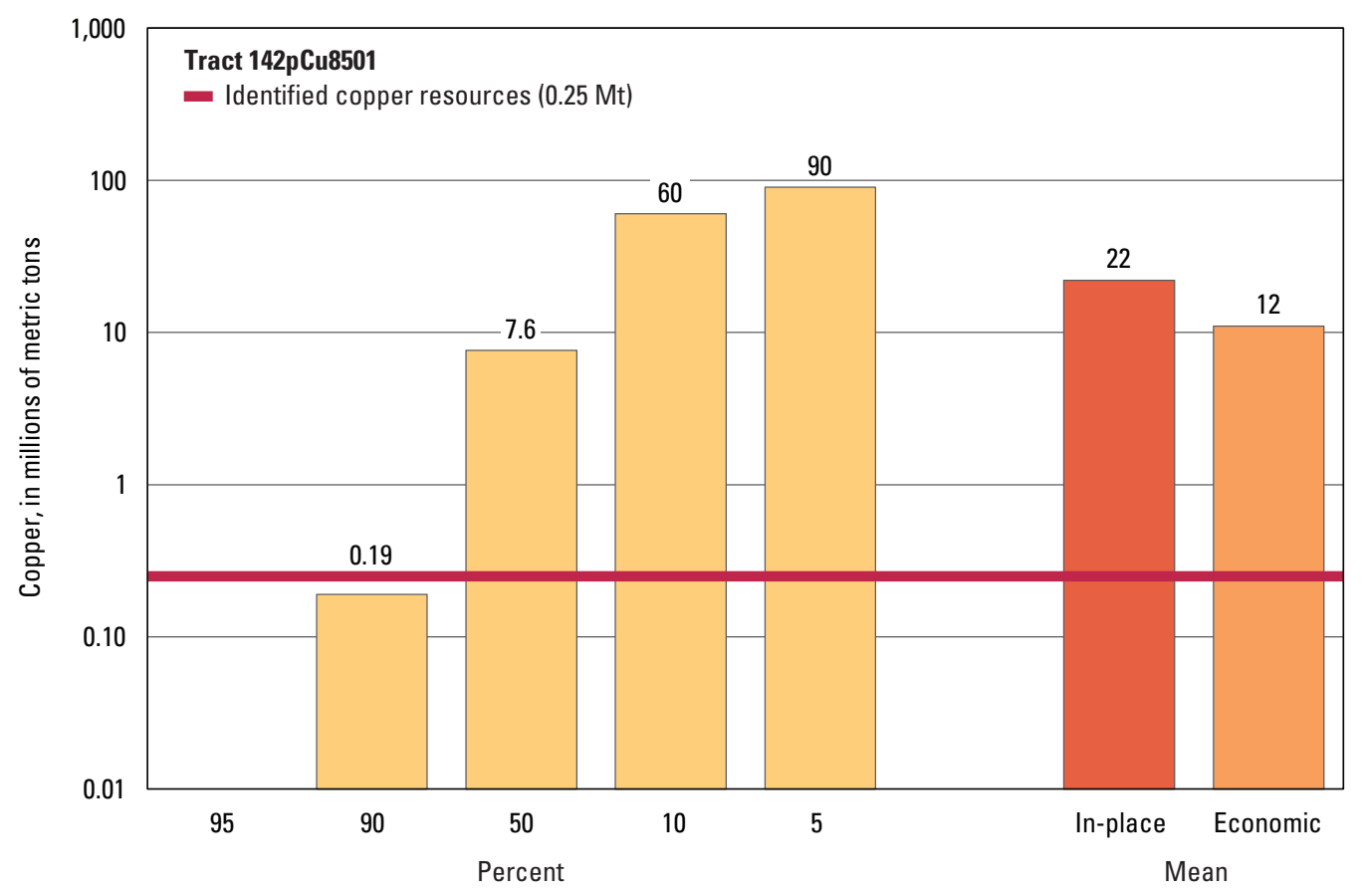

Graph showing the estimated probability distribution of undiscovered copper resources, where each bar represents the minimum amount estimated at the indicated percentage.

\section{Source}

Mihalasky, Ludington, Hammarstrom, and others, 2015, Porphyry copper assessment of the Central Asian Orogenic Belt and eastern Tethysides - China, Mongolia, Russia, Pakistan, Kazakhstan, Tajikistan, and India: U.S. Geological Survey Scientific Investigations Report 2010-5090-X, http://dx.doi.org/10.3133/sir20105090X. 


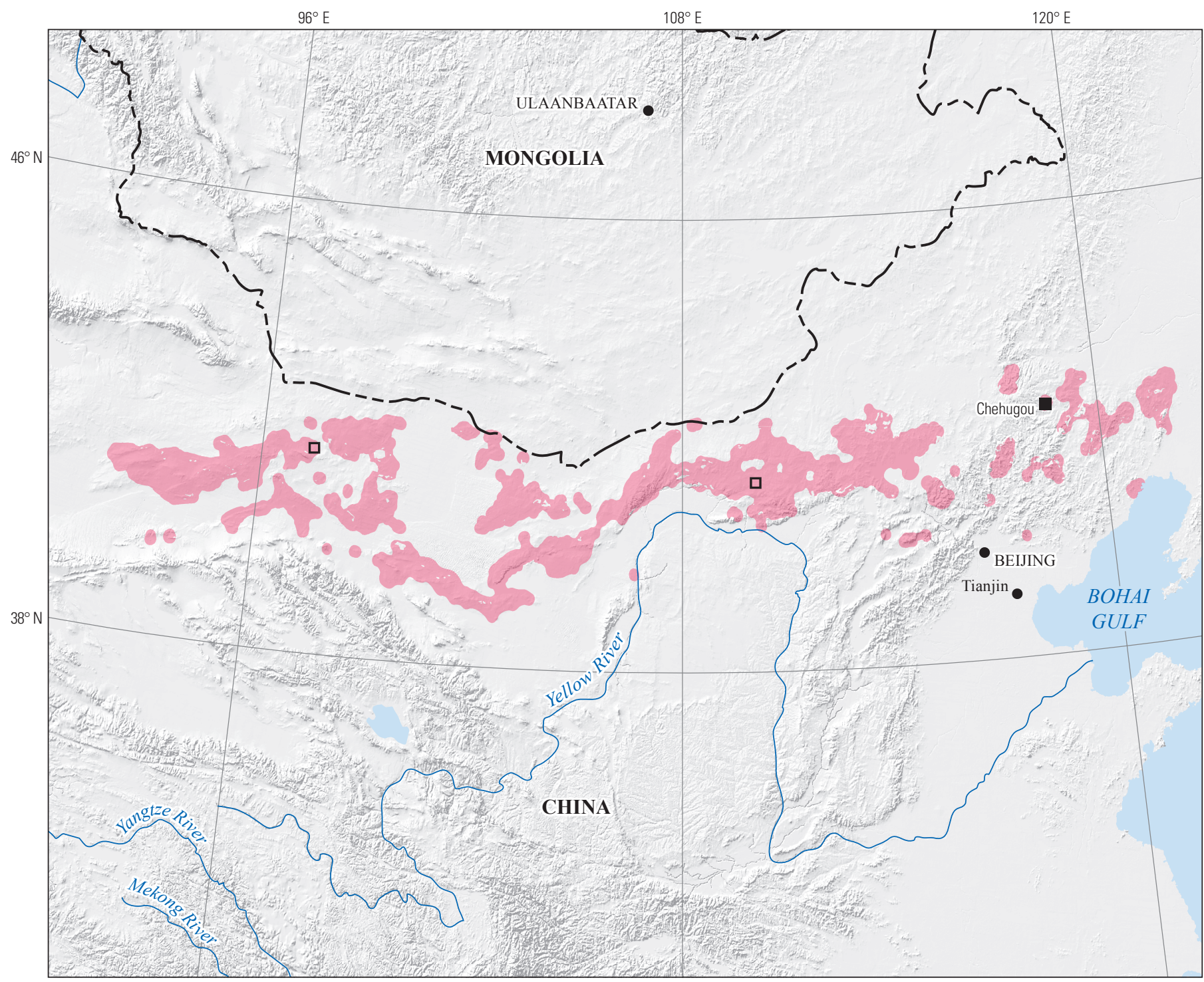

Political boundaries from U.S. Department of State (2009) Shaded relief from Earth Resources Observation and Science (EROS) Center (2011)

Asia North Albers Equal-Area Conic projection

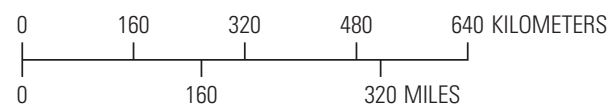

Central meridian $108^{\circ} \mathrm{E}$; l latitude of origin $30^{\circ} \mathrm{N}$.

\section{EXPLANATION}

\section{Assessed porphyry copper tract 142pCu8501}

- Porphyry copper deposit

Porphyry copper prospect

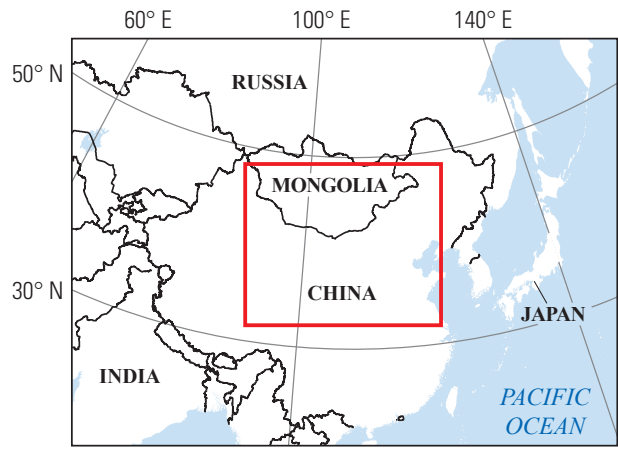




\title{
Plate 77. Porphyry Copper Assessment for Tract 142pCu8505, Kazakh-Tarim- Kazakhstan and China
}

\author{
Descriptive model: \\ Porphyry copper models (Cox, 1986a; John and others, 2010) \\ Grade and tonnage model: \\ General porphyry copper model (Singer, Berger, and Moring, 2008) \\ Economic filter depth percentages: \\ Economic filter cost setting: \\ Default -0 to 250 meters (m), $25 \%$; $>250$ to $500 \mathrm{~m}, 25 \%$; $>500 \mathrm{~m}$ to $1 \mathrm{~km}, 50 \%$ \\ Geologic feature assessed: \\ High cost \\ Devonian through Early Triassic igneous rocks that include the Balkash-Yili continental-margin- \\ arc and younger rocks related to the Indosinian orogeny (collision of China with Asia) \\ Number of known deposits: \\ 4
}

\section{Selected Resource Assessment Results for Porphyry Copper}

[Assessment depth, 1 kilometer $(\mathrm{km}) ; \mathrm{km}^{2}$, square kilometer; Mt, millions of metric tons]

\begin{tabular}{ccccccc}
\hline $\begin{array}{c}\text { Date of } \\
\text { assessment }\end{array}$ & $\begin{array}{c}\text { Tract area } \\
\left(\mathbf{k m}^{2}\right)\end{array}$ & $\begin{array}{c}\text { Identified } \\
\text { copper } \\
\text { resources } \\
\text { (Mt) }\end{array}$ & $\begin{array}{c}\text { Mean estimate of } \\
\text { in-place resources } \\
(\mathbf{M t})\end{array}$ & $\begin{array}{c}\text { Probability of } \mathbf{0} \\
\text { in-place resources } \\
\text { (percent) }\end{array}$ & $\begin{array}{c}\text { Mean estimate of } \\
\text { economic resources } \\
\text { (Mt) }\end{array}$ & $\begin{array}{c}\text { Probability of 0 } \\
\text { economic resources } \\
\text { (percent) }\end{array}$ \\
\hline 2012 & 344,293 & 6.7 & 39 & 3 & 19 \\
\hline
\end{tabular}

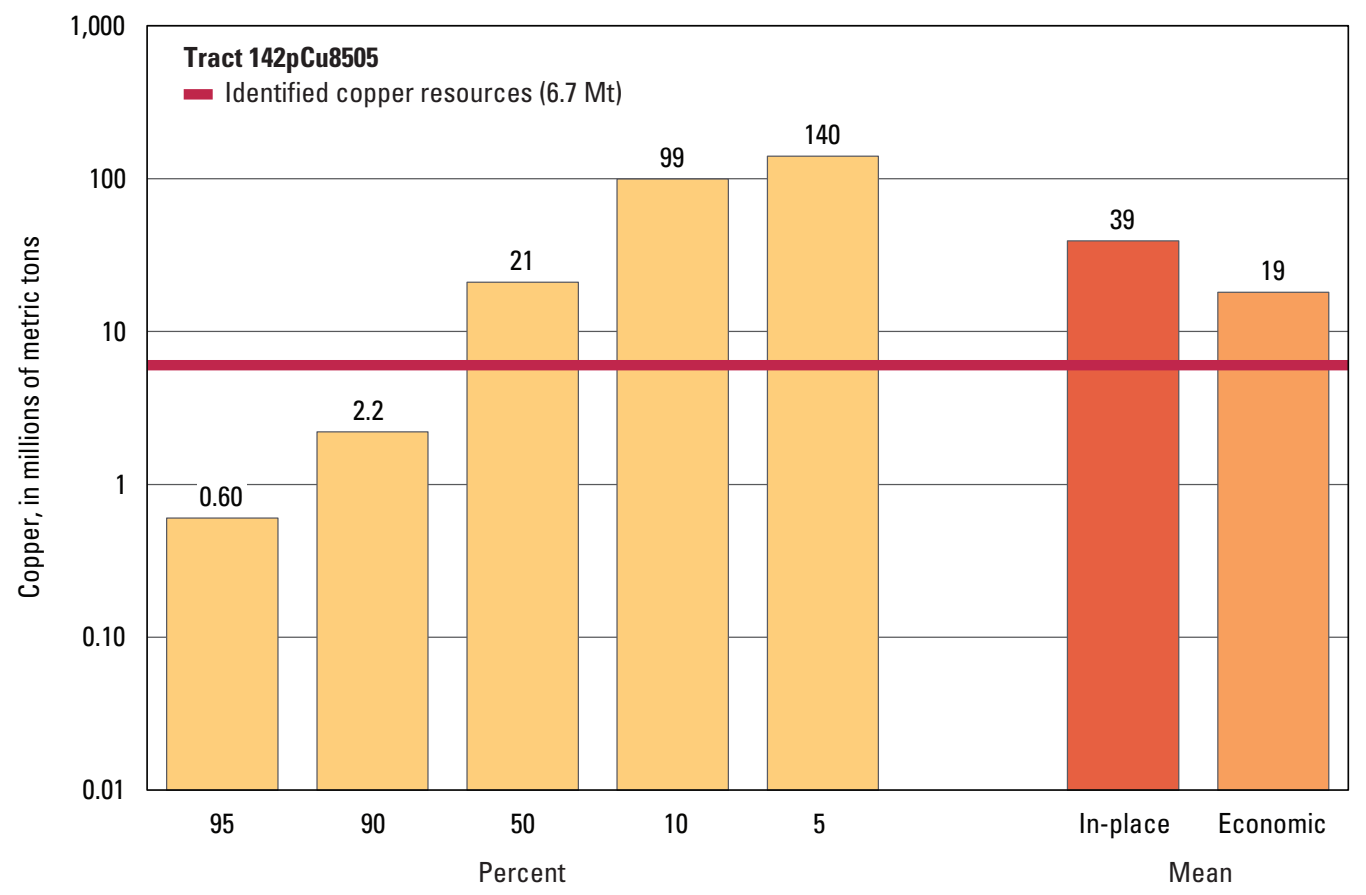

Graph showing the estimated probability distribution of undiscovered copper resources, where each bar represents the minimum amount estimated at the indicated percentage.

\section{Source}

Mihalasky, Ludington, Hammarstrom, and others, 2015, Porphyry copper assessment of the Central Asian Orogenic Belt and eastern Tethysides - China, Mongolia, Russia, Pakistan, Kazakhstan, Tajikistan, and India: U.S. Geological Survey Scientific Investigations Report 2010-5090-X, http://dx.doi.org/10.3133/sir20105090X. 


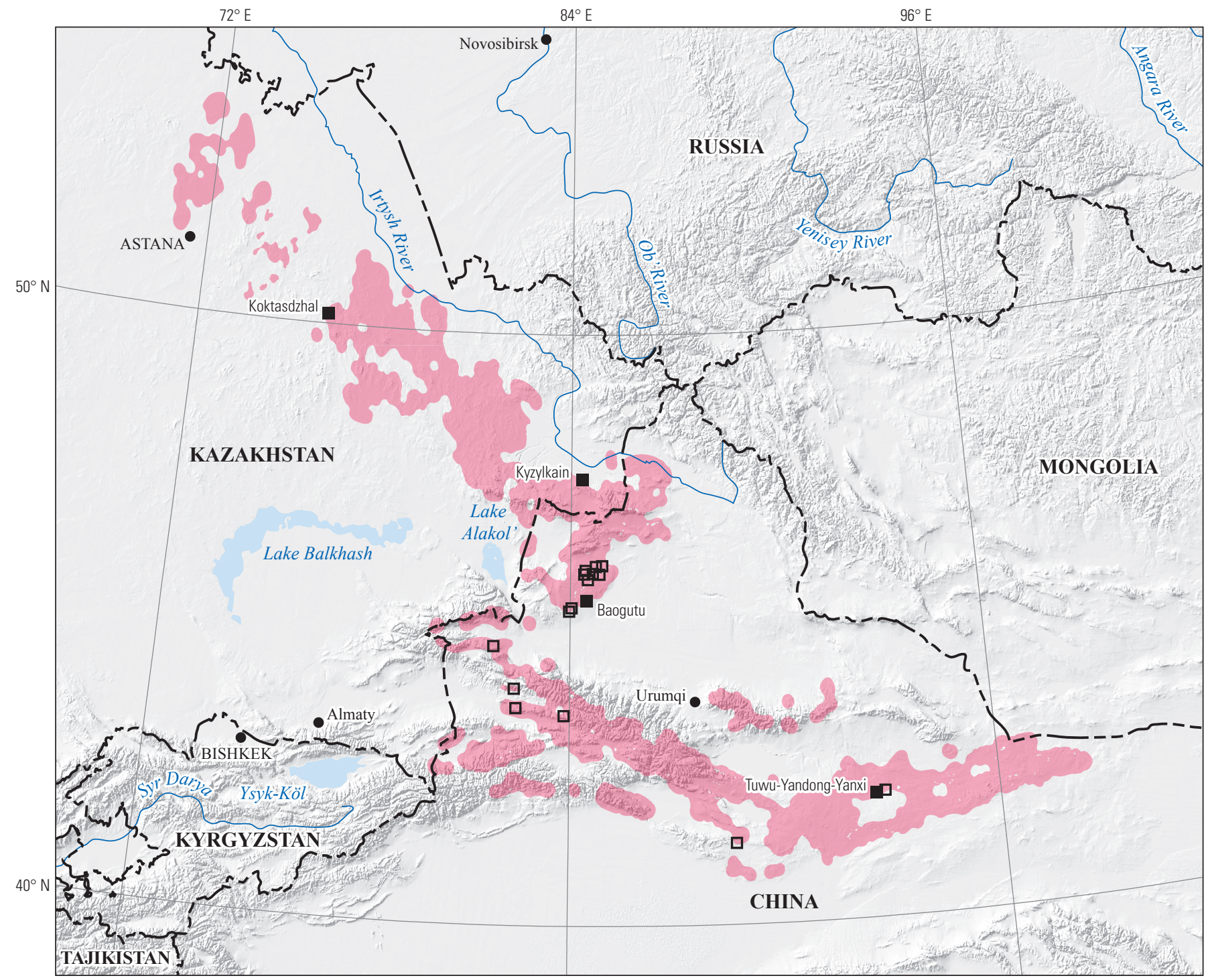

Political boundaries from U.S. Department of State (2009)

Shaded relief from Earth Resources Observation and

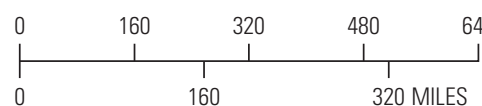

640 KILOMETERS

Science (EROS) Center (2011)

Asia North Albers Equal-Area Conic projection

Central meridian $85^{\circ} \mathrm{E}$.; latitude of origin $30^{\circ} \mathrm{N}$.

\section{EXPLANATION}

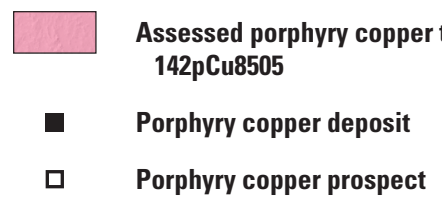

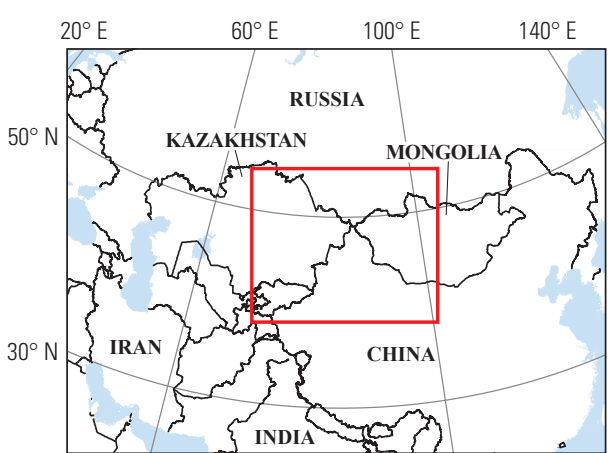




\section{Plate 78. Porphyry Copper Assessment for Tract 142pCu8502, Kazakh- Tianshan-Kazakhstan and China}

\author{
Descriptive model: \\ Grade and tonnage model: \\ Economic filter depth percentages: \\ Economic filter cost setting: \\ Geologic feature assessed:
}

Number of known deposits:
Porphyry copper models (Cox, 1986a; John and others, 2010)

General porphyry copper model (Singer, Berger, and Moring, 2008)

Default - 0 to 250 meters (m), 25\%; > 250 to $500 \mathrm{~m}, 25 \%$; >500 m to $1 \mathrm{~km}, 50 \%$

High cost

Cambrian through Silurian igneous rocks (Kipchak and Stepnyak-North Tienshan island arcs) in the western part of the Central Asian orogenic belt; partly covered by rocks of the late Paleozoic Balkash-Yili arc

3

\section{Selected Resource Assessment Results for Porphyry Copper}

[Assessment depth, 1 kilometer $(\mathrm{km}) ; \mathrm{km}^{2}$, square kilometer; Mt, millions of metric tons]

\begin{tabular}{ccccccc}
\hline $\begin{array}{c}\text { Date of } \\
\text { assessment }\end{array}$ & $\begin{array}{c}\text { Tract area } \\
\left(\mathbf{k m}^{2}\right)\end{array}$ & $\begin{array}{c}\text { Identified } \\
\text { copper } \\
\text { resources } \\
(\mathbf{M t})\end{array}$ & $\begin{array}{c}\text { Mean estimate of } \\
\text { in-place resources } \\
\text { (Mt) }\end{array}$ & $\begin{array}{c}\text { Probability of } \mathbf{0} \\
\text { in-place resources } \\
\text { (percent) }\end{array}$ & $\begin{array}{c}\text { Mean estimate of } \\
\text { economic resources } \\
\text { (Mt) }\end{array}$ & $\begin{array}{c}\text { Probability of 0 } \\
\text { economic resources } \\
\text { (percent) }\end{array}$ \\
\hline 2013 & 89,608 & 8.7 & 14 & 6 & 6.9 \\
\hline
\end{tabular}

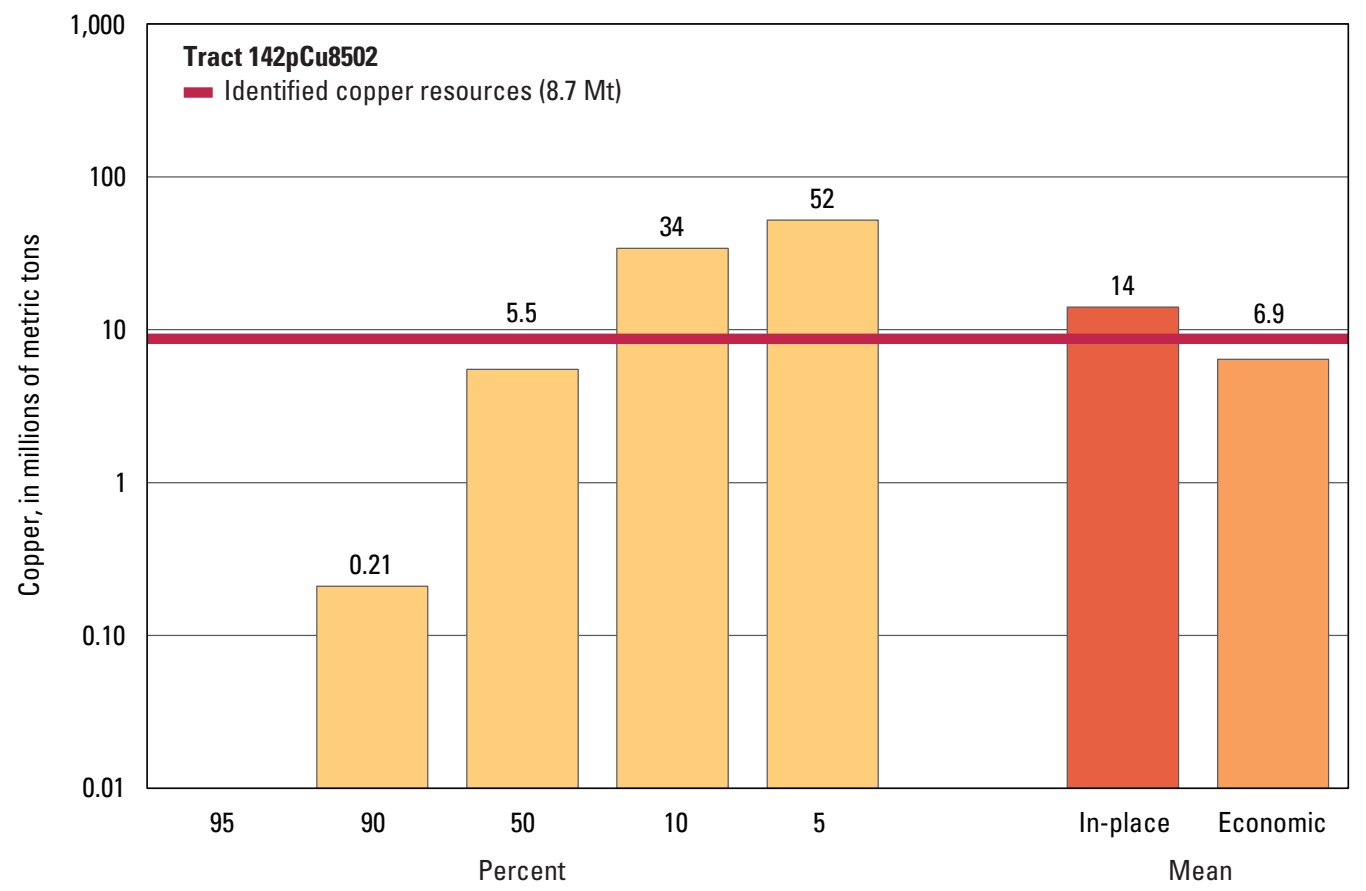

Graph showing the estimated probability distribution of undiscovered copper resources, where each bar represents the minimum amount estimated at the indicated percentage.

\section{Source}

Mihalasky, Ludington, Hammarstrom, and others, 2015, Porphyry copper assessment of the Central Asian Orogenic Belt and eastern Tethysides - China, Mongolia, Russia, Pakistan, Kazakhstan, Tajikistan, and India: U.S. Geological Survey Scientific Investigations Report 2010-5090-X, http://dx.doi.org/10.3133/sir20105090X. 


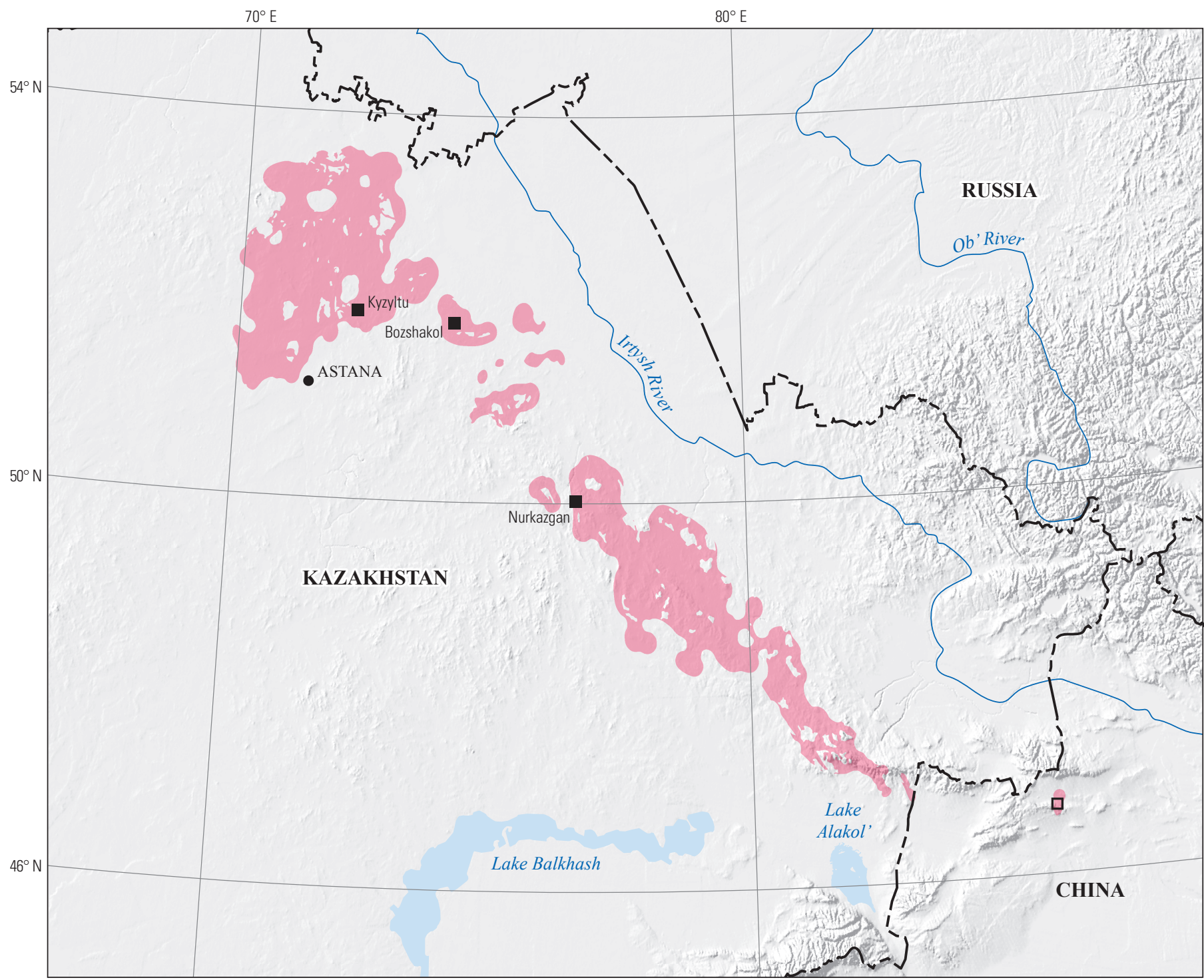

Political boundaries from U.S. Department of State (2009) Shaded relief from Earth Resources Observation and Science (EROS) Center (2011)

Asia North Albers Equal-Area Conic projection

Central meridian $78^{\circ} \mathrm{E}$. ; latitude of origin $30^{\circ} \mathrm{N}$.

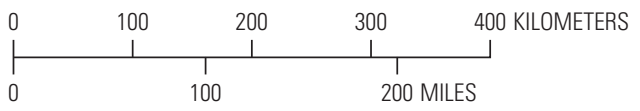

EXPLANATION

\section{Assessed porphyry copper tract} 142pCu8502

- Porphyry copper deposit

ㅁ Porphyry copper prospect

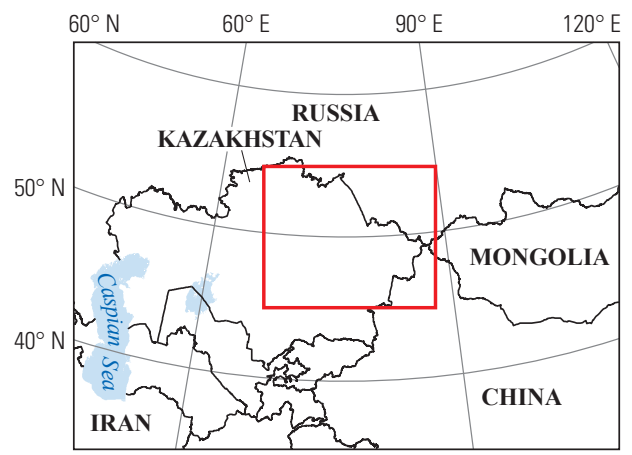




\title{
Plate 79. Porphyry Copper Assessment for Tract 142pCu8003a, Late Paleozoic Balkhash-Ili Magmatic Arc (East)—Kazakhstan
}

\author{
Descriptive model: \\ Porphyry copper models (Cox, 1986a; Berger and others, 2008) \\ Grade and tonnage model: \\ General porphyry copper model (Singer, Berger, and Moring, 2008) \\ Economic filter depth percentages: \\ Economic filter cost setting: \\ Default -0 to 250 meters (m), 25\%; > 250 to $500 \mathrm{~m}, 25 \%$; > $500 \mathrm{~m}$ to $1 \mathrm{~km}, 50 \%$ \\ High cost \\ Geologic feature assessed: \\ Early Carboniferous to Permian magmatic-arc and postcollisional rocks \\ Number of known deposits: \\ 1
}

\section{Selected Resource Assessment Results for Porphyry Copper}

[Assessment depth, 1 kilometer $(\mathrm{km}) ; \mathrm{km}^{2}$, square kilometer; Mt, millions of metric tons]

\begin{tabular}{ccccccc}
\hline \multirow{2}{*}{$\begin{array}{c}\text { Date of } \\
\text { assessment }\end{array}$} & $\begin{array}{c}\text { Tract area } \\
\left(\mathbf{k m}^{2}\right)\end{array}$ & $\begin{array}{c}\text { Identified } \\
\text { copper } \\
\text { resources } \\
(\mathbf{M t})\end{array}$ & $\begin{array}{c}\text { Mean estimate of } \\
\text { in-place resources } \\
(\mathbf{M t})\end{array}$ & $\begin{array}{c}\text { Probability of } \mathbf{0} \\
\text { in-place resources } \\
\text { (percent) }\end{array}$ & $\begin{array}{c}\text { Mean estimate of } \\
\text { economic resources } \\
\text { (Mt) }\end{array}$ & $\begin{array}{c}\text { Probability of } \mathbf{0} \\
\text { economic resources } \\
\text { (percent) }\end{array}$ \\
\hline 2009 & 46,385 & 10 & 11 & 7 & 5.4 \\
\hline
\end{tabular}

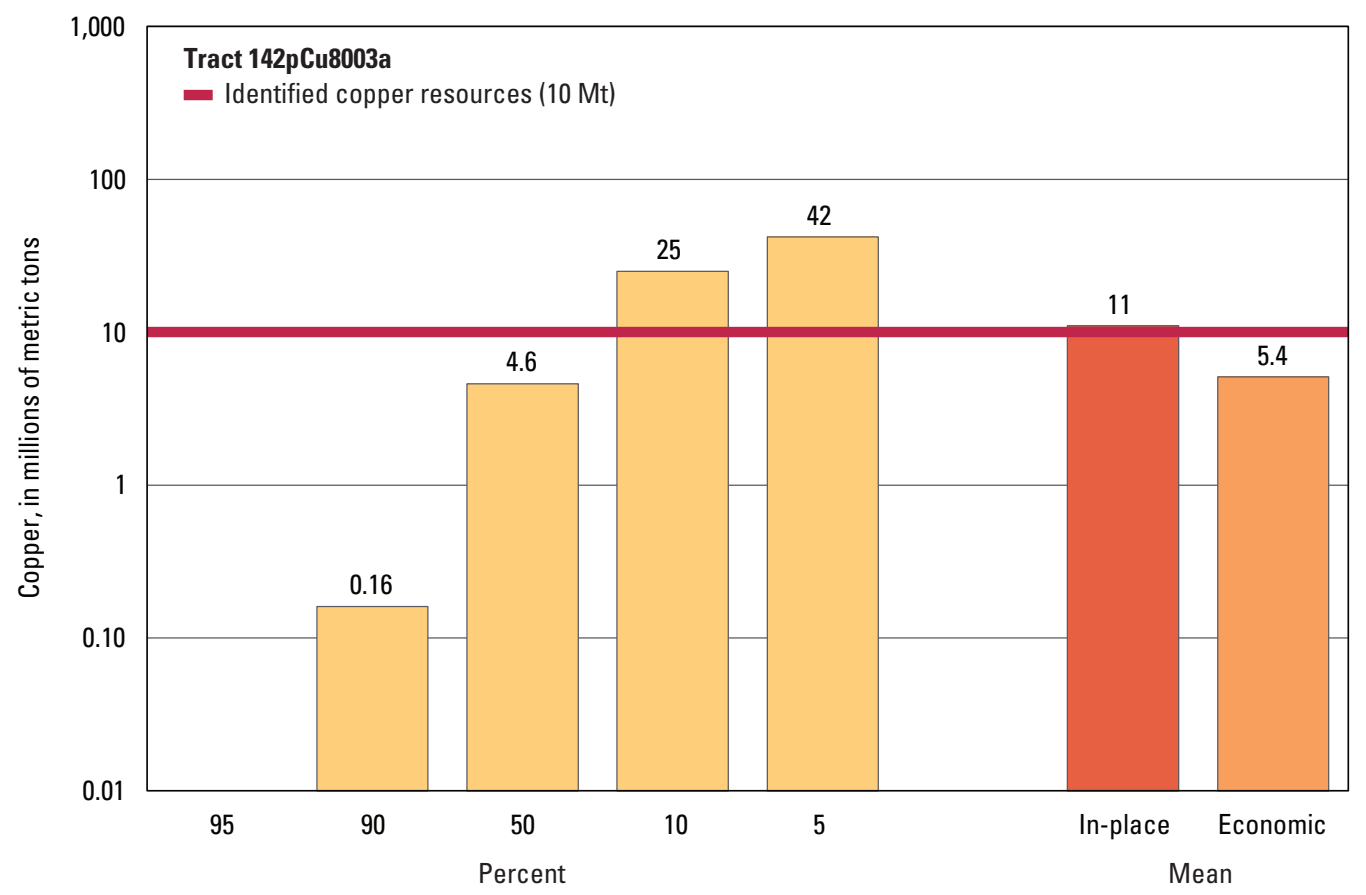

Graph showing the estimated probability distribution of undiscovered copper resources, where each bar represents the minimum amount estimated at the indicated percentage.

\section{Source}

Berger and others, 2014, Porphyry copper assessment of western Central Asia: U.S. Geological Survey Scientific Investigations Report 2010-5090-N, http://dx.doi.org/10.3133/sir20105090N. 


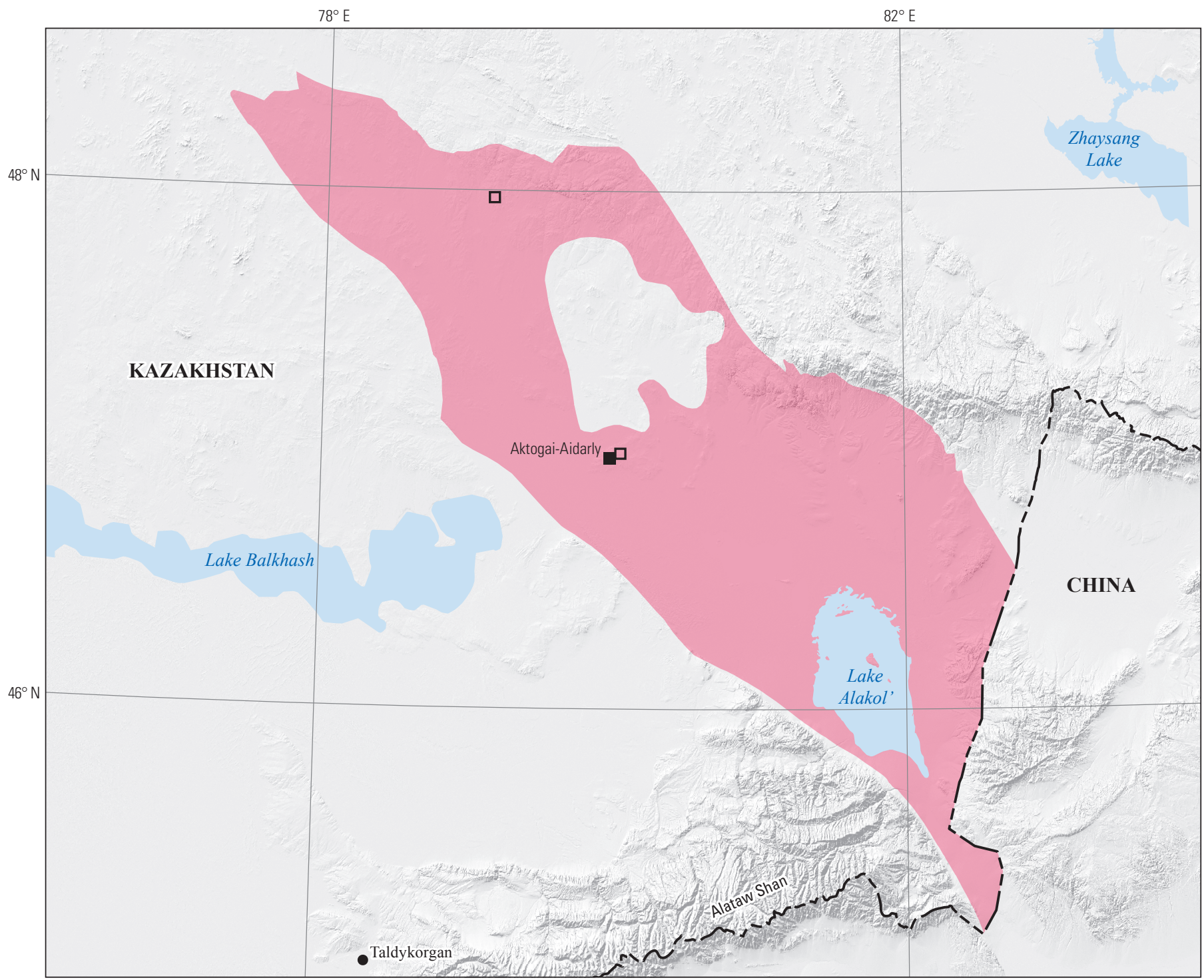

Political boundaries from U.S. Department of State (2009) Shaded relief from ESRI (2008)

Asia North Albers Equal-Area Conic projection

Central meridian $81^{\circ} \mathrm{E}$.; latitude of origin $30^{\circ} \mathrm{N}$.

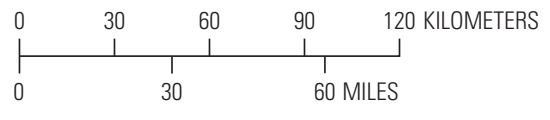

EXPLANATION

Assessed porphyry copper tract 142pCu8003a

- Porphyry copper deposit

․ Porphyry copper prospect

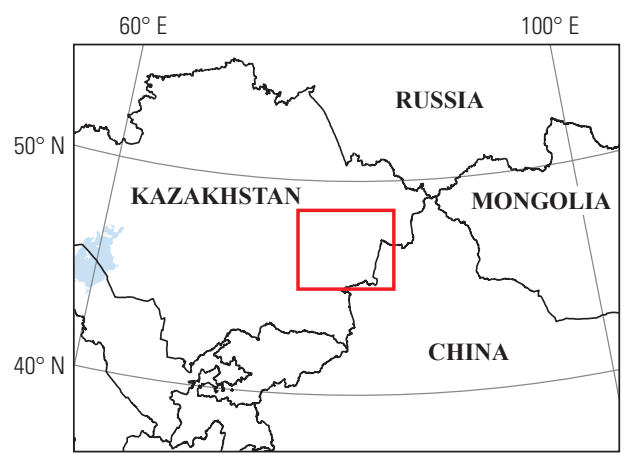




\title{
Plate 80. Porphyry Copper Assessment for Tract 142pCu8003b, Late Paleozoic Balkhash-Ili Magmatic Arc (North)—Kazakhstan
}

\author{
Descriptive model: \\ Porphyry copper models (Cox, 1986a; Berger and others, 2008) \\ Grade and tonnage model: \\ General porphyry copper model (Singer, Berger, and Moring, 2008) \\ Economic filter depth percentages: \\ Economic filter cost setting: \\ Geologic feature assessed: \\ Default -0 to 250 meters (m), $25 \% ;>250$ to $500 \mathrm{~m}, 25 \% ;>500 \mathrm{~m}$ to $1 \mathrm{~km}, 50 \%$ \\ High cost \\ Early Carboniferous to Permian magmatic-arc and postcollisional rocks \\ Number of known deposits: \\ 5
}

\section{Selected Resource Assessment Results for Porphyry Copper}

[Assessment depth, 1 kilometer $(\mathrm{km}) ; \mathrm{km}^{2}$, square kilometer; Mt, millions of metric tons]

\begin{tabular}{ccccccc}
\hline \multirow{2}{*}{$\begin{array}{c}\text { Date of } \\
\text { assessment }\end{array}$} & $\begin{array}{c}\text { Tract area } \\
\left(\mathbf{k m}^{2}\right)\end{array}$ & $\begin{array}{c}\text { Identified } \\
\text { copper } \\
\text { resources } \\
(\mathbf{M t})\end{array}$ & $\begin{array}{c}\text { Mean estimate of } \\
\text { in-place resources } \\
(\mathbf{M t})\end{array}$ & $\begin{array}{c}\text { Probability of } \mathbf{0} \\
\text { in-place resources } \\
\text { (percent) }\end{array}$ & $\begin{array}{c}\text { Mean estimate of } \\
\text { economic resources } \\
\text { (Mt) }\end{array}$ & $\begin{array}{c}\text { Probability of } \mathbf{0} \\
\text { economic resources } \\
\text { (percent) }\end{array}$ \\
\hline 2009 & 78,660 & 5.0 & 22 & 6 & 11 \\
\hline
\end{tabular}

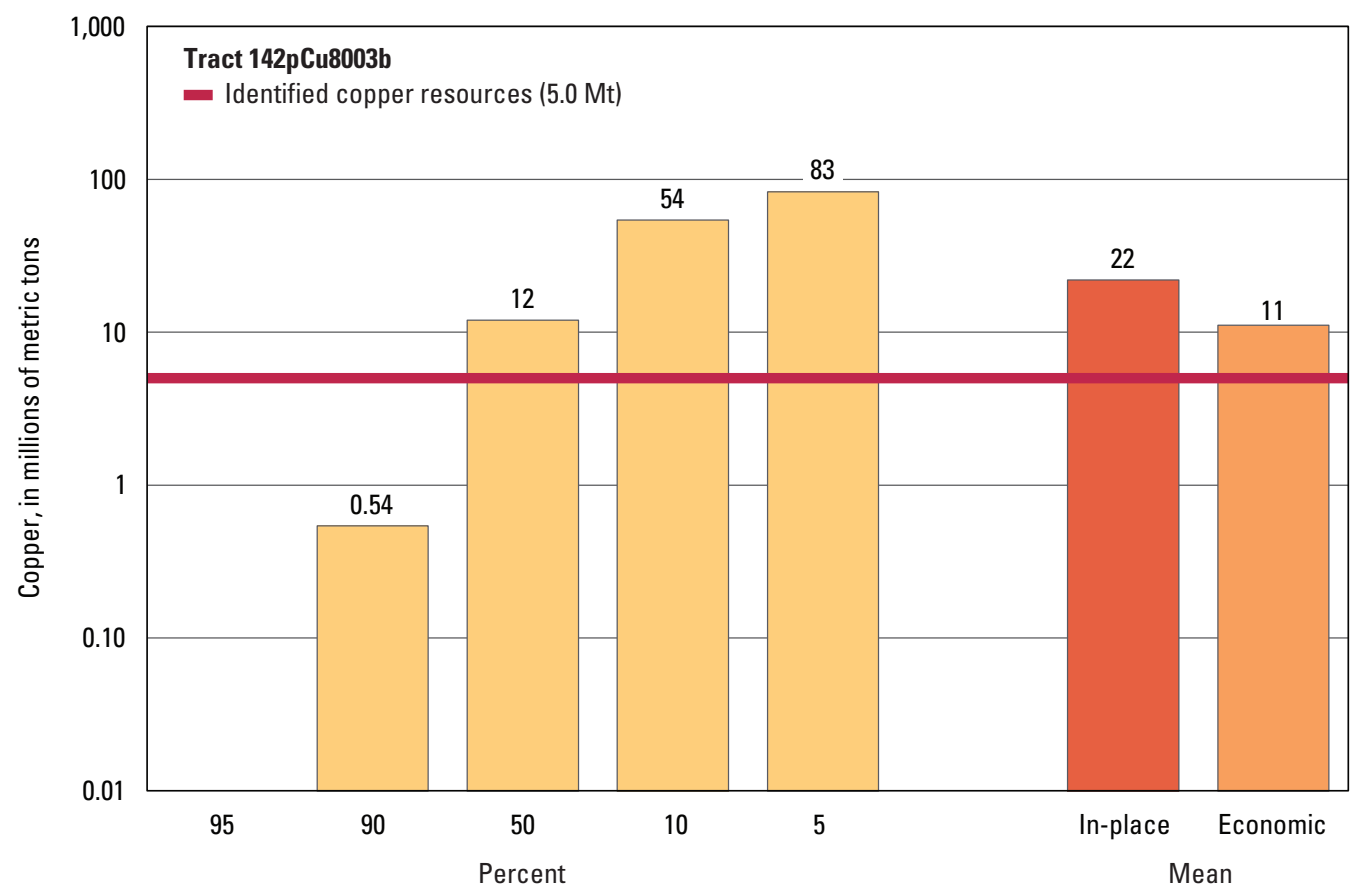

Graph showing the estimated probability distribution of undiscovered copper resources, where each bar represents the minimum amount estimated at the indicated percentage.

\section{Source}

Berger and others, 2014, Porphyry copper assessment of western Central Asia: U.S. Geological Survey Scientific Investigations Report 2010-5090-N, http://dx.doi.org/10.3133/sir20105090N. 


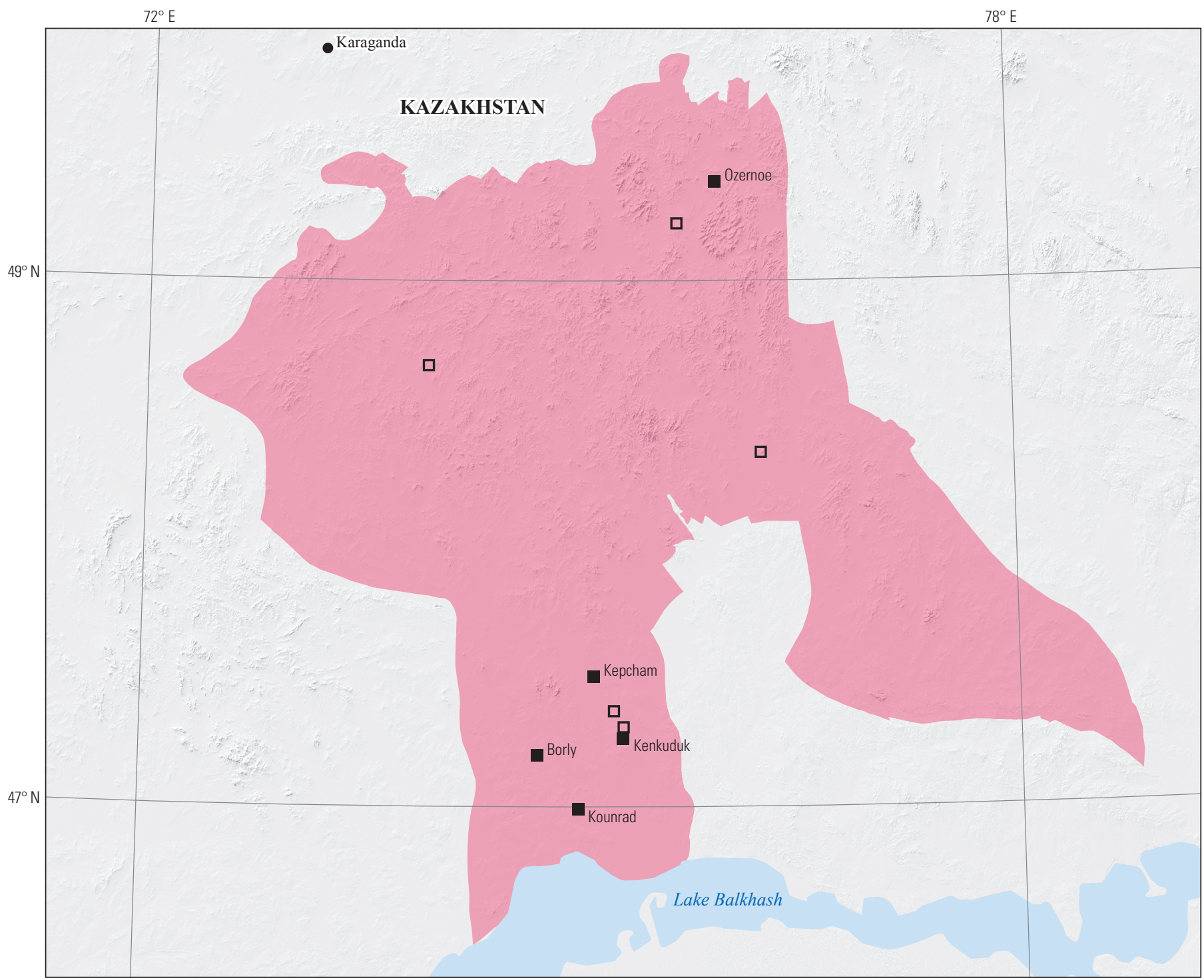

Political boundaries from U.S. Department of State (2009) Shaded relief from ESRI (2008)

Asia North Albers Equal-Area Conic projection

Central meridian $75^{\circ} \mathrm{E}$.; latitude of origin $30^{\circ} \mathrm{N}$.

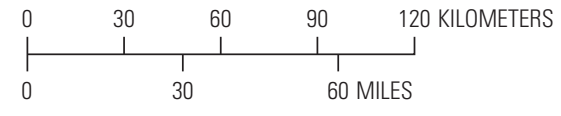

\section{EXPLANATION}

Assessed porphyry copper tract 142pCu8003b

- Porphyry copper deposit

$\square \quad$ Porphyry copper prospect

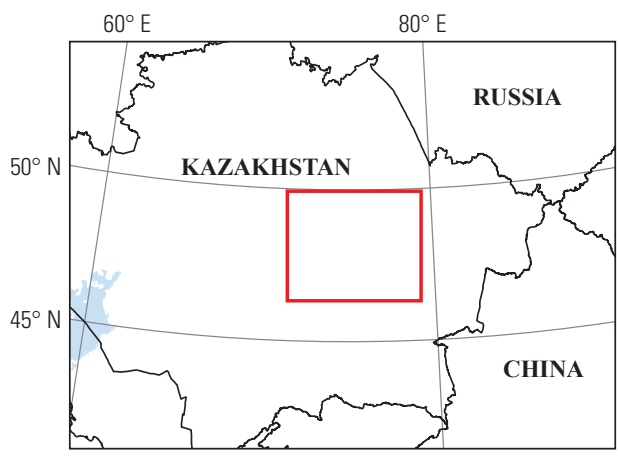




\title{
Plate 81. Porphyry Copper Assessment for Tract 142pCu8004, Late Paleozoic Central Balkhash-Ili Magmatic Arc-Kazakhstan
}

\author{
Descriptive model: \\ Porphyry copper models (Cox, 1986a; Berger and others, 2008) \\ Grade and tonnage model: \\ General porphyry copper model (Singer, Berger, and Moring, 2008) \\ Economic filter depth percentages: \\ Economic filter cost setting: \\ Geologic feature assessed: \\ Skewed deep - 0 to 250 meters (m), 10\%; > 250 to $500 \mathrm{~m}, 30 \%$; >500 m to $1 \mathrm{~km}, 60 \%$ \\ High cost \\ Late Carboniferous to Permian magmatic-arc rocks \\ Number of known deposits: \\ 0
}

\section{Selected Resource Assessment Results for Porphyry Copper}

[Assessment depth, 1 kilometer $(\mathrm{km}) ; \mathrm{km}^{2}$, square kilometer; Mt, millions of metric tons]

\begin{tabular}{|c|c|c|c|c|c|c|}
\hline \multirow[b]{2}{*}{$\begin{array}{c}\text { Date of } \\
\text { assessment }\end{array}$} & \multirow[b]{2}{*}{$\begin{array}{c}\text { Tract area } \\
\quad\left(\mathrm{km}^{2}\right)\end{array}$} & \multirow{2}{*}{$\begin{array}{l}\text { Identified } \\
\text { copper } \\
\text { resources } \\
\text { (Mt) }\end{array}$} & \multicolumn{4}{|c|}{ Undiscovered copper resource estimates } \\
\hline & & & $\begin{array}{l}\text { Mean estimate of } \\
\text { in-place resources } \\
\text { (Mt) }\end{array}$ & $\begin{array}{c}\text { Probability of } 0 \\
\text { in-place resources } \\
\text { (percent) }\end{array}$ & $\begin{array}{l}\text { Mean estimate of } \\
\text { economic resources } \\
\text { (Mt) }\end{array}$ & $\begin{array}{c}\text { Probability of } 0 \\
\text { economic resources } \\
\text { (percent) }\end{array}$ \\
\hline 2010 & 99,548 & 0 & 7.8 & 21 & 3.5 & 85 \\
\hline
\end{tabular}

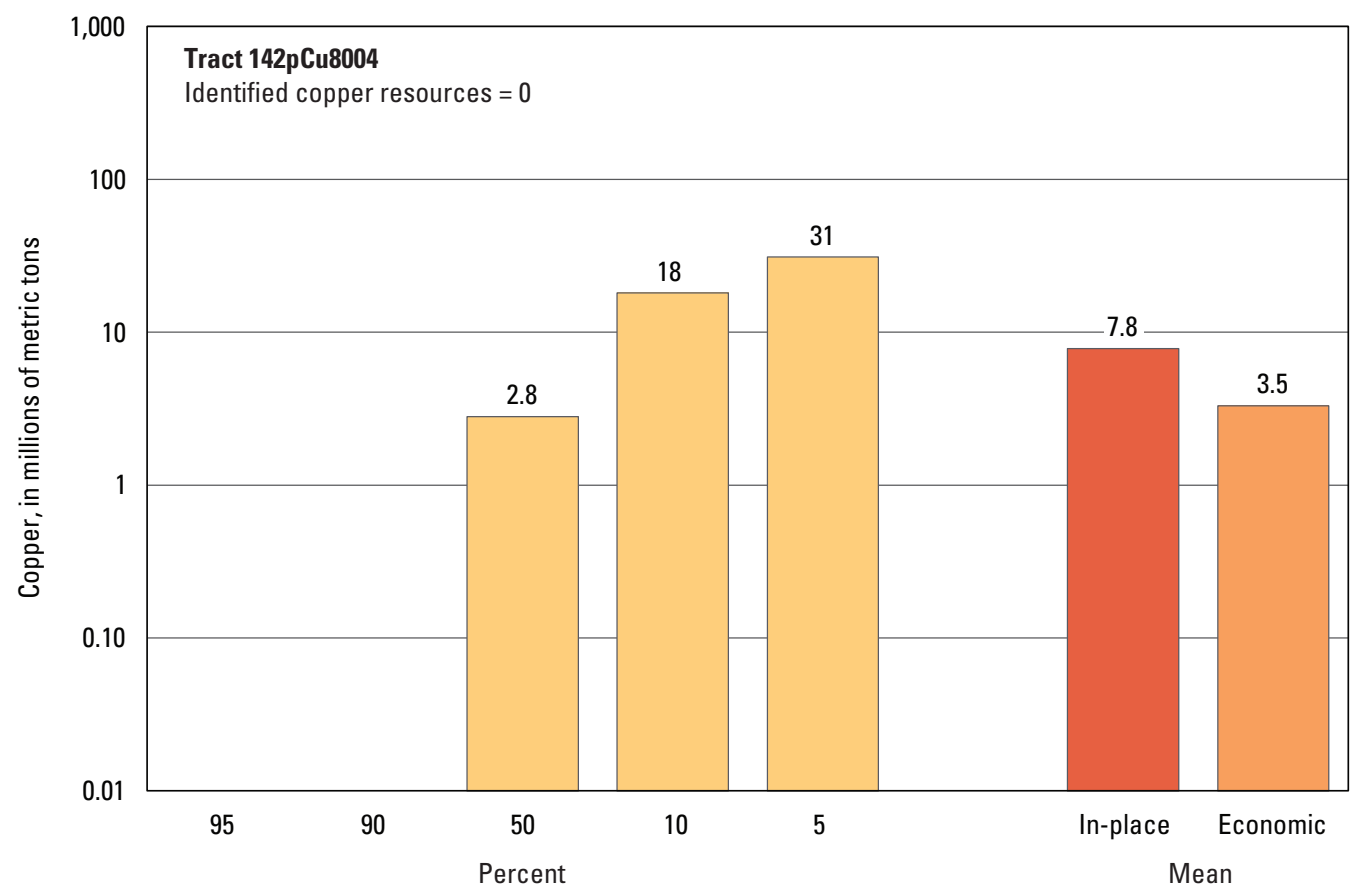

Graph showing the estimated probability distribution of undiscovered copper resources, where each bar represents the minimum amount estimated at the indicated percentage.

\section{Source}

Berger and others, 2014, Porphyry copper assessment of western Central Asia: U.S. Geological Survey Scientific Investigations Report 2010-5090-N, http://dx.doi.org/10.3133/sir20105090N. 


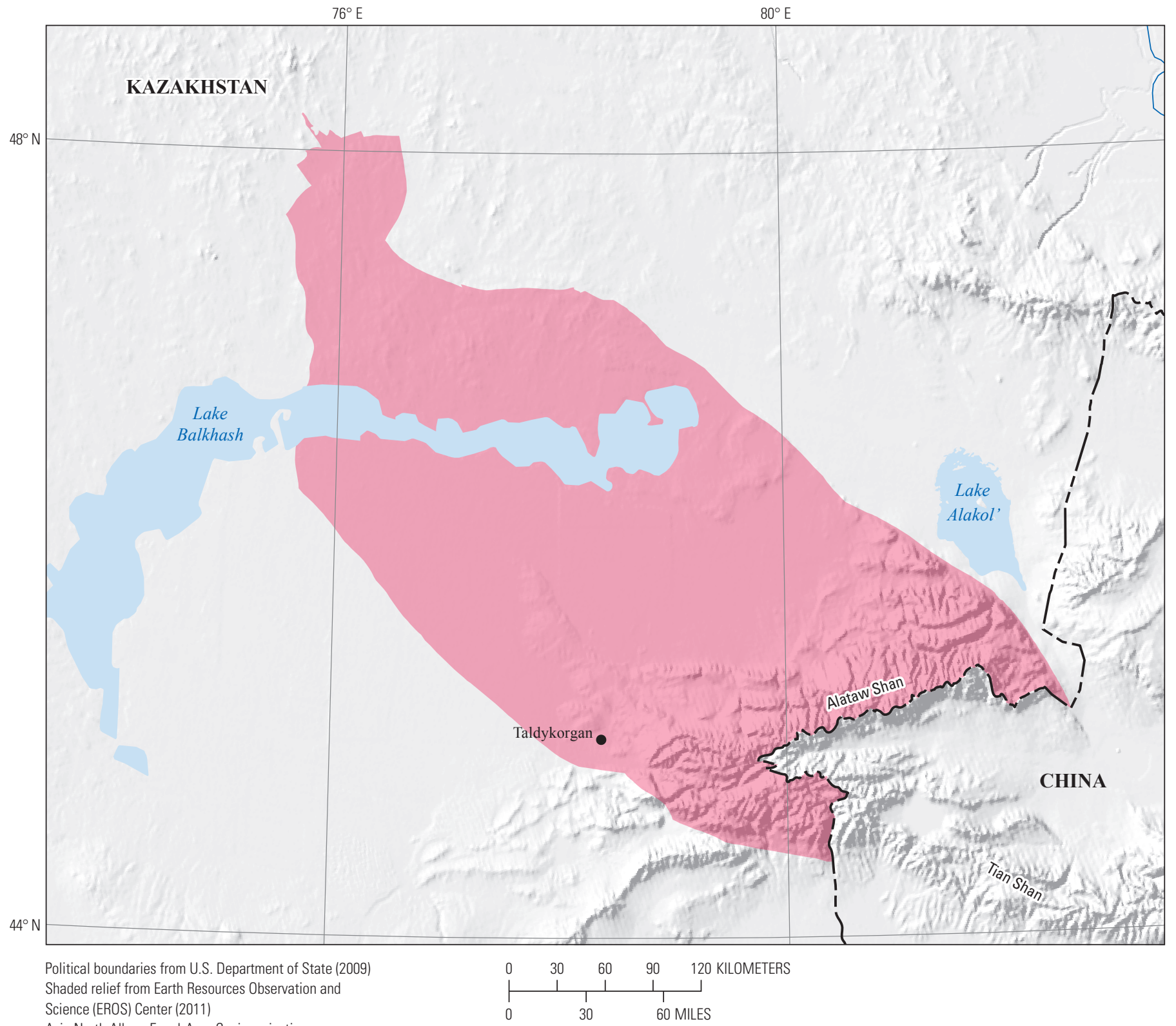

Asia North Albers Equal-Area Conic projection

Central meridian $78^{\circ} 30^{\prime} \mathrm{E}$.; latitude of origin $30^{\circ} \mathrm{N}$.

\section{EXPLANATION}

Assessed porphyry copper tract 142pCu8004

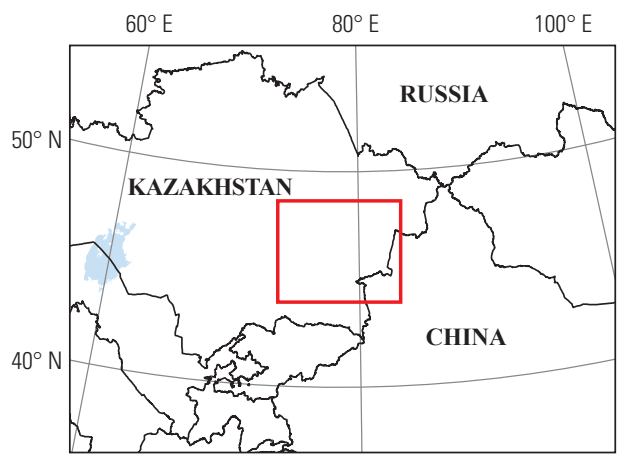




\title{
Plate 82. Porphyry Copper Assessment for Tract 142pCu8003d, Late Paleozoic Balkhash-Ili Magmatic Arc (Northwest)—Kazakhstan and Kyrgyzstan
}

\author{
Descriptive model: \\ Porphyry copper models (Cox, 1986a; Berger and others, 2008) \\ Grade and tonnage model: \\ General porphyry copper model (Singer, Berger, and Moring, 2008) \\ Economic filter depth percentages: \\ Economic filter cost setting: \\ Default - 0 to 250 meters (m), 25\%; > 250 to $500 \mathrm{~m}, 25 \%$; $>500 \mathrm{~m}$ to $1 \mathrm{~km}, 50 \%$ \\ High cost \\ Geologic feature assessed: \\ Early Carboniferous to Permian magmatic-arc and postcollisional rocks \\ Number of known deposits: \\ 2
}

\section{Selected Resource Assessment Results for Porphyry Copper}

[Assessment depth, 1 kilometer $(\mathrm{km}) ; \mathrm{km}^{2}$, square kilometer; Mt, millions of metric tons]

\begin{tabular}{ccccccc}
\hline \multirow{2}{*}{$\begin{array}{c}\text { Date of } \\
\text { assessment }\end{array}$} & $\begin{array}{c}\text { Tract area } \\
\left(\mathbf{k m}^{2}\right)\end{array}$ & $\begin{array}{c}\text { Identified } \\
\text { copper } \\
\text { resources } \\
(\mathbf{M t})\end{array}$ & $\begin{array}{c}\text { Mean estimate of } \\
\text { in-place resources } \\
(\mathbf{M t})\end{array}$ & $\begin{array}{c}\text { Probability of } \mathbf{0} \\
\text { in-place resources } \\
\text { (percent) }\end{array}$ & $\begin{array}{c}\text { Mean estimate of } \\
\text { economic resources } \\
\text { (Mt) }\end{array}$ & $\begin{array}{c}\text { Probability of } \mathbf{0} \\
\text { economic resources } \\
\text { (percent) }\end{array}$ \\
\hline 2009 & 111,149 & 3.3 & 7.8 & 20 & 3.8 \\
\hline
\end{tabular}

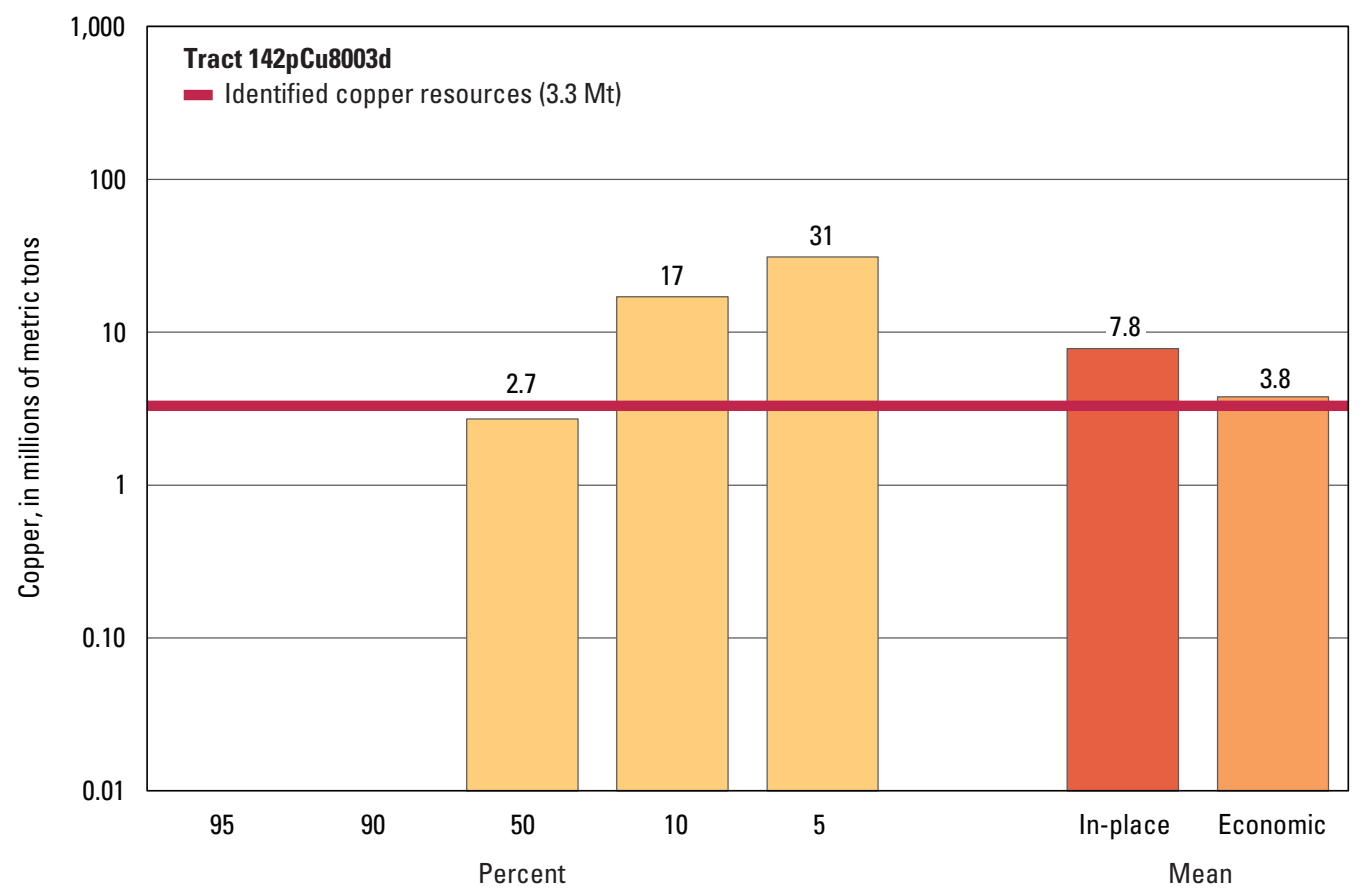

Graph showing the estimated probability distribution of undiscovered copper resources, where each bar represents the minimum amount estimated at the indicated percentage.

\section{Source}

Berger and others, 2014, Porphyry copper assessment of western Central Asia: U.S. Geological Survey Scientific Investigations Report 2010-5090-N, http://dx.doi.org/10.3133/sir20105090N. 


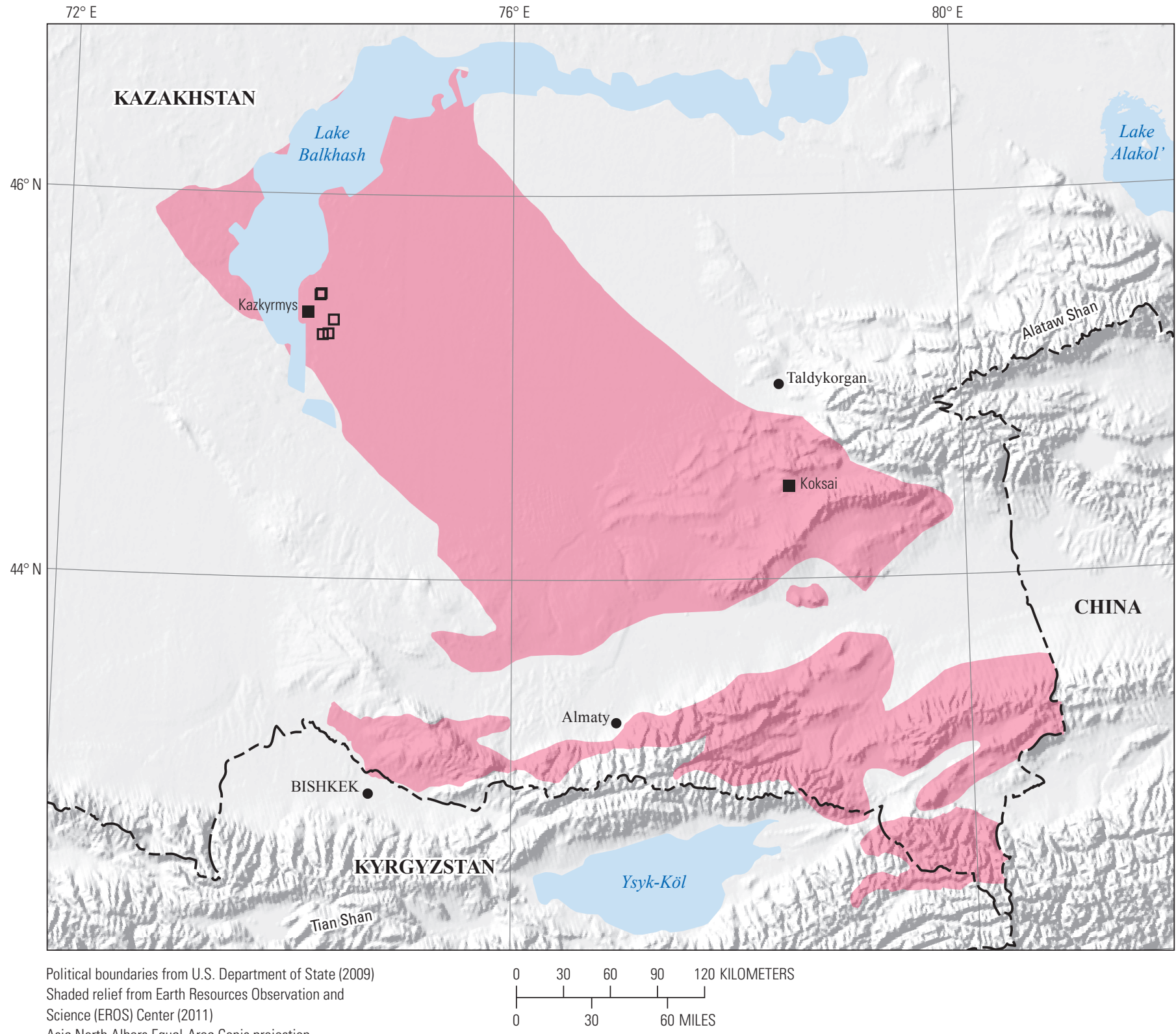

Asia North Albers Equal-Area Conic projection

Central meridian $76^{\circ} 30^{\prime} \mathrm{E}$.; latitude of origin $30^{\circ} \mathrm{N}$.

\section{EXPLANATION}

\section{Assessed porphyry copper tract 142pCu8003d}

- Porphyry copper deposit

ㅁ Porphyry copper prospect

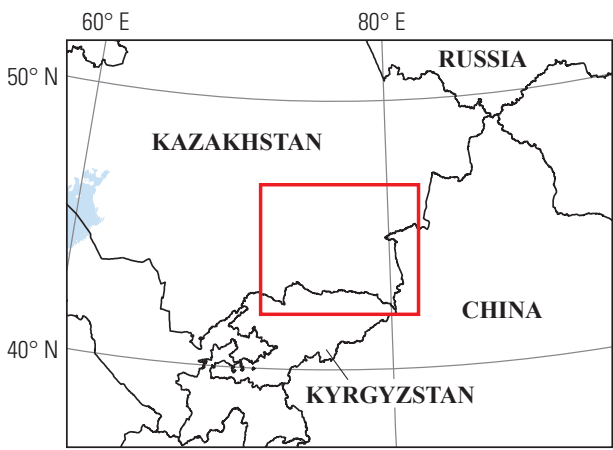




\title{
Plate 83. Porphyry Copper Assessment for Tract 142pCu8003c, Late Paleozoic Balkhash-Ili Magmatic Arc (West)—Kazakhstan
}

\author{
Descriptive model: \\ Porphyry copper models (Cox, 1986a; Berger and others, 2008) \\ Grade and tonnage model: \\ General porphyry copper model (Singer, Berger, and Moring, 2008) \\ Economic filter depth percentages: \\ Economic filter cost setting: \\ Default -0 to 250 meters (m), 25\%; > 250 to $500 \mathrm{~m}, 25 \%$; > $500 \mathrm{~m}$ to $1 \mathrm{~km}, 50 \%$ \\ High cost \\ Geologic feature assessed: \\ Early Carboniferous to Permian magmatic-arc and postcollisional rocks \\ Number of known deposits: \\ 2
}

\section{Selected Resource Assessment Results for Porphyry Copper}

[Assessment depth, 1 kilometer $(\mathrm{km}) ; \mathrm{km}^{2}$, square kilometer; Mt, millions of metric tons]

\begin{tabular}{|c|c|c|c|c|c|c|}
\hline \multirow[b]{2}{*}{$\begin{array}{c}\text { Date of } \\
\text { assessment }\end{array}$} & \multirow[b]{2}{*}{$\begin{array}{c}\text { Tract area } \\
\quad\left(\mathrm{km}^{2}\right)\end{array}$} & \multirow{2}{*}{$\begin{array}{l}\text { Identified } \\
\text { copper } \\
\text { resources } \\
\text { (Mt) }\end{array}$} & \multicolumn{4}{|c|}{ Undiscovered copper resource estimates } \\
\hline & & & $\begin{array}{l}\text { Mean estimate of } \\
\text { in-place resources } \\
\text { (Mt) }\end{array}$ & $\begin{array}{c}\text { Probability of } 0 \\
\text { in-place resources } \\
\text { (percent) }\end{array}$ & $\begin{array}{l}\text { Mean estimate of } \\
\text { economic resources } \\
\text { (Mt) }\end{array}$ & $\begin{array}{c}\text { Probability of } 0 \\
\text { economic resources } \\
\text { (percent) }\end{array}$ \\
\hline 2009 & 23,757 & 1.0 & 7.4 & 30 & 3.6 & 84 \\
\hline
\end{tabular}

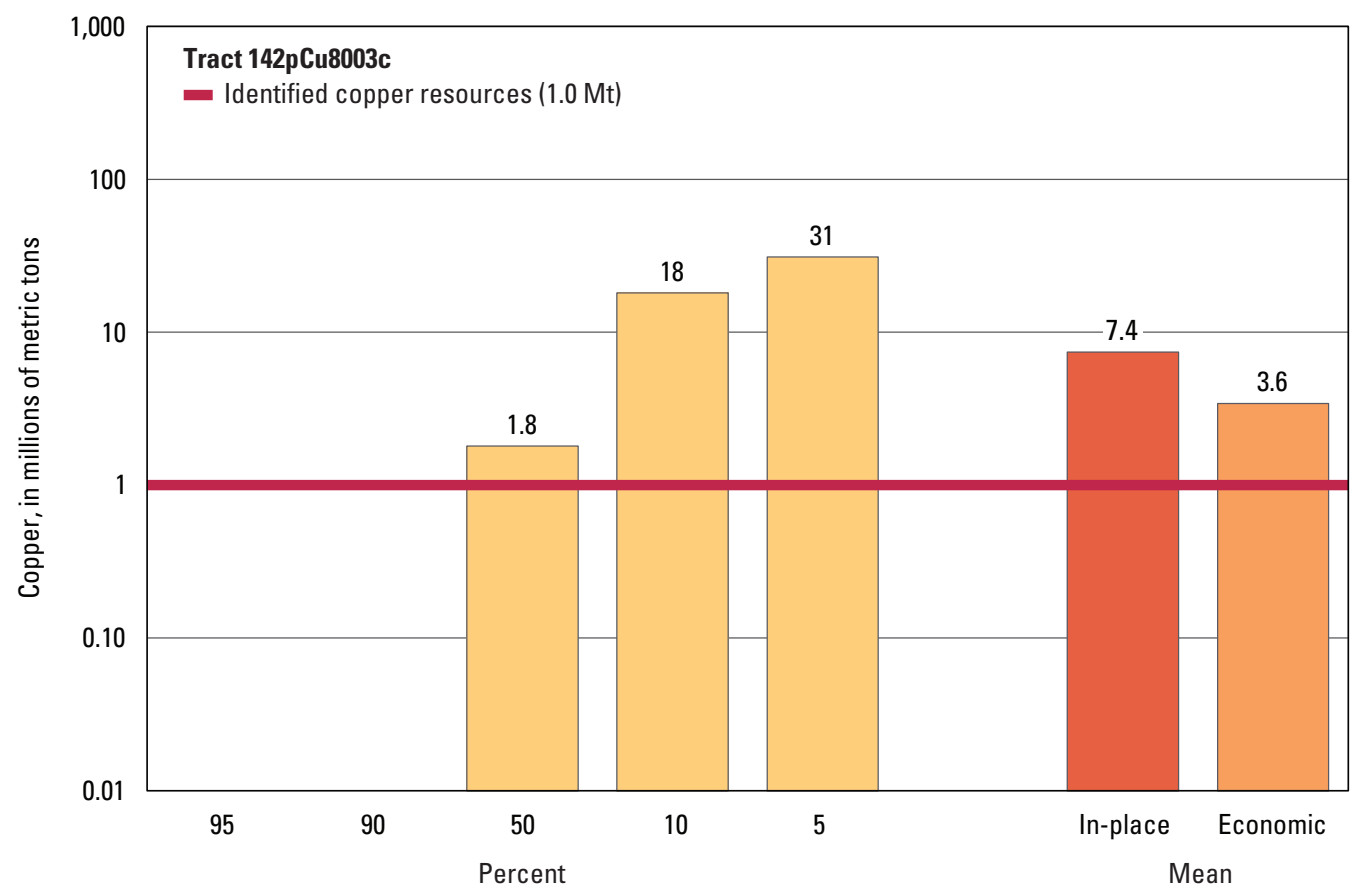

Graph showing the estimated probability distribution of undiscovered copper resources, where each bar represents the minimum amount estimated at the indicated percentage.

\section{Source}

Berger and others, 2014, Porphyry copper assessment of western Central Asia: U.S. Geological Survey Scientific Investigations Report 2010-5090-N, http://dx.doi.org/10.3133/sir20105090N. 


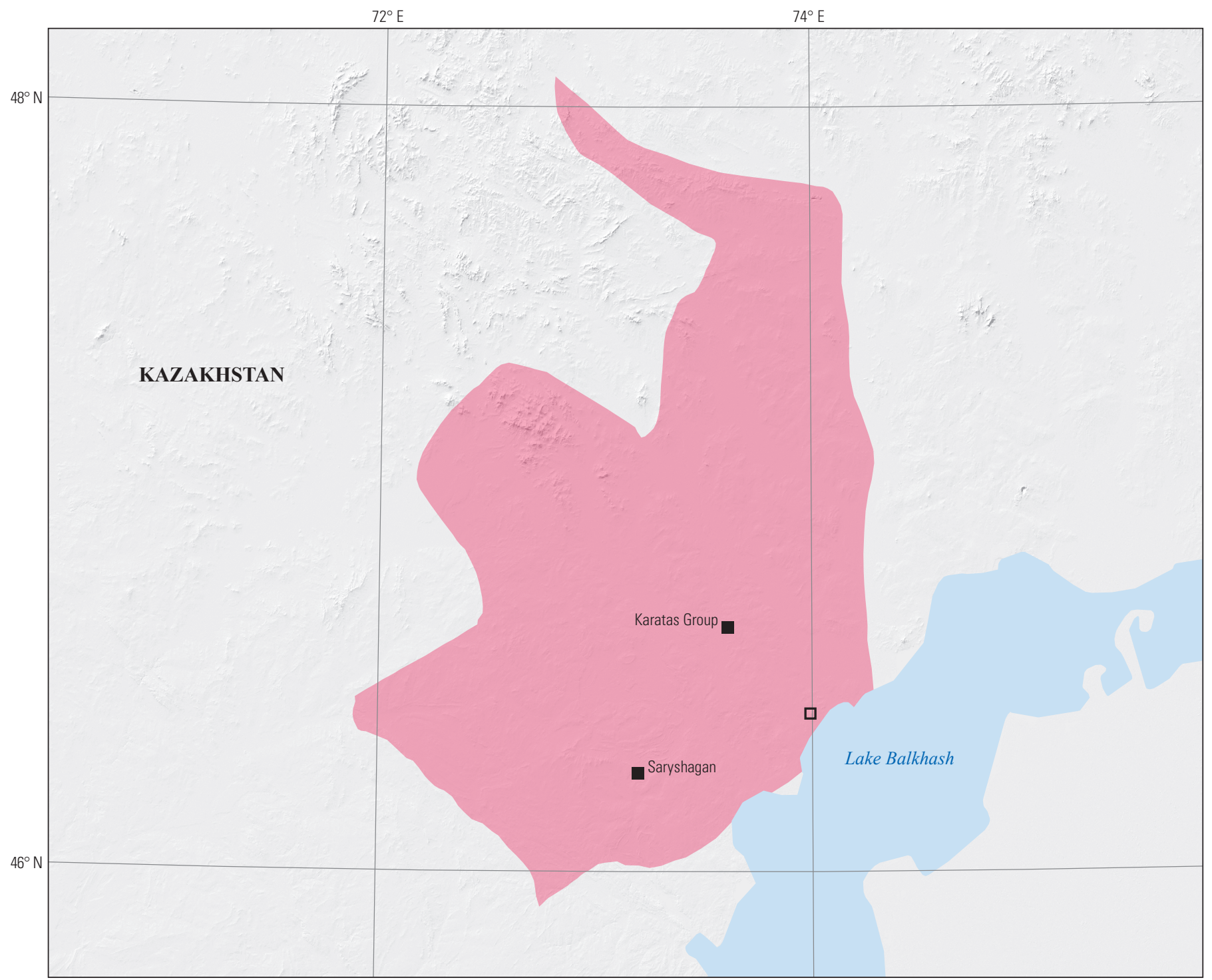

Political boundaries from U.S. Department of State (2009) Shaded relief from ESRI (2008)

Asia North Albers Equal-Area Conic projection

Central meridian $73^{\circ} 30^{\prime}$ E.; latitude of origin $30^{\circ} \mathrm{N}$.

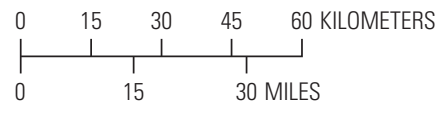

\section{EXPLANATION}

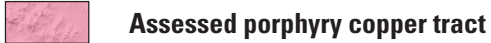
142pCu8003c

- Porphyry copper deposit

$\square \quad$ Porphyry copper prospect

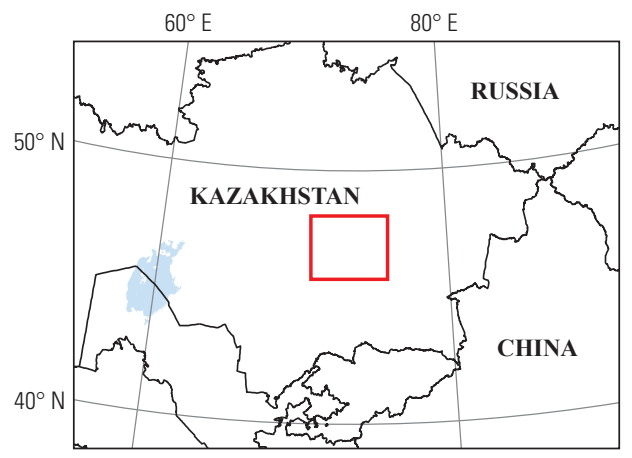




\title{
Plate 84. Porphyry Copper Assessment for Tract 142pCu8002, Ordovician North Tian Shan Magmatic Arc-Kazakhstan and Kyrgyzstan
}

\author{
Descriptive model: \\ Porphyry copper models (Cox, 1986a; Berger and others, 2008) \\ Grade and tonnage model: \\ General porphyry copper model (Singer, Berger, and Moring, 2008) \\ Economic filter depth percentages: \\ Economic filter cost setting: \\ Geologic feature assessed: \\ Default -0 to 250 meters (m), $25 \% ;>250$ to $500 \mathrm{~m}, 25 \% ;>500 \mathrm{~m}$ to $1 \mathrm{~km}, 50 \%$ \\ High cost \\ Middle to Late Ordovician North Tian Shan magmatic-arc rocks \\ Number of known deposits: \\ 2
}

\section{Selected Resource Assessment Results for Porphyry Copper}

[Assessment depth, 1 kilometer $(\mathrm{km}) ; \mathrm{km}^{2}$, square kilometer; Mt, millions of metric tons]

\begin{tabular}{ccccccc}
\hline \multirow{2}{*}{$\begin{array}{c}\text { Date of } \\
\text { assessment }\end{array}$} & $\begin{array}{c}\text { Tract area } \\
\left(\mathbf{k m}^{2}\right)\end{array}$ & $\begin{array}{c}\text { Identified } \\
\text { copper } \\
\text { resources } \\
(\mathbf{M t})\end{array}$ & $\begin{array}{c}\text { Mean estimate of } \\
\text { in-place resources } \\
(\mathbf{M t})\end{array}$ & $\begin{array}{c}\text { Probability of } \mathbf{0} \\
\text { in-place resources } \\
\text { (percent) }\end{array}$ & $\begin{array}{c}\text { Mean estimate of } \\
\text { economic resources } \\
\text { (Mt) }\end{array}$ & $\begin{array}{c}\text { Probability of } \mathbf{0} \\
\text { economic resources } \\
\text { (percent) }\end{array}$ \\
\hline 2009 & 8,124 & 2.0 & 5.2 & 30 & 2.5 \\
\hline
\end{tabular}

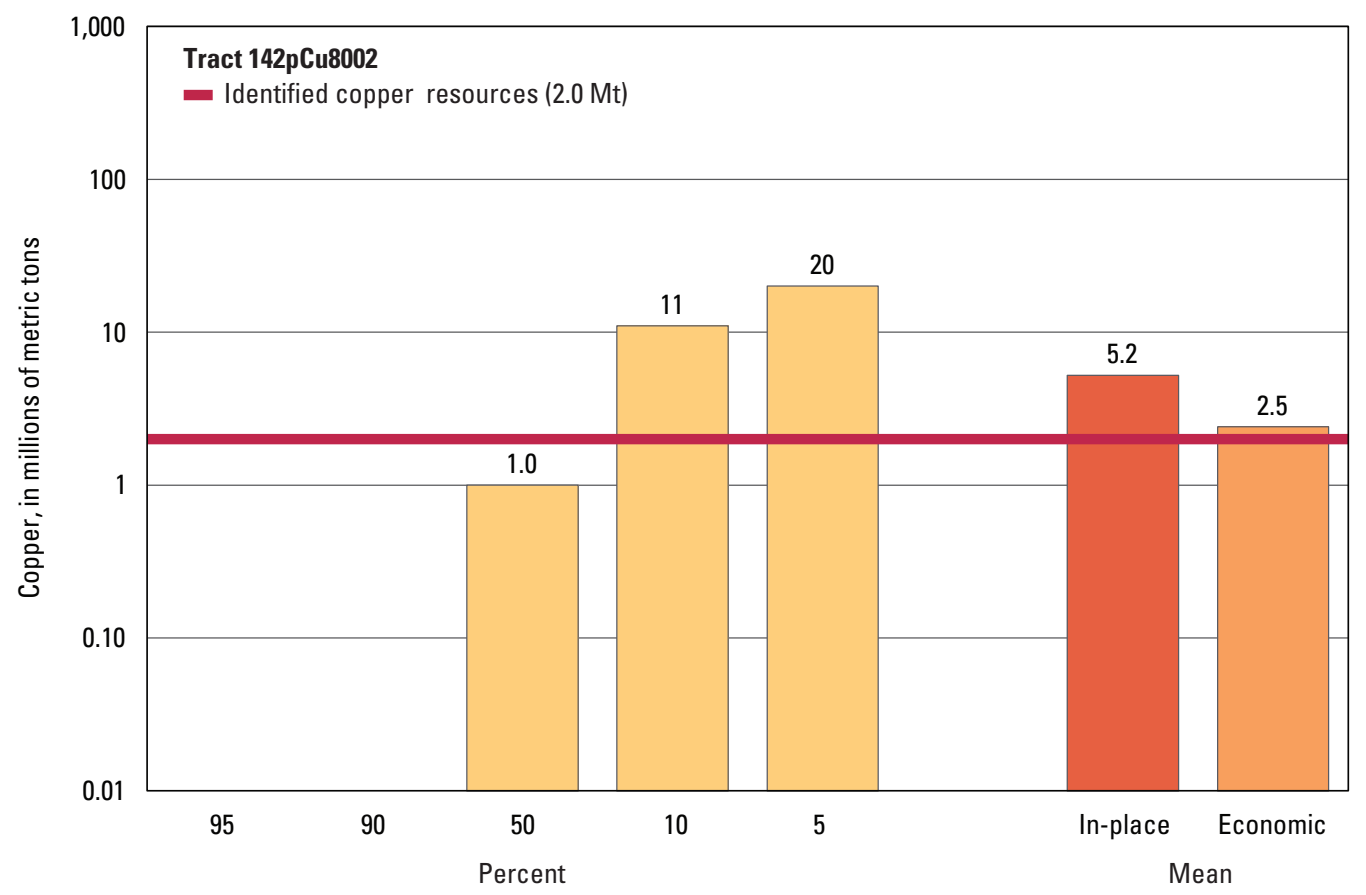

Graph showing the estimated probability distribution of undiscovered copper resources, where each bar represents the minimum amount estimated at the indicated percentage.

\section{Source}

Berger and others, 2014, Porphyry copper assessment of western Central Asia: U.S. Geological Survey Scientific Investigations Report 2010-5090-N, http://dx.doi.org/10.3133/sir20105090N. 


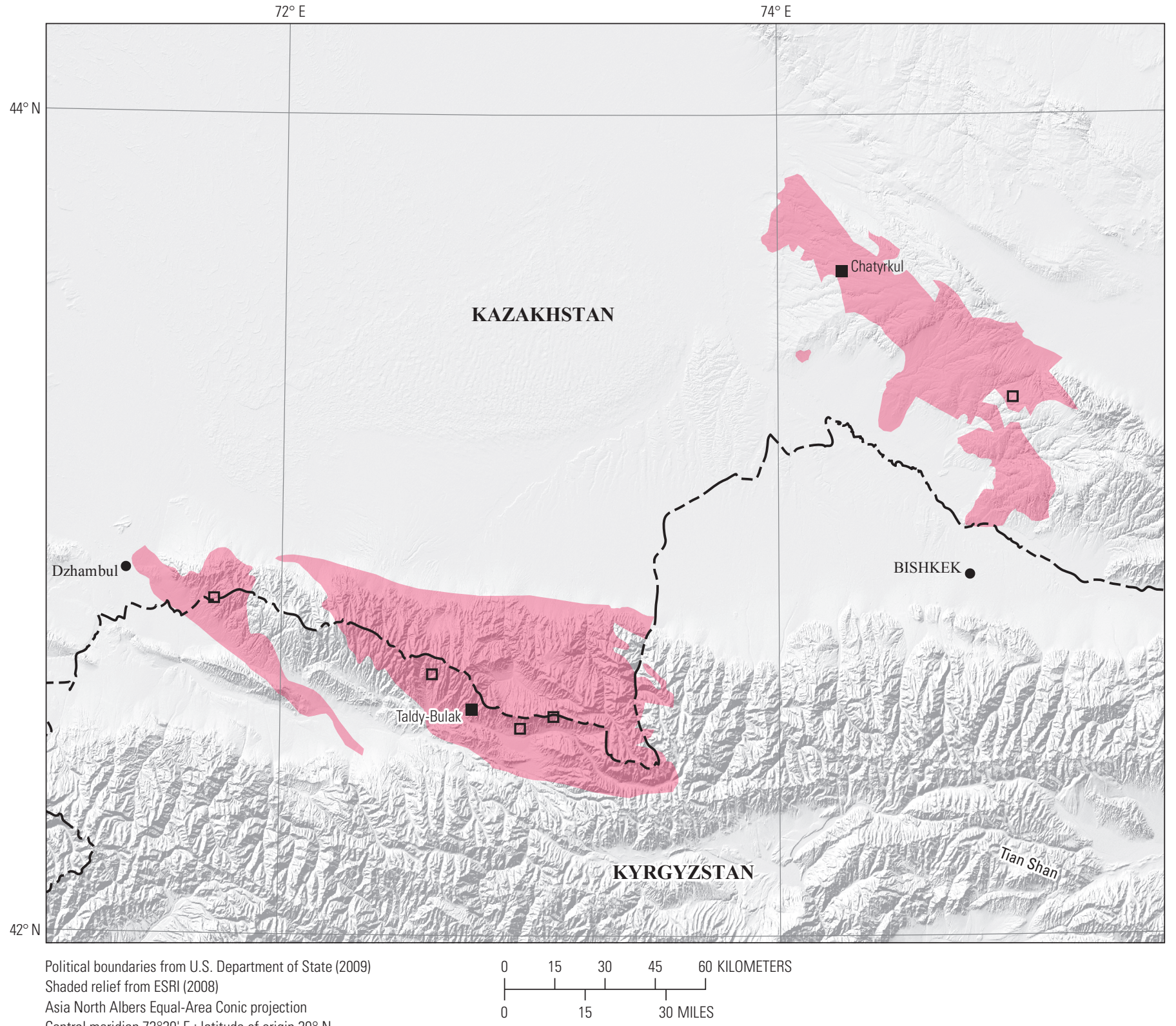

Central meridian $73^{\circ} 30^{\prime} \mathrm{E}$.; latitude of origin $30^{\circ} \mathrm{N}$.

EXPLANATION

\section{Assessed porphyry copper tract $142 \mathrm{pCu} 8002$}

- Porphyry copper deposit

ㅁ Porphyry copper prospect

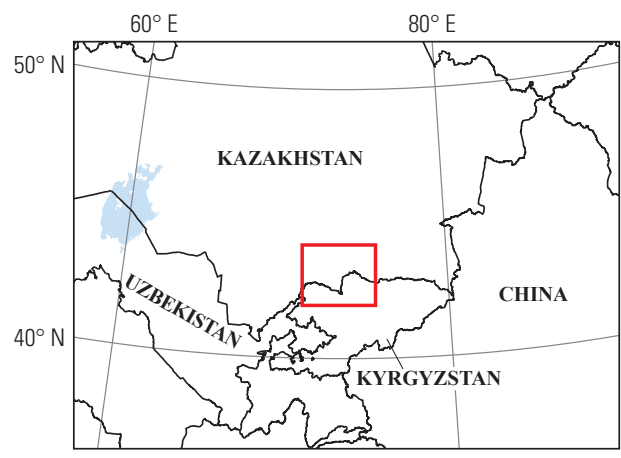




\section{Plate 85. Porphyry Copper Assessment for Tract 142pCu8001, Chatkal and Kurama Ranges-Kazakhstan, Kyrgyzstan, Tajikistan, and Uzbekistan}

\author{
Descriptive model: \\ Grade and tonnage model: \\ Economic filter depth percentages: \\ Economic filter cost setting: \\ Geologic feature assessed: \\ Number of known deposits:
}

\author{
Porphyry copper models (Cox, 1986a; Berger and others, 2008) \\ General porphyry copper model (Singer, Berger, and Moring, 2008) \\ Default -0 to 250 meters (m), 25\%; >250 to $500 \mathrm{~m}, 25 \%$; $>500 \mathrm{~m}$ to $1 \mathrm{~km}, 50 \%$ \\ High cost \\ Late Carboniferous to Permian magmatic-arc and postcollisional volcanic-plutonic complexes \\ 4
}

\section{Selected Resource Assessment Results for Porphyry Copper}

[Assessment depth, 1 kilometer $(\mathrm{km}) ; \mathrm{km}^{2}$, square kilometer; $\mathrm{Mt}$, millions of metric tons]

\begin{tabular}{ccccccc}
\hline \multirow{2}{*}{$\begin{array}{c}\text { Date of } \\
\text { assessment }\end{array}$} & $\begin{array}{c}\text { Tract area } \\
\left(\mathbf{k m}^{2}\right)\end{array}$ & $\begin{array}{c}\text { Identified } \\
\text { copper } \\
\text { resources } \\
(\mathbf{M t})\end{array}$ & $\begin{array}{c}\text { Mean estimate of } \\
\text { in-place resources } \\
(\mathbf{M t})\end{array}$ & $\begin{array}{c}\text { Probability of } \mathbf{0} \\
\text { in-place resources } \\
\text { (percent) }\end{array}$ & $\begin{array}{c}\text { Mean estimate of } \\
\text { economic resources } \\
\text { (Mt) }\end{array}$ & $\begin{array}{c}\text { Probability of } 0 \\
\text { economic resources } \\
\text { (percent) }\end{array}$ \\
\hline 2009 & 25,104 & 31 & 19 & 7 & 9.3 \\
\hline
\end{tabular}

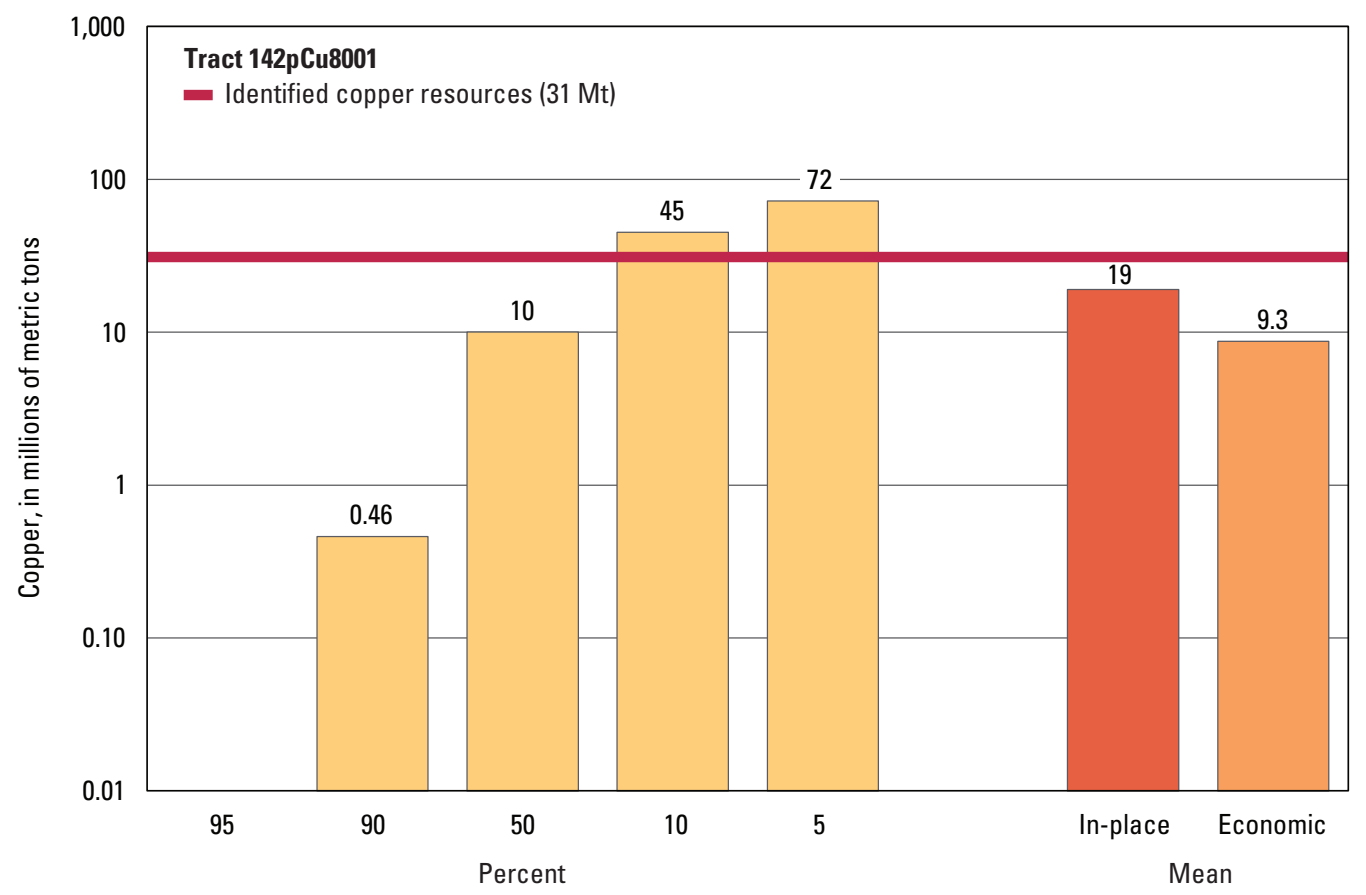

Graph showing the estimated probability distribution of undiscovered copper resources, where each bar represents the minimum amount estimated at the indicated percentage.

\section{Source}

Berger and others, 2014, Porphyry copper assessment of western Central Asia: U.S. Geological Survey Scientific Investigations Report 2010-5090-N, http://dx.doi.org/10.3133/sir20105090N. 


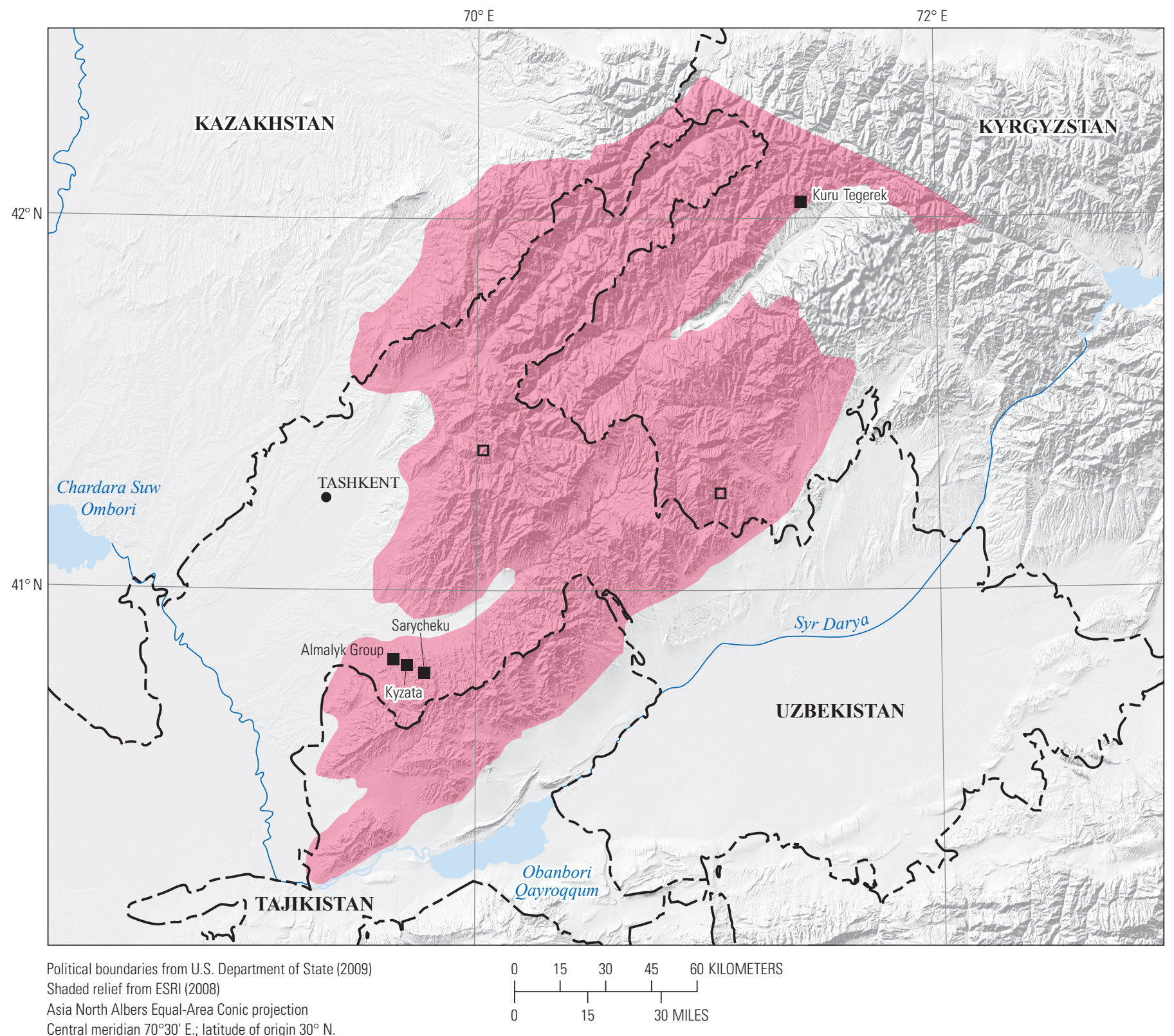

Central meridian $70^{\circ} 30^{\prime} \mathrm{E}$.; latitude of origin $30^{\circ} \mathrm{N}$

\section{EXPLANATION} Assessed porphyry copper tract
142pCu8001

- Porphyry copper deposit

ㅁ Porphyry copper prospect

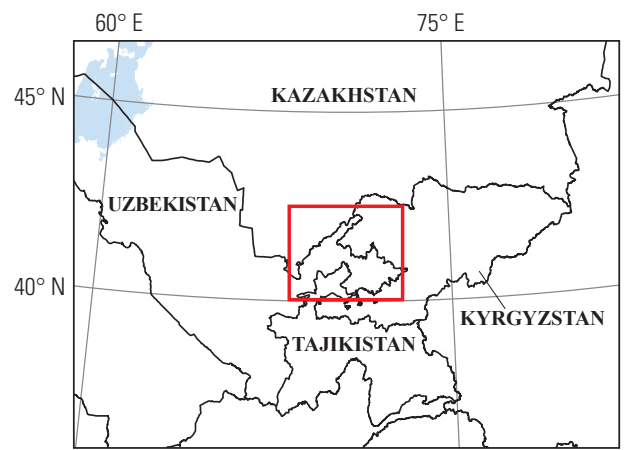




\title{
Plate 86. Porphyry Copper Assessment for Tract 142pCu8704, Coastal Pacific- China, Taiwan, and Vietnam
}

\author{
Descriptive model: \\ Porphyry copper models (Cox, 1986a; John and others, 2010) \\ Grade and tonnage model: \\ General porphyry copper model (Singer, Berger, and Moring, 2008) \\ Economic filter depth percentages: \\ Economic filter cost setting: \\ Geologic feature assessed: \\ Default -0 to 250 meters (m), $25 \% ;>250$ to $500 \mathrm{~m}, 25 \% ;>500 \mathrm{~m}$ to $1 \mathrm{~km}, 50 \%$ \\ Mixed cost \\ An assemblage of Jurassic and Cretaceous postsubduction volcanic and intrusive rocks in eastern \\ China and northern Vietnam \\ Number of known deposits: \\ 6
}

\section{Selected Resource Assessment Results for Porphyry Copper}

[Assessment depth, 1 kilometer ( $\mathrm{km}) ; \mathrm{km}^{2}$, square kilometer; Mt, millions of metric tons]

\begin{tabular}{ccccccc}
\hline $\begin{array}{c}\text { Date of } \\
\text { assessment }\end{array}$ & $\begin{array}{c}\text { Tract area } \\
\left(\mathbf{k m}^{2}\right)\end{array}$ & $\begin{array}{c}\text { Identified } \\
\text { copper } \\
\text { resources } \\
\text { (Mt) }\end{array}$ & $\begin{array}{c}\text { Mean estimate of } \\
\text { in-place resources } \\
(\mathbf{M t})\end{array}$ & $\begin{array}{c}\text { Probability of } \mathbf{0} \\
\text { in-place resources } \\
\text { (percent) }\end{array}$ & $\begin{array}{c}\text { Mean estimate of } \\
\text { economic resources } \\
\text { (Mt) }\end{array}$ & $\begin{array}{c}\text { Probability of 0 } \\
\text { economic resources } \\
\text { (percent) }\end{array}$ \\
\hline 2010 & 604,560 & 15 & 65 & 4 & 38 \\
\hline
\end{tabular}

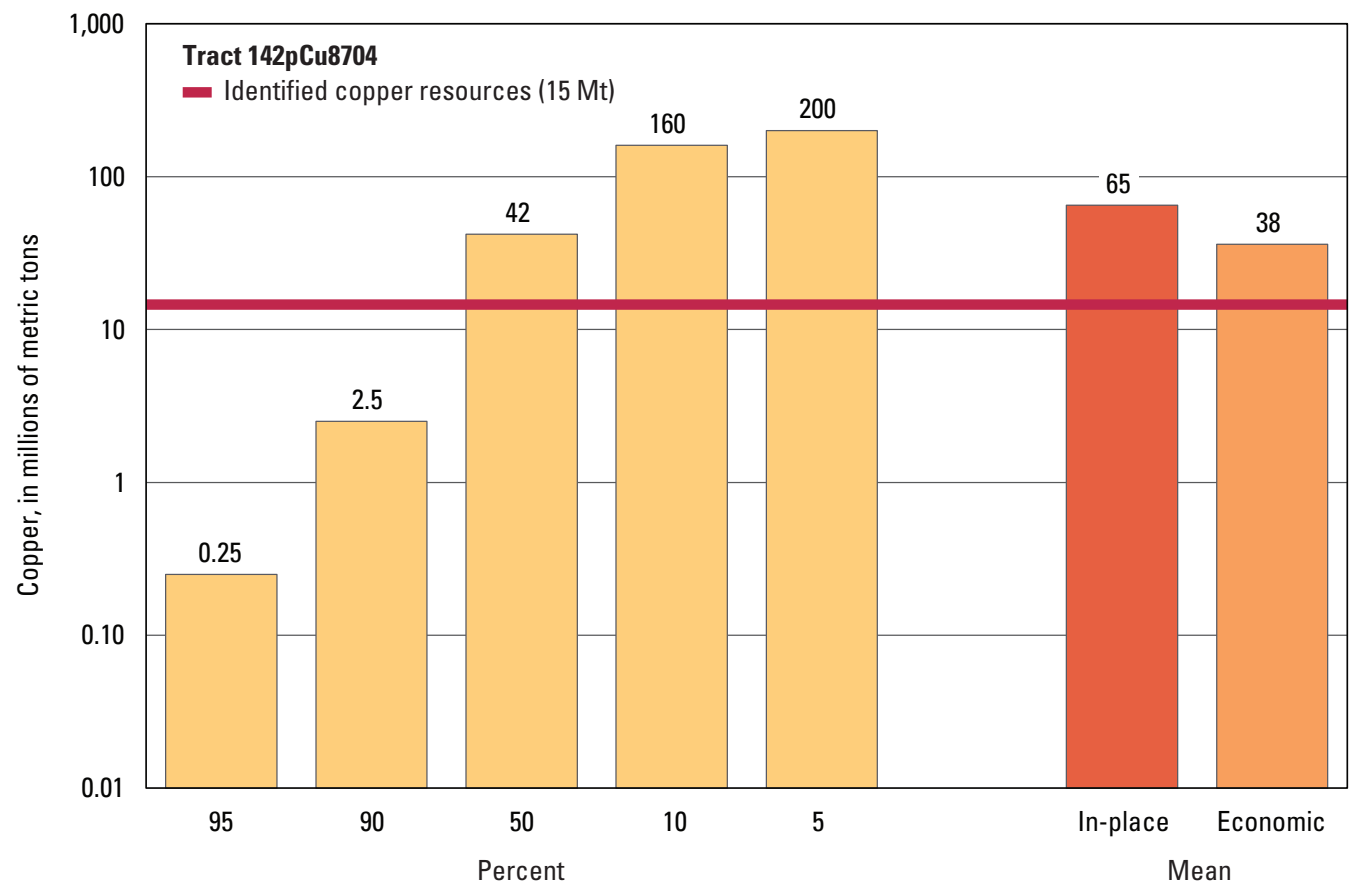

Graph showing the estimated probability distribution of undiscovered copper resources, where each bar represents the minimum amount estimated at the indicated percentage.

\section{Source}

Ludington, Mihalasky, and others, 2012, Porphyry copper assessment of the Mesozoic of East Asia—China, Vietnam, North Korea, Mongolia, and Russia: U.S. Geological Survey Scientific Investigations Report 2010-5090-G, http://pubs.usgs.gov/sir/2010/5090/g/. 


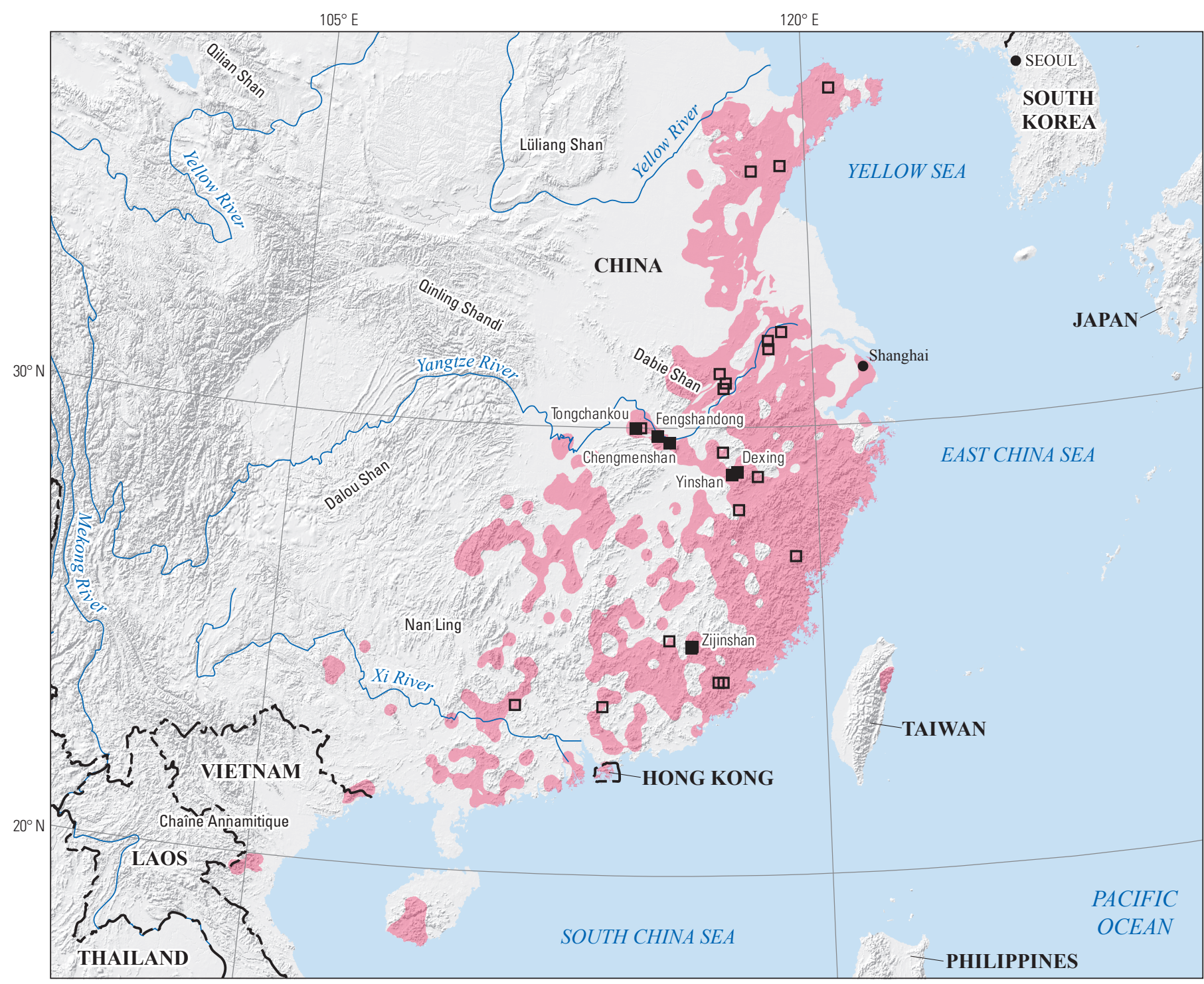

Political boundaries from U.S. Department of State (2009) Shaded relief from Earth Resources Observation and Science (EROS) Center (2011)

Asia North Albers Equal-Area Conic projection

Central meridian $116^{\circ} \mathrm{E}$; ; latitude of origin $30^{\circ} \mathrm{N}$

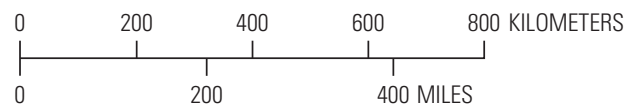

\section{EXPLANATION}

\begin{tabular}{cc}
\hline & $\begin{array}{c}\text { Assessed porphyry copper } \\
142 \mathrm{pC} 88704\end{array}$ \\
$\square$ & Porphyry copper deposit \\
$\square$ & Porphyry copper prospect
\end{tabular}

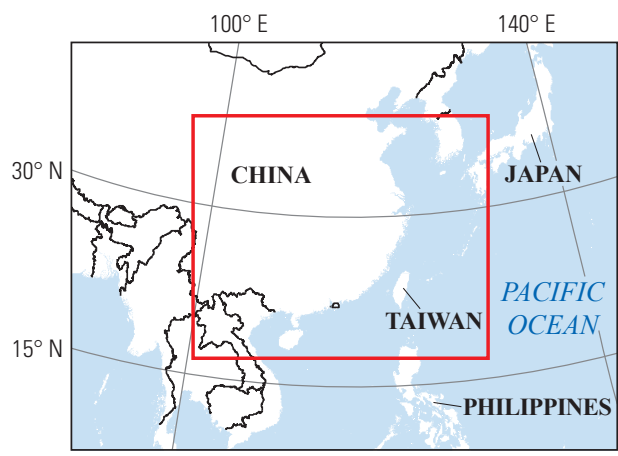




\section{Plate 87. Porphyry Copper Assessment for Tract 142pCu8705, East Qinling- China}

\section{Descriptive model:}

Grade and tonnage model:

Economic filter depth percentages:

Economic filter cost setting:

Geologic feature assessed:

Number of known deposits:
Porphyry copper models (Cox, 1986a; John and others, 2010)

Porphyry copper, copper-molybdenum subtype model (Singer, Berger, and Moring, 2008)

Default -0 to 250 meters (m), 25\%; > 250 to $500 \mathrm{~m}, 25 \%$; >500 m to $1 \mathrm{~km}, 50 \%$

Mixed cost

A linear belt of Jurassic and Cretaceous postsubduction intrusive rocks in central China 1

\section{Selected Resource Assessment Results for Porphyry Copper}

[Assessment depth, 1 kilometer $(\mathrm{km}) ; \mathrm{km}^{2}$, square kilometer; $\mathrm{Mt}$, millions of metric tons]

\begin{tabular}{ccccccc}
\hline \multirow{2}{*}{$\begin{array}{c}\text { Date of } \\
\text { assessment }\end{array}$} & $\begin{array}{c}\text { Tract area } \\
\left(\mathbf{k m}^{2}\right)\end{array}$ & $\begin{array}{c}\text { Identified } \\
\text { copper } \\
\text { resources } \\
(\mathbf{M t})\end{array}$ & $\begin{array}{c}\text { Mean estimate of } \\
\text { in-place resources } \\
(\mathbf{M t})\end{array}$ & $\begin{array}{c}\text { Probability of } \mathbf{0} \\
\text { in-place resources } \\
\text { (percent) }\end{array}$ & $\begin{array}{c}\text { Mean estimate of } \\
\text { economic resources } \\
\text { (Mt) }\end{array}$ & $\begin{array}{c}\text { Probability of 0 } \\
\text { economic resources } \\
\text { (percent) }\end{array}$ \\
\hline 2010 & 171,104 & 0.39 & 52 & 7 & 38 \\
\hline
\end{tabular}

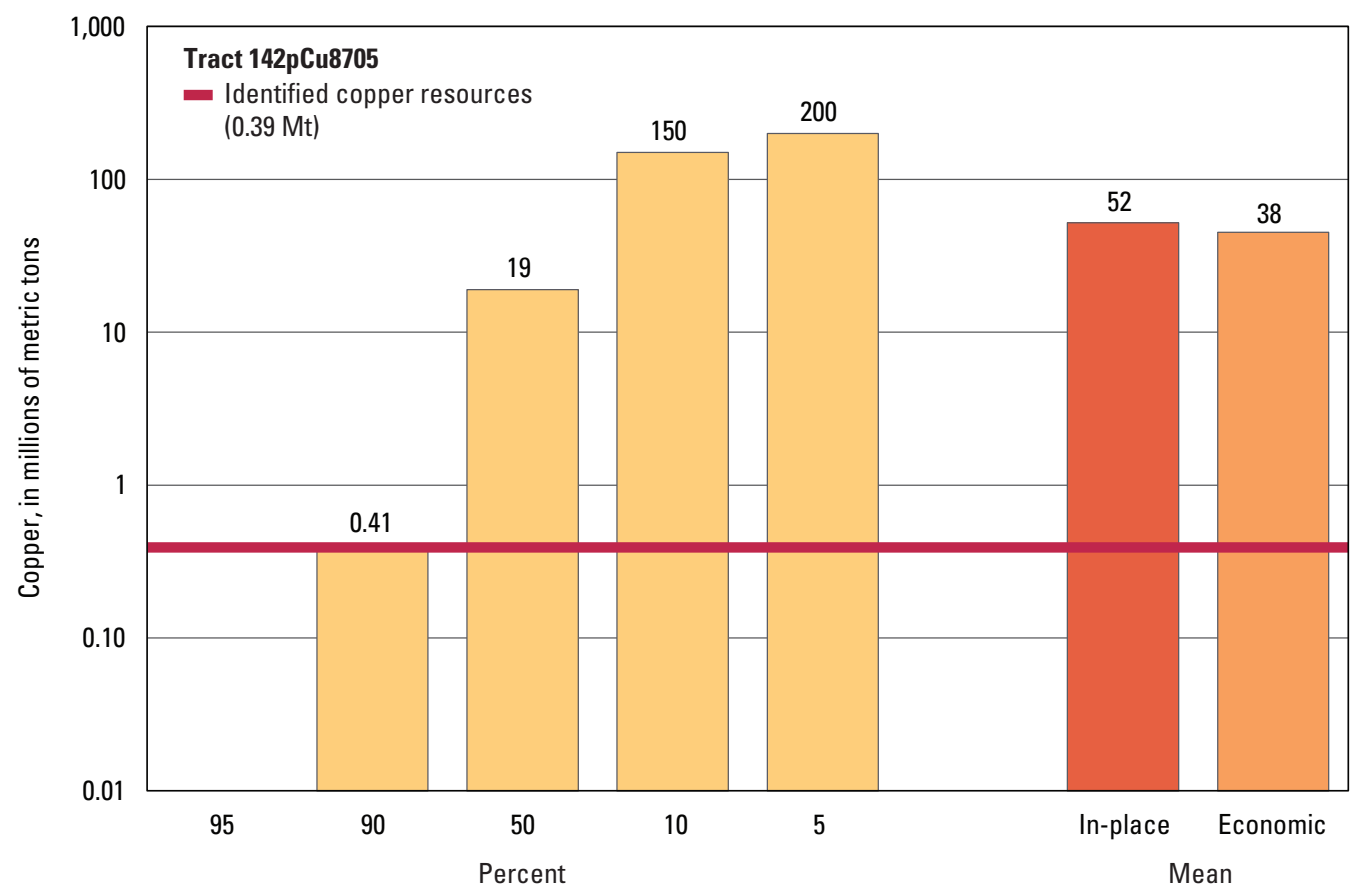

Graph showing the estimated probability distribution of undiscovered copper resources, where each bar represents the minimum amount estimated at the indicated percentage.

\section{Source}

Ludington, Mihalasky, and others, 2012, Porphyry copper assessment of the Mesozoic of East Asia - China, Vietnam, North Korea, Mongolia, and Russia: U.S. Geological Survey Scientific Investigations Report 2010-5090-G, http://pubs.usgs.gov/sir/2010/5090/g/. 


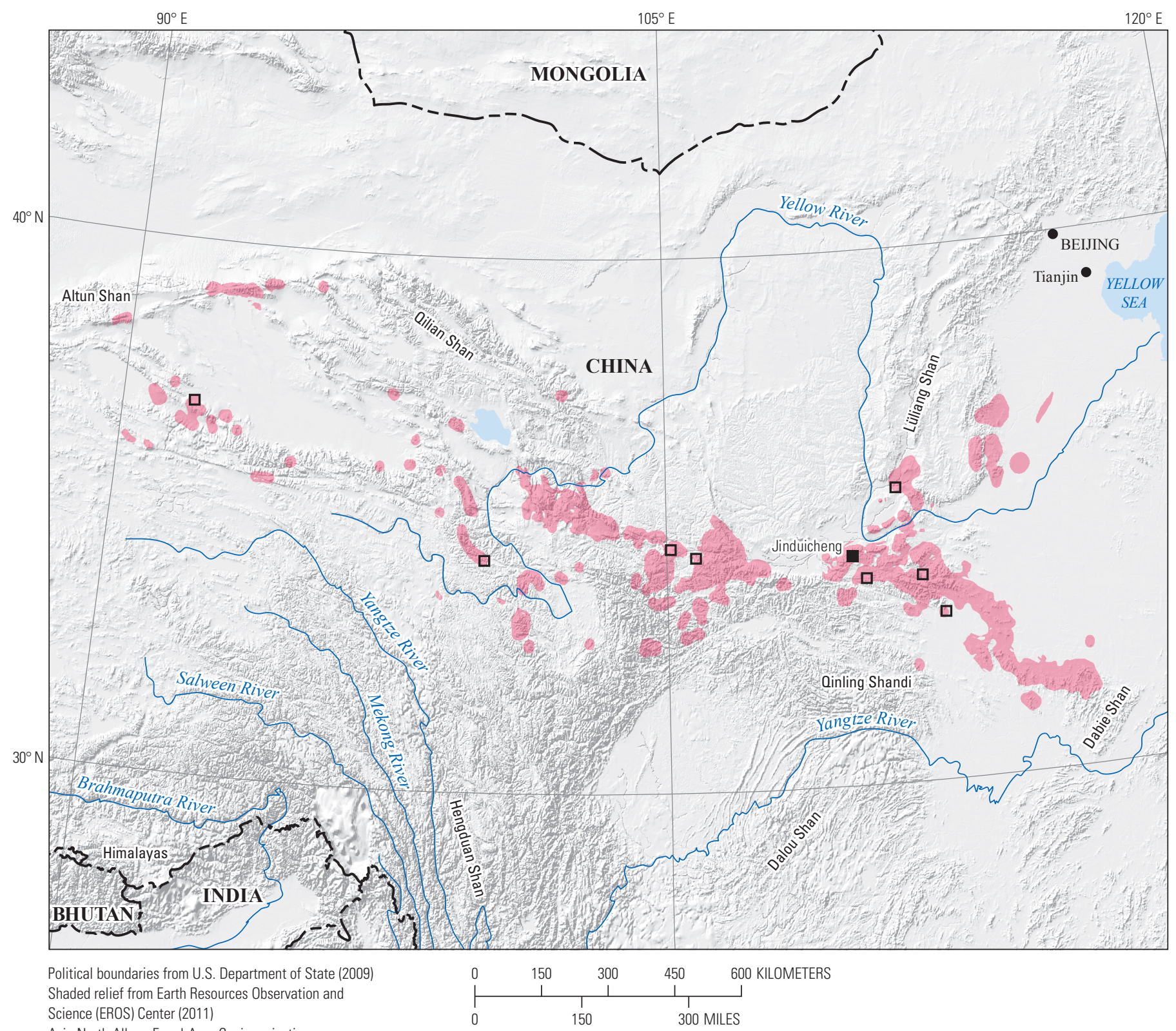

Asia North Albers Equal-Area Conic projection

Central meridian $103^{\circ} \mathrm{E}$; latitude of origin $30^{\circ} \mathrm{N}$.

EXPLANATION

Assessed porphyry copper tract 142pCu8705

- Porphyry copper deposit

Porphyry copper prospect

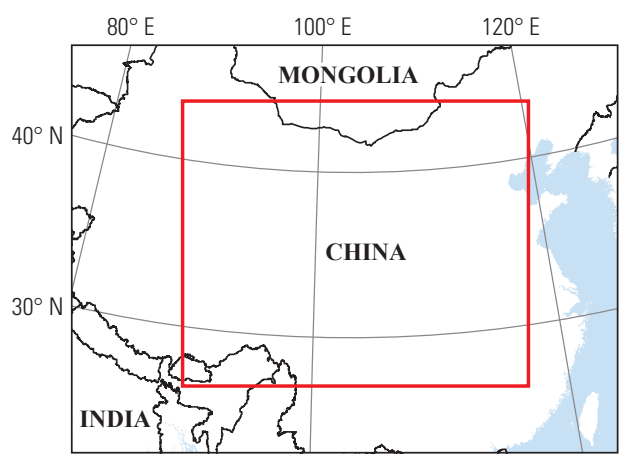




\section{Plate 88. Porphyry Copper Assessment for Tract 142pCu8701, Oinling-Dabie- China and Tajikistan}

\author{
Descriptive model: \\ Grade and tonnage model: \\ Economic filter depth percentages: \\ Economic filter cost setting: \\ Geologic feature assessed:
}

Number of known deposits:

\author{
Porphyry copper models (Cox, 1986a; John and others, 2010) \\ General porphyry copper model (Singer, Berger, and Moring, 2008) \\ Skewed shallow-0 to 250 meters (m), 35\%; > 250 to $500 \mathrm{~m}, 25 \%$; $>500 \mathrm{~m}$ to $1 \mathrm{~km}, 40 \%$ \\ High cost \\ Paleozoic through Triassic igneous rocks: (1) Cambro-Ordovician island arc; (2) Devonian \\ continental-margin arc related to north-directed subduction of the paleo-Tethyan ocean beneath \\ the North China, Qaidam, and Tarim cratons, and (3) Permo-Triassic rocks formed by collision \\ of the North China and Tarim cratons with the Eurasian continent
}

1

\section{Selected Resource Assessment Results for Porphyry Copper}

[Assessment depth, 1 kilometer $(\mathrm{km}) ; \mathrm{km}^{2}$, square kilometer; Mt, millions of metric tons]

\begin{tabular}{|c|c|c|c|c|c|c|}
\hline \multirow[b]{2}{*}{$\begin{array}{c}\text { Date of } \\
\text { assessment }\end{array}$} & \multirow[b]{2}{*}{$\begin{array}{l}\text { Tract area } \\
\quad\left(\mathbf{k m}^{2}\right)\end{array}$} & \multirow{2}{*}{$\begin{array}{l}\text { Identified } \\
\text { copper } \\
\text { resources } \\
\text { (Mt) }\end{array}$} & \multicolumn{4}{|c|}{ Undiscovered copper resource estimates } \\
\hline & & & $\begin{array}{l}\text { Mean estimate of } \\
\text { in-place resources } \\
\text { (Mt) }\end{array}$ & $\begin{array}{c}\text { Probability of } 0 \\
\text { in-place resources } \\
\text { (percent) }\end{array}$ & $\begin{array}{l}\text { Mean estimate of } \\
\text { economic resources } \\
\text { (Mt) }\end{array}$ & $\begin{array}{c}\text { Probability of } 0 \\
\text { economic resources } \\
\text { (percent) }\end{array}$ \\
\hline 2012 & 403,215 & 1.4 & 32 & 16 & 17 & 37 \\
\hline
\end{tabular}

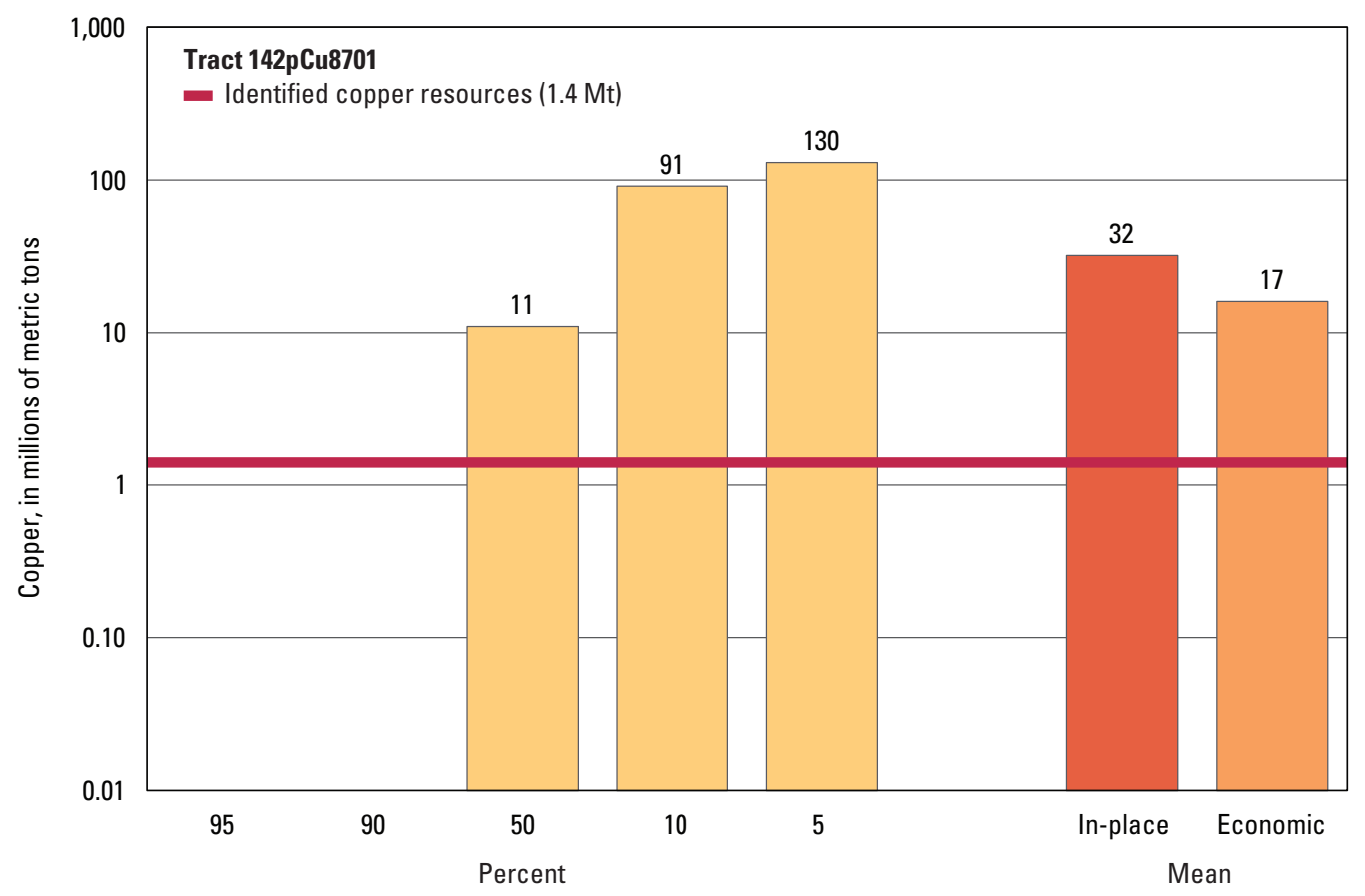

Graph showing the estimated probability distribution of undiscovered copper resources, where each bar represents the minimum amount estimated at the indicated percentage.

\section{Source}

Mihalasky, Ludington, Hammarstrom, and others, 2015, Porphyry copper assessment of the Central Asian Orogenic Belt and eastern Tethysides - China, Mongolia, Russia, Pakistan, Kazakhstan, Tajikistan, and India: U.S. Geological Survey Scientific Investigations Report 2010-5090-X, http://dx.doi.org/10.3133/sir20105090X. 


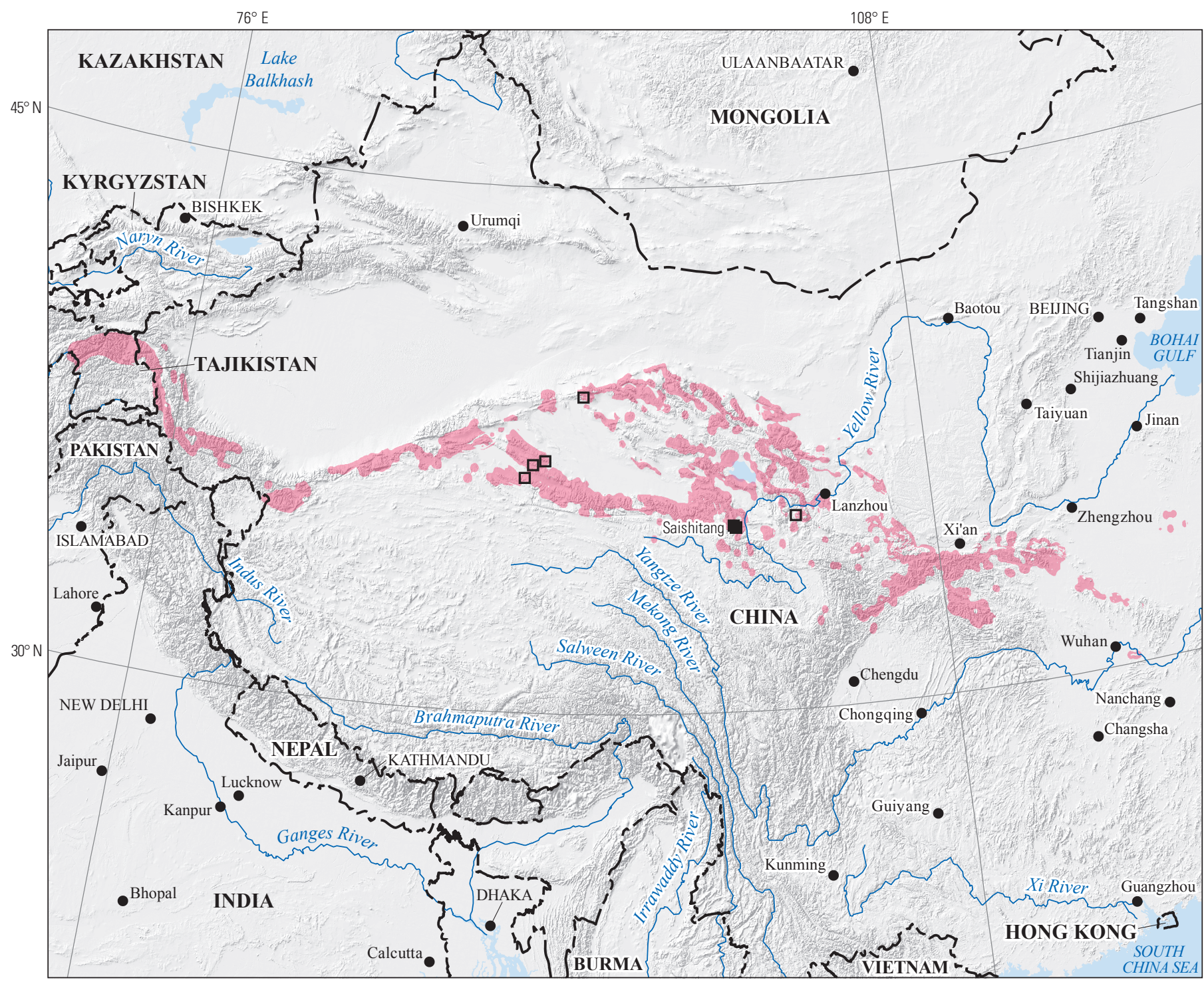

Political boundaries from U.S. Department of State (2009) Shaded relief from Earth Resources Observation and Science (EROS) Center (2011)

Asia North Albers Equal-Area Conic projection

Central meridian $92^{\circ} \mathrm{E}$.; latitude of origin $30^{\circ} \mathrm{N}$.

\section{EXPLANATION}

Assessed porphyry copper tract 142pCu8701

- Porphyry copper deposit

Porphyry copper prospect

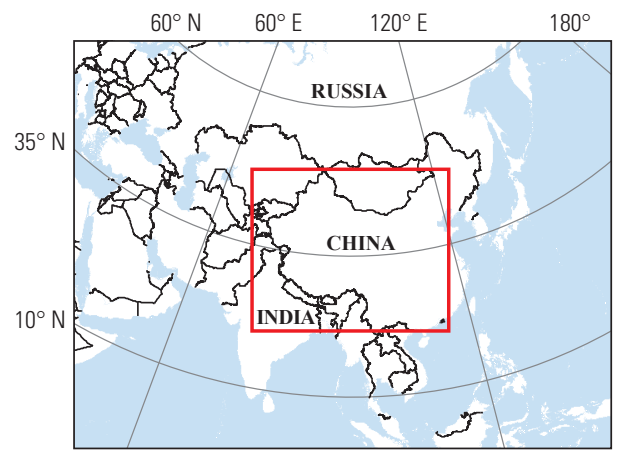




\section{Plate 89. Porphyry Copper Assessment for Tract 142pCu8706, Tethyan Gangdese-China, India, and Pakistan}

\author{
Descriptive model: \\ Grade and tonnage model: \\ Economic filter depth percentages: \\ Economic filter cost setting: \\ Geologic feature assessed:
}

Number of known deposits:
Porphyry copper models (Cox, 1986a; John and others, 2010)

General porphyry copper model (Singer, Berger, and Moring, 2008)

Default - 0 to 250 meters (m), 25\%; > 250 to $500 \mathrm{~m}, 25 \%$; > $500 \mathrm{~m}$ to $1 \mathrm{~km}, 50 \%$

High cost

Late Triassic, Yanshanian (Jurassic and Cretaceous) and early Tertiary igneous rocks in southwestern China that were formed during subduction of the Tethyan ocean below the southern margin of Asia

0

\section{Selected Resource Assessment Results for Porphyry Copper}

[Assessment depth, 1 kilometer (km); $\mathrm{km}^{2}$, square kilometer; Mt, millions of metric tons]

\begin{tabular}{ccccccc}
\hline \multirow{2}{*}{$\begin{array}{c}\text { Date of } \\
\text { assessment }\end{array}$} & $\begin{array}{c}\text { Tract area } \\
\left(\mathbf{k m}^{2}\right)\end{array}$ & $\begin{array}{c}\text { Identified } \\
\text { copper } \\
\text { resources } \\
(\mathbf{M t})\end{array}$ & $\begin{array}{c}\text { Mean estimate of } \\
\text { in-place resources } \\
(\mathbf{M t})\end{array}$ & $\begin{array}{c}\text { Probability of } \mathbf{0} \\
\text { in-place resources } \\
\text { (percent) }\end{array}$ & $\begin{array}{c}\text { Mean estimate of } \\
\text { economic resources } \\
\text { (Mt) }\end{array}$ & $\begin{array}{c}\text { Probability of } \mathbf{0} \\
\text { economic resources } \\
\text { (percent) }\end{array}$ \\
\hline 2013 & 289,647 & 0 & 28 & 7 & 14 \\
\hline
\end{tabular}

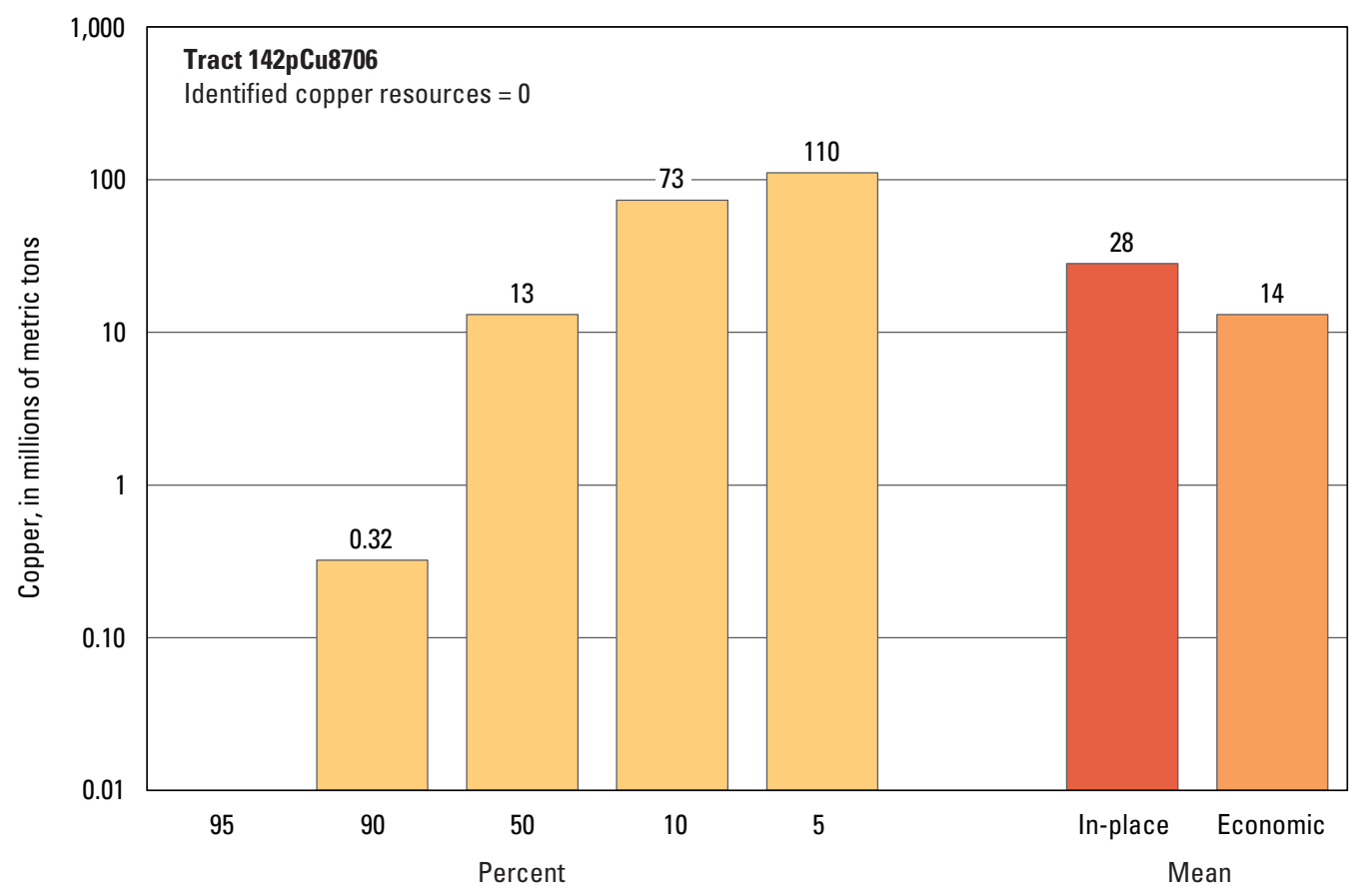

Graph showing the estimated probability distribution of undiscovered copper resources, where each bar represents the minimum amount estimated at the indicated percentage.

\section{Source}

Mihalasky, Ludington, Hammarstrom, and others, 2015, Porphyry copper assessment of the Central Asian Orogenic Belt and eastern Tethysides - China, Mongolia, Russia, Pakistan, Kazakhstan, Tajikistan, and India: U.S. Geological Survey Scientific Investigations Report 2010-5090-X, http://dx.doi.org/10.3133/sir20105090X. 


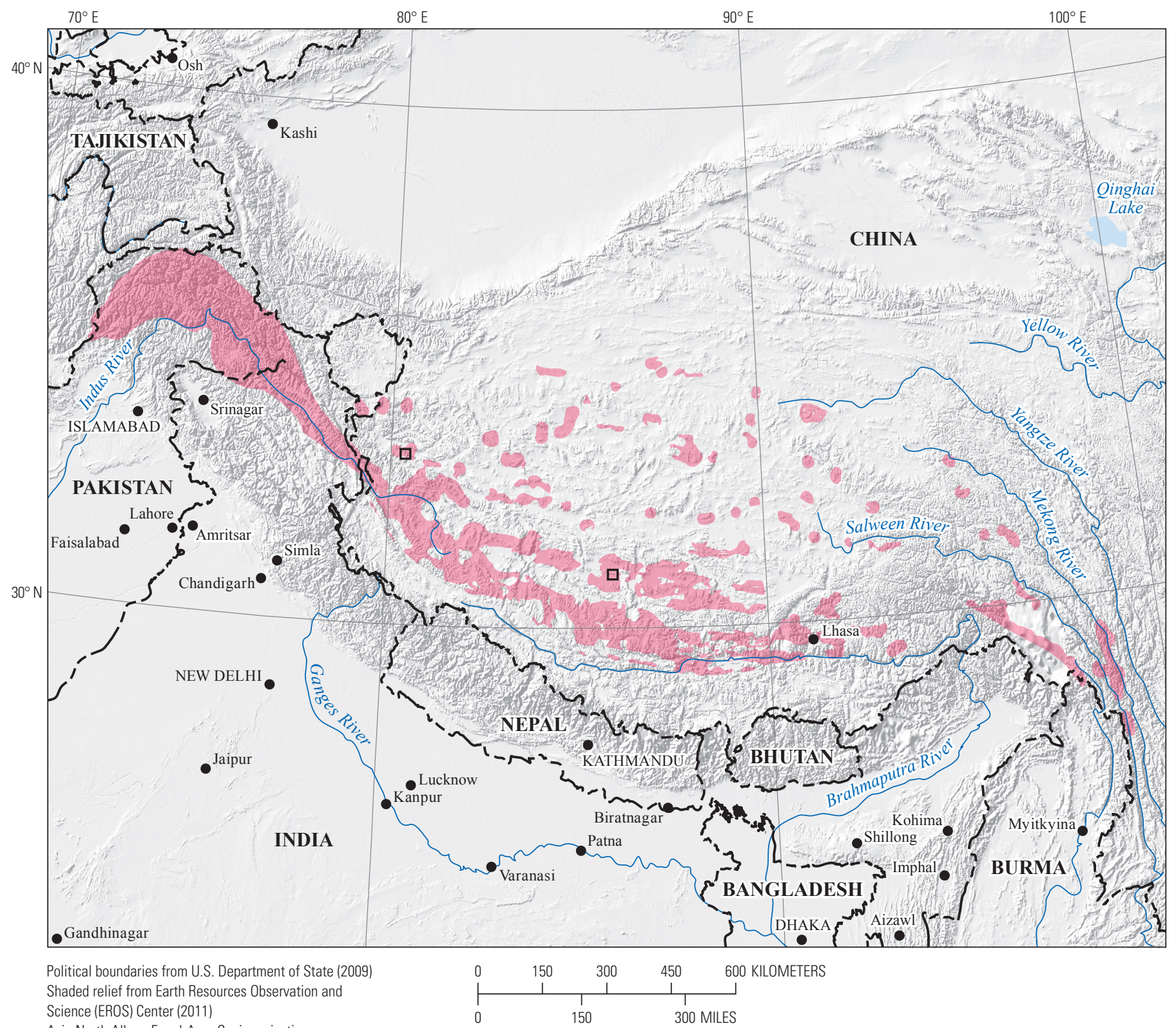

Asia North Albers Equal-Area Conic projection

Central meridian $85^{\circ} \mathrm{E}$.; latitude of origin $30^{\circ} \mathrm{N}$.

\section{EXPLANATION}

Assessed porphyry copper tract 142pCu8706

ㅁ Porphyry copper prospect

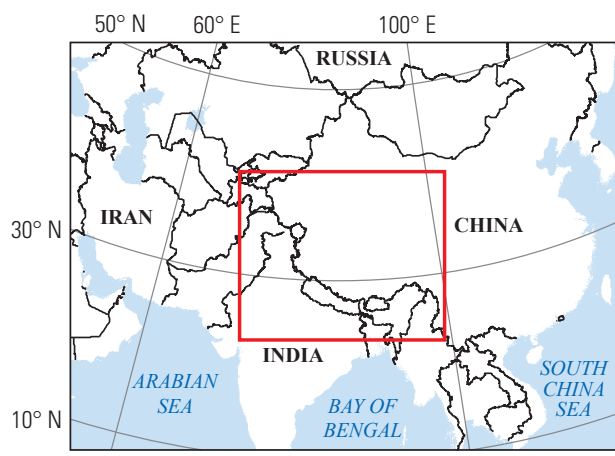




\section{Plate 90. Porphyry Copper Assessment for Tract 142pCu8712, Gangdese-China}

Descriptive model:

Grade and tonnage model:

Economic filter depth percentages:

Economic filter cost setting:

Geologic feature assessed:

Number of known deposits:
Porphyry copper models (Cox, 1986a; John and others, 2010)

General porphyry copper model (Singer, Berger, and Moring, 2008)

Default -0 to 250 meters (m), $25 \%$; $>250$ to $500 \mathrm{~m}, 25 \%$; $>500 \mathrm{~m}$ to $1 \mathrm{~km}, 50 \%$

High cost

A linear belt of Oligocene and Miocene postsubduction igneous rocks in southwestern China 3

\section{Selected Resource Assessment Results for Porphyry Copper}

[Assessment depth, 1 kilometer $(\mathrm{km}) ; \mathrm{km}^{2}$, square kilometer; Mt, millions of metric tons]

\begin{tabular}{ccccccc}
\hline $\begin{array}{c}\text { Date of } \\
\text { assessment }\end{array}$ & $\begin{array}{c}\text { Tract area } \\
\left(\mathbf{k m}^{2}\right)\end{array}$ & $\begin{array}{c}\text { Identified } \\
\text { copper } \\
\text { resources } \\
(\mathbf{M t})\end{array}$ & $\begin{array}{c}\text { Mean estimate of } \\
\text { in-place resources } \\
(\mathbf{M t})\end{array}$ & $\begin{array}{c}\text { Probability of } \mathbf{0} \\
\text { in-place resources } \\
\text { (percent) }\end{array}$ & $\begin{array}{c}\text { Mean estimate of } \\
\text { economic resources } \\
\text { (Mt) }\end{array}$ & $\begin{array}{c}\text { Probability of } \mathbf{0} \\
\text { economic resources } \\
\text { (percent) }\end{array}$ \\
\hline 2010 & 239,860 & 15 & 87 & 1 & 43 \\
\hline
\end{tabular}

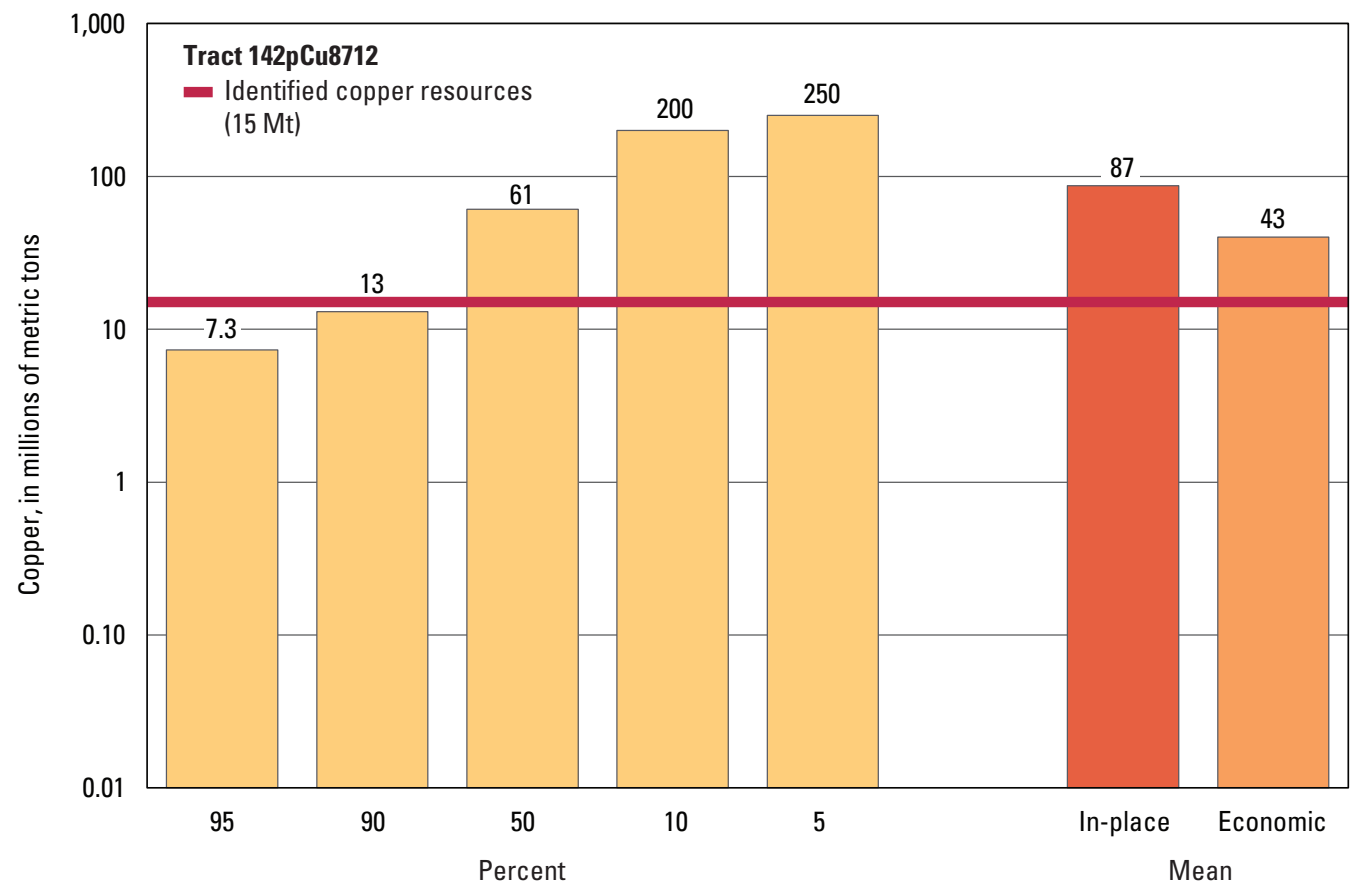

Graph showing the estimated probability distribution of undiscovered copper resources, where each bar represents the minimum amount estimated at the indicated percentage.

\section{Source}

Ludington, Hammarstrom, and others, 2012, Porphyry copper assessment of the Tibetan Plateau, China: U.S. Geological Survey Scientific Investigations Report 2010-5090-F, http://pubs.usgs.gov/sir/2010/5090/f/. 


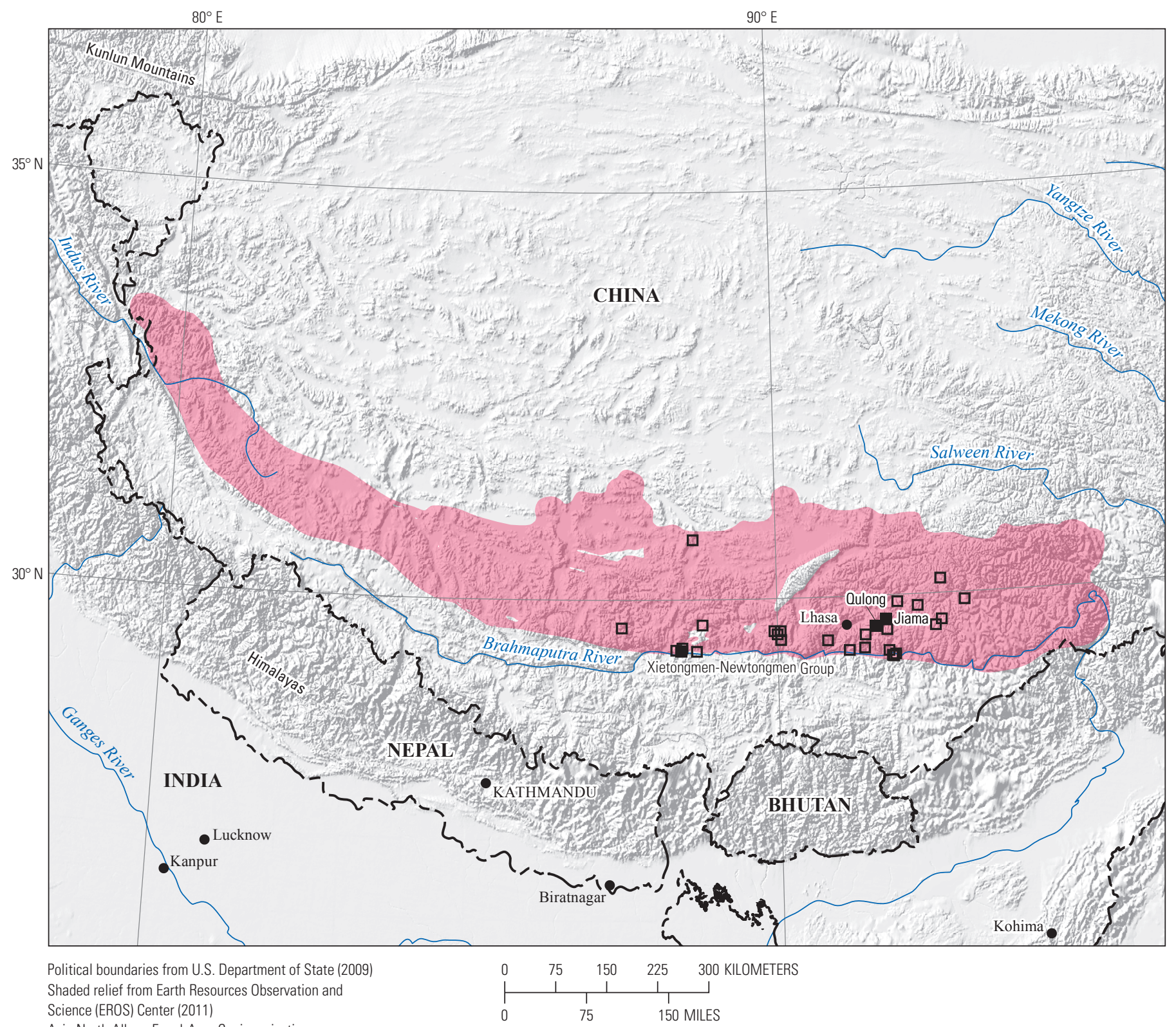

Asia North Albers Equal-Area Conic projection

Central meridian $87^{\circ} 30^{\prime} \mathrm{E}$.; latitude of origin $30^{\circ} \mathrm{N}$.

EXPLANATION

\section{Assessed porphyry copper tract 142pCu8712}

- Porphyry copper deposit

ㅁ Porphyry copper prospect

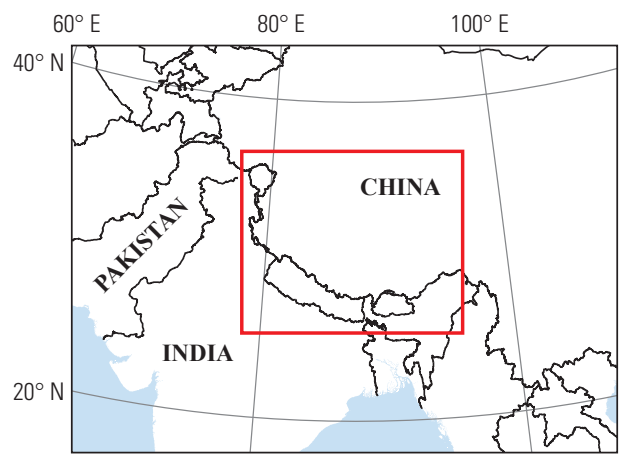




\title{
Plate 91. Porphyry Copper Assessment for Tract 142pCu8702, Jinsajiang- China
}

\author{
Descriptive model: \\ Porphyry copper models (Cox, 1986a; John and others, 2010) \\ Grade and tonnage model: \\ General porphyry copper model (Singer, Berger, and Moring, 2008) \\ Economic filter depth percentages: \\ Economic filter cost setting: \\ Geologic feature assessed: \\ Default -0 to 250 meters (m), $25 \% ;>250$ to $500 \mathrm{~m}, 25 \% ;>500 \mathrm{~m}$ to $1 \mathrm{~km}, 50 \%$ \\ Mixed cost \\ Carboniferous through Triassic rocks that were formed as continental arcs by subduction of the \\ paleo-Tethyan oceanic crust southward below northern Tibet and northward below northern \\ China \\ Number of known deposits: \\ 2
}

\section{Selected Resource Assessment Results for Porphyry Copper}

[Assessment depth, 1 kilometer $(\mathrm{km}) ; \mathrm{km}^{2}$, square kilometer; Mt, millions of metric tons]

\begin{tabular}{ccccccc}
\hline $\begin{array}{c}\text { Date of } \\
\text { assessment }\end{array}$ & $\begin{array}{c}\text { Tract area } \\
\left(\mathbf{k m}^{2}\right)\end{array}$ & $\begin{array}{c}\text { Identified } \\
\text { copper } \\
\text { resources } \\
\text { (Mt) }\end{array}$ & $\begin{array}{c}\text { Mean estimate of } \\
\text { in-place resources } \\
(\mathbf{M t})\end{array}$ & $\begin{array}{c}\text { Probability of } \mathbf{0} \\
\text { in-place resources } \\
\text { (percent) }\end{array}$ & $\begin{array}{c}\text { Mean estimate of } \\
\text { economic resources } \\
\text { (Mt) }\end{array}$ & $\begin{array}{c}\text { Probability of 0 } \\
\text { economic resources } \\
\text { (percent) }\end{array}$ \\
\hline 2013 & 111,687 & 4.5 & 20 & 4 & 12 \\
\hline
\end{tabular}

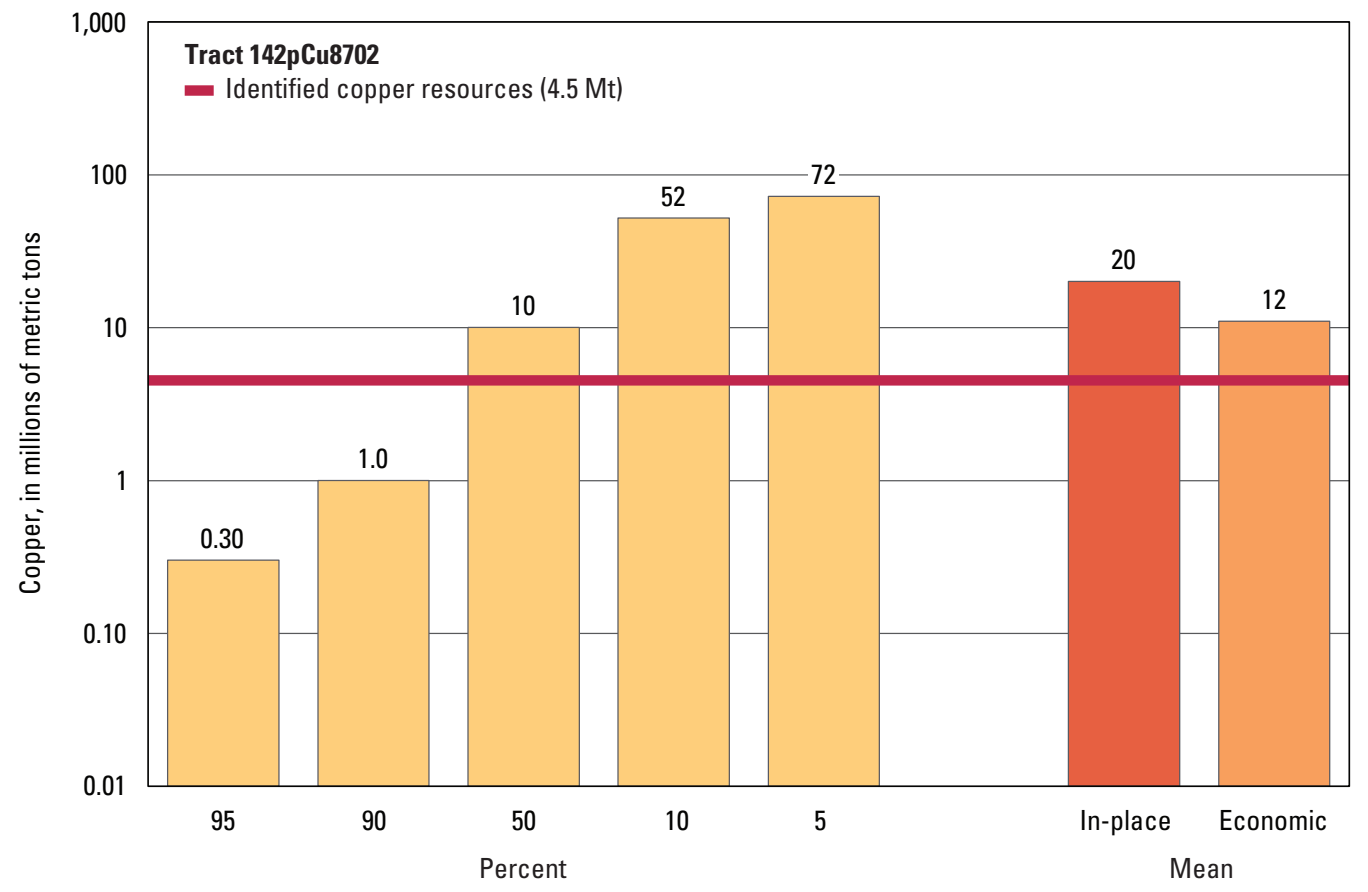

Graph showing the estimated probability distribution of undiscovered copper resources, where each bar represents the minimum amount estimated at the indicated percentage.

\section{Source}

Mihalasky, Ludington, Hammarstrom, and others, 2015, Porphyry copper assessment of the Central Asian Orogenic Belt and eastern Tethysides - China, Mongolia, Russia, Pakistan, Kazakhstan, Tajikistan, and India: U.S. Geological Survey Scientific Investigations Report 2010-5090-X, http://dx.doi.org/10.3133/sir20105090X. 


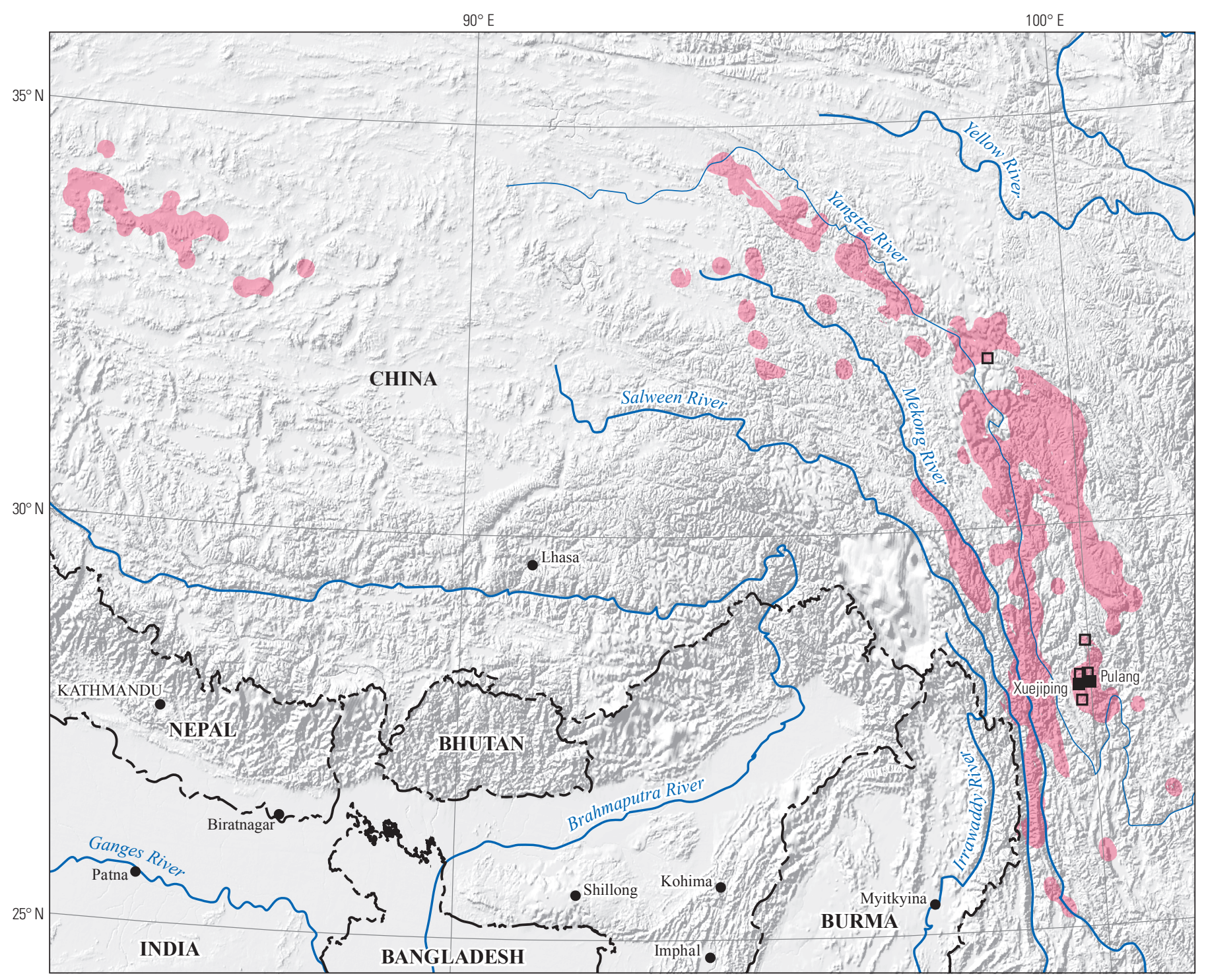

Political boundaries from U.S. Department of State (2009) Shaded relief from Earth Resources Observation and Science (EROS) Center (2011)

Asia North Albers Equal-Area Conic projection

Central meridian $93^{\circ} \mathrm{E}$.; latitude of origin $30^{\circ} \mathrm{N}$.

\section{EXPLANATION}

Assessed porphyry copper tract 142pCu8702

- Porphyry copper deposit

$\square \quad$ Porphyry copper prospect

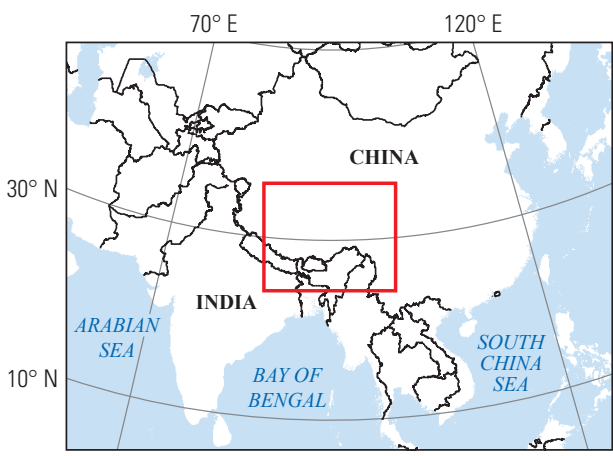




\section{Plate 92. Porphyry Copper Assessment for Tract 142pCu8710, Yulong—China}

Descriptive model:

Grade and tonnage model:

Economic filter depth percentages:

Economic filter cost setting:

Geologic feature assessed:

Number of known deposits:
Porphyry copper models (Cox, 1986a; John and others, 2010)

General porphyry copper model (Singer, Berger, and Moring, 2008)

Default -0 to 250 meters (m), $25 \%$; $>250$ to $500 \mathrm{~m}, 25 \%$; $>500 \mathrm{~m}$ to $1 \mathrm{~km}, 50 \%$

High cost

A curvilinear belt of Eocene postsubduction igneous rocks in southwestern China 6

\section{Selected Resource Assessment Results for Porphyry Copper}

[Assessment depth, 1 kilometer $(\mathrm{km})$; $\mathrm{km}^{2}$, square kilometer; Mt, millions of metric tons]

\begin{tabular}{ccccccc}
\hline $\begin{array}{c}\text { Date of } \\
\text { assessment }\end{array}$ & $\begin{array}{c}\text { Tract area } \\
\left(\mathbf{k m}^{2}\right)\end{array}$ & $\begin{array}{c}\text { Identified } \\
\text { copper } \\
\text { resources } \\
(\mathbf{M t})\end{array}$ & $\begin{array}{c}\text { Mean estimate of } \\
\text { in-place resources } \\
(\mathbf{M t})\end{array}$ & $\begin{array}{c}\text { Probability of } \mathbf{0} \\
\text { in-place resources } \\
\text { (percent) }\end{array}$ & $\begin{array}{c}\text { Mean estimate of } \\
\text { economic resources } \\
\text { (Mt) }\end{array}$ & $\begin{array}{c}\text { Probability of 0 } \\
\text { economic resources } \\
\text { (percent) }\end{array}$ \\
\hline 2010 & 112,470 & 11 & 32 & 3 & 16 \\
\hline
\end{tabular}

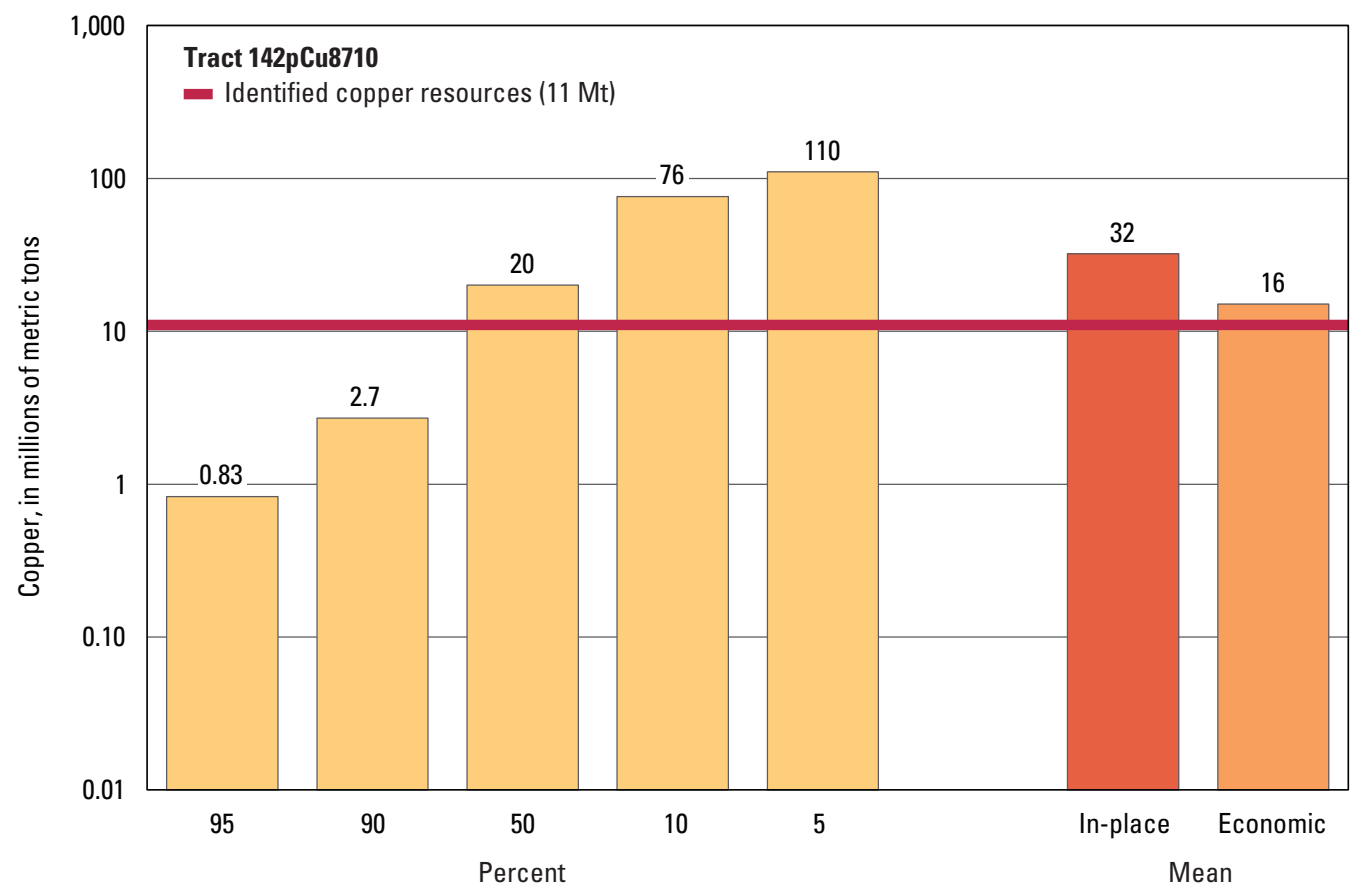

Graph showing the estimated probability distribution of undiscovered copper resources, where each bar represents the minimum amount estimated at the indicated percentage.

\section{Source}

Ludington, Hammarstrom, and others, 2012, Porphyry copper assessment of the Tibetan Plateau, China: U.S. Geological Survey Scientific Investigations Report 2010-5090-F, http://pubs.usgs.gov/sir/2010/5090/f/. 


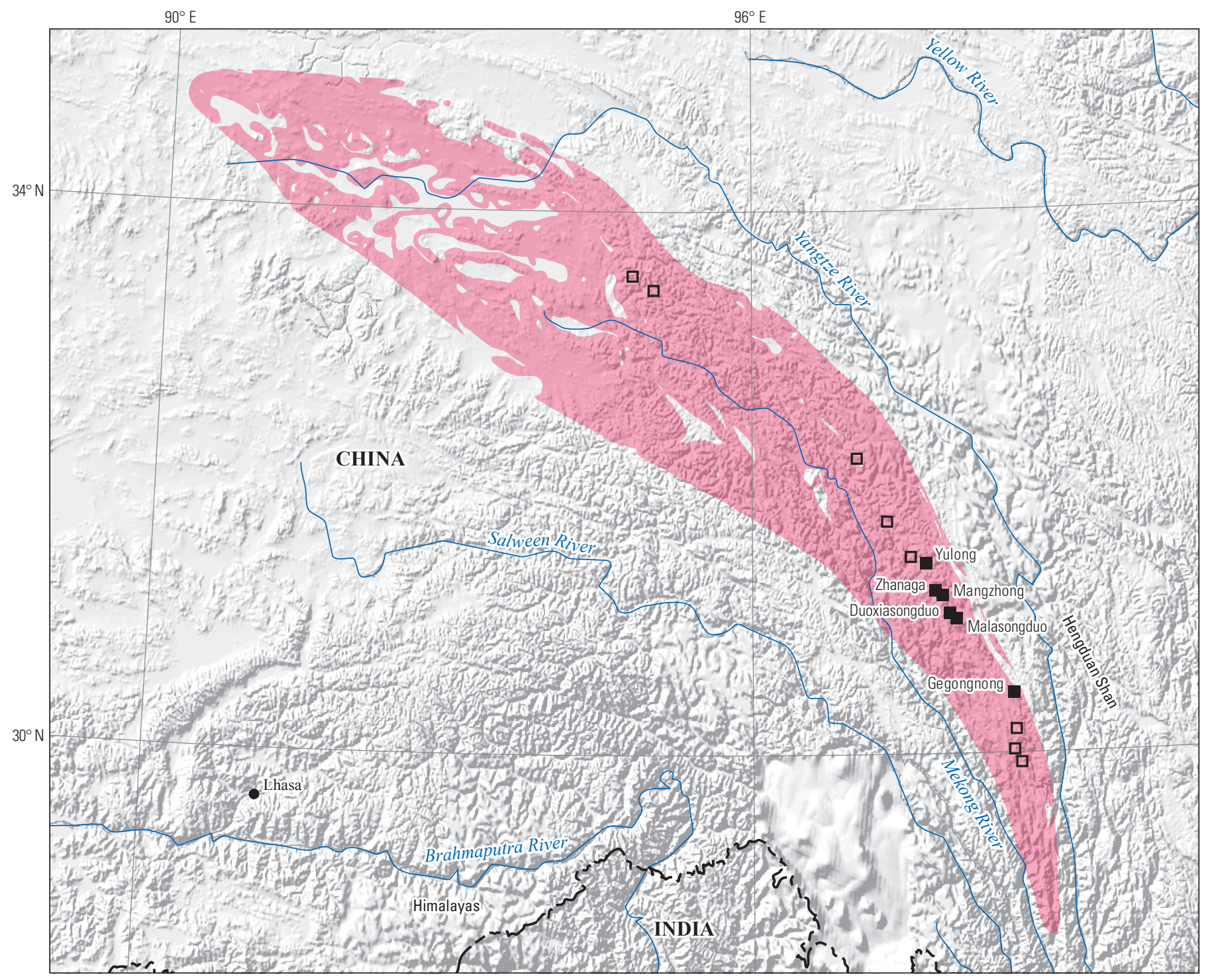

Political boundaries from U.S. Department of State (2009) Shaded relief from Earth Resources Observation and Science (EROS) Center (2011)

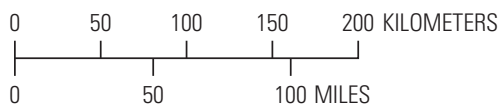

Asia North Albers Equal-Area Conic projection

Central meridian $95^{\circ} 30^{\prime} \mathrm{E}$.; latitude of origin $30^{\circ} \mathrm{N}$.

\section{EXPLANATION}

\section{Assessed porphyry copper tract 142pCu8710}

- Porphyry copper deposit

$\square \quad$ Porphyry copper prospect

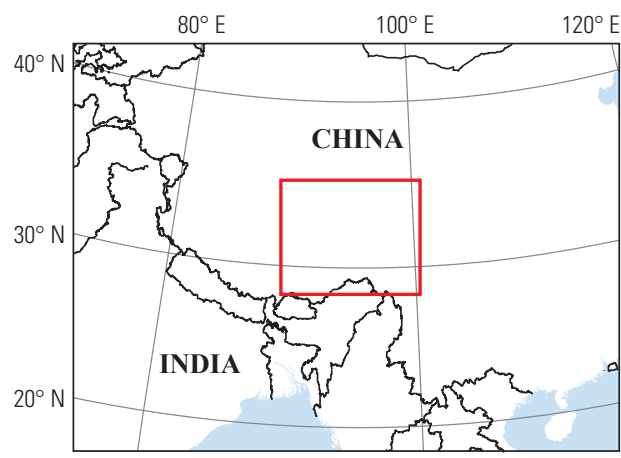




\section{Plate 93. Porphyry Copper Assessment for Tract 142pCu8711, Dali-China and Vietnam}

\section{Descriptive model:}

Grade and tonnage model:

Economic filter depth percentages:

Economic filter cost setting:

Geologic feature assessed:

Number of known deposits:
Porphyry copper models (Cox, 1986a; John and others, 2010)

Porphyry copper, copper-gold subtype model (Singer, Berger, and Moring, 2008)

Default -0 to 250 meters (m), $25 \%$; $>250$ to $500 \mathrm{~m}, 25 \%$; $>500 \mathrm{~m}$ to $1 \mathrm{~km}, 50 \%$

High cost

An assemblage of Eocene and Oligocene postsubduction igneous rocks in southwestern China 2

\section{Selected Resource Assessment Results for Porphyry Copper}

[Assessment depth, 1 kilometer $(\mathrm{km}) ; \mathrm{km}^{2}$, square kilometer; $\mathrm{Mt}$, millions of metric tons]

\begin{tabular}{ccccccc}
\hline $\begin{array}{c}\text { Date of } \\
\text { assessment }\end{array}$ & $\begin{array}{c}\text { Tract area } \\
\left(\mathbf{k m}^{2}\right)\end{array}$ & $\begin{array}{c}\text { Identified } \\
\text { copper } \\
\text { resources } \\
(\mathbf{M t})\end{array}$ & $\begin{array}{c}\text { Mean estimate of } \\
\text { in-place resources } \\
(\mathbf{M t})\end{array}$ & $\begin{array}{c}\text { Probability of } \mathbf{0} \\
\text { in-place resources } \\
\text { (percent) }\end{array}$ & $\begin{array}{c}\text { Mean estimate of } \\
\text { economic resources } \\
\text { (Mt) }\end{array}$ & $\begin{array}{c}\text { Probability of } \mathbf{0} \\
\text { economic resources } \\
\text { (percent) }\end{array}$ \\
\hline 2010 & 96,670 & 0.49 & 26 & 4 & 12 \\
\hline
\end{tabular}

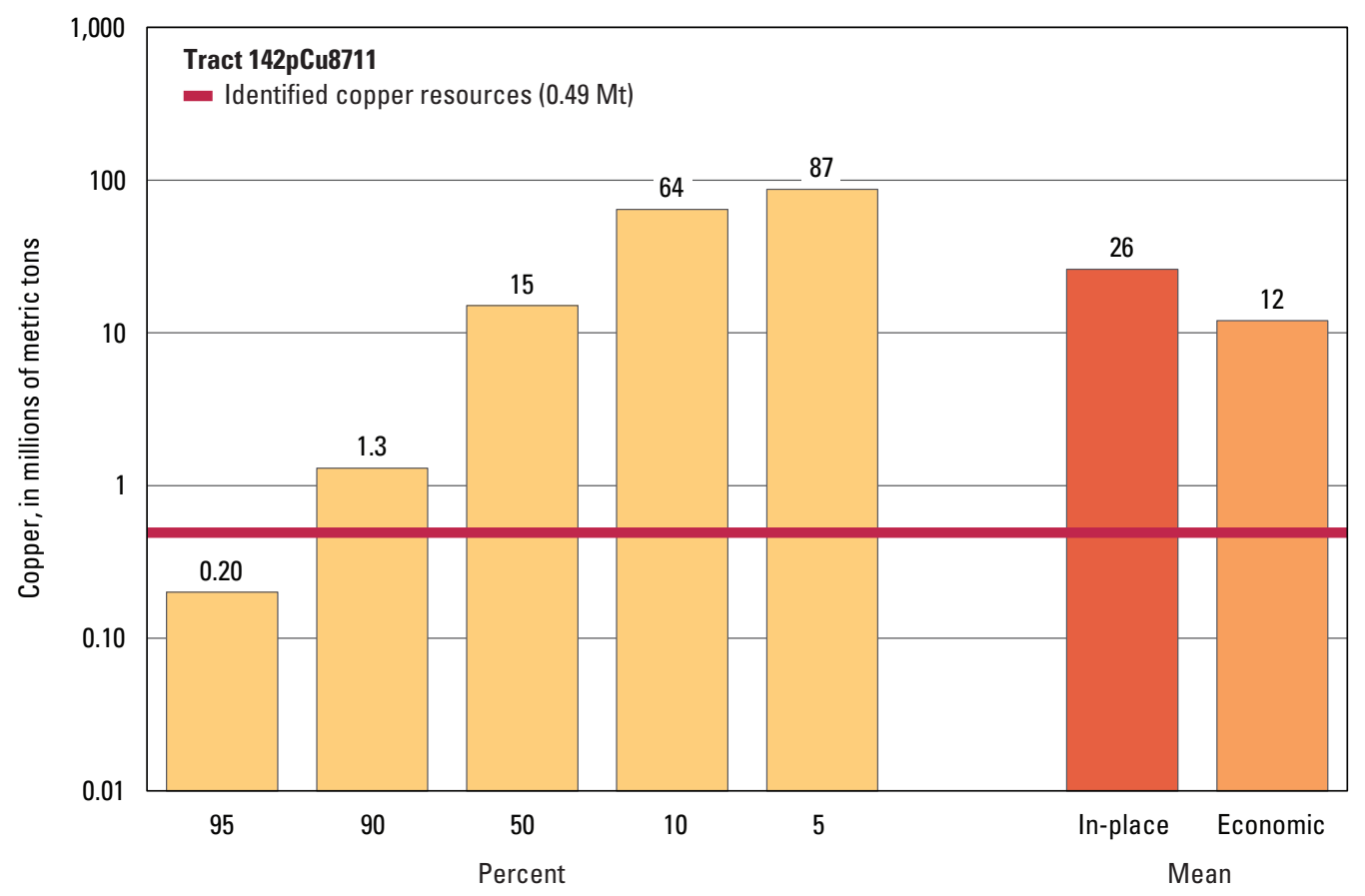

Graph showing the estimated probability distribution of undiscovered copper resources, where each bar represents the minimum amount estimated at the indicated percentage.

\section{Source}

Ludington, Hammarstrom, and others, 2012, Porphyry copper assessment of the Tibetan Plateau, China: U.S. Geological Survey Scientific Investigations Report 2010-5090-F, http:/pubs.usgs.gov/sir/2010/5090/f/. 

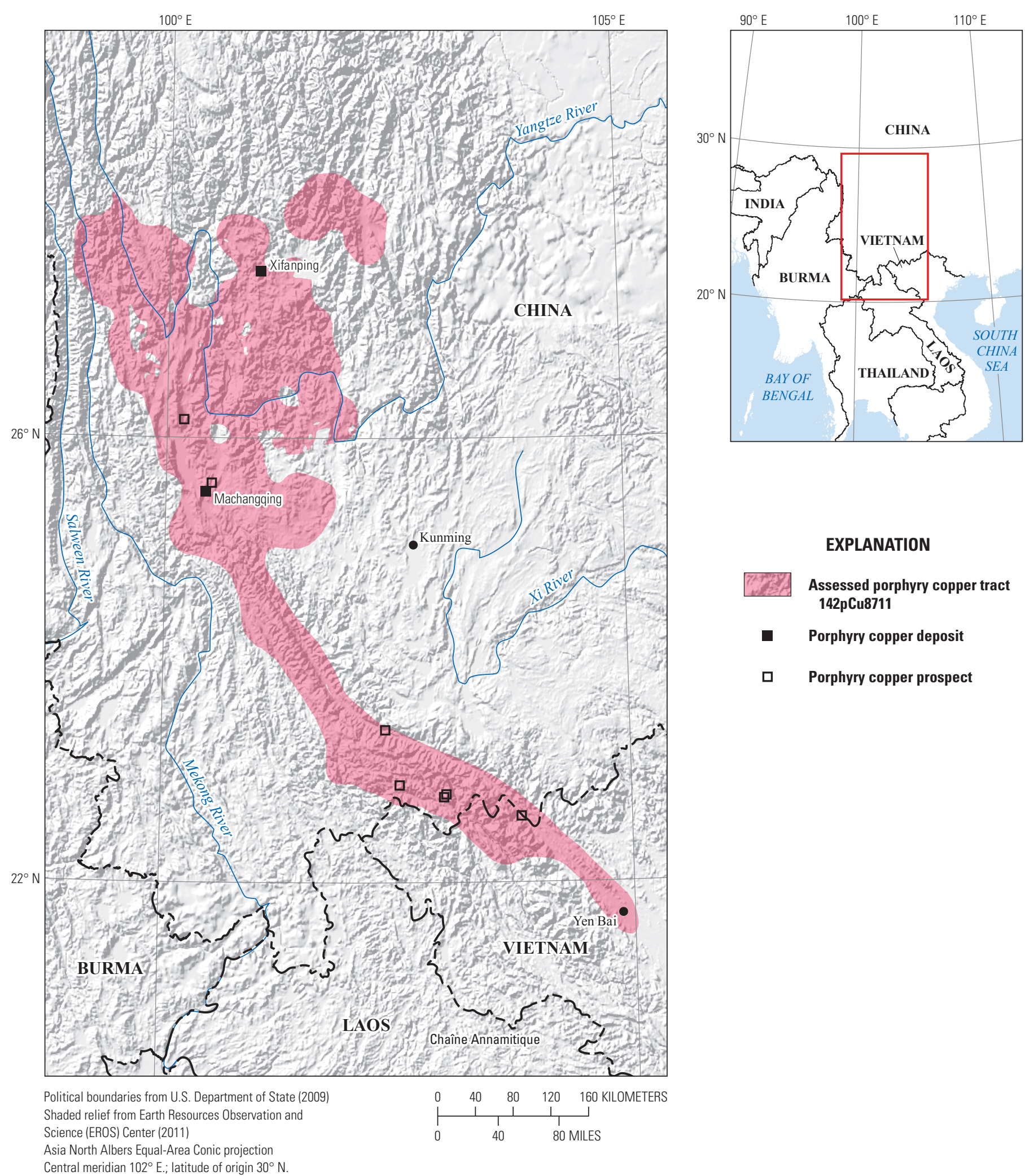

\section{EXPLANATION}

Assessed porphyry copper tract 142pCu8711

- Porphyry copper deposit

Porphyry copper prospect 


\section{Plate 94. Porphyry Copper Assessment for Tract 142pCu7024, Wuntho-Popa- Burma}

Descriptive model:

Grade and tonnage model:

Economic filter depth percentages:

Economic filter cost setting:

Geologic feature assessed:

Number of known deposits:
Porphyry copper models (Cox, 1986a; Berger and others, 2008; John and others, 2010)

General porphyry copper model (Singer, Berger, and Moring, 2008)

Skewed deep - 0 to 250 meters (m), 10\%; > 250 to $500 \mathrm{~m}, 30 \%$; >500 m to $1 \mathrm{~km}, 60 \%$

High cost

A linear belt of Late Cretaceous through Holocene volcanic rocks related to subduction of the Indian Ocean Plate below Indochina

1

\section{Selected Resource Assessment Results for Porphyry Copper}

[Assessment depth, 1 kilometer (km); $\mathrm{km}^{2}$, square kilometer; Mt, millions of metric tons]

\begin{tabular}{ccccccc}
\hline $\begin{array}{c}\text { Date of } \\
\text { assessment }\end{array}$ & $\begin{array}{c}\text { Tract area } \\
\left(\mathbf{k m}^{2}\right)\end{array}$ & $\begin{array}{c}\text { Identified } \\
\text { copper } \\
\text { resources } \\
\text { (Mt) }\end{array}$ & $\begin{array}{c}\text { Mean estimate of } \\
\text { in-place resources } \\
(\mathbf{M t})\end{array}$ & $\begin{array}{c}\text { Probability of } \mathbf{0} \\
\text { in-place resources } \\
\text { (percent) }\end{array}$ & $\begin{array}{c}\text { Mean estimate of } \\
\text { economic resources } \\
\text { (Mt) }\end{array}$ & $\begin{array}{c}\text { Probability of 0 } \\
\text { economic resources } \\
\text { (percent) }\end{array}$ \\
\hline 2010 & 45,257 & 6.3 & 8.8 & 29 & 4.0 \\
\hline
\end{tabular}

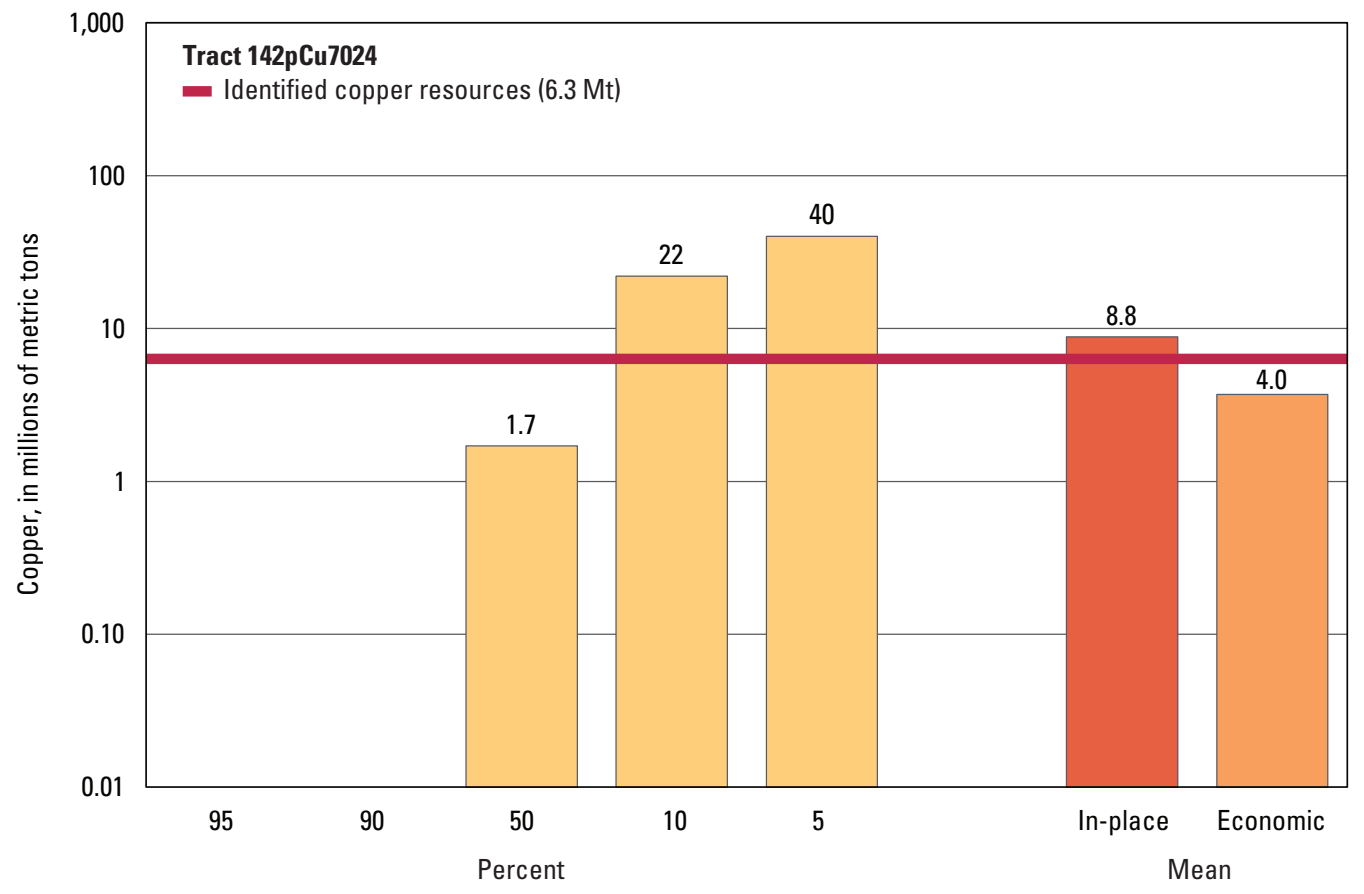

Graph showing the estimated probability distribution of undiscovered copper resources, where each bar represents the minimum amount estimated at the indicated percentage.

\section{Source}

Hammarstrom, Bookstrom, Dicken, and others, 2013, Porphyry copper assessment of Southeast Asia and Melanesia: U.S. Geological Survey Scientific Investigations Report 2010-5090-D, http://pubs.usgs.gov/sir/2010/5090/d/. 


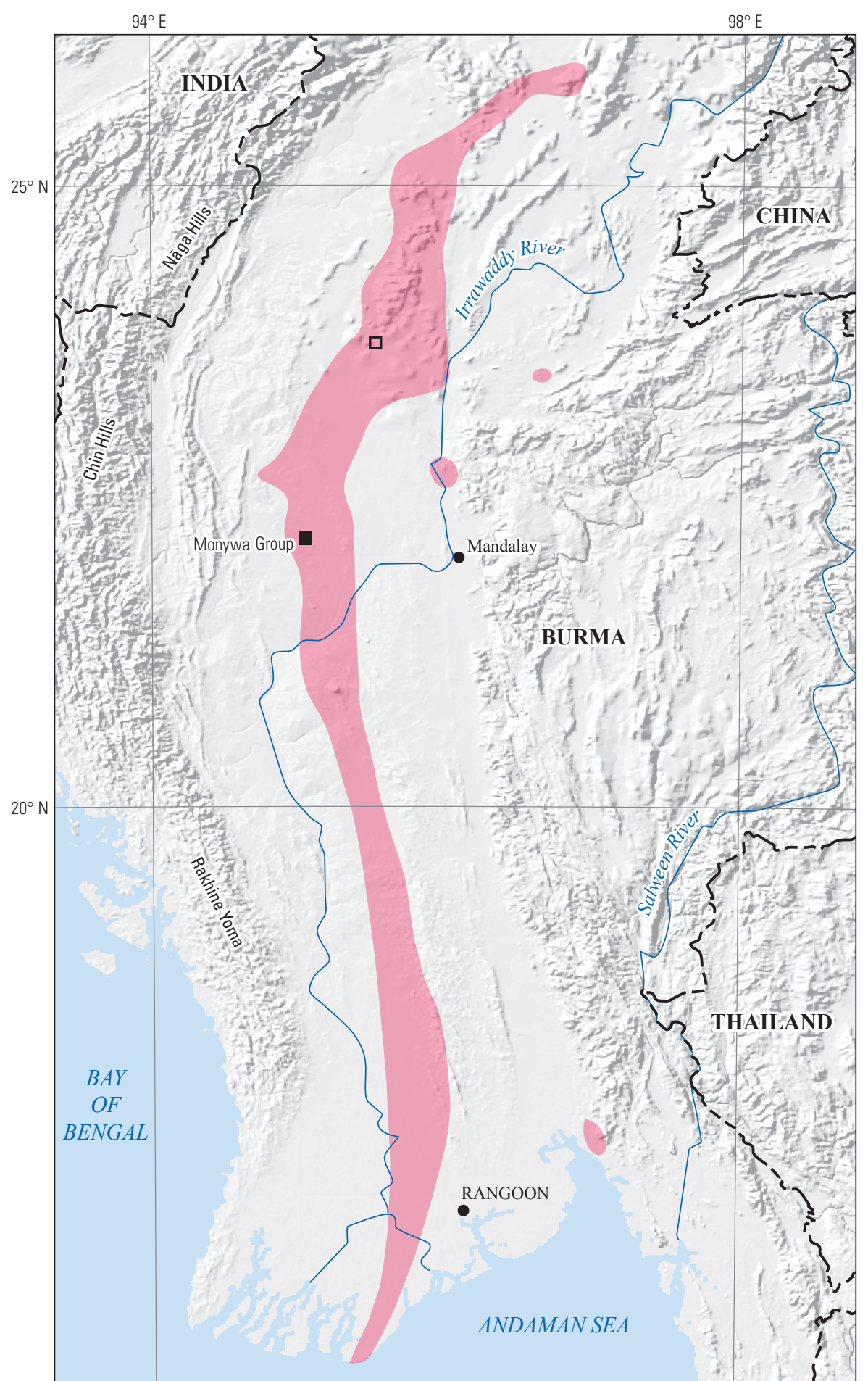

Political boundaries from U.S. Department of State (2009) Shaded relief from Earth Resources Observation and Science (EROS) Center (2011)

Asia South Albers Equal-Area Conic projection

Central meridian $95^{\circ} 30^{\prime} \mathrm{E}$.; latitude of origin $15^{\circ} \mathrm{S}$.

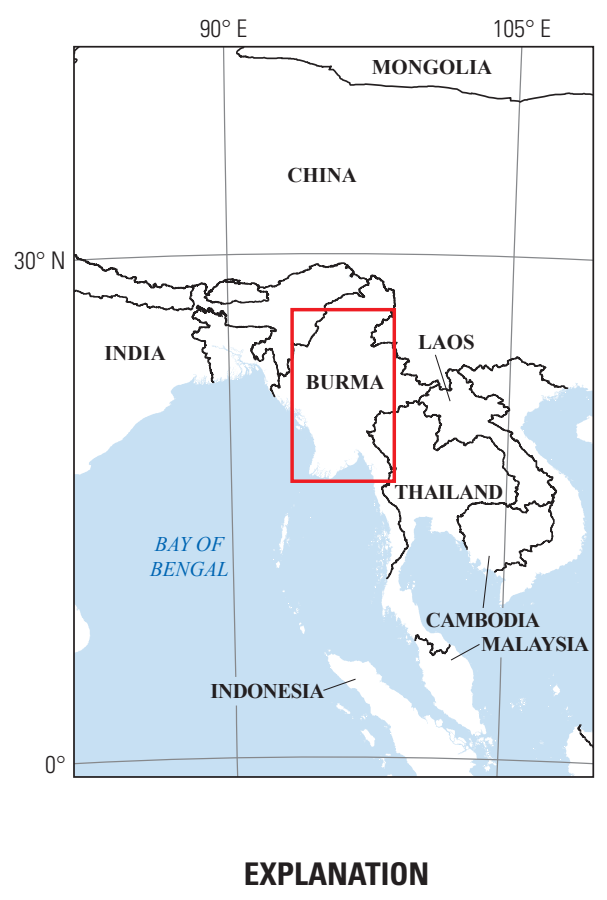

Assessed porphyry copper tract 142pCu7024

- Porphyry copper deposit

口 Porphyry copper prospect 


\section{Plate 95. Porphyry Copper Assessment for Tract 142pCu7021, Sukhothai- Cambodia, China, Laos, Burma, Thailand, and Vietnam}

Descriptive model:

Grade and tonnage model:

Economic filter depth percentages:

Economic filter cost setting:

Geologic feature assessed:

Number of known deposits:
Porphyry copper models (Berger and others, 2008; John and others, 2010); porphyry copper-gold models (Cox, 1986b; Cooke and others, 1998)

Porphyry copper, copper-gold subtype model (Singer, Berger, and Moring, 2008)

Default -0 to 250 meters (m), 25\%; > 250 to $500 \mathrm{~m}, 25 \%$; $>500 \mathrm{~m}$ to $1 \mathrm{~km}, 50 \%$

High cost

Carboniferous through Triassic island and continental arcs formed by subduction of paleo-Tethyan oceanic crust (the Loei and Truongson volcanic arcs)

\section{Selected Resource Assessment Results for Porphyry Copper}

[Assessment depth, 1 kilometer $(\mathrm{km}) ; \mathrm{km}^{2}$, square kilometer; Mt, millions of metric tons]

\begin{tabular}{|c|c|c|c|c|c|c|}
\hline \multirow[b]{2}{*}{$\begin{array}{c}\text { Date of } \\
\text { assessment }\end{array}$} & \multirow[b]{2}{*}{$\begin{array}{c}\text { Tract area } \\
\quad\left(\mathbf{k m}^{2}\right)\end{array}$} & \multirow{2}{*}{$\begin{array}{l}\text { Identified } \\
\text { copper } \\
\text { resources } \\
\text { (Mt) }\end{array}$} & \multicolumn{4}{|c|}{ Undiscovered copper resource estimates } \\
\hline & & & $\begin{array}{l}\text { Mean estimate of } \\
\text { in-place resources } \\
\text { (Mt) }\end{array}$ & $\begin{array}{c}\text { Probability of } 0 \\
\text { in-place resources } \\
\text { (percent) }\end{array}$ & $\begin{array}{l}\text { Mean estimate of } \\
\text { economic resources } \\
\text { (Mt) }\end{array}$ & $\begin{array}{c}\text { Probability of } 0 \\
\text { economic resources } \\
\text { (percent) }\end{array}$ \\
\hline 2010 & 354,260 & 1.2 & 37 & 3 & 18 & 20 \\
\hline
\end{tabular}

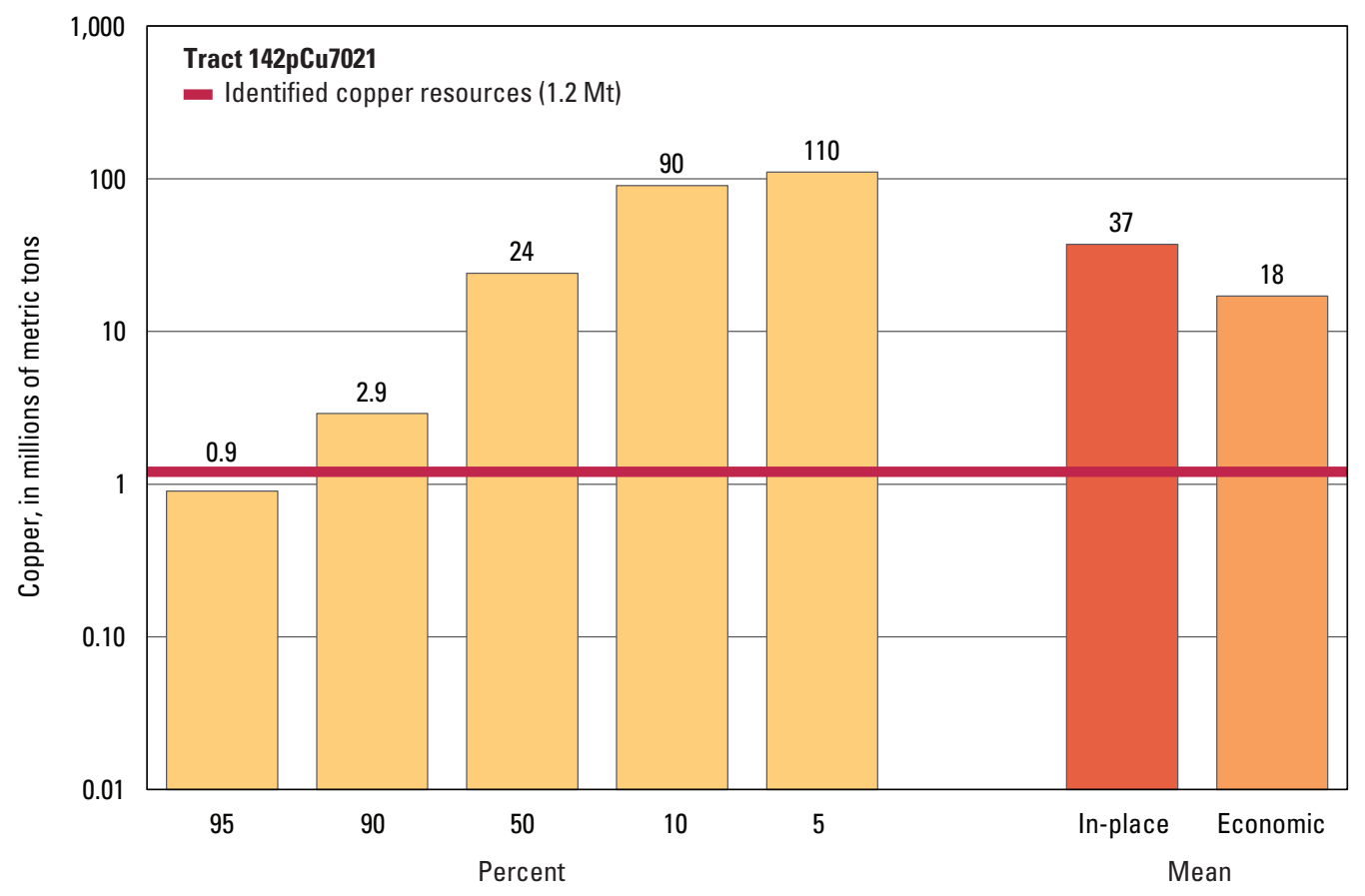

Graph showing the estimated probability distribution of undiscovered copper resources, where each bar represents the minimum amount estimated at the indicated percentage.

\section{Source}

Hammarstrom, Bookstrom, Dicken, and others, 2013, Porphyry copper assessment of Southeast Asia and Melanesia: U.S. Geological Survey Scientific Investigations Report 2010-5090-D, http://pubs.usgs.gov/sir/2010/5090/d/. 


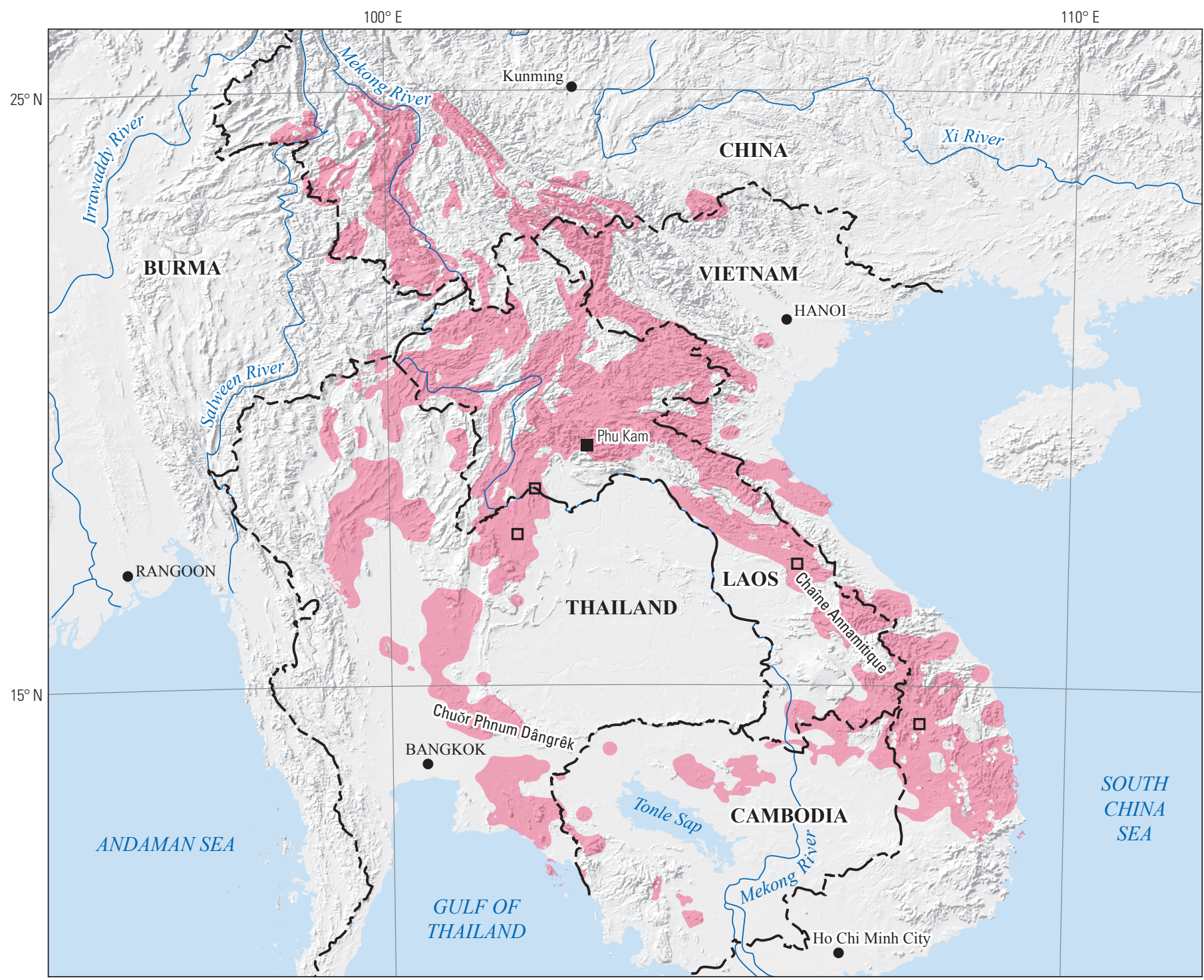

Political boundaries from U.S. Department of State (2009) Shaded relief from Earth Resources Observation and Science (EROS) Center (2011)

Asia South Albers Equal-Area Conic projection Central meridian $104^{\circ} \mathrm{E} . ;$ latitude of origin $15^{\circ} \mathrm{S}$.

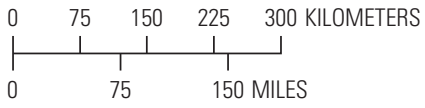

PorpLANATION




\title{
Plate 96. Porphyry Copper Assessment for Tract 142pCu7023, Mekong Delta- Cambodia, Laos, and Vietnam
}

\author{
Descriptive model: \\ Grade and tonnage model: \\ Porphyry copper models (Cox, 1986a; Berger and others, 2008; John and others, 2010) \\ Economic filter depth percentages: \\ Economic filter cost setting: \\ Geologic feature assessed: \\ General porphyry copper model (Singer, Berger, and Moring, 2008) \\ Default - 0 to 250 meters (m), 25\%; > 250 to $500 \mathrm{~m}, 25 \%$; >500 m to $1 \mathrm{~km}, 50 \%$ \\ High cost \\ A group of Jurassic and Cretaceous intrusive and volcanic rocks that are the result of subduction of \\ the Pacific Plate beneath southern Indochina \\ Number of known deposits: \\ 0
}

\section{Selected Resource Assessment Results for Porphyry Copper}

[Assessment depth, 1 kilometer ( $\mathrm{km}) ; \mathrm{km}^{2}$, square kilometer; Mt, millions of metric tons]

\begin{tabular}{ccccccc}
\hline $\begin{array}{c}\text { Date of } \\
\text { assessment }\end{array}$ & $\begin{array}{c}\text { Tract area } \\
\left.\mathbf{( k m}^{2}\right)\end{array}$ & $\begin{array}{c}\text { Identified } \\
\text { copper } \\
\text { resources } \\
\text { (Mt) }\end{array}$ & $\begin{array}{c}\text { Mean estimate of } \\
\text { in-place resources } \\
(\mathbf{M t})\end{array}$ & $\begin{array}{c}\text { Probability of } \mathbf{0} \\
\text { in-place resources } \\
\text { (percent) }\end{array}$ & $\begin{array}{c}\text { Mean estimate of } \\
\text { economic resources } \\
\text { (Mt) }\end{array}$ & $\begin{array}{c}\text { Probability of 0 } \\
\text { economic resources } \\
\text { (percent) }\end{array}$ \\
\hline 2010 & 91,216 & 0 & 28 & 6 & 14 \\
\hline
\end{tabular}

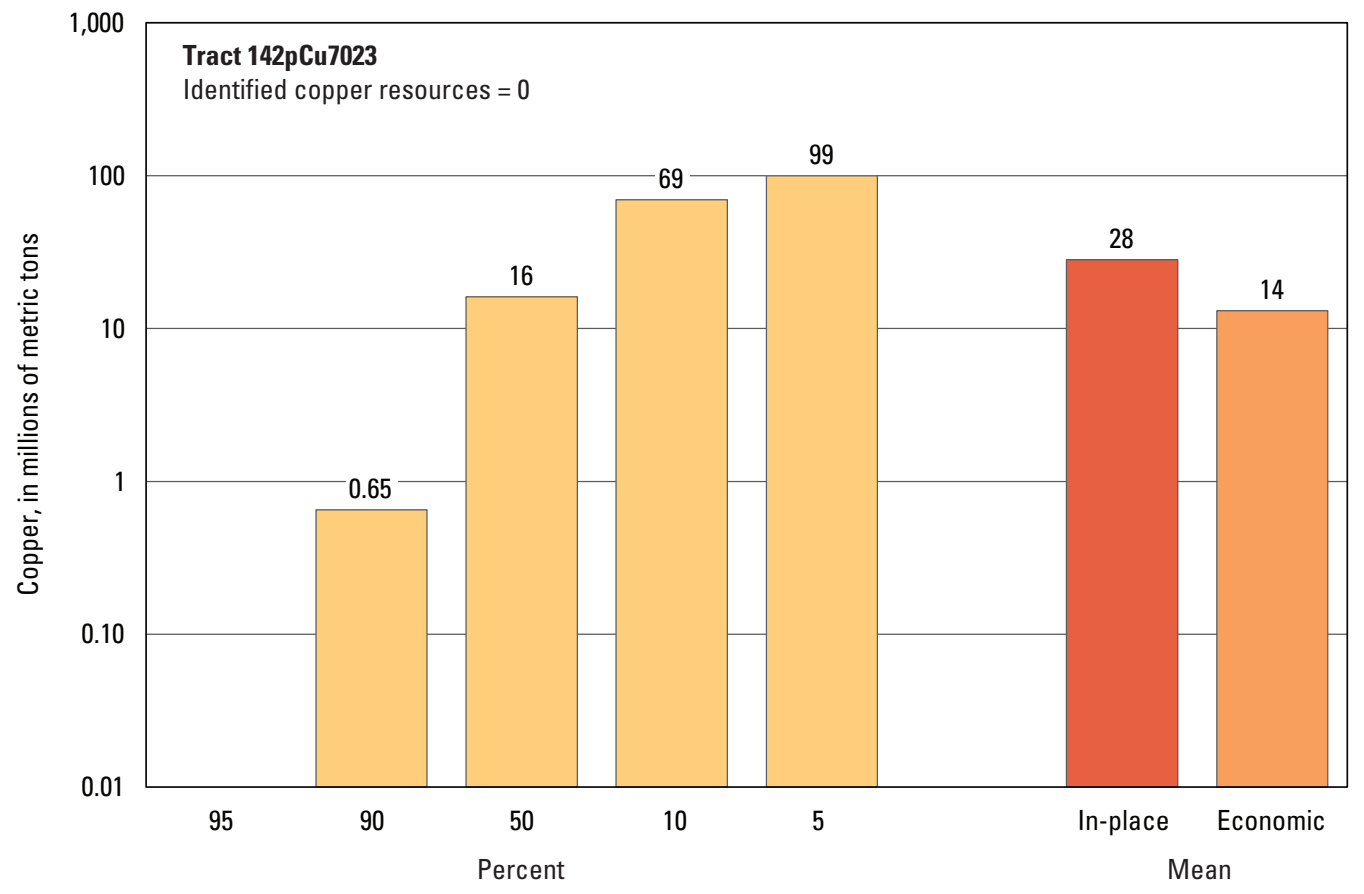

Graph showing the estimated probability distribution of undiscovered copper resources, where each bar represents the minimum amount estimated at the indicated percentage.

\section{Source}

Hammarstrom, Bookstrom, Dicken, and others, 2013, Porphyry copper assessment of Southeast Asia and Melanesia: U.S. Geological Survey Scientific Investigations Report 2010-5090-D, http://pubs.usgs.gov/sir/2010/5090/d/. 


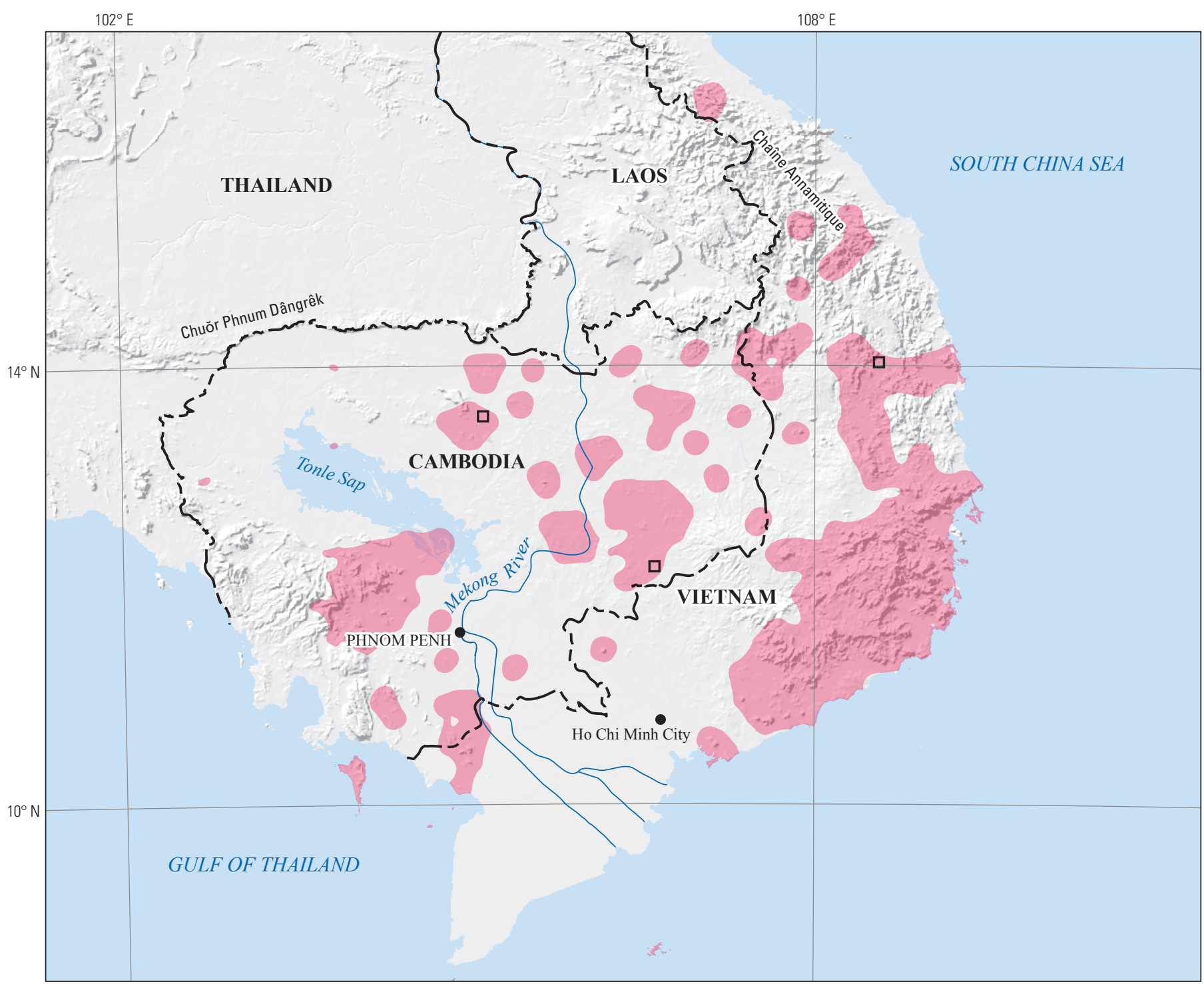

Political boundaries from U.S. Department of State (2009) Shaded relief from Earth Resources Observation and Science (EROS) Center (2011)

Asia South Albers Equal-Area Conic projection

Central meridian $107^{\circ} \mathrm{E}$. ; latitude of origin $15^{\circ} \mathrm{S}$.

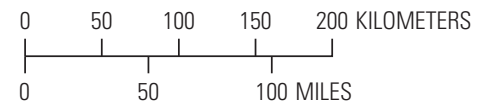

\section{EXPLANATION}

Assessed porphyry copper tract 142pCu7023

$\square \quad$ Porphyry copper prospect

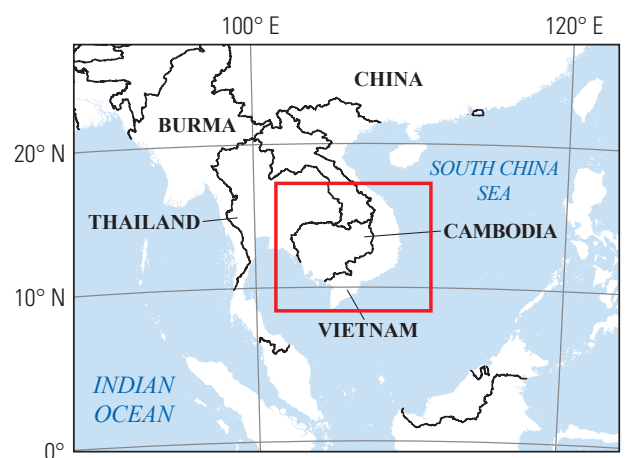




\section{Plate 97. Porphyry Copper Assessment for Tract 142pCu7022, Malaysia- Indonesia, Malaysia, Singapore, and Thailand}

Descriptive model:

Grade and tonnage model:

Economic filter depth percentages:

Economic filter cost setting:

Geologic feature assessed:

Number of known deposits:
Porphyry copper models (Berger and others, 2008; John and others, 2010); porphyry copper-gold models (Cox, 1986b; Cooke and others, 1998)

Porphyry copper, copper-gold subtype model (Singer, Berger, and Moring, 2008)

Default - 0 to 250 meters (m), 25\%; > 250 to $500 \mathrm{~m}, 25 \%$; $>500 \mathrm{~m}$ to $1 \mathrm{~km}, 50 \%$

High cost

Assemblage of Carboniferous through Triassic rocks formed as both island arcs and continental arcs by subduction of paleo-Tethyan oceanic crust below the East Malaya terrane

\section{Selected Resource Assessment Results for Porphyry Copper}

[Assessment depth, 1 kilometer $(\mathrm{km}) ; \mathrm{km}^{2}$, square kilometer; Mt, millions of metric tons]

\begin{tabular}{|c|c|c|c|c|c|c|}
\hline \multirow[b]{2}{*}{$\begin{array}{c}\text { Date of } \\
\text { assessment }\end{array}$} & \multirow[b]{2}{*}{$\begin{array}{c}\text { Tract area } \\
\quad\left(\mathbf{k m}^{2}\right)\end{array}$} & \multirow{2}{*}{$\begin{array}{l}\text { Identified } \\
\text { copper } \\
\text { resources } \\
\text { (Mt) }\end{array}$} & \multicolumn{4}{|c|}{ Undiscovered copper resource estimates } \\
\hline & & & $\begin{array}{l}\text { Mean estimate of } \\
\text { in-place resources } \\
\text { (Mt) }\end{array}$ & $\begin{array}{c}\text { Probability of } 0 \\
\text { in-place resources } \\
\text { (percent) }\end{array}$ & $\begin{array}{l}\text { Mean estimate of } \\
\text { economic resources } \\
\text { (Mt) }\end{array}$ & $\begin{array}{c}\text { Probability of } 0 \\
\text { economic resources } \\
\text { (percent) }\end{array}$ \\
\hline 2010 & 60,010 & 0.81 & 8.9 & 6 & 4.3 & 68 \\
\hline
\end{tabular}

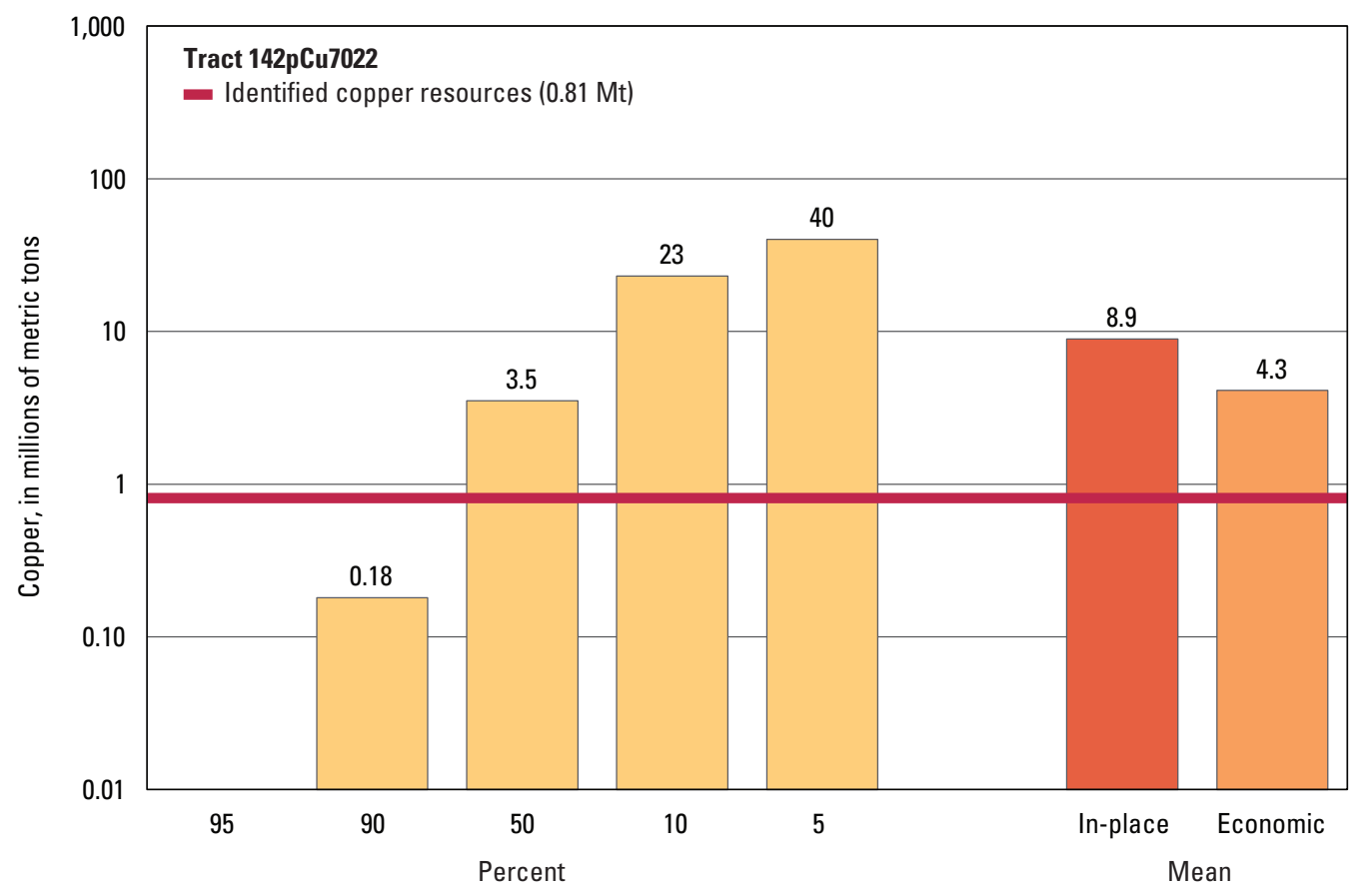

Graph showing the estimated probability distribution of undiscovered copper resources, where each bar represents the minimum amount estimated at the indicated percentage.

\section{Source}

Hammarstrom, Bookstrom, Dicken, and others, 2013, Porphyry copper assessment of Southeast Asia and Melanesia: U.S. Geological Survey Scientific Investigations Report 2010-5090-D, http://pubs.usgs.gov/sir/2010/5090/d/. 

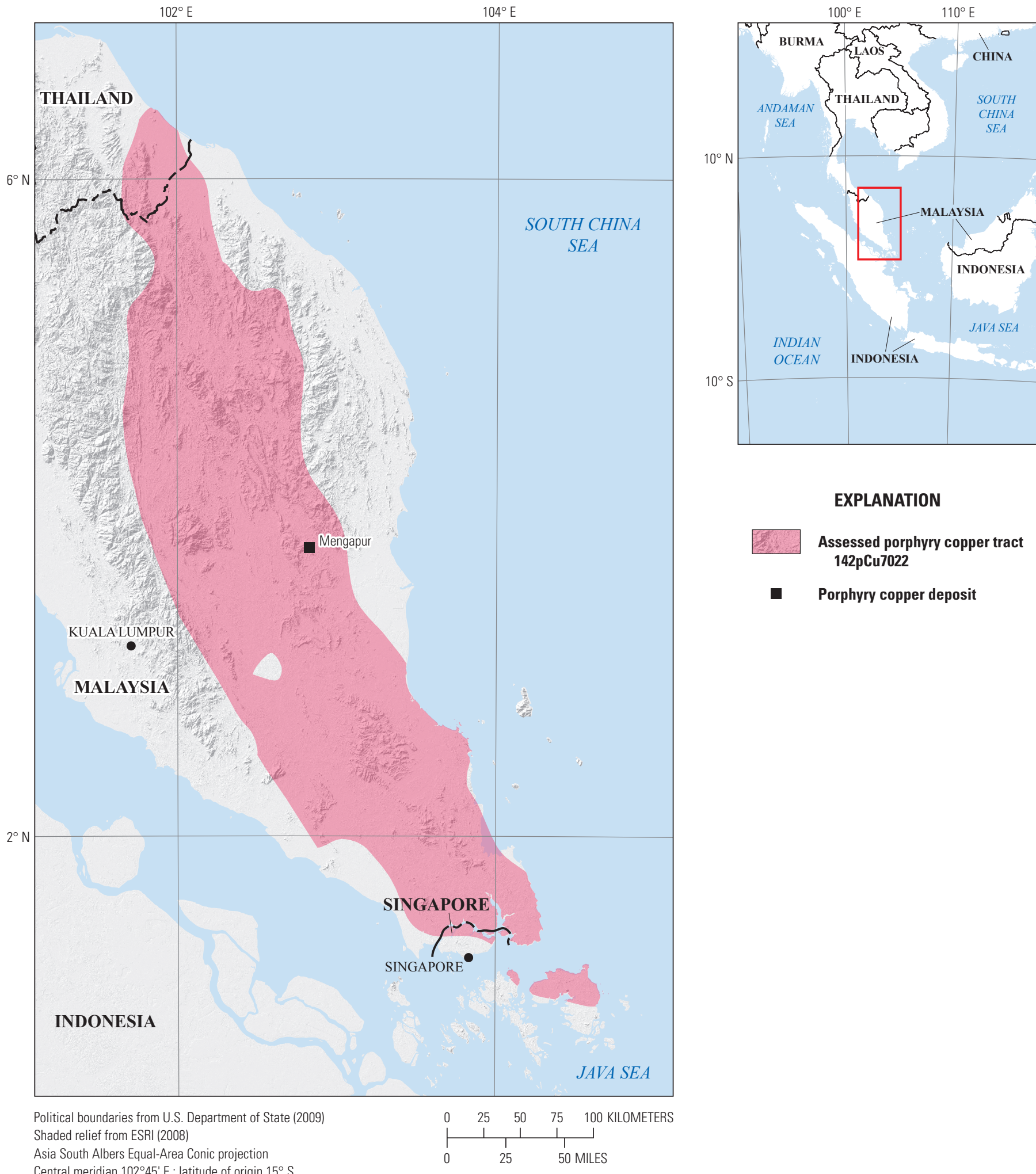

EXPLANATION

Assessed porphyry copper tract 142pCu7022

- Porphyry copper deposit

Asia South Albers Equal-Area Conic projection

Central meridian $102^{\circ} 45^{\prime} \mathrm{E}$; latitude of origin $15^{\circ} \mathrm{S}$ 


\title{
Plate 98. Porphyry Copper Assessment for Tract 142pCu7301abcd, Luzon Arc- Philippines and Taiwan
}

\author{
Descriptive model: \\ Grade and tonnage model: \\ Economic filter depth percentages: \\ Economic filter cost setting: \\ Geologic feature assessed: \\ Number of known deposits:
}

\author{
Porphyry copper models (Berger and others, 2008; John and others, 2010); porphyry copper-gold \\ models (Cox, 1986b; Cooke and others, 1998) \\ Porphyry copper, copper-gold subtype model (Singer, Berger, and Moring, 2008) \\ Default -0 to 250 meters (m), 25\%; > 250 to $500 \mathrm{~m}, 25 \%$; >500 m to $1 \mathrm{~km}, 50 \%$ \\ High cost \\ Oligocene to Holocene Luzon arc \\ 16
}

\section{Selected Resource Assessment Results for Porphyry Copper}

[Assessment depth, 1 kilometer ( $\mathrm{km}) ; \mathrm{km}^{2}$, square kilometer; Mt, millions of metric tons]

\begin{tabular}{ccccccc}
\hline $\begin{array}{c}\text { Date of } \\
\text { assessment }\end{array}$ & $\begin{array}{c}\text { Tract area } \\
\left(\mathbf{k m}^{2}\right)\end{array}$ & $\begin{array}{c}\text { Identified } \\
\text { copper } \\
\text { resources } \\
\text { (Mt) }\end{array}$ & $\begin{array}{c}\text { Mean estimate of } \\
\text { in-place resources } \\
(\mathbf{M t})\end{array}$ & $\begin{array}{c}\text { Probability of } \mathbf{0} \\
\text { in-place resources } \\
\text { (percent) }\end{array}$ & $\begin{array}{c}\text { Mean estimate of } \\
\text { economic resources } \\
\text { (Mt) }\end{array}$ & $\begin{array}{c}\text { Probability of 0 } \\
\text { economic resources } \\
\text { (percent) }\end{array}$ \\
\hline 2011 & 23,698 & 16 & 31 & 4 & 15 \\
\hline
\end{tabular}

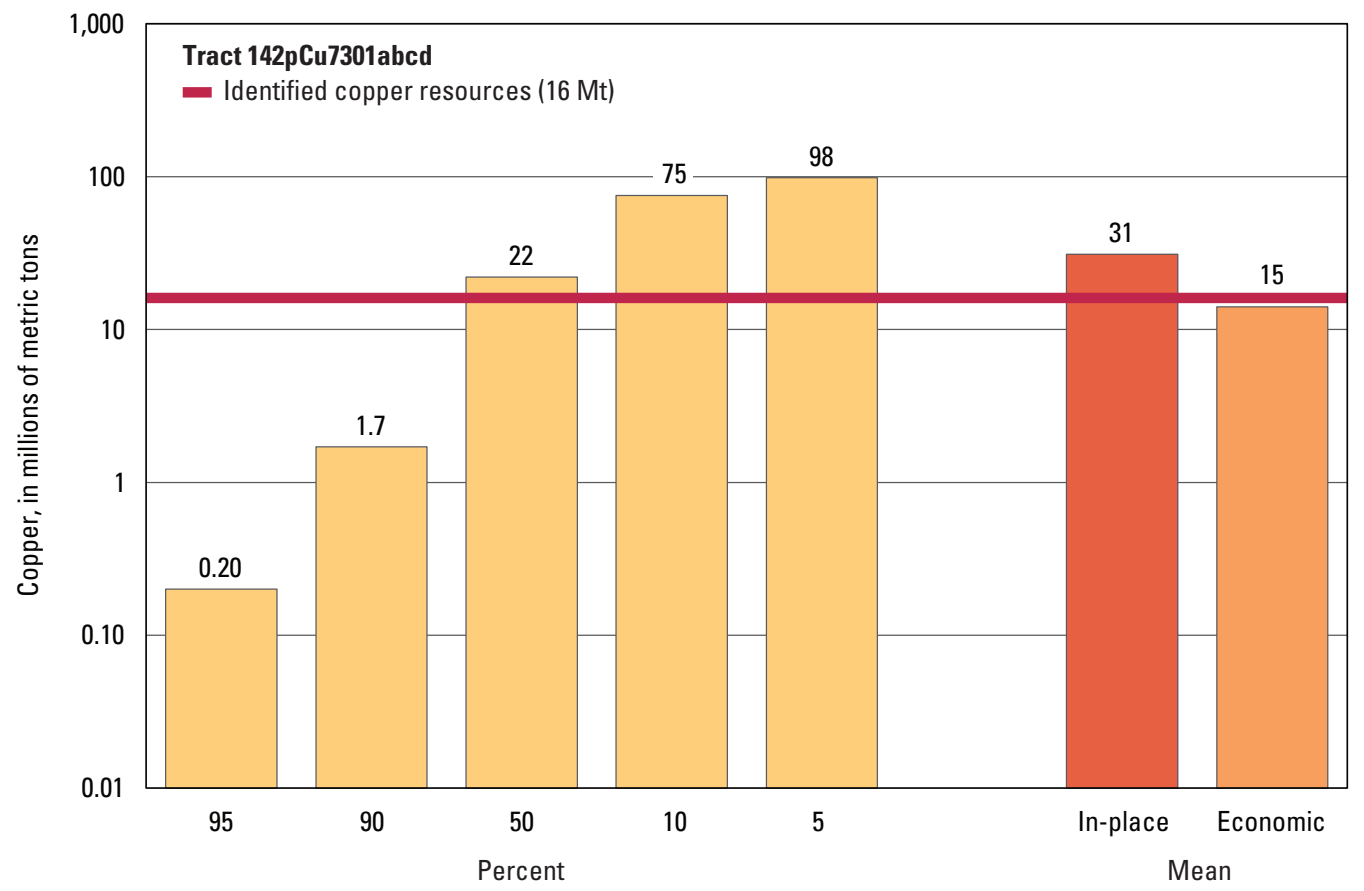

Graph showing the estimated probability distribution of undiscovered copper resources, where each bar represents the minimum amount estimated at the indicated percentage.

\section{Source}

Hammarstrom, Bookstrom, DeMarr, and others, 2014, Porphyry copper assessment of East and Southeast Asia—Philippines, Taiwan (Republic of China), Republic of Korea (South Korea), and Japan: U.S. Geological Survey Scientific Investigations Report 2010-5090-P, http://dx.doi.org/10.3133/sir20105090P. 


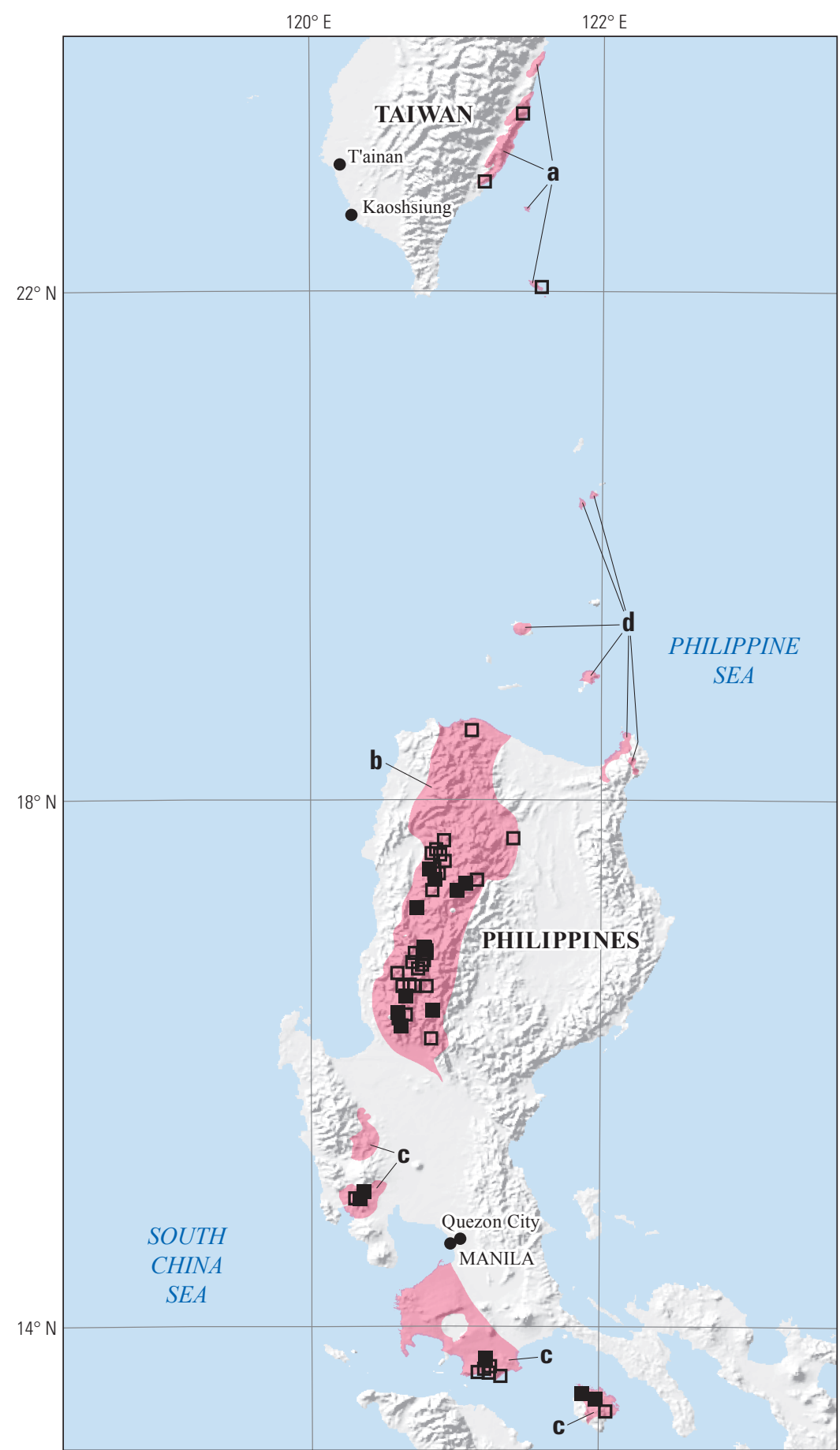

Political boundaries from U.S. Department of State (2009) Shaded relief from Earth Resources Observation and Science (EROS) Center (2011)

Asia South Albers Equal-Area Conic projection

Central meridian $120^{\circ} 45^{\prime} \mathrm{E}$.; latitude of origin $15^{\circ} \mathrm{S}$.

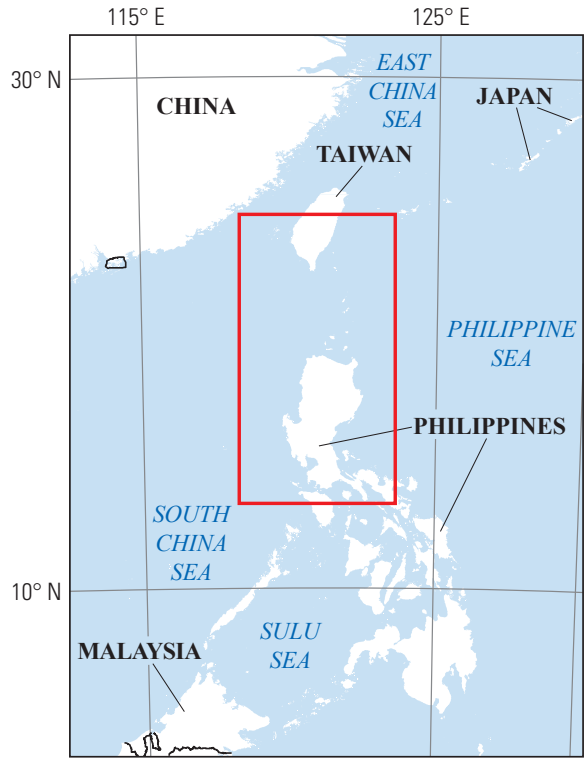

\section{EXPLANATION}

Assessed porphyry copper tract 142pCu7301abcd; details of sub-tracts are on the following pages

- Porphyry copper deposit

口 Porphyry copper prospect 


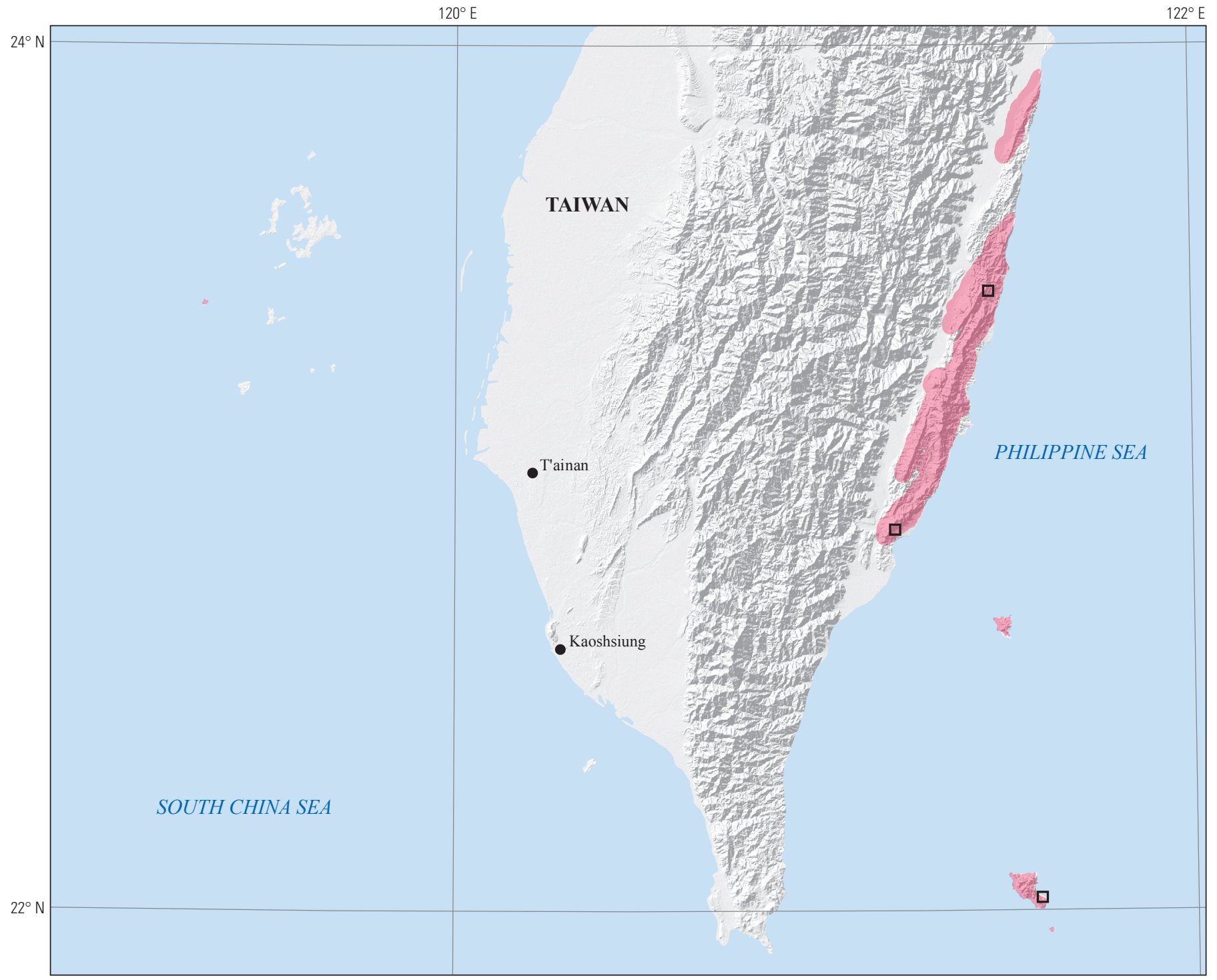

Political boundaries from U.S. Department of State (2009) Shaded relief from ESRI (2008)

Asia South Albers Equal-Area Conic projection

Central meridian $120^{\circ} 30^{\prime} \mathrm{E}$.; latitude of origin $15^{\circ} \mathrm{S}$.

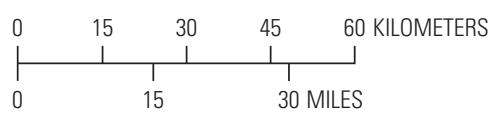

\section{EXPLANATION}

Assessed porphyry copper sub-tract 142pCu7301a

ㅁ Porphyry copper prospect

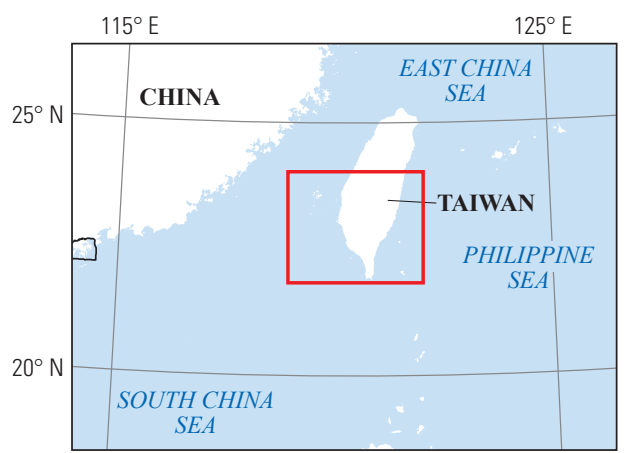



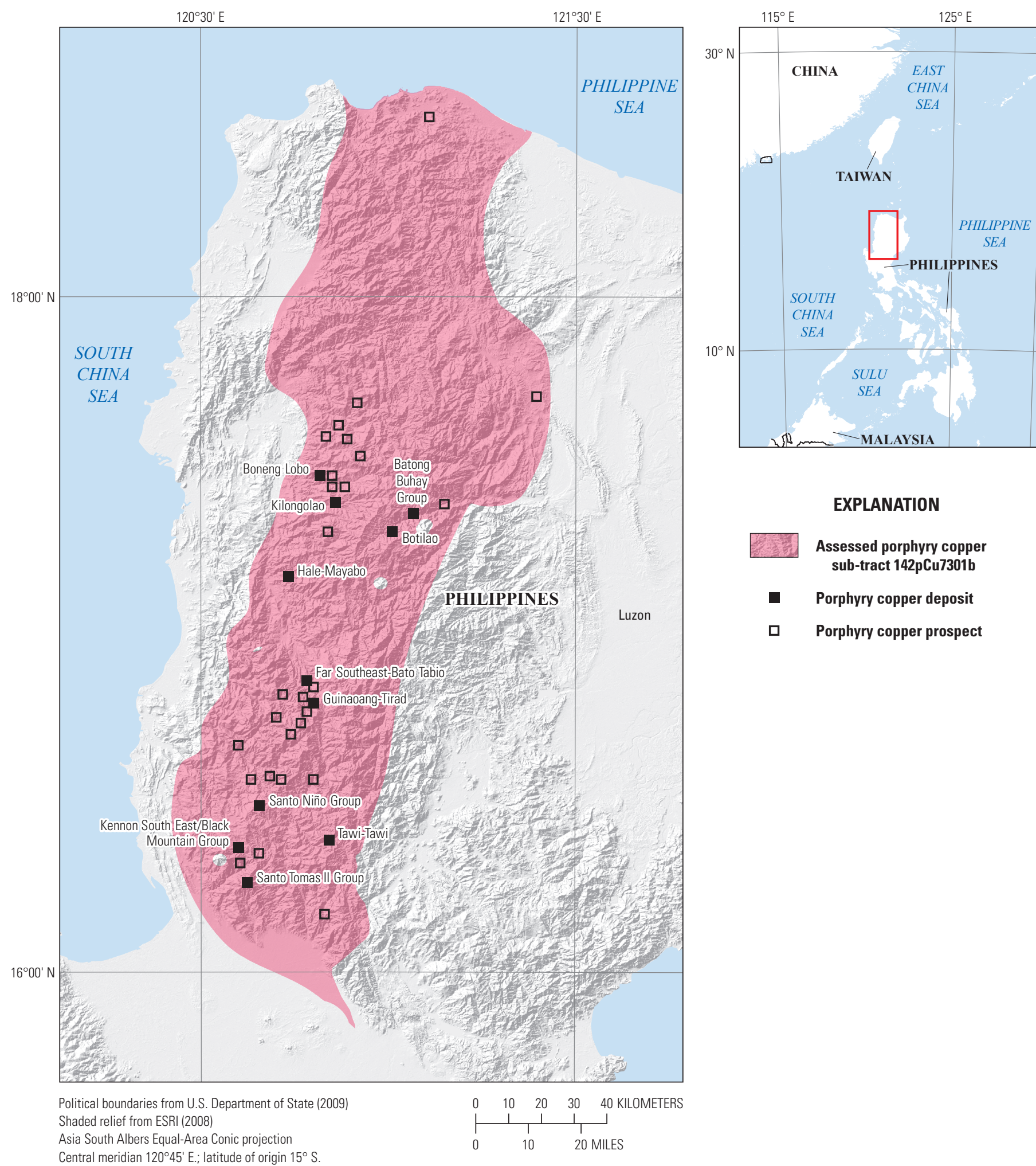

\section{EXPLANATION}

Assessed porphyry copper sub-tract 142pCu7301b

\section{Porphyry copper deposit}

Porphyry copper prospect 


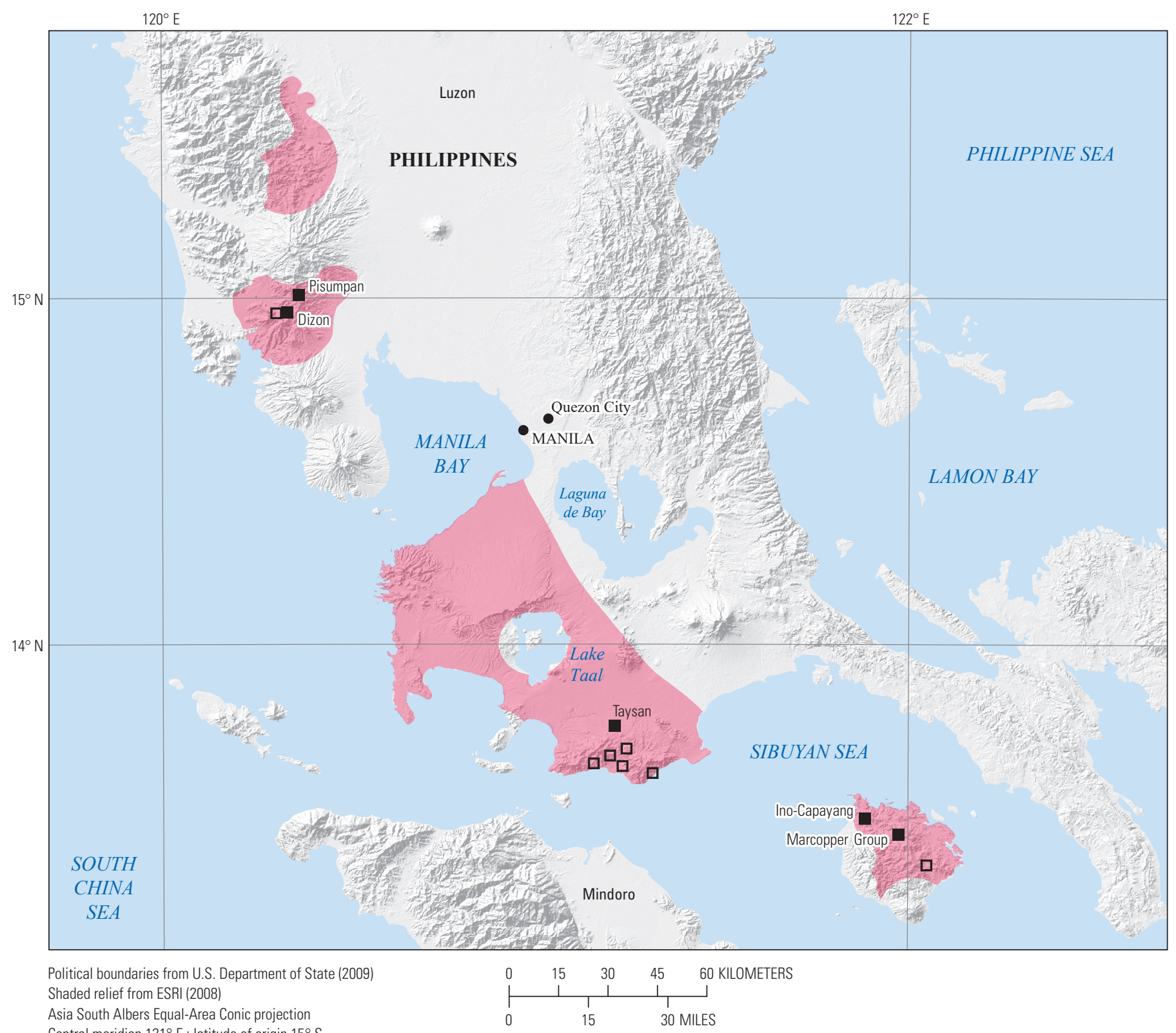

Central meridian $121^{\circ}$ E.; latitude of origin $15^{\circ} \mathrm{S}$

EXPLANATION

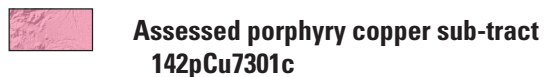
142pCu7301c

- Porphyry copper deposit

$\square \quad$ Porphyry copper prospect

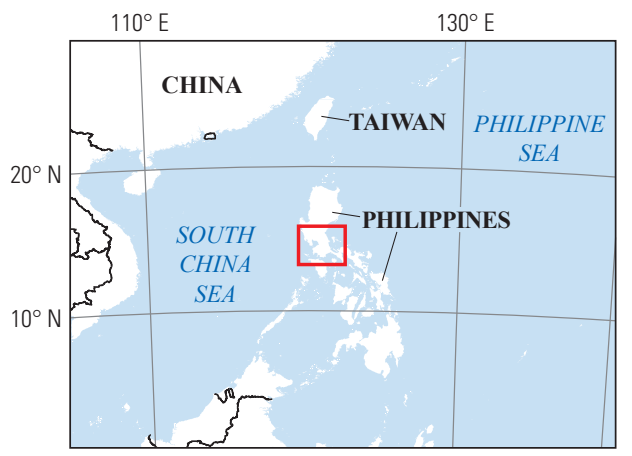



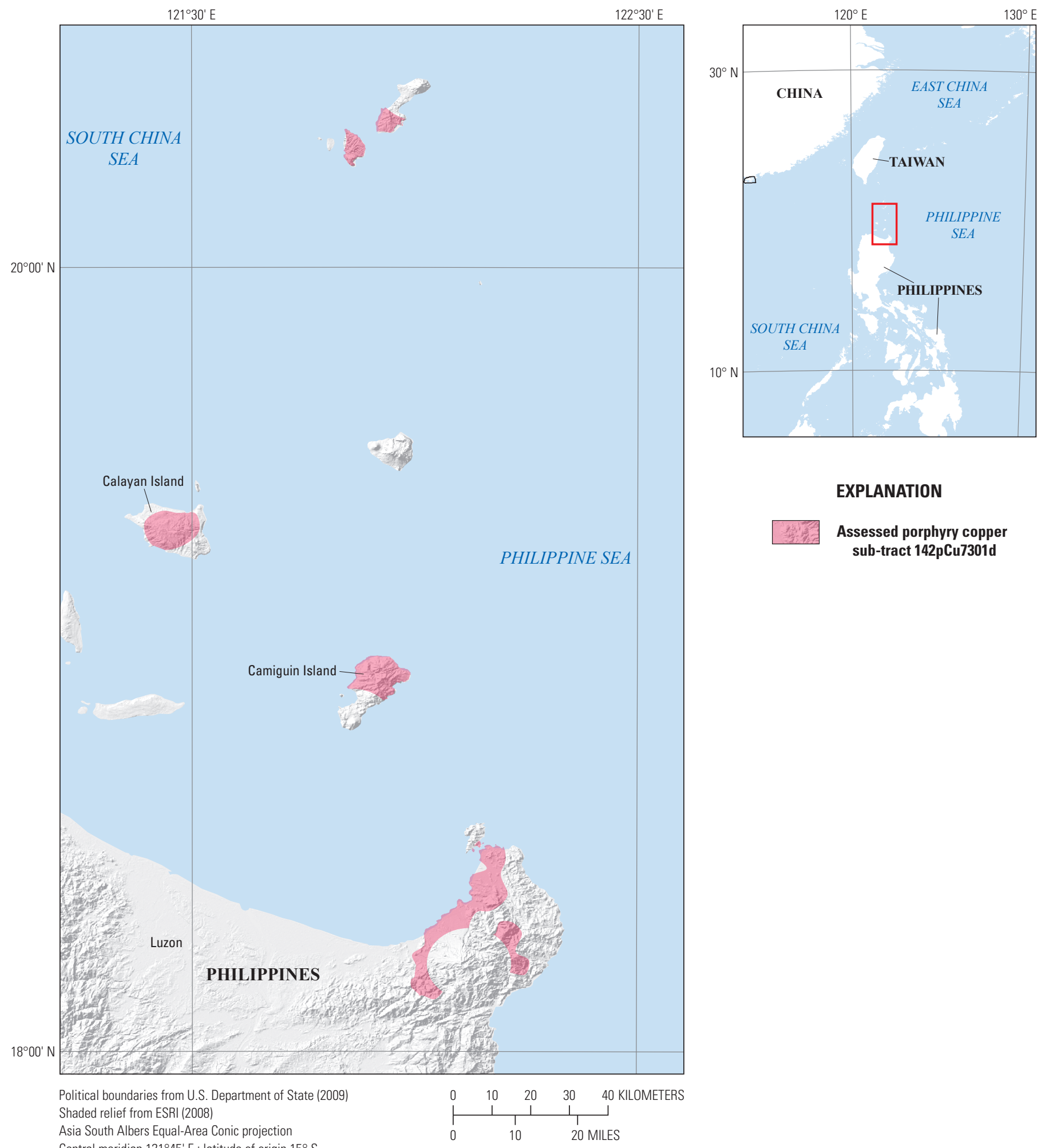

\section{EXPLANATION}

Assessed porphyry copper sub-tract 142pCu7301d

Central meridian $121^{\circ} 45^{\prime} \mathrm{E}$.; latitude of origin $15^{\circ} \mathrm{S}$. 


\section{Plate 99. Porphyry Copper Assessment for Tract 142pCu7304ab, Sierra Madre Arc-Philippines}

Descriptive model:

Grade and tonnage model:

Economic filter depth percentages:

Economic filter cost setting:

Geologic feature assessed:

Number of known deposits:
Porphyry copper models (Berger and others, 2008; John and others, 2010); porphyry copper-gold models (Cox, 1986b; Cooke and others, 1998)

Porphyry copper, copper-gold subtype model (Singer, Berger, and Moring, 2008)

Default -0 to 250 meters (m), 25\%; > 250 to $500 \mathrm{~m}, 25 \%$; $>500 \mathrm{~m}$ to $1 \mathrm{~km}, 50 \%$

High cost

Eocene-Oligocene Sierra Madre arc

1

\section{Selected Resource Assessment Results for Porphyry Copper}

[Assessment depth, 1 kilometer (km); $\mathrm{km}^{2}$, square kilometer; Mt, millions of metric tons]

\begin{tabular}{ccccccc}
\hline $\begin{array}{c}\text { Date of } \\
\text { assessment }\end{array}$ & $\begin{array}{c}\text { Tract area } \\
\left(\mathbf{k m}^{2}\right)\end{array}$ & $\begin{array}{c}\text { Identified } \\
\text { copper } \\
\text { resources } \\
\text { (Mt) }\end{array}$ & $\begin{array}{c}\text { Mean estimate of } \\
\text { in-place resources } \\
(\mathbf{M t})\end{array}$ & $\begin{array}{c}\text { Probability of } \mathbf{0} \\
\text { in-place resources } \\
\text { (percent) }\end{array}$ & $\begin{array}{c}\text { Mean estimate of } \\
\text { economic resources } \\
\text { (Mt) }\end{array}$ & $\begin{array}{c}\text { Probability of 0 } \\
\text { economic resources } \\
\text { (percent) }\end{array}$ \\
\hline 2010 & 13,966 & 0.31 & 1.4 & 69 & 0.69 \\
\hline
\end{tabular}

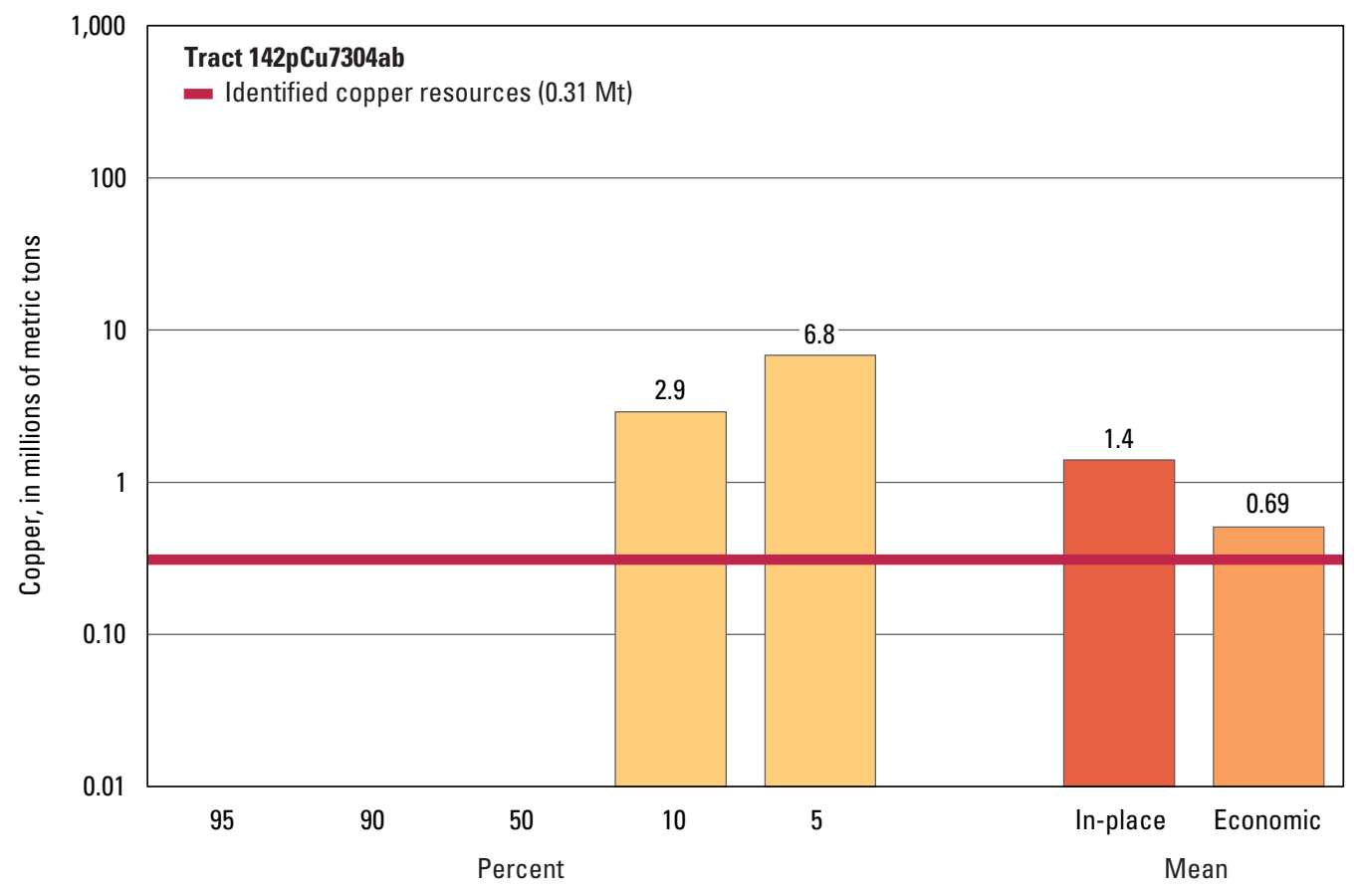

Graph showing the estimated probability distribution of undiscovered copper resources, where each bar represents the minimum amount estimated at the indicated percentage.

\section{Source}

Hammarstrom, Bookstrom, DeMarr, and others, 2014, Porphyry copper assessment of East and Southeast Asia—Philippines, Taiwan (Republic of China), Republic of Korea (South Korea), and Japan: U.S. Geological Survey Scientific Investigations Report 2010-5090-P, http://dx.doi.org/10.3133/sir20105090P. 

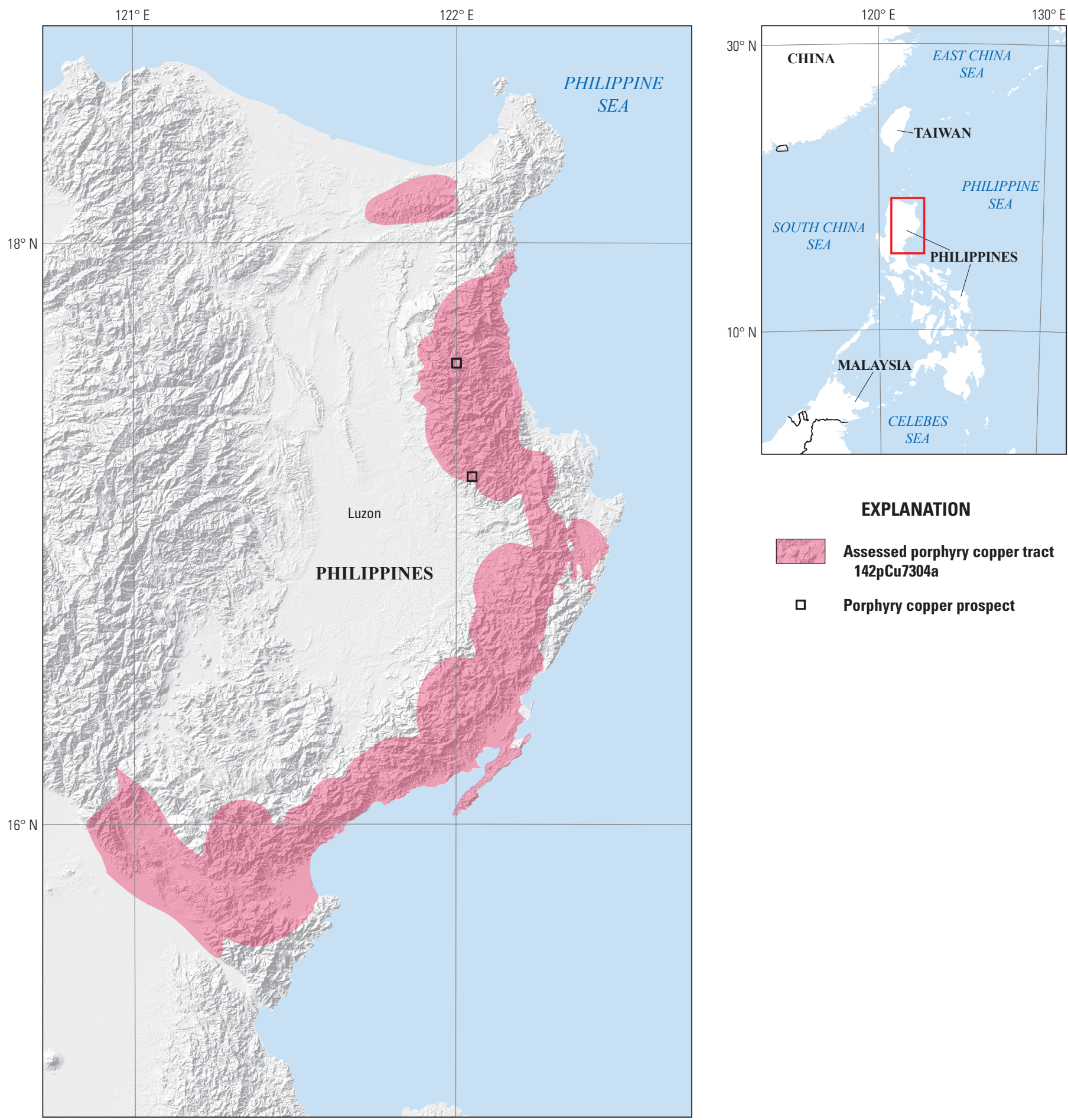

\section{EXPLANATION}

Assessed porphyry copper tract 142pCu7304a

Porphyry copper prospect

Political boundaries from U.S. Department of State (2009) Shaded relief from ESRI (2008)

Asia South Albers Equal-Area Conic projection

Central meridian $121^{\circ} 45^{\prime} \mathrm{E}$.; latitude of origin $15^{\circ} \mathrm{S}$.

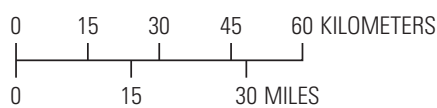



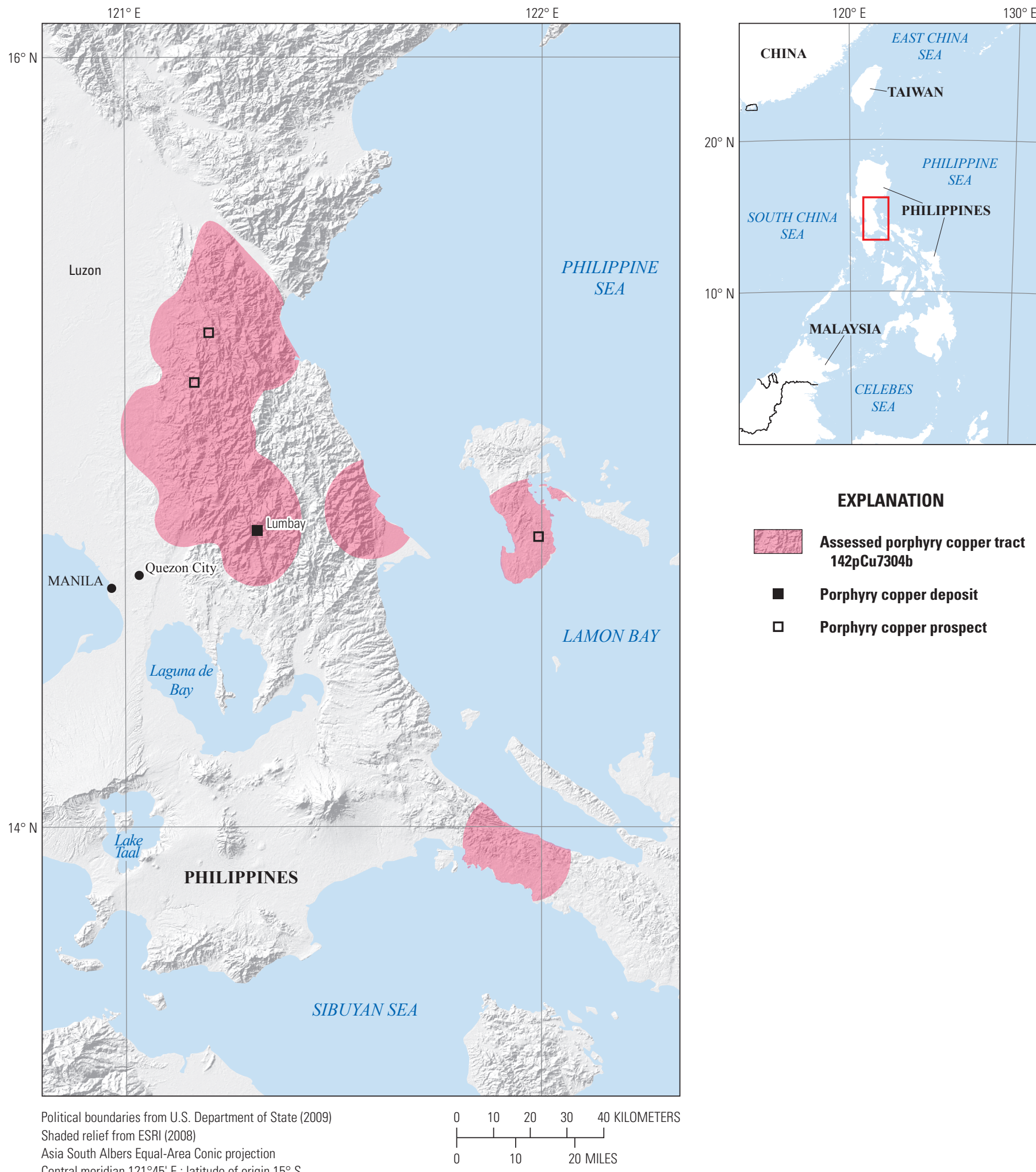

\section{EXPLANATION}

Assessed porphyry copper tract 142pCu7304b

- Porphyry copper deposit

Porphyry copper prospect

Asia South Albers Equal-Area Conic projection

Central meridian $121^{\circ} 45^{\prime} \mathrm{E}$.; latitude of origin $15^{\circ} \mathrm{S}$. 
Plate 100 follows. 


\title{
Plate 100. Porphyry Copper Assessment for Tract 142pCu7302, Cordon Alkalic Complex-Philippines
}

\author{
Descriptive model: \\ Porphyry copper models (Berger and others, 2008; John and others, 2010); porphyry copper-gold \\ models (Cox, 1986b; Cooke and others, 1998) \\ Grade and tonnage model: \\ Porphyry copper, copper-gold subtype model (Singer, Berger, and Moring, 2008) \\ Economic filter depth percentages: \\ Default -0 to 250 meters (m), $25 \%$; > 250 to $500 \mathrm{~m}, 25 \%$; $>500 \mathrm{~m}$ to $1 \mathrm{~km}, 50 \%$ \\ Economic filter cost setting: \\ High cost \\ Geologic feature assessed: \\ Late Oligocene to early Miocene potassium-rich alkalic magmatic rocks at the south end of \\ Cagayan rift basin \\ Number of known deposits: \\ 3
}

\section{Selected Resource Assessment Results for Porphyry Copper}

[Assessment depth, 1 kilometer $(\mathrm{km}) ; \mathrm{km}^{2}$, square kilometer; Mt, millions of metric tons]

\begin{tabular}{|c|c|c|c|c|c|c|}
\hline \multirow[b]{2}{*}{$\begin{array}{c}\text { Date of } \\
\text { assessment }\end{array}$} & \multirow[b]{2}{*}{$\begin{array}{c}\text { Tract area } \\
\quad\left(\mathbf{k m}^{2}\right)\end{array}$} & \multirow{2}{*}{$\begin{array}{l}\text { Identified } \\
\text { copper } \\
\text { resources } \\
\text { (Mt) }\end{array}$} & \multicolumn{4}{|c|}{ Undiscovered copper resource estimates } \\
\hline & & & $\begin{array}{l}\text { Mean estimate of } \\
\text { in-place resources } \\
\text { (Mt) }\end{array}$ & $\begin{array}{c}\text { Probability of } 0 \\
\text { in-place resources } \\
\text { (percent) }\end{array}$ & $\begin{array}{l}\text { Mean estimate of } \\
\text { economic resources } \\
\text { (Mt) }\end{array}$ & $\begin{array}{c}\text { Probability of } 0 \\
\text { economic resources } \\
\text { (percent) }\end{array}$ \\
\hline 2010 & 4,860 & 1.4 & 4.9 & 4 & 2.4 & 79 \\
\hline
\end{tabular}

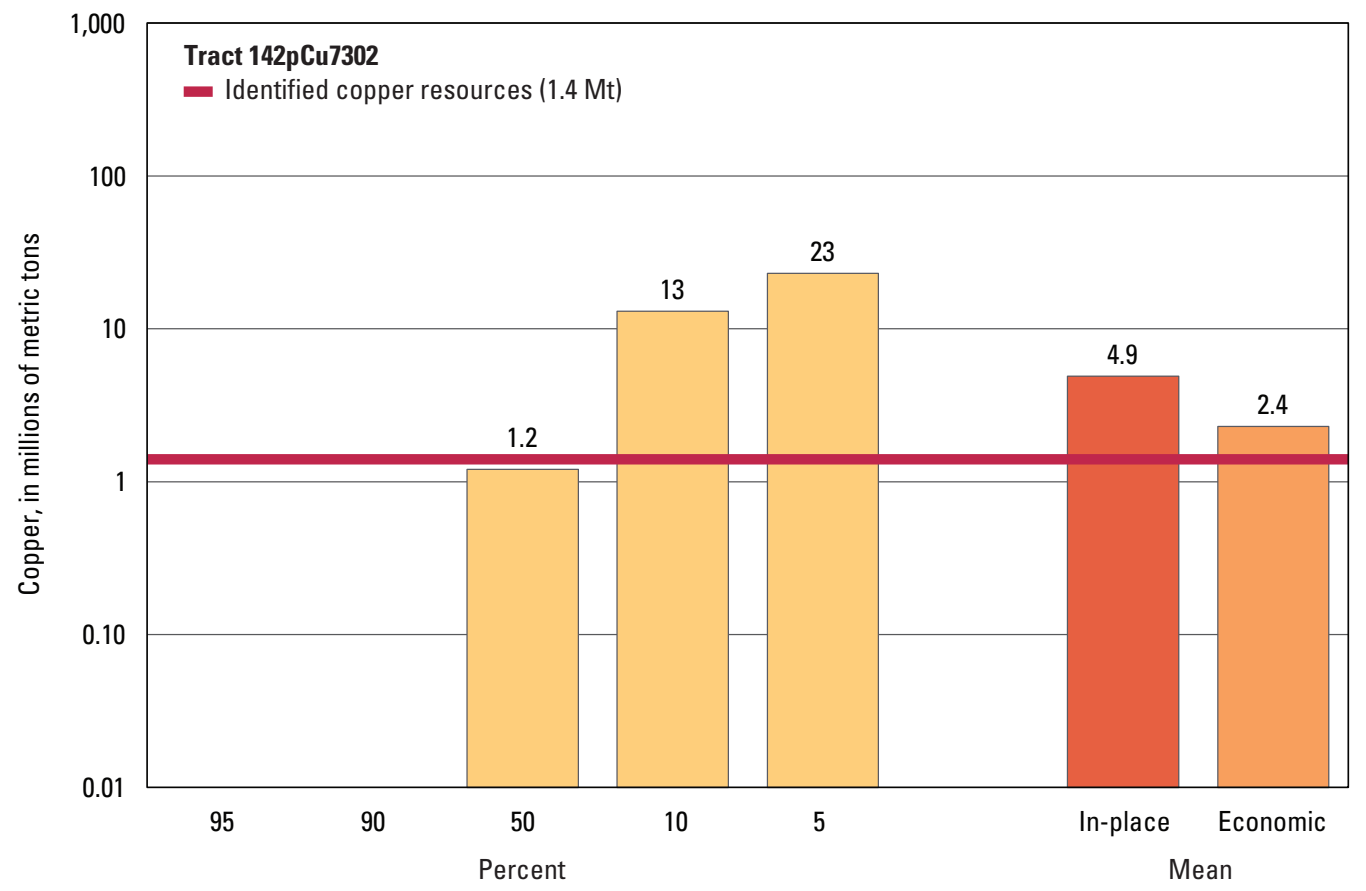

Graph showing the estimated probability distribution of undiscovered copper resources, where each bar represents the minimum amount estimated at the indicated percentage.

\section{Source}

Hammarstrom, Bookstrom, DeMarr, and others, 2014, Porphyry copper assessment of East and Southeast Asia-Philippines, Taiwan (Republic of China), Republic of Korea (South Korea), and Japan: U.S. Geological Survey Scientific Investigations Report 2010-5090-P, http://dx.doi.org/10.3133/sir20105090P. 


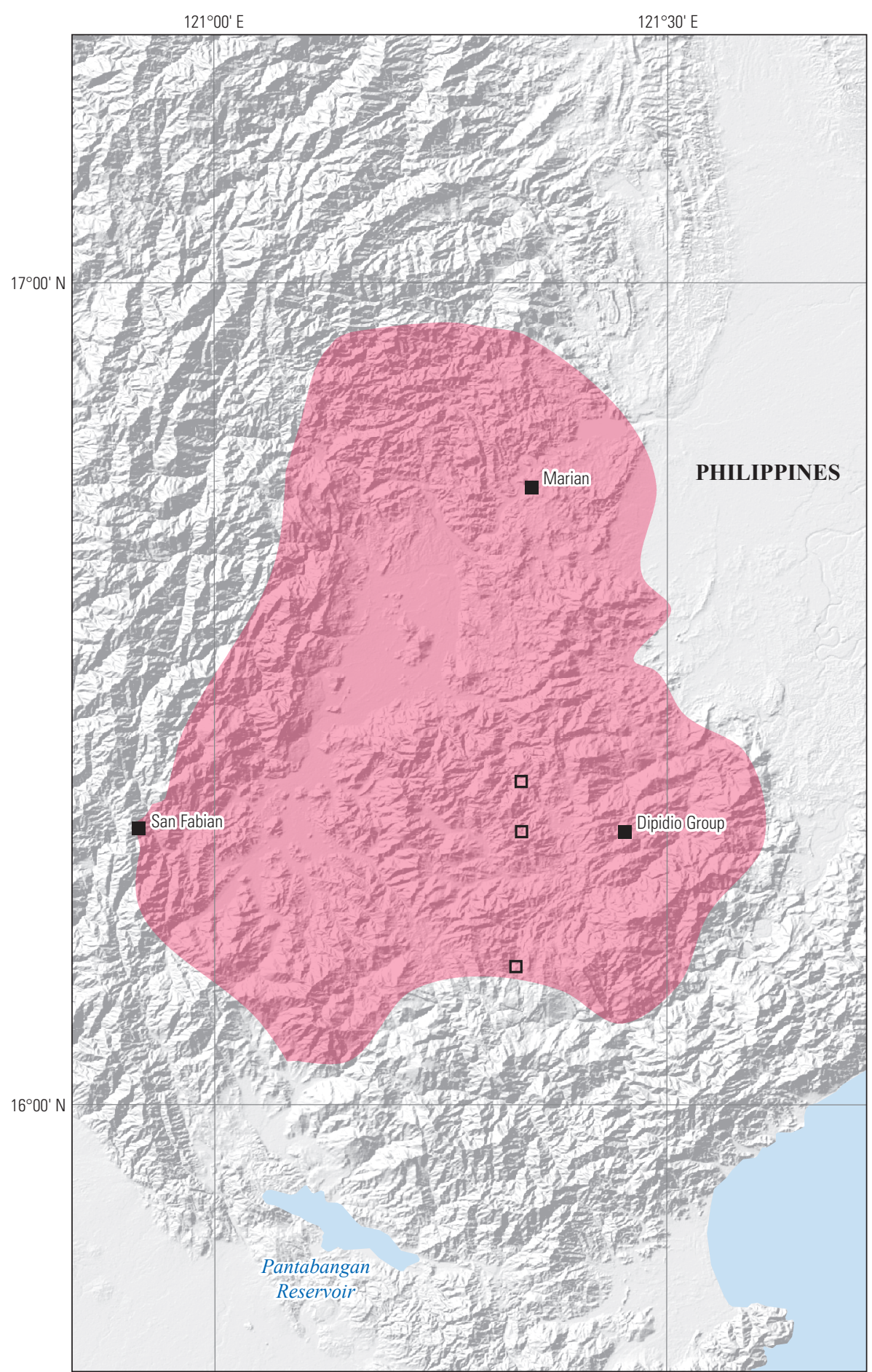

Political boundaries from U.S. Department of State (2009) Shaded relief from ESRI (2008)

Asia South Albers Equal-Area Conic projection

Central meridian $121^{\circ} 15^{\prime}$ E.; latitude of origin $15^{\circ} \mathrm{S}$.

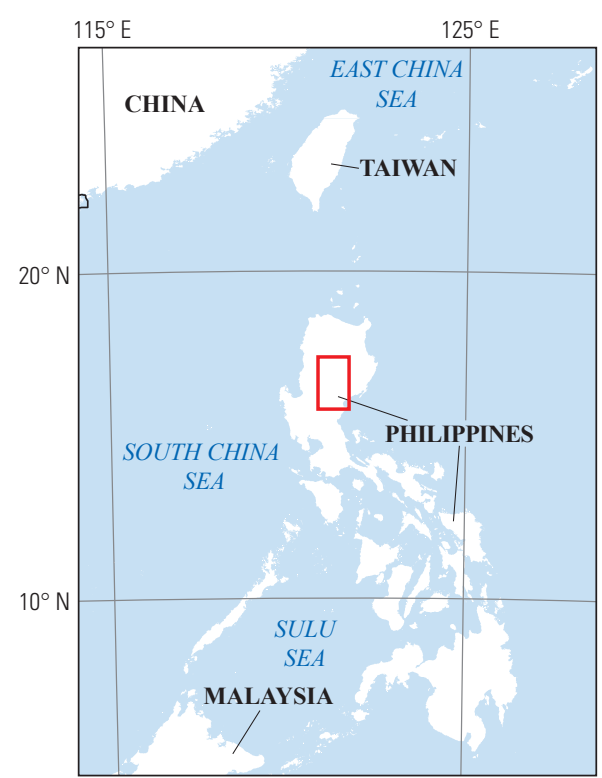

\section{EXPLANATION}

Assessed porphyry copper tract 142pCu7302

- Porphyry copper deposit

$\square \quad$ Porphyry copper prospect 


\section{Plate 101. Porphyry Copper Assessment for Tract 142pCu7309, Philippine Arc- Philippines}

Descriptive model:

Grade and tonnage model:

Economic filter depth percentages:

Economic filter cost setting:

Geologic feature assessed:

Number of known deposits:
Porphyry copper models (Berger and others, 2008; John and others, 2010); porphyry copper-gold models (Cox, 1986b; Cooke and others, 1998)

Porphyry copper, copper-gold subtype model (Singer, Berger, and Moring, 2008)

Default -0 to 250 meters (m), $25 \%$; > 250 to $500 \mathrm{~m}, 25 \%$; >500 m to $1 \mathrm{~km}, 50 \%$

High cost

Oligocene to Pleistocene Philippine arc

5

\section{Selected Resource Assessment Results for Porphyry Copper}

[Assessment depth, 1 kilometer (km); $\mathrm{km}^{2}$, square kilometer; Mt, millions of metric tons]

\begin{tabular}{ccccccc}
\hline $\begin{array}{c}\text { Date of } \\
\text { assessment }\end{array}$ & $\begin{array}{c}\text { Tract area } \\
\left(\mathbf{k m}^{2}\right)\end{array}$ & $\begin{array}{c}\text { Identified } \\
\text { copper } \\
\text { resources } \\
\text { (Mt) }\end{array}$ & $\begin{array}{c}\text { Mean estimate of } \\
\text { in-place resources } \\
(\mathbf{M t})\end{array}$ & $\begin{array}{c}\text { Probability of } \mathbf{0} \\
\text { in-place resources } \\
\text { (percent) }\end{array}$ & $\begin{array}{c}\text { Mean estimate of } \\
\text { economic resources } \\
\text { (Mt) }\end{array}$ & $\begin{array}{c}\text { Probability of 0 } \\
\text { economic resources } \\
\text { (percent) }\end{array}$ \\
\hline 2010 & 20,650 & 5.7 & 24 & 3 & 12 \\
\hline
\end{tabular}

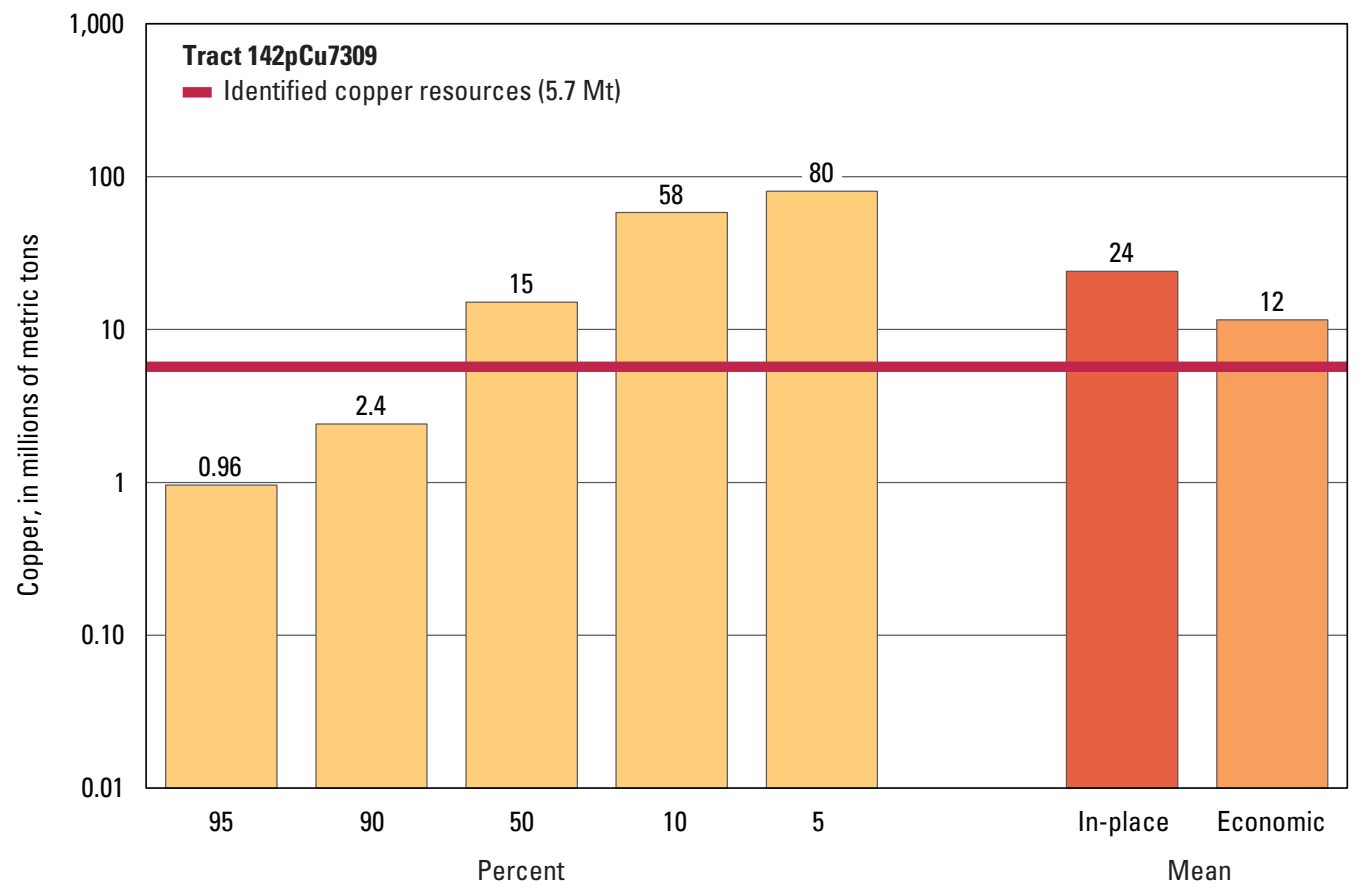

Graph showing the estimated probability distribution of undiscovered copper resources, where each bar represents the minimum amount estimated at the indicated percentage.

\section{Source}

Hammarstrom, Bookstrom, DeMarr, and others, 2014, Porphyry copper assessment of East and Southeast Asia—Philippines, Taiwan (Republic of China), Republic of Korea (South Korea), and Japan: U.S. Geological Survey Scientific Investigations Report 2010-5090-P, http://dx.doi.org/10.3133/sir20105090P. 

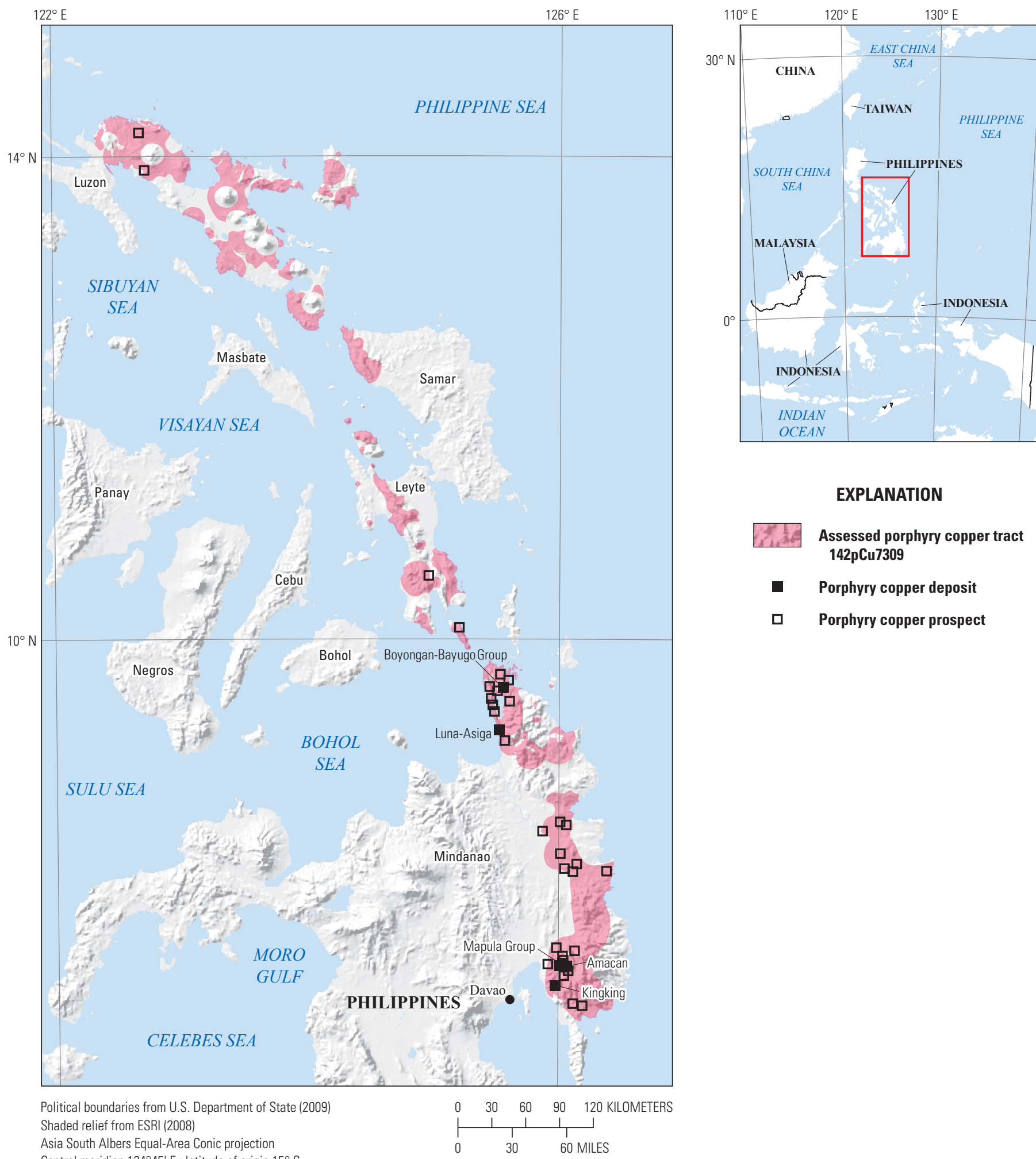

EXPLANATION

Assessed porphyry copper tract 142pCu7309

- Porphyry copper deposit

Porphyry copper prospect

Asia South Albers Equal-Area Conic projection

Central meridian $124^{\circ} 45^{\prime} \mathrm{E}$.; latitude of origin $15^{\circ} \mathrm{S}$ 


\section{Plate 102. Porphyry Copper Assessment for Tract 142pCu7311, Mindoro-Tablas- West Panay Area-Philippines}

Descriptive model:

Grade and tonnage model:

Economic filter depth percentages:

Economic filter cost setting:

Geologic feature assessed:

Number of known deposits:

\author{
Porphyry copper models (Berger and others, 2008; John and others, 2010); porphyry copper-gold \\ models (Cox, 1986b; Cooke and others, 1998) \\ Porphyry copper, copper-gold subtype model (Singer, Berger, and Moring, 2008) \\ Default -0 to 250 meters (m), 25\%; > 250 to $500 \mathrm{~m}, 25 \%$; >500 m to $1 \mathrm{~km}, 50 \%$ \\ High cost \\ Neogene Mindoro-Tablas-Western Panay magmatic arc \\ 0
}

\section{Selected Resource Assessment Results for Porphyry Copper}

[Assessment depth, 1 kilometer $(\mathrm{km}) ; \mathrm{km}^{2}$, square kilometer; Mt, millions of metric tons]

\begin{tabular}{ccccccc}
\hline $\begin{array}{c}\text { Date of } \\
\text { assessment }\end{array}$ & $\begin{array}{c}\text { Tract area } \\
\left.\mathbf{( k m}^{2}\right)\end{array}$ & $\begin{array}{c}\text { Identified } \\
\text { copper } \\
\text { resources } \\
\text { (Mt) }\end{array}$ & $\begin{array}{c}\text { Mean estimate of } \\
\text { in-place resources } \\
(\mathbf{M t})\end{array}$ & $\begin{array}{c}\text { Probability of } \mathbf{0} \\
\text { in-place resources } \\
\text { (percent) }\end{array}$ & $\begin{array}{c}\text { Mean estimate of } \\
\text { economic resources } \\
\text { (Mt) }\end{array}$ & $\begin{array}{c}\text { Probability of 0 } \\
\text { economic resources } \\
\text { (percent) }\end{array}$ \\
\hline 2011 & 9,168 & 0 & 3.2 & 29 & 1.5 \\
\hline
\end{tabular}

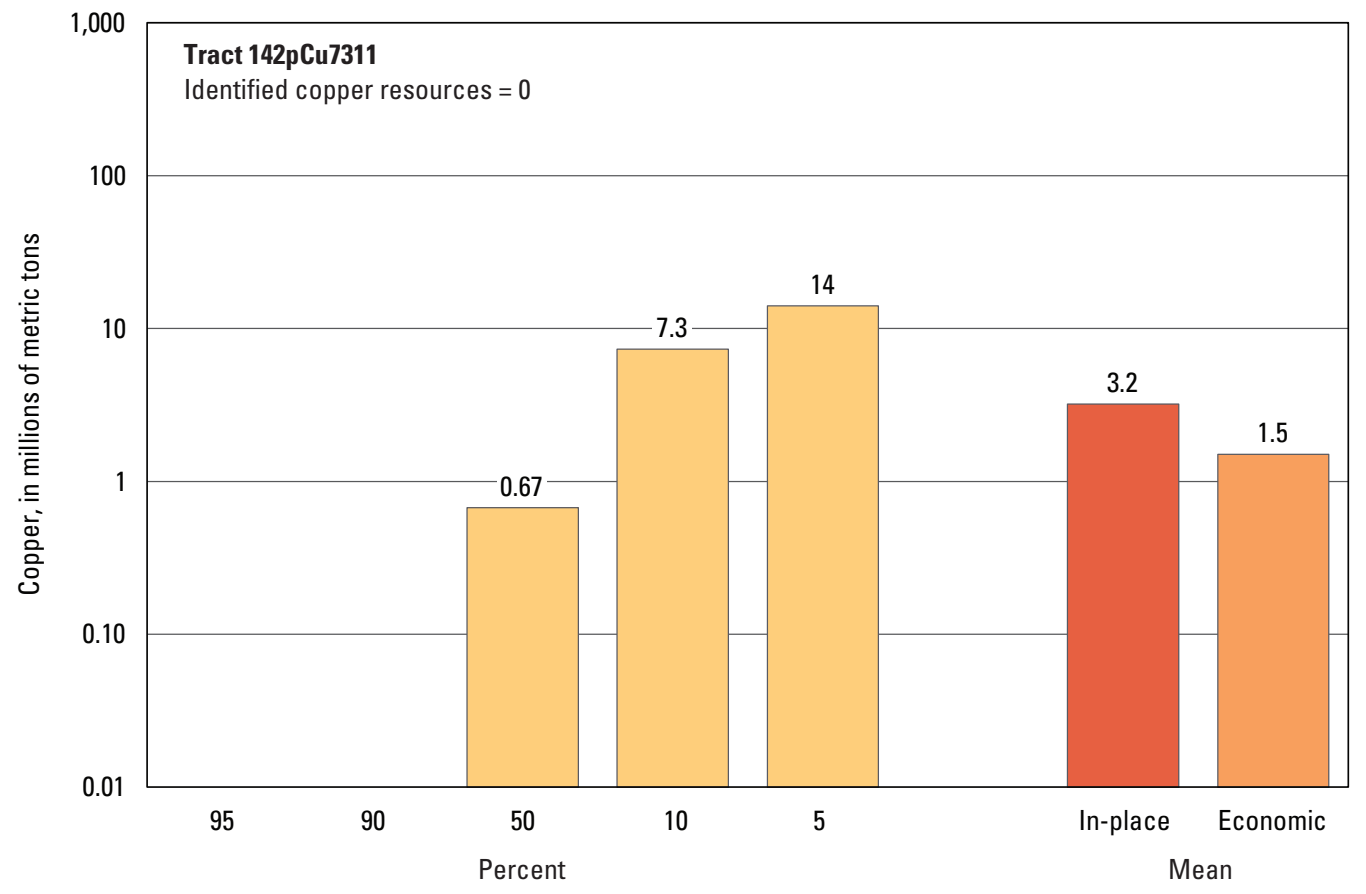

Graph showing the estimated probability distribution of undiscovered copper resources, where each bar represents the minimum amount estimated at the indicated percentage.

\section{Source}

Hammarstrom, Bookstrom, DeMarr, and others, 2014, Porphyry copper assessment of East and Southeast Asia—Philippines, Taiwan (Republic of China), Republic of Korea (South Korea), and Japan: U.S. Geological Survey Scientific Investigations Report 2010-5090-P, http://dx.doi.org/10.3133/sir20105090P. 


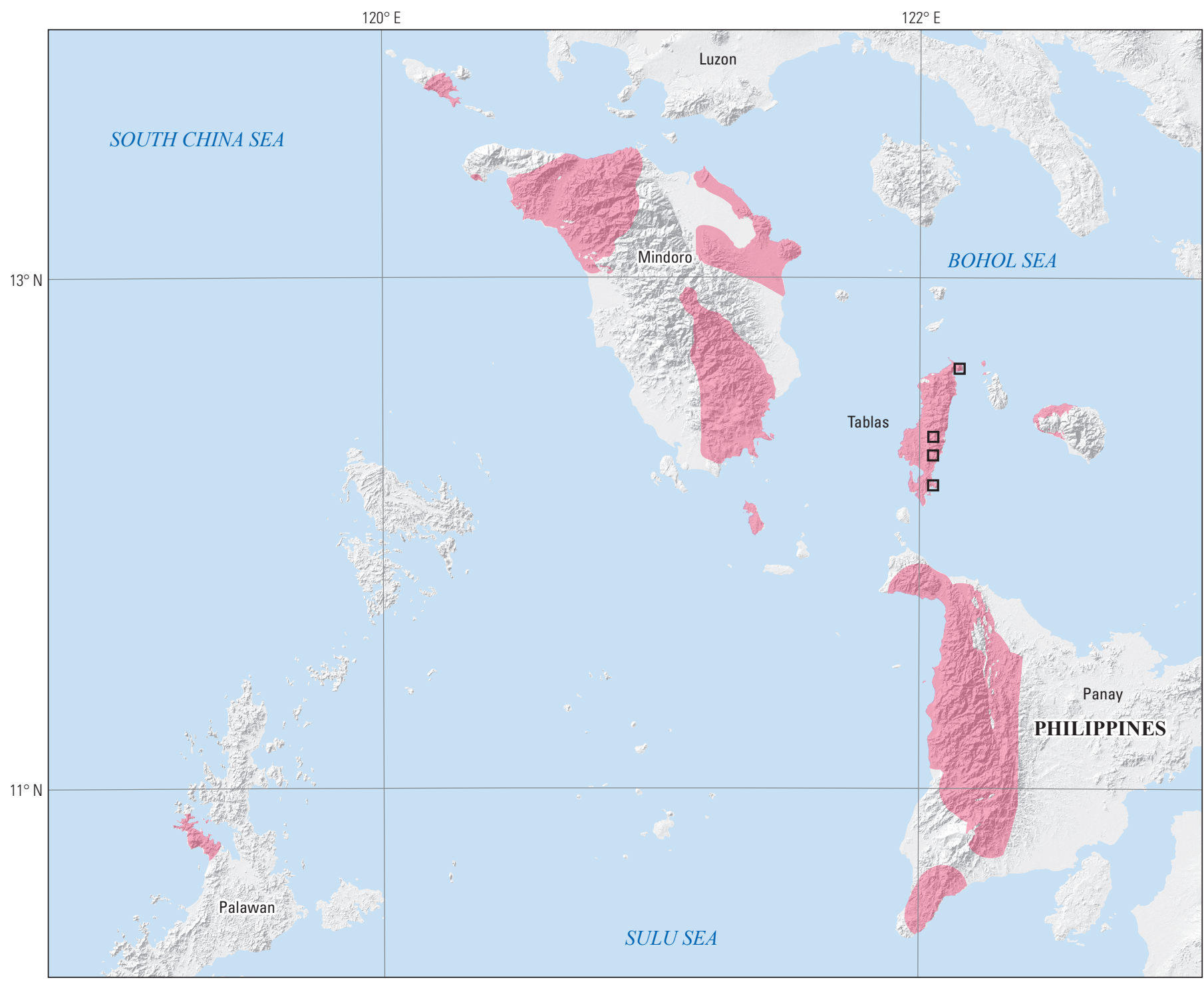

Political boundaries from U.S. Department of State (2009) Shaded relief from ESRI (2008)

Asia South Albers Equal-Area Conic projection

Central meridian $121^{\circ} \mathrm{E}$.; latitude of origin $15^{\circ} \mathrm{S}$.

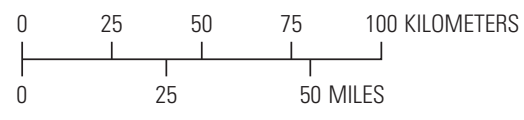

EXPLANATION

Assessed porphyry copper tract 142pCu7311

Porphyry copper prospect

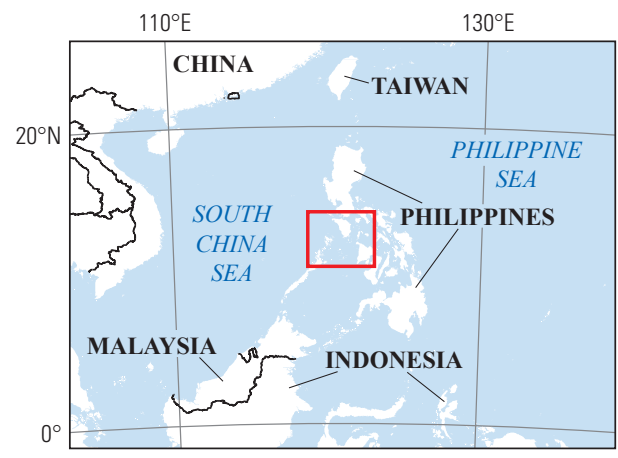




\section{Plate 103. Porphyry Copper Assessment for Tract 142pCu7305, Masbate-Negros Arc System-Philippines}

Descriptive model:

Grade and tonnage model:

Economic filter depth percentages:

Economic filter cost setting:

Geologic feature assessed:

Number of known deposits:
Porphyry copper models (Berger and others, 2008; John and others, 2010); porphyry copper-gold models (Cox, 1986b; Cooke and others, 1998)

General porphyry copper model (Singer, Berger, and Moring, 2008)

Skewed deep- 0 to 250 meters (m), 10\%; > 250 to $500 \mathrm{~m}, 30 \%$; >500 m to $1 \mathrm{~km}, 60 \%$

High cost

Eocene to Holocene Masbate-Negros island-arc system (diorites, andesite porphyry stocks, andesites, dacites)

5

\section{Selected Resource Assessment Results for Porphyry Copper}

[Assessment depth, 1 kilometer $(\mathrm{km}) ; \mathrm{km}^{2}$, square kilometer; Mt, millions of metric tons]

\begin{tabular}{ccccccc}
\hline \multirow{2}{*}{$\begin{array}{c}\text { Date of } \\
\text { assessment }\end{array}$} & $\begin{array}{c}\text { Tract area } \\
\left(\mathbf{k m}^{2}\right)\end{array}$ & $\begin{array}{c}\text { Identified } \\
\text { copper } \\
\text { resources } \\
(\mathbf{M t})\end{array}$ & $\begin{array}{c}\text { Mean estimate of } \\
\text { in-place resources } \\
(\mathbf{M t})\end{array}$ & $\begin{array}{c}\text { Probability of } \mathbf{0} \\
\text { in-place resources } \\
\text { (percent) }\end{array}$ & $\begin{array}{c}\text { Mean estimate of } \\
\text { economic resources } \\
\text { (Mt) }\end{array}$ & $\begin{array}{c}\text { Probability of } \mathbf{0} \\
\text { economic resources } \\
\text { (percent) }\end{array}$ \\
\hline 2010 & 12,226 & 6.8 & 7.8 & 20 & 3.5 \\
\hline
\end{tabular}

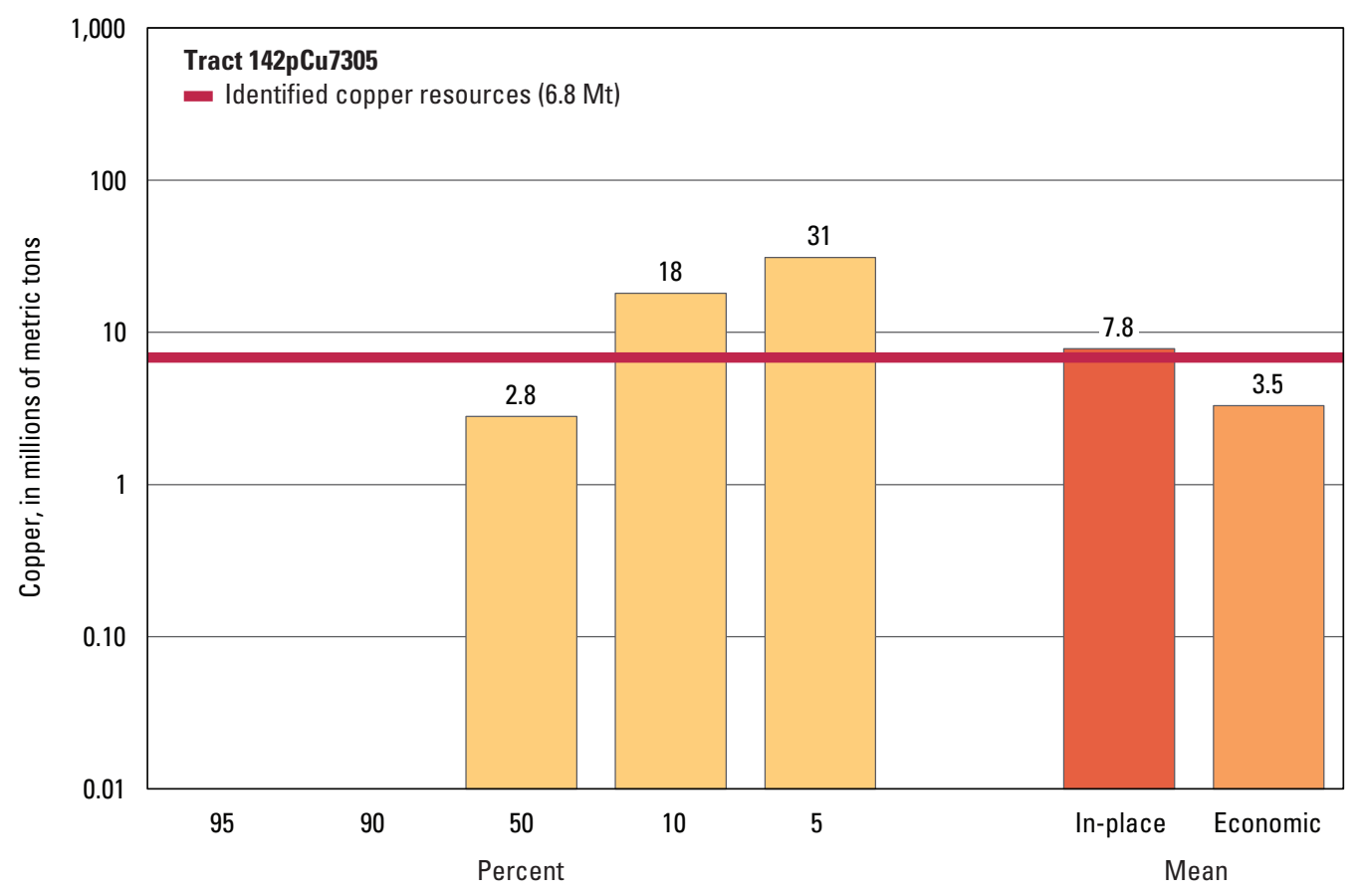

Graph showing the estimated probability distribution of undiscovered copper resources, where each bar represents the minimum amount estimated at the indicated percentage.

\section{Source}

Hammarstrom, Bookstrom, DeMarr, and others, 2014, Porphyry copper assessment of East and Southeast Asia-Philippines, Taiwan (Republic of China), Republic of Korea (South Korea), and Japan: U.S. Geological Survey Scientific Investigations Report 2010-5090-P, http://dx.doi.org/10.3133/sir20105090P. 

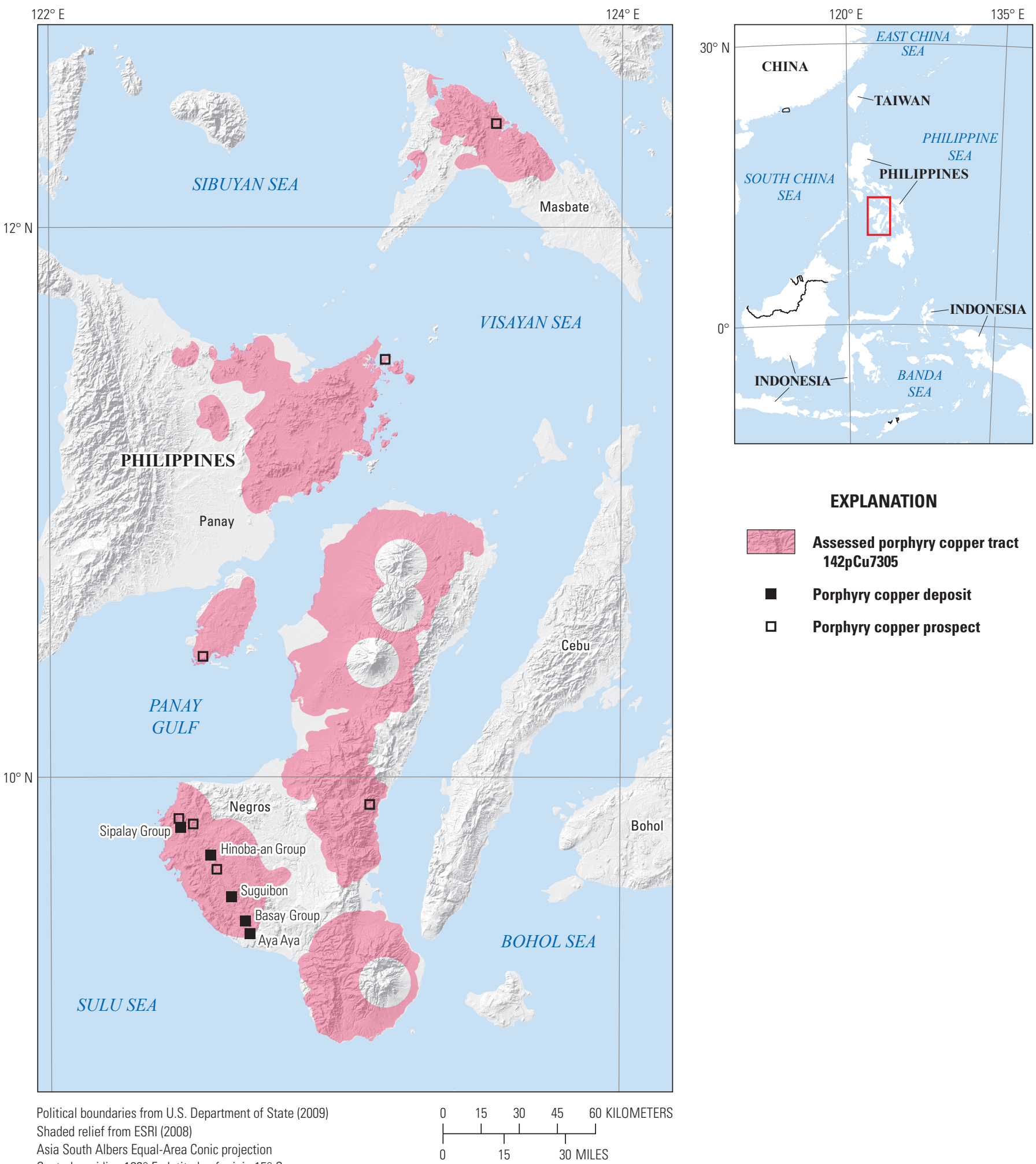

\section{EXPLANATION}

Assessed porphyry copper tract 142pCu7305

- Porphyry copper deposit

ㅁ Porphyry copper prospect

Asia South Albers Equal-Area Conic projection

Central meridian $123^{\circ} \mathrm{E}$.; latitude of origin $15^{\circ} \mathrm{S}$. 


\section{Plate 104. Porphyry Copper Assessment for Tract 142pCu7306, Bohol-Cebu Area-Philippines}

\section{Descriptive model:}

Grade and tonnage model:

Economic filter depth percentages:

Economic filter cost setting:

Geologic feature assessed:

Number of known deposits:

\author{
Porphyry copper models (Berger and others, 2008; John and others, 2010); porphyry copper-gold \\ models (Cox, 1986b; Cooke and others, 1998) \\ General porphyry copper model (Singer, Berger, and Moring, 2008) \\ Skewed shallow-0 to 250 meters (m), $35 \%$; > 250 to $500 \mathrm{~m}, 25 \%$; $>500 \mathrm{~m}$ to $1 \mathrm{~km}, 40 \%$ \\ High cost \\ Miocene Bohol arc; Cretaceous rocks on Cebu Island \\ 2
}

\section{Selected Resource Assessment Results for Porphyry Copper}

[Assessment depth, 1 kilometer $(\mathrm{km}) ; \mathrm{km}^{2}$, square kilometer; Mt, millions of metric tons]

\begin{tabular}{ccccccc}
\hline $\begin{array}{c}\text { Date of } \\
\text { assessment }\end{array}$ & $\begin{array}{c}\text { Tract area } \\
\left(\mathbf{k m}^{2}\right)\end{array}$ & $\begin{array}{c}\text { Identified } \\
\text { copper } \\
\text { resources } \\
\text { (Mt) }\end{array}$ & $\begin{array}{c}\text { Mean estimate of } \\
\text { in-place resources } \\
(\mathbf{M t})\end{array}$ & $\begin{array}{c}\text { Probability of } \mathbf{0} \\
\text { in-place resources } \\
\text { (percent) }\end{array}$ & $\begin{array}{c}\text { Mean estimate of } \\
\text { economic resources } \\
\text { (Mt) }\end{array}$ & $\begin{array}{c}\text { Probability of 0 } \\
\text { economic resources } \\
\text { (percent) }\end{array}$ \\
\hline 2011 & 2,601 & 6.4 & 5.0 & 30 & 2.6 & 86 \\
\hline
\end{tabular}

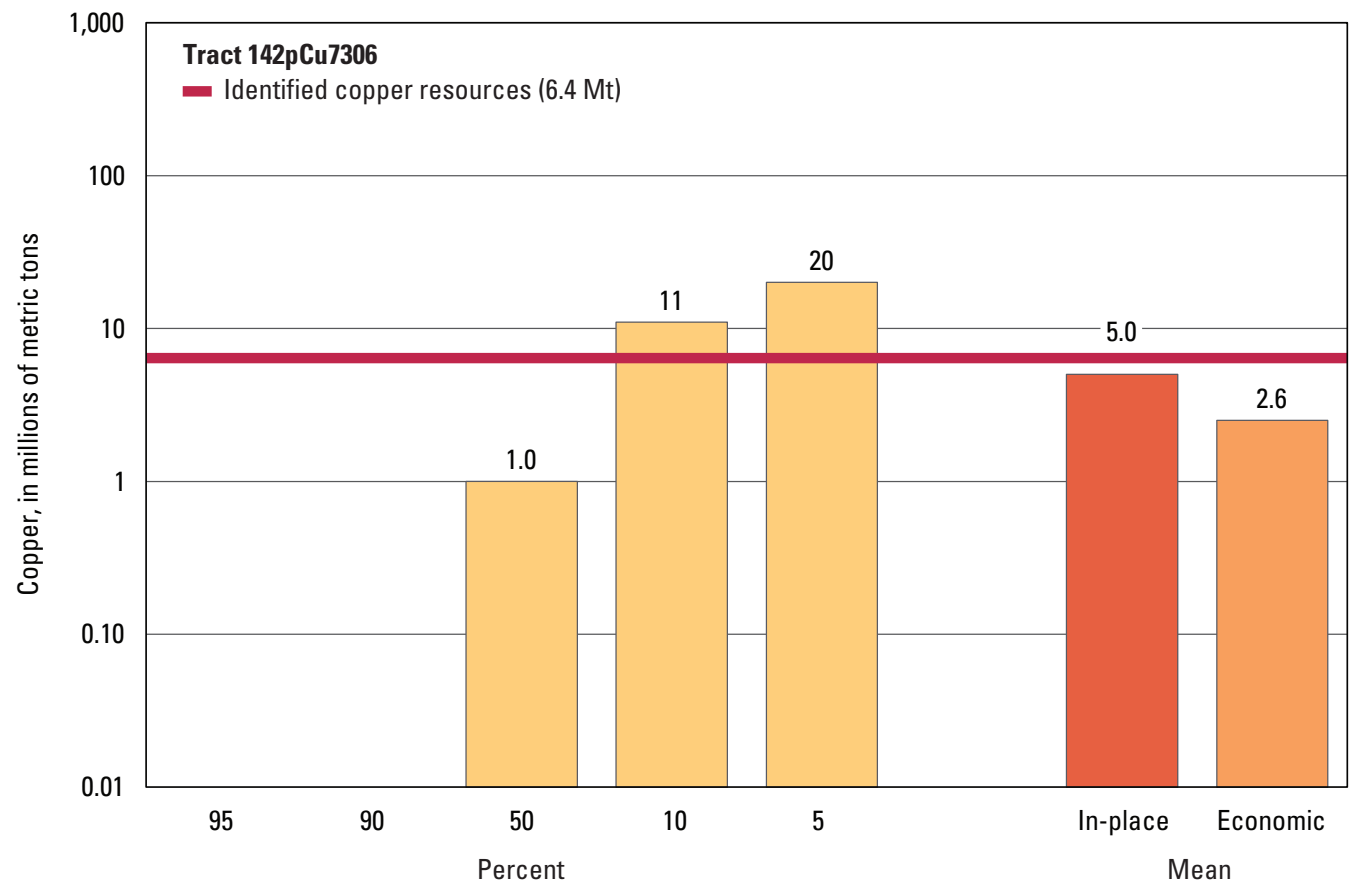

Graph showing the estimated probability distribution of undiscovered copper resources, where each bar represents the minimum amount estimated at the indicated percentage.

\section{Source}

Hammarstrom, Bookstrom, DeMarr, and others, 2014, Porphyry copper assessment of East and Southeast Asia—Philippines, Taiwan (Republic of China), Republic of Korea (South Korea), and Japan: U.S. Geological Survey Scientific Investigations Report 2010-5090-P, http://dx.doi.org/10.3133/sir20105090P. 


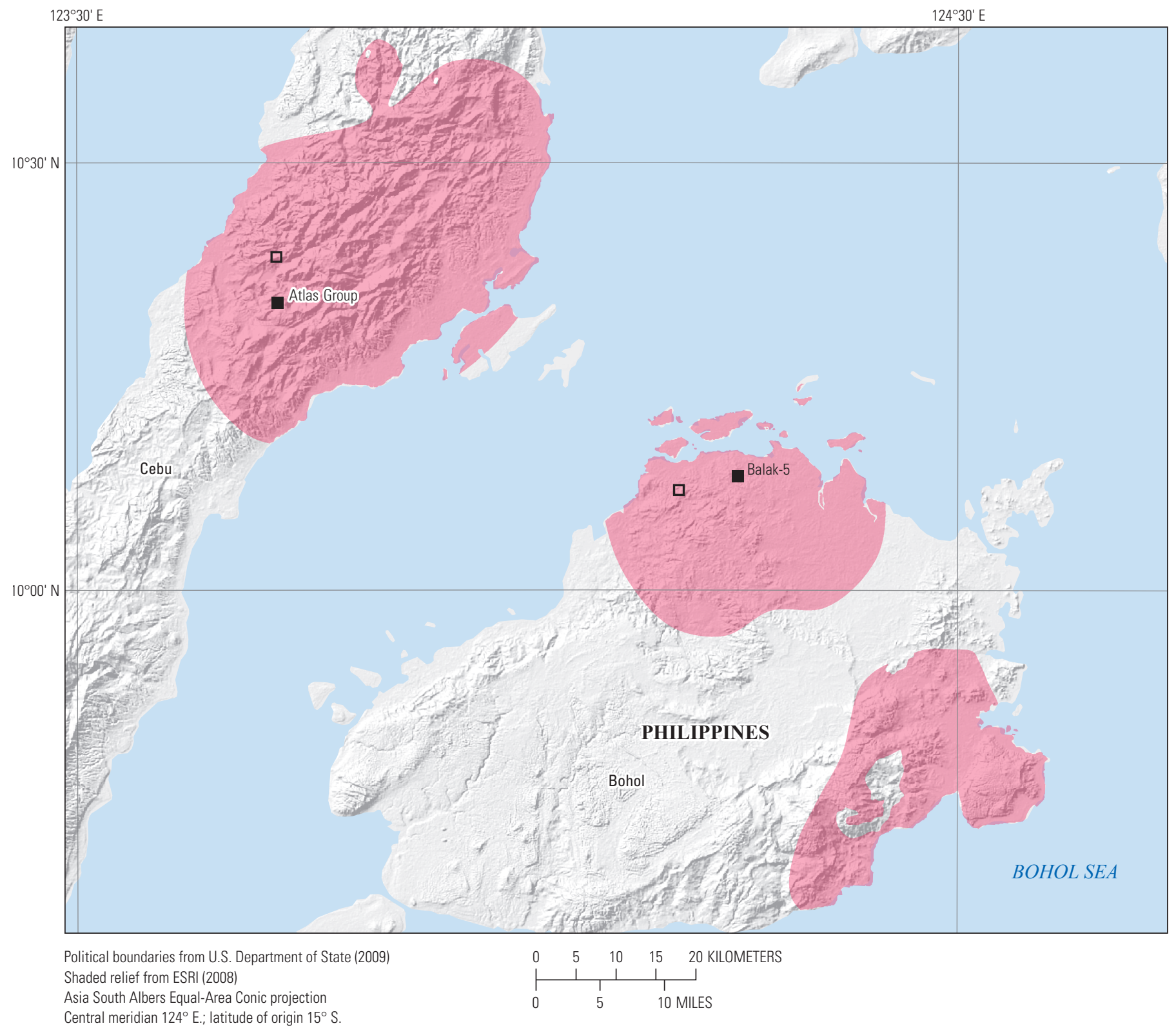

Central meridian $124^{\circ} \mathrm{E}$.; latitude of origin $15^{\circ} \mathrm{S}$

\section{EXPLANATION}

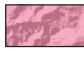

\section{Assessed porphyry copper tract} $142 \mathrm{pCu} 7306$

- Porphyry copper deposit

ㅁ Porphyry copper prospect

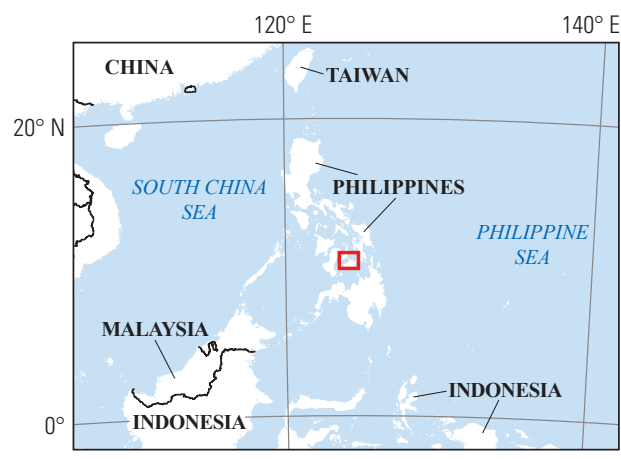




\section{Plate 105. Porphyry Copper Assessment for Tract 142pCu7307, Sulu-Zamboanga Arc-Philippines}

Descriptive model:

Grade and tonnage model:

Economic filter depth percentages:

Economic filter cost setting:

Geologic feature assessed:

Number of known deposits:
Porphyry copper models (Berger and others, 2008; John and others, 2010); porphyry copper-gold models (Cox, 1986b; Cooke and others, 1998)

Porphyry copper, copper-gold subtype model (Singer, Berger, and Moring, 2008)

Skewed deep- 0 to 250 meters (m), 10\%; > 250 to $500 \mathrm{~m}, 30 \%$; >500 m to $1 \mathrm{~km}, 60 \%$

High cost

Northern late Miocene to Holocene Sulu-Zamboanga arc

0

\section{Selected Resource Assessment Results for Porphyry Copper}

[Assessment depth, 1 kilometer (km); $\mathrm{km}^{2}$, square kilometer; Mt, millions of metric tons]

\begin{tabular}{ccccccc}
\hline $\begin{array}{c}\text { Date of } \\
\text { assessment }\end{array}$ & $\begin{array}{c}\text { Tract area } \\
\left(\mathbf{k m}^{2}\right)\end{array}$ & $\begin{array}{c}\text { Identified } \\
\text { copper } \\
\text { resources } \\
(\mathbf{M t})\end{array}$ & $\begin{array}{c}\text { Mean estimate of } \\
\text { in-place resources } \\
(\mathbf{M t})\end{array}$ & $\begin{array}{c}\text { Probability of } \mathbf{0} \\
\text { in-place resources } \\
\text { (percent) }\end{array}$ & $\begin{array}{c}\text { Mean estimate of } \\
\text { economic resources } \\
\text { (Mt) }\end{array}$ & $\begin{array}{c}\text { Probability of 0 } \\
\text { economic resources } \\
\text { (percent) }\end{array}$ \\
\hline 2010 & 10,179 & 0 & 2.5 & 30 & 1.1 \\
\hline
\end{tabular}

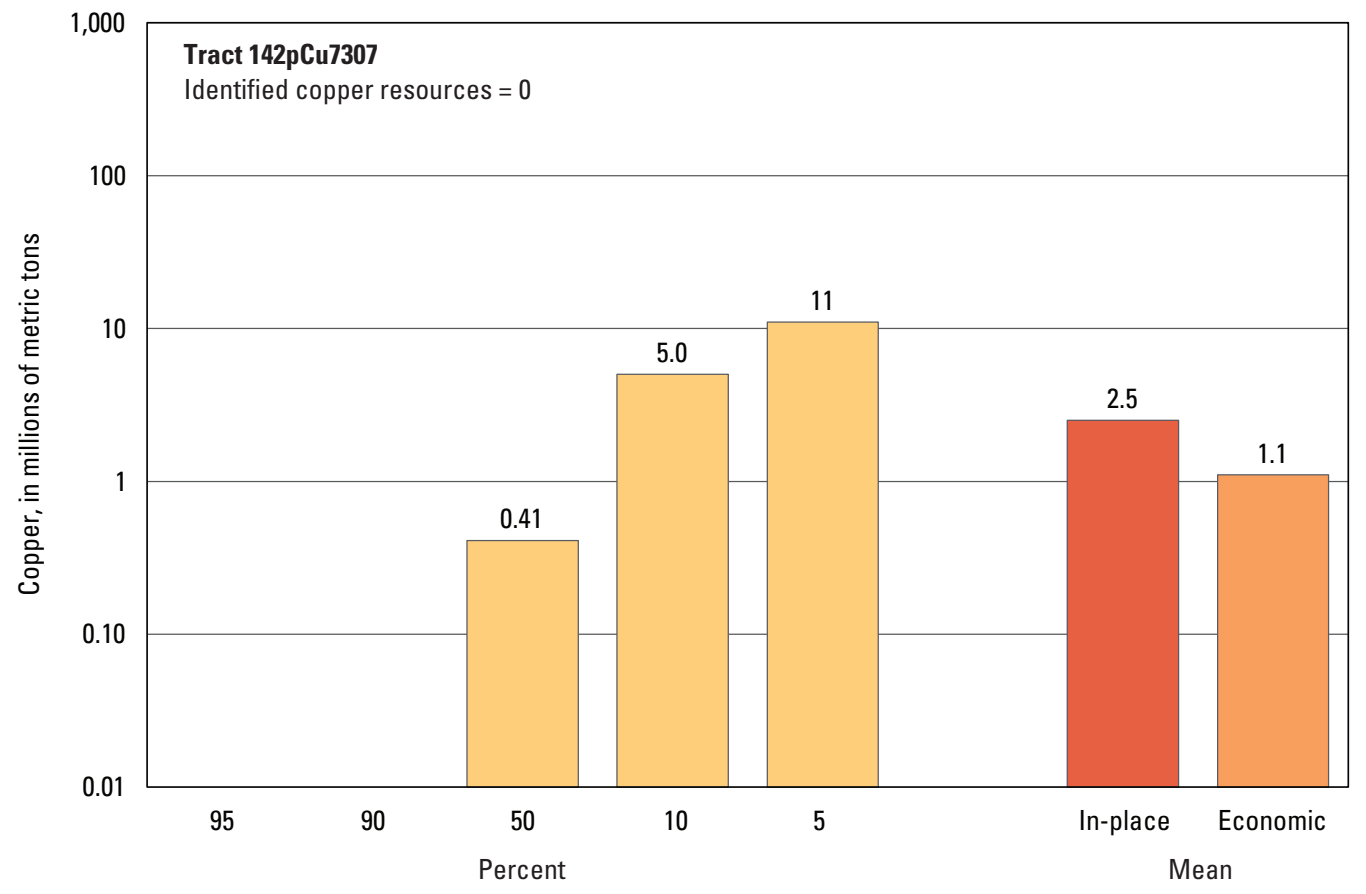

Graph showing the estimated probability distribution of undiscovered copper resources, where each bar represents the minimum amount estimated at the indicated percentage.

\section{Source}

Hammarstrom, Bookstrom, DeMarr, and others, 2014, Porphyry copper assessment of East and Southeast Asia-Philippines, Taiwan (Republic of China), Republic of Korea (South Korea), and Japan: U.S. Geological Survey Scientific Investigations Report 2010-5090-P, http://dx.doi.org/10.3133/sir20105090P. 


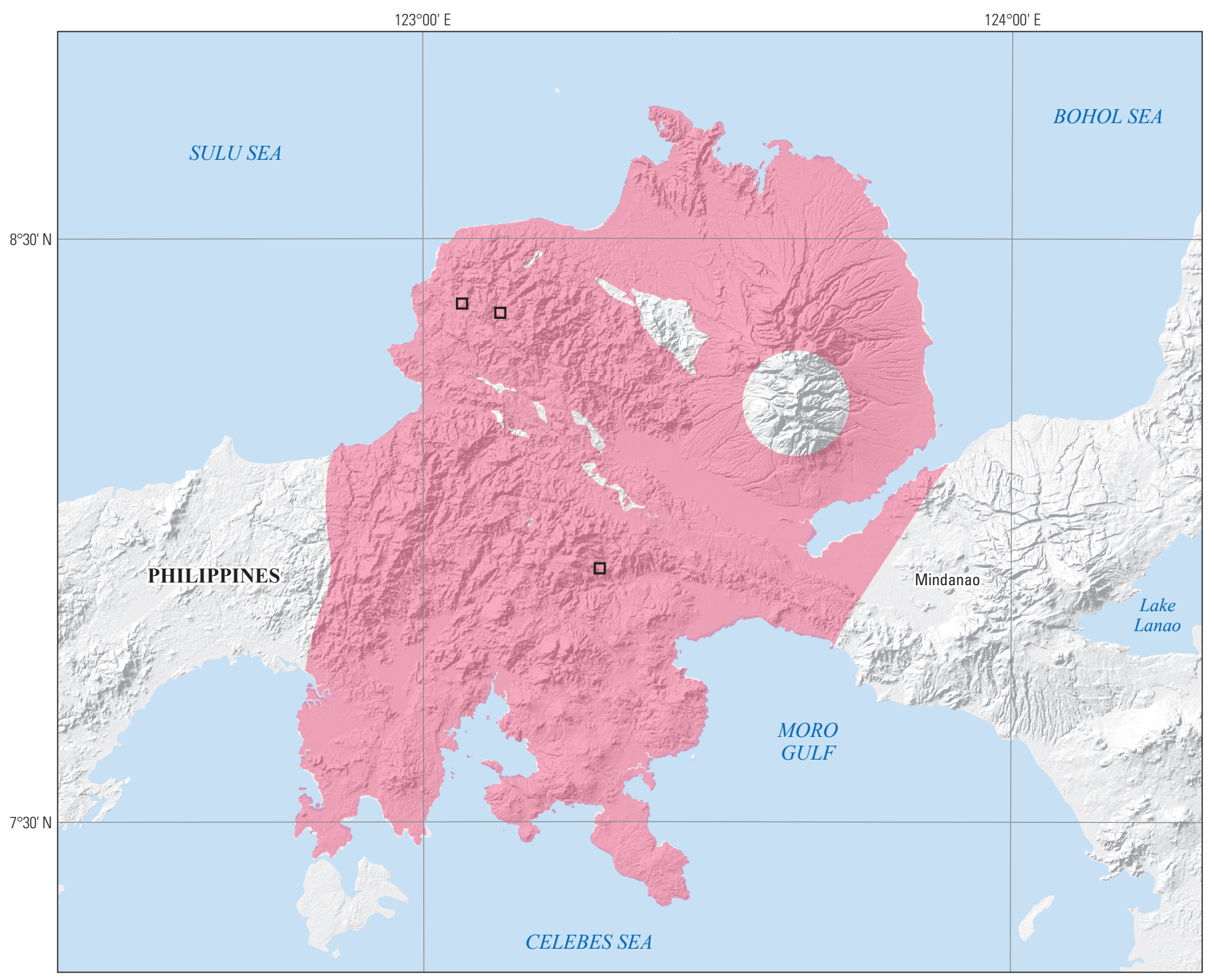

Political boundaries from U.S. Department of State (2009) Shaded relief from ESRI (2008)

Asia South Albers Equal-Area Conic projection

Central meridian $123^{\circ} 15^{\prime} \mathrm{E}$.; latitude of origin $15^{\circ} \mathrm{S}$.

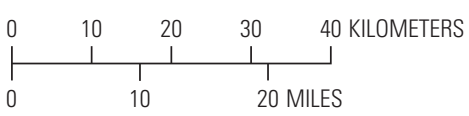

\section{EXPLANATION}

Assessed porphyry copper tract

142pCu7307

口 Porphyry copper prospect

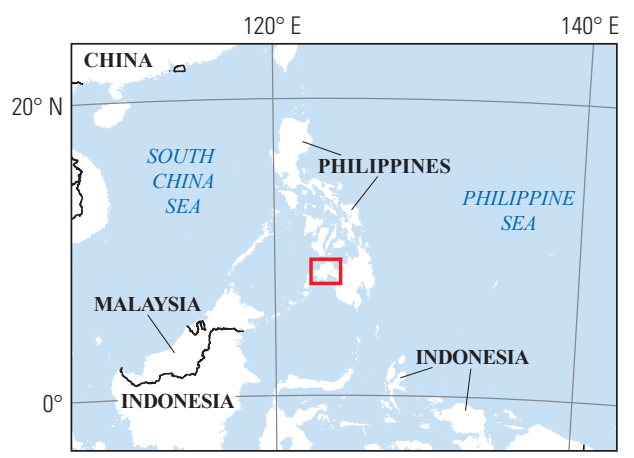




\section{Plate 106. Porphyry Copper Assessment for Tract 142pCu7308, Central Mindanao Volcanic Province-Philippines}

Descriptive model:

Grade and tonnage model:

Economic filter depth percentages:

Economic filter cost setting:

Geologic feature assessed:

Number of known deposits:
Porphyry copper models (Berger and others, 2008; John and others, 2010); porphyry copper-gold models (Cox, 1986b; Cooke and others, 1998)

Porphyry copper, copper-gold subtype model (Singer, Berger, and Moring, 2008)

Skewed deep- 0 to 250 meters (m), 10\%; > 250 to $500 \mathrm{~m}, 30 \%$; >500 m to $1 \mathrm{~km}, 60 \%$

High cost

Pliocene Central Mindanao volcanic province

0

\section{Selected Resource Assessment Results for Porphyry Copper}

[Assessment depth, 1 kilometer (km); $\mathrm{km}^{2}$, square kilometer; Mt, millions of metric tons]

\begin{tabular}{ccccccc}
\hline $\begin{array}{c}\text { Date of } \\
\text { assessment }\end{array}$ & $\begin{array}{c}\text { Tract area } \\
\left.\mathbf{( k m}^{2}\right)\end{array}$ & $\begin{array}{c}\text { Identified } \\
\text { copper } \\
\text { resources } \\
\text { (Mt) }\end{array}$ & $\begin{array}{c}\text { Mean estimate of } \\
\text { in-place resources } \\
(\mathbf{M t})\end{array}$ & $\begin{array}{c}\text { Probability of } \mathbf{0} \\
\text { in-place resources } \\
\text { (percent) }\end{array}$ & $\begin{array}{c}\text { Mean estimate of } \\
\text { economic resources } \\
\text { (Mt) }\end{array}$ & $\begin{array}{c}\text { Probability of 0 } \\
\text { economic resources } \\
\text { (percent) }\end{array}$ \\
\hline 2010 & 29,324 & 0 & 5.9 & 30 & 2.6 \\
\hline
\end{tabular}

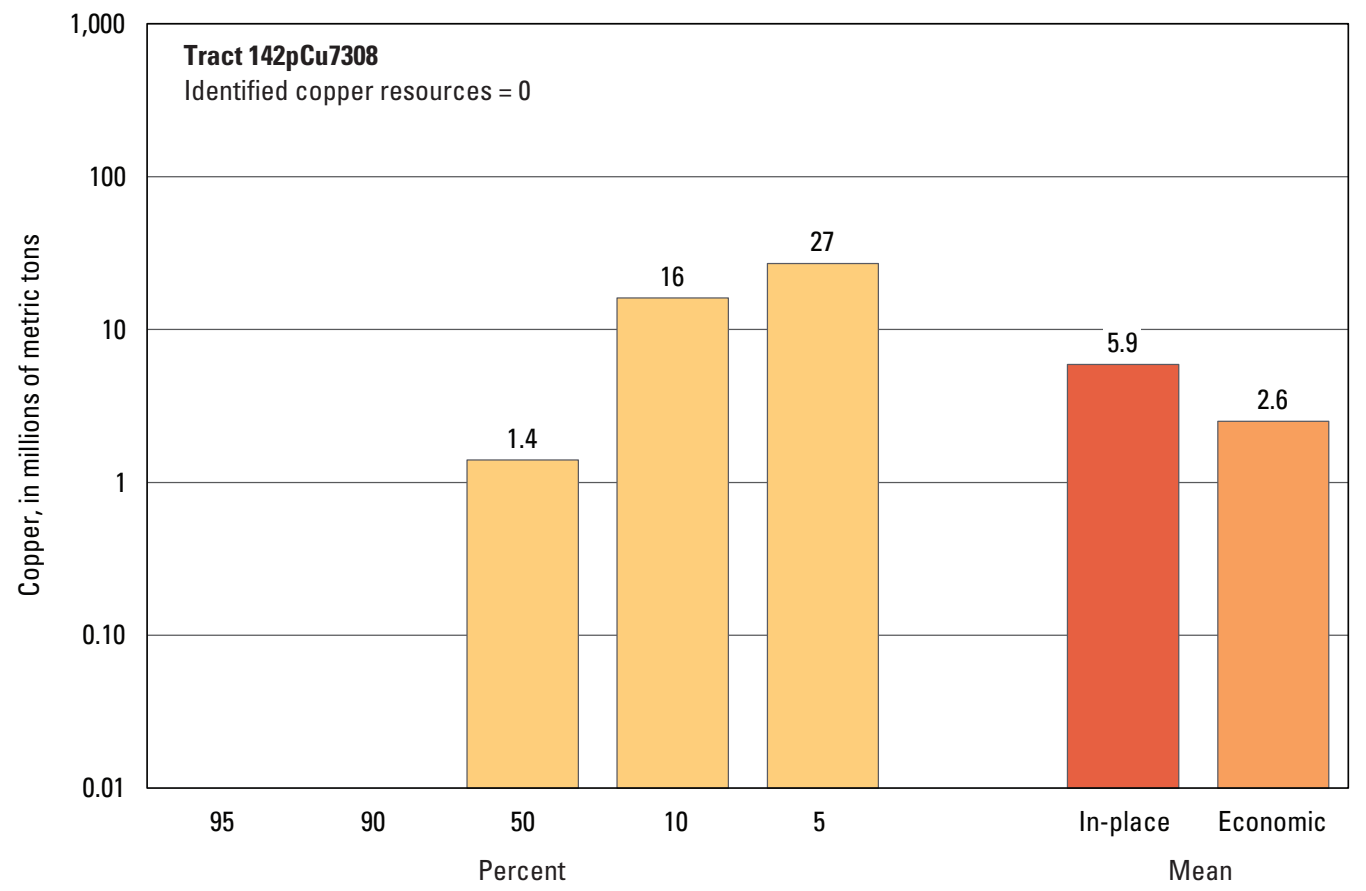

Graph showing the estimated probability distribution of undiscovered copper resources, where each bar represents the minimum amount estimated at the indicated percentage.

\section{Source}

Hammarstrom, Bookstrom, DeMarr, and others, 2014, Porphyry copper assessment of East and Southeast Asia—Philippines, Taiwan (Republic of China), Republic of Korea (South Korea), and Japan: U.S. Geological Survey Scientific Investigations Report 2010-5090-P, http://dx.doi.org/10.3133/sir20105090P. 


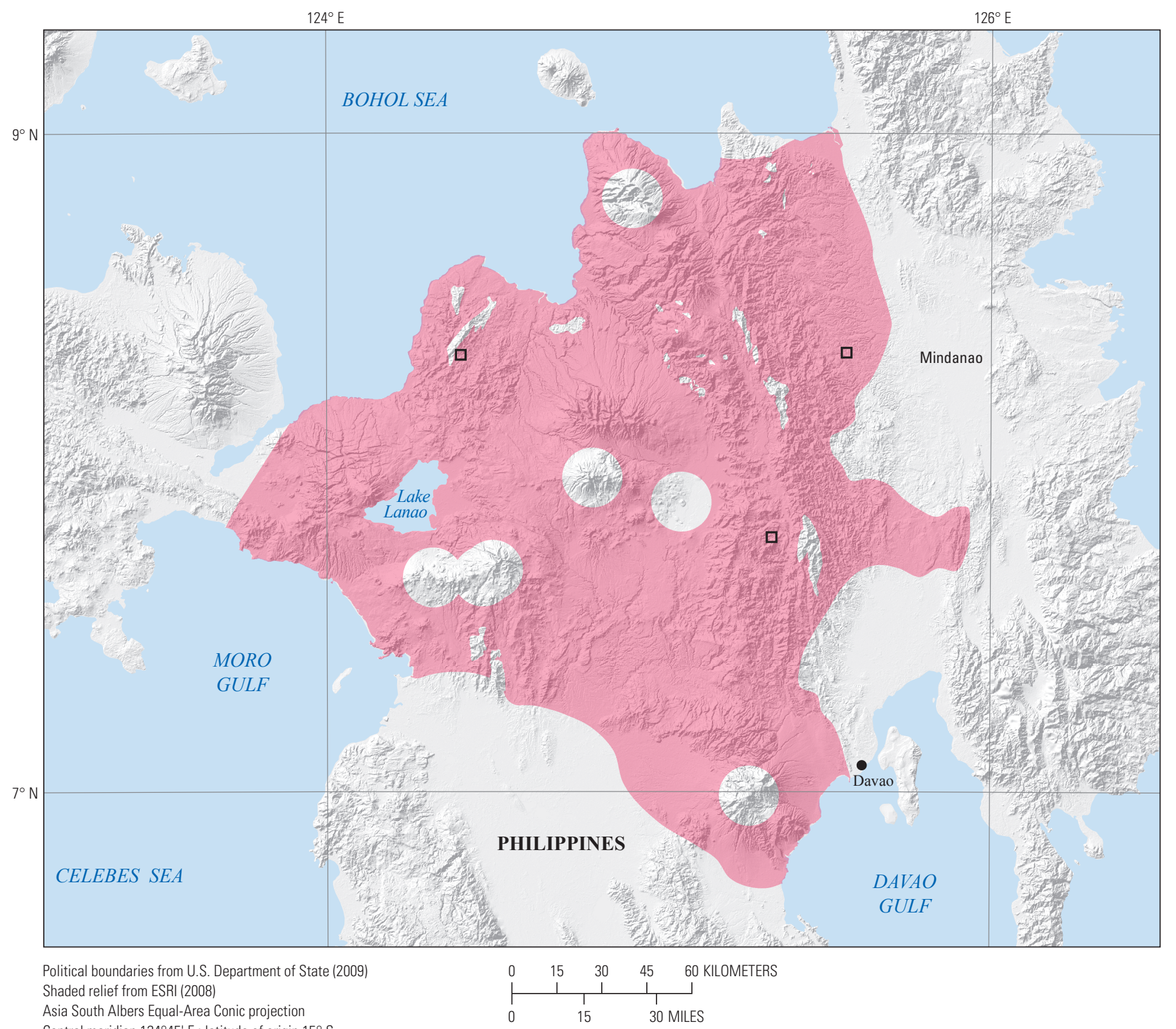

Central meridian $124^{\circ} 45^{\prime} \mathrm{E}$.; latitude of origin $15^{\circ} \mathrm{S}$.

\section{EXPLANATION}

Assessed porphyry copper tract 142pCu7308

ㅁ Porphyry copper prospect

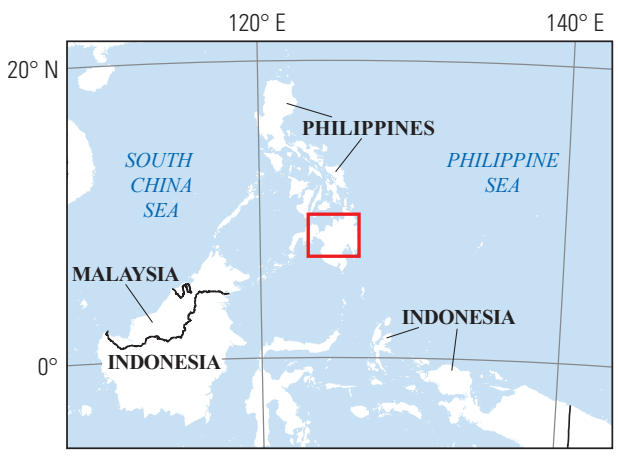




\section{Plate 107. Porphyry Copper Assessment for Tract 142pCu7312, Cotabato Arc- Philippines}

Descriptive model:

Grade and tonnage model:

Economic filter depth percentages:

Economic filter cost setting:

Geologic feature assessed:

Number of known deposits:
Porphyry copper models (Berger and others, 2008; John and others, 2010); porphyry copper-gold models (Cox, 1986b; Cooke and others, 1998)

General porphyry copper model (Singer, Berger, and Moring, 2008)

Default -0 to 250 meters (m), 25\%; > 250 to $500 \mathrm{~m}, 25 \%$; $>500 \mathrm{~m}$ to $1 \mathrm{~km}, 50 \%$

High cost

Miocene to Pleistocene Cotabato arc

1

\section{Selected Resource Assessment Results for Porphyry Copper}

[Assessment depth, 1 kilometer (km); $\mathrm{km}^{2}$, square kilometer; Mt, millions of metric tons]

\begin{tabular}{ccccccc}
\hline $\begin{array}{c}\text { Date of } \\
\text { assessment }\end{array}$ & $\begin{array}{c}\text { Tract area } \\
\left.\mathbf{( k m}^{2}\right)\end{array}$ & $\begin{array}{c}\text { Identified } \\
\text { copper } \\
\text { resources } \\
\text { (Mt) }\end{array}$ & $\begin{array}{c}\text { Mean estimate of } \\
\text { in-place resources } \\
(\mathbf{M t})\end{array}$ & $\begin{array}{c}\text { Probability of } \mathbf{0} \\
\text { in-place resources } \\
\text { (percent) }\end{array}$ & $\begin{array}{c}\text { Mean estimate of } \\
\text { economic resources } \\
\text { (Mt) }\end{array}$ & $\begin{array}{c}\text { Probability of 0 } \\
\text { economic resources } \\
\text { (percent) }\end{array}$ \\
\hline 2010 & 9,699 & 15 & 4.6 & 7 & 2.3 \\
\hline
\end{tabular}

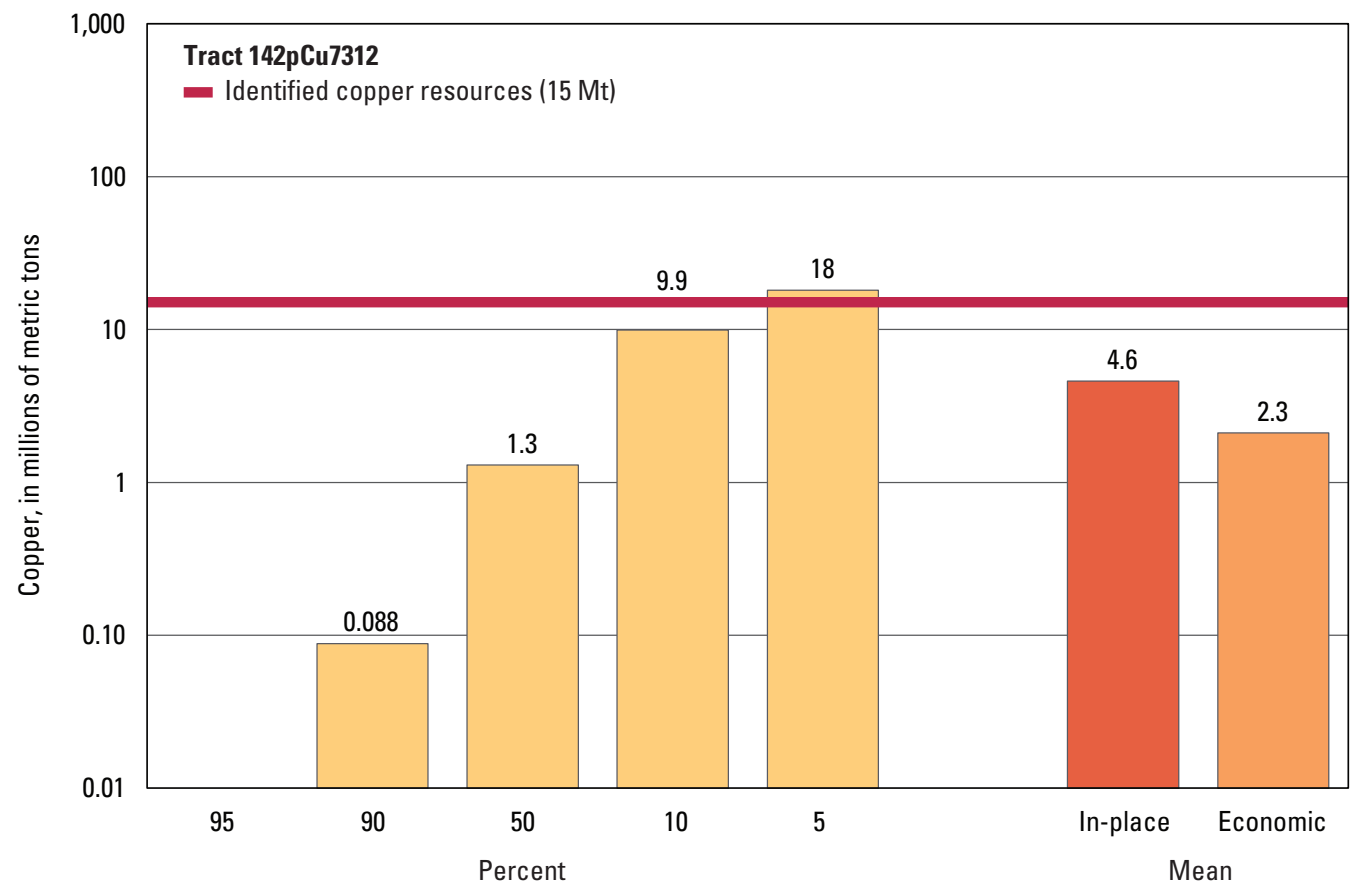

Graph showing the estimated probability distribution of undiscovered copper resources, where each bar represents the minimum amount estimated at the indicated percentage.

\section{Source}

Hammarstrom, Bookstrom, DeMarr, and others, 2014, Porphyry copper assessment of East and Southeast Asia—Philippines, Taiwan (Republic of China), Republic of Korea (South Korea), and Japan: U.S. Geological Survey Scientific Investigations Report 2010-5090-P, http://dx.doi.org/10.3133/sir20105090P. 


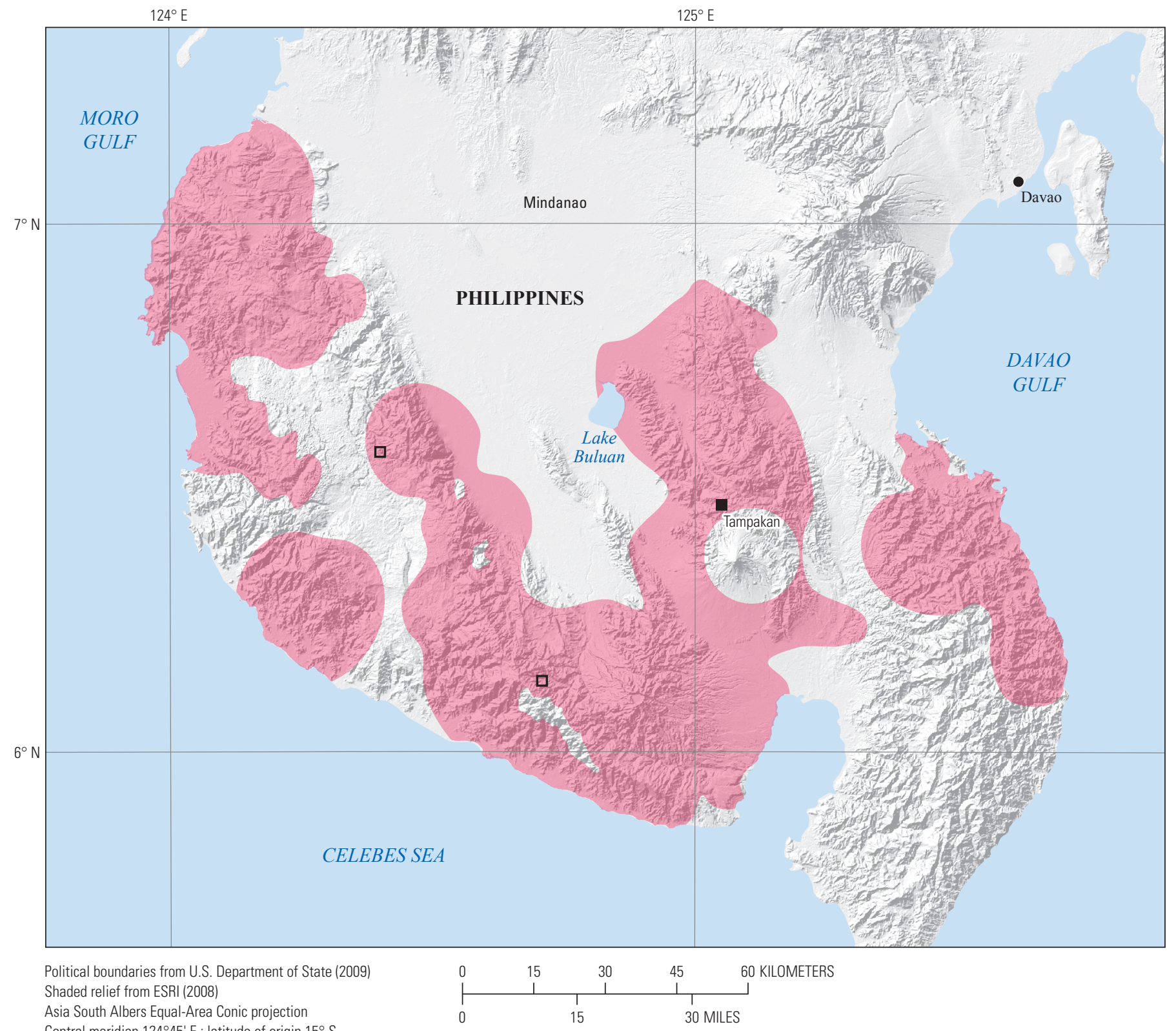

Central meridian $124^{\circ} 45^{\prime} \mathrm{E}$.; latitude of origin $15^{\circ} \mathrm{S}$.

EXPLANATION

Assessed porphyry copper tract 142pCu7312

- Porphyry copper deposit

ㅁ Porphyry copper prospect

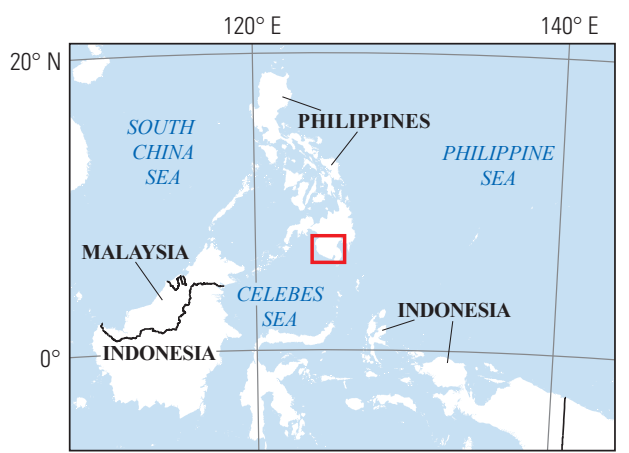




\section{Plate 108. Porphyry Copper Assessment for Tract 142pCu7019, Central Kalimantan-Indonesia and Malaysia}

Descriptive model:

Grade and tonnage model:

Economic filter depth percentages:

Economic filter cost setting:

Geologic feature assessed:

Number of known deposits:
Porphyry copper models (Berger and others, 2008; John and others, 2010); porphyry copper-gold models (Cox, 1986b; Cooke and others, 1998)

Porphyry copper, copper-gold subtype model (Singer, Berger, and Moring, 2008)

Default -0 to 250 meters (m), 25\%; >250 to $500 \mathrm{~m}, 25 \%$; $>500 \mathrm{~m}$ to $1 \mathrm{~km}, 50 \%$

High cost

A dispersed belt of Tertiary intermediate intrusive and volcanic rocks that postdate pre-Eocene subduction and deformation, uplift, and erosion of pre-Miocene rocks and continental basement in Kalimantan

1

\section{Selected Resource Assessment Results for Porphyry Copper}

[Assessment depth, 1 kilometer (km); km² , square kilometer; Mt, millions of metric tons]

\begin{tabular}{ccccccc}
\hline $\begin{array}{c}\text { Date of } \\
\text { assessment }\end{array}$ & $\begin{array}{c}\text { Tract area } \\
\left(\mathbf{k m}^{2}\right)\end{array}$ & $\begin{array}{c}\text { Identified } \\
\text { copper } \\
\text { resources } \\
(\mathbf{M t})\end{array}$ & $\begin{array}{c}\text { Mean estimate of } \\
\text { in-place resources } \\
(\mathbf{M t})\end{array}$ & $\begin{array}{c}\text { Probability of } 0 \\
\text { in-place resources } \\
\text { (percent) }\end{array}$ & $\begin{array}{c}\text { Mean estimate of } \\
\text { economic resources } \\
\text { (Mt) }\end{array}$ & $\begin{array}{c}\text { Probability of 0 } \\
\text { economic resources } \\
\text { (percent) }\end{array}$ \\
\hline 2010 & 144,580 & 0.94 & 40 & 3 & 19 \\
\hline
\end{tabular}

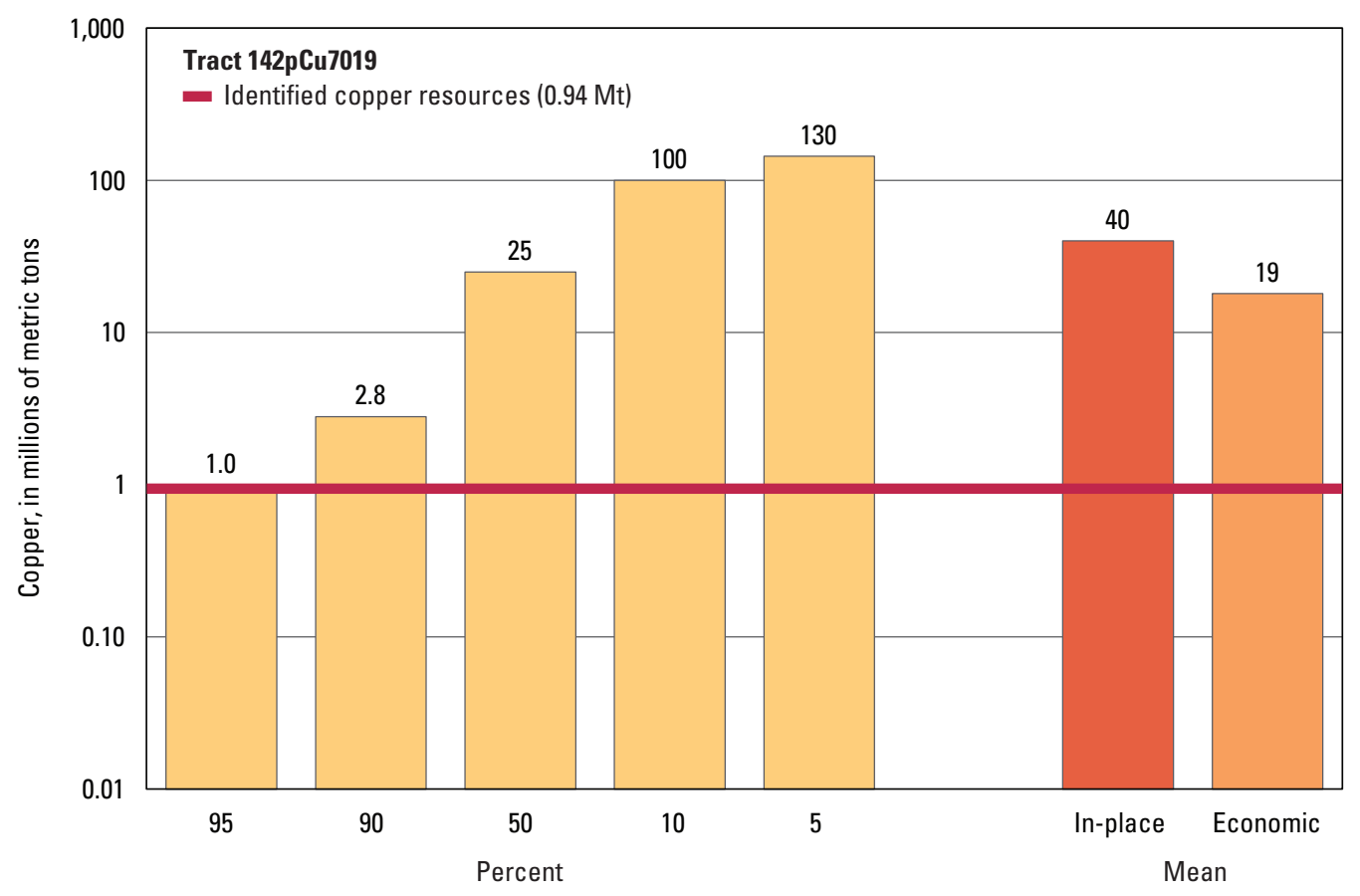

Graph showing the estimated probability distribution of undiscovered copper resources, where each bar represents the minimum amount estimated at the indicated percentage.

\section{Source}

Hammarstrom, Bookstrom, Dicken, and others, 2013, Porphyry copper assessment of Southeast Asia and Melanesia: U.S. Geological Survey Scientific Investigations Report 2010-5090-D, http://pubs.usgs.gov/sir/2010/5090/d/. 


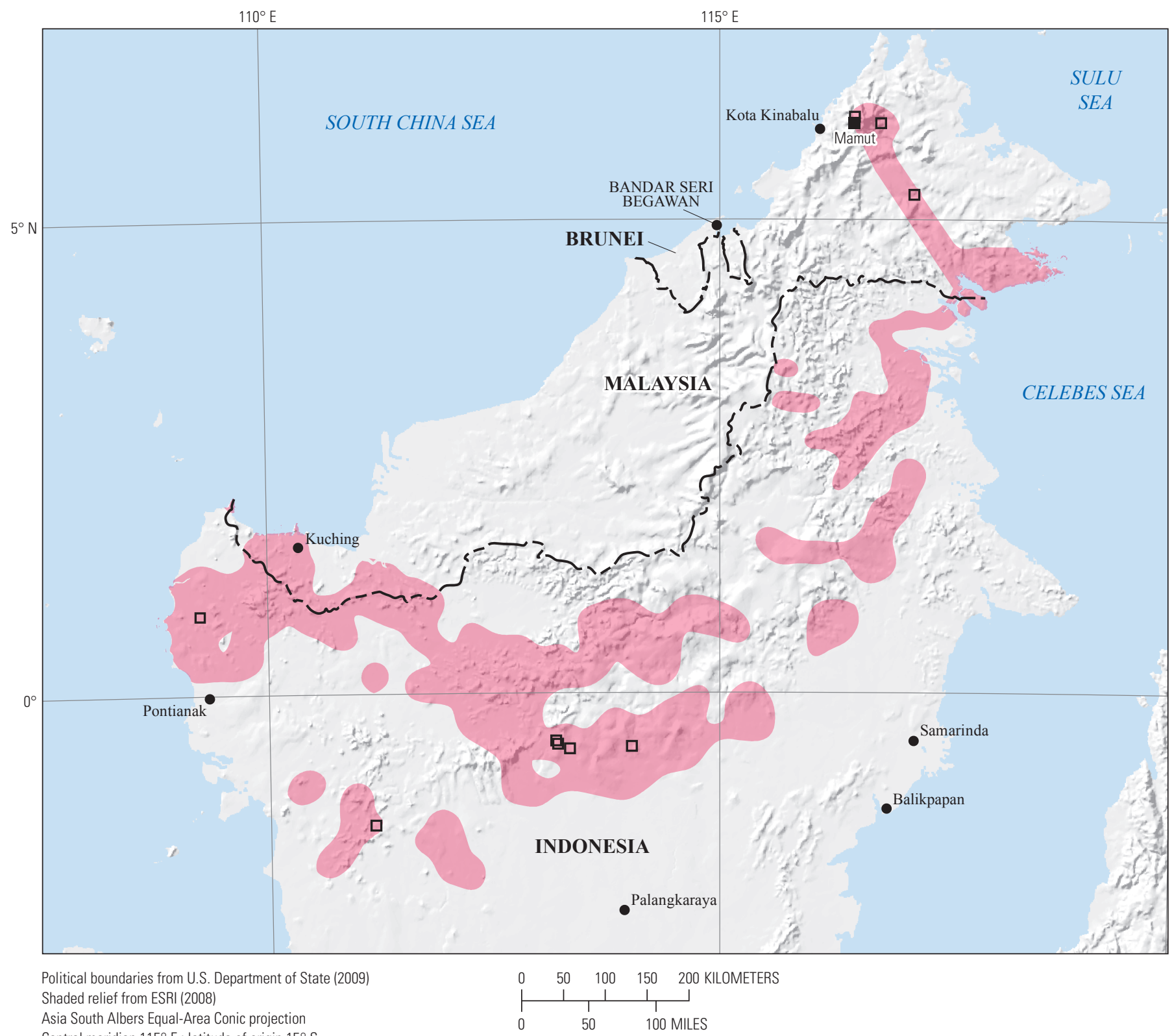

Central meridian $115^{\circ} \mathrm{E}$.; latitude of origin $15^{\circ} \mathrm{S}$.

EXPLANATION

Assessed porphyry copper tract 142pCu7019

- Porphyry copper deposit

$\square \quad$ Porphyry copper prospect

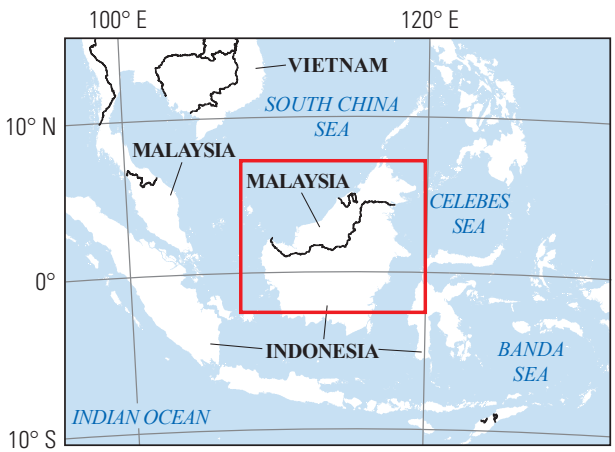




\section{Plate 109. Porphyry Copper Assessment for Tract 142pCu7020, Sumatra Island-Indonesia}

\author{
Descriptive model: \\ Grade and tonnage model: \\ Economic filter depth percentages: \\ Economic filter cost setting: \\ Geologic feature assessed:
}

Number of known deposits:
Porphyry copper models (Cox, 1986a; Berger and others, 2008; John and others, 2010)

General porphyry copper model (Singer, Berger, and Moring, 2008)

Default - 0 to 250 meters (m), 25\%; > 250 to $500 \mathrm{~m}, 25 \%$; >500 m to $1 \mathrm{~km}, 50 \%$

High cost

An Eocene to Pliocene continental magmatic arc that straddles the northwest-trending Sumatran fault zone in western Sumatra. The known porphyry copper deposit and the prospects in this tract are Miocene to Pliocene in age

1

\section{Selected Resource Assessment Results for Porphyry Copper}

[Assessment depth, 1 kilometer $(\mathrm{km}) ; \mathrm{km}^{2}$, square kilometer; Mt, millions of metric tons]

\begin{tabular}{ccccccc}
\hline \multirow{2}{*}{$\begin{array}{c}\text { Date of } \\
\text { assessment }\end{array}$} & $\begin{array}{c}\text { Tract area } \\
\left(\mathbf{k m}^{2}\right)\end{array}$ & $\begin{array}{c}\text { Identified } \\
\text { copper } \\
\text { resources } \\
(\mathbf{M t})\end{array}$ & $\begin{array}{c}\text { Mean estimate of } \\
\text { in-place resources } \\
(\mathbf{M t})\end{array}$ & $\begin{array}{c}\text { Probability of } \mathbf{0} \\
\text { in-place resources } \\
\text { (percent) }\end{array}$ & $\begin{array}{c}\text { Mean estimate of } \\
\text { economic resources } \\
\text { (Mt) }\end{array}$ & $\begin{array}{c}\text { Probability of } \mathbf{0} \\
\text { economic resources } \\
\text { (percent) }\end{array}$ \\
\hline 2010 & 131,027 & 0.90 & 23 & 7 & 11 \\
\hline
\end{tabular}

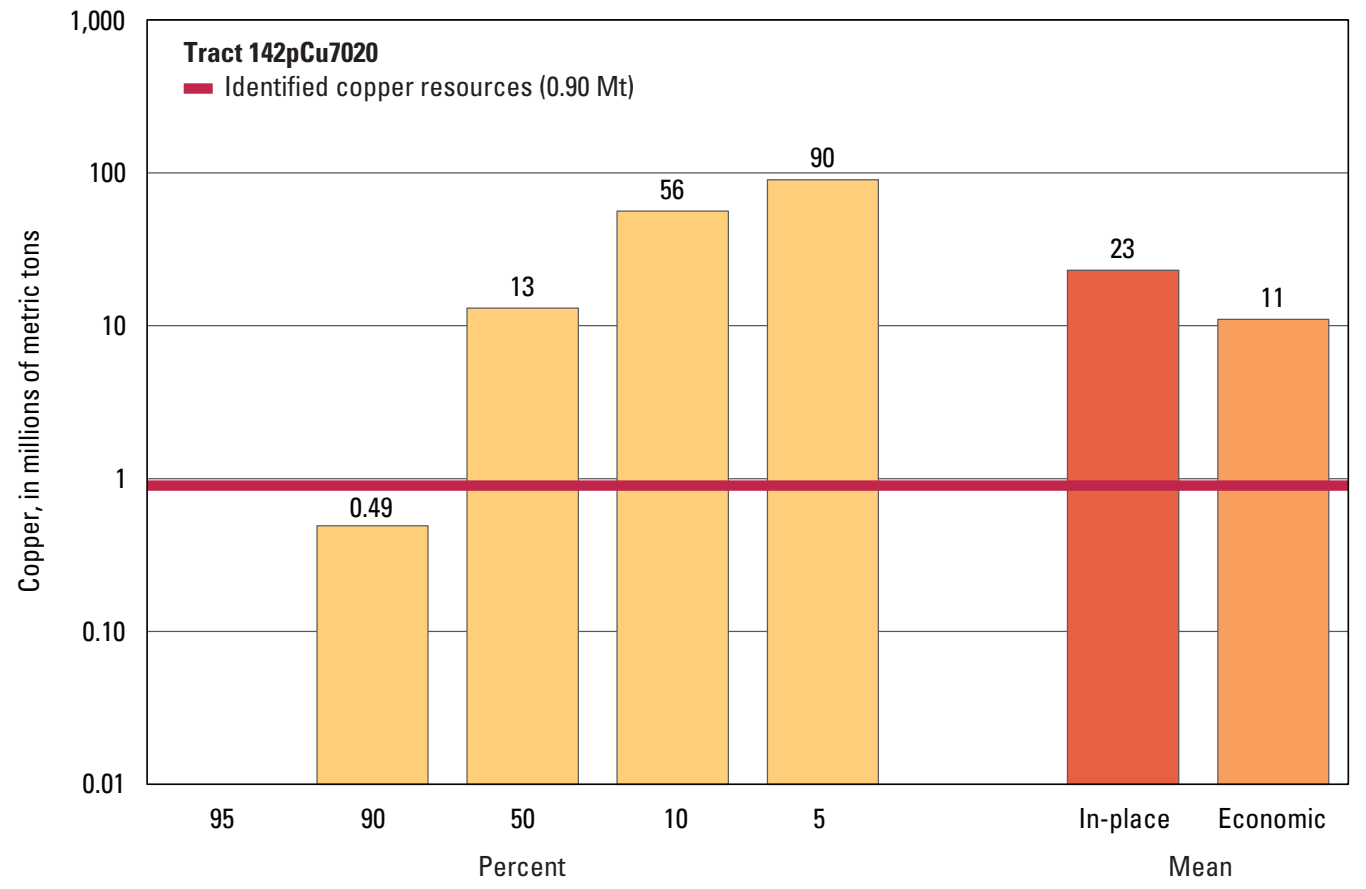

Graph showing the estimated probability distribution of undiscovered copper resources, where each bar represents the minimum amount estimated at the indicated percentage.

\section{Source}

Hammarstrom, Bookstrom, Dicken, and others, 2013, Porphyry copper assessment of Southeast Asia and Melanesia: U.S. Geological Survey Scientific Investigations Report 2010-5090-D, http://pubs.usgs.gov/sir/2010/5090/d/. 


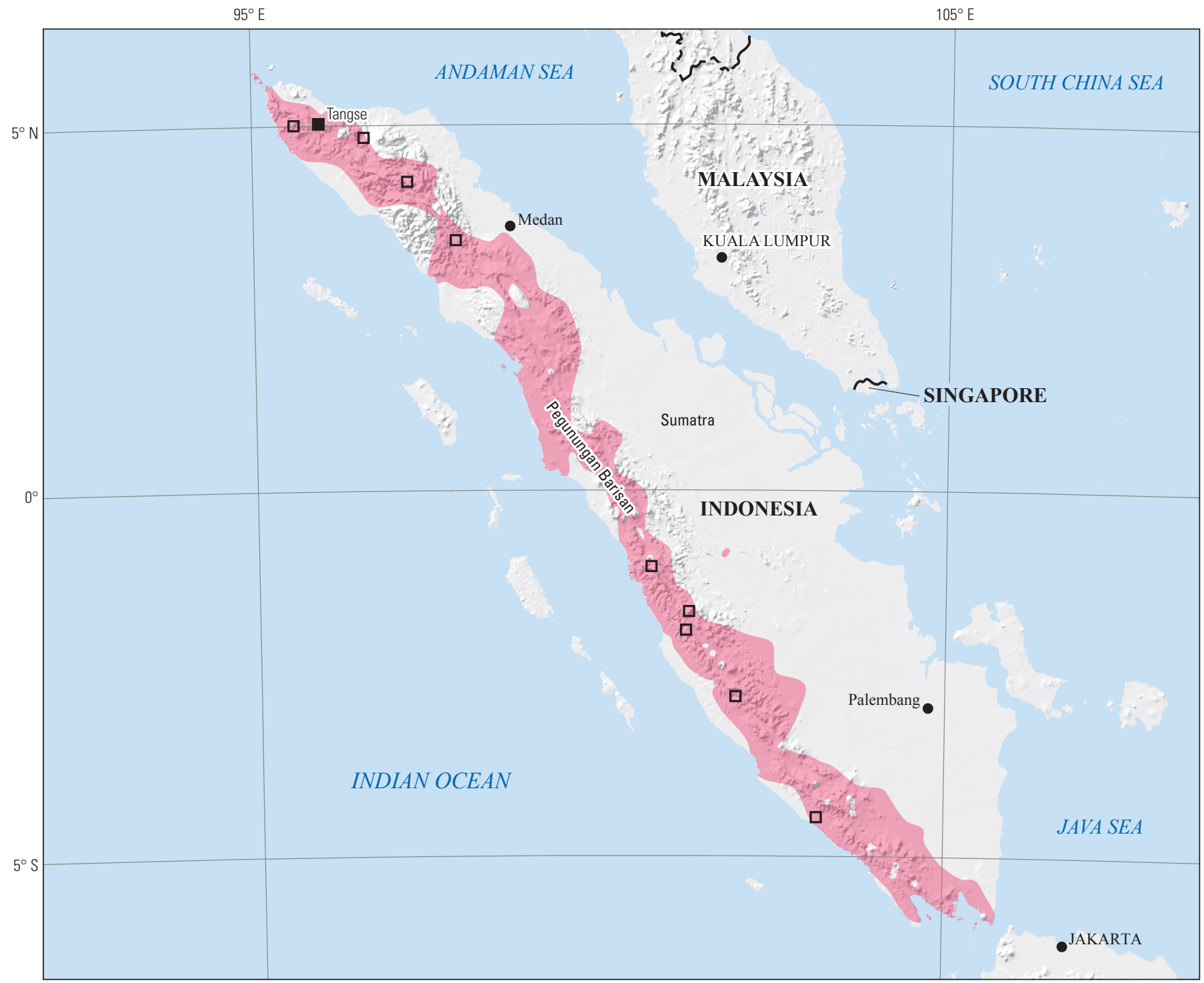

Political boundaries from U.S. Department of State (2009) Shaded relief from ESRI (2008)

Asia South Albers Equal-Area Conic projection

Central meridian $100^{\circ} 30^{\prime} \mathrm{E}$. ; latitude of origin $15^{\circ} \mathrm{S}$.

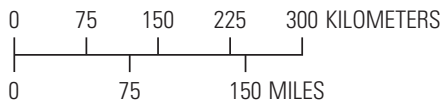

EXPLANATION

Assessed porphyry copper tract 142pCu7020

- Porphyry copper deposit

$\square \quad$ Porphyry copper prospect

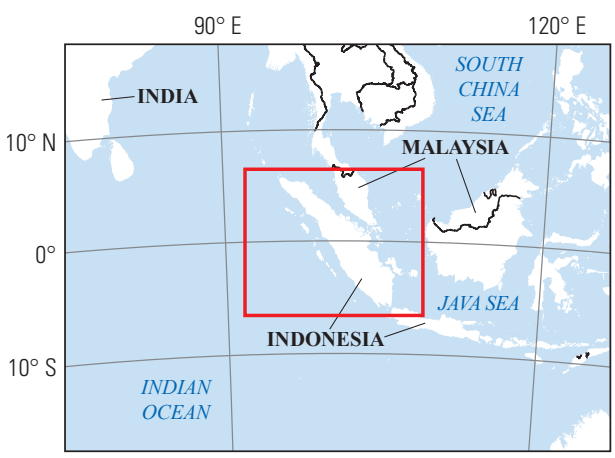




\section{Plate 110. Porphyry Copper Assessment for Tract 142pCu7025a, Sunda Banda Arc (West)—Indonesia}

\author{
Descriptive model: \\ Grade and tonnage model: \\ Economic filter depth percentages: \\ Economic filter cost setting: \\ Geologic feature assessed: \\ Number of known deposits:
}

\begin{abstract}
Porphyry copper models (Berger and others, 2008; John and others, 2010); porphyry copper-gold models (Cox, 1986b; Cooke and others, 1998)

Porphyry copper, copper-gold subtype model (Singer, Berger, and Moring, 2008)

Default -0 to 250 meters (m), 25\%; > 250 to $500 \mathrm{~m}, 25 \%$; >500 m to $1 \mathrm{~km}, 50 \%$

High cost

The western part of the Eocene to Holocene Sunda-Banda magmatic arc; Java Island

0 (1) (As shown on the map, one deposit was found after the assessment was done; the assessment results below reflect information available in 2010 for 0 deposits.)
\end{abstract}

\section{Selected Resource Assessment Results for Porphyry Copper}

[Assessment depth, 1 kilometer $(\mathrm{km}) ; \mathrm{km}^{2}$, square kilometer; Mt, millions of metric tons]

\begin{tabular}{|c|c|c|c|c|c|c|}
\hline \multirow[b]{2}{*}{$\begin{array}{c}\text { Date of } \\
\text { assessment }\end{array}$} & \multirow[b]{2}{*}{$\begin{array}{l}\text { Tract area } \\
\quad\left(\mathbf{k m}^{2}\right)\end{array}$} & \multirow{2}{*}{$\begin{array}{c}\text { Identified } \\
\text { copper } \\
\text { resources } \\
\text { (Mt) }\end{array}$} & \multicolumn{4}{|c|}{ Undiscovered copper resource estimates } \\
\hline & & & $\begin{array}{l}\text { Mean estimate of } \\
\text { in-place resources } \\
\text { (Mt) }\end{array}$ & $\begin{array}{c}\text { Probability of } 0 \\
\text { in-place resources } \\
\text { (percent) }\end{array}$ & $\begin{array}{l}\text { Mean estimate of } \\
\text { economic resources } \\
\text { (Mt) }\end{array}$ & $\begin{array}{c}\text { Probability of } 0 \\
\text { economic resources } \\
\text { (percent) }\end{array}$ \\
\hline 2010 & 61,201 & 0 & 10 & 6 & 4.8 & 62 \\
\hline
\end{tabular}

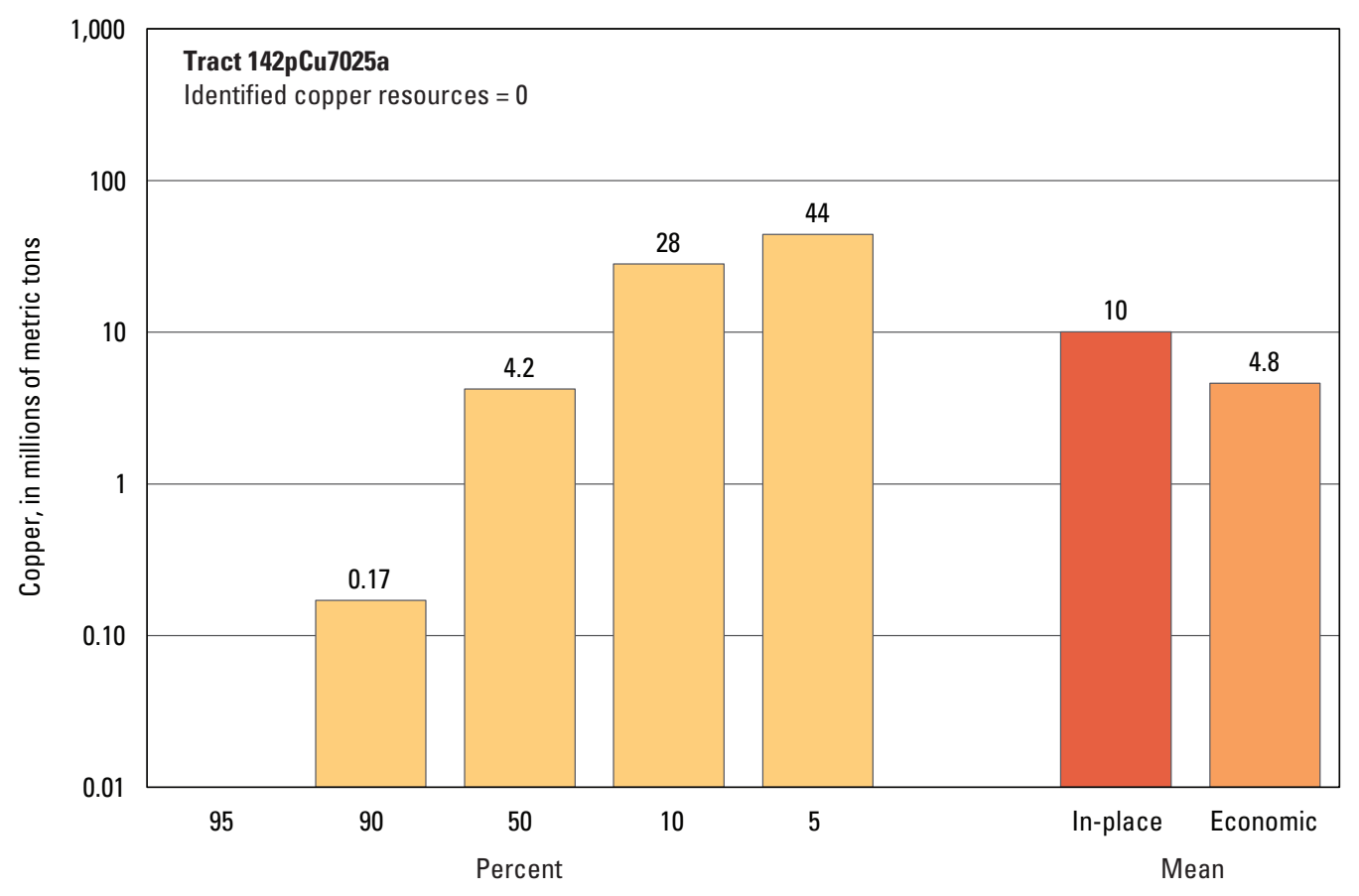

Graph showing the estimated probability distribution of undiscovered copper resources, where each bar represents the minimum amount estimated at the indicated percentage.

\section{Source}

Hammarstrom, Bookstrom, Dicken, and others, 2013, Porphyry copper assessment of Southeast Asia and Melanesia: U.S. Geological Survey Scientific Investigations Report 2010-5090-D, http://pubs.usgs.gov/sir/2010/5090/d/. 


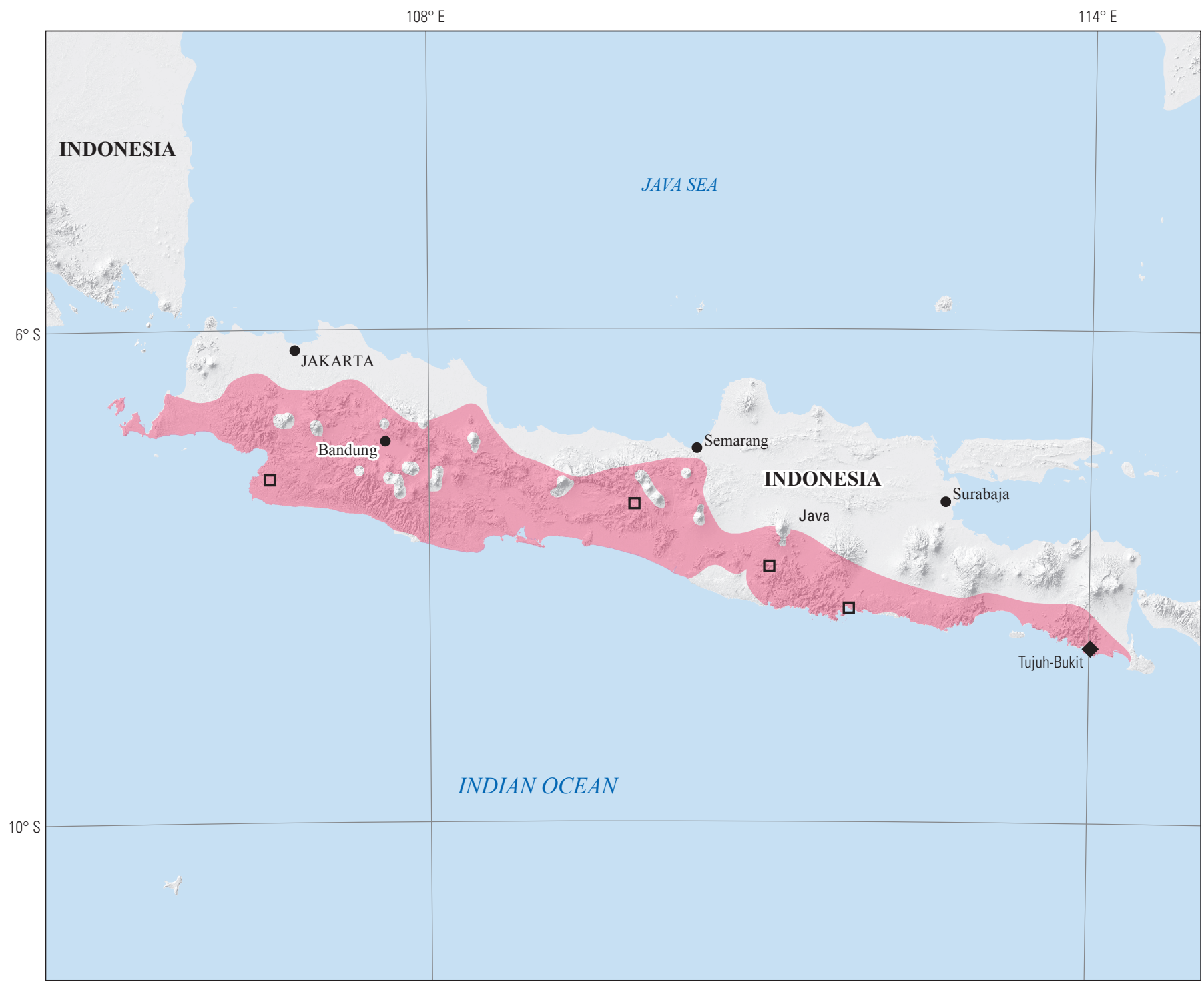

Political boundaries from U.S. Department of State (2009) Shaded relief from ESRI (2008)

Asia South Albers Equal-Area Conic projection

Central meridian $110^{\circ} \mathrm{E}$.; latitude of origin $15^{\circ} \mathrm{S}$

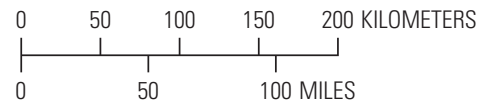

\section{EXPLANATION}

Assessed porphyry copper tract 142pCu7025a

Porphyry copper deposit discovered after the assessment

口 Porphyry copper prospect

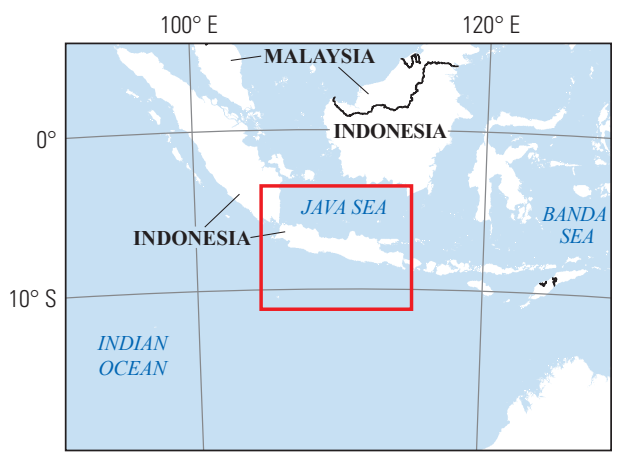




\section{Plate 111. Porphyry Copper Assessment for Tract 142pCu7025b, Sunda Banda Arc (Central)-Indonesia}

Descriptive model:

Grade and tonnage model:

Economic filter depth percentages:

Economic filter cost setting:

Geologic feature assessed:

Number of known deposits:
Porphyry copper models (Berger and others, 2008; John and others, 2010); porphyry copper-gold models (Cox, 1986b; Cooke and others, 1998)

Porphyry copper, copper-gold subtype model (Singer, Berger, and Moring, 2008)

Skewed deep- 0 to 250 meters (m), 10\%; > 250 to $500 \mathrm{~m}, 30 \%$; >500 m to $1 \mathrm{~km}, 60 \%$

High cost

The central part of the Eocene to Holocene Sunda-Banda magmatic arc; Bali Island to western Flores Island

1

\section{Selected Resource Assessment Results for Porphyry Copper}

[Assessment depth, 1 kilometer $(\mathrm{km}) ; \mathrm{km}^{2}$, square kilometer; Mt, millions of metric tons]

\begin{tabular}{|c|c|c|c|c|c|c|}
\hline \multirow[b]{2}{*}{$\begin{array}{c}\text { Date of } \\
\text { assessment }\end{array}$} & \multirow[b]{2}{*}{$\begin{array}{c}\text { Tract area } \\
\qquad\left(\mathbf{k m}^{2}\right)\end{array}$} & \multirow{2}{*}{$\begin{array}{l}\text { Identified } \\
\text { copper } \\
\text { resources } \\
\text { (Mt) }\end{array}$} & \multicolumn{4}{|c|}{ Undiscovered copper resource estimates } \\
\hline & & & $\begin{array}{l}\text { Mean estimate of } \\
\text { in-place resources } \\
\text { (Mt) }\end{array}$ & $\begin{array}{c}\text { Probability of } 0 \\
\text { in-place resources } \\
\text { (percent) }\end{array}$ & $\begin{array}{c}\text { Mean estimate of } \\
\text { economic resources } \\
\text { (Mt) }\end{array}$ & $\begin{array}{c}\text { Probability of } 0 \\
\text { economic resources } \\
\text { (percent) }\end{array}$ \\
\hline 2010 & 22,553 & 7.2 & 15 & 7 & 6.5 & 64 \\
\hline
\end{tabular}

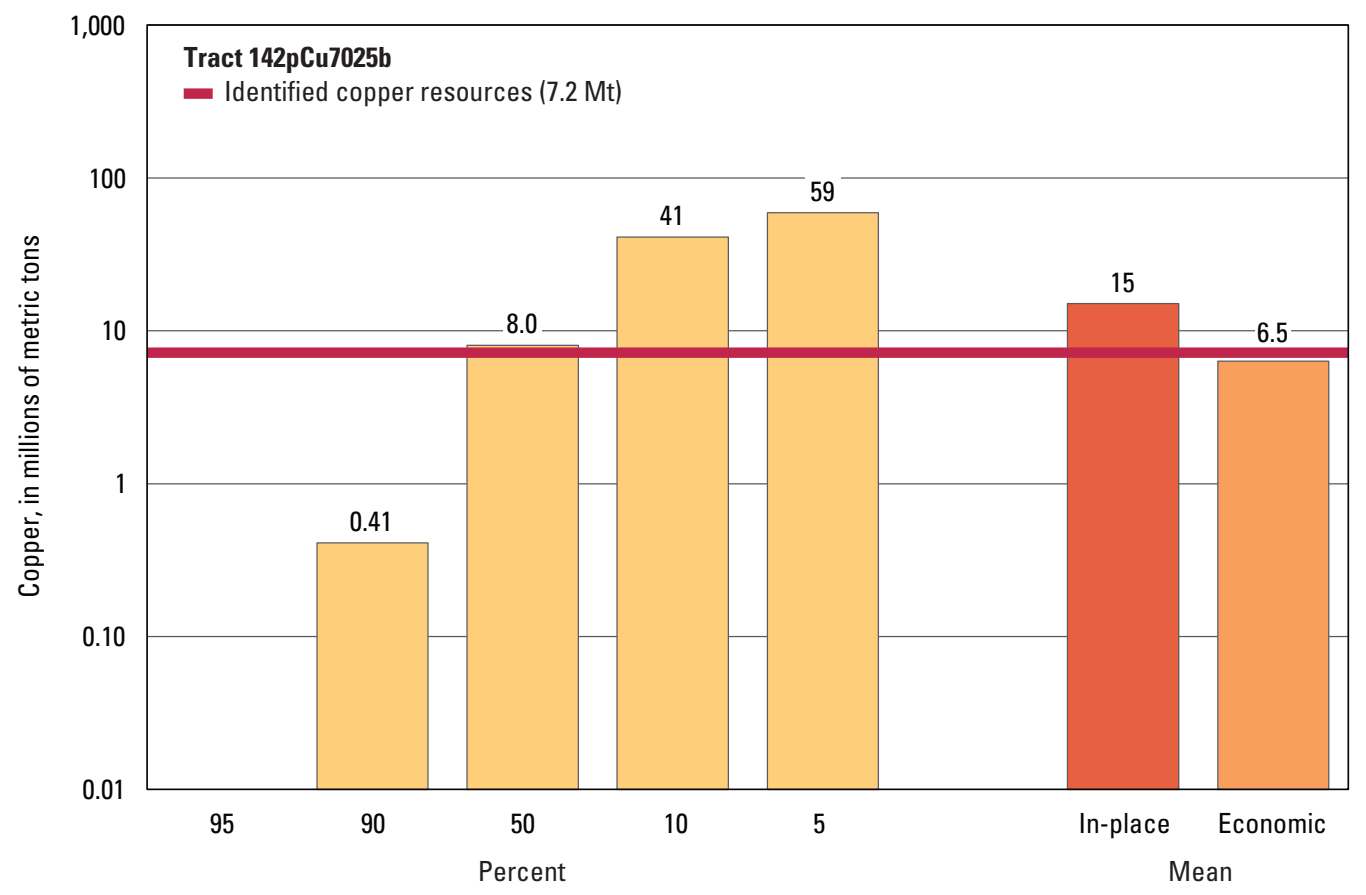

Graph showing the estimated probability distribution of undiscovered copper resources, where each bar represents the minimum amount estimated at the indicated percentage.

\section{Source}

Hammarstrom, Bookstrom, Dicken, and others, 2013, Porphyry copper assessment of Southeast Asia and Melanesia: U.S. Geological Survey Scientific Investigations Report 2010-5090-D, http://pubs.usgs.gov/sir/2010/5090/d/. 


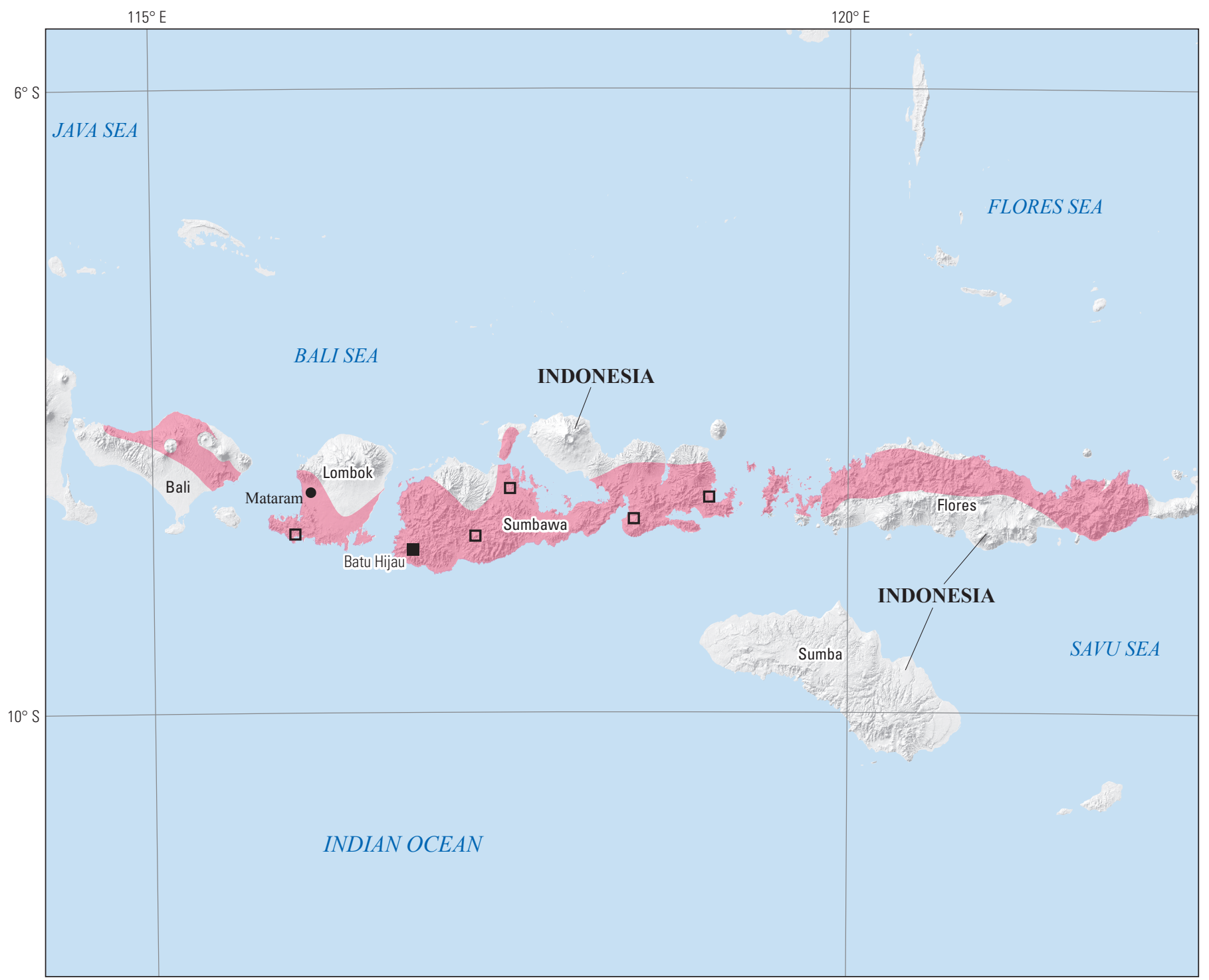

Political boundaries from U.S. Department of State (2009) Shaded relief from ESRI (2008)

Asia South Albers Equal-Area Conic projection

Central meridian $118^{\circ} 30^{\prime}$ E.; latitude of origin $15^{\circ} \mathrm{S}$.

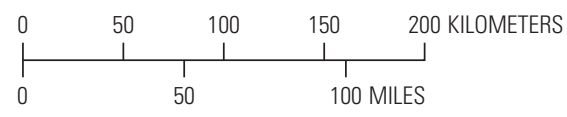

EXPLANATION

Assessed porphyry copper tract 142pCu7025b

- Porphyry copper deposit

ㅁ Porphyry copper prospect

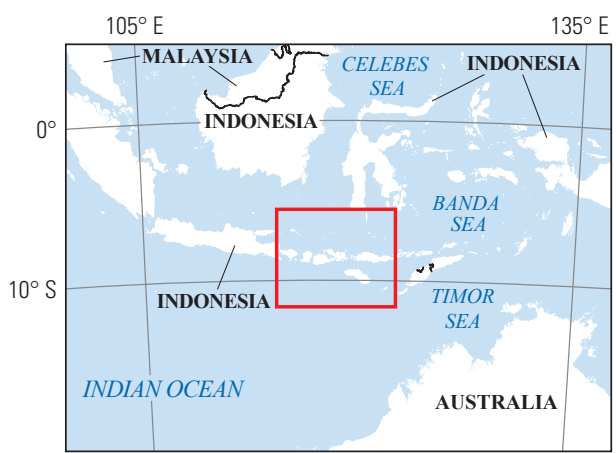




\section{Plate 112. Porphyry Copper Assessment for Tract 142pCu7025c, Sunda Banda Arc (East)—Indonesia}

Descriptive model:

Grade and tonnage model:

Economic filter depth percentages:

Economic filter cost setting:

Geologic feature assessed:

Number of known deposits:

\author{
Porphyry copper models (Berger and others, 2008; John and others, 2010); porphyry copper-gold \\ models (Cox, 1986b; Cooke and others, 1998) \\ Porphyry copper, copper-gold subtype model (Singer, Berger, and Moring, 2008) \\ Skewed deep- 0 to 250 meters (m), 10\%; > 250 to $500 \mathrm{~m}, 30 \%$; >500 m to $1 \mathrm{~km}, 60 \%$ \\ High cost \\ The eastern part of the Eocene to Holocene Sunda-Banda magmatic arc; eastern Flores Island to \\ Wetar Island \\ 0
}

\section{Selected Resource Assessment Results for Porphyry Copper}

[Assessment depth, 1 kilometer $(\mathrm{km}) ; \mathrm{km}^{2}$, square kilometer; Mt, millions of metric tons]

\begin{tabular}{|c|c|c|c|c|c|c|}
\hline \multirow[b]{2}{*}{$\begin{array}{c}\text { Date of } \\
\text { assessment }\end{array}$} & \multirow[b]{2}{*}{$\begin{array}{c}\text { Tract area } \\
\quad\left(\mathbf{k m}^{2}\right)\end{array}$} & \multirow{2}{*}{$\begin{array}{l}\text { Identified } \\
\text { copper } \\
\text { resources } \\
\text { (Mt) }\end{array}$} & \multicolumn{4}{|c|}{ Undiscovered copper resource estimates } \\
\hline & & & $\begin{array}{l}\text { Mean estimate of } \\
\text { in-place resources } \\
\text { (Mt) }\end{array}$ & $\begin{array}{c}\text { Probability of } 0 \\
\text { in-place resources } \\
\text { (percent) }\end{array}$ & $\begin{array}{l}\text { Mean estimate of } \\
\text { economic resources } \\
\text { (Mt) }\end{array}$ & $\begin{array}{c}\text { Probability of } 0 \\
\text { economic resources } \\
\text { (percent) }\end{array}$ \\
\hline 2010 & 5,665 & 0 & 2.1 & 59 & 0.91 & 97 \\
\hline
\end{tabular}

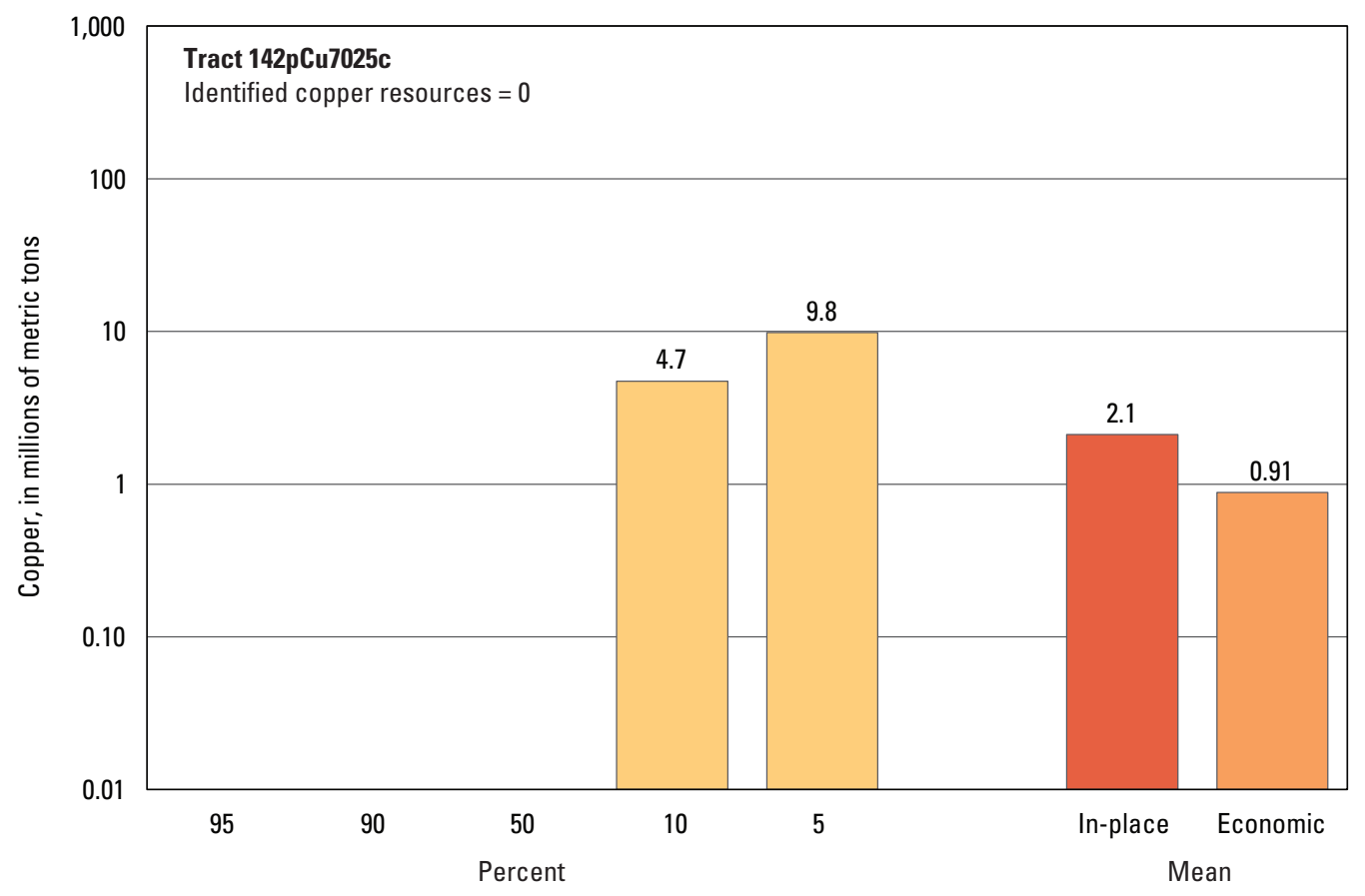

Graph showing the estimated probability distribution of undiscovered copper resources, where each bar represents the minimum amount estimated at the indicated percentage.

\section{Source}

Hammarstrom, Bookstrom, Dicken, and others, 2013, Porphyry copper assessment of Southeast Asia and Melanesia: U.S. Geological Survey Scientific Investigations Report 2010-5090-D, http://pubs.usgs.gov/sir/2010/5090/d/. 


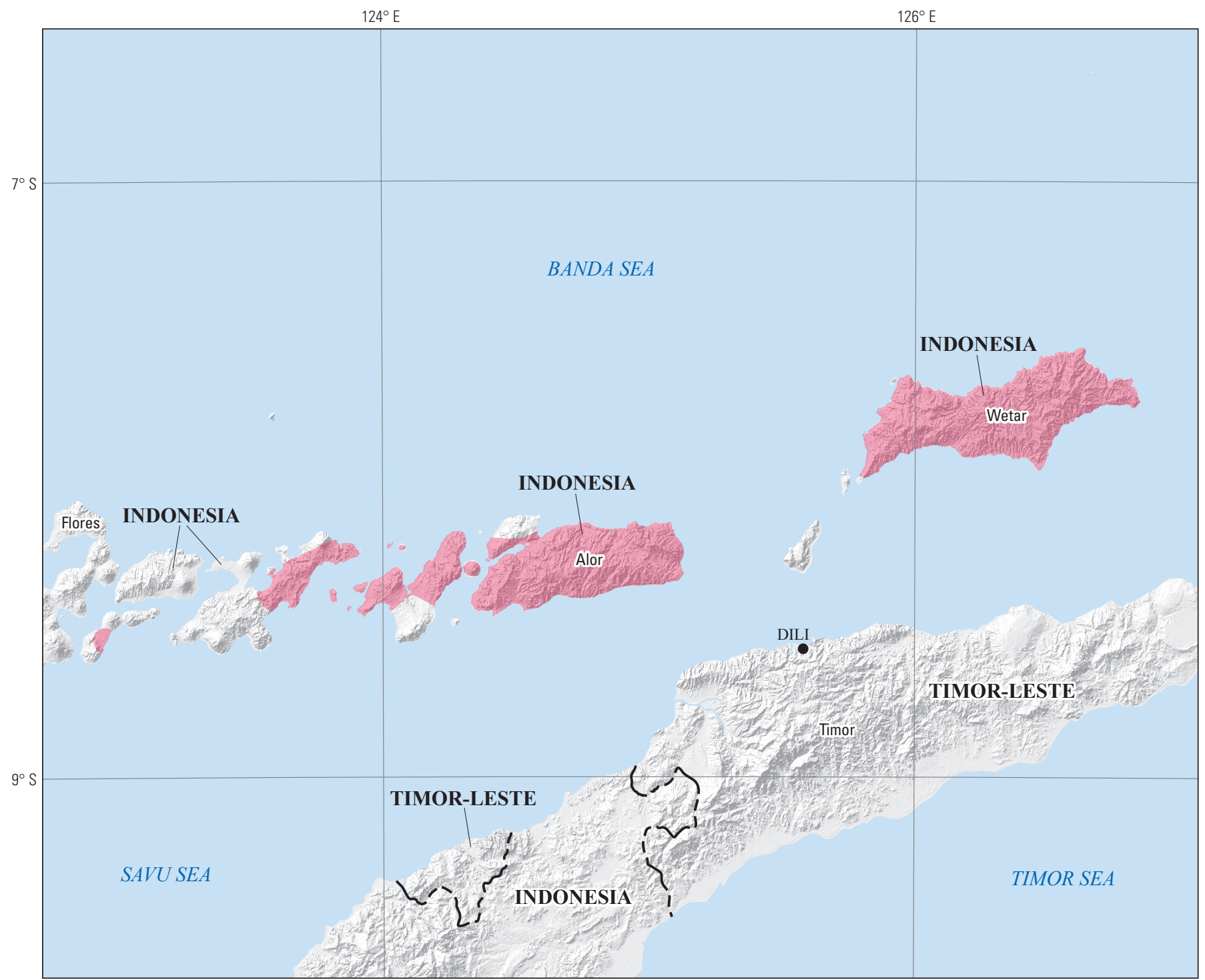

Political boundaries from U.S. Department of State (2009) Shaded relief from ESRI (2008)

Asia South Albers Equal-Area Conic projection

Central meridian $125^{\circ}$ E.; latitude of origin $15^{\circ} \mathrm{S}$.

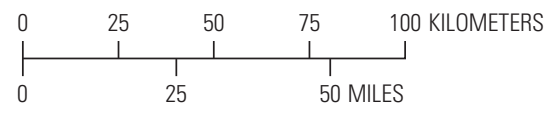

\section{EXPLANATION}

Assessed porphyry copper tract 142pCu7025c

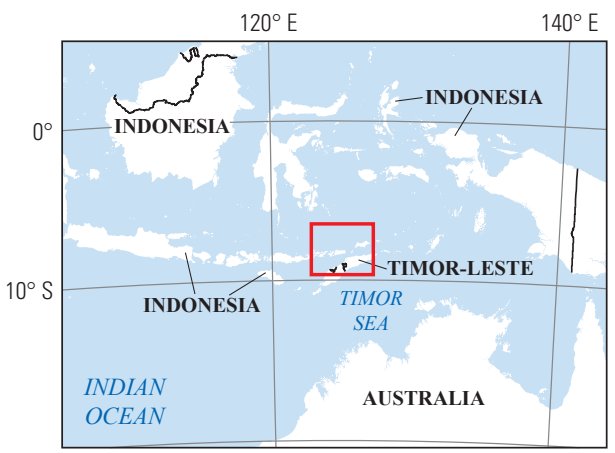




\section{Plate 113. Porphyry Copper Assessment for Tract 142pCu7026, West Sulawesi-Indonesia}

Descriptive model:

Grade and tonnage model:

Economic filter depth percentages:

Economic filter cost setting:

Geologic feature assessed:

Number of known deposits:

\begin{abstract}
Porphyry copper models (Berger and others, 2008; John and others, 2010); porphyry copper-gold models (Cox, 1986b; Cooke and others, 1998)

Porphyry copper, copper-gold subtype model (Singer, Berger, and Moring, 2008)

Default -0 to 250 meters (m), 25\%; >250 to $500 \mathrm{~m}, 25 \%$; $>500 \mathrm{~m}$ to $1 \mathrm{~km}, 50 \%$

High cost

The tract includes Miocene to Pliocene igneous rocks in the southern portion of the 1,200-km-long Sulawesi-Sangihe magmatic arc, located in southwestern Sulawesi
\end{abstract}

0

\section{Selected Resource Assessment Results for Porphyry Copper}

[Assessment depth, 1 kilometer $(\mathrm{km}) ; \mathrm{km}^{2}$, square kilometer; Mt, millions of metric tons]

\begin{tabular}{|c|c|c|c|c|c|c|}
\hline \multirow[b]{2}{*}{$\begin{array}{c}\text { Date of } \\
\text { assessment }\end{array}$} & \multirow[b]{2}{*}{$\begin{array}{c}\text { Tract area } \\
\quad\left(\mathbf{k m}^{2}\right)\end{array}$} & \multirow{2}{*}{$\begin{array}{l}\text { Identified } \\
\text { copper } \\
\text { resources } \\
\text { (Mt) }\end{array}$} & \multicolumn{4}{|c|}{ Undiscovered copper resource estimates } \\
\hline & & & $\begin{array}{l}\text { Mean estimate of } \\
\text { in-place resources } \\
\text { (Mt) }\end{array}$ & $\begin{array}{c}\text { Probability of } 0 \\
\text { in-place resources } \\
\text { (percent) }\end{array}$ & $\begin{array}{l}\text { Mean estimate of } \\
\text { economic resources } \\
\text { (Mt) }\end{array}$ & $\begin{array}{c}\text { Probability of } 0 \\
\text { economic resources } \\
\text { (percent) }\end{array}$ \\
\hline 2010 & 60,272 & 0 & 3.4 & 30 & 1.6 & 90 \\
\hline
\end{tabular}

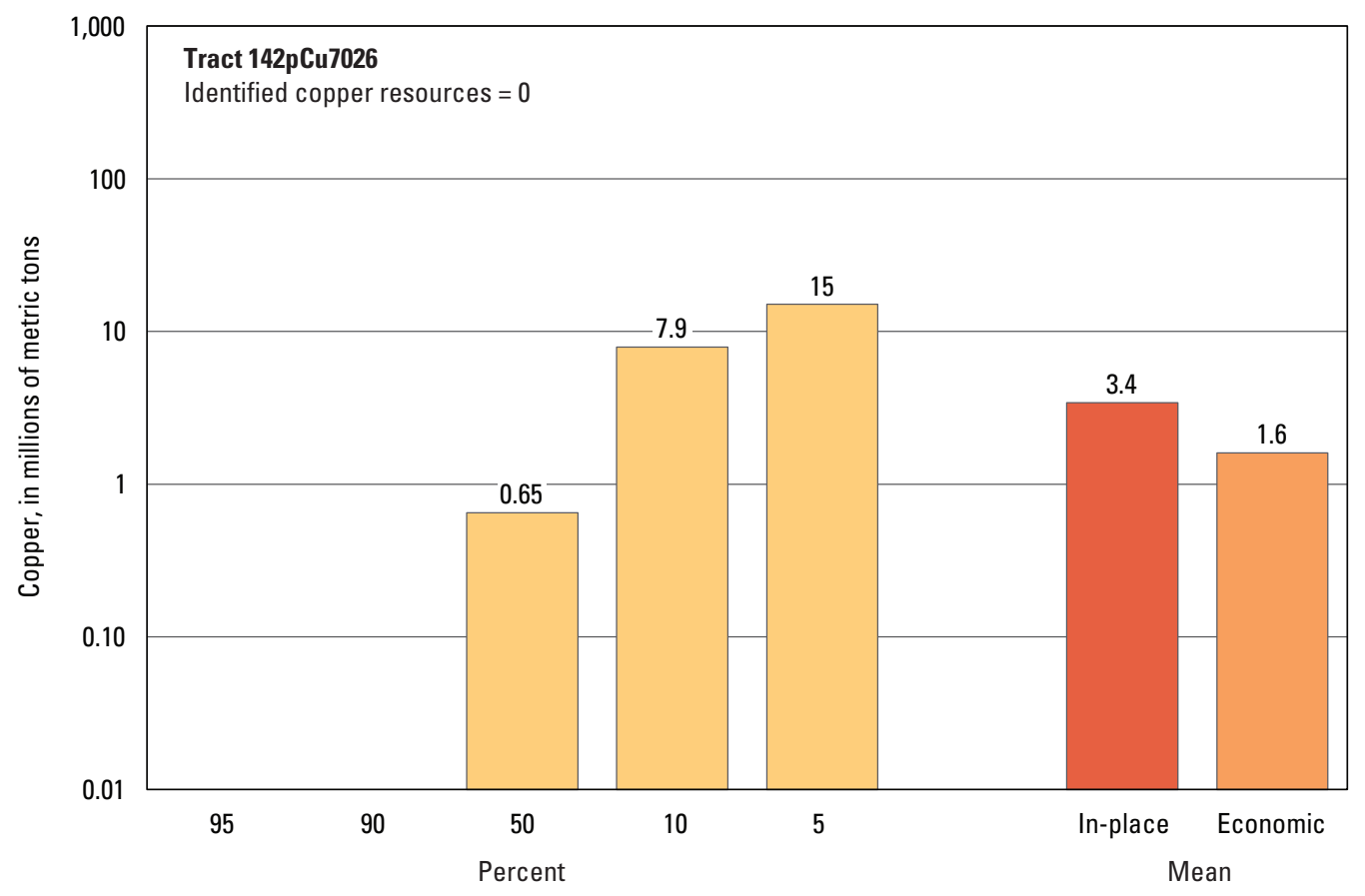

Graph showing the estimated probability distribution of undiscovered copper resources, where each bar represents the minimum amount estimated at the indicated percentage.

\section{Source}

Hammarstrom, Bookstrom, Dicken, and others, 2013, Porphyry copper assessment of Southeast Asia and Melanesia: U.S. Geological Survey Scientific Investigations Report 2010-5090-D, http://pubs.usgs.gov/sir/2010/5090/d/. 

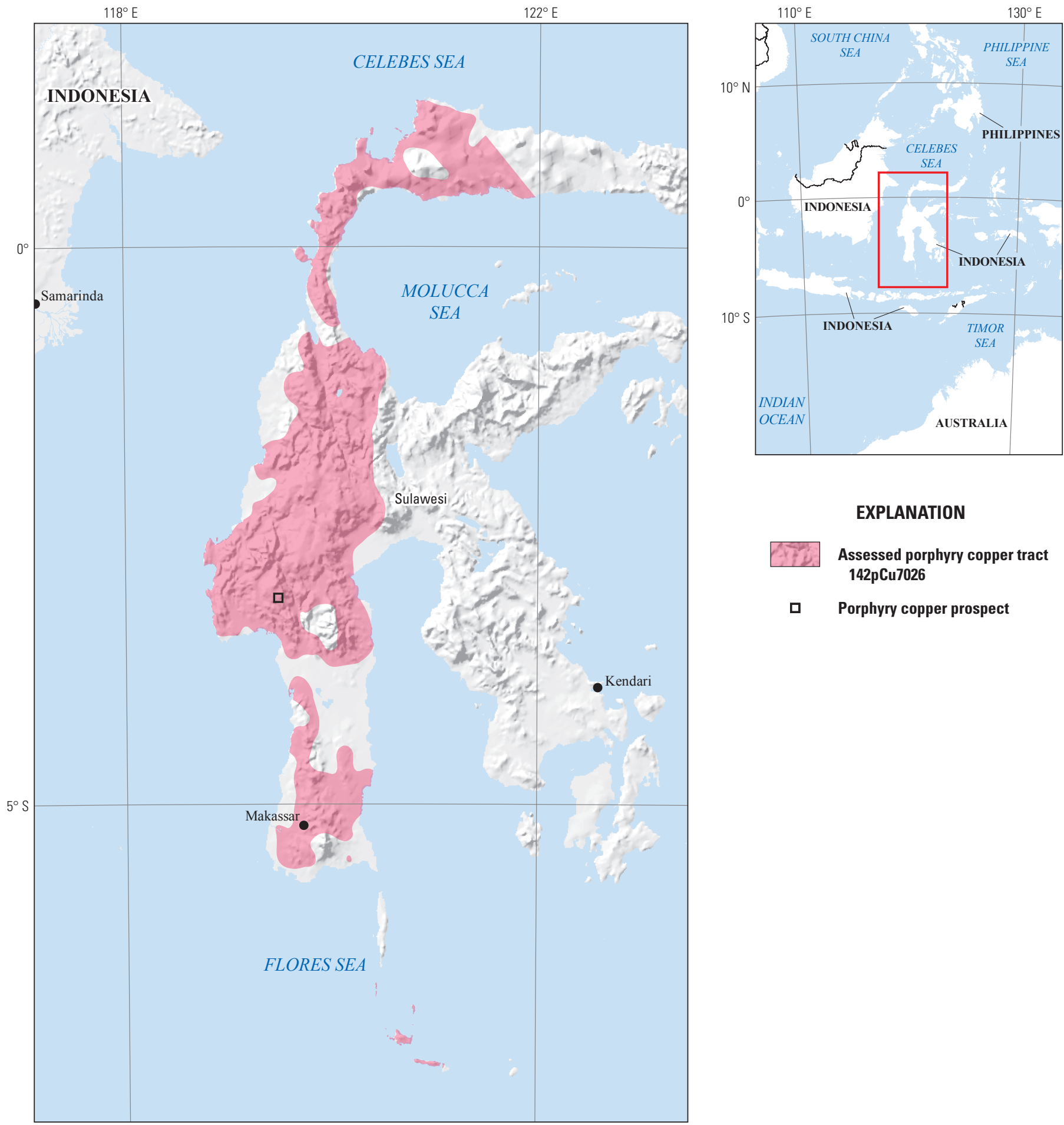

EXPLANATION

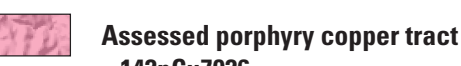
142pCu7026

ㅁ Porphyry copper prospect

Political boundaries from U.S. Department of State (2009)

Shaded relief from Earth Resources Observation and

Science (EROS) Center (2011)

Asia South Albers Equal-Area Conic projection

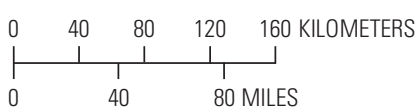

Central meridian $120^{\circ} 30^{\prime} \mathrm{E}$.; latitude of origin $15^{\circ} \mathrm{S}$. 


\section{Plate 114. Porphyry Copper Assessment for Tract 142pCu7027, North Sulawesi- Sangihe-Indonesia}

\section{Descriptive model:}

Grade and tonnage model:

Economic filter depth percentages:

Economic filter cost setting:

Geologic feature assessed:

Number of known deposits:

\author{
Porphyry copper models (Berger and others, 2008; John and others, 2010); porphyry copper-gold \\ models (Cox, 1986b; Cooke and others, 1998) \\ Porphyry copper, copper-gold subtype model (Singer, Berger, and Moring, 2008) \\ Default -0 to 250 meters (m), 25\%; > 250 to $500 \mathrm{~m}, 25 \%$; >500 m to $1 \mathrm{~km}, 50 \%$ \\ High cost \\ This tract includes the Miocene to Pliocene volcanic and intrusive rock portion of the North \\ Sulawesi-Sangihe magmatic arc \\ 2
}

\section{Selected Resource Assessment Results for Porphyry Copper}

[Assessment depth, 1 kilometer $(\mathrm{km}) ; \mathrm{km}^{2}$, square kilometer; Mt, millions of metric tons]

\begin{tabular}{|c|c|c|c|c|c|c|}
\hline \multirow[b]{2}{*}{$\begin{array}{c}\text { Date of } \\
\text { assessment }\end{array}$} & \multirow[b]{2}{*}{$\begin{array}{c}\text { Tract area } \\
\quad\left(\mathbf{k m}^{2}\right)\end{array}$} & \multirow{2}{*}{$\begin{array}{l}\text { Identified } \\
\text { copper } \\
\text { resources } \\
\text { (Mt) }\end{array}$} & \multicolumn{4}{|c|}{ Undiscovered copper resource estimates } \\
\hline & & & $\begin{array}{l}\text { Mean estimate of } \\
\text { in-place resources } \\
\text { (Mt) }\end{array}$ & $\begin{array}{c}\text { Probability of } 0 \\
\text { in-place resources } \\
\text { (percent) }\end{array}$ & $\begin{array}{l}\text { Mean estimate of } \\
\text { economic resources } \\
\text { (Mt) }\end{array}$ & $\begin{array}{c}\text { Probability of } 0 \\
\text { economic resources } \\
\text { (percent) }\end{array}$ \\
\hline 2010 & 20,325 & 2.0 & 8.9 & 6 & 4.3 & 68 \\
\hline
\end{tabular}

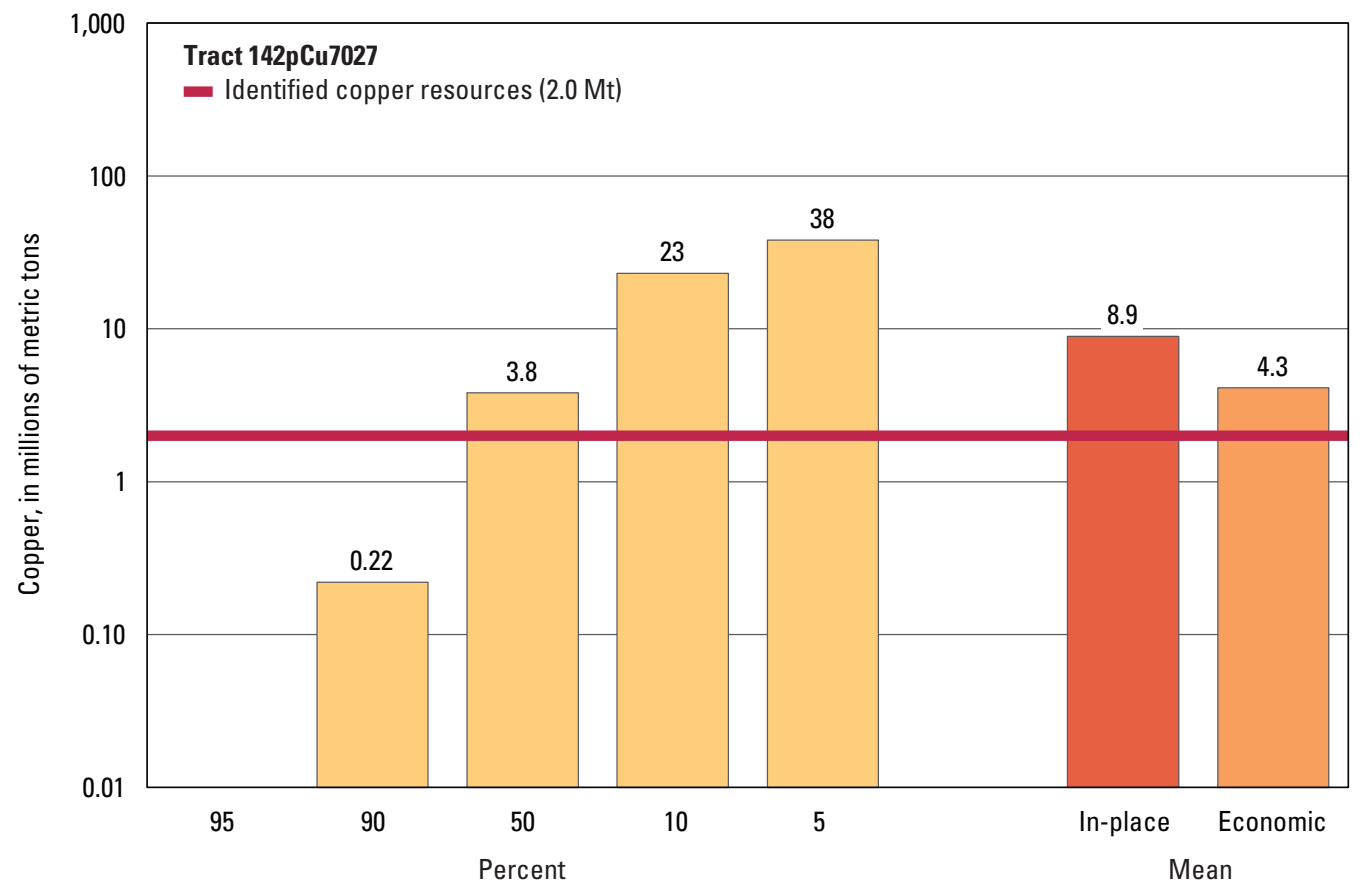

Graph showing the estimated probability distribution of undiscovered copper resources, where each bar represents the minimum amount estimated at the indicated percentage.

\section{Source}

Hammarstrom, Bookstrom, Dicken, and others, 2013, Porphyry copper assessment of Southeast Asia and Melanesia: U.S. Geological Survey Scientific Investigations Report 2010-5090-D, http://pubs.usgs.gov/sir/2010/5090/d/. 


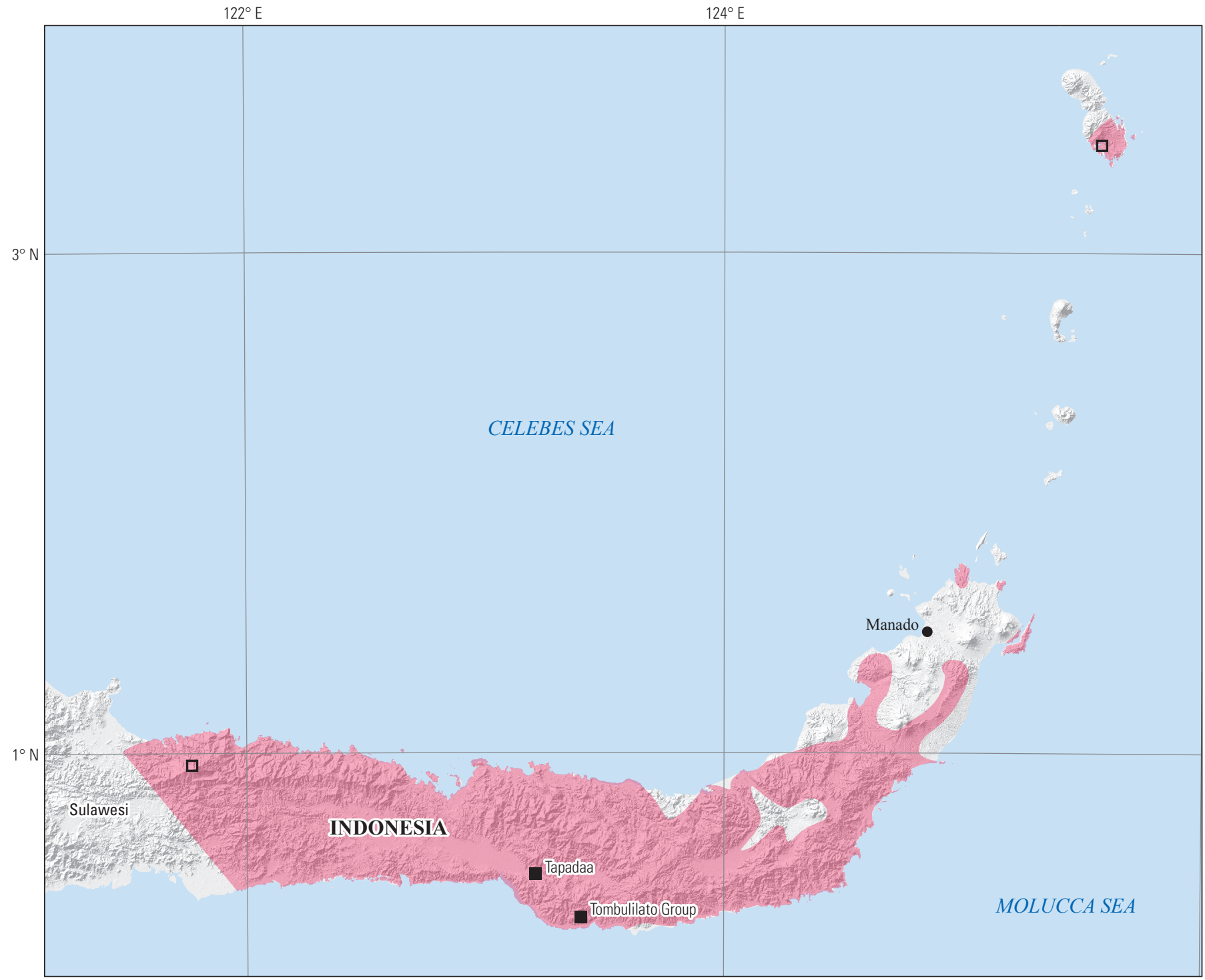

Political boundaries from U.S. Department of State (2009) Shaded relief from ESRI (2008)

Asia South Albers Equal-Area Conic projection

Central meridian $123^{\circ} 30^{\prime}$ E.; latitude of origin $15^{\circ} \mathrm{S}$.

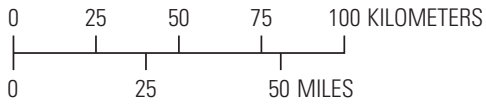

EXPLANATION

Assessed porphyry copper tract 142pCu7027

- Porphyry copper deposit

ㅁ Porphyry copper prospect

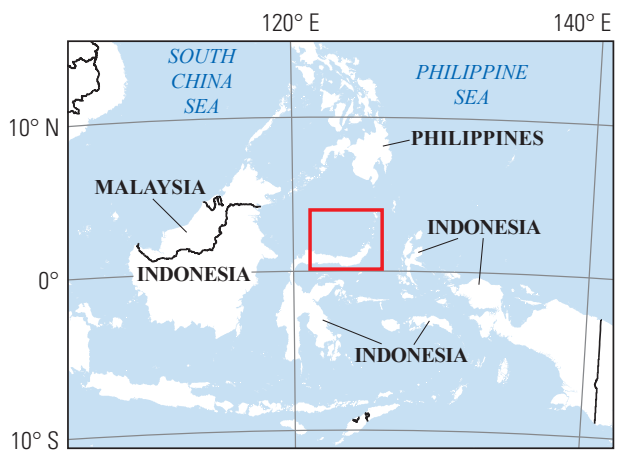




\section{Plate 115. Porphyry Copper Assessment for Tract 142pCu7202, Halmahera Arc, North Molucca Islands-Indonesia}

Descriptive model:

Grade and tonnage model:

Economic filter depth percentages:

Economic filter cost setting:

Geologic feature assessed:

Number of known deposits:
Porphyry copper models (Berger and others, 2008; John and others, 2010); porphyry copper-gold models (Cox, 1986b; Cooke and others, 1998)

Porphyry copper, copper-gold subtype model (Singer, Berger, and Moring, 2008)

Skewed deep- 0 to 250 meters (m), 10\%; > 250 to $500 \mathrm{~m}, 30 \%$; >500 m to $1 \mathrm{~km}, 60 \%$

High cost

Neogene Halmahera island arc

1

\section{Selected Resource Assessment Results for Porphyry Copper}

[Assessment depth, 1 kilometer (km); $\mathrm{km}^{2}$, square kilometer; Mt, millions of metric tons]

\begin{tabular}{ccccccc}
\hline $\begin{array}{c}\text { Date of } \\
\text { assessment }\end{array}$ & $\begin{array}{c}\text { Tract area } \\
\left(\mathbf{k m}^{2}\right)\end{array}$ & $\begin{array}{c}\text { Identified } \\
\text { copper } \\
\text { resources } \\
\text { (Mt) }\end{array}$ & $\begin{array}{c}\text { Mean estimate of } \\
\text { in-place resources } \\
(\mathbf{M t})\end{array}$ & $\begin{array}{c}\text { Probability of } \mathbf{0} \\
\text { in-place resources } \\
\text { (percent) }\end{array}$ & $\begin{array}{c}\text { Mean estimate of } \\
\text { economic resources } \\
\text { (Mt) }\end{array}$ & $\begin{array}{c}\text { Probability of 0 } \\
\text { economic resources } \\
\text { (percent) }\end{array}$ \\
\hline 2010 & 12,245 & 0.25 & 4.8 & 31 & 2.1 \\
\hline
\end{tabular}

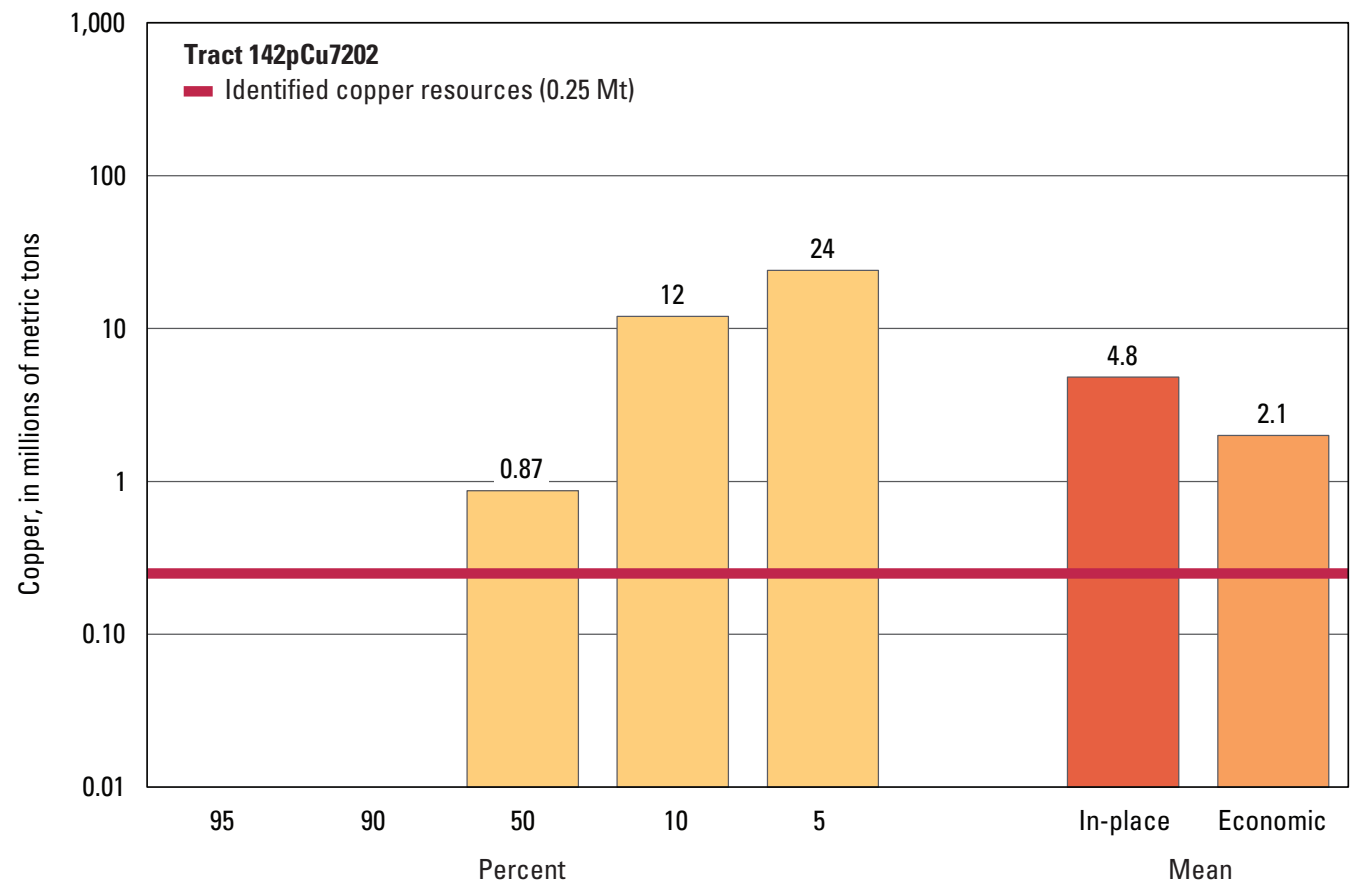

Graph showing the estimated probability distribution of undiscovered copper resources, where each bar represents the minimum amount estimated at the indicated percentage.

\section{Source}

Hammarstrom, Bookstrom, Dicken, and others, 2013, Porphyry copper assessment of Southeast Asia and Melanesia: U.S. Geological Survey Scientific Investigations Report 2010-5090-D, http://pubs.usgs.gov/sir/2010/5090/d/. 

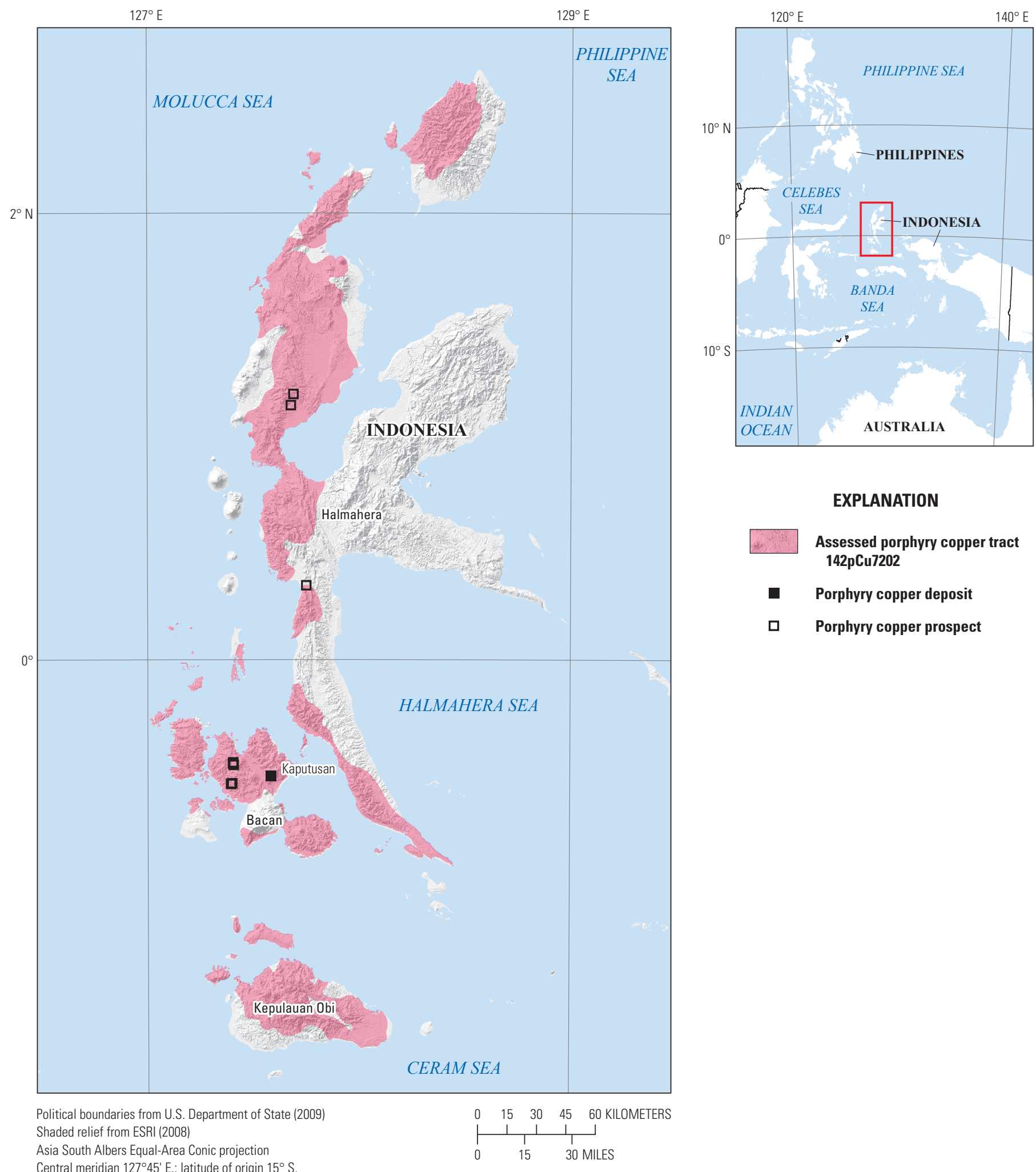

\section{EXPLANATION}

Assessed porphyry copper tract 142pCu7202

- Porphyry copper deposit

Porphyry copper prospect

Central meridian $127^{\circ} 45^{\prime} \mathrm{E}$ : latitude of origin $15^{\circ} \mathrm{S}$ 


\section{Plate 116. Porphyry Copper Assessment for Tract 142pCu7201, Ambon Arc, Central Molucca Islands-Indonesia}

\section{Descriptive model:}

Grade and tonnage model:

Economic filter depth percentages:

Economic filter cost setting:

Geologic feature assessed:

Number of known deposits:

\author{
Porphyry copper models (Berger and others, 2008; John and others, 2010); porphyry copper-gold \\ models (Cox, 1986b; Cooke and others, 1998) \\ Porphyry copper, copper-gold subtype model (Singer, Berger, and Moring, 2008) \\ Skewed deep - 0 to 250 meters (m), 10\%; > 250 to $500 \mathrm{~m}, 30 \%$; >500 m to $1 \mathrm{~km}, 60 \%$ \\ High cost \\ Pliocene to Quaternary Ambon island arc (northern Outer Banda arc), eastern Indonesia \\ 0
}

\section{Selected Resource Assessment Results for Porphyry Copper}

[Assessment depth, 1 kilometer $(\mathrm{km}) ; \mathrm{km}^{2}$, square kilometer; Mt, millions of metric tons]

\begin{tabular}{ccccccc}
\hline $\begin{array}{c}\text { Date of } \\
\text { assessment }\end{array}$ & $\begin{array}{c}\text { Tract area } \\
\left(\mathbf{k m}^{2}\right)\end{array}$ & $\begin{array}{c}\text { Identified } \\
\text { copper } \\
\text { resources } \\
\text { (Mt) }\end{array}$ & $\begin{array}{c}\text { Mean estimate of } \\
\text { in-place resources } \\
(\mathbf{M t})\end{array}$ & $\begin{array}{c}\text { Probability of } \mathbf{0} \\
\text { in-place resources } \\
\text { (percent) }\end{array}$ & $\begin{array}{c}\text { Mean estimate of } \\
\text { economic resources } \\
\text { (Mt) }\end{array}$ & $\begin{array}{c}\text { Probability of 0 } \\
\text { economic resources } \\
\text { (percent) }\end{array}$ \\
\hline 2010 & 1,537 & 0 & 3.1 & 30 & 1.3 \\
\hline
\end{tabular}

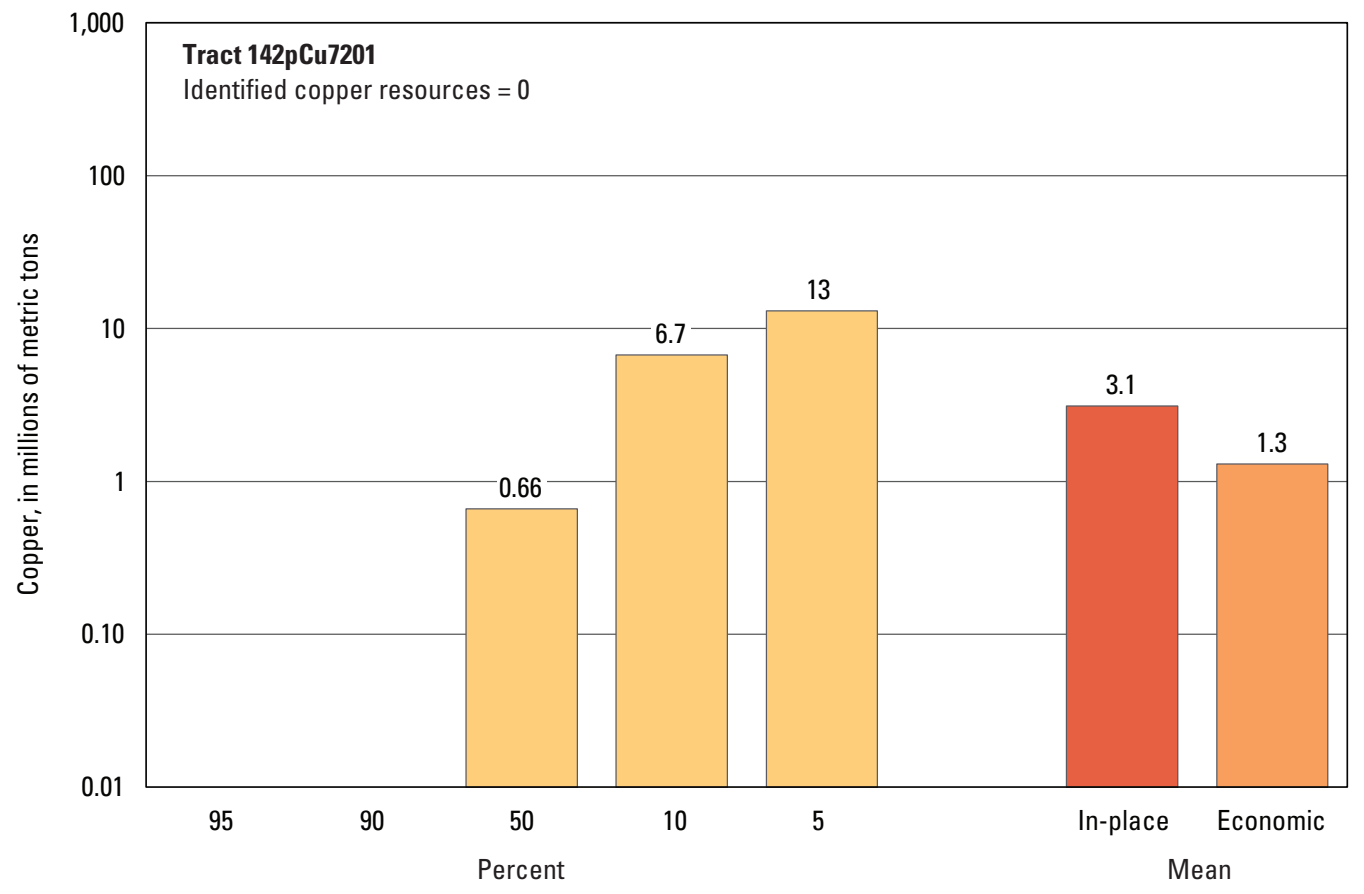

Graph showing the estimated probability distribution of undiscovered copper resources, where each bar represents the minimum amount estimated at the indicated percentage.

\section{Source}

Hammarstrom, Bookstrom, Dicken, and others, 2013, Porphyry copper assessment of Southeast Asia and Melanesia: U.S. Geological Survey Scientific Investigations Report 2010-5090-D, http://pubs.usgs.gov/sir/2010/5090/d/. 


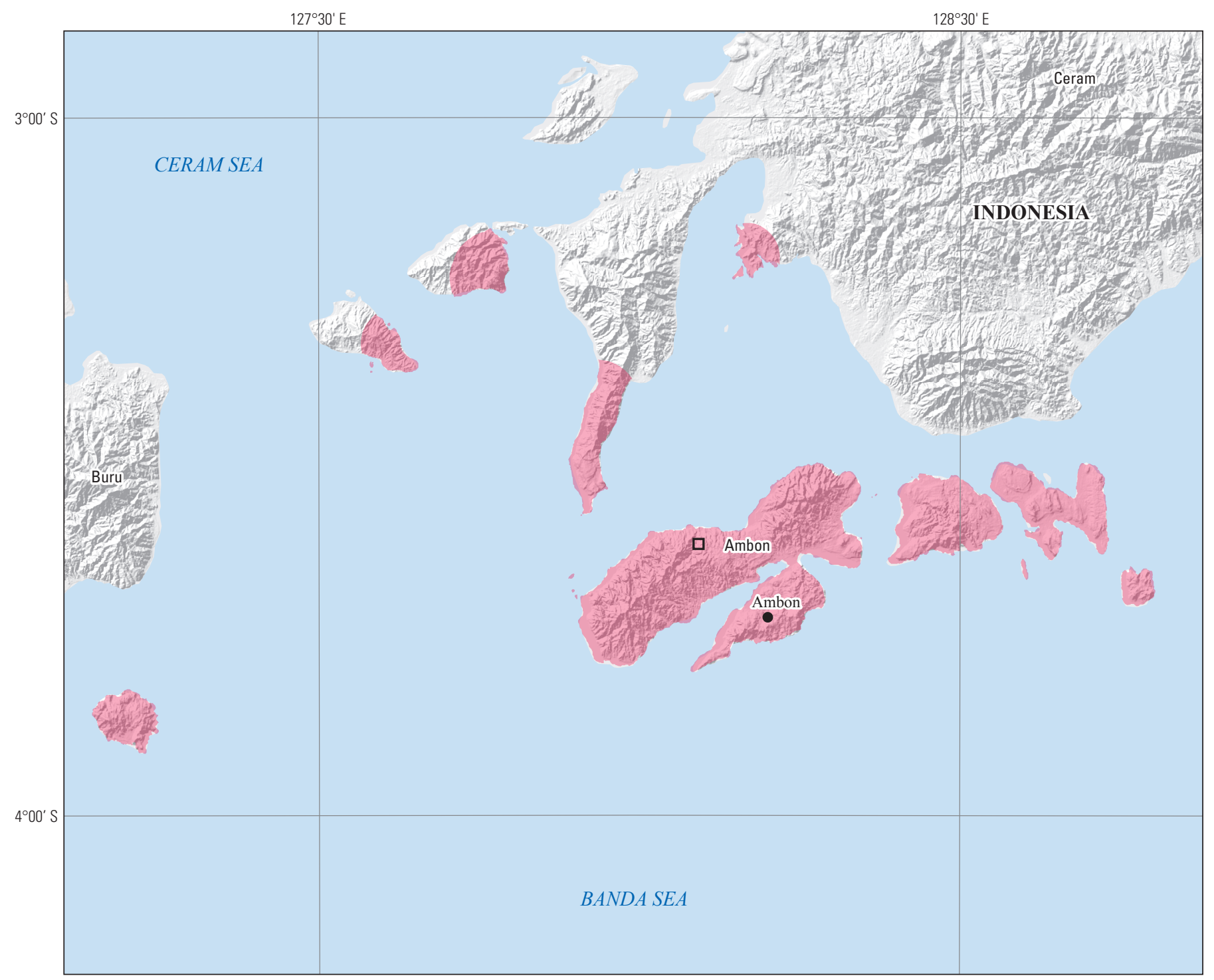

Political boundaries from U.S. Department of State (2009) Shaded relief from ESRI (2008)

Asia South Albers Equal-Area Conic projection

Central meridian $128^{\circ} \mathrm{E}$.; latitude of origin $15^{\circ} \mathrm{S}$.

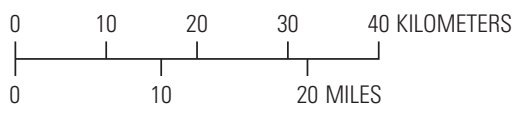

EXPLANATION

1. Assessed porphyry copper tract 142pCu7201

$\square \quad$ Porphyry copper prospect

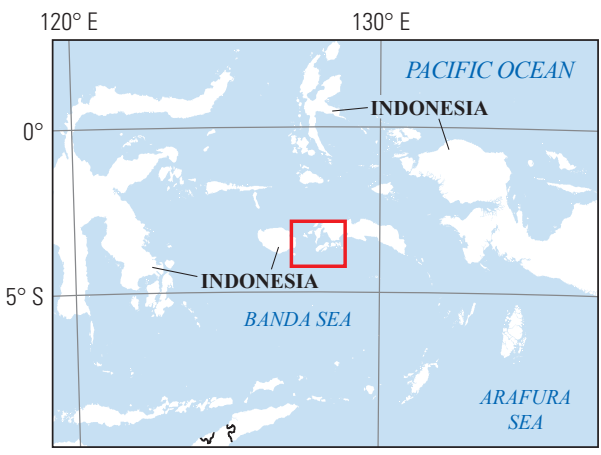




\title{
Plate 117. Porphyry Copper Assessment for Tract 142pCu7208, Inner Melanesian Arc Terranes I-Indonesia
}

\author{
Descriptive model: \\ Porphyry copper models (Berger and others, 2008; John and others, 2010) \\ Grade and tonnage model: \\ NA \\ Economic filter depth percentages: \\ NA \\ Economic filter cost setting: \\ NA \\ Geologic feature assessed: \\ Late Cretaceous to early Miocene accreted Inner Melanesian magmatic arc terranes of western \\ New Guinea Island (Indonesia) \\ Number of known deposits: \\ 0
}

\section{Selected Resource Assessment Results for Porphyry Copper}

[Assessment depth, 1 kilometer $(\mathrm{km}) ; \mathrm{km}^{2}$, square kilometer; Mt, millions of metric tons; NA, not applicable, as a quantitative assessment was not done]

\begin{tabular}{|c|c|c|c|c|c|c|}
\hline \multirow[b]{2}{*}{$\begin{array}{c}\text { Date of } \\
\text { assessment }\end{array}$} & \multirow[b]{2}{*}{$\begin{array}{c}\text { Tract area } \\
\quad\left(\mathbf{k m}^{2}\right)\end{array}$} & \multirow{2}{*}{$\begin{array}{l}\text { Identified } \\
\text { copper } \\
\text { resources } \\
\text { (Mt) }\end{array}$} & \multicolumn{4}{|c|}{ Undiscovered copper resource estimates } \\
\hline & & & $\begin{array}{l}\text { Mean estimate of } \\
\text { in-place resources } \\
\text { (Mt) }\end{array}$ & $\begin{array}{c}\text { Probability of } 0 \\
\text { in-place resources } \\
\text { (percent) }\end{array}$ & $\begin{array}{l}\text { Mean estimate of } \\
\text { economic resources } \\
\text { (Mt) }\end{array}$ & $\begin{array}{c}\text { Probability of } 0 \\
\text { economic resources } \\
\text { (percent) }\end{array}$ \\
\hline 2010 & 7,717 & 0 & NA & NA & NA & NA \\
\hline
\end{tabular}

\section{Qualitative Assessment}

Tract 142pCu7208 (Inner Melanesian Arc Terranes I-Indonesia) was delineated to recognize that Late Cretaceous to Miocene igneous rocks that are permissive for the occurrence of porphyry copper deposits are present in the accreted terranes along the western part of northern New Guinea Island and on offshore islands. The presence of coeval volcanic and plutonic rocks suggests that, at least in some areas, the erosion levels may be appropriate for preservation of deposits. However, the team had too little information available to make resource estimates. More information about the exploration history, ages, and lithologies of permissive igneous rocks would be helpful to assess the porphyry potential of the tract area. See tract 009pCu7208 (Inner Melanesian Arc Terranes II-Papua New Guinea and Indonesia) for the eastward continuation of this tract into Papua New Guinea (pl. 123). Because Indonesia and Papua New Guinea are in two different United Nations world regions, the codes 142 and 009 are used in the identifiers of these two tracts.

\section{Source}

Hammarstrom, Bookstrom, Dicken, and others, 2013, Porphyry copper assessment of Southeast Asia and Melanesia: U.S. Geological Survey Scientific Investigations Report 2010-5090-D, http://pubs.usgs.gov/sir/2010/5090/d/. 


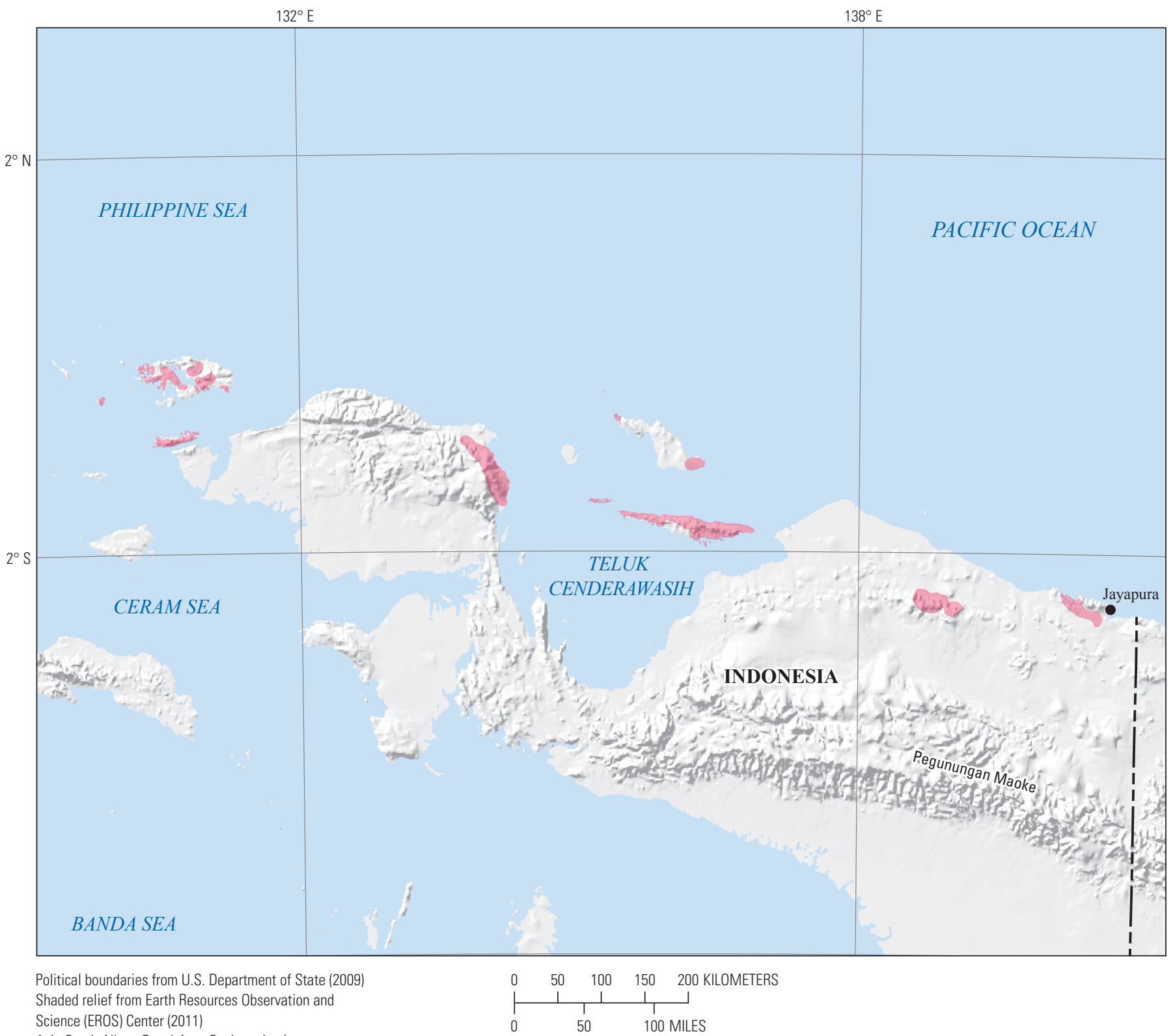

Asia South Albers Equal-Area Conic projection

Central meridian $135^{\circ} 30^{\prime}$ E.; latitude of origin $15^{\circ} \mathrm{S}$.

EXPLANATION

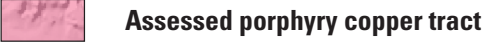
142pCu7208

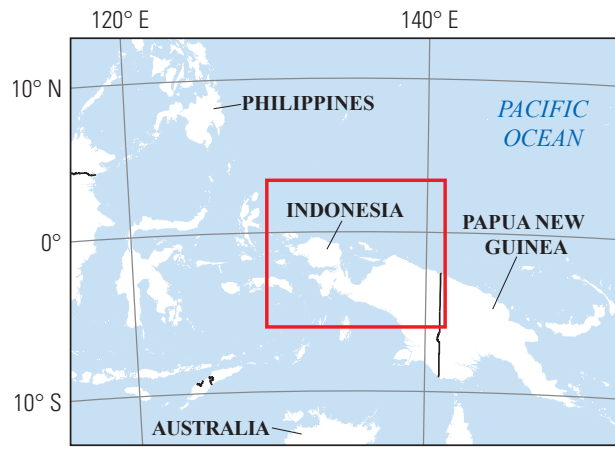




\section{Plate 118. Porphyry Copper Assessment for Tract 142pCu7205, Moon-Utawa- Ular Merah Areas-Indonesia}

Descriptive model:

Grade and tonnage model:

Economic filter depth percentages:

Economic filter cost setting:

Geologic feature assessed:

Number of known deposits:
Porphyry copper models (Berger and others, 2008; John and others, 2010); porphyry copper-gold models (Cox, 1986b; Cooke and others, 1998)

Porphyry copper, copper-gold subtype model (Singer, Berger, and Moring, 2008)

Default -0 to 250 meters (m), 25\%; > 250 to $500 \mathrm{~m}, 25 \%$; $>500 \mathrm{~m}$ to $1 \mathrm{~km}, 50 \%$

High cost

Miocene Moon-Utawa arc and coeval rocks in the Ular Merah area of Papua and West Papua Provinces, Indonesia

0

\section{Selected Resource Assessment Results for Porphyry Copper}

[Assessment depth, 1 kilometer $(\mathrm{km}) ; \mathrm{km}^{2}$, square kilometer; Mt, millions of metric tons]

\begin{tabular}{|c|c|c|c|c|c|c|}
\hline \multirow[b]{2}{*}{$\begin{array}{c}\text { Date of } \\
\text { assessment }\end{array}$} & \multirow[b]{2}{*}{$\begin{array}{c}\text { Tract area } \\
\quad\left(\mathbf{k m}^{2}\right)\end{array}$} & \multirow{2}{*}{$\begin{array}{l}\text { Identified } \\
\text { copper } \\
\text { resources } \\
\text { (Mt) }\end{array}$} & \multicolumn{4}{|c|}{ Undiscovered copper resource estimates } \\
\hline & & & $\begin{array}{l}\text { Mean estimate of } \\
\text { in-place resources } \\
\text { (Mt) }\end{array}$ & $\begin{array}{c}\text { Probability of } 0 \\
\text { in-place resources } \\
\text { (percent) }\end{array}$ & $\begin{array}{l}\text { Mean estimate of } \\
\text { economic resources } \\
\text { (Mt) }\end{array}$ & $\begin{array}{c}\text { Probability of } 0 \\
\text { economic resources } \\
\text { (percent) }\end{array}$ \\
\hline 2010 & 13,577 & 0 & 3.2 & 30 & 1.5 & 90 \\
\hline
\end{tabular}

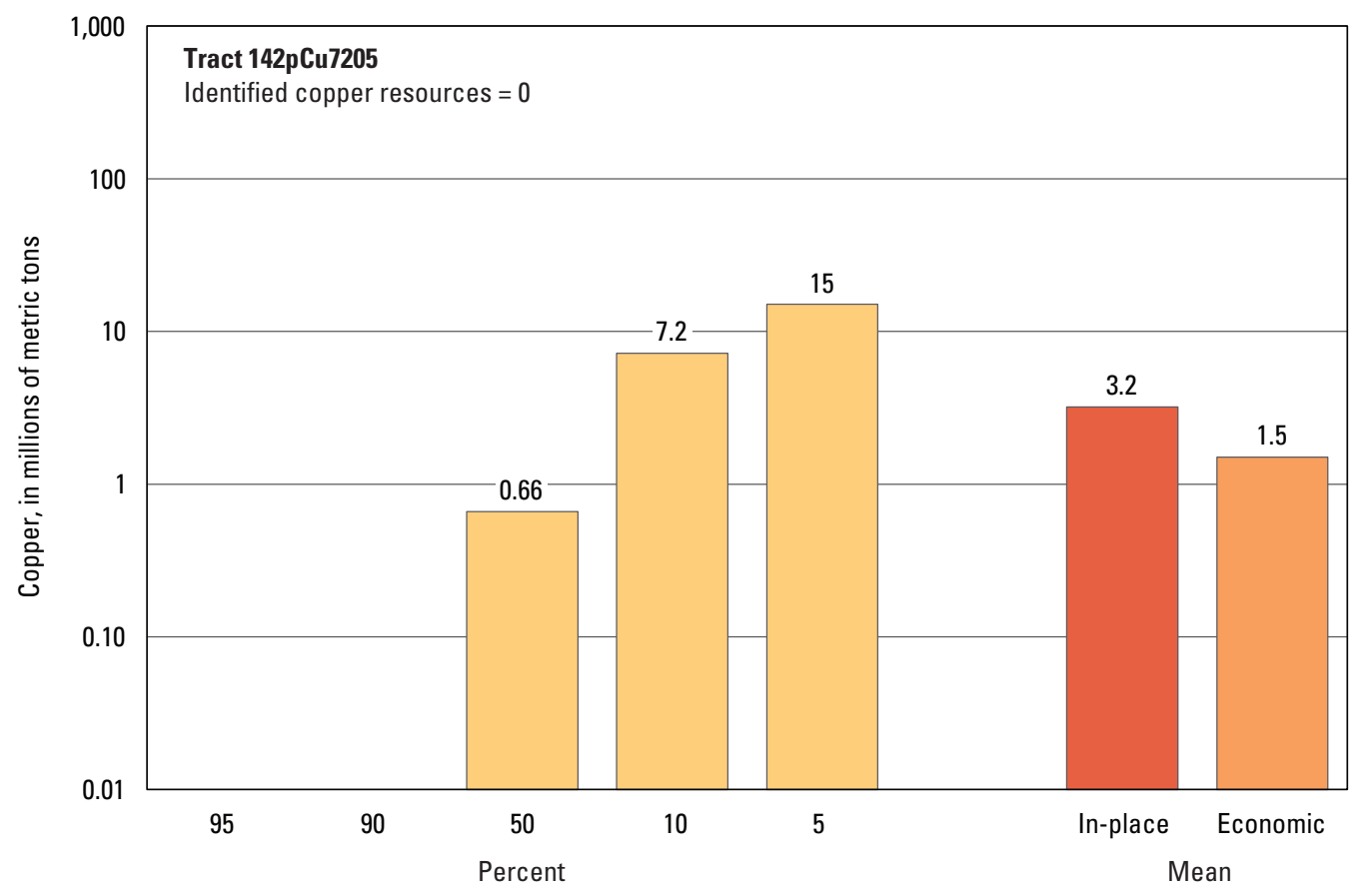

Graph showing the estimated probability distribution of undiscovered copper resources, where each bar represents the minimum amount estimated at the indicated percentage.

\section{Source}

Hammarstrom, Bookstrom, Dicken, and others, 2013, Porphyry copper assessment of Southeast Asia and Melanesia: U.S. Geological Survey Scientific Investigations Report 2010-5090-D, http://pubs.usgs.gov/sir/2010/5090/d/. 


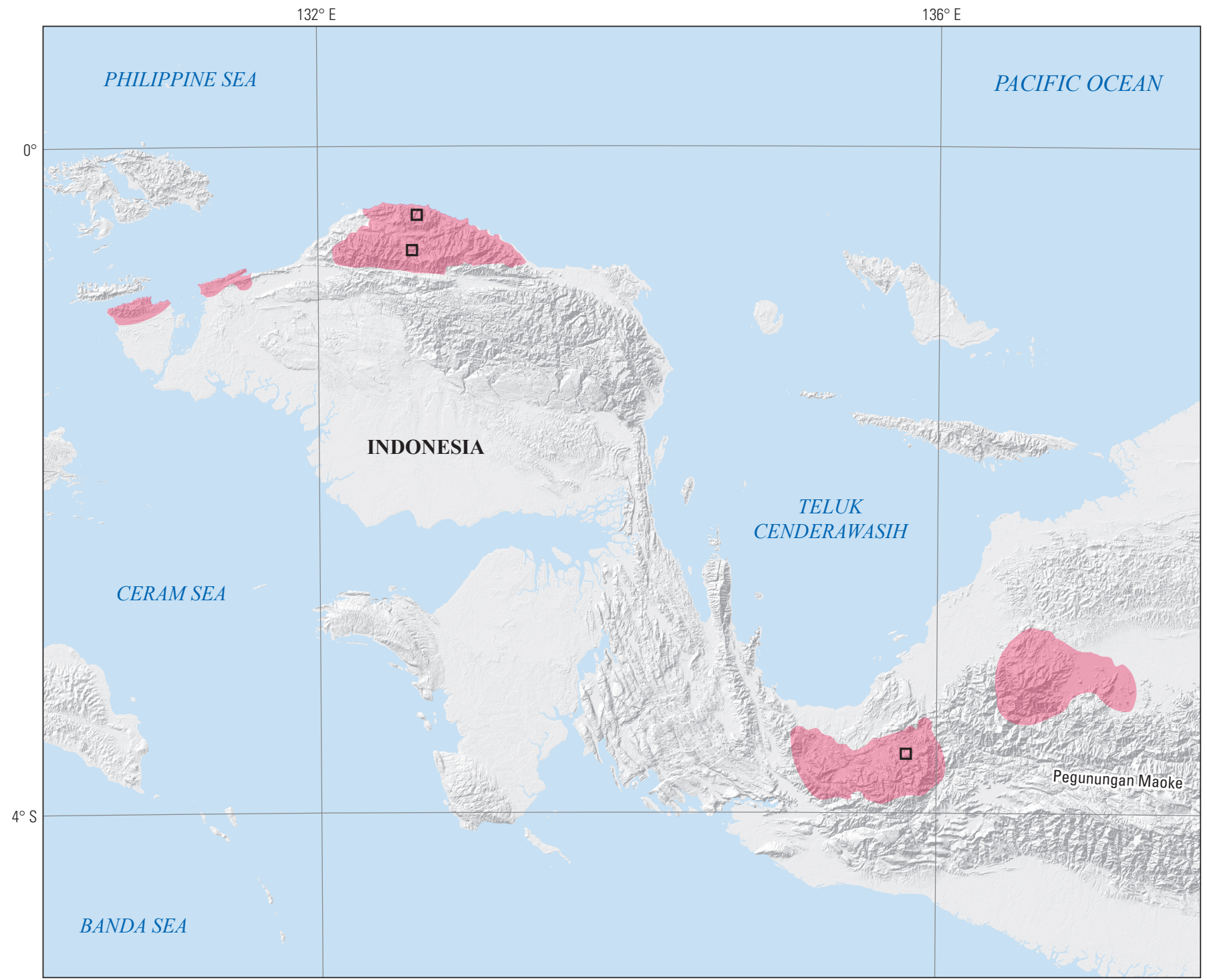

Political boundaries from U.S. Department of State (2009) Shaded relief from ESRI (2008)

Asia South Albers Equal-Area Conic projection

Central meridian $134^{\circ} \mathrm{E}$. ; latitude of origin $15^{\circ} \mathrm{S}$.

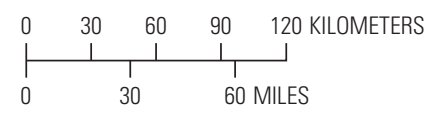

EXPLANATION

Assessed porphyry copper tract 142pCu7205

$\square \quad$ Porphyry copper prospect

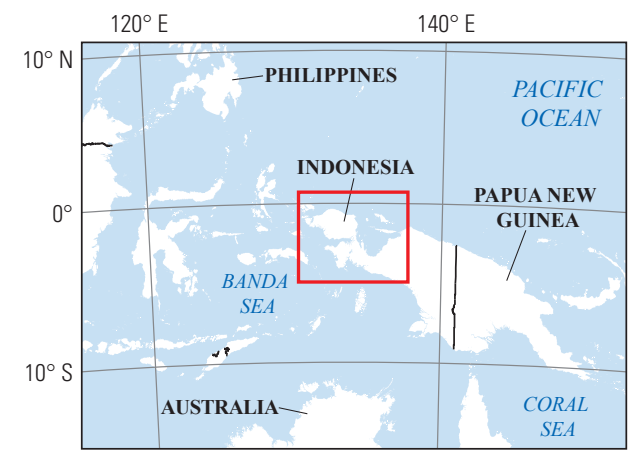




\section{Plate 119. Porphyry Copper Assessment for Tract 142pCu7203, Western Medial New Guinea Magmatic Belt—Indonesia}

Descriptive model:

Grade and tonnage model:

Economic filter depth percentages:

Economic filter cost setting:

Geologic feature assessed:

Number of known deposits:
Porphyry copper models (Berger and others, 2008; John and others, 2010); porphyry copper-gold models (Cox, 1986b; Cooke and others, 1998)

Porphyry copper, copper-gold subtype model (Singer, Berger, and Moring, 2008)

Default -0 to 250 meters (m), 25\%; > 250 to $500 \mathrm{~m}, 25 \%$; $>500 \mathrm{~m}$ to $1 \mathrm{~km}, 50 \%$

High cost

Eastern part of the late Miocene to Pliocene-Pleistocene Medial New Guinea magmatic belt 1

\section{Selected Resource Assessment Results for Porphyry Copper}

[Assessment depth, 1 kilometer (km); $\mathrm{km}^{2}$, square kilometer; Mt, millions of metric tons]

\begin{tabular}{ccccccc}
\hline $\begin{array}{c}\text { Date of } \\
\text { assessment }\end{array}$ & $\begin{array}{c}\text { Tract area } \\
\left(\mathbf{k m}^{2}\right)\end{array}$ & $\begin{array}{c}\text { Identified } \\
\text { copper } \\
\text { resources } \\
\text { (Mt) }\end{array}$ & $\begin{array}{c}\text { Mean estimate of } \\
\text { in-place resources } \\
(\mathbf{M t})\end{array}$ & $\begin{array}{c}\text { Probability of } \mathbf{0} \\
\text { in-place resources } \\
\text { (percent) }\end{array}$ & $\begin{array}{c}\text { Mean estimate of } \\
\text { economic resources } \\
\text { (Mt) }\end{array}$ & $\begin{array}{c}\text { Probability of 0 } \\
\text { economic resources } \\
\text { (percent) }\end{array}$ \\
\hline 2010 & 13,268 & 24 & 14 & 6 & 6.7 \\
\hline
\end{tabular}

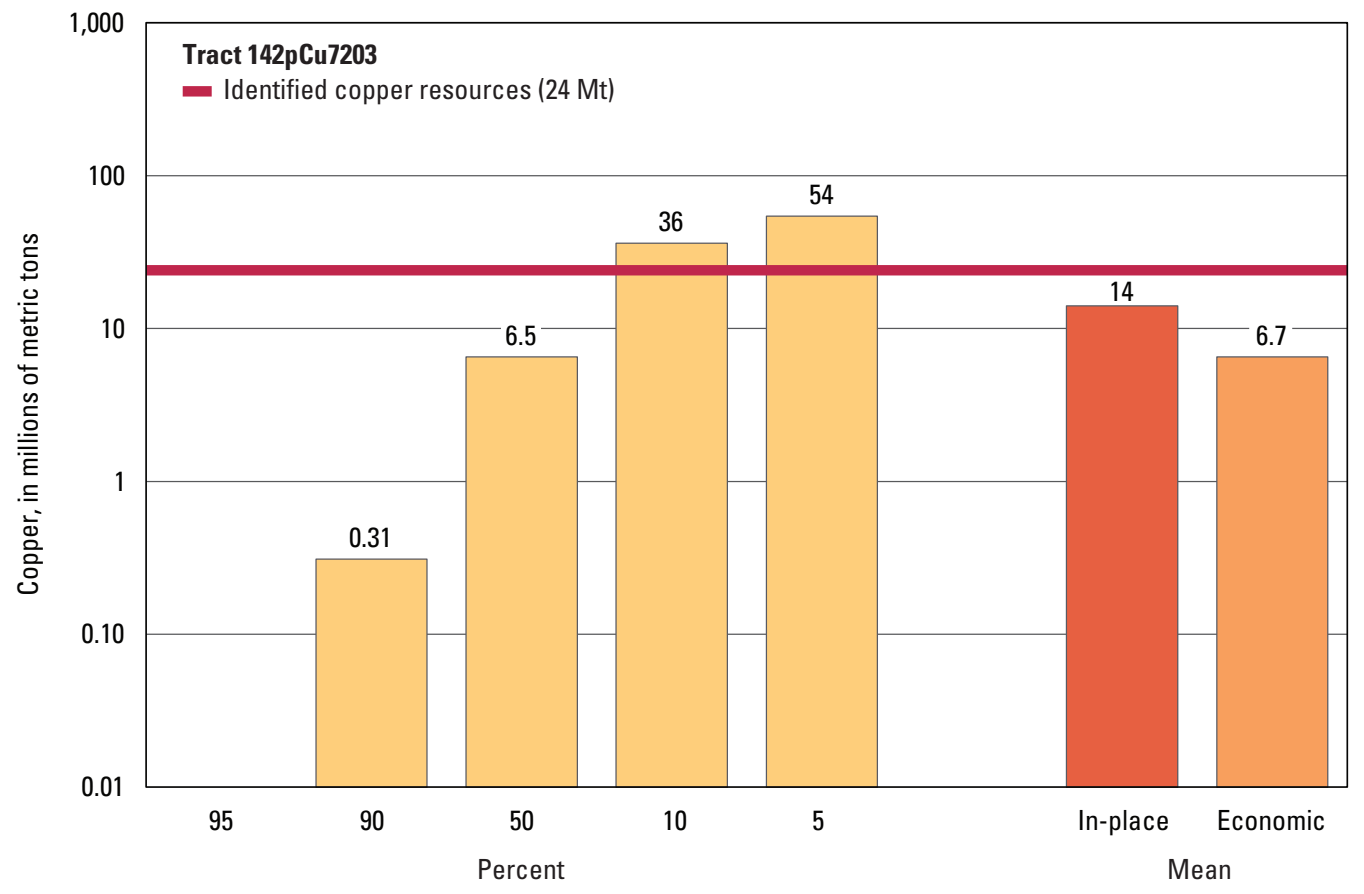

Graph showing the estimated probability distribution of undiscovered copper resources, where each bar represents the minimum amount estimated at the indicated percentage.

\section{Source}

Hammarstrom, Bookstrom, Dicken, and others, 2013, Porphyry copper assessment of Southeast Asia and Melanesia: U.S. Geological Survey Scientific Investigations Report 2010-5090-D, http://pubs.usgs.gov/sir/2010/5090/d/. 


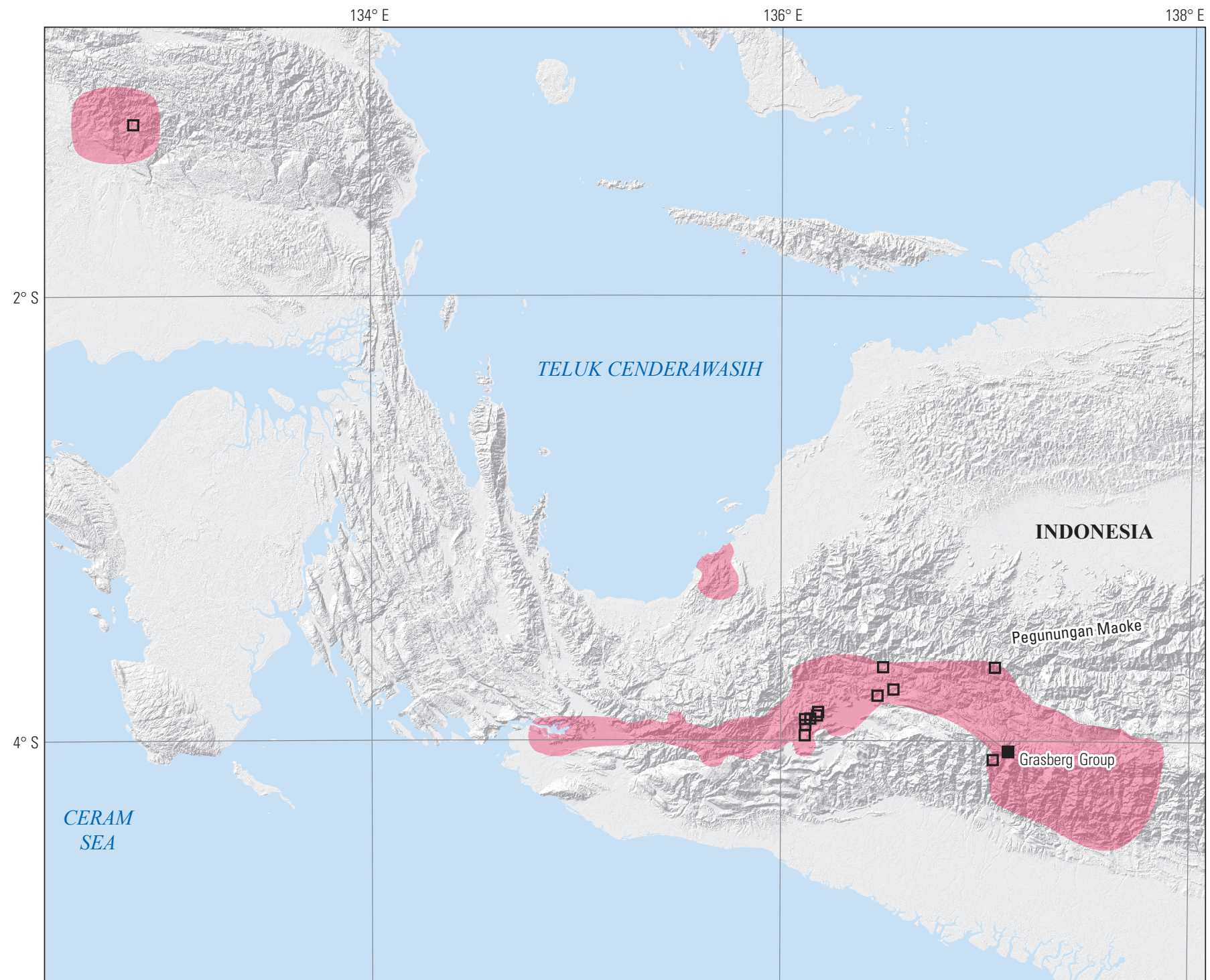

Political boundaries from U.S. Department of State (2009) Shaded relief from ESRI (2008)

Asia South Albers Equal-Area Conic projection

Central meridian $135^{\circ} \mathrm{E}$.; latitude of origin $15^{\circ} \mathrm{S}$.

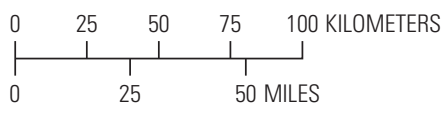

EXPLANATION

Assessed porphyry copper tract 142pCu7203

- Porphyry copper deposit

$\square \quad$ Porphyry copper prospect

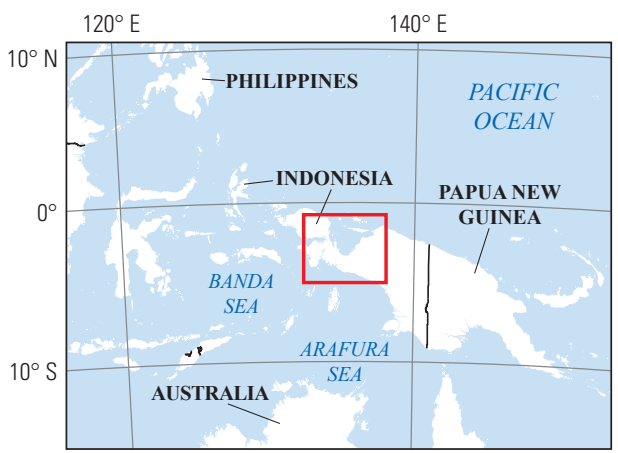




\title{
Plate 120. Porphyry Copper Assessment for Tract 142pCu7204, Rotanburg- Taratatua Area-Indonesia and Papua New Guinea
}

\author{
Descriptive model: $\quad$ Porphyry copper models (Cox, 1986a; John and others, 2010) \\ Grade and tonnage model: NA \\ Economic filter depth percentages: NA \\ Economic filter cost setting: $\quad$ NA \\ Geologic feature assessed: $\quad$ Late Miocene to Pliocene-Pleistocene intrusive rocks \\ Number of known deposits: $\quad 0$
}

\section{Selected Resource Assessment Results for Porphyry Copper}

[Assessment depth, 1 kilometer $(\mathrm{km})$; $\mathrm{km}^{2}$, square kilometer; Mt, millions of metric tons; NA, not applicable, as a quantitative assessment was not done]

\begin{tabular}{ccccccc}
\hline \multirow{2}{*}{$\begin{array}{c}\text { Date of } \\
\text { assessment }\end{array}$} & $\begin{array}{c}\text { Tract area } \\
\left(\mathbf{k m}^{2}\right)\end{array}$ & $\begin{array}{c}\text { Identified } \\
\text { copper } \\
\text { resources } \\
(\mathbf{M t})\end{array}$ & $\begin{array}{c}\text { Mean estimate of } \\
\text { in-place resources } \\
(\mathbf{M t})\end{array}$ & $\begin{array}{c}\text { Probability of } \mathbf{0} \\
\text { in-place resources } \\
\text { (percent) }\end{array}$ & $\begin{array}{c}\text { Mean estimate of } \\
\text { economic resources } \\
\text { (Mt) }\end{array}$ & $\begin{array}{c}\text { Probability of } \mathbf{0} \\
\text { economic resources } \\
\text { (percent) }\end{array}$ \\
\hline 2010 & 9,371 & 0 & NA & NA & NA \\
\hline
\end{tabular}

\section{Qualitative Assessment}

Some geologic maps indicate that the igneous rocks in tract $142 \mathrm{pCu} 7204$ (Rotanburg-Taratatua Area-Indonesia and Papua New Guinea) may be related to those in the Grasberg-Ertsberg area to the west in tract 142pCu7203 (pl. 119) that hosts the world-class Grasberg Group porphyry copper system. The tract area may be too deeply eroded to preserve porphyry copper deposits. On the basis of a lack of additional information and anecdotal reports of lack of mineralization, this tract was considered permissive, but no quantitative assessment was done. Further work in the tract area may change the outlook for undiscovered deposits in the tract area.

\section{Source}

Hammarstrom, Bookstrom, Dicken, and others, 2013, Porphyry copper assessment of Southeast Asia and Melanesia: U.S. Geological Survey Scientific Investigations Report 2010-5090-D, http://pubs.usgs.gov/sir/2010/5090/d/. 


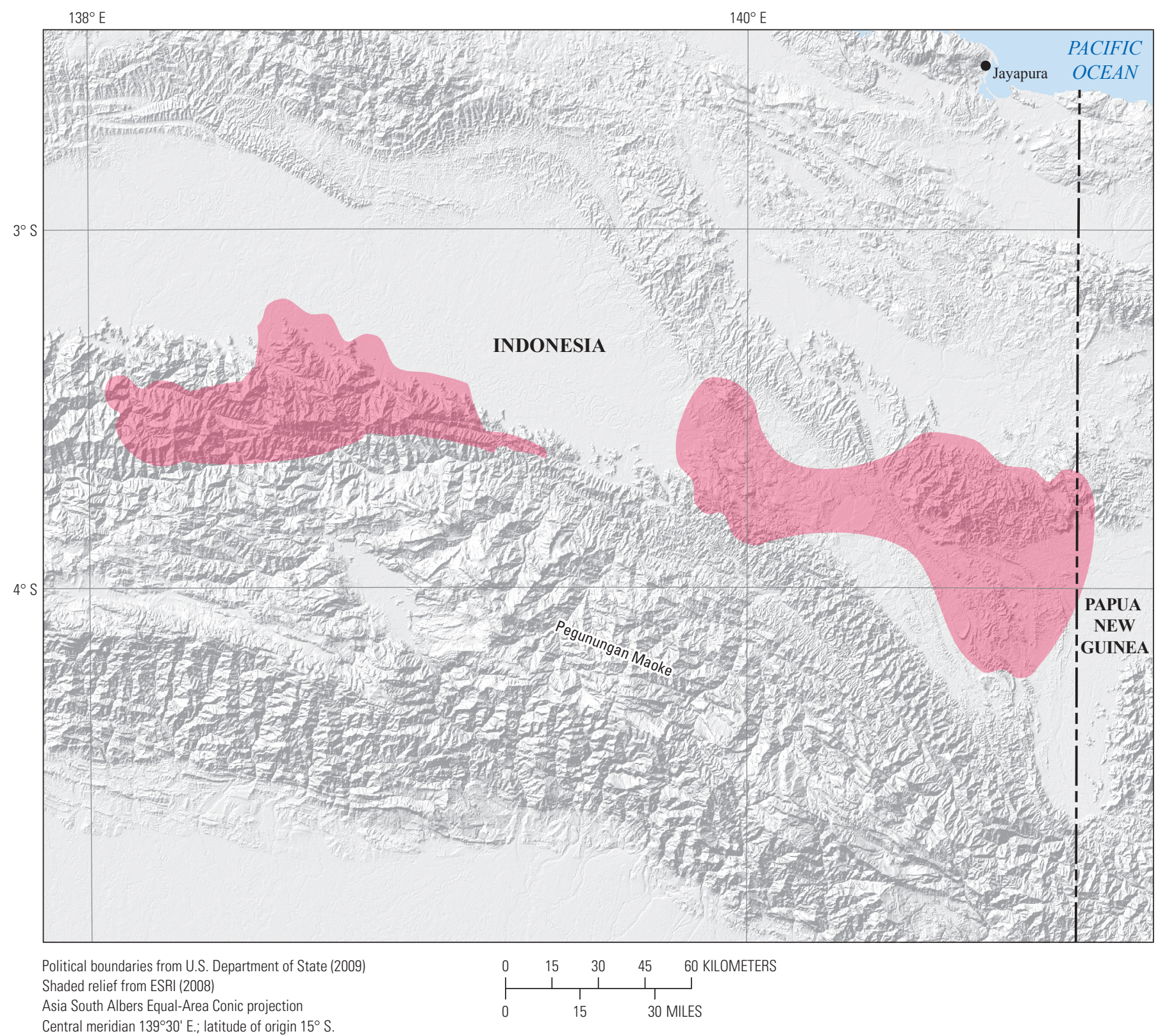

Central meridian $139^{\circ} 30^{\prime} \mathrm{E}$.; latitude of origin $15^{\circ} \mathrm{S}$

EXPLANATION

Assessed porphyry copper tract 142pCu7204

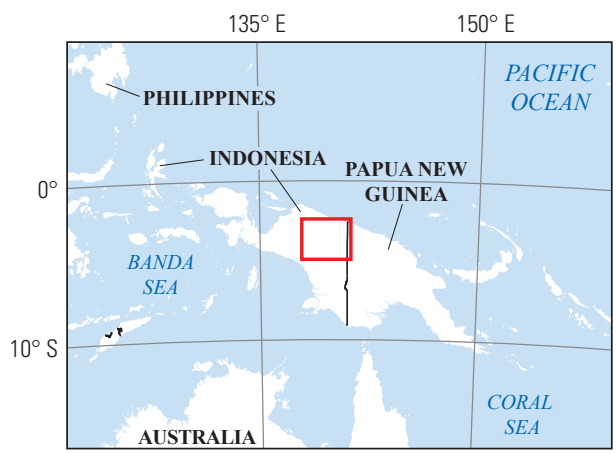




\section{Plate 121. Porphyry Copper Assessment for Tract 009pCu7203a, Eastern Medial New Guinea Magmatic Belt (West)—Papua New Guinea and Indonesia}

\section{Descriptive model:}

Grade and tonnage model:

Economic filter depth percentages:

Economic filter cost setting:

Geologic feature assessed:

Number of known deposits:

\author{
Porphyry copper models (Berger and others, 2008; John and others, 2010); porphyry copper-gold \\ models (Cox, 1986b; Cooke and others, 1998) \\ Porphyry copper, copper-gold subtype model (Singer, Berger, and Moring, 2008) \\ Default -0 to 250 meters (m), 25\%; > 250 to $500 \mathrm{~m}, 25 \%$; >500 m to $1 \mathrm{~km}, 50 \%$ \\ High cost \\ Late Miocene to Pliocene-Pleistocene Medial New Guinea magmatic belt \\ 3
}

\section{Selected Resource Assessment Results for Porphyry Copper}

[Assessment depth, 1 kilometer $(\mathrm{km})$; $\mathrm{km}^{2}$, square kilometer; Mt, millions of metric tons]

\begin{tabular}{ccccccc}
\hline $\begin{array}{c}\text { Date of } \\
\text { assessment }\end{array}$ & $\begin{array}{c}\text { Tract area } \\
\left(\mathbf{k m}^{2}\right)\end{array}$ & $\begin{array}{c}\text { Identified } \\
\text { copper } \\
\text { resources } \\
\text { (Mt) }\end{array}$ & $\begin{array}{c}\text { Mean estimate of } \\
\text { in-place resources } \\
(\mathbf{M t})\end{array}$ & $\begin{array}{c}\text { Probability of } \mathbf{0} \\
\text { in-place resources } \\
\text { (percent) }\end{array}$ & $\begin{array}{c}\text { Mean estimate of } \\
\text { economic resources } \\
\text { (Mt) }\end{array}$ & $\begin{array}{c}\text { Probability of 0 } \\
\text { economic resources } \\
\text { (percent) }\end{array}$ \\
\hline 2010 & 14,229 & 6.1 & 5.1 & 29 & 2.5 & 85 \\
\hline
\end{tabular}

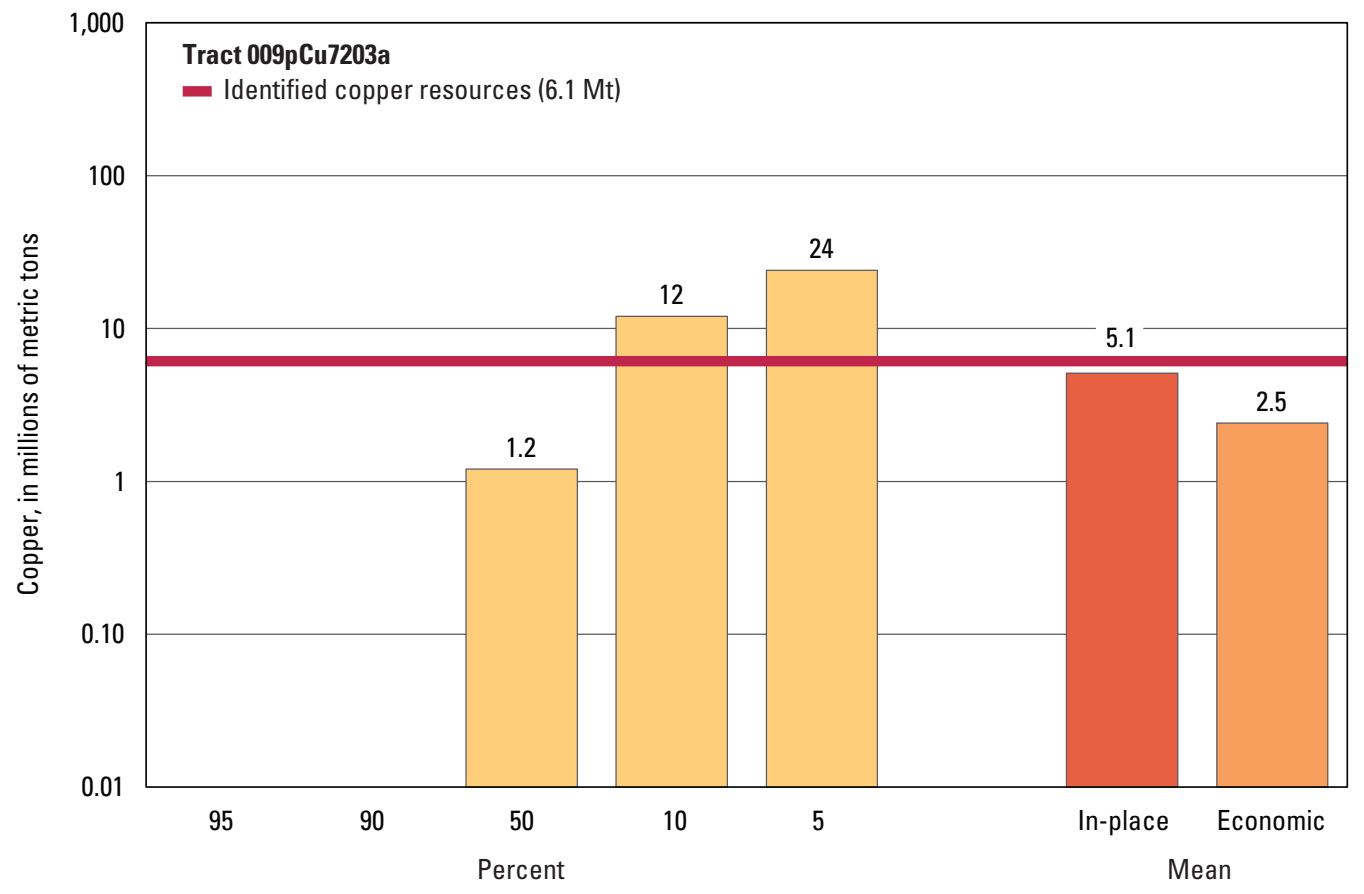

Graph showing the estimated probability distribution of undiscovered copper resources, where each bar represents the minimum amount estimated at the indicated percentage.

\section{Source}

Hammarstrom, Bookstrom, Dicken, and others, 2013, Porphyry copper assessment of Southeast Asia and Melanesia: U.S. Geological Survey Scientific Investigations Report 2010-5090-D, http://pubs.usgs.gov/sir/2010/5090/d/. 


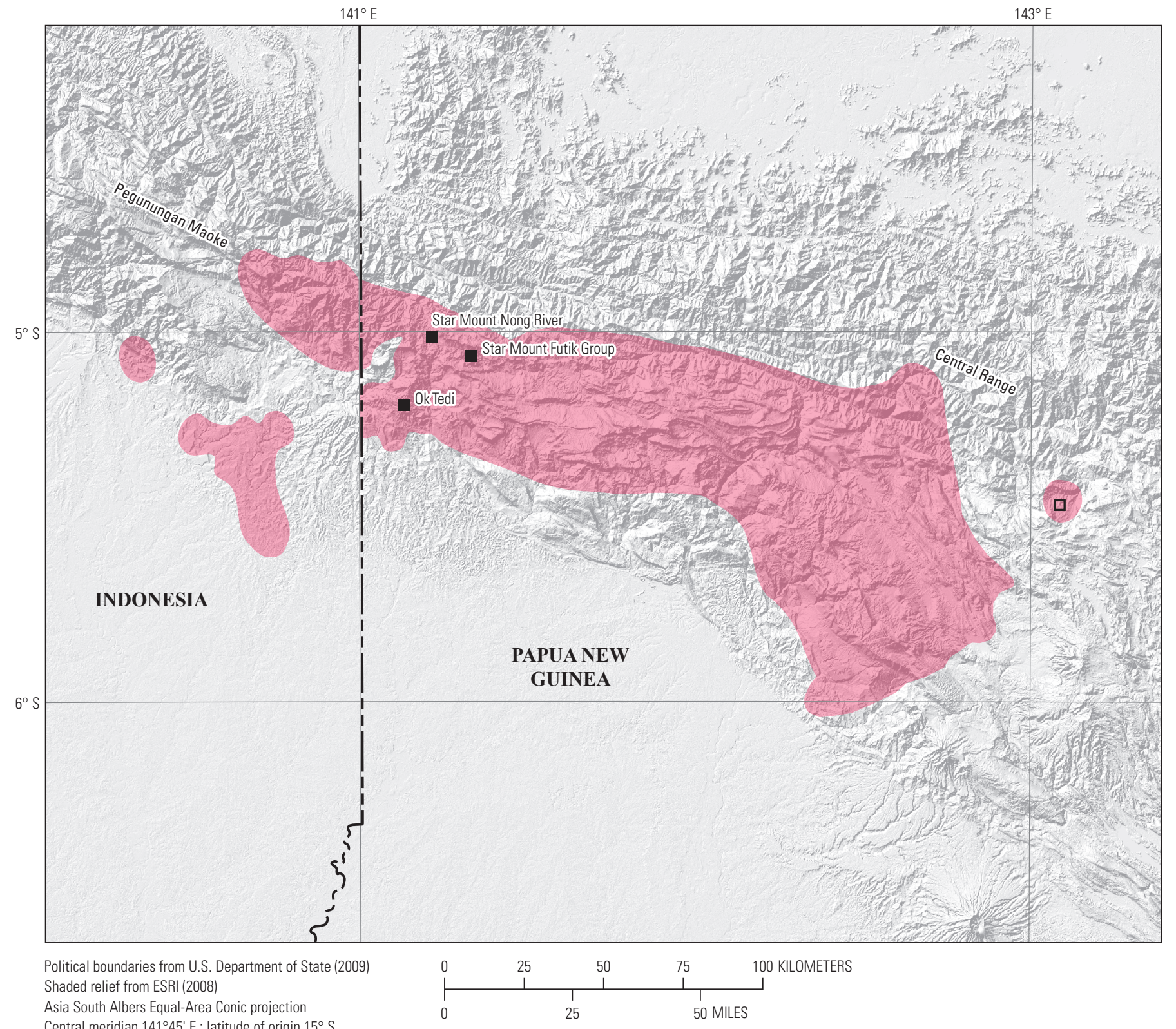

Central meridian $141^{\circ} 45^{\prime} \mathrm{E}$.; latitude of origin $15^{\circ} \mathrm{S}$

EXPLANATION

- Assessed porphyry copper tract 009pCu7203a

Porphyry copper deposit

ㅁ Porphyry copper prospect

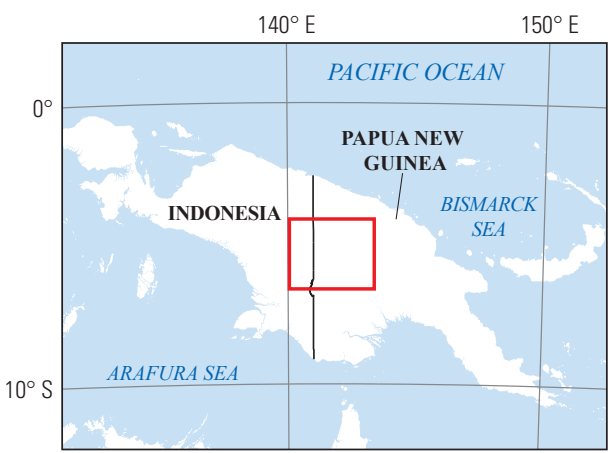




\section{Plate 122. Porphyry Copper Assessment for Tract 009pCu7203b, Eastern Medial New Guinea Magmatic Belt (East)—Papua New Guinea}

Descriptive model:

Grade and tonnage model:

Economic filter depth percentages:

Economic filter cost setting:

Geologic feature assessed:

Number of known deposits:

\author{
Porphyry copper models (Berger and others, 2008; John and others, 2010); porphyry copper-gold \\ models (Cox, 1986b; Cooke and others, 1998) \\ Porphyry copper, copper-gold subtype model (Singer, Berger, and Moring, 2008) \\ Skewed deep- 0 to 250 meters (m), 10\%; > 250 to $500 \mathrm{~m}, 30 \%$; >500 m to $1 \mathrm{~km}, 60 \%$ \\ High cost \\ Late Miocene to Pliocene-Pleistocene Medial New Guinea magmatic belt \\ 3
}

\section{Selected Resource Assessment Results for Porphyry Copper}

[Assessment depth, 1 kilometer $(\mathrm{km})$; $\mathrm{km}^{2}$, square kilometer; Mt, millions of metric tons]

\begin{tabular}{ccccccc}
\hline $\begin{array}{c}\text { Date of } \\
\text { assessment }\end{array}$ & $\begin{array}{c}\text { Tract area } \\
\left(\mathbf{k m}^{2}\right)\end{array}$ & $\begin{array}{c}\text { Identified } \\
\text { copper } \\
\text { resources } \\
\text { (Mt) }\end{array}$ & $\begin{array}{c}\text { Mean estimate of } \\
\text { in-place resources } \\
(\mathbf{M t})\end{array}$ & $\begin{array}{c}\text { Probability of } \mathbf{0} \\
\text { in-place resources } \\
\text { (percent) }\end{array}$ & $\begin{array}{c}\text { Mean estimate of } \\
\text { economic resources } \\
\text { (Mt) }\end{array}$ & $\begin{array}{c}\text { Probability of 0 } \\
\text { economic resources } \\
\text { (percent) }\end{array}$ \\
\hline 2010 & 53,222 & 11 & 20 & 7 & 8.7 \\
\hline
\end{tabular}

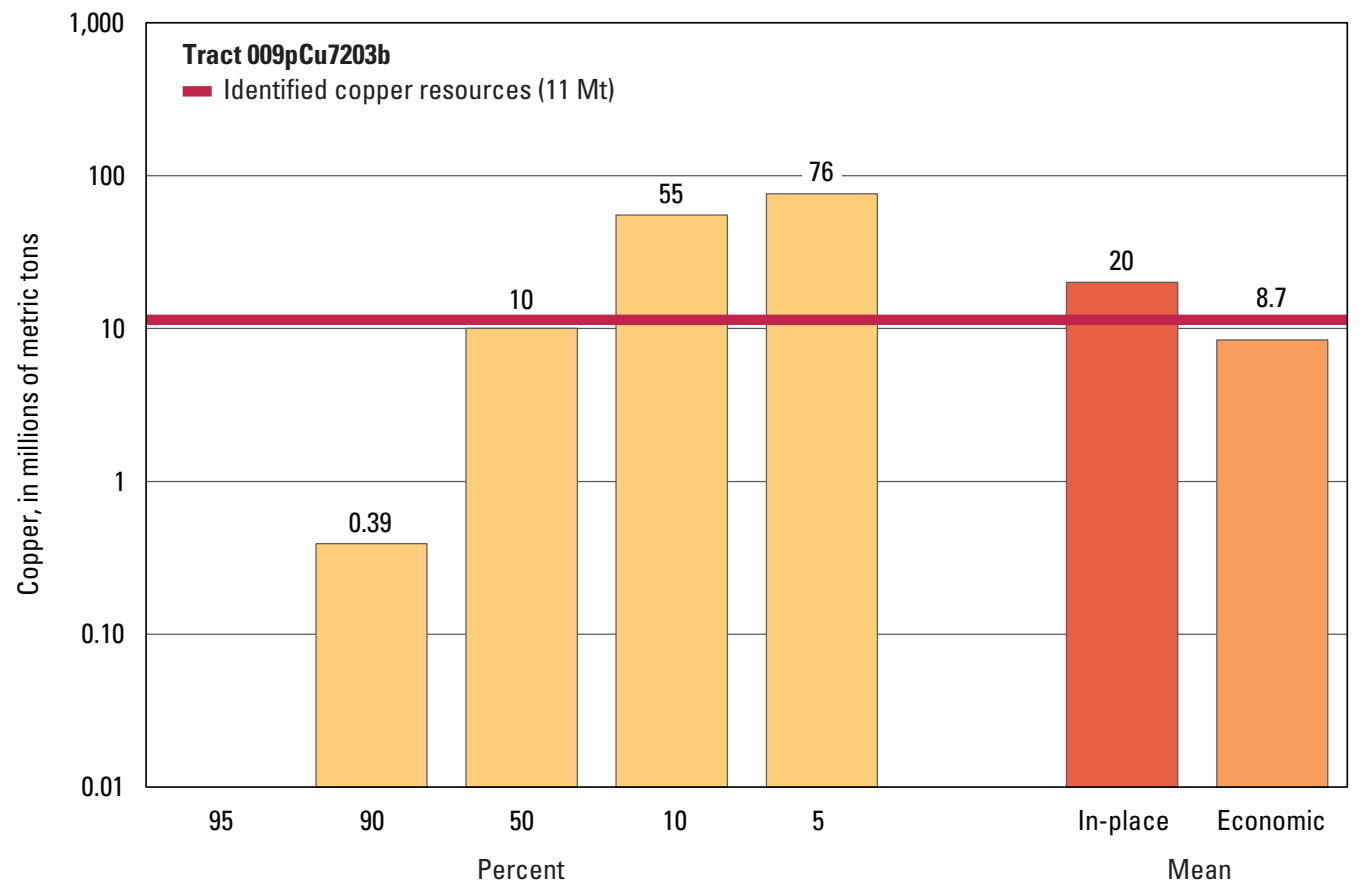

Graph showing the estimated probability distribution of undiscovered copper resources, where each bar represents the minimum amount estimated at the indicated percentage.

\section{Source}

Hammarstrom, Bookstrom, Dicken, and others, 2013, Porphyry copper assessment of Southeast Asia and Melanesia: U.S. Geological Survey Scientific Investigations Report 2010-5090-D, http://pubs.usgs.gov/sir/2010/5090/d/. 


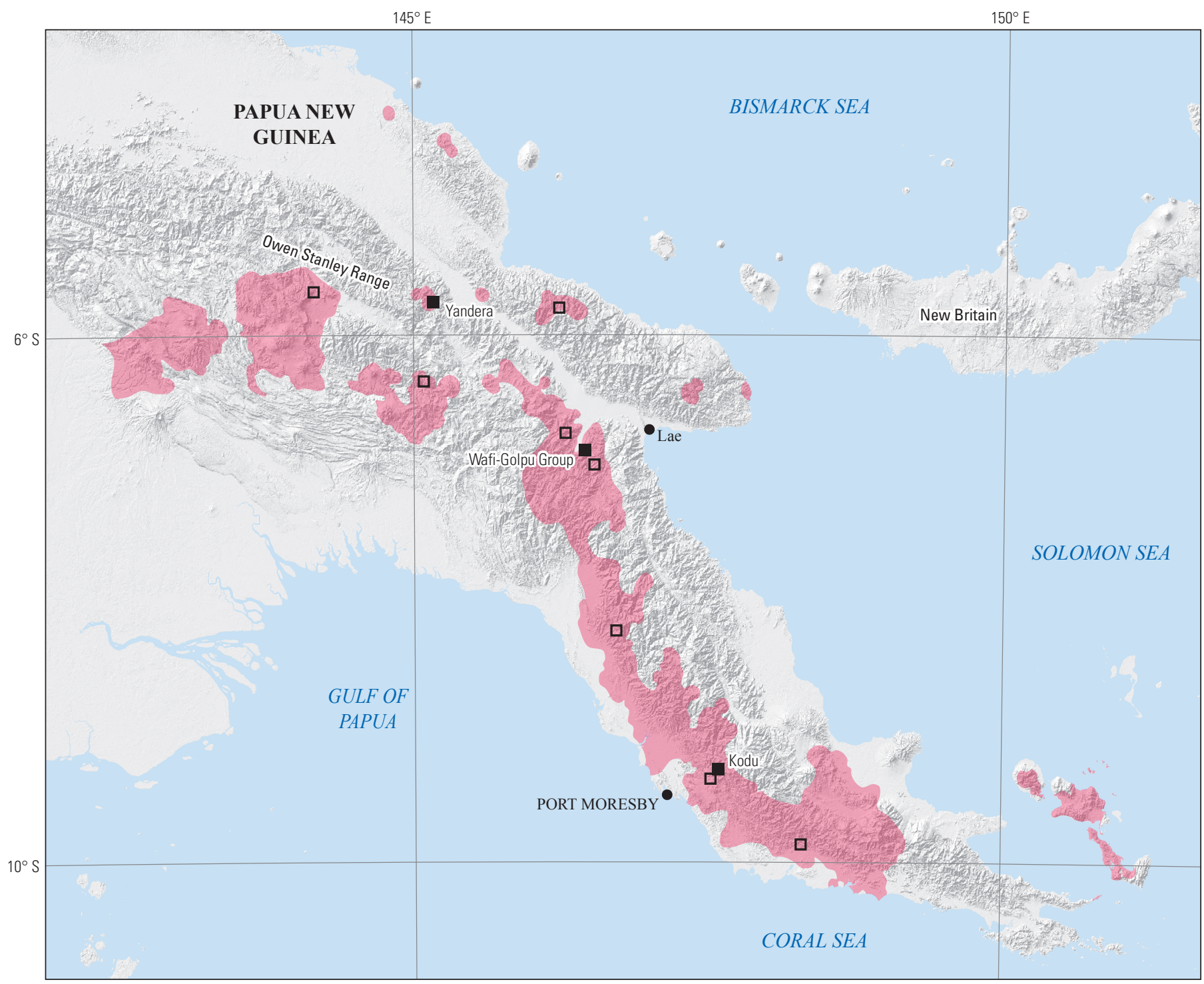

Political boundaries from U.S. Department of State (2009) Shaded relief from ESRI (2008)

Asia South Albers Equal-Area Conic projection

Central meridian $146^{\circ} 30^{\prime}$ E.; latitude of origin $15^{\circ} \mathrm{S}$.

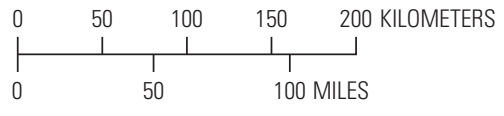

\section{EXPLANATION}

\section{Assessed porphyry copper tract} 009pCu7203b

- Porphyry copper deposit

ㅁ Porphyry copper prospect

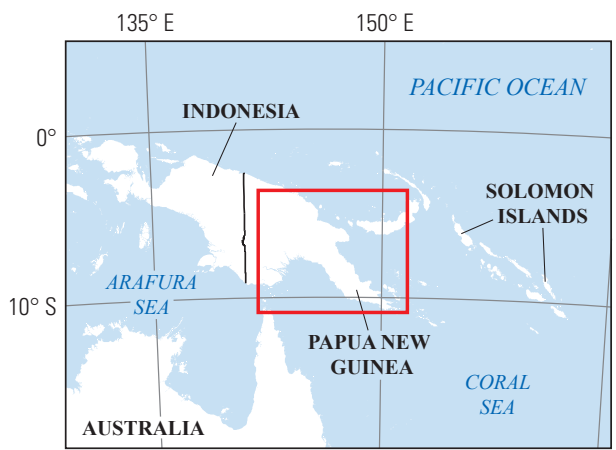




\title{
Plate 123. Porphyry Copper Assessment for Tract 009pCu7208, Inner Melanesian Arc Terranes II-Papua New Guinea and Indonesia
}

\author{
Descriptive model: $\quad$ Porphyry copper models (Berger and others, 2008; John and others, 2010) \\ Grade and tonnage model: NA \\ Economic filter depth percentages: $\quad$ NA \\ Economic filter cost setting: $\quad$ NA \\ Geologic feature assessed: $\quad$ Late Cretaceous to early Miocene accreted Inner Melanesian magmatic arc terranes of New Guinea \\ Island \\ Number of known deposits: $\quad 0$
}

\section{Selected Resource Assessment Results for Porphyry Copper}

[Assessment depth, 1 kilometer $(\mathrm{km}) ; \mathrm{km}^{2}$, square kilometer; Mt, millions of metric tons; NA, not applicable, as a quantitative assessment was not done]

\begin{tabular}{ccccccc}
\hline $\begin{array}{c}\text { Date of } \\
\text { assessment }\end{array}$ & $\begin{array}{c}\text { Tract area } \\
\left(\mathbf{k m}^{2}\right)\end{array}$ & $\begin{array}{c}\text { Identified } \\
\text { copper } \\
\text { resources } \\
(\mathbf{M t})\end{array}$ & $\begin{array}{c}\text { Mean estimate of } \\
\text { in-place resources } \\
(\mathbf{M t})\end{array}$ & $\begin{array}{c}\text { Probability of } \mathbf{0} \\
\text { in-place resources } \\
\text { (percent) }\end{array}$ & $\begin{array}{c}\text { Mean estimate of } \\
\text { economic resources } \\
\text { (Mt) }\end{array}$ & $\begin{array}{c}\text { Probability of } 0 \\
\text { economic resources } \\
\text { (percent) }\end{array}$ \\
\hline 2010 & 29,141 & 0 & NA & NA & NA \\
\hline
\end{tabular}

\section{Qualitative Assessment}

Tract 009pCu7208 (Inner Melanesian Arc Terranes II-Papua New Guinea and Indonesia) was delineated to recognize that Late Cretaceous to Miocene igneous rocks that are permissive for the occurrence of porphyry copper deposits are present in the accreted terranes along the eastern part of northern New Guinea Island and on offshore islands. The presence of coeval volcanic and plutonic rocks suggests that, at least in some areas, the erosion levels may be appropriate for preservation of deposits. However, the team had too little information available to make resource estimates. More information about the exploration history, ages, and lithologies of permissive igneous rocks would be helpful to assess the porphyry potential of the tract area. See tract 142pCu7208 (Inner Melanesian Arc Terranes I-Indonesia) for the western continuation of this tract into Indonesia (pl. 117). Because Indonesia and Papua New Guinea are in two different United Nations world regions, the codes 142 and 009 are used in the identifiers of these two tracts.

\section{Source}

Hammarstrom, Bookstrom, Dicken, and others, 2013, Porphyry copper assessment of Southeast Asia and Melanesia: U.S. Geological Survey Scientific Investigations Report 2010-5090-D, http://pubs.usgs.gov/sir/2010/5090/d/. 


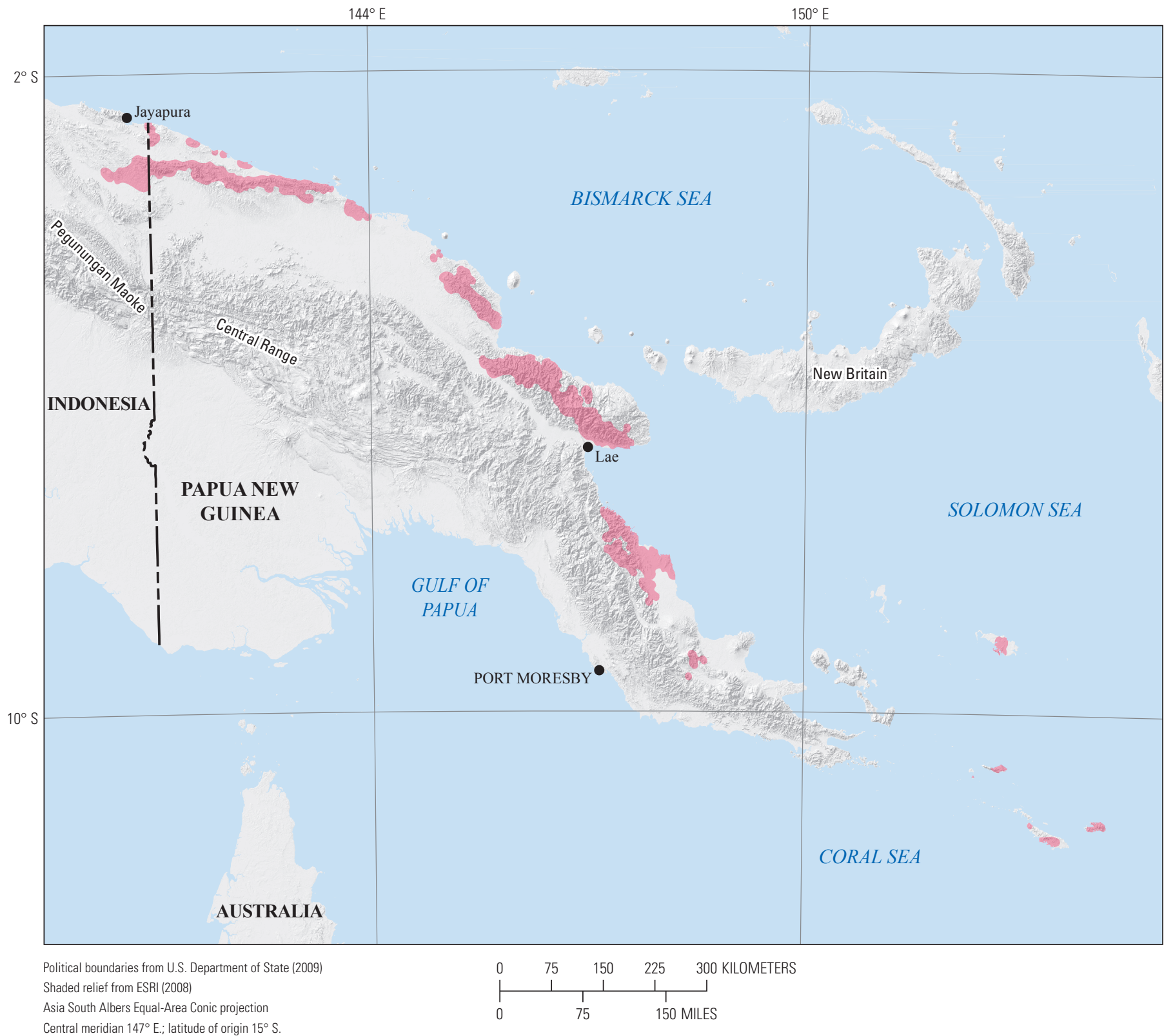

Central meridian $147^{\circ} \mathrm{E}$.; latitude of origin $15^{\circ} \mathrm{S}$.

\section{EXPLANATION}

Assessed porphyry copper tract $009 p$ Cu7208

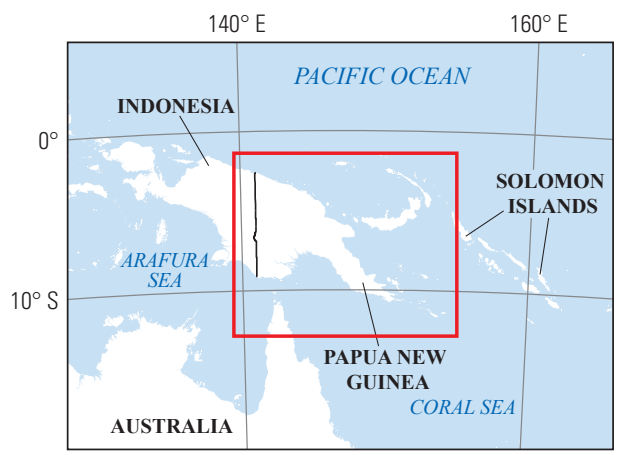




\section{Plate 124. Porphyry Copper Assessment for Tract 009pCu7205, Maramuni Arc- Papua New Guinea}

Descriptive model:

Grade and tonnage model:

Economic filter depth percentages:

Economic filter cost setting:

Geologic feature assessed:

Number of known deposits:
Porphyry copper models (Berger and others, 2008; John and others, 2010); porphyry copper-gold models (Cox, 1986b; Cooke and others, 1998)

Porphyry copper, copper-gold subtype model (Singer, Berger, and Moring, 2008)

Skewed shallow-0 to 250 meters (m), $35 \%$; > 250 to $500 \mathrm{~m}, 25 \%$; $>500 \mathrm{~m}$ to $1 \mathrm{~km}, 40 \%$

High cost

Miocene Maramuni magmatic arc

1

\section{Selected Resource Assessment Results for Porphyry Copper}

[Assessment depth, 1 kilometer (km); $\mathrm{km}^{2}$, square kilometer; Mt, millions of metric tons]

\begin{tabular}{ccccccc}
\hline $\begin{array}{c}\text { Date of } \\
\text { assessment }\end{array}$ & $\begin{array}{c}\text { Tract area } \\
\left.\mathbf{( k m}^{2}\right)\end{array}$ & $\begin{array}{c}\text { Identified } \\
\text { copper } \\
\text { resources } \\
\text { (Mt) }\end{array}$ & $\begin{array}{c}\text { Mean estimate of } \\
\text { in-place resources } \\
(\mathbf{M t})\end{array}$ & $\begin{array}{c}\text { Probability of } \mathbf{0} \\
\text { in-place resources } \\
\text { (percent) }\end{array}$ & $\begin{array}{c}\text { Mean estimate of } \\
\text { economic resources } \\
\text { (Mt) }\end{array}$ & $\begin{array}{c}\text { Probability of 0 } \\
\text { economic resources } \\
\text { (percent) }\end{array}$ \\
\hline 2010 & 38,975 & 8.6 & 9.9 & 20 & 5.1 \\
\hline
\end{tabular}

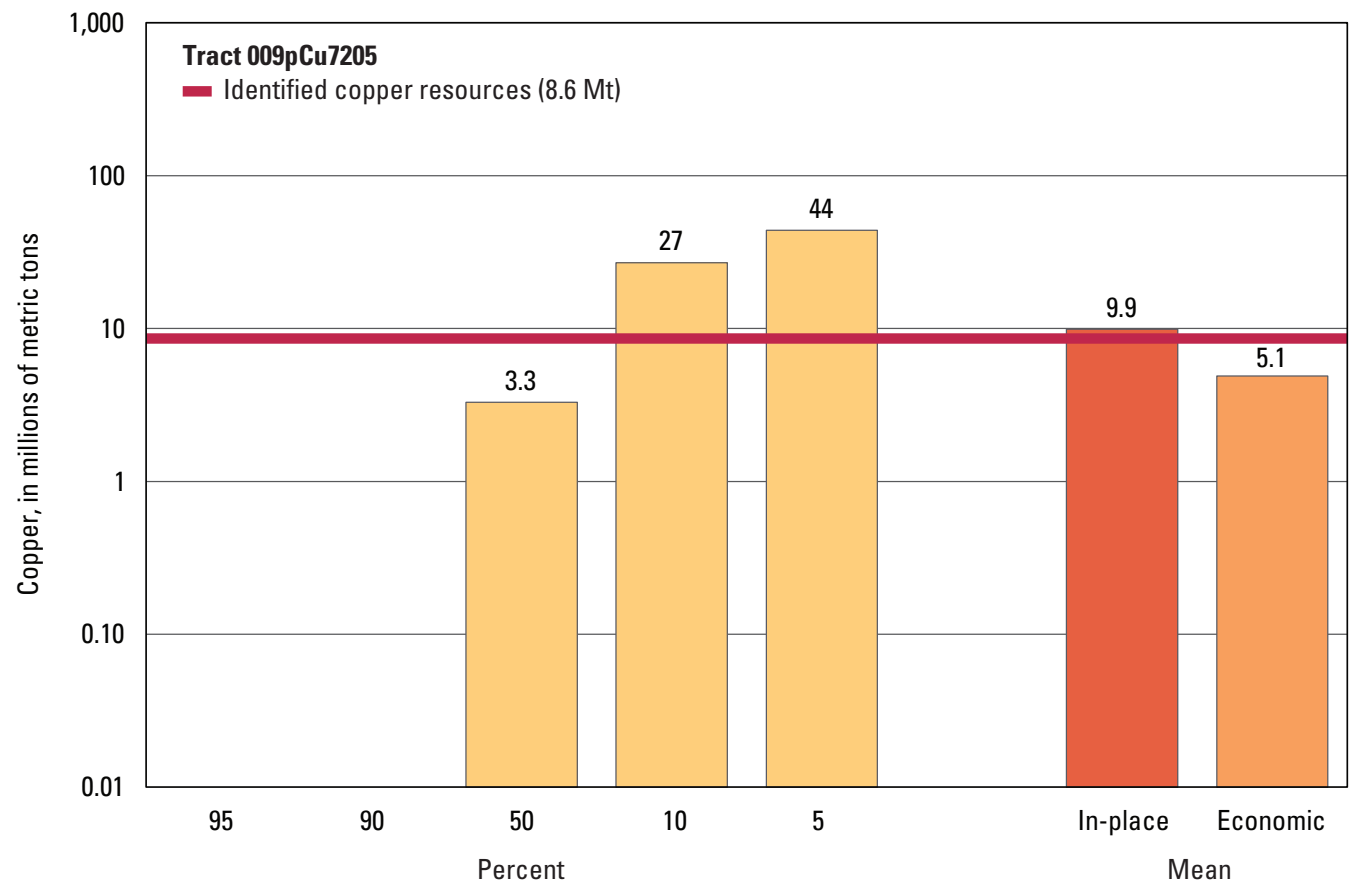

Graph showing the estimated probability distribution of undiscovered copper resources, where each bar represents the minimum amount estimated at the indicated percentage.

\section{Source}

Hammarstrom, Bookstrom, Dicken, and others, 2013, Porphyry copper assessment of Southeast Asia and Melanesia: U.S. Geological Survey Scientific Investigations Report 2010-5090-D, http://pubs.usgs.gov/sir/2010/5090/d/. 


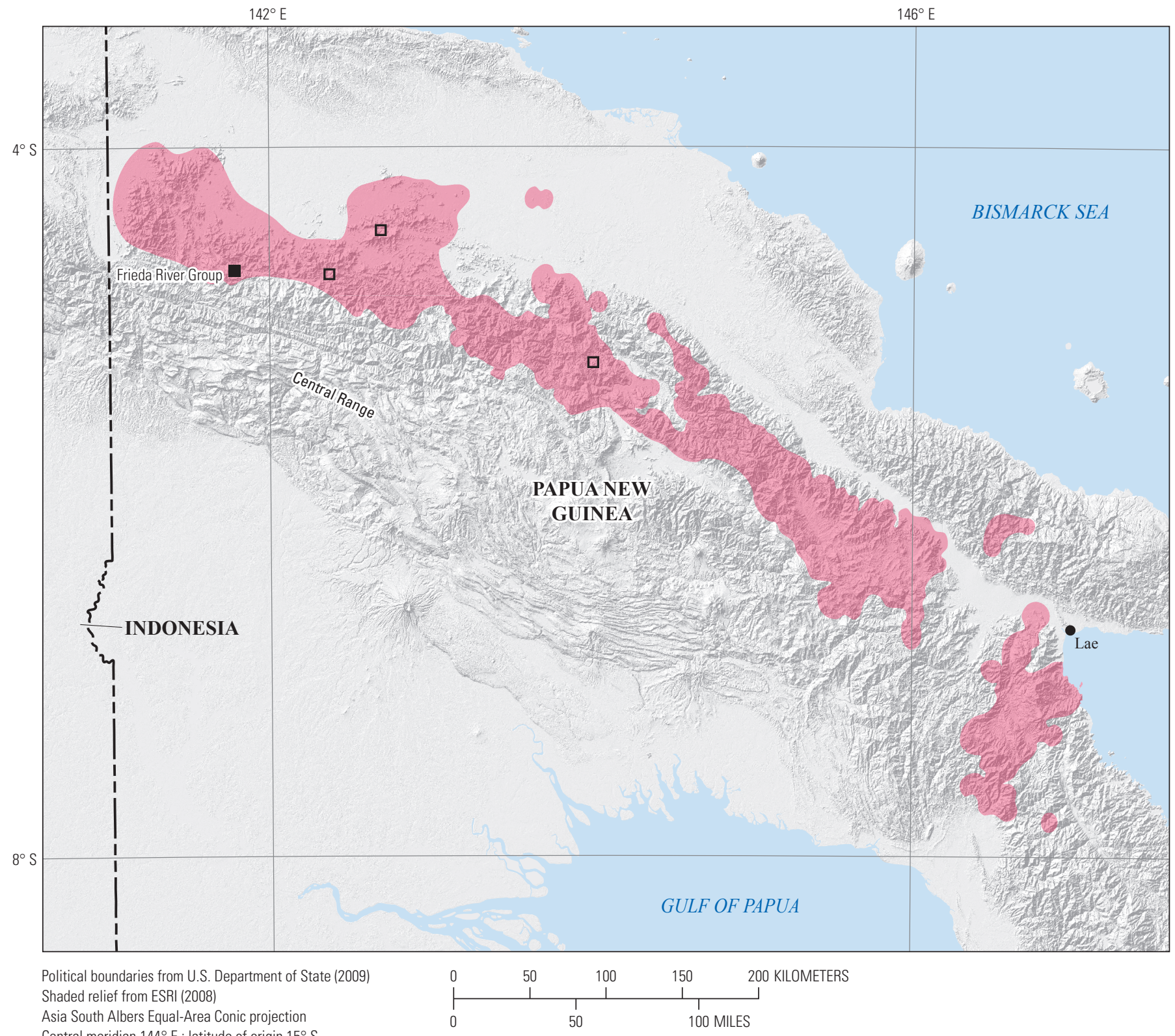

Central meridian $144^{\circ} \mathrm{E}$; l latitude of origin $15^{\circ} \mathrm{S}$.

EXPLANATION

Assessed porphyry copper tract 009pCu7205

- Porphyry copper deposit

Porphyry copper prospect

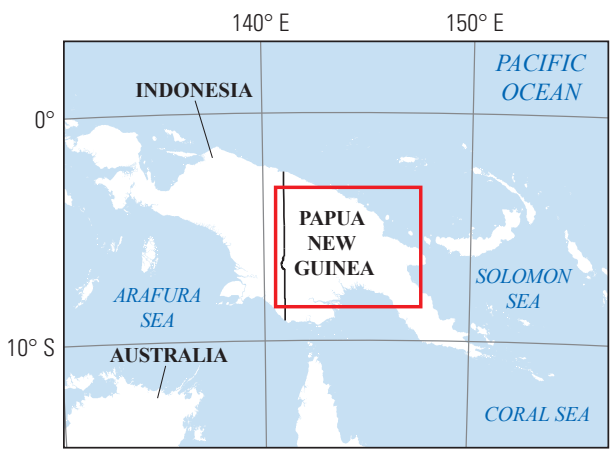




\title{
Plate 125. Porphyry Copper Assessment for Tract 009pCu7206, Miocene Alkalic Rocks, Southeastern New Guinea Island—Papua New Guinea
}

\author{
Descriptive model: \\ Porphyry copper models (Berger and others, 2008; John and others, 2010); porphyry copper-gold \\ models (Cox, 1986b; Cooke and others, 1998) \\ Grade and tonnage model: \\ Porphyry copper, copper-gold subtype model (Singer, Berger, and Moring, 2008) \\ Economic filter depth percentages: \\ Default -0 to 250 meters (m), $25 \%$; > 250 to $500 \mathrm{~m}, 25 \%$; $>500 \mathrm{~m}$ to $1 \mathrm{~km}, 50 \%$ \\ Economic filter cost setting: \\ High cost \\ Geologic feature assessed: \\ Number of known deposits: \\ Miocene alkalic island-arc intrusive rocks \\ 0
}

\section{Selected Resource Assessment Results for Porphyry Copper}

[Assessment depth, 1 kilometer ( $\mathrm{km}) ; \mathrm{km}^{2}$, square kilometer; Mt, millions of metric tons]

\begin{tabular}{ccccccc}
\hline $\begin{array}{c}\text { Date of } \\
\text { assessment }\end{array}$ & $\begin{array}{c}\text { Tract area } \\
\left(\mathbf{k m}^{2}\right)\end{array}$ & $\begin{array}{c}\text { Identified } \\
\text { copper } \\
\text { resources } \\
(\mathbf{M t})\end{array}$ & $\begin{array}{c}\text { Mean estimate of } \\
\text { in-place resources } \\
(\mathbf{M t})\end{array}$ & $\begin{array}{c}\text { Probability of } \mathbf{0} \\
\text { in-place resources } \\
\text { (percent) }\end{array}$ & $\begin{array}{c}\text { Mean estimate of } \\
\text { economic resources } \\
\text { (Mt) }\end{array}$ & $\begin{array}{c}\text { Probability of } \mathbf{0} \\
\text { economic resources } \\
\text { (percent) }\end{array}$ \\
\hline 2010 & 1,638 & 0 & 1.2 & 71 & 0.58 \\
\hline
\end{tabular}

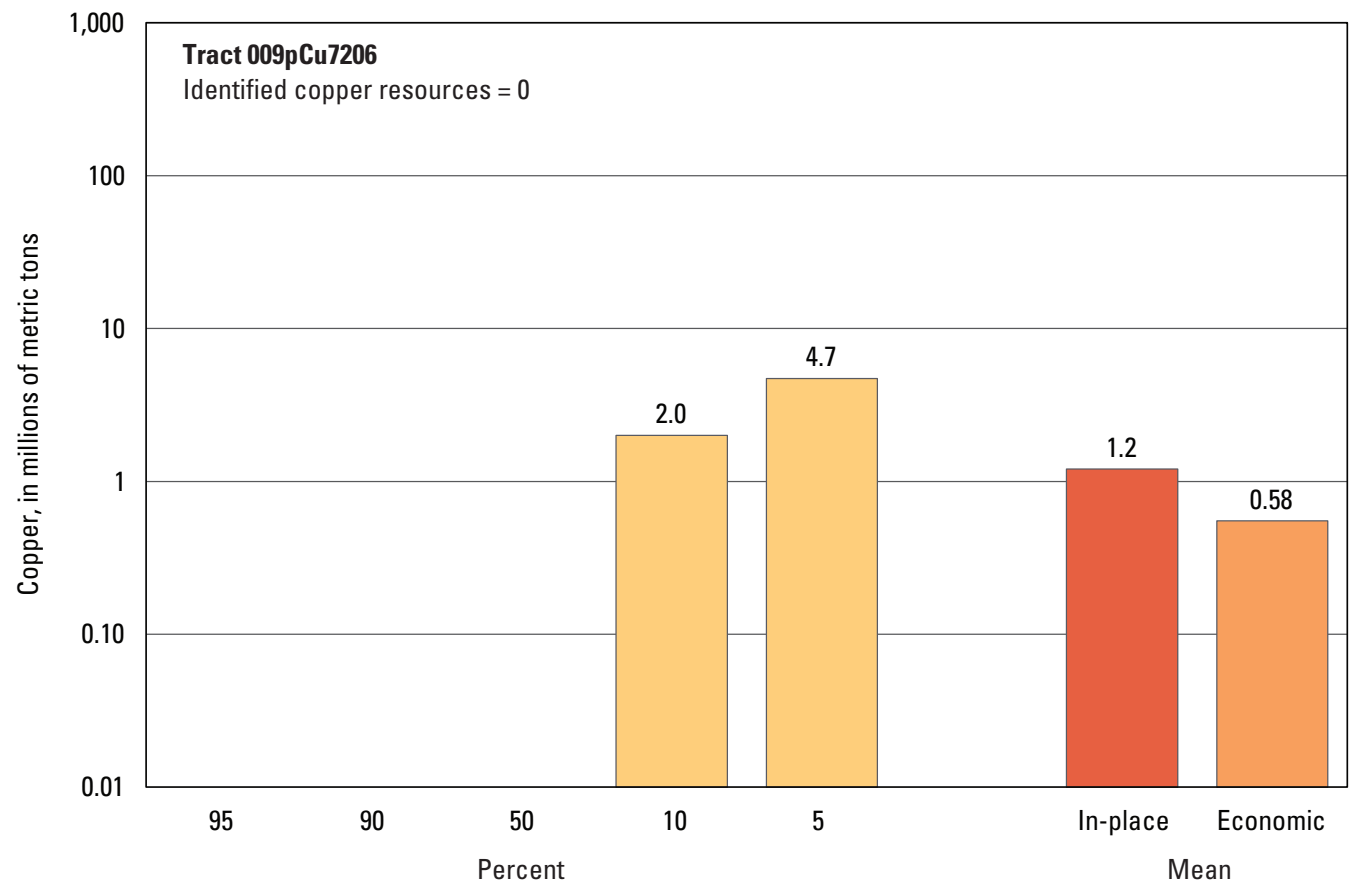

Graph showing the estimated probability distribution of undiscovered copper resources, where each bar represents the minimum amount estimated at the indicated percentage.

\section{Source}

Hammarstrom, Bookstrom, Dicken, and others, 2013, Porphyry copper assessment of Southeast Asia and Melanesia: U.S. Geological Survey Scientific Investigations Report 2010-5090-D, http://pubs.usgs.gov/sir/2010/5090/d/. 


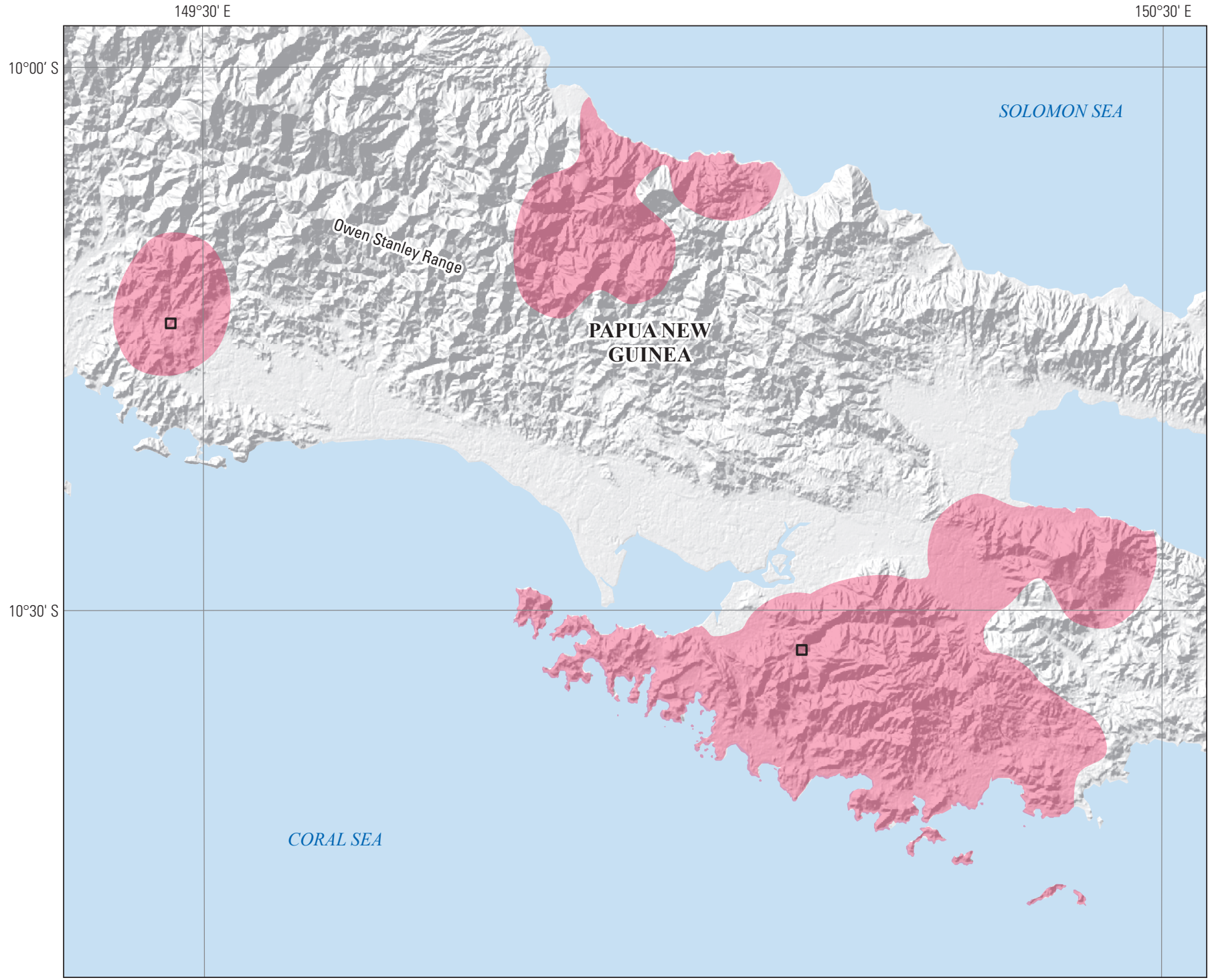

Political boundaries from U.S. Department of State (2009) Shaded relief from ESRI (2008)

Asia South Albers Equal-Area Conic projection Central meridian $150^{\circ} \mathrm{E}$.; latitude of origin $15^{\circ} \mathrm{S}$

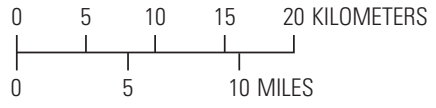

\section{EXPLANATION}

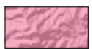

Assessed porphyry copper tract $009 p$ Cu7206

$\square \quad$ Porphyry copper prospect

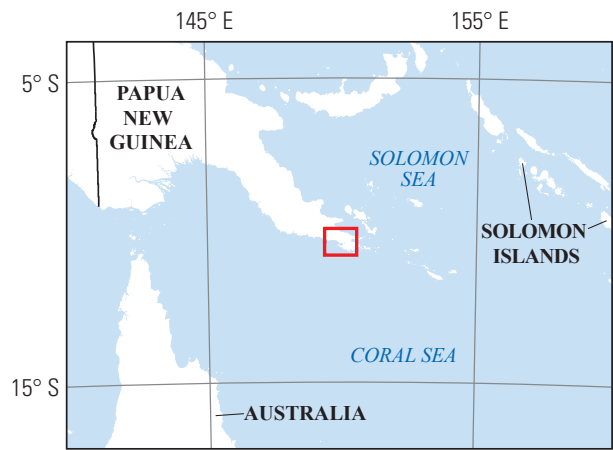




\section{Plate 126. Porphyry Copper Assessment for Tract 009pCu7209, Inner Melanesian Arc (New Britain)—Papua New Guinea}

Descriptive model:

Grade and tonnage model:

Economic filter depth percentages:

Economic filter cost setting:

Geologic feature assessed:

Number of known deposits:
Porphyry copper models (Berger and others, 2008; John and others, 2010); porphyry copper-gold models (Cox, 1986b; Cooke and others, 1998)

General porphyry copper model (Singer, Berger, and Moring, 2008)

Skewed deep- 0 to 250 meters (m), 10\%; > 250 to $500 \mathrm{~m}, 30 \%$; >500 m to $1 \mathrm{~km}, 60 \%$

High cost

Late Cretaceous to early Miocene Inner Melanesian magmatic arc on New Britain

1

\section{Selected Resource Assessment Results for Porphyry Copper}

[Assessment depth, 1 kilometer (km); $\mathrm{km}^{2}$, square kilometer; Mt, millions of metric tons]

\begin{tabular}{ccccccc}
\hline $\begin{array}{c}\text { Date of } \\
\text { assessment }\end{array}$ & $\begin{array}{c}\text { Tract area } \\
\left(\mathbf{k m}^{2}\right)\end{array}$ & $\begin{array}{c}\text { Identified } \\
\text { copper } \\
\text { resources } \\
\text { (Mt) }\end{array}$ & $\begin{array}{c}\text { Mean estimate of } \\
\text { in-place resources } \\
(\mathbf{M t})\end{array}$ & $\begin{array}{c}\text { Probability of } \mathbf{0} \\
\text { in-place resources } \\
\text { (percent) }\end{array}$ & $\begin{array}{c}\text { Mean estimate of } \\
\text { economic resources } \\
\text { (Mt) }\end{array}$ & $\begin{array}{c}\text { Probability of 0 } \\
\text { economic resources } \\
\text { (percent) }\end{array}$ \\
\hline 2010 & 17,987 & 0.72 & 8.5 & 7 & 3.8 \\
\hline
\end{tabular}

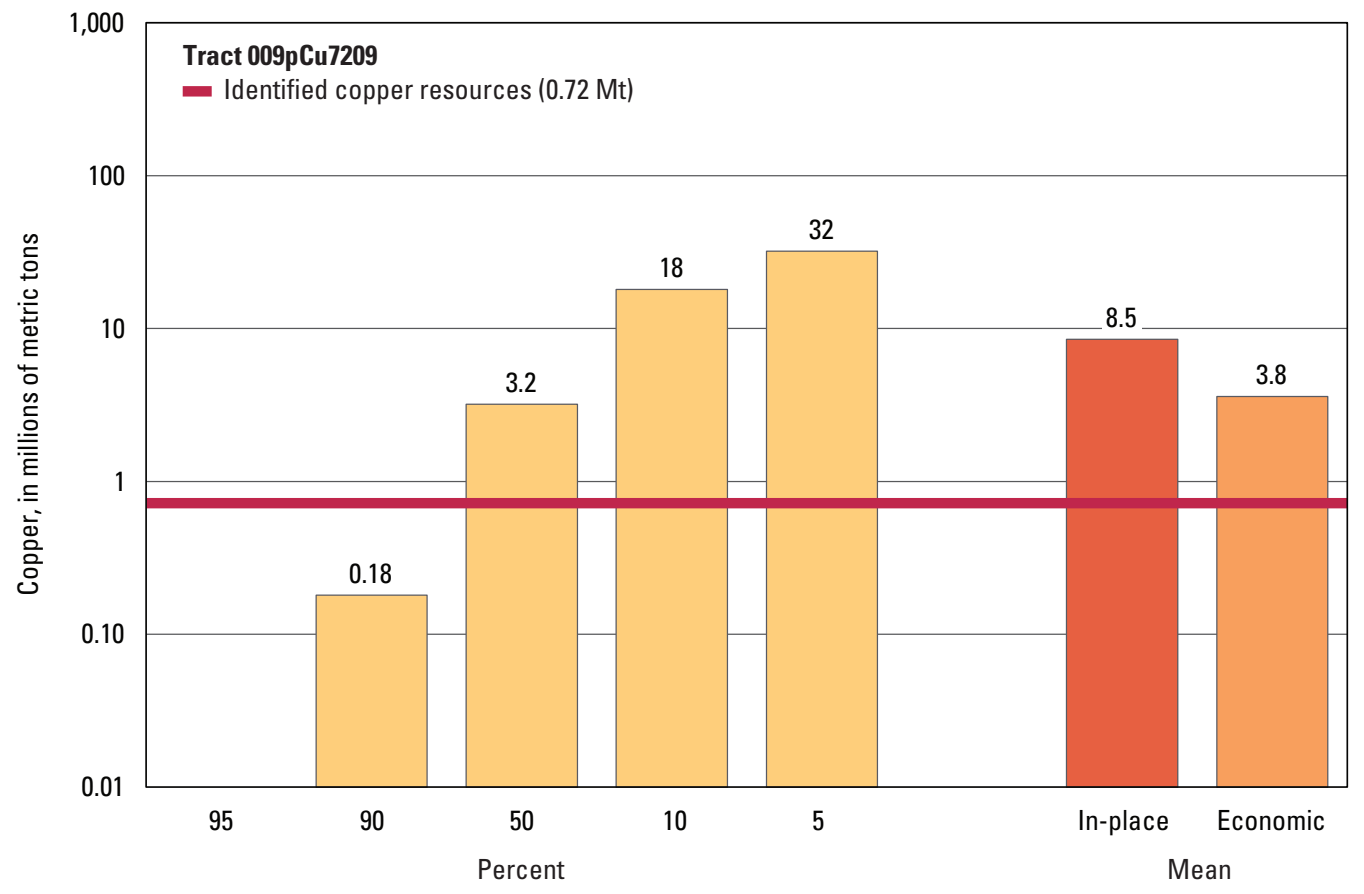

Graph showing the estimated probability distribution of undiscovered copper resources, where each bar represents the minimum amount estimated at the indicated percentage.

\section{Source}

Hammarstrom, Bookstrom, Dicken, and others, 2013, Porphyry copper assessment of Southeast Asia and Melanesia: U.S. Geological Survey Scientific Investigations Report 2010-5090-D, http://pubs.usgs.gov/sir/2010/5090/d/. 


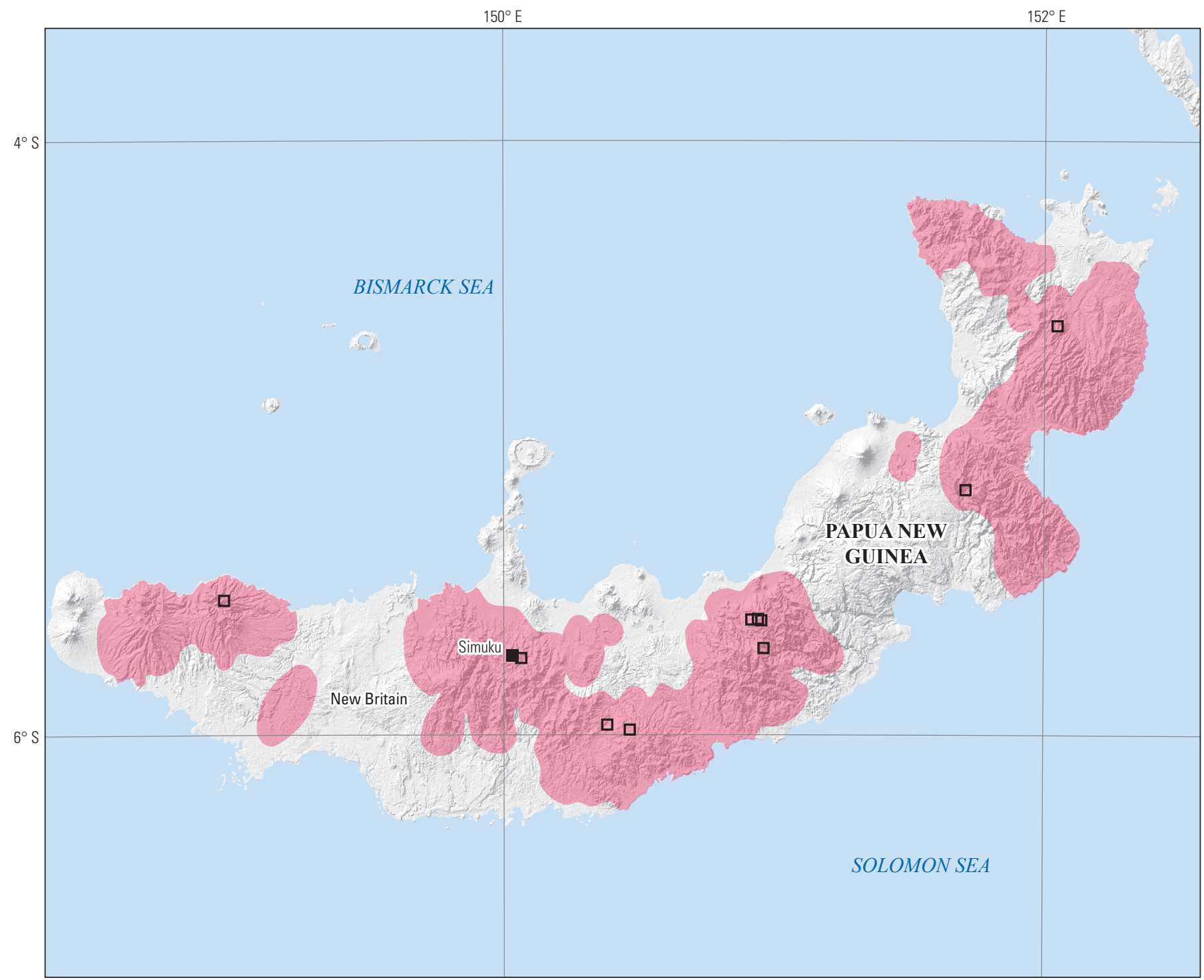

Political boundaries from U.S. Department of State (2009) Shaded relief from ESRI (2008)

Asia South Albers Equal-Area Conic projection

Central meridian $150^{\circ} 30^{\prime}$ E.; latitude of origin $15^{\circ} \mathrm{S}$.

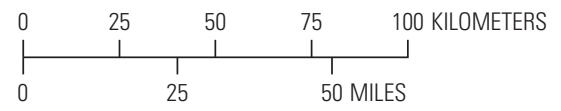

EXPLANATION

Assessed porphyry copper tract 009pCu7209

- Porphyry copper deposit

Porphyry copper prospect

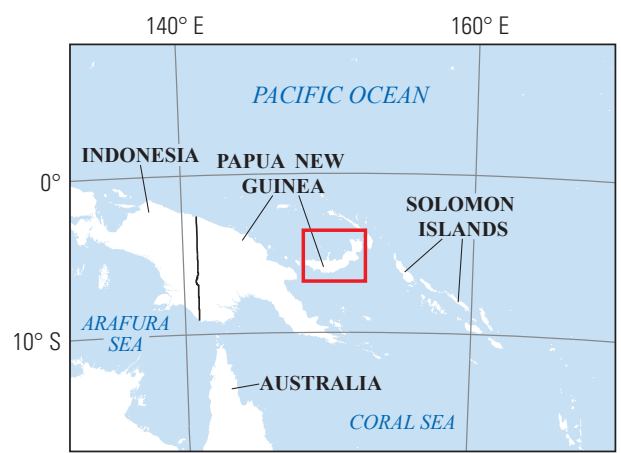




\section{Plate 127. Porphyry Copper Assessment for Tract 009pCu7207, Outer Melanesian Arc I-Papua New Guinea}

Descriptive model:

Grade and tonnage model:

Economic filter depth percentages:

Economic filter cost setting:

Geologic feature assessed:

Number of known deposits:
Porphyry copper models (Berger and others, 2008; John and others, 2010); porphyry copper-gold models (Cox, 1986b; Cooke and others, 1998)

Porphyry copper, copper-gold subtype model (Singer, Berger, and Moring, 2008)

Skewed deep - 0 to 250 meters (m), 10\%; > 250 to $500 \mathrm{~m}, 30 \%$; >500 m to $1 \mathrm{~km}, 60 \%$

High cost

Eocene to Holocene Outer Melanesian magmatic arc, Papua New Guinea

2

\section{Selected Resource Assessment Results for Porphyry Copper}

[Assessment depth, 1 kilometer (km); $\mathrm{km}^{2}$, square kilometer; Mt, millions of metric tons]

\begin{tabular}{ccccccc}
\hline $\begin{array}{c}\text { Date of } \\
\text { assessment }\end{array}$ & $\begin{array}{c}\text { Tract area } \\
\left(\mathbf{k m}^{2}\right)\end{array}$ & $\begin{array}{c}\text { Identified } \\
\text { copper } \\
\text { resources } \\
\text { (Mt) }\end{array}$ & $\begin{array}{c}\text { Mean estimate of } \\
\text { in-place resources } \\
(\mathbf{M t})\end{array}$ & $\begin{array}{c}\text { Probability of } \mathbf{0} \\
\text { in-place resources } \\
\text { (percent) }\end{array}$ & $\begin{array}{c}\text { Mean estimate of } \\
\text { economic resources } \\
\text { (Mt) }\end{array}$ & $\begin{array}{c}\text { Probability of 0 } \\
\text { economic resources } \\
\text { (percent) }\end{array}$ \\
\hline 2010 & 16,834 & 7.2 & 17 & 4 & 7.4 \\
\hline
\end{tabular}

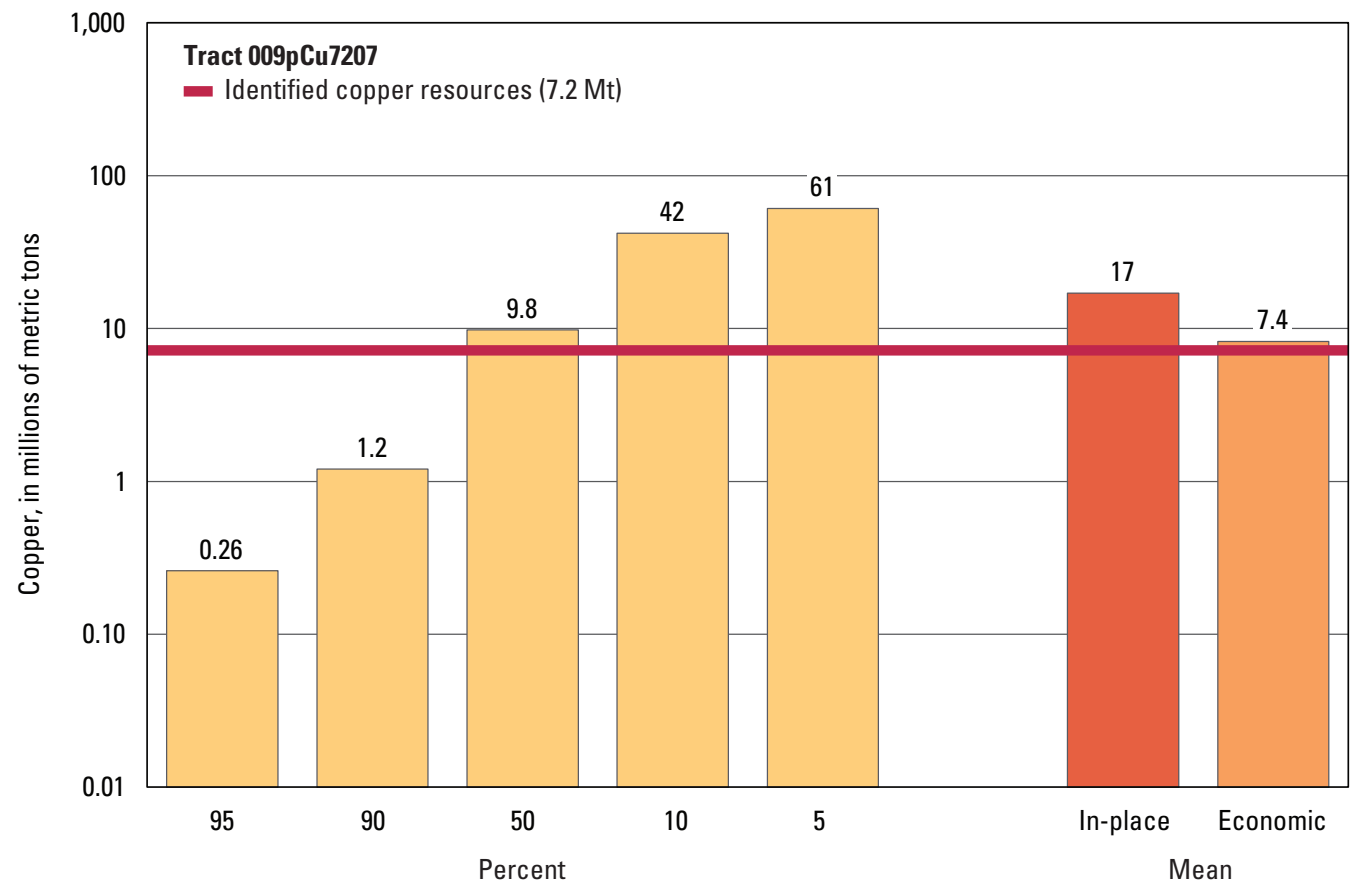

Graph showing the estimated probability distribution of undiscovered copper resources, where each bar represents the minimum amount estimated at the indicated percentage.

\section{Source}

Hammarstrom, Bookstrom, Dicken, and others, 2013, Porphyry copper assessment of Southeast Asia and Melanesia: U.S. Geological Survey Scientific Investigations Report 2010-5090-D, http://pubs.usgs.gov/sir/2010/5090/d/. 


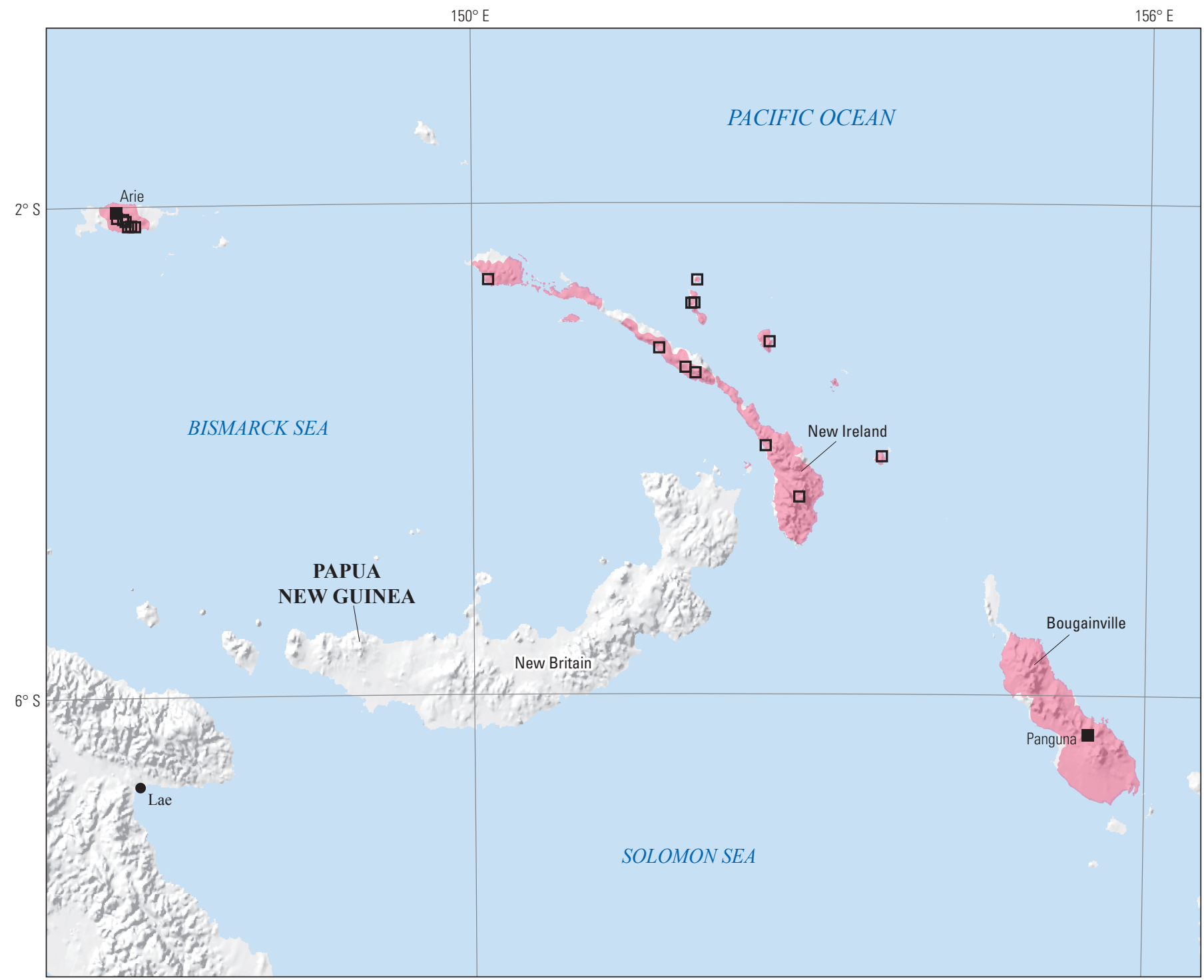

Political boundaries from U.S. Department of State (2009) Shaded relief from ESRI (2008)

Asia South Albers Equal-Area Conic projection Central meridian $152^{\circ} \mathrm{E}$.; latitude of origin $15^{\circ} \mathrm{S}$.

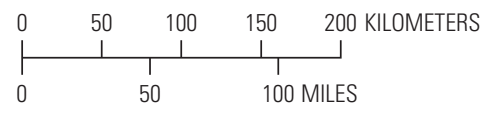

EXPLANATION

Assessed porphyry copper tract 009 p 7207

- Porphyry copper deposit

ㅁ Porphyry copper prospect

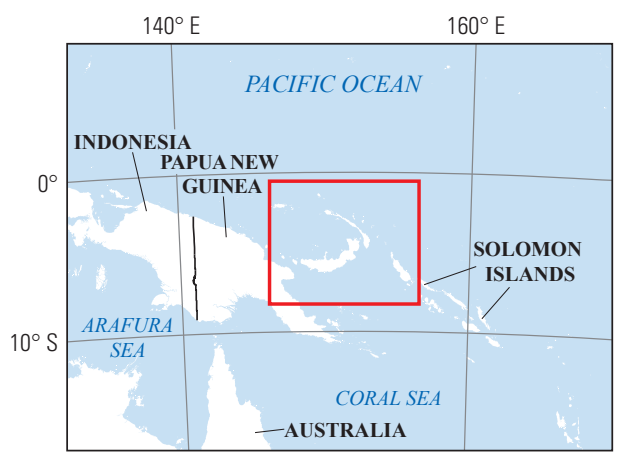




\section{Plate 128. Porphyry Copper Assessment for Tract 009pCu7210, Outer Melanesian Arc-Solomon Islands, Vanuatu, and Fiji}

Descriptive model:

Grade and tonnage model:

Economic filter depth percentages:

Economic filter cost setting:

Geologic feature assessed:

Number of known deposits:
Porphyry copper models (Berger and others, 2008; John and others, 2010); porphyry copper-gold models (Cox, 1986b; Cooke and others, 1998)

Porphyry copper, copper-gold subtype model (Singer, Berger, and Moring, 2008)

Skewed deep- 0 to 250 meters (m), 10\%; > 250 to $500 \mathrm{~m}, 30 \%$; >500 m to $1 \mathrm{~km}, 60 \%$

High cost

Eocene-Oligocene to late Miocene-Pliocene-Pleistocene Outer Melanesian magmatic arc and Melanesian borderlands in the Solomon Islands, Vanuatu, and Fiji

3

\section{Selected Resource Assessment Results for Porphyry Copper}

[Assessment depth, 1 kilometer $(\mathrm{km})$; $\mathrm{km}^{2}$, square kilometer; Mt, millions of metric tons]

\begin{tabular}{|c|c|c|c|c|c|c|}
\hline \multirow[b]{2}{*}{$\begin{array}{c}\text { Date of } \\
\text { assessment }\end{array}$} & \multirow[b]{2}{*}{$\begin{array}{c}\text { Tract area } \\
\qquad\left(\mathbf{k m}^{2}\right)\end{array}$} & \multirow{2}{*}{$\begin{array}{l}\text { Identified } \\
\text { copper } \\
\text { resources } \\
\text { (Mt) }\end{array}$} & \multicolumn{4}{|c|}{ Undiscovered copper resource estimates } \\
\hline & & & $\begin{array}{l}\text { Mean estimate of } \\
\text { in-place resources } \\
\text { (Mt) }\end{array}$ & $\begin{array}{c}\text { Probability of } 0 \\
\text { in-place resources } \\
\text { (percent) }\end{array}$ & $\begin{array}{c}\text { Mean estimate of } \\
\text { economic resources } \\
\text { (Mt) }\end{array}$ & $\begin{array}{c}\text { Probability of } 0 \\
\text { economic resources } \\
\text { (percent) }\end{array}$ \\
\hline 2011 & 38,180 & 6.9 & 16 & 7 & 7.0 & 61 \\
\hline
\end{tabular}

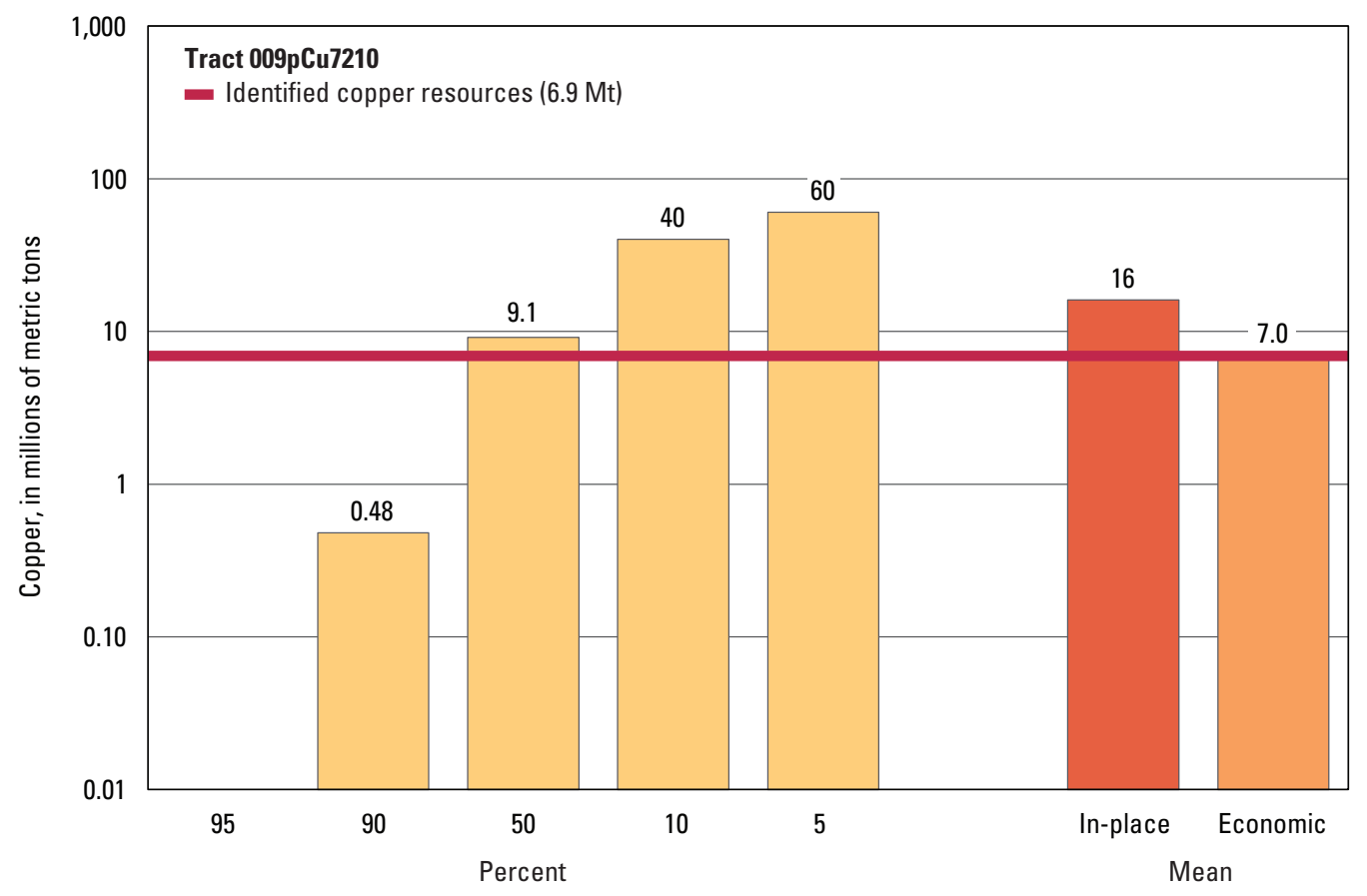

Graph showing the estimated probability distribution of undiscovered copper resources, where each bar represents the minimum amount estimated at the indicated percentage.

\section{Source}

Hammarstrom, Bookstrom, Dicken, and others, 2013, Porphyry copper assessment of Southeast Asia and Melanesia: U.S. Geological Survey Scientific Investigations Report 2010-5090-D, http://pubs.usgs.gov/sir/2010/5090/d/. 


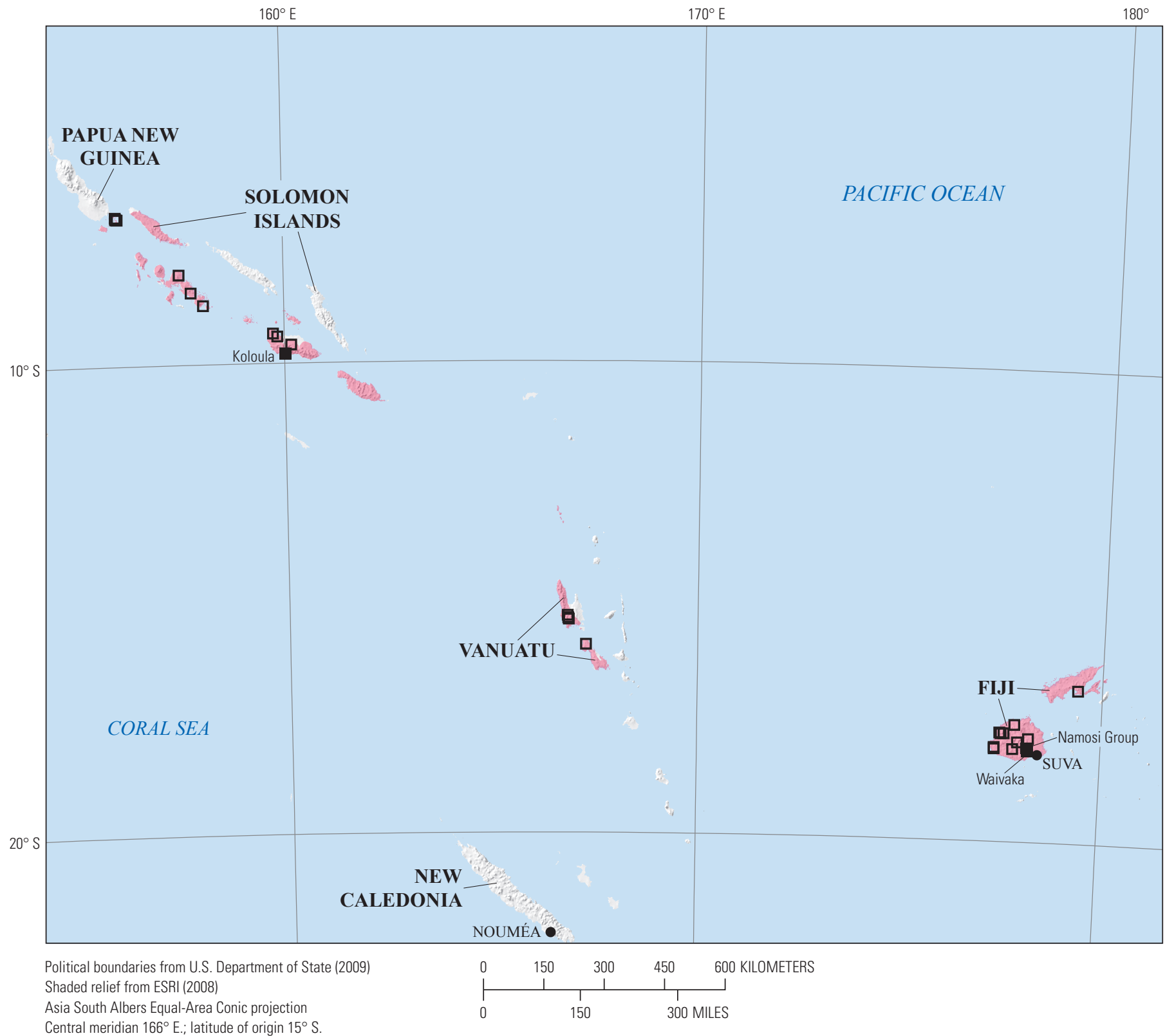

Central meridian $166^{\circ} \mathrm{E}$.; latitude of origin $15^{\circ} \mathrm{S}$.

EXPLANATION

Assessed porphyry copper tract 009pCu7210

- Porphyry copper deposit

․ Porphyry copper prospect

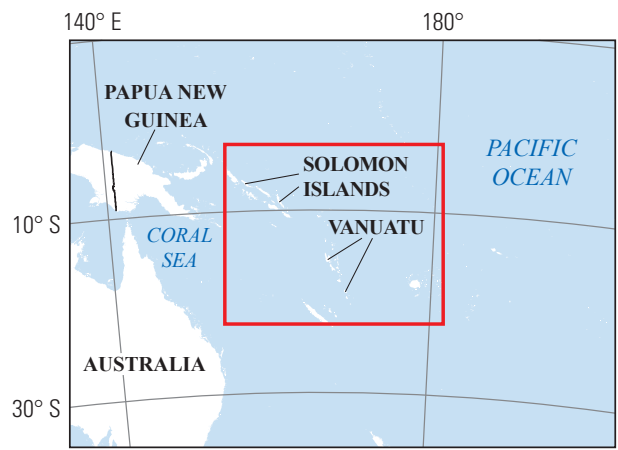




\section{Plate 129. Porphyry Copper Assessment for Tract 009pCu8004d, East Tasmanide (North)_Australia}

Descriptive model:

Grade and tonnage model:

Economic filter depth percentages:

Economic filter cost setting:

Geologic feature assessed:

Number of known deposits:
Porphyry copper models (Cox, 1986a; John and others, 2010); porphyry copper-gold models (Cox, 1986b; Panteleyev, 1995b, 2005b; Cooke and others, 1998; Jaireth and Miezitis, 2004); porphyry copper-molybdenum model (Cox, 1986c); porphyry $\mathrm{Cu} \pm \mathrm{Mo} \pm \mathrm{Au}$ models (Panteleyev, 1995a, 2005a)

NA

NA

NA

Continental magmatic arcs of Silurian to Early Cretaceous age, mostly in the New England orogen and North Queensland orogen, Australia

0

\section{Selected Resource Assessment Results for Porphyry Copper}

[Assessment depth, 1 kilometer $(\mathrm{km}) ; \mathrm{km}^{2}$, square kilometer; Mt, millions of metric tons; NA, not applicable, as a quantitative assessment was not done]

\begin{tabular}{ccccccc}
\hline \multirow{2}{*}{$\begin{array}{c}\text { Date of } \\
\text { assessment }\end{array}$} & $\begin{array}{c}\text { Tract area } \\
\left(\mathbf{k m}^{2}\right)\end{array}$ & $\begin{array}{c}\text { Identified } \\
\text { copper } \\
\text { resources } \\
(\mathbf{M t})\end{array}$ & $\begin{array}{c}\text { Mean estimate of } \\
\text { in-place resources } \\
(\mathbf{M t})\end{array}$ & $\begin{array}{c}\text { Probability of } \mathbf{0} \\
\text { in-place resources } \\
\text { (percent) }\end{array}$ & $\begin{array}{c}\text { Mean estimate of } \\
\text { economic resources } \\
\text { (Mt) }\end{array}$ & $\begin{array}{c}\text { Probability of } \mathbf{0} \\
\text { economic resources } \\
\text { (percent) }\end{array}$ \\
\hline 2010 & 34,759 & 0 & NA & NA & NA & NA \\
\hline
\end{tabular}

\section{Qualitative Assessment}

For purposes of assessment of undiscovered porphyry copper resources, successive magmatic belts were combined into one permissive tract, $009 \mathrm{pCu} 8004$ (East Tasmanide-Australia), because they are spatially contiguous and have similar assemblages of permissive rocks. Only the Central sub-tract was assessed quantitatively (pl. 130, sub-tract 009pCu8004b). The South sub-tract of the East Tasmanide tract is defined by igneous rocks of permissive composition at the southern end of the New England orogen in northeastern New South Wales (pl. 132, sub-tract 009pCu8004c). This South sub-tract contains no known porphyry copper deposits or significant prospects, and the distribution of permissive rocks suggests that the area of this sub-tract is too deeply eroded for preservation of porphyry copper deposits. The probability that the North sub-tract (this plate, sub-tract 009pCu8004d) contains undiscovered porphyry copper deposits was qualitatively judged to be very low. The Island Arc sub-tract (pl. 131, sub-tract 009pCu8004a) contains no known pre-accretionary porphyry copper deposits or significant prospects; the probability that it contains undiscovered pre-accretionary porphyry copper deposits was qualitatively judged to be very low.

\section{Source}

Bookstrom and others, 2014, Porphyry copper assessment of eastern Australia: U.S. Geological Survey Scientific Investigations Report 2010-5090-L, http://dx.doi.org/10.3133/sir20105090L. 

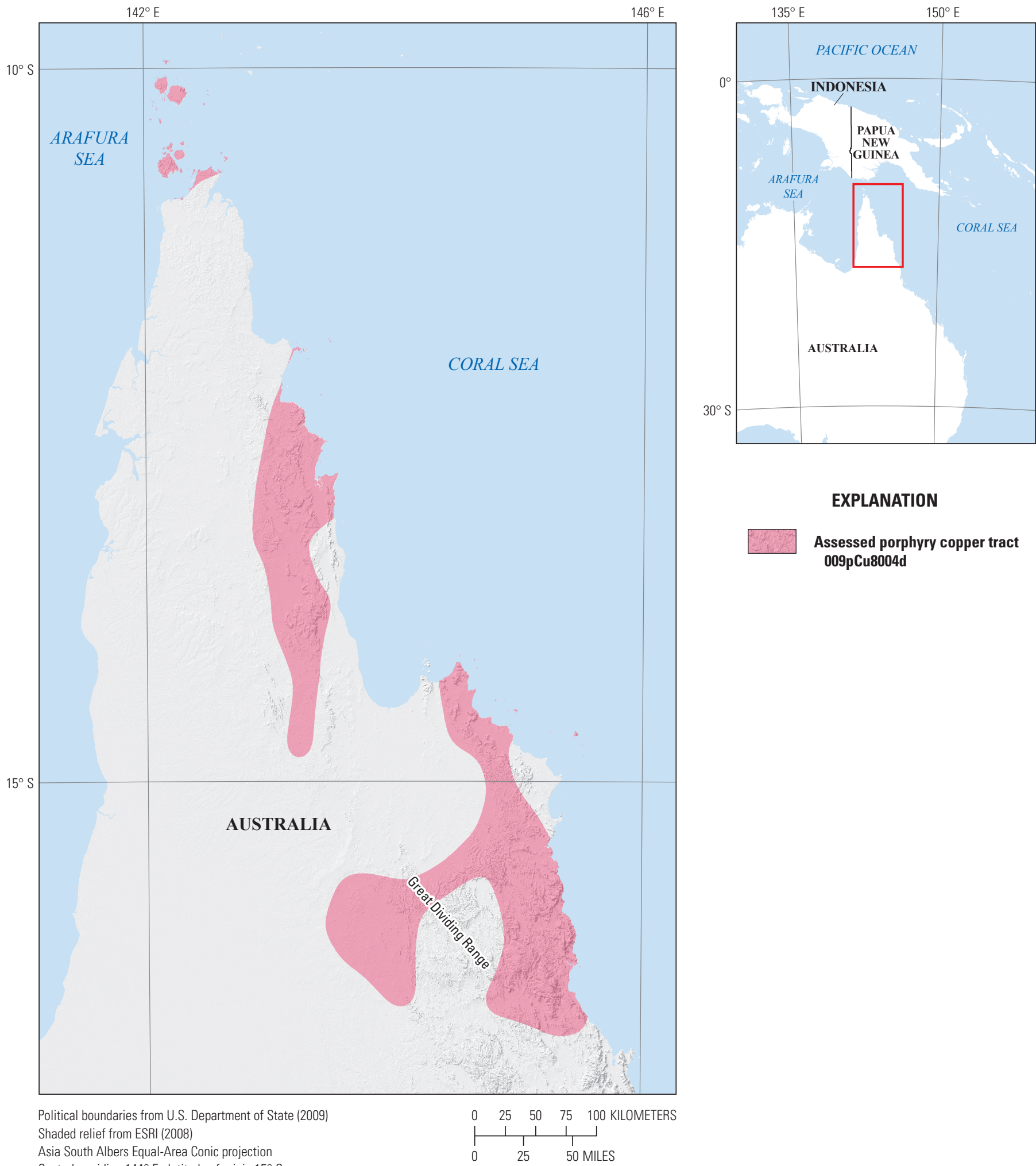

Assessed porphyry copper tract 009pCu8004d

Asia South Albers Equal-Area Conic projection

Central meridian $144^{\circ} \mathrm{E}$.; latitude of origin $15^{\circ} \mathrm{S}$. 


\section{Plate 130. Porphyry Copper Assessment for Tract 009pCu8004b, East Tasmanide (Central)-Australia}

Descriptive model:

Grade and tonnage model:

Economic filter depth percentages:

Economic filter cost setting:

Geologic feature assessed:

Number of known deposits:
Porphyry copper models (Cox, 1986a; John and others, 2010); porphyry copper-gold models (Cox, 1986b; Panteleyev, 1995b, 2005b; Cooke and others, 1998; Jaireth and Miezitis, 2004); porphyry copper-molybdenum model (Cox, 1986c); porphyry $\mathrm{Cu} \pm \mathrm{Mo} \pm \mathrm{Au}$ models (Panteleyev, 1995a, 2005a)

Eastern Australia custom model (Bookstrom and others, 2014)

Default -0 to 250 meters (m), $25 \%$; $>250$ to $500 \mathrm{~m}, 25 \%$; $>500 \mathrm{~m}$ to $1 \mathrm{~km}, 50 \%$

Typical cost

Continental magmatic arcs of Silurian to Early Cretaceous age, mostly in the New England orogen and North Queensland orogen, Australia

14

\section{Selected Resource Assessment Results for Porphyry Copper}

[Assessment depth, 1 kilometer $(\mathrm{km}) ; \mathrm{km}^{2}$, square kilometer; Mt, millions of metric tons]

\begin{tabular}{ccccccc}
\hline \multirow{2}{*}{$\begin{array}{c}\text { Date of } \\
\text { assessment }\end{array}$} & $\begin{array}{c}\text { Tract area } \\
\left(\mathbf{k m}^{2}\right)\end{array}$ & $\begin{array}{c}\text { Identified } \\
\text { copper } \\
\text { resources } \\
(\mathbf{M t})\end{array}$ & $\begin{array}{c}\text { Mean estimate of } \\
\text { in-place resources } \\
(\mathbf{M t})\end{array}$ & $\begin{array}{c}\text { Probability of } \mathbf{0} \\
\text { in-place resources } \\
\text { (percent) }\end{array}$ & $\begin{array}{c}\text { Mean estimate of } \\
\text { economic resources } \\
\text { (Mt) }\end{array}$ & $\begin{array}{c}\text { Probability of 0 } \\
\text { economic resources } \\
\text { (percent) }\end{array}$ \\
\hline 2010 & 290,646 & 2.3 & 0.28 & 9 & 0 \\
\hline
\end{tabular}

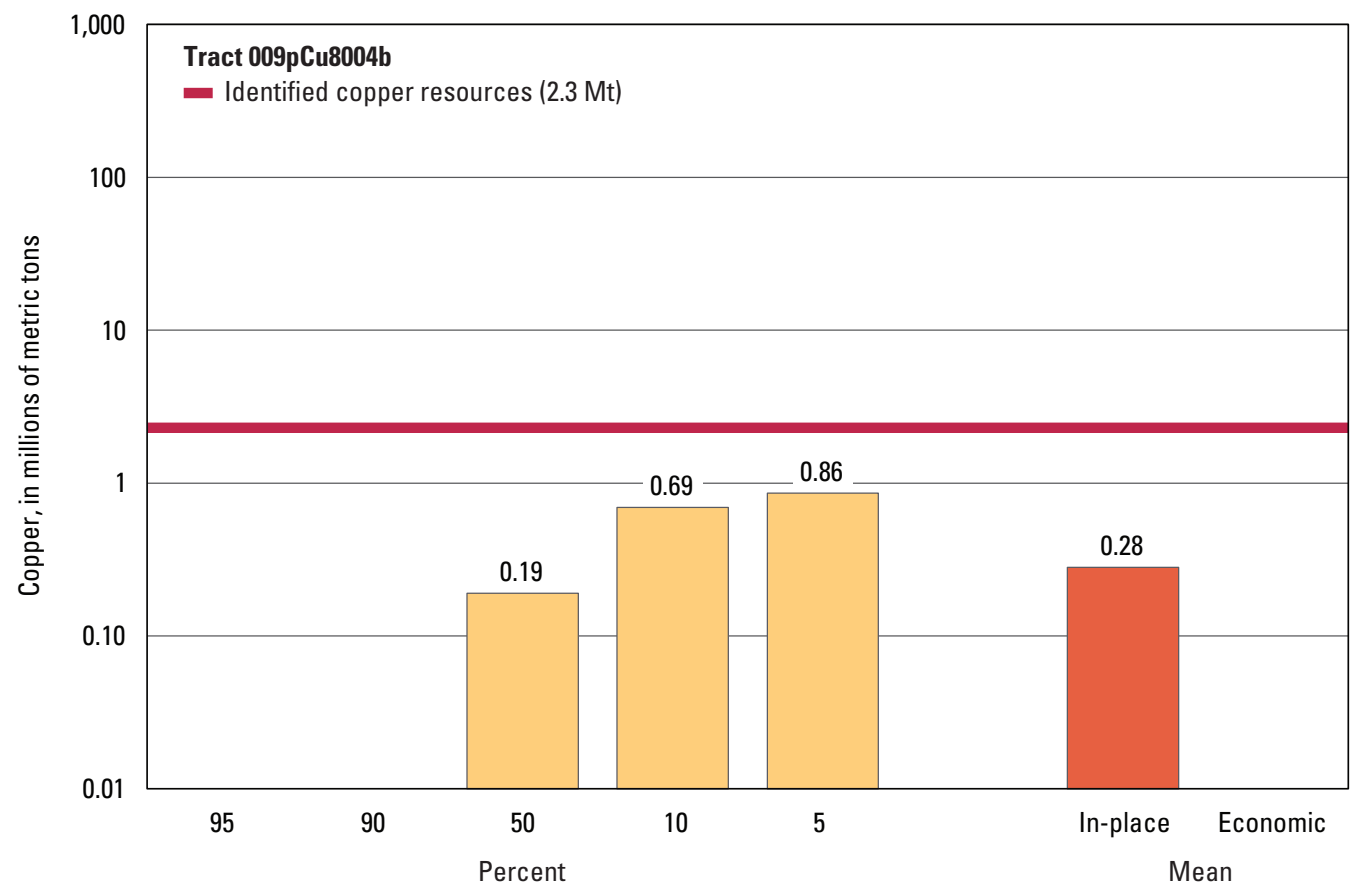

Graph showing the estimated probability distribution of undiscovered copper resources, where each bar represents the minimum amount estimated at the indicated percentage.

\section{Source}

Bookstrom and others, 2014, Porphyry copper assessment of eastern Australia: U.S. Geological Survey Scientific Investigations Report 2010-5090-L, http://dx.doi.org/10.3133/sir20105090L. 


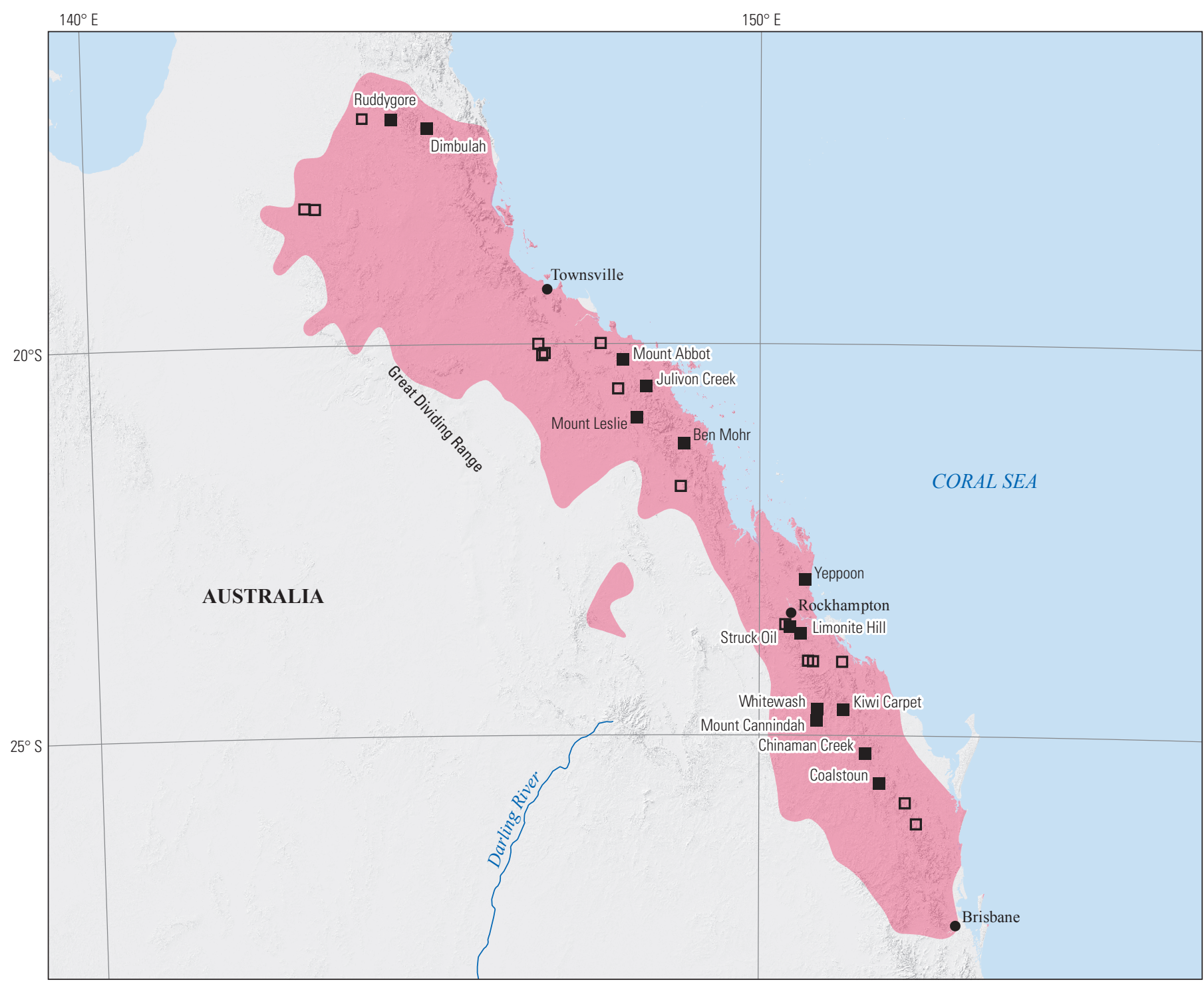

Political boundaries from U.S. Department of State (2009) Shaded relief from ESRI (2008)

Asia South Albers Equal-Area Conic projection Central meridian $149^{\circ} \mathrm{E}$.; latitude of origin $15^{\circ} \mathrm{S}$.

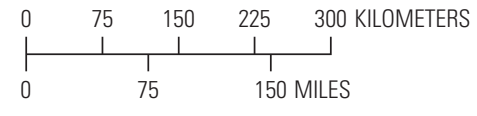

EXPLANATION

Assessed porphyry copper tract 009pCu8004b

- Porphyry copper deposit

ㅁ Porphyry copper prospect

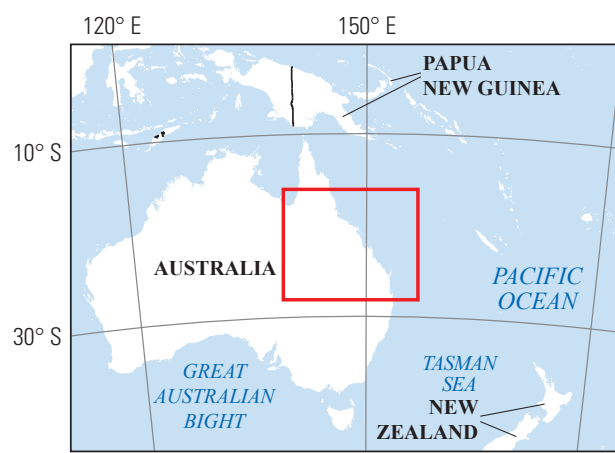




\title{
Plate 131. Porphyry Copper Assessment for Tract 009pCu8004a, East Tasmanide (Island Arc)_Australia
}

\author{
Descriptive model: \\ Porphyry copper models (Cox, 1986a; John and others, 2010); porphyry copper-gold models \\ (Cox, 1986b; Panteleyev, 1995b, 2005b; Cooke and others, 1998; Jaireth and Miezitis, 2004); \\ porphyry copper-molybdenum model (Cox, 1986c); porphyry $\mathrm{Cu} \pm \mathrm{Mo} \pm \mathrm{Au}$ models (Panteleyev, \\ 1995a, 2005a) \\ Grade and tonnage model: NA \\ Economic filter depth percentages: NA \\ Economic filter cost setting: NA \\ Geologic feature assessed: $\quad$ Paleozoic igneous rocks formed offshore in island arcs and subsequently accreted to the eastern \\ Australia continental margin \\ Number of known deposits: \\ 0
}

\section{Selected Resource Assessment Results for Porphyry Copper}

[Assessment depth, 1 kilometer $(\mathrm{km}) ; \mathrm{km}^{2}$, square kilometer; Mt, millions of metric tons; NA, not applicable, as a quantitative assessment was not done]

\begin{tabular}{ccccccc}
\hline $\begin{array}{c}\text { Date of } \\
\text { assessment }\end{array}$ & $\begin{array}{c}\text { Tract area } \\
\left(\mathbf{k m}^{2}\right)\end{array}$ & $\begin{array}{c}\text { Identified } \\
\text { copper } \\
\text { resources } \\
(\mathbf{M t})\end{array}$ & $\begin{array}{c}\text { Mean estimate of } \\
\text { in-place resources } \\
(\mathbf{M t})\end{array}$ & $\begin{array}{c}\text { Probability of } \mathbf{0} \\
\text { in-place resources } \\
\text { (percent) }\end{array}$ & $\begin{array}{c}\text { Mean estimate of } \\
\text { economic resources } \\
\text { (Mt) }\end{array}$ & $\begin{array}{c}\text { Probability of 0 } \\
\text { economic resources } \\
\text { (percent) }\end{array}$ \\
\hline 2010 & 16,741 & 0 & NA & NA & NA \\
\hline
\end{tabular}

\section{Qualitative Assessment}

For purposes of assessment of undiscovered porphyry copper resources, successive magmatic belts were combined into one permissive tract, $009 \mathrm{pCu} 8004$ (East Tasmanide-Australia), because they are spatially contiguous and have similar assemblages of permissive rocks. Only the Central sub-tract was assessed quantitatively (pl. 130, sub-tract 009pCu8004b). The Island Arc sub-tract (this plate, sub-tract $009 \mathrm{pCu} 8004 \mathrm{a}$ ) contains no known pre-accretionary porphyry copper deposits or significant prospects; the probability that it contains undiscovered pre-accretionary porphyry copper deposits was qualitatively judged to be very low.

\section{Source}

Bookstrom and others, 2014, Porphyry copper assessment of eastern Australia: U.S. Geological Survey Scientific Investigations Report 2010-5090-L, http://dx.doi.org/10.3133/sir20105090L. 

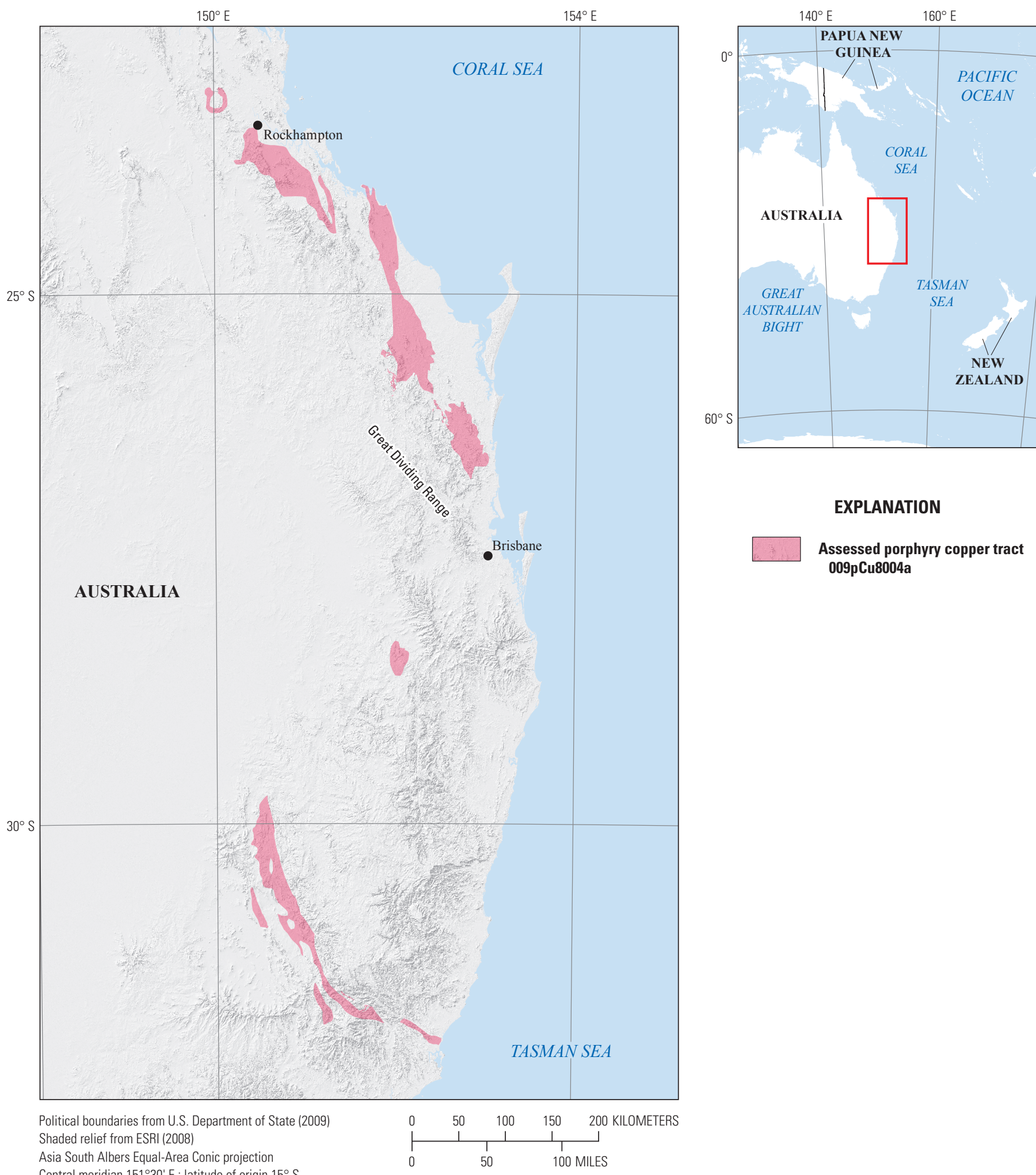

EXPLANATION

Assessed porphyry copper tract 009pCu8004a

Asia South Albers Equal-Area Conic projection

Central meridian $151^{\circ} 30^{\prime} \mathrm{E}$.; latitude of origin $15^{\circ} \mathrm{S}$ 


\title{
Plate 132. Porphyry Copper Assessment for Tract 009pCu8004c, East Tasmanide (South)-Australia
}

\author{
Descriptive model: \\ Porphyry copper models (Cox, 1986a; John and others, 2010); porphyry copper-gold models \\ (Cox, 1986b; Panteleyev, 1995b, 2005b; Cooke and others, 1998; Jaireth and Miezitis, 2004); \\ porphyry copper-molybdenum model (Cox, 1986c); porphyry $\mathrm{Cu} \pm \mathrm{Mo} \pm \mathrm{Au}$ models (Panteleyev, \\ 1995a, 2005a) \\ Grade and tonnage model: NA \\ Economic filter depth percentages: NA \\ Economic filter cost setting: NA \\ Geologic feature assessed: $\quad$ Continental magmatic arcs of Silurian to Early Cretaceous age, mostly in the New England orogen \\ and North Queensland orogen, Australia \\ Number of known deposits: \\ 0
}

\section{Selected Resource Assessment Results for Porphyry Copper}

[Assessment depth, 1 kilometer $(\mathrm{km}) ; \mathrm{km}^{2}$, square kilometer; Mt, millions of metric tons; NA, not applicable, as a quantitative assessment was not done]

\begin{tabular}{ccccccc}
\hline \multirow{2}{*}{$\begin{array}{c}\text { Date of } \\
\text { assessment }\end{array}$} & $\begin{array}{c}\text { Tract area } \\
\left(\mathbf{k m}^{2}\right)\end{array}$ & $\begin{array}{c}\text { Identified } \\
\text { copper } \\
\text { resources } \\
(\mathbf{M t})\end{array}$ & $\begin{array}{c}\text { Mean estimate of } \\
\text { in-place resources } \\
(\mathbf{M t})\end{array}$ & $\begin{array}{c}\text { Probability of } \mathbf{0} \\
\text { in-place resources } \\
\text { (percent) }\end{array}$ & $\begin{array}{c}\text { Mean estimate of } \\
\text { economic resources } \\
\text { (Mt) }\end{array}$ & $\begin{array}{c}\text { Probability of } \mathbf{0} \\
\text { economic resources } \\
\text { (percent) }\end{array}$ \\
\hline 2010 & 76,737 & 0 & NA & NA & NA & NA \\
\hline
\end{tabular}

\section{Qualitative Assessment}

For purposes of assessment of undiscovered porphyry copper resources, successive magmatic belts were combined into one permissive tract, 009pCu8004 (East Tasmanide-Australia), because they are spatially contiguous and have similar assemblages of permissive rocks. Only the Central sub-tract was assessed quantitatively (pl. 130, sub-tract 009pCu8004b). The South sub-tract (this plate, sub-tract $009 \mathrm{pCu} 8004 \mathrm{c}$ ) of the East Tasmanide tract is defined by igneous rocks of permissive composition at the southern end of the New England orogen in northeastern New South Wales. This South sub-tract contains no known porphyry copper deposits or significant prospects, and the distribution of permissive rocks suggests that the area of this sub-tract is too deeply eroded for preservation of porphyry copper deposits. The probability that the South sub-tract contains undiscovered porphyry copper deposits was qualitatively judged to be very low.

\section{Source}

Bookstrom and others, 2014, Porphyry copper assessment of eastern Australia: U.S. Geological Survey Scientific Investigations Report 2010-5090-L, http://dx.doi.org/10.3133/sir20105090L. 

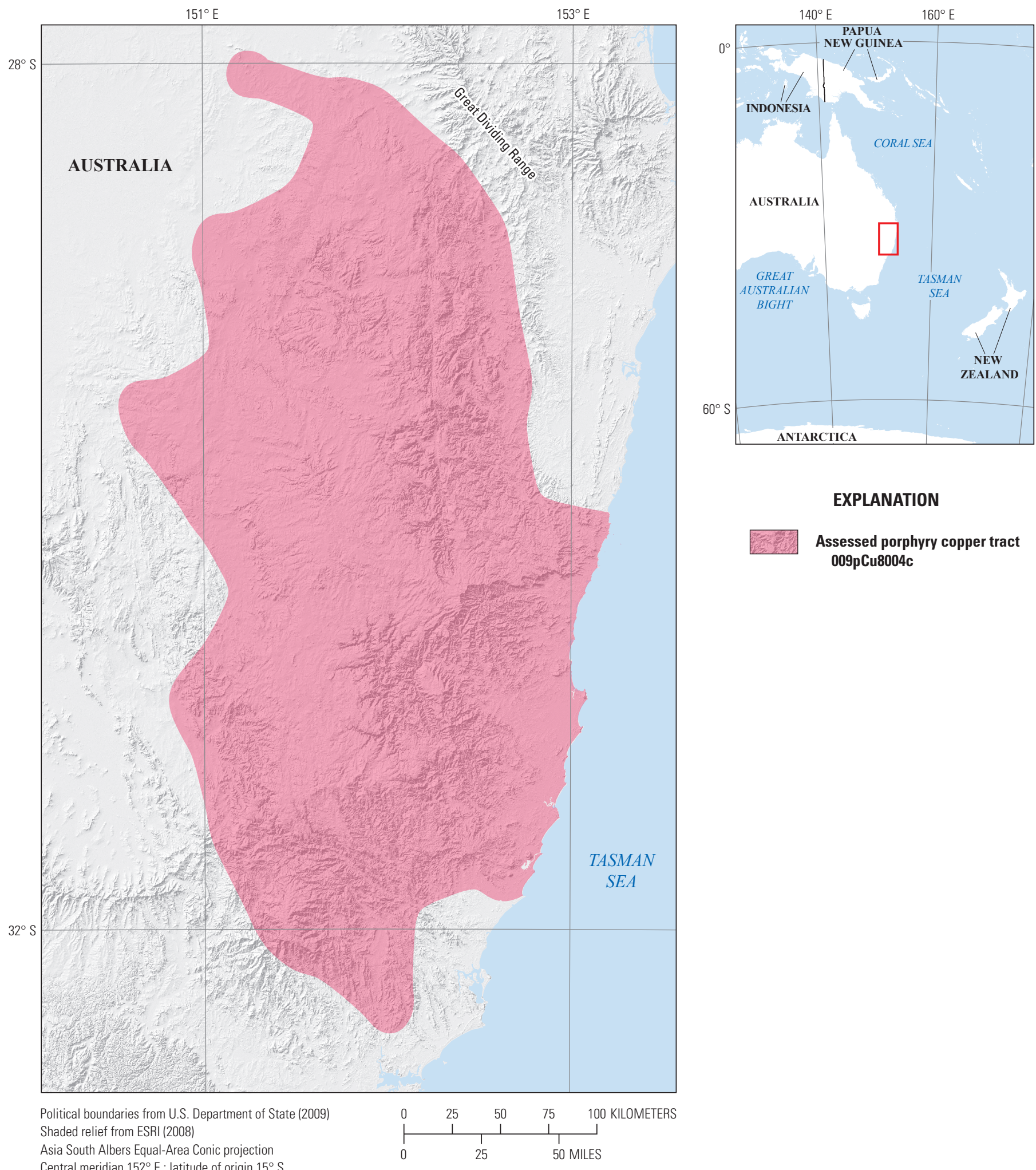

\section{EXPLANATION}

Assessed porphyry copper tract 009pCu8004c

Asia South Albers Equal-Area Conic projection

Central meridian $152^{\circ} \mathrm{E}$.; latitude of origin $15^{\circ} \mathrm{S}$ 


\section{Plate 133. Porphyry Copper Assessment for Tract 009pCu8002, Macquarie- Australia}

Descriptive model:

Grade and tonnage model:

Economic filter depth percentages:

Economic filter cost setting:

Geologic feature assessed:

Number of known deposits:
Porphyry copper models (Cox, 1986a; John and others, 2010); porphyry copper-gold models (Cox, 1986b; Panteleyev, 1995b, 2005b; Cooke and others, 1998; Jaireth and Miezitis, 2004); porphyry $\mathrm{Cu} \pm \mathrm{Mo} \pm \mathrm{Au}$ models (Panteleyev, 1995a, 2005a)

Porphyry copper, copper-gold subtype model (Singer, Berger, and Moring, 2008)

Skewed deep - 0 to 250 meters (m), 10\%; >250 to $500 \mathrm{~m}, 30 \%$; >500 m to $1 \mathrm{~km}, 60 \%$

Typical cost

Macquarie arc, an accreted island-arc of Ordovician to Early Silurian age in the Lachlan orogen 9

\section{Selected Resource Assessment Results for Porphyry Copper}

[Assessment depth, 1 kilometer (km); $\mathrm{km}^{2}$, square kilometer; Mt, millions of metric tons]

\begin{tabular}{ccccccc}
\hline $\begin{array}{c}\text { Date of } \\
\text { assessment }\end{array}$ & $\begin{array}{c}\text { Tract area } \\
\left(\mathbf{k m}^{2}\right)\end{array}$ & $\begin{array}{c}\text { Identified } \\
\text { copper } \\
\text { resources } \\
(\mathbf{M t})\end{array}$ & $\begin{array}{c}\text { Mean estimate of } \\
\text { in-place resources } \\
(\mathbf{M t})\end{array}$ & $\begin{array}{c}\text { Probability of } \mathbf{0} \\
\text { in-place resources } \\
\text { (percent) }\end{array}$ & $\begin{array}{c}\text { Mean estimate of } \\
\text { economic resources } \\
\text { (Mt) }\end{array}$ & $\begin{array}{c}\text { Probability of } 0 \\
\text { economic resources } \\
\text { (percent) }\end{array}$ \\
\hline 2010 & 41,463 & 13 & 21 & 4 & 14 \\
\hline
\end{tabular}

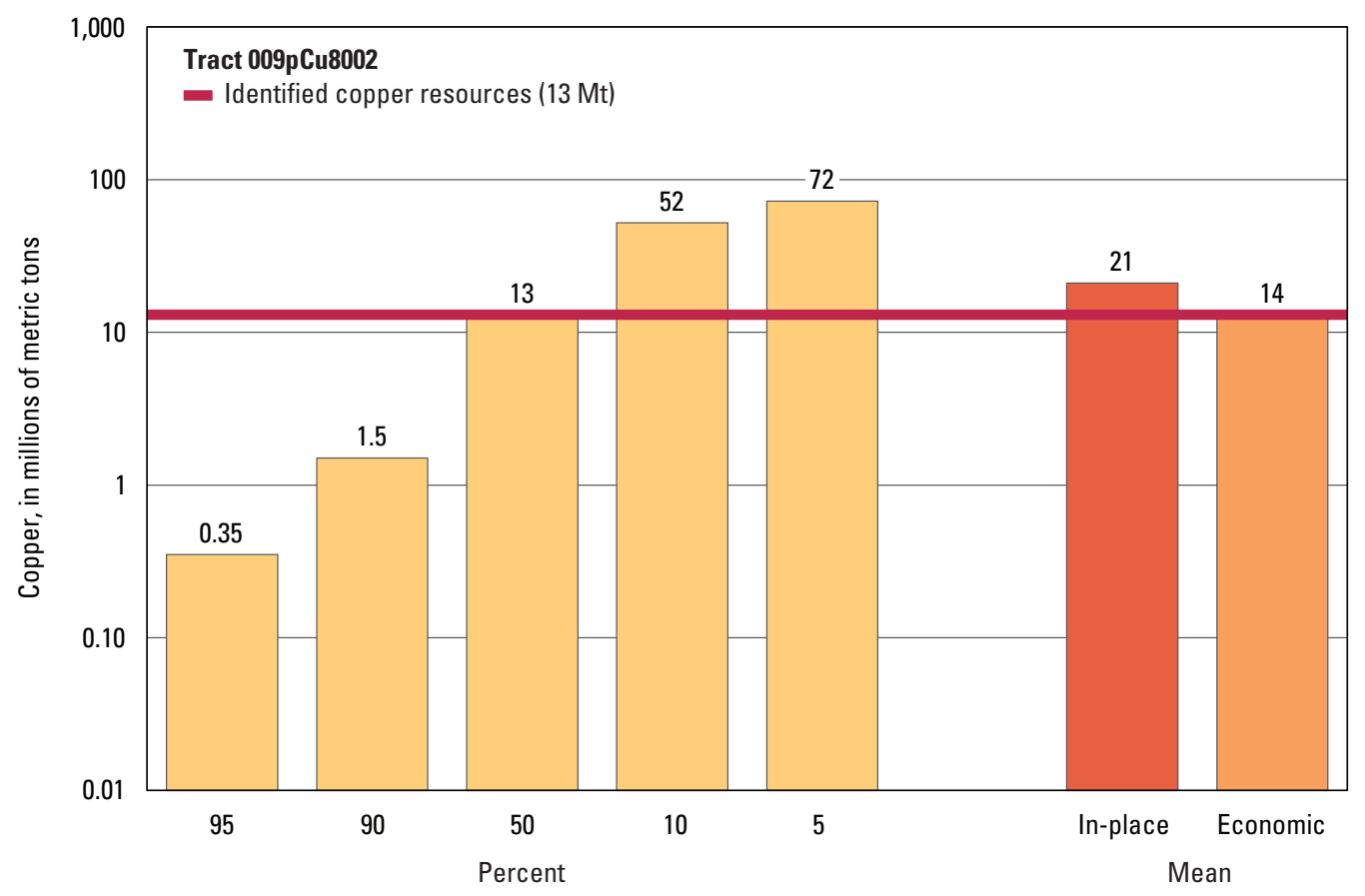

Graph showing the estimated probability distribution of undiscovered copper resources, where each bar represents the minimum amount estimated at the indicated percentage.

\section{Source}

Bookstrom and others, 2014, Porphyry copper assessment of eastern Australia: U.S. Geological Survey Scientific Investigations Report 2010-5090-L, http://dx.doi.org/10.3133/sir20105090L. 

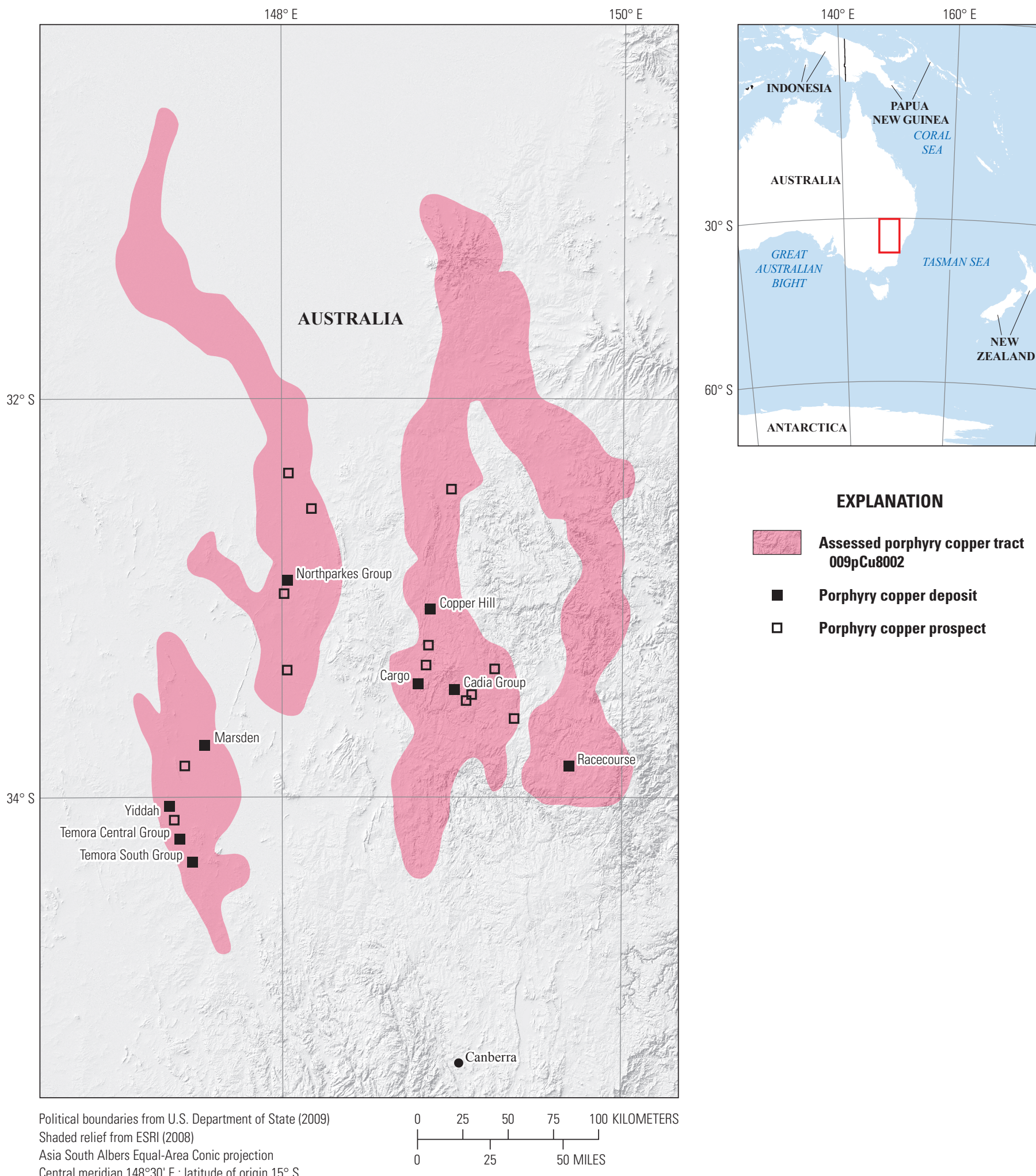

\section{EXPLANATION}

Assessed porphyry copper tract $009 \mathrm{pCu} 8002$

- Porphyry copper deposit

Porphyry copper prospect 


\section{Plate 134. Porphyry Copper Assessment for Tract 009pCu8003, Yeoval- Australia}

Descriptive model:

Grade and tonnage model:

Economic filter depth percentages:

Economic filter cost setting:

Geologic feature assessed:

Number of known deposits:
Porphyry copper models (Cox, 1986a; John and others, 2010); porphyry $\mathrm{Cu} \pm \mathrm{Mo} \pm \mathrm{Au}$ models (Panteleyev, 1995a, 2005a)

Eastern Australia custom model (Bookstrom and others, 2014)

Default -0 to 250 meters (m), $25 \%$; > 250 to $500 \mathrm{~m}, 25 \%$; $>500 \mathrm{~m}$ to $1 \mathrm{~km}, 50 \%$

Typical cost

Continental magmatic arc of Late Silurian to Early Devonian age in the Lachlan orogen

1

\section{Selected Resource Assessment Results for Porphyry Copper}

[Assessment depth, 1 kilometer (km); $\mathrm{km}^{2}$, square kilometer; Mt, millions of metric tons]

\begin{tabular}{ccccccc}
\hline $\begin{array}{c}\text { Date of } \\
\text { assessment }\end{array}$ & $\begin{array}{c}\text { Tract area } \\
\left(\mathbf{k m}^{2}\right)\end{array}$ & $\begin{array}{c}\text { Identified } \\
\text { copper } \\
\text { resources } \\
\text { (Mt) }\end{array}$ & $\begin{array}{c}\text { Mean estimate of } \\
\text { in-place resources } \\
(\mathbf{M t})\end{array}$ & $\begin{array}{c}\text { Probability of } \mathbf{0} \\
\text { in-place resources } \\
\text { (percent) }\end{array}$ & $\begin{array}{c}\text { Mean estimate of } \\
\text { economic resources } \\
\text { (Mt) }\end{array}$ & $\begin{array}{c}\text { Probability of 0 } \\
\text { economic resources } \\
\text { (percent) }\end{array}$ \\
\hline 2010 & 53,157 & 0.049 & 0.071 & 24 & 0 \\
\hline
\end{tabular}

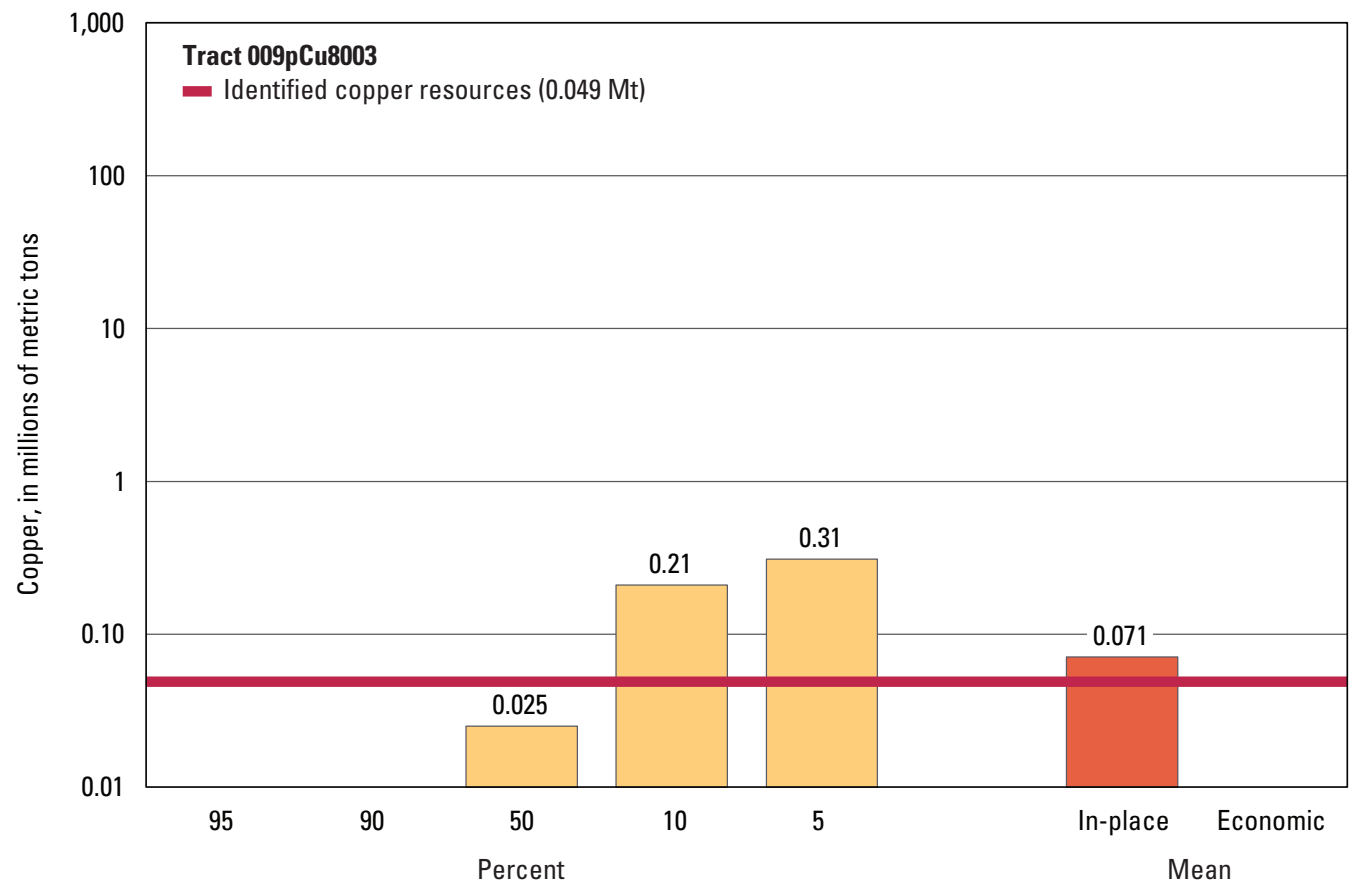

Graph showing the estimated probability distribution of undiscovered copper resources, where each bar represents the minimum amount estimated at the indicated percentage.

\section{Source}

Bookstrom and others, 2014, Porphyry copper assessment of eastern Australia: U.S. Geological Survey Scientific Investigations Report 2010-5090-L, http://dx.doi.org/10.3133/sir20105090L. 

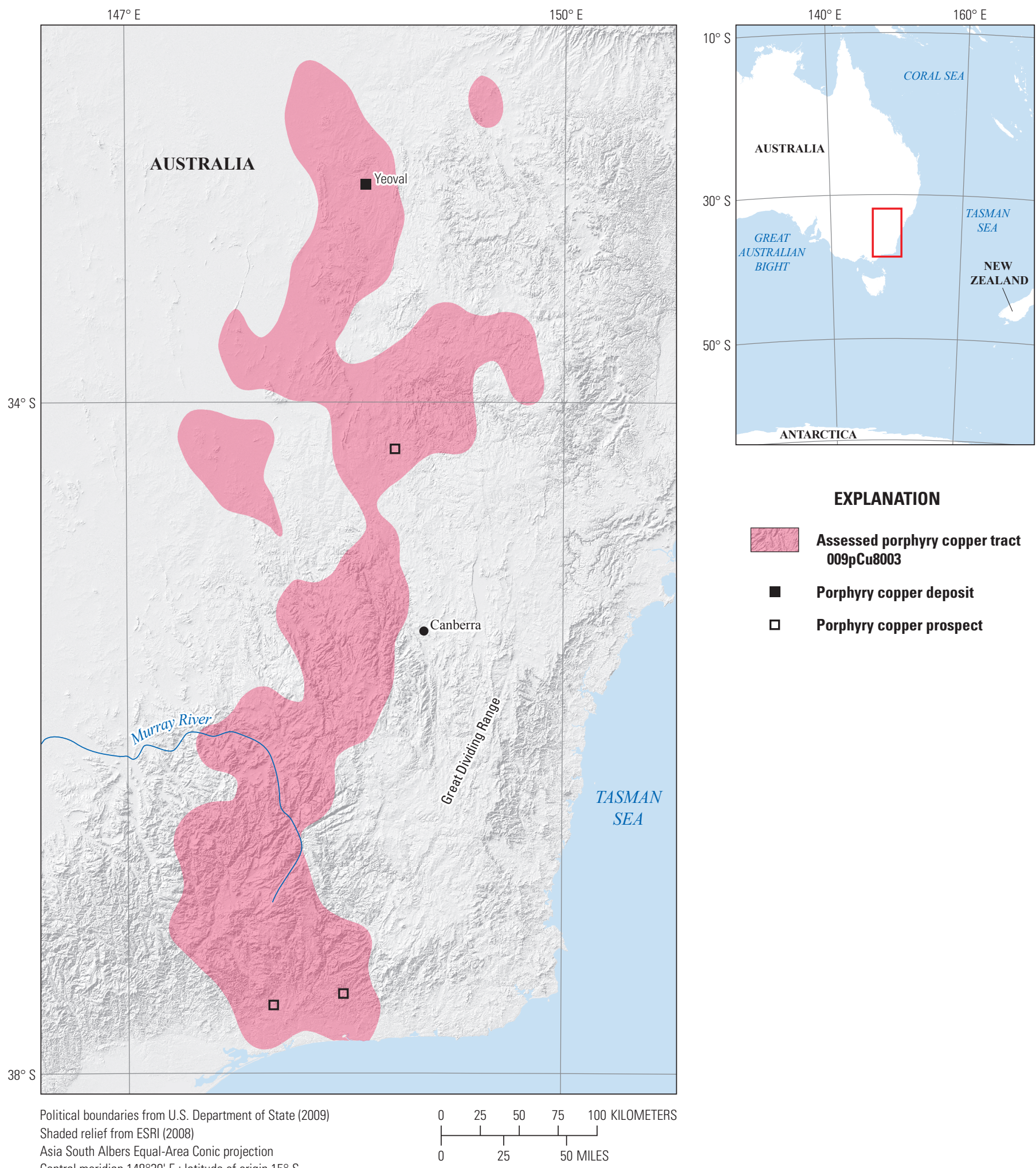

\section{EXPLANATION}

Assessed porphyry copper tract 009pCu8003

- Porphyry copper deposit

$\square \quad$ Porphyry copper prospect

Asia South Albers Equal-Area Conic projection

Central meridian $148^{\circ} 30^{\prime} \mathrm{E}$.; latitude of origin $15^{\circ} \mathrm{S}$. 


\section{Plate 135. Porphyry Copper Assessment for Tract 009pCu8001b, Delamerian (Victoria)-Australia}

Descriptive model:

Grade and tonnage model:

Economic filter depth percentages:

Economic filter cost setting:

Geologic feature assessed:

Number of known deposits:
Porphyry copper models (Cox, 1986a; John and others, 2010); porphyry copper-gold models (Cox, 1986b; Panteleyev, 1995b, 2005b; Cooke and others, 1998; Jaireth and Miezitis, 2004); porphyry $\mathrm{Cu} \pm \mathrm{Mo} \pm \mathrm{Au}$ models (Panteleyev, 1995a, 2005a)

NA

NA

NA

Accreted island arcs and continental magmatic arcs of Cambrian age in the Delamerian orogen 0

\section{Selected Resource Assessment Results for Porphyry Copper}

[Assessment depth, 1 kilometer $(\mathrm{km}) ; \mathrm{km}^{2}$, square kilometer; Mt, millions of metric tons; NA, not applicable, as a quantitative assessment was not done]

\begin{tabular}{ccccccc}
\hline \multirow{2}{*}{$\begin{array}{c}\text { Date of } \\
\text { assessment }\end{array}$} & $\begin{array}{c}\text { Tract area } \\
\left(\mathbf{k m}^{2}\right)\end{array}$ & $\begin{array}{c}\text { Identified } \\
\text { copper } \\
\text { resources } \\
(\mathbf{M t})\end{array}$ & $\begin{array}{c}\text { Mean estimate of } \\
\text { in-place resources } \\
(\mathbf{M t})\end{array}$ & $\begin{array}{c}\text { Probability of } \mathbf{0} \\
\text { in-place resources } \\
\text { (percent) }\end{array}$ & $\begin{array}{c}\text { Mean estimate of } \\
\text { economic resources } \\
\text { (Mt) }\end{array}$ & $\begin{array}{c}\text { Probability of } \mathbf{0} \\
\text { economic resources } \\
\text { (percent) }\end{array}$ \\
\hline 2010 & 1,314 & 0 & NA & NA & NA \\
\hline
\end{tabular}

\section{Qualitative Assessment}

Although volcanic and volcaniclastic rocks that occur within the Victoria sub-tract (009pCu8001b) of the DelamerianAustralia tract are considered marginally permissive for the occurrence of porphyry copper, they contain no known porphyry copper deposits or prospects. Furthermore, no intrusive rocks are exposed. Therefore, this sub-tract was not quantitatively assessed for porphyry copper resources. In a qualitative assessment, the team concluded that the Victoria sub-tract is unlikely to contain significant undiscovered porphyry copper resources.

\section{Source}

Bookstrom and others, 2014, Porphyry copper assessment of eastern Australia: U.S. Geological Survey Scientific Investigations Report 2010-5090-L, http://dx.doi.org/10.3133/sir20105090L. 


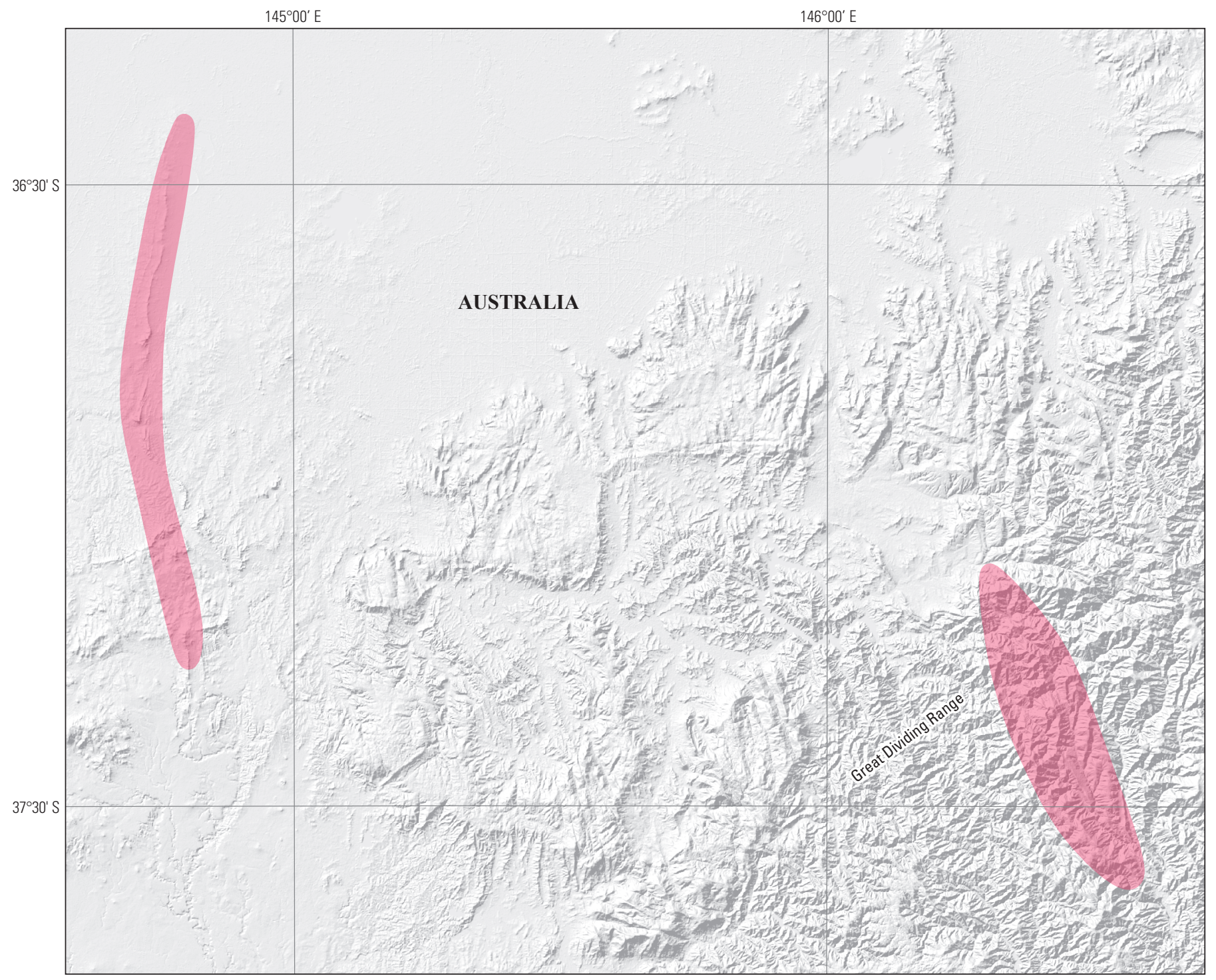

Political boundaries from U.S. Department of State (2009) Shaded relief from ESRI (2008)

Asia South Albers Equal-Area Conic projection Central meridian $145^{\circ} 30^{\prime} \mathrm{E}$.; latitude of origin $15^{\circ} \mathrm{S}$.

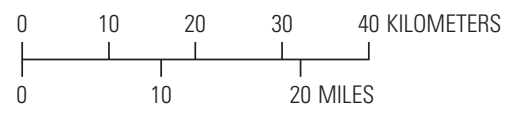

EXPLANATION

㞔翟

Assessed porphyry copper tract 009pCu8001b

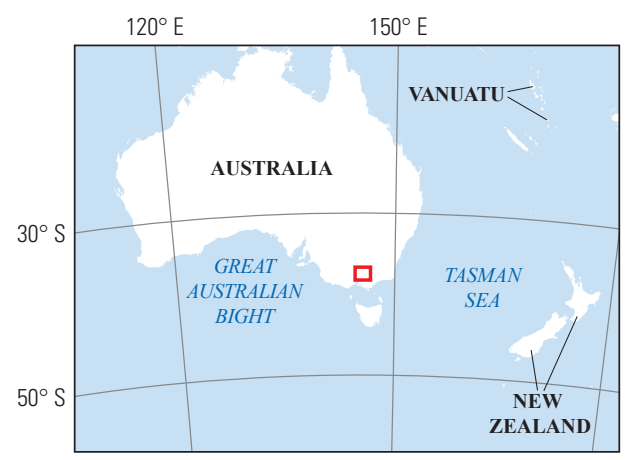




\section{Plate 136. Porphyry Copper Assessment for Tract 009pCu8001c, Delamerian (Tasmania)_Australia}

Descriptive model:

Grade and tonnage model:

Economic filter depth percentages:

Economic filter cost setting:

Geologic feature assessed:

Number of known deposits:
Porphyry copper models (Cox, 1986a; John and others, 2010); porphyry copper-gold models (Cox, 1986b; Panteleyev, 1995b, 2005b; Cooke and others, 1998; Jaireth and Miezitis, 2004); porphyry $\mathrm{Cu} \pm \mathrm{Mo} \pm \mathrm{Au}$ models (Panteleyev, 1995a, 2005a)

NA

NA

NA

Accreted island arcs and continental magmatic arcs of Cambrian age in the Delamerian orogen 0

\section{Selected Resource Assessment Results for Porphyry Copper}

[Assessment depth, 1 kilometer $(\mathrm{km}) ; \mathrm{km}^{2}$, square kilometer; Mt, millions of metric tons; NA, not applicable, as a quantitative assessment was not done]

\begin{tabular}{ccccccc}
\hline \multirow{2}{*}{$\begin{array}{c}\text { Date of } \\
\text { assessment }\end{array}$} & $\begin{array}{c}\text { Tract area } \\
\left(\mathbf{k m}^{2}\right)\end{array}$ & $\begin{array}{c}\text { Identified } \\
\text { copper } \\
\text { resources } \\
(\mathbf{M t})\end{array}$ & $\begin{array}{c}\text { Mean estimate of } \\
\text { in-place resources } \\
(\mathbf{M t})\end{array}$ & $\begin{array}{c}\text { Probability of } \mathbf{0} \\
\text { in-place resources } \\
\text { (percent) }\end{array}$ & $\begin{array}{c}\text { Mean estimate of } \\
\text { economic resources } \\
\text { (Mt) }\end{array}$ & $\begin{array}{c}\text { Probability of } \mathbf{0} \\
\text { economic resources } \\
\text { (percent) }\end{array}$ \\
\hline 2010 & 9,328 & 0 & NA & NA & NA \\
\hline
\end{tabular}

\section{Qualitative Assessment}

The Tasmania sub-tract (009pCu8001c) of the Delamerian-Australia tract includes some igneous rock types that are permissive for the occurrence of porphyry copper deposits. However, no porphyry copper deposits or prospects are known. The tract does host other types of deposits unrelated to the porphyry copper type. The assessment team concluded that this permissive sub-tract has significantly less potential to contain undiscovered porphyry copper deposits than the Adelaide sub-tract (pl. 137, sub-tract 009pCu8001a) of the Delamerian-Australia tract.

\section{Source}

Bookstrom and others, 2014, Porphyry copper assessment of eastern Australia: U.S. Geological Survey Scientific Investigations Report 2010-5090-L, http://dx.doi.org/10.3133/sir20105090L. 

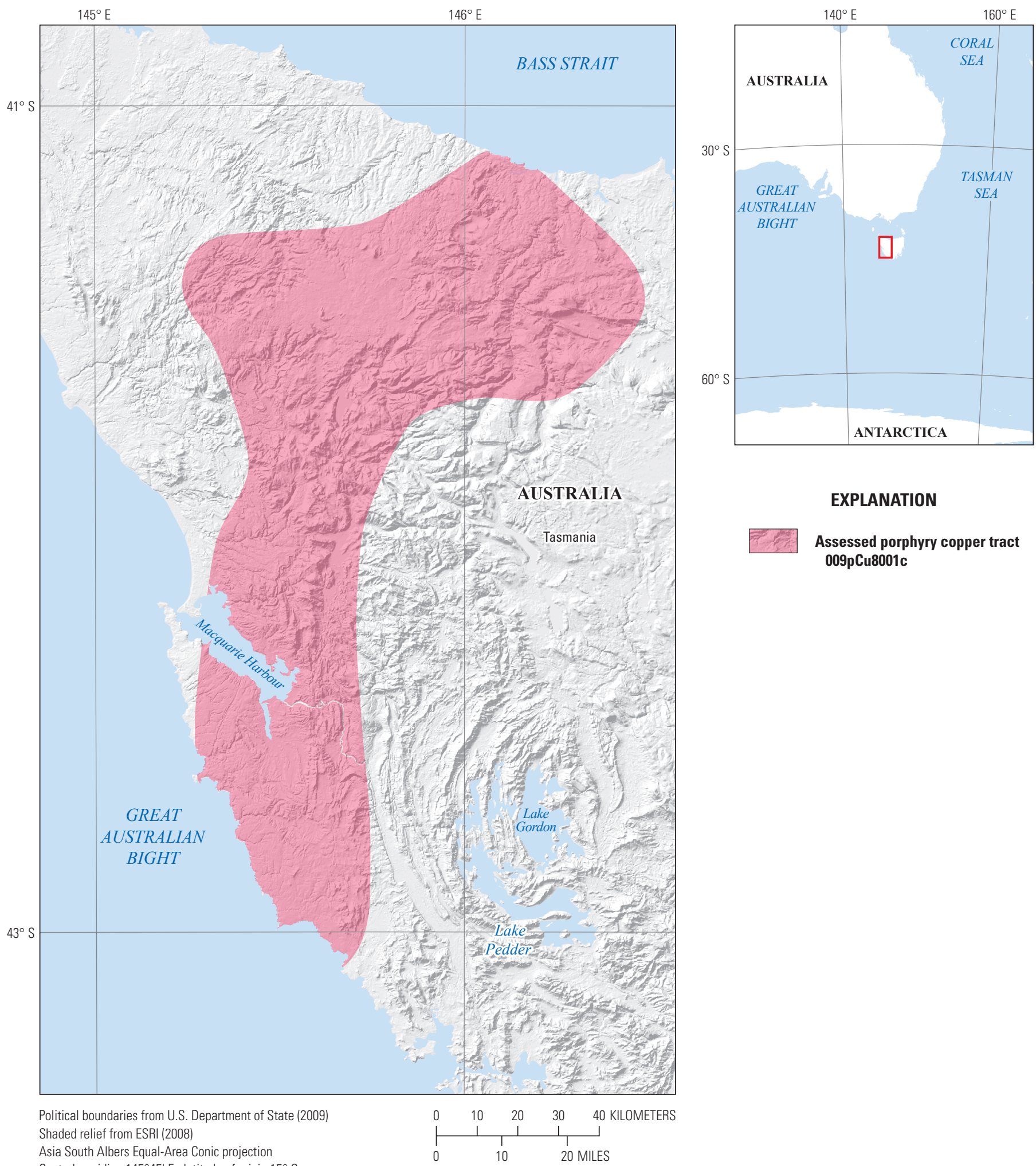

EXPLANATION

Assessed porphyry copper tract 009pCu8001c

Asia South Albers Equal-Area Conic projection

Central meridian $145^{\circ} 45^{\prime} \mathrm{E}$.; latitude of origin $15^{\circ} \mathrm{S}$. 


\section{Plate 137. Porphyry Copper Assessment for Tract 009pCu8001a, Delamerian (Adelaide)—Australia}

Descriptive model:

Grade and tonnage model:

Economic filter depth percentages:

Economic filter cost setting:

Geologic feature assessed:

Number of known deposits:
Porphyry copper models (Cox, 1986a; John and others, 2010); porphyry copper-gold models (Cox, 1986b; Panteleyev, 1995b, 2005b; Cooke and others, 1998; Jaireth and Miezitis, 2004); porphyry $\mathrm{Cu} \pm \mathrm{Mo} \pm \mathrm{Au}$ models (Panteleyev, 1995a, 2005a)

Eastern Australia custom model (Bookstrom and others, 2014)

Skewed deep - 0 to 250 meters (m), 10\%; > 250 to $500 \mathrm{~m}, 30 \%$; >500 m to $1 \mathrm{~km}, 60 \%$

Typical cost

Accreted island arcs and continental magmatic arcs of Cambrian age in the Delamerian orogen 0

\section{Selected Resource Assessment Results for Porphyry Copper}

[Assessment depth, 1 kilometer (km); $\mathrm{km}^{2}$, square kilometer; Mt, millions of metric tons]

\begin{tabular}{ccccccc}
\hline \multirow{2}{*}{$\begin{array}{c}\text { Date of } \\
\text { assessment }\end{array}$} & $\begin{array}{c}\text { Tract area } \\
\left(\mathbf{k m}^{2}\right)\end{array}$ & $\begin{array}{c}\text { Identified } \\
\text { copper } \\
\text { resources } \\
(\mathbf{M t})\end{array}$ & $\begin{array}{c}\text { Mean estimate of } \\
\text { in-place resources } \\
(\mathbf{M t})\end{array}$ & $\begin{array}{c}\text { Probability of } \mathbf{0} \\
\text { in-place resources } \\
\text { (percent) }\end{array}$ & $\begin{array}{c}\text { Mean estimate of } \\
\text { economic resources } \\
\text { (Mt) }\end{array}$ & $\begin{array}{c}\text { Probability of } \mathbf{0} \\
\text { economic resources } \\
\text { (percent) }\end{array}$ \\
\hline 2010 & 50,747 & 0 & 0.14 & 27 & 0 \\
\hline
\end{tabular}

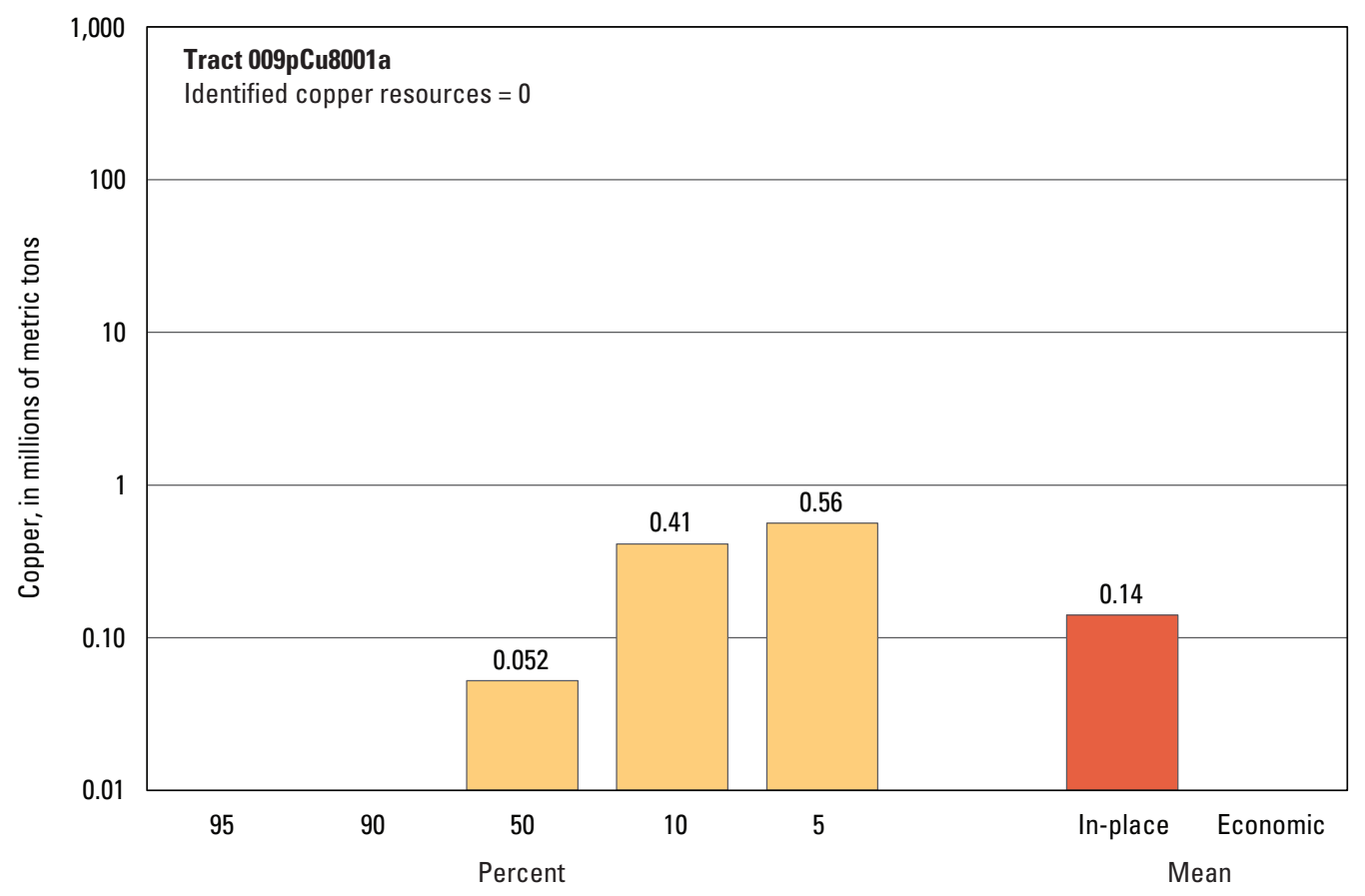

Graph showing the estimated probability distribution of undiscovered copper resources, where each bar represents the minimum amount estimated at the indicated percentage.

\section{Source}

Bookstrom and others, 2014, Porphyry copper assessment of eastern Australia: U.S. Geological Survey Scientific Investigations Report 2010-5090-L, http://dx.doi.org/10.3133/sir20105090L. 

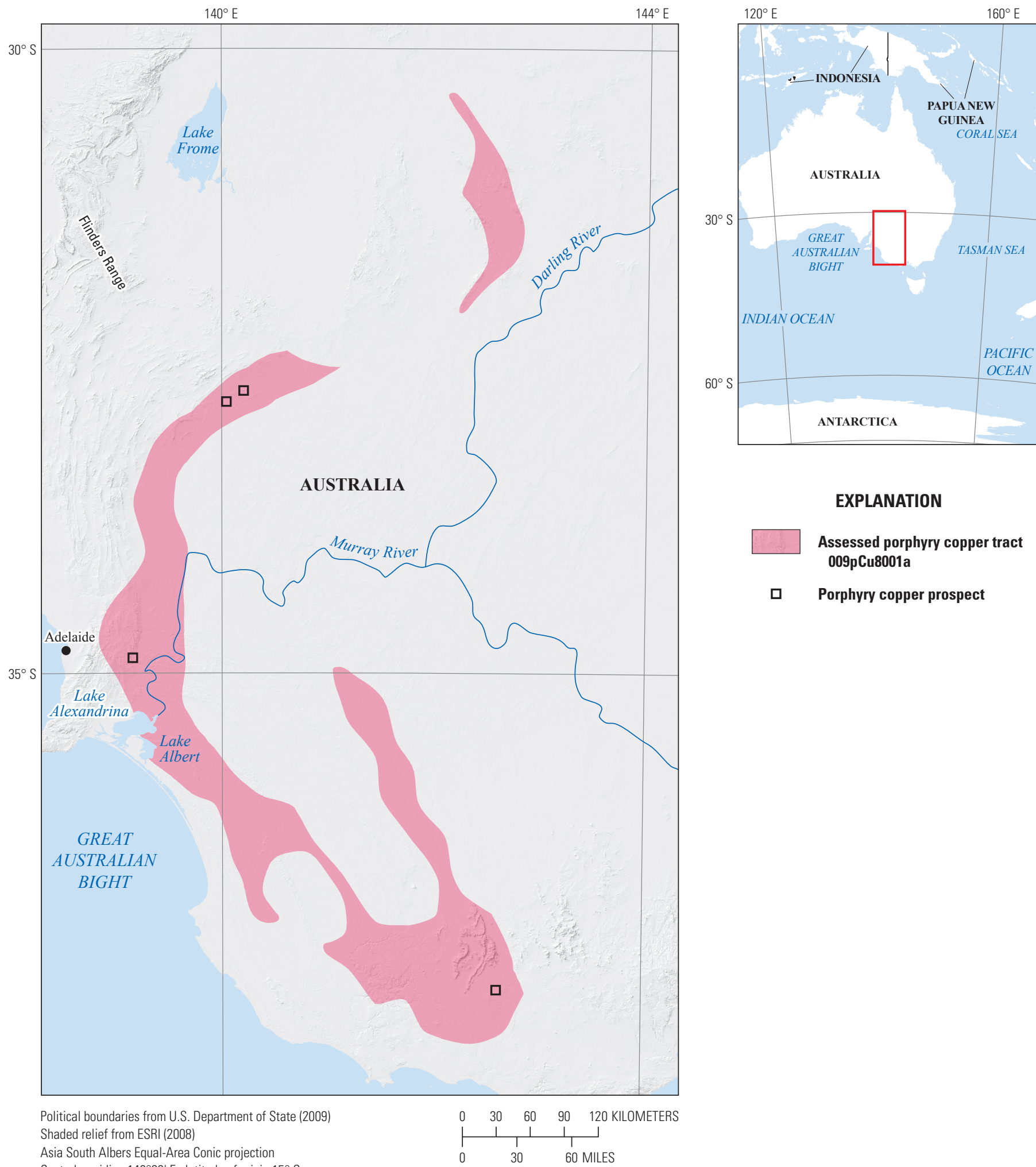

\section{EXPLANATION}

Assessed porphyry copper tract 009pCu8001a

Porphyry copper prospect

Asia South Albers Equal-Area Conic projection

Central meridian $140^{\circ} 30^{\prime} \mathrm{E}$.; latitude of origin $15^{\circ} \mathrm{S}$. 


\section{Plate 138. Porphyry Copper Assessment for Tract 142pCu8901, Darra Alasang- Afghanistan}

Descriptive model:

Grade and tonnage model:

Economic filter depth percentages:

Economic filter cost setting:

Geologic feature assessed:

Number of known deposits:
Porphyry copper models (Cox, 1986a; John and others, 2010)

General porphyry copper model (Singer, Berger, and Moring, 2008)

Skewed shallow-0 to 250 meters (m), $35 \%$; $>250$ to $500 \mathrm{~m}, 25 \% ;>500 \mathrm{~m}$ to $1 \mathrm{~km}, 40 \%$

High cost

A Carboniferous through Triassic continental margin arc in northern Afghanistan

0

\section{Selected Resource Assessment Results for Porphyry Copper}

[Assessment depth, 1 kilometer $(\mathrm{km})$; $\mathrm{km}^{2}$, square kilometer; $\mathrm{Mt}$, millions of metric tons]

\begin{tabular}{ccccccc}
\hline \multirow{2}{*}{$\begin{array}{c}\text { Date of } \\
\text { assessment }\end{array}$} & $\begin{array}{c}\text { Tract area } \\
\left(\mathbf{k m}^{2}\right)\end{array}$ & $\begin{array}{c}\text { Identified } \\
\text { copper } \\
\text { resources } \\
(\mathbf{M t})\end{array}$ & $\begin{array}{c}\text { Mean estimate of } \\
\text { in-place resources } \\
(\mathbf{M t})\end{array}$ & $\begin{array}{c}\text { Probability of } \mathbf{0} \\
\text { in-place resources } \\
\text { (percent) }\end{array}$ & $\begin{array}{c}\text { Mean estimate of } \\
\text { economic resources } \\
\text { (Mt) }\end{array}$ & $\begin{array}{c}\text { Probability of } \mathbf{0} \\
\text { economic resources } \\
\text { (percent) }\end{array}$ \\
\hline 2006 & 35,088 & 0 & 4.0 & 31 & 2.1 \\
\hline
\end{tabular}

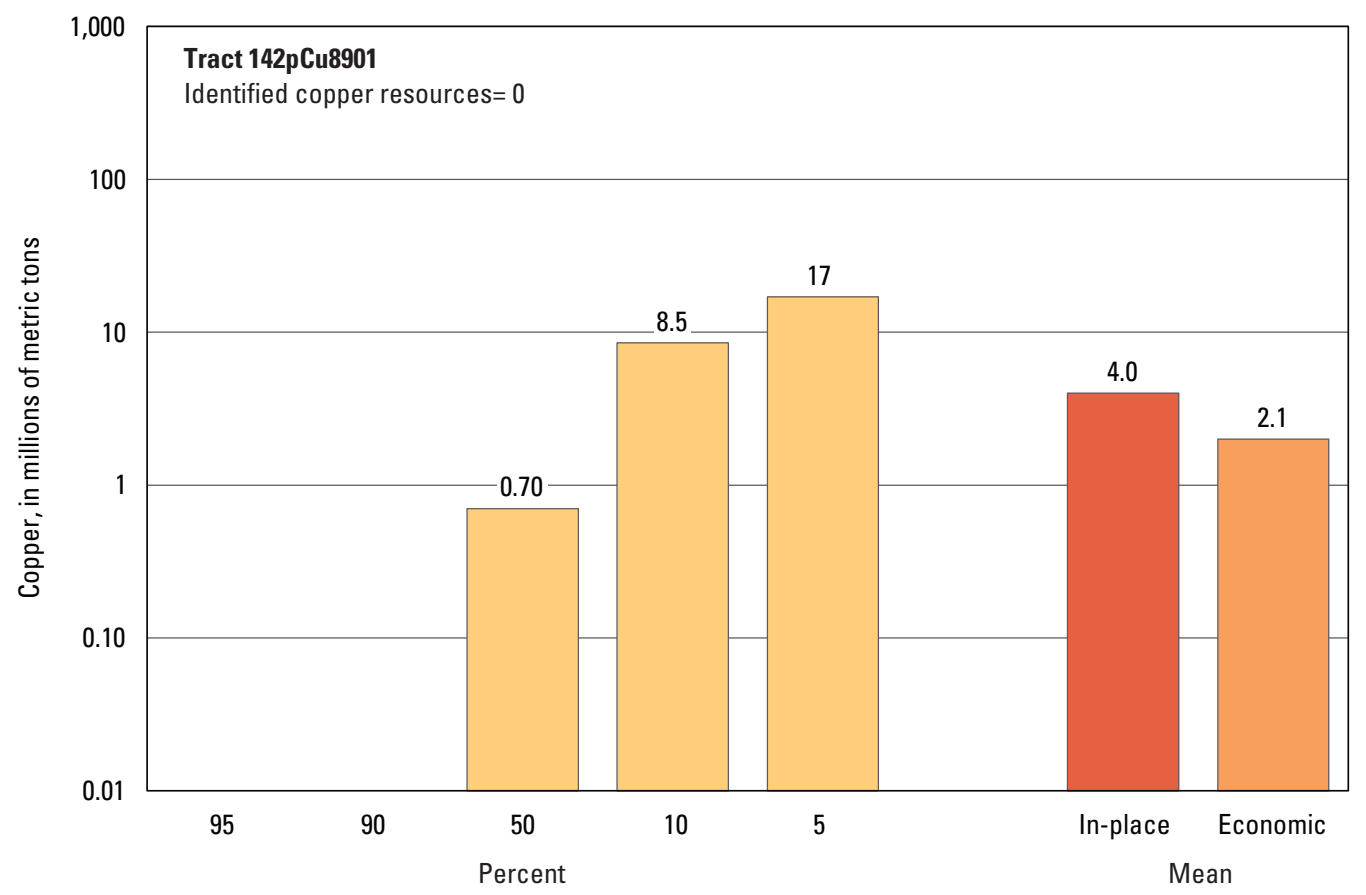

Graph showing the estimated probability distribution of undiscovered copper resources, where each bar represents the minimum amount estimated at the indicated percentage.

\section{Source}

Ludington, Orris, and others, 2007, Preliminary mineral resource assessment of selected mineral deposit types in Afghanistan: U.S. Geological Survey Open-File Report 2007-1005, http://pubs.usgs.gov/of/2007/1005/. 


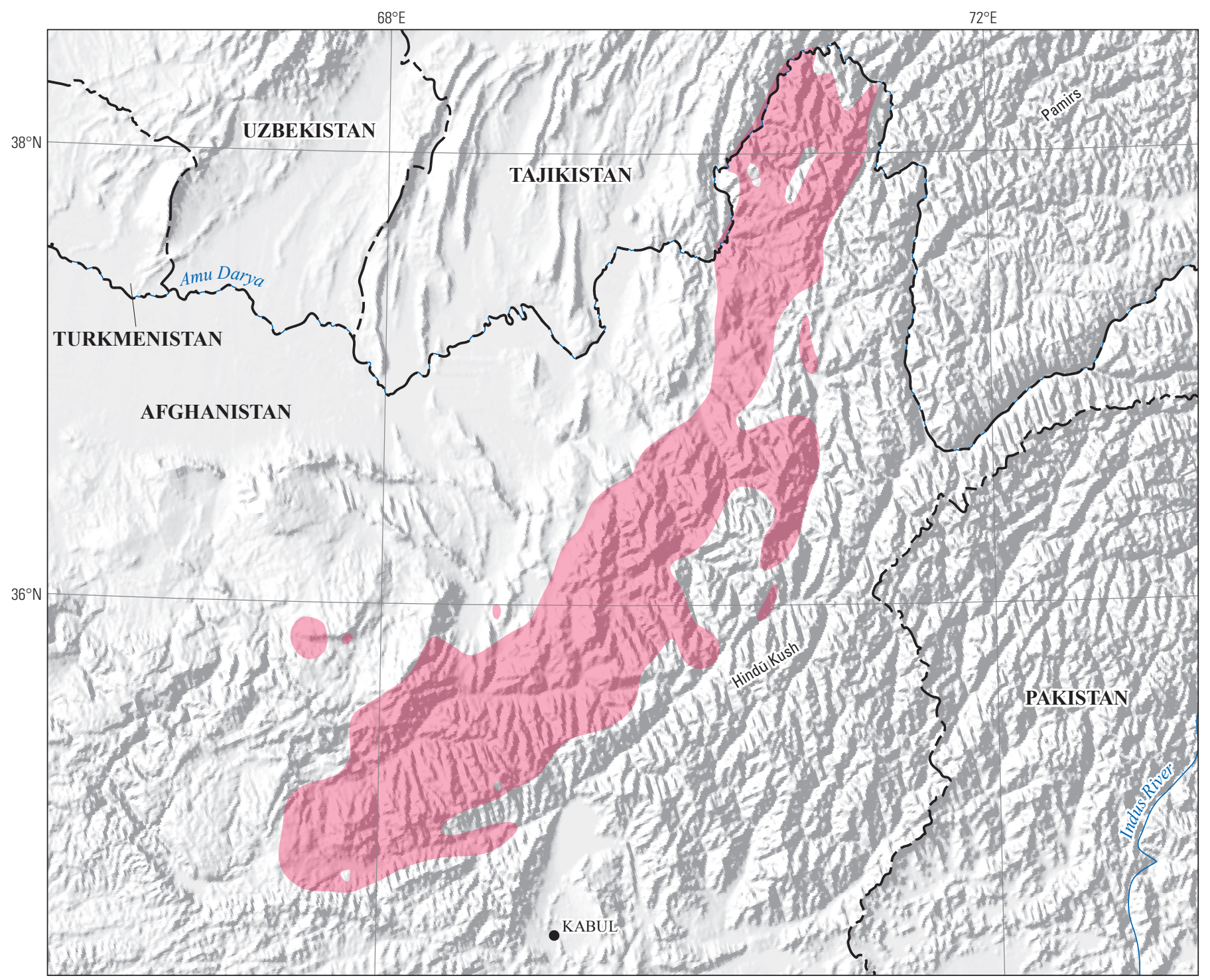

Political boundaries from U.S. Department of State (2009) Shaded relief from Earth Resources Observation and Science (EROS) Center (2011)

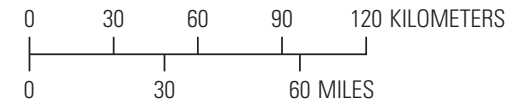

Asia North Albers Equal-Area Conic projection

Central meridian $69^{\circ} 45^{\prime} \mathrm{E}$.; latitude of origin $30^{\circ} \mathrm{N}$.

EXPLANATION

Assessed porphyry copper tract 142pCu8901

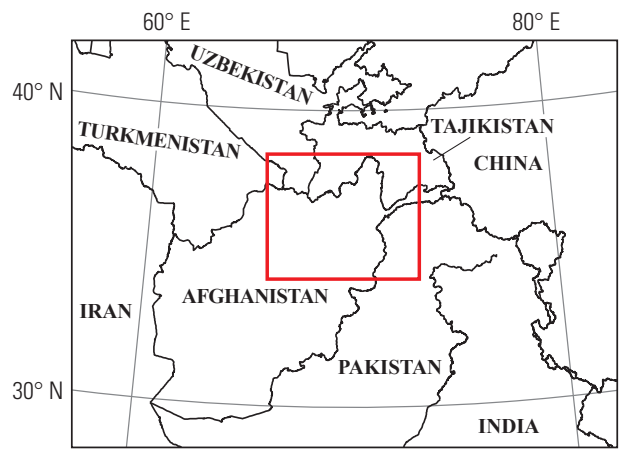




\section{Plate 139. Porphyry Copper Assessment for Tract 142pCu8902, Kundalyan- Afghanistan}

Descriptive model:

Grade and tonnage model:

Economic filter depth percentages:

Economic filter cost setting:

Geologic feature assessed:

Number of known deposits:
Porphyry copper models (Cox, 1986a; John and others, 2010)

General porphyry copper model (Singer, Berger, and Moring, 2008)

Skewed shallow-0 to 250 meters (m), $35 \%$; $>250$ to $500 \mathrm{~m}, 25 \% ;>500 \mathrm{~m}$ to $1 \mathrm{~km}, 40 \%$

High cost

An assemblage of Cretaceous intrusive rocks in central Afghanistan

0

\section{Selected Resource Assessment Results for Porphyry Copper}

[Assessment depth, 1 kilometer $(\mathrm{km})$; $\mathrm{km}^{2}$, square kilometer; $\mathrm{Mt}$, millions of metric tons]

\begin{tabular}{ccccccc}
\hline \multirow{2}{*}{$\begin{array}{c}\text { Date of } \\
\text { assessment }\end{array}$} & $\begin{array}{c}\text { Tract area } \\
\left(\mathbf{k m}^{2}\right)\end{array}$ & $\begin{array}{c}\text { Identified } \\
\text { copper } \\
\text { resources } \\
(\mathbf{M t})\end{array}$ & $\begin{array}{c}\text { Mean estimate of } \\
\text { in-place resources } \\
(\mathbf{M t})\end{array}$ & $\begin{array}{c}\text { Probability of } \mathbf{0} \\
\text { in-place resources } \\
\text { (percent) }\end{array}$ & $\begin{array}{c}\text { Mean estimate of } \\
\text { economic resources } \\
\text { (Mt) }\end{array}$ & $\begin{array}{c}\text { Probability of } \mathbf{0} \\
\text { economic resources } \\
\text { (percent) }\end{array}$ \\
\hline 2006 & 4,446 & 0 & 4.0 & 29 & 2.1 \\
\hline
\end{tabular}

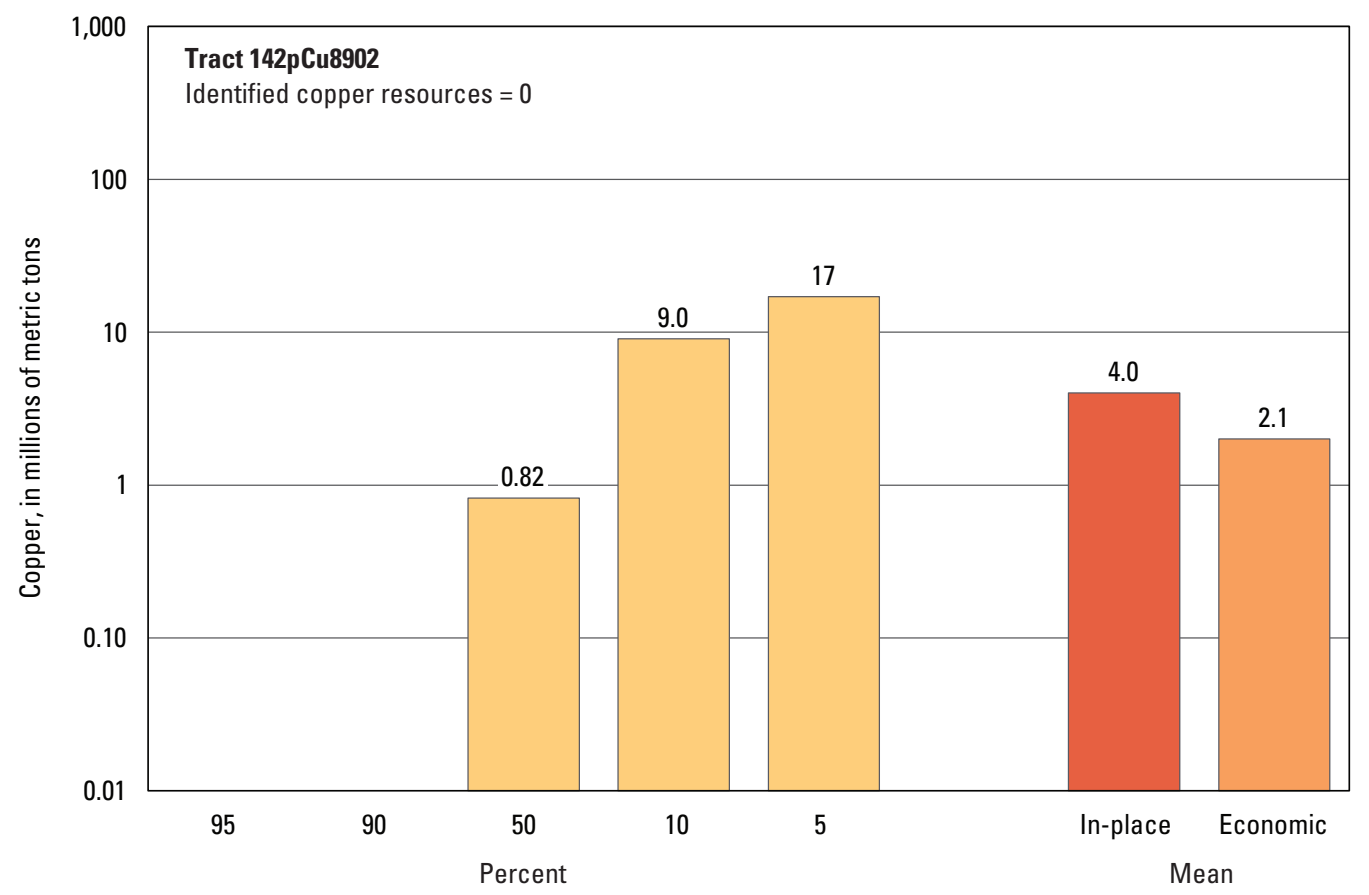

Graph showing the estimated probability distribution of undiscovered copper resources, where each bar represents the minimum amount estimated at the indicated percentage.

\section{Source}

Ludington, Orris, and others, 2007, Preliminary mineral resource assessment of selected mineral deposit types in Afghanistan: U.S. Geological Survey Open-File Report 2007-1005, http://pubs.usgs.gov/of/2007/1005/. 


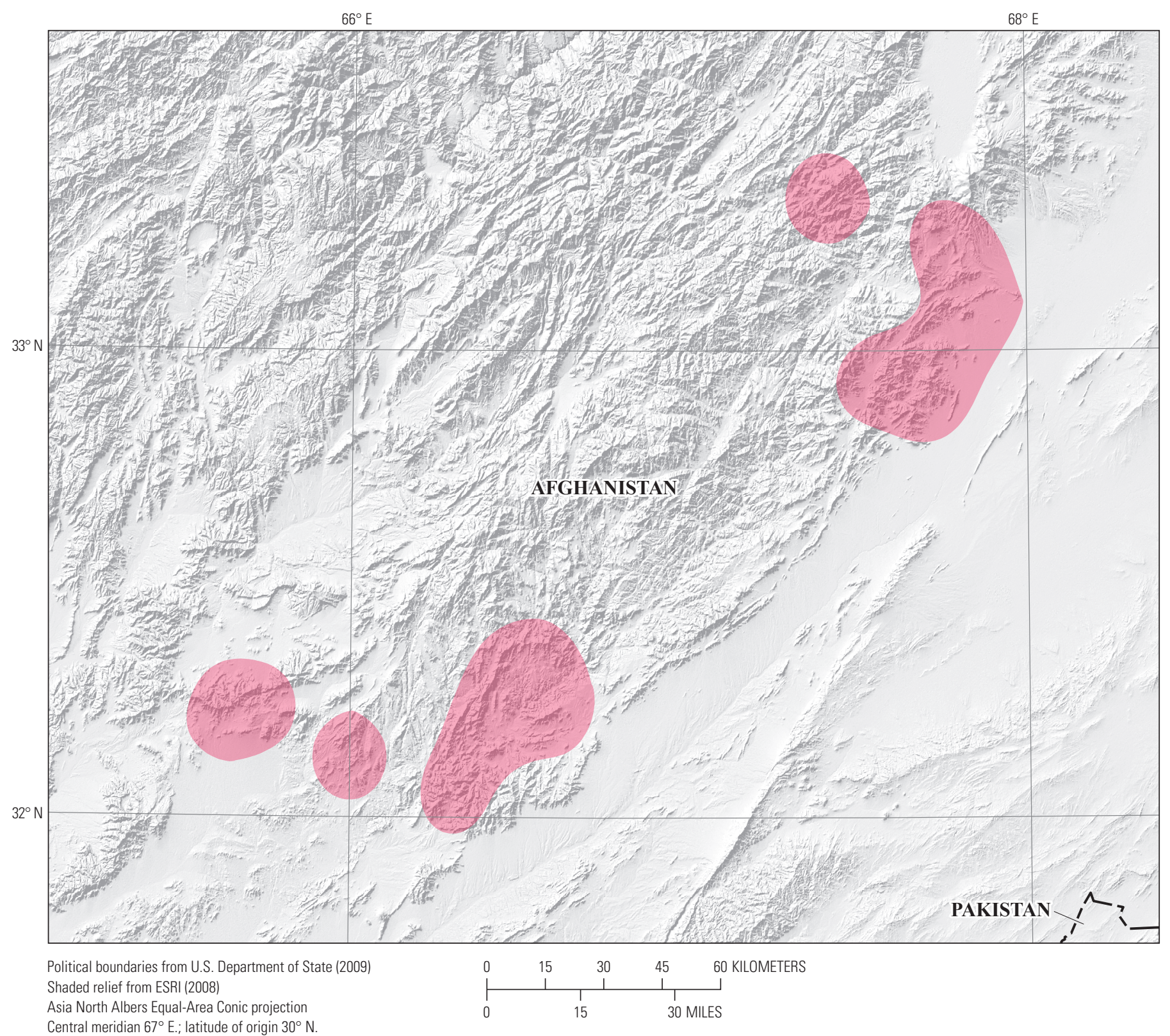

Central meridian $67^{\circ} \mathrm{E}$.; latitude of origin $30^{\circ} \mathrm{N}$.

EXPLANATION

Assessed porphyry copper tract 142pCu8902

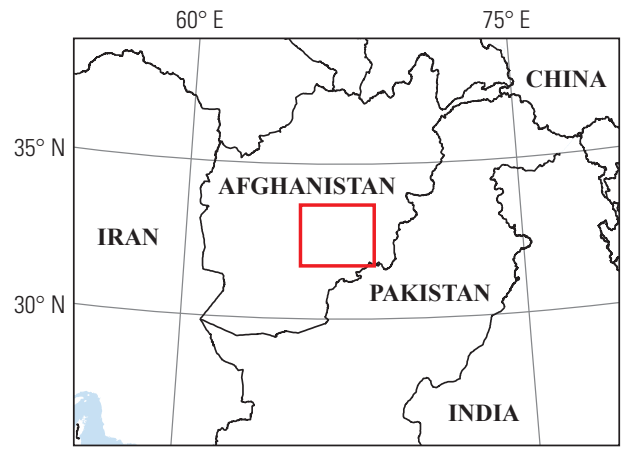




\section{Plate 140. Porphyry Copper Assessment for Tract 142pCu8903, Oruzgan- Afghanistan}

Descriptive model:

Grade and tonnage model:

Economic filter depth percentages:

Economic filter cost setting:

Geologic feature assessed:

Number of known deposits:
Porphyry copper models (Cox, 1986a; John and others, 2010)

General porphyry copper model (Singer, Berger, and Moring, 2008)

Default -0 to 250 meters (m), $25 \% ;>250$ to $500 \mathrm{~m}, 25 \% ;>500 \mathrm{~m}$ to $1 \mathrm{~km}, 50 \%$

High cost

An assemblage of Tertiary igneous rocks in central and western Afghanistan

0

\section{Selected Resource Assessment Results for Porphyry Copper}

[Assessment depth, 1 kilometer $(\mathrm{km})$; $\mathrm{km}^{2}$, square kilometer; $\mathrm{Mt}$, millions of metric tons]

\begin{tabular}{ccccccc}
\hline \multirow{2}{*}{$\begin{array}{c}\text { Date of } \\
\text { assessment }\end{array}$} & $\begin{array}{c}\text { Tract area } \\
\left(\mathbf{k m}^{2}\right)\end{array}$ & $\begin{array}{c}\text { Identified } \\
\text { copper } \\
\text { resources } \\
(\mathbf{M t})\end{array}$ & $\begin{array}{c}\text { Mean estimate of } \\
\text { in-place resources } \\
(\mathbf{M t})\end{array}$ & $\begin{array}{c}\text { Probability of } \mathbf{0} \\
\text { in-place resources } \\
\text { (percent) }\end{array}$ & $\begin{array}{c}\text { Mean estimate of } \\
\text { economic resources } \\
\text { (Mt) }\end{array}$ & $\begin{array}{c}\text { Probability of } \mathbf{0} \\
\text { economic resources } \\
\text { (percent) }\end{array}$ \\
\hline 2006 & 82,464 & 0 & 10 & 20 & 4.9 \\
\hline
\end{tabular}

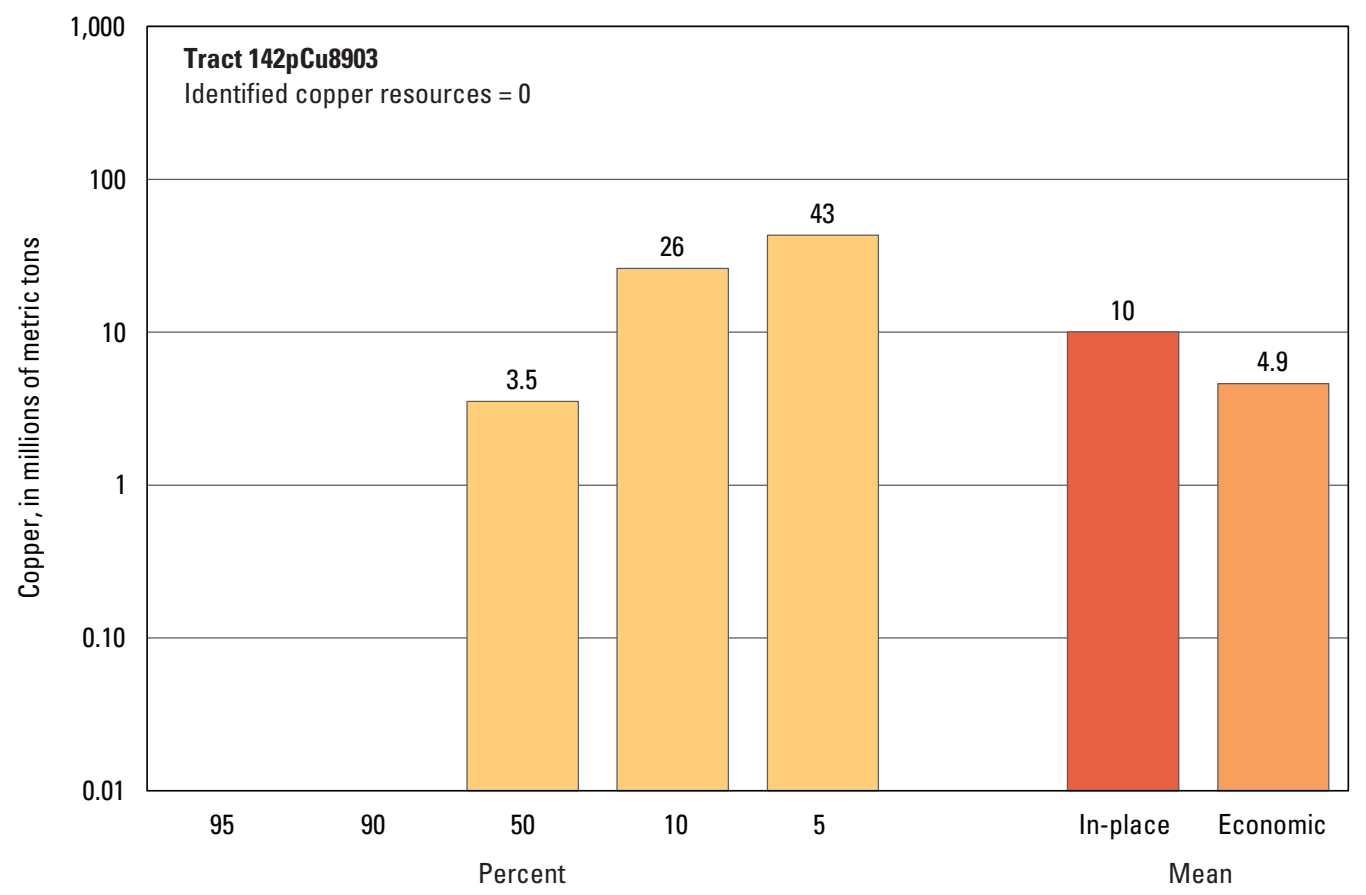

Graph showing the estimated probability distribution of undiscovered copper resources, where each bar represents the minimum amount estimated at the indicated percentage.

\section{Source}

Ludington, Orris, and others, 2007, Preliminary mineral resource assessment of selected mineral deposit types in Afghanistan: U.S. Geological Survey Open-File Report 2007-1005, http://pubs.usgs.gov/of/2007/1005/. 


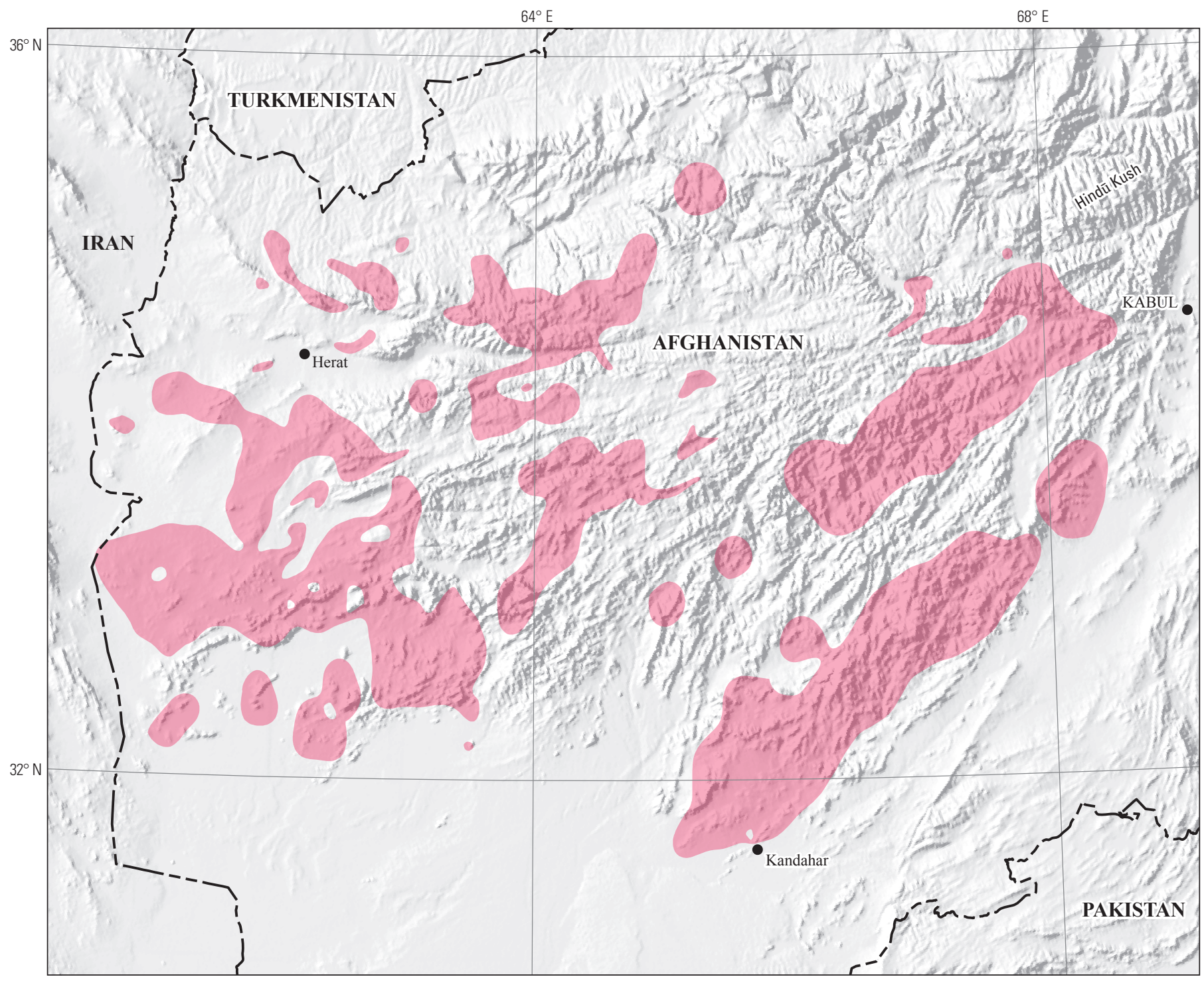

Political boundaries from U.S. Department of State (2009) Shaded relief from Earth Resources Observation and Science (EROS) Center (2011)

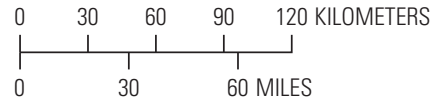

Asia North Albers Equal-Area Conic projection

Central meridian $64^{\circ} 30^{\prime} \mathrm{E}$.; latitude of origin $30^{\circ} \mathrm{N}$.

EXPLANATION

Assessed porphyry copper tract 142pCu8903

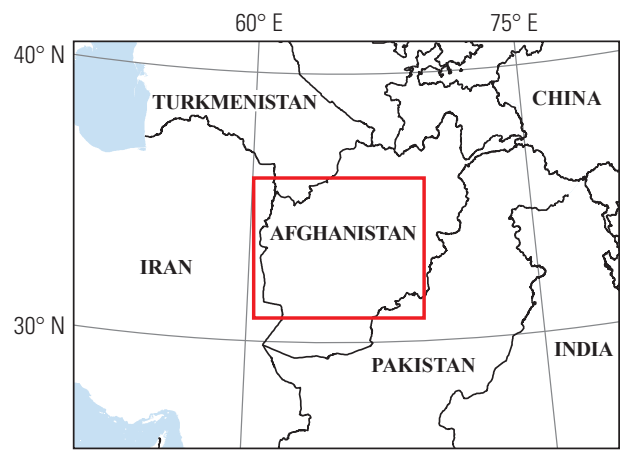




\title{
Plate 141. Porphyry Copper Assessment for Tract 142pCu8904, Spin Boldak- Afghanistan and Pakistan
}

\author{
Descriptive model: \\ Porphyry copper models (Cox, 1986a; John and others, 2010) \\ Grade and tonnage model: \\ General porphyry copper model (Singer, Berger, and Moring, 2008) \\ Economic filter depth percentages: \\ Economic filter cost setting: \\ Geologic feature assessed: \\ Skewed shallow-0 to 250 meters (m), $35 \% ;>250$ to $500 \mathrm{~m}, 25 \%$; $>500 \mathrm{~m}$ to $1 \mathrm{~km}, 40 \%$ \\ High cost \\ A belt of Tertiary igneous rocks in southeastern Afghanistan \\ Number of known deposits: \\ 0
}

\section{Selected Resource Assessment Results for Porphyry Copper}

[Assessment depth, 1 kilometer $(\mathrm{km}) ; \mathrm{km}^{2}$, square kilometer; Mt, millions of metric tons]

\begin{tabular}{ccccccc}
\hline \multirow{2}{*}{$\begin{array}{c}\text { Date of } \\
\text { assessment }\end{array}$} & $\begin{array}{c}\text { Tract area } \\
\left(\mathbf{k m}^{2}\right)\end{array}$ & $\begin{array}{c}\text { Identified } \\
\text { copper } \\
\text { resources } \\
(\mathbf{M t})\end{array}$ & $\begin{array}{c}\text { Mean estimate of } \\
\text { in-place resources } \\
(\mathbf{M t})\end{array}$ & $\begin{array}{c}\text { Probability of } \mathbf{0} \\
\text { in-place resources } \\
\text { (percent) }\end{array}$ & $\begin{array}{c}\text { Mean estimate of } \\
\text { economic resources } \\
\text { (Mt) }\end{array}$ & $\begin{array}{c}\text { Probability of } \mathbf{0} \\
\text { economic resources } \\
\text { (percent) }\end{array}$ \\
\hline 2006 & 7,452 & 0 & 4.4 & 31 & 2.3 \\
\hline
\end{tabular}

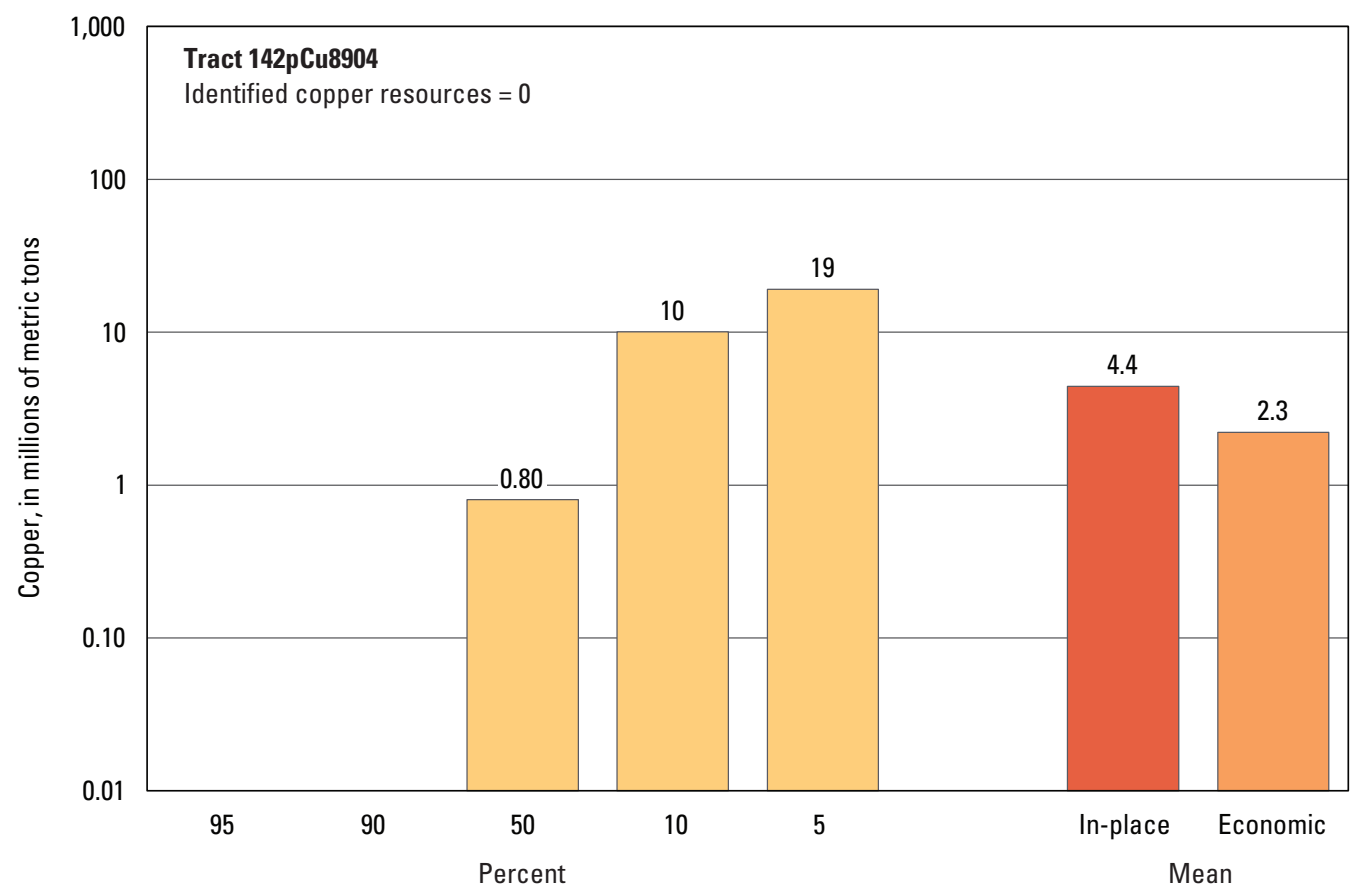

Graph showing the estimated probability distribution of undiscovered copper resources, where each bar represents the minimum amount estimated at the indicated percentage.

\section{Source}

Ludington, Orris, and others, 2007, Preliminary mineral resource assessment of selected mineral deposit types in Afghanistan: U.S. Geological Survey Open-File Report 2007-1005, http://pubs.usgs.gov/of/2007/1005/. 

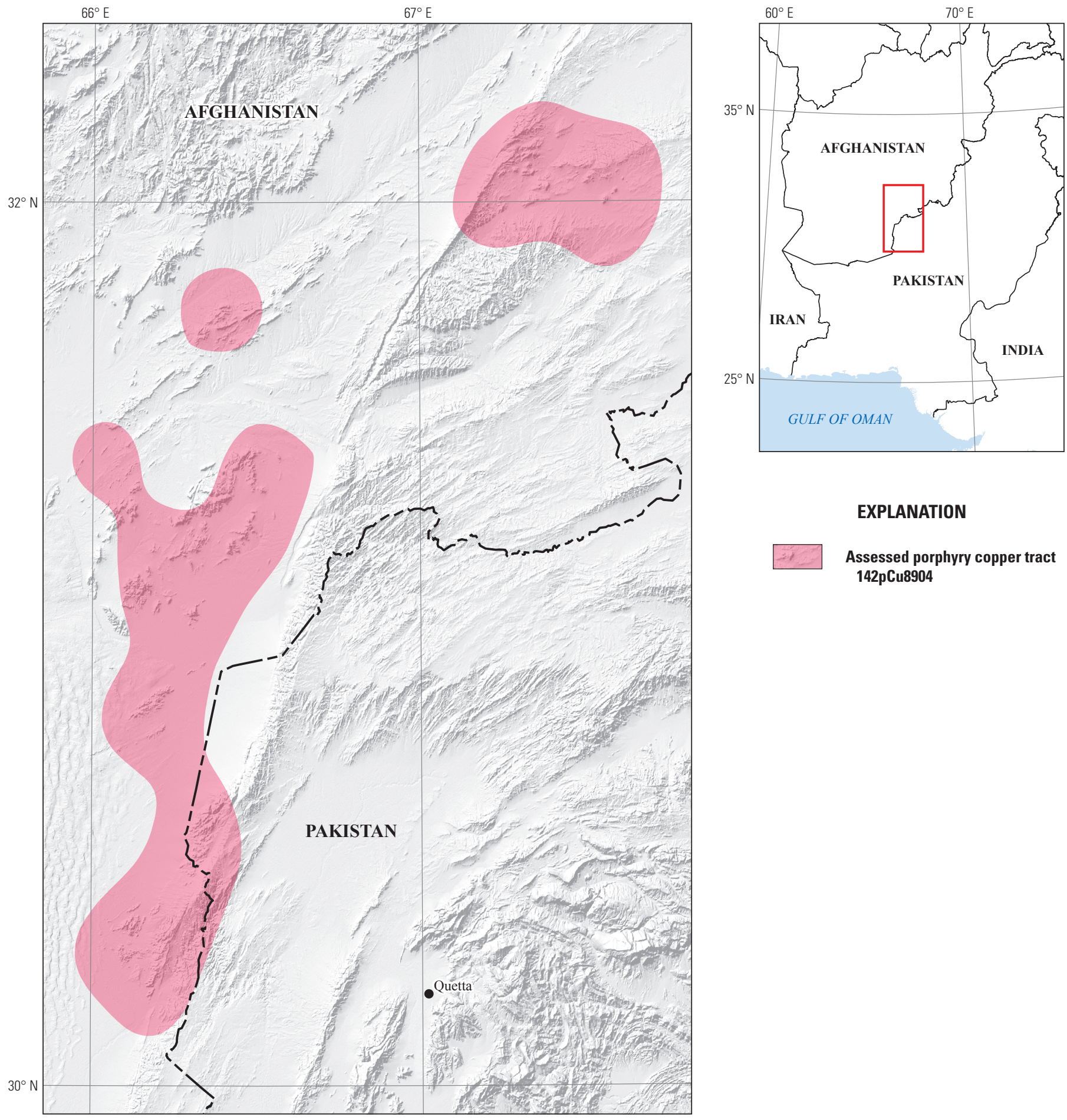

\section{Assessed porphyry copper tract 142pCu8904}

Political boundaries from U.S. Department of State (2009) Shaded relief from ESRI (2008)

Asia North Albers Equal-Area Conic projection

Central meridian $66^{\circ} 30^{\prime} \mathrm{E}$.; latitude of origin $30^{\circ} \mathrm{N}$.

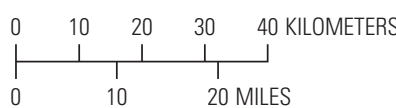




\section{Plate 142. Porphyry Copper Assessment for Tract 142pCu9013, Chagai- Afghanistan, Pakistan, and Iran}

Descriptive model:

Grade and tonnage model:

Economic filter depth percentages:

Economic filter cost setting:

Geologic feature assessed:

Number of known deposits:
Porphyry copper models (Cox, 1986a; Berger and others, 2008; John and others, 2010)

General porphyry copper model (Singer, Berger, and Moring, 2008)

Default - 0 to 250 meters (m), 25\%; > 250 to $500 \mathrm{~m}, 25 \%$; >500 m to $1 \mathrm{~km}, 50 \%$

Typical cost

Middle Eocene to late Miocene island-arc to continental-arc rocks of the Tethyan metallogenic belt 4

\section{Selected Resource Assessment Results for Porphyry Copper}

[Assessment depth, 1 kilometer $(\mathrm{km}) ; \mathrm{km}^{2}$, square kilometer; $\mathrm{Mt}$, millions of metric tons]

\begin{tabular}{ccccccc}
\hline $\begin{array}{c}\text { Date of } \\
\text { assessment }\end{array}$ & $\begin{array}{c}\text { Tract area } \\
\left(\mathbf{k m}^{2}\right)\end{array}$ & $\begin{array}{c}\text { Identified } \\
\text { copper } \\
\text { resources } \\
(\mathbf{M t})\end{array}$ & $\begin{array}{c}\text { Mean estimate of } \\
\text { in-place resources } \\
(\mathbf{M t})\end{array}$ & $\begin{array}{c}\text { Probability of } \mathbf{0} \\
\text { in-place resources } \\
\text { (percent) }\end{array}$ & $\begin{array}{c}\text { Mean estimate of } \\
\text { economic resources } \\
\text { (Mt) }\end{array}$ & $\begin{array}{c}\text { Probability of } \mathbf{0} \\
\text { economic resources } \\
\text { (percent) }\end{array}$ \\
\hline 2012 & 19,075 & 26 & 12 & 7 & 8.0 \\
\hline
\end{tabular}

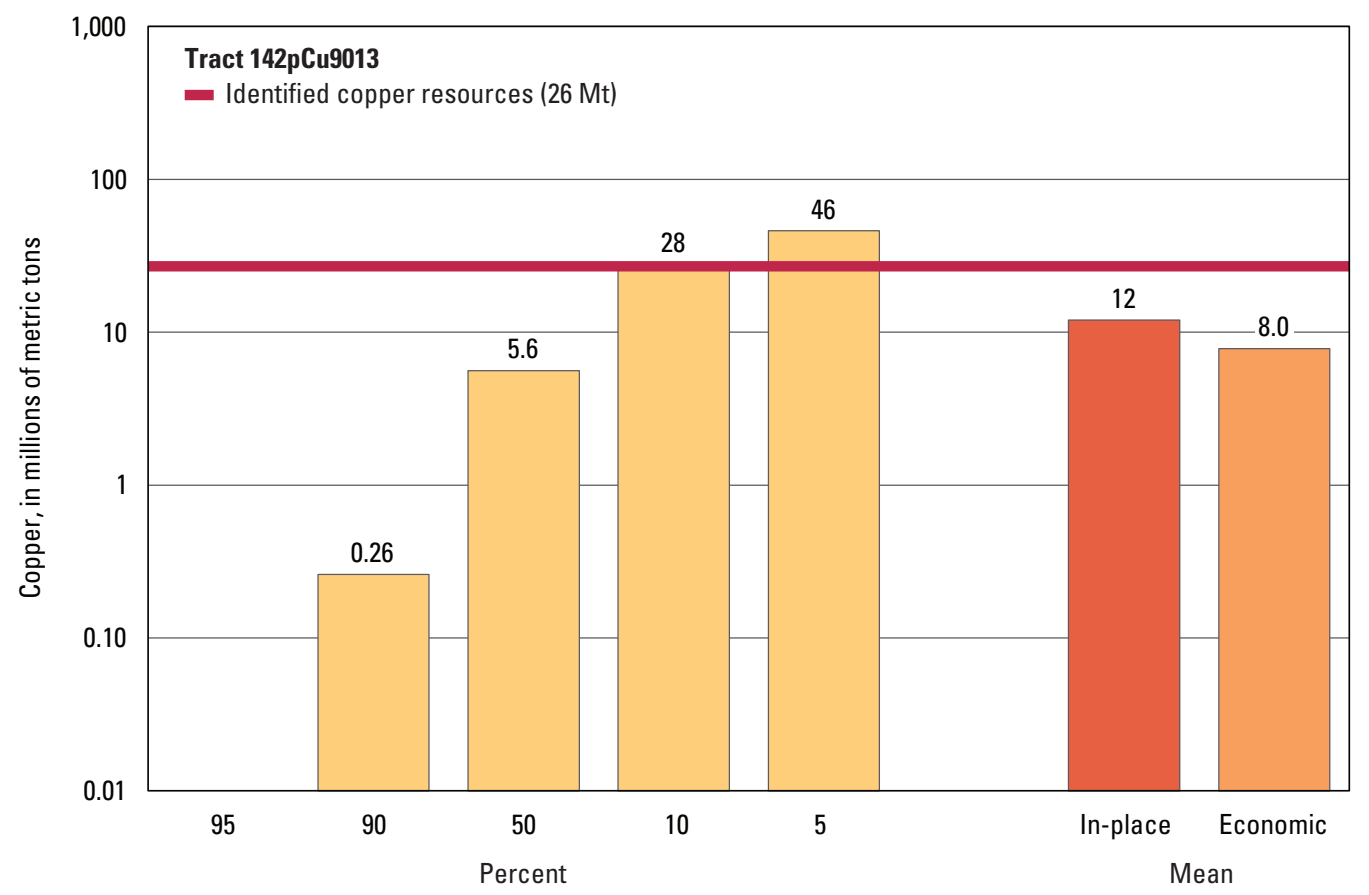

Graph showing the estimated probability distribution of undiscovered copper resources, where each bar represents the minimum amount estimated at the indicated percentage.

\section{Source}

Zürcher and others, 2015, Porphyry copper assessment of the Tethys region of western and southern Asia: U.S. Geological Survey Scientific Investigations Report 2010-5090-V, http://dx.doi.org/10.3133/sir20105090V. 


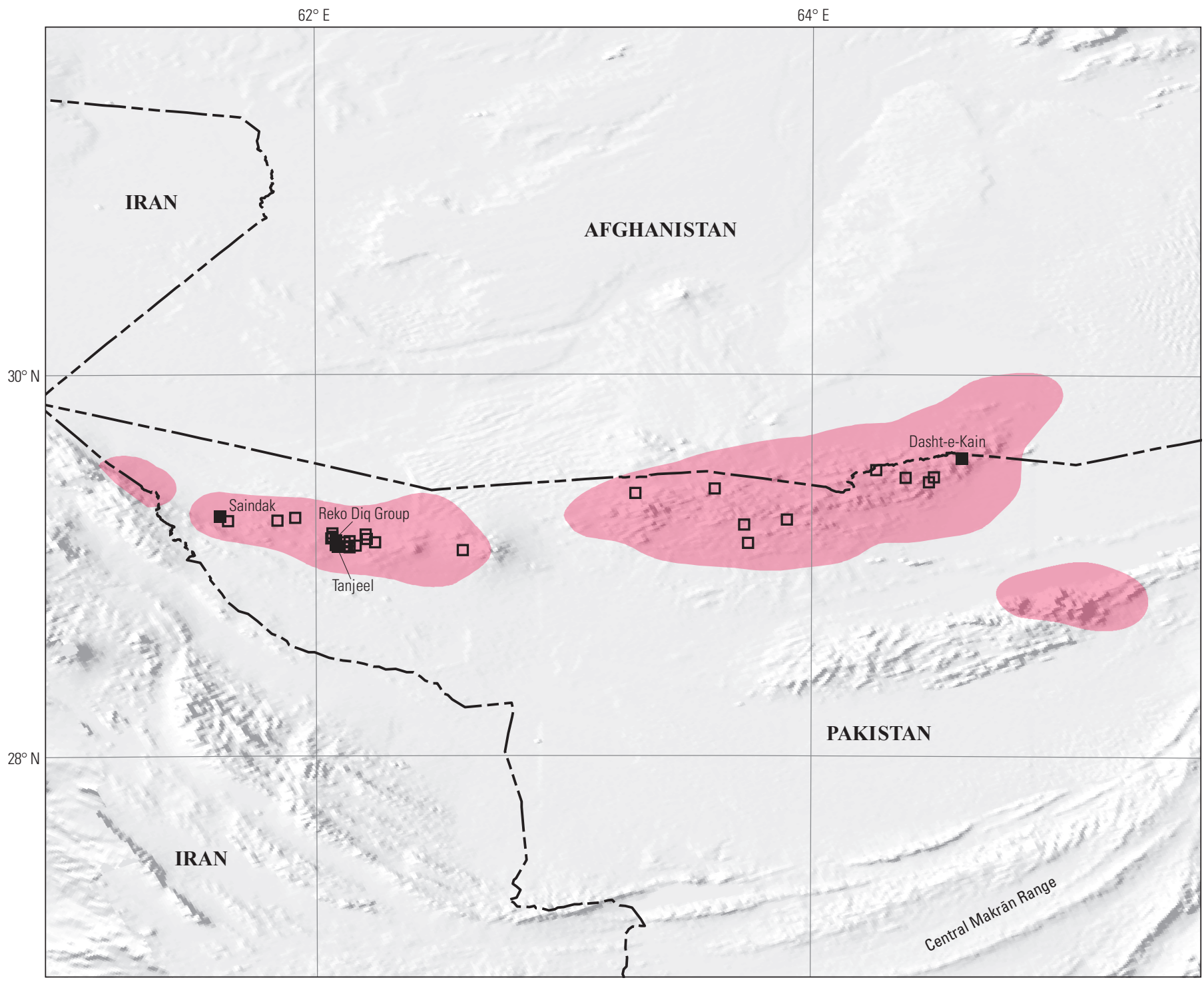

Political boundaries from U.S. Department of State (2009) Shaded relief from Earth Resources Observation and Science (EROS) Center (2011)

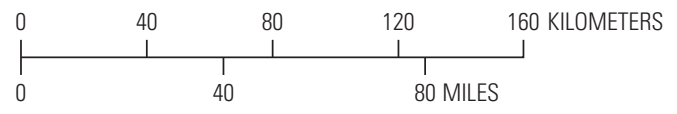

Asia South Albers Equal-Area Conic projection Central meridian $63^{\circ} \mathrm{E}$. ; latitude of origin $15^{\circ} \mathrm{S}$.

EXPLANATION

Assessed porphyry copper tract 142 Cu9013

- Porphyry copper deposit

$\square \quad$ Porphyry copper prospect

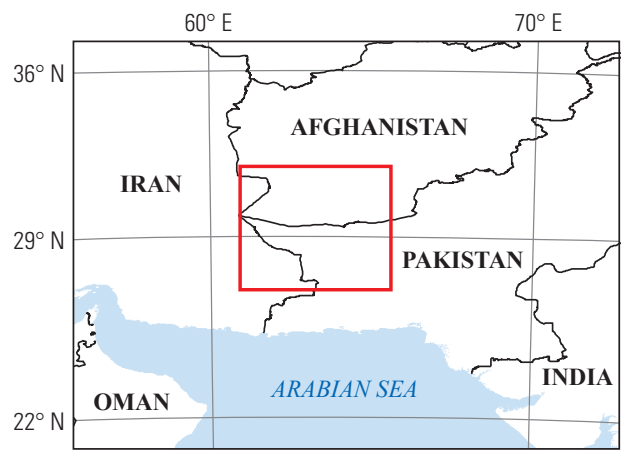




\title{
Plate 143. Porphyry Copper Assessment for Tract 142pCu9017c, Pliocene- Quaternary (Bazman) —Afghanistan, Pakistan, and Iran
}

\author{
Descriptive model: \\ Porphyry copper models (Cox, 1986a; Berger and others, 2008; John and others, 2010) \\ Grade and tonnage model: \\ NA \\ Economic filter depth percentages: \\ NA \\ Economic filter cost setting: \\ NA \\ Geologic feature assessed: \\ Late Miocene to Holocene continental-arc rocks and postcollisional rocks recording magmatism of \\ the Tethyan metallogenic belt \\ Number of known deposits: \\ 0
}

\section{Selected Resource Assessment Results for Porphyry Copper}

[Assessment depth, 1 kilometer $(\mathrm{km}) ; \mathrm{km}^{2}$, square kilometer; Mt, millions of metric tons; NA, not applicable, as a quantitative assessment was not done]

\begin{tabular}{|c|c|c|c|c|c|c|}
\hline \multirow[b]{2}{*}{$\begin{array}{c}\text { Date of } \\
\text { assessment }\end{array}$} & \multirow[b]{2}{*}{$\begin{array}{l}\text { Tract area } \\
\quad\left(\mathbf{k m}^{2}\right)\end{array}$} & \multirow{2}{*}{$\begin{array}{l}\text { Identified } \\
\text { copper } \\
\text { resources } \\
\text { (Mt) }\end{array}$} & \multicolumn{4}{|c|}{ Undiscovered copper resource estimates } \\
\hline & & & $\begin{array}{l}\text { Mean estimate of } \\
\text { in-place resources } \\
\text { (Mt) }\end{array}$ & $\begin{array}{c}\text { Probability of } 0 \\
\text { in-place resources } \\
\text { (percent) }\end{array}$ & $\begin{array}{c}\text { Mean estimate of } \\
\text { economic resources } \\
\text { (Mt) }\end{array}$ & $\begin{array}{c}\text { Probability of } 0 \\
\text { economic resources } \\
\text { (percent) }\end{array}$ \\
\hline 2013 & 21,298 & 0 & NA & NA & NA & NA \\
\hline
\end{tabular}

\section{Qualitative Assessment}

Tract 142pCu9017 is permissive for Pliocene to Quaternary porphyry copper deposits in the Tethyan region and includes three sub-tracts. Sub-tracts 142pCu9017a (pl. 164, Pliocene-Quaternary (Konya)—Turkey sub-tract) and 142pCu9017b (pl. 158, Pliocene-Quaternary (Postcollisional) - Iran, Armenia, Azerbaijan, Georgia, Turkey, and Russia) lie to the west of the Bazman sub-tract $142 \mathrm{pCu} 9017 \mathrm{c}$.

For sub-tract 142pCu9017c (this plate), the subduction-related setting is permissive for porphyry copper deposits; however, factors that greatly diminish the favorability include the predominance of volcanic rocks with levels of preservation that are, for the most part, too shallow for porphyry systems. The fledgling arc-building event represented by this sub-tract has been active only during the past 8 million years, and the relatively short timeframe may account for the paucity of porphyry copper occurrences. The presence of a low-grade porphyry copper-gold system at depth (0.14-percent copper at 128 meters in drill core) in an altered intrusion associated with the Koh-i-Sultan stratovolcano is shown as the prospect on the map. Despite the permissive geology, the geologic favorability was deemed unlikely to add significant copper resources to the overall assessment (less than a 10-percent chance of one undiscovered deposit). Therefore, a quantitative assessment of undiscovered porphyry copper deposits in the Bazman sub-tract was not warranted.

\section{Source}

Zürcher and others, 2015, Porphyry copper assessment of the Tethys region of western and southern Asia: U.S. Geological Survey Scientific Investigations Report 2010-5090-V, http://dx.doi.org/10.3133/sir20105090V. 


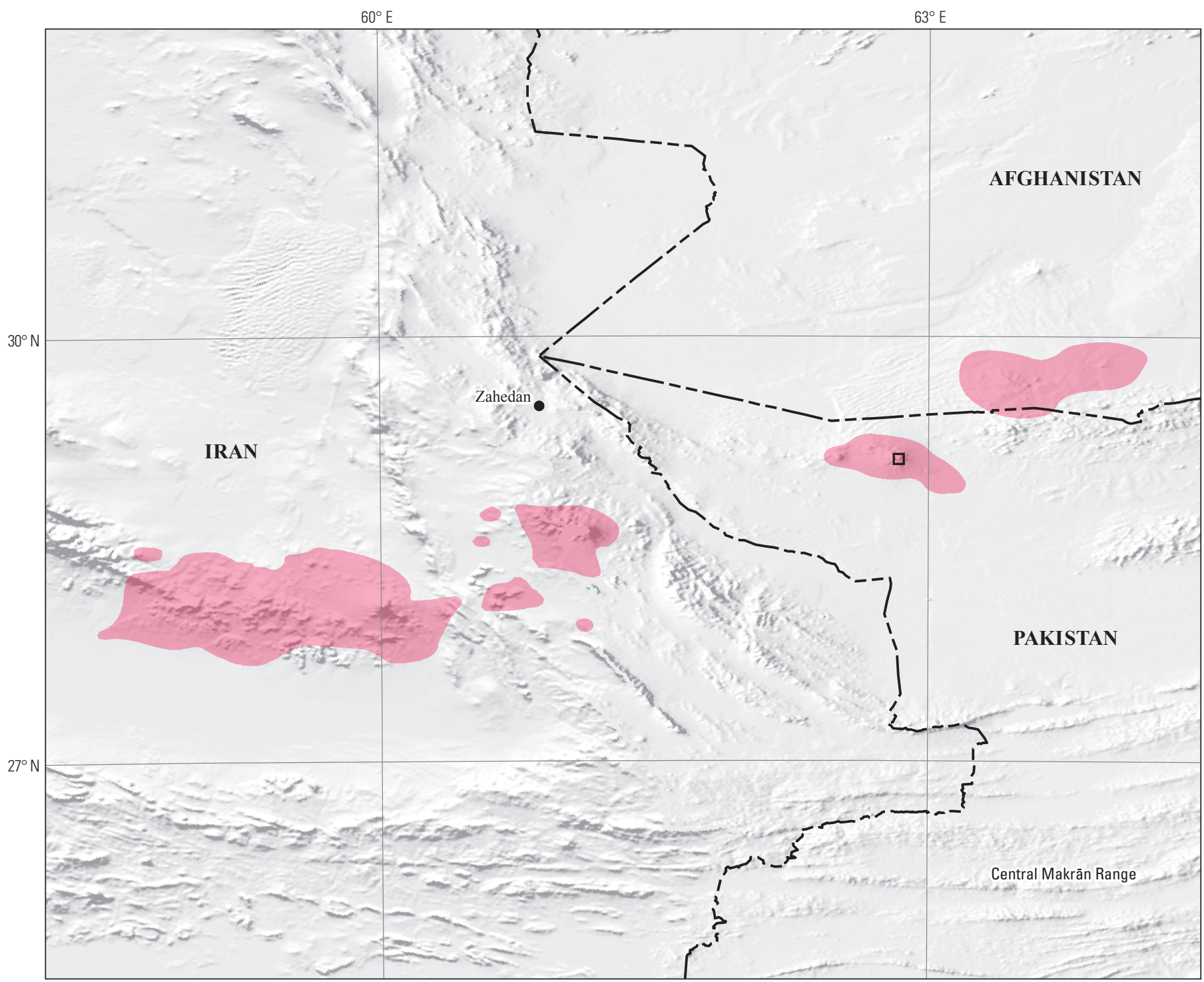

Political boundaries from U.S. Department of State (2009) Shaded relief from Earth Resources Observation and Science (EROS) Center (2011)

Asia South Albers Equal-Area Conic projection Central meridian $62^{\circ} \mathrm{E}$. ; latitude of origin $15^{\circ} \mathrm{S}$.

EXPLANATION

Assessed porphyry copper tract 142pCu9017c

Porphyry copper prospect

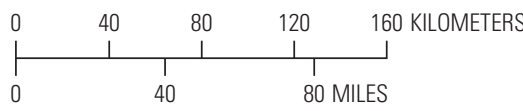

80 MILES

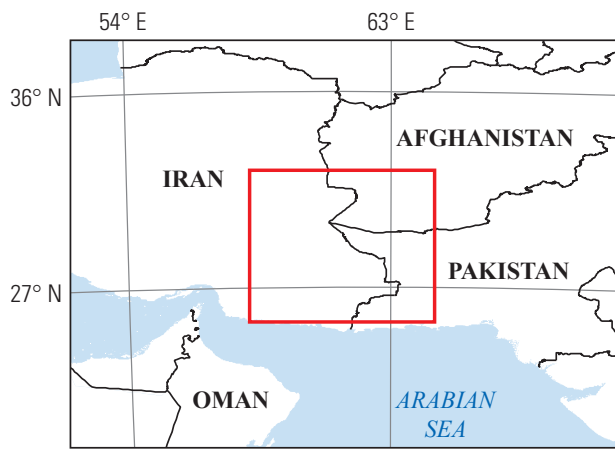




\section{Plate 144. Porphyry Copper Assessment for Tract 142pCu9012, Sistan-Iran}

Descriptive model:

Grade and tonnage model:

Economic filter depth percentages:

Economic filter cost setting:

Geologic feature assessed:

Number of known deposits:
Porphyry copper models (Cox, 1986a; Berger and others, 2008; John and others, 2010)

General porphyry copper model (Singer, Berger, and Moring, 2008)

Default -0 to 250 meters (m), $25 \%$; $>250$ to $500 \mathrm{~m}, 25 \%$; $>500 \mathrm{~m}$ to $1 \mathrm{~km}, 50 \%$

Typical cost

A Late Cretaceous to early Miocene island-arc volcano-plutonic belt within the Sistan suture zone associated with the Tethyan metallogenic belt

0

\section{Selected Resource Assessment Results for Porphyry Copper}

[Assessment depth, 1 kilometer $(\mathrm{km}) ; \mathrm{km}^{2}$, square kilometer; Mt, millions of metric tons]

\begin{tabular}{ccccccc}
\hline $\begin{array}{c}\text { Date of } \\
\text { assessment }\end{array}$ & $\begin{array}{c}\text { Tract area } \\
\left.\mathbf{( k m}^{2}\right)\end{array}$ & $\begin{array}{c}\text { Identified } \\
\text { copper } \\
\text { resources } \\
(\mathbf{M t})\end{array}$ & $\begin{array}{c}\text { Mean estimate of } \\
\text { in-place resources } \\
(\mathbf{M t})\end{array}$ & $\begin{array}{c}\text { Probability of } \mathbf{0} \\
\text { in-place resources } \\
\text { (percent) }\end{array}$ & $\begin{array}{c}\text { Mean estimate of } \\
\text { economic resources } \\
\text { (Mt) }\end{array}$ & $\begin{array}{c}\text { Probability of } 0 \\
\text { economic resources } \\
\text { (percent) }\end{array}$ \\
\hline 2013 & 32,820 & 0 & 9.8 & 20 & 6.6 \\
\hline
\end{tabular}

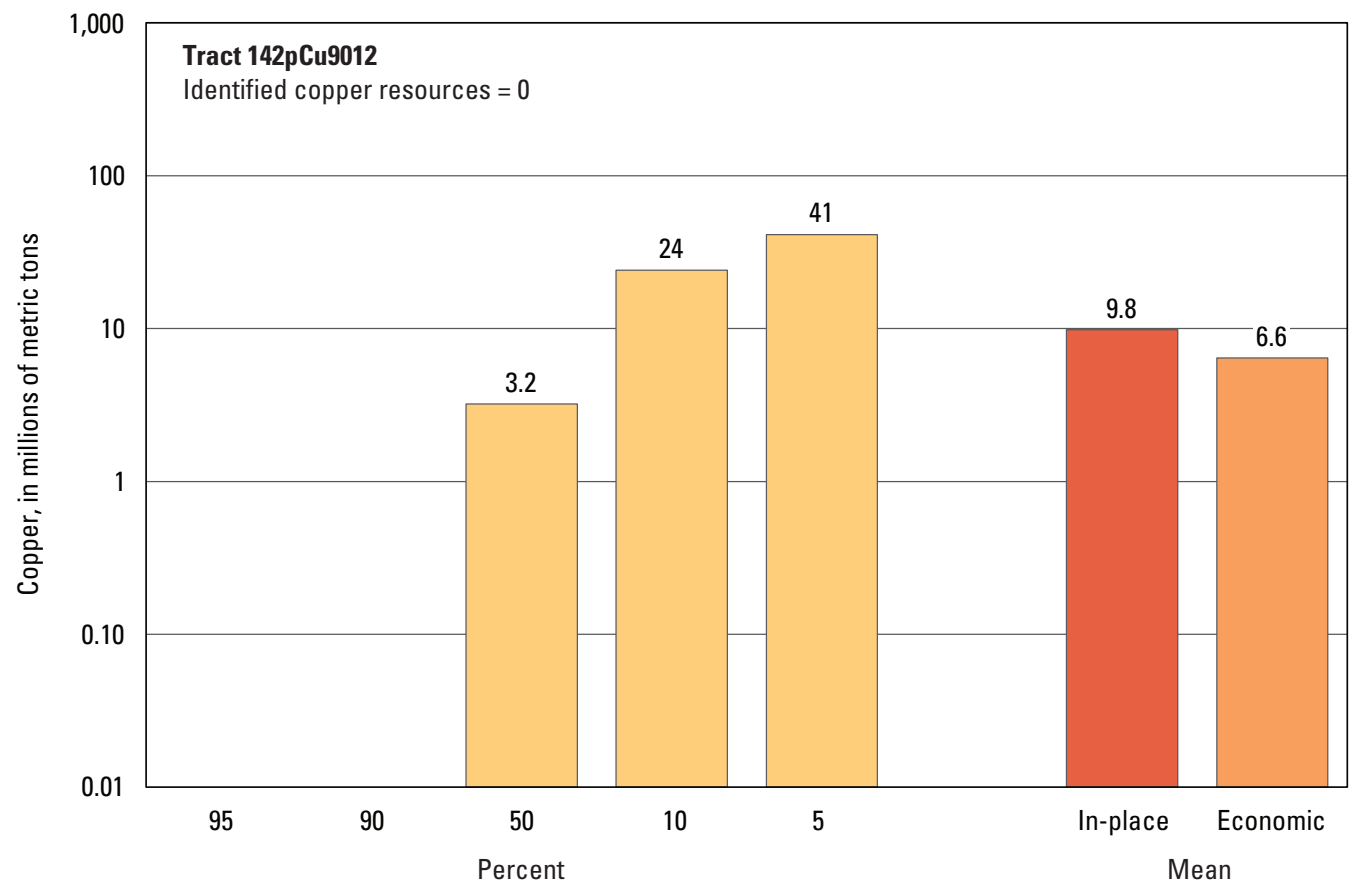

Graph showing the estimated probability distribution of undiscovered copper resources, where each bar represents the minimum amount estimated at the indicated percentage.

\section{Source}

Zürcher and others, 2015, Porphyry copper assessment of the Tethys region of western and southern Asia: U.S. Geological Survey Scientific Investigations Report 2010-5090-V, http://dx.doi.org/10.3133/sir20105090V. 


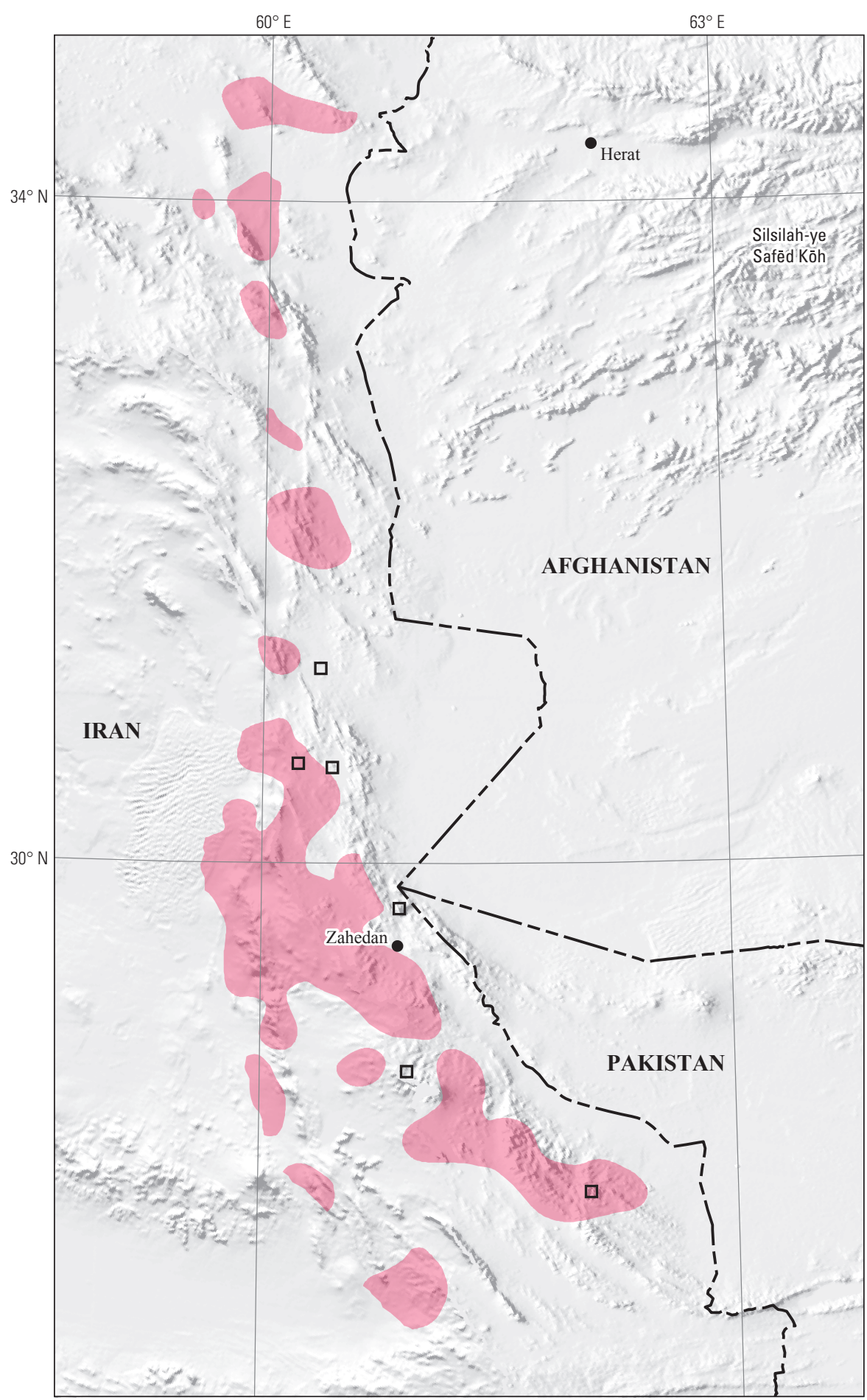

Political boundaries from U.S. Department of State (2009)

Shaded relief from Earth Resources Observation and Science (EROS) Center (2011)

Europe Albers Equal-Area Conic projection

Central meridian $61^{\circ}$ E.; latitude of origin $30^{\circ} \mathrm{N}$.

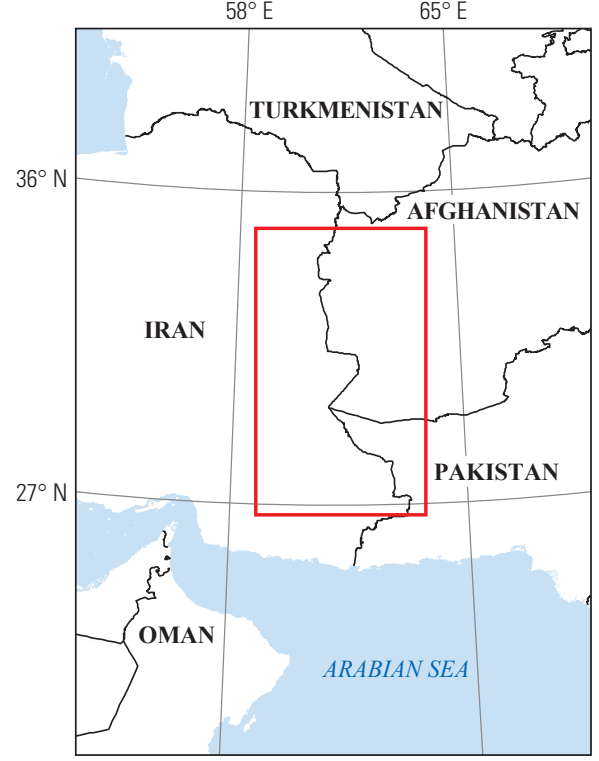

EXPLANATION

Assessed porphyry copper tract 142 Cu9012

ㅁ Porphyry copper prospect 


\section{Plate 145. Porphyry Copper Assessment for Tract 142pCu9010, Lut Tertiary- Iran}

Descriptive model:

Grade and tonnage model:

Economic filter depth percentages:

Economic filter cost setting:

Geologic feature assessed:

Number of known deposits:
Porphyry copper models (Cox, 1986a; Berger and others, 2008; John and others, 2010)

Porphyry copper, copper-gold subtype model (Singer, Berger, and Moring, 2008)

Skewed deep - 0 to 250 meters (m), 10\%; > 250 to $500 \mathrm{~m}, 30 \%$; $>500 \mathrm{~m}$ to $1 \mathrm{~km}, 60 \%$

Typical cost

A 700-km-long and as much as 250-km-wide subduction-related magmatic arc of middle Eocene to early Miocene age associated with the Tethyan metallogenic belt

0

\section{Selected Resource Assessment Results for Porphyry Copper}

[Assessment depth, 1 kilometer $(\mathrm{km}) ; \mathrm{km}^{2}$, square kilometer; Mt, millions of metric tons]

\begin{tabular}{ccccccc}
\hline $\begin{array}{c}\text { Date of } \\
\text { assessment }\end{array}$ & $\begin{array}{c}\text { Tract area } \\
\left(\mathbf{k m}^{2}\right)\end{array}$ & $\begin{array}{c}\text { Identified } \\
\text { copper } \\
\text { resources } \\
(\mathbf{M t})\end{array}$ & $\begin{array}{c}\text { Mean estimate of } \\
\text { in-place resources } \\
(\mathbf{M t})\end{array}$ & $\begin{array}{c}\text { Probability of } \mathbf{0} \\
\text { in-place resources } \\
\text { (percent) }\end{array}$ & $\begin{array}{c}\text { Mean estimate of } \\
\text { economic resources } \\
\text { (Mt) }\end{array}$ & $\begin{array}{c}\text { Probability of } 0 \\
\text { economic resources } \\
\text { (percent) }\end{array}$ \\
\hline 2012 & 56,256 & 0 & 7.5 & 20 & 5.0 \\
\hline
\end{tabular}

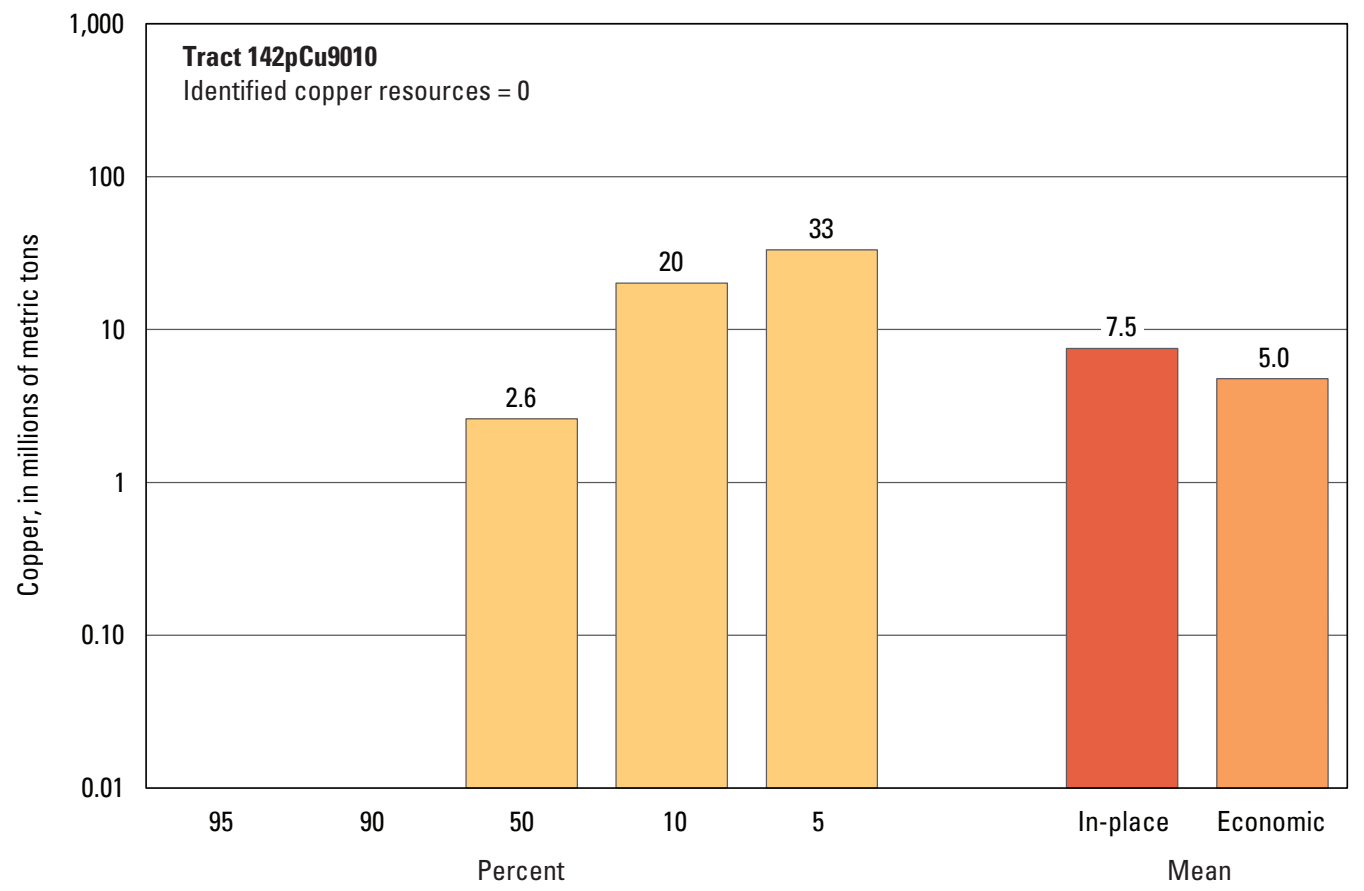

Graph showing the estimated probability distribution of undiscovered copper resources, where each bar represents the minimum amount estimated at the indicated percentage.

\section{Source}

Zürcher and others, 2015, Porphyry copper assessment of the Tethys region of western and southern Asia: U.S. Geological Survey Scientific Investigations Report 2010-5090-V, http://dx.doi.org/10.3133/sir20105090V. 


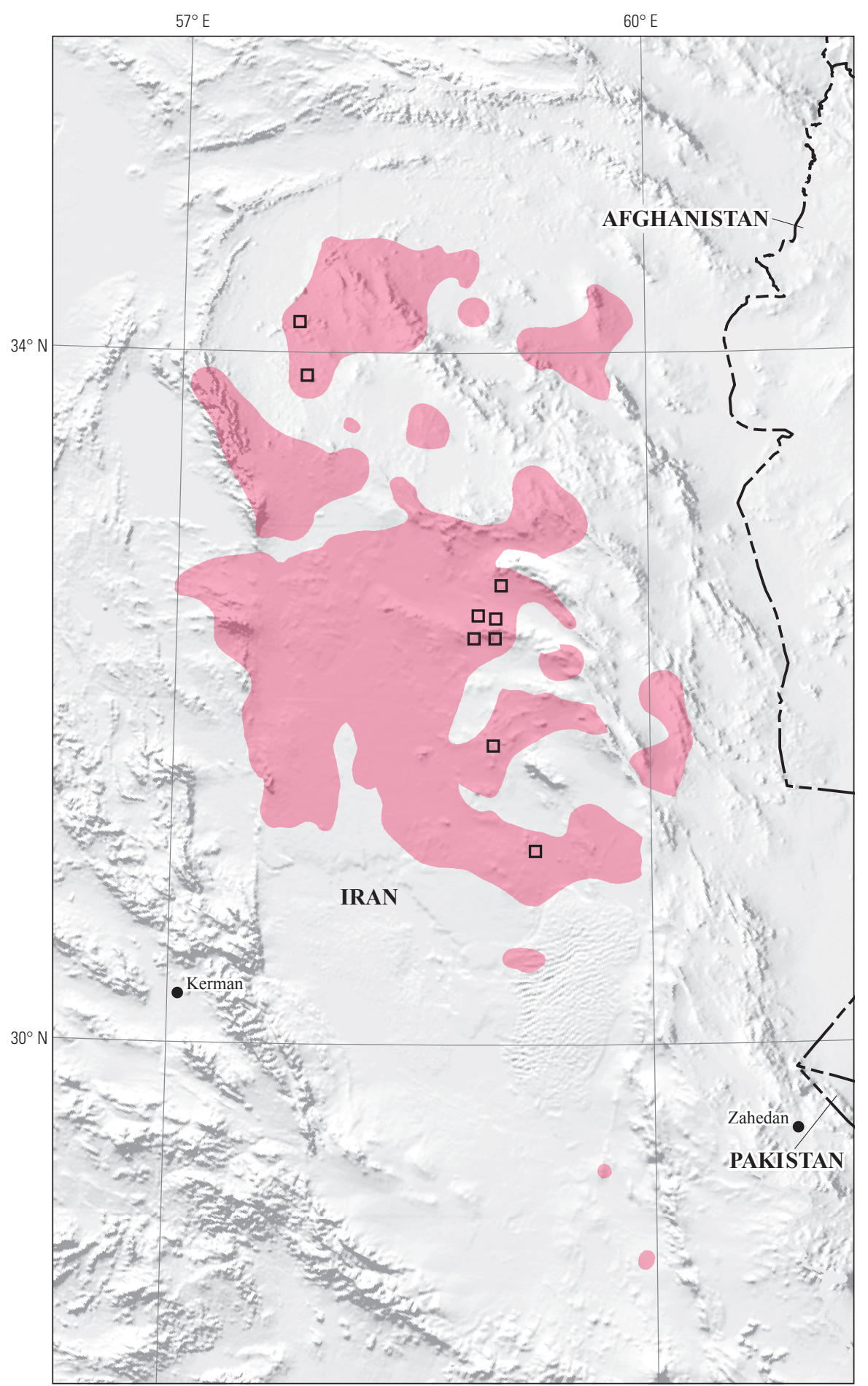

Political boundaries from U.S. Department of State (2009) Shaded relief from Earth Resources Observation and Science (EROS) Center (2011)

Europe Albers Equal-Area Conic projection

Central meridian $59^{\circ} \mathrm{E}$.; latitude of origin $30^{\circ} \mathrm{N}$.

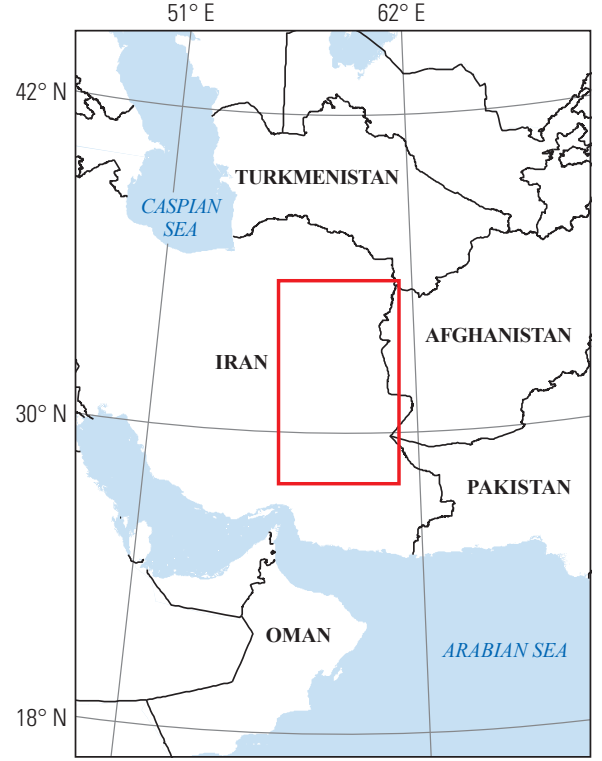

EXPLANATION

Assessed porphyry copper tract 142pCu9010

$\square \quad$ Porphyry copper prospect 


\section{Plate 146. Porphyry Copper Assessment for Tract 142pCu9000, Lut Jurassic- Iran}

Descriptive model:

Grade and tonnage model:

Economic filter depth percentages:

Economic filter cost setting:

Geologic feature assessed:

Number of known deposits:
Porphyry copper models (Cox, 1986a; Berger and others, 2008; John and others, 2010)

NA

NA

NA

Middle Jurassic continental-arc rocks of the Tethyan metallogenic belt

0

\section{Selected Resource Assessment Results for Porphyry Copper}

[Assessment depth, 1 kilometer $(\mathrm{km})$; $\mathrm{km}^{2}$, square kilometer; Mt, millions of metric tons; NA, not applicable, as a quantitative assessment was not done]

\begin{tabular}{ccccccc}
\hline \multirow{2}{*}{$\begin{array}{c}\text { Date of } \\
\text { assessment }\end{array}$} & $\begin{array}{c}\text { Tract area } \\
\left(\mathbf{k m}^{2}\right)\end{array}$ & $\begin{array}{c}\text { Identified } \\
\text { copper } \\
\text { resources } \\
(\mathbf{M t})\end{array}$ & $\begin{array}{c}\text { Mean estimate of } \\
\text { in-place resources } \\
(\mathbf{M t})\end{array}$ & $\begin{array}{c}\text { Probability of } \mathbf{0} \\
\text { in-place resources } \\
\text { (percent) }\end{array}$ & $\begin{array}{c}\text { Mean estimate of } \\
\text { economic resources } \\
\text { (Mt) }\end{array}$ & $\begin{array}{c}\text { Probability of } \mathbf{0} \\
\text { economic resources } \\
\text { (percent) }\end{array}$ \\
\hline 2013 & 2,965 & 0 & NA & NA & NA \\
\hline
\end{tabular}

\section{Qualitative Assessment}

The Middle Jurassic continental-arc setting of tract 142pCu9000 (Lut Jurassic-Iran) is permissive for the occurrence of porphyry copper deposits. However, insufficient information is available to characterize the geology and copper resources of the only porphyry copper prospect positively identified to date in the poorly preserved, deeply exhumed, and extensively covered Lut Jurassic tract. The lack of Jurassic volcanic rocks, the dominance of rocks having felsic calc-alkalic to peraluminous igneous compositions, deep-seated tin-bearing metal associations in related hydrothermal systems, and the fact that rocks younger than Jurassic age cover about 67 percent of the tract area all indicate a low favorability for undiscovered porphyry copper deposits. The near absence of porphyry prospects of Jurassic age in the Tethyan region further adds considerable uncertainty. Despite the permissive geology and the presence of one positively identified porphyry copper prospect, the geologic favorability was deemed too low to add significant undiscovered porphyry copper resources to the overall assessment.

\section{Source}

Zürcher and others, 2015, Porphyry copper assessment of the Tethys region of western and southern Asia: U.S. Geological Survey Scientific Investigations Report 2010-5090-V, http://dx.doi.org/10.3133/sir20105090V. 


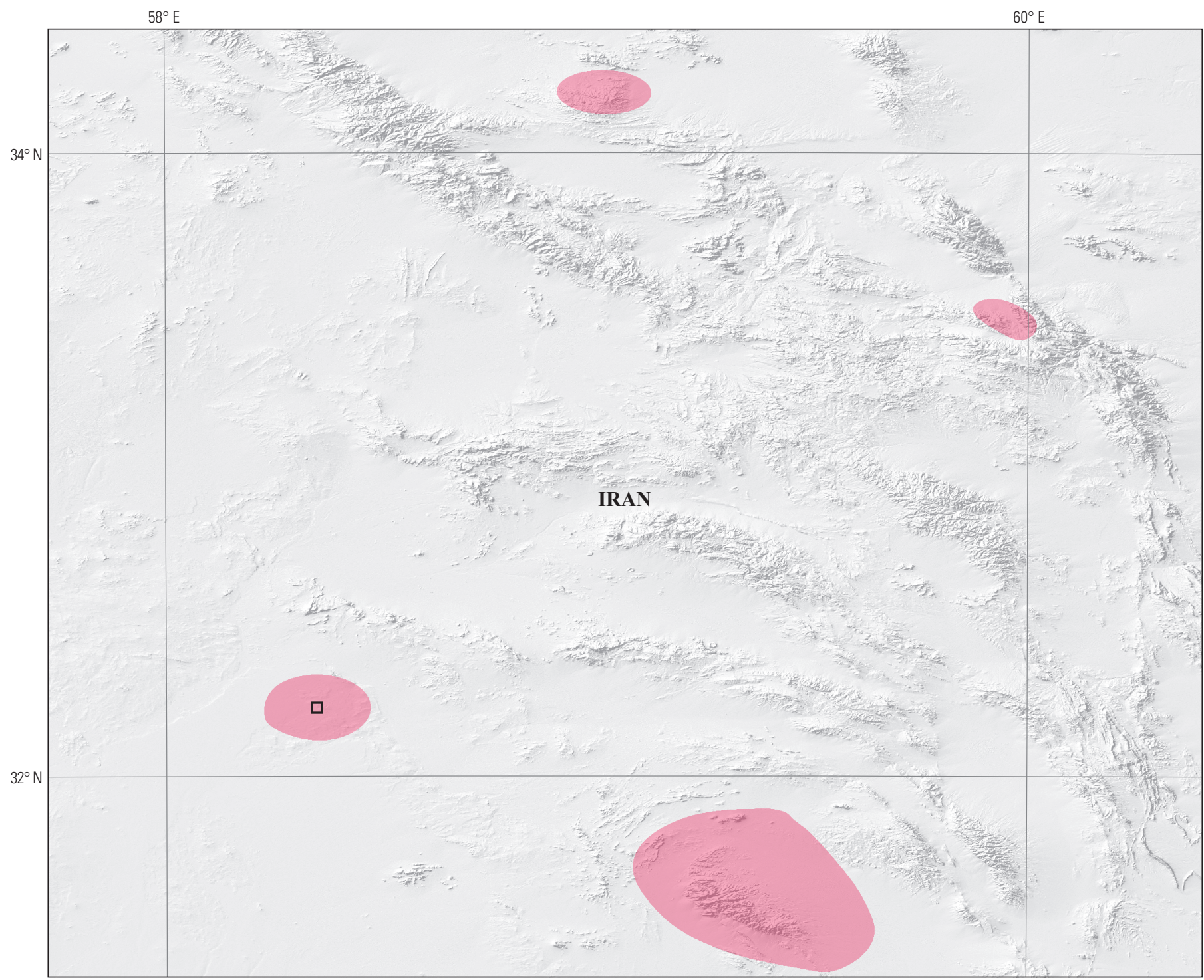

Political boundaries from U.S. Department of State (2009) Shaded relief from ESRI (2008)

Asia South Albers Equal-Area Conic projection Central meridian $59^{\circ} \mathrm{E}$.; latitude of origin $15^{\circ} \mathrm{S}$.

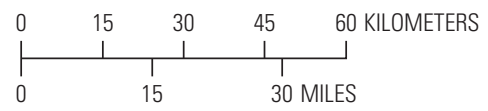

\section{EXPLANATION}

Assessed porphyry copper tract 142pCu9000

$\square \quad$ Porphyry copper prospect

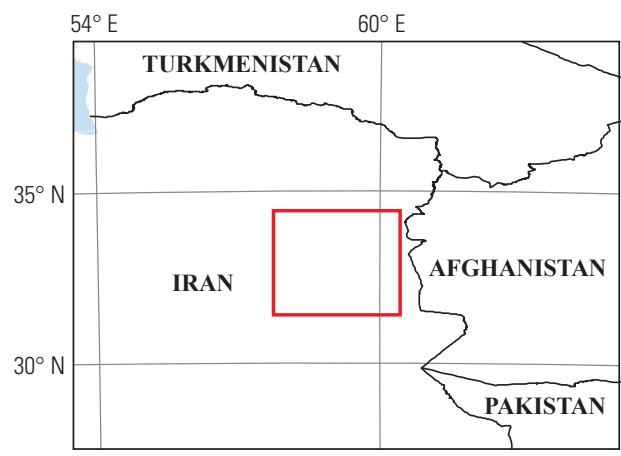




\title{
Plate 147. Porphyry Copper Assessment for Tract 142pCu9006, Lut Cretaceous-Iran
}

\author{
Descriptive model: \\ Porphyry copper models (Cox, 1986a; Berger and others, 2008; John and others, 2010) \\ Grade and tonnage model: \\ NA \\ Economic filter depth percentages: \\ NA \\ Economic filter cost setting: \\ NA \\ Geologic feature assessed: \\ Late Cretaceous-Paleocene continental-arc rocks of the Tethyan metallogenic belt \\ Number of known deposits: \\ 0
}

\section{Selected Resource Assessment Results for Porphyry Copper}

[Assessment depth, 1 kilometer $(\mathrm{km})$; $\mathrm{km}^{2}$, square kilometer; Mt, millions of metric tons; NA, not applicable, as a quantitative assessment was not done]

\begin{tabular}{ccccccc}
\hline \multirow{2}{*}{$\begin{array}{c}\text { Date of } \\
\text { assessment }\end{array}$} & $\begin{array}{c}\text { Tract area } \\
\left(\mathbf{k m}^{2}\right)\end{array}$ & $\begin{array}{c}\text { Identified } \\
\text { copper } \\
\text { resources } \\
(\mathbf{M t})\end{array}$ & $\begin{array}{c}\text { Mean estimate of } \\
\text { in-place resources } \\
(\mathbf{M t})\end{array}$ & $\begin{array}{c}\text { Probability of } \mathbf{0} \\
\text { in-place resources } \\
\text { (percent) }\end{array}$ & $\begin{array}{c}\text { Mean estimate of } \\
\text { economic resources } \\
\text { (Mt) }\end{array}$ & $\begin{array}{c}\text { Probability of } \mathbf{0} \\
\text { economic resources } \\
\text { (percent) }\end{array}$ \\
\hline 2013 & 12,030 & 0 & NA & NA & NA \\
\hline
\end{tabular}

\section{Qualitative Assessment}

Tract 142pCu9006 (Lut Cretaceous-Iran) is delimited by permissive units of an erratically exposed 800-km-long subduction-related continental arc of Late Cretaceous-Paleocene age in eastern Iran. One copper-molybdenum-(gold) porphyry prospect and one tin-molybdenum-copper porphyry-related occurrence have been identified in this tract. Rocks younger than Cretaceous cover about 74 percent of the tract area. The low permissive unit volcanic-to-plutonic ratio of 16 implies that the level of preservation is generally deep, whereas the high percentage of younger cover rocks suggests that unidentified porphyry systems of this age range are likely to be buried. Exploration for porphyry deposits of this age range appears to have been limited in this region. Despite the permissive geology and the presence of prospects, the assessment team concluded that the favorability was too low to add significant undiscovered porphyry copper resources to the overall assessment (less than a 10-percent chance of one undiscovered deposit).

\section{Source}

Zürcher and others, 2015, Porphyry copper assessment of the Tethys region of western and southern Asia: U.S. Geological Survey Scientific Investigations Report 2010-5090-V, http://dx.doi.org/10.3133/sir20105090V. 


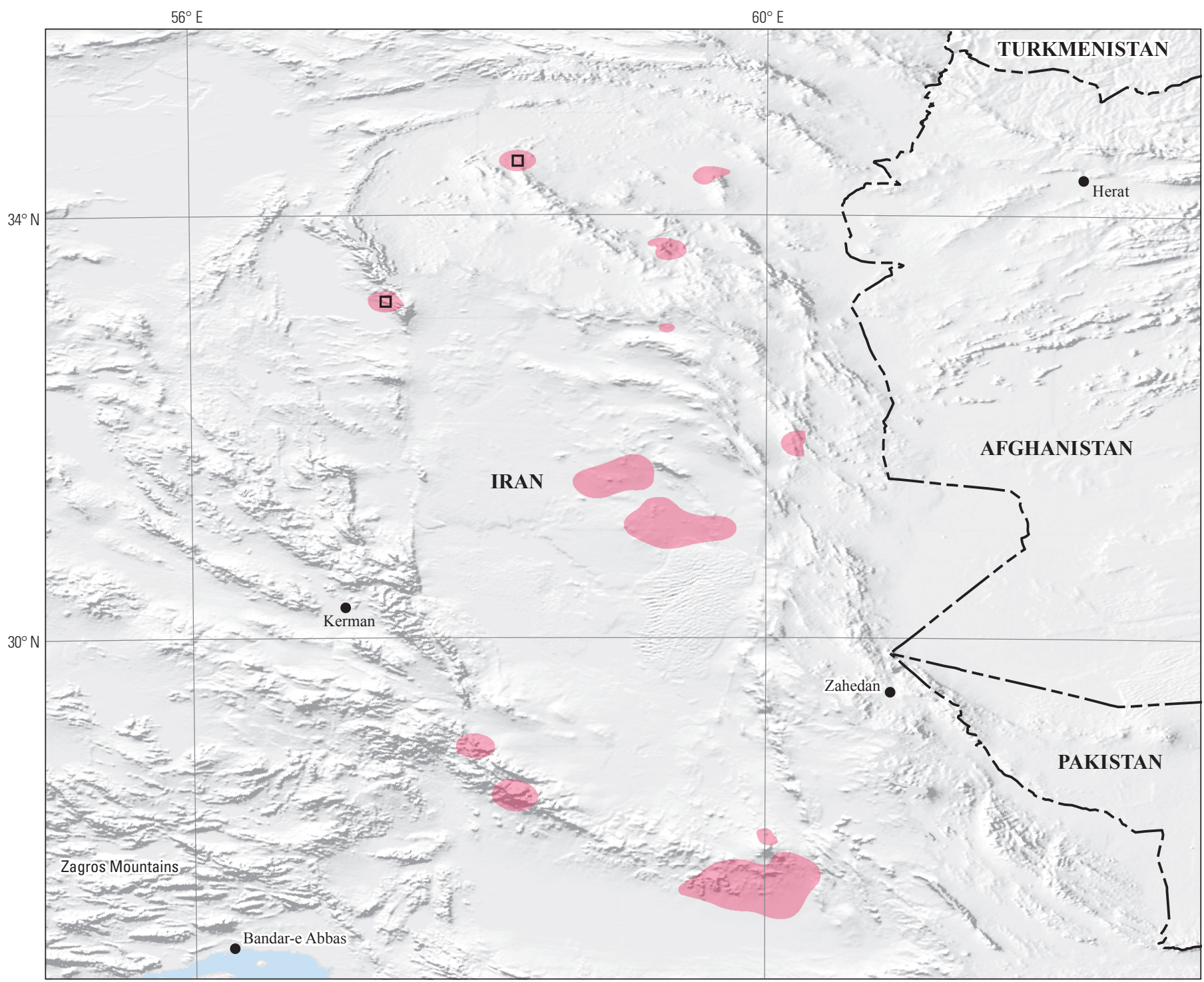

Political boundaries from U.S. Department of State (2009) Shaded relief from Earth Resources Observation and Science (EROS) Center (2011)

Asia South Albers Equal-Area Conic projection Central meridian $59^{\circ} \mathrm{E}$.; latitude of origin $15^{\circ} \mathrm{S}$.

\section{EXPLANATION}

Assessed porphyry copper tract 142pCu9006

ㅁ Porphyry copper prospect
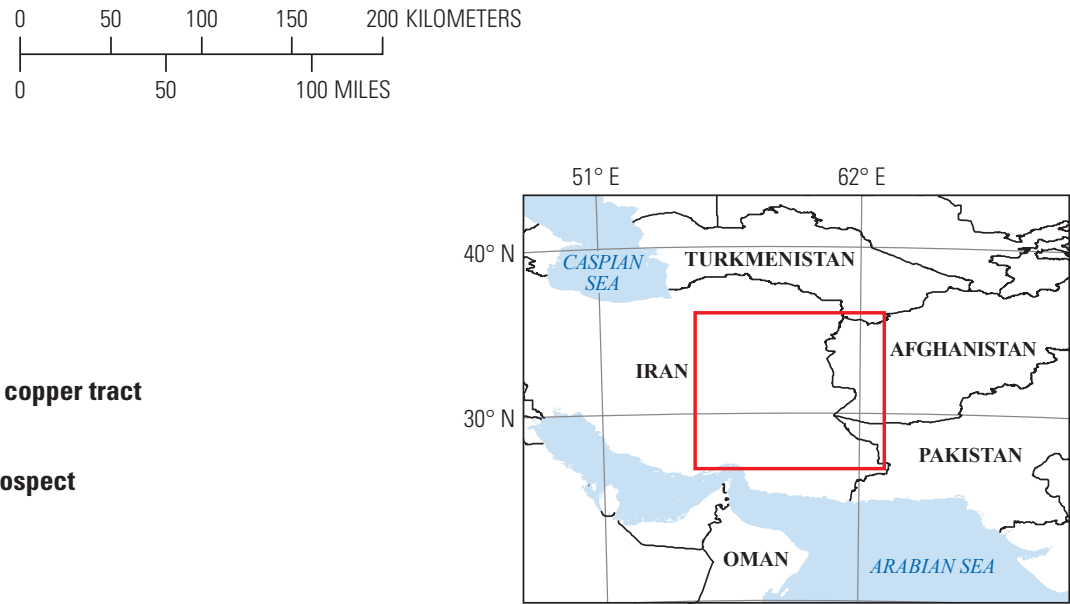


\section{Plate 148. Porphyry Copper Assessment for Tract 142pCu9011, Makran—Iran}

Descriptive model:

Grade and tonnage model:

Economic filter depth percentages:

Economic filter cost setting:

Geologic feature assessed:

Number of known deposits:
Porphyry copper models (Cox, 1986a; Berger and others, 2008; John and others, 2010)

NA

NA

NA

Late Cretaceous to late Eocene island-arc rocks of the Tethyan metallogenic belt

0

\section{Selected Resource Assessment Results for Porphyry Copper}

[Assessment depth, 1 kilometer $(\mathrm{km}) ; \mathrm{km}^{2}$, square kilometer; Mt, millions of metric tons; NA, not applicable, as a quantitative assessment was not done]

\begin{tabular}{ccccccc}
\hline \multirow{2}{*}{$\begin{array}{c}\text { Date of } \\
\text { assessment }\end{array}$} & $\begin{array}{c}\text { Tract area } \\
\left(\mathbf{k m}^{2}\right)\end{array}$ & $\begin{array}{c}\text { Identified } \\
\text { copper } \\
\text { resources } \\
(\mathbf{M t})\end{array}$ & $\begin{array}{c}\text { Mean estimate of } \\
\text { in-place resources } \\
(\mathbf{M t})\end{array}$ & $\begin{array}{c}\text { Probability of } \mathbf{0} \\
\text { in-place resources } \\
\text { (percent) }\end{array}$ & $\begin{array}{c}\text { Mean estimate of } \\
\text { economic resources } \\
\text { (Mt) }\end{array}$ & $\begin{array}{c}\text { Probability of } 0 \\
\text { economic resources } \\
\text { (percent) }\end{array}$ \\
\hline 2013 & 24,117 & 0 & NA & NA & NA \\
\hline
\end{tabular}

\section{Qualitative Assessment}

Tract 142pCu9011 (Makran-Iran) is an arcuate area in southeastern Iran that is $420 \mathrm{~km}$ long and up to $110 \mathrm{~km}$ wide; this east-west-trending belt of permissive rocks represents a Late Cretaceous-early Paleocene back-arc setting exposed in the north, as well as a late Paleocene-late Eocene fore-arc environment in the south. The back-arc and fore-arc environments are separated by a fragment of cratonic crust. No porphyry prospects are identified in the tract area. The permissive units are deeply exhumed in this fold-and-thrust belt. Because of the exhumation and the thick intervening syn-orogenic and younger sedimentary cover rocks that together occupy 84 percent of the tract area, appropriate exposure levels for porphyry systems of this age range appear to be limited. Despite the permissive geology, the assessment team concluded that the favorability was too low to add significant undiscovered porphyry copper resources to the overall assessment (less than a 10-percent chance of one undiscovered deposit).

\section{Source}

Zürcher and others, 2015, Porphyry copper assessment of the Tethys region of western and southern Asia: U.S. Geological Survey Scientific Investigations Report 2010-5090-V, http://dx.doi.org/10.3133/sir20105090V. 


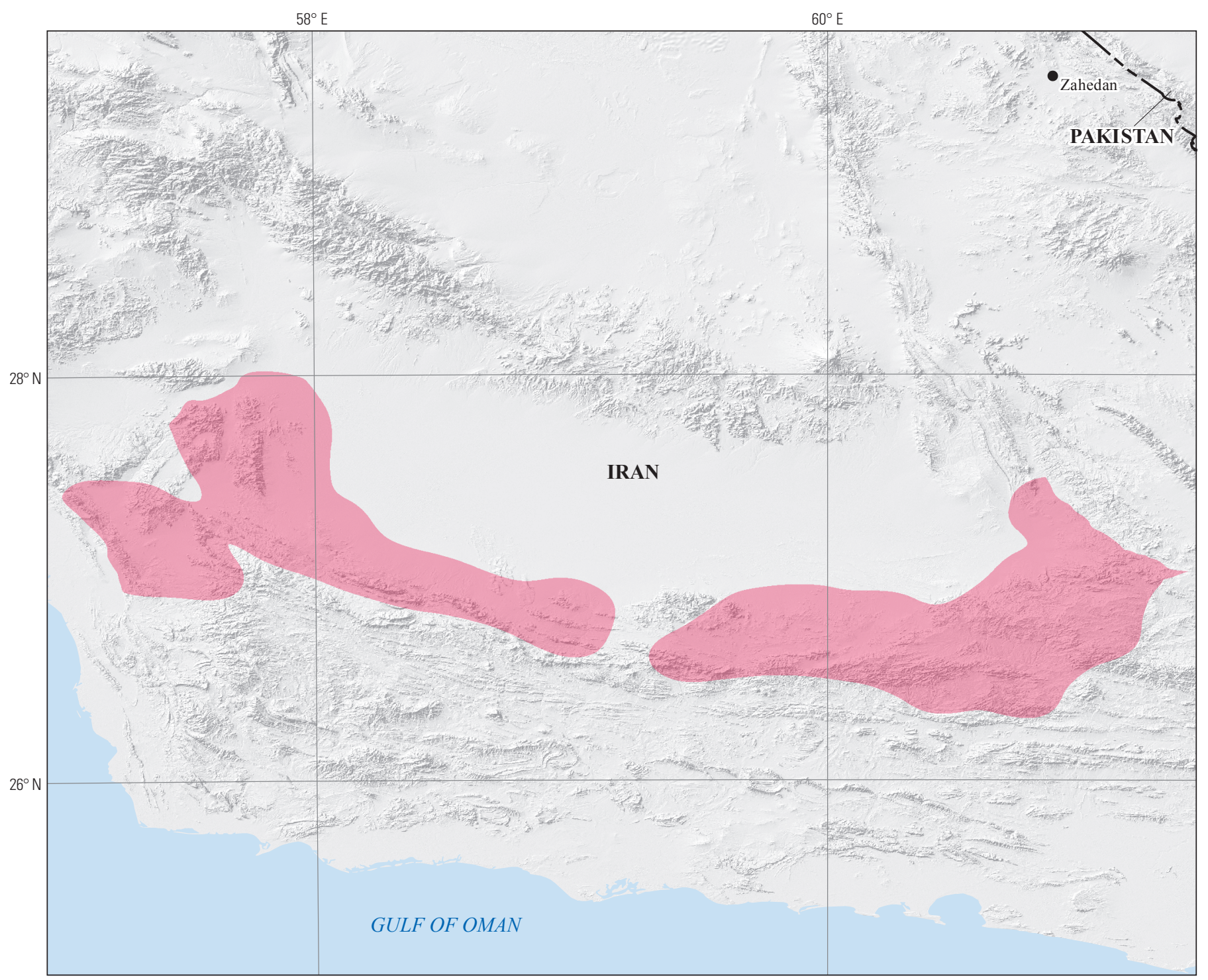

Political boundaries from U.S. Department of State (2009) Shaded relief from ESRI (2008)

Asia South Albers Equal-Area Conic projection Central meridian $60^{\circ} \mathrm{E}$.; latitude of origin $15^{\circ} \mathrm{S}$.

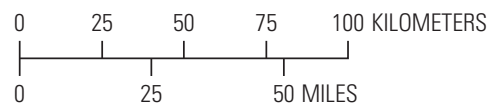

\section{EXPLANATION}

Assessed porphyry copper tract 142pCu9011

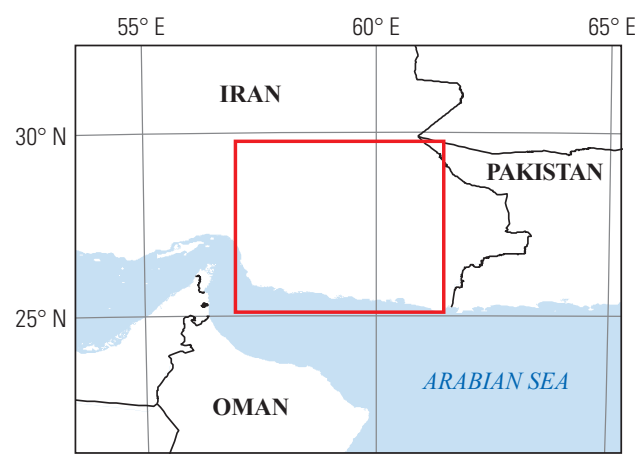




\section{Plate 149. Porphyry Copper Assessment for Tract 142pCu9009, Khorasan- Afghanistan and Iran}

Descriptive model:

Grade and tonnage model:

Economic filter depth percentages:

Economic filter cost setting:

Geologic feature assessed:

Number of known deposits:
Porphyry copper models (Cox, 1986a; Berger and others, 2008; John and others, 2010)

Porphyry copper, copper-gold subtype model (Singer, Berger, and Moring, 2008)

Skewed deep - 0 to 250 meters (m), 10\%; > 250 to $500 \mathrm{~m}, 30 \%$; $>500 \mathrm{~m}$ to $1 \mathrm{~km}, 60 \%$

Typical cost

Late Cretaceous to middle Miocene island-arc rocks of the Tethyan metallogenic belt 0

\section{Selected Resource Assessment Results for Porphyry Copper}

[Assessment depth, 1 kilometer $(\mathrm{km})$; $\mathrm{km}^{2}$, square kilometer; $\mathrm{Mt}$, millions of metric tons]

\begin{tabular}{ccccccc}
\hline \multirow{2}{*}{$\begin{array}{c}\text { Date of } \\
\text { assessment }\end{array}$} & $\begin{array}{c}\text { Tract area } \\
\left(\mathbf{k m}^{2}\right)\end{array}$ & $\begin{array}{c}\text { Identified } \\
\text { copper } \\
\text { resources } \\
(\mathbf{M t})\end{array}$ & $\begin{array}{c}\text { Mean estimate of } \\
\text { in-place resources } \\
(\mathbf{M t})\end{array}$ & $\begin{array}{c}\text { Probability of } \mathbf{0} \\
\text { in-place resources } \\
\text { (percent) }\end{array}$ & $\begin{array}{c}\text { Mean estimate of } \\
\text { economic resources } \\
\text { (Mt) }\end{array}$ & $\begin{array}{c}\text { Probability of } \mathbf{0} \\
\text { economic resources } \\
\text { (percent) }\end{array}$ \\
\hline 2013 & 38,311 & 0 & 8.1 & 20 & 5.5 \\
\hline
\end{tabular}

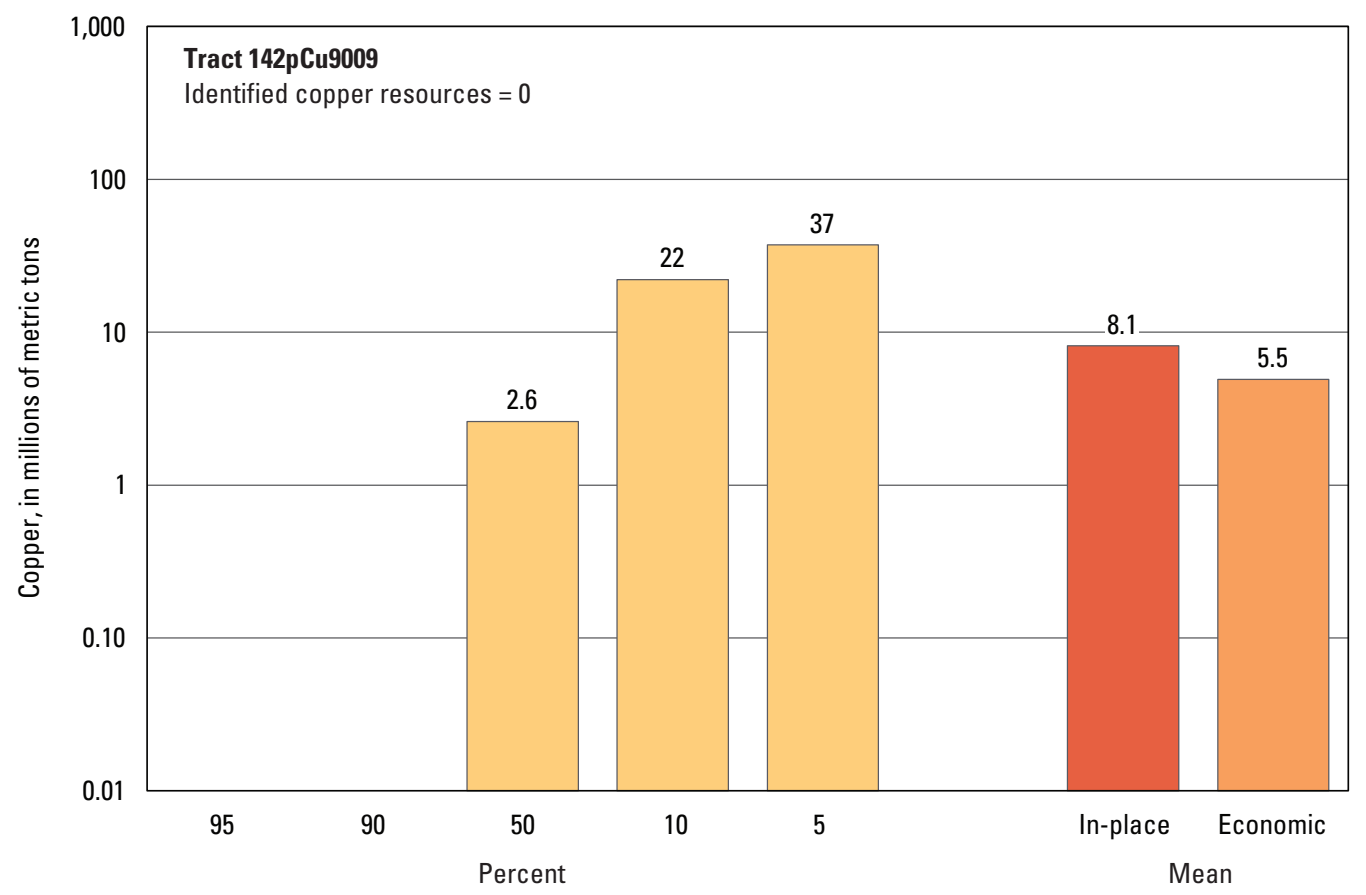

Graph showing the estimated probability distribution of undiscovered copper resources, where each bar represents the minimum amount estimated at the indicated percentage.

\section{Source}

Zürcher and others, 2015, Porphyry copper assessment of the Tethys region of western and southern Asia: U.S. Geological Survey Scientific Investigations Report 2010-5090-V, http://dx.doi.org/10.3133/sir20105090V. 


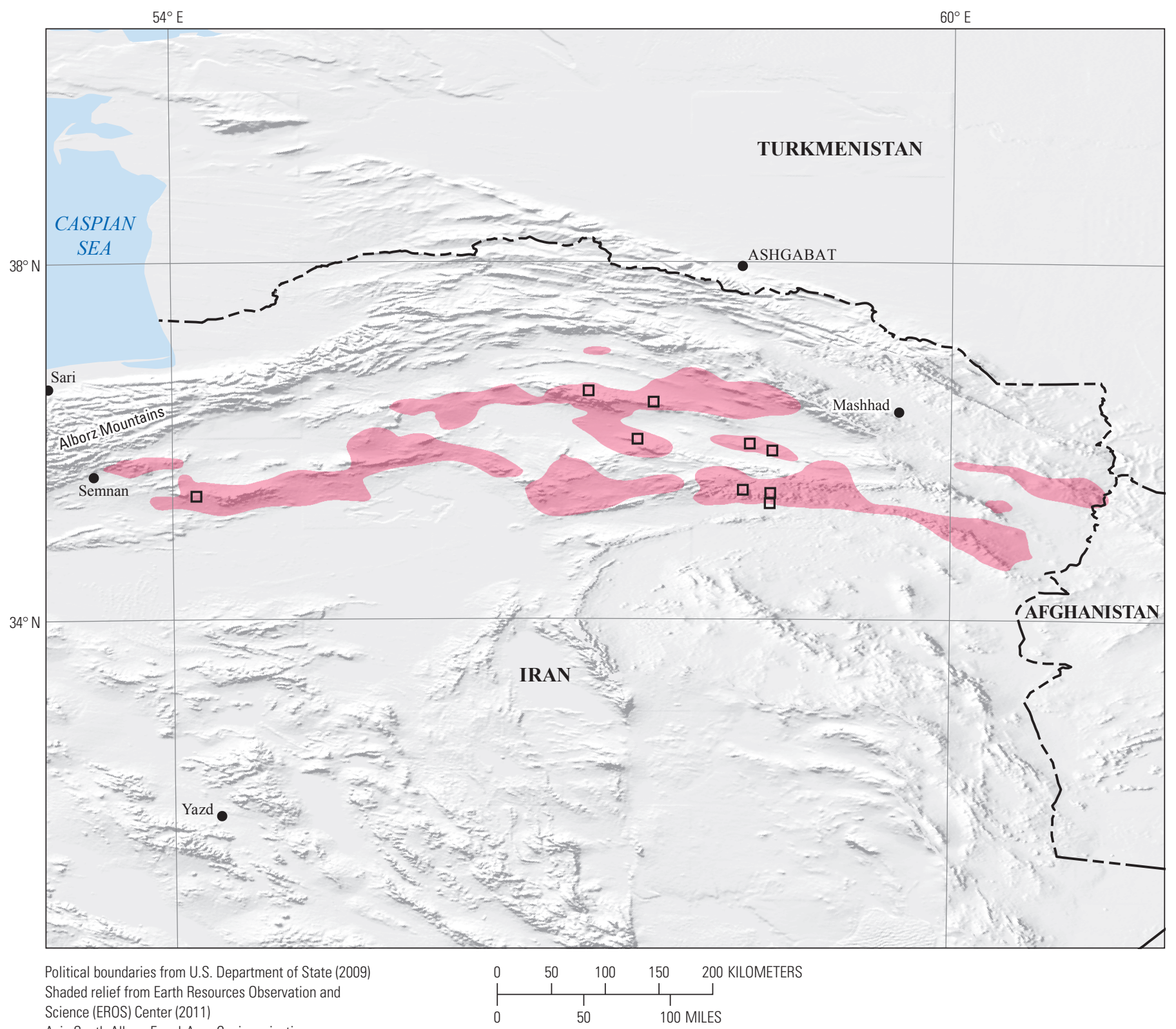

Asia South Albers Equal-Area Conic projection

Central meridian $57^{\circ} \mathrm{E}$.; latitude of origin $15^{\circ} \mathrm{S}$.

\section{EXPLANATION}

Assessed porphyry copper tract 142pCu9009

Porphyry copper prospect

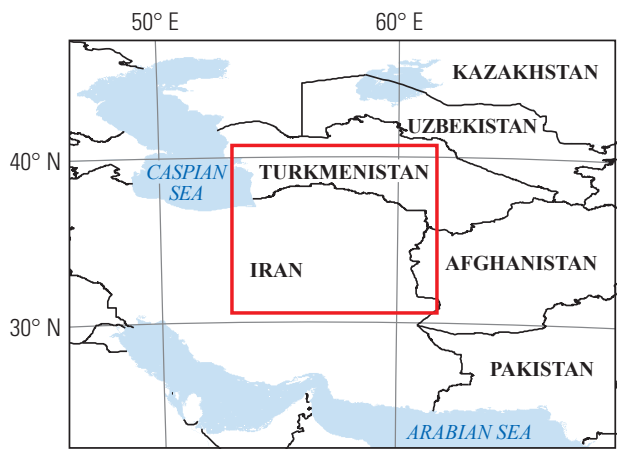




\section{Plate 150. Porphyry Copper Assessment for Tract 142pCu9016, Kerman-Iran}

Descriptive model:

Grade and tonnage model:

Economic filter depth percentages:

Economic filter cost setting:

Geologic feature assessed:

Number of known deposits:
Porphyry copper models (Cox, 1986a; Berger and others, 2008; John and others, 2010)

General porphyry copper model (Singer, Berger, and Moring, 2008)

Default -0 to 250 meters (m), $25 \%$; $>250$ to $500 \mathrm{~m}, 25 \%$; $>500 \mathrm{~m}$ to $1 \mathrm{~km}, 50 \%$

Typical cost

Late Eocene to early Pliocene continental to syn-collisional arc of the Tethyan metallogenic belt 12

\section{Selected Resource Assessment Results for Porphyry Copper}

[Assessment depth, 1 kilometer $(\mathrm{km}) ; \mathrm{km}^{2}$, square kilometer; Mt, millions of metric tons]

\begin{tabular}{ccccccc}
\hline $\begin{array}{c}\text { Date of } \\
\text { assessment }\end{array}$ & $\begin{array}{c}\text { Tract area } \\
\left(\mathbf{k m}^{2}\right)\end{array}$ & $\begin{array}{c}\text { Identified } \\
\text { copper } \\
\text { resources } \\
(\mathbf{M t})\end{array}$ & $\begin{array}{c}\text { Mean estimate of } \\
\text { in-place resources } \\
(\mathbf{M t})\end{array}$ & $\begin{array}{c}\text { Probability of } \mathbf{0} \\
\text { in-place resources } \\
\text { (percent) }\end{array}$ & $\begin{array}{c}\text { Mean estimate of } \\
\text { economic resources } \\
\text { (Mt) }\end{array}$ & $\begin{array}{c}\text { Probability of } \mathbf{0} \\
\text { economic resources } \\
\text { (percent) }\end{array}$ \\
\hline 2012 & 32,800 & 15 & 22 & 3 & 15 \\
\hline
\end{tabular}

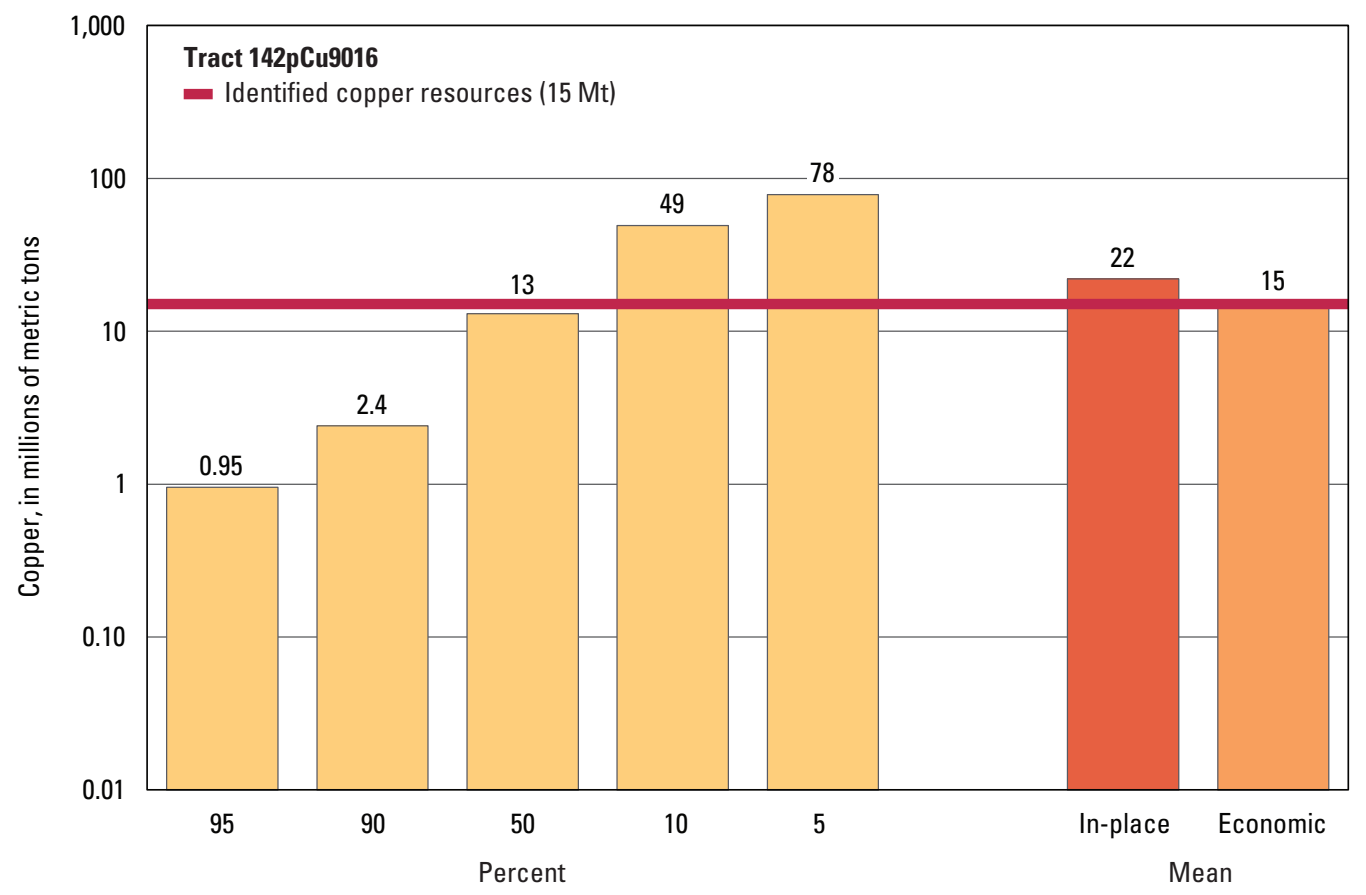

Graph showing the estimated probability distribution of undiscovered copper resources, where each bar represents the minimum amount estimated at the indicated percentage.

\section{Source}

Zürcher and others, 2015, Porphyry copper assessment of the Tethys region of western and southern Asia: U.S. Geological Survey Scientific Investigations Report 2010-5090-V, http://dx.doi.org/10.3133/sir20105090V. 


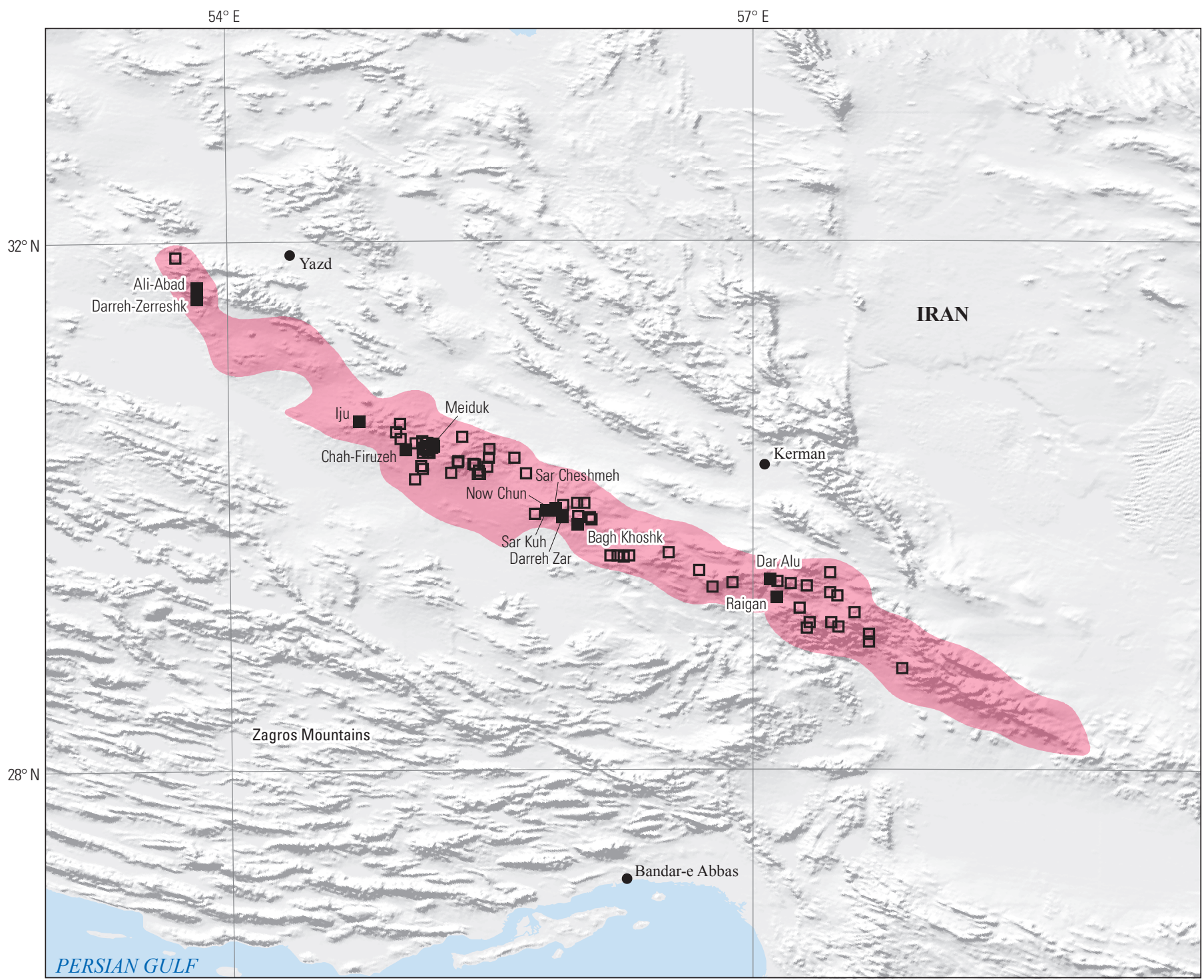

Political boundaries from U.S. Department of State (2009) Shaded relief from Earth Resources Observation and Science (EROS) Center (2011)

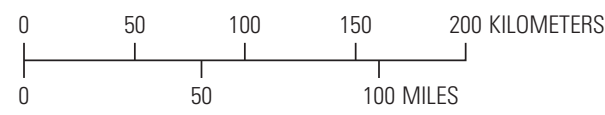

Asia South Albers Equal-Area Conic projection Central meridian $57^{\circ} \mathrm{E}$.; latitude of origin $15^{\circ} \mathrm{S}$.

\section{EXPLANATION}

Assessed porphyry copper tract 142pCu9016

- Porphyry copper deposit

ㅁ Porphyry copper prospect

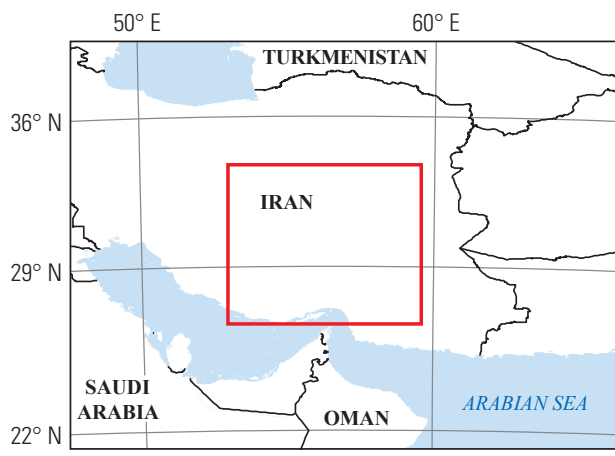




\section{Plate 151. Porphyry Copper Assessment for Tract 142pCu9015, Yazd—Iran}

Descriptive model:

Grade and tonnage model:

Economic filter depth percentages:

Economic filter cost setting:

Geologic feature assessed:

Number of known deposits:
Porphyry copper models (Cox, 1986a; Berger and others, 2008; John and others, 2010)

General porphyry copper model (Singer, Berger, and Moring, 2008)

Default -0 to 250 meters (m), $25 \%$; $>250$ to $500 \mathrm{~m}, 25 \%$; $>500 \mathrm{~m}$ to $1 \mathrm{~km}, 50 \%$

Typical cost

Middle Eocene to middle Miocene back-arc and continental-arc rocks of the Tethyan metallogenic belt

2

\section{Selected Resource Assessment Results for Porphyry Copper}

[Assessment depth, 1 kilometer $(\mathrm{km}) ; \mathrm{km}^{2}$, square kilometer; Mt, millions of metric tons]

\begin{tabular}{ccccccc}
\hline \multirow{2}{*}{$\begin{array}{c}\text { Date of } \\
\text { assessment }\end{array}$} & $\begin{array}{c}\text { Tract area } \\
\left(\mathbf{k m}^{2}\right)\end{array}$ & $\begin{array}{c}\text { Identified } \\
\text { copper } \\
\text { resources } \\
(\mathbf{M t})\end{array}$ & $\begin{array}{c}\text { Mean estimate of } \\
\text { in-place resources } \\
(\mathbf{M t})\end{array}$ & $\begin{array}{c}\text { Probability of } \mathbf{0} \\
\text { in-place resources } \\
\text { (percent) }\end{array}$ & $\begin{array}{c}\text { Mean estimate of } \\
\text { economic resources } \\
\text { (Mt) }\end{array}$ & $\begin{array}{c}\text { Probability of 0 } \\
\text { economic resources } \\
\text { (percent) }\end{array}$ \\
\hline 2012 & 25,711 & 0.27 & 13 & 6 & 8.7 \\
\hline
\end{tabular}

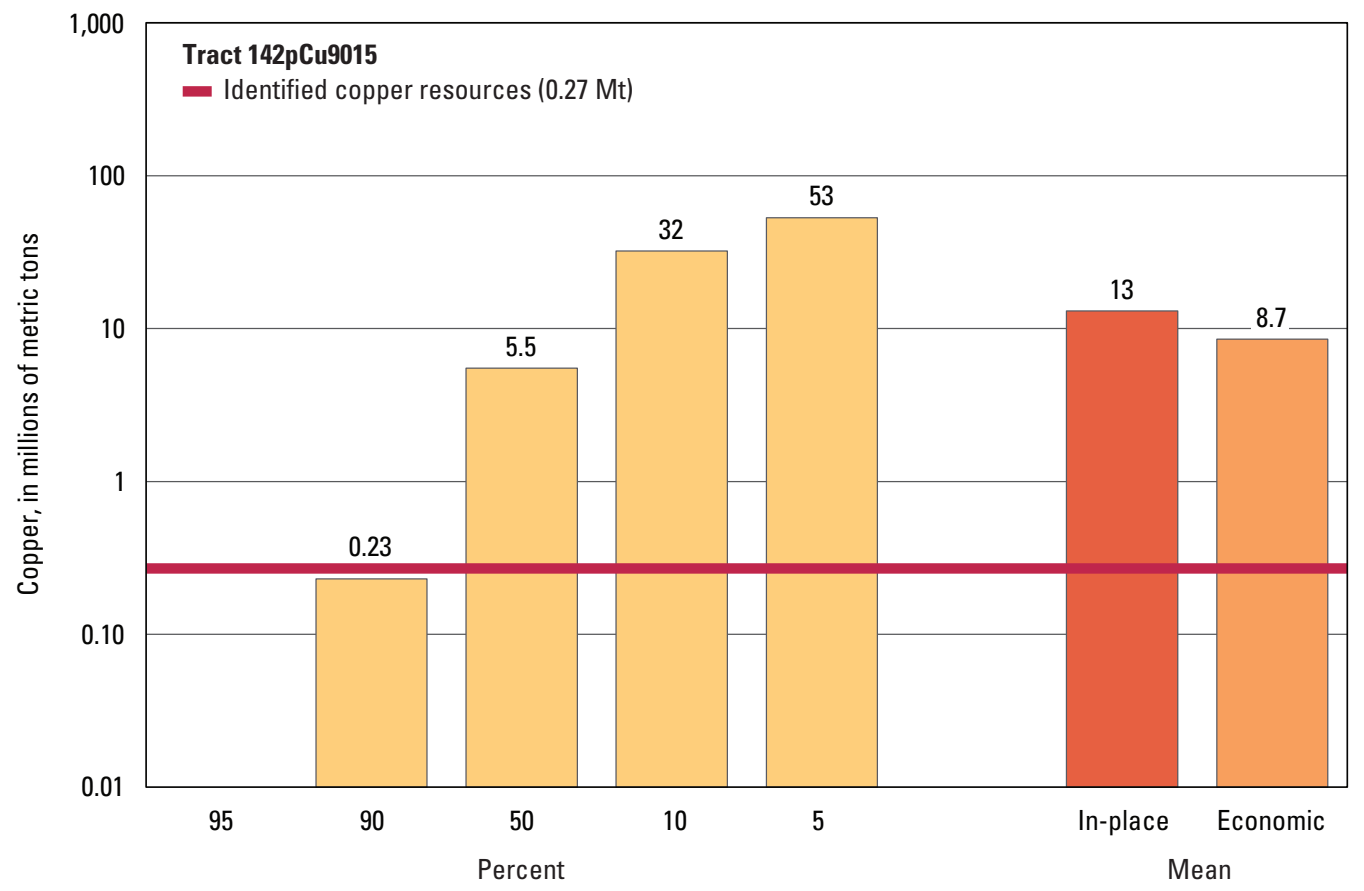

Graph showing the estimated probability distribution of undiscovered copper resources, where each bar represents the minimum amount estimated at the indicated percentage.

\section{Source}

Zürcher and others, 2015, Porphyry copper assessment of the Tethys region of western and southern Asia: U.S. Geological Survey Scientific Investigations Report 2010-5090-V, http://dx.doi.org/10.3133/sir20105090V. 


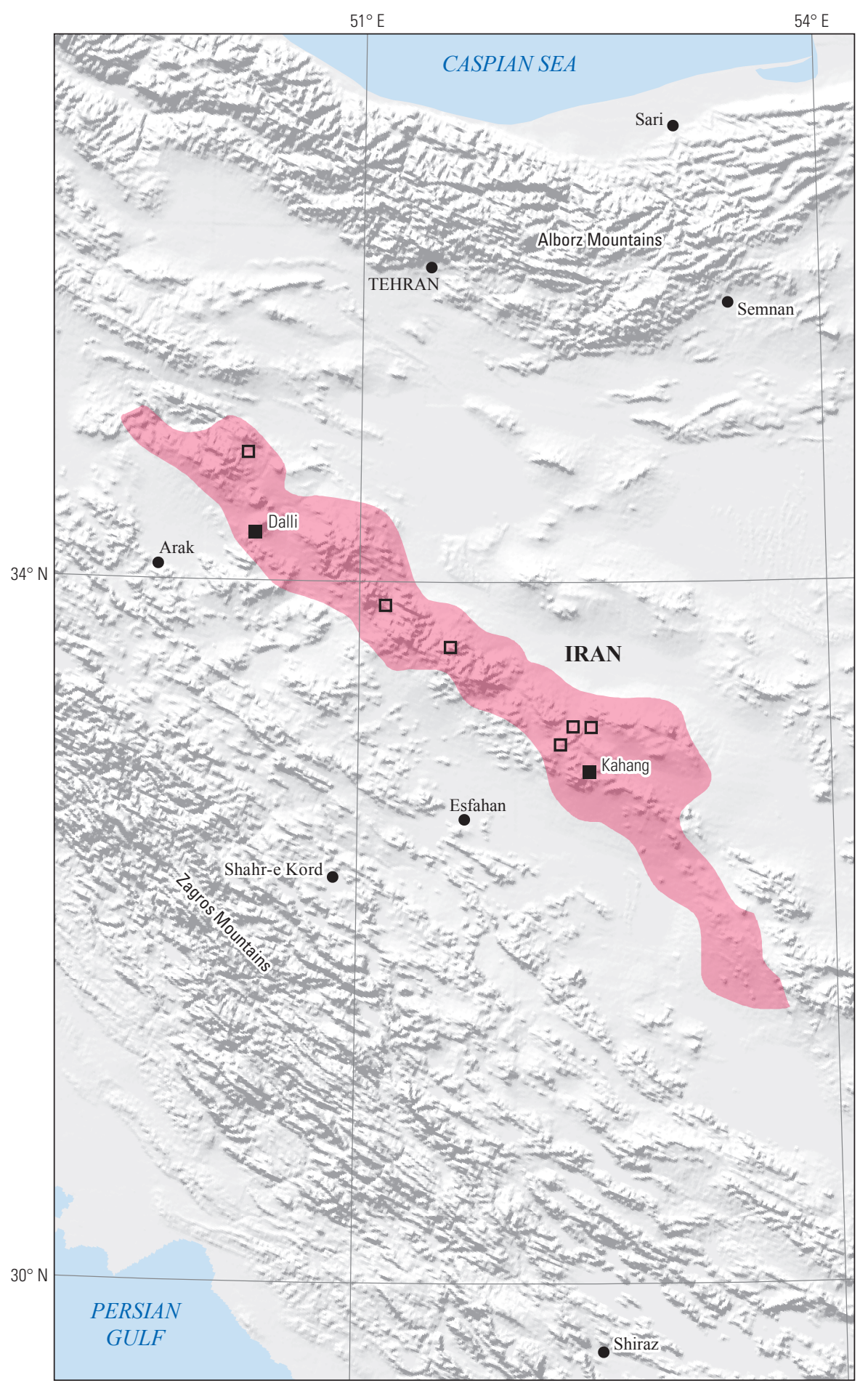

Political boundaries from U.S. Department of State (2009) Shaded relief from Earth Resources Observation and Science (EROS) Center (2011)

Europe Albers Equal-Area Conic projection

Central meridian $52^{\circ} \mathrm{E}$.; latitude of origin $30^{\circ} \mathrm{N}$.

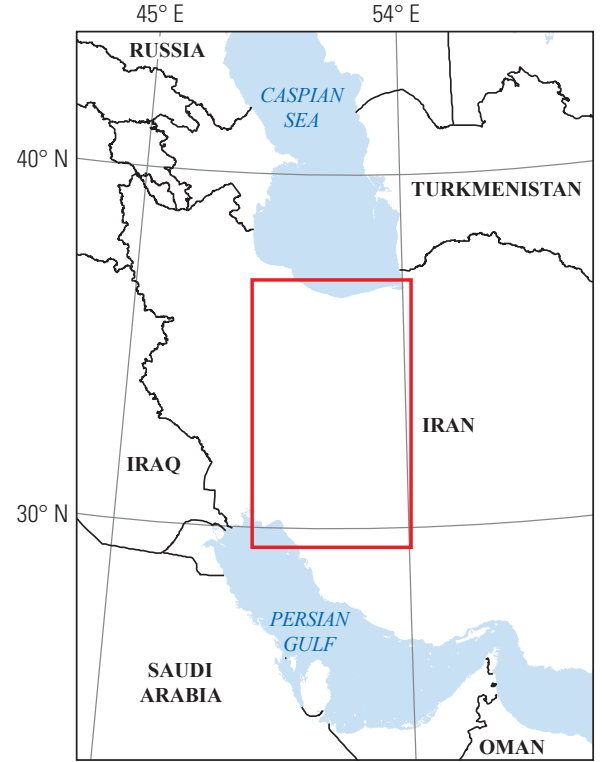

\section{EXPLANATION}

- Assessed porphyry copper tract 142pCu9015

- Porphyry copper deposit

Porphyry copper prospect 


\section{Plate 152. Porphyry Copper Assessment for Tract 142pCu9008, Esfahan-Iran, Iraq, and Turkey}

Descriptive model:

Grade and tonnage model:

Economic filter depth percentages:

Economic filter cost setting:

Geologic feature assessed:

Number of known deposits:
Porphyry copper models (Cox, 1986a; Berger and others, 2008; John and others, 2010)

General porphyry copper model (Singer, Berger, and Moring, 2008)

Default -0 to 250 meters (m), $25 \% ;>250$ to $500 \mathrm{~m}, 25 \%$; $>500 \mathrm{~m}$ to $1 \mathrm{~km}, 50 \%$

Typical cost

Late Paleocene to middle-late Eocene back-arc rocks of the Tethyan metallogenic belt 1

\section{Selected Resource Assessment Results for Porphyry Copper}

[Assessment depth, 1 kilometer $(\mathrm{km})$; $\mathrm{km}^{2}$, square kilometer; $\mathrm{Mt}$, millions of metric tons]

\begin{tabular}{|c|c|c|c|c|c|c|}
\hline \multirow[b]{2}{*}{$\begin{array}{c}\text { Date of } \\
\text { assessment }\end{array}$} & \multirow[b]{2}{*}{$\begin{array}{c}\text { Tract area } \\
\quad\left(\mathrm{km}^{2}\right)\end{array}$} & \multirow{2}{*}{$\begin{array}{l}\text { Identified } \\
\text { copper } \\
\text { resources } \\
\text { (Mt) }\end{array}$} & \multicolumn{4}{|c|}{ Undiscovered copper resource estimates } \\
\hline & & & $\begin{array}{l}\text { Mean estimate of } \\
\text { in-place resources } \\
\text { (Mt) }\end{array}$ & $\begin{array}{c}\text { Probability of } 0 \\
\text { in-place resources } \\
\text { (percent) }\end{array}$ & $\begin{array}{l}\text { Mean estimate of } \\
\text { economic resources } \\
\text { (Mt) }\end{array}$ & $\begin{array}{c}\text { Probability of } 0 \\
\text { economic resources } \\
\text { (percent) }\end{array}$ \\
\hline 2013 & 56,857 & 0.64 & 15 & 20 & 10 & 37 \\
\hline
\end{tabular}

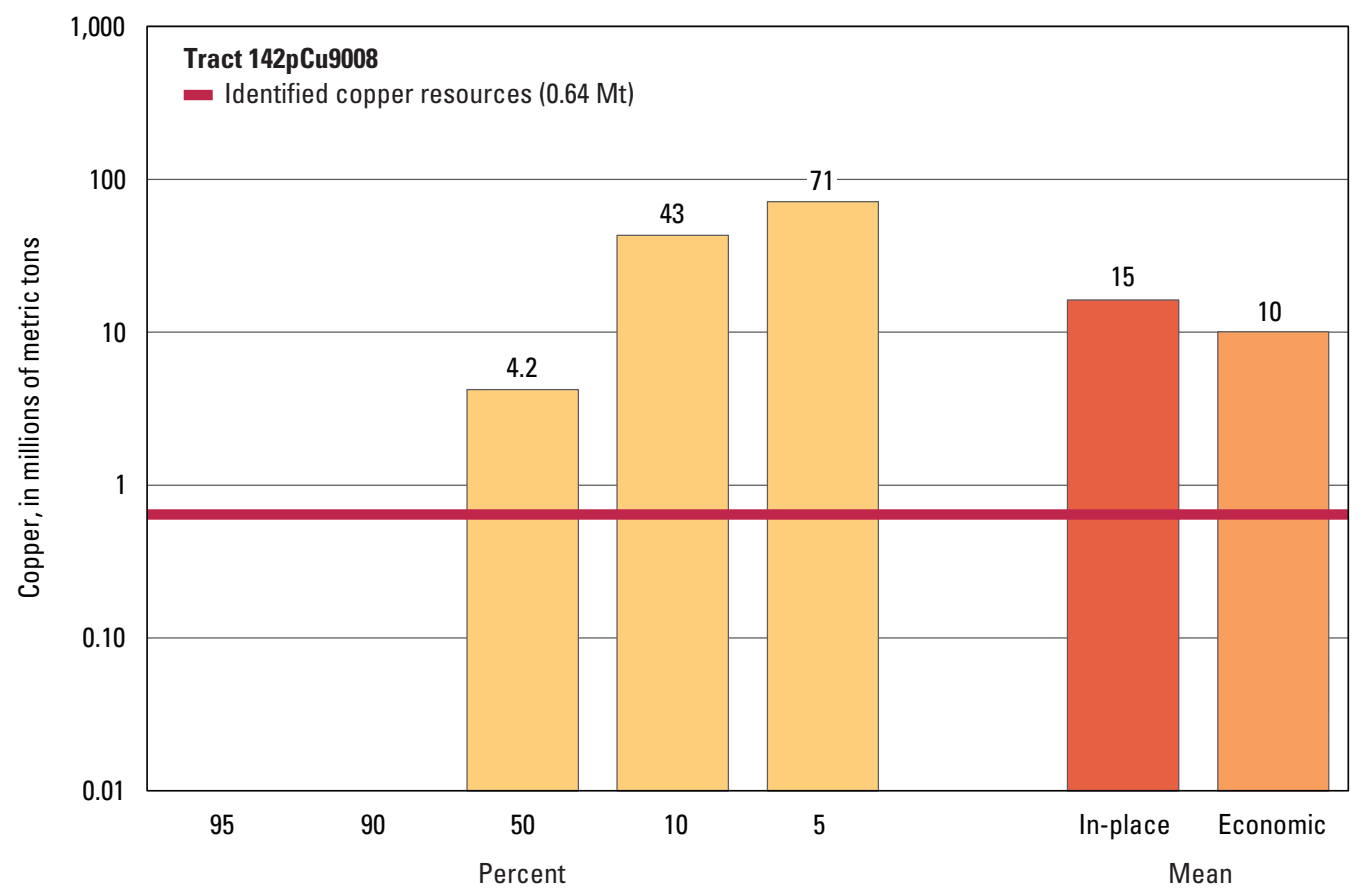

Graph showing the estimated probability distribution of undiscovered copper resources, where each bar represents the minimum amount estimated at the indicated percentage.

\section{Source}

Zürcher and others, 2015, Porphyry copper assessment of the Tethys region of western and southern Asia: U.S. Geological Survey Scientific Investigations Report 2010-5090-V, http://dx.doi.org/10.3133/sir20105090V. 


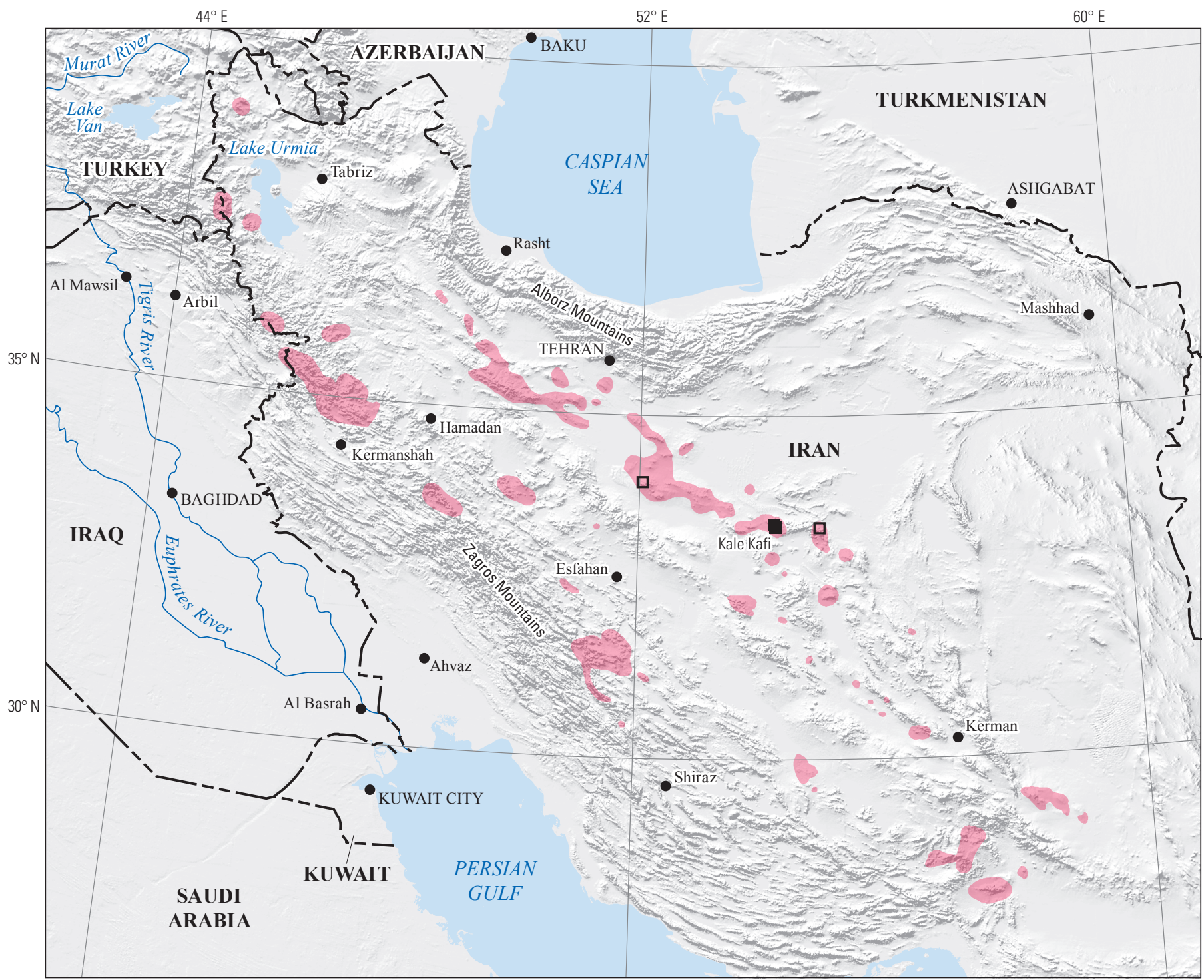

Political boundaries from U.S. Department of State (2009) Shaded relief from Earth Resources Observation and Science (EROS) Center (2011)

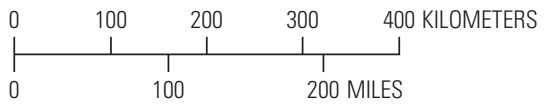

Europe Albers Equal-Area Conic projection

Central meridian $54^{\circ} \mathrm{E}$.; latitude of origin $30^{\circ} \mathrm{N}$.

EXPLANATION

Assessed porphyry copper tract 142pCu9008

- Porphyry copper deposit

ㅁ Porphyry copper prospect

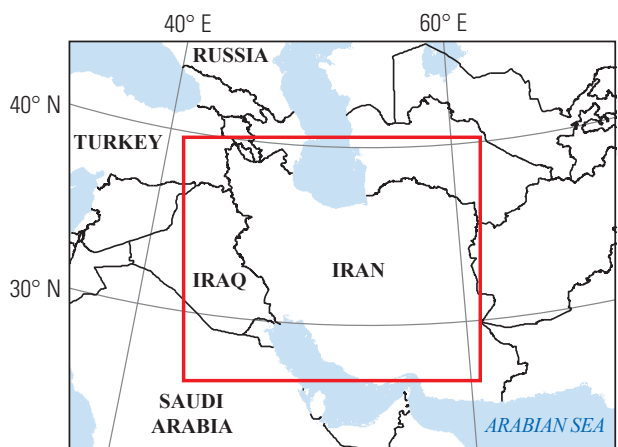




\section{Plate 153. Porphyry Copper Assessment for Tract 142pCu9014c, Azerbaijan (Caucasus)—Iran, Azerbaijan, and Armenia}

\section{Descriptive model:}

Grade and tonnage model:

Economic filter depth percentages:

Economic filter cost setting:

Geologic feature assessed:

Number of known deposits:

\author{
Porphyry copper models (Cox, 1986a; Berger and others, 2008; John and others, 2010) \\ General porphyry copper model (Singer, Berger, and Moring, 2008) \\ Default -0 to 250 meters (m), 25\%; > 250 to $500 \mathrm{~m}, 25 \%$; >500 m to $1 \mathrm{~km}, 50 \%$ \\ Typical cost \\ Late Eocene to early Miocene postcollisional magmatism of the Tethyan metallogenic belt \\ 5
}

\section{Selected Resource Assessment Results for Porphyry Copper}

[Assessment depth, 1 kilometer $(\mathrm{km})$; $\mathrm{km}^{2}$, square kilometer; $\mathrm{Mt}$, millions of metric tons]

\begin{tabular}{|c|c|c|c|c|c|c|}
\hline \multirow[b]{2}{*}{$\begin{array}{c}\text { Date of } \\
\text { assessment }\end{array}$} & \multirow[b]{2}{*}{$\begin{array}{c}\text { Tract area } \\
\quad\left(\mathrm{km}^{2}\right)\end{array}$} & \multirow{2}{*}{$\begin{array}{l}\text { Identified } \\
\text { copper } \\
\text { resources } \\
\text { (Mt) }\end{array}$} & \multicolumn{4}{|c|}{ Undiscovered copper resource estimates } \\
\hline & & & $\begin{array}{l}\text { Mean estimate of } \\
\text { in-place resources } \\
\text { (Mt) }\end{array}$ & $\begin{array}{c}\text { Probability of } 0 \\
\text { in-place resources } \\
\text { (percent) }\end{array}$ & $\begin{array}{l}\text { Mean estimate of } \\
\text { economic resources } \\
\text { (Mt) }\end{array}$ & $\begin{array}{c}\text { Probability of } 0 \\
\text { economic resources } \\
\text { (percent) }\end{array}$ \\
\hline 2012 & 58,270 & 11 & 27 & 7 & 18 & 13 \\
\hline
\end{tabular}

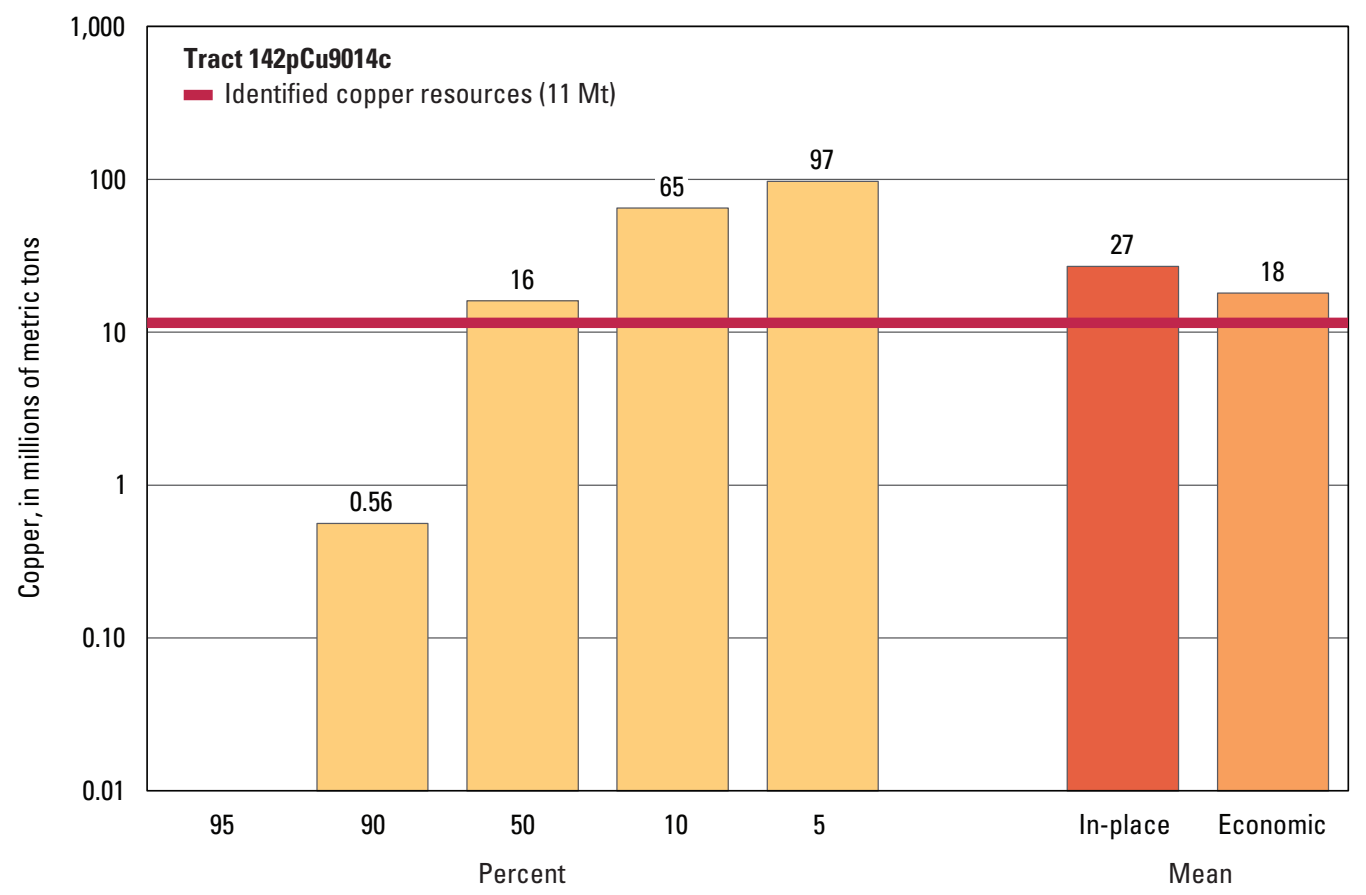

Graph showing the estimated probability distribution of undiscovered copper resources, where each bar represents the minimum amount estimated at the indicated percentage.

\section{Source}

Zürcher and others, 2015, Porphyry copper assessment of the Tethys region of western and southern Asia: U.S. Geological Survey Scientific Investigations Report 2010-5090-V, http://dx.doi.org/10.3133/sir20105090V. 


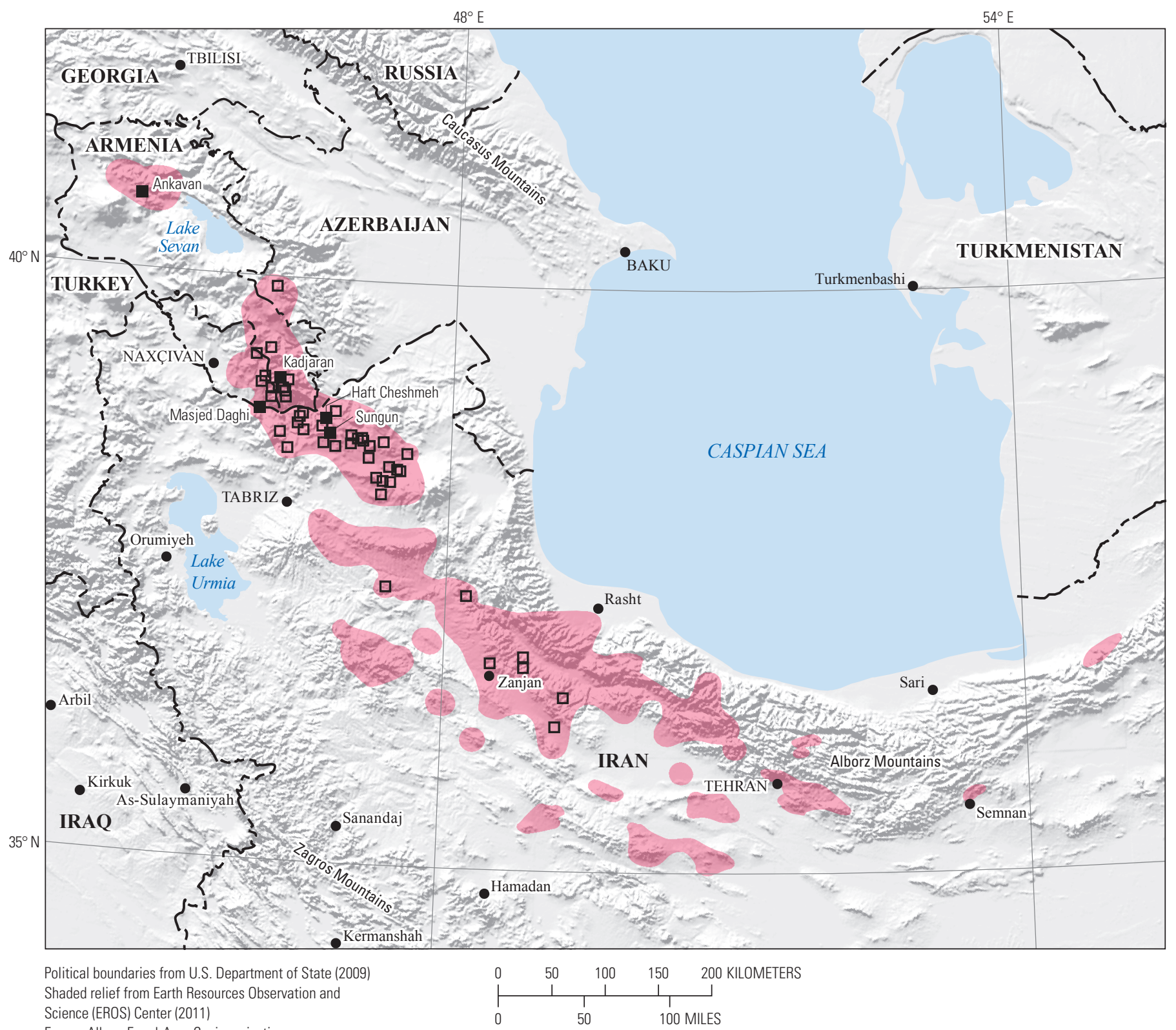

Europe Albers Equal-Area Conic projection

Central meridian $51^{\circ} \mathrm{E}$.; latitude of origin $30^{\circ} \mathrm{N}$.

EXPLANATION

Assessed porphyry copper tract 142pCu9014c

- Porphyry copper deposit

ㅁ Porphyry copper prospect

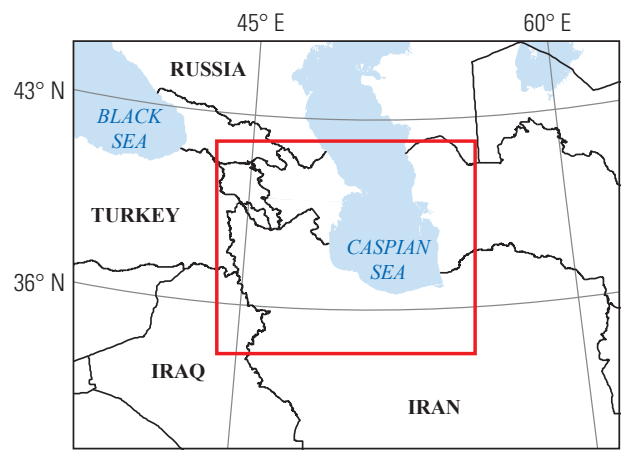




\section{Plate 154. Porphyry Copper Assessment for Tract 142pCu9003, Sanandaj- Sirjan-Iran, Iraq, and Turkey}

\author{
Descriptive model: \\ Grade and tonnage model: \\ Economic filter depth percentages: \\ Economic filter cost setting: \\ Geologic feature assessed: \\ Number of known deposits:
}

\author{
Porphyry copper models (Cox, 1986a; Berger and others, 2008; John and others, 2010) \\ NA \\ NA \\ NA \\ Late Triassic-Early Cretaceous continental-arc rocks of the Tethyan metallogenic belt \\ 0
}

\section{Selected Resource Assessment Results for Porphyry Copper}

[Assessment depth, 1 kilometer $(\mathrm{km})$; $\mathrm{km}^{2}$, square kilometer; Mt, millions of metric tons; NA, not applicable, as a quantitative assessment was not done]

\begin{tabular}{ccccccc}
\hline $\begin{array}{c}\text { Date of } \\
\text { assessment }\end{array}$ & $\begin{array}{c}\text { Tract area } \\
\left(\mathbf{k m}^{2}\right)\end{array}$ & $\begin{array}{c}\text { Identified } \\
\text { copper } \\
\text { resources } \\
(\mathbf{M t})\end{array}$ & $\begin{array}{c}\text { Mean estimate of } \\
\text { in-place resources } \\
(\mathbf{M t})\end{array}$ & $\begin{array}{c}\text { Probability of } \mathbf{0} \\
\text { in-place resources } \\
\text { (percent) }\end{array}$ & $\begin{array}{c}\text { Mean estimate of } \\
\text { economic resources } \\
\text { (Mt) }\end{array}$ & $\begin{array}{c}\text { Probability of 0 } \\
\text { economic resources } \\
\text { (percent) }\end{array}$ \\
\hline 2013 & 20,160 & 0 & NA & NA & NA \\
\hline
\end{tabular}

\section{Qualitative Assessment}

The long-lasting and mature continental-arc setting of tract 142pCu9003 (Sanandaj-Sirjan-Iran, Iraq, and Turkey) is permissive for the occurrence of porphyry copper deposits. However, factors that diminish the favorability include synmineralization and postmineralization deformation events that have highly exhumed this region, largely exposing metamorphosed rocks and deeper more evolved peraluminous plutons with tin and tungsten associations. Permissive Late Triassic to Early Cretaceous volcanic and plutonic units make up less than 10 percent of the tract area. Older basement underlies about 13 percent, broadly coeval nonpermissive rocks account for 25 percent, and younger rocks cover about 50 percent of the tract area. Even though one porphyry copper prospect is known, the low percentage of permissive units and high percentage of younger cover imply that levels of preservation are too deep and that the extent of younger cover is too extensive for porphyry systems to be exposed.

\section{Source}

Zürcher and others, 2015, Porphyry copper assessment of the Tethys region of western and southern Asia: U.S. Geological Survey Scientific Investigations Report 2010-5090-V, http://dx.doi.org/10.3133/sir20105090V. 


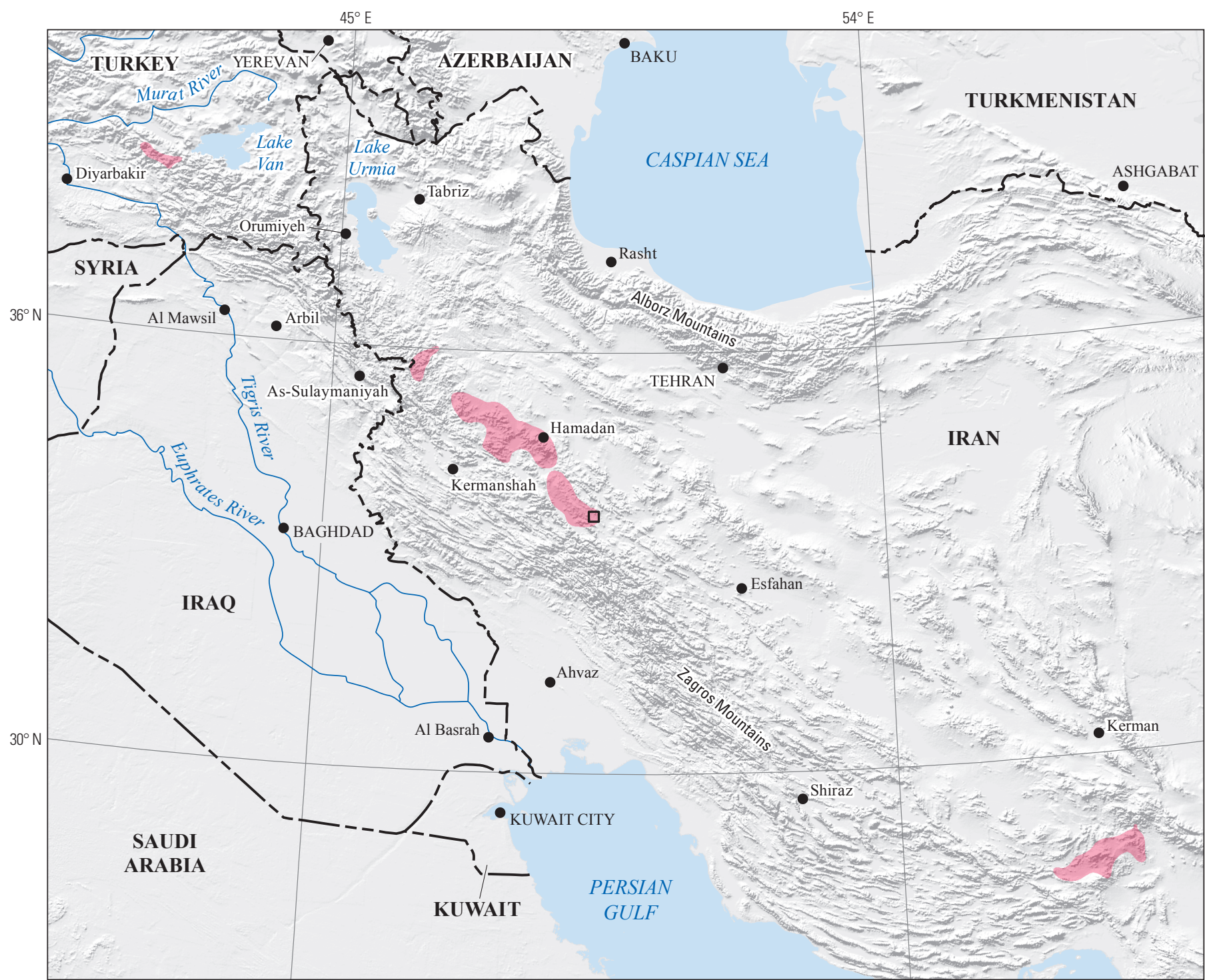

Political boundaries from U.S. Department of State (2009) Shaded relief from Earth Resources Observation and Science (EROS) Center (2011)

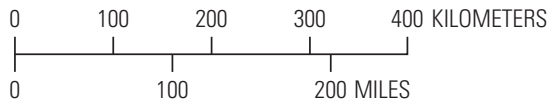

Europe Albers Equal-Area Conic projection

Central meridian $50^{\circ} \mathrm{E}$.; latitude of origin $30^{\circ} \mathrm{N}$.

\section{EXPLANATION}

\section{Assessed porphyry copper tract} 142pCu9003

Porphyry copper prospect

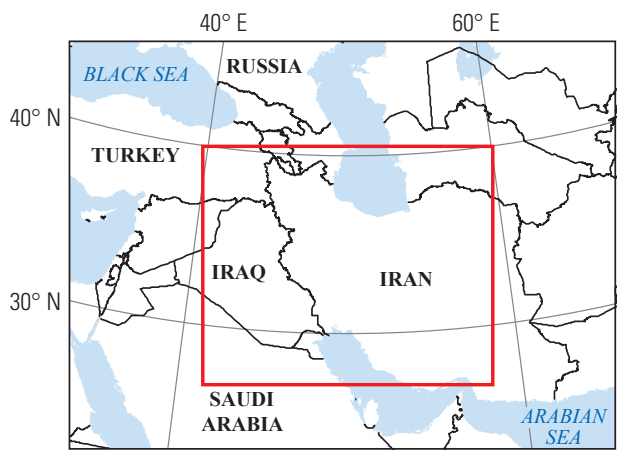




\title{
Plate 155. Porphyry Copper Assessment for Tract 142pCu9004c, Pontide (Asia)- Caucasus-Iran, Azerbaijan, Armenia, and Georgia
}

\author{
Descriptive model: \\ Grade and tonnage model: \\ Porphyry copper models (Cox, 1986a; Berger and others, 2008; John and others, 2010) \\ Economic filter depth percentages: \\ Economic filter cost setting: \\ Geologic feature assessed: \\ General porphyry copper model (Singer, Berger, and Moring, 2008) \\ Skewed deep-0 to 250 meters (m), 10\%; > 250 to $500 \mathrm{~m}, 30 \%$; >500 m to $1 \mathrm{~km}, 60 \%$ \\ Typical cost \\ Late Cretaceous to middle Eocene island-are to continental arc rocks and back-arc rocks of the \\ Tethyan metallogenic belt \\ Number of known deposits: \\ 0
}

\section{Selected Resource Assessment Results for Porphyry Copper}

[Assessment depth, 1 kilometer ( $\mathrm{km}) ; \mathrm{km}^{2}$, square kilometer; Mt, millions of metric tons]

\begin{tabular}{ccccccc}
\hline $\begin{array}{c}\text { Date of } \\
\text { assessment }\end{array}$ & $\begin{array}{c}\text { Tract area } \\
\left.\mathbf{( k m}^{2}\right)\end{array}$ & $\begin{array}{c}\text { Identified } \\
\text { copper } \\
\text { resources } \\
\text { (Mt) }\end{array}$ & $\begin{array}{c}\text { Mean estimate of } \\
\text { in-place resources } \\
(\mathbf{M t})\end{array}$ & $\begin{array}{c}\text { Probability of } \mathbf{0} \\
\text { in-place resources } \\
\text { (percent) }\end{array}$ & $\begin{array}{c}\text { Mean estimate of } \\
\text { economic resources } \\
\text { (Mt) }\end{array}$ & $\begin{array}{c}\text { Probability of 0 } \\
\text { economic resources } \\
\text { (percent) }\end{array}$ \\
\hline 2013 & 24,289 & 0 & 3.3 & 31 & 2.1 \\
\hline
\end{tabular}

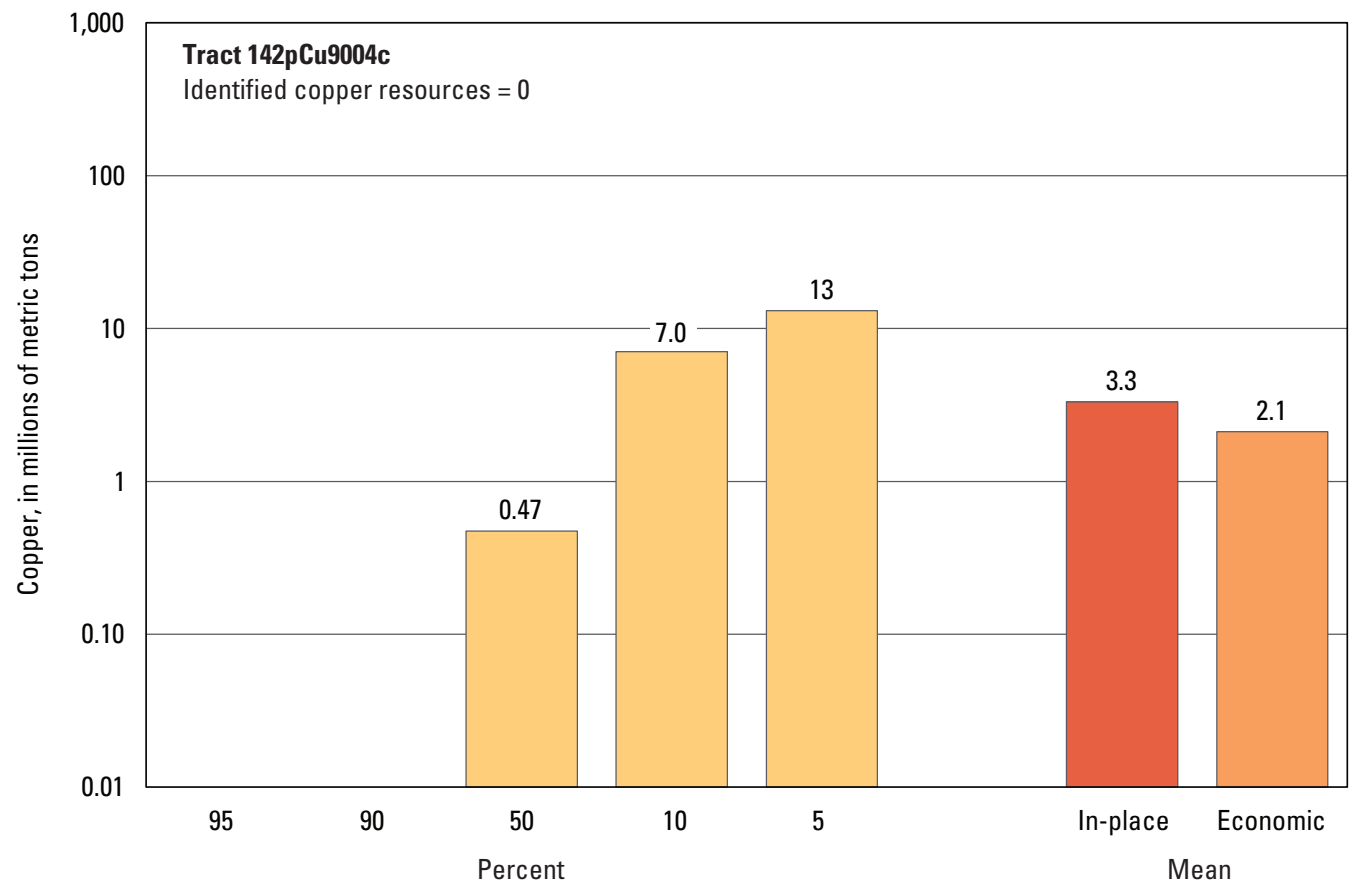

Graph showing the estimated probability distribution of undiscovered copper resources, where each bar represents the minimum amount estimated at the indicated percentage.

\section{Source}

Zürcher and others, 2015, Porphyry copper assessment of the Tethys region of western and southern Asia: U.S. Geological Survey Scientific Investigations Report 2010-5090-V, http://dx.doi.org/10.3133/sir20105090V. 


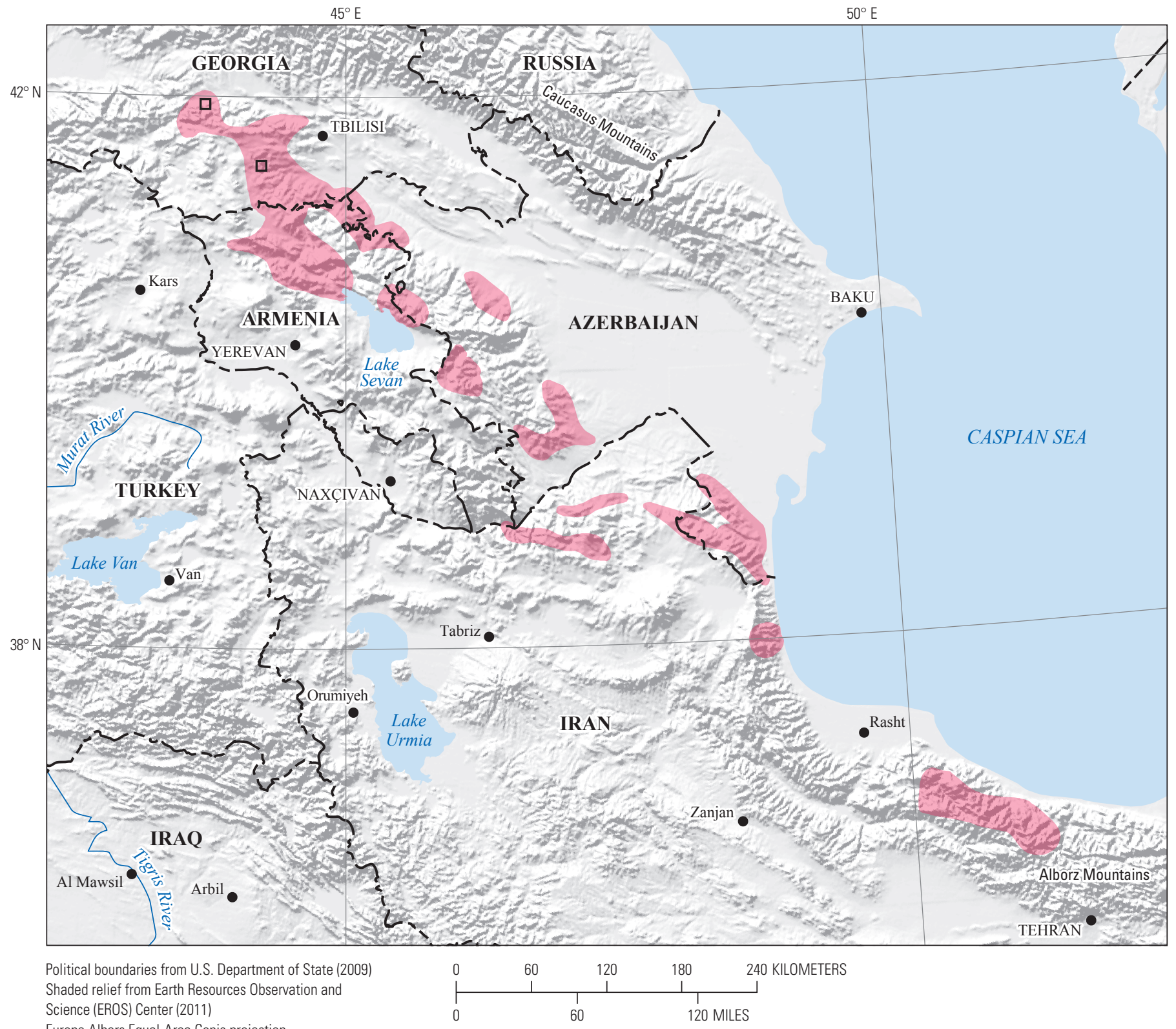

Europe Albers Equal-Area Conic projection

Central meridian $45^{\circ} \mathrm{E}$. ; latitude of origin $30^{\circ} \mathrm{N}$.

\section{EXPLANATION}

27. Assessed porphyry copper tract $142 \mathrm{pCu} 9004 \mathrm{c}$

ㅁ Porphyry copper prospect

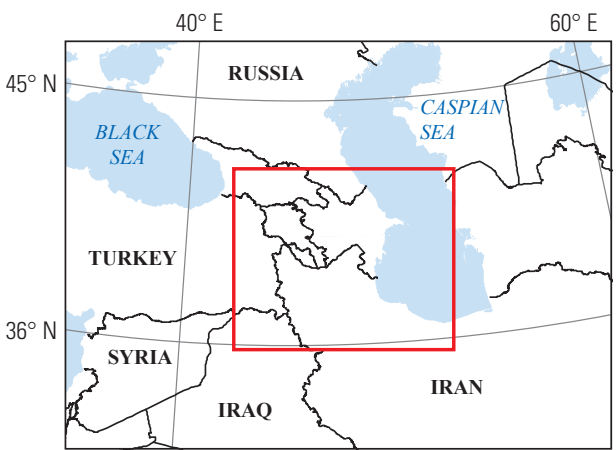




\title{
Plate 156. Porphyry Copper Assessment for Tract 142pCu9001, Cimmeride Lesser Caucasus-Armenia, Azerbaijan, Georgia, and Iran
}

\author{
Descriptive model: \\ Grade and tonnage model: \\ Porphyry copper models (Cox, 1986a; Berger and others, 2008; John and others, 2010) \\ Economic filter depth percentages: \\ Economic filter cost setting: \\ Geologic feature assessed: \\ Number of known deposits: \\ General porphyry copper model (Singer, Berger, and Moring, 2008) \\ Custom - 0 to 250 meters (m), 17\%; >250 to $500 \mathrm{~m}, 28 \%$; >500 m to $1 \mathrm{~km}, 55 \%$ \\ Typical cost \\ Middle Jurassic to Early Cretaceous island-arc to continental-arc rocks of the Tethyan metallogenic \\ belt \\ 3
}

\section{Selected Resource Assessment Results for Porphyry Copper}

[Assessment depth, 1 kilometer ( $\mathrm{km}) ; \mathrm{km}^{2}$, square kilometer; Mt, millions of metric tons]

\begin{tabular}{ccccccc}
\hline $\begin{array}{c}\text { Date of } \\
\text { assessment }\end{array}$ & $\begin{array}{c}\text { Tract area } \\
\left(\mathbf{k m}^{2}\right)\end{array}$ & $\begin{array}{c}\text { Identified } \\
\text { copper } \\
\text { resources } \\
(\mathbf{M t})\end{array}$ & $\begin{array}{c}\text { Mean estimate of } \\
\text { in-place resources } \\
(\mathbf{M t})\end{array}$ & $\begin{array}{c}\text { Probability of } \mathbf{0} \\
\text { in-place resources } \\
\text { (percent) }\end{array}$ & $\begin{array}{c}\text { Mean estimate of } \\
\text { economic resources } \\
\text { (Mt) }\end{array}$ & $\begin{array}{c}\text { Probability of 0 } \\
\text { economic resources } \\
\text { (percent) }\end{array}$ \\
\hline 2012 & 17,369 & 2.3 & 7.1 & 19 & 4.7 \\
\hline
\end{tabular}

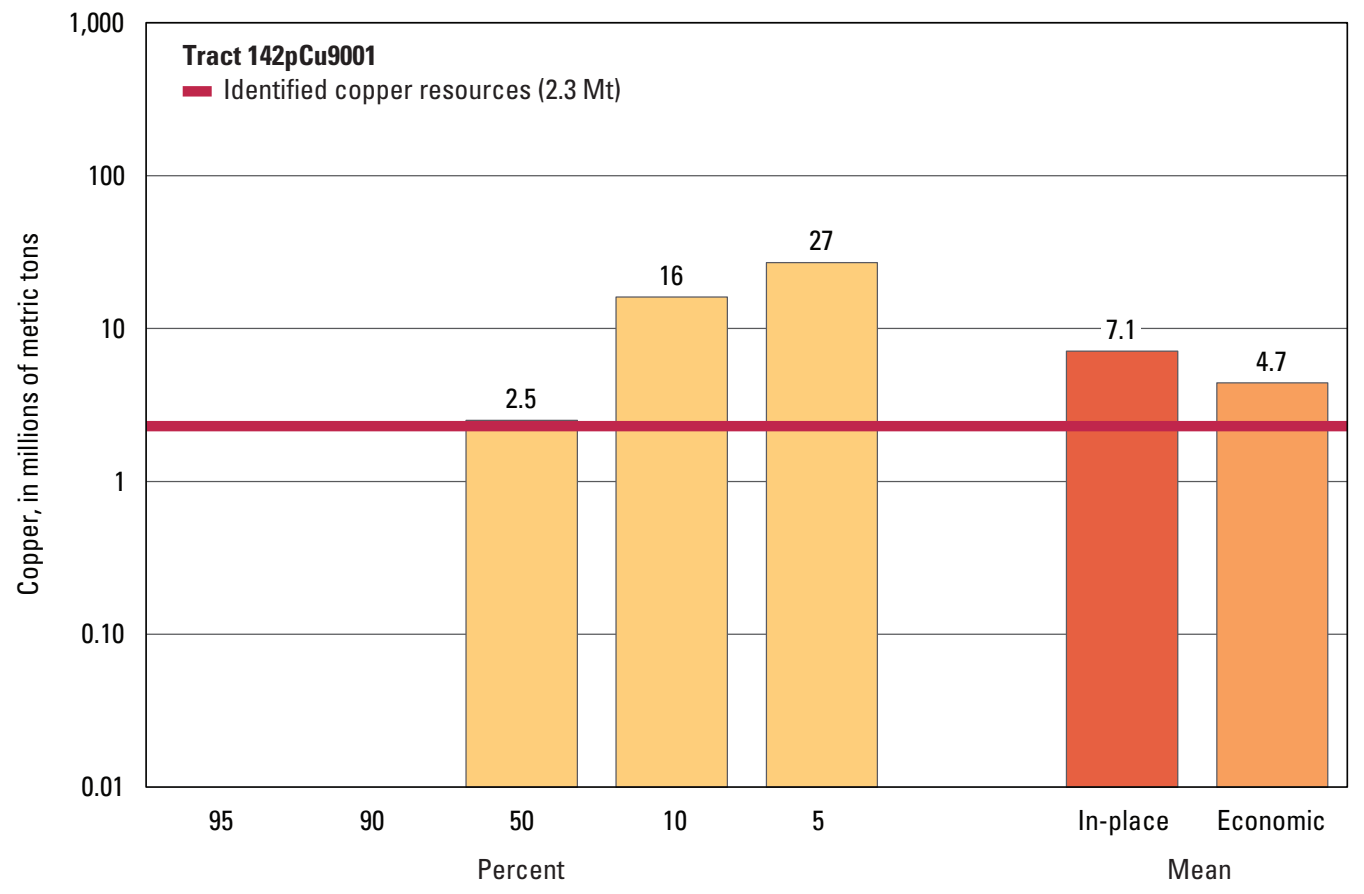

Graph showing the estimated probability distribution of undiscovered copper resources, where each bar represents the minimum amount estimated at the indicated percentage.

\section{Source}

Zürcher and others, 2015, Porphyry copper assessment of the Tethys region of western and southern Asia: U.S. Geological Survey Scientific Investigations Report 2010-5090-V, http://dx.doi.org/10.3133/sir20105090V. 


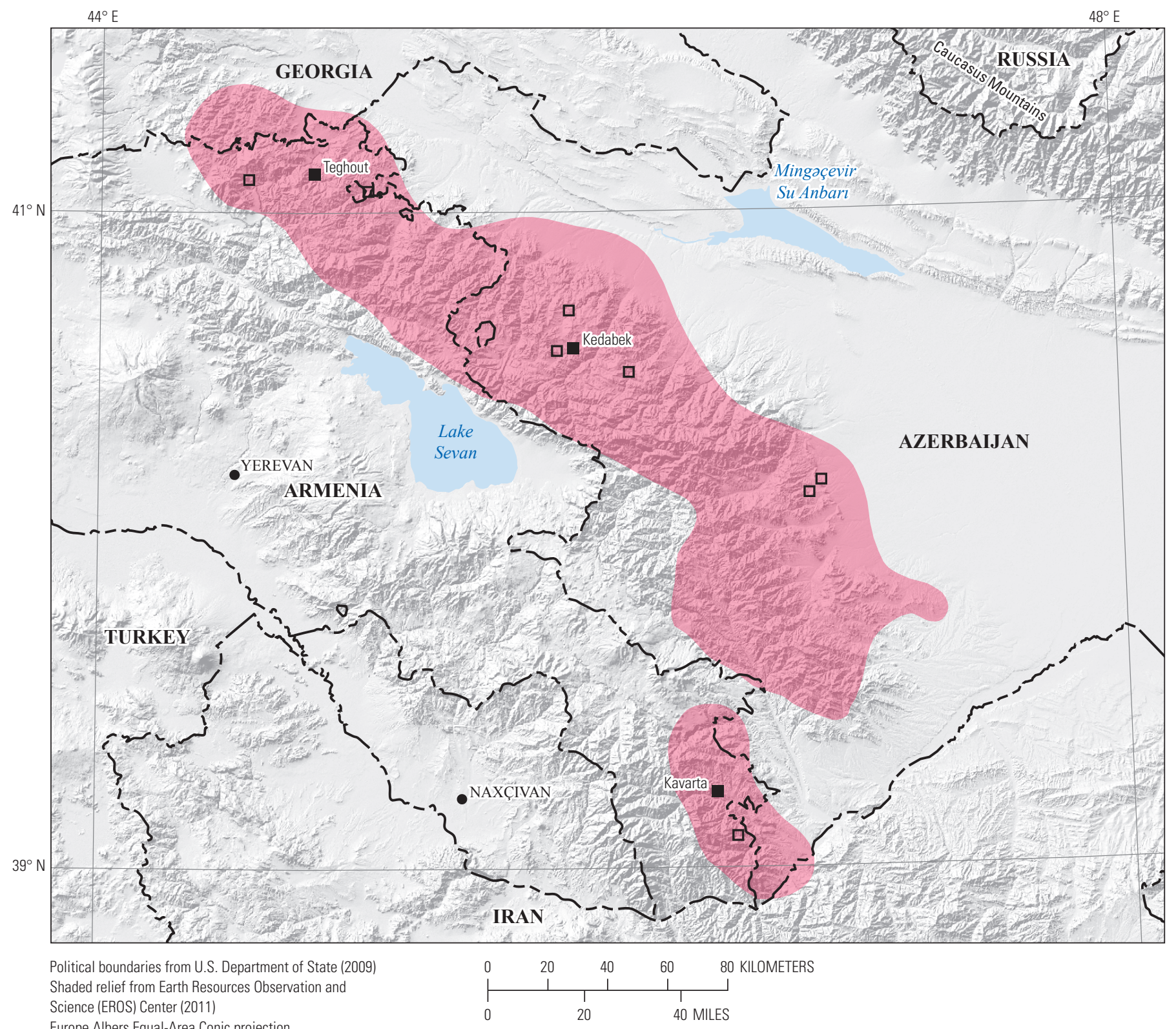

Europe Albers Equal-Area Conic projection

Central meridian $45^{\circ} \mathrm{E}$.; latitude of origin $30^{\circ} \mathrm{N}$.

\section{EXPLANATION}

Assessed porphyry copper tract 142pCu9001

- Porphyry copper deposit

Porphyry copper prospect

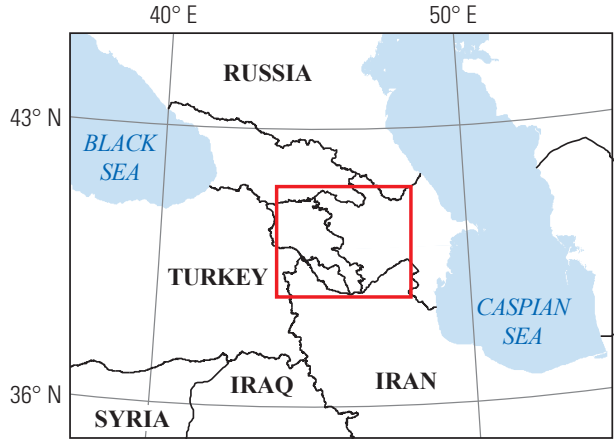




\title{
Plate 157. Porphyry Copper Assessment for Tract 142pCu9002, Cimmeride Greater Caucasus-Azerbaijan, Georgia, and Russia
}

\author{
Descriptive model: \\ Porphyry copper models (Cox, 1986a; Berger and others, 2008; John and others, 2010) \\ Grade and tonnage model: \\ NA \\ Economic filter depth percentages: \\ NA \\ Economic filter cost setting: \\ NA \\ Geologic feature assessed: \\ Middle Jurassic back-arc and island-arc rocks of the Tethyan metallogenic belt \\ Number of known deposits: \\ 0
}

\section{Selected Resource Assessment Results for Porphyry Copper}

[Assessment depth, 1 kilometer $(\mathrm{km})$; $\mathrm{km}^{2}$, square kilometer; Mt, millions of metric tons; NA, not applicable, as a quantitative assessment was not done]

\begin{tabular}{ccccccc}
\hline \multirow{2}{*}{$\begin{array}{c}\text { Date of } \\
\text { assessment }\end{array}$} & $\begin{array}{c}\text { Tract area } \\
\left(\mathbf{k m}^{2}\right)\end{array}$ & $\begin{array}{c}\text { Identified } \\
\text { copper } \\
\text { resources } \\
(\mathbf{M t})\end{array}$ & $\begin{array}{c}\text { Mean estimate of } \\
\text { in-place resources } \\
(\mathbf{M t})\end{array}$ & $\begin{array}{c}\text { Probability of } \mathbf{0} \\
\text { in-place resources } \\
\text { (percent) }\end{array}$ & $\begin{array}{c}\text { Mean estimate of } \\
\text { economic resources } \\
\text { (Mt) }\end{array}$ & $\begin{array}{c}\text { Probability of 0 } \\
\text { economic resources } \\
\text { (percent) }\end{array}$ \\
\hline 2013 & 16,688 & 0 & NA & NA & NA \\
\hline
\end{tabular}

\section{Qualitative Assessment}

The back-arc and island-arc setting of tract 142pCu9002 (Cimmeride Greater Caucasus-Azerbaijan, Georgia, and Russia) is permissive for porphyry copper deposits, despite the fact that no porphyry-related systems are known. The very high ratio of areas of permissive Middle Jurassic volcanic units to volcanic and plutonic rocks (\{volcanic/[volcanic + plutonic $]\}=91)$ in this complex fold-and-thrust belt implies that any porphyry copper systems may largely be concealed. The absence of known porphyry-related occurrences further suggests that the region may have experienced limited exploration for this type of deposit, adding considerable uncertainty. Despite the permissive geology, the assessment team concluded that favorability was too low to add significant undiscovered copper resources to the overall assessment (less than a 10-percent chance of one undiscovered deposit).

\section{Source}

Zürcher and others, 2015, Porphyry copper assessment of the Tethys region of western and southern Asia: U.S. Geological Survey Scientific Investigations Report 2010-5090-V, http://dx.doi.org/10.3133/sir20105090V. 


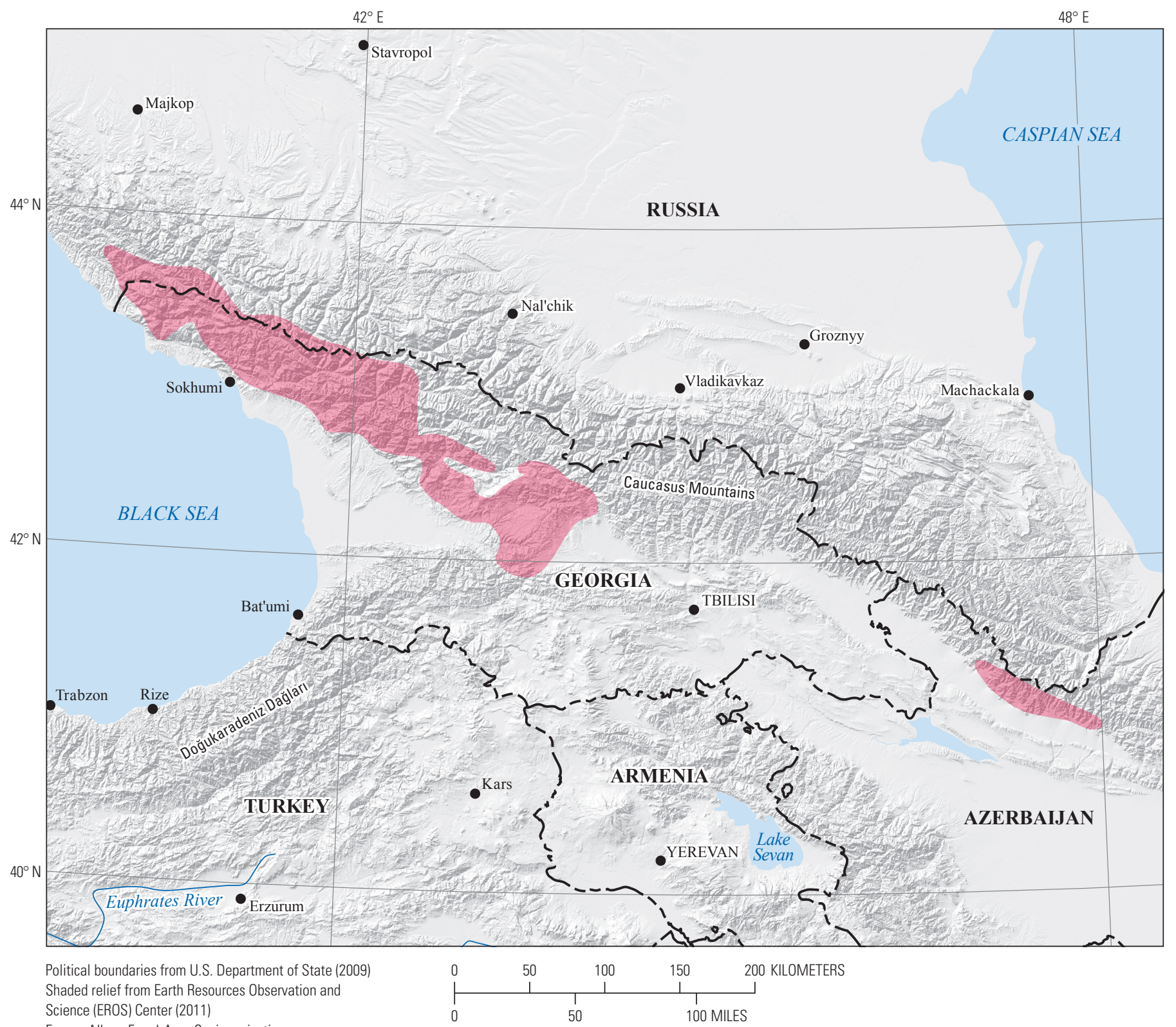

Europe Albers Equal-Area Conic projection

Central meridian $45^{\circ}$ E.; latitude of origin $30^{\circ} \mathrm{N}$.

\section{EXPLANATION}

Assessed porphyry copper tract 142pCu9002

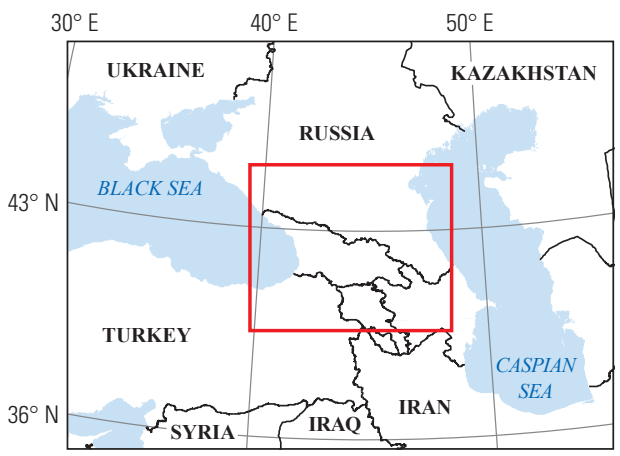




\section{Plate 158. Porphyry Copper Assessment for Tract 142pCu9017b, Pliocene- Quaternary (Postcollisional)—Iran, Armenia, Azerbaijan, Georgia, Turkey, and Russia}

$\begin{array}{ll}\text { Descriptive model: } & \text { Porphyry copper models (Cox, 1986a; Berger and others, 2008; John and others, 2010) } \\ \text { Grade and tonnage model: } & \text { NA } \\ \text { Economic filter depth percentages: } & \text { NA } \\ \text { Economic filter cost setting: } & \text { NA } \\ \text { Geologic feature assessed: } & \text { Late Miocene to Holocene postcollisional rocks recording magmatism of the Tethyan metallogenic } \\ \text { Number of known deposits: } & 0\end{array}$

\section{Selected Resource Assessment Results for Porphyry Copper}

[Assessment depth, 1 kilometer $(\mathrm{km}) ; \mathrm{km}^{2}$, square kilometer; Mt, millions of metric tons; NA, not applicable, as a quantitative assessment was not done]

\begin{tabular}{|c|c|c|c|c|c|c|}
\hline \multirow[b]{2}{*}{$\begin{array}{c}\text { Date of } \\
\text { assessment }\end{array}$} & \multirow[b]{2}{*}{$\begin{array}{c}\text { Tract area } \\
\quad\left(\mathrm{km}^{2}\right)\end{array}$} & \multirow{2}{*}{$\begin{array}{l}\text { Identified } \\
\text { copper } \\
\text { resources } \\
\text { (Mt) }\end{array}$} & \multicolumn{4}{|c|}{ Undiscovered copper resource estimates } \\
\hline & & & $\begin{array}{l}\text { Mean estimate of } \\
\text { in-place resources } \\
\text { (Mt) }\end{array}$ & $\begin{array}{c}\text { Probability of } 0 \\
\text { in-place resources } \\
\text { (percent) }\end{array}$ & $\begin{array}{l}\text { Mean estimate of } \\
\text { economic resources } \\
\text { (Mt) }\end{array}$ & $\begin{array}{c}\text { Probability of } 0 \\
\text { economic resources } \\
\text { (percent) }\end{array}$ \\
\hline 2013 & 193,763 & 0 & NA & NA & NA & NA \\
\hline
\end{tabular}

\section{Qualitative Assessment}

Tract $142 \mathrm{pCu} 9017$ is permissive for Pliocene to Quaternary porphyry copper deposits in the Tethyan region and includes three sub-tracts. Sub-tract 142pCu9017c (pl. 143, Pliocene-Quaternary (Bazman) - Afghanistan, Pakistan, and Iran) lies to the east of sub-tract 142pCu9017b (this plate), and sub-tract 142pCu9017a (pl. 164, Pliocene-Quaternary (Konya)—Turkey) lies to the west.

The postcollisional setting of sub-tract $142 \mathrm{pCu} 9017 \mathrm{~b}$ is permissive for the occurrence of porphyry copper deposits. However, this sub-tract is dominated by volcanic rocks with levels of preservation that are, for the most part, too shallow for porphyry systems. This sub-tract hosts numerous epithermal systems and several active geothermal systems, and porphyrystyle alteration has been recognized under some of these systems. Three prospects associated with the sub-tract and shown on the map are, from north to south, an epithermal and copper-molybdenum porphyry prospect in northwestern Iran, a molybdenum-(copper) porphyry occurrence near Tehran, and a copper-gold porphyry prospect in the southern Urumieh-Dokhtar Magmatic Belt.

Advanced stages of exploration for porphyry copper deposits of the Pliocene to Quaternary age range in the Tethyan region appear to have been limited. Despite the permissive geology, the geologic favorability was deemed too low to add significant undiscovered porphyry copper resources to the overall assessment.

\section{Source}

Zürcher and others, 2015, Porphyry copper assessment of the Tethys region of western and southern Asia: U.S. Geological Survey Scientific Investigations Report 2010-5090-V, http://dx.doi.org/10.3133/sir20105090V. 


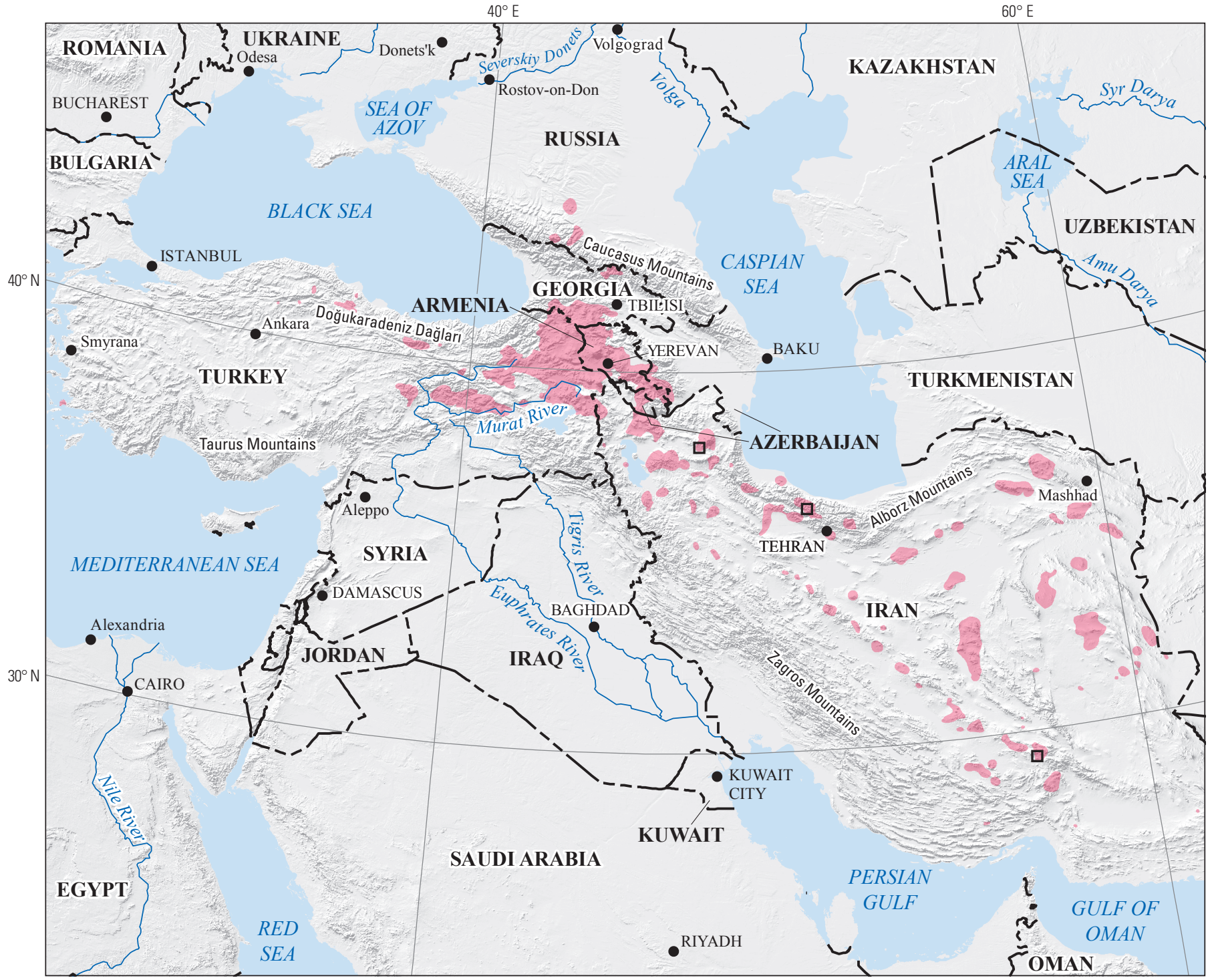

Political boundaries from U.S. Department of State (2009) Shaded relief from Earth Resources Observation and Science (EROS) Center (2011)

Europe Albers Equal-Area Conic projection

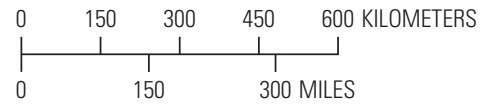

Central meridian $47^{\circ} \mathrm{E}$; l latitude of origin $30^{\circ} \mathrm{N}$.

\section{EXPLANATION}

Assessed porphyry copper tract 142pCu9017b

ㅁ Porphyry copper prospect

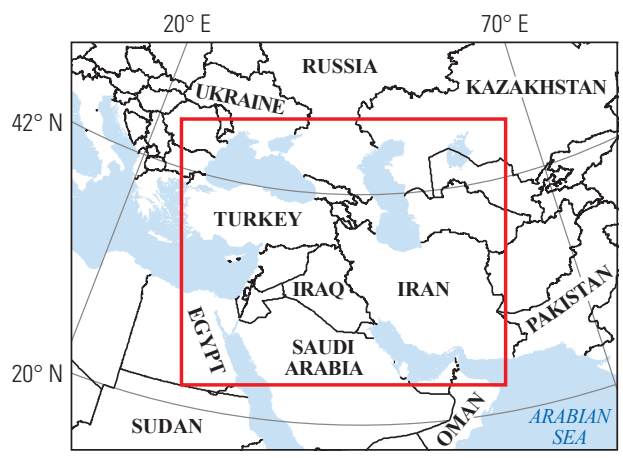




\section{Plate 159. Porphyry Copper Assessment for Tract 142pCu9007, Border Folds- Iran, Iraq, and Turkey}

\section{Descriptive model:}

Grade and tonnage model:

Economic filter depth percentages:

Economic filter cost setting:

Geologic feature assessed:

Number of known deposits:
Porphyry copper models (Cox, 1986a; Berger and others, 2008; John and others, 2010)

General porphyry copper model (Singer, Berger, and Moring, 2008)

Skewed shallow-0 to 250 meters (m), 35\%; > 250 to $500 \mathrm{~m}, 25 \%$; $>500 \mathrm{~m}$ to $1 \mathrm{~km}, 40 \%$

Typical cost

Late Cretaceous to early Paleocene continental arc of the Tethyan metallogenic belt

0

\section{Selected Resource Assessment Results for Porphyry Copper}

[Assessment depth, 1 kilometer $(\mathrm{km}) ; \mathrm{km}^{2}$, square kilometer; $\mathrm{Mt}$, millions of metric tons]

\begin{tabular}{ccccccc}
\hline \multirow{2}{*}{$\begin{array}{c}\text { Date of } \\
\text { assessment }\end{array}$} & $\begin{array}{c}\text { Tract area } \\
\left(\mathbf{k m}^{2}\right)\end{array}$ & $\begin{array}{c}\text { Identified } \\
\text { copper } \\
\text { resources } \\
(\mathbf{M t})\end{array}$ & $\begin{array}{c}\text { Mean estimate of } \\
\text { in-place resources } \\
(\mathbf{M t})\end{array}$ & $\begin{array}{c}\text { Probability of } \mathbf{0} \\
\text { in-place resources } \\
\text { (percent) }\end{array}$ & $\begin{array}{c}\text { Mean estimate of } \\
\text { economic resources } \\
\text { (Mt) }\end{array}$ & $\begin{array}{c}\text { Probability of } \mathbf{0} \\
\text { economic resources } \\
\text { (percent) }\end{array}$ \\
\hline 2012 & 45,285 & 0 & 4.6 & 31 & 3.2 \\
\hline
\end{tabular}

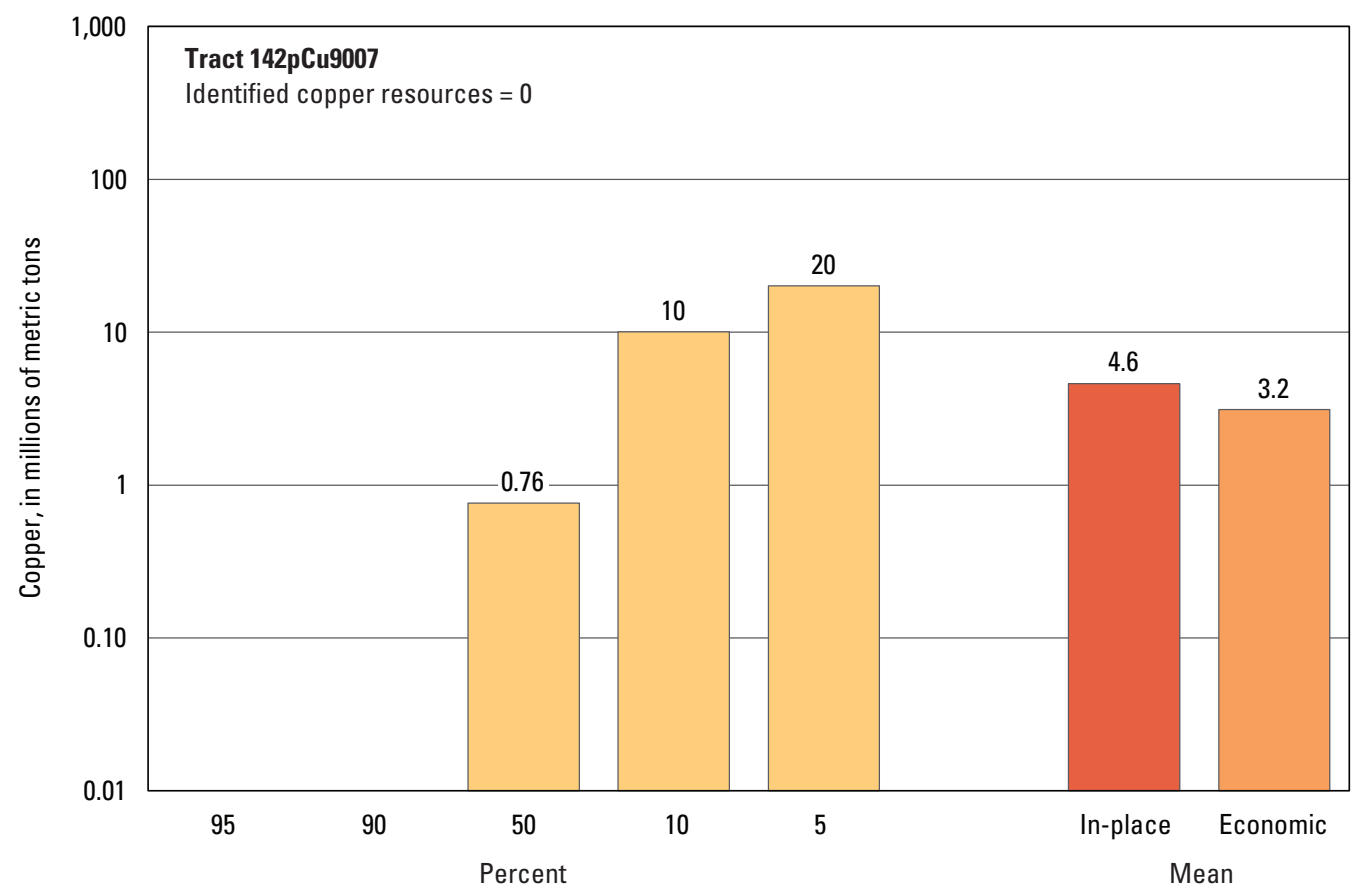

Graph showing the estimated probability distribution of undiscovered copper resources, where each bar represents the minimum amount estimated at the indicated percentage.

\section{Source}

Zürcher and others, 2015, Porphyry copper assessment of the Tethys region of western and southern Asia: U.S. Geological Survey Scientific Investigations Report 2010-5090-V, http://dx.doi.org/10.3133/sir20105090V. 


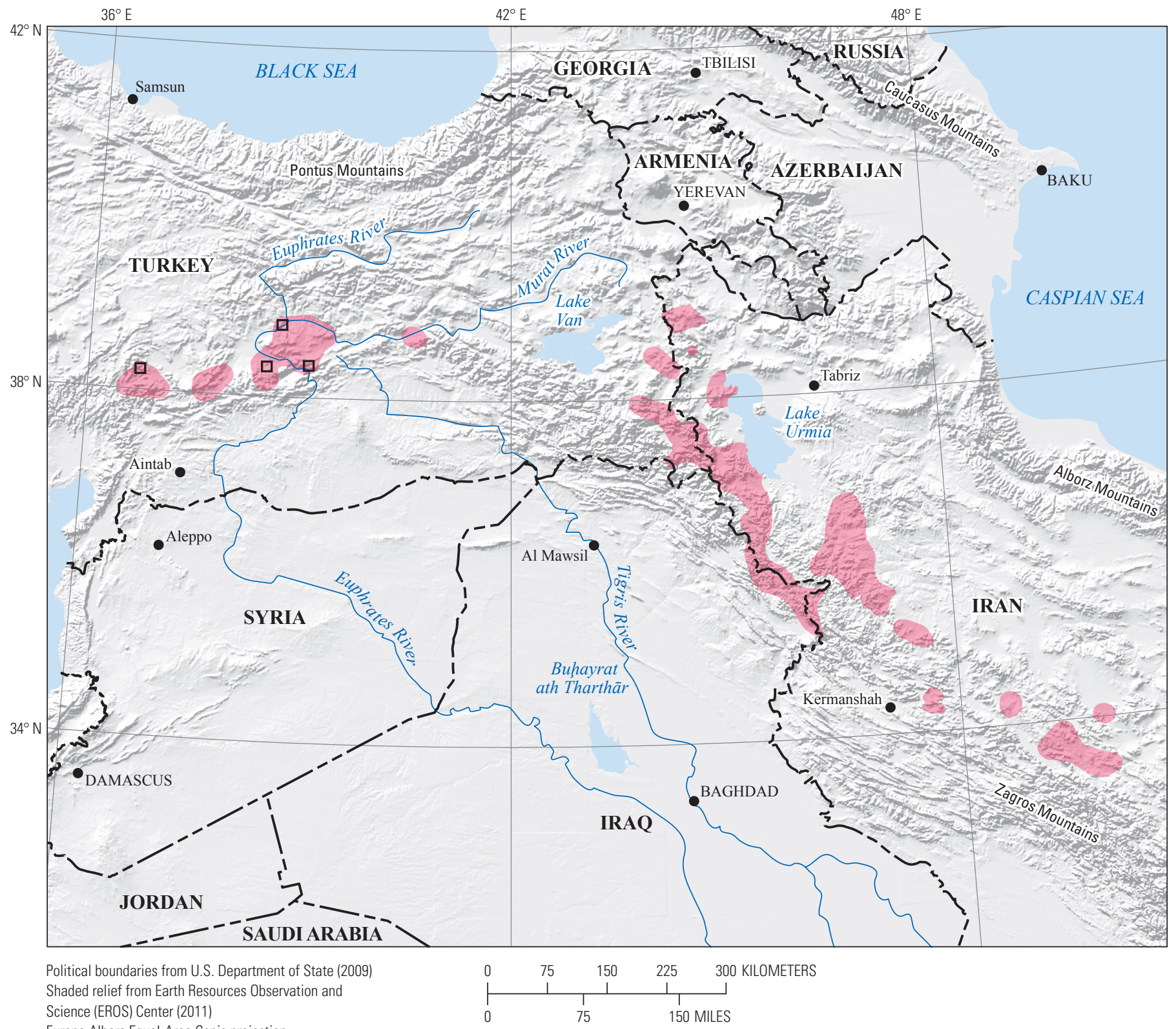

Europe Albers Equal-Area Conic projection

Central meridian $42^{\circ} \mathrm{E}$.; latitude of origin $30^{\circ} \mathrm{N}$.

\section{EXPLANATION}

Assessed porphyry copper tract 142pCu9007

ㅁorphyry copper prospect

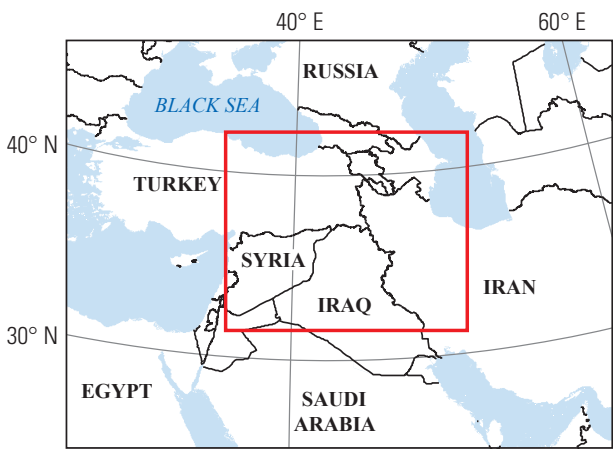




\title{
Plate 160. Porphyry Copper Assessment for Tract 142pCu9004b, Pontide (Asia, Northeastern)-Turkey and Georgia
}

\author{
Descriptive model: \\ Grade and tonnage model: \\ Porphyry copper models (Cox, 1986a; Berger and others, 2008; John and others, 2010) \\ Economic filter depth percentages: \\ Economic filter cost setting: \\ Geologic feature assessed: \\ General porphyry copper model (Singer, Berger, and Moring, 2008) \\ Default - 0 to 250 meters (m), 25\%; > 250 to $500 \mathrm{~m}, 25 \%$; >500 m to $1 \mathrm{~km}, 50 \%$ \\ Typical cost \\ Late Cretaceous to middle Eocene island-arc to continental-arc rocks, back-arc rocks, and \\ postcollisional rocks recording magmatism of the Tethyan metallogenic belt \\ Number of known deposits: \\ 4
}

\section{Selected Resource Assessment Results for Porphyry Copper}

[Assessment depth, 1 kilometer ( $\mathrm{km}) ; \mathrm{km}^{2}$, square kilometer; Mt, millions of metric tons]

\begin{tabular}{ccccccc}
\hline $\begin{array}{c}\text { Date of } \\
\text { assessment }\end{array}$ & $\begin{array}{c}\text { Tract area } \\
\left(\mathbf{k m}^{2}\right)\end{array}$ & $\begin{array}{c}\text { Identified } \\
\text { copper } \\
\text { resources } \\
\text { (Mt) }\end{array}$ & $\begin{array}{c}\text { Mean estimate of } \\
\text { in-place resources } \\
(\mathbf{M t})\end{array}$ & $\begin{array}{c}\text { Probability of } \mathbf{0} \\
\text { in-place resources } \\
\text { (percent) }\end{array}$ & $\begin{array}{c}\text { Mean estimate of } \\
\text { economic resources } \\
\text { (Mt) }\end{array}$ & $\begin{array}{c}\text { Probability of 0 } \\
\text { economic resources } \\
\text { (percent) }\end{array}$ \\
\hline 2013 & 45,539 & 1.5 & 15 & 7 & 10 & 26 \\
\hline
\end{tabular}

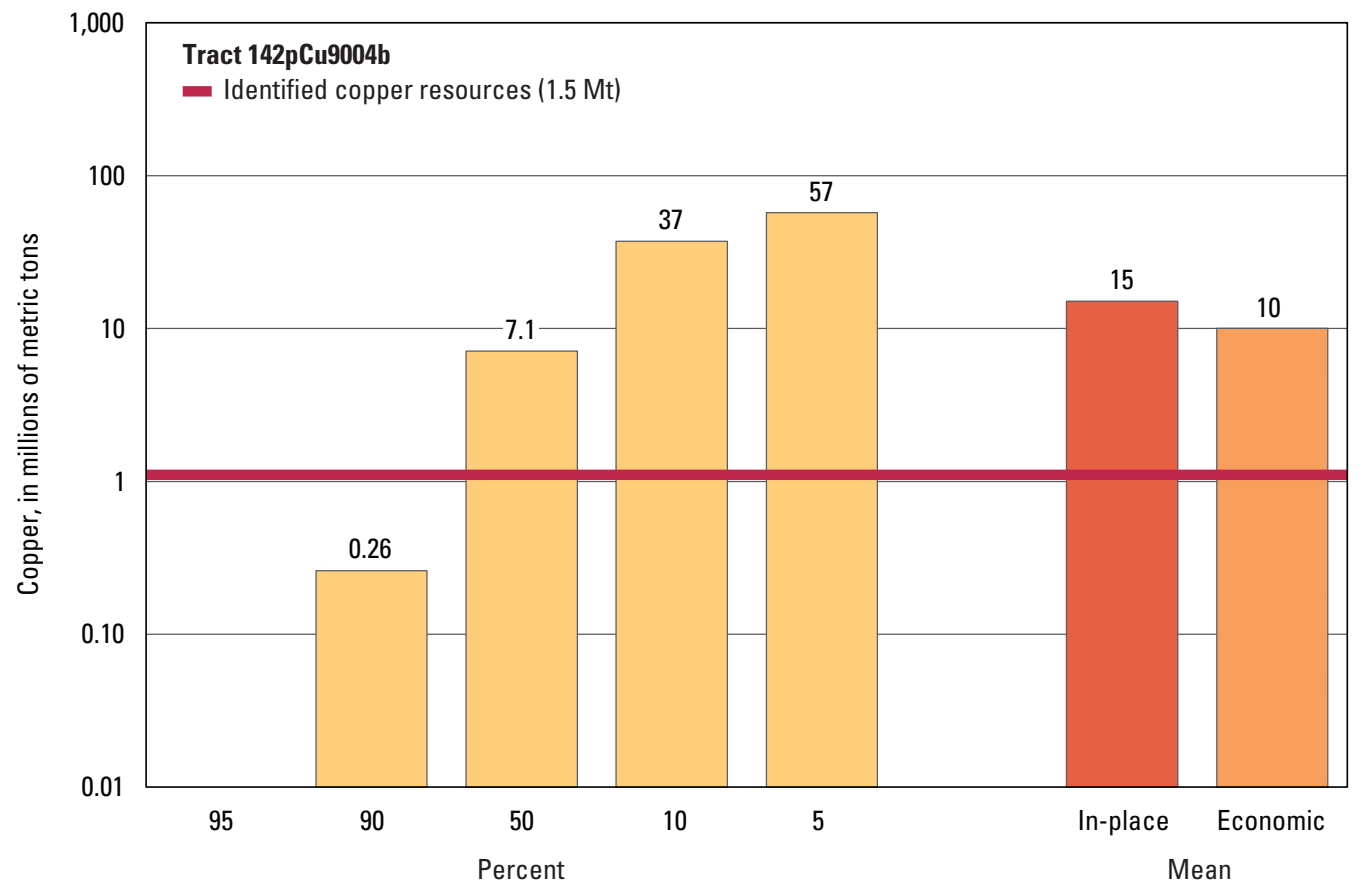

Graph showing the estimated probability distribution of undiscovered copper resources, where each bar represents the minimum amount estimated at the indicated percentage.

\section{Source}

Zürcher and others, 2015, Porphyry copper assessment of the Tethys region of western and southern Asia: U.S. Geological Survey Scientific Investigations Report 2010-5090-V, http://dx.doi.org/10.3133/sir20105090V. 


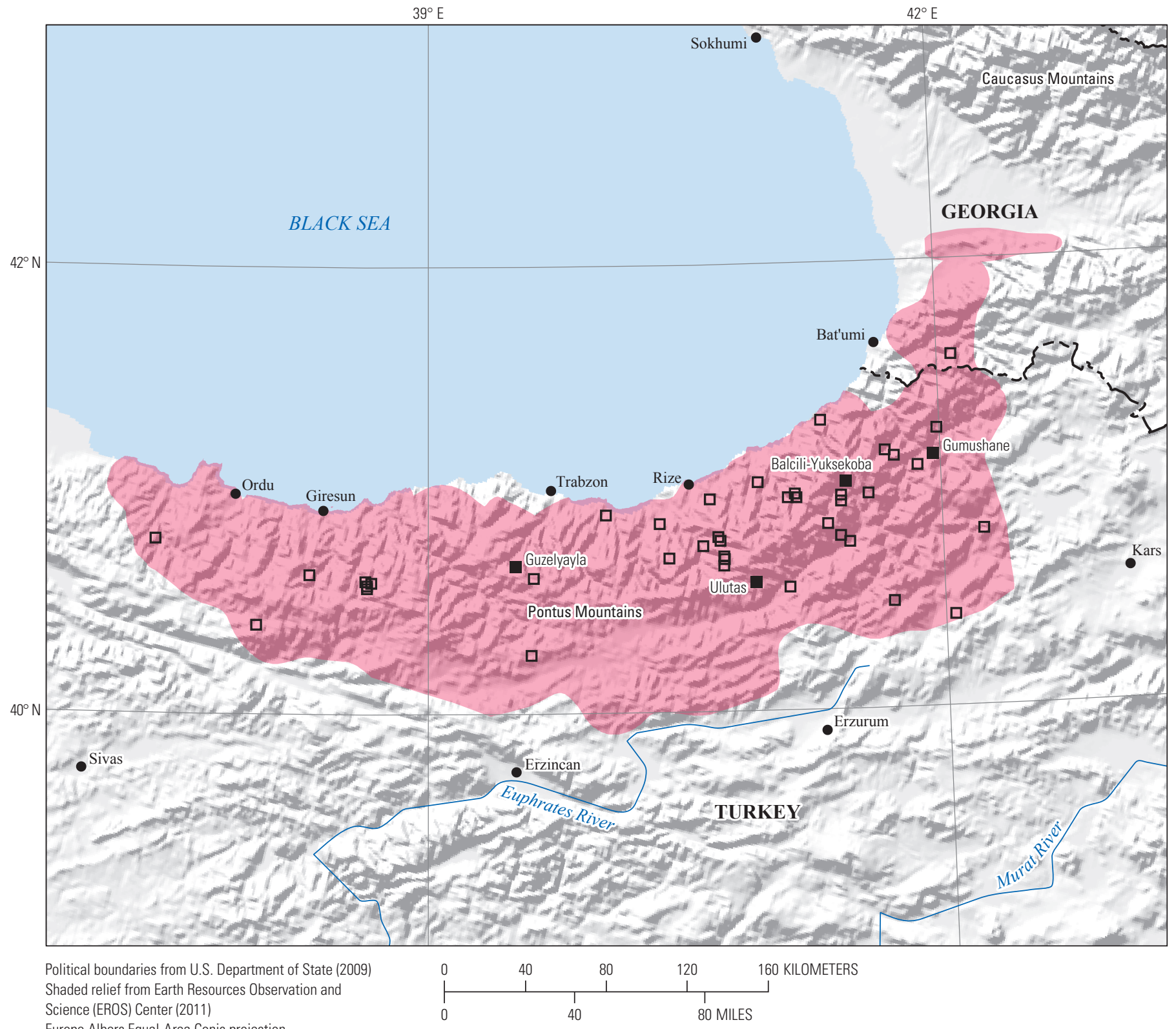

Europe Albers Equal-Area Conic projection

Central meridian $39^{\circ} \mathrm{E}$. ; latitude of origin $30^{\circ} \mathrm{N}$.

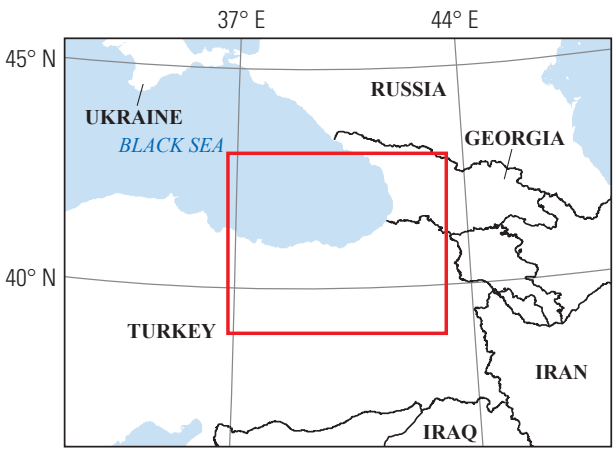




\section{Plate 161. Porphyry Copper Assessment for Tract 142pCu9014b, Azerbaijan (East)-Turkey}

Descriptive model:

Grade and tonnage model:

Economic filter depth percentages:

Economic filter cost setting:

Geologic feature assessed:

Number of known deposits:
Porphyry copper models (Cox, 1986a; Berger and others, 2008; John and others, 2010)

General porphyry copper model (Singer, Berger, and Moring, 2008)

Skewed deep - 0 to 250 meters (m), 10\%; > 250 to $500 \mathrm{~m}, 30 \%$; >500 m to $1 \mathrm{~km}, 60 \%$

Typical cost

Late Eocene to early Miocene back-arc rocks recording magmatism of the Tethyan metallogenic belt

1

\section{Selected Resource Assessment Results for Porphyry Copper}

[Assessment depth, 1 kilometer (km); $\mathrm{km}^{2}$, square kilometer; Mt, millions of metric tons]

\begin{tabular}{ccccccc}
\hline $\begin{array}{c}\text { Date of } \\
\text { assessment }\end{array}$ & $\begin{array}{c}\text { Tract area } \\
\left(\mathbf{k m}^{2}\right)\end{array}$ & $\begin{array}{c}\text { Identified } \\
\text { copper } \\
\text { resources } \\
\text { (Mt) }\end{array}$ & $\begin{array}{c}\text { Mean estimate of } \\
\text { in-place resources } \\
(\mathbf{M t})\end{array}$ & $\begin{array}{c}\text { Probability of } \mathbf{0} \\
\text { in-place resources } \\
\text { (percent) }\end{array}$ & $\begin{array}{c}\text { Mean estimate of } \\
\text { economic resources } \\
\text { (Mt) }\end{array}$ & $\begin{array}{c}\text { Probability of 0 } \\
\text { economic resources } \\
\text { (percent) }\end{array}$ \\
\hline 2013 & 7,754 & 1.7 & 1.5 & 69 & 0.97 \\
\hline
\end{tabular}

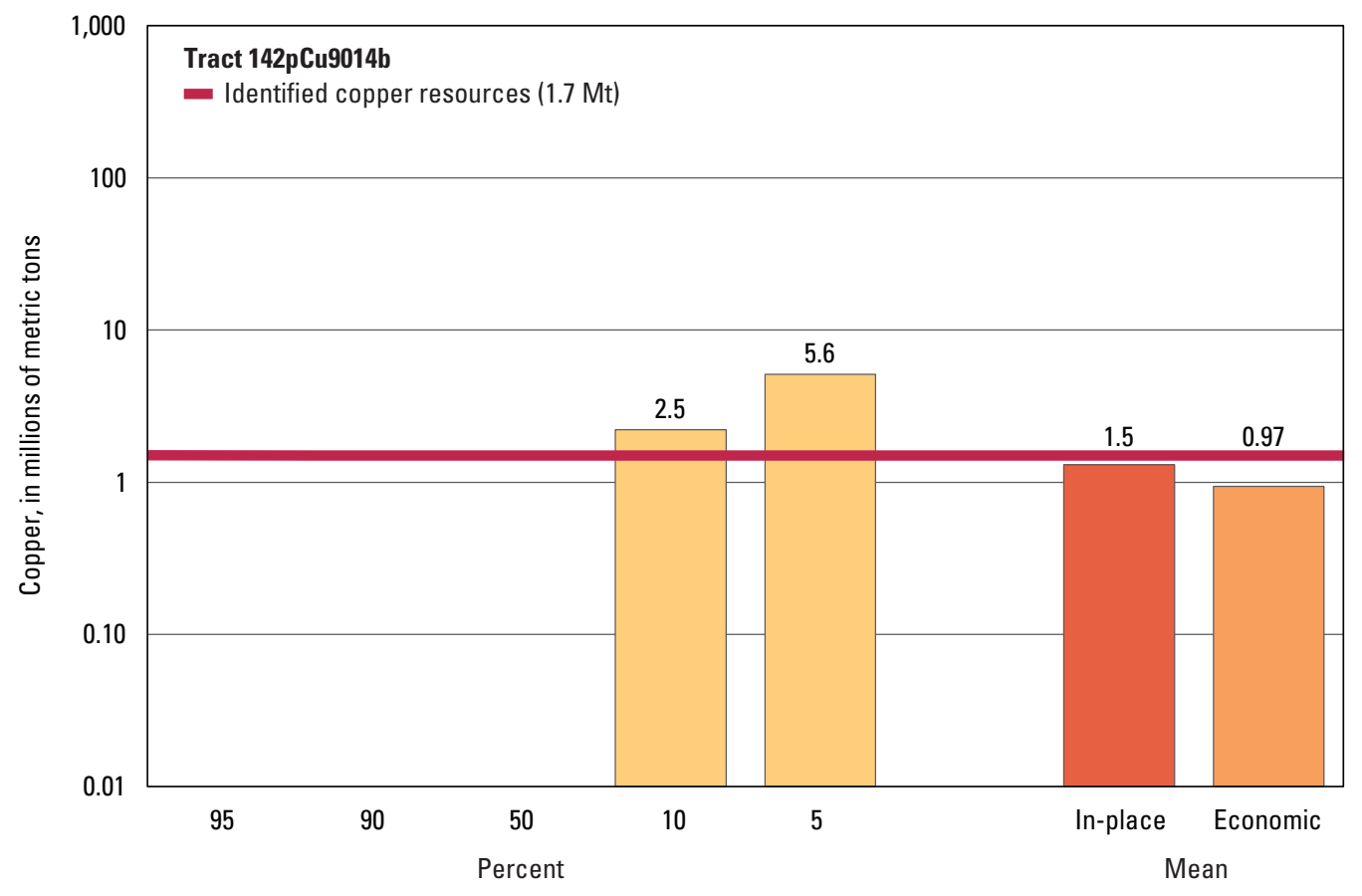

Graph showing the estimated probability distribution of undiscovered copper resources, where each bar represents the minimum amount estimated at the indicated percentage.

\section{Source}

Zürcher and others, 2015, Porphyry copper assessment of the Tethys region of western and southern Asia: U.S. Geological Survey Scientific Investigations Report 2010-5090-V, http://dx.doi.org/10.3133/sir20105090V. 


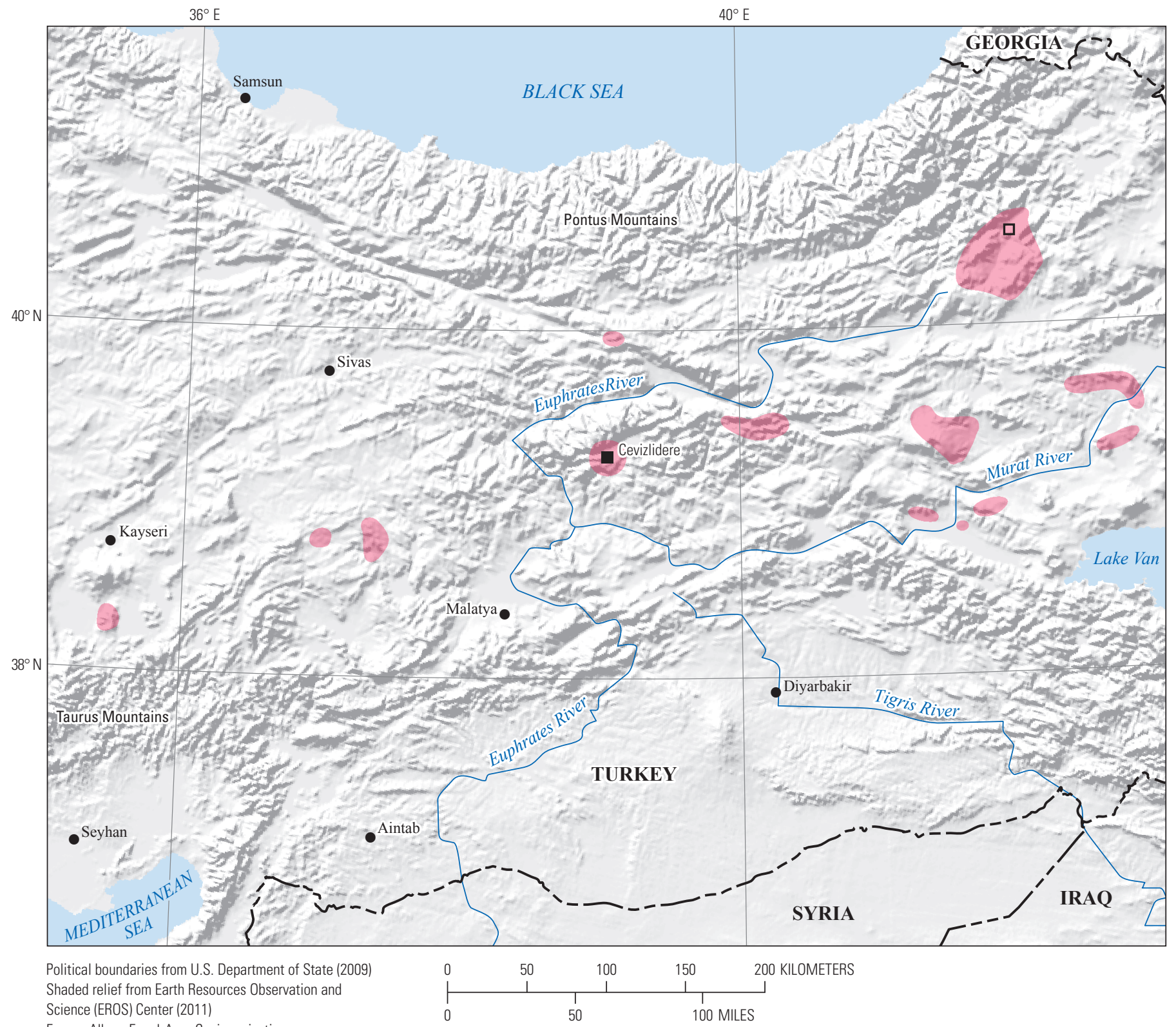

Europe Albers Equal-Area Conic projection

Central meridian $39^{\circ} \mathrm{E}$.; latitude of origin $30^{\circ} \mathrm{N}$.

\section{EXPLANATION}

Assessed porphyry copper tract 142pCu9014b

- Porphyry copper deposit

Porphyry copper prospect

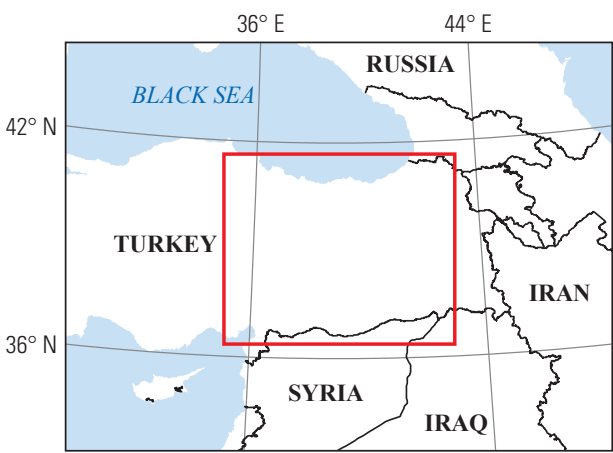




\title{
Plate 162. Porphyry Copper Assessment for Tract 142pCu9005c, Anatolide- Tauride (Eastern Turkey-Caucasus) — Iran, Azerbaijan, Armenia, and Turkey
}

\author{
Descriptive model: \\ Grade and tonnage model: \\ Porphyry copper models (Cox, 1986a; Berger and others, 2008; John and others, 2010) \\ Economic filter depth percentages: \\ Economic filter cost setting: \\ Geologic feature assessed: \\ General porphyry copper model (Singer, Berger, and Moring, 2008) \\ Default - 0 to 250 meters (m), 25\%; > 250 to $500 \mathrm{~m}, 25 \%$; >500 m to $1 \mathrm{~km}, 50 \%$ \\ Typical cost \\ Late Cretaceous to middle-late Eocene arc- and back-arc-related rocks and rocks recording \\ syncollisional to postcollisional magmatism of the Tethyan metallogenic belt \\ Number of known deposits: \\ 4
}

\section{Selected Resource Assessment Results for Porphyry Copper}

[Assessment depth, 1 kilometer ( $\mathrm{km}) ; \mathrm{km}^{2}$, square kilometer; Mt, millions of metric tons]

\begin{tabular}{ccccccc}
\hline $\begin{array}{c}\text { Date of } \\
\text { assessment }\end{array}$ & $\begin{array}{c}\text { Tract area } \\
\left.\mathbf{( k m}^{2}\right)\end{array}$ & $\begin{array}{c}\text { Identified } \\
\text { copper } \\
\text { resources } \\
\text { (Mt) }\end{array}$ & $\begin{array}{c}\text { Mean estimate of } \\
\text { in-place resources } \\
(\mathbf{M t})\end{array}$ & $\begin{array}{c}\text { Probability of } \mathbf{0} \\
\text { in-place resources } \\
\text { (percent) }\end{array}$ & $\begin{array}{c}\text { Mean estimate of } \\
\text { economic resources } \\
\text { (Mt) }\end{array}$ & $\begin{array}{c}\text { Probability of 0 } \\
\text { economic resources } \\
\text { (percent) }\end{array}$ \\
\hline 2013 & 21,675 & 1.2 & 8.2 & 21 & 5.5 \\
\hline
\end{tabular}

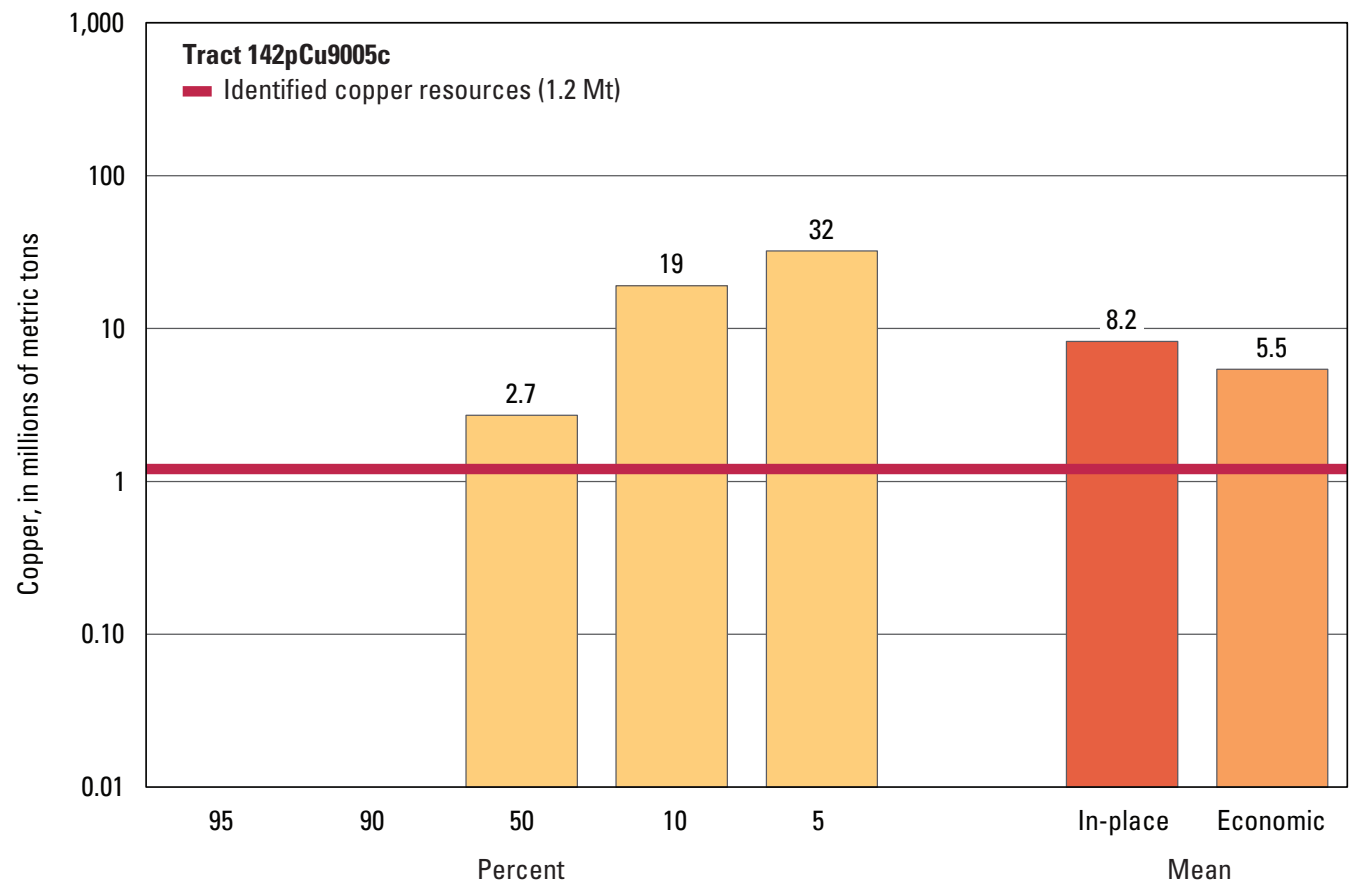

Graph showing the estimated probability distribution of undiscovered copper resources, where each bar represents the minimum amount estimated at the indicated percentage.

\section{Source}

Zürcher and others, 2015, Porphyry copper assessment of the Tethys region of western and southern Asia: U.S. Geological Survey Scientific Investigations Report 2010-5090-V, http://dx.doi.org/10.3133/sir20105090V. 


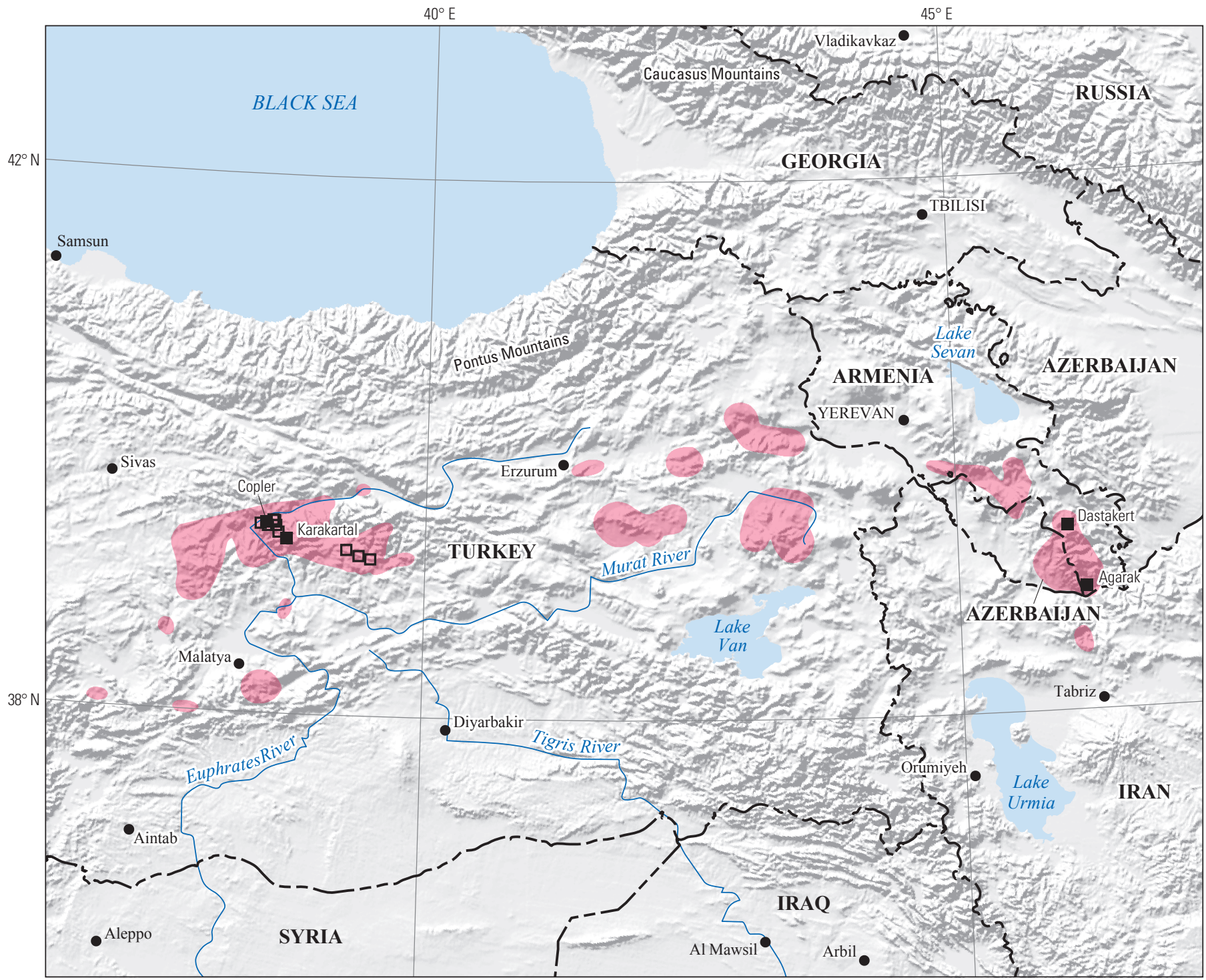

Political boundaries from U.S. Department of State (2009) Shaded relief from Earth Resources Observation and Science (EROS) Center (2011)

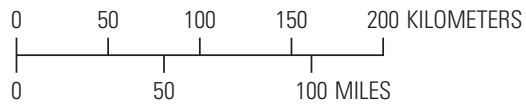

Europe Albers Equal-Area Conic projection

Central meridian $42^{\circ} \mathrm{E}$.; latitude of origin $30^{\circ} \mathrm{N}$.

\section{EXPLANATION}

Assessed porphyry copper tract 142pCu9005c

- Porphyry copper deposit

Porphyry copper prospect

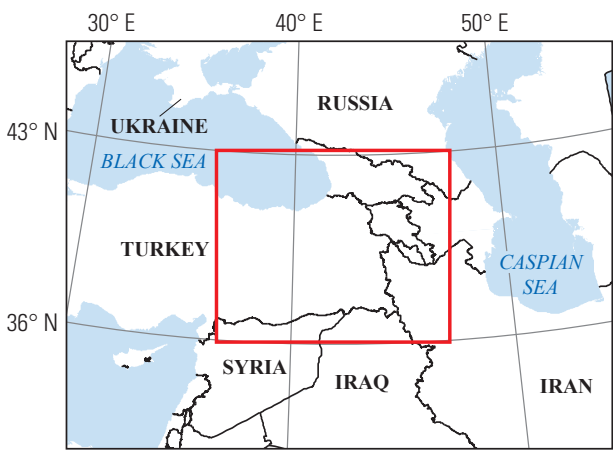




\section{Plate 163. Porphyry Copper Assessment for Tract 142pCu9005b, Anatolide- Tauride (Central)-Turkey}

\section{Descriptive model:}

Grade and tonnage model:

Economic filter depth percentages:

Economic filter cost setting:

Geologic feature assessed:

Number of known deposits:

\begin{abstract}
Porphyry copper models (Cox, 1986a; Berger and others, 2008; John and others, 2010)
General porphyry copper model (Singer, Berger, and Moring, 2008)

Skewed shallow-0 to 250 meters (m), 35\%; > 250 to $500 \mathrm{~m}, 25 \%$; >500 m to $1 \mathrm{~km}, 40 \%$

Typical cost

Late Cretaceous to middle-late Eocene arc- and back-arc-related rocks and rocks recording syncollisional to postcollisional magmatism of the Tethyan metallogenic belt

0
\end{abstract}

\section{Selected Resource Assessment Results for Porphyry Copper}

[Assessment depth, 1 kilometer (km); $\mathrm{km}^{2}$, square kilometer; Mt, millions of metric tons]

\begin{tabular}{ccccccc}
\hline $\begin{array}{c}\text { Date of } \\
\text { assessment }\end{array}$ & $\begin{array}{c}\text { Tract area } \\
\left(\mathbf{k m}^{2}\right)\end{array}$ & $\begin{array}{c}\text { Identified } \\
\text { copper } \\
\text { resources } \\
(\mathbf{M t})\end{array}$ & $\begin{array}{c}\text { Mean estimate of } \\
\text { in-place resources } \\
(\mathbf{M t})\end{array}$ & $\begin{array}{c}\text { Probability of } \mathbf{0} \\
\text { in-place resources } \\
\text { (percent) }\end{array}$ & $\begin{array}{c}\text { Mean estimate of } \\
\text { economic resources } \\
\text { (Mt) }\end{array}$ & $\begin{array}{c}\text { Probability of 0 } \\
\text { economic resources } \\
\text { (percent) }\end{array}$ \\
\hline 2013 & 36,208 & 0 & 1.3 & 70 & 0.90 \\
\hline
\end{tabular}

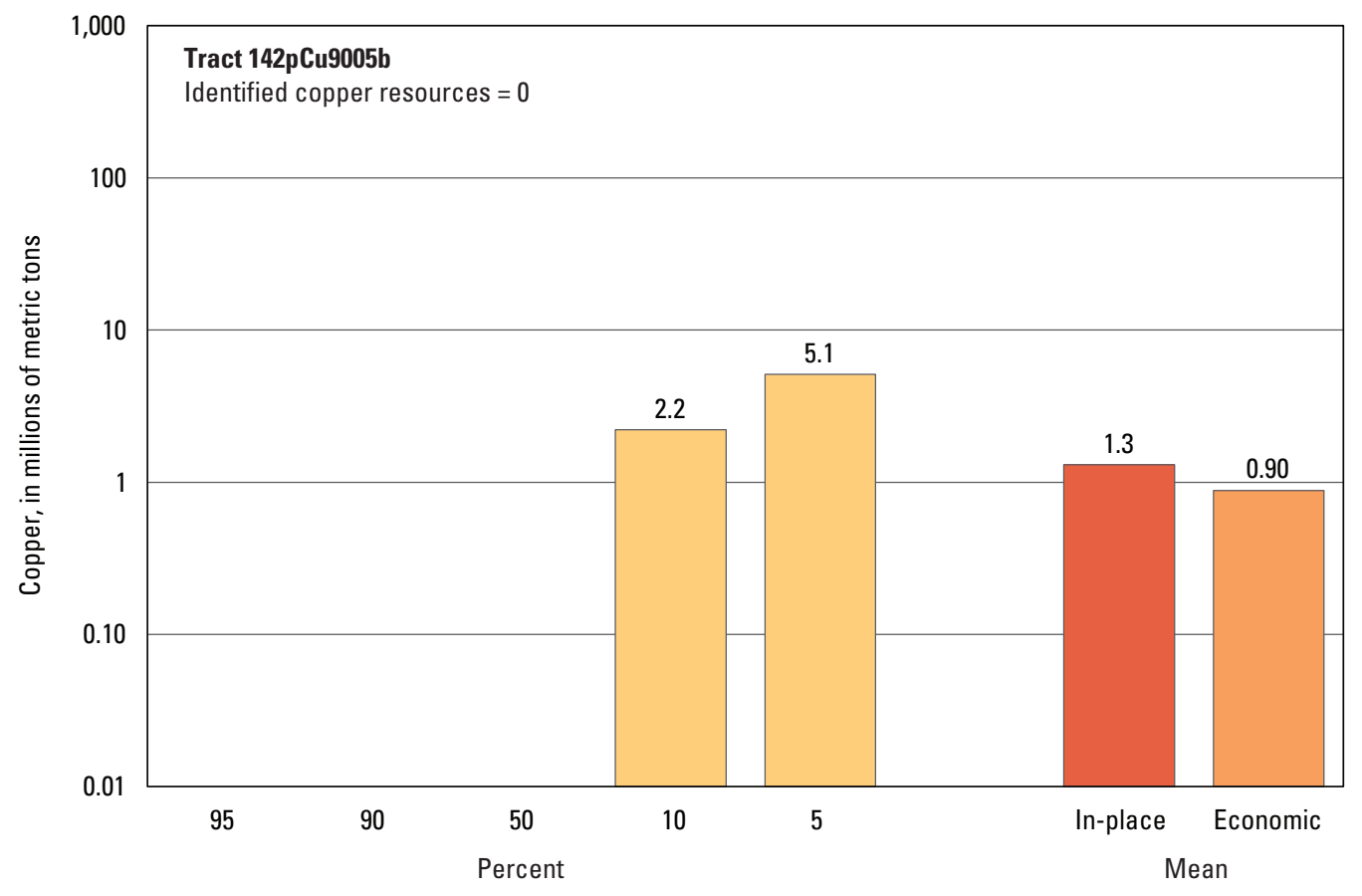

Graph showing the estimated probability distribution of undiscovered copper resources, where each bar represents the minimum amount estimated at the indicated percentage.

\section{Source}

Zürcher and others, 2015, Porphyry copper assessment of the Tethys region of western and southern Asia: U.S. Geological Survey Scientific Investigations Report 2010-5090-V, http://dx.doi.org/10.3133/sir20105090V. 


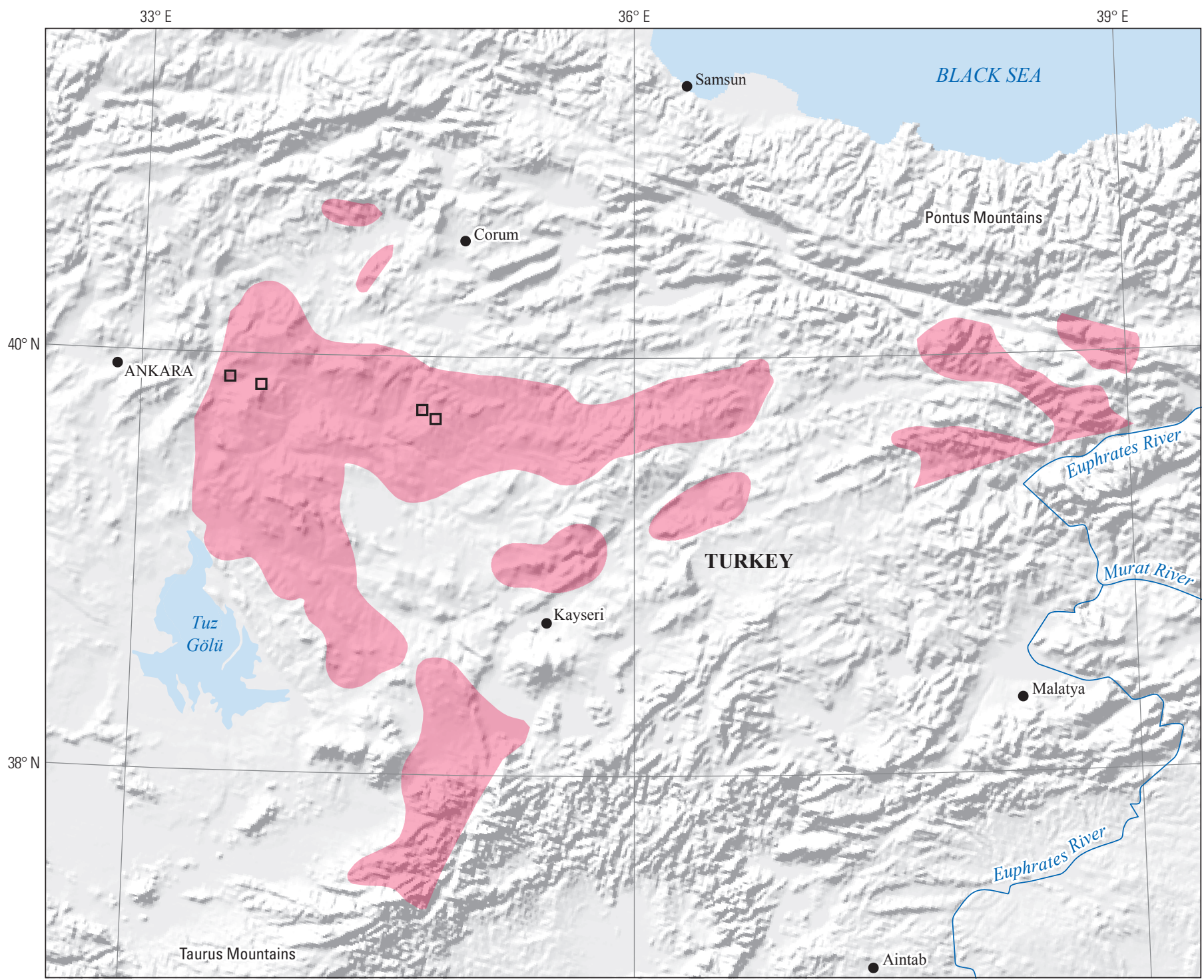

Political boundaries from U.S. Department of State (2009) Shaded relief from Earth Resources Observation and Science (EROS) Center (2011)

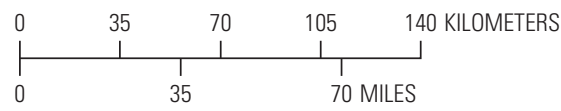

Europe Albers Equal-Area Conic projection

Central meridian $36^{\circ} \mathrm{E}$.; latitude of origin $30^{\circ} \mathrm{N}$.

\section{EXPLANATION}

Assessed porphyry copper tract 142pCu9005b

Porphyry copper prospect

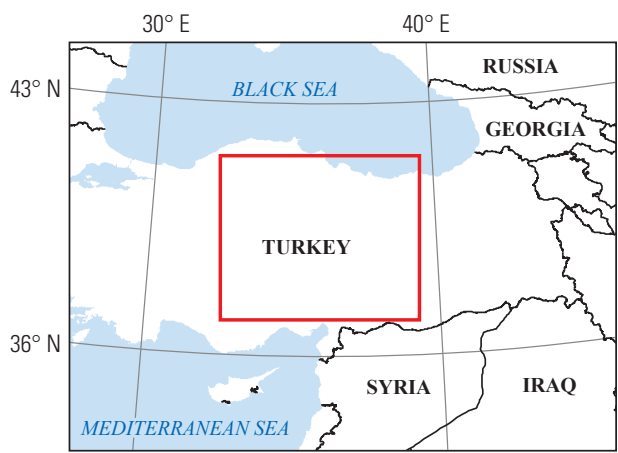




\title{
Plate 164. Porphyry Copper Assessment for Tract 142pCu9017a, Pliocene- Quaternary (Konya)-Turkey
}

\author{
Descriptive model: \\ Porphyry copper models (Cox, 1986a; Berger and others, 2008; John and others, 2010) \\ Grade and tonnage model: \\ NA \\ Economic filter depth percentages: \\ NA \\ Economic filter cost setting: \\ NA \\ Geologic feature assessed: \\ The Konya arc: a late Miocene to Holocene continental-arc and back-arc volcano-plutonic belt \\ related to the active Hellenic-Cyprian subduction zone \\ Number of known deposits: \\ 0
}

\section{Selected Resource Assessment Results for Porphyry Copper}

[Assessment depth, 1 kilometer $(\mathrm{km}) ; \mathrm{km}^{2}$, square kilometer; Mt, millions of metric tons; NA, not applicable, as a quantitative assessment was not done]

\begin{tabular}{ccccccc}
\hline $\begin{array}{c}\text { Date of } \\
\text { assessment }\end{array}$ & $\begin{array}{c}\text { Tract area } \\
\left(\mathbf{k m}^{2}\right)\end{array}$ & $\begin{array}{c}\text { Identified } \\
\text { copper } \\
\text { resources } \\
(\mathbf{M t})\end{array}$ & $\begin{array}{c}\text { Mean estimate of } \\
\text { in-place resources } \\
(\mathbf{M t})\end{array}$ & $\begin{array}{c}\text { Probability of } \mathbf{0} \\
\text { in-place resources } \\
\text { (percent) }\end{array}$ & $\begin{array}{c}\text { Mean estimate of } \\
\text { economic resources } \\
\text { (Mt) }\end{array}$ & $\begin{array}{c}\text { Probability of } 0 \\
\text { economic resources } \\
\text { (percent) }\end{array}$ \\
\hline 2013 & 11,788 & 0 & NA & NA & NA \\
\hline
\end{tabular}

\section{Qualitative Assessment}

Tract 142pCu9017 is permissive for Pliocene to Quaternary porphyry copper deposits in the Tethyan region and includes three sub-tracts. Sub-tracts 142pCu9017b (pl. 158, Pliocene-Quaternary (Postcollisional)-Iran, Armenia, Azerbaijan, Georgia, Turkey, and Russia) and 142pCu9017a (this plate) lie to the east of sub-tract 142pCu9017c (pl. 143, Pliocene-Quaternary (Bazman)-Afghanistan, Pakistan, and Iran).

The Pliocene-Quaternary (Konya) - Turkey sub-tract 142pCu9017a (this plate) is partially superimposed on parts of two older sub-tracts: the Anatolide-Tauride (Central) - Turkey sub-tract 142pCu9005b (pl. 163) and the Azerbaijan (East)Turkey sub-tract $142 \mathrm{pCu} 9014 \mathrm{~b}$ (pl. 161). Factors that greatly diminish the favorability of the Konya sub-tract for porphyry copper deposits include the predominance of volcanic rocks with levels of preservation that are, for the most part, too shallow for porphyry systems. With the exception of one acid-sulfate epithermal and associated copper-gold-molybdenum porphyry prospect, exploration for porphyry copper deposits in this region is in its early stages. Despite the permissive geology, the geologic favorability was deemed unlikely to add significant copper resources to the overall assessment (less than a 10-percent chance of one undiscovered deposit). Therefore, a quantitative assessment of undiscovered porphyry copper deposits in the Konya sub-tract was not warranted.

\section{Source}

Zürcher and others, 2015, Porphyry copper assessment of the Tethys region of western and southern Asia: U.S. Geological Survey Scientific Investigations Report 2010-5090-V, http://dx.doi.org/10.3133/sir20105090V. 


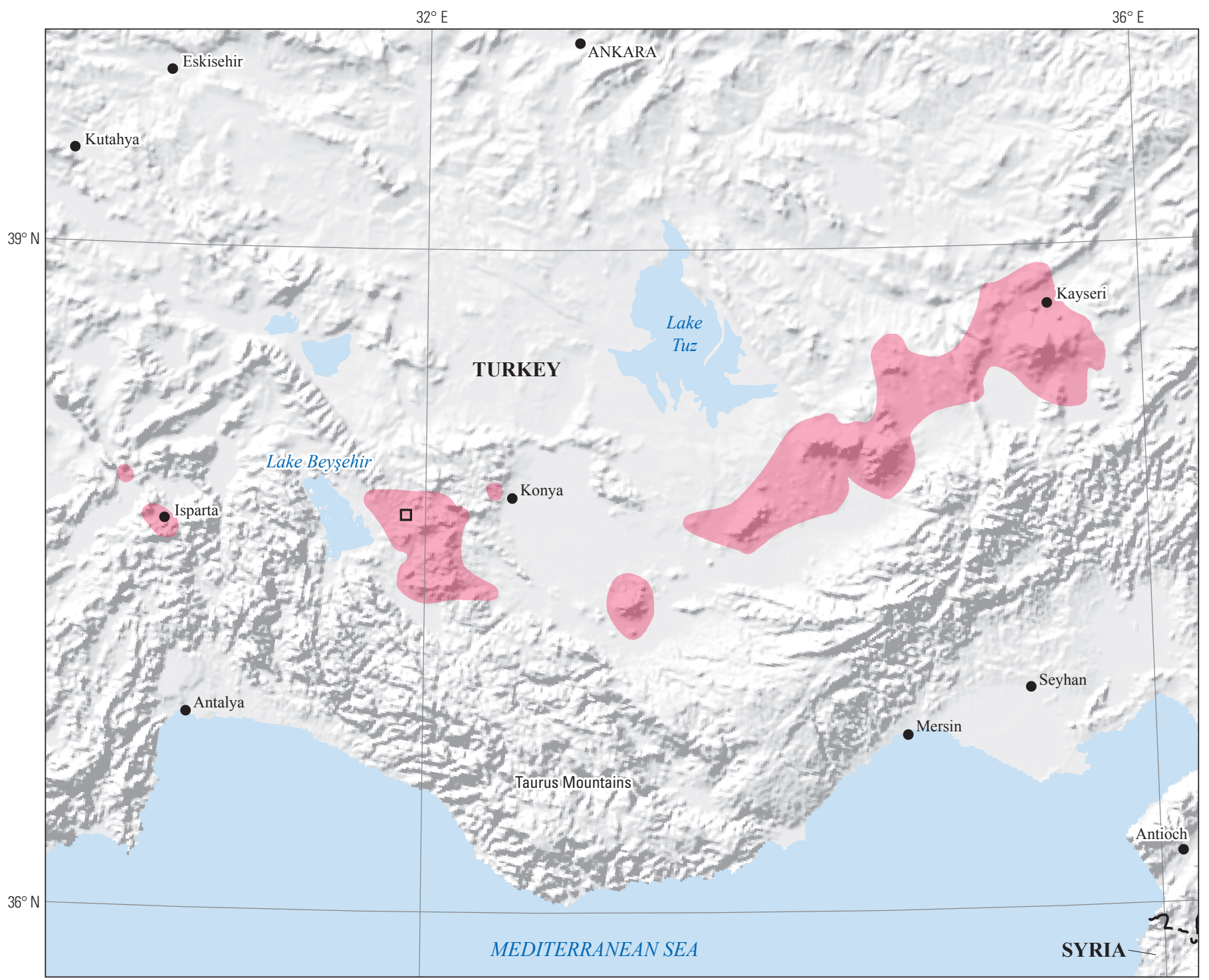

Political boundaries from U.S. Department of State (2009) Shaded relief from Earth Resources Observation and Science (EROS) Center (2011)

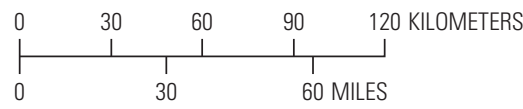

Europe Albers Equal-Area Conic projection

Central meridian $33^{\circ} \mathrm{E}$.; latitude of origin $30^{\circ} \mathrm{N}$.

\section{EXPLANATION}

Assessed porphyry copper tract 142pCu9017a

$\square \quad$ Porphyry copper prospect

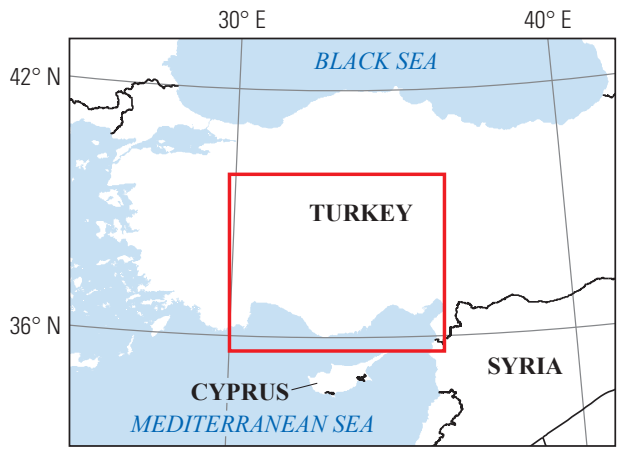




\title{
Plate 165. Porphyry Copper Assessment for Tract 142pCu9004a, Pontide (Asia, Northwestern)-Turkey
}

\author{
Descriptive model: \\ Porphyry copper models (Cox, 1986a; Berger and others, 2008; John and others, 2010) \\ Grade and tonnage model: \\ General porphyry copper model (Singer, Berger, and Moring, 2008) \\ Economic filter depth percentages: \\ Economic filter cost setting: \\ Custom - 0 to 250 meters (m), 17\%; >250 to $500 \mathrm{~m}, 28 \%$; >500 m to $1 \mathrm{~km}, 55 \%$ \\ Geologic feature assessed: \\ Typical cost \\ Late Cretaceous to middle Eocene fore-arc and back-arc rocks and rocks recording postcollisional \\ magmatism of the Tethyan metallogenic belt \\ Number of known deposits: \\ 1
}

\section{Selected Resource Assessment Results for Porphyry Copper}

[Assessment depth, 1 kilometer ( $\mathrm{km}) ; \mathrm{km}^{2}$, square kilometer; Mt, millions of metric tons]

\begin{tabular}{ccccccc}
\hline $\begin{array}{c}\text { Date of } \\
\text { assessment }\end{array}$ & $\begin{array}{c}\text { Tract area } \\
\left.\mathbf{( k m}^{2}\right)\end{array}$ & $\begin{array}{c}\text { Identified } \\
\text { copper } \\
\text { resources } \\
\text { (Mt) }\end{array}$ & $\begin{array}{c}\text { Mean estimate of } \\
\text { in-place resources } \\
(\mathbf{M t})\end{array}$ & $\begin{array}{c}\text { Probability of } \mathbf{0} \\
\text { in-place resources } \\
\text { (percent) }\end{array}$ & $\begin{array}{c}\text { Mean estimate of } \\
\text { economic resources } \\
\text { (Mt) }\end{array}$ & $\begin{array}{c}\text { Probability of 0 } \\
\text { economic resources } \\
\text { (percent) }\end{array}$ \\
\hline 2013 & 32,671 & 0.40 & 4.1 & 29 & 2.7 & 77 \\
\hline
\end{tabular}

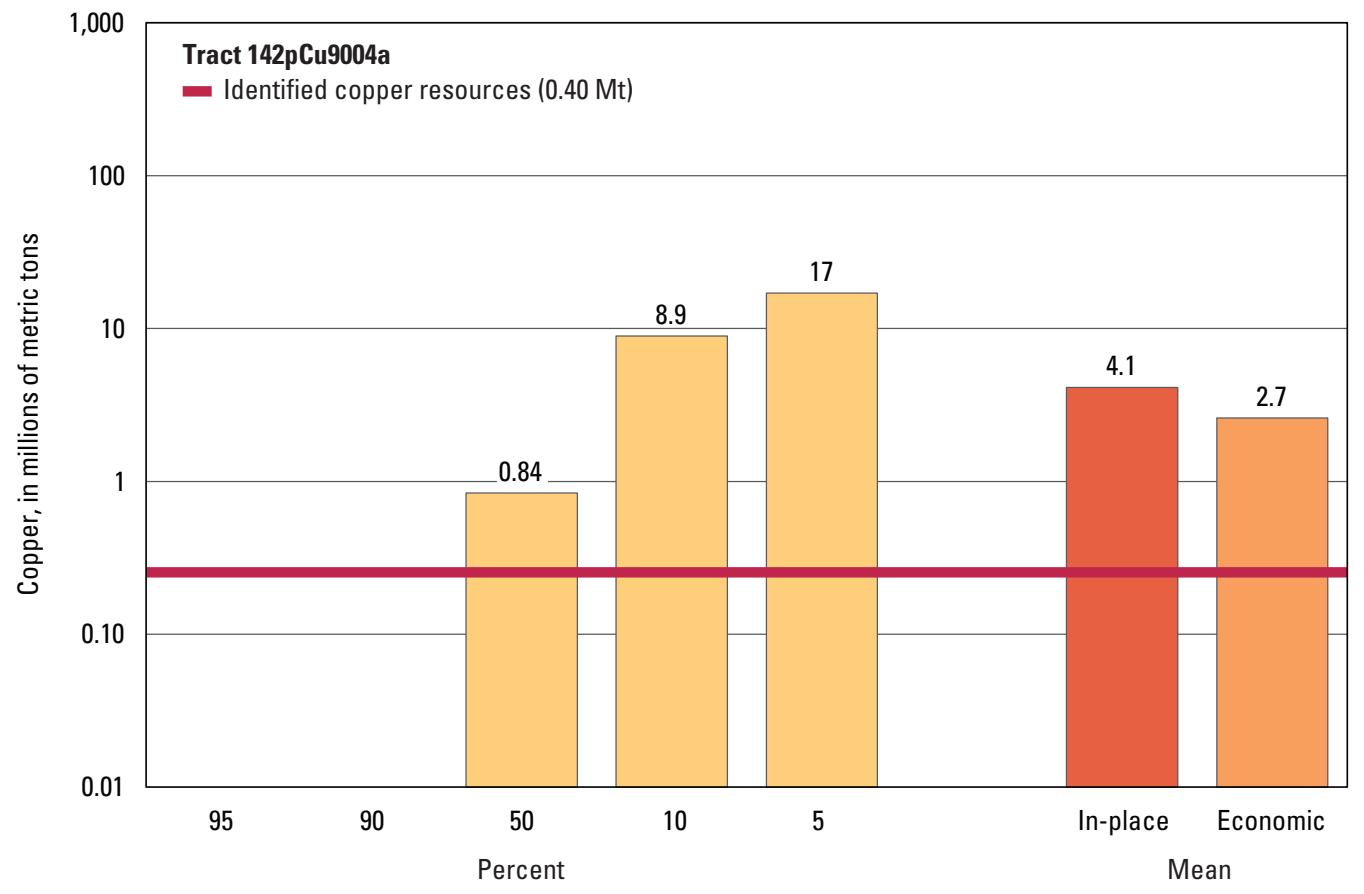

Graph showing the estimated probability distribution of undiscovered copper resources, where each bar represents the minimum amount estimated at the indicated percentage.

\section{Source}

Zürcher and others, 2015, Porphyry copper assessment of the Tethys region of western and southern Asia: U.S. Geological Survey Scientific Investigations Report 2010-5090-V, http://dx.doi.org/10.3133/sir20105090V. 


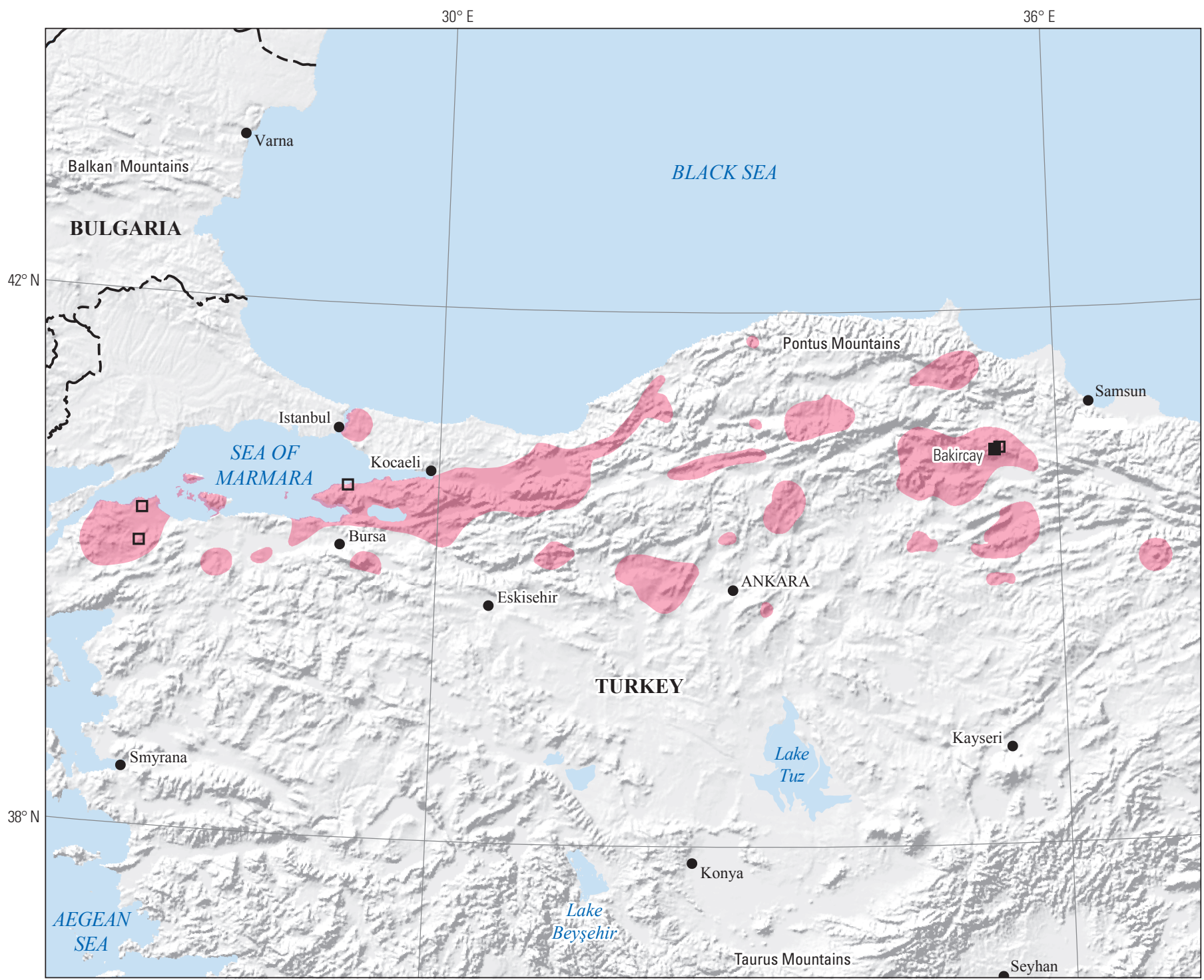

Political boundaries from U.S. Department of State (2009) Shaded relief from Earth Resources Observation and Science (EROS) Center (2011)

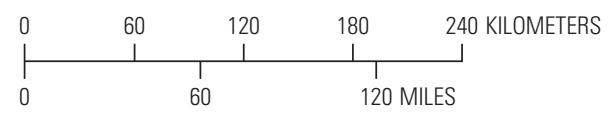

Europe Albers Equal-Area Conic projection

Central meridian $33^{\circ} \mathrm{E}$.; latitude of origin $30^{\circ} \mathrm{N}$.

\section{EXPLANATION}

Litent Assessed porphyry copper tract 142pCu9004a

- Porphyry copper deposit

ㅁ Porphyry copper prospect

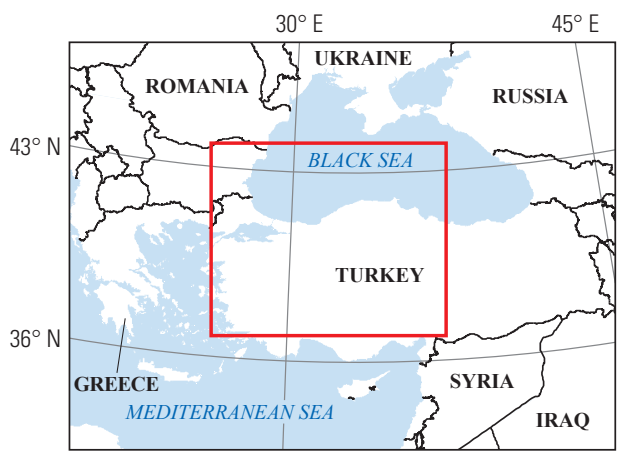




\title{
Plate 166. Porphyry Copper Assessment for Tract 142pCu9005a, Anatolide- Tauride (West) - Turkey
}

\author{
Descriptive model: \\ Grade and tonnage model: \\ Porphyry copper models (Cox, 1986a; Berger and others, 2008; John and others, 2010) \\ Economic filter depth percentages: \\ Economic filter cost setting: \\ Geologic feature assessed: \\ General porphyry copper model (Singer, Berger, and Moring, 2008) \\ Skewed shallow-0 to 250 meters (m), 35\%; > 250 to $500 \mathrm{~m}, 25 \%$; $>500 \mathrm{~m}$ to $1 \mathrm{~km}, 40 \%$ \\ Typical cost \\ Late Cretaceous to middle Eocene arc-related rocks and rocks recording postcollisional \\ magmatism of the Tethyan metallogenic belt \\ Number of known deposits: \\ 2
}

\section{Selected Resource Assessment Results for Porphyry Copper}

[Assessment depth, 1 kilometer $(\mathrm{km}) ; \mathrm{km}^{2}$, square kilometer; Mt, millions of metric tons]

\begin{tabular}{ccccccc}
\hline $\begin{array}{c}\text { Date of } \\
\text { assessment }\end{array}$ & $\begin{array}{c}\text { Tract area } \\
\left(\mathbf{k m}^{2}\right)\end{array}$ & $\begin{array}{c}\text { Identified } \\
\text { copper } \\
\text { resources } \\
(\mathbf{M t})\end{array}$ & $\begin{array}{c}\text { Mean estimate of } \\
\text { in-place resources } \\
(\mathbf{M t})\end{array}$ & $\begin{array}{c}\text { Probability of } \mathbf{0} \\
\text { in-place resources } \\
\text { (percent) }\end{array}$ & $\begin{array}{c}\text { Mean estimate of } \\
\text { economic resources } \\
\text { (Mt) }\end{array}$ & $\begin{array}{c}\text { Probability of 0 } \\
\text { economic resources } \\
\text { (percent) }\end{array}$ \\
\hline 2013 & 5,940 & 0.38 & 3.0 & 31 & 2.1 & 79 \\
\hline
\end{tabular}

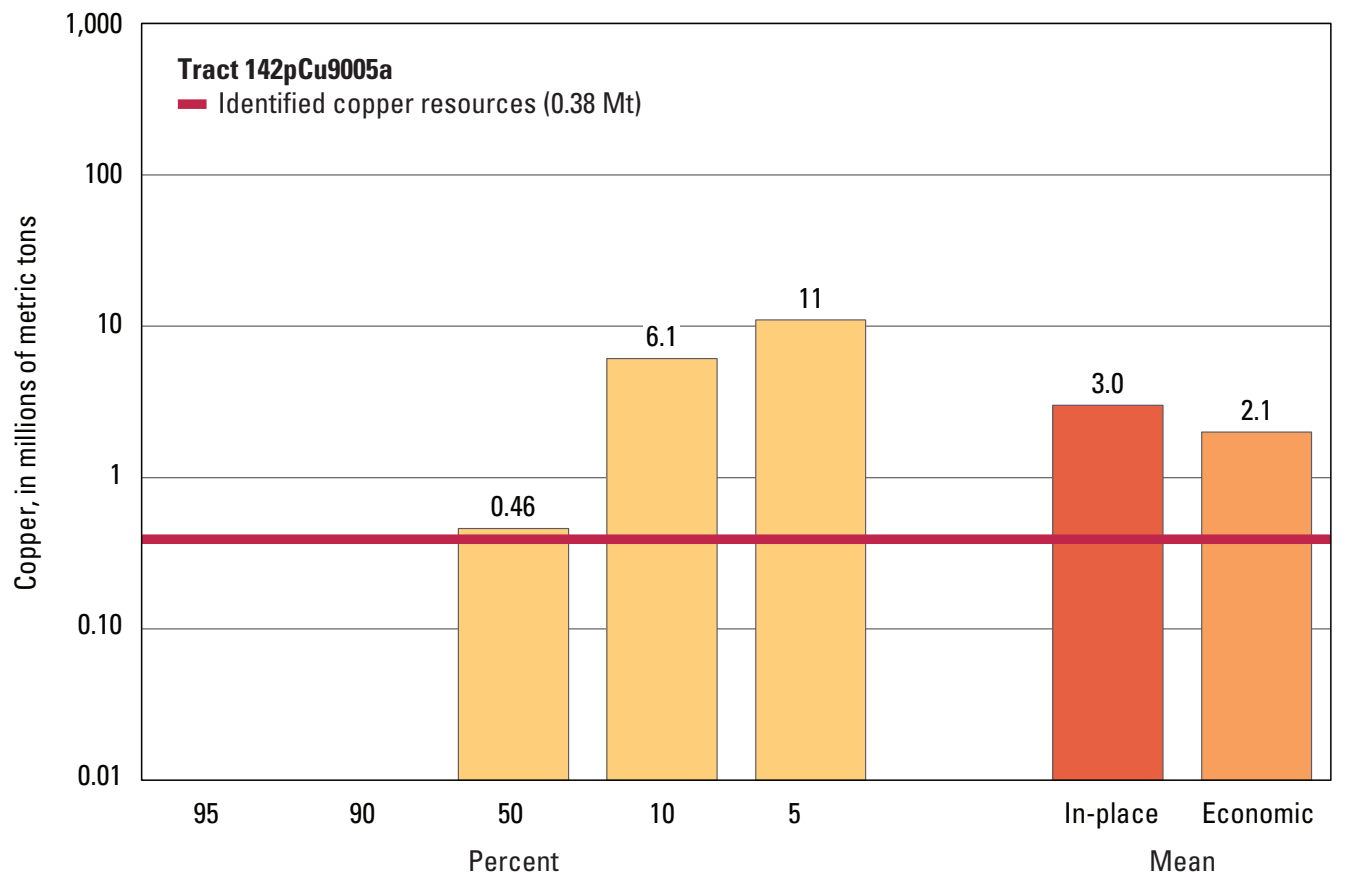

Graph showing the estimated probability distribution of undiscovered copper resources, where each bar represents the minimum amount estimated at the indicated percentage.

\section{Source}

Zürcher and others, 2015, Porphyry copper assessment of the Tethys region of western and southern Asia: U.S. Geological Survey Scientific Investigations Report 2010-5090-V, http://dx.doi.org/10.3133/sir20105090V. 


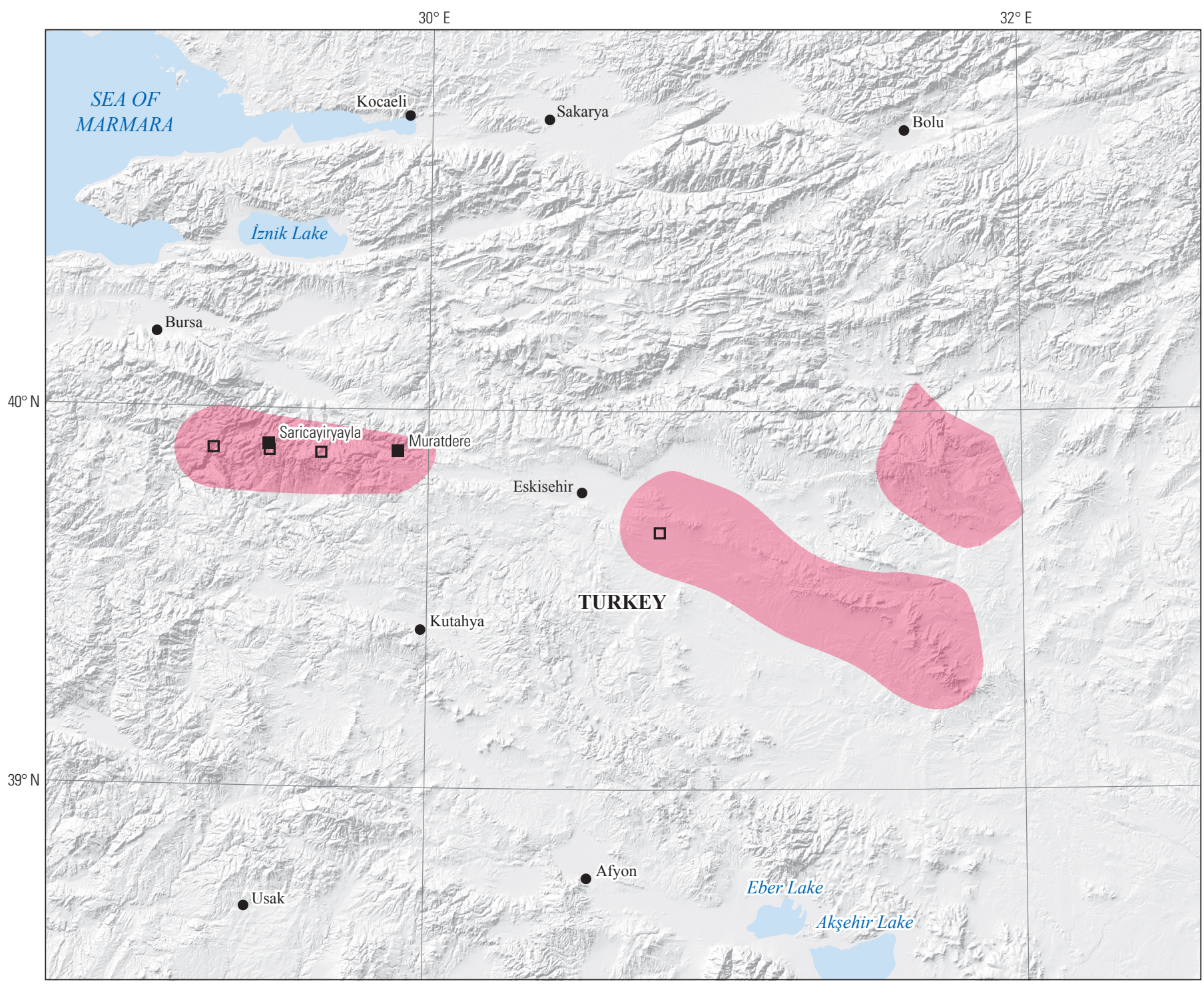

Political boundaries from U.S. Department of State (2009) Shaded relief from Earth Resources Observation and Science (EROS) Center (2011)

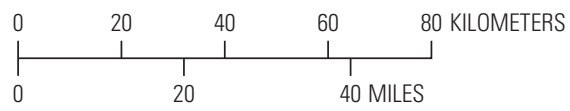

Europe Albers Equal-Area Conic projection

Central meridian $31^{\circ} \mathrm{E}$.; latitude of origin $30^{\circ} \mathrm{N}$.

\section{EXPLANATION}

Assessed porphyry copper tract 142pCu9005a

- Porphyry copper deposit

口 Porphyry copper prospect

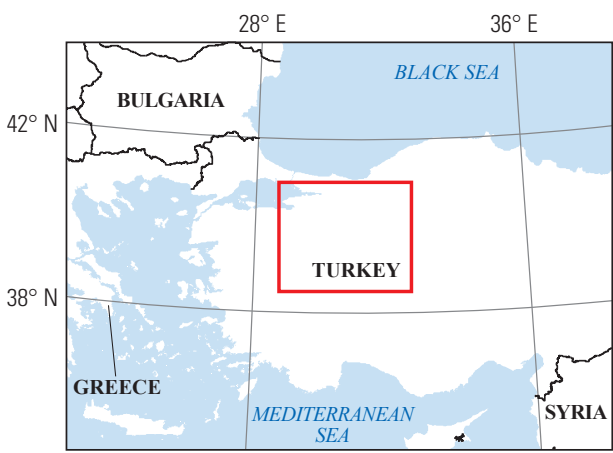




\title{
Plate 167. Porphyry Copper Assessment for Tract 142pCu9014a, Azerbaijan (West)-Turkey
}

\author{
Descriptive model: \\ Grade and tonnage model: \\ Porphyry copper models (Cox, 1986a; Berger and others, 2008; John and others, 2010) \\ Economic filter depth percentages: \\ General porphyry copper model (Singer, Berger, and Moring, 2008) \\ Economic filter cost setting: \\ Geologic feature assessed: \\ Default -0 to 250 meters (m), 25\%; > 250 to $500 \mathrm{~m}, 25 \%$; $>500 \mathrm{~m}$ to $1 \mathrm{~km}, 50 \%$ \\ Typical cost \\ Late Eocene to early Miocene rocks recording back-arc magmatism of the Tethyan metallogenic \\ belt \\ Number of known deposits: \\ 3
}

\section{Selected Resource Assessment Results for Porphyry Copper}

[Assessment depth, 1 kilometer ( $\mathrm{km}) ; \mathrm{km}^{2}$, square kilometer; Mt, millions of metric tons]

\begin{tabular}{ccccccc}
\hline $\begin{array}{c}\text { Date of } \\
\text { assessment }\end{array}$ & $\begin{array}{c}\text { Tract area } \\
\left(\mathbf{k m}^{2}\right)\end{array}$ & $\begin{array}{c}\text { Identified } \\
\text { copper } \\
\text { resources } \\
\text { (Mt) }\end{array}$ & $\begin{array}{c}\text { Mean estimate of } \\
\text { in-place resources } \\
(\mathbf{M t})\end{array}$ & $\begin{array}{c}\text { Probability of } \mathbf{0} \\
\text { in-place resources } \\
\text { (percent) }\end{array}$ & $\begin{array}{c}\text { Mean estimate of } \\
\text { economic resources } \\
\text { (Mt) }\end{array}$ & $\begin{array}{c}\text { Probability of 0 } \\
\text { economic resources } \\
\text { (percent) }\end{array}$ \\
\hline 2013 & 65,178 & 1.1 & 14 & 7 & 9.4 \\
\hline
\end{tabular}

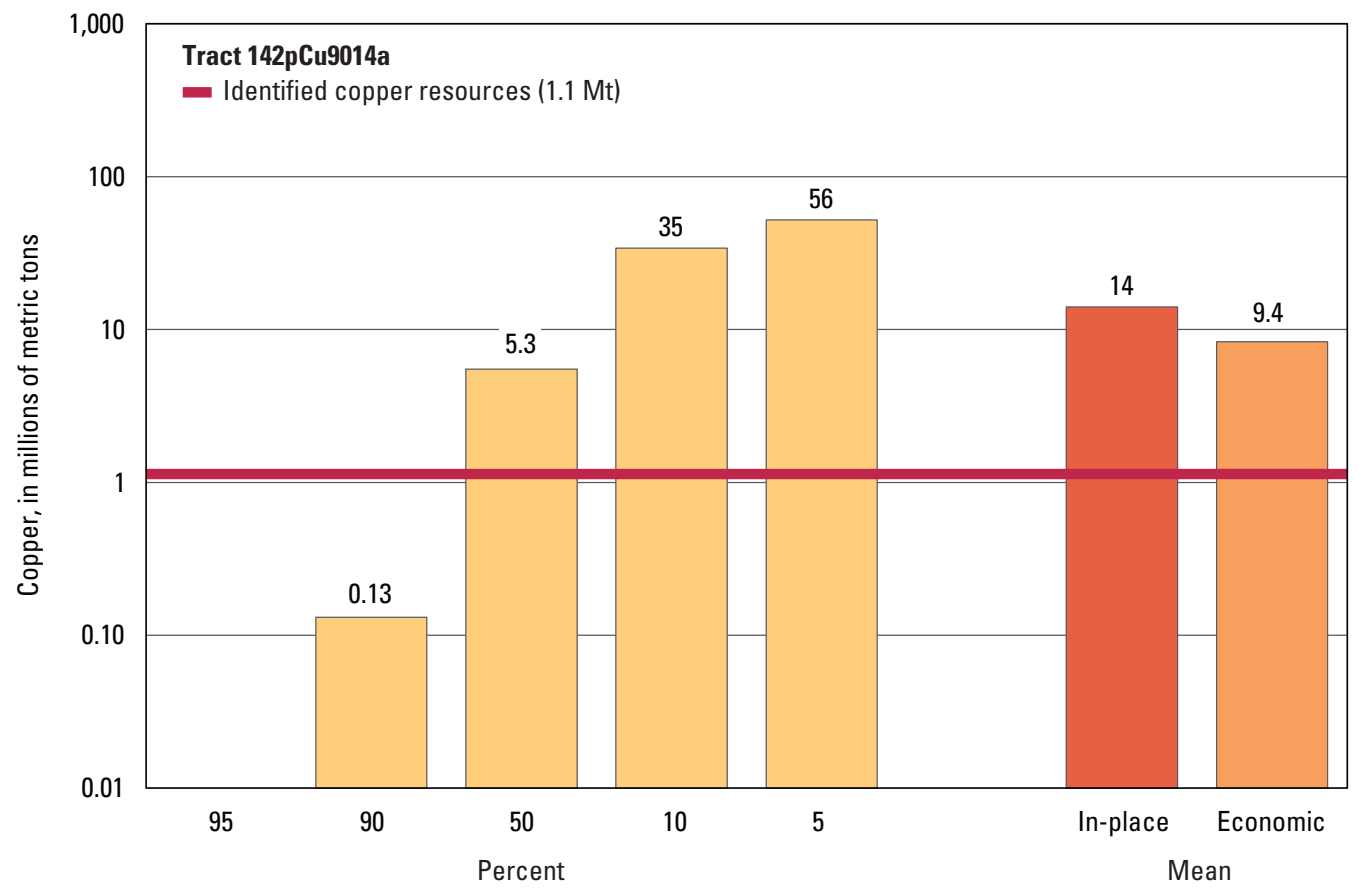

Graph showing the estimated probability distribution of undiscovered copper resources, where each bar represents the minimum amount estimated at the indicated percentage.

\section{Source}

Zürcher and others, 2015, Porphyry copper assessment of the Tethys region of western and southern Asia: U.S. Geological Survey Scientific Investigations Report 2010-5090-V, http://dx.doi.org/10.3133/sir20105090V. 


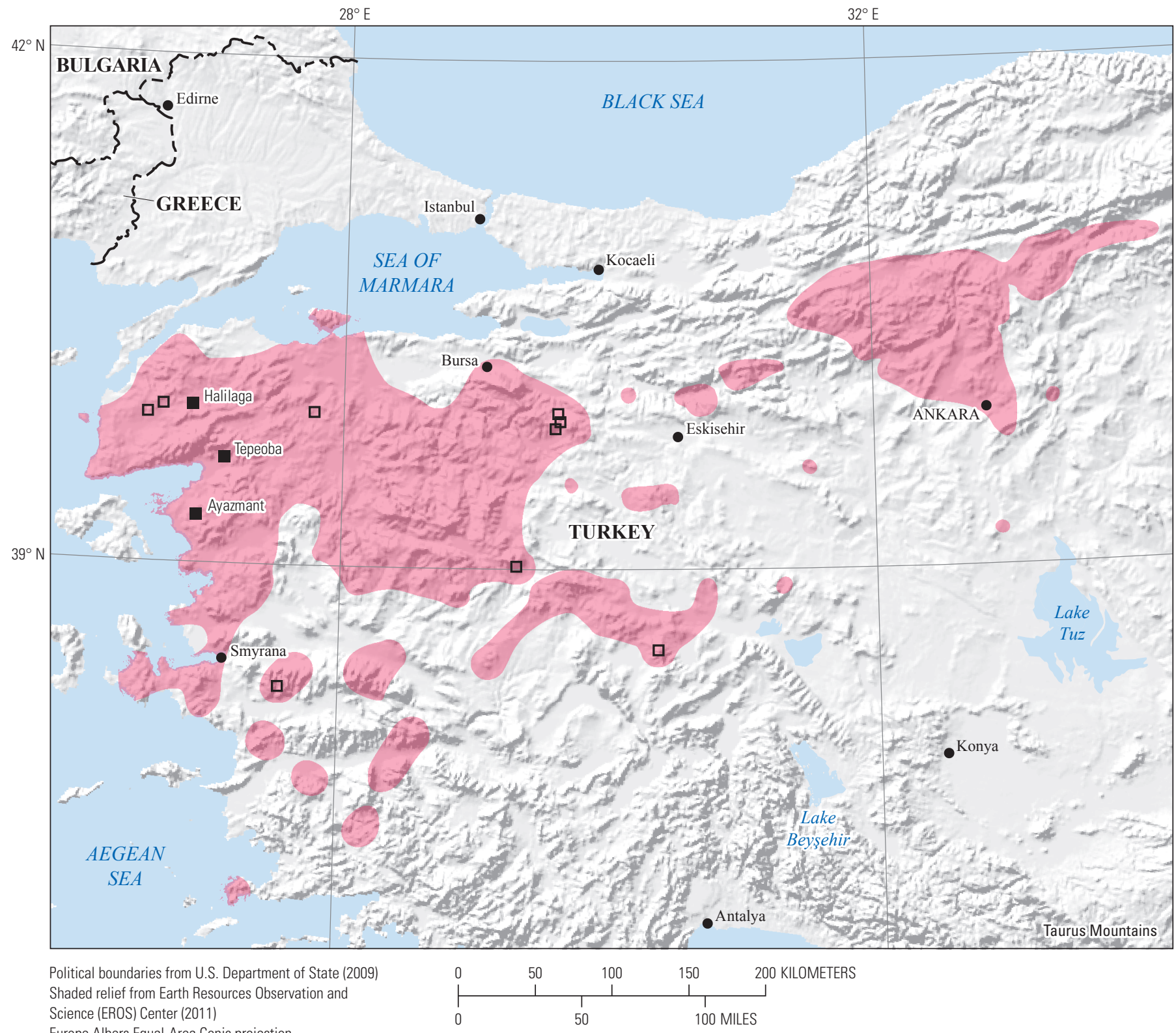

Europe Albers Equal-Area Conic projection

Central meridian $30^{\circ} \mathrm{E}$.; latitude of origin $30^{\circ} \mathrm{N}$.

EXPLANATION

\section{Assessed porphyry copper tract} 142pCu9014a

- Porphyry copper deposit

Porphyry copper prospect

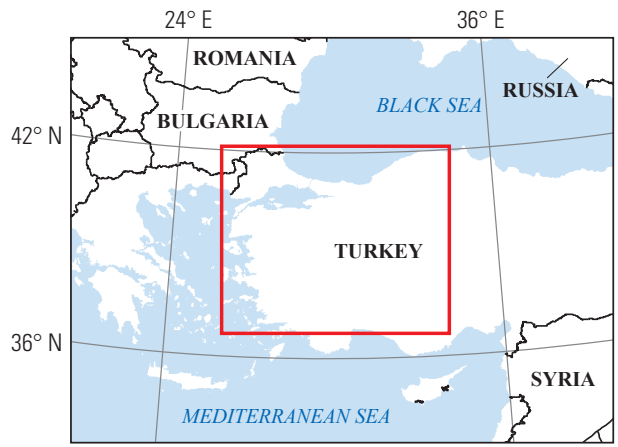




\title{
Plate 168. Porphyry Copper Assessment for Tract 150pCu6001, Transylvania- Balkan Mountains-Bulgaria, Serbia, Romania, and Turkey
}

\author{
Descriptive model: \\ Porphyry copper models (Cox, 1986a; Berger and others, 2008; John and others, 2010) \\ Grade and tonnage model: \\ General porphyry copper model (Singer, Berger, and Moring, 2008) \\ Economic filter depth percentages: \\ Economic filter cost setting: \\ Geologic feature assessed: \\ Default -0 to 250 meters (m), $25 \%$; > 250 to $500 \mathrm{~m}, 25 \%$; >500 m to $1 \mathrm{~km}, 50 \%$ \\ Mixed cost \\ Late Cretaceous and Paleocene calc-alkalic volcanic and intrusive rocks in the westernmost part of \\ the Late Cretaceous Tethyan Eurasian metallogenic belt \\ Number of known deposits: \\ 15
}

\section{Selected Resource Assessment Results for Porphyry Copper}

[Assessment depth, 1 kilometer ( $\mathrm{km}) ; \mathrm{km}^{2}$, square kilometer; Mt, millions of metric tons]

\begin{tabular}{ccccccc}
\hline $\begin{array}{c}\text { Date of } \\
\text { assessment }\end{array}$ & $\begin{array}{c}\text { Tract area } \\
\left(\mathbf{k m}^{2}\right)\end{array}$ & $\begin{array}{c}\text { Identified } \\
\text { copper } \\
\text { resources } \\
\text { (Mt) }\end{array}$ & $\begin{array}{c}\text { Mean estimate of } \\
\text { in-place resources } \\
(\mathbf{M t})\end{array}$ & $\begin{array}{c}\text { Probability of } \mathbf{0} \\
\text { in-place resources } \\
\text { (percent) }\end{array}$ & $\begin{array}{c}\text { Mean estimate of } \\
\text { economic resources } \\
\text { (Mt) }\end{array}$ & $\begin{array}{c}\text { Probability of 0 } \\
\text { economic resources } \\
\text { (percent) }\end{array}$ \\
\hline 2010 & 28,469 & 30 & 16 & 4 & 10 & 29 \\
\hline
\end{tabular}

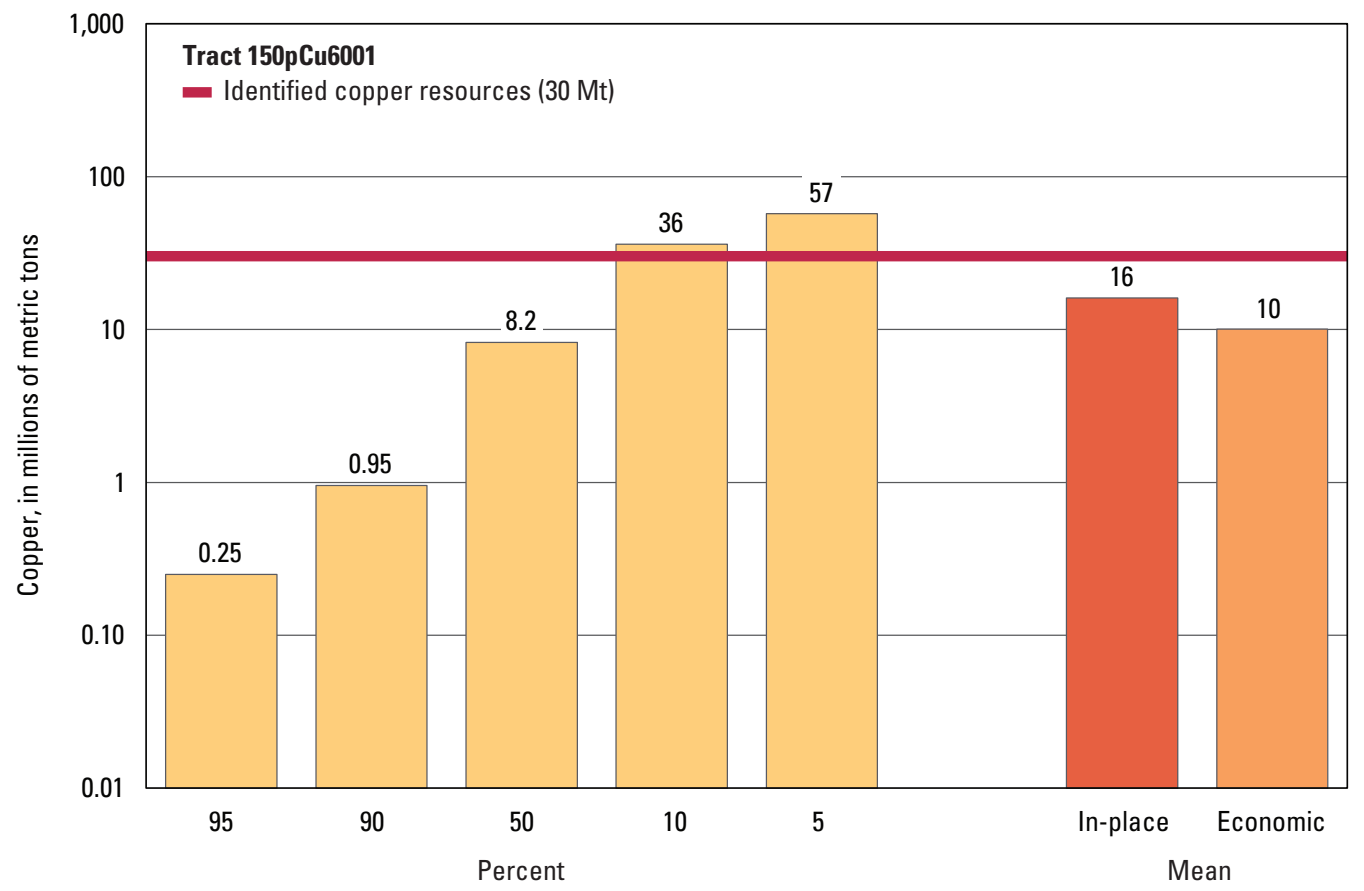

Graph showing the estimated probability distribution of undiscovered copper resources, where each bar represents the minimum amount estimated at the indicated percentage.

\section{Source}

Sutphin and others, 2013, Porphyry copper assessment of Europe, exclusive of the Fennoscandian Shield: U.S. Geological Survey Scientific Investigations Report 2010-5090-K, http://pubs.usgs.gov/sir/2010/5090/k/. 


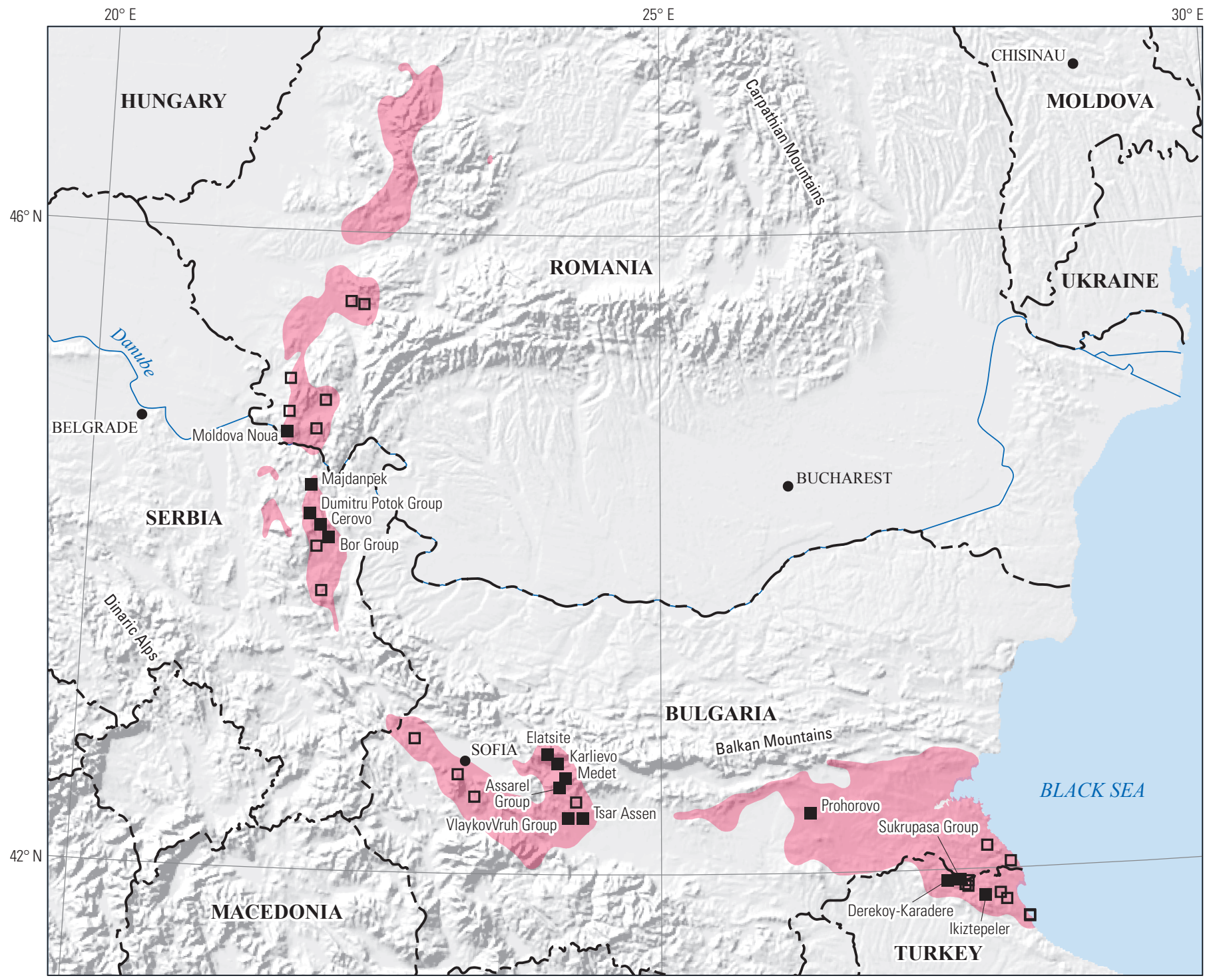

Political boundaries from U.S. Department of State (2009) Shaded relief from Earth Resources Observation and Science (EROS) Center (2011)

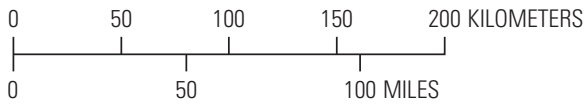

Europe Albers Equal-Area Conic projection

Central meridian $24^{\circ} 45^{\prime} \mathrm{E}$.; latitude of origin $30^{\circ} \mathrm{N}$.

\section{EXPLANATION}

Assessed porphyry copper tract 150pCu6001

- Porphyry copper deposit

口 Porphyry copper prospect

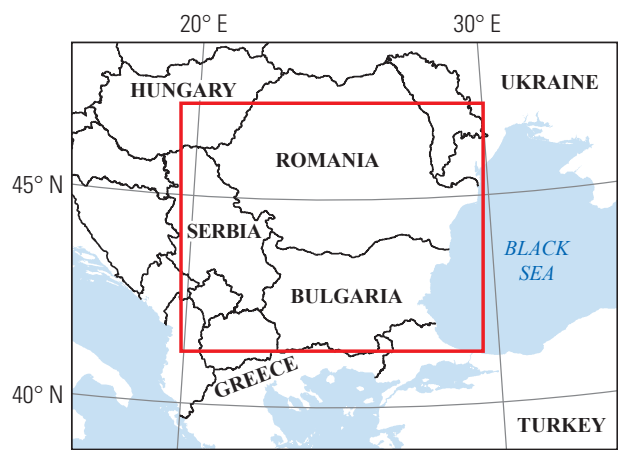




\section{Plate 169. Porphyry Copper Assessment for Tract 150pCu6003, Apuseni Mountains-Romania}

Descriptive model:

Grade and tonnage model:

Economic filter depth percentages:

Economic filter cost setting:

Geologic feature assessed:

Number of known deposits:

\author{
Porphyry copper, copper-gold subtype models (Cox, 1986b; Berger and others, 2008; John and \\ others, 2010) \\ Porphyry copper, copper-gold subtype model (Singer, Berger, and Moring, 2008) \\ Default -0 to 250 meters (m), 25\%; > 250 to $500 \mathrm{~m}, 25 \%$; >500 m to $1 \mathrm{~km}, 50 \%$ \\ Mixed cost \\ Miocene intrusive and volcanic intermediate and acidic rocks of the Golden Quadrilateral and \\ surrounding areas in the Apuseni Mountains of southern Romania \\ 7
}

\section{Selected Resource Assessment Results for Porphyry Copper}

[Assessment depth, 1 kilometer $(\mathrm{km}) ; \mathrm{km}^{2}$, square kilometer; Mt, millions of metric tons]

\begin{tabular}{|c|c|c|c|c|c|c|}
\hline \multirow[b]{2}{*}{$\begin{array}{c}\text { Date of } \\
\text { assessment }\end{array}$} & \multirow[b]{2}{*}{$\begin{array}{c}\text { Tract area } \\
\quad\left(\mathbf{k m}^{2}\right)\end{array}$} & \multirow{2}{*}{$\begin{array}{l}\text { Identified } \\
\text { copper } \\
\text { resources } \\
\text { (Mt) }\end{array}$} & \multicolumn{4}{|c|}{ Undiscovered copper resource estimates } \\
\hline & & & $\begin{array}{l}\text { Mean estimate of } \\
\text { in-place resources } \\
\text { (Mt) }\end{array}$ & $\begin{array}{c}\text { Probability of } 0 \\
\text { in-place resources } \\
\text { (percent) }\end{array}$ & $\begin{array}{l}\text { Mean estimate of } \\
\text { economic resources } \\
\text { (Mt) }\end{array}$ & $\begin{array}{c}\text { Probability of } 0 \\
\text { economic resources } \\
\text { (percent) }\end{array}$ \\
\hline 2010 & 4,156 & 5.7 & 10 & 7 & 5.4 & 64 \\
\hline
\end{tabular}

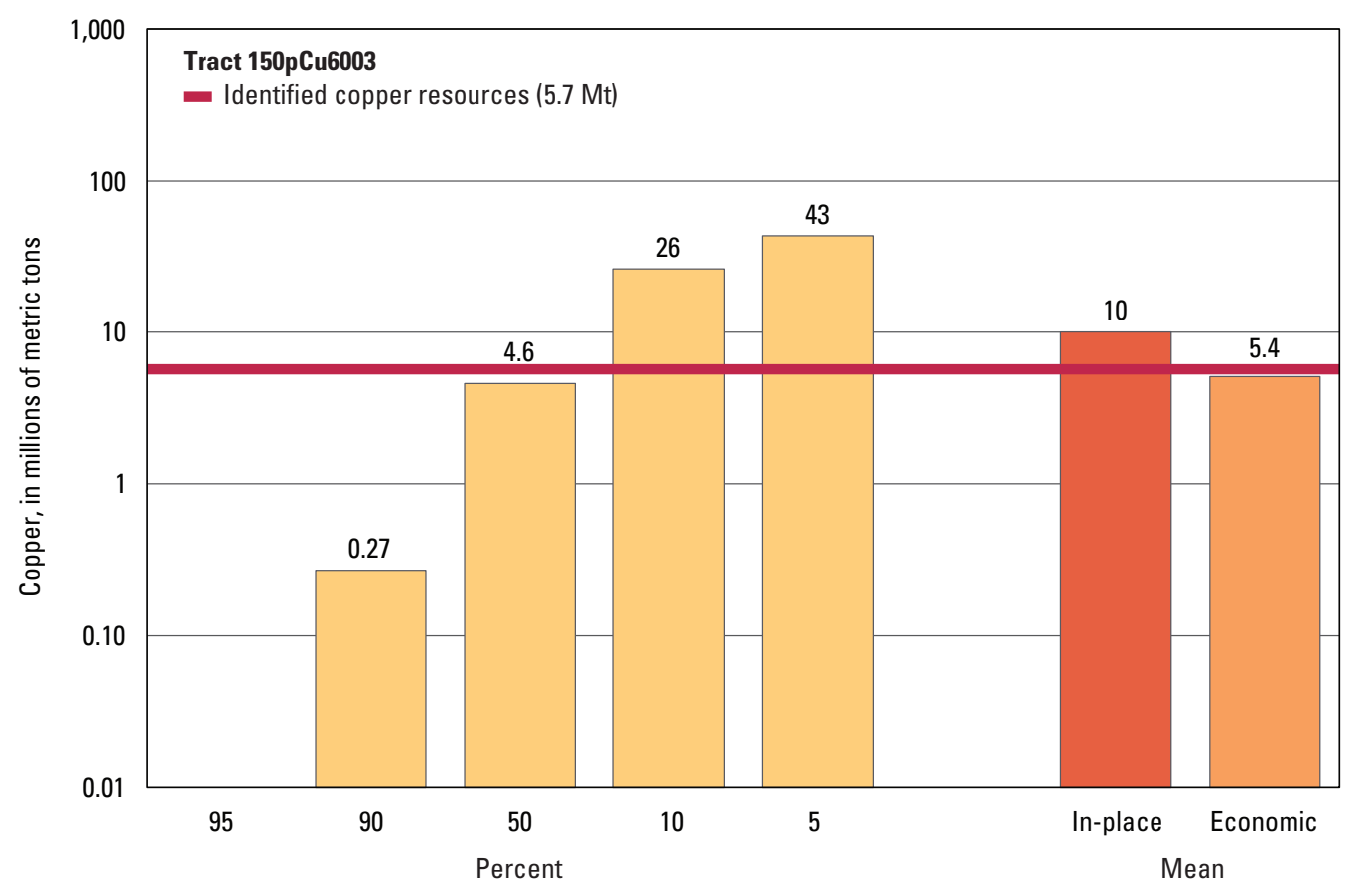

Graph showing the estimated probability distribution of undiscovered copper resources, where each bar represents the minimum amount estimated at the indicated percentage.

\section{Source}

Sutphin and others, 2013, Porphyry copper assessment of Europe, exclusive of the Fennoscandian Shield: U.S. Geological Survey Scientific Investigations Report 2010-5090-K, http://pubs.usgs.gov/sir/2010/5090/k/. 


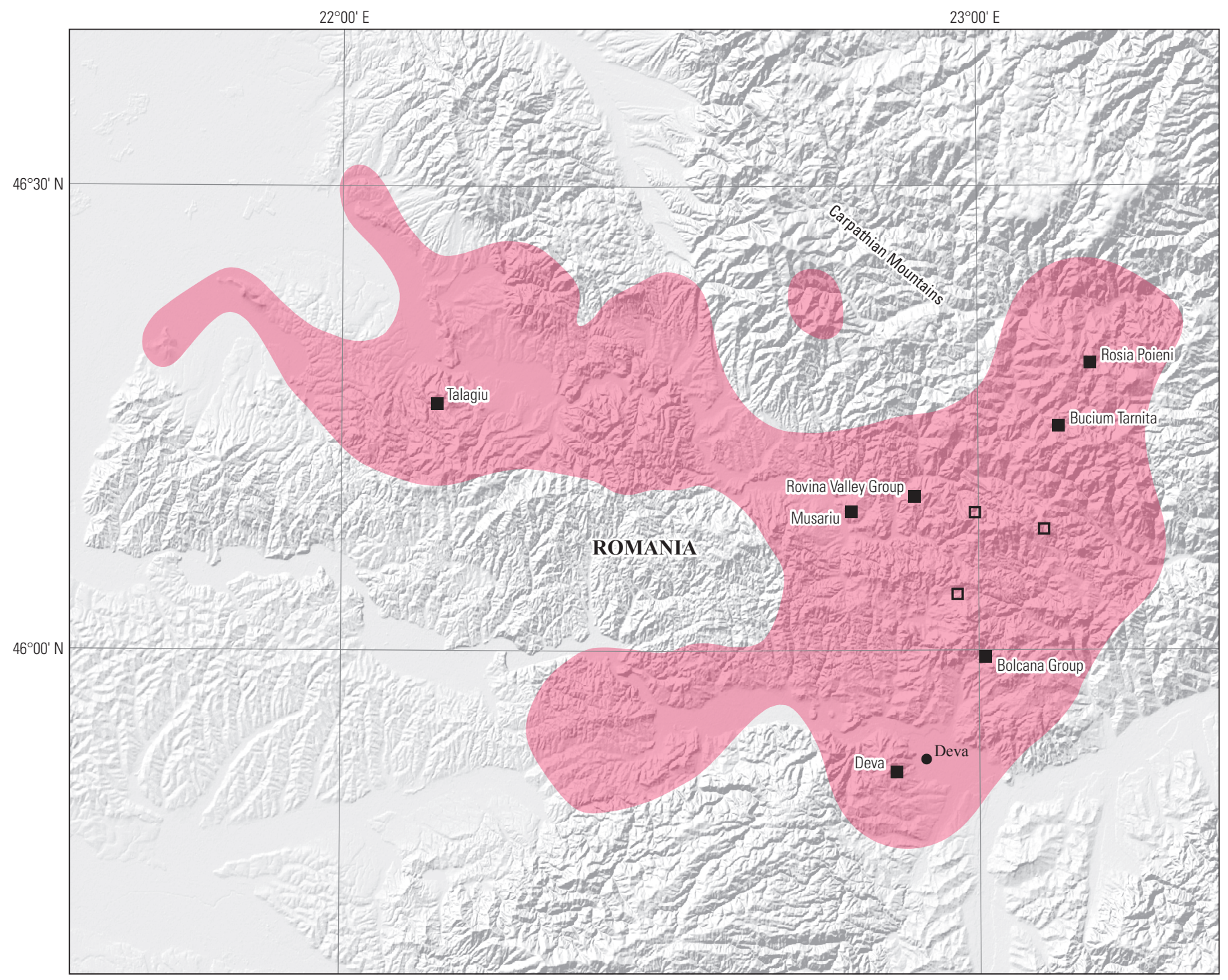

Political boundaries from U.S. Department of State (2009) Shaded relief from ESRI (2008)

Europe Albers Equal-Area Conic projection

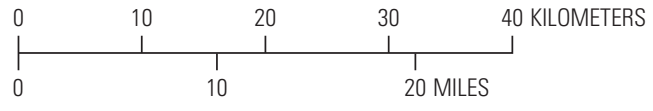

Central meridian $22^{\circ} 30^{\prime}$ E.; latitude of origin $30^{\circ} \mathrm{N}$

\section{EXPLANATION}

Assessed porphyry copper tract 150 Cu6003

- Porphyry copper deposit

Porphyry copper prospect

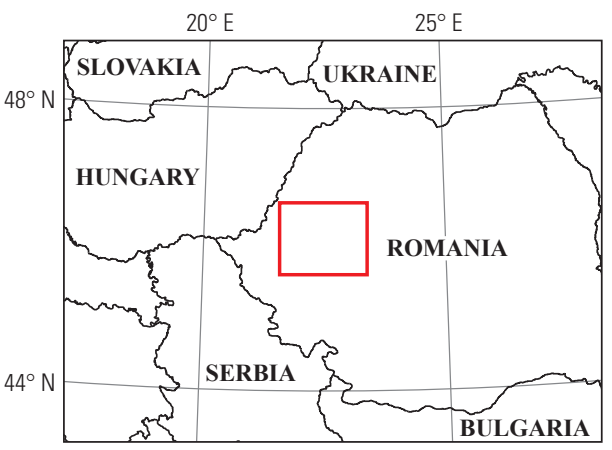




\section{Plate 170. Porphyry Copper Assessment for Tract 150pCu6004, Northern Carpathians-Hungary, Romania, Slovakia, and Ukraine}

Descriptive model:

Grade and tonnage model:

Economic filter depth percentages:

Economic filter cost setting:

Geologic feature assessed:

Number of known deposits:
Porphyry copper, copper-gold subtype models (Cox, 1986b; Berger and others, 2008; John and others, 2010)

Porphyry copper, copper-gold subtype model (Singer, Berger, and Moring, 2008)

Skewed deep-0 to 250 meters (m), 10\%; > 250 to $500 \mathrm{~m}, 30 \%$; >500 m to $1 \mathrm{~km}, 60 \%$

Mixed cost

An arcuate belt of calc-alkalic volcanic and intrusive rocks that formed in a postsubduction setting due to extension, lithospheric thinning, and mantle upwelling

\section{Selected Resource Assessment Results for Porphyry Copper}

[Assessment depth, 1 kilometer $(\mathrm{km}) ; \mathrm{km}^{2}$, square kilometer; Mt, millions of metric tons]

\begin{tabular}{|c|c|c|c|c|c|c|}
\hline \multirow[b]{2}{*}{$\begin{array}{c}\text { Date of } \\
\text { assessment }\end{array}$} & \multirow[b]{2}{*}{$\begin{array}{c}\text { Tract area } \\
\quad\left(\mathbf{k m}^{2}\right)\end{array}$} & \multirow{2}{*}{$\begin{array}{l}\text { Identified } \\
\text { copper } \\
\text { resources } \\
\text { (Mt) }\end{array}$} & \multicolumn{4}{|c|}{ Undiscovered copper resource estimates } \\
\hline & & & $\begin{array}{l}\text { Mean estimate of } \\
\text { in-place resources } \\
\text { (Mt) }\end{array}$ & $\begin{array}{c}\text { Probability of } 0 \\
\text { in-place resources } \\
\text { (percent) }\end{array}$ & $\begin{array}{l}\text { Mean estimate of } \\
\text { economic resources } \\
\text { (Mt) }\end{array}$ & $\begin{array}{c}\text { Probability of } 0 \\
\text { economic resources } \\
\text { (percent) }\end{array}$ \\
\hline 2010 & 28,846 & 0.73 & 7.9 & 19 & 3.9 & 81 \\
\hline
\end{tabular}

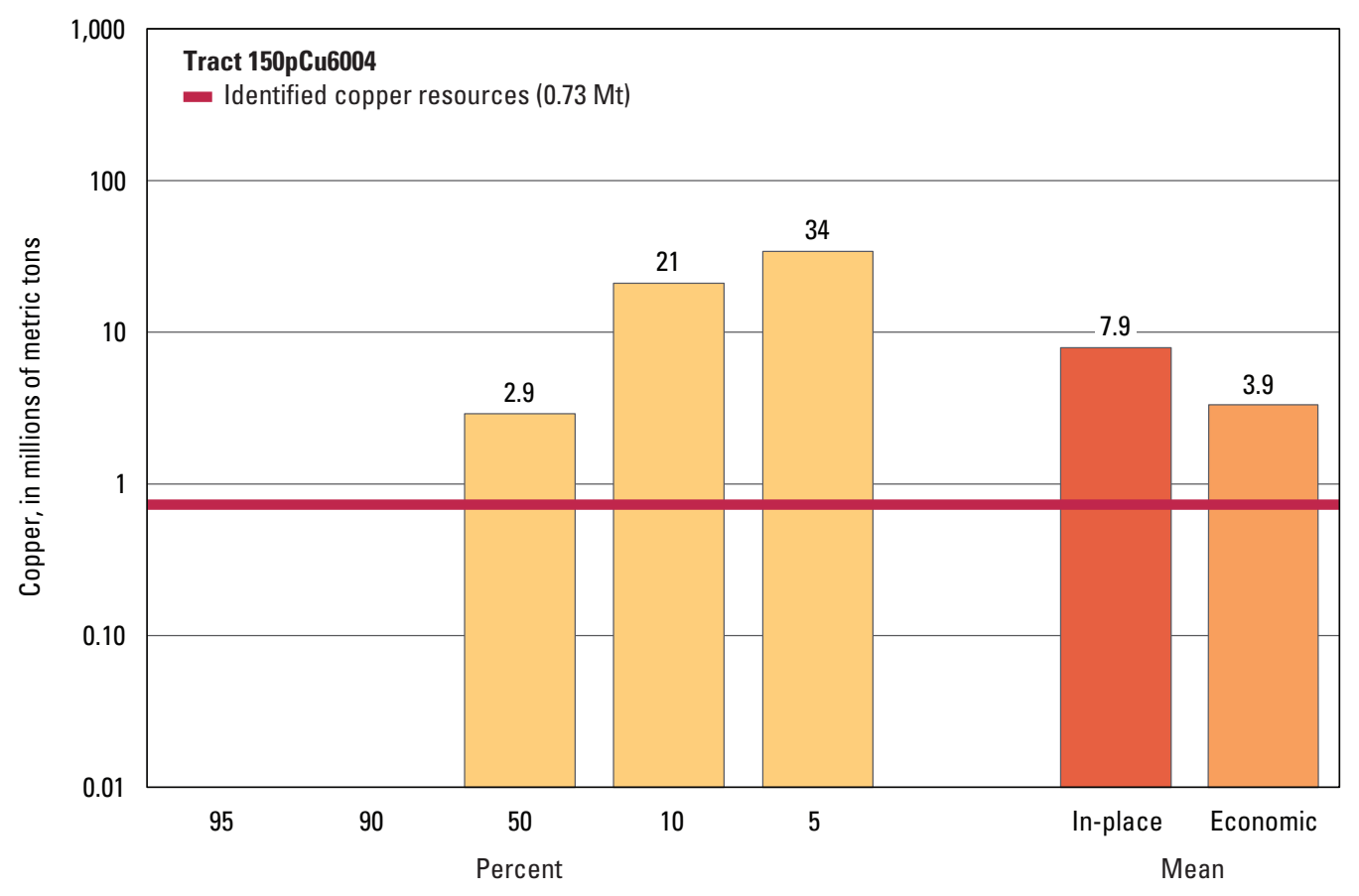

Graph showing the estimated probability distribution of undiscovered copper resources, where each bar represents the minimum amount estimated at the indicated percentage.

\section{Source}

Sutphin and others, 2013, Porphyry copper assessment of Europe, exclusive of the Fennoscandian Shield: U.S. Geological Survey Scientific Investigations Report 2010-5090-K, http://pubs.usgs.gov/sir/2010/5090/k/. 


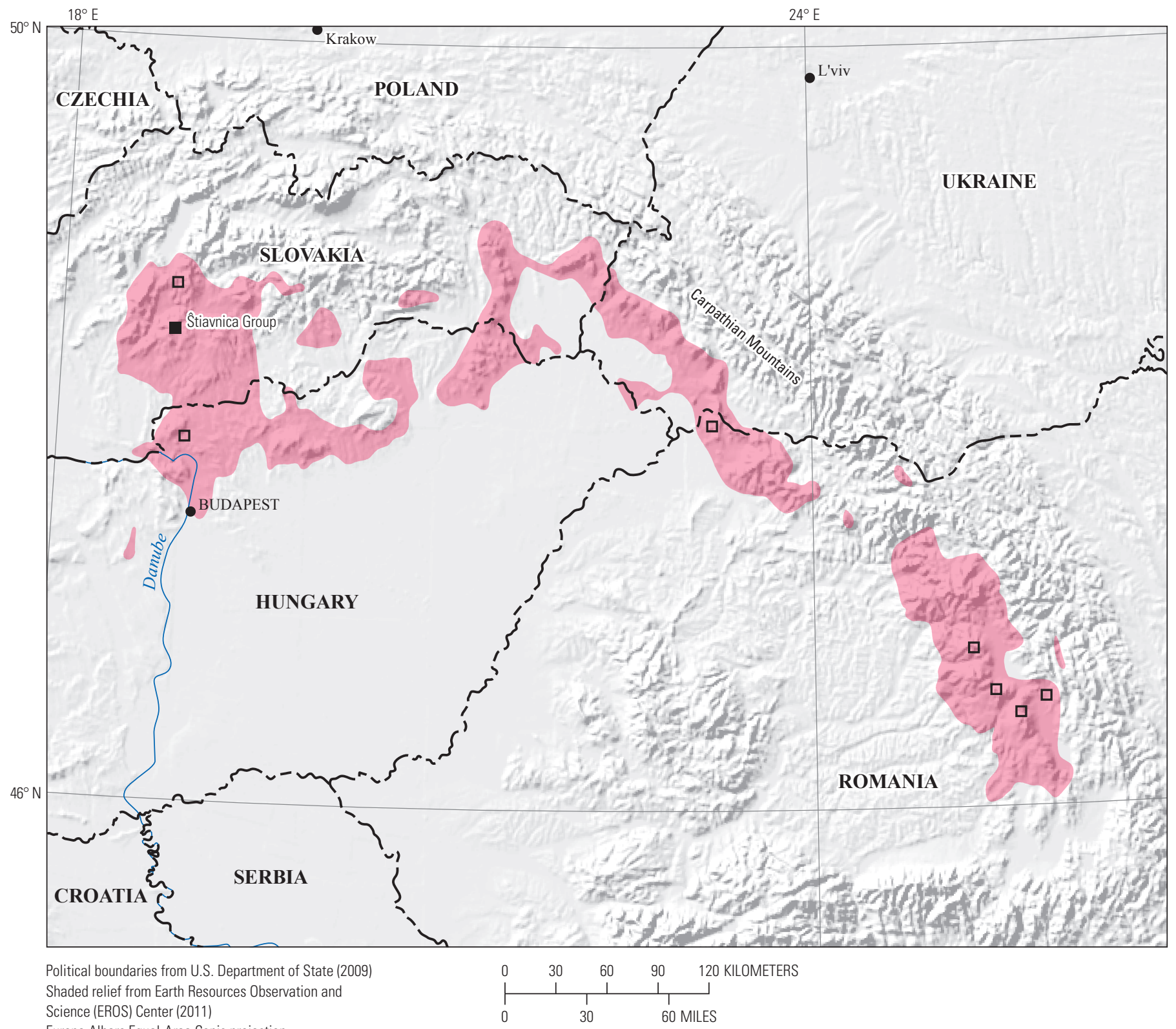

Europe Albers Equal-Area Conic projection

Central meridian $22^{\circ} 45^{\prime} \mathrm{E}$.; latitude of origin $30^{\circ} \mathrm{N}$.

\section{EXPLANATION}

D/A Assessed porphyry copper tract 150pCu6004

- Porphyry copper deposit

$\square \quad$ Porphyry copper prospect

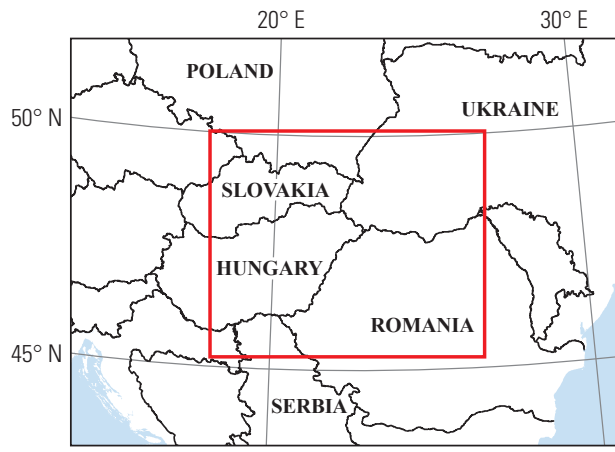




\section{Plate 171. Porphyry Copper Assessment for Tract 150pCu6002, Dinaride-Aegean Region-Eastern Europe}

Descriptive model:

Grade and tonnage model:

Economic filter depth percentages:

Economic filter cost setting:

Geologic feature assessed:

Number of known deposits:

\author{
Porphyry copper, copper-gold subtype models (Cox, 1986b; Berger and others, 2008; John and \\ others, 2010) \\ Porphyry copper, copper-gold subtype model (Singer, Berger, and Moring, 2008) \\ Default -0 to 250 meters (m), 25\%; >250 to $500 \mathrm{~m}, 25 \%$; $>500 \mathrm{~m}$ to $1 \mathrm{~km}, 50 \%$ \\ Mixed cost \\ Paleocene to Miocene calc-alkalic volcanic and intrusive rocks that formed in a postsubduction \\ environment; includes the Serbomacedonian-Rhodope metallogenic belt \\ 4
}

\section{Selected Resource Assessment Results for Porphyry Copper}

[Assessment depth, 1 kilometer $(\mathrm{km}) ; \mathrm{km}^{2}$, square kilometer; Mt, millions of metric tons]

\begin{tabular}{|c|c|c|c|c|c|c|}
\hline \multirow[b]{2}{*}{$\begin{array}{c}\text { Date of } \\
\text { assessment }\end{array}$} & \multirow[b]{2}{*}{$\begin{array}{c}\text { Tract area } \\
\quad\left(\mathbf{k m}^{2}\right)\end{array}$} & \multirow{2}{*}{$\begin{array}{l}\text { Identified } \\
\text { copper } \\
\text { resources } \\
\text { (Mt) }\end{array}$} & \multicolumn{4}{|c|}{ Undiscovered copper resource estimates } \\
\hline & & & $\begin{array}{l}\text { Mean estimate of } \\
\text { in-place resources } \\
\text { (Mt) }\end{array}$ & $\begin{array}{c}\text { Probability of } 0 \\
\text { in-place resources } \\
\text { (percent) }\end{array}$ & $\begin{array}{l}\text { Mean estimate of } \\
\text { economic resources } \\
\text { (Mt) }\end{array}$ & $\begin{array}{c}\text { Probability of } 0 \\
\text { economic resources } \\
\text { (percent) }\end{array}$ \\
\hline 2010 & 92,723 & 7.2 & 12 & 7 & 7.7 & 59 \\
\hline
\end{tabular}

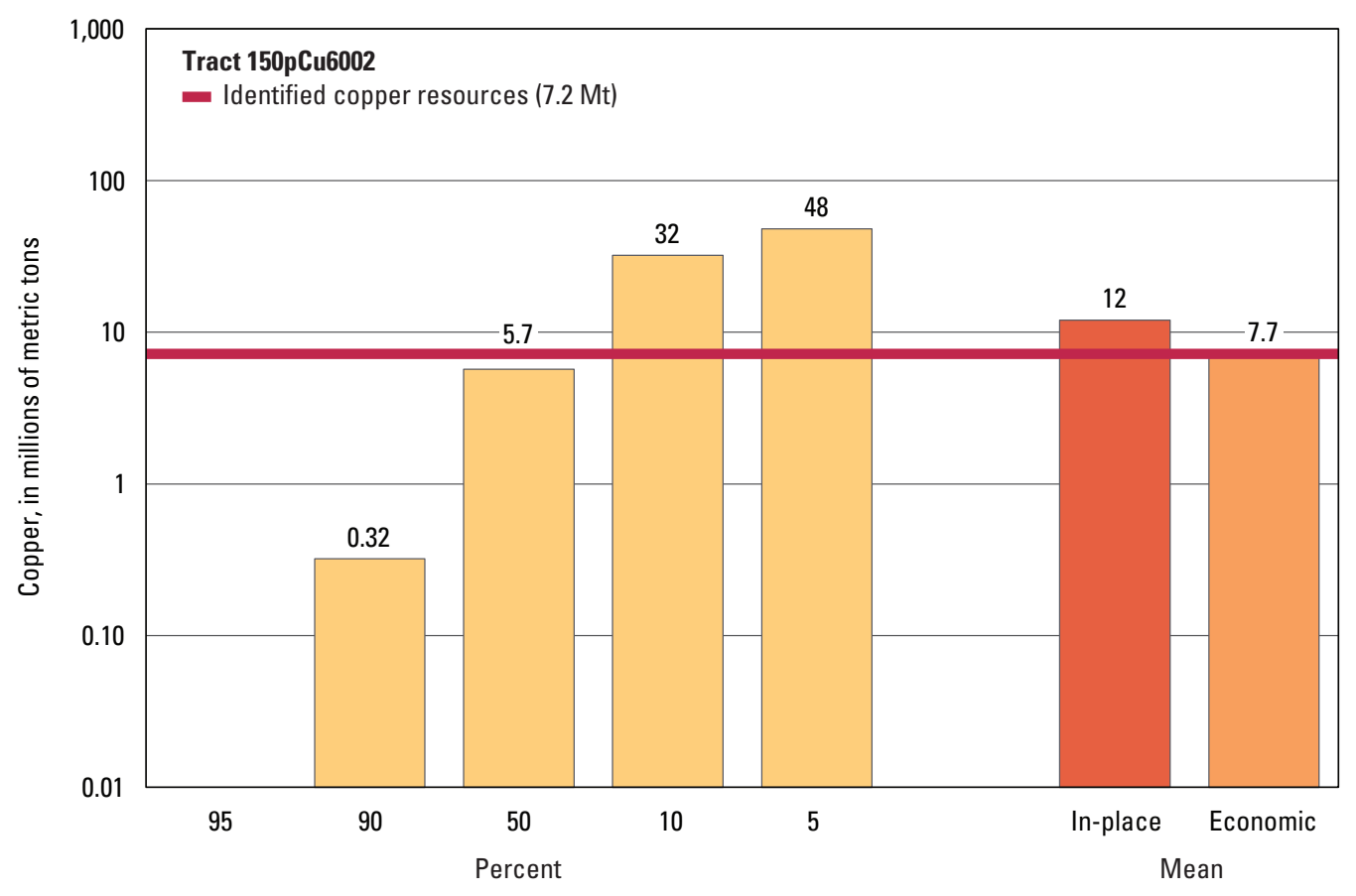

Graph showing the estimated probability distribution of undiscovered copper resources, where each bar represents the minimum amount estimated at the indicated percentage.

\section{Source}

Sutphin and others, 2013, Porphyry copper assessment of Europe, exclusive of the Fennoscandian Shield: U.S. Geological Survey Scientific Investigations Report 2010-5090-K, http://pubs.usgs.gov/sir/2010/5090/k/. 


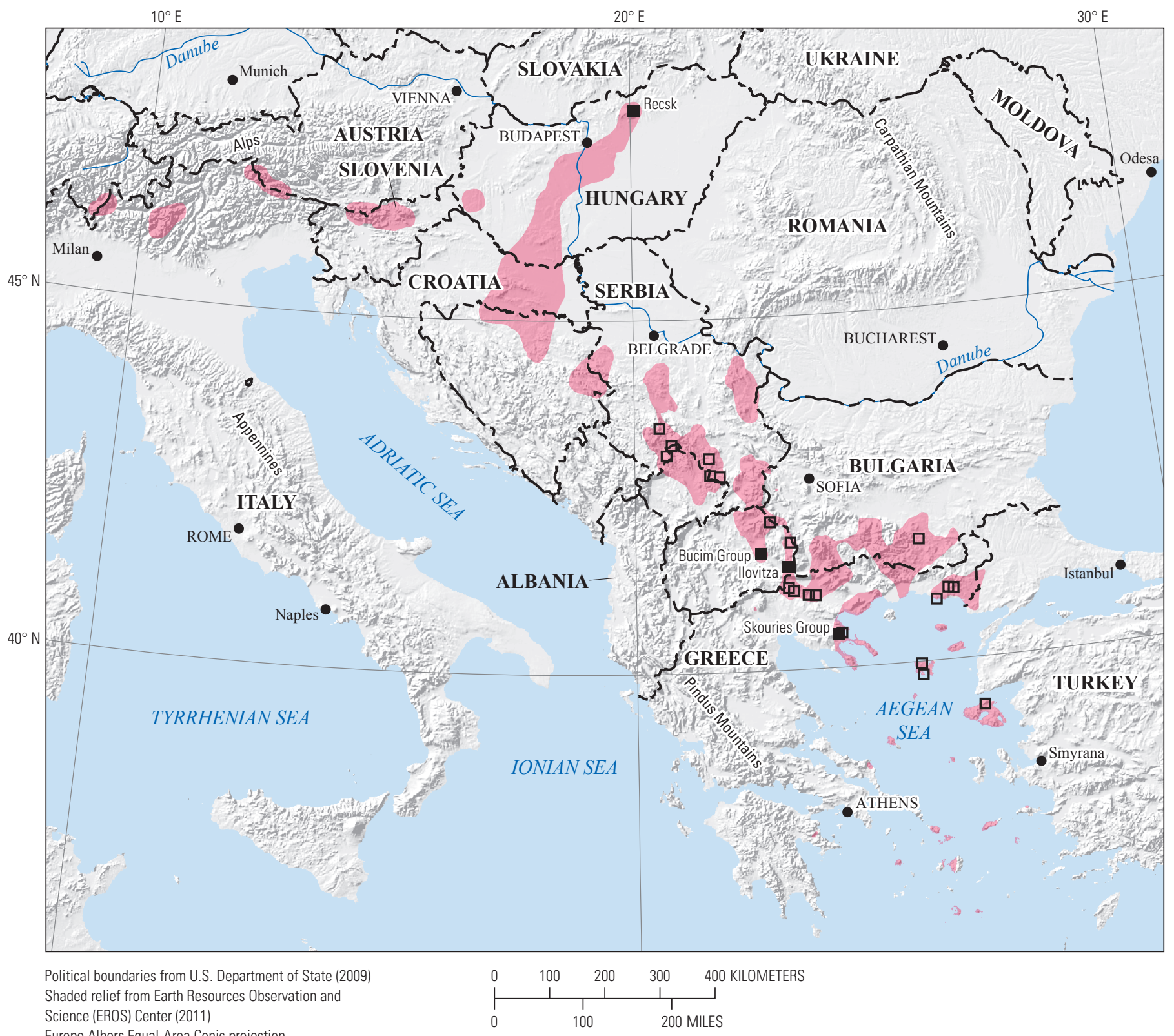

Europe Albers Equal-Area Conic projection

Central meridian $19^{\circ} \mathrm{E}$.; latitude of origin $30^{\circ} \mathrm{N}$.

\section{EXPLANATION}

Assessed porphyry copper tract
150pCu6002

- Porphyry copper deposit

Porphyry copper prospect

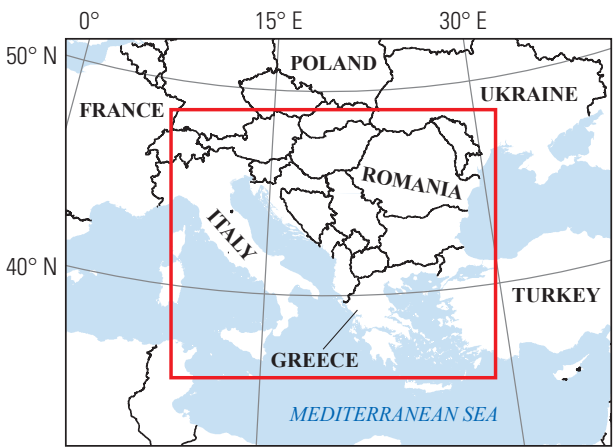




\section{Plate 172. Porphyry Copper Assessment for Tract 142pCu8202, Tagil-Polar Urals-Russia}

\section{Descriptive model:}

Grade and tonnage model:

Economic filter depth percentages:

Economic filter cost setting:

Geologic feature assessed:

Number of known deposits:

\author{
Porphyry copper models (Cox, 1986a; Berger and others, 2008; John and others, 2010) \\ General porphyry copper model (Singer, Berger, and Moring, 2008) \\ Default -0 to 250 meters (m), $25 \%$; $>250$ to $500 \mathrm{~m}, 25 \%$; $>500 \mathrm{~m}$ to $1 \mathrm{~km}, 50 \%$ \\ High cost \\ Silurian to Late Devonian Tagil intra-oceanic volcanic arc and middle Paleozoic calc-alkalic \\ intrusions and volcanic rocks of the northern and polar Urals \\ 0
}

\section{Selected Resource Assessment Results for Porphyry Copper}

[Assessment depth, 1 kilometer (km); $\mathrm{km}^{2}$, square kilometer; Mt, millions of metric tons]

\begin{tabular}{ccccccc}
\hline $\begin{array}{c}\text { Date of } \\
\text { assessment }\end{array}$ & $\begin{array}{c}\text { Tract area } \\
\left(\mathbf{k m}^{2}\right)\end{array}$ & $\begin{array}{c}\text { Identified } \\
\text { copper } \\
\text { resources } \\
(\mathbf{M t})\end{array}$ & $\begin{array}{c}\text { Mean estimate of } \\
\text { in-place resources } \\
(\mathbf{M t})\end{array}$ & $\begin{array}{c}\text { Probability of } \mathbf{0} \\
\text { in-place resources } \\
\text { (percent) }\end{array}$ & $\begin{array}{c}\text { Mean estimate of } \\
\text { economic resources } \\
\text { (Mt) }\end{array}$ & $\begin{array}{c}\text { Probability of 0 } \\
\text { economic resources } \\
\text { (percent) }\end{array}$ \\
\hline 2016 & 49,605 & 0 & 17 & 6 & 8.3 \\
\hline
\end{tabular}

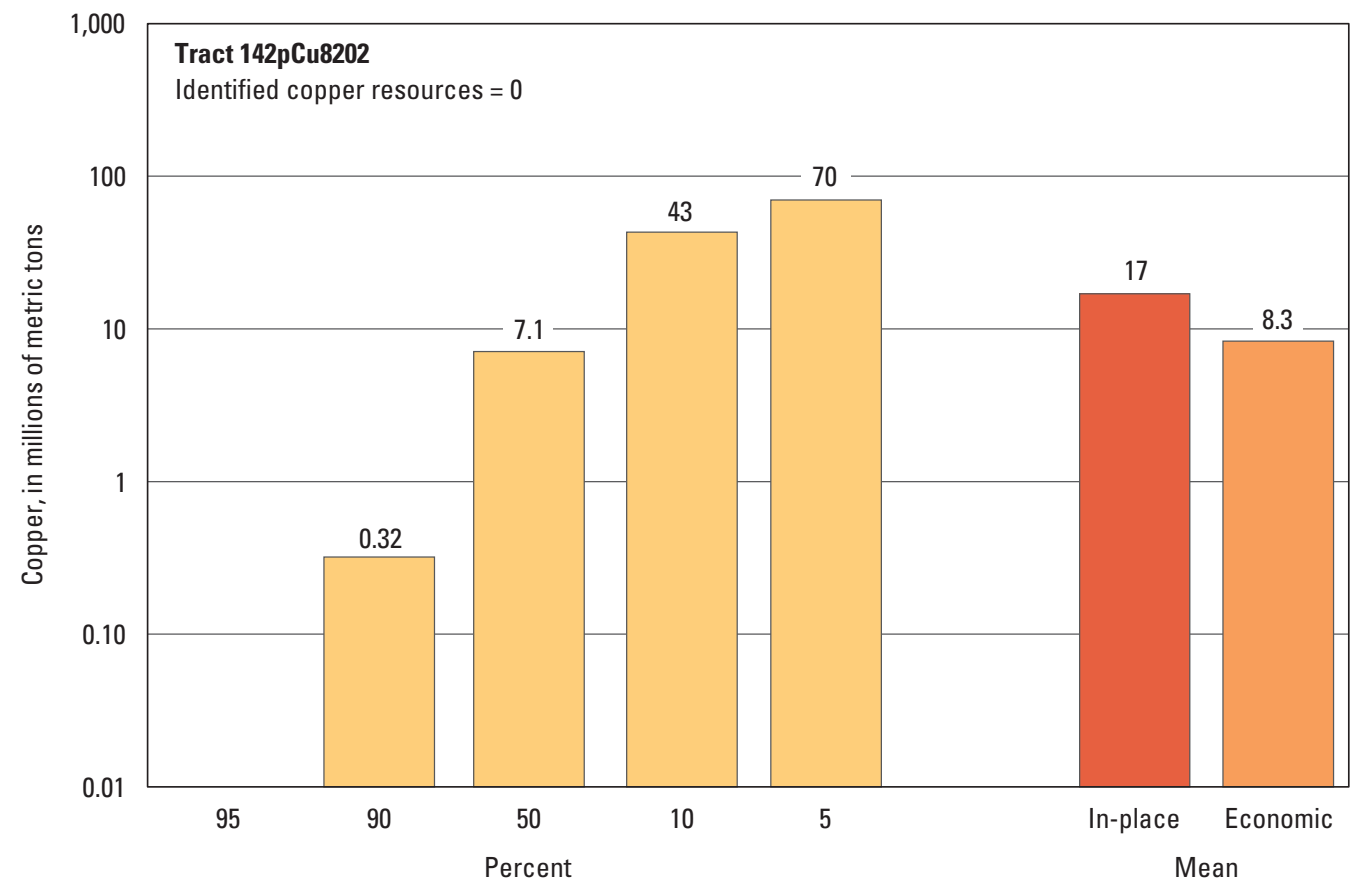

Graph showing the estimated probability distribution of undiscovered copper resources, where each bar represents the minimum amount estimated at the indicated percentage.

\section{Source}

Hammarstrom, Mihalasky, and others, 2017, Undiscovered porphyry copper resources in the Urals-A probabilistic mineral resource assessment: Ore Geology Reviews, http://dx.doi.org/10.1016/j.oregeorev.2016.09.007. 

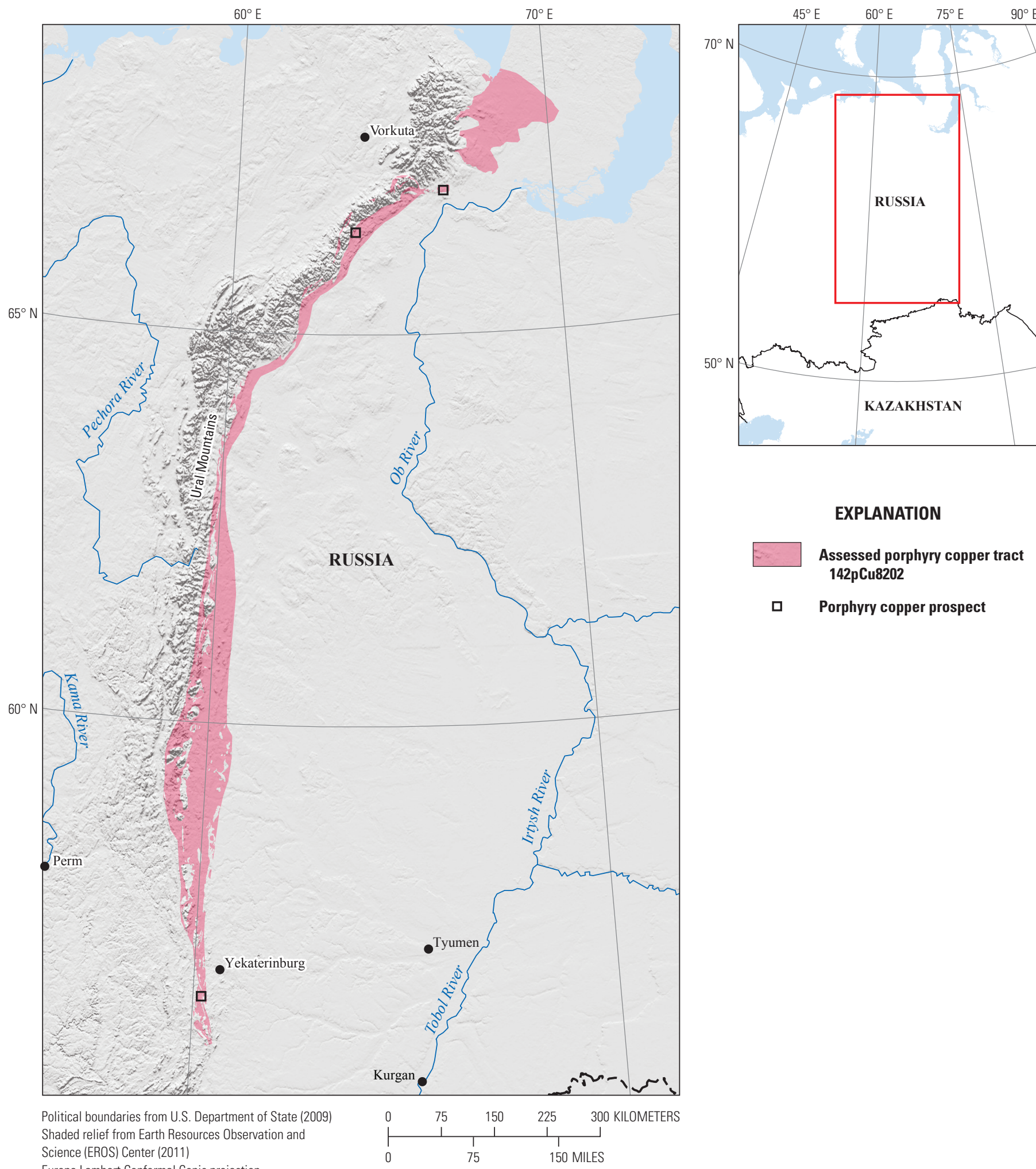

EXPLANATION

Assessed porphyry copper tract 142pCu8202

口 Porphyry copper prospect

Europe Lambert Conformal Conic projection

Central meridian $64^{\circ} \mathrm{E}$.; latitude of origin $40^{\circ} \mathrm{N}$. 


\title{
Plate 173. Porphyry Copper Assessment for Tract 142pCu8201, Magnitogorsk- Russia and Kazakhstan
}

\author{
Descriptive model: \\ Grade and tonnage model: \\ Porphyry copper models (Cox, 1986a; Berger and others, 2008; John and others, 2010) \\ Economic filter depth percentages: \\ Economic filter cost setting: \\ Geologic feature assessed: \\ General porphyry copper model (Singer, Berger, and Moring, 2008) \\ Default - 0 to 250 meters (m), 25\%; > 250 to $500 \mathrm{~m}, 25 \%$; > $500 \mathrm{~m}$ to $1 \mathrm{~km}, 50 \%$ \\ Mixed cost \\ Middle to Late Devonian rocks of the Magnitogorsk intra-oceanic volcanic arc \\ Number of known deposits: \\ 1
}

\section{Selected Resource Assessment Results for Porphyry Copper}

[Assessment depth, 1 kilometer $(\mathrm{km}) ; \mathrm{km}^{2}$, square kilometer; Mt, millions of metric tons]

\begin{tabular}{|c|c|c|c|c|c|c|}
\hline \multirow[b]{2}{*}{$\begin{array}{c}\text { Date of } \\
\text { assessment }\end{array}$} & \multirow[b]{2}{*}{$\begin{array}{c}\text { Tract area } \\
\quad\left(\mathrm{km}^{2}\right)\end{array}$} & \multirow{2}{*}{$\begin{array}{l}\text { Identified } \\
\text { copper } \\
\text { resources } \\
\text { (Mt) }\end{array}$} & \multicolumn{4}{|c|}{ Undiscovered copper resource estimates } \\
\hline & & & $\begin{array}{l}\text { Mean estimate of } \\
\text { in-place resources } \\
\text { (Mt) }\end{array}$ & $\begin{array}{c}\text { Probability of } 0 \\
\text { in-place resources } \\
\text { (percent) }\end{array}$ & $\begin{array}{l}\text { Mean estimate of } \\
\text { economic resources } \\
\text { (Mt) }\end{array}$ & $\begin{array}{c}\text { Probability of } 0 \\
\text { economic resources } \\
\text { (percent) }\end{array}$ \\
\hline 2016 & 49,321 & 0.041 & 17 & 4 & 10 & 59 \\
\hline
\end{tabular}

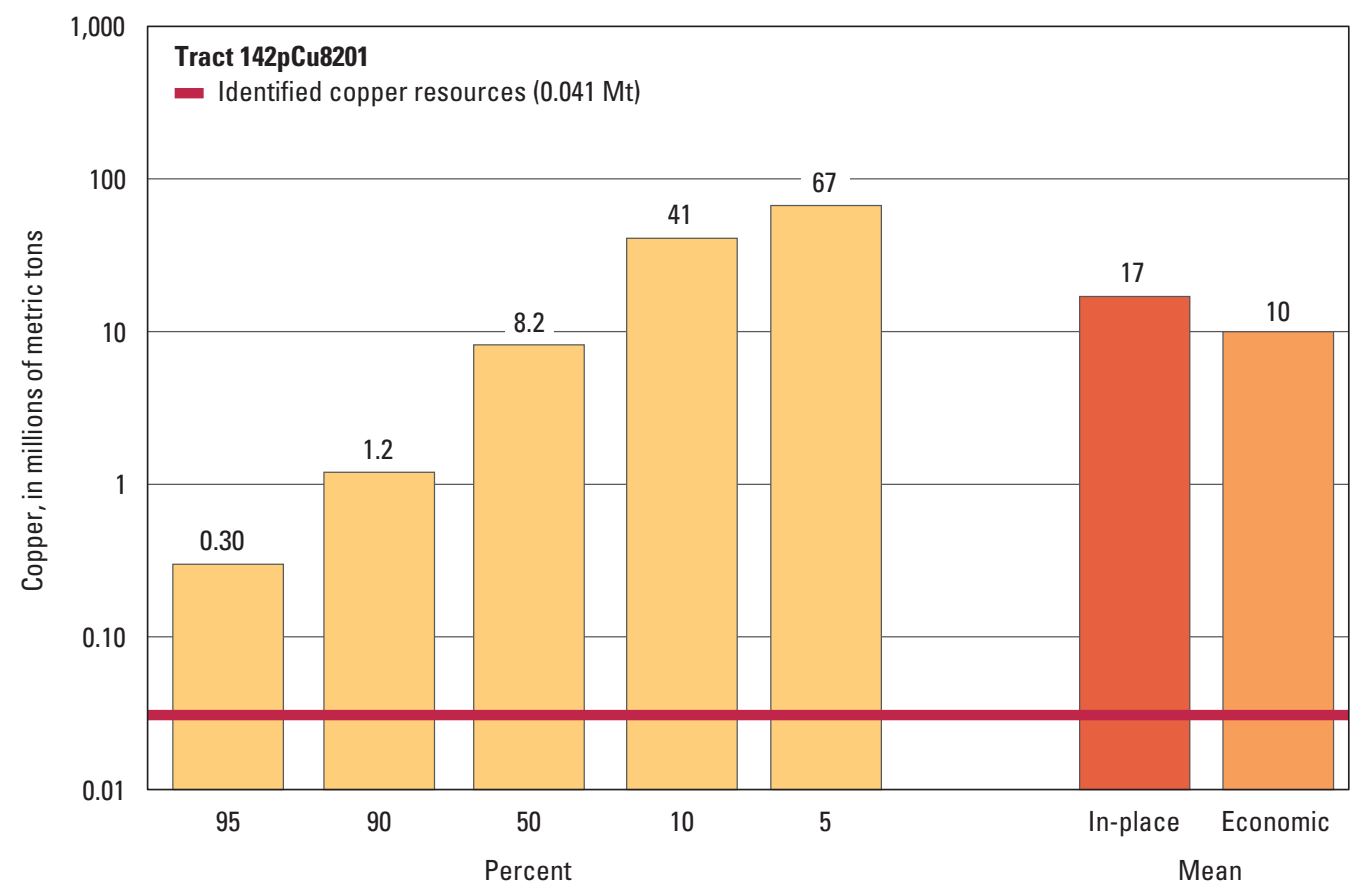

Graph showing the estimated probability distribution of undiscovered copper resources, where each bar represents the minimum amount estimated at the indicated percentage.

\section{Source}

Hammarstrom, Mihalasky, and others, 2017, Undiscovered porphyry copper resources in the Urals-A probabilistic mineral resource assessment: Ore Geology Reviews, http://dx.doi.org/10.1016/j.oregeorev.2016.09.007. 

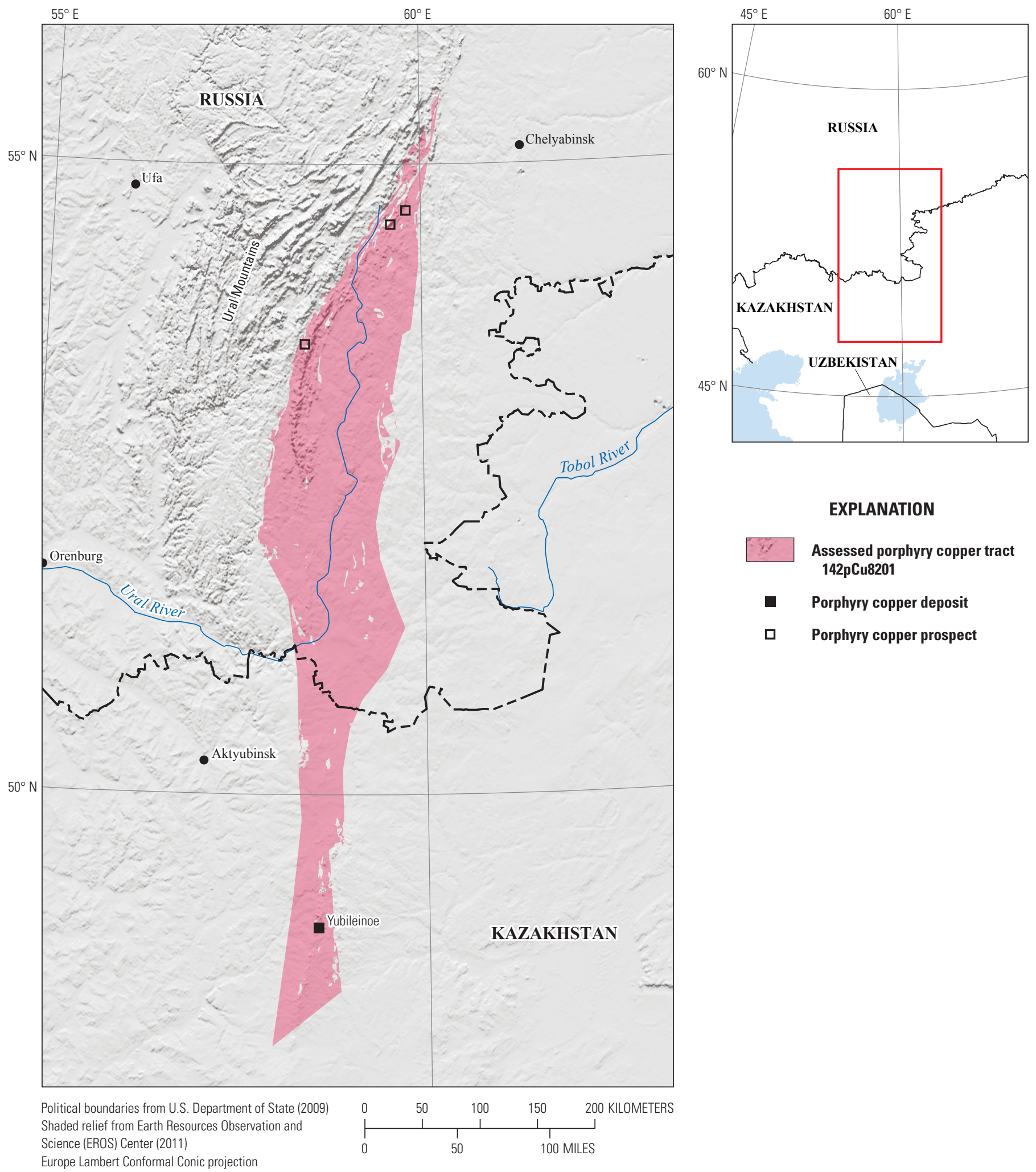

Assessed porphyry copper tract 142pCu8201

- Porphyry copper deposit

Porphyry copper prospect 


\title{
Plate 174. Porphyry Copper Assessment for Tract 142pCu8203, East Uralian- Russia and Kazakhstan
}

\author{
Descriptive model: \\ Grade and tonnage model: \\ Porphyry copper models (Cox, 1986a; Berger and others, 2008; John and others, 2010) \\ Economic filter depth percentages: \\ Economic filter cost setting: \\ Geologic feature assessed: \\ General porphyry copper model (Singer, Berger, and Moring, 2008) \\ Default - 0 to 250 meters (m), 25\%; > 250 to $500 \mathrm{~m}, 25 \%$; >500 m to $1 \mathrm{~km}, 50 \%$ \\ Mixed cost \\ Late Devonian to early Carboniferous volcanic-arc fragments intruded by syncollisional and \\ postcollisional Carboniferous and Permian granites in the East Uralian tectonic zone \\ Number of known deposits: \\ 2
}

\section{Selected Resource Assessment Results for Porphyry Copper}

[Assessment depth, 1 kilometer ( $\mathrm{km}) ; \mathrm{km}^{2}$, square kilometer; Mt, millions of metric tons]

\begin{tabular}{ccccccc}
\hline $\begin{array}{c}\text { Date of } \\
\text { assessment }\end{array}$ & $\begin{array}{c}\text { Tract area } \\
\left(\mathbf{k m}^{2}\right)\end{array}$ & $\begin{array}{c}\text { Identified } \\
\text { copper } \\
\text { resources } \\
(\mathbf{M t})\end{array}$ & $\begin{array}{c}\text { Mean estimate of } \\
\text { in-place resources } \\
(\mathbf{M t})\end{array}$ & $\begin{array}{c}\text { Probability of } \mathbf{0} \\
\text { in-place resources } \\
\text { (percent) }\end{array}$ & $\begin{array}{c}\text { Mean estimate of } \\
\text { economic resources } \\
\text { (Mt) }\end{array}$ & $\begin{array}{c}\text { Probability of 0 } \\
\text { economic resources } \\
\text { (percent) }\end{array}$ \\
\hline 2015 & 80,239 & 1.6 & 24 & 3 & 14 \\
\hline
\end{tabular}

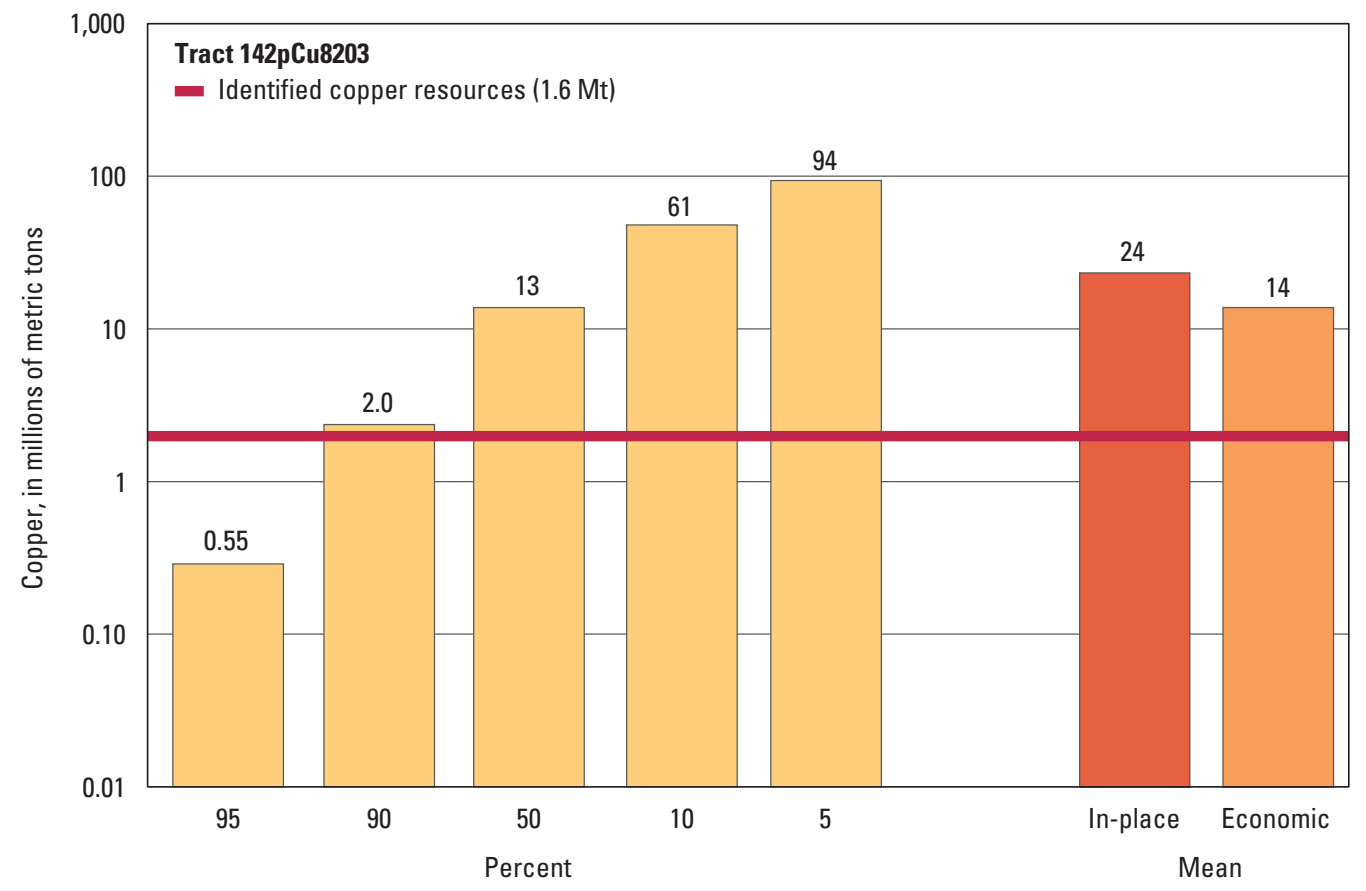

Graph showing the estimated probability distribution of undiscovered copper resources, where each bar represents the minimum amount estimated at the indicated percentage.

\section{Source}

Hammarstrom, Mihalasky, and others, 2017, Undiscovered porphyry copper resources in the Urals-A probabilistic mineral resource assessment: Ore Geology Reviews, http://dx.doi.org/10.1016/j.oregeorev.2016.09.007. 


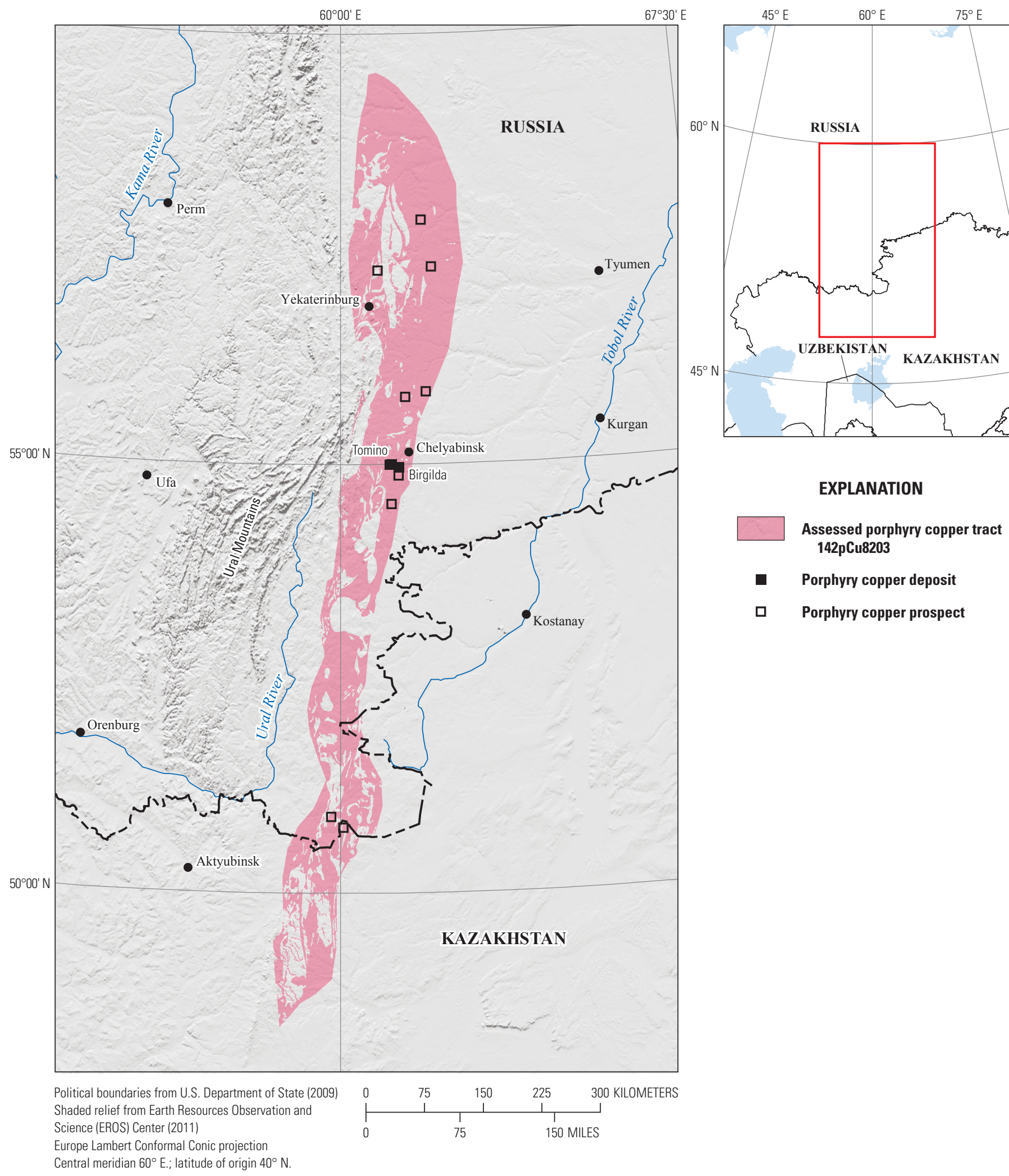




\section{Plate 175. Porphyry Copper Assessment for Tract 142pCu8204, Transuralian- Kazakhstan and Russia}

\author{
Descriptive model: \\ Grade and tonnage model: \\ Economic filter depth percentages: \\ Economic filter cost setting: \\ Geologic feature assessed:
}

Number of known deposits:
Porphyry copper models (Cox, 1986a; Berger and others, 2008)

General porphyry copper model (Singer, Berger, and Moring, 2008)

Skewed deep - 0 to 250 meters (m), 10\%; > 250 to $500 \mathrm{~m}, 30 \%$; >500 m to $1 \mathrm{~km}, 60 \%$

High cost

Early Carboniferous subduction-related calc-alkalic complexes in the Transuralian tectonic zone; includes Valerianovka continental margin arc in the east and Alexandrovskaya and Irgizskaya arcs in the west

4

\section{Selected Resource Assessment Results for Porphyry Copper}

[Assessment depth, 1 kilometer (km); $\mathrm{km}^{2}$, square kilometer; Mt, millions of metric tons]

\begin{tabular}{ccccccc}
\hline \multirow{2}{*}{$\begin{array}{c}\text { Date of } \\
\text { assessment }\end{array}$} & $\begin{array}{c}\text { Tract area } \\
\left(\mathbf{k m}^{2}\right)\end{array}$ & $\begin{array}{c}\text { Identified } \\
\text { copper } \\
\text { resources } \\
(\mathbf{M t})\end{array}$ & $\begin{array}{c}\text { Mean estimate of } \\
\text { in-place resources } \\
(\mathbf{M t})\end{array}$ & $\begin{array}{c}\text { Probability of } \mathbf{0} \\
\text { in-place resources } \\
\text { (percent) }\end{array}$ & $\begin{array}{c}\text { Mean estimate of } \\
\text { economic resources } \\
\text { (Mt) }\end{array}$ & $\begin{array}{c}\text { Probability of } \mathbf{0} \\
\text { economic resources } \\
\text { (percent) }\end{array}$ \\
\hline 2016 & 128,788 & 4.3 & 24 & 4 & 11 \\
\hline
\end{tabular}

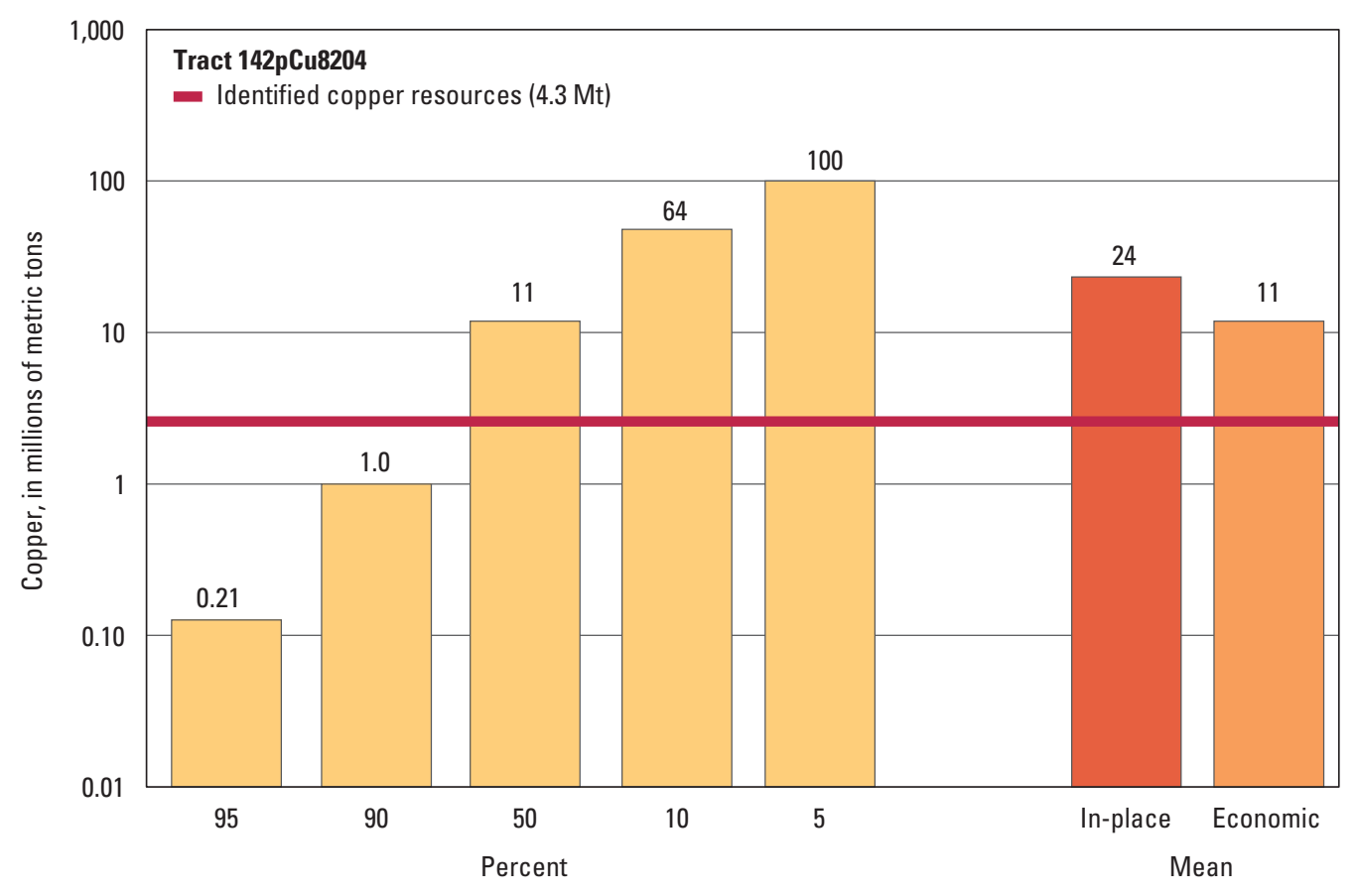

Graph showing the estimated probability distribution of undiscovered copper resources, where each bar represents the minimum amount estimated at the indicated percentage.

\section{Source}

Hammarstrom, Mihalasky, and others, 2017, Undiscovered porphyry copper resources in the Urals-A probabilistic mineral resource assessment: Ore Geology Reviews, http://dx.doi.org/10.1016/j.oregeorev.2016.09.007. 

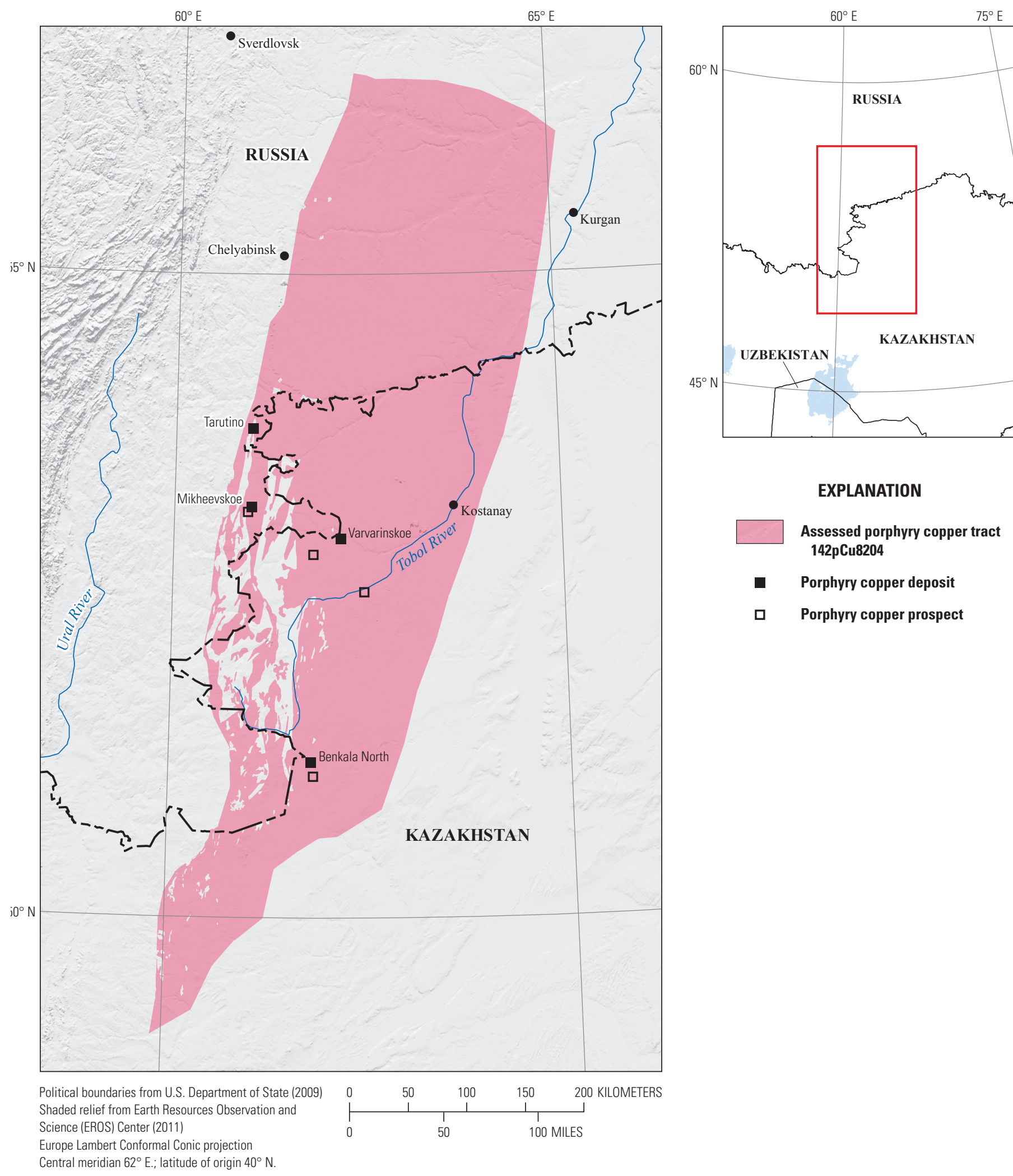

\section{EXPLANATION}

Assessed porphyry copper tract 142pCu8204

- Porphyry copper deposit

Porphyry copper prospect 


\section{Plate 176. Porphyry Copper Assessment for Tract 150pCu6006, Southern and Central European Variscan-France, Italy, and Poland}

\begin{tabular}{|c|c|c|c|c|c|c|}
\hline \multicolumn{3}{|c|}{ Descriptive model: } & \multicolumn{4}{|c|}{ Porphyry copper models (Cox, 1986a; Berger and others, 2008; John and others, 2010) } \\
\hline \multicolumn{3}{|c|}{ Grade and tonnage model: } & \multicolumn{4}{|l|}{ NA } \\
\hline \multicolumn{3}{|c|}{ Economic filter depth percentages: } & \multicolumn{4}{|l|}{ NA } \\
\hline \multicolumn{3}{|c|}{ Geologic feature assessed: } & \multicolumn{4}{|c|}{$\begin{array}{l}\text { Discrete areas of intrusive and volcanic rocks of the late Paleozoic Variscan orogeny, where some } \\
\text { evidence of porphyry-style hydrothermal activity is preserved }\end{array}$} \\
\hline \multicolumn{7}{|c|}{ Selected Resource Assessment Results for Porphyry Copper } \\
\hline \multicolumn{7}{|c|}{ [Assessment depth, 1 kilometer $(\mathrm{km}) ; \mathrm{km}^{2}$, square kilometer; Mt, millions of metric tons; NA, not applicable, as a quantitative assessment was not done] } \\
\hline $\begin{array}{c}\text { Date of } \\
\text { assessment }\end{array}$ & $\begin{array}{l}\text { Tract area } \\
\quad\left(\mathbf{k m}^{2}\right)\end{array}$ & $\begin{array}{l}\text { Identified } \\
\text { copper } \\
\text { resources } \\
\text { (Mt) }\end{array}$ & \multicolumn{4}{|c|}{ Undiscovered copper resource estimates } \\
\hline 2010 & 45,963 & 0.88 & NA & NA & NA & NA \\
\hline
\end{tabular}

\section{Qualitative Assessment}

Tract 150pCu6006 (Southern and Central European Variscan-France, Italy, and Poland) contains pluton-related copper deposits of Variscan age that are widely scattered throughout Europe. The Myszków porphyry copper deposit and nearby prospects in Poland and prospects in the French Massif Central and in Sardinia, occur within the tract. Permissive Variscan rocks crop out as intrusions in uplifted massifs. Coeval volcanic rocks typically are absent, and the level of erosion is such that porphyry copper deposits that may have formed in association with Variscan rocks have probably been lost to erosion unless preserved under younger cover or in down-dropped basins. Deep erosion has removed nearly all of the subvolcanic environments in which porphyry copper deposits may have formed in parts of the Massif Central of France. Postmineralization structural disruption makes it difficult to delineate coherent magmatic arcs or belts. The assessment team concluded that no probabilistic estimate was warranted.

\section{Source}

Sutphin and others, 2013, Porphyry copper assessment of Europe, exclusive of the Fennoscandian Shield: U.S. Geological Survey Scientific Investigations Report 2010-5090-K, http://pubs.usgs.gov/sir/2010/5090/k/. 


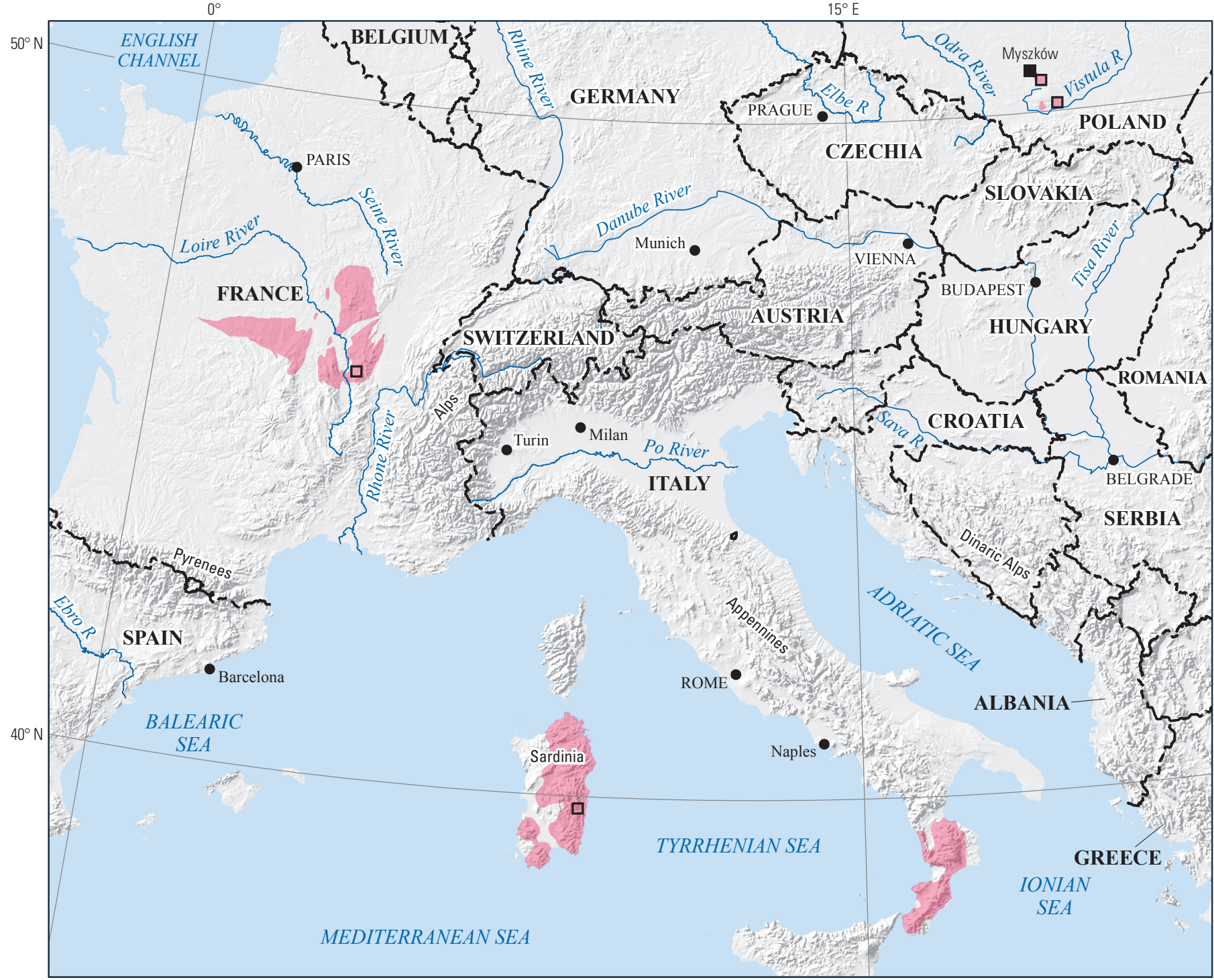

Political boundaries from U.S. Department of State (2009) Shaded relief from Earth Resources Observation and Science (EROS) Center (2011)

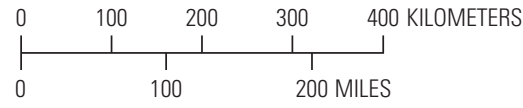

Europe Albers Equal-Area Conic projection

Central meridian $13^{\circ} \mathrm{E}$. ; latitude of origin $30^{\circ} \mathrm{N}$.

\section{EXPLANATION}

Assessed porphyry copper tract 150pCu6006

- Porphyry copper deposit

ㅁ Porphyry copper prospect

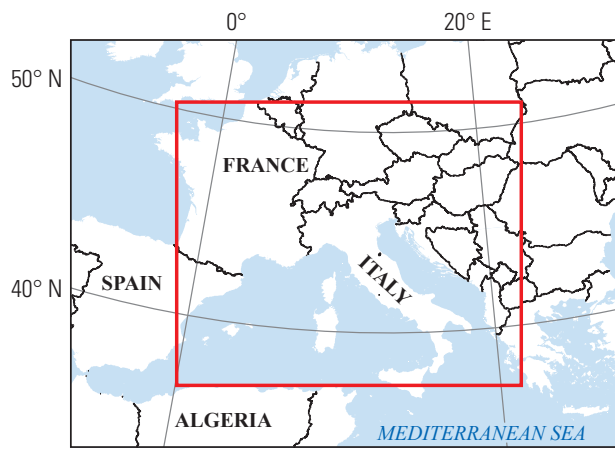




\title{
Plate 177. Porphyry Copper Assessment for Tract 150pCu6005, Western Peri- Mediterranean Region—Italy, Morocco, Algeria, and Spain
}

\author{
Descriptive model: \\ Porphyry copper models (Cox, 1986a; Berger and others, 2008; John and others, 2010) \\ Grade and tonnage model: \\ NA \\ Economic filter depth percentages: \\ NA \\ Economic filter cost setting: \\ NA \\ Geologic feature assessed: \\ Fragments of Oligocene and Miocene postcollisional volcanic belts related to the Alpine orogeny \\ in the western peri-Mediterranean area \\ Number of known deposits: \\ 1
}

\section{Selected Resource Assessment Results for Porphyry Copper}

[Assessment depth, 1 kilometer $(\mathrm{km}) ; \mathrm{km}^{2}$, square kilometer; Mt, millions of metric tons; NA, not applicable, as a quantitative assessment was not done]

\begin{tabular}{ccccccc}
\hline $\begin{array}{c}\text { Date of } \\
\text { assessment }\end{array}$ & $\begin{array}{c}\text { Tract area } \\
\left(\mathbf{k m}^{2}\right)\end{array}$ & $\begin{array}{c}\text { Identified } \\
\text { copper } \\
\text { resources } \\
(\mathbf{M t})\end{array}$ & $\begin{array}{c}\text { Mean estimate of } \\
\text { in-place resources } \\
(\mathbf{M t})\end{array}$ & $\begin{array}{c}\text { Probability of } \mathbf{0} \\
\text { in-place resources } \\
\text { (percent) }\end{array}$ & $\begin{array}{c}\text { Mean estimate of } \\
\text { economic resources } \\
\text { (Mt) }\end{array}$ & $\begin{array}{c}\text { Probability of } 0 \\
\text { economic resources } \\
\text { (percent) }\end{array}$ \\
\hline 2010 & 9,461 & 0.13 & NA & NA & NA \\
\hline
\end{tabular}

\section{Qualitative Assessment}

Tract 150pCu6005 (Western Peri-Mediterranean Region-Italy, Morocco, Algeria, and Spain) contains calc-alkalic volcanic rocks of the Betic Cordillera in Spain that are permissive for porphyry copper deposits; all of the known mineralization in the region is epithermal. No data were available on the depth of volcanic cover, although caldera structures and volcanic domes suggest that the volcanic pile may be thick, and there were no specific indications of porphyry-related systems at depth. Deep drilling, below or adjacent to, epithermal systems might change this analysis. Although the igneous rocks in the Rif Mountains of Morocco are permissive, the andesitic volcanic rocks may be too thick and the exposed skarn may represent too deep a level of exposure for porphyry copper deposits, if they ever formed, to be present within $1 \mathrm{~km}$ of the surface. On the basis of the small tract area and low grade of the identified resources at the Calabona deposit in Sardinia, Italy, and the lack of any reported copper occurrences or alteration suggestive of porphyry systems in the Betic-Rif mountain belt of Spain and northeastern Morocco and the Tell Atlas Mountains in Algeria, the assessment team concluded that no probabilistic estimate was warranted.

\section{Source}

Sutphin and others, 2013, Porphyry copper assessment of Europe, exclusive of the Fennoscandian Shield: U.S. Geological Survey Scientific Investigations Report 2010-5090-K, http://pubs.usgs.gov/sir/2010/5090/k/. 


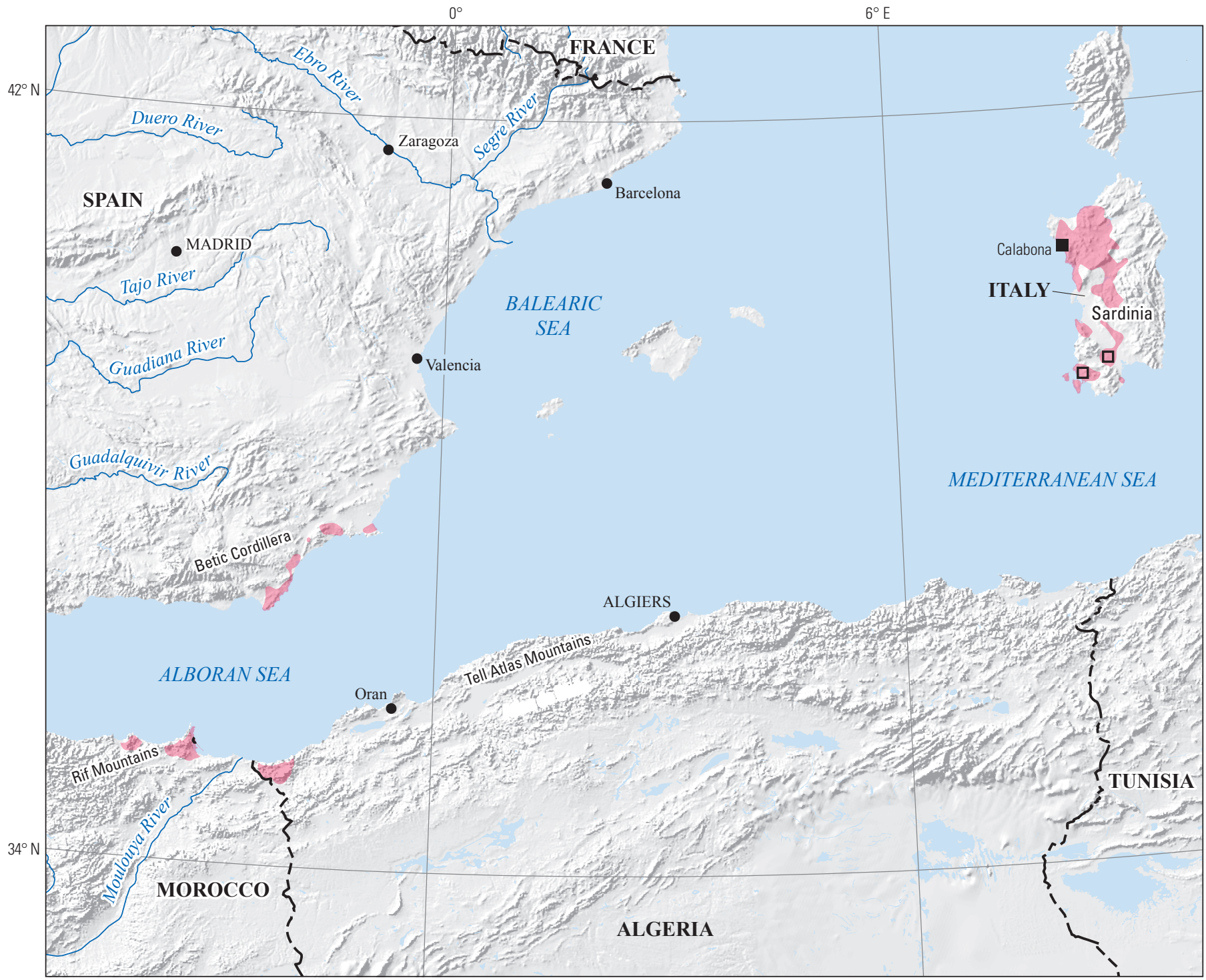

Political boundaries from U.S. Department of State (2009) Shaded relief from Earth Resources Observation and Science (EROS) Center (2011)

Europe Albers Equal-Area Conic projection

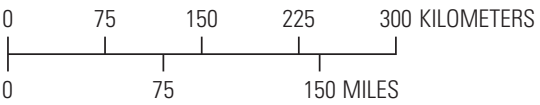

Central meridian $2^{\circ} 30^{\prime} \mathrm{E}$.; latitude of origin $30^{\circ} \mathrm{N}$

EXPLANATION

\section{Assessed porphyry copper tract} 150pCu6005

- Porphyry copper deposit

ㅁ Porphyry copper prospect

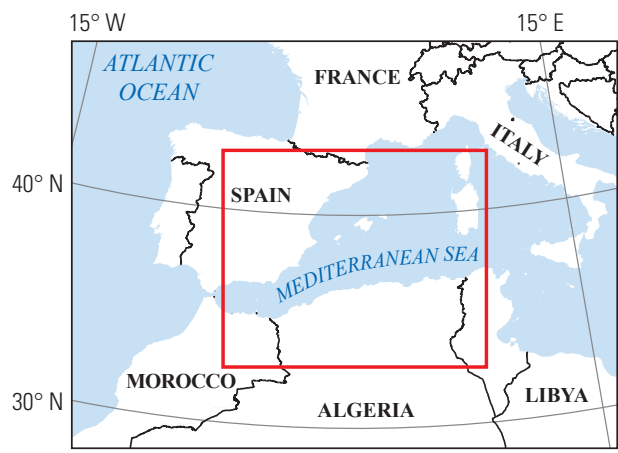




\section{Plate 178. Porphyry Copper Assessment for Tract 150pCu6007, Western European Caledonian-Belgium and United Kingdom}

\begin{tabular}{|c|c|c|c|c|c|c|}
\hline \multicolumn{3}{|c|}{ Descriptive model: } & \multicolumn{4}{|c|}{ Porphyry copper models (Cox, 1986a; Berger and others, 2008; John and others, 2010) } \\
\hline \multicolumn{3}{|c|}{ Grade and tonnage model: } & \multicolumn{4}{|c|}{ NA } \\
\hline \multicolumn{3}{|c|}{ Economic filter depth percentages: } & \multicolumn{4}{|l|}{ NA } \\
\hline \multicolumn{3}{|c|}{ Geologic feature assessed: } & \multicolumn{4}{|c|}{$\begin{array}{l}\text { Fragments of a Late Cambrian to earliest Devonian continental-margin arc formed during the } \\
\text { Caledonian orogeny }\end{array}$} \\
\hline \multicolumn{7}{|c|}{ Selected Resource Assessment Results for Porphyry Copper } \\
\hline \multicolumn{7}{|c|}{ [Assessment depth, 1 kilometer $(\mathrm{km}) ; \mathrm{km}^{2}$, square kilometer; Mt, millions of metric tons; NA, not applicable, as a quantitative assessment was not done] } \\
\hline $\begin{array}{c}\text { Date of } \\
\text { assessment }\end{array}$ & $\begin{array}{l}\text { Tract area } \\
\quad\left(\mathbf{k m}^{2}\right)\end{array}$ & $\begin{array}{l}\text { Identified } \\
\text { copper } \\
\text { resources } \\
\text { (Mt) }\end{array}$ & \multicolumn{4}{|c|}{ Undiscovered copper resource estimates } \\
\hline 2010 & 17,471 & 0.63 & NA & NA & NA & NA \\
\hline
\end{tabular}

\section{Qualitative Assessment}

Two porphyry copper deposits associated with the Late Cambrian to earliest Devonian Caledonian orogeny are known in western Europe: one is in Wales (United Kingdom) and the other is in Belgium. Neither has ever been mined. They are both included in tract 150pCu6007 (Western European Caledonian-Belgium and United Kingdom). Caledonian porphyry copper occurrences are widely scattered throughout Europe. Postmineralization tectonic disruption precludes delineation of coherent magmatic arcs or belts. Caledonian deposits and prospects in Europe that have been investigated have not proven to represent significant resources. Porphyry copper deposits of Caledonian age are present in other parts of the world, such as the Cadia Group deposits ( $\sim 10 \mathrm{Mt}$ contained copper) in the Macquarie arc of eastern Australia (pl. 133) and the Bozshakol deposit ( $\sim .7 \mathrm{Mt}$ contained copper) in Kazakhstan (pl. 78). On the basis of available data and the past exploration results at known prospects, the assessment team concluded that a probabilistic assessment for undiscovered Caledonian age porphyry copper deposits within $1 \mathrm{~km}$ of the surface was not warranted for tract $150 \mathrm{pCu} 6007$. Any future interest in the porphyry copper within the tract rocks is likely to focus on extensions of identified resources.

\section{Source}

Sutphin and others, 2013, Porphyry copper assessment of Europe, exclusive of the Fennoscandian Shield: U.S. Geological Survey Scientific Investigations Report 2010-5090-K, http://pubs.usgs.gov/sir/2010/5090/k/. 


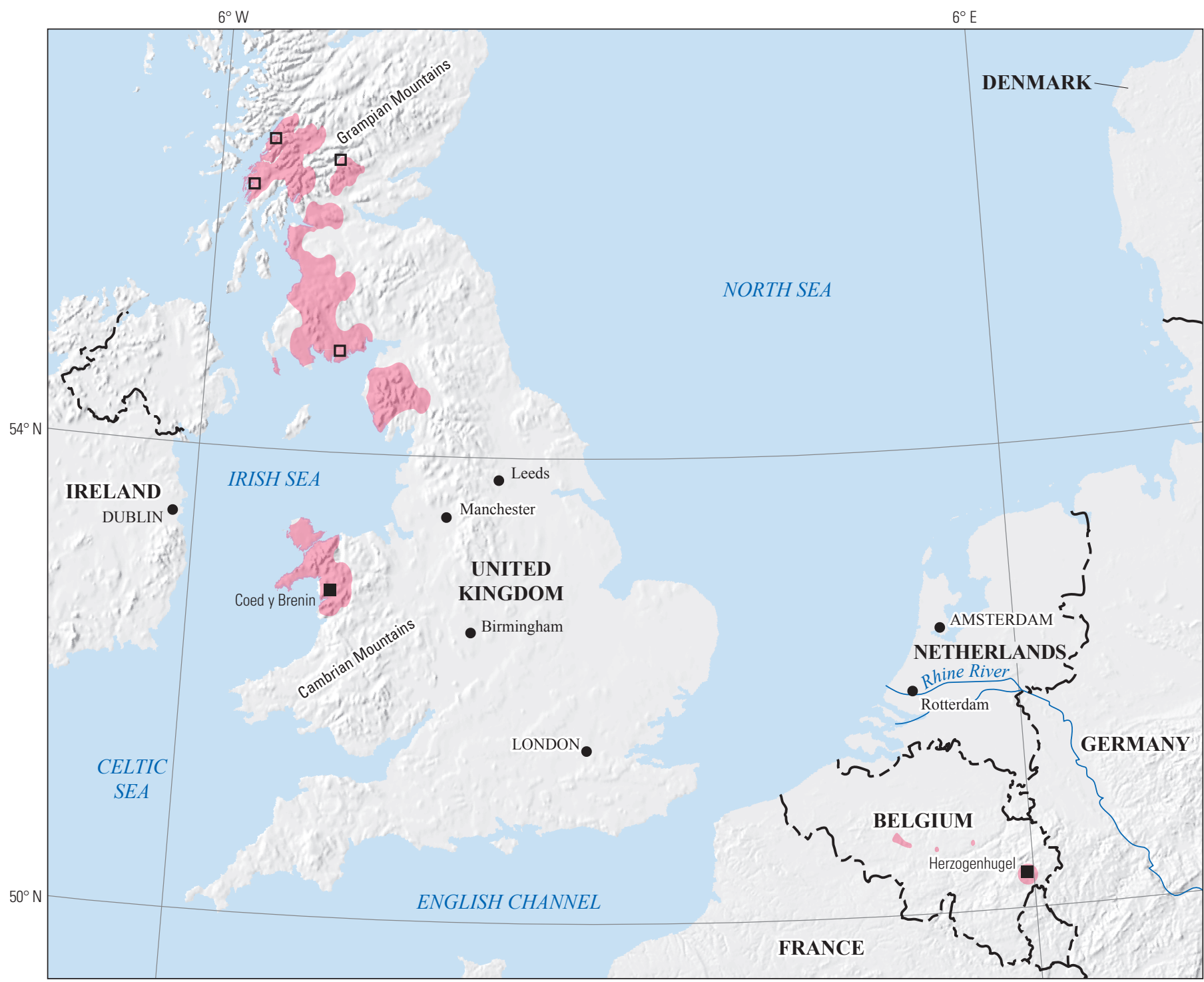

Political boundaries from U.S. Department of State (2009) Shaded relief from Earth Resources Observation and Science (EROS) Center (2011)

Europe Albers Equal-Area Conic Projection

Central meridian $0^{\circ}$; latitude of origin $30^{\circ} \mathrm{N}$

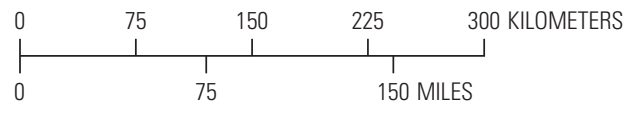

\section{EXPLANATION}

\section{Assessed porphyry copper tract 150pCu6007 \\ - Porphyry copper deposit \\ Porphyry copper prospect}

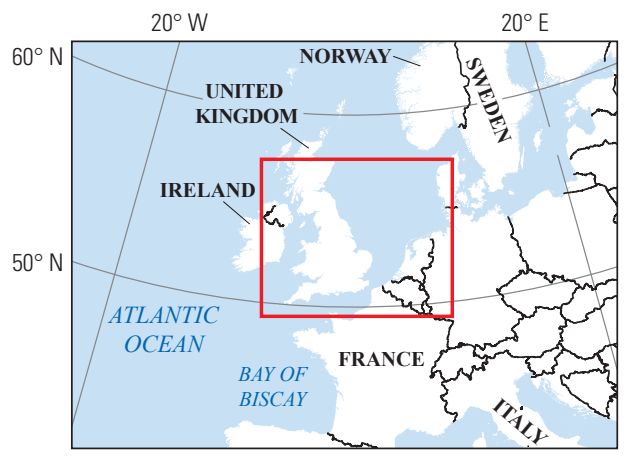




\title{
Plate 179. Porphyry Copper Assessment for Tract 150pCu6108, Southern Ostrobothnia-Finland
}

\author{
Descriptive model: $\quad$ Porphyry copper (gold, molybdenum) model (Eilu, 2014) \\ Grade and tonnage model: $\quad$ Precambrian porphyry copper model (Rasilainen, 2014) \\ Economic filter depth percentages: $\quad$ Default -0 to 250 meters (m), 25\%; >250 to $500 \mathrm{~m}, 25 \%$; $>500 \mathrm{~m}$ to $1 \mathrm{~km}, 50 \%$ \\ Economic filter cost setting: Typical cost \\ Geologic feature assessed: $\quad$ Early orogenic to synorogenic Paleoproterozoic (1.89-1.88 Ga?) granitoid rocks along the western \\ margin of the Central Finland granitoid complex \\ Number of known deposits: \\ 0
}

\section{Selected Resource Assessment Results for Porphyry Copper}

[Assessment depth, 1 kilometer ( $\mathrm{km}) ; \mathrm{km}^{2}$, square kilometer; Mt, millions of metric tons]

\begin{tabular}{ccccccc}
\hline $\begin{array}{c}\text { Date of } \\
\text { assessment }\end{array}$ & $\begin{array}{c}\text { Tract area } \\
\left.\mathbf{( k m}^{2}\right)\end{array}$ & $\begin{array}{c}\text { Identified } \\
\text { copper } \\
\text { resources } \\
\text { (Mt) }\end{array}$ & $\begin{array}{c}\text { Mean estimate of } \\
\text { in-place resources } \\
(\mathbf{M t})\end{array}$ & $\begin{array}{c}\text { Probability of } \mathbf{0} \\
\text { in-place resources } \\
\text { (percent) }\end{array}$ & $\begin{array}{c}\text { Mean estimate of } \\
\text { economic resources } \\
\text { (Mt) }\end{array}$ & $\begin{array}{c}\text { Probability of 0 } \\
\text { economic resources } \\
\text { (percent) }\end{array}$ \\
\hline 2012 & 2,317 & 0 & 0.31 & 70 & 0.052 \\
\hline
\end{tabular}

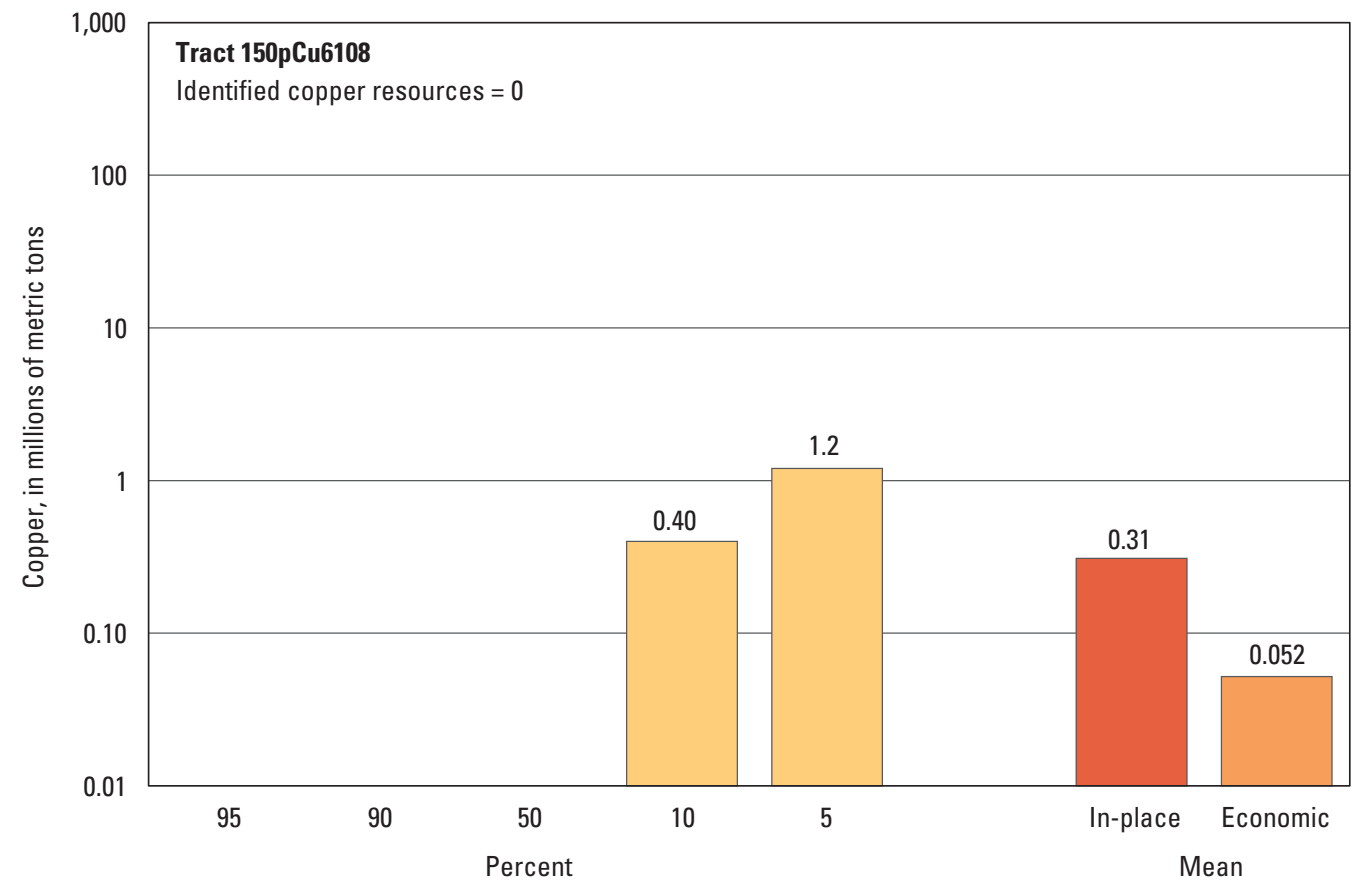

Graph showing the estimated probability distribution of undiscovered copper resources, where each bar represents the minimum amount estimated at the indicated percentage.

\section{Source}

Rasilainen and others, 2014, Quantitative assessment of undiscovered resources in volcanogenic massive sulphide deposits, porphyry copper deposits and Outokumpu-type deposits in Finland: Geological Survey of Finland Report of Investigation 208, http://tupa.gtk.fi/julkaisu/tutkimusraportti/tr_208.pdf. 

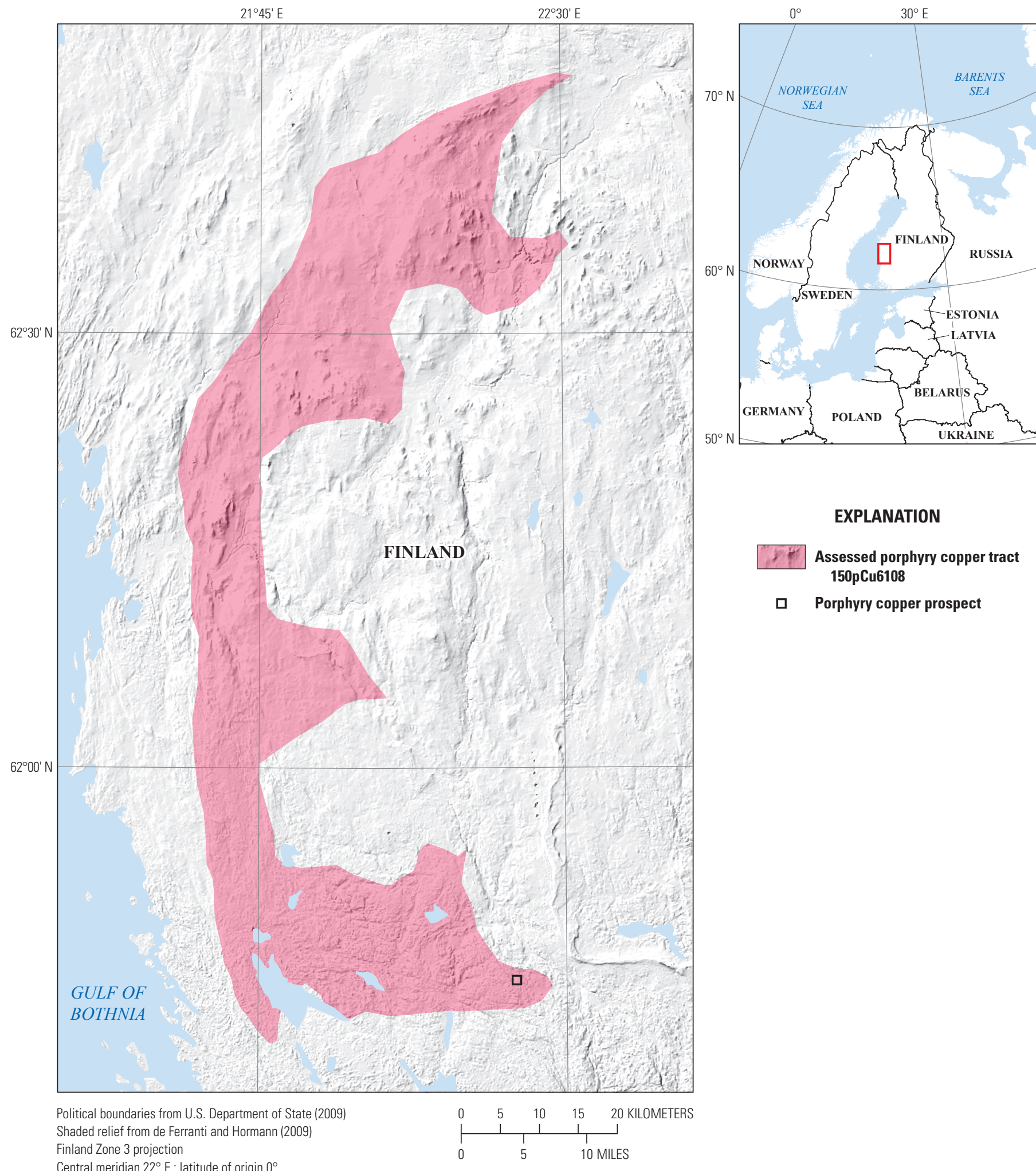

Assessed porphyry copper tract 150pCu6108

ㅁ Porphyry copper prospect 


\section{Plate 180. Porphyry Copper Assessment for Tract 150pCu6104, Häme-Finland}

Descriptive model:

Grade and tonnage model:

Economic filter depth percentages:

Economic filter cost setting:

Geologic feature assessed:

Number of known deposits:
Porphyry copper (gold, molybdenum) model (Eilu, 2014)

Precambrian porphyry copper model (Rasilainen, 2014)

Default -0 to 250 meters (m), $25 \%$; $>250$ to $500 \mathrm{~m}, 25 \%$; $>500 \mathrm{~m}$ to $1 \mathrm{~km}, 50 \%$

Typical cost

Early orogenic to synorogenic Paleoproterozoic (1.89-1.88 Ga) granitoid rock within the Häme volcanic belt of southern Finland

0

\section{Selected Resource Assessment Results for Porphyry Copper}

[Assessment depth, 1 kilometer $(\mathrm{km}) ; \mathrm{km}^{2}$, square kilometer; Mt, millions of metric tons]

\begin{tabular}{ccccccc}
\hline $\begin{array}{c}\text { Date of } \\
\text { assessment }\end{array}$ & $\begin{array}{c}\text { Tract area } \\
\left(\mathbf{k m}^{2}\right)\end{array}$ & $\begin{array}{c}\text { Identified } \\
\text { copper } \\
\text { resources } \\
(\mathbf{M t})\end{array}$ & $\begin{array}{c}\text { Mean estimate of } \\
\text { in-place resources } \\
(\mathbf{M t})\end{array}$ & $\begin{array}{c}\text { Probability of } \mathbf{0} \\
\text { in-place resources } \\
\text { (percent) }\end{array}$ & $\begin{array}{c}\text { Mean estimate of } \\
\text { economic resources } \\
\text { (Mt) }\end{array}$ & $\begin{array}{c}\text { Probability of 0 } \\
\text { economic resources } \\
\text { (percent) }\end{array}$ \\
\hline 2012 & 4,716 & 0 & 1.9 & 7 & 0.32 \\
\hline
\end{tabular}

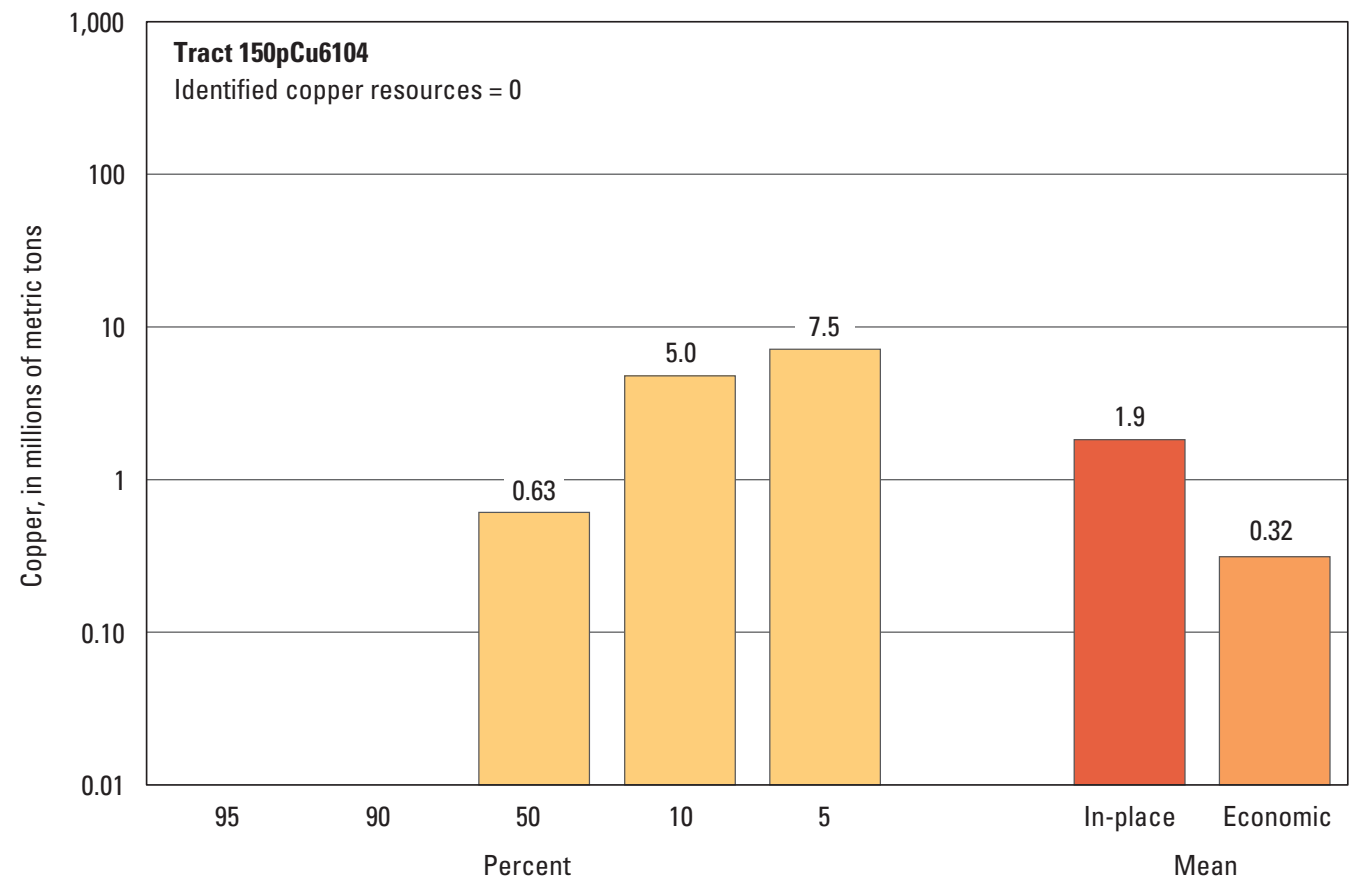

Graph showing the estimated probability distribution of undiscovered copper resources, where each bar represents the minimum amount estimated at the indicated percentage.

\section{Source}

Rasilainen and others, 2014, Quantitative assessment of undiscovered resources in volcanogenic massive sulphide deposits, porphyry copper deposits and Outokumpu-type deposits in Finland: Geological Survey of Finland Report of Investigation 208, http://tupa.gtk.fi/julkaisu/tutkimusraportti/tr_208.pdf. 


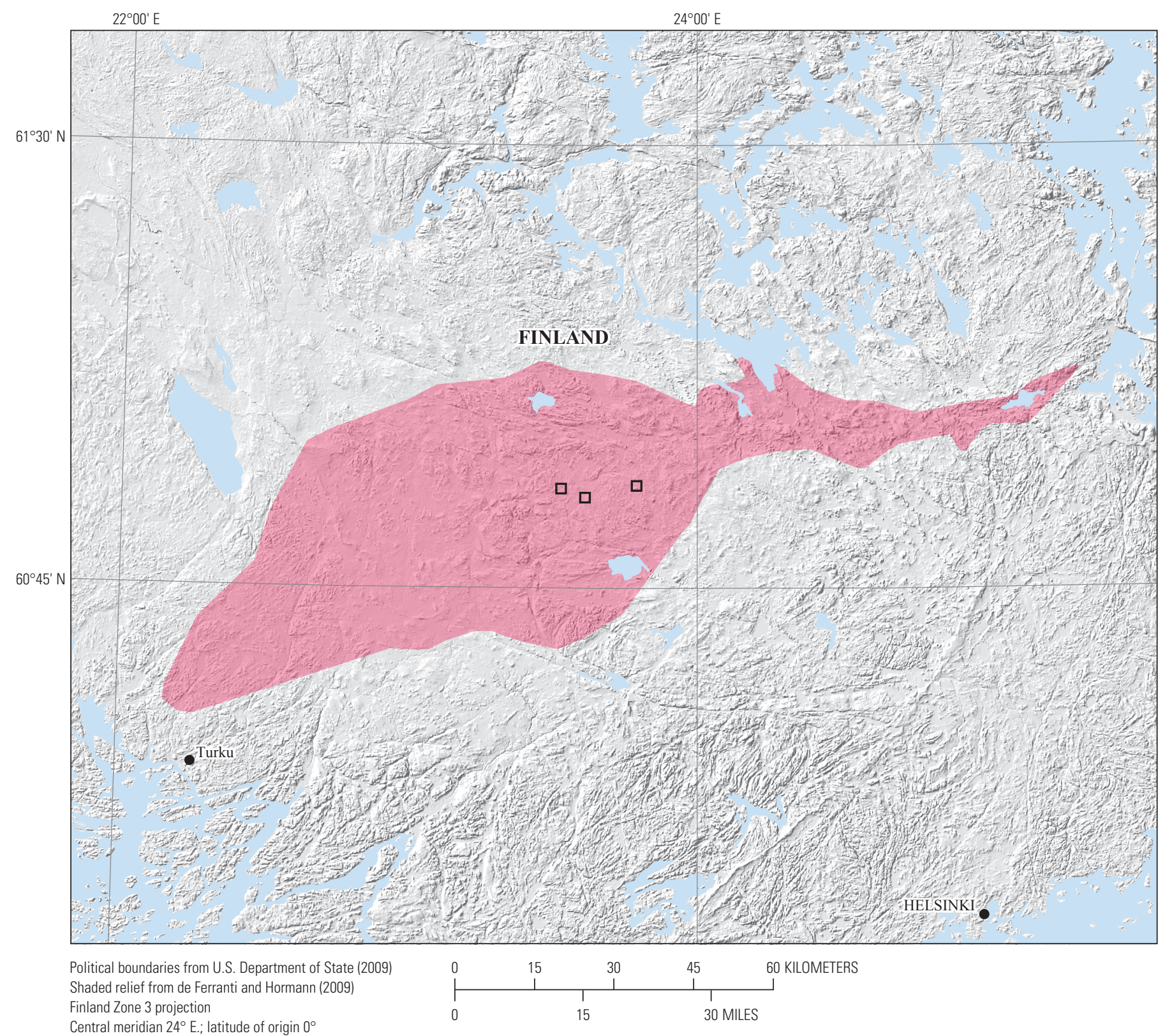

Central meridian $24^{\circ} \mathrm{E}$.; latitude of origin $0^{\circ}$

EXPLANATION

Assessed porphyry copper tract 150pCu6104

Porphyry copper prospect

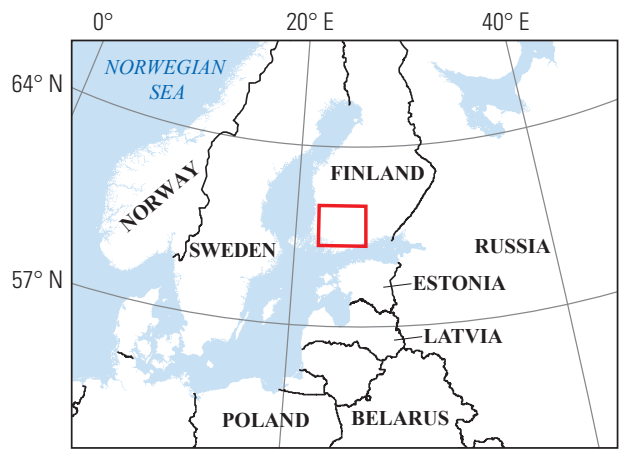




\title{
Plate 181. Porphyry Copper Assessment for Tract 150pCu6101, Central Finland-Finland
}

\author{
Descriptive model: $\quad$ Porphyry copper (gold, molybdenum) model (Eilu, 2014) \\ Grade and tonnage model: $\quad$ Precambrian porphyry copper model (Rasilainen, 2014) \\ Economic filter depth percentages: $\quad$ Default -0 to 250 meters (m), 25\%; >250 to $500 \mathrm{~m}, 25 \%$; $>500 \mathrm{~m}$ to $1 \mathrm{~km}, 50 \%$ \\ Economic filter cost setting: Typical cost \\ Geologic feature assessed: $\quad$ Early orogenic to synorogenic Paleoproterozoic $(1.89-1.88 \mathrm{Ga})$ granitoid rocks along the southern \\ part of the Central Finland granitoid complex \\ Number of known deposits: \\ 0
}

\section{Selected Resource Assessment Results for Porphyry Copper}

[Assessment depth, 1 kilometer ( $\mathrm{km}) ; \mathrm{km}^{2}$, square kilometer; Mt, millions of metric tons]

\begin{tabular}{ccccccc}
\hline $\begin{array}{c}\text { Date of } \\
\text { assessment }\end{array}$ & $\begin{array}{c}\text { Tract area } \\
\left.\mathbf{( k m}^{2}\right)\end{array}$ & $\begin{array}{c}\text { Identified } \\
\text { copper } \\
\text { resources } \\
\text { (Mt) }\end{array}$ & $\begin{array}{c}\text { Mean estimate of } \\
\text { in-place resources } \\
(\mathbf{M t})\end{array}$ & $\begin{array}{c}\text { Probability of } \mathbf{0} \\
\text { in-place resources } \\
\text { (percent) }\end{array}$ & $\begin{array}{c}\text { Mean estimate of } \\
\text { economic resources } \\
\text { (Mt) }\end{array}$ & $\begin{array}{c}\text { Probability of 0 } \\
\text { economic resources } \\
\text { (percent) }\end{array}$ \\
\hline 2012 & 3,859 & 0 & 0.76 & 31 & 0.31 \\
\hline
\end{tabular}

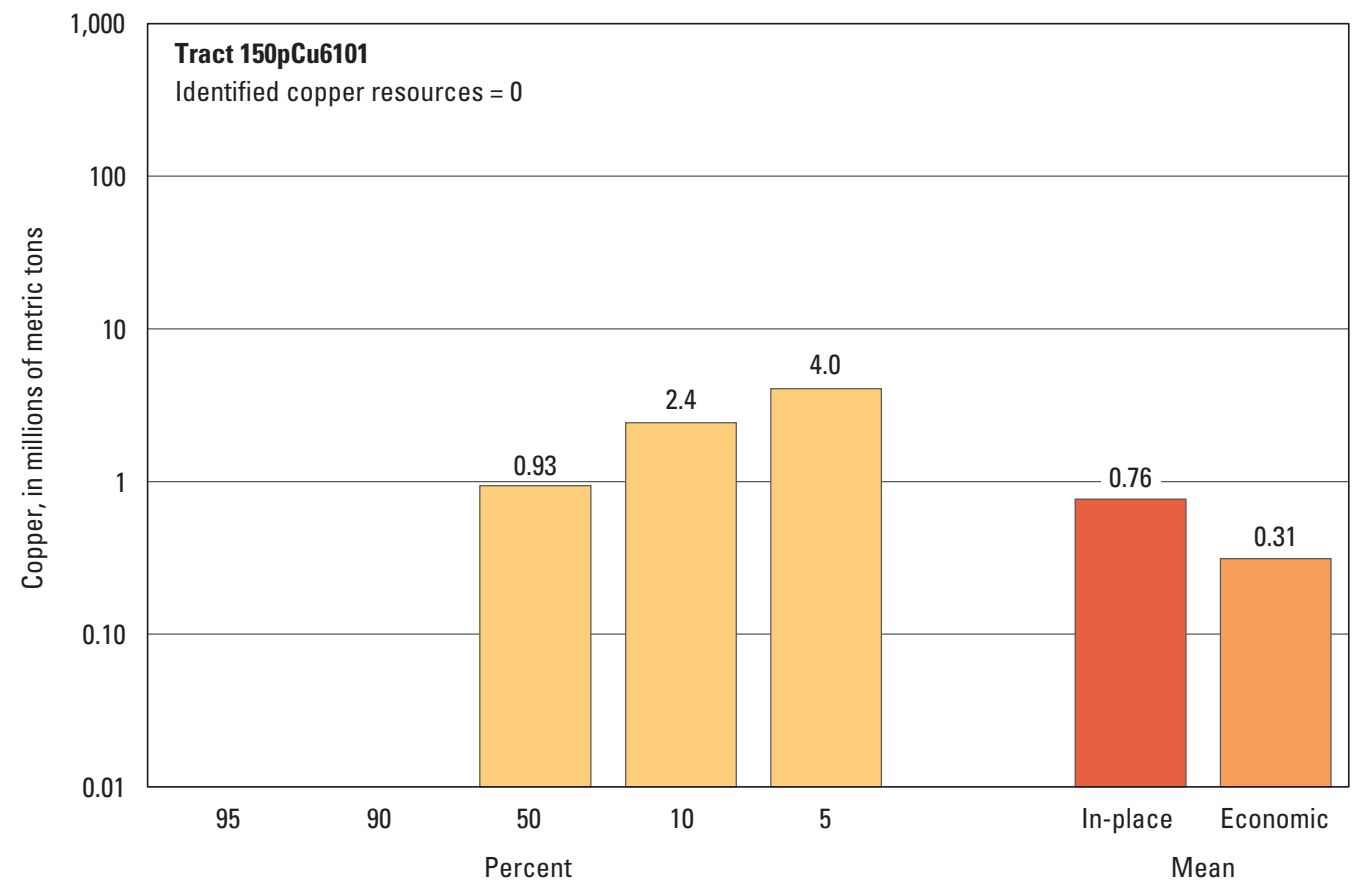

Graph showing the estimated probability distribution of undiscovered copper resources, where each bar represents the minimum amount estimated at the indicated percentage.

\section{Source}

Rasilainen and others, 2014, Quantitative assessment of undiscovered resources in volcanogenic massive sulphide deposits, porphyry copper deposits and Outokumpu-type deposits in Finland: Geological Survey of Finland Report of Investigation 208, http://tupa.gtk.fi/julkaisu/tutkimusraportti/tr_208.pdf. 


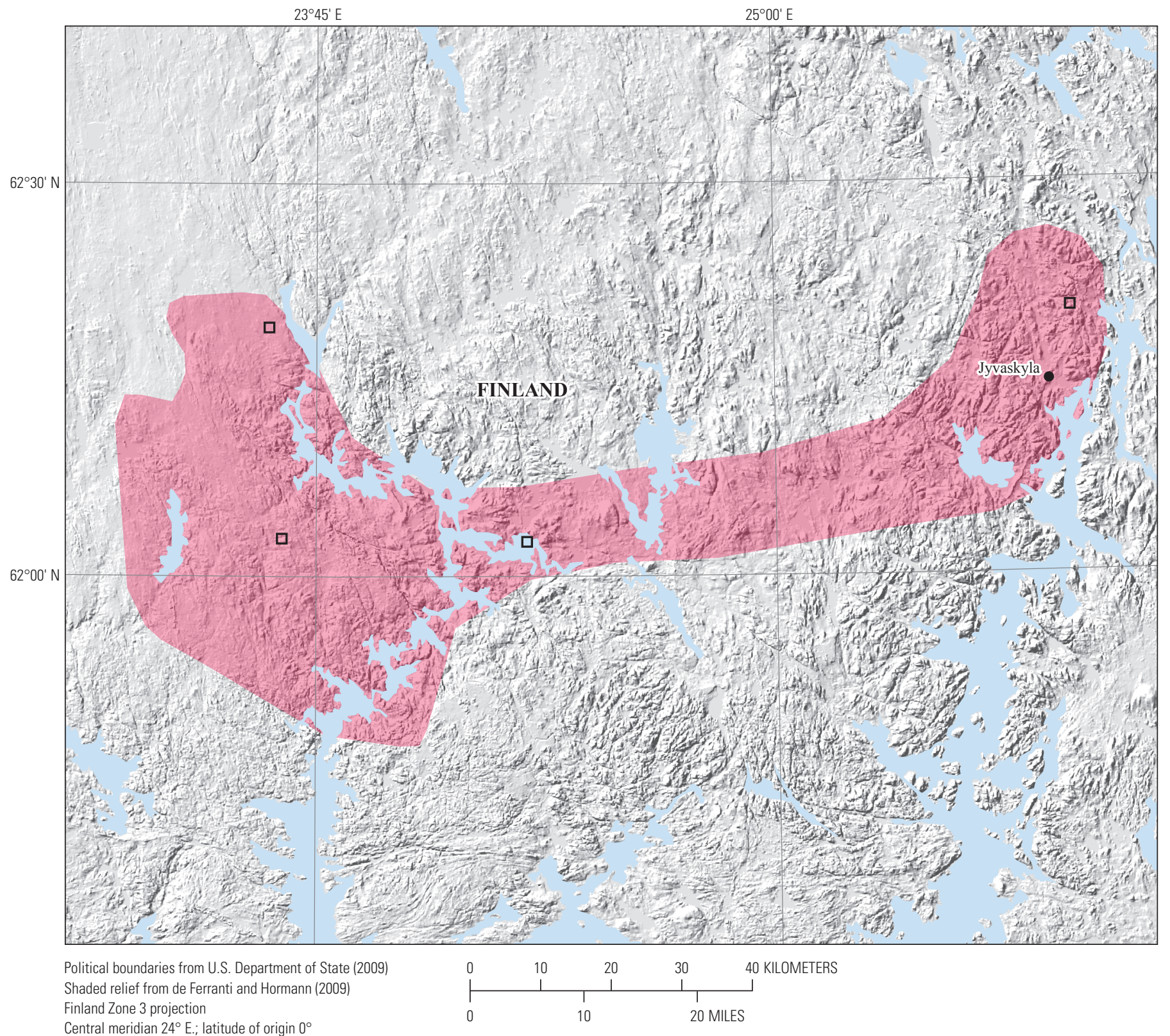

Central meridian $24^{\circ} \mathrm{E}$.; latitude of origin $0^{\circ}$

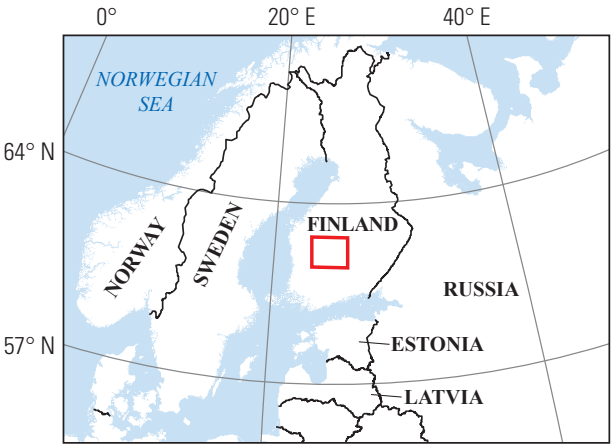




\section{Plate 182. Porphyry Copper Assessment for Tract 150pCu6105, Mäntsälä- Finland}

\author{
Descriptive model: \\ Grade and tonnage model: \\ Economic filter depth percentages: \\ Economic filter cost setting: \\ Geologic feature assessed: \\ Number of known deposits:
}

\author{
Porphyry copper (gold, molybdenum) model (Eilu, 2014) \\ Precambrian porphyry copper model (Rasilainen, 2014) \\ Default -0 to 250 meters (m), $25 \%$; $>250$ to $500 \mathrm{~m}, 25 \%$; $>500 \mathrm{~m}$ to $1 \mathrm{~km}, 50 \%$ \\ Typical cost \\ Early orogenic to synorogenic Paleoproterozoic (1.89-1.88 Ga) granitoid rocks in southern Finland \\ 0
}

\section{Selected Resource Assessment Results for Porphyry Copper}

[Assessment depth, 1 kilometer $(\mathrm{km}) ; \mathrm{km}^{2}$, square kilometer; $\mathrm{Mt}$, millions of metric tons]

\begin{tabular}{ccccccc}
\hline \multirow{2}{*}{$\begin{array}{c}\text { Date of } \\
\text { assessment }\end{array}$} & $\begin{array}{c}\text { Tract area } \\
\left(\mathbf{k m}^{2}\right)\end{array}$ & $\begin{array}{c}\text { Identified } \\
\text { copper } \\
\text { resources } \\
(\mathbf{M t})\end{array}$ & $\begin{array}{c}\text { Mean estimate of } \\
\text { in-place resources } \\
(\mathbf{M t})\end{array}$ & $\begin{array}{c}\text { Probability of } \mathbf{0} \\
\text { in-place resources } \\
\text { (percent) }\end{array}$ & $\begin{array}{c}\text { Mean estimate of } \\
\text { economic resources } \\
\text { (Mt) }\end{array}$ & $\begin{array}{c}\text { Probability of } \mathbf{0} \\
\text { economic resources } \\
\text { (percent) }\end{array}$ \\
\hline 2012 & 1,730 & 0 & 0.27 & 70 & 0.046 \\
\hline
\end{tabular}

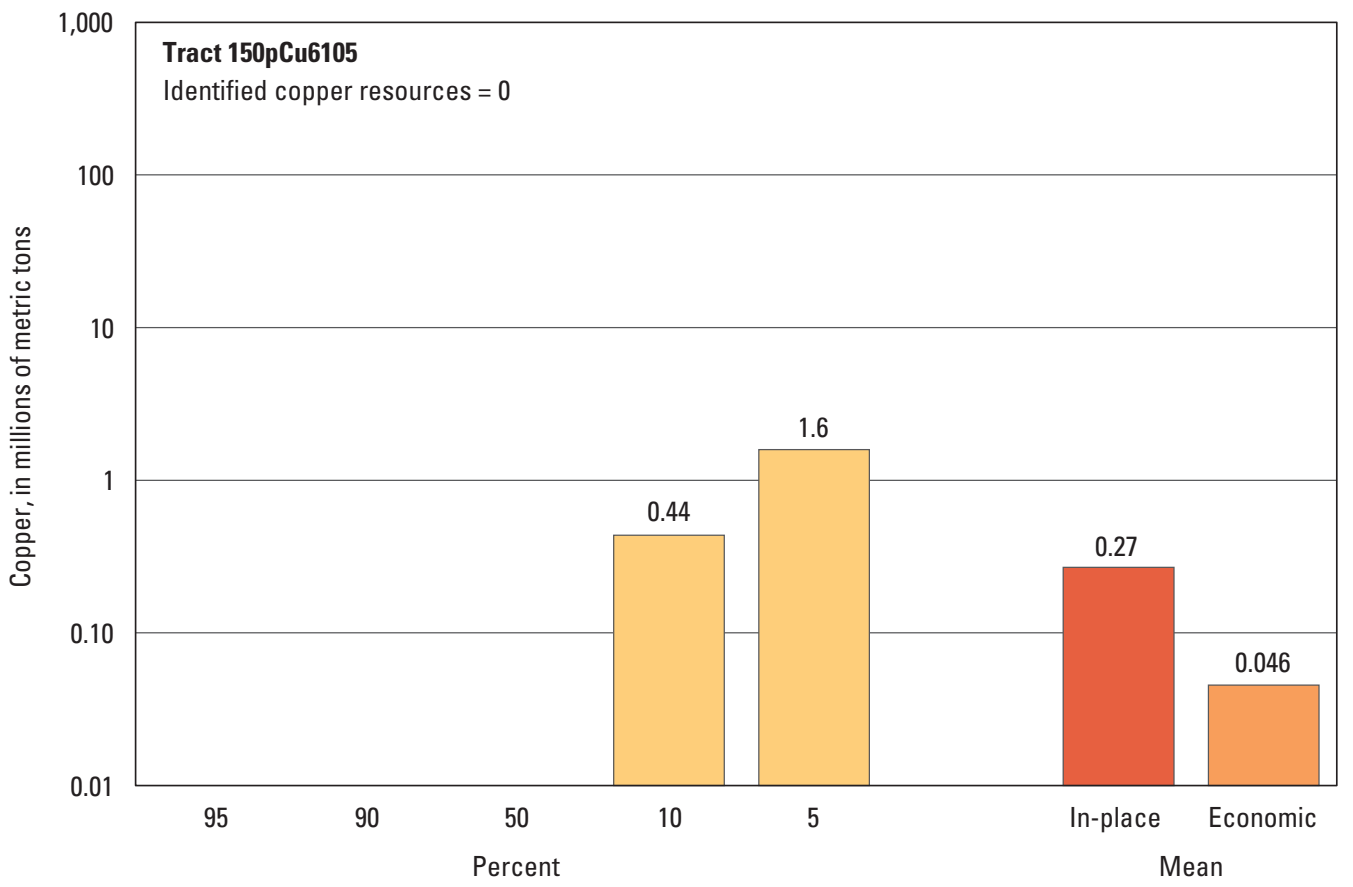

Graph showing the estimated probability distribution of undiscovered copper resources, where each bar represents the minimum amount estimated at the indicated percentage.

\section{Source}

Rasilainen and others, 2014, Quantitative assessment of undiscovered resources in volcanogenic massive sulphide deposits, porphyry copper deposits and Outokumpu-type deposits in Finland: Geological Survey of Finland Report of Investigation 208, http://tupa.gtk.fi/julkaisu/tutkimusraportti/tr_208.pdf. 


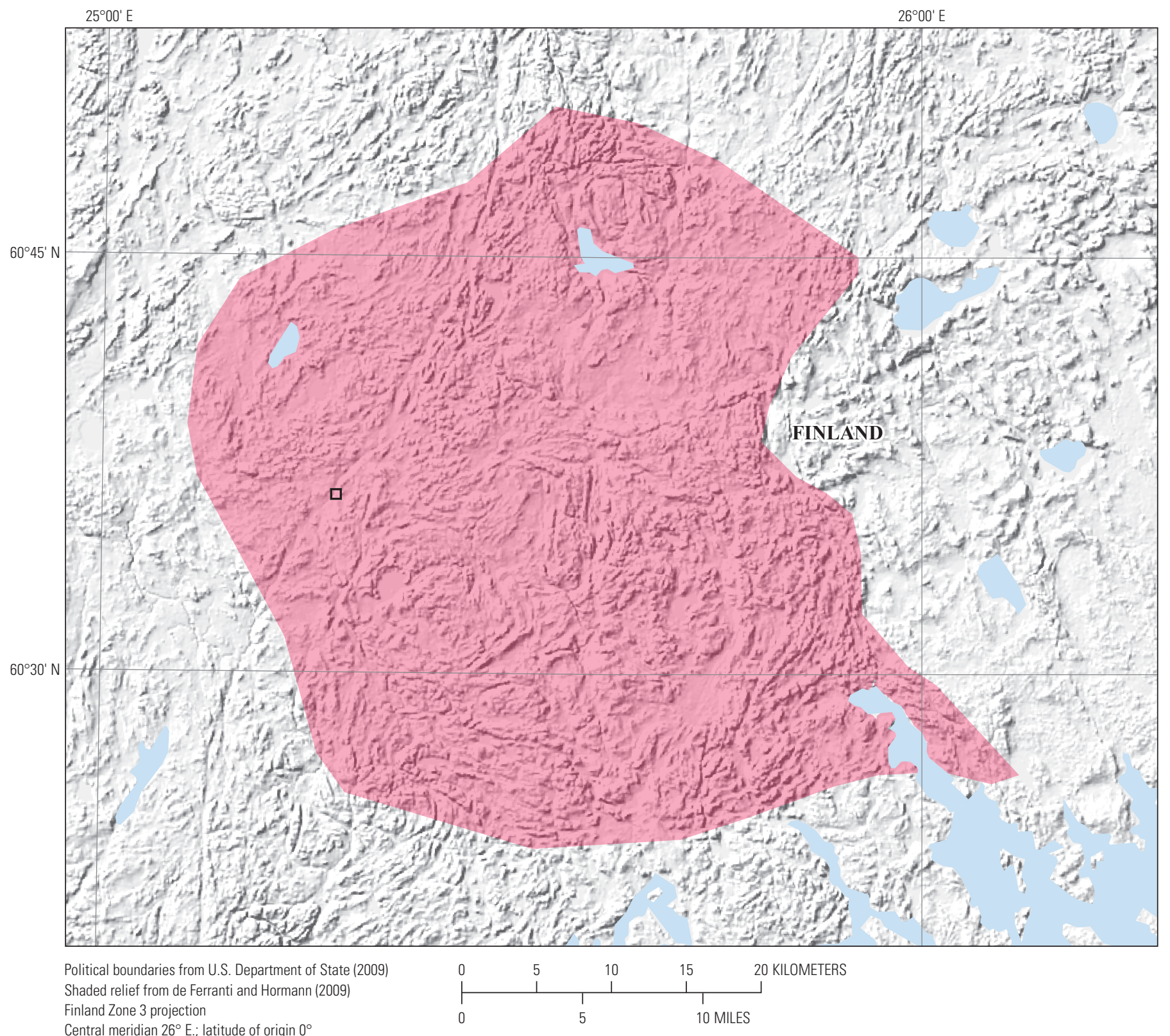

Central meridian $26^{\circ} \mathrm{E}$.; latitude of origin $0^{\circ}$

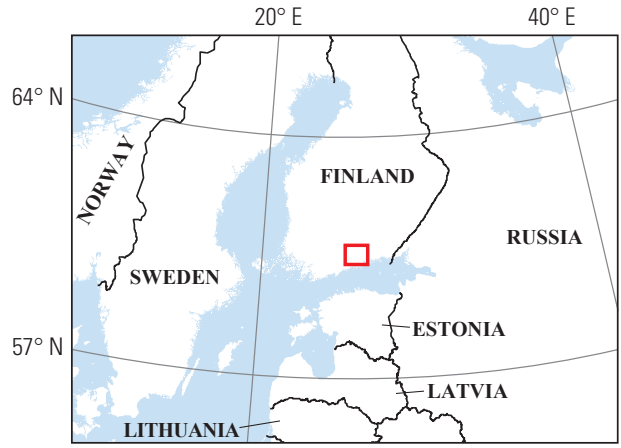




\title{
Plate 183. Porphyry Copper Assessment for Tract 150pCu6107, Ruokolahti- Finland
}

\author{
Descriptive model: $\quad$ Porphyry copper (gold, molybdenum) model (Eilu, 2014) \\ Grade and tonnage model: $\quad$ Precambrian porphyry copper model (Rasilainen, 2014) \\ Economic filter depth percentages: $\quad$ Default -0 to 250 meters (m), 25\%; >250 to $500 \mathrm{~m}, 25 \%$; $>500 \mathrm{~m}$ to $1 \mathrm{~km}, 50 \%$ \\ Economic filter cost setting: Typical cost \\ Geologic feature assessed: $\quad$ Early orogenic to synorogenic Paleoproterozoic (1.89-1.88 Ga?) granitoid rocks in southern \\ Finland \\ Number of known deposits: \\ 0
}

\section{Selected Resource Assessment Results for Porphyry Copper}

[Assessment depth, 1 kilometer ( $\mathrm{km}) ; \mathrm{km}^{2}$, square kilometer; Mt, millions of metric tons]

\begin{tabular}{ccccccc}
\hline $\begin{array}{c}\text { Date of } \\
\text { assessment }\end{array}$ & $\begin{array}{c}\text { Tract area } \\
\left.\mathbf{( k m}^{2}\right)\end{array}$ & $\begin{array}{c}\text { Identified } \\
\text { copper } \\
\text { resources } \\
\text { (Mt) }\end{array}$ & $\begin{array}{c}\text { Mean estimate of } \\
\text { in-place resources } \\
(\mathbf{M t})\end{array}$ & $\begin{array}{c}\text { Probability of } \mathbf{0} \\
\text { in-place resources } \\
\text { (percent) }\end{array}$ & $\begin{array}{c}\text { Mean estimate of } \\
\text { economic resources } \\
\text { (Mt) }\end{array}$ & $\begin{array}{c}\text { Probability of 0 } \\
\text { economic resources } \\
\text { (percent) }\end{array}$ \\
\hline 2012 & 805 & 0 & 0.23 & 71 & 0.039 \\
\hline
\end{tabular}

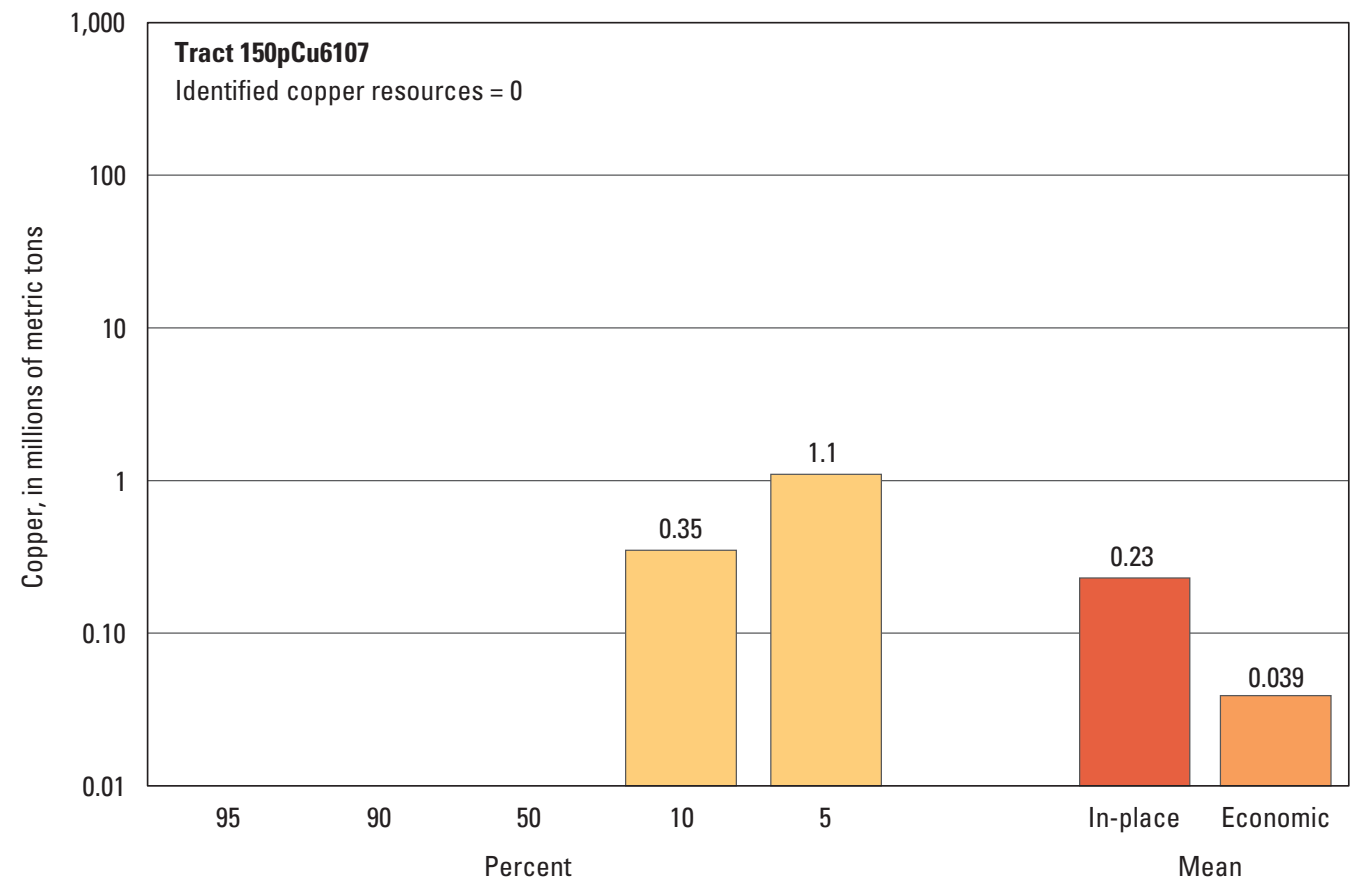

Graph showing the estimated probability distribution of undiscovered copper resources, where each bar represents the minimum amount estimated at the indicated percentage.

\section{Source}

Rasilainen and others, 2014, Quantitative assessment of undiscovered resources in volcanogenic massive sulphide deposits, porphyry copper deposits and Outokumpu-type deposits in Finland: Geological Survey of Finland Report of Investigation 208, http://tupa.gtk.fi/julkaisu/tutkimusraportti/tr_208.pdf. 


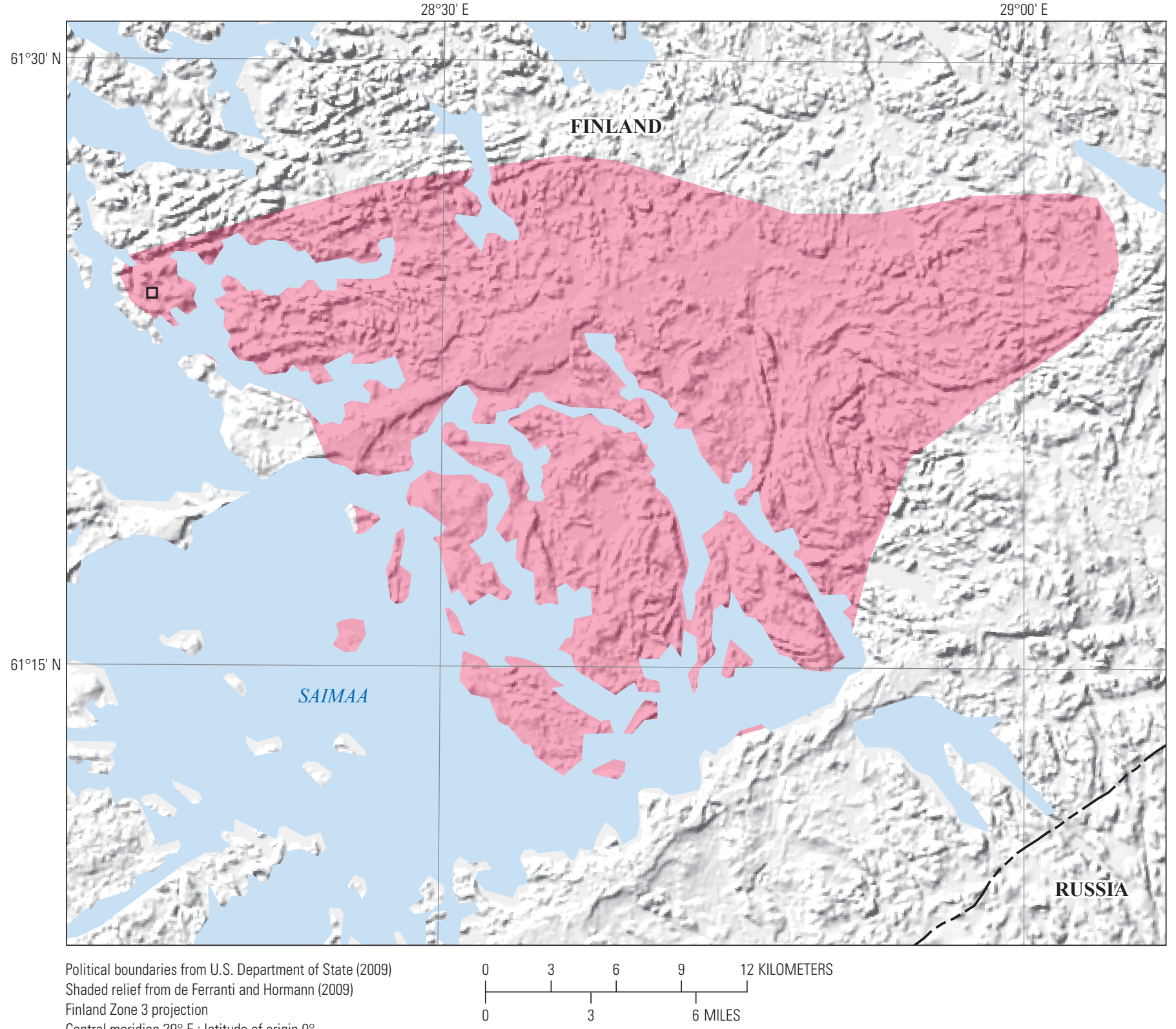

Central meridian $29^{\circ} \mathrm{E}$.; latitude of origin $0^{\circ}$

EXPLANATION

Assessed porphyry copper tract 150pCu6107

ㅁ Porphyry copper prospect

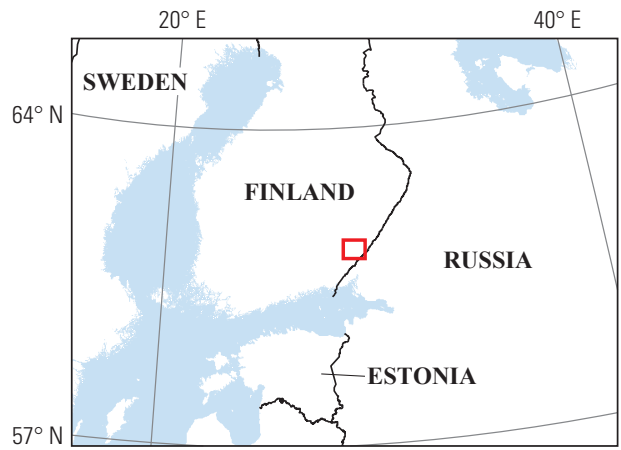




\title{
Plate 184. Porphyry Copper Assessment for Tract 150pCu6110, Tampere- Finland
}

\author{
Descriptive model: $\quad$ Porphyry copper (gold, molybdenum) model (Eilu, 2014) \\ Grade and tonnage model: $\quad$ Precambrian porphyry copper model (Rasilainen, 2014) \\ Economic filter depth percentages: $\quad$ Default -0 to 250 meters (m), 25\%; >250 to $500 \mathrm{~m}, 25 \%$; $>500 \mathrm{~m}$ to $1 \mathrm{~km}, 50 \%$ \\ Economic filter cost setting: Typical cost \\ Geologic feature assessed: $\quad$ Early orogenic to synorogenic Paleoproterozoic $(1.89-1.88 \mathrm{Ga})$ granitoid rocks along the southern \\ part of the Central Finland granitoid complex \\ Number of known deposits: \\ 0
}

\section{Selected Resource Assessment Results for Porphyry Copper}

[Assessment depth, 1 kilometer ( $\mathrm{km}) ; \mathrm{km}^{2}$, square kilometer; Mt, millions of metric tons]

\begin{tabular}{ccccccc}
\hline $\begin{array}{c}\text { Date of } \\
\text { assessment }\end{array}$ & $\begin{array}{c}\text { Tract area } \\
\left(\mathbf{k m}^{2}\right)\end{array}$ & $\begin{array}{c}\text { Identified } \\
\text { copper } \\
\text { resources } \\
\text { (Mt) }\end{array}$ & $\begin{array}{c}\text { Mean estimate of } \\
\text { in-place resources } \\
(\mathbf{M t})\end{array}$ & $\begin{array}{c}\text { Probability of } \mathbf{0} \\
\text { in-place resources } \\
\text { (percent) }\end{array}$ & $\begin{array}{c}\text { Mean estimate of } \\
\text { economic resources } \\
\text { (Mt) }\end{array}$ & $\begin{array}{c}\text { Probability of 0 } \\
\text { economic resources } \\
\text { (percent) }\end{array}$ \\
\hline 2012 & 5,046 & 0 & 2.0 & 7 & 0.34 \\
\hline
\end{tabular}

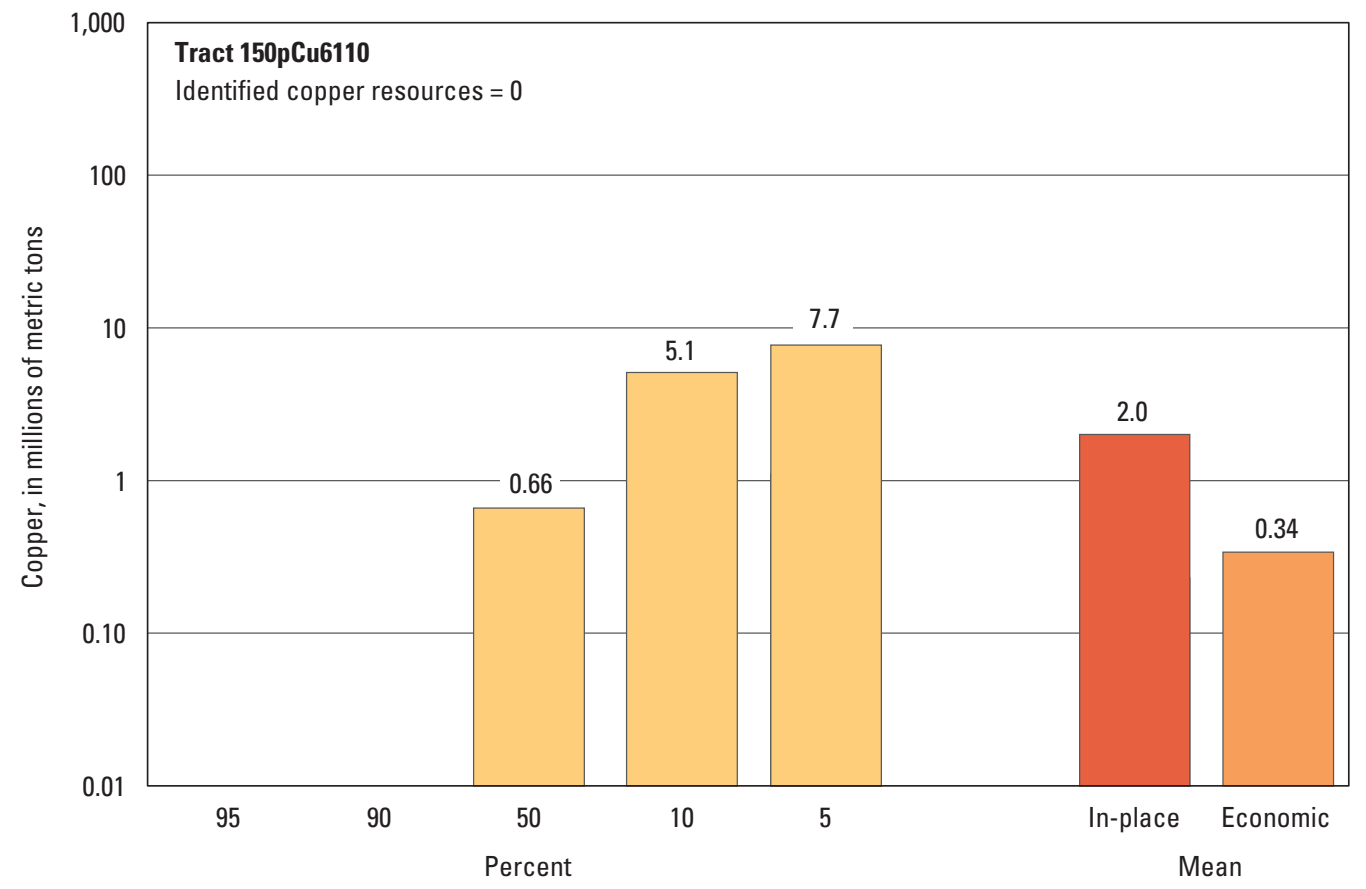

Graph showing the estimated probability distribution of undiscovered copper resources, where each bar represents the minimum amount estimated at the indicated percentage.

\section{Source}

Rasilainen and others, 2014, Quantitative assessment of undiscovered resources in volcanogenic massive sulphide deposits, porphyry copper deposits and Outokumpu-type deposits in Finland: Geological Survey of Finland Report of Investigation 208, http://tupa.gtk.fi/julkaisu/tutkimusraportti/tr_208.pdf. 


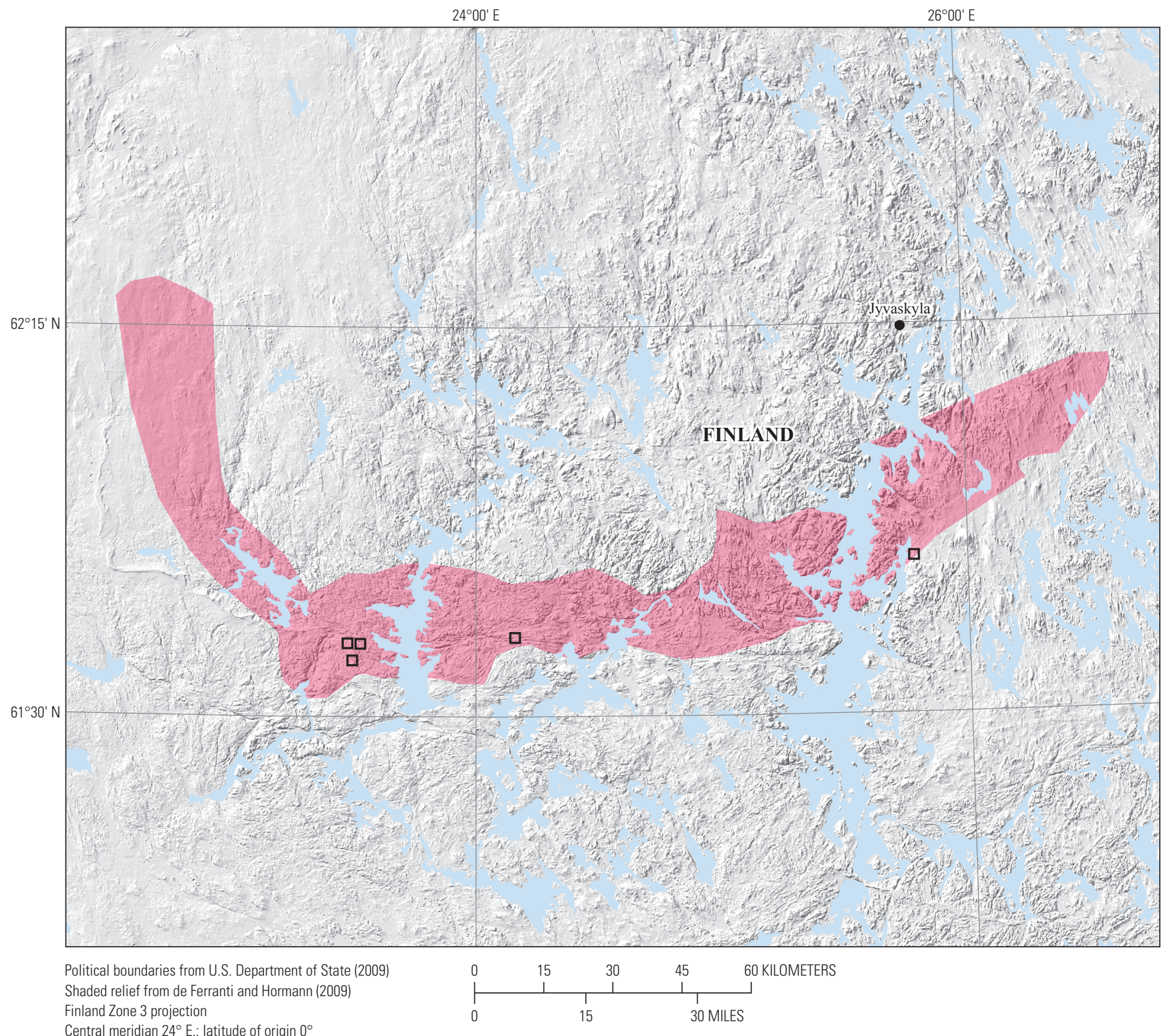

Central meridian $24^{\circ}$ E.; latitude of origin $0^{\circ}$

EXPLANATION

Assessed porphyry copper tract 150pCu6110

$\square \quad$ Porphyry copper prospect

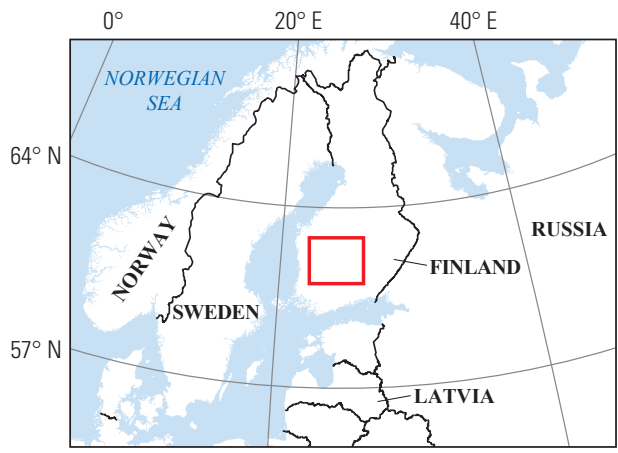




\title{
Plate 185. Porphyry Copper Assessment for Tract 150pCu6109, Southern Savo- Finland
}

\author{
Descriptive model: $\quad$ Porphyry copper (gold, molybdenum) model (Eilu, 2014) \\ Grade and tonnage model: $\quad$ Precambrian porphyry copper model (Rasilainen, 2014) \\ Economic filter depth percentages: $\quad$ Default -0 to 250 meters (m), 25\%; $>250$ to $500 \mathrm{~m}, 25 \% ;>500 \mathrm{~m}$ to $1 \mathrm{~km}, 50 \%$ \\ Economic filter cost setting: \\ Geologic feature assessed: \\ Typical cost \\ Synorogenic Paleoproterozoic (1.89-1.88 Ga?) granitoid rocks that intruded Svecofennian mica \\ gneisses and mafic volcanic rocks in southeastern Finland \\ Number of known deposits: \\ 0
}

\section{Selected Resource Assessment Results for Porphyry Copper}

[Assessment depth, 1 kilometer ( $\mathrm{km}) ; \mathrm{km}^{2}$, square kilometer; Mt, millions of metric tons]

\begin{tabular}{ccccccc}
\hline $\begin{array}{c}\text { Date of } \\
\text { assessment }\end{array}$ & $\begin{array}{c}\text { Tract area } \\
\left(\mathbf{k m}^{2}\right)\end{array}$ & $\begin{array}{c}\text { Identified } \\
\text { copper } \\
\text { resources } \\
\text { (Mt) }\end{array}$ & $\begin{array}{c}\text { Mean estimate of } \\
\text { in-place resources } \\
(\mathbf{M t})\end{array}$ & $\begin{array}{c}\text { Probability of } \mathbf{0} \\
\text { in-place resources } \\
\text { (percent) }\end{array}$ & $\begin{array}{c}\text { Mean estimate of } \\
\text { economic resources } \\
\text { (Mt) }\end{array}$ & $\begin{array}{c}\text { Probability of 0 } \\
\text { economic resources } \\
\text { (percent) }\end{array}$ \\
\hline 2012 & 603 & 0 & 0.28 & 7 & 0.047 \\
\hline
\end{tabular}

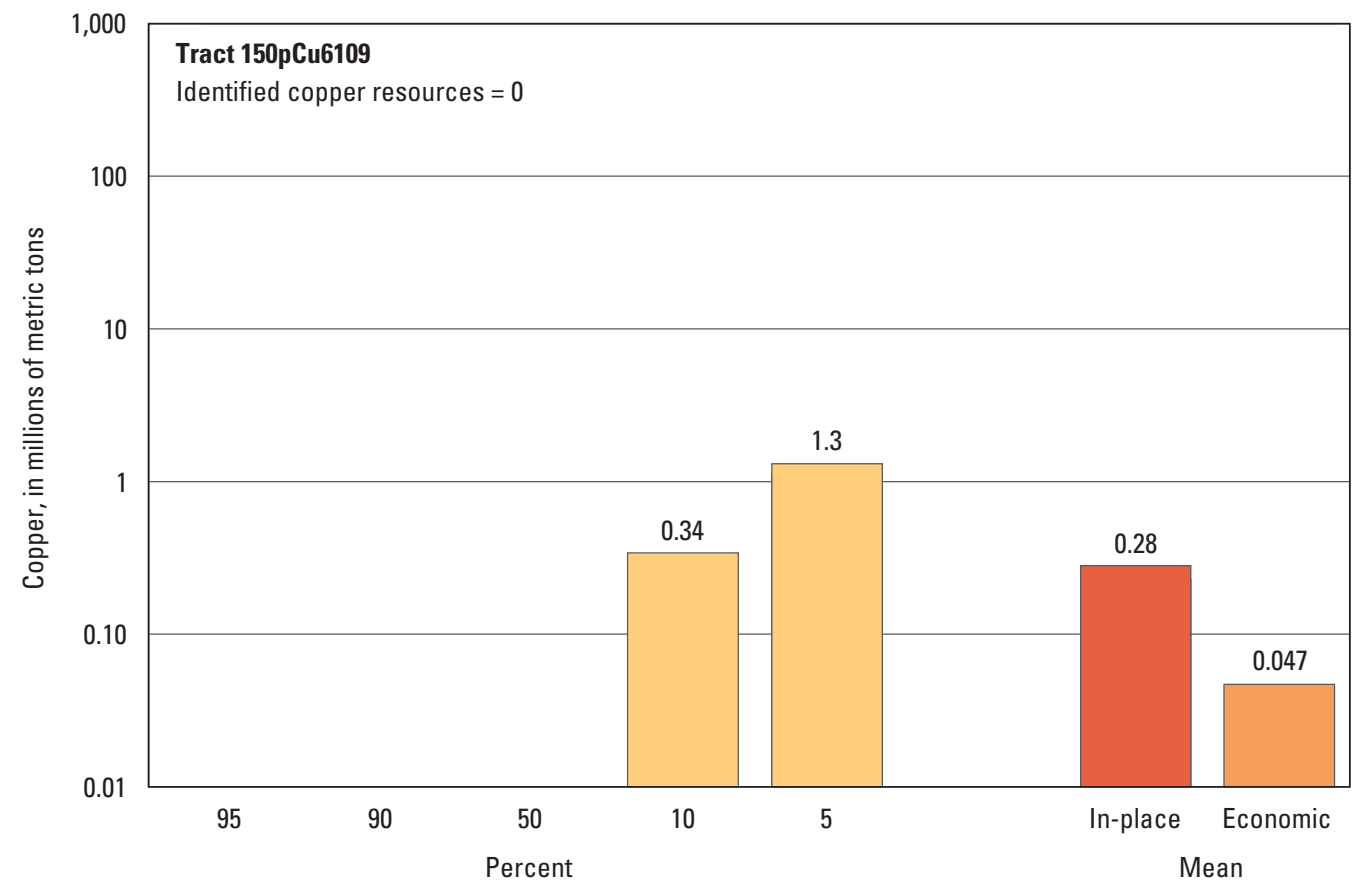

Graph showing the estimated probability distribution of undiscovered copper resources, where each bar represents the minimum amount estimated at the indicated percentage.

\section{Source}

Rasilainen and others, 2014, Quantitative assessment of undiscovered resources in volcanogenic massive sulphide deposits, porphyry copper deposits and Outokumpu-type deposits in Finland: Geological Survey of Finland Report of Investigation 208, http://tupa.gtk.fi/julkaisu/tutkimusraportti/tr_208.pdf. 


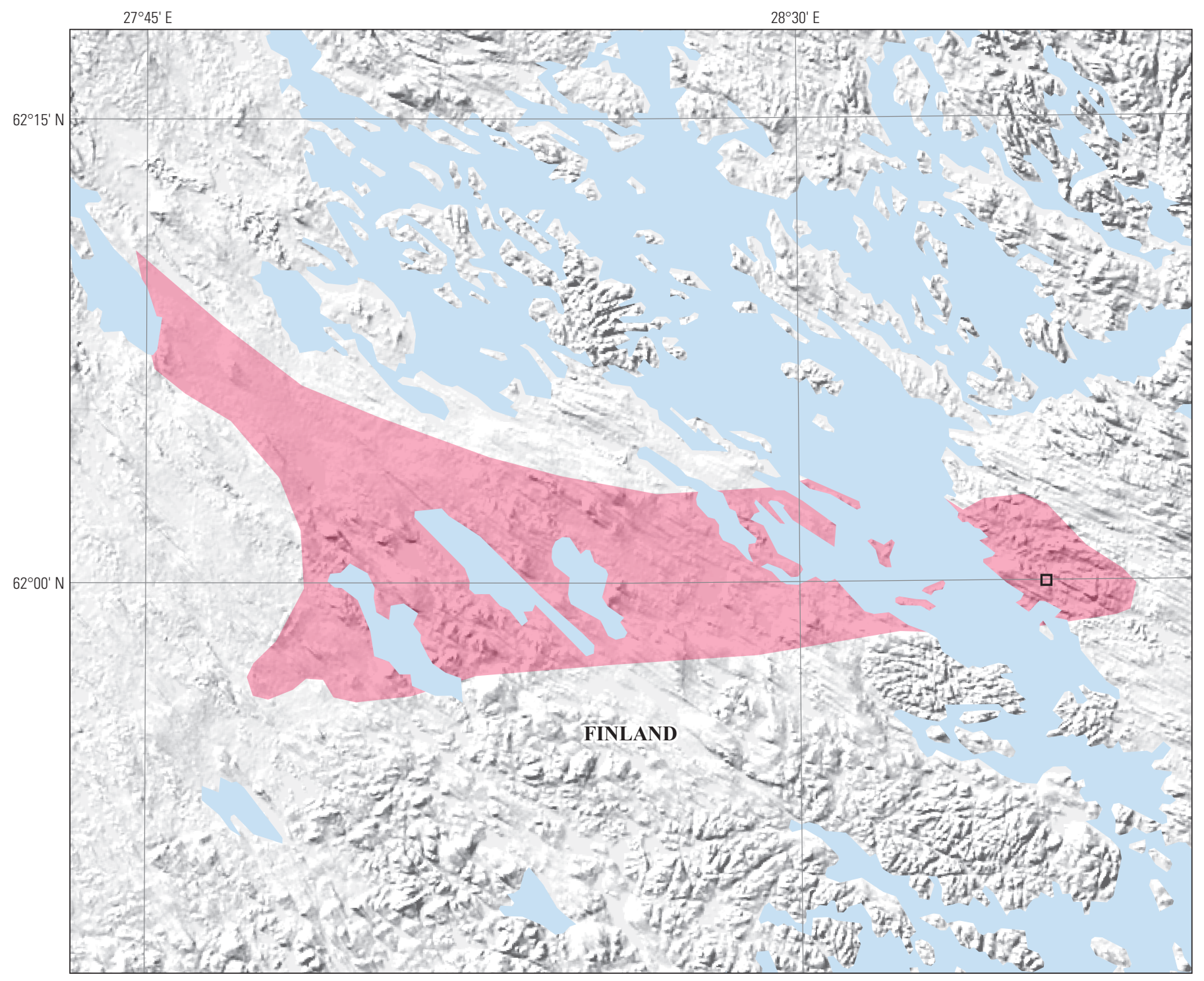

Political boundaries from U.S. Department of State (2009) Shaded relief from de Ferranti and Hormann (2009) Finland Zone 3 projection

Central meridian $28^{\circ} \mathrm{E}$.; latitude of origin $0^{\circ}$

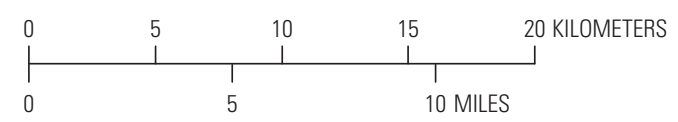

\section{EXPLANATION}

Assessed porphyry copper tract 150pCu6109

口 Porphyry copper prospect

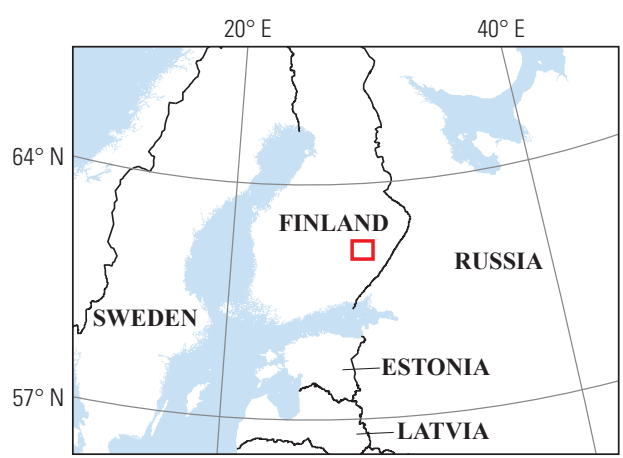




\title{
Plate 186. Porphyry Copper Assessment for Tract 150pCu6102, Central Ostrobothnia-Finland
}

\author{
Descriptive model: $\quad$ Porphyry copper (gold, molybdenum) model (Eilu, 2014) \\ Grade and tonnage model: $\quad$ Precambrian porphyry copper model (Rasilainen, 2014) \\ Economic filter depth percentages: $\quad$ Default -0 to 250 meters (m), 25\%; >250 to $500 \mathrm{~m}, 25 \%$; $>500 \mathrm{~m}$ to $1 \mathrm{~km}, 50 \%$ \\ Economic filter cost setting: Typical cost \\ Geologic feature assessed: $\quad$ Felsic intrusive rocks of the northern part of the Paleoproterozoic (1.88 Ga) Central Finland \\ granitoid complex \\ Number of known deposits: \\ 1
}

\section{Selected Resource Assessment Results for Porphyry Copper}

[Assessment depth, 1 kilometer ( $\mathrm{km}) ; \mathrm{km}^{2}$, square kilometer; Mt, millions of metric tons]

\begin{tabular}{ccccccc}
\hline $\begin{array}{c}\text { Date of } \\
\text { assessment }\end{array}$ & $\begin{array}{c}\text { Tract area } \\
\left(\mathbf{k m}^{2}\right)\end{array}$ & $\begin{array}{c}\text { Identified } \\
\text { copper } \\
\text { resources } \\
\text { (Mt) }\end{array}$ & $\begin{array}{c}\text { Mean estimate of } \\
\text { in-place resources } \\
(\mathbf{M t})\end{array}$ & $\begin{array}{c}\text { Probability of } \mathbf{0} \\
\text { in-place resources } \\
\text { (percent) }\end{array}$ & $\begin{array}{c}\text { Mean estimate of } \\
\text { economic resources } \\
\text { (Mt) }\end{array}$ & $\begin{array}{c}\text { Probability of 0 } \\
\text { economic resources } \\
\text { (percent) }\end{array}$ \\
\hline 2012 & 11,155 & 0.045 & 1.9 & 7 & 0.32 \\
\hline
\end{tabular}

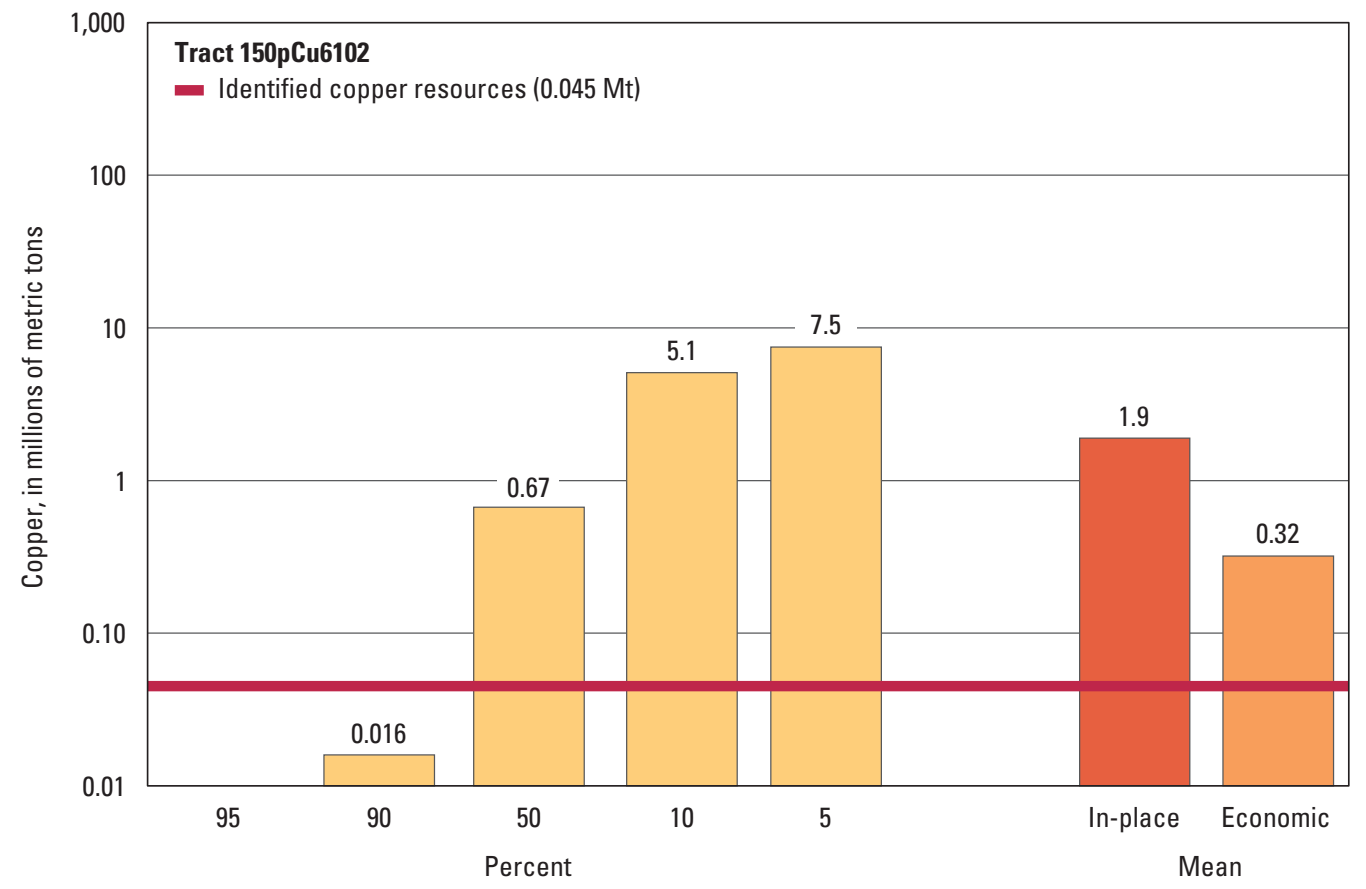

Graph showing the estimated probability distribution of undiscovered copper resources, where each bar represents the minimum amount estimated at the indicated percentage.

\section{Source}

Rasilainen and others, 2014, Quantitative assessment of undiscovered resources in volcanogenic massive sulphide deposits, porphyry copper deposits and Outokumpu-type deposits in Finland: Geological Survey of Finland Report of Investigation 208, http://tupa.gtk.fi/julkaisu/tutkimusraportti/tr_208.pdf. 

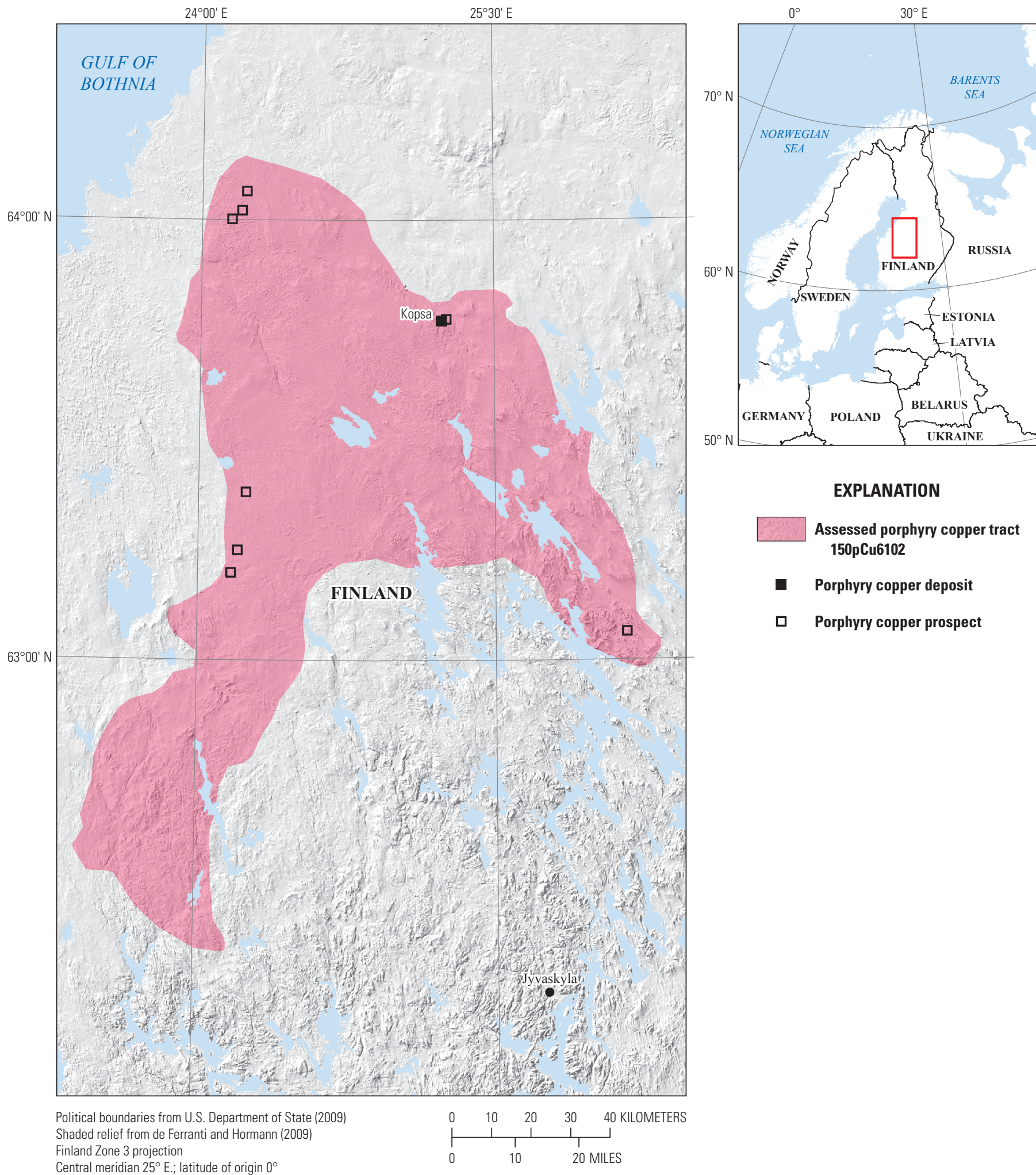

\section{EXPLANATION}

Assessed porphyry copper tract 150pCu6102

- Porphyry copper deposit

$\square \quad$ Porphyry copper prospect 


\title{
Plate 187. Porphyry Copper Assessment for Tract 150pCu6103, Haaparanta- Finland
}

\author{
Descriptive model: \\ Porphyry copper (gold, molybdenum) model (Eilu, 2014) \\ Grade and tonnage model: \\ Precambrian porphyry copper model (Rasilainen, 2014) \\ Economic filter depth percentages: \\ Default -0 to 250 meters (m), $25 \%$; $>250$ to $500 \mathrm{~m}, 25 \% ;>500 \mathrm{~m}$ to $1 \mathrm{~km}, 50 \%$ \\ Economic filter cost setting: \\ Geologic feature assessed: \\ Typical cost \\ Extent of known intrusions of the Paleoproterozoic (1.88 Ga) Haaparanta suite in Finland \\ Number of known deposits: \\ 0
}

\section{Selected Resource Assessment Results for Porphyry Copper}

[Assessment depth, 1 kilometer $(\mathrm{km}) ; \mathrm{km}^{2}$, square kilometer; Mt, millions of metric tons]

\begin{tabular}{ccccccc}
\hline \multirow{2}{*}{$\begin{array}{c}\text { Date of } \\
\text { assessment }\end{array}$} & $\begin{array}{c}\text { Tract area } \\
\left(\mathbf{k m}^{2}\right)\end{array}$ & $\begin{array}{c}\text { Identified } \\
\text { copper } \\
\text { resources } \\
(\mathbf{M t})\end{array}$ & $\begin{array}{c}\text { Mean estimate of } \\
\text { in-place resources } \\
(\mathbf{M t})\end{array}$ & $\begin{array}{c}\text { Probability of } \mathbf{0} \\
\text { in-place resources } \\
\text { (percent) }\end{array}$ & $\begin{array}{c}\text { Mean estimate of } \\
\text { economic resources } \\
\text { (Mt) }\end{array}$ & $\begin{array}{c}\text { Probability of } \mathbf{0} \\
\text { economic resources } \\
\text { (percent) }\end{array}$ \\
\hline 2012 & 5,823 & 0 & 1.5 & 20 & 0.25 \\
\hline
\end{tabular}

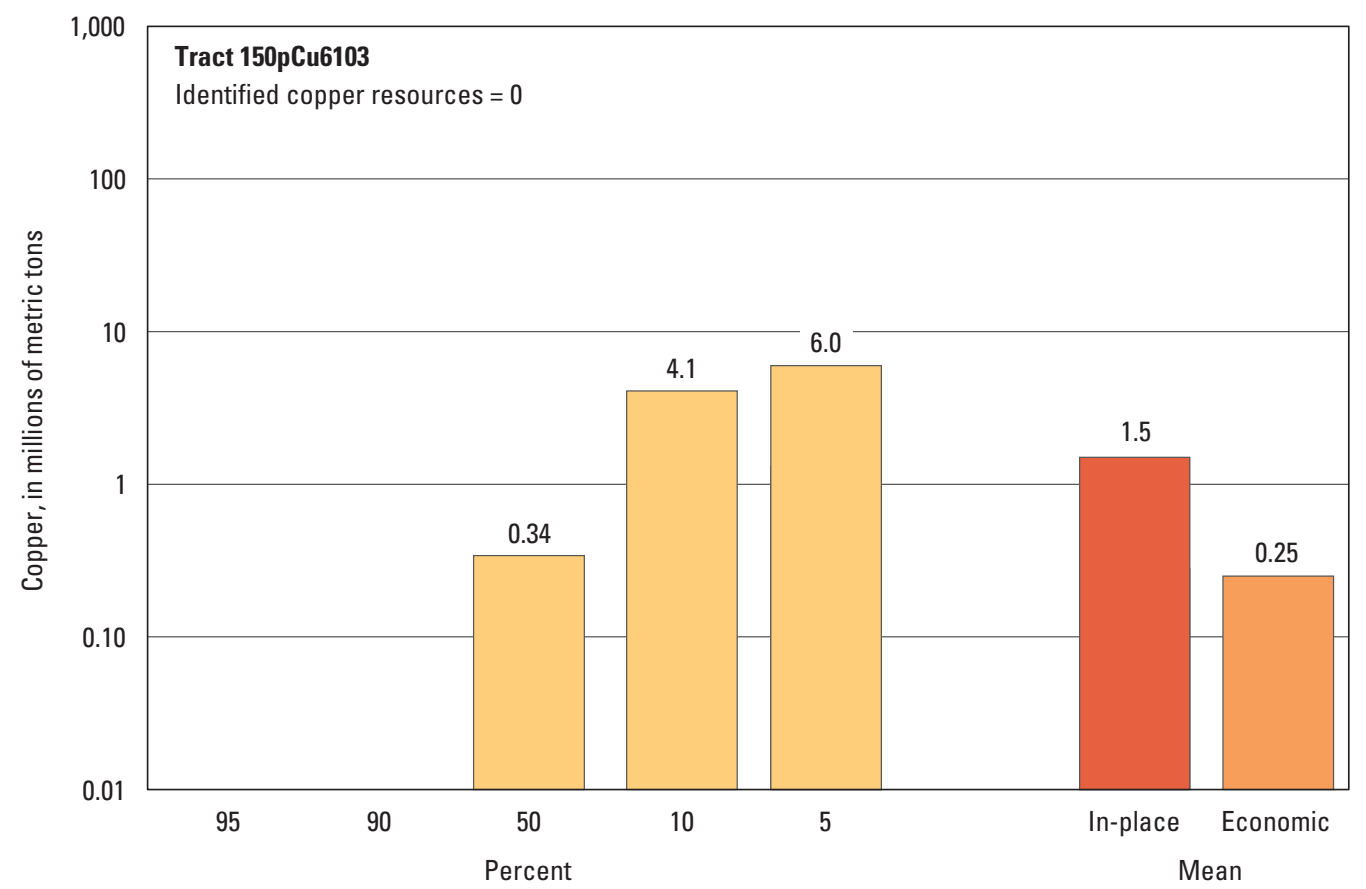

Graph showing the estimated probability distribution of undiscovered copper resources, where each bar represents the minimum amount estimated at the indicated percentage.

\section{Source}

Rasilainen and others, 2014, Quantitative assessment of undiscovered resources in volcanogenic massive sulphide deposits, porphyry copper deposits and Outokumpu-type deposits in Finland: Geological Survey of Finland Report of Investigation 208, http://tupa.gtk.fi/julkaisu/tutkimusraportti/tr_208.pdf. 

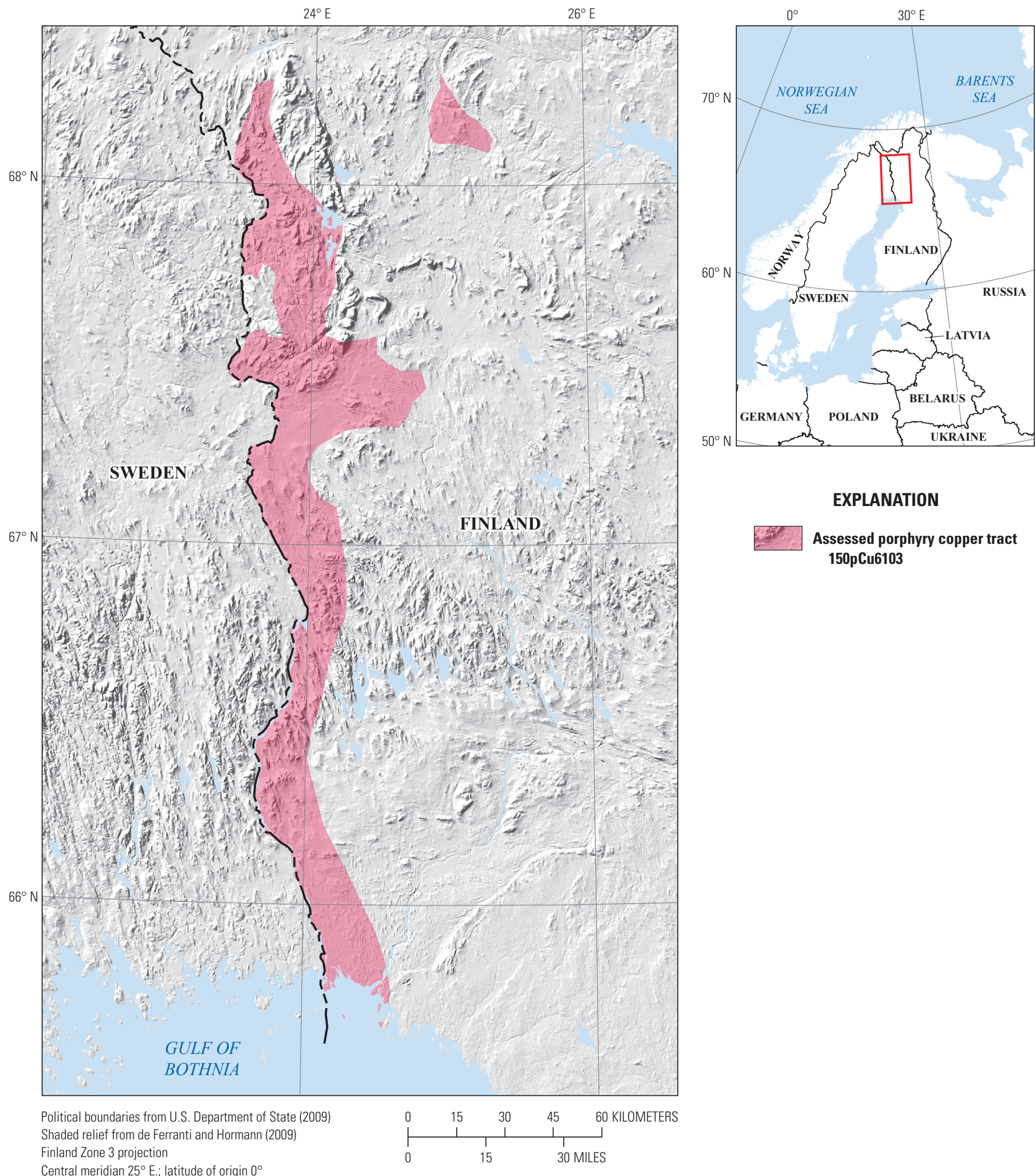

\section{Assessed porphyry copper tract $150 p$ Cu6103}

Central meridian $25^{\circ} \mathrm{E}$; l latitude of origin $0^{\circ}$ 


\section{Plate 188. Porphyry Copper Assessment for Tract 150pCu6106, Nilipää—Finland}

Descriptive model:

Grade and tonnage model:

Economic filter depth percentages:

Economic filter cost setting:

Geologic feature assessed:

Number of known deposits:
Porphyry copper (gold, molybdenum) model (Eilu, 2014)

Precambrian porphyry copper model (Rasilainen, 2014)

Default -0 to 250 meters (m), $25 \%$; $>250$ to $500 \mathrm{~m}, 25 \%$; $>500 \mathrm{~m}$ to $1 \mathrm{~km}, 50 \%$

Typical cost

Paleoproterozoic $(2.1 \mathrm{Ga})$ granitoid intrusions in the contact zone of the Central Lapland granitoid complex and greenstone belt along the Venejoki fault in Finland

0

\section{Selected Resource Assessment Results for Porphyry Copper}

[Assessment depth, 1 kilometer $(\mathrm{km}) ; \mathrm{km}^{2}$, square kilometer; Mt, millions of metric tons]

\begin{tabular}{ccccccc}
\hline $\begin{array}{c}\text { Date of } \\
\text { assessment }\end{array}$ & $\begin{array}{c}\text { Tract area } \\
\left(\mathbf{k m}^{2}\right)\end{array}$ & $\begin{array}{c}\text { Identified } \\
\text { copper } \\
\text { resources } \\
\text { (Mt) }\end{array}$ & $\begin{array}{c}\text { Mean estimate of } \\
\text { in-place resources } \\
(\mathbf{M t})\end{array}$ & $\begin{array}{c}\text { Probability of } \mathbf{0} \\
\text { in-place resources } \\
\text { (percent) }\end{array}$ & $\begin{array}{c}\text { Mean estimate of } \\
\text { economic resources } \\
\text { (Mt) }\end{array}$ & $\begin{array}{c}\text { Probability of 0 } \\
\text { economic resources } \\
\text { (percent) }\end{array}$ \\
\hline 2012 & 2,035 & 0 & 0.21 & 70 & 0.035 \\
\hline
\end{tabular}

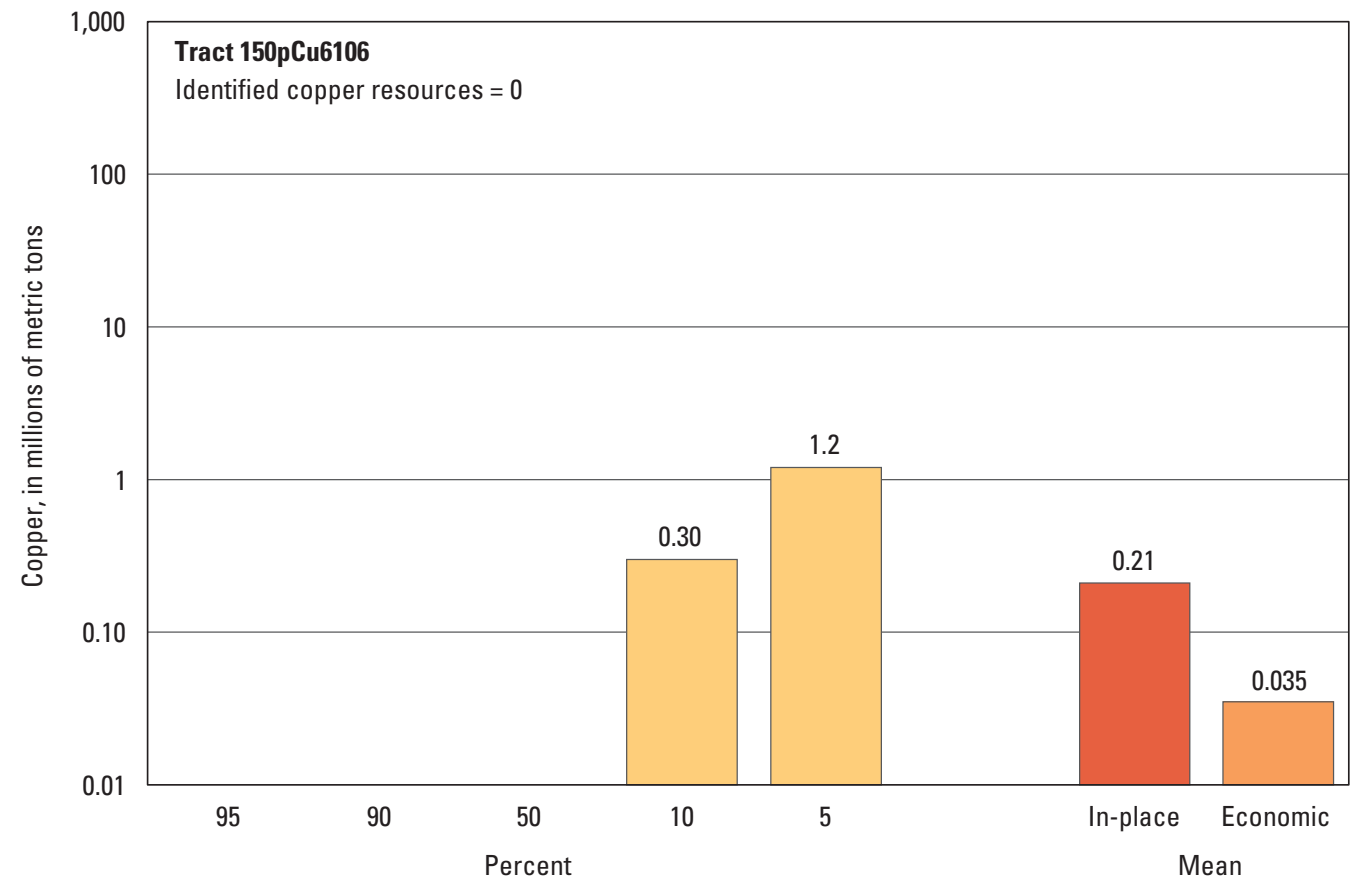

Graph showing the estimated probability distribution of undiscovered copper resources, where each bar represents the minimum amount estimated at the indicated percentage.

\section{Source}

Rasilainen and others, 2014, Quantitative assessment of undiscovered resources in volcanogenic massive sulphide deposits, porphyry copper deposits and Outokumpu-type deposits in Finland: Geological Survey of Finland Report of Investigation 208, http://tupa.gtk.fi/julkaisu/tutkimusraportti/tr_208.pdf. 


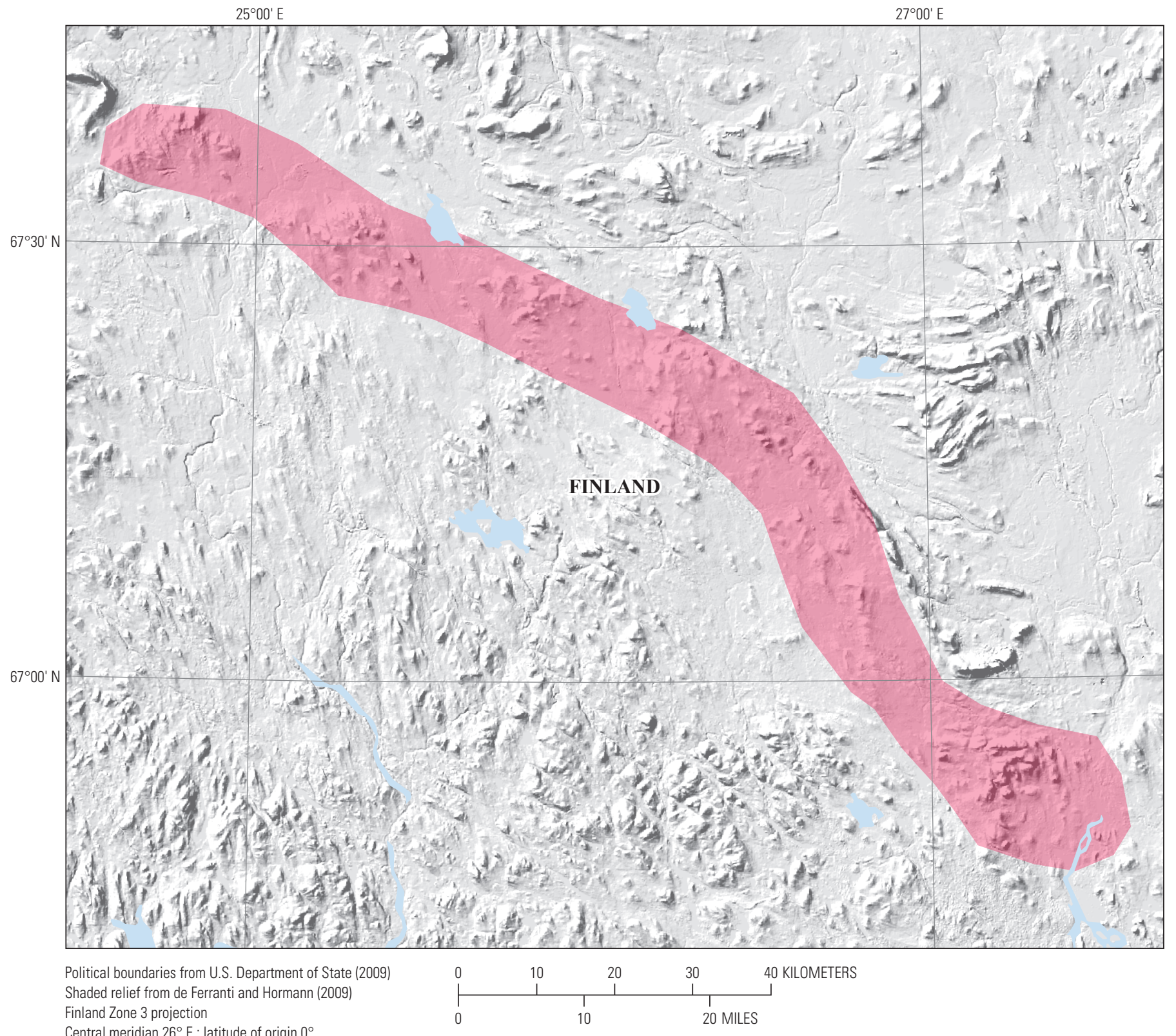

Central meridian $26^{\circ} \mathrm{E}$.; latitude of origin $0^{\circ}$

EXPLANATION

Assessed porphyry copper tract 150pCu6106

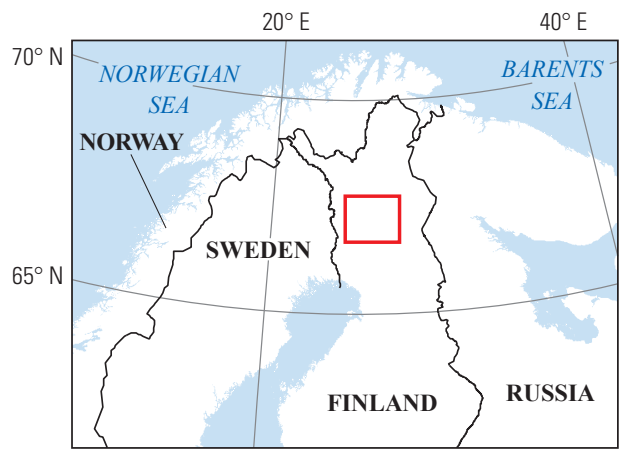



Plates 189-236. Results of Regional-Scale Sediment-Hosted Stratabound Copper

Assessments 


\title{
Plate 189. Sediment-Hosted Stratabound Copper Assessment for Tract 005ssCu5100, Neuquén Basin-Argentina and Chile
}

\author{
Descriptive model: \\ Geologic feature assessed: \\ Number of known deposits:
}

Sediment-hosted stratabound copper-Sandstone copper subtype model (Cox and others, 2007; Zientek, Hayes, and Hammarstrom, 2013) Jurassic to Cretaceous sedimentary rocks of the Neuquén Basin 9

\section{Selected Resource Assessment Results for Sediment-Hosted Stratabound Copper}

[Assessment depth, 0 kilometer ( $\mathrm{km}) ; \mathrm{km}^{2}$, square kilometer; Mt, millions of metric tons]

\begin{tabular}{ccccc}
\hline $\begin{array}{c}\text { Date of } \\
\text { assessment }\end{array}$ & $\begin{array}{c}\text { Tract area } \\
\left.\mathbf{( k m}^{2}\right)\end{array}$ & $\begin{array}{c}\text { Identified } \\
\text { copper } \\
\text { resources } \\
(\mathbf{M t})\end{array}$ & $\begin{array}{c}\text { Analytic hierarchy process- } \\
\text { Alternative utility* } \\
\text { (percent) }\end{array}$ & Overall rank \\
\hline 2012 & 126,175 & 0.18 & 9.23 & 7th of 10 areas \\
\hline
\end{tabular}

"Alternative utility is a numerical weight derived from evaluation of three assessment criteria.

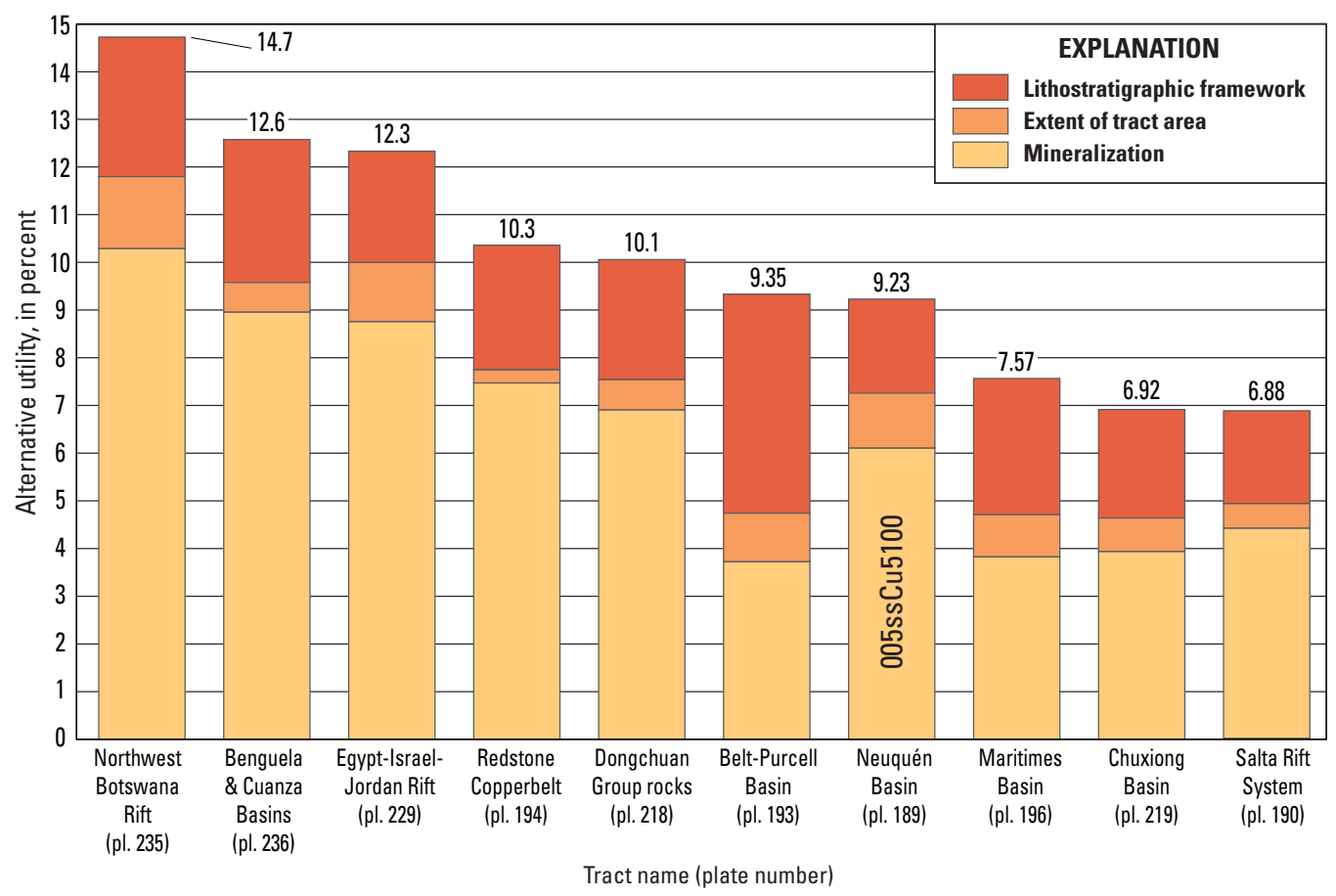

Graph showing qualitative ranking of basins determined by the analytic hierarchy process (AHP). Alternative utility is the overall score derived from the AHP method.

\section{Source}

Zientek, Wintzer, and others, 2015, Qualitative assessment of selected areas of the world for undiscovered sediment-hosted stratabound copper deposits: U.S. Geological Survey Scientific Investigations Report 2010-5090-Y, http://dx.doi.org/10.3133/sir20105090Y. 

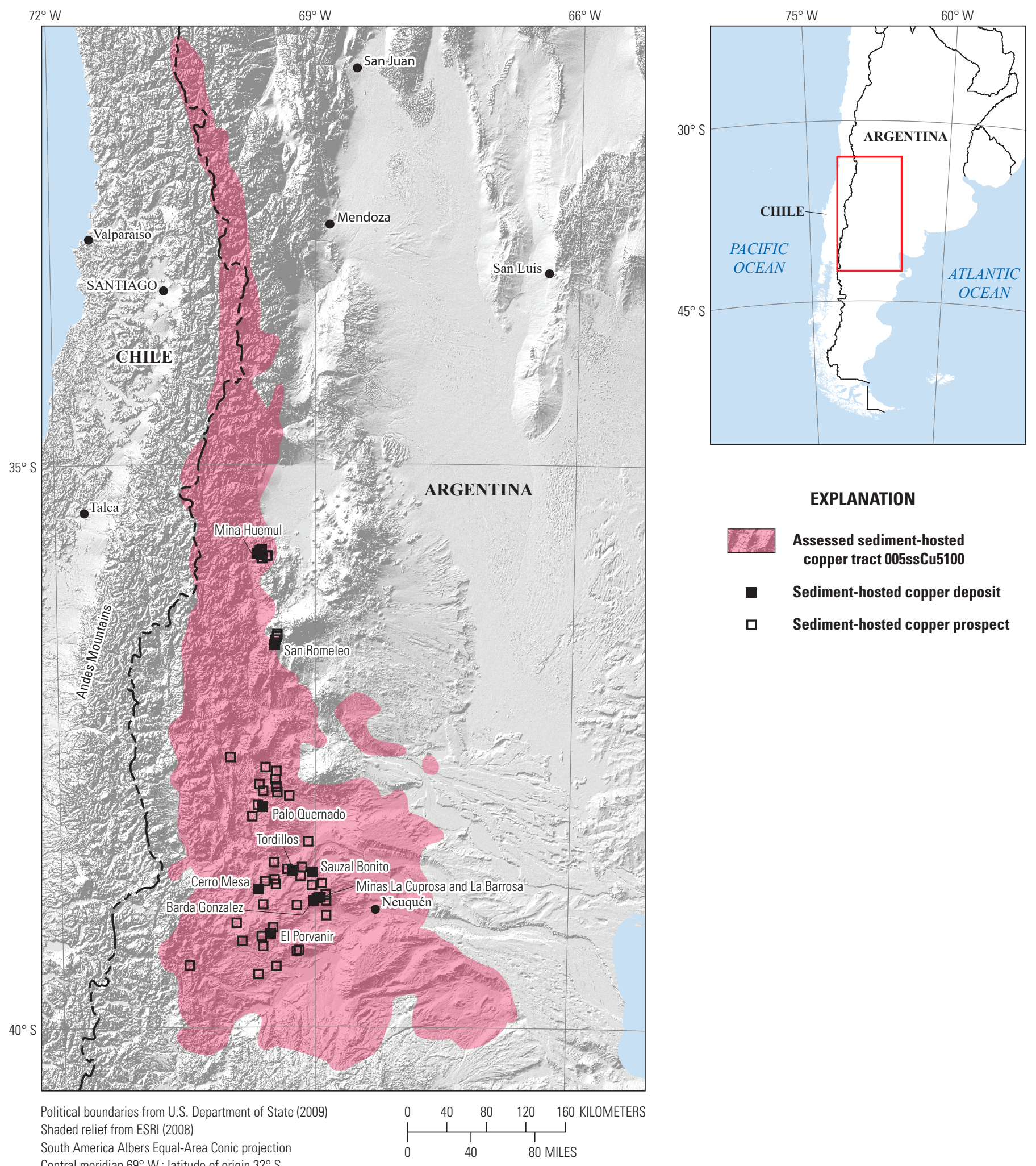


\title{
Plate 190. Sediment-Hosted Stratabound Copper Assessment for Tract 005rfCu5101, Salta Rift System—Argentina
}

\author{
Descriptive model: \\ Geologic feature assessed: \\ Number of known deposits:
}
Sediment-hosted stratabound copper-Reduced-facies copper subtype model (Cox and others, 2007; Zientek, Hayes, and Hammarstrom, 2013)
Marine carbonaceous and continental clastic rocks of the Upper Cretaceous Lecho and Yacoraite Formations and Pirgua Subgroup of the Salta Group, Salta Rift System

2

\section{Selected Resource Assessment Results for Sediment-Hosted Stratabound Copper}

[Assessment depth, 0 kilometer $(\mathrm{km}) ; \mathrm{km}^{2}$, square kilometer; Mt, millions of metric tons]

\begin{tabular}{|c|c|c|c|c|}
\hline \multirow[b]{2}{*}{$\begin{array}{c}\text { Date of } \\
\text { assessment }\end{array}$} & \multirow[b]{2}{*}{$\begin{array}{l}\text { Tract area } \\
\qquad\left(\mathbf{k m}^{2}\right)\end{array}$} & \multirow{2}{*}{$\begin{array}{l}\text { Identified } \\
\text { copper } \\
\text { resources } \\
\text { (Mt) }\end{array}$} & \multicolumn{2}{|c|}{ Qualitative assessment ranking } \\
\hline & & & $\begin{array}{c}\text { Analytic hierarchy process- } \\
\text { Alternative utility* } \\
\text { (percent) }\end{array}$ & Overall rank \\
\hline 2012 & 27,345 & 0.21 & 6.88 & 10 th of 10 areas \\
\hline
\end{tabular}

"Alternative utility is a numerical weight derived from evaluation of three assessment criteria.

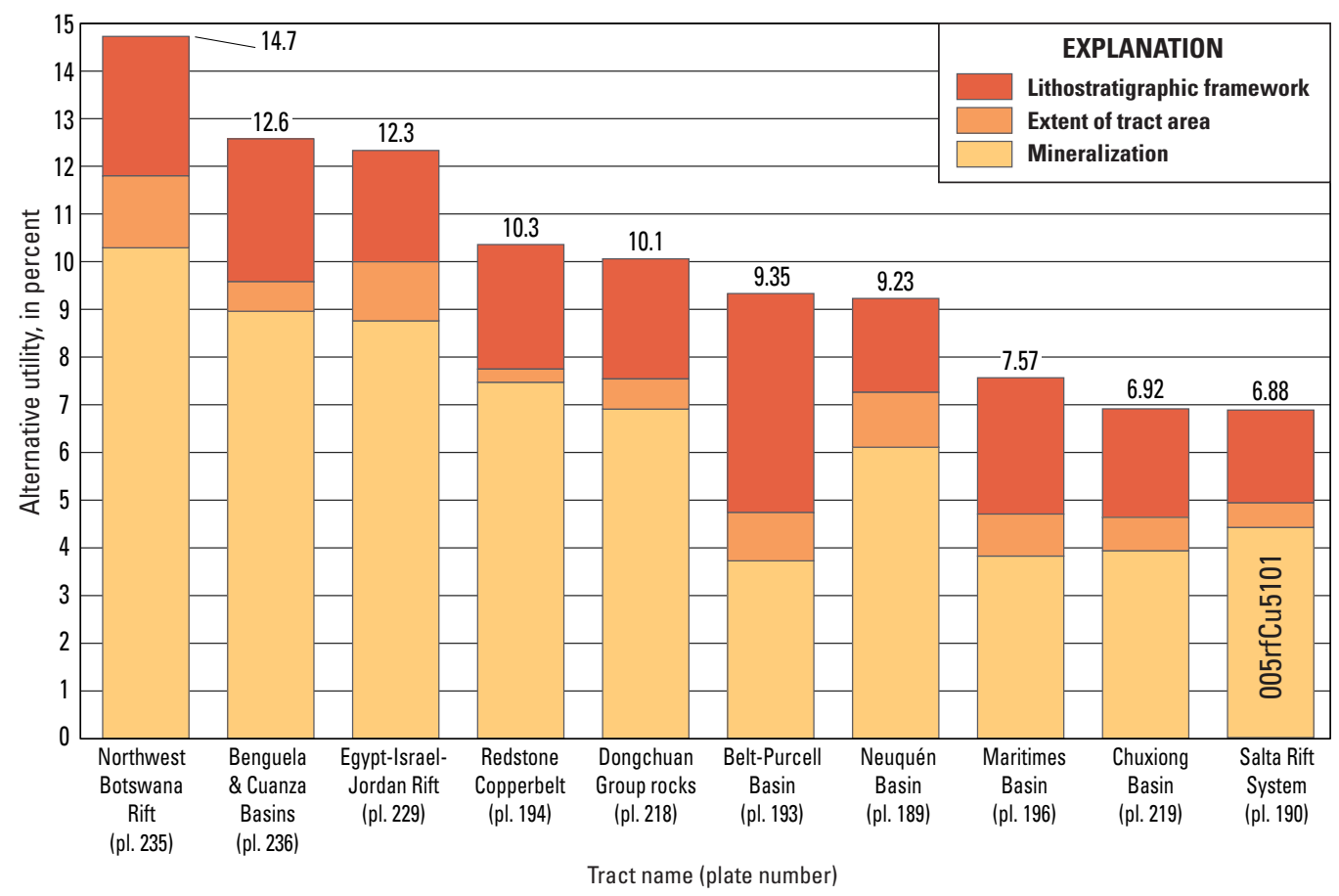

Graph showing qualitative ranking of basins determined by the analytic hierarchy process (AHP). Alternative utility is the overall score derived from the AHP method.

\section{Source}

Zientek, Wintzer, and others, 2015, Qualitative assessment of selected areas of the world for undiscovered sediment-hosted stratabound copper deposits: U.S. Geological Survey Scientific Investigations Report 2010-5090-Y, http://dx.doi.org/10.3133/sir20105090Y. 


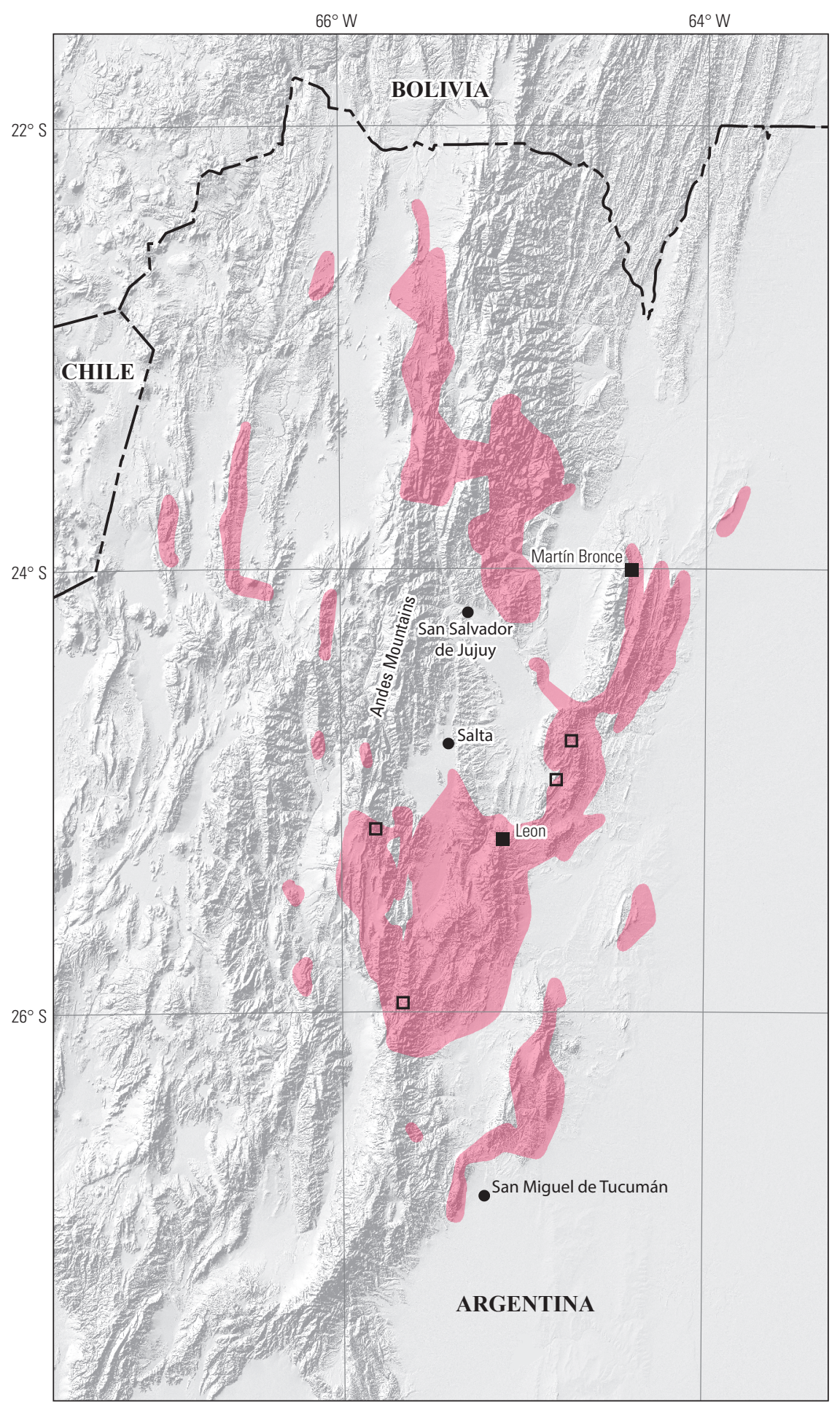

Political boundaries from U.S. Department of State (2009) Shaded relief from ESRI (2008)

South America Albers Equal-Area Conic projection

Central meridian $65^{\circ} \mathrm{W}$.; latitude of origin $32^{\circ} \mathrm{S}$.

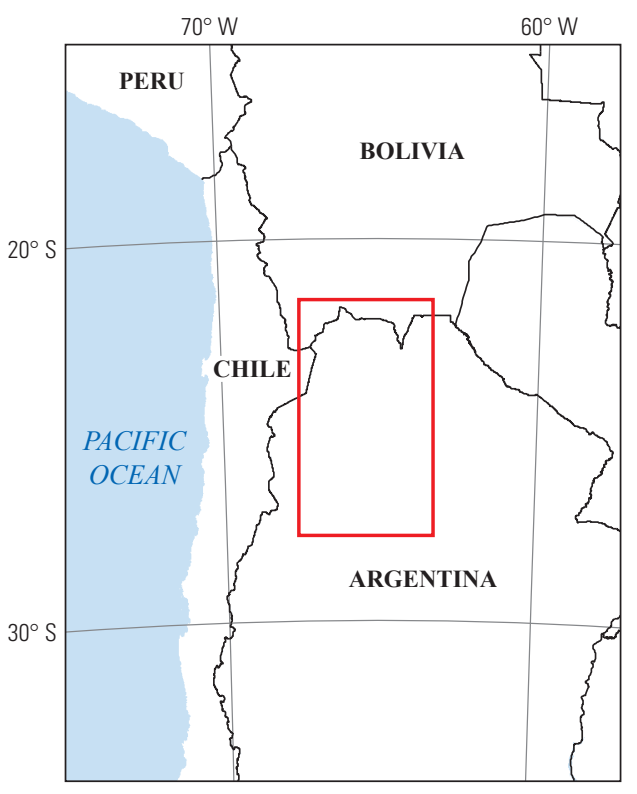

\section{EXPLANATION}

Assessed sediment-hosted copper tract $005 \mathrm{rfCu} 5101$

- Sediment-hosted copper deposit

ㄴ Sediment-hosted copper prospect 


\title{
Plate 191. Sediment-Hosted Stratabound Copper Assessment for Tract 003rfnbCu3002, Great Plains (GP04), Anadarko-Palo Duro-Midland Permian Basin-United States
}

\author{
Descriptive model: \\ Sediment-hosted stratabound copper-Reduced-facies-nonbrecciated copper subtype model \\ (Cox and others, 2007; Zientek, Hayes, and Hammarstrom, 2013) \\ Grade and tonnage model: \\ Geologic feature assessed: \\ Sediment-hosted stratabound copper-Reduced-facies-nonbrecciated copper subtype model \\ (Zientek, Hayes, and Taylor, 2013) \\ Marine carbonaceous rocks of the Permian (Guadalupian) Flowerpot Shale interbedded with \\ continental clastic rocks of the San Angelo Formation, Anadarko, Palo Duro, and Midland \\ Permian Basins \\ Number of known deposits: \\ 3
}

\section{Selected Resource Assessment Results for Sediment-Hosted Stratabound Copper}

[Assessment depth, 1 kilometer (km); km², square kilometer; Mt, millions of metric tons]

\begin{tabular}{ccccccc}
\hline $\begin{array}{c}\text { Date of } \\
\text { assessment }\end{array}$ & $\begin{array}{c}\text { Tract area } \\
\left(\mathbf{k m}^{2}\right)\end{array}$ & $\begin{array}{c}\text { Identified } \\
\text { copper } \\
\text { resources } \\
(\mathbf{M t})\end{array}$ & $\begin{array}{c}\text { Median estimate of } \\
\text { in-place resources } \\
(\mathbf{M t})\end{array}$ & $\begin{array}{c}\text { Mean estimate of } \\
\text { in-place resources } \\
\text { (Mt) }\end{array}$ & $\begin{array}{c}\text { Probability of mean } \\
\text { or greater } \\
\text { (percent) }\end{array}$ & $\begin{array}{c}\text { Probability of } \mathbf{0} \\
\text { in-place resources } \\
\text { (percent) }\end{array}$ \\
\hline 1998 & 186,791 & 0.046 & 5.8 & 16 & 32 \\
\hline
\end{tabular}

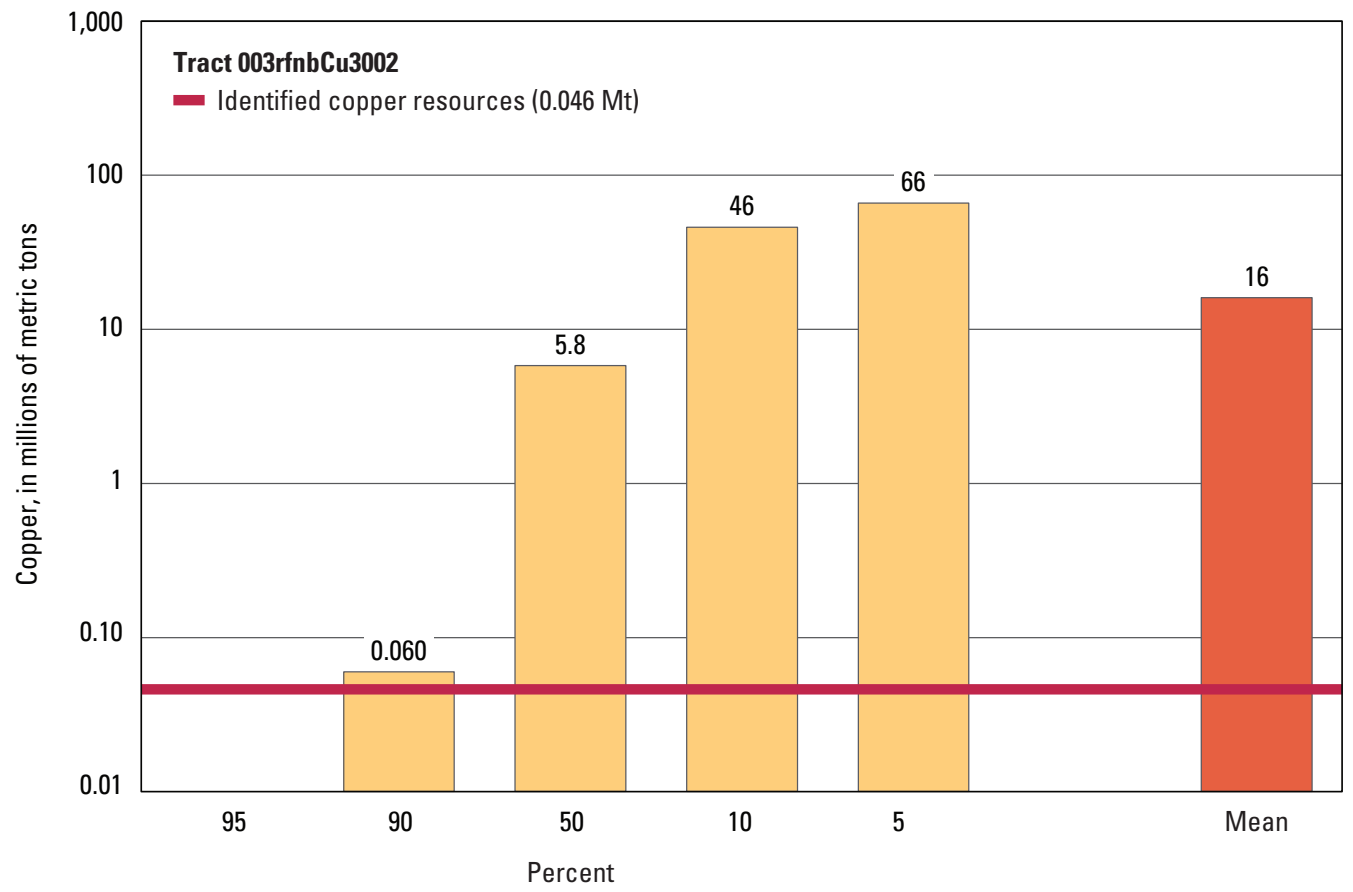

Graph showing the estimated probability distribution of undiscovered copper resources, where each bar represents the minimum amount estimated at the indicated percentage.

\section{Source}

U.S. Geological Survey National Mineral Resource Assessment Team, 2002, Assessment of undiscovered deposits of gold, silver, copper, lead, and zinc in the United States: U.S. Geological Survey Open-File Report 02-198, http://pubs.usgs.gov/of/2002/of02-198/. 


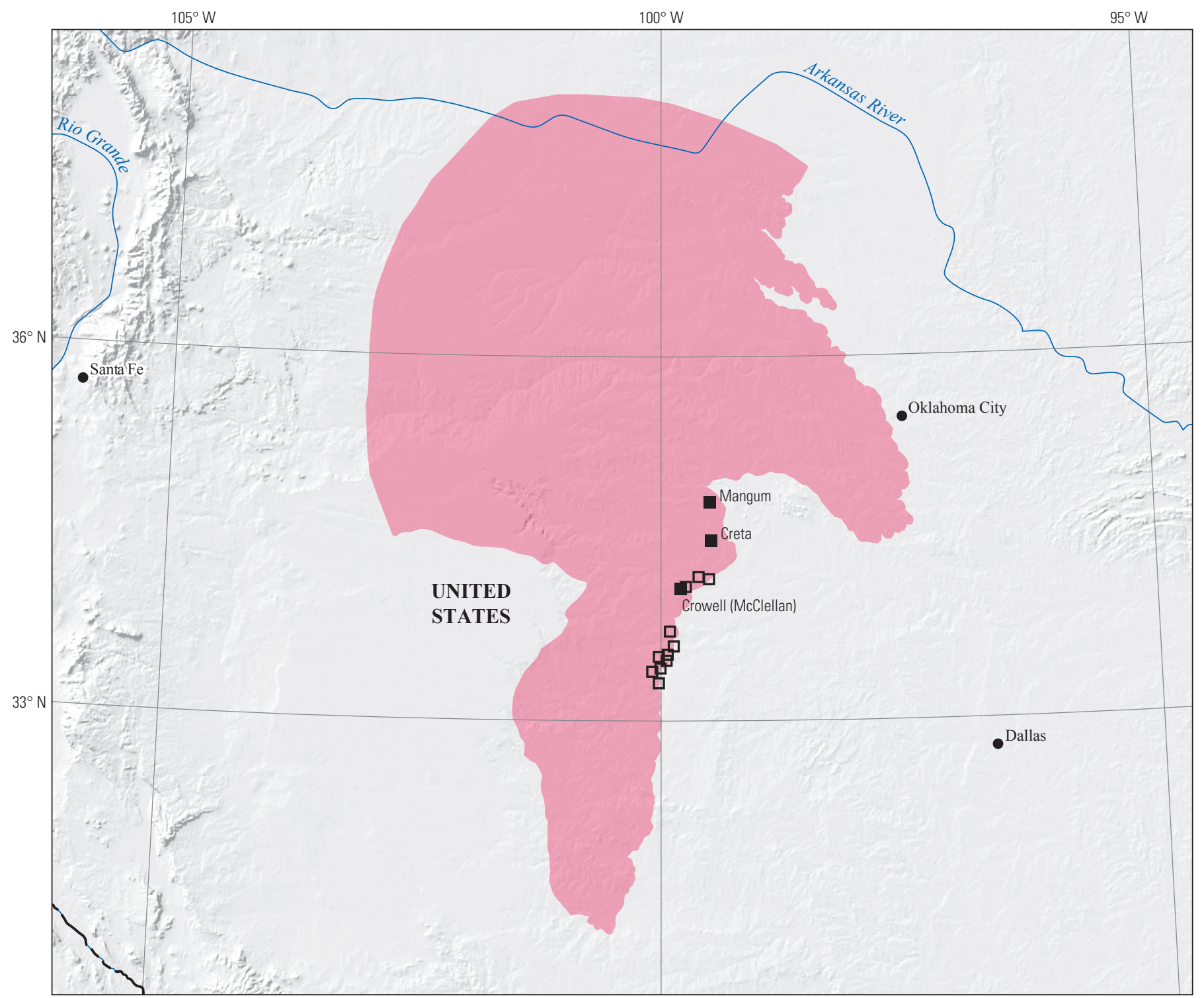

Political boundaries from U.S. Department of State (2009)

Shaded relief from Earth Resources Observation and Science (EROS) Center (2011)

U.S. Contiguous States Albers Equal-Area Conic projection

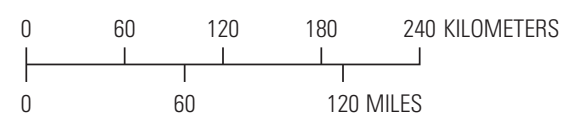

Central meridian $100^{\circ} 0^{\prime} \mathrm{W}$.; latitude of origin $37^{\circ} 30^{\prime} \mathrm{N}$.

\section{EXPLANATION}

Assessed sediment-hosted copper tract 003rfnbCu3002

- Sediment-hosted copper deposit

$\square \quad$ Sediment-hosted copper prospect

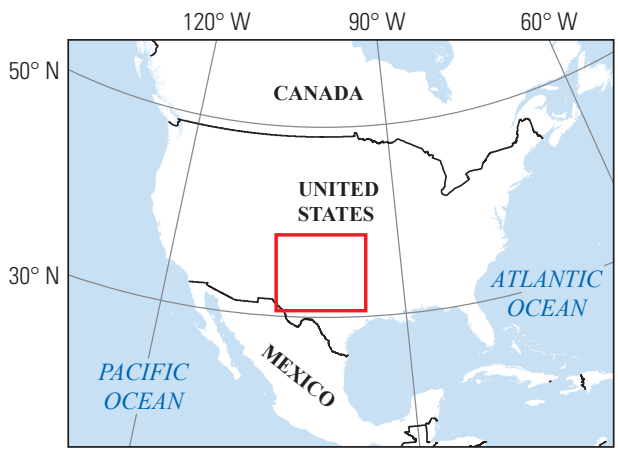




\title{
Plate 192. Sediment-Hosted Stratabound Copper Assessment for Tract 003rfnbCu3003, Lake Superior (LS07), Midcontinent Rift—United States
}

\author{
Descriptive model: \\ Grade and tonnage model: \\ Geologic feature assessed: \\ Number of known deposits:
}

Sediment-hosted stratabound copper-Reduced-facies-nonbrecciated copper subtype model (Cox and others, 2007; Zientek, Hayes, and Hammarstrom, 2013)

Sediment-hosted stratabound copper-Reduced-facies-nonbrecciated copper subtype model (Zientek, Hayes, and Taylor, 2013)

Marine carbonaceous rocks of the Mesoproterozoic Nonesuch Formation overlying Mesoproterozoic continental clastic rocks of the Copper Harbor Formation, Midcontinent Rift 2

\section{Selected Resource Assessment Results for Sediment-Hosted Stratabound Copper}

[Assessment depth, 1 kilometer (km); $\mathrm{km}^{2}$, square kilometer; Mt, millions of metric tons]

\begin{tabular}{|c|c|c|c|c|c|c|}
\hline \multirow[b]{2}{*}{$\begin{array}{c}\text { Date of } \\
\text { assessment }\end{array}$} & \multirow[b]{2}{*}{$\begin{array}{c}\text { Tract area } \\
\quad\left(\mathbf{k m}^{2}\right)\end{array}$} & \multirow{2}{*}{$\begin{array}{l}\text { Identified } \\
\text { copper } \\
\text { resources } \\
\text { (Mt) }\end{array}$} & \multicolumn{4}{|c|}{ Undiscovered copper resource estimates } \\
\hline & & & $\begin{array}{l}\text { Median estimate of } \\
\text { in-place resources } \\
\text { (Mt) }\end{array}$ & $\begin{array}{l}\text { Mean estimate of } \\
\text { in-place resources } \\
\text { (Mt) }\end{array}$ & $\begin{array}{c}\text { Probability of mean } \\
\text { or greater } \\
\text { (percent) }\end{array}$ & $\begin{array}{c}\text { Probability of } 0 \\
\text { in-place resources } \\
\text { (percent) }\end{array}$ \\
\hline 1998 & 123,147 & 9.4 & 10 & 18 & 35 & 4 \\
\hline
\end{tabular}

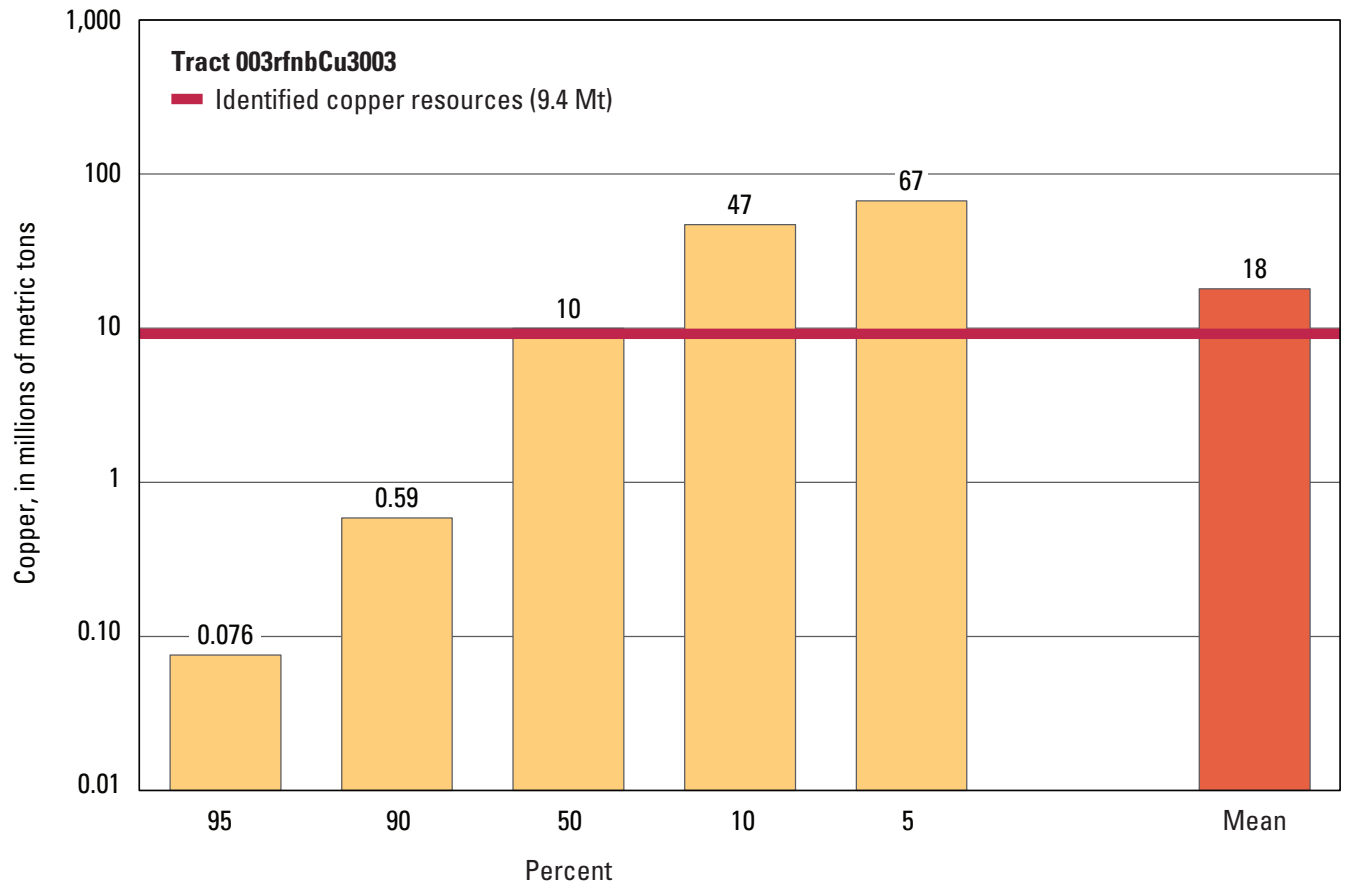

Graph showing the estimated probability distribution of undiscovered copper resources, where each bar represents the minimum amount estimated at the indicated percentage.

\section{Source}

U.S. Geological Survey National Mineral Resource Assessment Team, 2002, Assessment of undiscovered deposits of gold, silver, copper, lead, and zinc in the United States: U.S. Geological Survey Open-File Report 02-198, http://pubs.usgs.gov/of/2002/of02-198/. 


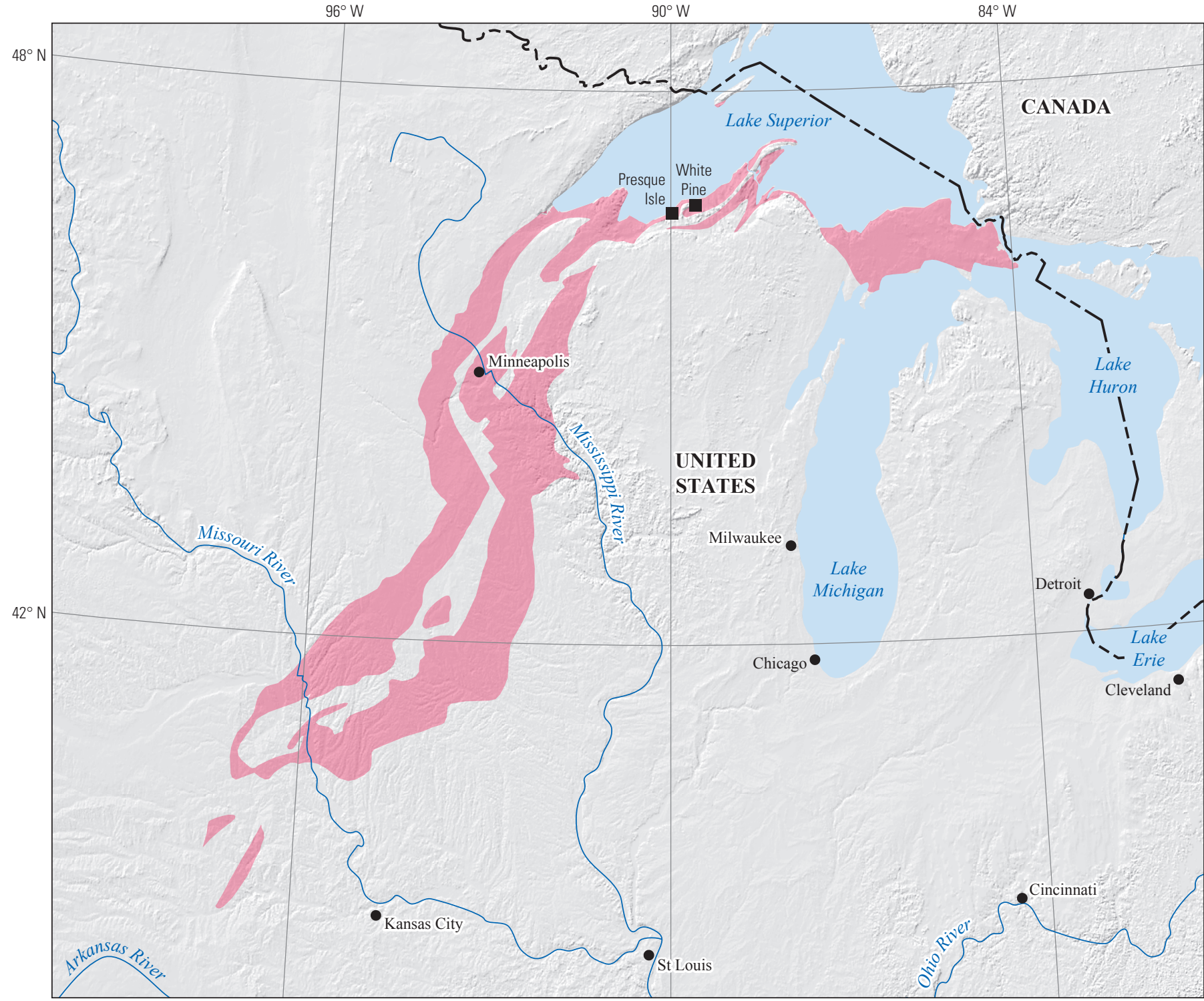

Political boundaries from U.S. Department of State (2009)

Shaded relief from Earth Resources Observation and Science (EROS) Center (2011)

North America Albers Equal-Area Conic projection Central meridian $90^{\circ} \mathrm{W}$.; latitude of origin $40^{\circ} \mathrm{N}$.

\section{EXPLANATION}

Assessed sediment-hosted copper tract 003rfnbCu3003

Sediment-hosted copper deposit
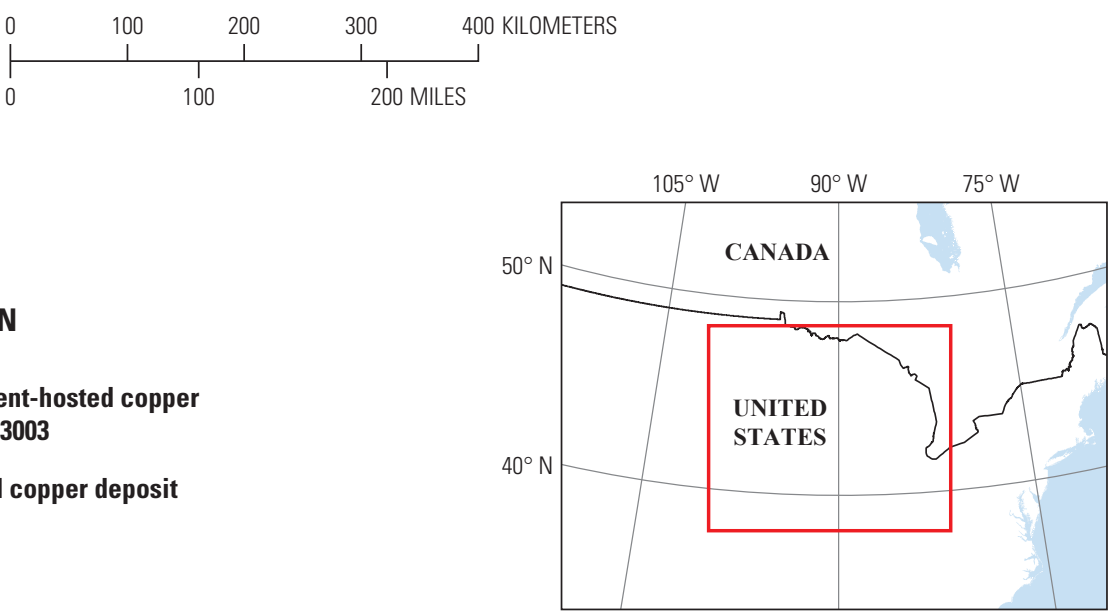


\title{
Plate 193. Sediment-Hosted Stratabound Copper Assessment for Tract 003ssCu3100, Belt-Purcell Basin—United States and Canada
}

\author{
Descriptive model: \\ Grade and tonnage model: \\ Geologic feature assessed: \\ Number of known deposits:
}

Sediment-hosted stratabound copper-Sandstone copper subtype model (Cox and others, 2007; Zientek, Hayes, and Hammarstrom, 2013)

Sediment-hosted stratabound copper-Sandstone copper subtype model (Zientek, Hayes, and Taylor, 2013)

Coarse-grained siliciclastic rocks of the Middle Proterozoic Revett and Creston Formations, Belt-Purcell Basin

11

\section{Selected Resource Assessment Results for Sediment-Hosted Stratabound Copper-Comparison of Results from Two Methods}

Data Related to the Estimated Probability Distribution of Undiscovered Copper Resources

[Assessment depth, 1 kilometer (km); km², square kilometer; Mt, millions of metric tons]

\begin{tabular}{ccccccc}
\hline \multirow{2}{*}{$\begin{array}{c}\text { Date of } \\
\text { assessment }\end{array}$} & $\begin{array}{c}\text { Tract area } \\
\left(\mathbf{k m}^{2}\right)\end{array}$ & $\begin{array}{c}\text { Identified } \\
\text { copper } \\
\text { resources } \\
(\mathbf{M t})\end{array}$ & $\begin{array}{c}\text { Median estimate of } \\
\text { in-place resources } \\
(\mathbf{M t})\end{array}$ & $\begin{array}{c}\text { Mean estimate of } \\
\text { in-place resources } \\
\text { (Mt) }\end{array}$ & $\begin{array}{c}\text { Probability of mean } \\
\text { or greater } \\
\text { (percent) }\end{array}$ & $\begin{array}{c}\text { Probability of } 0 \\
\text { in-place resources } \\
\text { (percent) }\end{array}$ \\
\hline 1998 & 1,633 & 3.2 & 5.2 & 10 & 33 \\
\hline
\end{tabular}

Data Related to the Alternative Utility Derived from the Analytic Hierarchy Process (AHP)

[Assessment depth, 0 kilometer $(\mathrm{km}) ; \mathrm{km}^{2}$, square kilometer; Mt, millions of metric tons]

\begin{tabular}{ccccc}
\hline $\begin{array}{c}\text { Date of } \\
\text { assessment }\end{array}$ & $\begin{array}{c}\text { Tract area } \\
\left.\mathbf{( k m}^{2}\right)\end{array}$ & $\begin{array}{c}\text { Identified } \\
\text { copper } \\
\text { resources } \\
(\mathbf{M t})\end{array}$ & $\begin{array}{c}\text { Analytic hierarchy process- } \\
\text { Alternative utility* } \\
\text { (percent) }\end{array}$ & Overall rank \\
\hline 2012 & 1,633 & 3.2 & 9.35 & 6th of 10 areas \\
\hline
\end{tabular}

*Alternative utility is a numerical weight derived from evaluation of three assessment criteria.

\section{Sources}

U.S. Geological Survey National Mineral Resource Assessment Team, 2002, Assessment of undiscovered deposits of gold, silver, copper, lead, and zinc in the United States: U.S. Geological Survey Open-File Report 02-198, http://pubs.usgs.gov/of/2002/of02-198/.

Zientek, Wintzer, and others, 2015, Qualitative assessment of selected areas of the world for undiscovered sediment-hosted stratabound copper deposits: U.S. Geological Survey Scientific Investigations Report 2010-5090-Y, http://dx.doi.org/10.3133/sir20105090Y. 


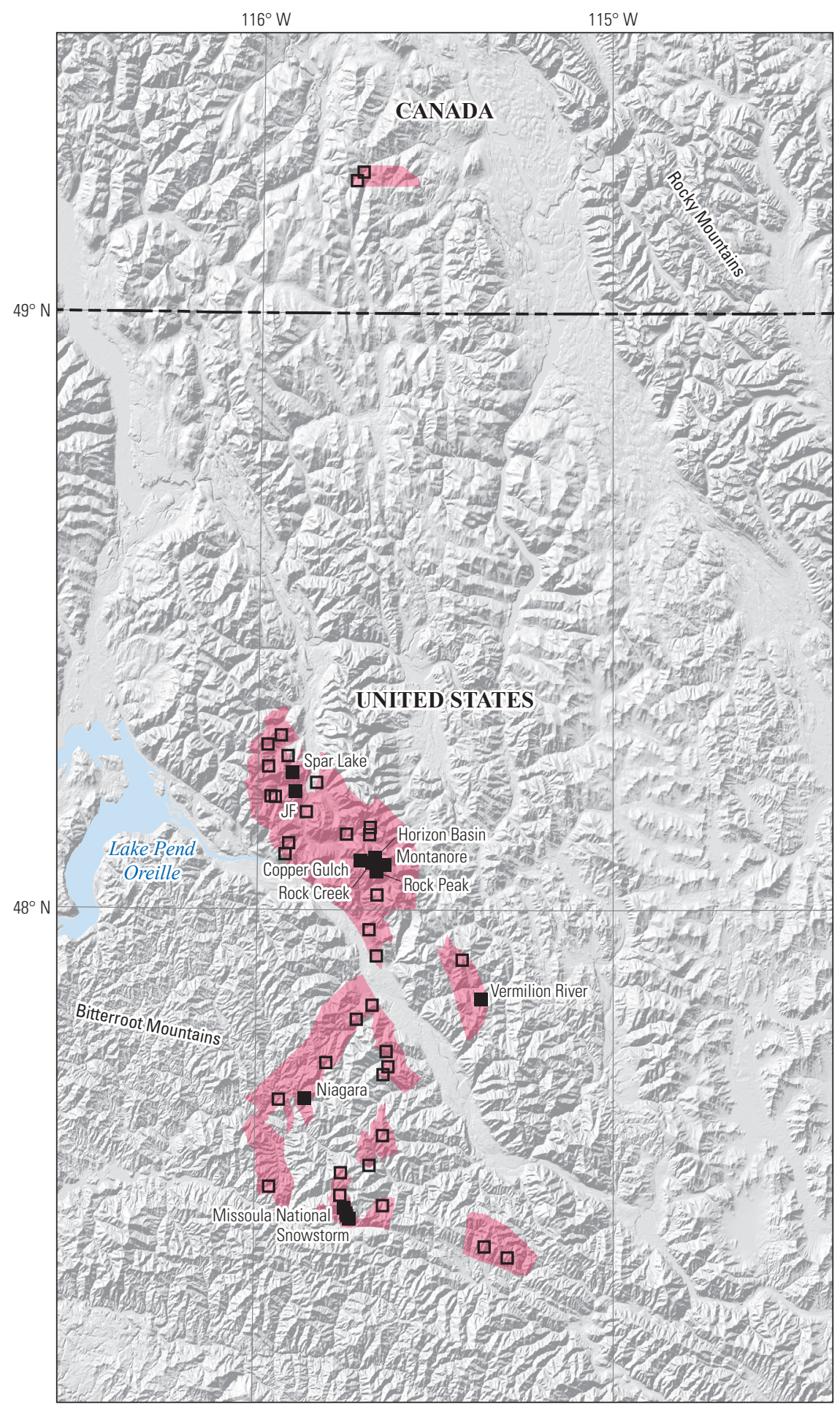

Political boundaries from U.S. Department of State (2009) Shaded relief from ESRI (2008)

North America Albers Equal-Area Conic projection

Central meridian $115^{\circ} \mathrm{W}$.; latitude of origin $40^{\circ} \mathrm{N}$.

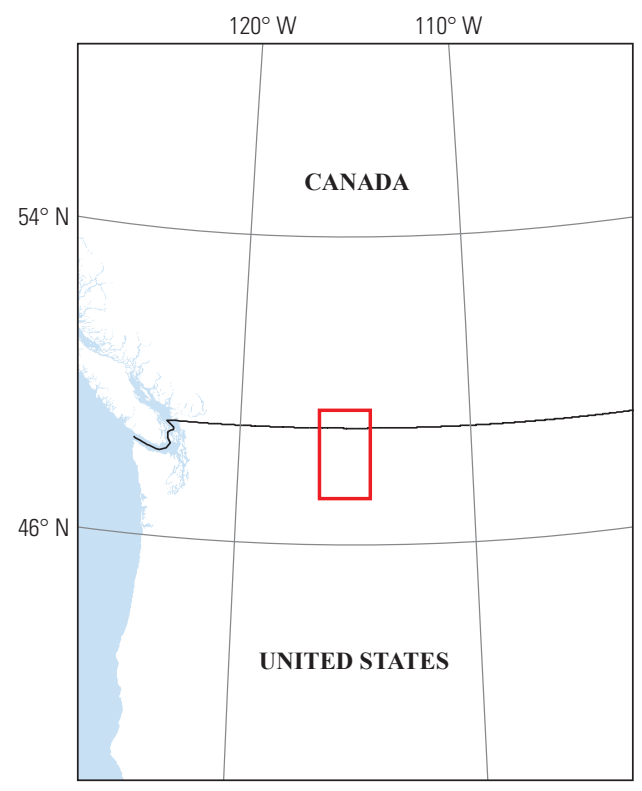

\section{EXPLANATION}

198 Assessed sediment-hosted copper tract 003ssCu3100

- Sediment-hosted copper deposit

$\square \quad$ Sediment-hosted copper prospect 


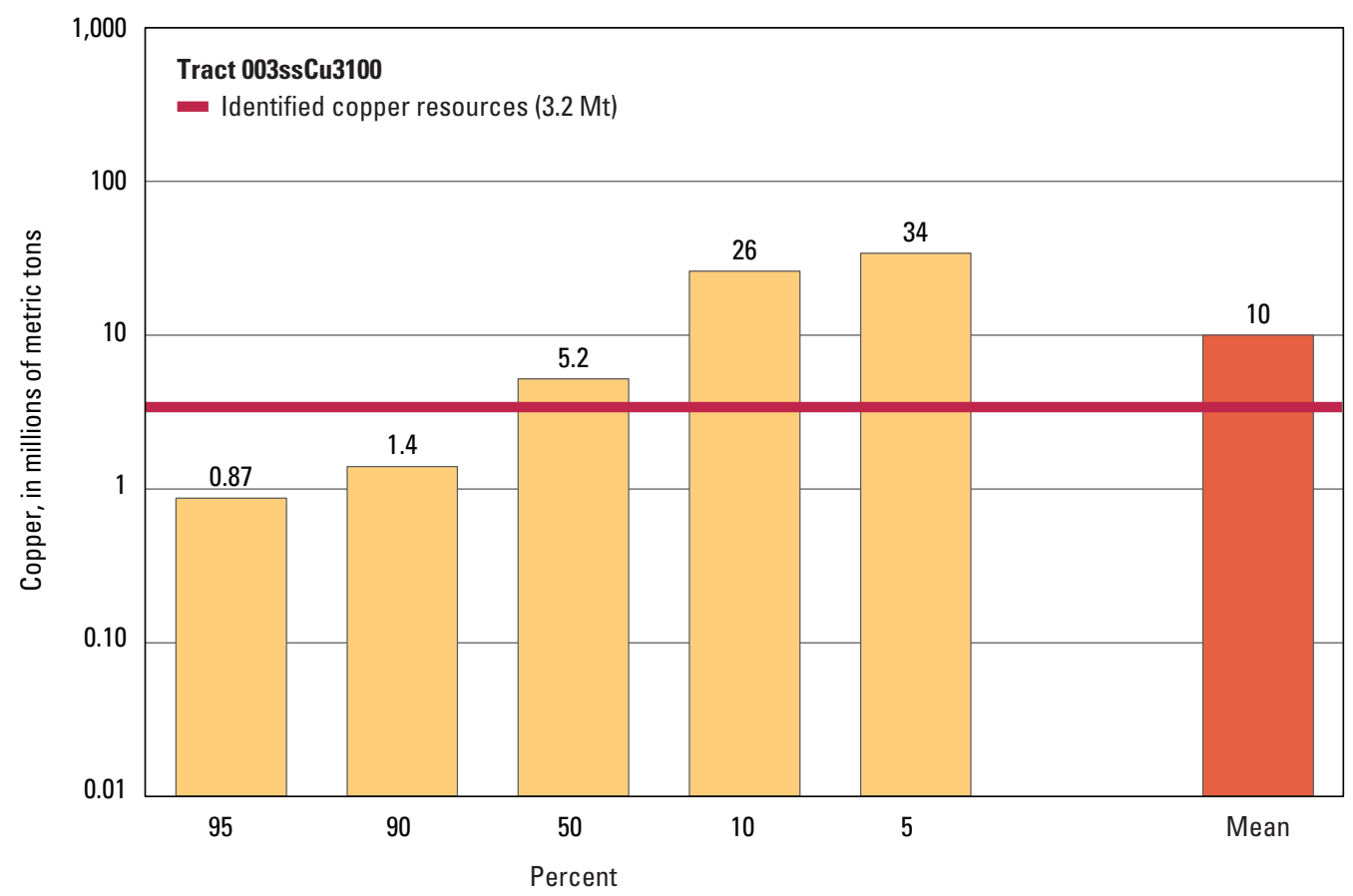

Graph showing the estimated probability distribution of undiscovered copper resources, where each bar represents the minimum amount estimated at the indicated percentage. 


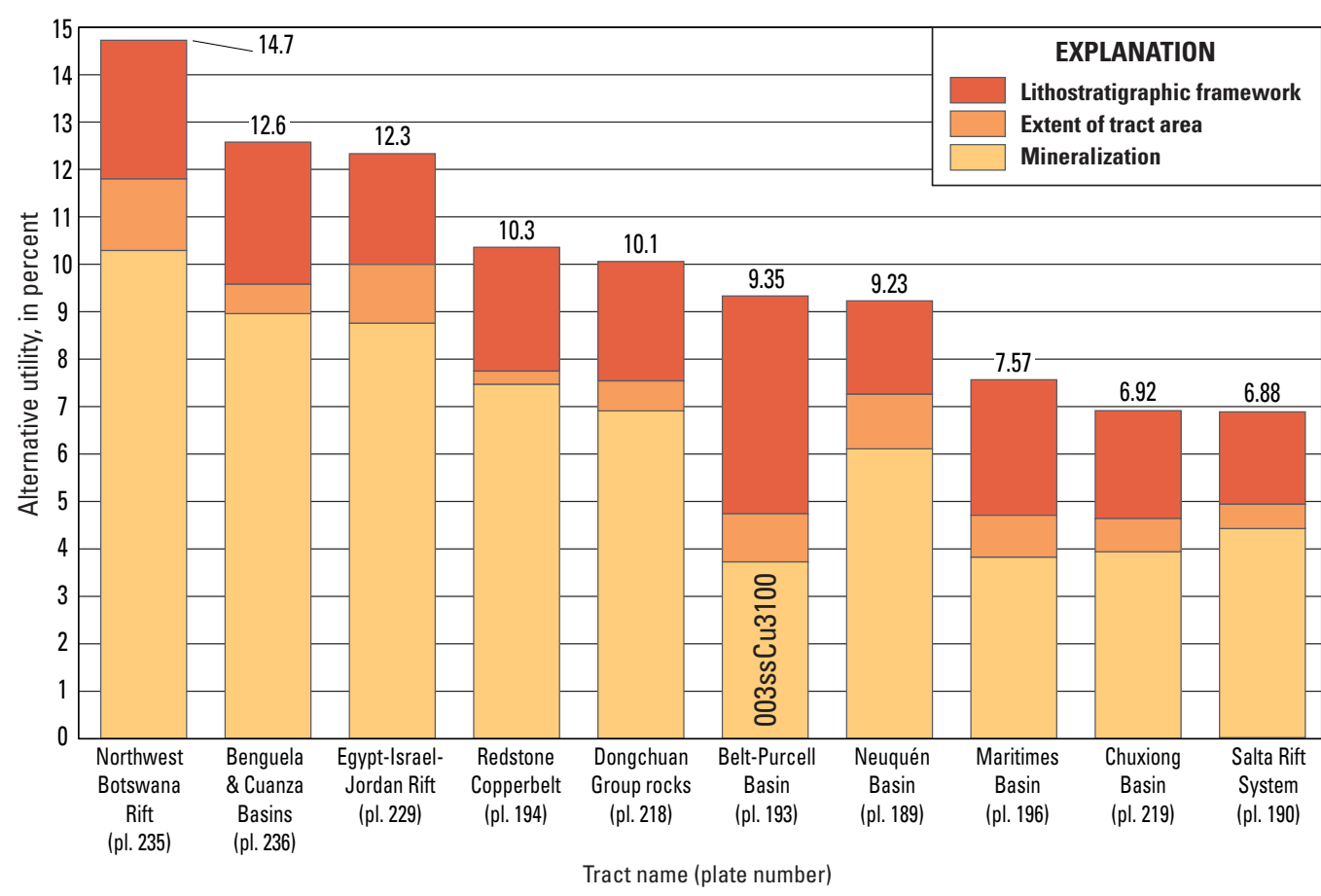

Graph showing qualitative ranking of basins determined by the analytic hierarchy process (AHP). Alternative utility is the overall score derived from the AHP method. 


\title{
Plate 194. Sediment-Hosted Stratabound Copper Assessment for Tract 003rfCu3000, Redstone Copperbelt-Canada
}

\author{
Descriptive model: \\ Sediment-hosted stratabound copper-Reduced-facies copper subtype model (Cox and others, \\ 2007; Zientek, Hayes, and Hammarstrom, 2013) \\ Geologic feature assessed: \\ Marine carbonaceous rocks of the Neoproterozoic Coppercap Formation, Redstone Copperbelt, \\ Mackenzie Mountains \\ Number of known deposits: \\ 3
}

\section{Selected Resource Assessment Results for Sediment-Hosted Stratabound Copper}

[Assessment depth, 0 kilometer $(\mathrm{km}) ; \mathrm{km}^{2}$, square kilometer; Mt, millions of metric tons]

\begin{tabular}{ccccc}
\hline $\begin{array}{c}\text { Date of } \\
\text { assessment }\end{array}$ & $\begin{array}{c}\text { Tract area } \\
\left(\mathbf{k m}^{2}\right)\end{array}$ & $\begin{array}{c}\text { Identified } \\
\text { copper } \\
\text { resources } \\
(\mathbf{M t})\end{array}$ & $\begin{array}{c}\text { Analytic hierarchy process- } \\
\text { Alternative utility* } \\
\text { (percent) }\end{array}$ & Overall rank \\
\hline 2012 & 8,923 & 1.4 & 10.3 & 4th of 10 areas \\
\hline
\end{tabular}

"Alternative utility is a numerical weight derived from evaluation of three assessment criteria.

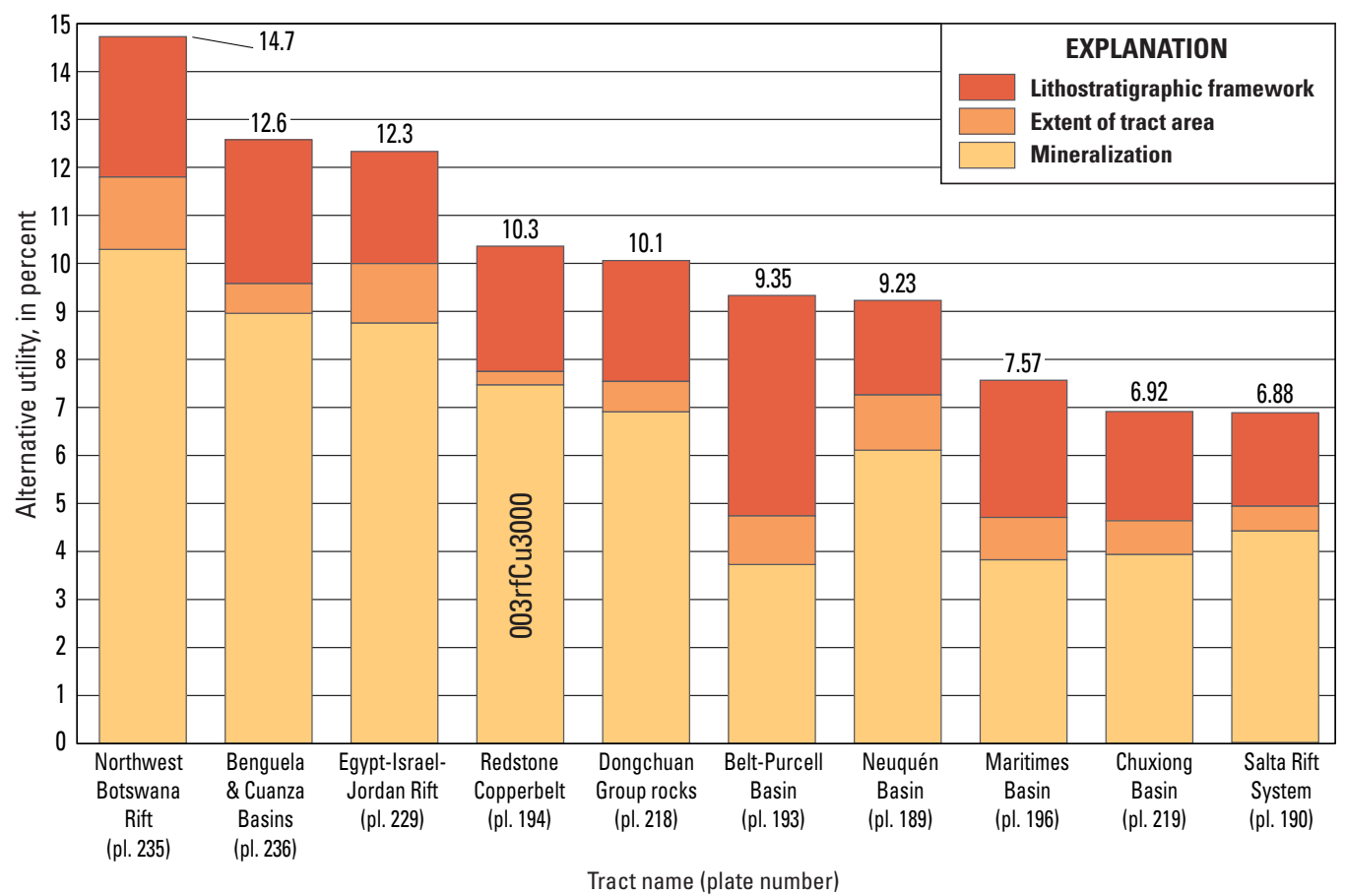

Graph showing qualitative ranking of basins determined by the analytic hierarchy process (AHP). Alternative utility is the overall score derived from the AHP method.

\section{Source}

Zientek, Wintzer, and others, 2015, Qualitative assessment of selected areas of the world for undiscovered sediment-hosted stratabound copper deposits: U.S. Geological Survey Scientific Investigations Report 2010-5090-Y, http://dx.doi.org/10.3133/sir20105090Y. 

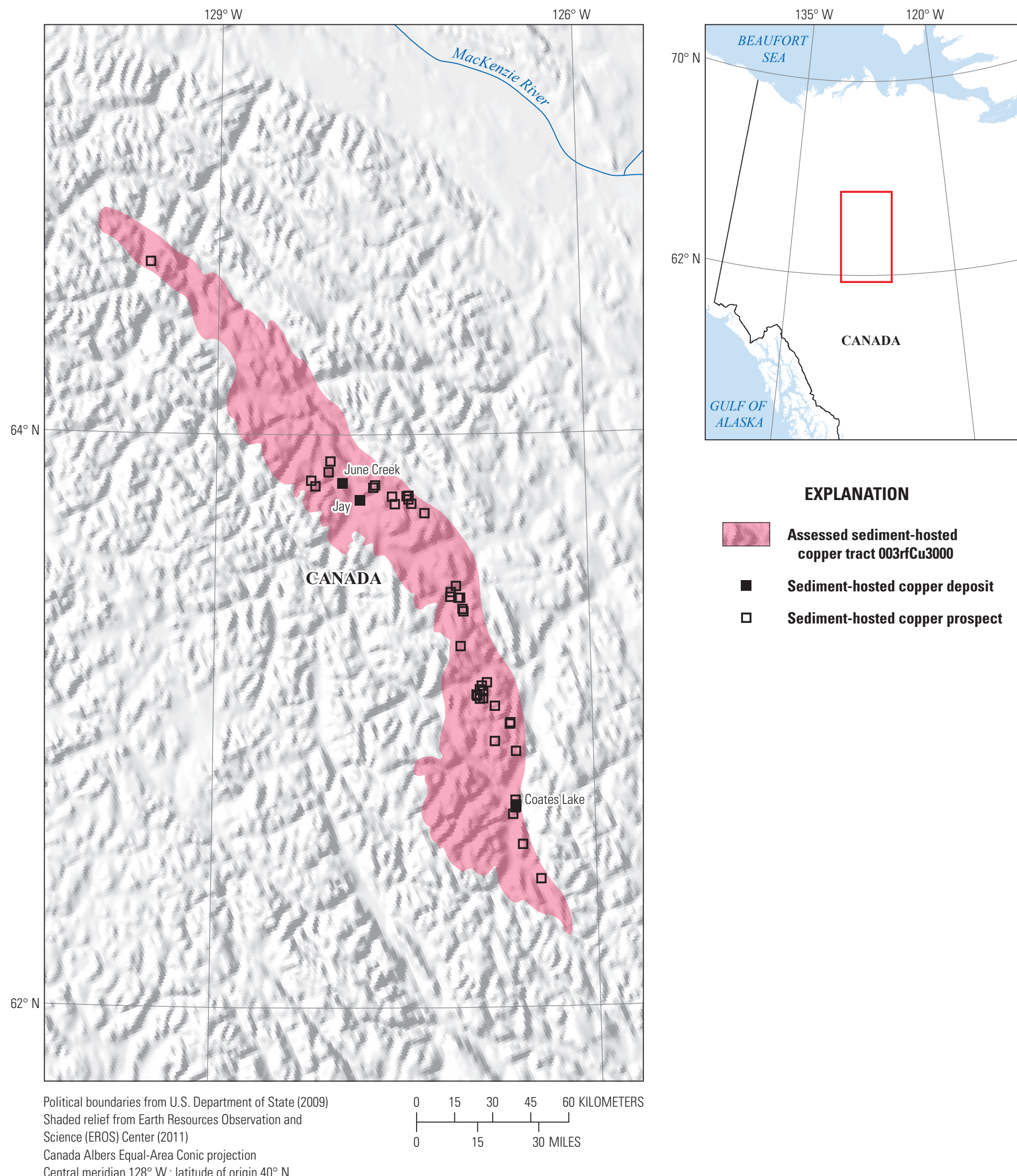

\section{EXPLANATION}

Assessed sediment-hosted copper tract 003 rfCu3000

- Sediment-hosted copper deposit

ㅁ Sediment-hosted copper prospect 


\title{
Plate 195. Sediment-Hosted Stratabound Copper Assessment for Tract 003rfnbCu3004, Southern Appalachian Mountains (SA18), Culpeper Basin- United States
}

\author{
Descriptive model: \\ Sediment-hosted stratabound copper-Reduced-facies-nonbrecciated copper subtype model \\ (Cox and others, 2007; Zientek, Hayes, and Hammarstrom, 2013) \\ Grade and tonnage model: \\ Sediment-hosted stratabound copper-Reduced-facies-nonbrecciated copper subtype model \\ (Zientek, Hayes, and Taylor, 2013) \\ Geologic feature assessed: \\ Triassic lacustrine carbonaceous mudstone intervals within sequences of continental sandstone and \\ siltstones of the Newark Supergroup, Culpeper Basin \\ Number of known deposits: \\ 0
}

\section{Selected Resource Assessment Results for Sediment-Hosted Stratabound Copper}

[Assessment depth, 1 kilometer $(\mathrm{km}) ; \mathrm{km}^{2}$, square kilometer; Mt, millions of metric tons]

\begin{tabular}{ccccccc}
\hline $\begin{array}{c}\text { Date of } \\
\text { assessment }\end{array}$ & $\begin{array}{c}\text { Tract area } \\
\left(\mathbf{k m}^{2}\right)\end{array}$ & $\begin{array}{c}\text { Identified } \\
\text { copper } \\
\text { resources } \\
(\mathbf{M t})\end{array}$ & $\begin{array}{c}\text { Median estimate of } \\
\text { in-place resources } \\
(\mathbf{M t})\end{array}$ & $\begin{array}{c}\text { Mean estimate of } \\
\text { in-place resources } \\
\text { (Mt) }\end{array}$ & $\begin{array}{c}\text { Probability of mean } \\
\text { or greater } \\
\text { (percent) }\end{array}$ & $\begin{array}{c}\text { Probability of } \mathbf{0} \\
\text { in-place resources } \\
\text { (percent) }\end{array}$ \\
\hline 1998 & 11,566 & 0 & 1.4 & 6.6 & 25 \\
\hline
\end{tabular}

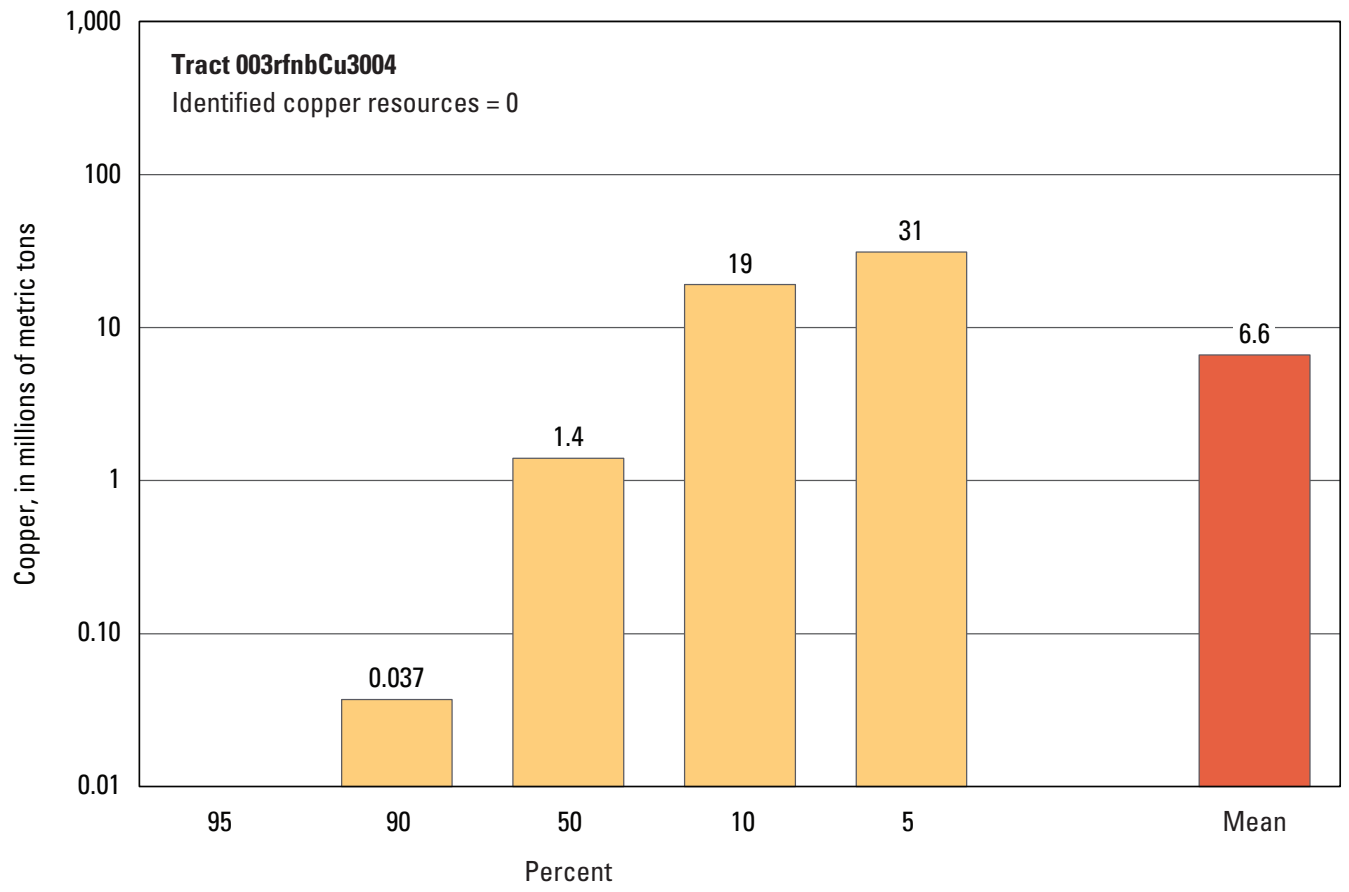

Graph showing the estimated probability distribution of undiscovered copper resources, where each bar represents the minimum amount estimated at the indicated percentage.

\section{Source}

U.S. Geological Survey National Mineral Resource Assessment Team, 2002, Assessment of undiscovered deposits of gold, silver, copper, lead, and zinc in the United States: U.S. Geological Survey Open-File Report 02-198, http://pubs.usgs.gov/of/2002/of02-198/. 


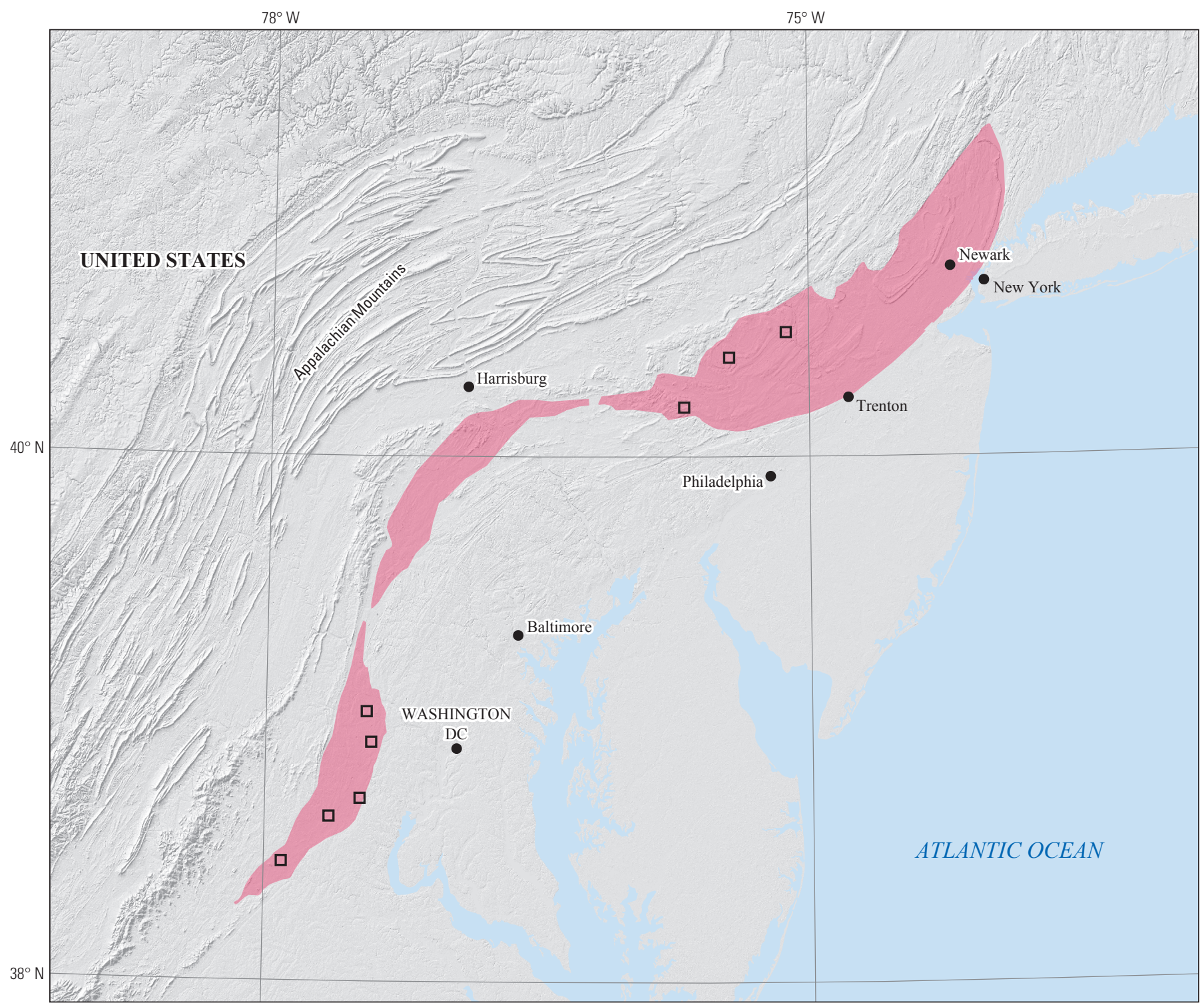

Political boundaries from U.S. Department of State (2009) Shaded relief from ESRI (2008)

North America Albers Equal-Area Conic projection

Central meridian $76^{\circ} \mathrm{W}$.; latitude of origin $40^{\circ} \mathrm{N}$.

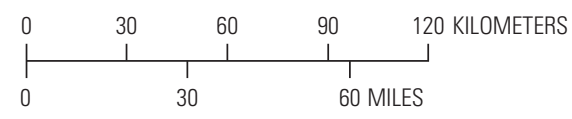

EXPLANATION

Assessed sediment-hosted copper tract 003rfnbCu3004

$\square \quad$ Sediment-hosted copper prospect

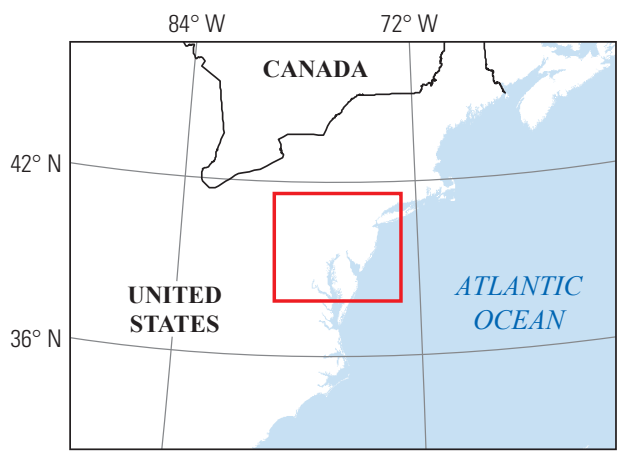




\title{
Plate 196. Sediment-Hosted Stratabound Copper Assessment for Tract 003shCu1000, Maritimes Basin-Canada
}

\author{
Descriptive model: \\ Geologic feature assessed: \\ Number of known deposits:
}

Sediment-hosted stratabound copper model (Cox and others, 2007; Zientek, Hayes, and Hammarstrom, 2013)

Carboniferous sedimentary rocks, Maritimes Basin

2

\section{Selected Resource Assessment Results for Sediment-Hosted Stratabound Copper}

[Assessment depth, 0 kilometer ( $\mathrm{km}) ; \mathrm{km}^{2}$, square kilometer; Mt, millions of metric tons]

\begin{tabular}{ccccc}
\hline $\begin{array}{c}\text { Date of } \\
\text { assessment }\end{array}$ & $\begin{array}{c}\text { Tract area } \\
\left.\mathbf{( k m}^{2}\right)\end{array}$ & $\begin{array}{c}\text { Identified } \\
\text { copper } \\
\text { resources } \\
(\mathbf{M t})\end{array}$ & $\begin{array}{c}\text { Analytic hierarchy process- } \\
\text { Alternative utility* } \\
\text { (percent) }\end{array}$ & Overall rank \\
\hline 2012 & 71,941 & 0.050 & 7.57 & 8th of 10 areas \\
\hline
\end{tabular}

"Alternative utility is a numerical weight derived from evaluation of three assessment criteria.

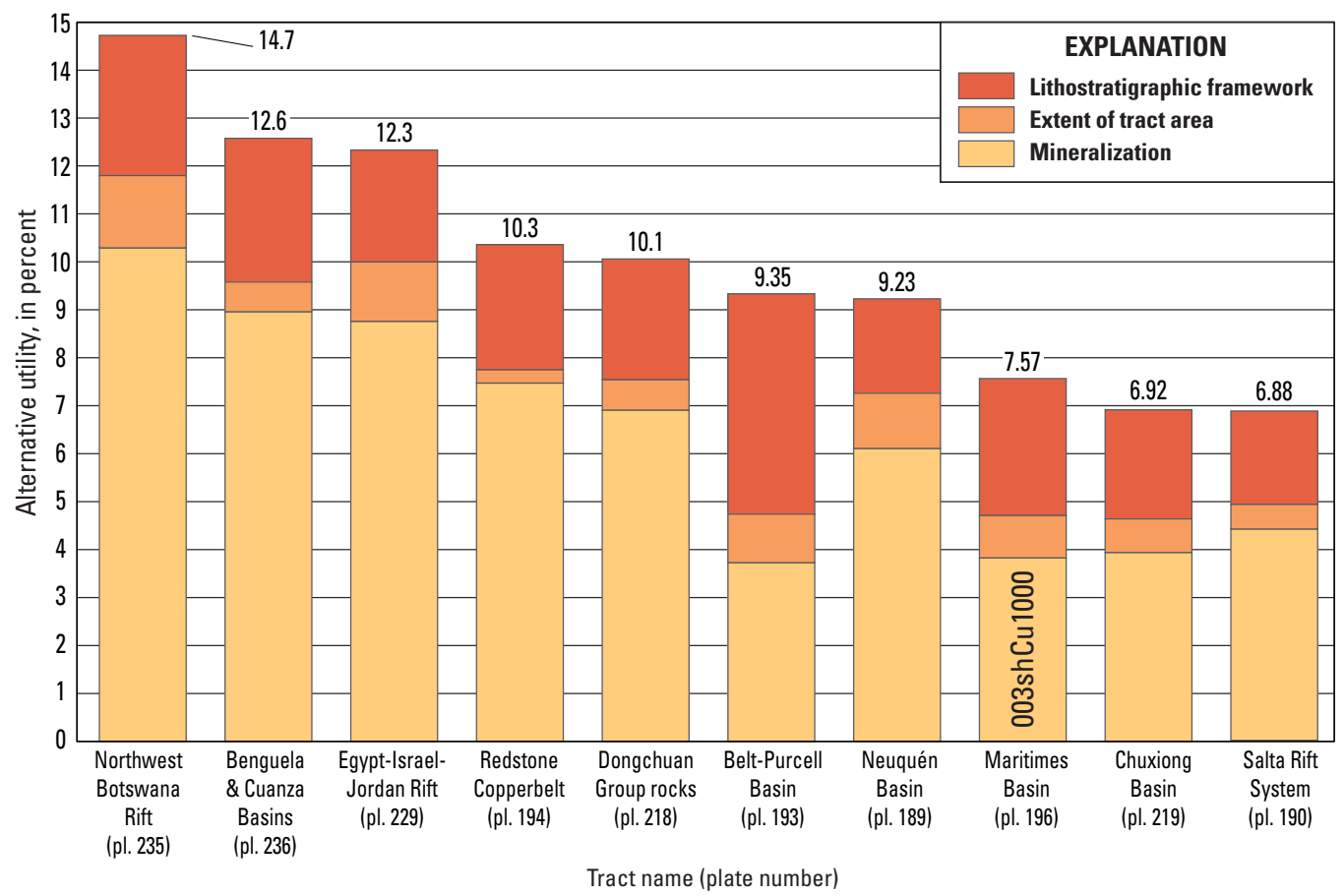

Graph showing qualitative ranking of basins determined by the analytic hierarchy process (AHP). Alternative utility is the overall score derived from the AHP method.

\section{Source}

Zientek, Wintzer, and others, 2015, Qualitative assessment of selected areas of the world for undiscovered sediment-hosted stratabound copper deposits: U.S. Geological Survey Scientific Investigations Report 2010-5090-Y, http://dx.doi.org/10.3133/sir20105090Y. 


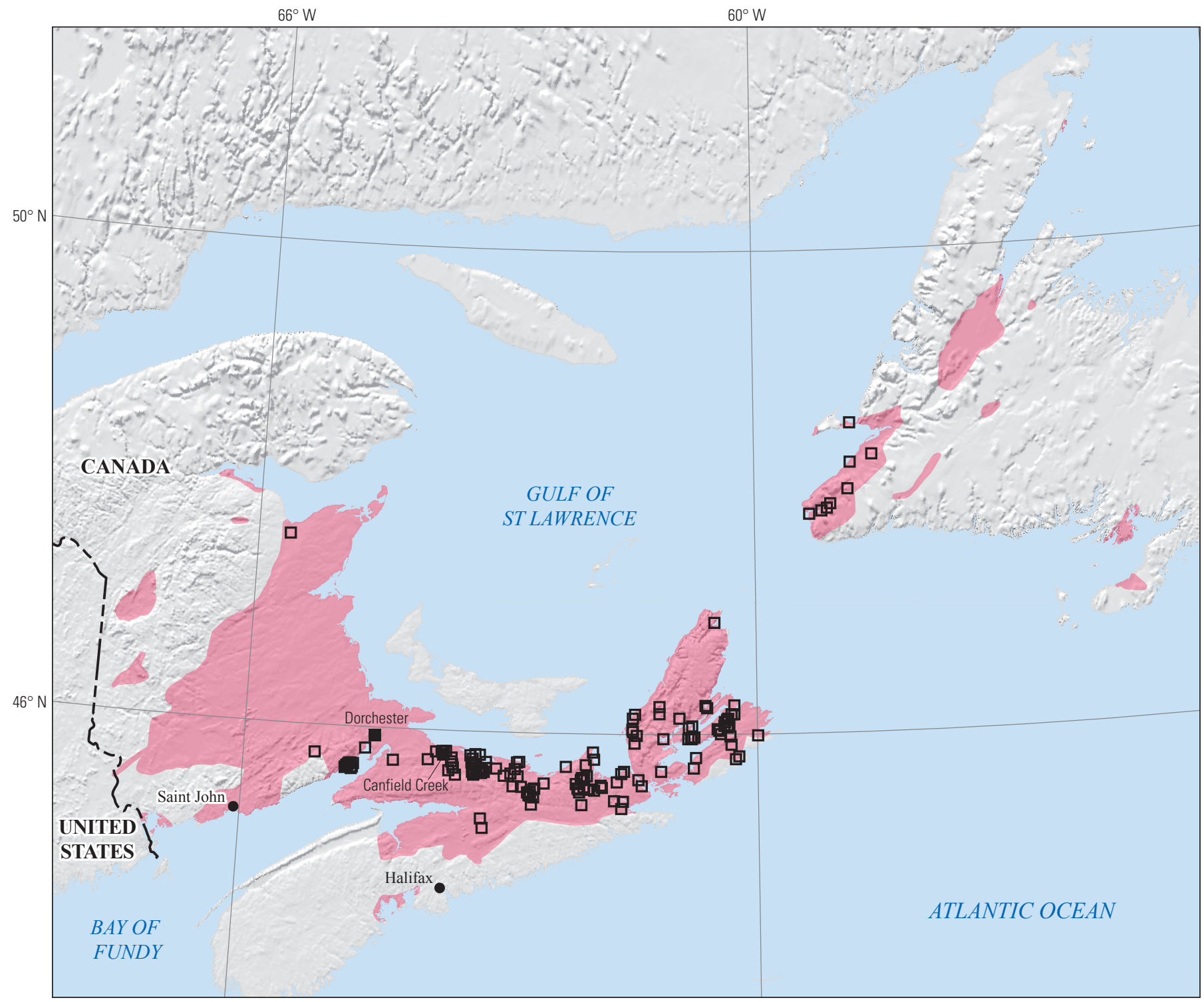

Political boundaries from U.S. Department of State (2009)

Shaded relief from Earth Resources Observation and Science (EROS) Center (2011)

Canada Albers Equal-Area Conic projection

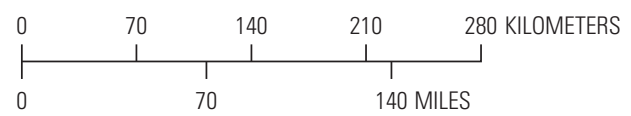

Central meridian $61^{\circ} \mathrm{W}$; l latitude of origin $40^{\circ} \mathrm{N}$.

\section{EXPLANATION}

\section{Assessed sediment-hosted copper tract $003 \mathrm{shCu} 1000$}

- Sediment-hosted copper deposit

$\square \quad$ Sediment-hosted copper prospect

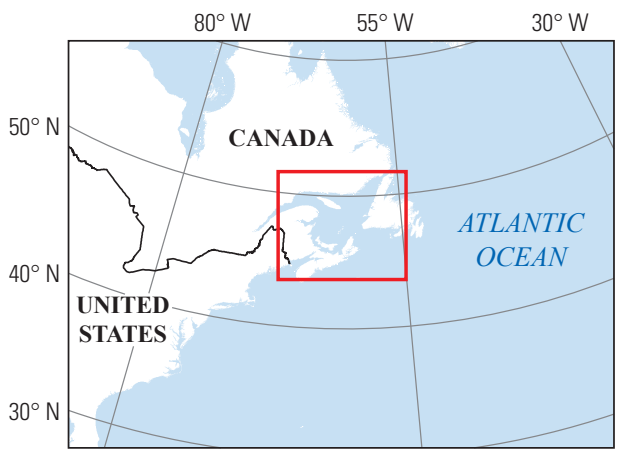




\title{
Plate 197. Sediment-Hosted Stratabound Copper Assessment for Tract 003rfnbCu0004, Ravnefjeld Formation (CE 2 and CE 4-15), Central European Basin System-Greenland
}

\author{
Descriptive model: \\ Sediment-hosted stratabound copper-Reduced-facies-nonbrecciated copper subtype model (Cox \\ and others, 2007; Zientek, Hayes, and Hammarstrom, 2013) \\ Grade and tonnage model: \\ Sediment-hosted stratabound copper-Reduced-facies-nonbrecciated copper subtype model \\ (Zientek, Hayes, and Taylor, 2013) \\ Geologic feature assessed: \\ Marine carbonaceous rocks of the upper Permian Ravnefjeld Formation (Zechstein 1 equivalent) \\ overlying Devonian to lower Permian continental clastic sedimentary and volcanic rocks, central \\ East Greenland \\ Number of known deposits: \\ 0
}

\section{Selected Resource Assessment Results for Sediment-Hosted Stratabound Copper}

[Assessment depth, 1 kilometer (km); km², square kilometer; Mt, millions of metric tons]

\begin{tabular}{ccccccc}
\hline \multirow{2}{*}{$\begin{array}{c}\text { Date of } \\
\text { assessment }\end{array}$} & $\begin{array}{c}\text { Tract area } \\
\left(\mathbf{k m}^{2}\right)\end{array}$ & $\begin{array}{c}\text { Identified } \\
\text { copper } \\
\text { resources } \\
(\mathbf{M t})\end{array}$ & $\begin{array}{c}\text { Median estimate of } \\
\text { in-place resources } \\
(\mathbf{M t})\end{array}$ & $\begin{array}{c}\text { Mean estimate of } \\
\text { in-place resources } \\
\text { (Mt) }\end{array}$ & $\begin{array}{c}\text { Probability of mean } \\
\text { or greater } \\
\text { (percent) }\end{array}$ & $\begin{array}{c}\text { Probability of } 0 \\
\text { in-place resources } \\
\text { (percent) }\end{array}$ \\
\hline 2009 & 2,176 & 0 & 0 & 0.27 & 4
\end{tabular}

"Estimates from Stensgaard and others (2011) were revised slightly to conform with project protocols for spatial aggregation and definition of identified resources.

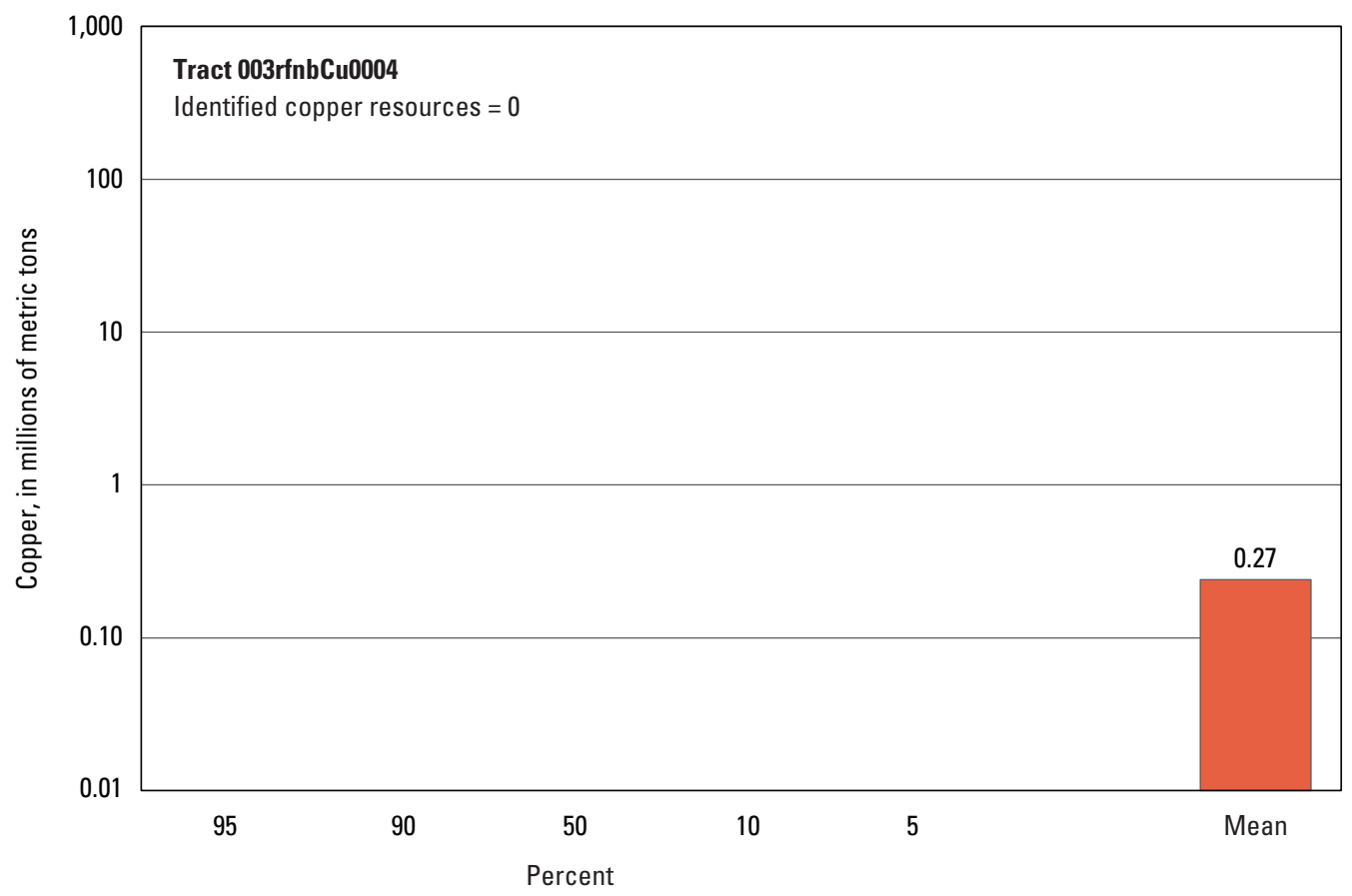

Graph showing the estimated probability distribution of undiscovered copper resources, where each bar represents the minimum amount estimated at the indicated percentage.

\section{Source}

Stensgaard and others, 2011, Quantitative mineral resource assessment-Sedimentary-hosted copper in Greenland: Geological Survey of Denmark and Greenland (GEUS) Report 2011/104. 


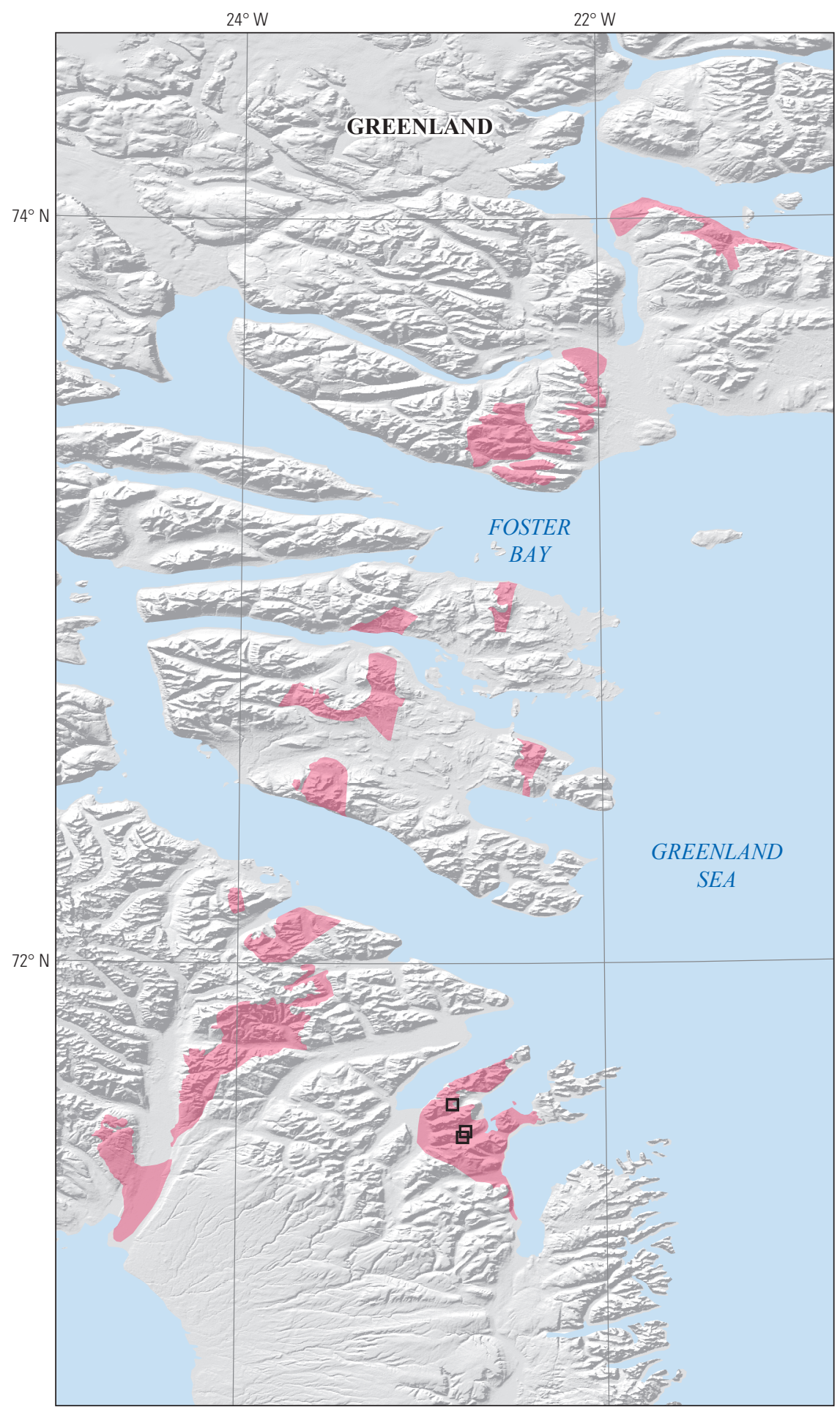

Political boundaries from U.S. Department of State (2009) Shaded relief from Howat and others (2014) North America Albers Equal-Area Conic projection Central meridian $23^{\circ} \mathrm{W}$.; latitude of origin $40^{\circ} \mathrm{N}$.

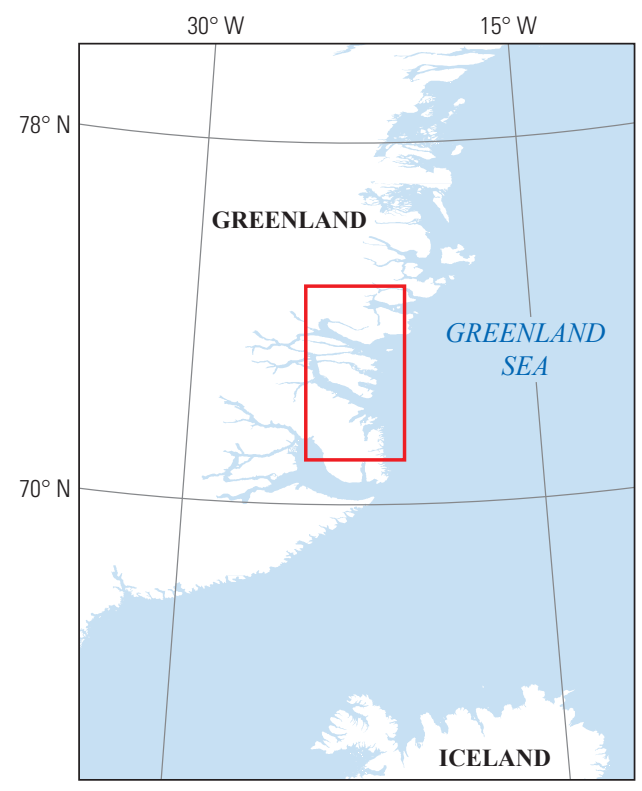

\section{EXPLANATION}

Assessed sediment-hosted copper tract 003rfnbCu0004

Sediment-hosted copper prospect 


\title{
Plate 198. Sediment-Hosted Stratabound Copper Assessment for Tract 003rfnbCu0001, Pingel Dal Beds (CE 1B), Jameson Land Basin—Greenland
}

\author{
Descriptive model: \\ Sediment-hosted stratabound copper-Reduced-facies-nonbrecciated copper subtype model \\ (Cox and others, 2007; Zientek, Hayes, and Hammarstrom, 2013) \\ Grade and tonnage model: \\ Sediment-hosted stratabound copper-Reduced-facies-nonbrecciated copper subtype model \\ (Zientek, Hayes, and Taylor, 2013) \\ Geologic feature assessed: \\ Lacustrine carbonaceous rocks of the Upper Triassic Pingel Dal Beds of the Edderfugledal \\ Member, Fleming Fjord Formation, Jameson Land Basin, central East Greenland \\ Number of known deposits: \\ 0
}

\section{Selected Resource Assessment Results for Sediment-Hosted Stratabound Copper}

[Assessment depth, 1 kilometer (km); $\mathrm{km}^{2}$, square kilometer; Mt, millions of metric tons]

\begin{tabular}{ccccccc}
\hline $\begin{array}{c}\text { Date of } \\
\text { assessment }\end{array}$ & $\begin{array}{c}\text { Tract area } \\
\left(\mathbf{k m}^{2}\right)\end{array}$ & $\begin{array}{c}\text { Identified } \\
\text { copper } \\
\text { resources } \\
(\mathbf{M t})\end{array}$ & $\begin{array}{c}\text { Median estimate of } \\
\text { in-place resources } \\
(\mathbf{M t})\end{array}$ & $\begin{array}{c}\text { Mean estimate of } \\
\text { in-place resources } \\
\text { (Mt) }\end{array}$ & $\begin{array}{c}\text { Probability of mean } \\
\text { or greater } \\
\text { (percent) }\end{array}$ & $\begin{array}{c}\text { Probability of } 0 \\
\text { in-place resources } \\
\text { (percent) }\end{array}$ \\
\hline 2009 & 917 & 0 & 0 & 0.17 & 3 \\
\hline
\end{tabular}

*Estimates from Stensgaard and others (2011) were revised slightly to conform with project protocols for spatial aggregation and definition of identified resources.

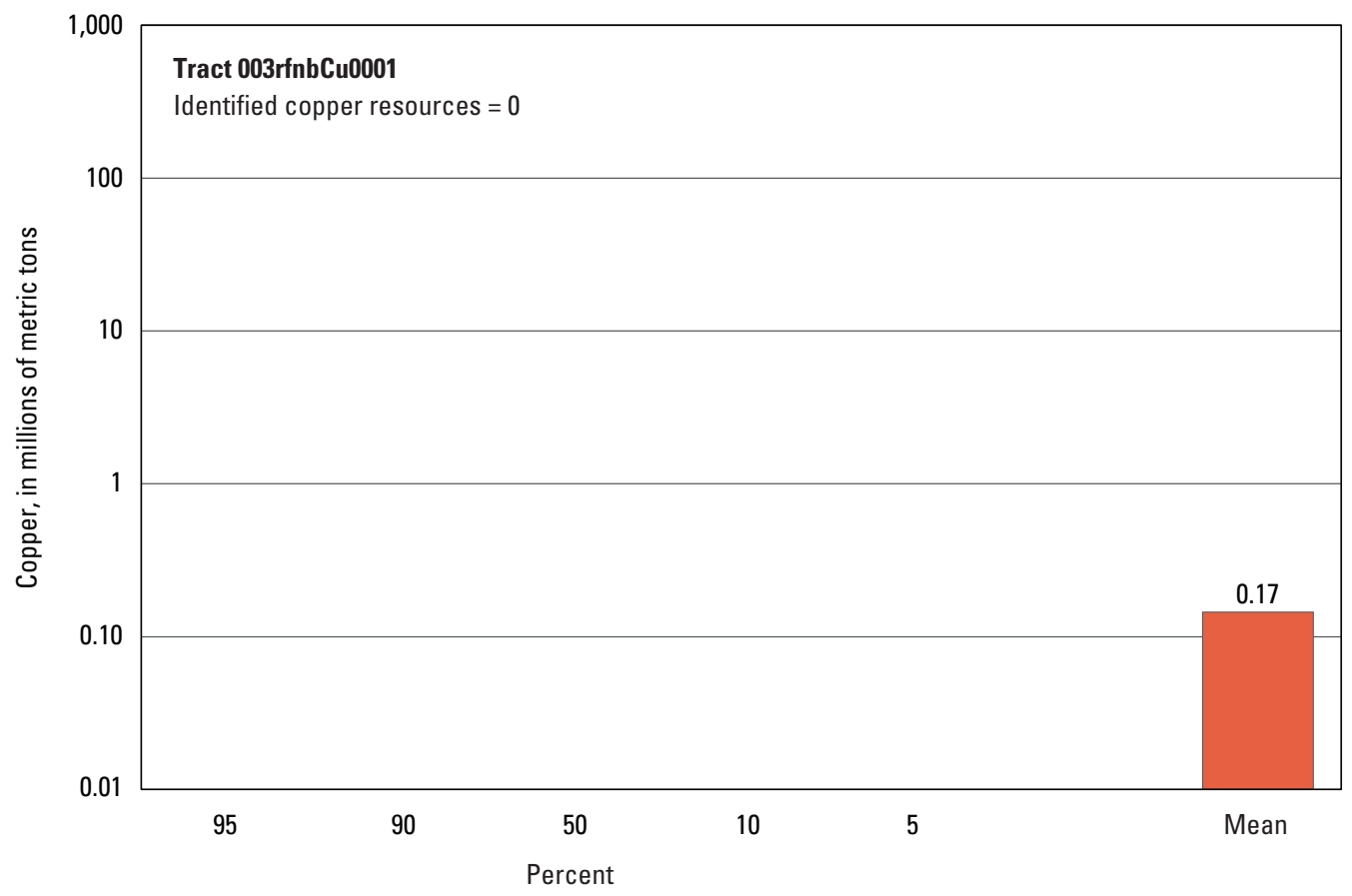

Graph showing the estimated probability distribution of undiscovered copper resources, where each bar represents the minimum amount estimated at the indicated percentage.

\section{Source}

Stensgaard and others, 2011, Quantitative mineral resource assessment—Sedimentary-hosted copper in Greenland: Geological Survey of Denmark and Greenland (GEUS) Report 2011/104. 


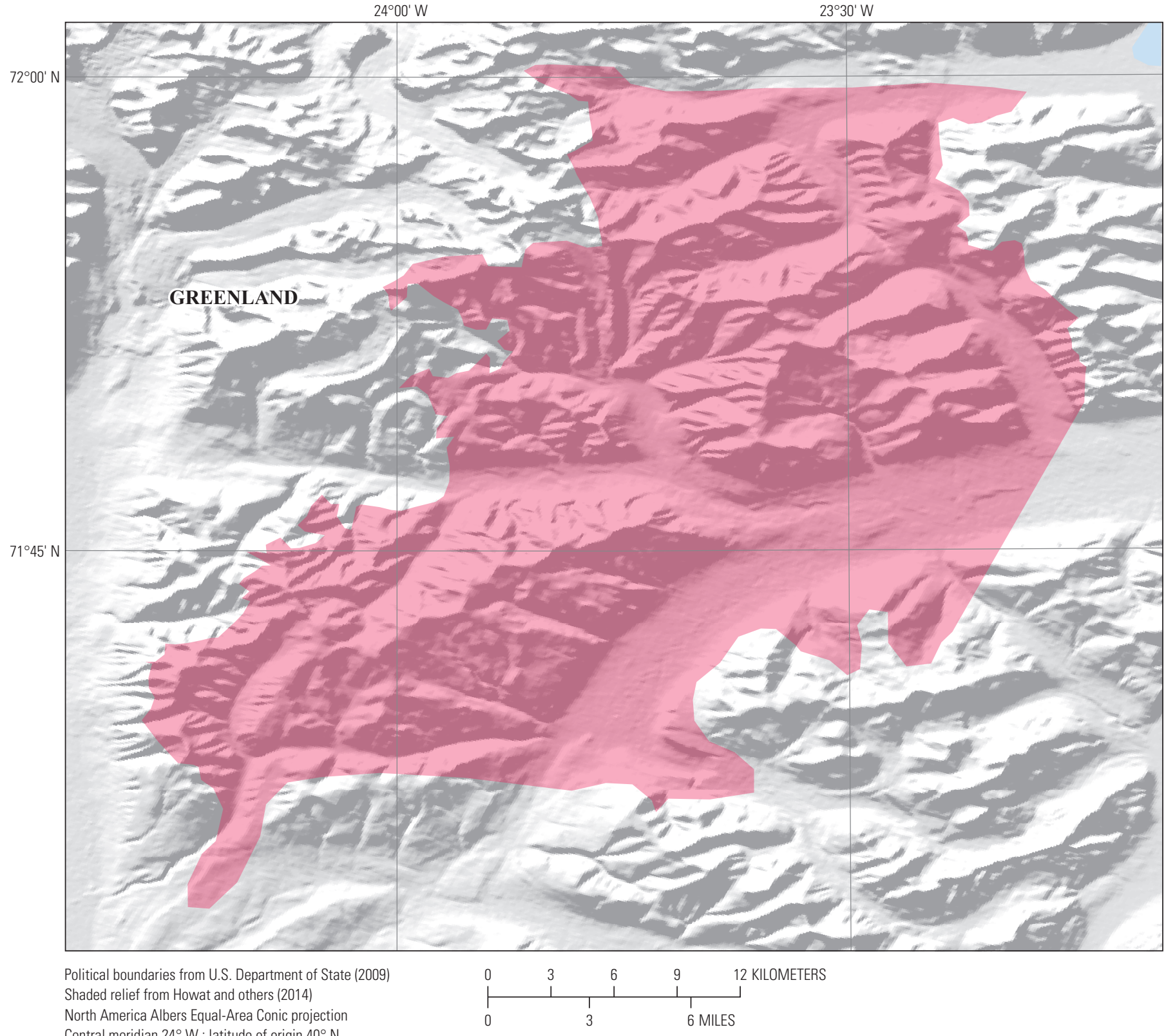

Central meridian $24^{\circ} \mathrm{W}$.; latitude of origin $40^{\circ} \mathrm{N}$.

\section{EXPLANATION}

Assessed sediment-hosted copper tract 003rfnbCu0001

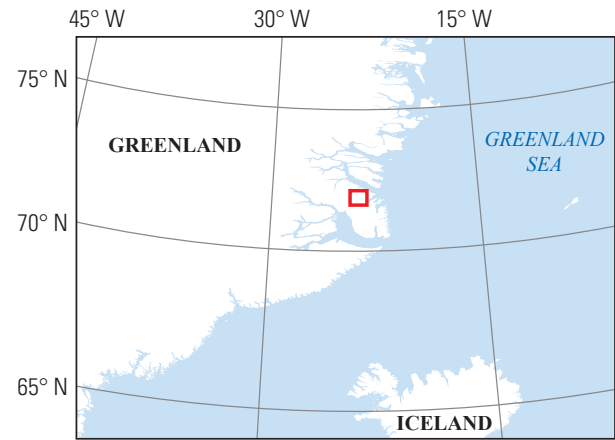




\title{
Plate 199. Sediment-Hosted Stratabound Copper Assessment for Tract 003rfnbCu0005, Pingel Dal Beds (CE 1A), Jameson Land Basin—Greenland
}

\author{
Descriptive model: \\ Sediment-hosted stratabound copper-Reduced-facies-nonbrecciated copper subtype model \\ (Cox and others, 2007; Zientek, Hayes, and Hammarstrom, 2013) \\ Grade and tonnage model: \\ Sediment-hosted stratabound copper-Reduced-facies-nonbrecciated copper subtype model \\ (Zientek, Hayes, and Taylor, 2013) \\ Geologic feature assessed: \\ Lacustrine carbonaceous rocks of the Upper Triassic Pingel Dal Beds of the Edderfugledal \\ Member, Fleming Fjord Formation, Jameson Land Basin, central East Greenland \\ Number of known deposits: \\ 0
}

\section{Selected Resource Assessment Results for Sediment-Hosted Stratabound Copper}

[Assessment depth, 1 kilometer (km); $\mathrm{km}^{2}$, square kilometer; Mt, millions of metric tons]

\begin{tabular}{ccccccc}
\hline $\begin{array}{c}\text { Date of } \\
\text { assessment }\end{array}$ & $\begin{array}{c}\text { Tract area } \\
\left(\mathbf{k m}^{2}\right)\end{array}$ & $\begin{array}{c}\text { Identified } \\
\text { copper } \\
\text { resources } \\
(\mathbf{M t})\end{array}$ & $\begin{array}{c}\text { Median estimate of } \\
\text { in-place resources } \\
(\mathbf{M t})\end{array}$ & $\begin{array}{c}\text { Mean estimate of } \\
\text { in-place resources } \\
\text { (Mt) }\end{array}$ & $\begin{array}{c}\text { Probability of mean } \\
\text { or greater } \\
\text { (percent) }\end{array}$ & $\begin{array}{c}\text { Probability of } \mathbf{0} \\
\text { in-place resources } \\
\text { (percent) }\end{array}$ \\
\hline 2009 & 2,507 & 0 & 0 & 0.68 & 7 & 91 \\
\hline
\end{tabular}

*Estimates from Stensgaard and others (2011) were revised slightly to conform with project protocols for spatial aggregation and definition of identified resources.

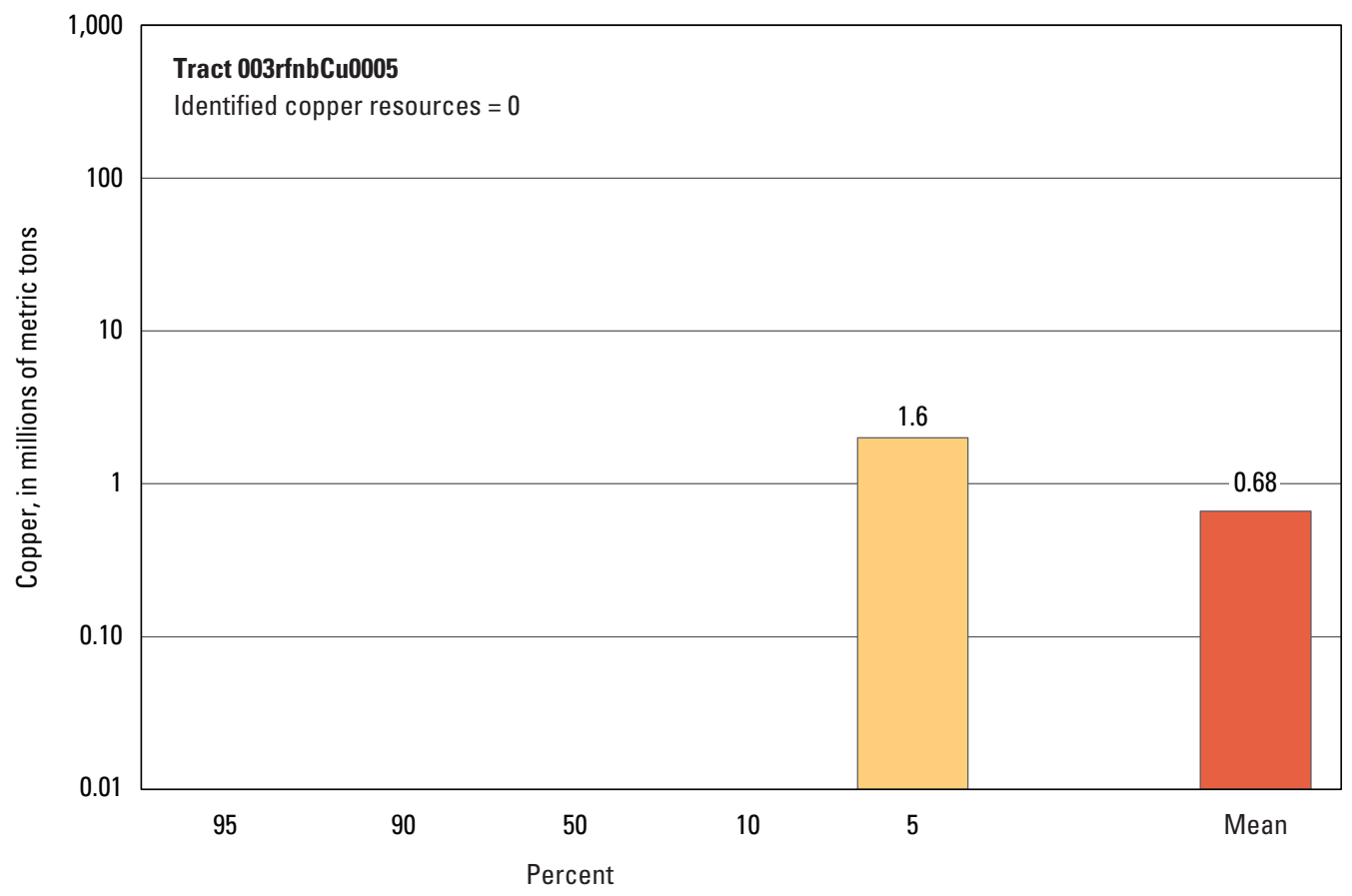

Graph showing the estimated probability distribution of undiscovered copper resources, where each bar represents the minimum amount estimated at the indicated percentage.

\section{Source}

Stensgaard and others, 2011, Quantitative mineral resource assessment-Sedimentary-hosted copper in Greenland: Geological Survey of Denmark and Greenland (GEUS) Report 2011/104. 

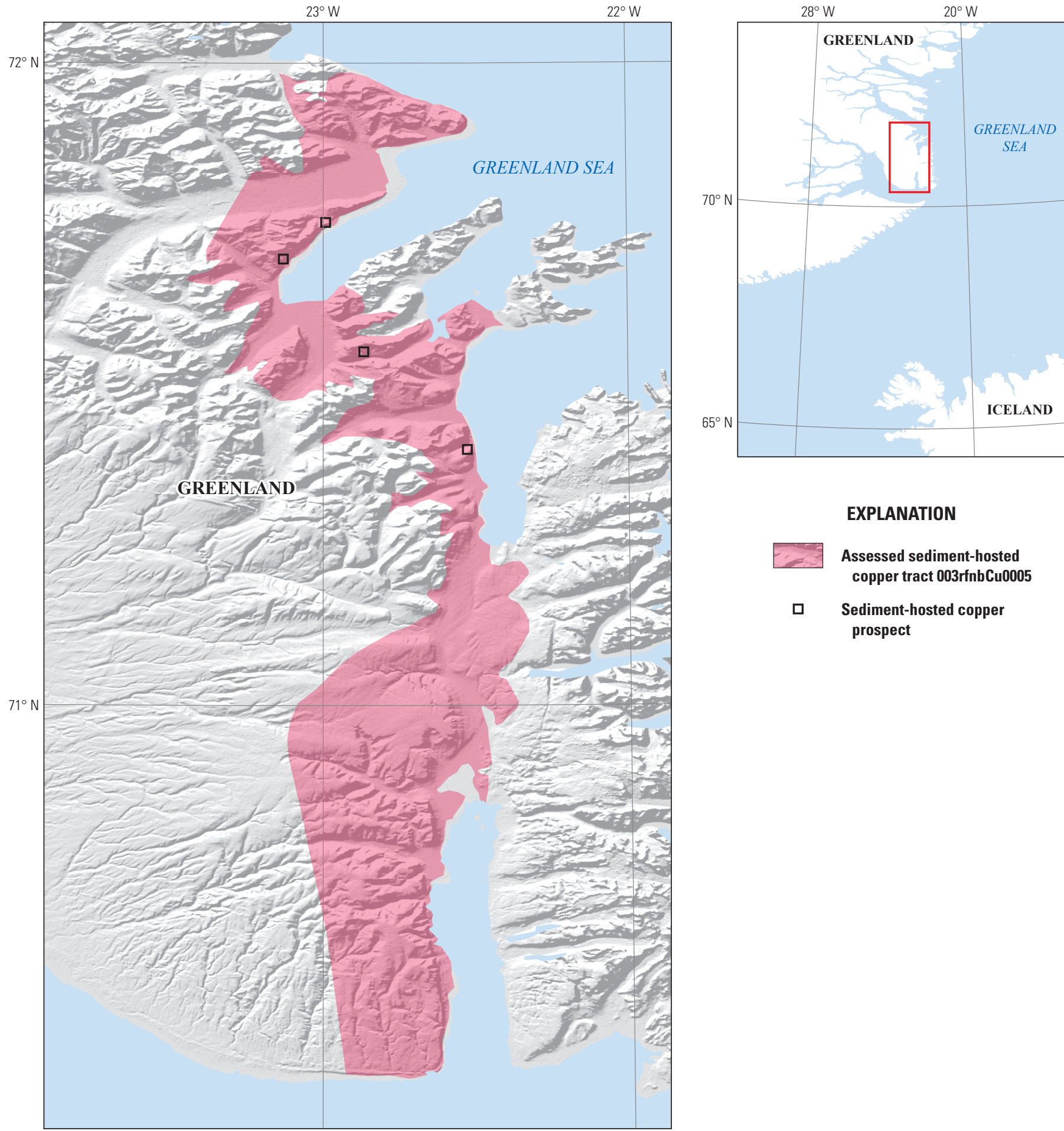

\section{EXPLANATION}

Assessed sediment-hosted copper tract 003rfnbCu0005

ㅁ Sediment-hosted copper prospect

Political boundaries from U.S. Department of State (2009) Shaded relief from Howat and others (2014) North America Albers Equal-Area Conic projection Central meridian $23^{\circ} \mathrm{W}$.; latitude of origin $40^{\circ} \mathrm{N}$.

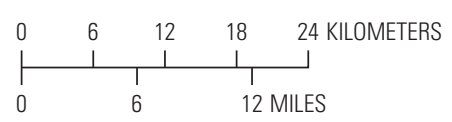




\title{
Plate 200. Sediment-Hosted Stratabound Copper Assessment for Tract 003ssCu0001, Huledal Formation (CE 15), Jameson Land Basin—Greenland
}

\author{
Descriptive model: \\ Sediment-hosted stratabound copper-Sandstone copper subtype model (Cox and others, 2007; \\ Zientek, Hayes, and Hammarstrom, 2013) \\ Grade and tonnage model: \\ Geologic feature assessed: \\ Sediment-hosted stratabound copper-Sandstone copper subtype model (Zientek, Hayes, and \\ Taylor, 2013) \\ Coarse-grained siliciclastic rocks of the Permian Huledal Formation, Jameson Land Basin, central \\ East Greenland \\ Number of known deposits: \\ 0
}

\section{Selected Resource Assessment Results for Sediment-Hosted Stratabound Copper}

[Assessment depth, 1 kilometer $(\mathrm{km}) ; \mathrm{km}^{2}$, square kilometer; Mt, millions of metric tons]

\begin{tabular}{ccccccc}
\hline $\begin{array}{c}\text { Date of } \\
\text { assessment }\end{array}$ & $\begin{array}{c}\text { Tract area } \\
\left(\mathbf{k m}^{2}\right)\end{array}$ & $\begin{array}{c}\text { Identified } \\
\text { copper } \\
\text { resources } \\
(\mathbf{M t})\end{array}$ & $\begin{array}{c}\text { Median estimate of } \\
\text { in-place resources } \\
(\mathbf{M t})\end{array}$ & $\begin{array}{c}\text { Mean estimate of } \\
\text { in-place resources } \\
\text { (Mt) }\end{array}$ & $\begin{array}{c}\text { Probability of mean } \\
\text { or greater } \\
\text { (percent) }\end{array}$ & $\begin{array}{c}\text { Probability of } 0 \\
\text { in-place resources } \\
\text { (percent) }\end{array}$ \\
\hline 2009 & 154 & 0 & 0 & 0.012 & 3 \\
\hline
\end{tabular}

"Estimates from Stensgaard and others (2011) were revised slightly to conform with project protocols for spatial aggregation and definition of identified resources.

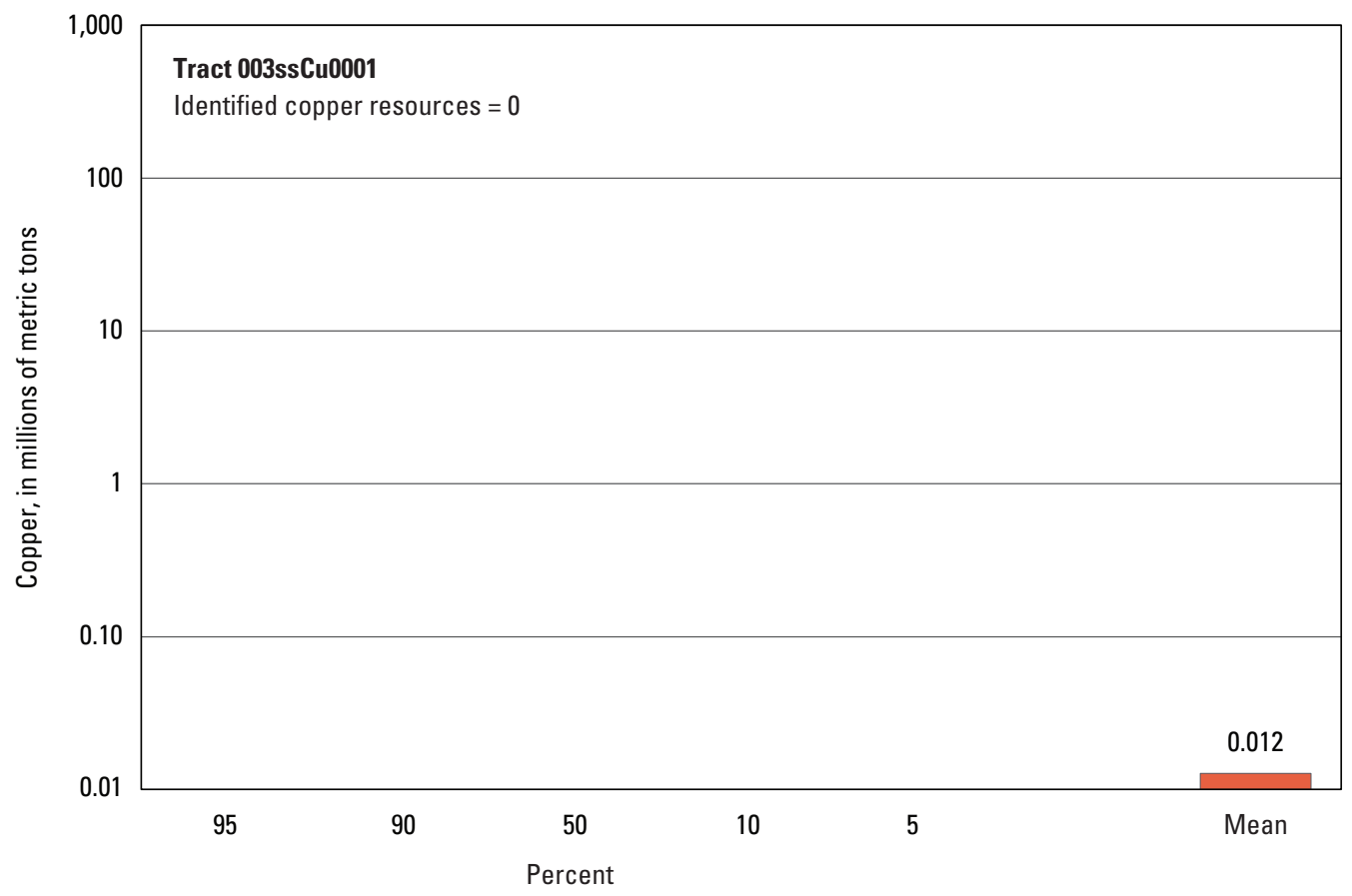

Graph showing the estimated probability distribution of undiscovered copper resources, where each bar represents the minimum amount estimated at the indicated percentage.

\section{Source}

Stensgaard and others, 2011, Quantitative mineral resource assessment-Sedimentary-hosted copper in Greenland: Geological Survey of Denmark and Greenland (GEUS) Report 2011/104. 


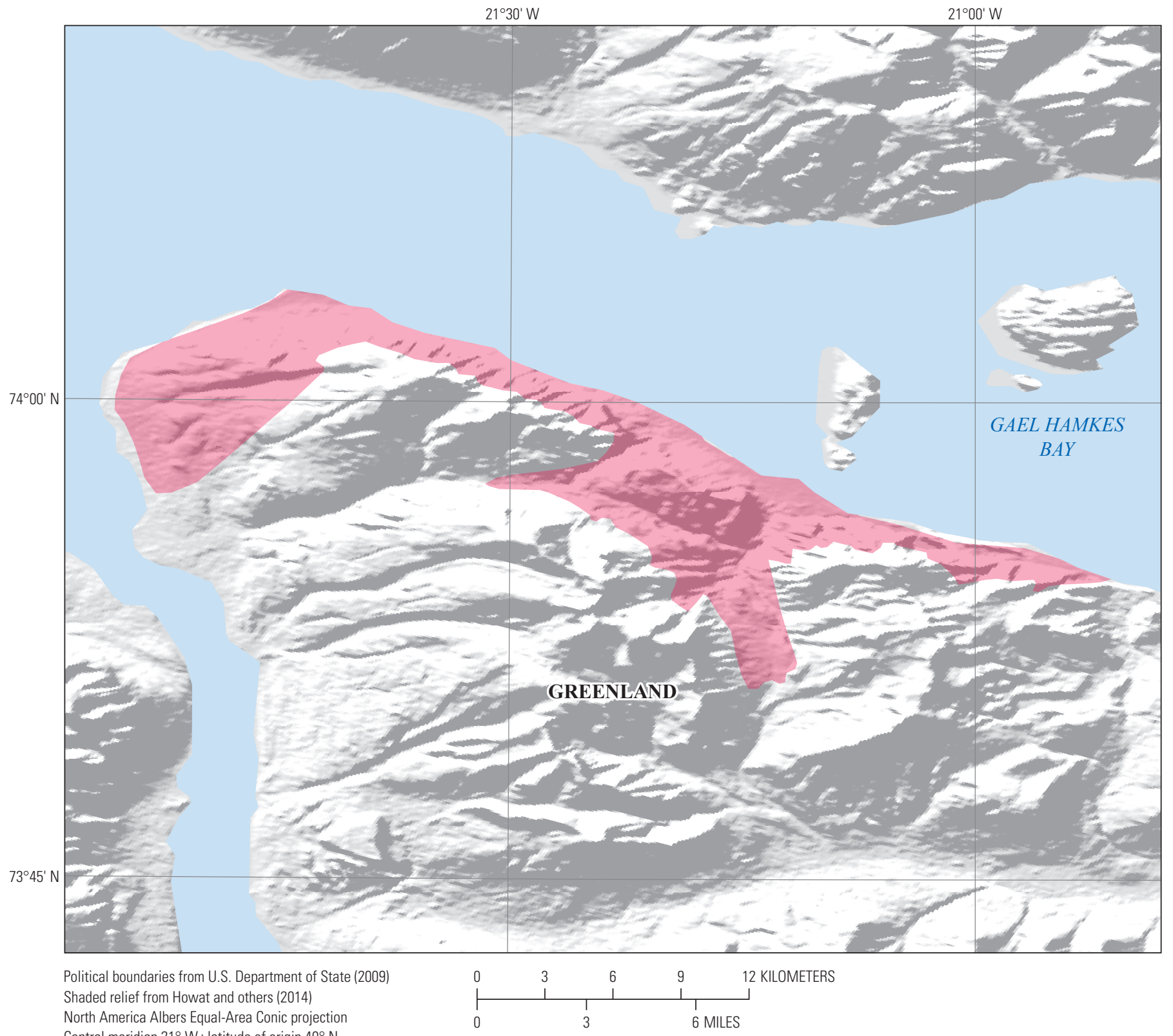

列

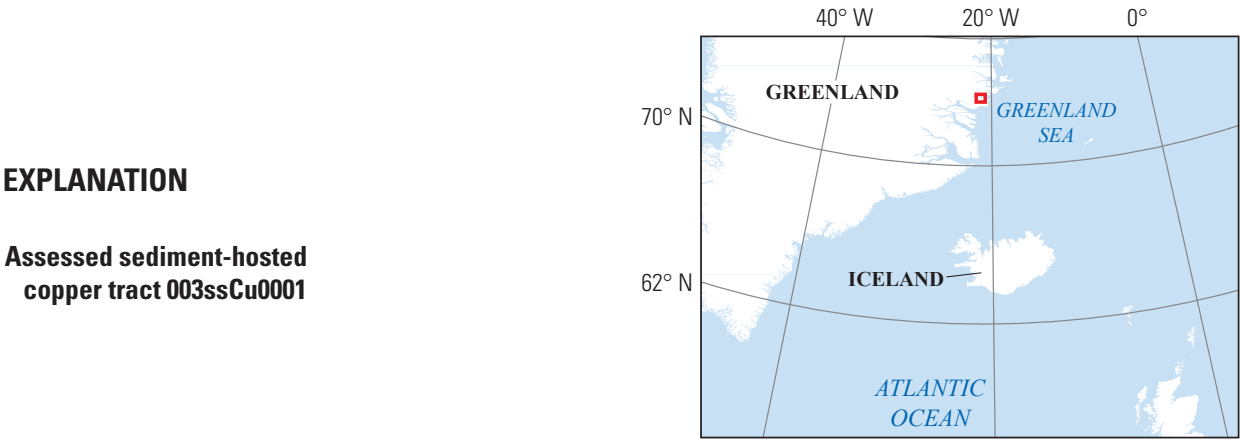




\section{Plate 201. Sediment-Hosted Stratabound Copper Assessment for Tract 003ssCu0002, Huledal Formation (CE 13-14), Jameson Land Basin-Greenland}

Descriptive model:

Grade and tonnage model:

Geologic feature assessed:

Number of known deposits:
Sediment-hosted stratabound copper-Sandstone copper subtype model (Cox and others, 2007; Zientek, Hayes, and Hammarstrom, 2013)

Sediment-hosted stratabound copper-Sandstone copper subtype model (Zientek, Hayes, and Taylor, 2013)

Coarse-grained siliciclastic rocks of the Permian Huledal Formation, Jameson Land Basin, central East Greenland

0

\section{Selected Resource Assessment Results for Sediment-Hosted Stratabound Copper}

[Assessment depth, 1 kilometer $(\mathrm{km}) ; \mathrm{km}^{2}$, square kilometer; Mt, millions of metric tons]

\begin{tabular}{ccccccc}
\hline $\begin{array}{c}\text { Date of } \\
\text { assessment }\end{array}$ & $\begin{array}{c}\text { Tract area } \\
\left(\mathbf{k m}^{2}\right)\end{array}$ & $\begin{array}{c}\text { Identified } \\
\text { copper } \\
\text { resources } \\
(\mathbf{M t})\end{array}$ & $\begin{array}{c}\text { Median estimate of } \\
\text { in-place resources } \\
(\mathbf{M t})\end{array}$ & $\begin{array}{c}\text { Mean estimate of } \\
\text { in-place resources } \\
\text { (Mt) }\end{array}$ & $\begin{array}{c}\text { Probability of mean } \\
\text { or greater } \\
\text { (percent) }\end{array}$ & $\begin{array}{c}\text { Probability of } 0 \\
\text { in-place resources } \\
\text { (percent) }\end{array}$ \\
\hline 2009 & 362 & 0 & 0.13 & 0.92 & 14 \\
\hline
\end{tabular}

*Estimates from Stensgaard and others (2011) were revised slightly to conform with project protocols for spatial aggregation and definition of identified resources.

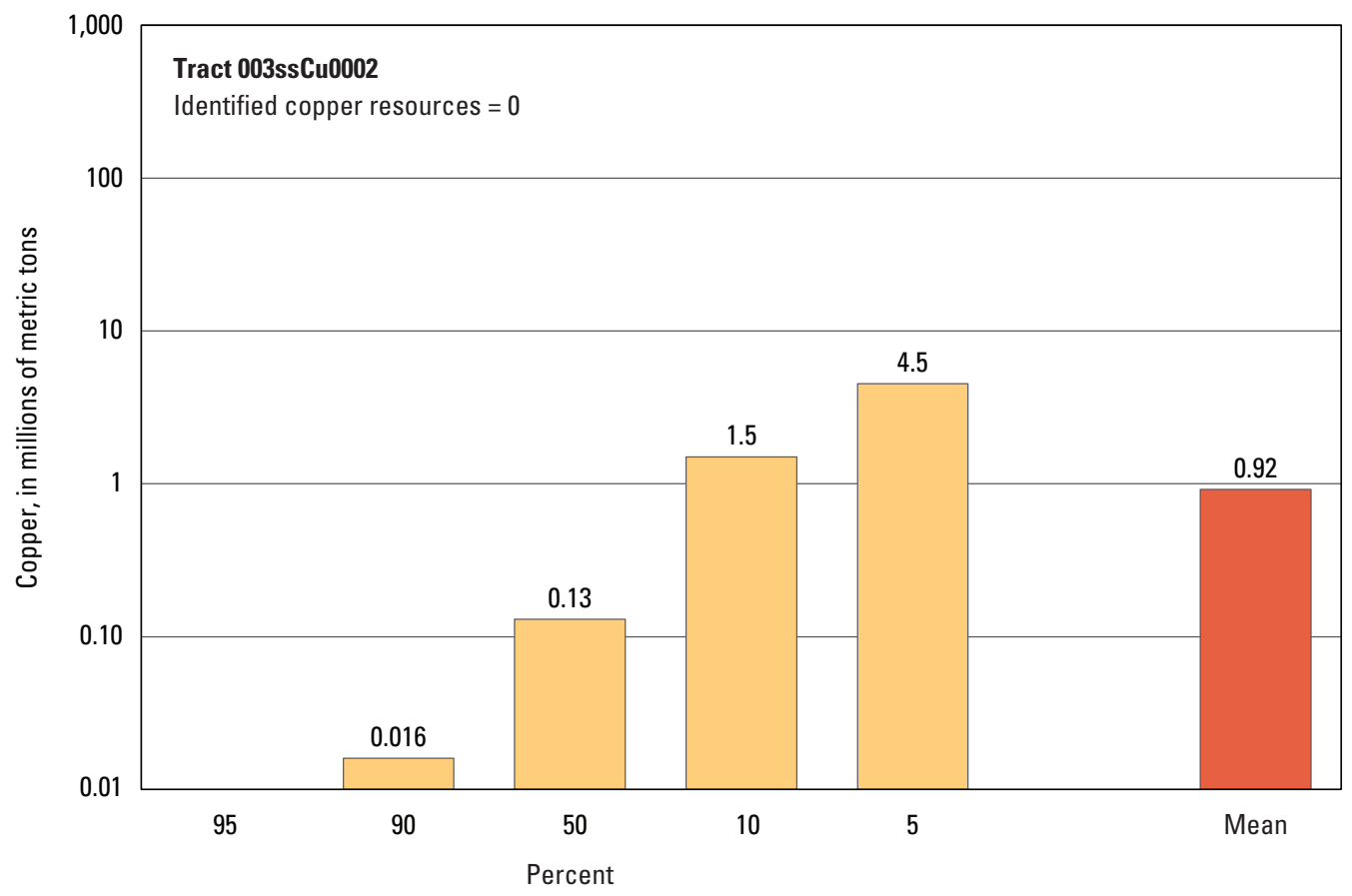

Graph showing the estimated probability distribution of undiscovered copper resources, where each bar represents the minimum amount estimated at the indicated percentage.

\section{Source}

Stensgaard and others, 2011, Quantitative mineral resource assessment—Sedimentary-hosted copper in Greenland: Geological Survey of Denmark and Greenland (GEUS) Report 2011/104. 


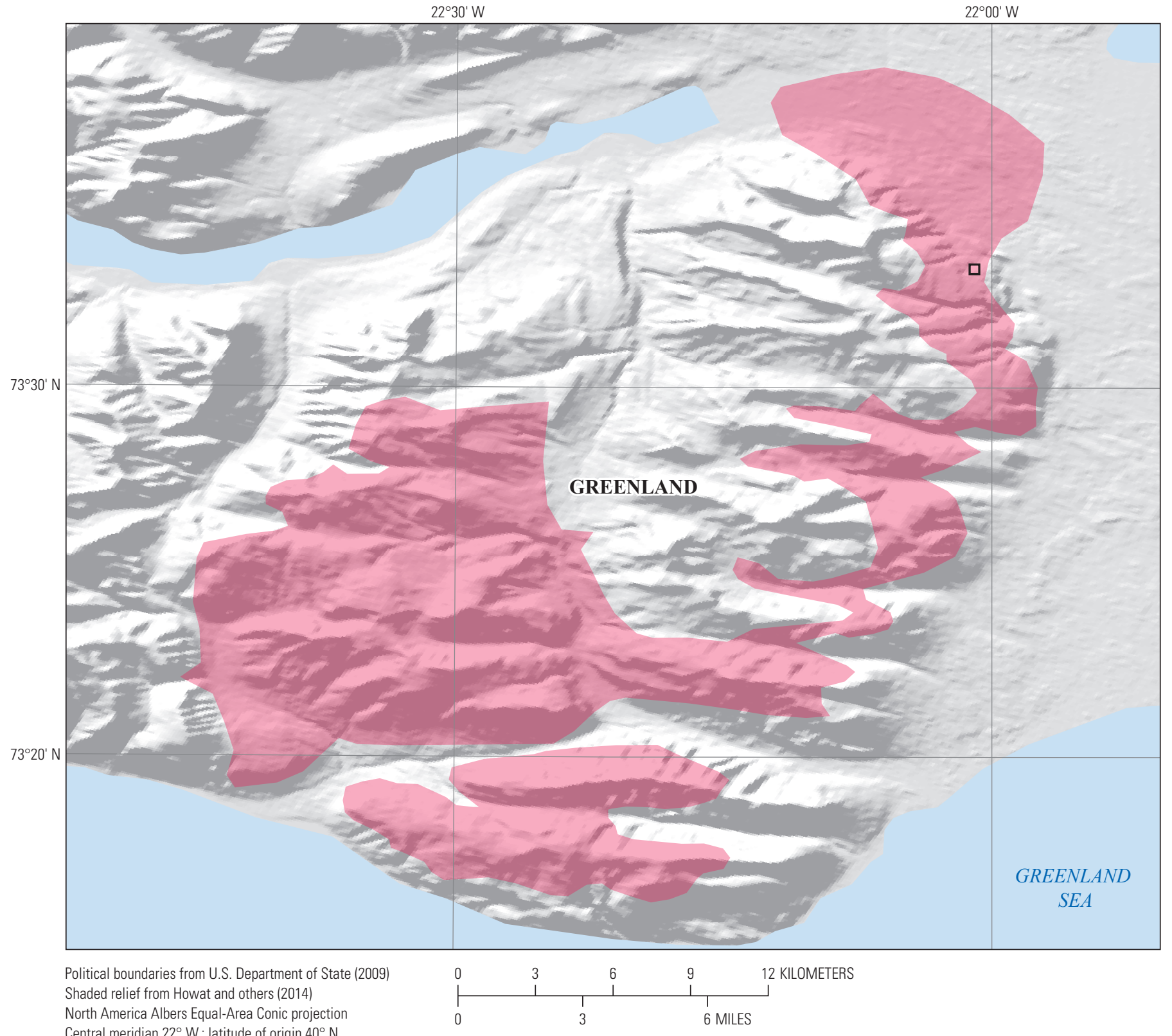

Central meridian $22^{\circ} \mathrm{W}$.; latitude of origin $40^{\circ} \mathrm{N}$.

\section{EXPLANATION}

Assessed sediment-hosted copper tract 003ssCu0002

ㄴ Sediment-hosted copper prospect

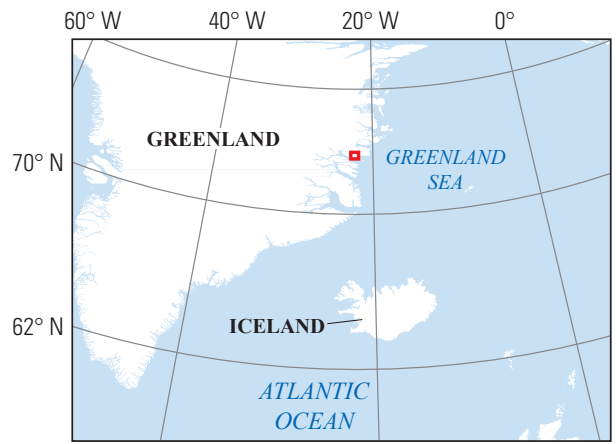




\title{
Plate 202. Sediment-Hosted Stratabound Copper Assessment for Tract 003ssCu0003, Huledal Formation (CE 2), Jameson Land Basin—Greenland
}

\author{
Descriptive model: \\ Sediment-hosted stratabound copper-Sandstone copper subtype model (Cox and others, 2007; \\ Zientek, Hayes, and Hammarstrom, 2013) \\ Grade and tonnage model: \\ Geologic feature assessed: \\ Sediment-hosted stratabound copper-Sandstone copper subtype model (Zientek, Hayes, and \\ Taylor, 2013) \\ Coarse-grained siliciclastic rocks of the Permian Huledal Formation, Jameson Land Basin, central \\ East Greenland \\ Number of known deposits: \\ 0
}

\section{Selected Resource Assessment Results for Sediment-Hosted Stratabound Copper}

[Assessment depth, 1 kilometer (km); $\mathrm{km}^{2}$, square kilometer; Mt, millions of metric tons]

\begin{tabular}{ccccccc}
\hline $\begin{array}{c}\text { Date of } \\
\text { assessment }\end{array}$ & $\begin{array}{c}\text { Tract area } \\
\left(\mathbf{k m}^{2}\right)\end{array}$ & $\begin{array}{c}\text { Identified } \\
\text { copper } \\
\text { resources } \\
(\mathbf{M t})\end{array}$ & $\begin{array}{c}\text { Median estimate of } \\
\text { in-place resources } \\
(\mathbf{M t})\end{array}$ & $\begin{array}{c}\text { Mean estimate of } \\
\text { in-place resources } \\
\text { (Mt) }\end{array}$ & $\begin{array}{c}\text { Probability of mean } \\
\text { or greater } \\
\text { (percent) }\end{array}$ & $\begin{array}{c}\text { Probability of } 0 \\
\text { in-place resources } \\
\text { (percent) }\end{array}$ \\
\hline 2009 & 395 & 0 & 0 & 0.12 & 5 & 93 \\
\hline
\end{tabular}

*Estimates from Stensgaard and others (2011) were revised slightly to conform with project protocols for spatial aggregation and definition of identified resources.

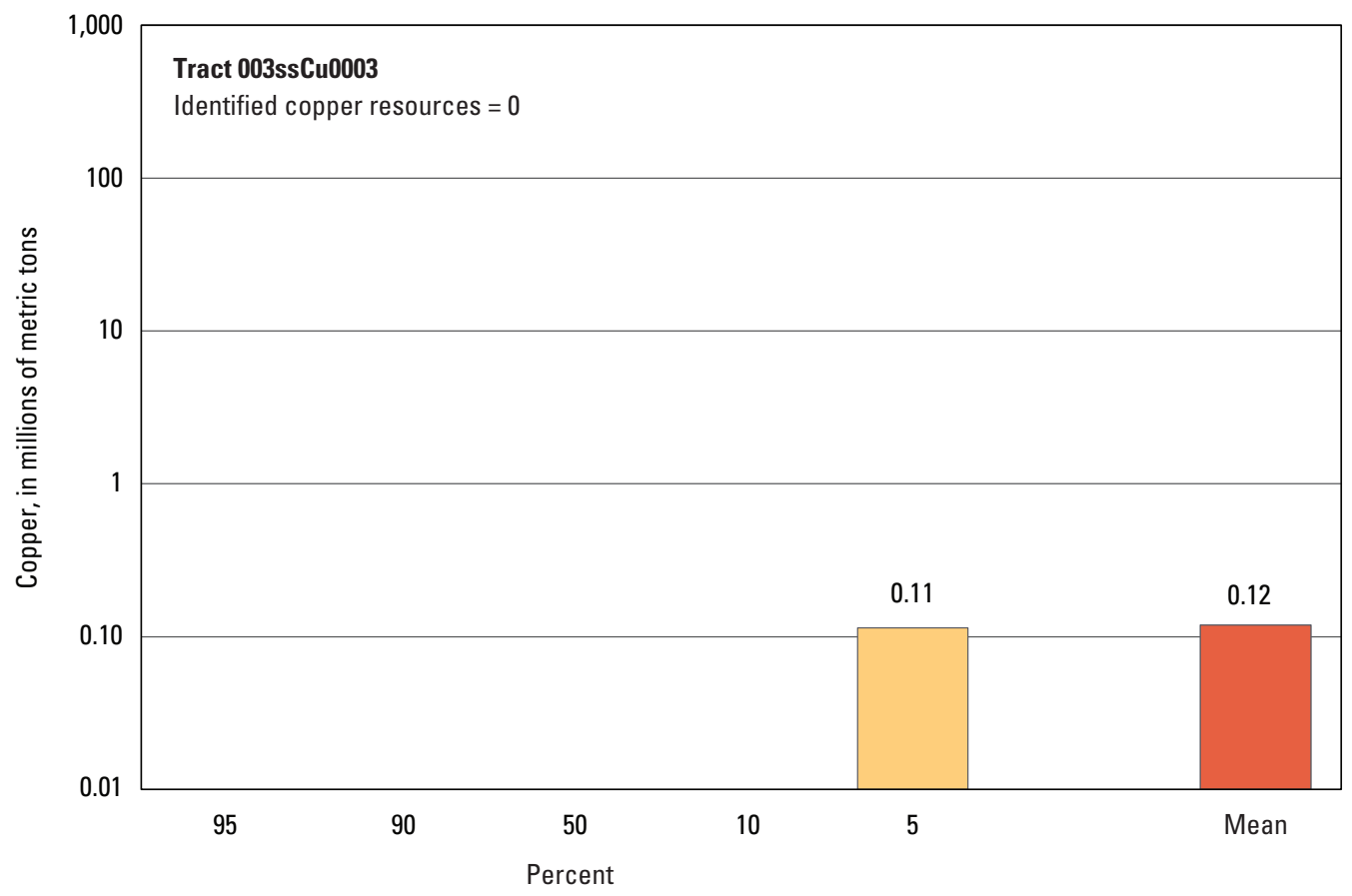

Graph showing the estimated probability distribution of undiscovered copper resources, where each bar represents the minimum amount estimated at the indicated percentage.

\section{Source}

Stensgaard and others, 2011, Quantitative mineral resource assessment-Sedimentary-hosted copper in Greenland: Geological Survey of Denmark and Greenland (GEUS) Report 2011/104. 


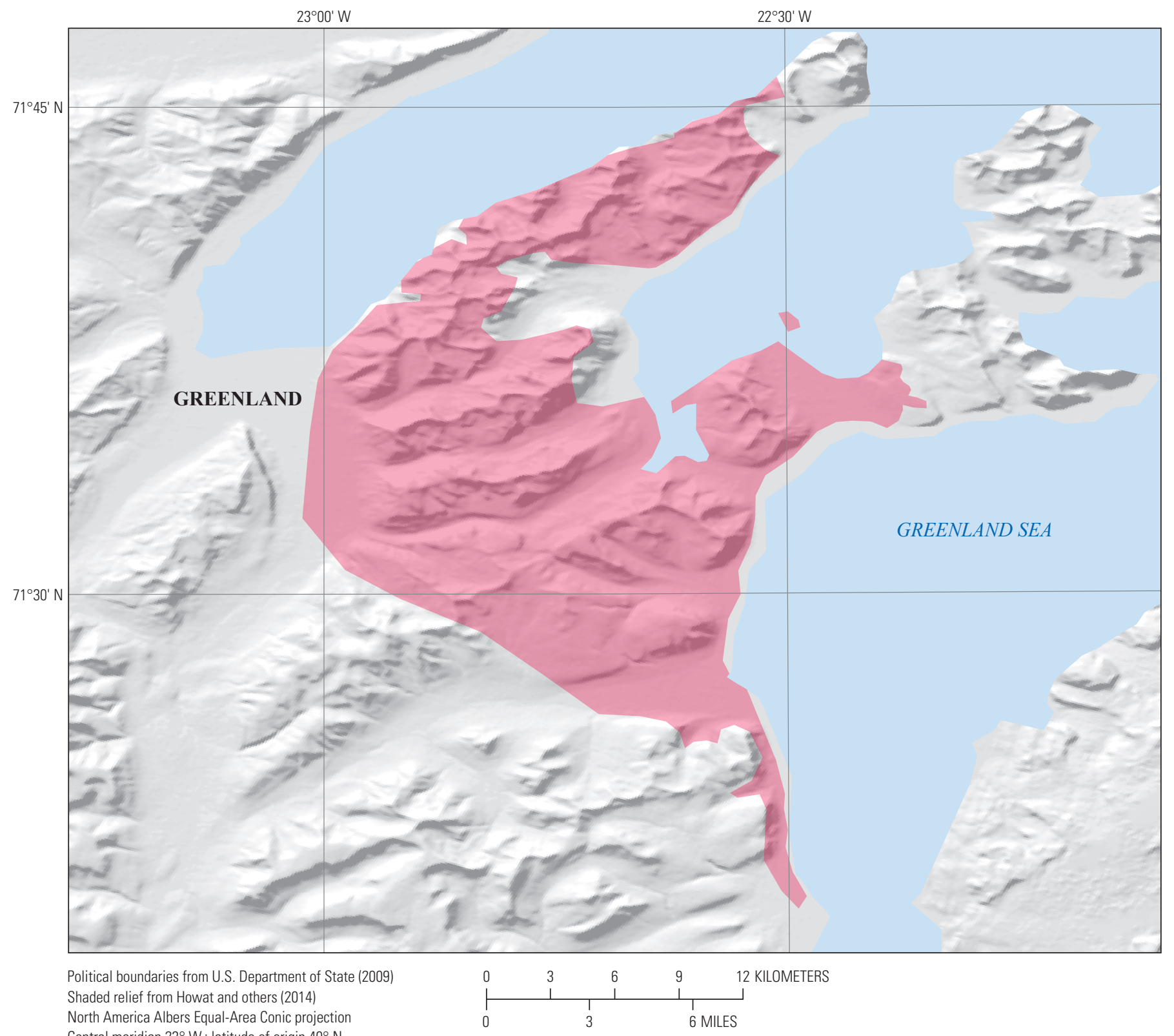

Central meridian $23^{\circ} \mathrm{W}$ - latitude of origin $40^{\circ} \mathrm{N}$

EXPLANATION

Assessed sediment-hosted copper tract 003ssCu0003

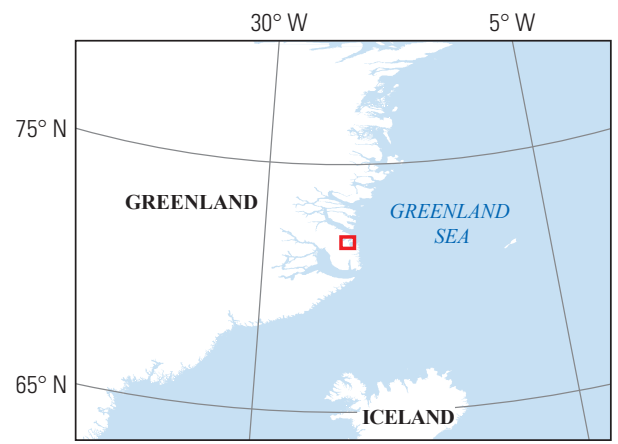




\title{
Plate 203. Sediment-Hosted Stratabound Copper Assessment for Tract 003ssCu0004, Huledal Formation (CE 8-12), Jameson Land Basin-Greenland
}

\author{
Descriptive model: \\ Sediment-hosted stratabound copper-Sandstone copper subtype model (Cox and others, 2007; \\ Zientek, Hayes, and Hammarstrom, 2013) \\ Grade and tonnage model: \\ Geologic feature assessed: \\ Sediment-hosted stratabound copper-Sandstone copper subtype model (Zientek, Hayes, and \\ Taylor, 2013) \\ Coarse-grained siliciclastic rocks of the Permian Huledal Formation, Jameson Land Basin, central \\ East Greenland \\ Number of known deposits: \\ 0
}

\section{Selected Resource Assessment Results for Sediment-Hosted Stratabound Copper}

[Assessment depth, 1 kilometer $(\mathrm{km}) ; \mathrm{km}^{2}$, square kilometer; Mt, millions of metric tons]

\begin{tabular}{ccccccc}
\hline $\begin{array}{c}\text { Date of } \\
\text { assessment }\end{array}$ & $\begin{array}{c}\text { Tract area } \\
\left(\mathbf{k m}^{2}\right)\end{array}$ & $\begin{array}{c}\text { Identified } \\
\text { copper } \\
\text { resources } \\
(\mathbf{M t})\end{array}$ & $\begin{array}{c}\text { Median estimate of } \\
\text { in-place resources } \\
(\mathbf{M t})\end{array}$ & $\begin{array}{c}\text { Mean estimate of } \\
\text { in-place resources } \\
\text { (Mt) }\end{array}$ & $\begin{array}{c}\text { Probability of mean } \\
\text { or greater } \\
\text { (percent) }\end{array}$ & $\begin{array}{c}\text { Probability of } \mathbf{0} \\
\text { in-place resources } \\
\text { (percent) }\end{array}$ \\
\hline 2009 & 445 & 0 & 0.13 & 1.2 & 13 \\
\hline
\end{tabular}

"Estimates from Stensgaard and others (2011) were revised slightly to conform with project protocols for spatial aggregation and definition of identified resources.

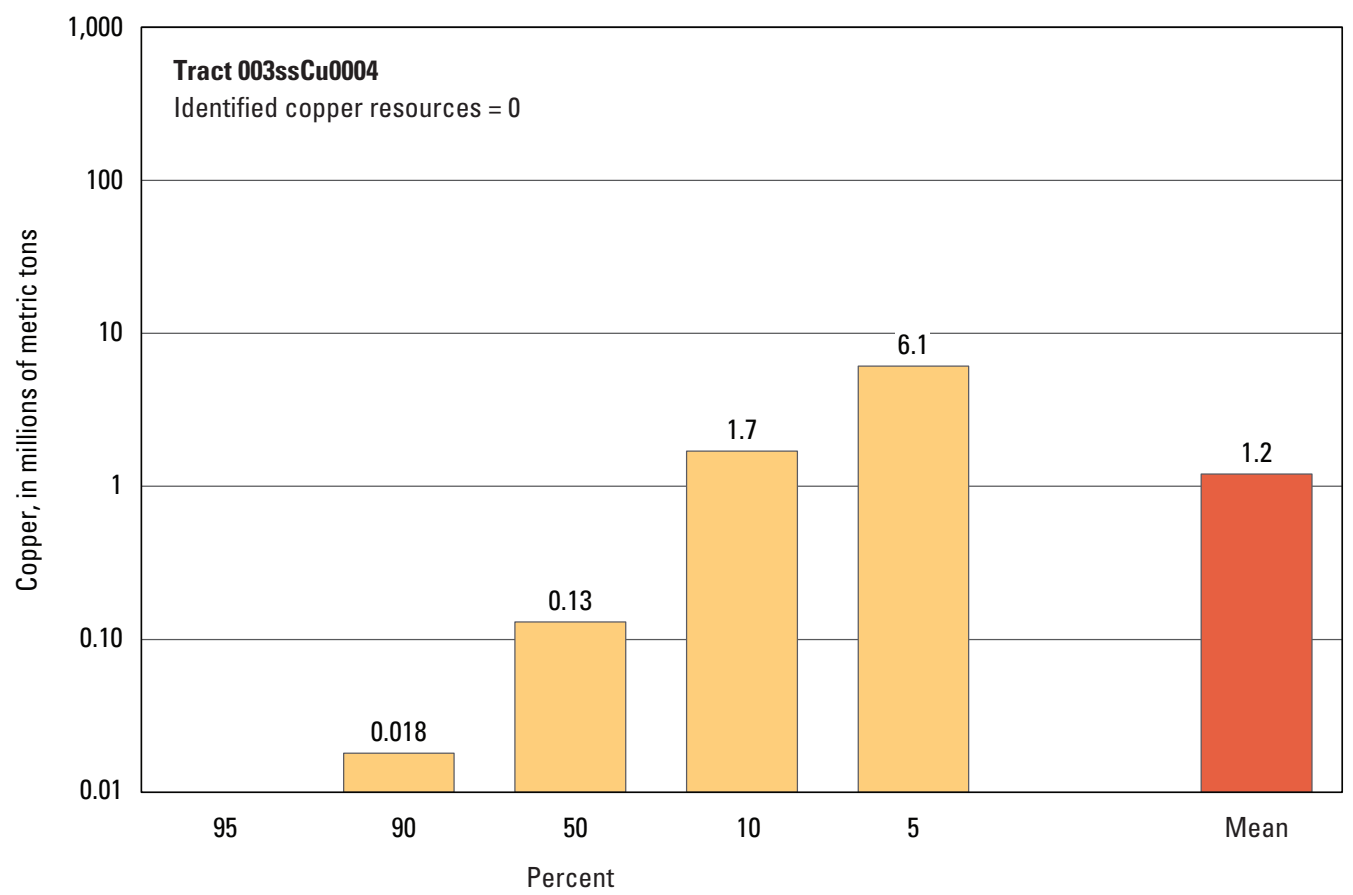

Graph showing the estimated probability distribution of undiscovered copper resources, where each bar represents the minimum amount estimated at the indicated percentage.

\section{Source}

Stensgaard and others, 2011, Quantitative mineral resource assessment-Sedimentary-hosted copper in Greenland: Geological Survey of Denmark and Greenland (GEUS) Report 2011/104. 


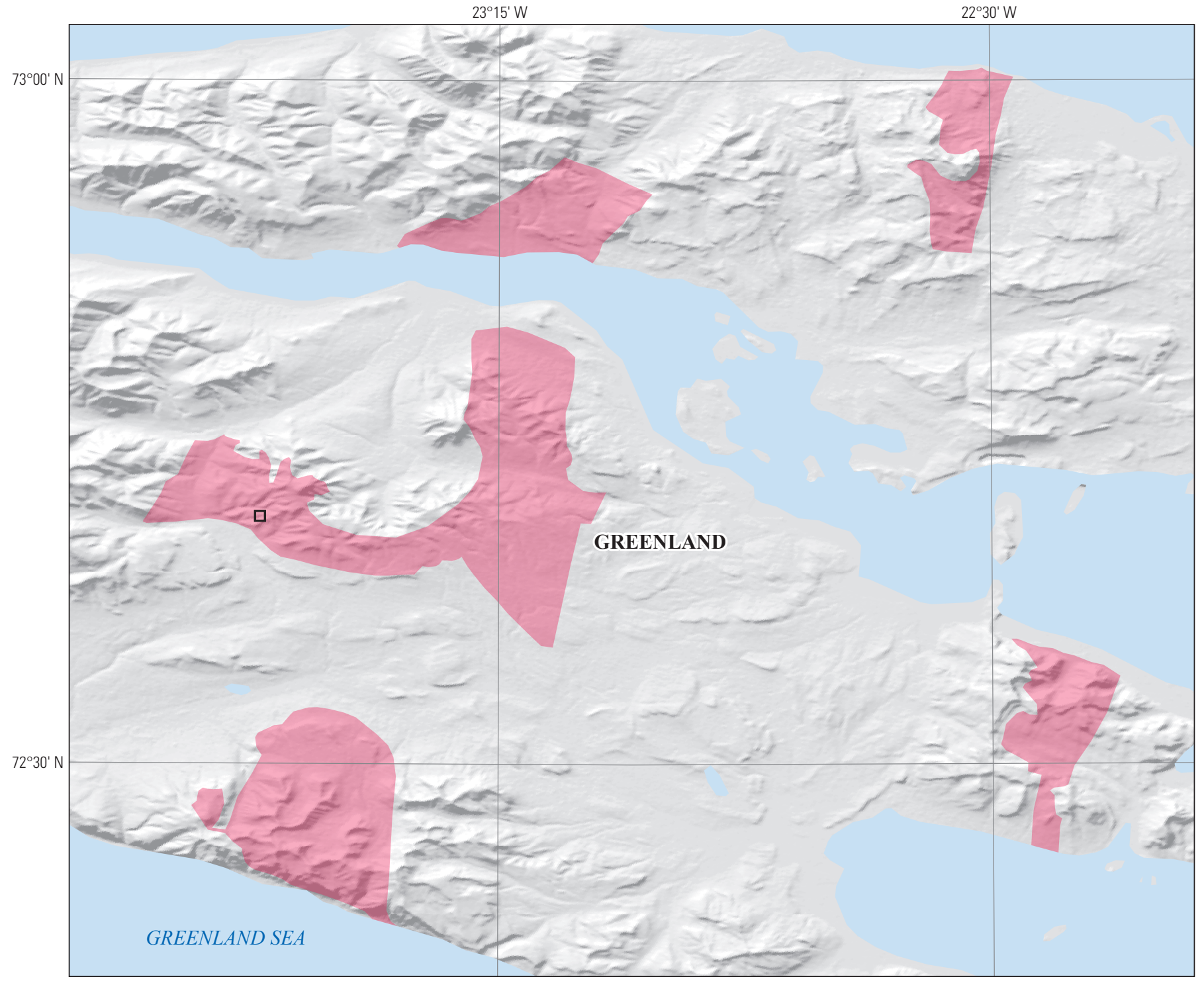

Political boundaries from U.S. Department of State (2009) Shaded relief from Howat and others (2014) North America Albers Equal-Area Conic projection Central meridian $23^{\circ} \mathrm{W}$.; latitude of origin $40^{\circ} \mathrm{N}$.

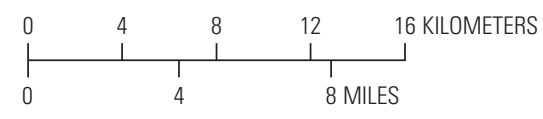

EXPLANATION

Assessed sediment-hosted copper tract 003ssCu0004

$\square \quad$ Sediment-hosted copper prospect

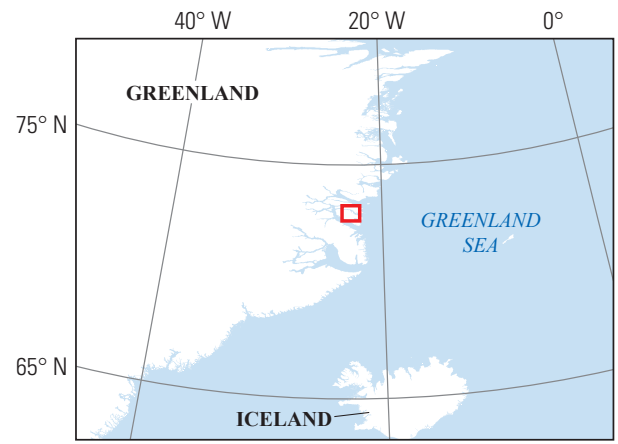




\section{Plate 204. Sediment-Hosted Stratabound Copper Assessment for Tract 003ssCu0005, Huledal Formation (CE 4-7), Jameson Land Basin-Greenland}

Descriptive model:

Grade and tonnage model:

Geologic feature assessed:

Number of known deposits:
Sediment-hosted stratabound copper-Sandstone copper subtype model (Cox and others, 2007; Zientek, Hayes, and Hammarstrom, 2013)

Sediment-hosted stratabound copper-Sandstone copper subtype model (Zientek, Hayes, and Taylor, 2013)

Coarse-grained siliciclastic rocks of the Permian Huledal Formation, Jameson Land Basin, central East Greenland

0

\section{Selected Resource Assessment Results for Sediment-Hosted Stratabound Copper}

[Assessment depth, 1 kilometer $(\mathrm{km}) ; \mathrm{km}^{2}$, square kilometer; Mt, millions of metric tons]

\begin{tabular}{ccccccc}
\hline $\begin{array}{c}\text { Date of } \\
\text { assessment }\end{array}$ & $\begin{array}{c}\text { Tract area } \\
\left.\mathbf{( k m}^{2}\right)\end{array}$ & $\begin{array}{c}\text { Identified } \\
\text { copper } \\
\text { resources } \\
(\mathbf{M t})\end{array}$ & $\begin{array}{c}\text { Median estimate of } \\
\text { in-place resources } \\
\text { (Mt) }\end{array}$ & $\begin{array}{c}\text { Mean estimate of } \\
\text { in-place resources } \\
\text { (Mt) }\end{array}$ & $\begin{array}{c}\text { Probability of mean } \\
\text { or greater } \\
\text { (percent) }\end{array}$ & $\begin{array}{c}\text { Probability of 0 } \\
\text { in-place resources } \\
\text { (percent) }\end{array}$ \\
\hline 2009 & 821 & 0 & 0 & 0.099 & 6 \\
\hline
\end{tabular}

"Estimates from Stensgaard and others (2011) were revised slightly to conform with project protocols for spatial aggregation and definition of identified resources.

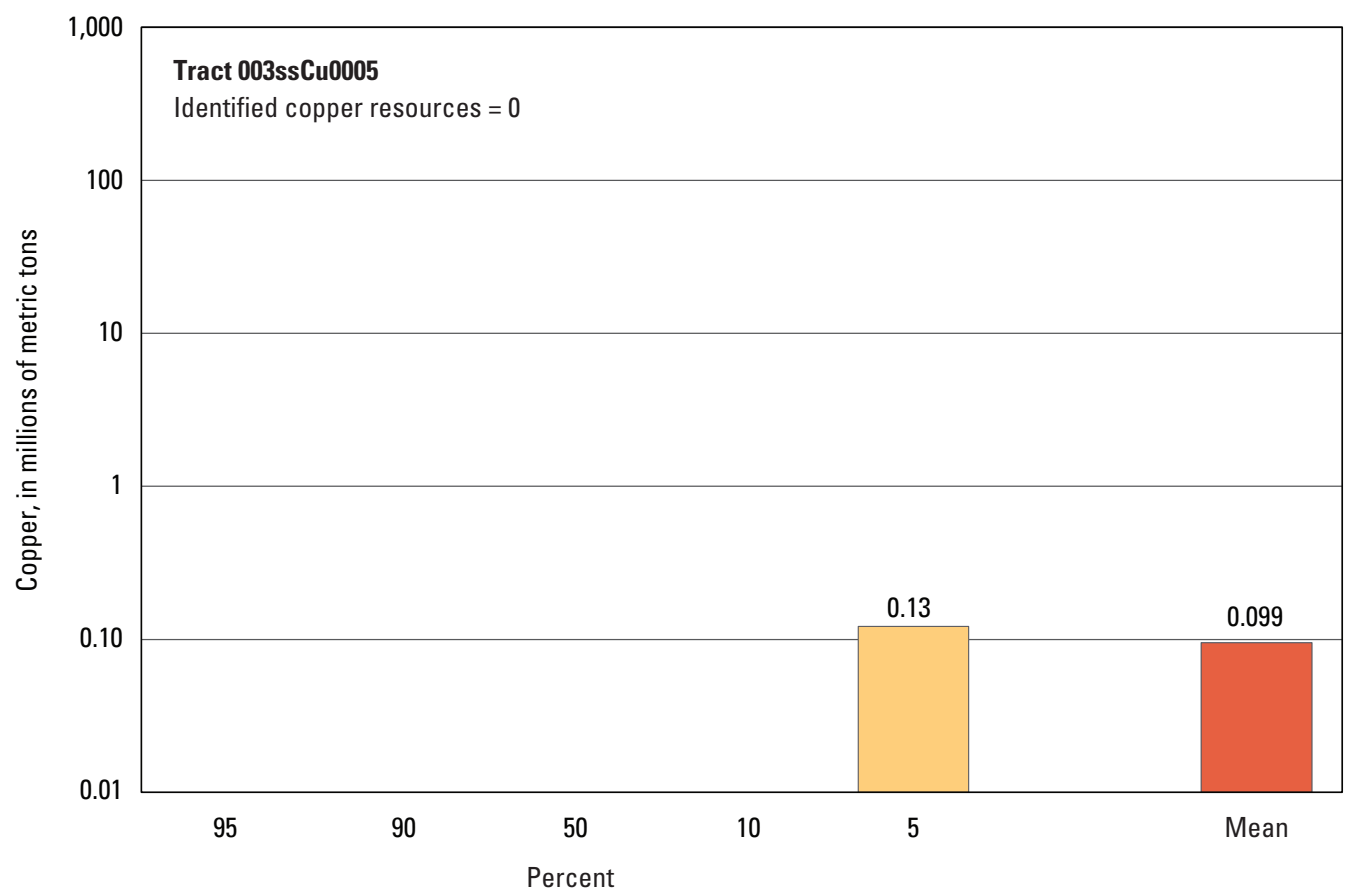

Graph showing the estimated probability distribution of undiscovered copper resources, where each bar represents the minimum amount estimated at the indicated percentage.

\section{Source}

Stensgaard and others, 2011, Quantitative mineral resource assessment-Sedimentary-hosted copper in Greenland: Geological Survey of Denmark and Greenland (GEUS) Report 2011/104. 

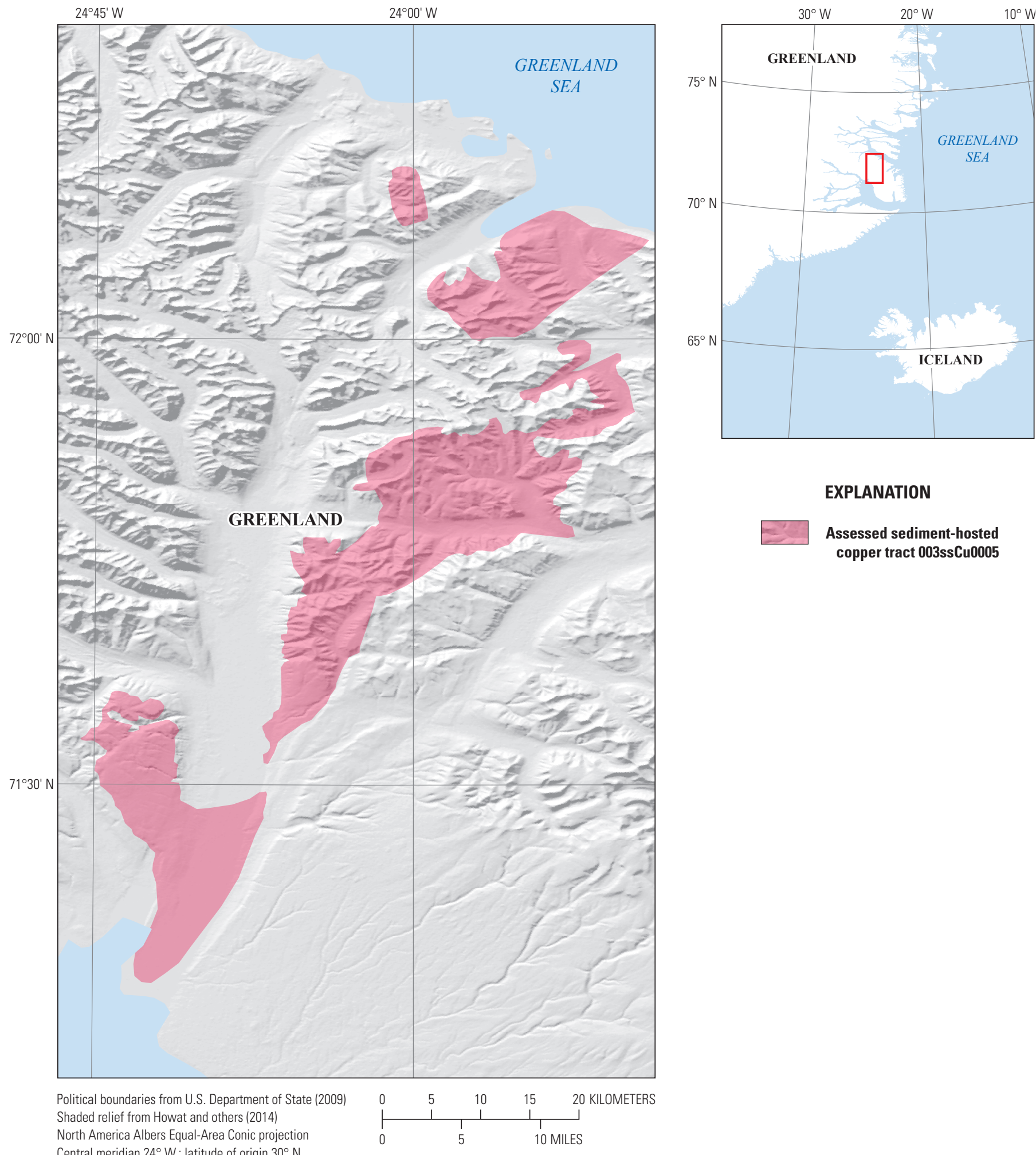

EXPLANATION

Assessed sediment-hosted copper tract 003ssCu0005

Area Conic projection

Central meridian $24^{\circ} \mathrm{W}$; ; latitude of origin $30^{\circ} \mathrm{N}$. 


\section{Plate 205. Sediment-Hosted Stratabound Copper Assessment for Tract 003rfnbCu0002, Eleonore Bay Supergroup (CE 7-8), Eleonore Bay Basin- Greenland}

\author{
Descriptive model: \\ Grade and tonnage model: \\ Geologic feature assessed:
}

Number of known deposits:

\begin{abstract}
Sediment-hosted stratabound copper-Reduced-facies-nonbrecciated copper subtype model (Cox and others, 2007; Zientek, Hayes, and Hammarstrom, 2013)

Sediment-hosted stratabound copper-Reduced-facies-nonbrecciated copper subtype model (Zientek, Hayes, and Taylor, 2013)

Calcareous and dolomitic shales of the uppermost part of the Neoproterozoic Ymer $\varnothing$ Group overlying shallow-marine and continental siliciclastic sedimentary rocks of the Nathorst Land and Lyell Land Groups of the Neoproterozoic Eleonore Bay Supergroup, Eleonore Bay Basin, North-East Greenland

0
\end{abstract}

\section{Selected Resource Assessment Results for Sediment-Hosted Stratabound Copper}

[Assessment depth, 1 kilometer (km); $\mathrm{km}^{2}$, square kilometer; Mt, millions of metric tons]

\begin{tabular}{ccccccc}
\hline \multirow{2}{*}{$\begin{array}{c}\text { Date of } \\
\text { assessment }\end{array}$} & $\begin{array}{c}\text { Tract area } \\
\left(\mathbf{k m}^{2}\right)\end{array}$ & $\begin{array}{c}\text { Identified } \\
\text { copper } \\
\text { resources } \\
(\mathbf{M t})\end{array}$ & $\begin{array}{c}\text { Median estimate of } \\
\text { in-place resources } \\
(\mathbf{M t})\end{array}$ & $\begin{array}{c}\text { Mean estimate of } \\
\text { in-place resources } \\
\text { (Mt) }\end{array}$ & $\begin{array}{c}\text { Probability of mean } \\
\text { or greater } \\
\text { (percent) }\end{array}$ & $\begin{array}{c}\text { Probability of } \mathbf{0} \\
\text { in-place resources } \\
\text { (percent) }\end{array}$ \\
\hline 2009 & 998 & 0 & 0 & 0.70 & 7 \\
\hline
\end{tabular}

"Estimates from Stensgaard and others (2011) were revised slightly to conform with project protocols for spatial aggregation and definition of identified resources.

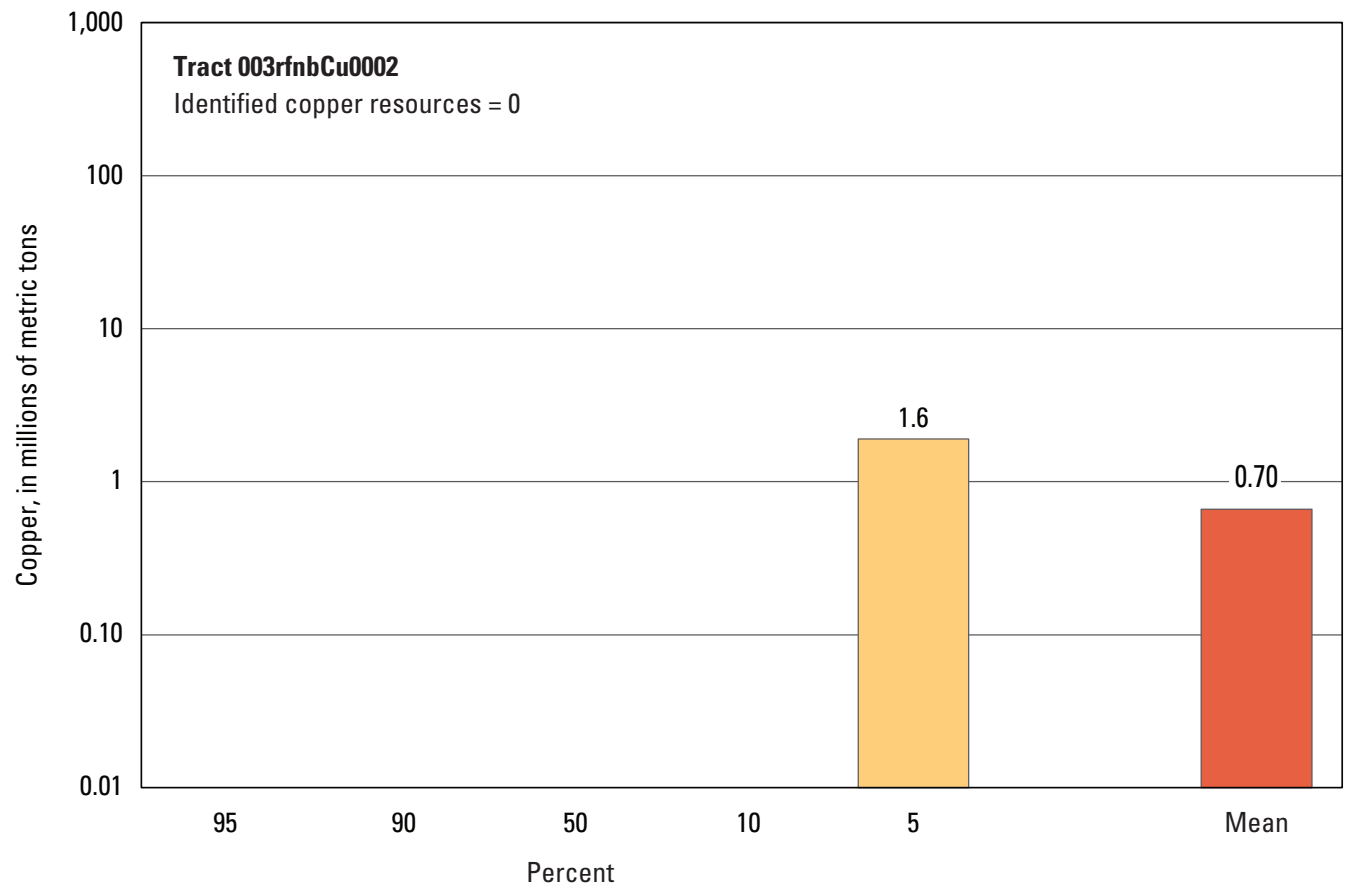

Graph showing the estimated probability distribution of undiscovered copper resources, where each bar represents the minimum amount estimated at the indicated percentage.

\section{Source}

Stensgaard and others, 2011, Quantitative mineral resource assessment-Sedimentary-hosted copper in Greenland: Geological Survey of Denmark and Greenland (GEUS) Report 2011/104. 


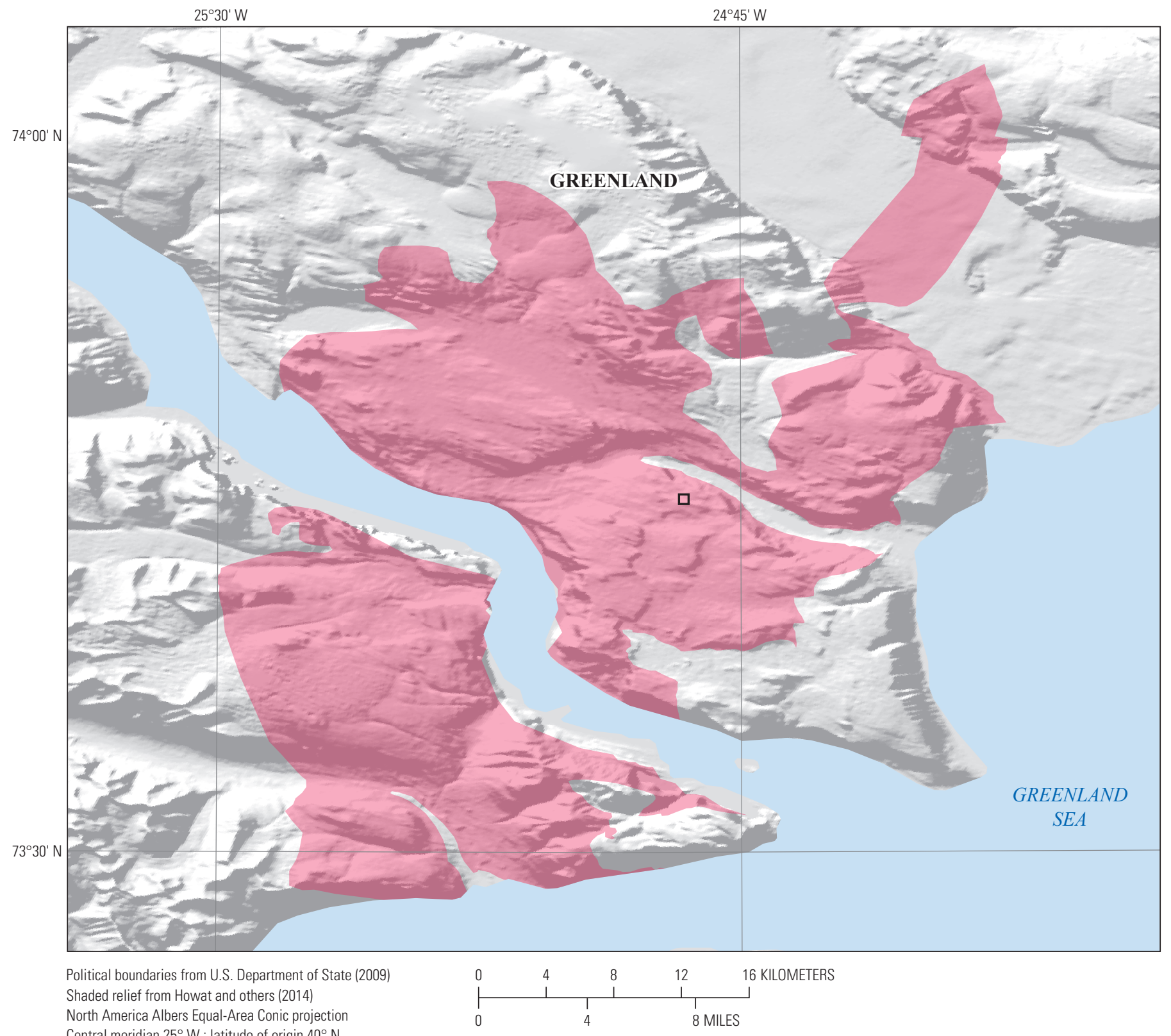

Central meridian $25^{\circ} \mathrm{W}$.; latitude of origin $40^{\circ} \mathrm{N}$.

\section{EXPLANATION}

Assessed sediment-hosted copper tract 003rfnbCu0002

$\square \quad$ Sediment-hosted copper prospect

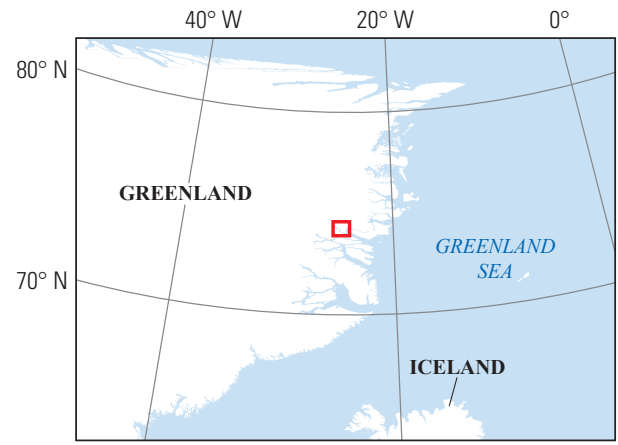




\section{Plate 206. Sediment-Hosted Stratabound Copper Assessment for Tract 003rfnbCu0003, Eleonore Bay Supergroup (CE 1-6 and CE 9-16), Eleonore Bay Basin-Greenland}

\author{
Descriptive model: \\ Grade and tonnage model: \\ Geologic feature assessed:
}

Number of known deposits:

\begin{abstract}
Sediment-hosted stratabound copper-Reduced-facies-nonbrecciated copper subtype model (Cox and others, 2007; Zientek, Hayes, and Hammarstrom, 2013)

Sediment-hosted stratabound copper-Reduced-facies-nonbrecciated copper subtype model (Zientek, Hayes, and Taylor, 2013)

Calcareous and dolomitic shales of the uppermost part of the Neoproterozoic Ymer $\varnothing$ Group overlying shallow-marine and continental siliciclastic sedimentary rocks of the Nathorst Land and Lyell Land Groups of the Neoproterozoic Eleonore Bay Supergroup, Eleonore Bay Basin, North-East Greenland

0
\end{abstract}

\section{Selected Resource Assessment Results for Sediment-Hosted Stratabound Copper}

[Assessment depth, 1 kilometer (km); $\mathrm{km}^{2}$, square kilometer; Mt, millions of metric tons]

\begin{tabular}{ccccccc}
\hline $\begin{array}{c}\text { Date of } \\
\text { assessment }\end{array}$ & $\begin{array}{c}\text { Tract area } \\
\left(\mathbf{k m}^{2}\right)\end{array}$ & $\begin{array}{c}\text { Identified } \\
\text { copper } \\
\text { resources } \\
(\mathbf{M t})\end{array}$ & $\begin{array}{c}\text { Median estimate of } \\
\text { in-place resources } \\
(\mathbf{M t})\end{array}$ & $\begin{array}{c}\text { Mean estimate of } \\
\text { in-place resources } \\
\text { (Mt) }\end{array}$ & $\begin{array}{c}\text { Probability of mean } \\
\text { or greater } \\
\text { (percent) }\end{array}$ & $\begin{array}{c}\text { Probability of } 0 \\
\text { in-place resources } \\
\text { (percent) }\end{array}$ \\
\hline 2009 & 2,057 & 0 & 0 & 0.56 & 5 \\
\hline
\end{tabular}

"Estimates from Stensgaard and others (2011) were revised slightly to conform with project protocols for spatial aggregation and definition of identified resources.

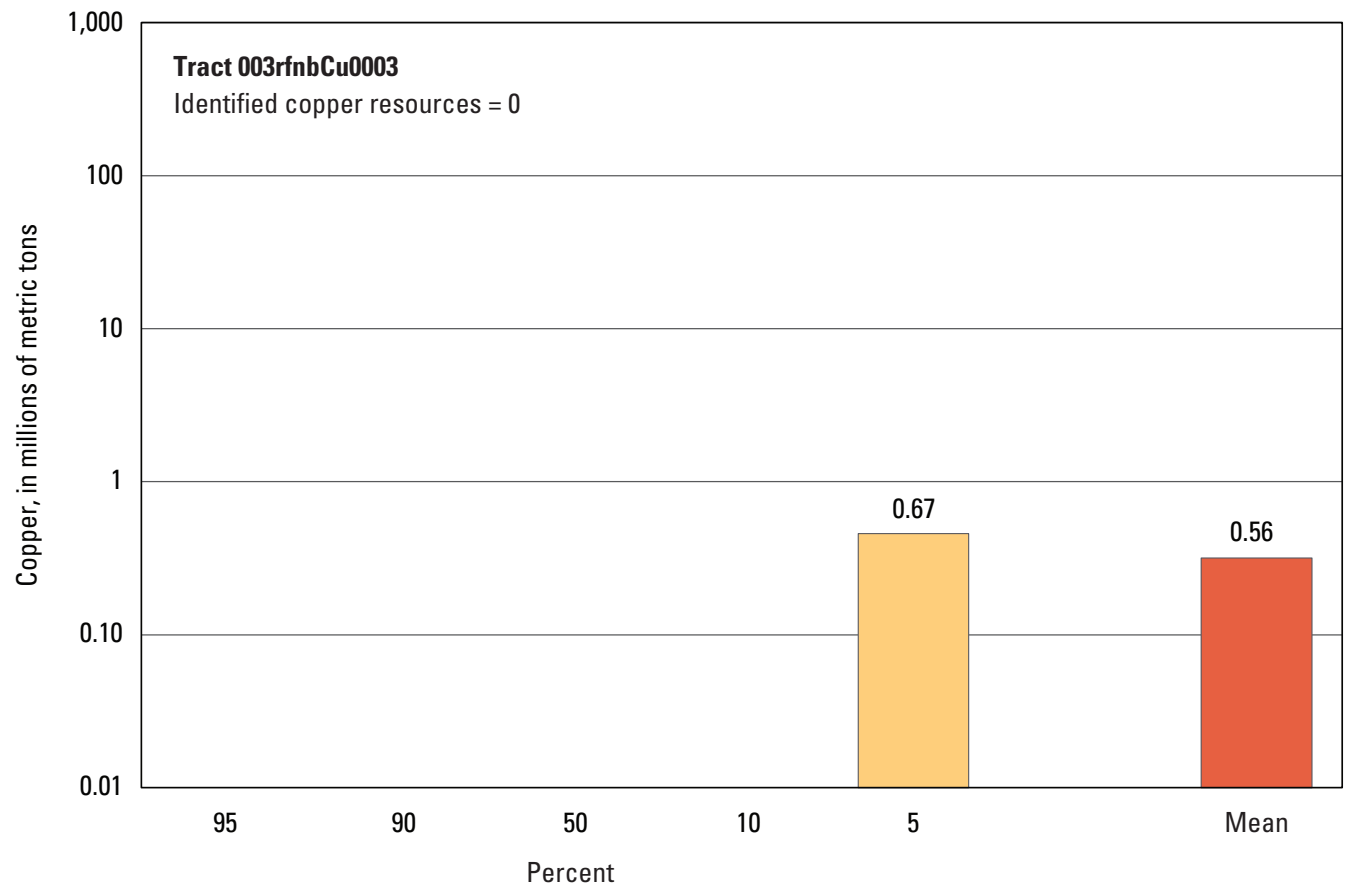

Graph showing the estimated probability distribution of undiscovered copper resources, where each bar represents the minimum amount estimated at the indicated percentage.

\section{Source}

Stensgaard and others, 2011, Quantitative mineral resource assessment-Sedimentary-hosted copper in Greenland: Geological Survey of Denmark and Greenland (GEUS) Report 2011/104. 

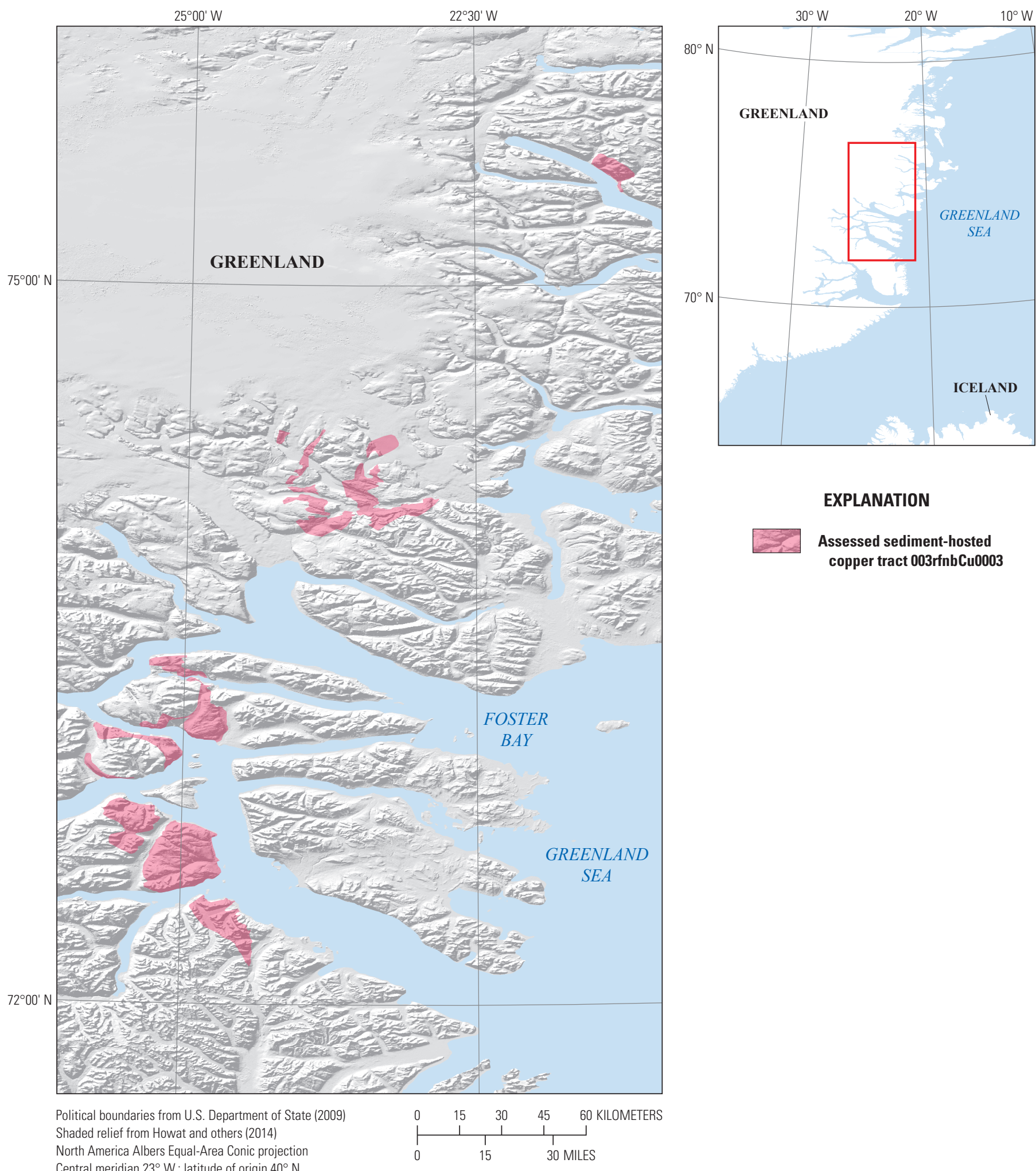

\section{EXPLANATION}

Assessed sediment-hosted copper tract 003rfnbCu0003

Central meridian $23^{\circ} \mathrm{W}$.; latitude of origin $40^{\circ} \mathrm{N}$. 


\title{
Plate 207. Sediment-Hosted Stratabound Copper Assessment for Tract 150ssCu0001, Sulban, Kodar-Udokan Trough—Russia
}

\author{
Descriptive model: \\ Sediment-hosted stratabound copper-Sandstone copper subtype model (Cox and others, 2007; \\ Zientek, Hayes, and Hammarstrom, 2013) \\ Grade and tonnage model: \\ Geologic feature assessed: \\ Sediment-hosted stratabound copper-Sandstone copper subtype model (Zientek, Hayes, and \\ Taylor, 2013) \\ Paleoproterozoic coarse-grained siliciclastic rocks in the Chinei and Kemen Groups, \\ Kodar-Udokan Trough \\ Number of known deposits: \\ 0
}

\section{Selected Resource Assessment Results for Sediment-Hosted Stratabound Copper}

[Assessment depth, 2 kilometers $(\mathrm{km}) ; \mathrm{km}^{2}$, square kilometer; Mt, millions of metric tons]

\begin{tabular}{ccccccc}
\hline \multirow{2}{*}{$\begin{array}{c}\text { Date of } \\
\text { assessment }\end{array}$} & $\begin{array}{c}\text { Tract area } \\
\left(\mathbf{k m}^{2}\right)\end{array}$ & $\begin{array}{c}\text { Identified } \\
\text { copper } \\
\text { resources } \\
(\mathbf{M t})\end{array}$ & $\begin{array}{c}\text { Median estimate of } \\
\text { in-place resources } \\
(\mathbf{M t})\end{array}$ & $\begin{array}{c}\text { Mean estimate of } \\
\text { in-place resources } \\
\text { (Mt) }\end{array}$ & $\begin{array}{c}\text { Probability of mean } \\
\text { or greater } \\
\text { (percent) }\end{array}$ & $\begin{array}{c}\text { Probability of } \mathbf{0} \\
\text { in-place resources } \\
\text { (percent) }\end{array}$ \\
\hline 2009 & 591 & 0 & 1.8 & 5.3 & 25 \\
\hline
\end{tabular}

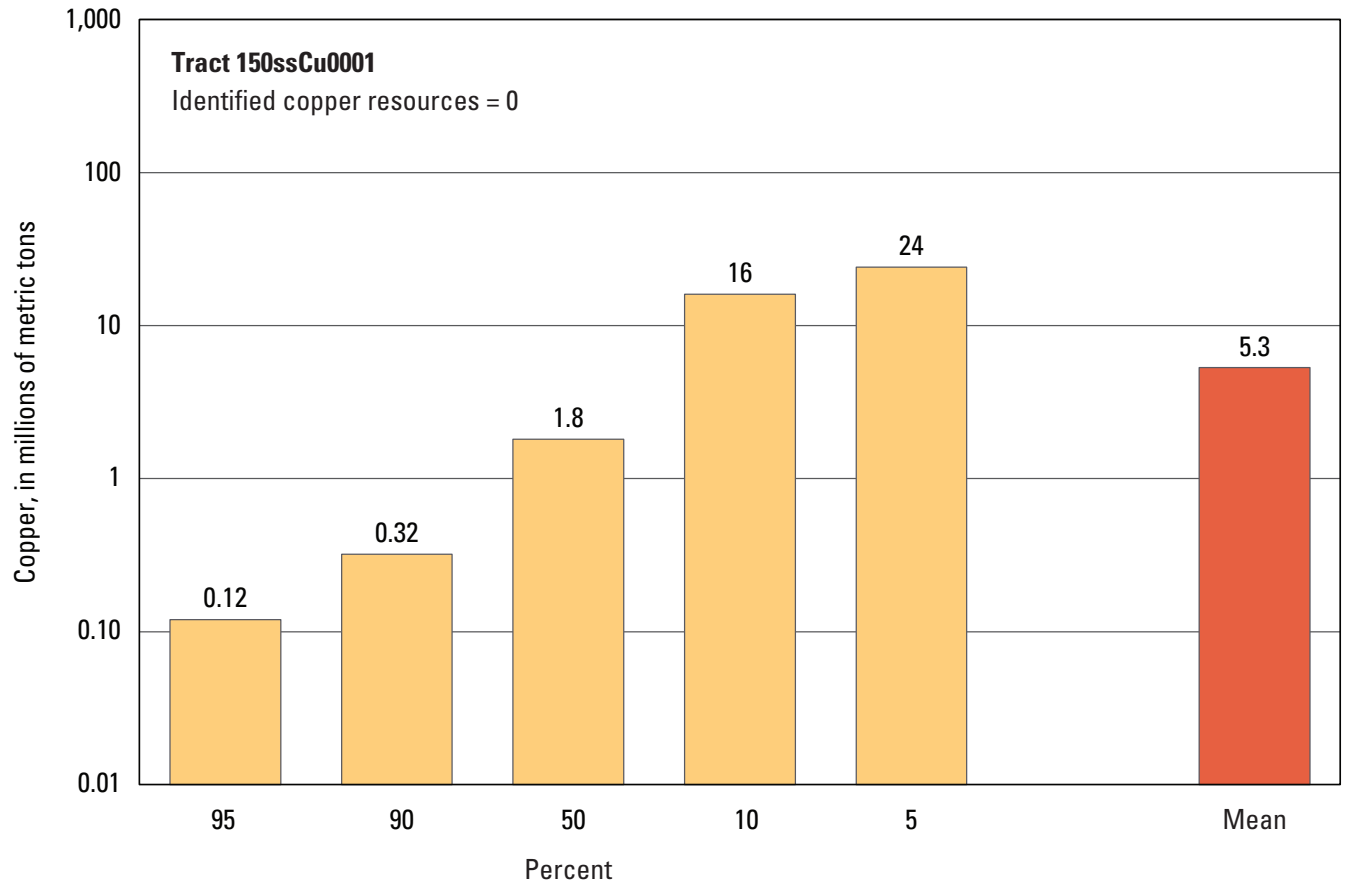

Graph showing the estimated probability distribution of undiscovered copper resources, where each bar represents the minimum amount estimated at the indicated percentage.

\section{Source}

Zientek, Chechetkin, and others, 2014, Assessment of undiscovered sandstone copper deposits of the Kodar-Udokan area, Russia: U.S. Geological Survey Scientific Investigations Report 2010-5090-M, http://dx.doi.org/10.3133/sir20105090M. 


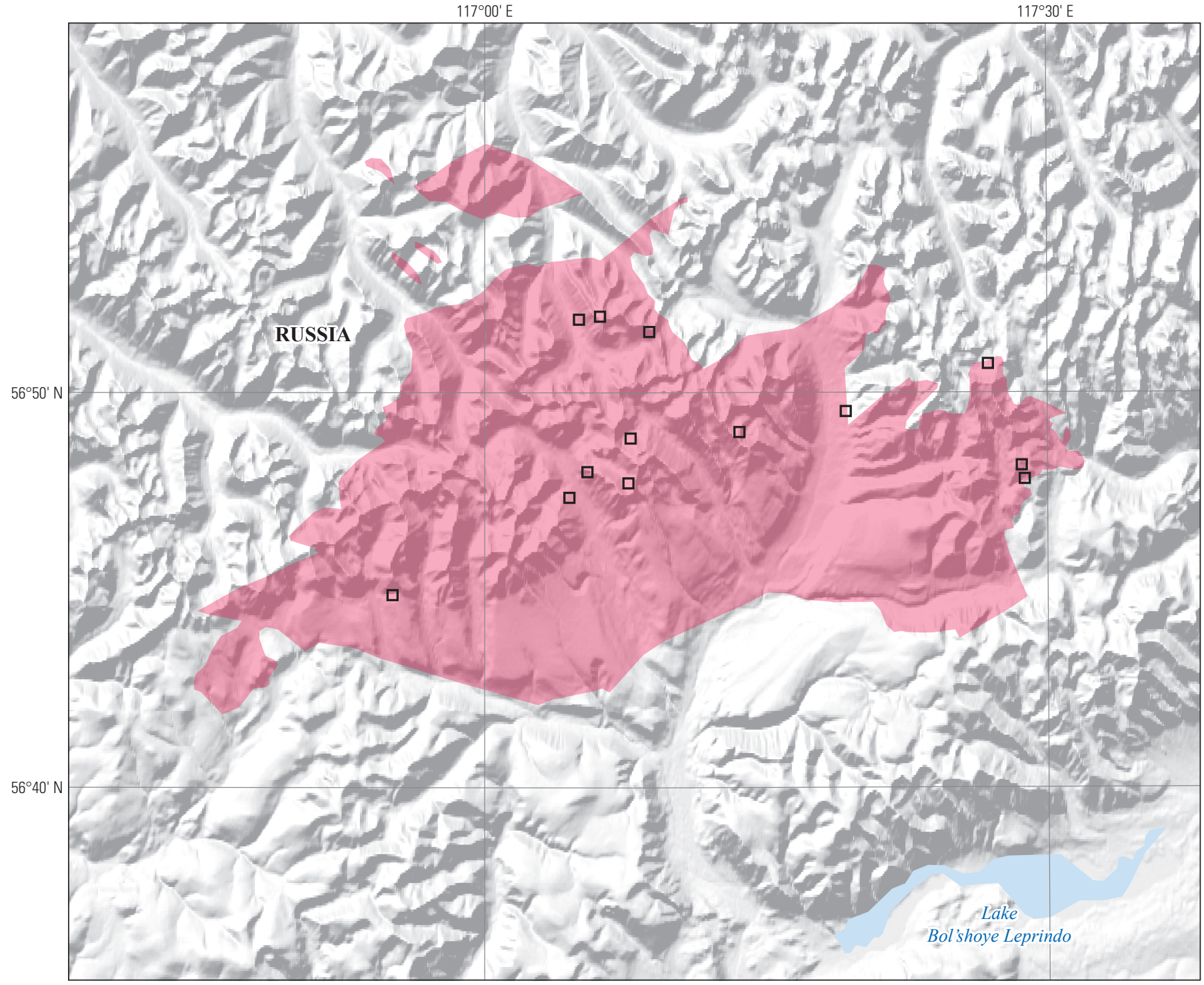

Political boundaries from U.S. Department of State (2009) Shaded relief from ESRI (2008)

Asia North Albers Equal-Area Conic projection

Central meridian $117^{\circ} \mathrm{E}$.; latitude of origin $30^{\circ} \mathrm{N}$.

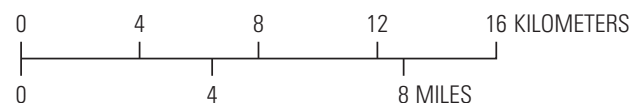

\section{EXPLANATION}

\section{Assessed sediment-hosted} copper tract 150ssCu0001

$\square \quad$ Sediment-hosted copper prospect

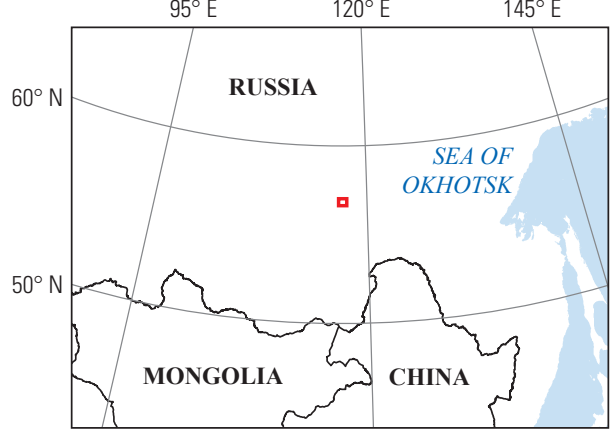




\title{
Plate 208. Sediment-Hosted Stratabound Copper Assessment for Tract 150ssCu0002, Saku, Kodar-Udokan Trough-Russia
}

\author{
Descriptive model: \\ Grade and tonnage model: \\ Geologic feature assessed: \\ Number of known deposits:
}

Sediment-hosted stratabound copper-Sandstone copper subtype model (Cox and others, 2007; Zientek, Hayes, and Hammarstrom, 2013)

Sediment-hosted stratabound copper-Sandstone copper subtype model (Zientek, Hayes, and Taylor, 2013)

Paleoproterozoic coarse-grained siliciclastic rocks in the Kemen Group, Kodar-Udokan Trough 1

\section{Selected Resource Assessment Results for Sediment-Hosted Stratabound Copper}

[Assessment depth, 2 kilometers $(\mathrm{km}) ; \mathrm{km}^{2}$, square kilometer; Mt, millions of metric tons]

\begin{tabular}{ccccccc}
\hline $\begin{array}{c}\text { Date of } \\
\text { assessment }\end{array}$ & $\begin{array}{c}\text { Tract area } \\
\left(\mathbf{k m}^{2}\right)\end{array}$ & $\begin{array}{c}\text { Identified } \\
\text { copper } \\
\text { resources } \\
\text { (Mt) }\end{array}$ & $\begin{array}{c}\text { Median estimate of } \\
\text { in-place resources } \\
(\mathbf{M t})\end{array}$ & $\begin{array}{c}\text { Mean estimate of } \\
\text { in-place resources } \\
\text { (Mt) }\end{array}$ & $\begin{array}{c}\text { Probability of mean } \\
\text { or greater } \\
\text { (percent) }\end{array}$ & $\begin{array}{c}\text { Probability of 0 } \\
\text { in-place resources } \\
\text { (percent) }\end{array}$ \\
\hline 2009 & 826 & 19 & 1.5 & 4.7 & 24 \\
\hline
\end{tabular}

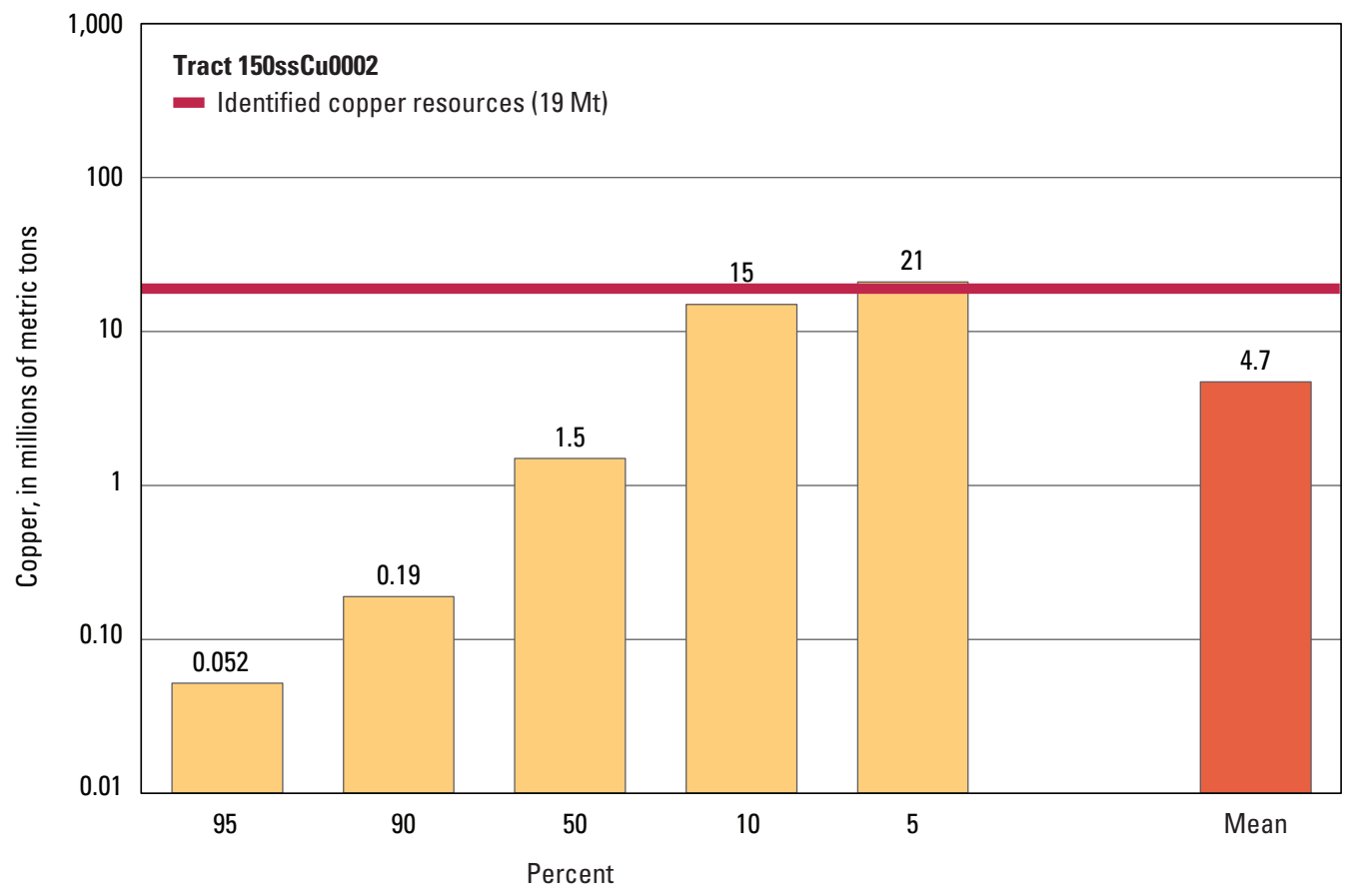

Graph showing the estimated probability distribution of undiscovered copper resources, where each bar represents the minimum amount estimated at the indicated percentage.

\section{Source}

Zientek, Chechetkin, and others, 2014, Assessment of undiscovered sandstone copper deposits of the Kodar-Udokan area, Russia: U.S. Geological Survey Scientific Investigations Report 2010-5090-M, http://dx.doi.org/10.3133/sir20105090M. 


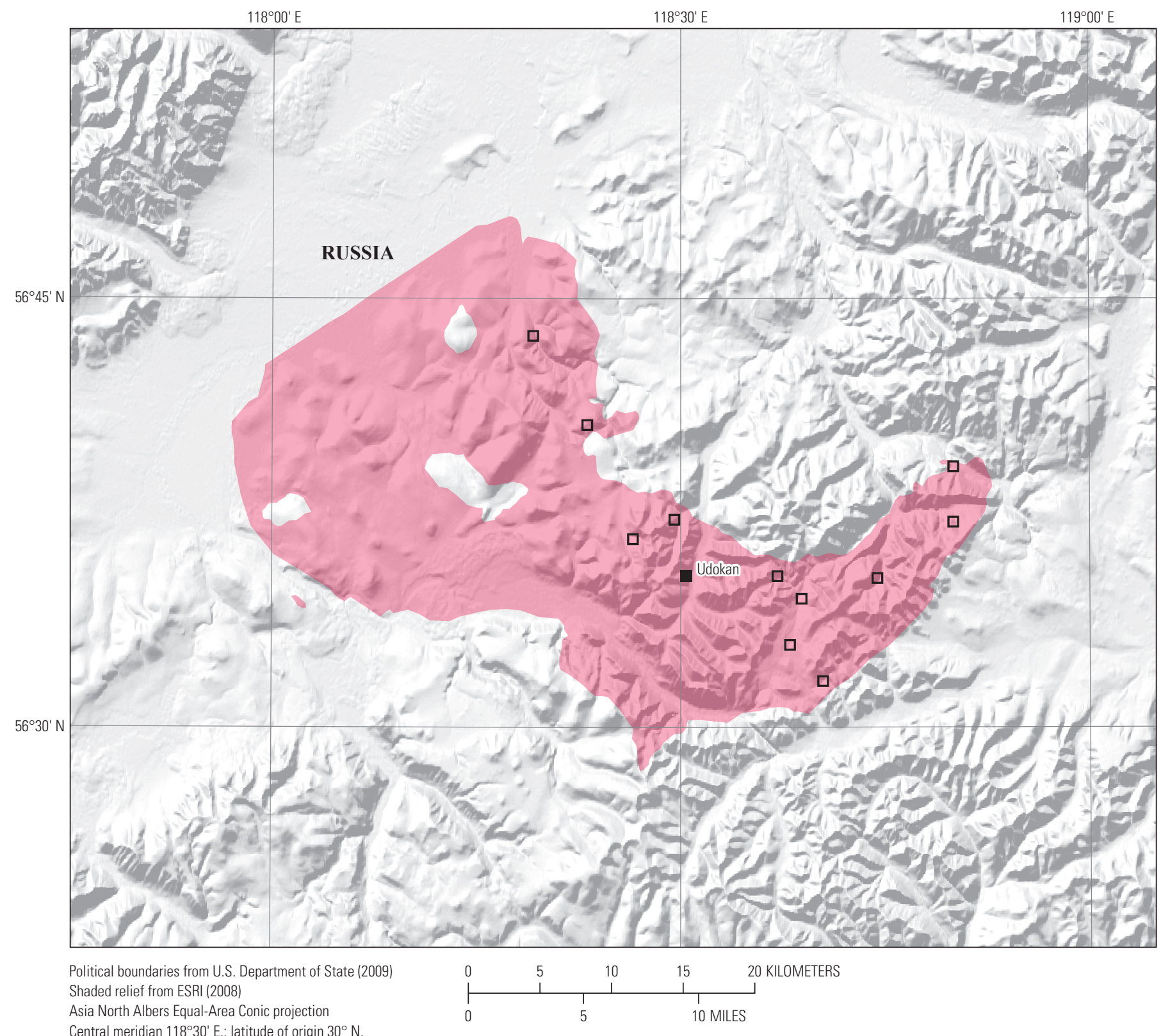

Central meridian $118^{\circ} 30^{\prime}$ E.; latitude of origin $30^{\circ} \mathrm{N}$.

\section{EXPLANATION}

\begin{tabular}{|c|c|}
\hline$y=$ & $\begin{array}{l}\text { Assessed sediment-hosted } \\
\text { copper tract 150ssCu0002 }\end{array}$ \\
\hline & Sediment-hosted copper deposit \\
\hline त & Sediment-hosted copper prospect \\
\hline
\end{tabular}

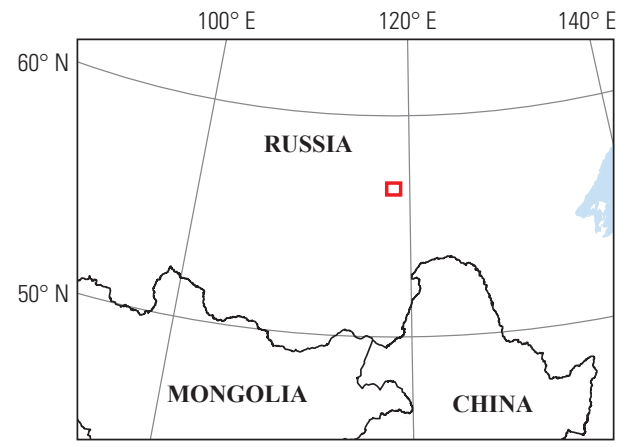




\title{
Plate 209. Sediment-Hosted Stratabound Copper Assessment for Tract 150ssCu0003, Ingamakit, Kodar-Udokan Trough—Russia
}

\author{
Descriptive model: \\ Sediment-hosted stratabound copper-Sandstone copper subtype model (Cox and others, 2007; \\ Zientek, Hayes, and Hammarstrom, 2013) \\ Grade and tonnage model: \\ Sediment-hosted stratabound copper-Sandstone copper subtype model (Zientek, Hayes, and \\ Taylor, 2013) \\ Geologic feature assessed: \\ Paleoproterozoic coarse-grained siliciclastic rocks in the Chinei and Kemen Groups, \\ Kodar-Udokan Trough \\ Number of known deposits: \\ 0
}

\section{Selected Resource Assessment Results for Sediment-Hosted Stratabound Copper}

[Assessment depth, 2 kilometers ( $\mathrm{km}) ; \mathrm{km}^{2}$, square kilometer; Mt, millions of metric tons]

\begin{tabular}{ccccccc}
\hline \multirow{2}{*}{$\begin{array}{c}\text { Date of } \\
\text { assessment }\end{array}$} & $\begin{array}{c}\text { Tract area } \\
\left(\mathbf{k m}^{2}\right)\end{array}$ & $\begin{array}{c}\text { Identified } \\
\text { copper } \\
\text { resources } \\
(\mathbf{M t})\end{array}$ & $\begin{array}{c}\text { Median estimate of } \\
\text { in-place resources } \\
(\mathbf{M t})\end{array}$ & $\begin{array}{c}\text { Mean estimate of } \\
\text { in-place resources } \\
\text { (Mt) }\end{array}$ & $\begin{array}{c}\text { Probability of mean } \\
\text { or greater } \\
\text { (percent) }\end{array}$ & $\begin{array}{c}\text { Probability of } \mathbf{0} \\
\text { in-place resources } \\
\text { (percent) }\end{array}$ \\
\hline 2009 & 565 & 0 & 1.1 & 3.9 & 23 \\
\hline
\end{tabular}

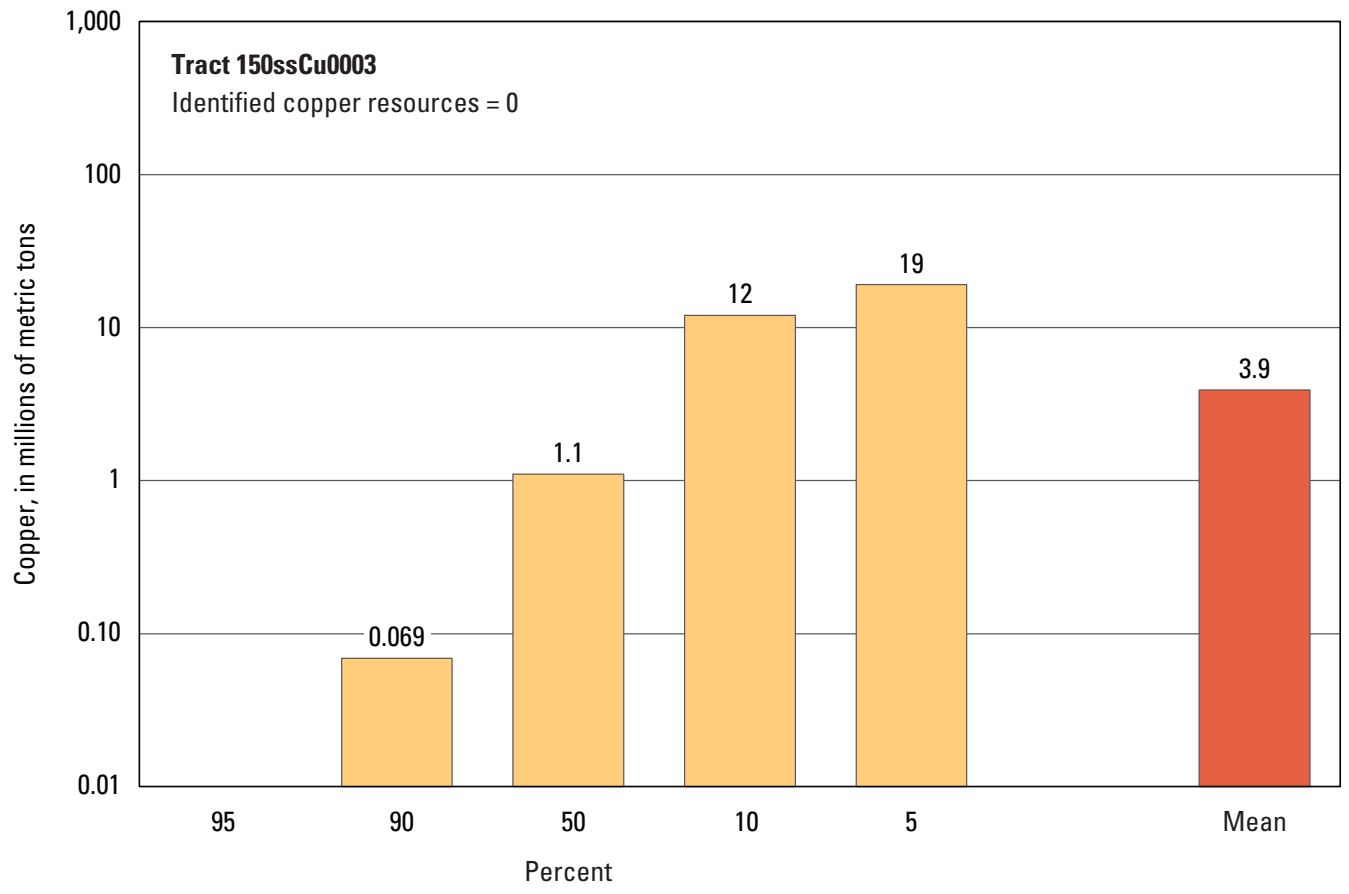

Graph showing the estimated probability distribution of undiscovered copper resources, where each bar represents the minimum amount estimated at the indicated percentage.

\section{Source}

Zientek, Chechetkin, and others, 2014, Assessment of undiscovered sandstone copper deposits of the Kodar-Udokan area, Russia: U.S. Geological Survey Scientific Investigations Report 2010-5090-M, http://dx.doi.org/10.3133/sir20105090M. 


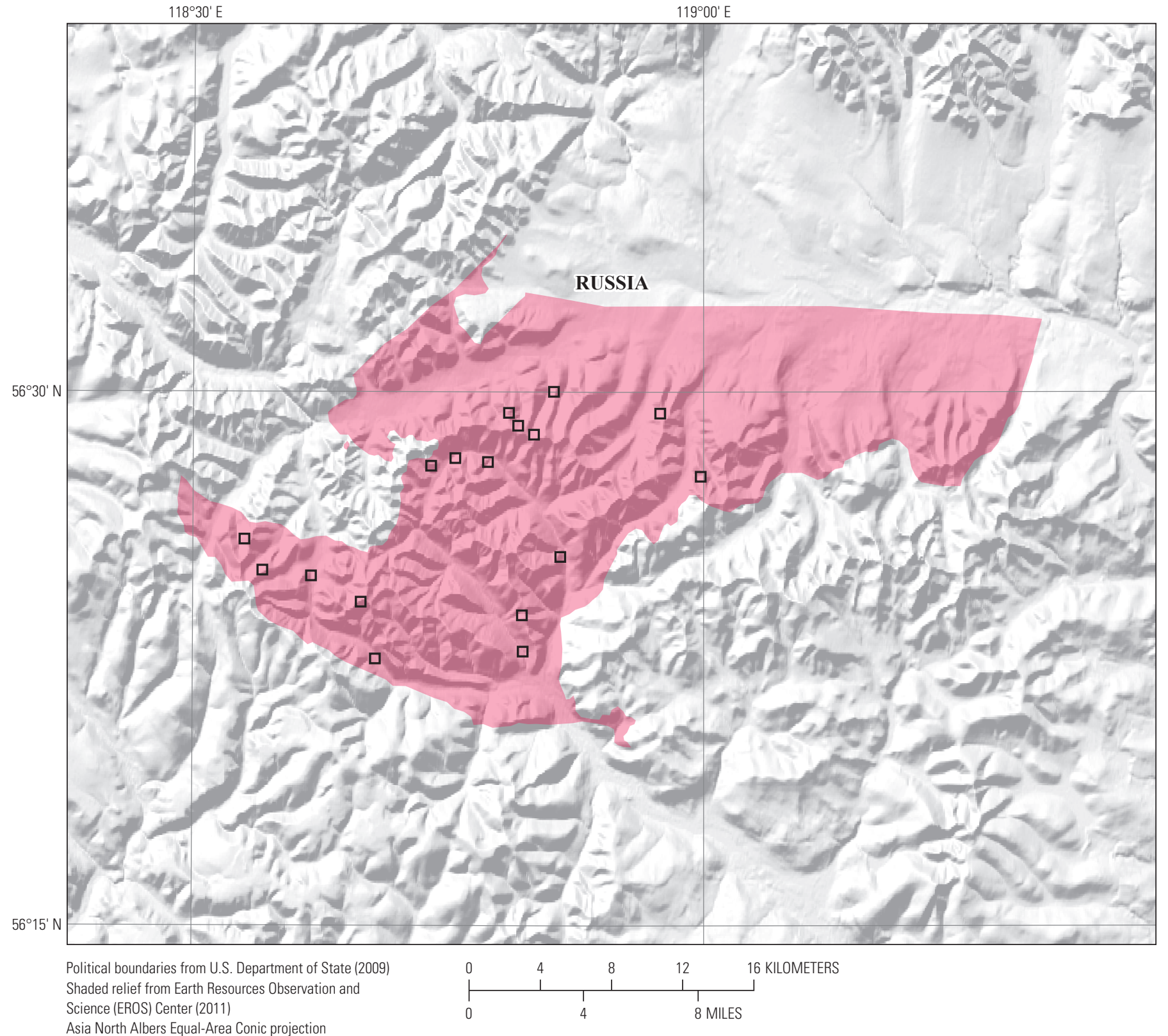

Asia North Albers Equal-Area Conic projection

Central meridian $119^{\circ} \mathrm{E}$.; latitude of origin $30^{\circ} \mathrm{N}$.

\section{EXPLANATION}

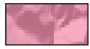

Assessed sediment-hosted copper tract 150ssCu0003

$\square \quad$ Sediment-hosted copper prospect

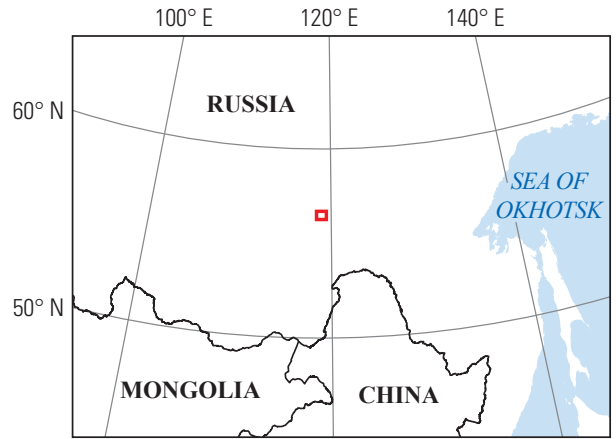




\title{
Plate 210. Sediment-Hosted Stratabound Copper Assessment for Tract 150ssCu0004, Unkur, Kodar-Udokan Trough—Russia
}

\author{
Descriptive model: \\ Grade and tonnage model: \\ Geologic feature assessed: \\ Number of known deposits:
}

Sediment-hosted stratabound copper-Sandstone copper subtype model (Cox and others, 2007; Zientek, Hayes, and Hammarstrom, 2013)

Sediment-hosted stratabound copper-Sandstone copper subtype model (Zientek, Hayes, and Taylor, 2013)

Paleoproterozoic coarse-grained siliciclastic rocks in the Kemen Group of the Udokan Complex 1

\section{Selected Resource Assessment Results for Sediment-Hosted Stratabound Copper}

[Assessment depth, 2 kilometers $(\mathrm{km}) ; \mathrm{km}^{2}$, square kilometer; Mt, millions of metric tons]

\begin{tabular}{ccccccc}
\hline $\begin{array}{c}\text { Date of } \\
\text { assessment }\end{array}$ & $\begin{array}{c}\text { Tract area } \\
\left(\mathbf{k m}^{2}\right)\end{array}$ & $\begin{array}{c}\text { Identified } \\
\text { copper } \\
\text { resources } \\
(\mathbf{M t})\end{array}$ & $\begin{array}{c}\text { Median estimate of } \\
\text { in-place resources } \\
(\mathbf{M t})\end{array}$ & $\begin{array}{c}\text { Mean estimate of } \\
\text { in-place resources } \\
\text { (Mt) }\end{array}$ & $\begin{array}{c}\text { Probability of mean } \\
\text { or greater } \\
\text { (percent) }\end{array}$ & $\begin{array}{c}\text { Probability of } 0 \\
\text { in-place resources } \\
\text { (percent) }\end{array}$ \\
\hline 2009 & 301 & 0.68 & 0.29 & 1.8 & 15 \\
\hline
\end{tabular}

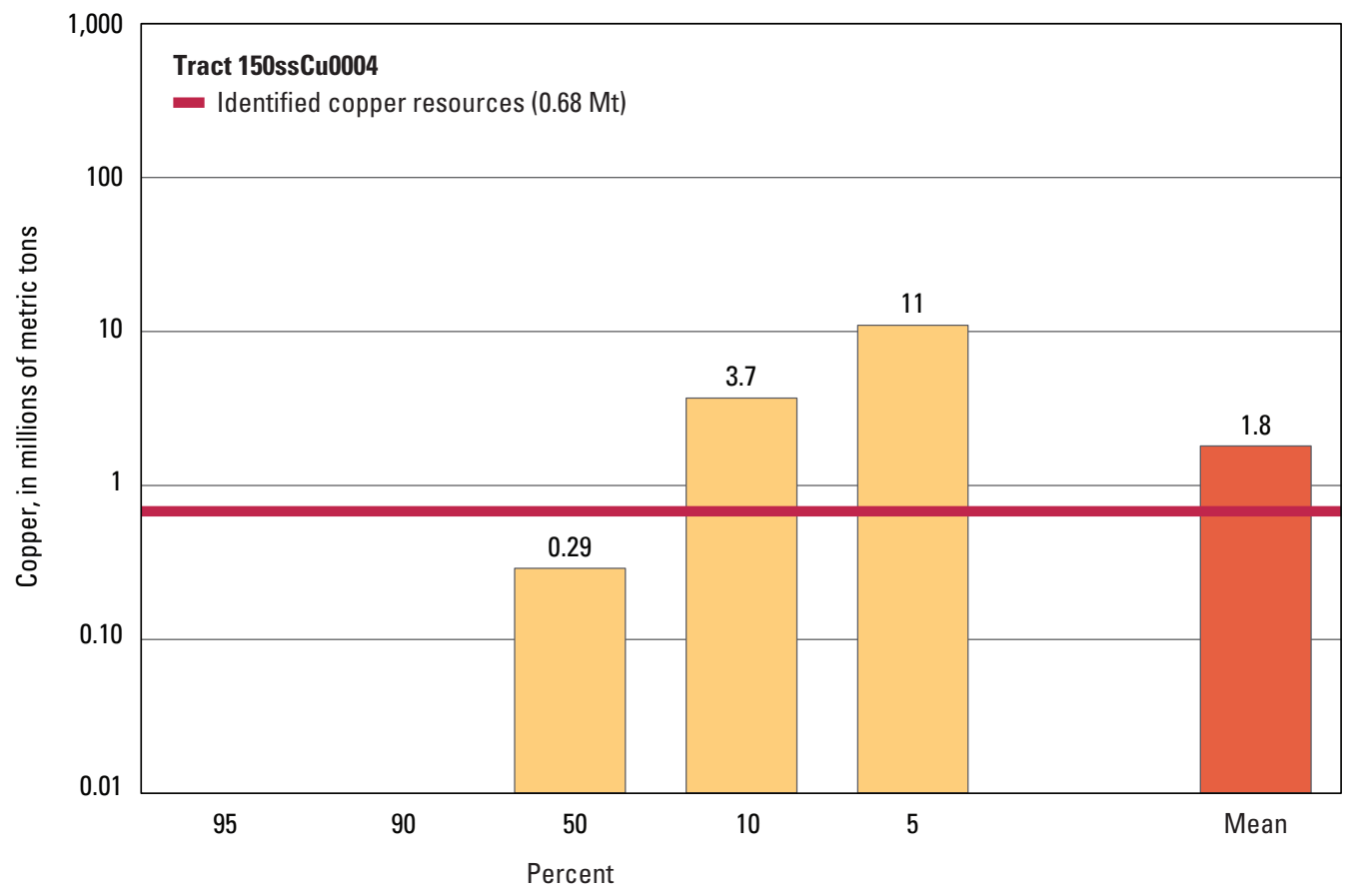

Graph showing the estimated probability distribution of undiscovered copper resources, where each bar represents the minimum amount estimated at the indicated percentage.

\section{Source}

Zientek, Chechetkin, and others, 2014, Assessment of undiscovered sandstone copper deposits of the Kodar-Udokan area, Russia: U.S. Geological Survey Scientific Investigations Report 2010-5090-M, http://dx.doi.org/10.3133/sir20105090M. 


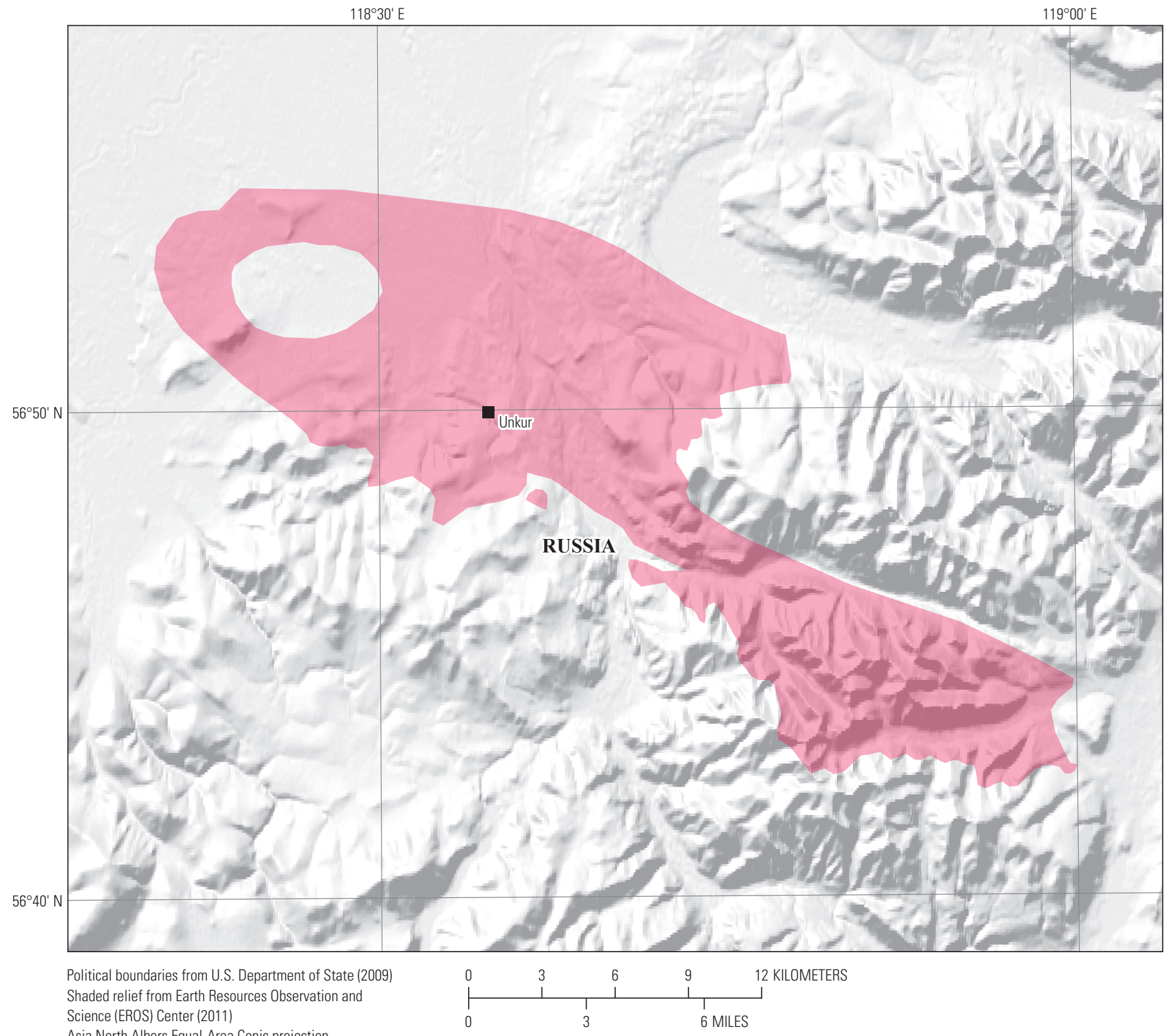

Asia North Albers Equal-Area Conic projection Central meridian $118^{\circ} \mathrm{E}$; ; latitude of origin $30^{\circ} \mathrm{N}$.

\section{EXPLANATION}

Assessed sediment-hosted copper tract 150ssCu0004

- Sediment-hosted copper deposit

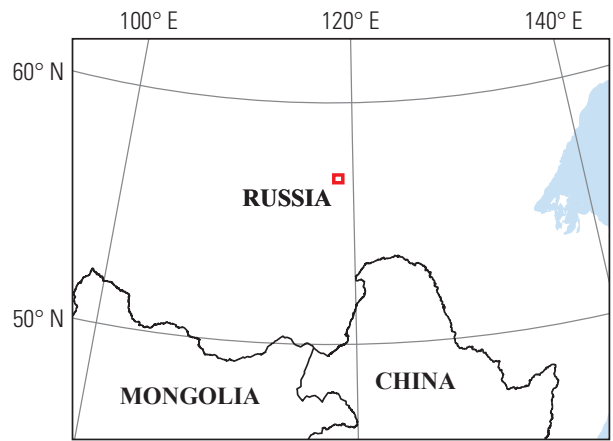




\section{Plate 211. Sediment-Hosted Stratabound Copper Assessment for Tract 150ssCu0005, Krasnoe, Kodar-Udokan Trough-Russia}

\section{Descriptive model:}

Grade and tonnage model:

Geologic feature assessed:

Number of known deposits:

\author{
Sediment-hosted stratabound copper-Sandstone copper subtype model (Cox and others, 2007; \\ Zientek, Hayes, and Hammarstrom, 2013) \\ Sediment-hosted stratabound copper-Sandstone copper subtype model (Zientek, Hayes, and \\ Taylor, 2013) \\ Paleoproterozoic coarse-grained siliciclastic rocks in the Chinei and Kemen Groups, \\ Kodar-Udokan Trough \\ 0
}

\section{Selected Resource Assessment Results for Sediment-Hosted Stratabound Copper}

[Assessment depth, 2 kilometers (km); km², square kilometer; Mt, millions of metric tons]

\begin{tabular}{ccccccc}
\hline $\begin{array}{c}\text { Date of } \\
\text { assessment }\end{array}$ & $\begin{array}{c}\text { Tract area } \\
\left(\mathbf{k m}^{2}\right)\end{array}$ & $\begin{array}{c}\text { Identified } \\
\text { copper } \\
\text { resources } \\
(\mathbf{M t})\end{array}$ & $\begin{array}{c}\text { Median estimate of } \\
\text { in-place resources } \\
(\mathbf{M t})\end{array}$ & $\begin{array}{c}\text { Mean estimate of } \\
\text { in-place resources } \\
\text { (Mt) }\end{array}$ & $\begin{array}{c}\text { Probability of mean } \\
\text { or greater } \\
\text { (percent) }\end{array}$ & $\begin{array}{c}\text { Probability of } 0 \\
\text { in-place resources } \\
\text { (percent) }\end{array}$ \\
\hline 2009 & 603 & 0 & 0.97 & 3.6 & 21 \\
\hline
\end{tabular}

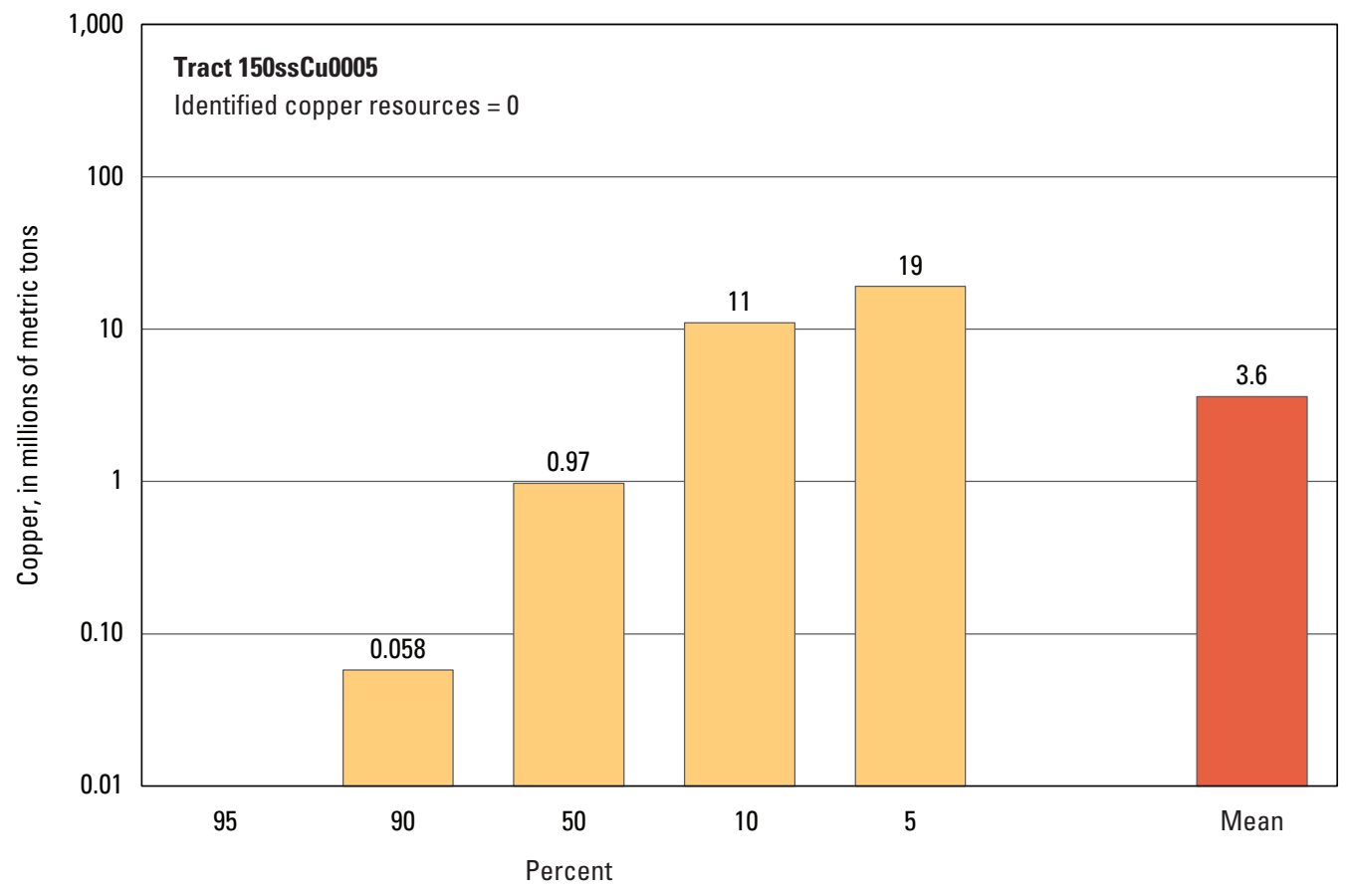

Graph showing the estimated probability distribution of undiscovered copper resources, where each bar represents the minimum amount estimated at the indicated percentage.

\section{Source}

Zientek, Chechetkin, and others, 2014, Assessment of undiscovered sandstone copper deposits of the Kodar-Udokan area, Russia: U.S. Geological Survey Scientific Investigations Report 2010-5090-M, http://dx.doi.org/10.3133/sir20105090M. 


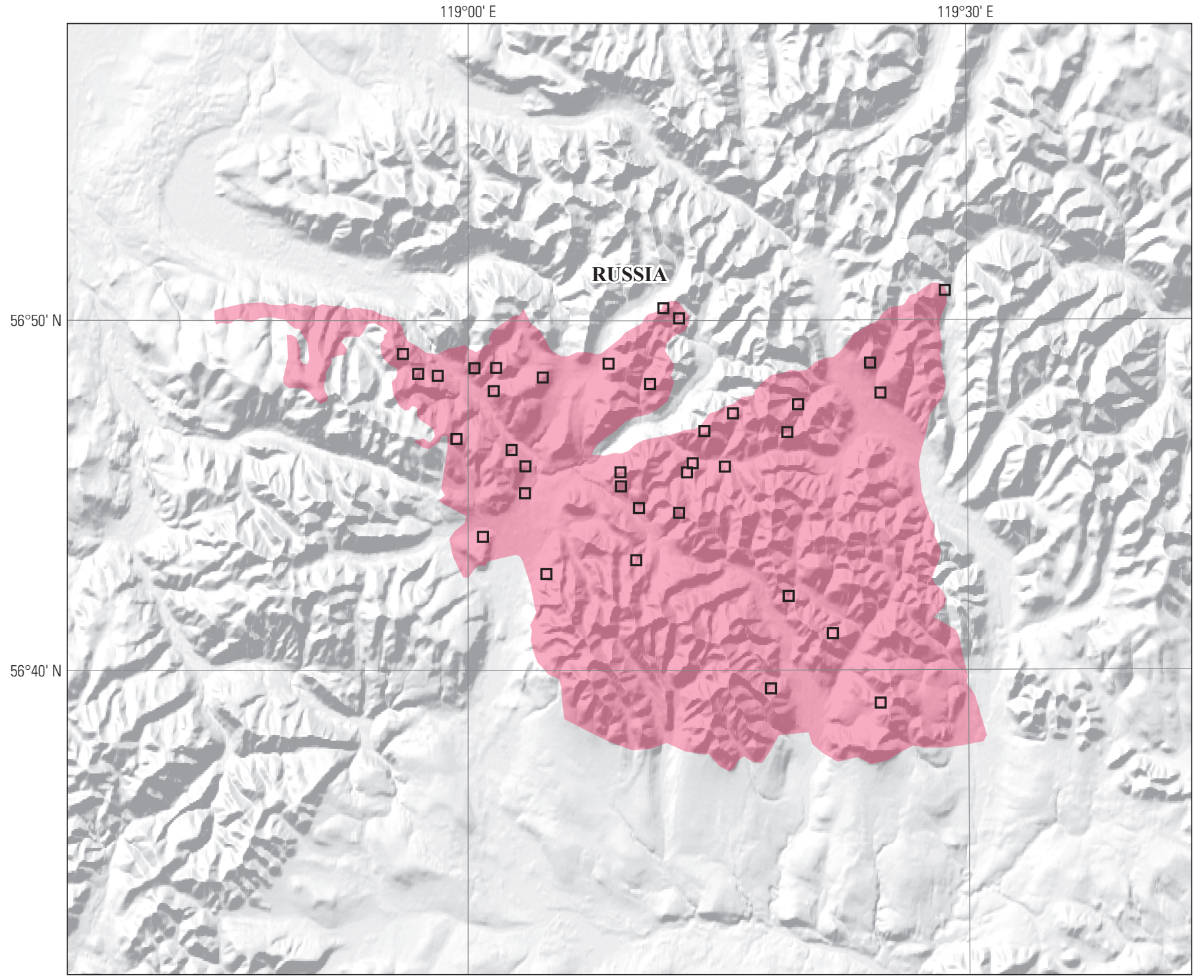

Political boundaries from U.S. Department of State (2009)

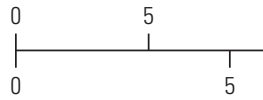

10 Shaded relief from Earth Resources Observation and Science (EROS) Center (2011)

Asia North Albers Equal-Area Conic projection

Central meridian $119^{\circ}$ E.; latitude of origin $30^{\circ} \mathrm{N}$.

EXPLANATION

Assessed sediment-hosted
copper tract 150ssCu0005

ㄴ Sediment-hosted copper prospect

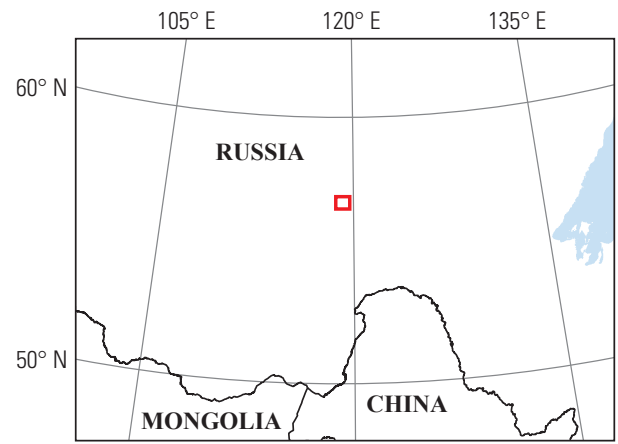




\title{
Plate 212. Sediment-Hosted Stratabound Copper Assessment for Tract 150ssCu0006, Burpala, Kodar-Udokan Trough-Russia
}

\author{
Descriptive model: \\ Sediment-hosted stratabound copper-Sandstone copper subtype model (Cox and others, 2007; \\ Zientek, Hayes, and Hammarstrom, 2013) \\ Grade and tonnage model: \\ Geologic feature assessed: \\ Sediment-hosted stratabound copper-Sandstone copper subtype model (Zientek, Hayes, and \\ Taylor, 2013) \\ Paleoproterozoic coarse-grained siliciclastic rocks in the Chinei and Kemen Groups, \\ Kodar-Udokan Trough \\ Number of known deposits: \\ 0
}

\section{Selected Resource Assessment Results for Sediment-Hosted Stratabound Copper}

[Assessment depth, 2 kilometers ( $\mathrm{km}) ; \mathrm{km}^{2}$, square kilometer; Mt, millions of metric tons]

\begin{tabular}{ccccccc}
\hline \multirow{2}{*}{$\begin{array}{c}\text { Date of } \\
\text { assessment }\end{array}$} & $\begin{array}{c}\text { Tract area } \\
\left(\mathbf{k m}^{2}\right)\end{array}$ & $\begin{array}{c}\text { Identified } \\
\text { copper } \\
\text { resources } \\
(\mathbf{M t})\end{array}$ & $\begin{array}{c}\text { Median estimate of } \\
\text { in-place resources } \\
(\mathbf{M t})\end{array}$ & $\begin{array}{c}\text { Mean estimate of } \\
\text { in-place resources } \\
\text { (Mt) }\end{array}$ & $\begin{array}{c}\text { Probability of mean } \\
\text { or greater } \\
\text { (percent) }\end{array}$ & $\begin{array}{c}\text { Probability of } \mathbf{0} \\
\text { in-place resources } \\
\text { (percent) }\end{array}$ \\
\hline 2009 & 129 & 0 & 0.18 & 1.3 & 14 \\
\hline
\end{tabular}

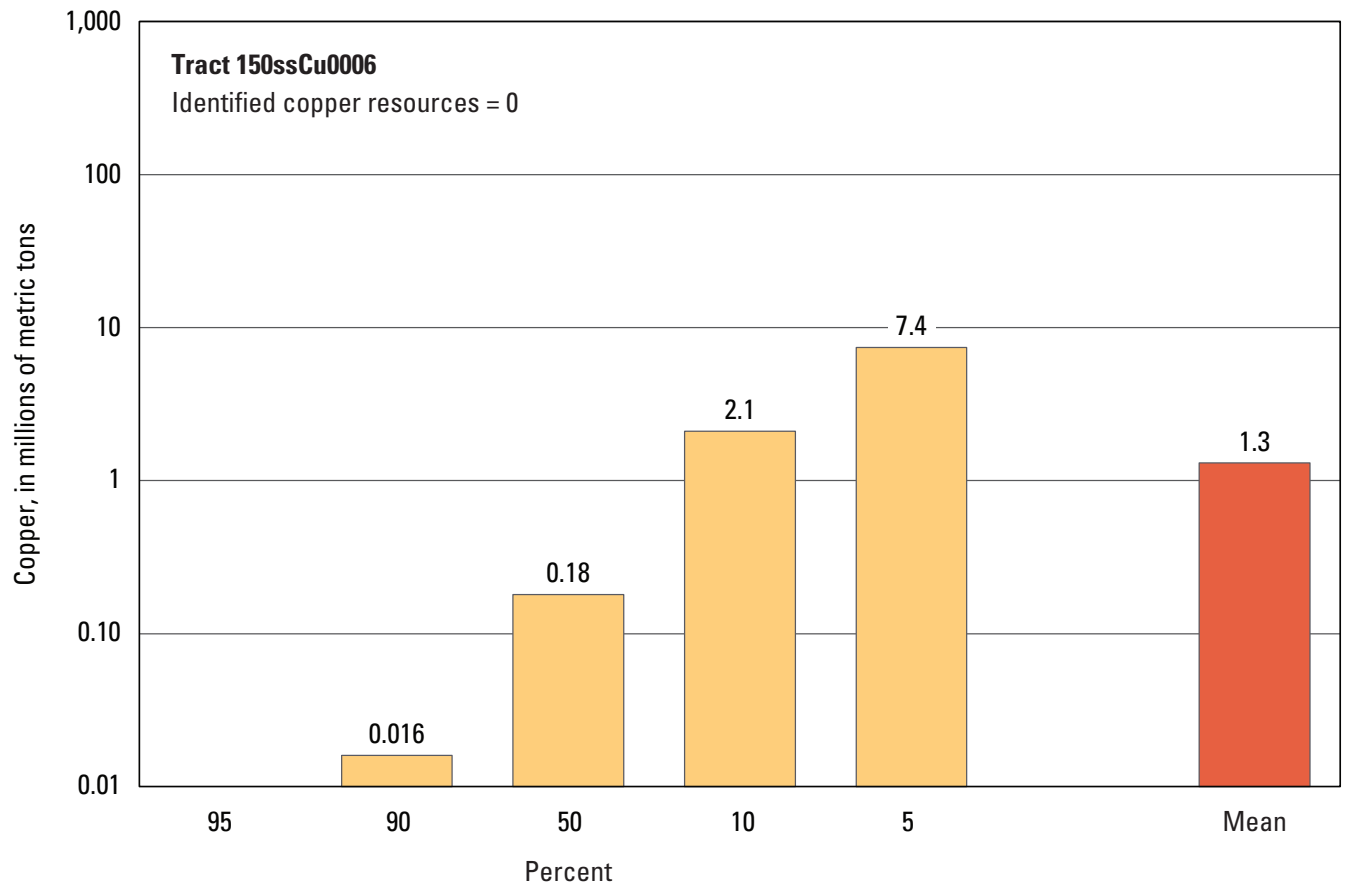

Graph showing the estimated probability distribution of undiscovered copper resources, where each bar represents the minimum amount estimated at the indicated percentage.

\section{Source}

Zientek, Chechetkin, and others, 2014, Assessment of undiscovered sandstone copper deposits of the Kodar-Udokan area, Russia: U.S. Geological Survey Scientific Investigations Report 2010-5090-M, http://dx.doi.org/10.3133/sir20105090M. 


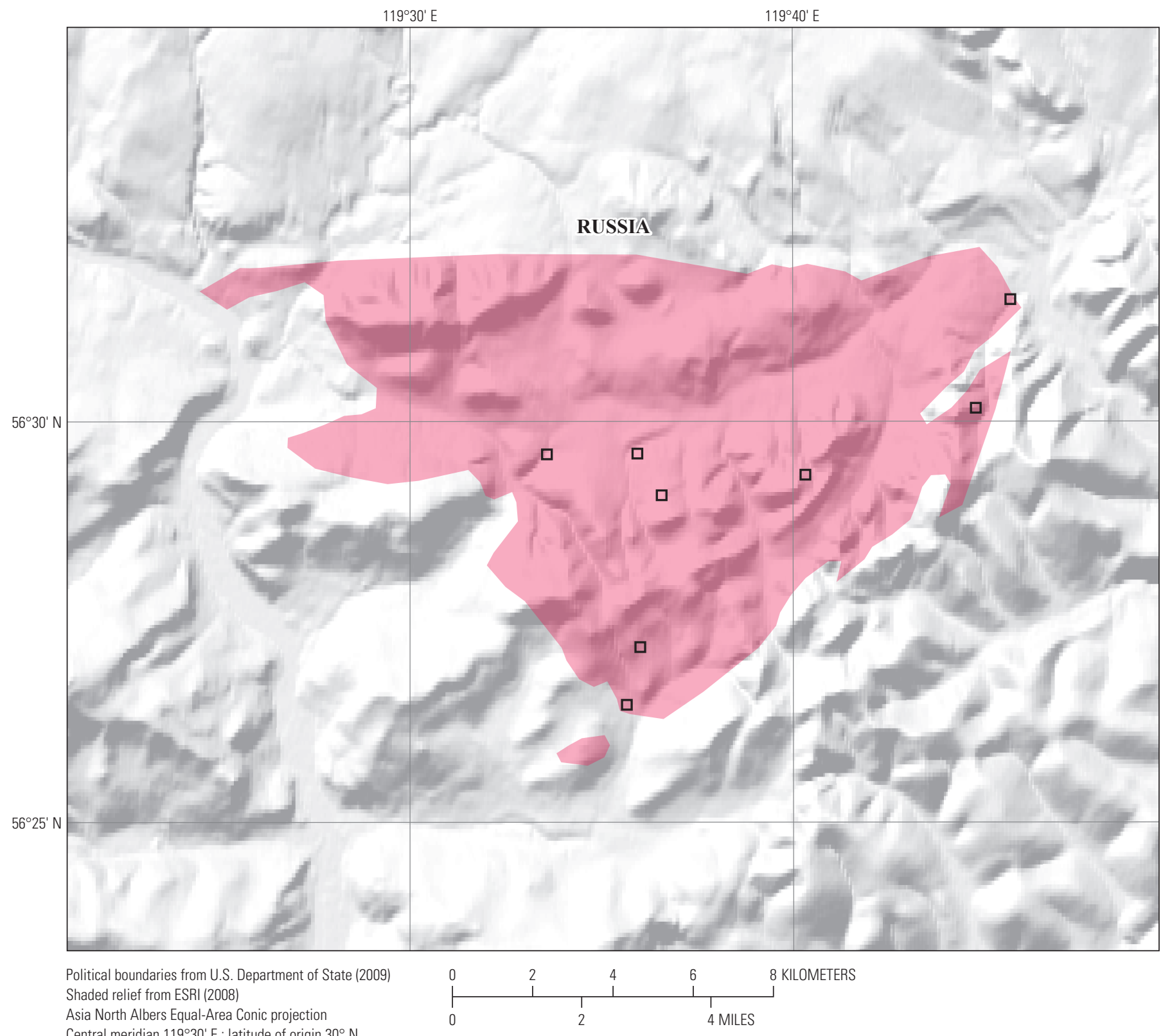

Central meridian $119^{\circ} 30^{\prime} \mathrm{E}$.; latitude of origin $30^{\circ} \mathrm{N}$.

\section{EXPLANATION}

Assessed sediment-hosted copper tract 150ssCu0006

ㅁ Sediment-hosted copper prospect

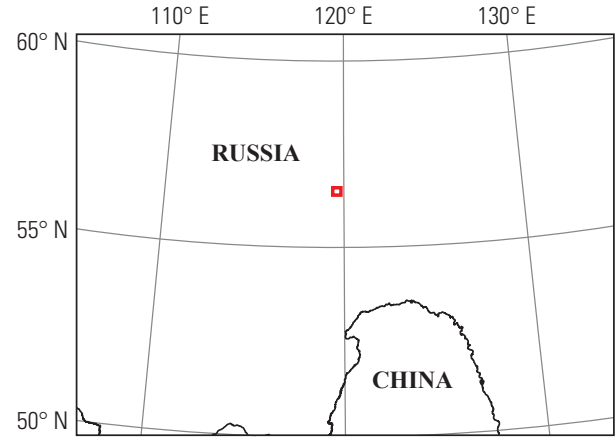




\title{
Plate 213. Sediment-Hosted Stratabound Copper Assessment for Tract 142ssCu8001, Dzhezkazgan Subbasin, Chu-Sarysu Basin-Kazakhstan
}

\author{
Descriptive model: \\ Sediment-hosted stratabound copper-Sandstone copper subtype model (Cox and others, 2007; \\ Zientek, Hayes, and Hammarstrom, 2013) \\ Grade and tonnage model: \\ Geologic feature assessed: \\ Sediment-hosted stratabound copper-Sandstone copper subtype model (Zientek, Hayes, and \\ Taylor, 2013) \\ Structural subbasin extending north from the main body of the Chu-Sarysu Basin, upper \\ Carboniferous nonmarine alluvial clastic sequence (red beds): Dzhezkazgan and Taskuduk \\ Formations \\ Number of known deposits: \\ 6
}

\section{Selected Resource Assessment Results for Sediment-Hosted Stratabound Copper}

[Assessment depth, 2 kilometers (km); $\mathrm{km}^{2}$, square kilometer; Mt, millions of metric tons]

\begin{tabular}{ccccccc}
\hline \multirow{2}{*}{$\begin{array}{c}\text { Date of } \\
\text { assessment }\end{array}$} & $\begin{array}{c}\text { Tract area } \\
\left(\mathbf{k m}^{2}\right)\end{array}$ & $\begin{array}{c}\text { Identified } \\
\text { copper } \\
\text { resources } \\
(\mathbf{M t})\end{array}$ & $\begin{array}{c}\text { Median estimate of } \\
\text { in-place resources } \\
(\mathbf{M t})\end{array}$ & $\begin{array}{c}\text { Mean estimate of } \\
\text { in-place resources } \\
\text { (Mt) }\end{array}$ & $\begin{array}{c}\text { Probability of mean } \\
\text { or greater } \\
\text { (percent) }\end{array}$ & $\begin{array}{c}\text { Probability of 0 } \\
\text { in-place resources } \\
\text { (percent) }\end{array}$ \\
\hline 2009 & 753 & 25 & 1.7 & 5.1 & 25 \\
\hline
\end{tabular}

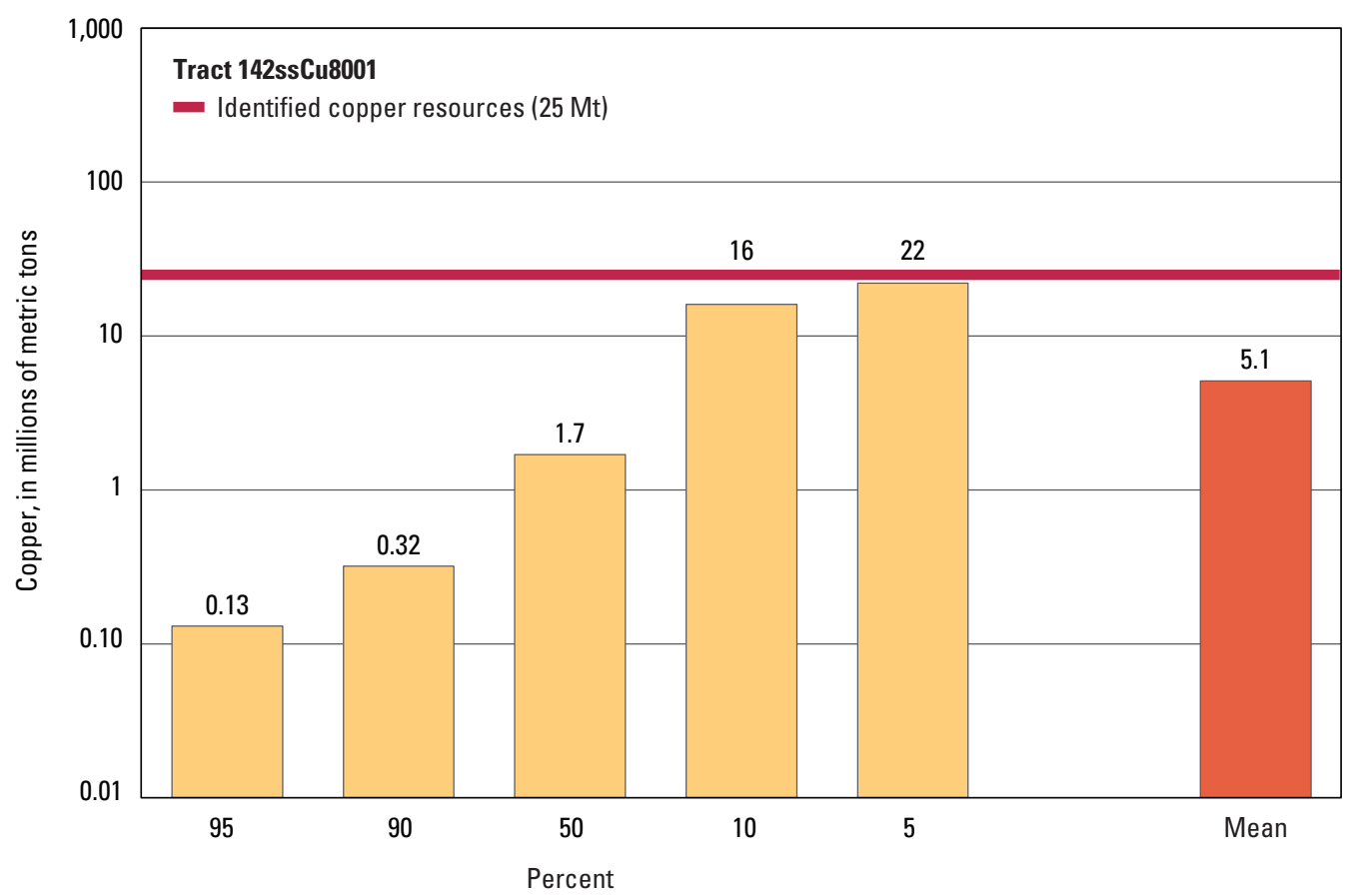

Graph showing the estimated probability distribution of undiscovered copper resources, where each bar represents the minimum amount estimated at the indicated percentage.

\section{Source}

Box and others, 2012, Sandstone copper assessment of the Chu-Sarysu Basin, central Kazakhstan: U.S. Geological Survey Scientific Investigations Report 2010-5090-E, http://pubs.usgs.gov/sir/2010/5090/e/. 

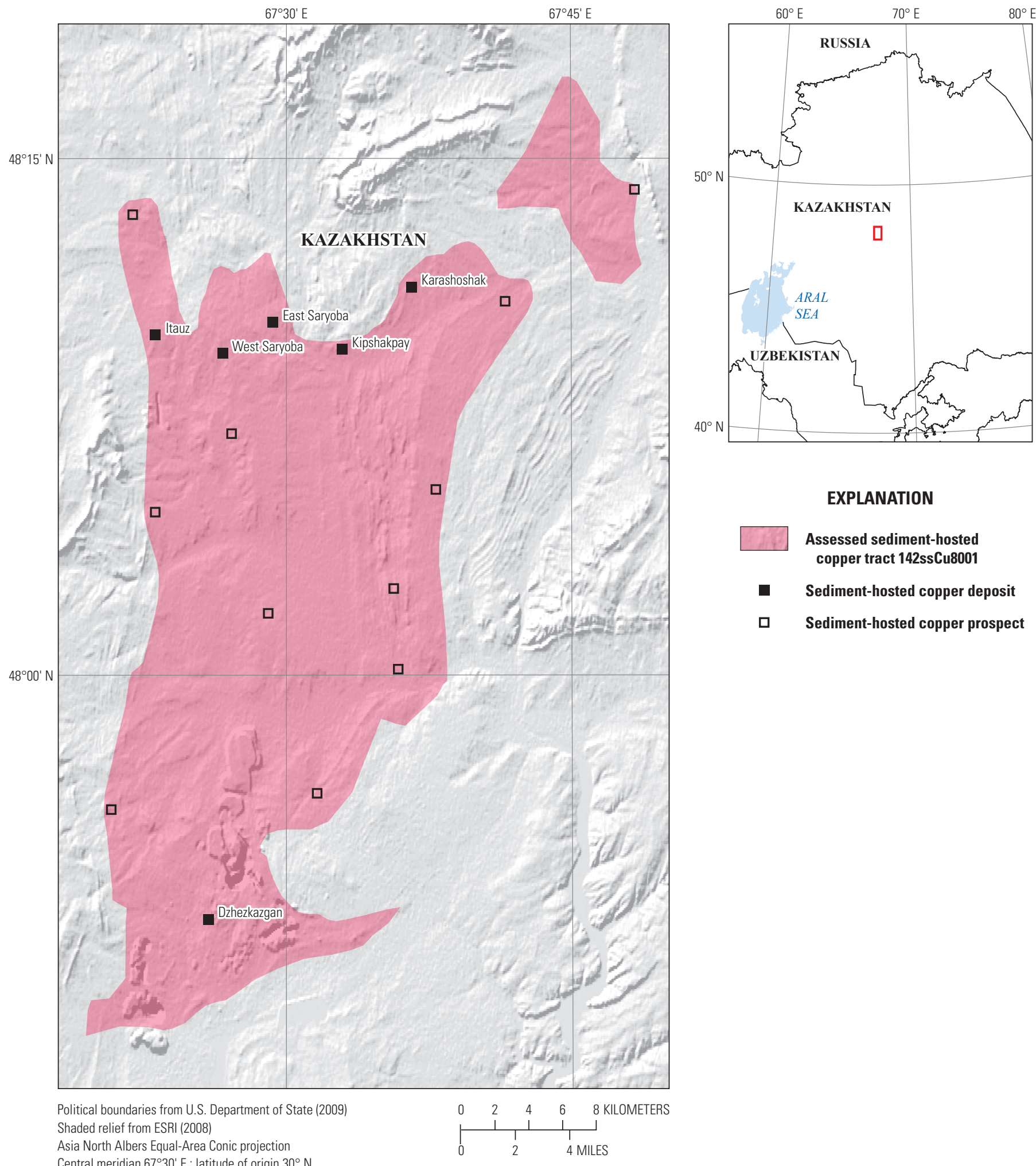

EXPLANATION

Assessed sediment-hosted copper tract 142ssCu8001

- Sediment-hosted copper deposit

$\square \quad$ Sediment-hosted copper prospect

Central meridian $67^{\circ} 30^{\prime} \mathrm{E}$.; latitude of origin $30^{\circ} \mathrm{N}$. 


\title{
Plate 214. Sediment-Hosted Stratabound Copper Assessment for Tract 142ssCu8002, Tesbulak Subbasin, Chu-Sarysu Basin-Kazakhstan
}

\author{
Descriptive model: \\ Grade and tonnage model: \\ Geologic feature assessed: \\ Number of known deposits:
}

Sediment-hosted stratabound copper-Sandstone copper subtype model (Cox and others, 2007; Zientek, Hayes, and Hammarstrom, 2013)

Sediment-hosted stratabound copper-Sandstone copper subtype model (Zientek, Hayes, and Taylor, 2013)

Northeastern structural subbasin of the Chu-Sarysu Basin, upper Carboniferous nonmarine alluvial clastic sequence (red beds): Dzhezkazgan and Taskuduk Formations

2

\section{Selected Resource Assessment Results for Sediment-Hosted Stratabound Copper}

[Assessment depth, 2 kilometers ( $\mathrm{km}) ; \mathrm{km}^{2}$, square kilometer; Mt, millions of metric tons]

\begin{tabular}{ccccccc}
\hline \multirow{2}{*}{$\begin{array}{c}\text { Date of } \\
\text { assessment }\end{array}$} & $\begin{array}{c}\text { Tract area } \\
\left(\mathbf{k m}^{2}\right)\end{array}$ & $\begin{array}{c}\text { Identified } \\
\text { copper } \\
\text { resources } \\
(\mathbf{M t})\end{array}$ & $\begin{array}{c}\text { Median estimate of } \\
\text { in-place resources } \\
(\mathbf{M t})\end{array}$ & $\begin{array}{c}\text { Mean estimate of } \\
\text { in-place resources } \\
\text { (Mt) }\end{array}$ & $\begin{array}{c}\text { Probability of mean } \\
\text { or greater } \\
\text { (percent) }\end{array}$ & $\begin{array}{c}\text { Probability of } \mathbf{0} \\
\text { in-place resources } \\
\text { (percent) }\end{array}$ \\
\hline 2009 & 31,681 & 2.7 & 4.8 & 9.9 & 33 \\
\hline
\end{tabular}

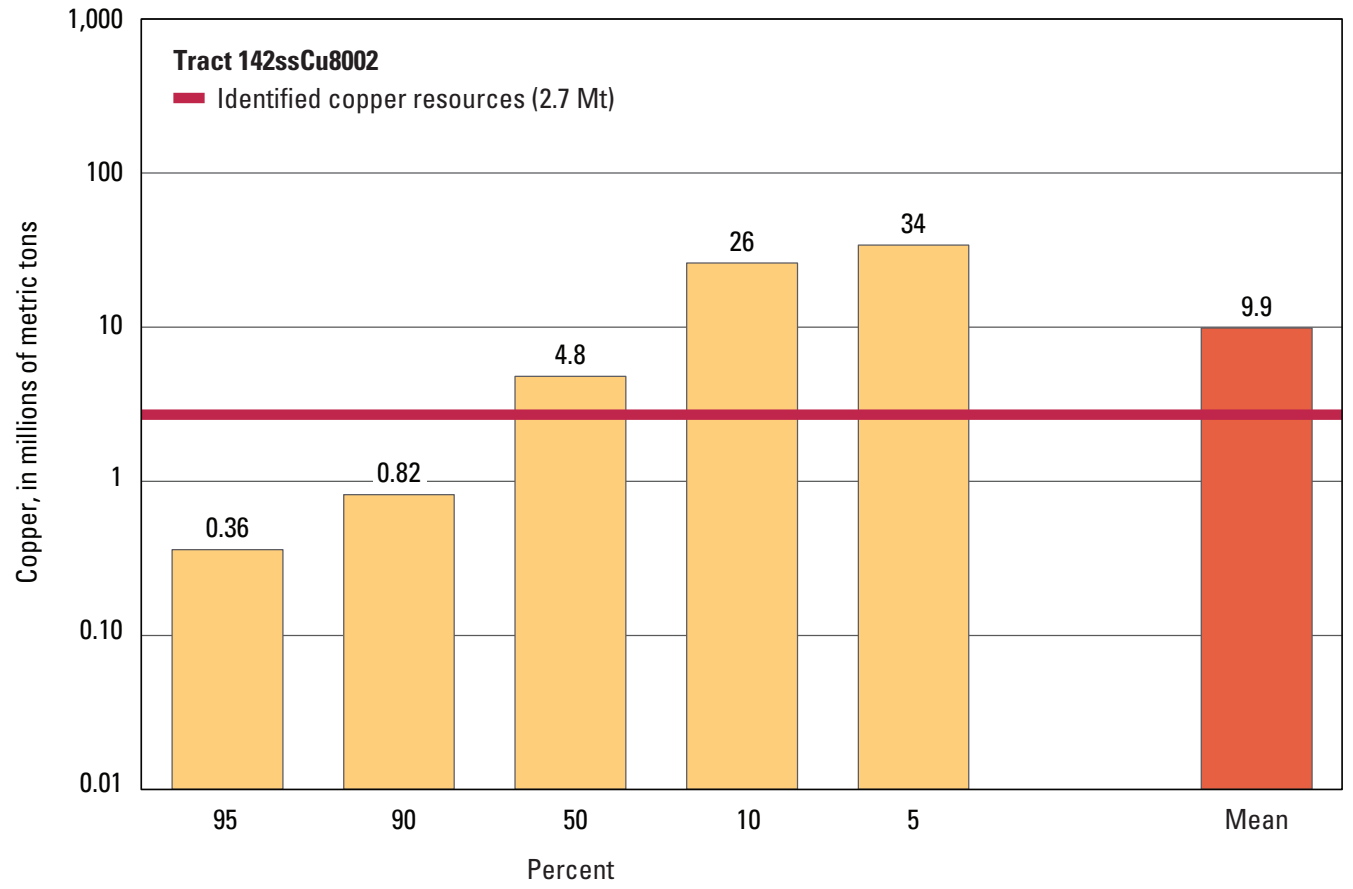

Graph showing the estimated probability distribution of undiscovered copper resources, where each bar represents the minimum amount estimated at the indicated percentage.

\section{Source}

Box and others, 2012, Sandstone copper assessment of the Chu-Sarysu Basin, central Kazakhstan: U.S. Geological Survey Scientific Investigations Report 2010-5090-E, http://pubs.usgs.gov/sir/2010/5090/e/. 

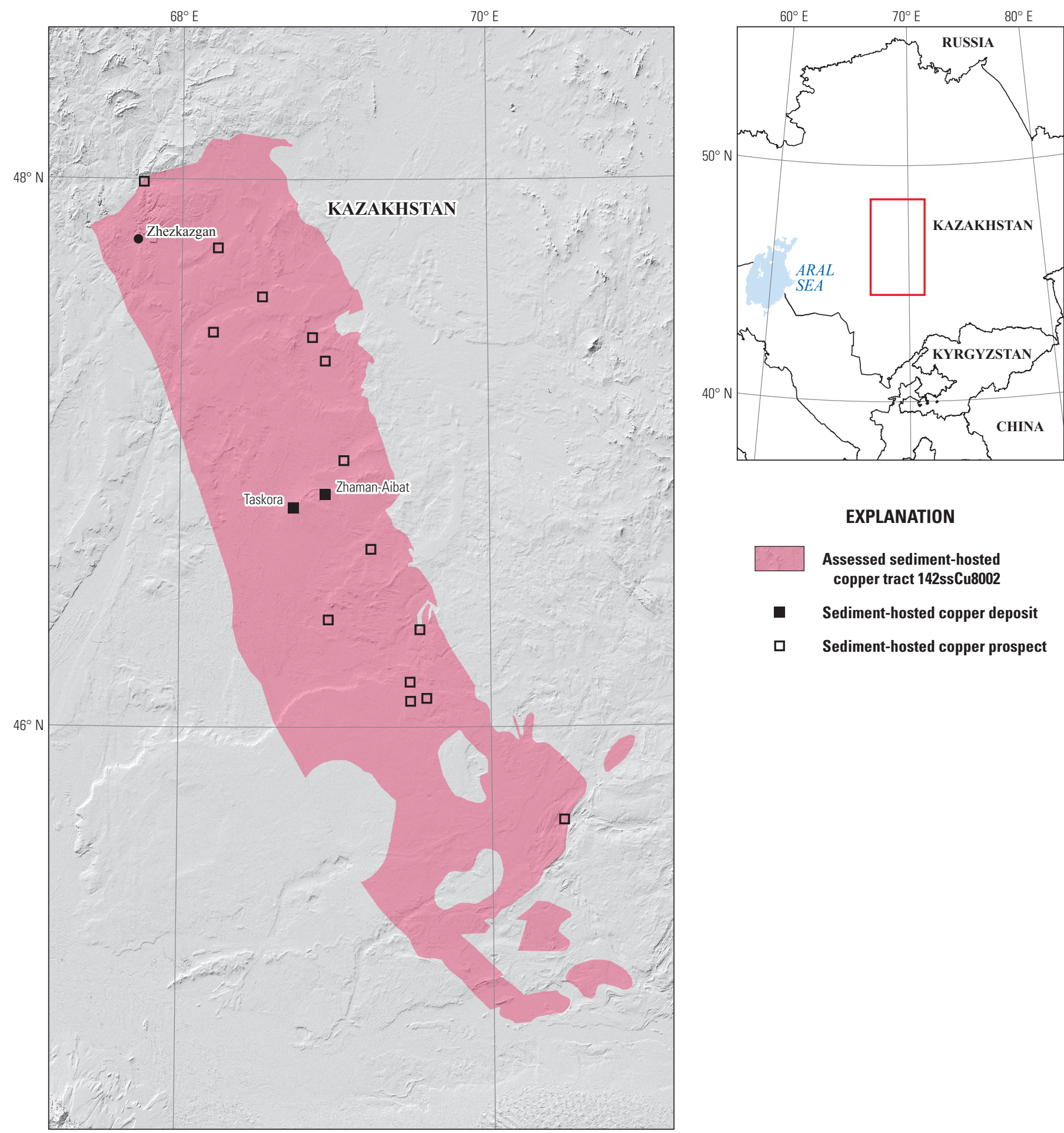

\section{EXPLANATION}

\section{Assessed sediment-hosted} copper tract 142 ssCu8002

- Sediment-hosted copper deposit

$\square \quad$ Sediment-hosted copper prospect

Political boundaries from U.S. Department of State (2009) Shaded relief from ESRI (2008)

Asia North Albers Equal-Area Conic projection

Central meridian $69^{\circ} \mathrm{E}$.; latitude of origin $30^{\circ} \mathrm{N}$.

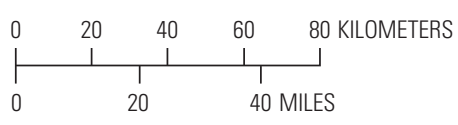




\title{
Plate 215. Sediment-Hosted Stratabound Copper Assessment for Tract 142ssCu8003, Kokpansor Subbasin, Chu-Sarysu Basin-Kazakhstan
}

\author{
Descriptive model: \\ Grade and tonnage model: \\ Geologic feature assessed: \\ Number of known deposits:
}

Sediment-hosted stratabound copper-Sandstone copper subtype model (Cox and others, 2007; Zientek, Hayes, and Hammarstrom, 2013)

Sediment-hosted stratabound copper-Sandstone copper subtype model (Zientek, Hayes, and Taylor, 2013)

Northwestern structural subbasin of the Chu-Sarysu Basin, upper Carboniferous nonmarine alluvial clastic sequence (red beds): Dzhezkazgan and Taskuduk Formations

0

\section{Selected Resource Assessment Results for Sediment-Hosted Stratabound Copper}

[Assessment depth, 2 kilometers ( $\mathrm{km}) ; \mathrm{km}^{2}$, square kilometer; Mt, millions of metric tons]

\begin{tabular}{ccccccc}
\hline \multirow{2}{*}{$\begin{array}{c}\text { Date of } \\
\text { assessment }\end{array}$} & $\begin{array}{c}\text { Tract area } \\
\left(\mathbf{k m}^{2}\right)\end{array}$ & $\begin{array}{c}\text { Identified } \\
\text { copper } \\
\text { resources } \\
(\mathbf{M t})\end{array}$ & $\begin{array}{c}\text { Median estimate of } \\
\text { in-place resources } \\
(\mathbf{M t})\end{array}$ & $\begin{array}{c}\text { Mean estimate of } \\
\text { in-place resources } \\
\text { (Mt) }\end{array}$ & $\begin{array}{c}\text { Probability of mean } \\
\text { or greater } \\
\text { (percent) }\end{array}$ & $\begin{array}{c}\text { Probability of } \mathbf{0} \\
\text { in-place resources } \\
\text { (percent) }\end{array}$ \\
\hline 2009 & 28,227 & 0 & 3.2 & 8.0 & 30 \\
\hline
\end{tabular}

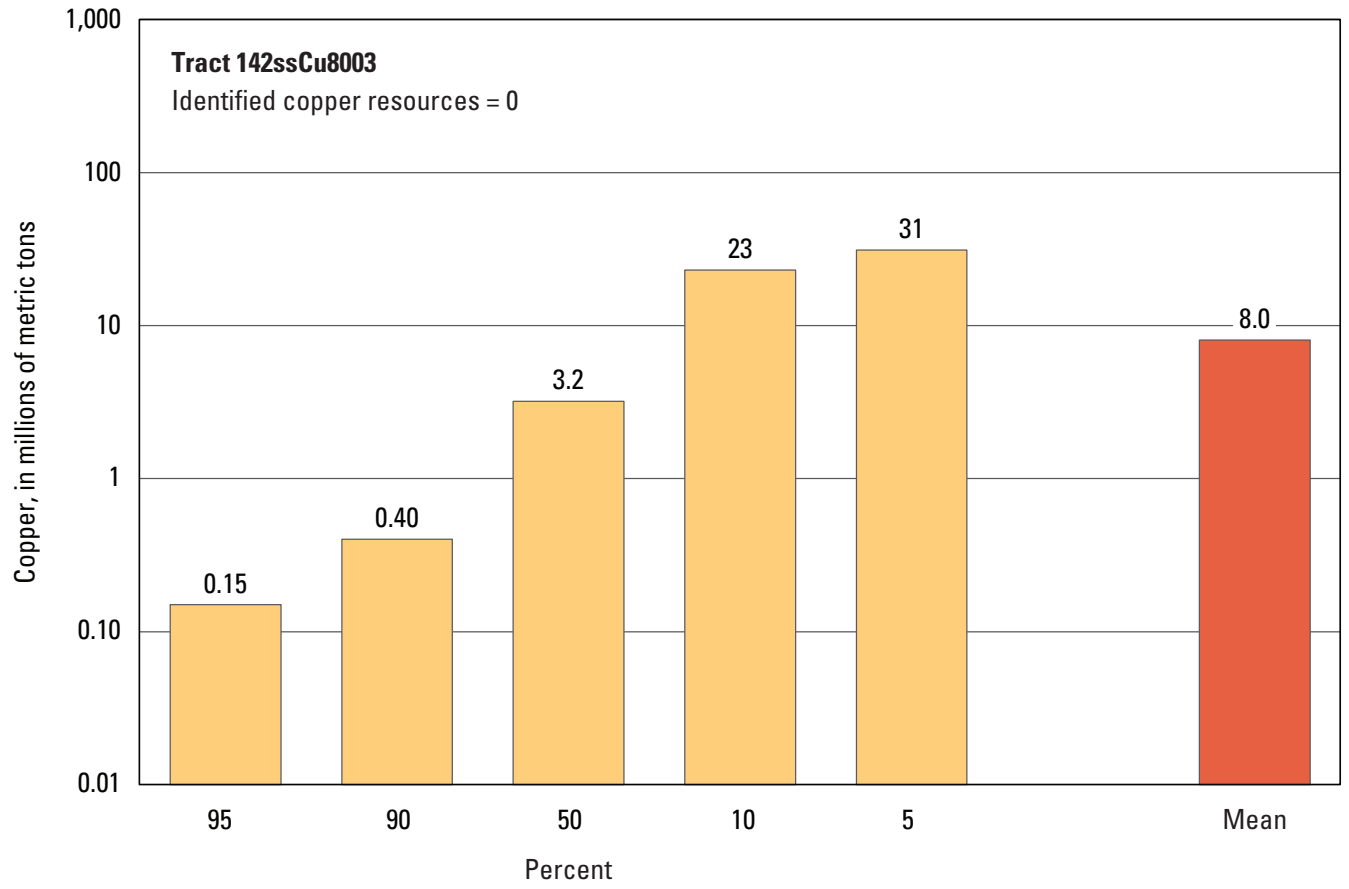

Graph showing the estimated probability distribution of undiscovered copper resources, where each bar represents the minimum amount estimated at the indicated percentage.

\section{Source}

Box and others, 2012, Sandstone copper assessment of the Chu-Sarysu Basin, central Kazakhstan: U.S. Geological Survey Scientific Investigations Report 2010-5090-E, http://pubs.usgs.gov/sir/2010/5090/e/. 

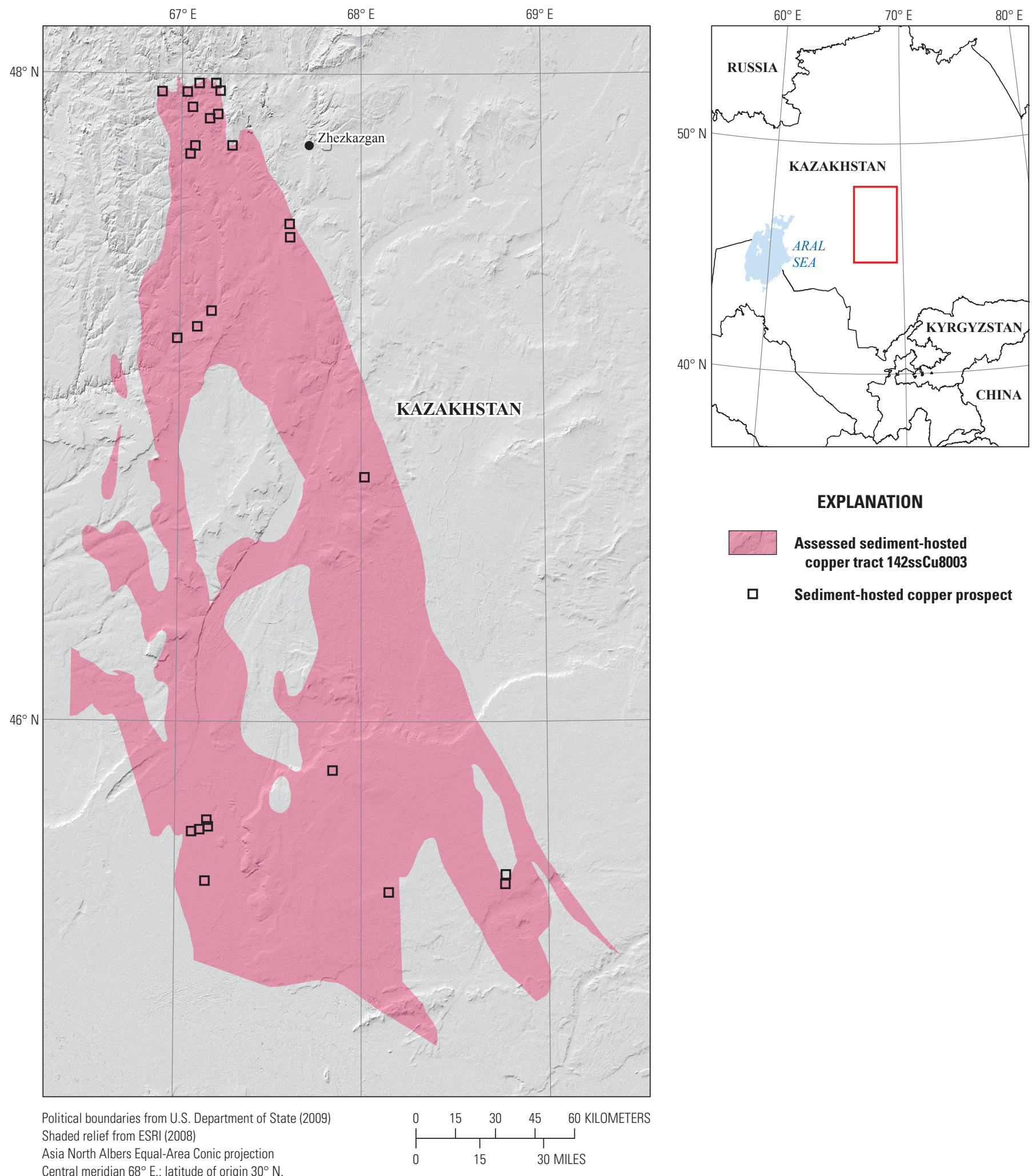

\section{EXPLANATION}

Assessed sediment-hosted copper tract 142 ssCu8003

ㅁ Sediment-hosted copper prospect 


\title{
Plate 216. Sediment-Hosted Stratabound Copper Assessment for Tract 142ssCu8004, Muyunkum Subbasin, Chu-Sarysu Basin—Kazakhstan and Kyrgyzstan
}

\author{
Descriptive model: \\ Grade and tonnage model: \\ Geologic feature assessed: \\ Number of known deposits:
}

Sediment-hosted stratabound copper-Sandstone copper subtype model (Cox and others, 2007; Zientek, Hayes, and Hammarstrom, 2013)

Sediment-hosted stratabound copper-Sandstone copper subtype model (Zientek, Hayes, and Taylor, 2013)

Southern structural subbasin of the Chu-Sarysu Basin, upper Carboniferous nonmarine alluvial clastic sequence (red beds): Dzhezkazgan and Taskuduk Formations

0

\section{Selected Resource Assessment Results for Sediment-Hosted Stratabound Copper}

[Assessment depth, 2 kilometers $(\mathrm{km}) ; \mathrm{km}^{2}$, square kilometer; Mt, millions of metric tons]

\begin{tabular}{ccccccc}
\hline $\begin{array}{c}\text { Date of } \\
\text { assessment }\end{array}$ & $\begin{array}{c}\text { Tract area } \\
\left(\mathbf{k m}^{2}\right)\end{array}$ & $\begin{array}{c}\text { Identified } \\
\text { copper } \\
\text { resources } \\
(\mathbf{M t})\end{array}$ & $\begin{array}{c}\text { Median estimate of } \\
\text { in-place resources } \\
(\mathbf{M t})\end{array}$ & $\begin{array}{c}\text { Mean estimate of } \\
\text { in-place resources } \\
\text { (Mt) }\end{array}$ & $\begin{array}{c}\text { Probability of mean } \\
\text { or greater } \\
\text { (percent) }\end{array}$ & $\begin{array}{c}\text { Probability of } \mathbf{0} \\
\text { in-place resources } \\
\text { (percent) }\end{array}$ \\
\hline 2009 & 64,856 & 0 & 0.21 & 2.1 & 18 \\
\hline
\end{tabular}

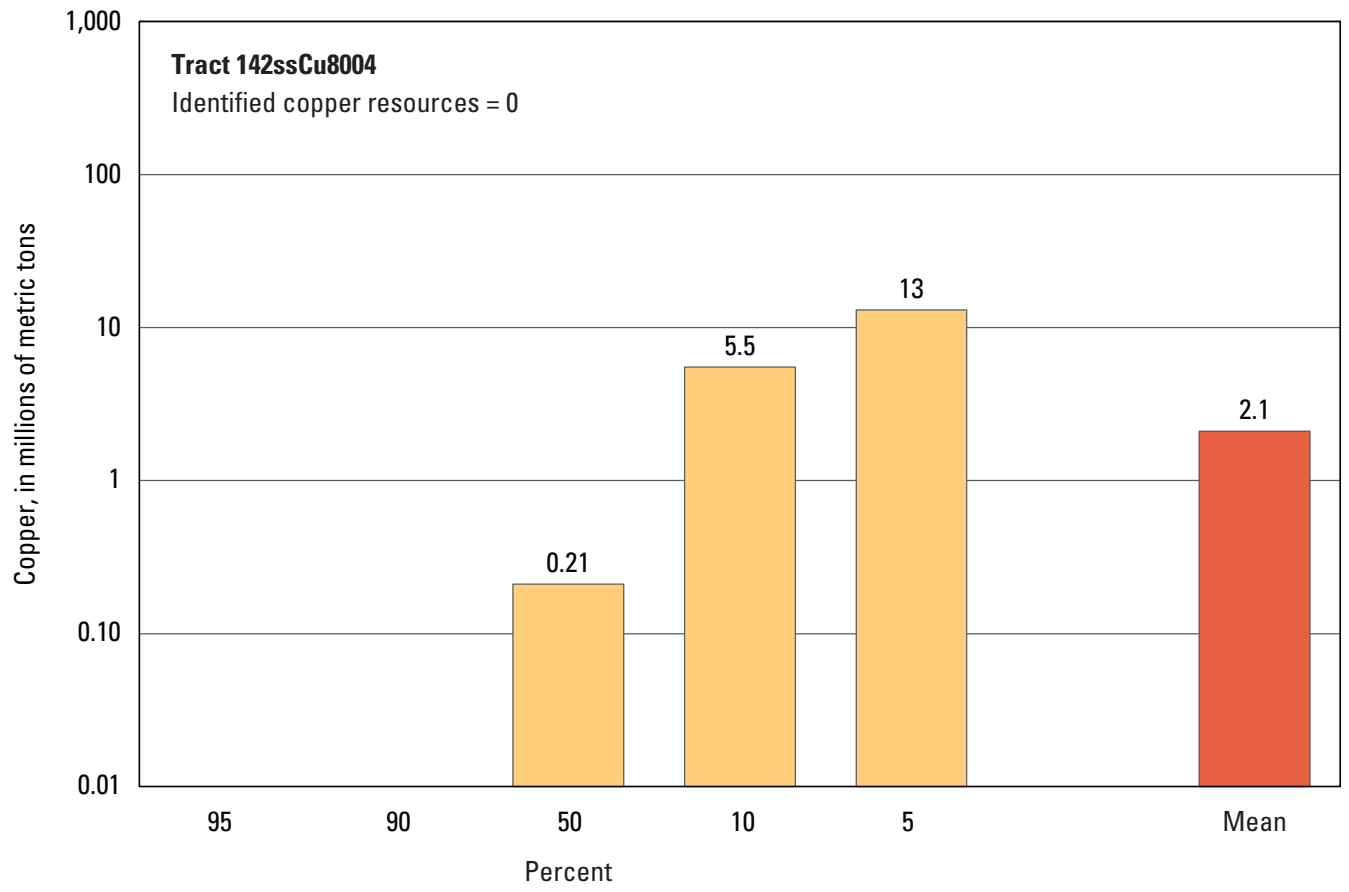

Graph showing the estimated probability distribution of undiscovered copper resources, where each bar represents the minimum amount estimated at the indicated percentage.

\section{Source}

Box and others, 2012, Sandstone copper assessment of the Chu-Sarysu Basin, central Kazakhstan: U.S. Geological Survey Scientific Investigations Report 2010-5090-E, http://pubs.usgs.gov/sir/2010/5090/e/. 


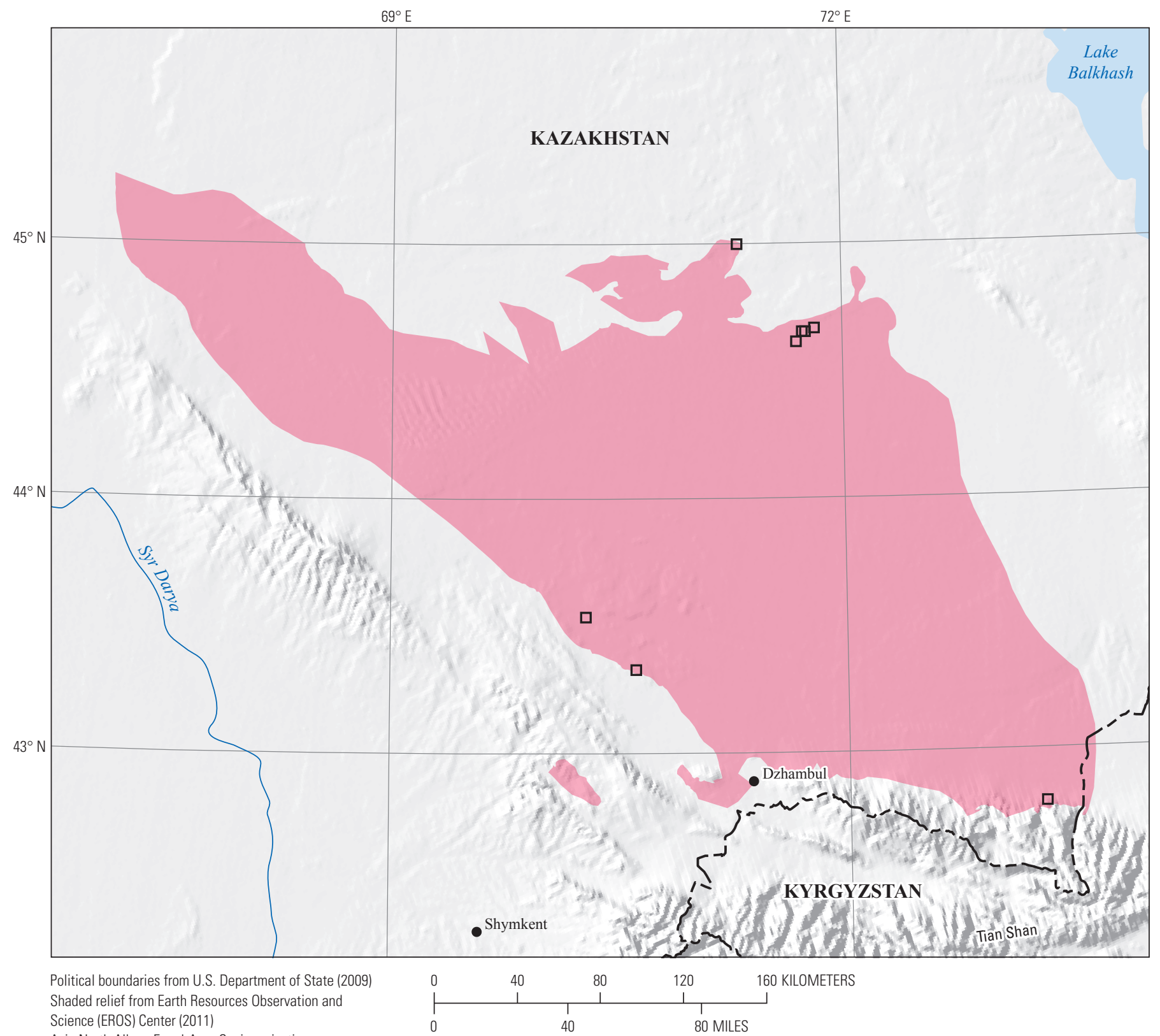

Asia North Albers Equal-Area Conic projection

Central meridian $70^{\circ} \mathrm{E}$.; latitude of origin $30^{\circ} \mathrm{N}$.

\section{EXPLANATION}

Assessed sediment-hosted copper tract 142ssCu8004

ㄴ Sediment-hosted copper prospect

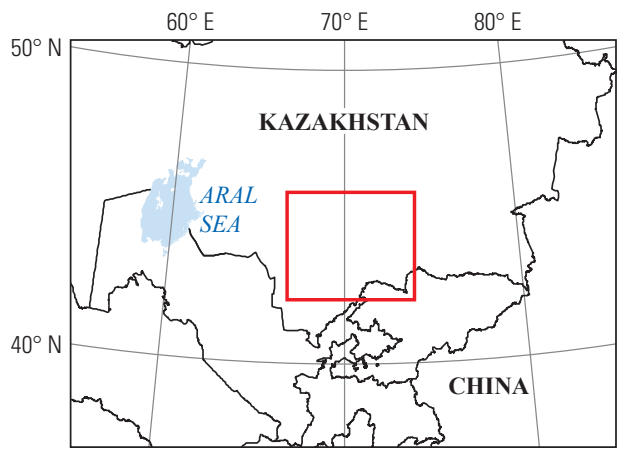




\title{
Plate 217. Sediment-Hosted Stratabound Copper Assessment for Tract 142ssCu8050, Teniz Basin—Kazakhstan
}

\author{
Descriptive model: \\ Grade and tonnage model: \\ Geologic feature assessed: \\ Number of known deposits:
}

Sediment-hosted stratabound copper-Sandstone copper subtype model (Cox and others, 2007; Zientek, Hayes, and Hammarstrom, 2013)

Sediment-hosted stratabound copper-Sandstone copper subtype model (Zientek, Hayes, and Taylor, 2013)

Middle and upper Carboniferous and lower Permian coarse-grained siliciclastic strata, Teniz Basin 0

\section{Selected Resource Assessment Results for Sediment-Hosted Stratabound Copper}

[Assessment depth, 2 kilometers $(\mathrm{km}) ; \mathrm{km}^{2}$, square kilometer; Mt, millions of metric tons]

\begin{tabular}{ccccccc}
\hline $\begin{array}{c}\text { Date of } \\
\text { assessment }\end{array}$ & $\begin{array}{c}\text { Tract area } \\
\left(\mathbf{k m}^{2}\right)\end{array}$ & $\begin{array}{c}\text { Identified } \\
\text { copper } \\
\text { resources } \\
(\mathbf{M t})\end{array}$ & $\begin{array}{c}\text { Median estimate of } \\
\text { in-place resources } \\
(\mathbf{M t})\end{array}$ & $\begin{array}{c}\text { Mean estimate of } \\
\text { in-place resources } \\
\text { (Mt) }\end{array}$ & $\begin{array}{c}\text { Probability of mean } \\
\text { or greater } \\
\text { (percent) }\end{array}$ & $\begin{array}{c}\text { Probability of } \mathbf{0} \\
\text { in-place resources } \\
\text { (percent) }\end{array}$ \\
\hline 2011 & 49,714 & 0 & 3.7 & 8.9 & 31 \\
\hline
\end{tabular}

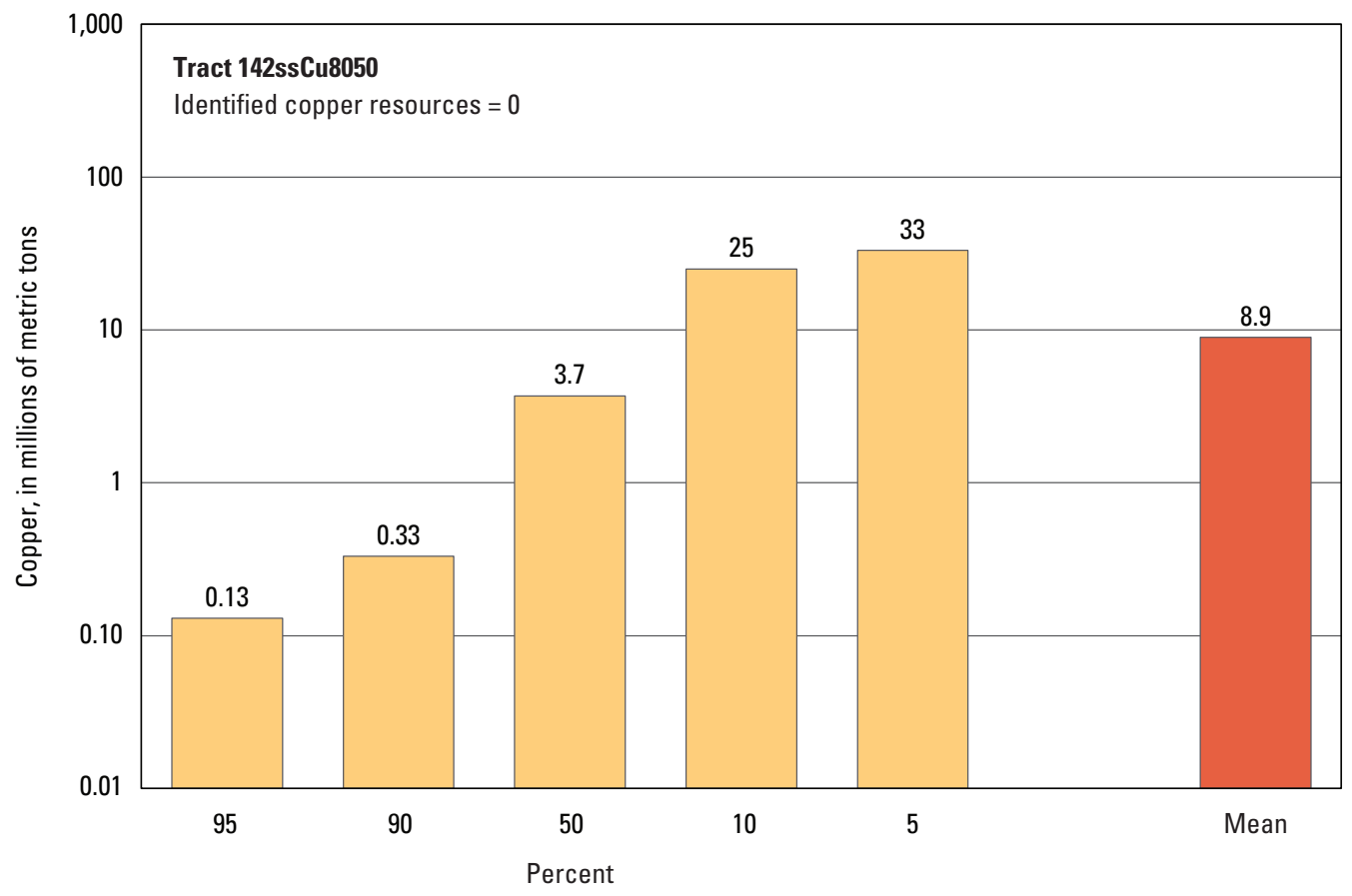

Graph showing the estimated probability distribution of undiscovered copper resources, where each bar represents the minimum amount estimated at the indicated percentage.

\section{Source}

Cossette and others, 2014, Sandstone copper assessment of the Teniz Basin, Kazakhstan: U.S. Geological Survey Scientific Investigations Report 2010-5090-R, http://dx.doi.org/10.3133/sir20105090R. 


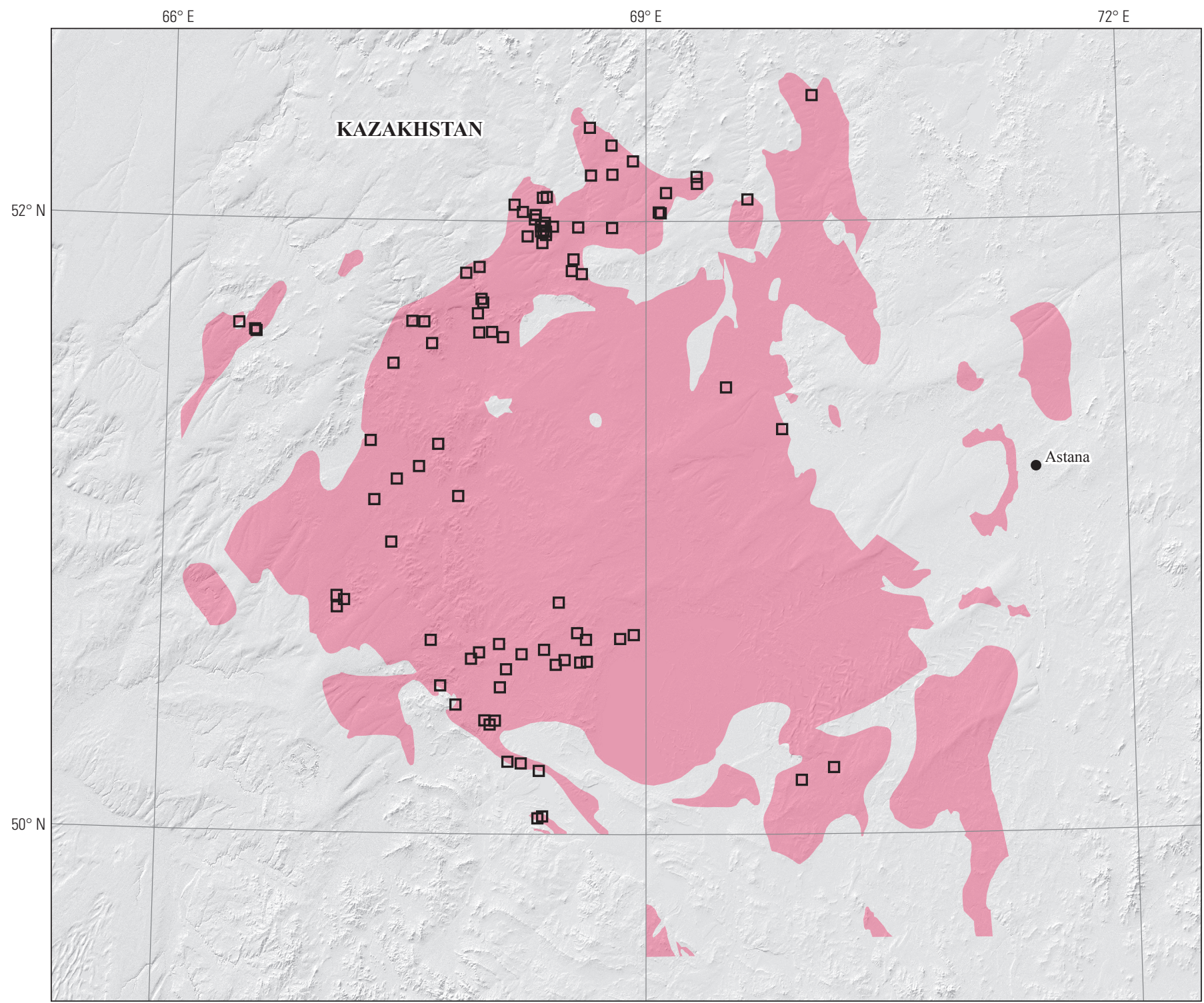

Political boundaries from U.S. Department of State (2009) Shaded relief from ESRI (2008)

Asia North Albers Equal-Area Conic projection

Central meridian $69^{\circ} \mathrm{E}$.; latitude of origin $30^{\circ} \mathrm{N}$

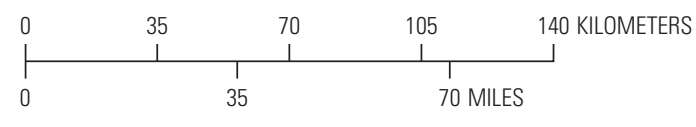

EXPLANATION

Assessed sediment-hosted copper tract 142ssCu8050

$\square \quad$ Sediment-hosted copper prospect

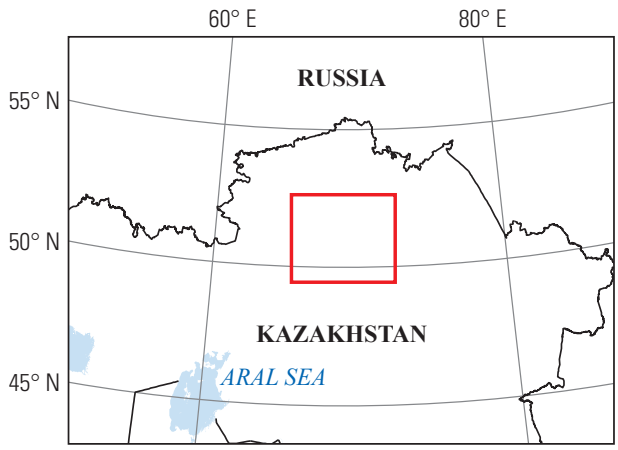




\title{
Plate 218. Sediment-Hosted Stratabound Copper Assessment for Tract 142rfCu4000, Dongchuan Group Rocks, Yangtze Block, South China Craton- China
}

\author{
Descriptive model: \\ Sediment-hosted stratabound copper-Reduced-facies copper subtype model (Cox and others, \\ 2007; Zientek, Hayes, and Hammarstrom, 2013) \\ Geologic feature assessed: \\ Marine carbonaceous rocks of the Paleoproterozoic to Mesoproterozoic Luoxue Formation, \\ Yangtze Block, South China Craton \\ Number of known deposits: \\ 8
}

\section{Selected Resource Assessment Results for Sediment-Hosted Stratabound Copper}

[Assessment depth, 0 kilometer $(\mathrm{km}) ; \mathrm{km}^{2}$, square kilometer; Mt, millions of metric tons]

\begin{tabular}{|c|c|c|c|c|}
\hline \multirow[b]{2}{*}{$\begin{array}{c}\text { Date of } \\
\text { assessment }\end{array}$} & \multirow[b]{2}{*}{$\begin{array}{c}\text { Tract area } \\
\qquad\left(\mathbf{k m}^{2}\right)\end{array}$} & \multirow{2}{*}{$\begin{array}{l}\text { Identified } \\
\text { copper } \\
\text { resources } \\
\text { (Mt) }\end{array}$} & \multicolumn{2}{|c|}{ Qualitative assessment ranking } \\
\hline & & & $\begin{array}{c}\text { Analytic hierarchy process- } \\
\text { Alternative utility* } \\
\text { (percent) }\end{array}$ & Overall rank \\
\hline 2012 & 8,747 & 3.2 & 10.1 & 5 th of 10 areas \\
\hline
\end{tabular}

"Alternative utility is a numerical weight derived from evaluation of three assessment criteria.

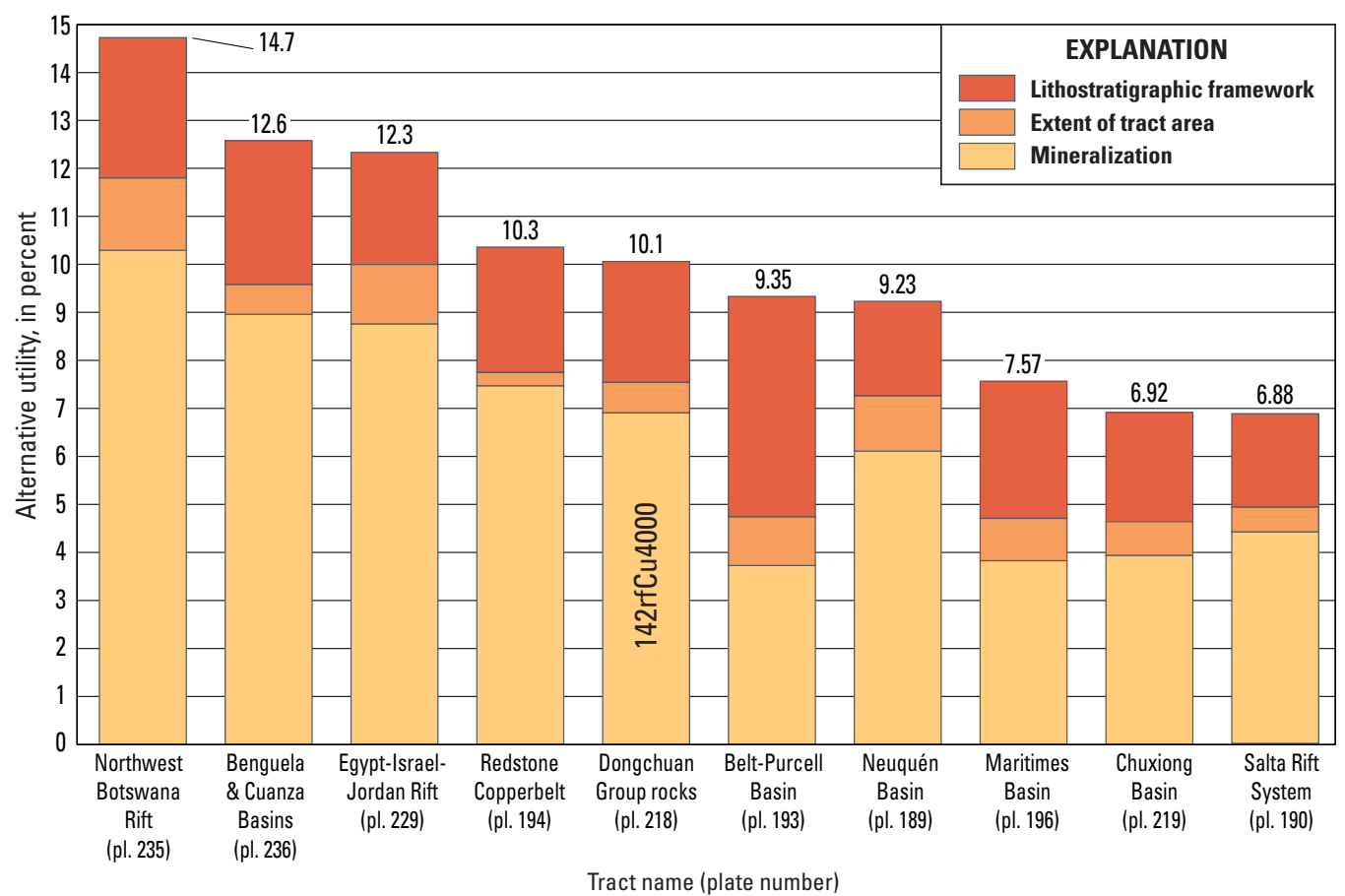

Graph showing qualitative ranking of basins determined by the analytic hierarchy process (AHP). Alternative utility is the overall score derived from the AHP method.

\section{Source}

Zientek, Wintzer, and others, 2015, Qualitative assessment of selected areas of the world for undiscovered sediment-hosted stratabound copper deposits: U.S. Geological Survey Scientific Investigations Report 2010-5090-Y, http://dx.doi.org/10.3133/sir20105090Y. 


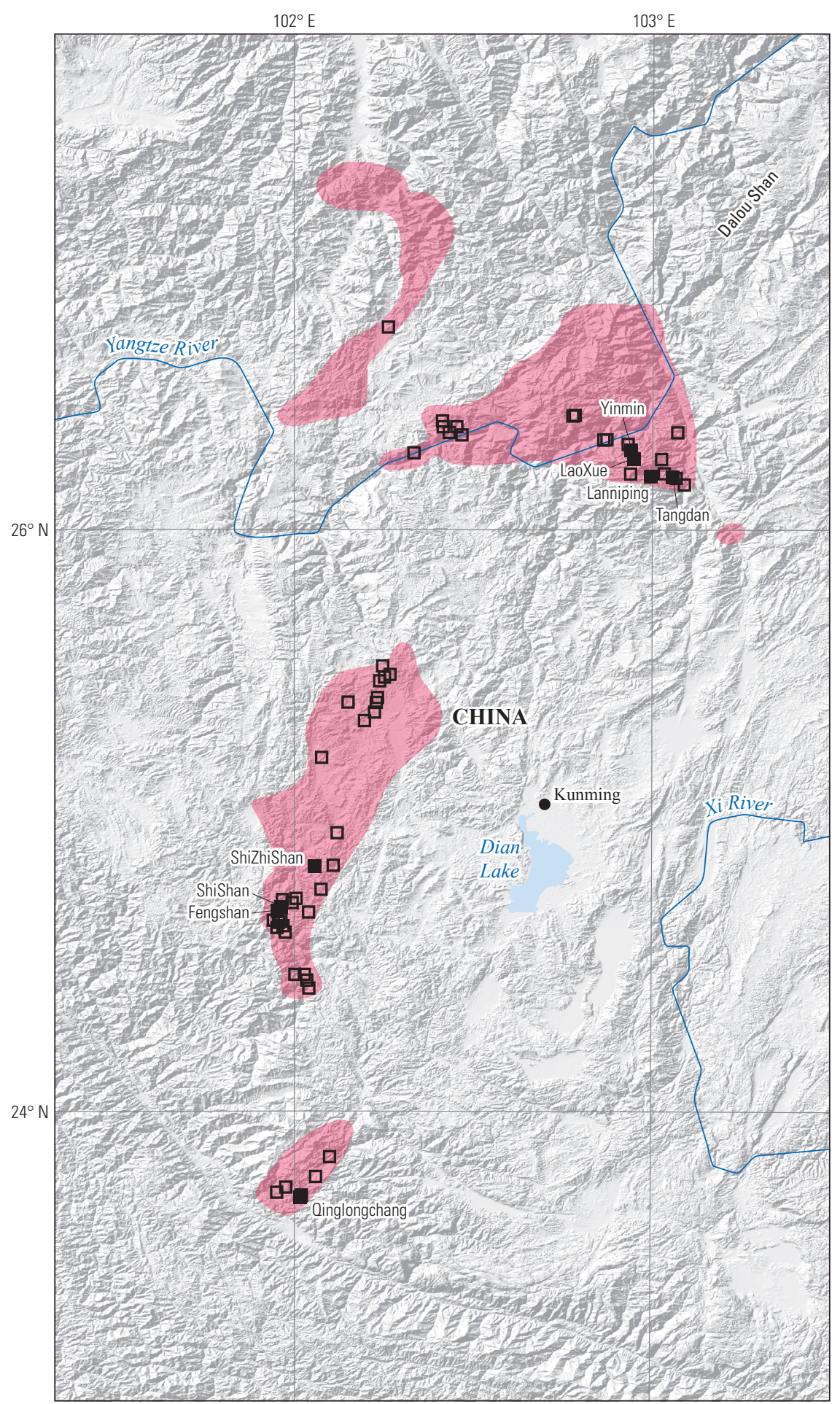

Political boundaries from U.S. Department of State (2009) Shaded relief from ESRI (2008)

Asia South Albers Equal-Area Conic projection

Central meridian $102^{\circ} \mathrm{E}$.; latitude of origin $15^{\circ} \mathrm{S}$.

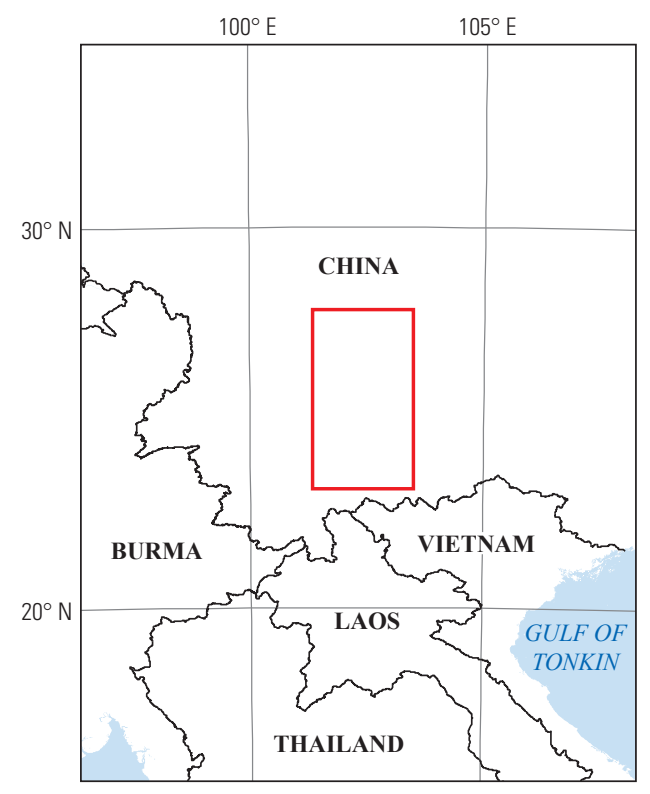

\section{EXPLANATION}

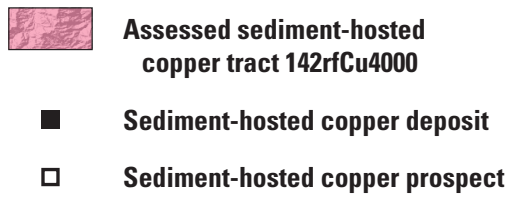




\title{
Plate 219. Sediment-Hosted Stratabound Copper Assessment for Tract 142ssCu6000, Chuxiong Basin-China
}

\author{
Descriptive model: \\ Geologic feature assessed: \\ Number of known deposits:
}

Sediment-hosted stratabound copper-Sandstone copper subtype model (Cox and others, 2007; Zientek, Hayes, and Hammarstrom, 2013)

Cretaceous, coarse-grained siliciclastic rocks, Chuxiong Basin

12

\section{Selected Resource Assessment Results for Sediment-Hosted Stratabound Copper}

[Assessment depth, 0 kilometer ( $\mathrm{km}) ; \mathrm{km}^{2}$, square kilometer; Mt, millions of metric tons]

\begin{tabular}{ccccc}
\hline $\begin{array}{c}\text { Date of } \\
\text { assessment }\end{array}$ & $\begin{array}{c}\text { Tract area } \\
\left.\mathbf{( k m}^{2}\right)\end{array}$ & $\begin{array}{c}\text { Identified } \\
\text { copper } \\
\text { resources } \\
(\mathbf{M t})\end{array}$ & $\begin{array}{c}\text { Analytic hierarchy process- } \\
\text { Alternative utility* } \\
\text { (percent) }\end{array}$ & Overall rank \\
\hline 2012 & 19,847 & 1.3 & 6.92 & 9th of 10 areas \\
\hline
\end{tabular}

"Alternative utility is a numerical weight derived from evaluation of three assessment criteria.

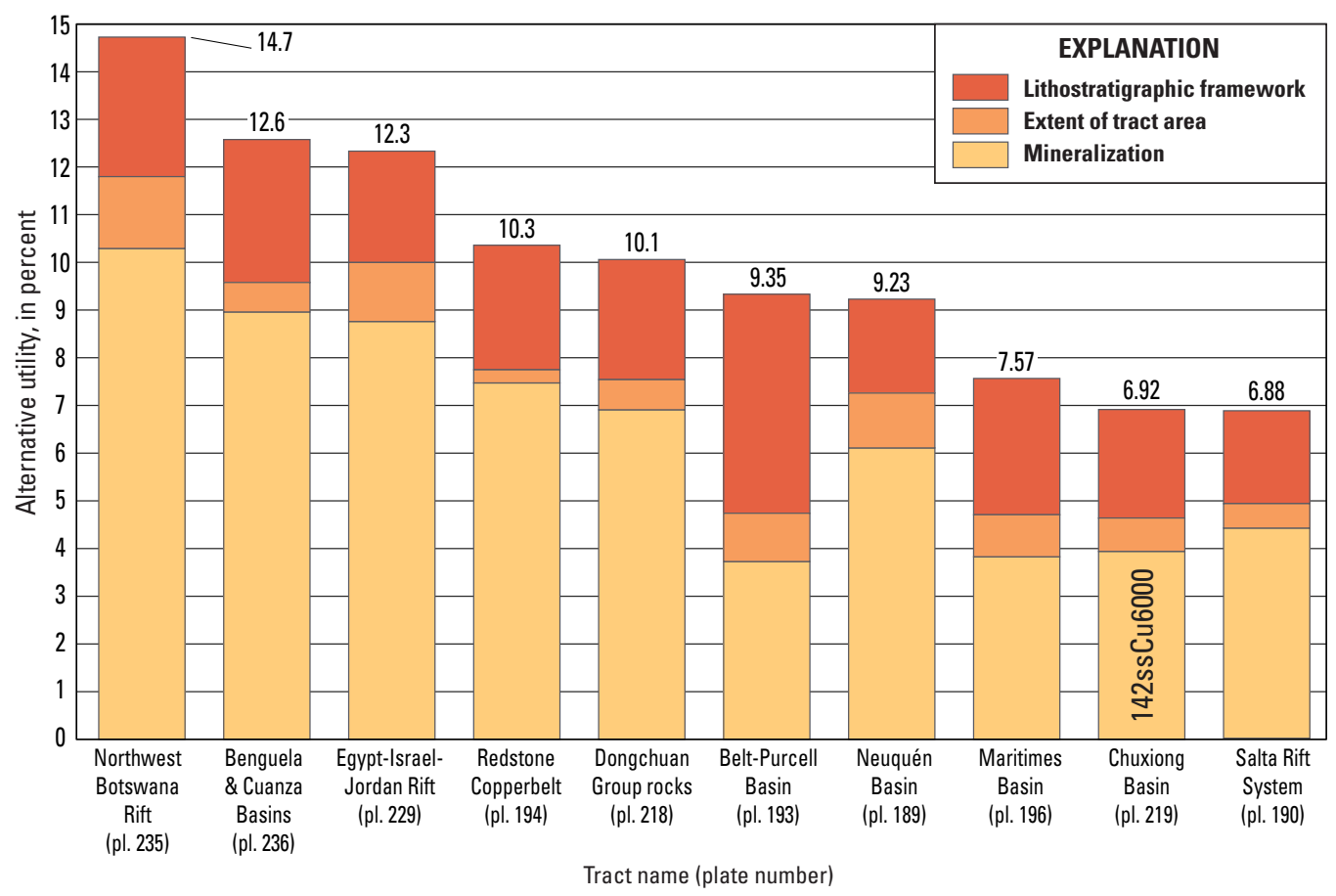

Graph showing qualitative ranking of basins determined by the analytic hierarchy process (AHP). Alternative utility is the overall score derived from the AHP method.

\section{Source}

Zientek, Wintzer, and others, 2015, Qualitative assessment of selected areas of the world for undiscovered sediment-hosted stratabound copper deposits: U.S. Geological Survey Scientific Investigations Report 2010-5090-Y, http://dx.doi.org/10.3133/sir20105090Y. 


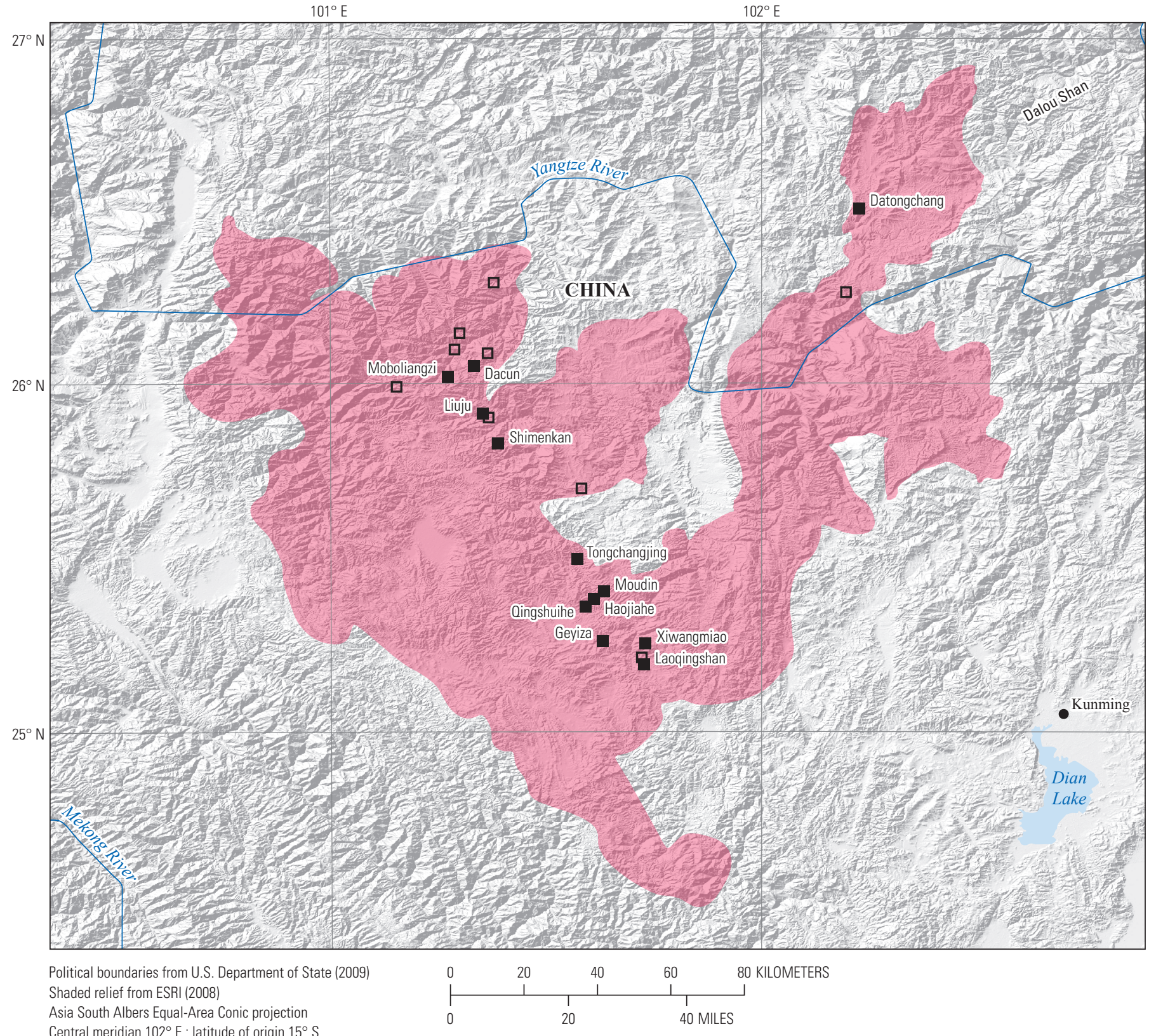

Central meridian $102^{\circ} \mathrm{E}$.; latitude of origin $15^{\circ} \mathrm{S}$

EXPLANATION

\begin{tabular}{|l|l}
\hline & $\begin{array}{c}\text { Assessed sediment-hosted } \\
\text { copper tract 142ssCu6000 }\end{array}$ \\
- Sediment-hosted copper deposit \\
口 $\quad$ Sediment-hosted copper prospect
\end{tabular}

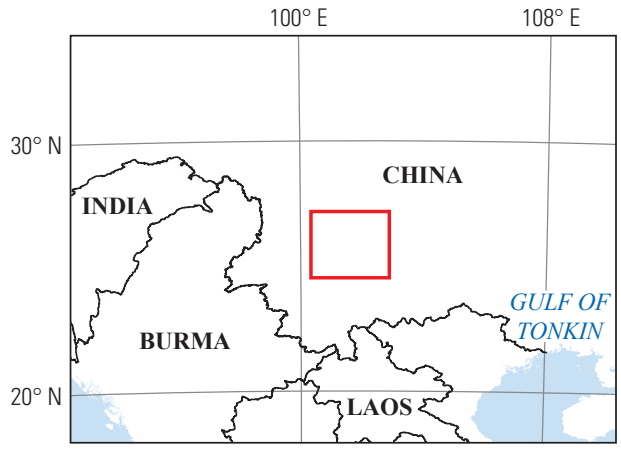




\section{Plate 220. Sediment-Hosted Stratabound Copper Assessment for Tract 150rfnbCu0001, Hercynian-Thüringian Basin, Southern Permian Basin—Germany}

\author{
Descriptive model: \\ Grade and tonnage model: \\ Geologic feature assessed:
}

Number of known deposits:

\begin{abstract}
Sediment-hosted stratabound copper-Reduced-facies-nonbrecciated copper subtype model (Cox and others, 2007; Zientek, Hayes, and Hammarstrom, 2013)

Sediment-hosted stratabound copper-Reduced-facies-nonbrecciated copper subtype model (Zientek, Hayes, and Taylor, 2013)

Marine carbonaceous rocks of the Lopingian (Upper Permian) Kupferschiefer bed overlying Permian reservoir-facies, continental clastic rocks of the upper Rotliegend Formation in the Hercynian-Thüringian Basin, Southern Permian Basin
\end{abstract}

4

\section{Selected Resource Assessment Results for Sediment-Hosted Stratabound Copper}

[Assessment depth, 2.5 kilometers ( $\mathrm{km}) ; \mathrm{km}^{2}$, square kilometer; Mt, millions of metric tons]

\begin{tabular}{ccccccc}
\hline \multirow{2}{*}{$\begin{array}{c}\text { Date of } \\
\text { assessment }\end{array}$} & $\begin{array}{c}\text { Tract area } \\
\left(\mathbf{k m}^{2}\right)\end{array}$ & $\begin{array}{c}\text { Identified } \\
\text { copper } \\
\text { resources } \\
(\mathbf{M t})\end{array}$ & $\begin{array}{c}\text { Median estimate of } \\
\text { in-place resources } \\
(\mathbf{M t})\end{array}$ & $\begin{array}{c}\text { Mean estimate of } \\
\text { in-place resources } \\
\text { (Mt) }\end{array}$ & $\begin{array}{c}\text { Probability of mean } \\
\text { or greater } \\
\text { (percent) }\end{array}$ & $\begin{array}{c}\text { Probability of } 0 \\
\text { in-place resources } \\
\text { (percent) }\end{array}$ \\
\hline 2010 & 18,268 & 3.0 & 0 & 4.2 & 17 \\
\hline
\end{tabular}

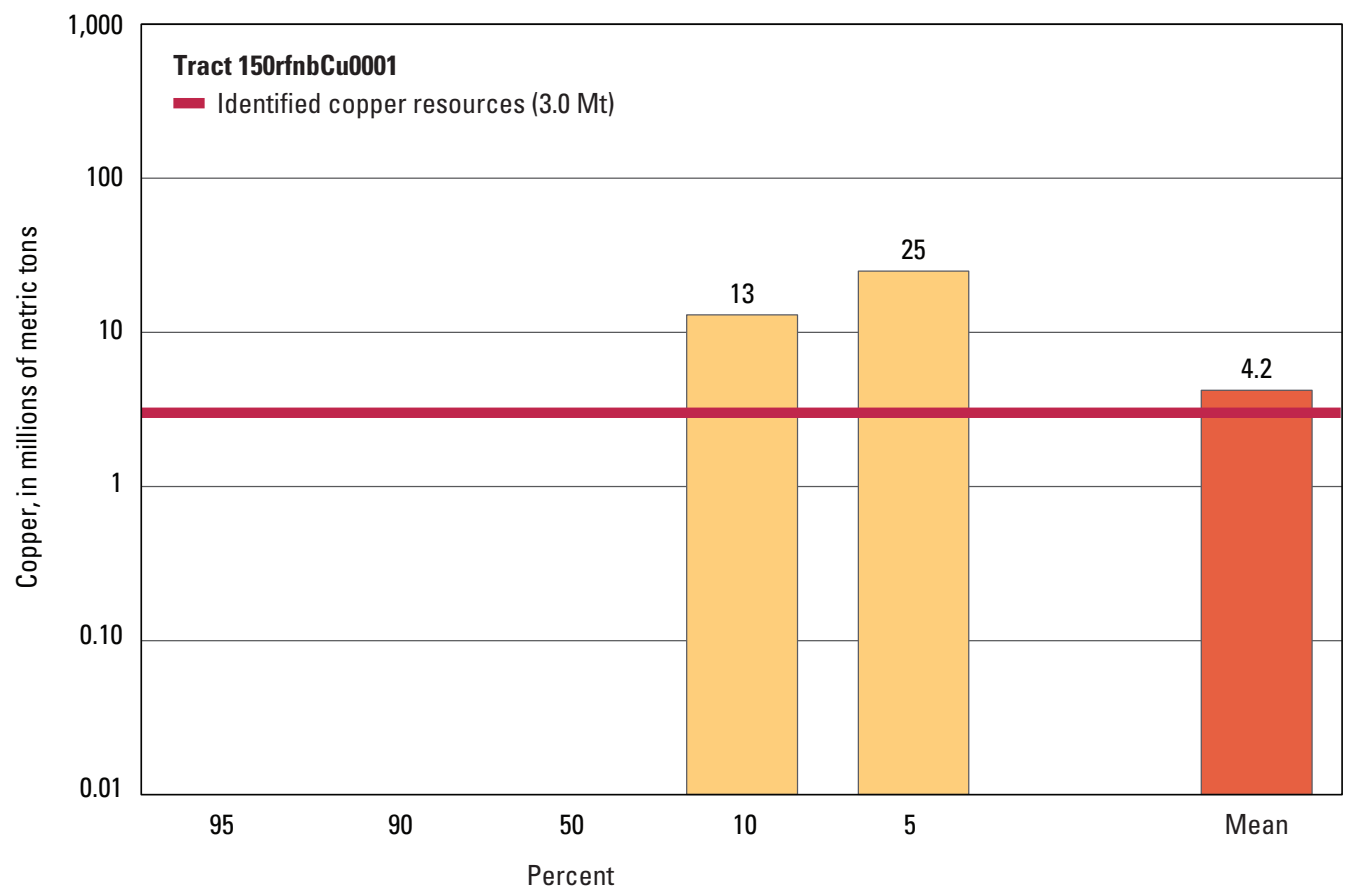

Graph showing the estimated probability distribution of undiscovered copper resources, where each bar represents the minimum amount estimated at the indicated percentage.

\section{Source}

Zientek, Oszczepalski, and others, 2015, Assessment of undiscovered copper resources associated with the Permian Kupferschiefer, Southern Permian Basin, Europe: U.S. Geological Survey Scientific Investigations Report 2010-5090-U, http://dx.doi.org/10.3133/sir20105090U. 


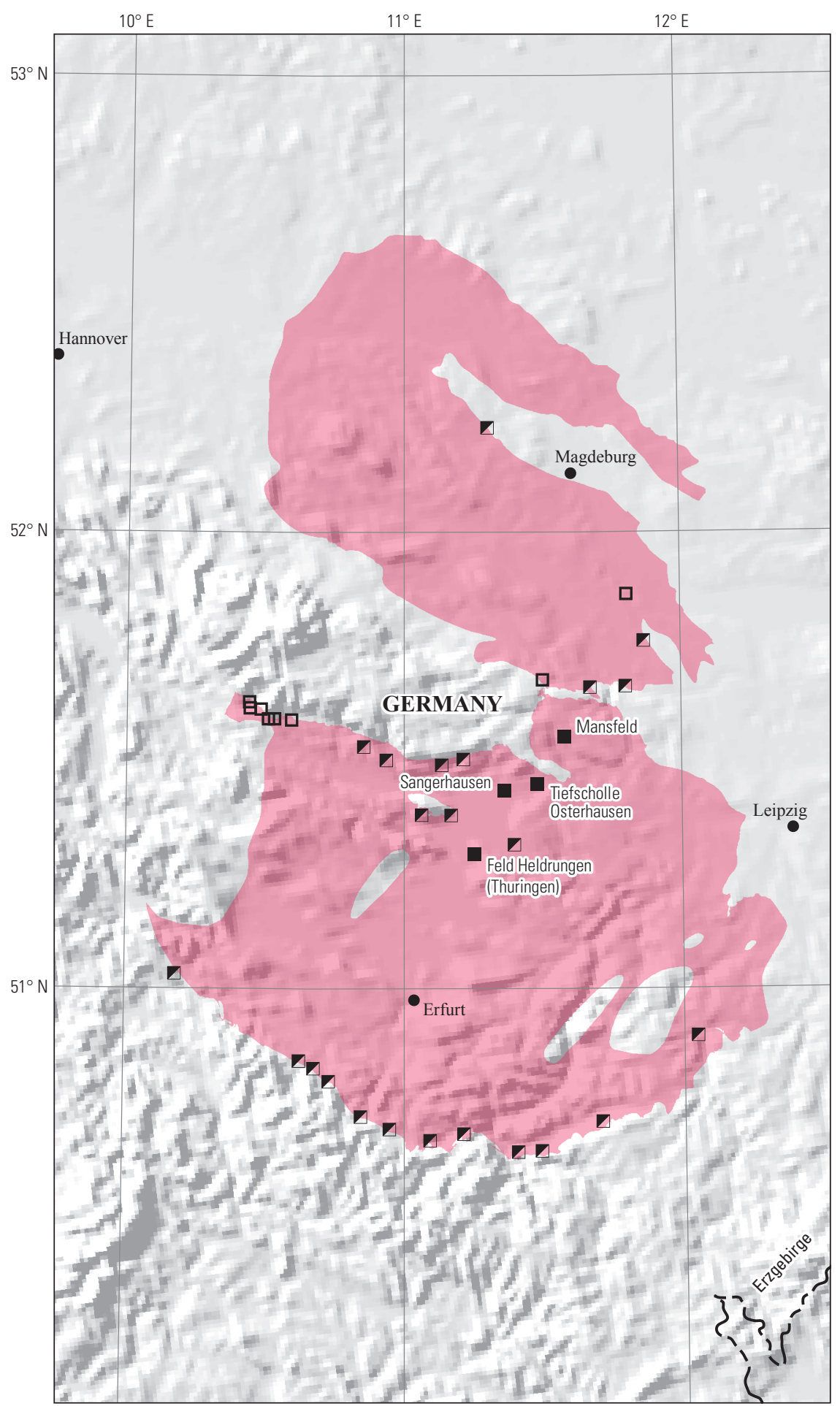

Political boundaries from U.S. Department of State (2009) Shaded relief from Earth Resources Observation and Science (EROS) Center (2011)

Europe Albers Equal-Area Conic projection

Central meridian $11^{\circ} \mathrm{E}$.; latitude of origin $30^{\circ} \mathrm{N}$.

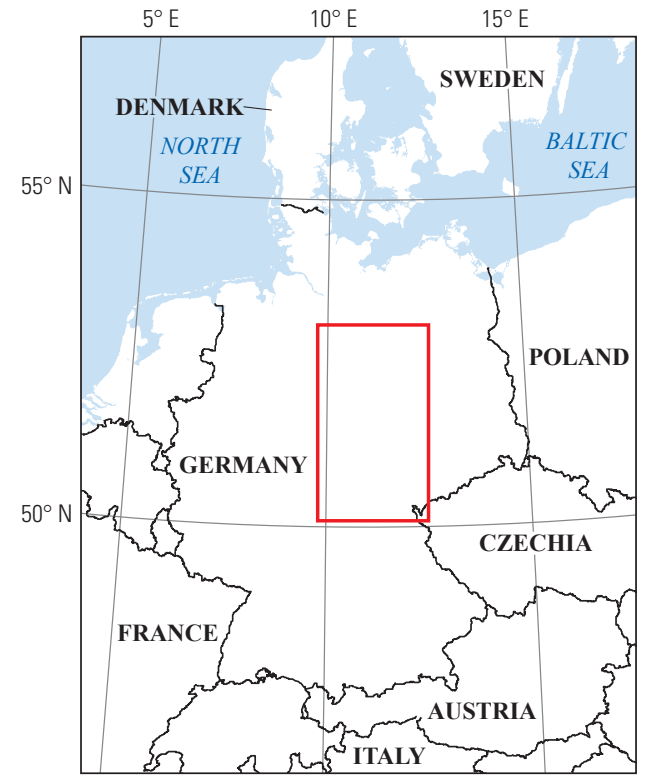

\section{EXPLANATION}

\section{Assessed sediment-hosted} copper tract 150rfnbCu0001

- Sediment-hosted copper deposit

$\square \quad$ Sediment-hosted copper prospect

\ Sediment-hosted copper significant historic occurence 


\section{Plate 221. Sediment-Hosted Stratabound Copper Assessment for Tract 150rfnbCu0002, Hessian Depression, Southern Permian Basin-Germany}

\author{
Descriptive model: \\ Grade and tonnage model: \\ Geologic feature assessed:
}

Number of known deposits:
Sediment-hosted stratabound copper-Reduced-facies-nonbrecciated copper subtype model (Cox and others, 2007; Zientek, Hayes, and Hammarstrom, 2013)

Sediment-hosted stratabound copper-Reduced-facies-nonbrecciated copper subtype model (Zientek, Hayes, and Taylor, 2013)

Marine carbonaceous rocks of the Lopingian (Upper Permian) Kupferschiefer bed overlying Permian reservoir-facies, continental clastic rocks of the upper Rotliegend Formation in the Hessian Depression, Southern Permian Basin

1

\section{Selected Resource Assessment Results for Sediment-Hosted Stratabound Copper}

[Assessment depth, 2.5 kilometers ( $\mathrm{km}) ; \mathrm{km}^{2}$, square kilometer; Mt, millions of metric tons]

\begin{tabular}{ccccccc}
\hline \multirow{2}{*}{$\begin{array}{c}\text { Date of } \\
\text { assessment }\end{array}$} & $\begin{array}{c}\text { Tract area } \\
\left(\mathbf{k m}^{2}\right)\end{array}$ & $\begin{array}{c}\text { Identified } \\
\text { copper } \\
\text { resources } \\
(\mathbf{M t})\end{array}$ & $\begin{array}{c}\text { Median estimate of } \\
\text { in-place resources } \\
(\mathbf{M t})\end{array}$ & $\begin{array}{c}\text { Mean estimate of } \\
\text { in-place resources } \\
\text { (Mt) }\end{array}$ & $\begin{array}{c}\text { Probability of mean } \\
\text { or greater } \\
\text { (percent) }\end{array}$ & $\begin{array}{c}\text { Probability of } 0 \\
\text { in-place resources } \\
\text { (percent) }\end{array}$ \\
\hline 2010 & 38,172 & 0.42 & 5.7 & 15 & 32 \\
\hline
\end{tabular}

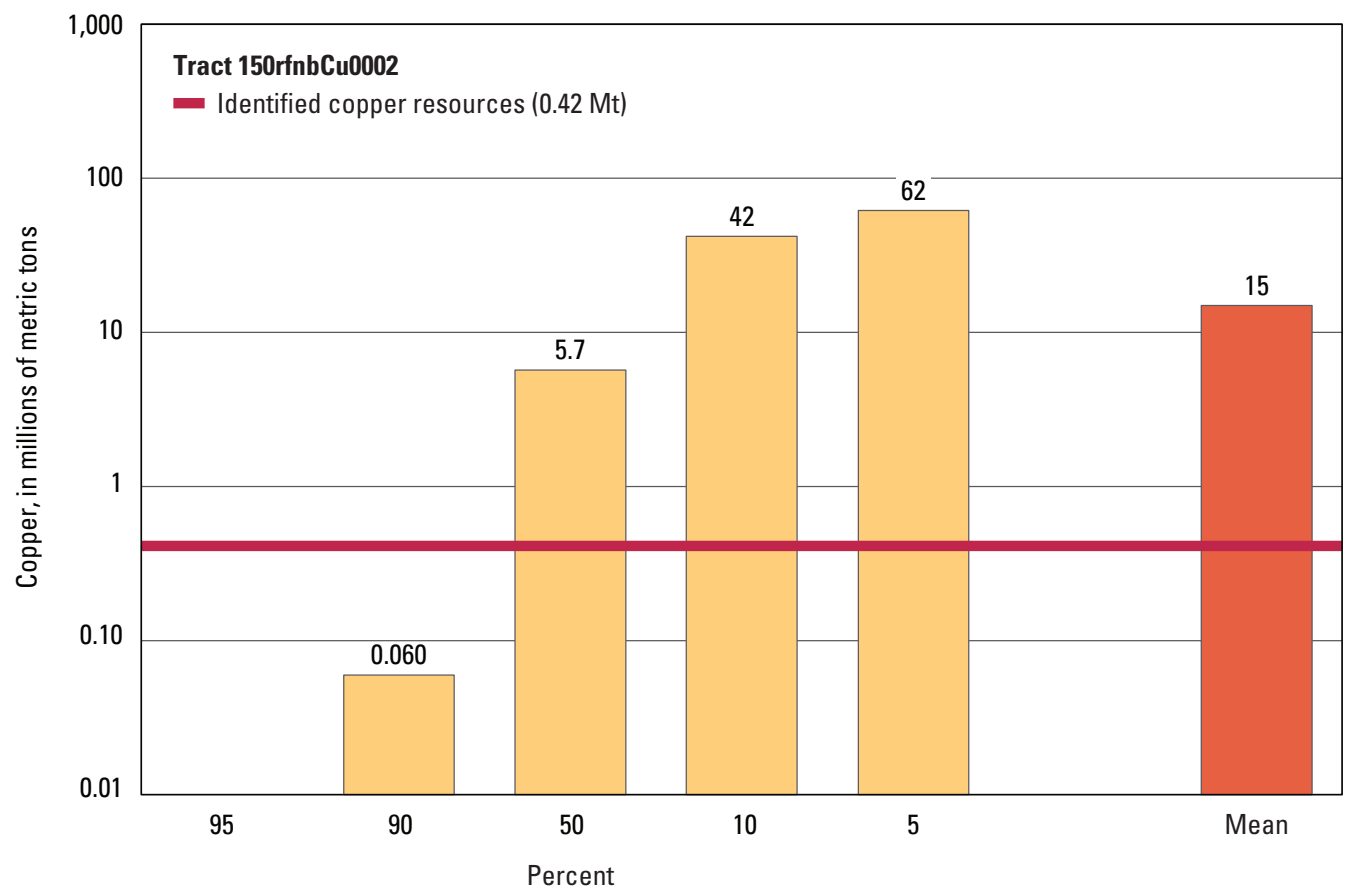

Graph showing the estimated probability distribution of undiscovered copper resources, where each bar represents the minimum amount estimated at the indicated percentage.

\section{Source}

Zientek, Oszczepalski, and others, 2015, Assessment of undiscovered copper resources associated with the Permian Kupferschiefer, Southern Permian Basin, Europe: U.S. Geological Survey Scientific Investigations Report 2010-5090-U, http://dx.doi.org/10.3133/sir20105090U. 

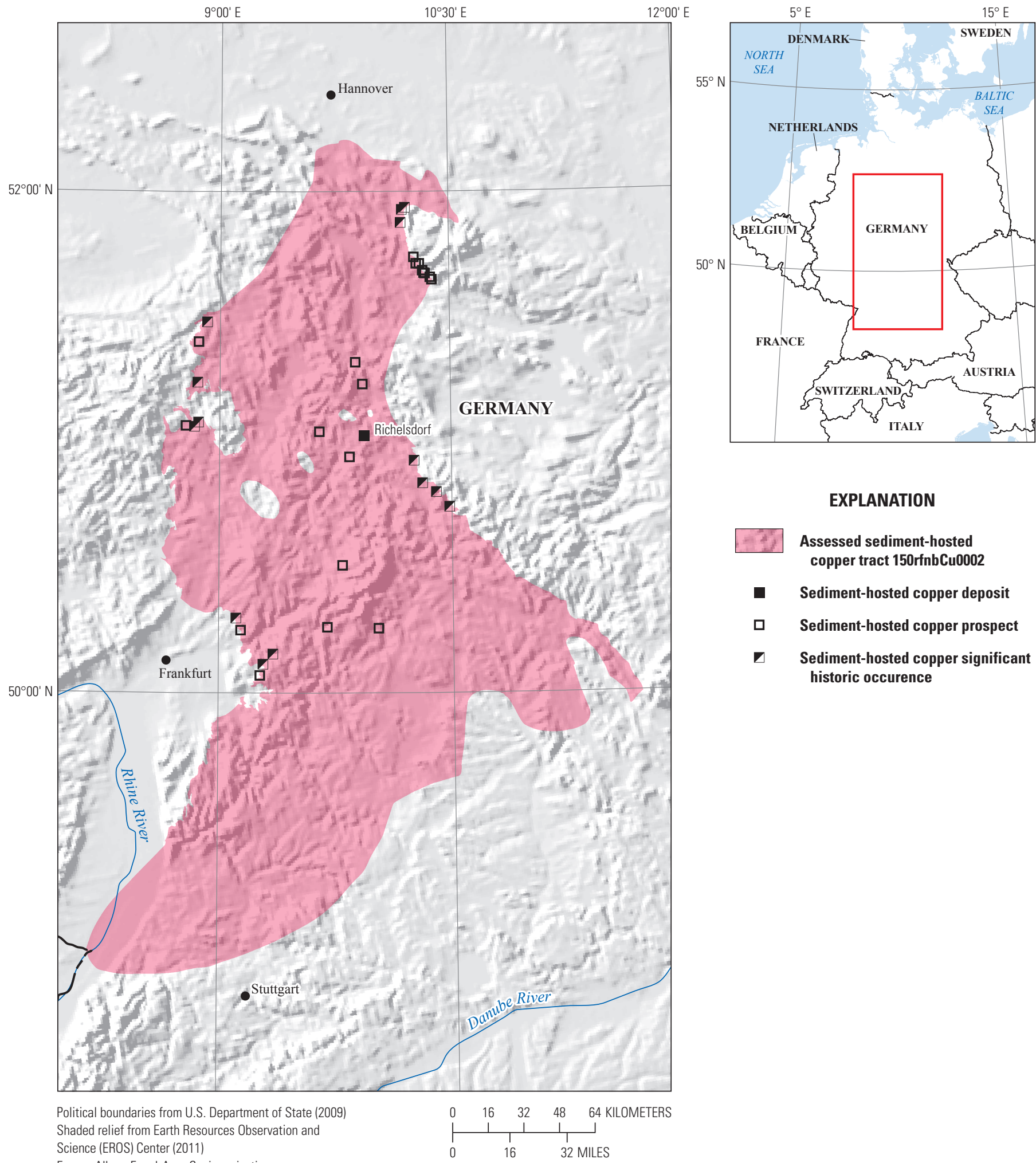

\section{EXPLANATION}

4. Assessed sediment-hosted copper tract 150rfnbCu0002

- Sediment-hosted copper deposit

$\square \quad$ Sediment-hosted copper prospect

\. Sediment-hosted copper significant historic occurence

Science (EROS) Center (2011)

Europe Albers Equal-Area Conic projection

Central meridian $10^{\circ} \mathrm{E}$.; latitude of origin $30^{\circ} \mathrm{N}$. 


\title{
Plate 222. Sediment-Hosted Stratabound Copper Assessment for Tract 150rfnbCu0003, North Sea, Southern Permian Basin-Netherlands and United Kingdom
}

\author{
Descriptive model: \\ Sediment-hosted stratabound copper-Reduced-facies-nonbrecciated copper subtype model \\ (Cox and others, 2007; Zientek, Hayes, and Hammarstrom, 2013) \\ Geologic feature assessed: \\ Marine carbonaceous rocks of the Lopingian (Upper Permian) Kupferschiefer bed overlying \\ Permian reservoir-facies, continental clastic rocks of the upper Rotliegend Formation in the \\ North Sea area, Southern Permian Basin \\ Number of known deposits: \\ 0
}

\section{Selected Resource Assessment Results for Sediment-Hosted Stratabound Copper}

[Assessment depth, 2.5 kilometers $(\mathrm{km})$; km², square kilometer; Mt, millions of metric tons; NA, not applicable, as no quantitative or AHP assessment was done]

\begin{tabular}{ccccccc}
\hline \multirow{2}{*}{$\begin{array}{c}\text { Date of } \\
\text { assessment }\end{array}$} & $\begin{array}{c}\text { Tract area } \\
\left(\mathbf{k m}^{2}\right)\end{array}$ & $\begin{array}{c}\text { Identified } \\
\text { copper } \\
\text { resources } \\
(\mathbf{M t})\end{array}$ & $\begin{array}{c}\text { Median estimate of } \\
\text { in-place resources } \\
(\mathbf{M t})\end{array}$ & $\begin{array}{c}\text { Mean estimate of } \\
\text { in-place resources } \\
\text { (Mt) }\end{array}$ & $\begin{array}{c}\text { Probability of mean } \\
\text { or greater } \\
\text { (percent) }\end{array}$ & $\begin{array}{c}\text { Probability of } 0 \\
\text { in-place resources } \\
\text { (percent) }\end{array}$ \\
\hline 2010 & 23,893 & 0 & NA & NA & NA \\
\hline
\end{tabular}

\section{Qualitative Assessment}

The stratigraphic equivalents of the well-mineralized Kupferschiefer beds were deposited over most of the Netherlands and northeastern England. No economic concentrations of copper are known in the permissive rocks in England. In the Netherlands, the depth to the Copper Shale Member of the Werra Formation, which is equivalent to the Kupferschiefer, is greater than $1 \mathrm{~km}$ and no information was found on the metal content of the shale in this area.

Tract $150 \mathrm{rfnbCu} 0003$ outlines a broadly permissive area for copper deposits on the basis of geology alone. The area is unlikely to contain deposits and no further assessment was done.

\section{Source}

Zientek, Oszczepalski, and others, 2015, Assessment of undiscovered copper resources associated with the Permian Kupferschiefer, Southern Permian Basin, Europe: U.S. Geological Survey Scientific Investigations Report 2010-5090-U, http://dx.doi.org/10.3133/sir20105090U. 


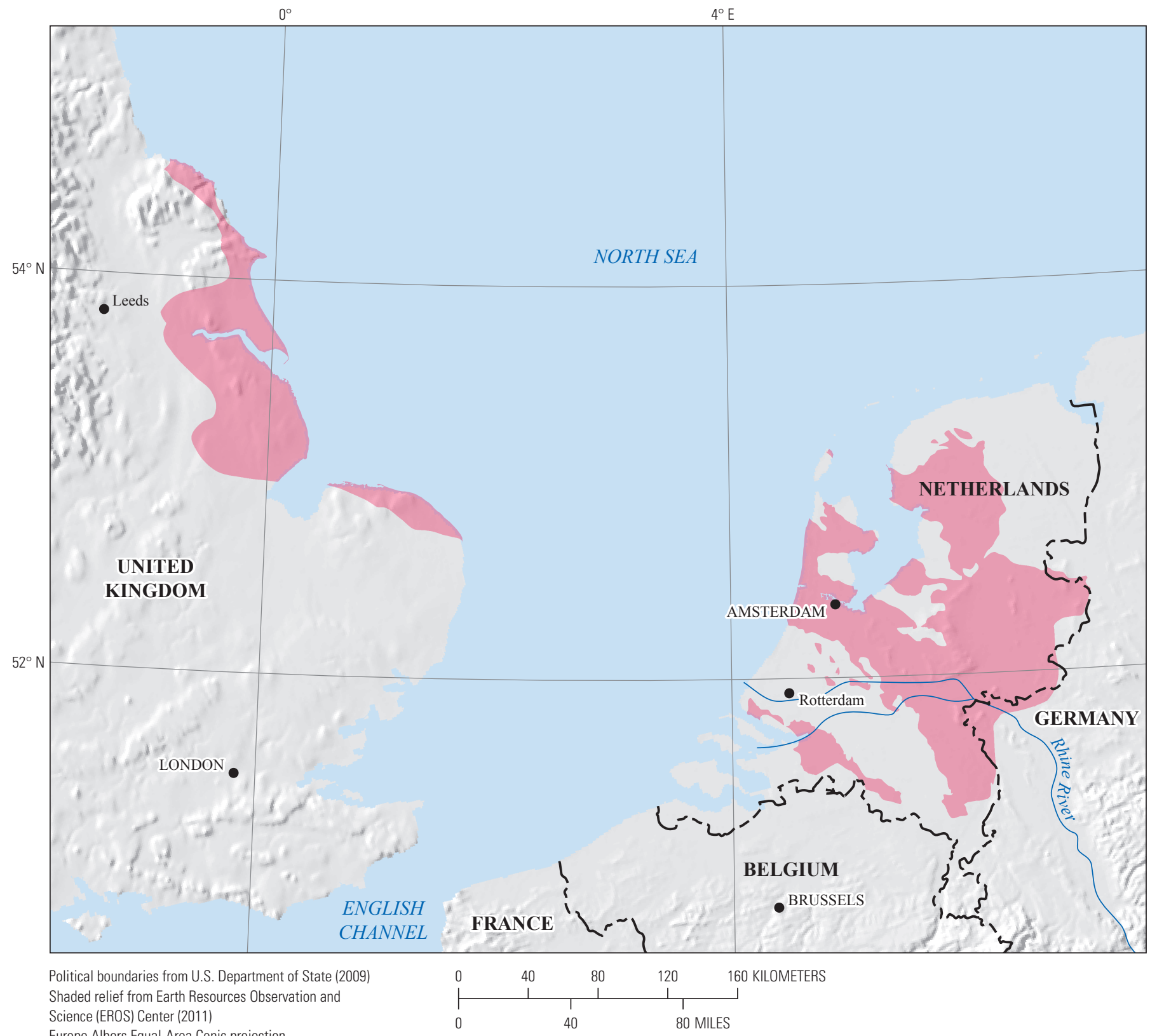

Europe Albers Equal-Area Conic projection

Central meridian $3^{\circ} \mathrm{E}$; l latitude of origin $30^{\circ} \mathrm{N}$.

EXPLANATION

Assessed sediment-hosted copper tract 150rfnbCu0003

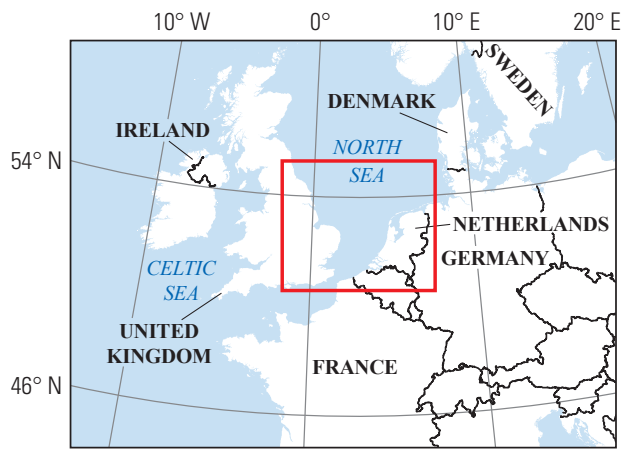




\section{Plate 223. Sediment-Hosted Stratabound Copper Assessment for Tract 150rfnbCu0004, Dolny Śląsk (Lower Silesia), Southern Permian Basin-Poland and Germany}

\author{
Descriptive model: \\ Grade and tonnage model: \\ Geologic feature assessed:
}

Number of known deposits:

\begin{abstract}
Sediment-hosted stratabound copper-Reduced-facies-nonbrecciated copper subtype model (Cox and others, 2007; Zientek, Hayes, and Hammarstrom, 2013)

Sediment-hosted stratabound copper-Reduced-facies-nonbrecciated copper subtype model (Zientek, Hayes, and Taylor, 2013)

Marine carbonaceous rocks of the Lopingian (Upper Permian) Kupferschiefer bed overlying Permian reservoir-facies, continental clastic rocks of the upper Rotliegend Formation in the Fore-Sudetic, Intra-Sudetic, and North Sudetic Basins, Southern Permian Basin
\end{abstract}

3

\section{Selected Resource Assessment Results for Sediment-Hosted Stratabound Copper}

[Assessment depth, 2.5 kilometers (km); $\mathrm{km}^{2}$, square kilometer; Mt, millions of metric tons]

\begin{tabular}{ccccccc}
\hline \multirow{2}{*}{$\begin{array}{c}\text { Date of } \\
\text { assessment }\end{array}$} & $\begin{array}{c}\text { Tract area } \\
\left(\mathbf{k m}^{2}\right)\end{array}$ & $\begin{array}{c}\text { Identified } \\
\text { copper } \\
\text { resources } \\
(\mathbf{M t})\end{array}$ & $\begin{array}{c}\text { Median estimate of } \\
\text { in-place resources } \\
(\mathbf{M t})\end{array}$ & $\begin{array}{c}\text { Mean estimate of } \\
\text { in-place resources } \\
\text { (Mt) }\end{array}$ & $\begin{array}{c}\text { Probability of mean } \\
\text { or greater } \\
\text { (percent) }\end{array}$ & $\begin{array}{c}\text { Probability of } \mathbf{0} \\
\text { in-place resources } \\
\text { (percent) }\end{array}$ \\
\hline 2010 & 18,670 & 74 & 84 & 96 & 44 \\
\hline
\end{tabular}

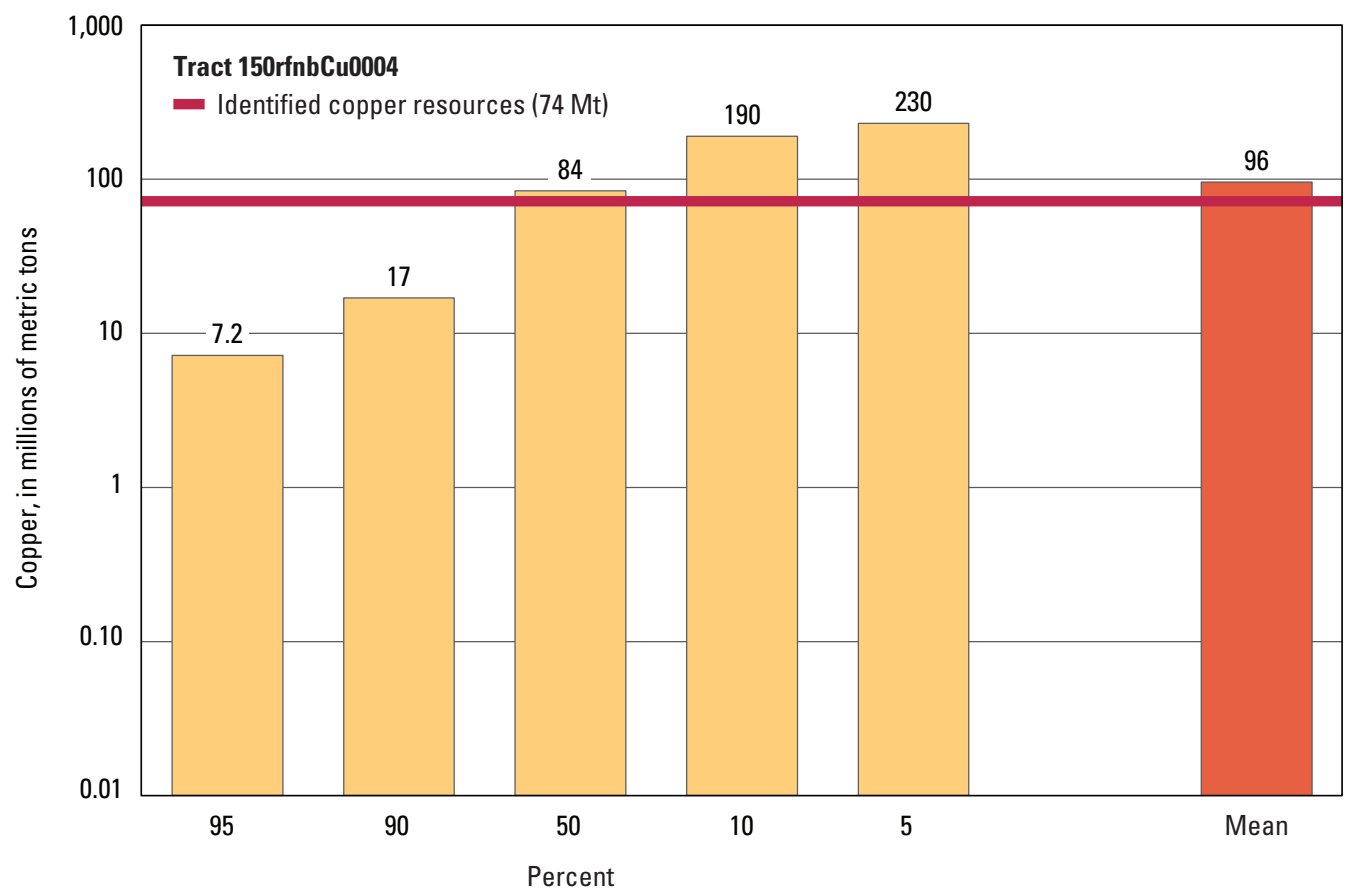

Graph showing the estimated probability distribution of undiscovered copper resources, where each bar represents the minimum amount estimated at the indicated percentage.

\section{Source}

Zientek, Oszczepalski, and others, 2015, Assessment of undiscovered copper resources associated with the Permian Kupferschiefer, Southern Permian Basin, Europe: U.S. Geological Survey Scientific Investigations Report 2010-5090-U, http://dx.doi.org/10.3133/sir20105090U. 

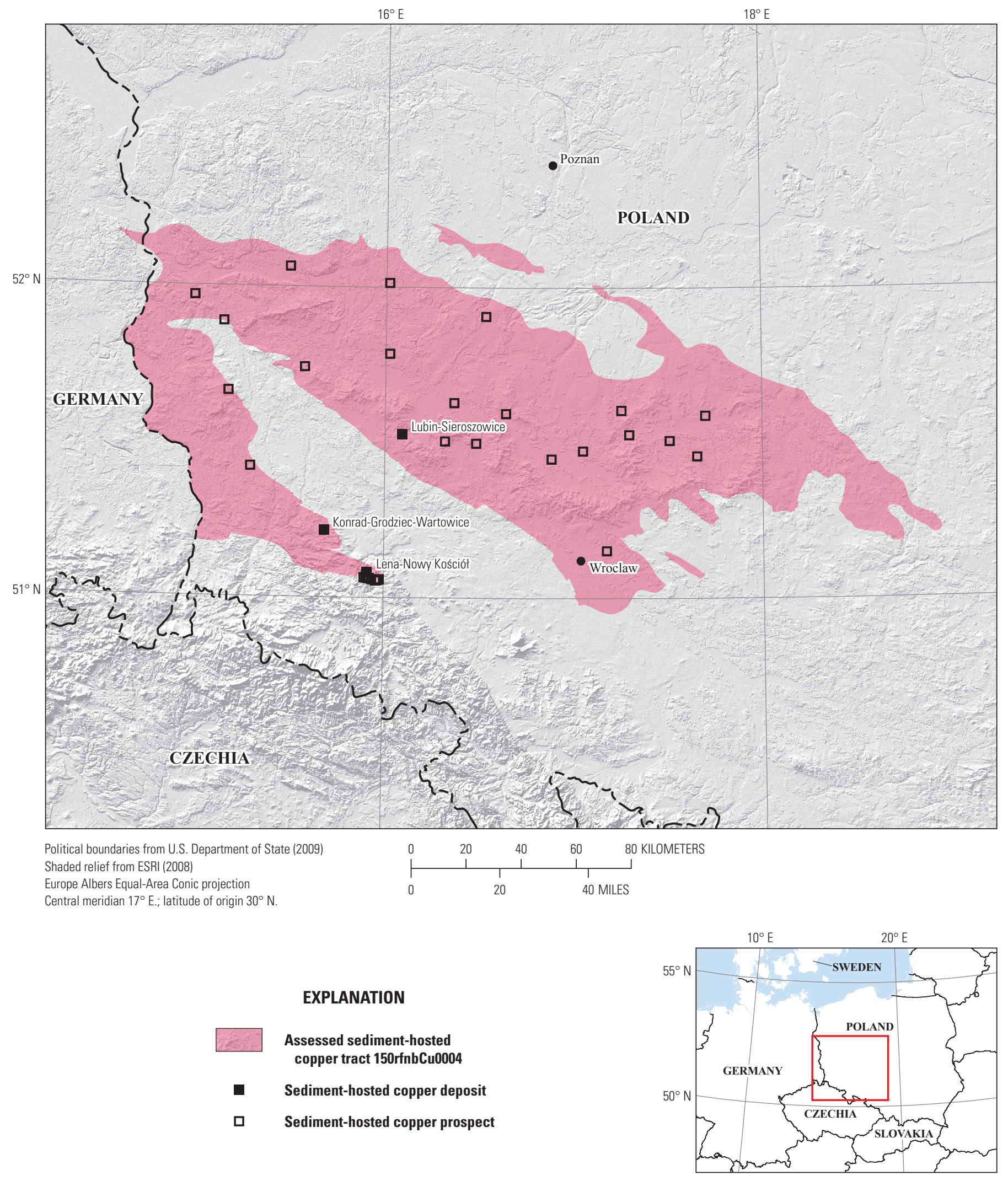


\section{Plate 224. Sediment-Hosted Stratabound Copper Assessment for Tract 150rfnbCu0005, Spremberg-Wittenberg, Southern Permian Basin-Germany}

\author{
Descriptive model: \\ Grade and tonnage model: \\ Geologic feature assessed:
}

Number of known deposits:

\begin{abstract}
Sediment-hosted stratabound copper-Reduced-facies-nonbrecciated copper subtype model (Cox and others, 2007; Zientek, Hayes, and Hammarstrom, 2013)

Sediment-hosted stratabound copper-Reduced-facies-nonbrecciated copper subtype model (Zientek, Hayes, and Taylor, 2013)

Marine carbonaceous rocks of the Lopingian (Upper Permian) Kupferschiefer bed overlying Permian reservoir-facies, continental clastic rocks of the upper Rotliegend Formation in the Barnim Basin in the Spremberg-Wittenberg area of the Southern Permian Basin
\end{abstract}

2

\section{Selected Resource Assessment Results for Sediment-Hosted Stratabound Copper}

[Assessment depth, 2.5 kilometers ( $\mathrm{km}) ; \mathrm{km}^{2}$, square kilometer; Mt, millions of metric tons]

\begin{tabular}{ccccccc}
\hline \multirow{2}{*}{$\begin{array}{c}\text { Date of } \\
\text { assessment }\end{array}$} & $\begin{array}{c}\text { Tract area } \\
\left(\mathbf{k m}^{2}\right)\end{array}$ & $\begin{array}{c}\text { Identified } \\
\text { copper } \\
\text { resources } \\
(\mathbf{M t})\end{array}$ & $\begin{array}{c}\text { Median estimate of } \\
\text { in-place resources } \\
(\mathbf{M t})\end{array}$ & $\begin{array}{c}\text { Mean estimate of } \\
\text { in-place resources } \\
\text { (Mt) }\end{array}$ & $\begin{array}{c}\text { Probability of mean } \\
\text { or greater } \\
\text { (percent) }\end{array}$ & $\begin{array}{c}\text { Probability of } 0 \\
\text { in-place resources } \\
\text { (percent) }\end{array}$ \\
\hline 2010 & 6,144 & 1.5 & 3.3 & 11 & 30 \\
\hline
\end{tabular}

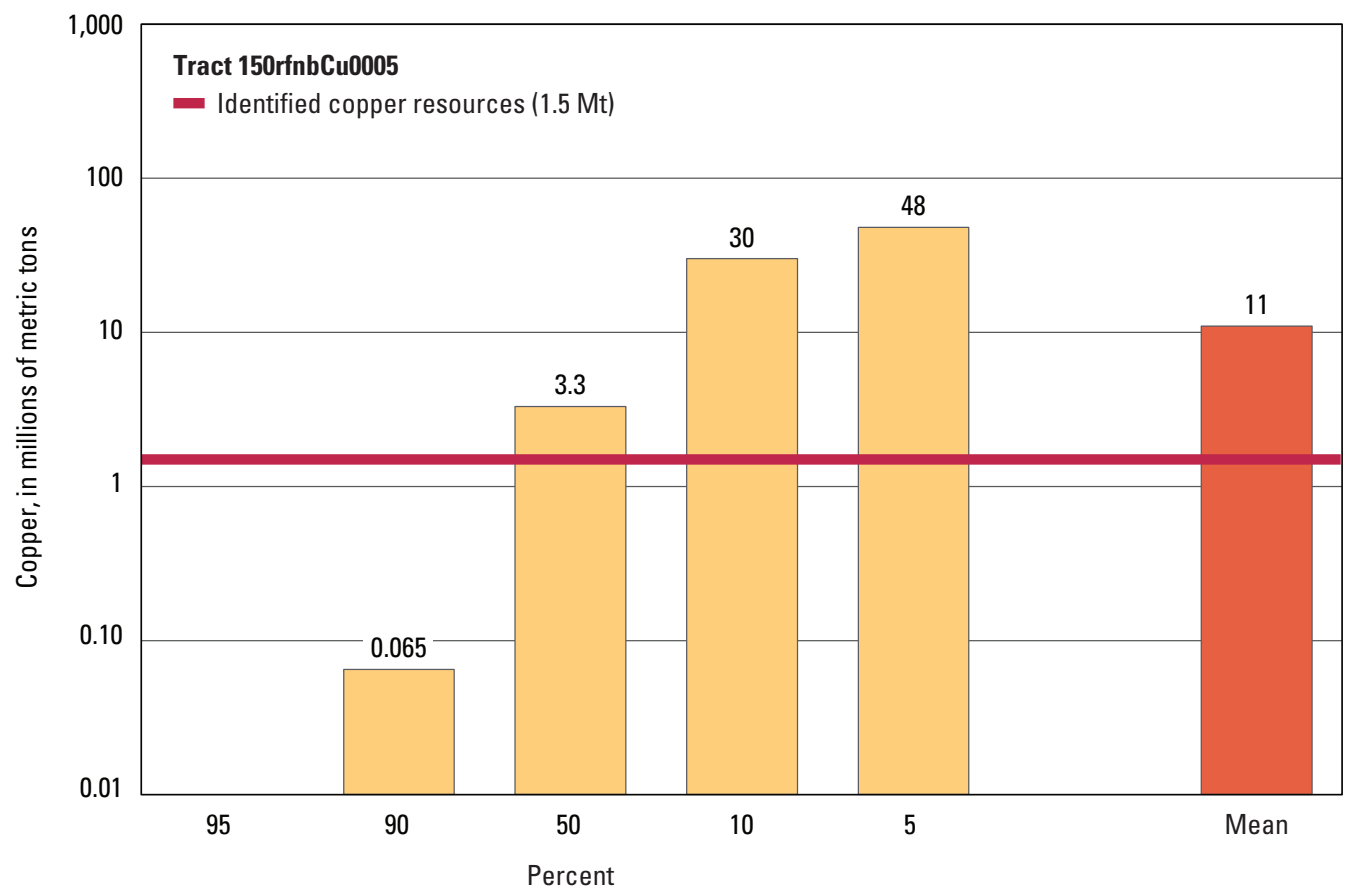

Graph showing the estimated probability distribution of undiscovered copper resources, where each bar represents the minimum amount estimated at the indicated percentage.

\section{Source}

Zientek, Oszczepalski, and others, 2015, Assessment of undiscovered copper resources associated with the Permian Kupferschiefer, Southern Permian Basin, Europe: U.S. Geological Survey Scientific Investigations Report 2010-5090-U, http://dx.doi.org/10.3133/sir20105090U. 


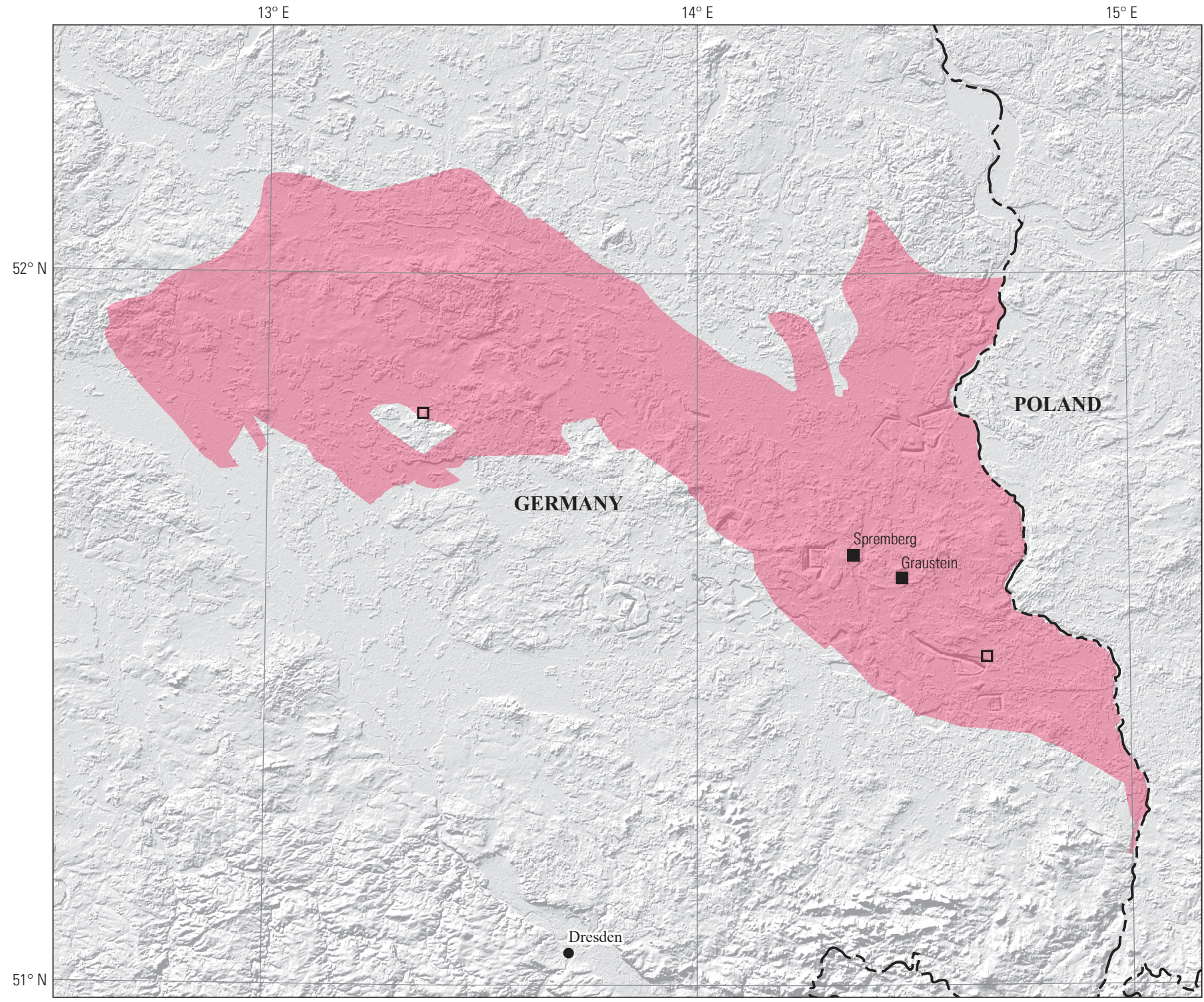

Political boundaries from U.S. Department of State (2009) Shaded relief from ESRI (2008)

Europe Albers Equal-Area Conic projection

Central meridian $14^{\circ} \mathrm{E} . ;$ latitude of origin $30^{\circ} \mathrm{N}$

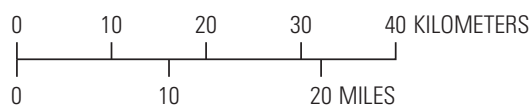

\section{EXPLANATION}

\section{Assessed sediment-hosted copper tract 150rfnbCu0005}

- Sediment-hosted copper deposit

ㄴ Sediment-hosted copper prospect

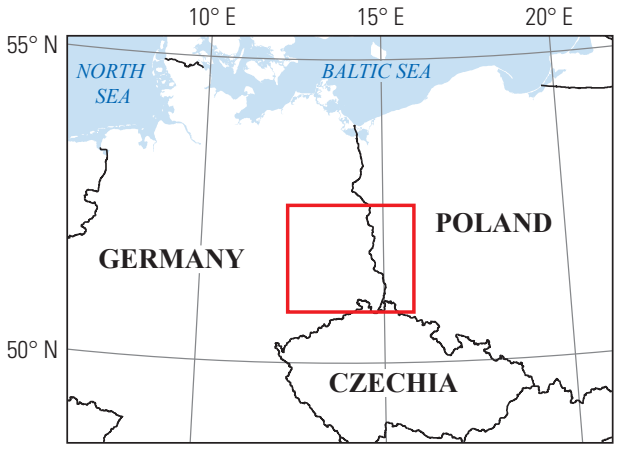




\section{Plate 225. Sediment-Hosted Stratabound Copper Assessment for Tract 150rfnbCu0006, Baltic Basin, Southern Permian Basin—Lithuania, Poland, and Russia}

Descriptive model:

Geologic feature assessed:

Number of known deposits:

\author{
Sediment-hosted stratabound copper-Reduced-facies-nonbrecciated copper subtype model \\ (Cox and others, 2007; Zientek, Hayes, and Hammarstrom, 2013) \\ Marine carbonaceous rocks of the Lopingian (Upper Permian) Kupferschiefer bed overlying \\ Permian reservoir-facies, continental clastic rocks of the upper Rotliegend Formation in the \\ Baltic Basin, Southern Permian Basin \\ 0
}

\section{Selected Resource Assessment Results for Sediment-Hosted Stratabound Copper}

[Assessment depth, 2.5 kilometers $(\mathrm{km})$; km², square kilometer; Mt, millions of metric tons; NA, not applicable, as no quantitative or AHP assessment was done]

\begin{tabular}{ccccccc}
\hline \multirow{2}{*}{$\begin{array}{c}\text { Date of } \\
\text { assessment }\end{array}$} & $\begin{array}{c}\text { Tract area } \\
\left(\mathbf{k m}^{2}\right)\end{array}$ & $\begin{array}{c}\text { Identified } \\
\text { copper } \\
\text { resources } \\
(\mathbf{M t})\end{array}$ & $\begin{array}{c}\text { Median estimate of } \\
\text { in-place resources } \\
(\mathbf{M t})\end{array}$ & $\begin{array}{c}\text { Mean estimate of } \\
\text { in-place resources } \\
\text { (Mt) }\end{array}$ & $\begin{array}{c}\text { Probability of mean } \\
\text { or greater } \\
\text { (percent) }\end{array}$ & $\begin{array}{c}\text { Probability of } 0 \\
\text { in-place resources } \\
\text { (percent) }\end{array}$ \\
\hline 2010 & 53,084 & 0 & NA & NA & NA \\
\hline
\end{tabular}

\section{Qualitative Assessment}

Tract $150 \mathrm{rfnbCu} 0006$ consists of three areas in the Baltic Basin where Kupferschiefer or correlative rocks occur. Likely host rocks for copper mineralization are thin in these areas. Metal concentrations and mineralogy encountered in drilling do not indicate the presence of a significant copper ore system. Therefore, no further assessment was done.

\section{Source}

Zientek, Oszczepalski, and others, 2015, Assessment of undiscovered copper resources associated with the Permian Kupferschiefer, Southern Permian Basin, Europe: U.S. Geological Survey Scientific Investigations Report 2010-5090-U, http://dx.doi.org/10.3133/sir20105090U. 


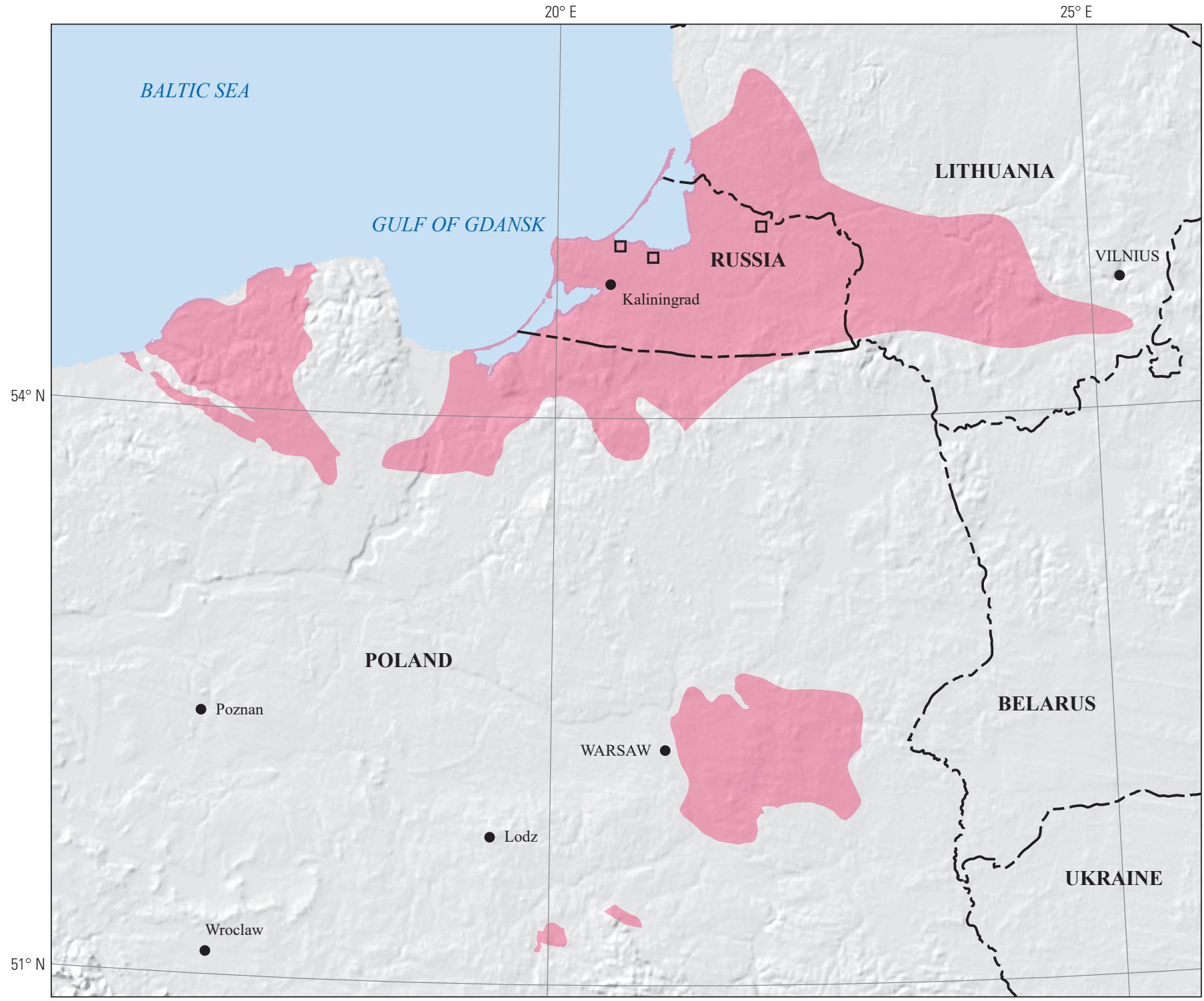

Political boundaries from U.S. Department of State (2009) Shaded relief from Earth Resources Observation and Science (EROS) Center (2011)

Europe Albers Equal-Area Conic projection

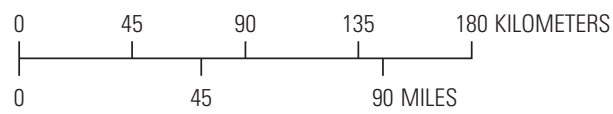

Central meridian $21^{\circ} \mathrm{E}$.; latitude of origin $30^{\circ} \mathrm{N}$

\section{EXPLANATION}

Assessed sediment-hosted copper tract 150rfnbCu0006

$\square \quad$ Sediment-hosted copper prospect

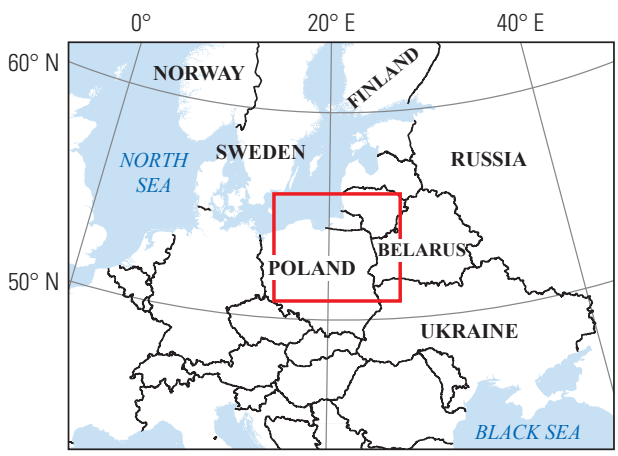




\section{Plate 226. Sediment-Hosted Stratabound Copper Assessment for Tract 150rfnbCu0007, Jutland Peninsula, Southern Permian Basin—Denmark and Germany}

Descriptive model:

Geologic feature assessed:

Number of known deposits:

\author{
Sediment-hosted stratabound copper-Reduced-facies-nonbrecciated copper subtype model \\ (Cox and others, 2007; Zientek, Hayes, and Hammarstrom, 2013) \\ Marine carbonaceous rocks of the Lopingian (Upper Permian) Kupferschiefer bed overlying \\ Permian reservoir-facies, continental clastic rocks of the upper Rotliegend Formation near \\ Jutland, Southern Permian Basin \\ 0
}

\section{Selected Resource Assessment Results for Sediment-Hosted Stratabound Copper}

[Assessment depth, 2.5 kilometers $(\mathrm{km})$; km², square kilometer; Mt, millions of metric tons; NA, not applicable, as no quantitative or AHP assessment was done]

\begin{tabular}{ccccccc}
\hline \multirow{2}{*}{$\begin{array}{c}\text { Date of } \\
\text { assessment }\end{array}$} & $\begin{array}{c}\text { Tract area } \\
\left(\mathbf{k m}^{2}\right)\end{array}$ & $\begin{array}{c}\text { Identified } \\
\text { copper } \\
\text { resources } \\
(\mathbf{M t})\end{array}$ & $\begin{array}{c}\text { Median estimate of } \\
\text { in-place resources } \\
(\mathbf{M t})\end{array}$ & $\begin{array}{c}\text { Mean estimate of } \\
\text { in-place resources } \\
\text { (Mt) }\end{array}$ & $\begin{array}{c}\text { Probability of mean } \\
\text { or greater } \\
\text { (percent) }\end{array}$ & $\begin{array}{c}\text { Probability of } 0 \\
\text { in-place resources } \\
\text { (percent) }\end{array}$ \\
\hline 2010 & 4,157 & 0 & NA & NA & NA \\
\hline
\end{tabular}

\section{Qualitative Assessment}

Permissive tract 150rfnbCu0007 occurs where the Kupferschiefer overlies Rotliegend rocks in the Jutland Peninsula. This tract has a generally favorable paleotopographic setting where the Kupferschiefer and subjacent Rotliegend onlap on local basement rock highs. However, the basal Zechstein rocks (including the Kupferschiefer) are buried everywhere by at least $1.3 \mathrm{~km}$ of younger sedimentary rocks. The tract locally contains Rote Fäule alteration, a positive indication of copper mineralization. However, copper concentrations in 10 holes along the 190-km length of the alteration zone are only slightly above background levels, and no significant copper enrichments have been identified within the tract area.

\section{Source}

Zientek, Oszczepalski, and others, 2015, Assessment of undiscovered copper resources associated with the Permian Kupferschiefer, Southern Permian Basin, Europe: U.S. Geological Survey Scientific Investigations Report 2010-5090-U, http://dx.doi.org/10.3133/sir20105090U. 


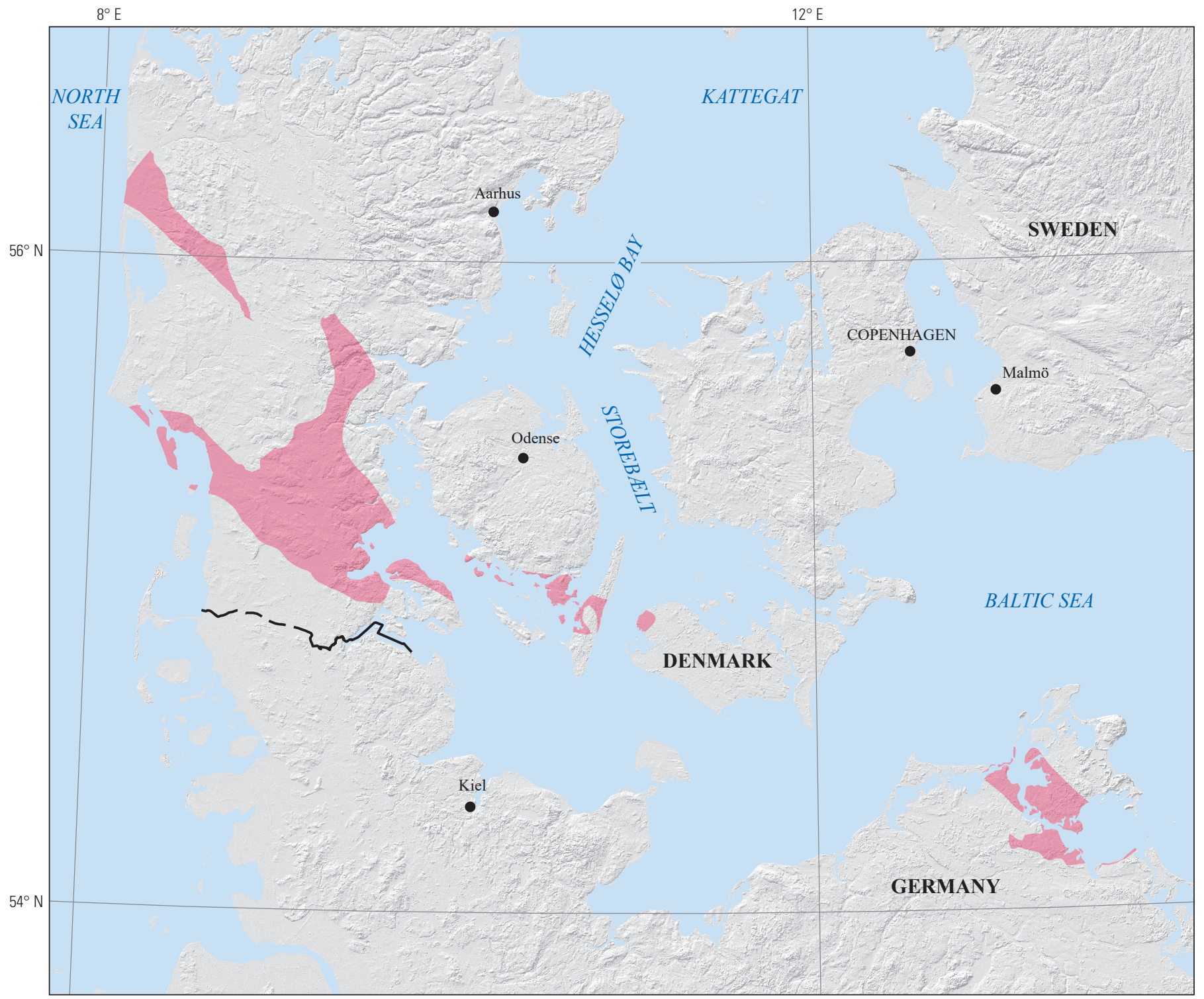

Political boundaries from U.S. Department of State (2009) Shaded relief from ESRI (2008)

Europe Albers Equal-Area Conic projection

Central meridian $11^{\circ}$ E.; latitude of origin $30^{\circ} \mathrm{N}$.

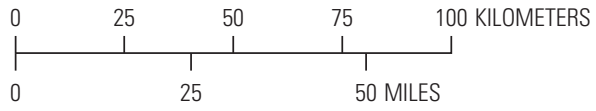

EXPLANATION

Assessed sediment-hosted copper tract 150rfnbCu0007

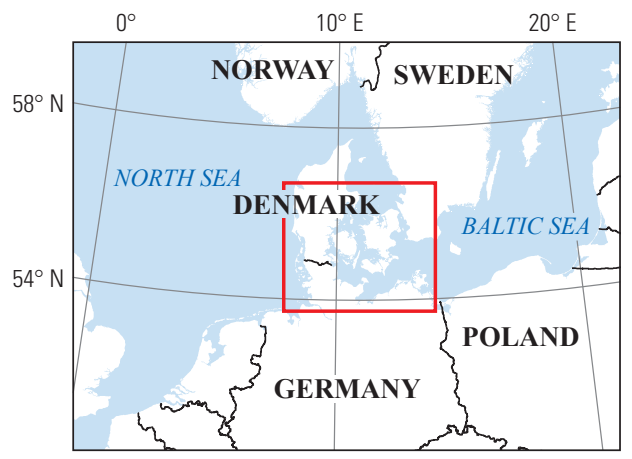




\title{
Plate 227. Sediment-Hosted Stratabound Copper Assessment for Tract 142rfCu4001, Aynak (sedcu01), Kabul Block-Afghanistan
}

\author{
Descriptive model: \\ Sediment-hosted stratabound copper-Reduced-facies copper subtype model (Cox and others, \\ 2007; Zientek, Hayes, and Hammarstrom, 2013) \\ Grade and tonnage model: \\ Sediment-hosted copper-Reduced-facies copper subtype model (30b.2) (Zientek, Hayes, and \\ Taylor, 2013) \\ Geologic feature assessed: \\ Neoproterozoic to Lower Cambrian Loy Khwar Formation, Kabul Block \\ Number of known deposits: \\ 6
}

\section{Selected Resource Assessment Results for Sediment-Hosted Stratabound Copper}

[Assessment depth, 1 kilometer (km); $\mathrm{km}^{2}$, square kilometer; Mt, millions of metric tons]

\begin{tabular}{ccccccc}
\hline $\begin{array}{c}\text { Date of } \\
\text { assessment }\end{array}$ & $\begin{array}{c}\text { Tract area } \\
\left(\mathbf{k m}^{2}\right)\end{array}$ & $\begin{array}{c}\text { Identified } \\
\text { copper } \\
\text { resources } \\
(\mathbf{M t})\end{array}$ & $\begin{array}{c}\text { Median estimate of } \\
\text { in-place resources } \\
(\mathbf{M t})\end{array}$ & $\begin{array}{c}\text { Mean estimate of } \\
\text { in-place resources } \\
\text { (Mt) }\end{array}$ & $\begin{array}{c}\text { Probability of mean } \\
\text { or greater } \\
\text { (percent) }\end{array}$ & $\begin{array}{c}\text { Probability of } \mathbf{0} \\
\text { in-place resources } \\
\text { (percent) }\end{array}$ \\
\hline 2007 & 4,439 & 6.4 & 4.8 & 13 & 31 \\
\hline
\end{tabular}

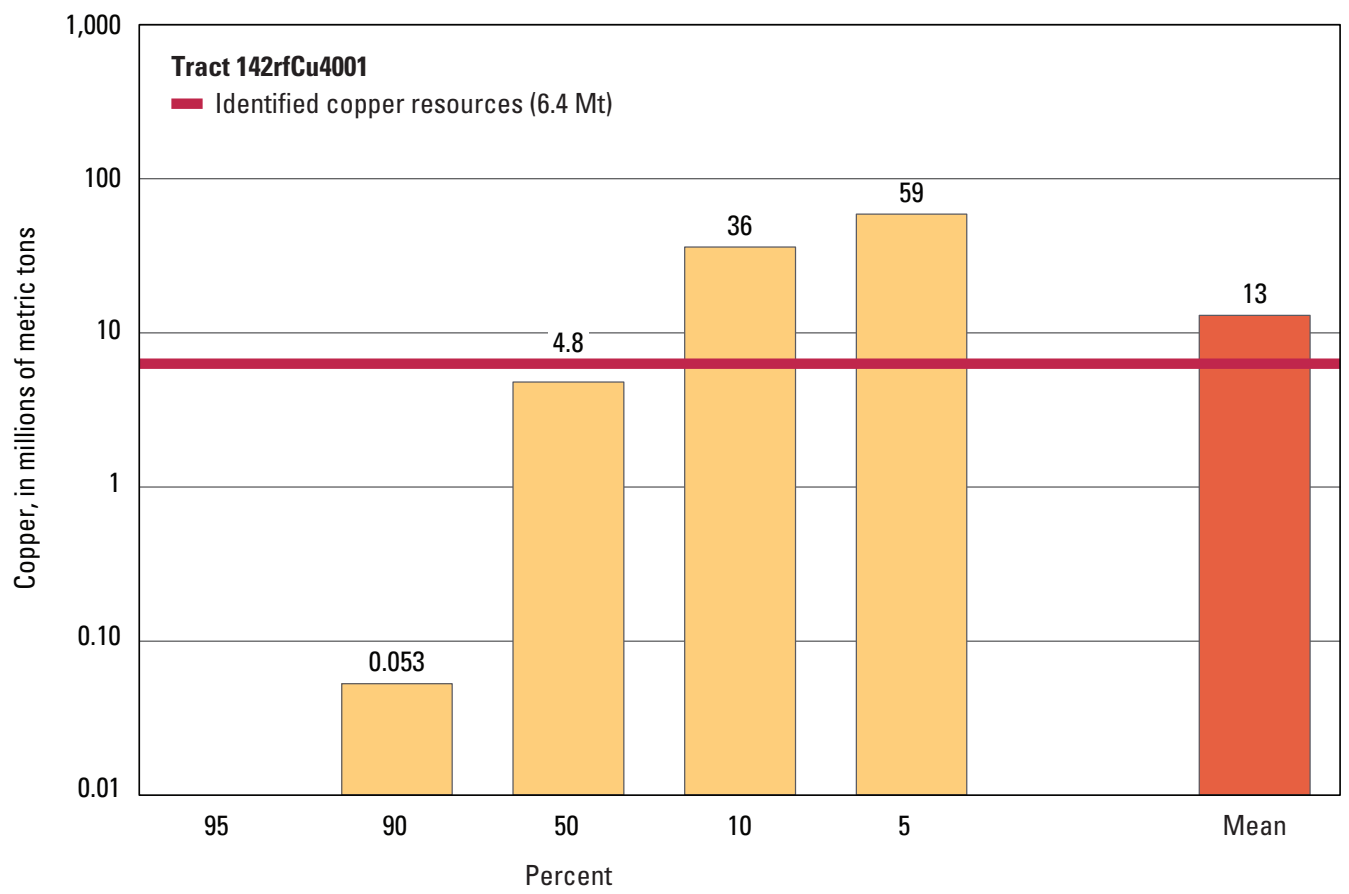

Graph showing the estimated probability distribution of undiscovered copper resources, where each bar represents the minimum amount estimated at the indicated percentage.

\section{Source}

Peters and others, 2007, Preliminary non-fuel mineral resource assessment of Afghanistan: U.S. Geological Survey Open-File Report 2007-1214, http://pubs.usgs.gov/of/2007/1214/. 

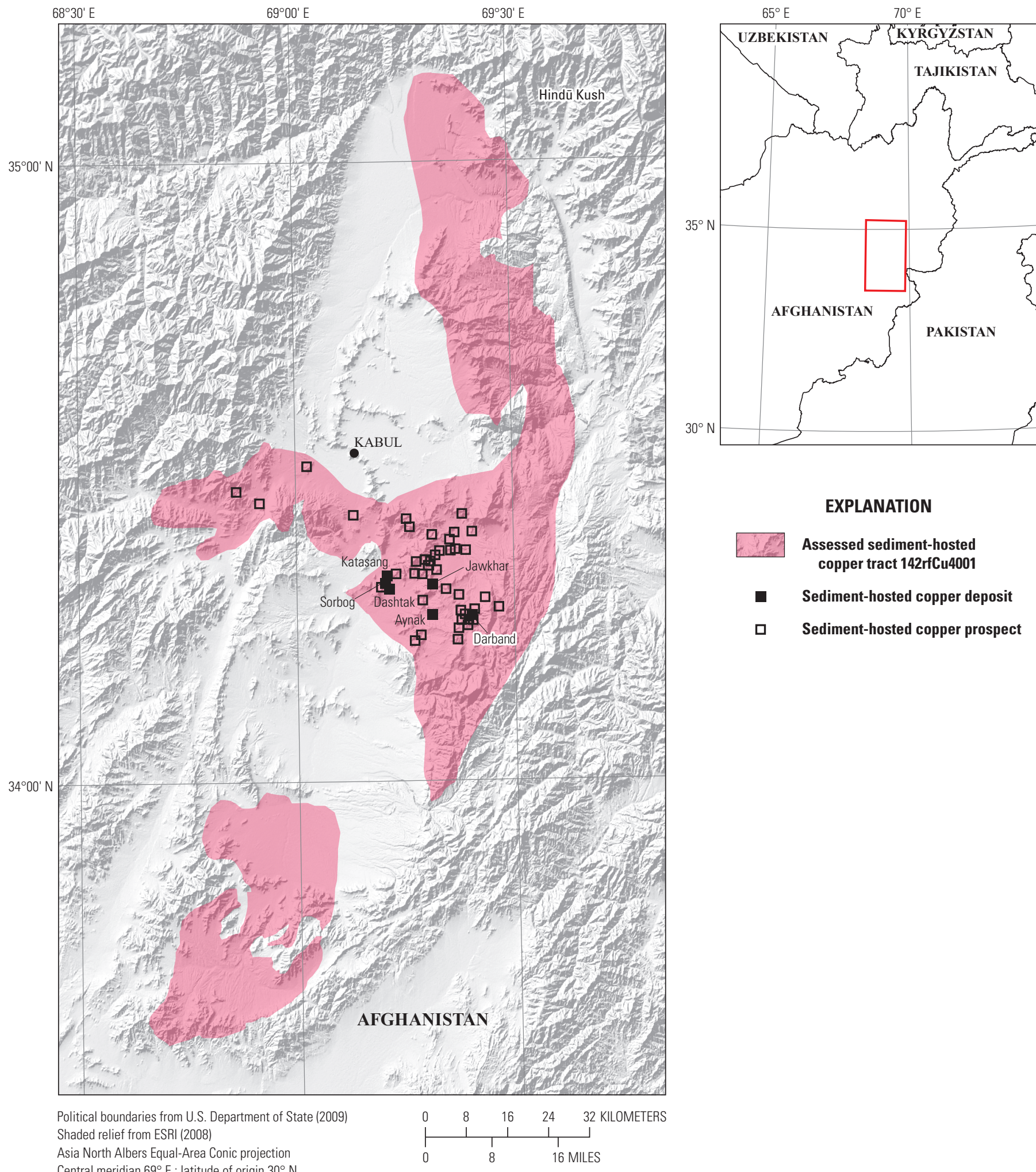

\section{EXPLANATION}

Assessed sediment-hosted copper tract 142rfCu4001

- Sediment-hosted copper deposit

ㅁ Sediment-hosted copper prospect 


\section{Plate 228. Sediment-Hosted Stratabound Copper Assessment for Tract 142rfCu4002, Kundalyan (sedcu02), Kundalyan Area-Afghanistan}

Descriptive model:

Geologic feature assessed:

Number of known deposits:
Sediment-hosted stratabound copper-Reduced-facies copper subtype model (Cox and others, 2007; Zientek, Hayes, and Hammarstrom, 2013)

Neoproterozoic to Lower Cambrian Loy Khwar Formation in the southwestern part of Zabul Province

0

\section{Selected Resource Assessment Results for Sediment-Hosted Stratabound Copper}

[Assessment depth, 1 kilometer $(\mathrm{km}) ; \mathrm{km}^{2}$, square kilometer; Mt, millions of metric tons; NA, not applicable, as no quantitative or AHP assessment was done]

\begin{tabular}{ccccccc}
\hline \multirow{2}{*}{$\begin{array}{c}\text { Date of } \\
\text { assessment }\end{array}$} & $\begin{array}{c}\text { Tract area } \\
\left(\mathbf{k m}^{2}\right)\end{array}$ & $\begin{array}{c}\text { Identified } \\
\text { copper } \\
\text { resources } \\
(\mathbf{M t})\end{array}$ & $\begin{array}{c}\text { Median estimate of } \\
\text { in-place resources } \\
(\mathbf{M t})\end{array}$ & $\begin{array}{c}\text { Mean estimate of } \\
\text { in-place resources } \\
\text { (Mt) }\end{array}$ & $\begin{array}{c}\text { Probability of mean } \\
\text { or greater } \\
\text { (percent) }\end{array}$ & $\begin{array}{c}\text { Probability of } 0 \\
\text { in-place resources } \\
\text { (percent) }\end{array}$ \\
\hline 2007 & 331 & 0 & NA & NA & NA & NA \\
\hline
\end{tabular}

\section{Qualitative Assessment}

No known stratabound copper-bearing mineral occurrences are within any of the tract areas, although a number of copper skarn occurrences are present in the southern parts of tract 142rfCu4002. No known exploration for stratabound copper deposits has taken place within the tract. However, extensive exploration for igneous-related, base- and precious-metal deposits has occurred throughout and adjacent to most parts of the tract. Intermediate-scale $(1: 100,000)$ geologic mapping of the parts of the tract that have anomalous concentrations of copper minerals would improve the assessment.

An optimistic factor for undiscovered deposits is that large copper resources occur in tract 142rfCu4001 (pl. 227) to the north in the same stratigraphic sequence. However, no known stratabound occurrences are present in tract $142 \mathrm{rfCu} 4002$. No quantitative assessment was made due to low probabilities of occurrence and insufficient knowledge about the tract.

\section{Source}

Peters and others, 2007, Preliminary non-fuel mineral resource assessment of Afghanistan: U.S. Geological Survey Open-File Report 2007-1214, http://pubs.usgs.gov/of/2007/1214/. 


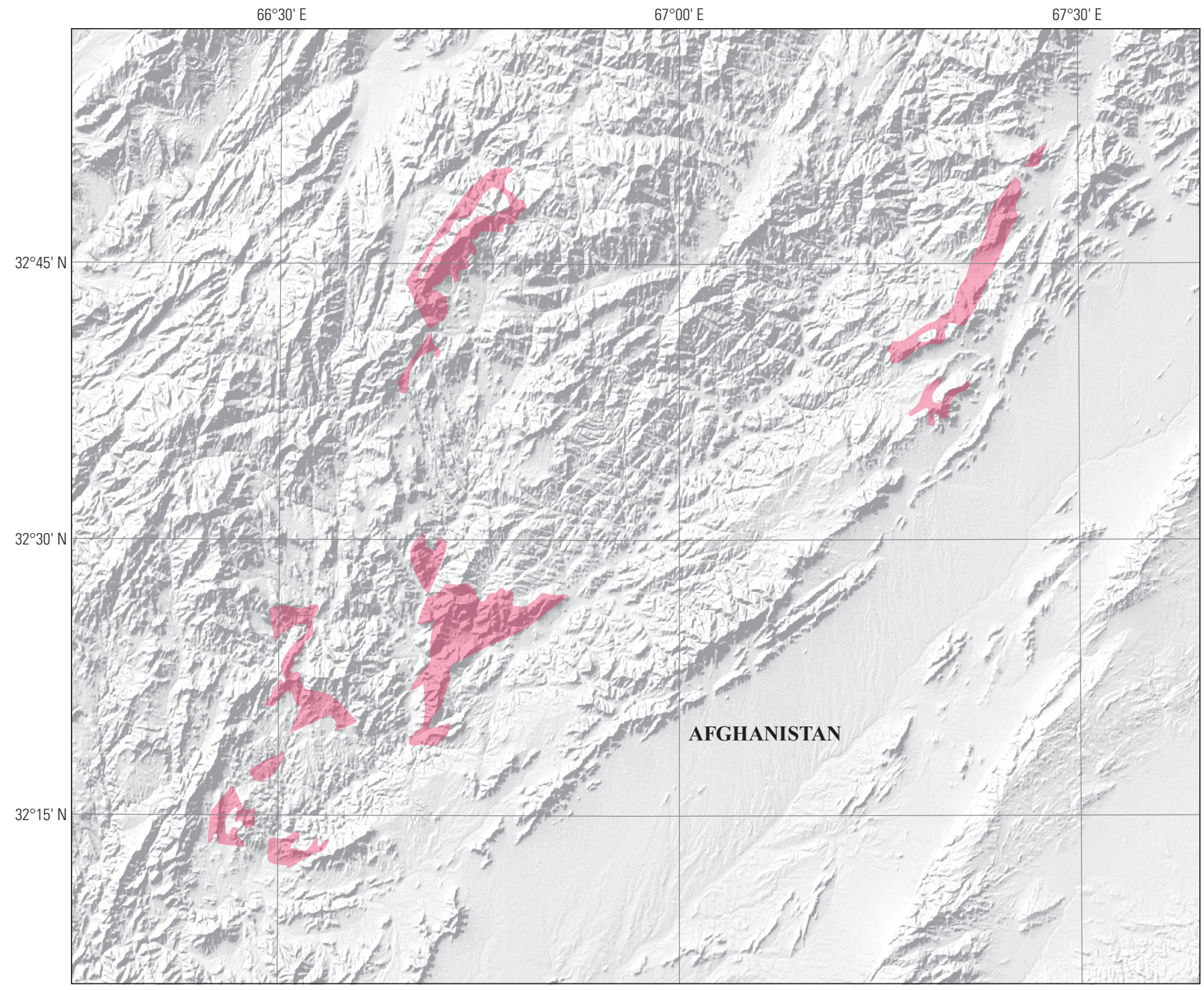

Political boundaries from U.S. Department of State (2009) Shaded relief from Earth Resources Observation and Science (EROS) Center (2011)

Asia North Albers Equal-Area Conic projection

Central meridian $67^{\circ} \mathrm{E}$.; latitude of origin $30^{\circ} \mathrm{N}$.

EXPLANATION

Assessed sediment-hosted copper tract 142 rfCu4002

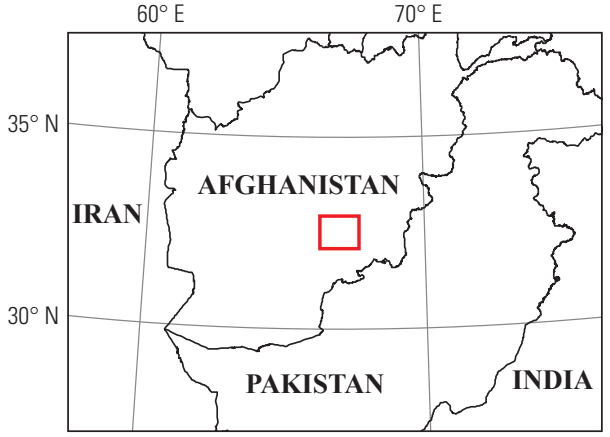




\title{
Plate 229. Sediment-Hosted Stratabound Copper Assessment for Tract 002rfCu2001, Egypt-Israel-Jordan Rift-Egypt, Israel, and Jordan
}

\author{
Descriptive model: \\ Geologic feature assessed: \\ Number of known deposits:
}

Sediment-hosted stratabound copper-Reduced-facies copper subtype model (Cox and others, 2007; Zientek, Hayes, and Hammarstrom, 2013)

Marine carbonaceous rocks of the Middle Cambrian Burj, Timna, and Nasib Formations, Egypt-Israel-Jordan Rift

4

\section{Selected Resource Assessment Results for Sediment-Hosted Stratabound Copper}

[Assessment depth, 0 kilometers $(\mathrm{km}) ; \mathrm{km}^{2}$, square kilometer; Mt, millions of metric tons]

\begin{tabular}{|c|c|c|c|c|}
\hline \multirow[b]{2}{*}{$\begin{array}{c}\text { Date of } \\
\text { assessment }\end{array}$} & \multirow[b]{2}{*}{$\begin{array}{c}\text { Tract area } \\
\quad\left(\mathbf{k m}^{2}\right)\end{array}$} & \multirow{2}{*}{$\begin{array}{l}\text { Identified } \\
\text { copper } \\
\text { resources } \\
\text { (Mt) }\end{array}$} & \multicolumn{2}{|c|}{ Qualitative assessment ranking } \\
\hline & & & $\begin{array}{c}\text { Analytic hierarchy process- } \\
\text { Alternative utility* } \\
\text { (percent) }\end{array}$ & Overall rank \\
\hline 2012 & 25,992 & 1.5 & 12.3 & $3 \mathrm{~d}$ of 10 areas \\
\hline
\end{tabular}

"Alternative utility is a numerical weight derived from evaluation of three assessment criteria.

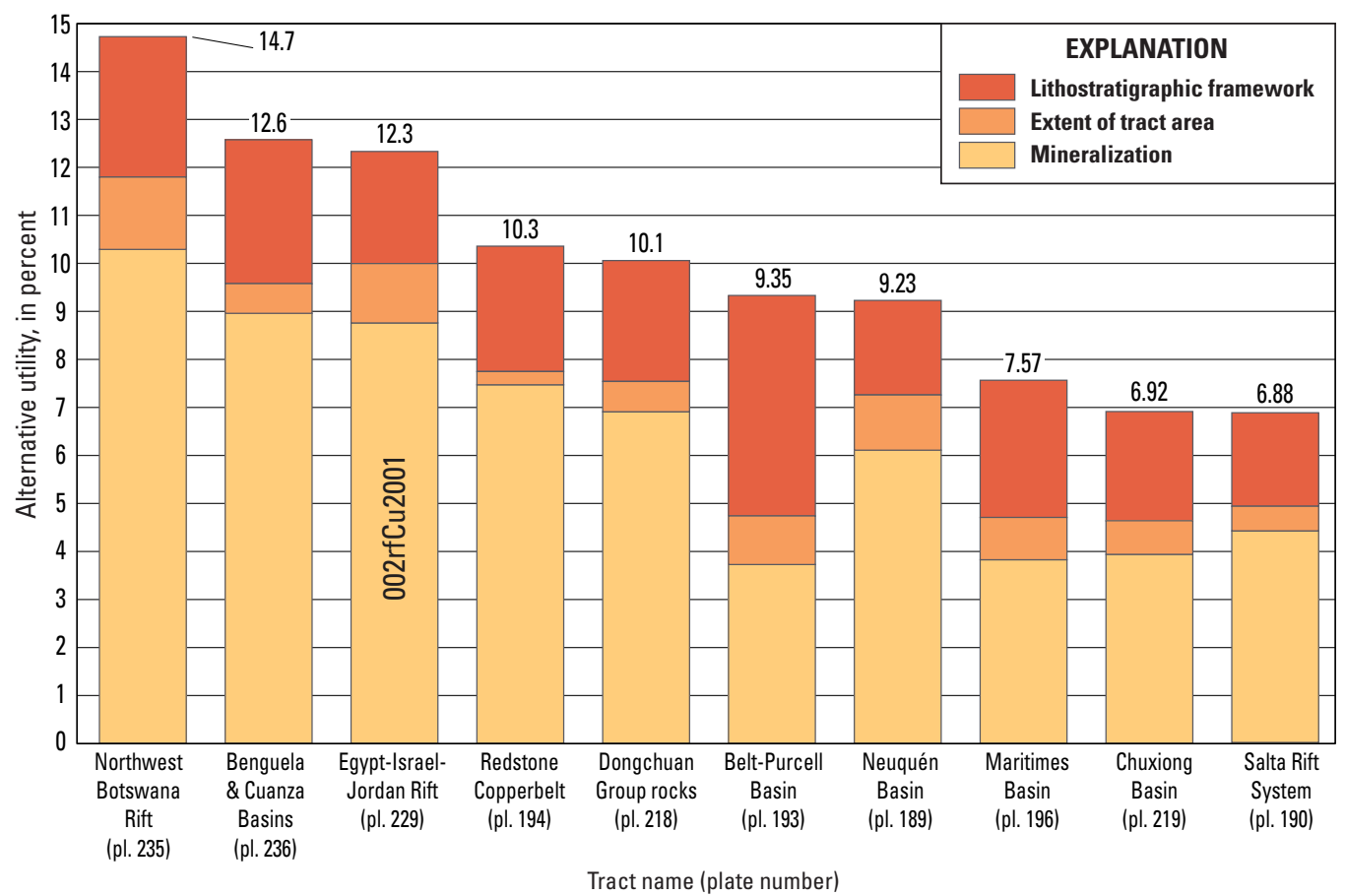

Graph showing qualitative ranking of basins determined by the analytic hierarchy process (AHP). Alternative utility is the overall score derived from the AHP method.

\section{Source}

Zientek, Wintzer, and others, 2015, Qualitative assessment of selected areas of the world for undiscovered sediment-hosted stratabound copper deposits: U.S. Geological Survey Scientific Investigations Report 2010-5090-Y, http://dx.doi.org/10.3133/sir20105090Y. 


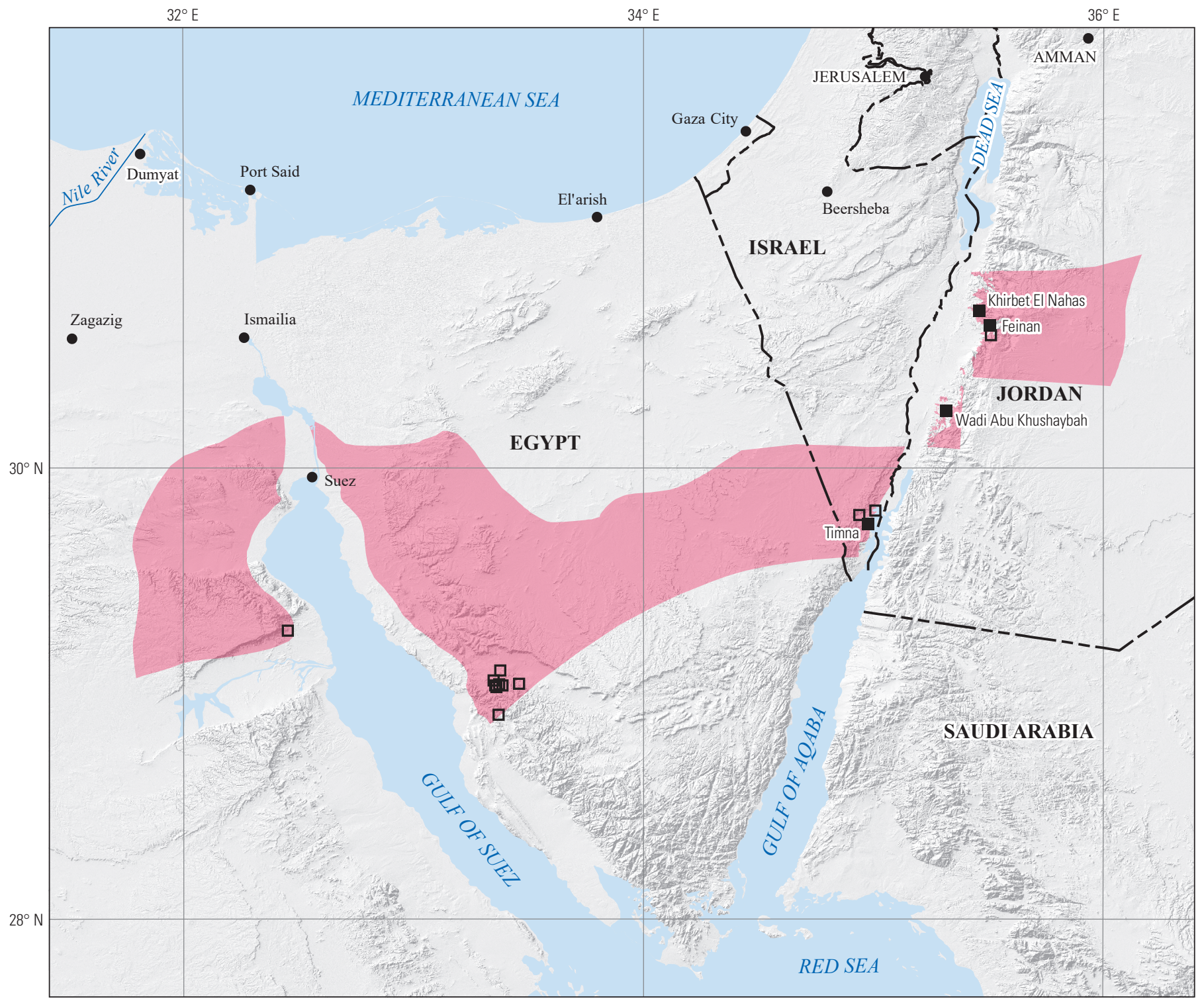

Political boundaries from U.S. Department of State (2009) Shaded relief from ESRI (2008)

Africa Albers Equal-Area Conic projection

Central meridian $34^{\circ} \mathrm{E}$; , latitude of origin $0^{\circ}$

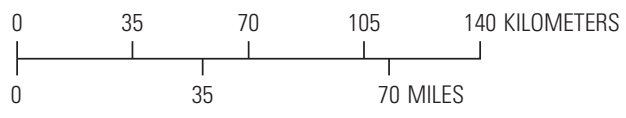

\section{EXPLANATION}

Assessed sediment-hosted copper tract 002rfCu2001

- Sediment-hosted copper deposit

Sediment-hosted copper prospect

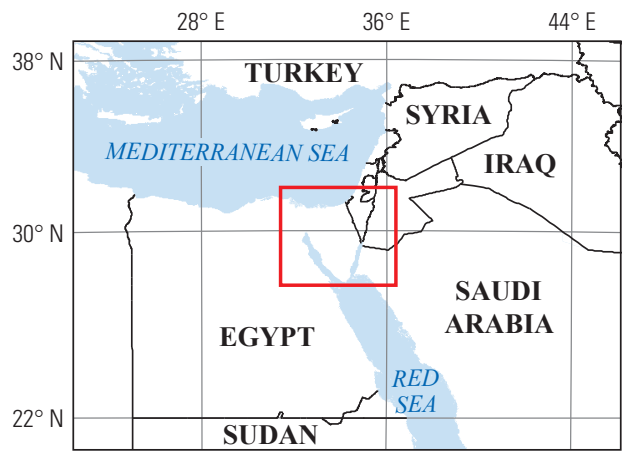




\title{
Plate 230. Sediment-Hosted Stratabound Copper Assessment for Tract 002rfceCu1000a, Southern Carbonate Écaille, Katanga Basin-Democratic Republic of the Congo
}

\author{
Descriptive model: \\ Grade and tonnage model: \\ Geologic feature assessed: \\ Number of known deposits:
}

Sediment-hosted stratabound copper-Reduced-facies-carbonate-écaille copper subtype model (Cox and others, 2007; Zientek, Hayes, and Hammarstrom, 2013)

Sediment-hosted stratabound copper-Reduced-facies-carbonate-écaille copper subtype model (Zientek, Hayes, and Taylor, 2013)

Marine carbonaceous rocks of the Neoproterozoic Mines Subgroup that overlie Neoproterozoic continental clastic rocks of the Roches Argilo-Talqueuses (R.A.T.) Subgroup, Katanga Basin

2

\section{Selected Resource Assessment Results for Sediment-Hosted Stratabound Copper}

[Assessment depth, 2 kilometers ( $\mathrm{km}) ; \mathrm{km}^{2}$, square kilometer; Mt, millions of metric tons]

\begin{tabular}{ccccccc}
\hline $\begin{array}{c}\text { Date of } \\
\text { assessment }\end{array}$ & $\begin{array}{c}\text { Tract area } \\
\left(\mathbf{k m}^{2}\right)\end{array}$ & $\begin{array}{c}\text { Identified } \\
\text { copper } \\
\text { resources } \\
(\mathbf{M t})\end{array}$ & $\begin{array}{c}\text { Median estimate of } \\
\text { in-place resources } \\
(\mathbf{M t})\end{array}$ & $\begin{array}{c}\text { Mean estimate of } \\
\text { in-place resources } \\
\text { (Mt) }\end{array}$ & $\begin{array}{c}\text { Probability of mean } \\
\text { or greater } \\
\text { (percent) }\end{array}$ & $\begin{array}{c}\text { Probability of } \mathbf{0} \\
\text { in-place resources } \\
\text { (percent) }\end{array}$ \\
\hline 2010 & 1,334 & 0.15 & 9.1 & 13 & 37 \\
\hline
\end{tabular}

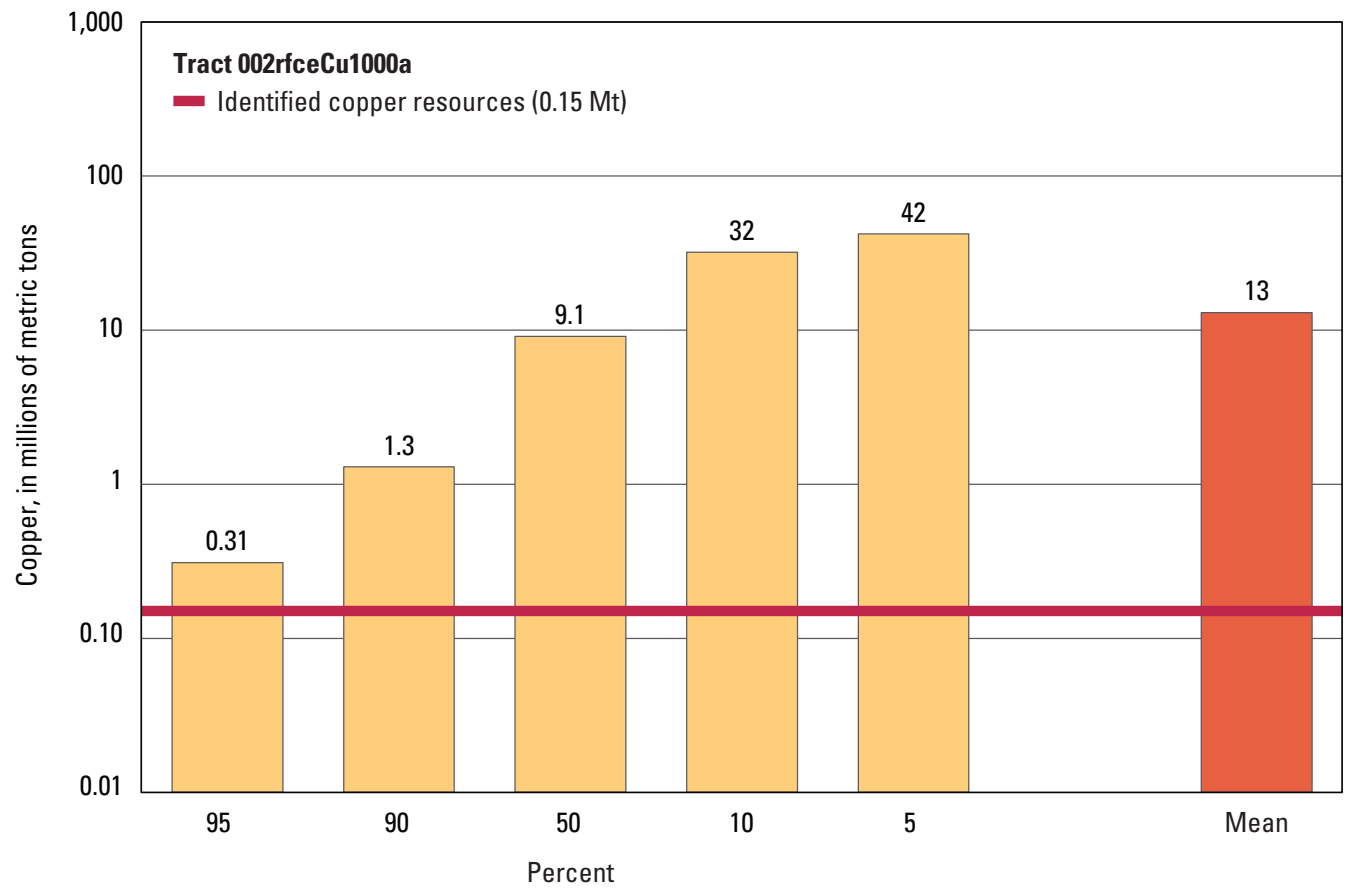

Graph showing the estimated probability distribution of undiscovered copper resources, where each bar represents the minimum amount estimated at the indicated percentage.

\section{Source}

Zientek, Bliss, and others, 2014, Sediment-hosted stratabound copper assessment of the Neoproterozoic Roan Group, Central African Copperbelt, Katanga Basin, Democratic Republic of the Congo and Zambia: U.S. Geological Survey Scientific Investigations Report 2010-5090-T, http://dx.doi.org/10.3133/sir20105090T. 


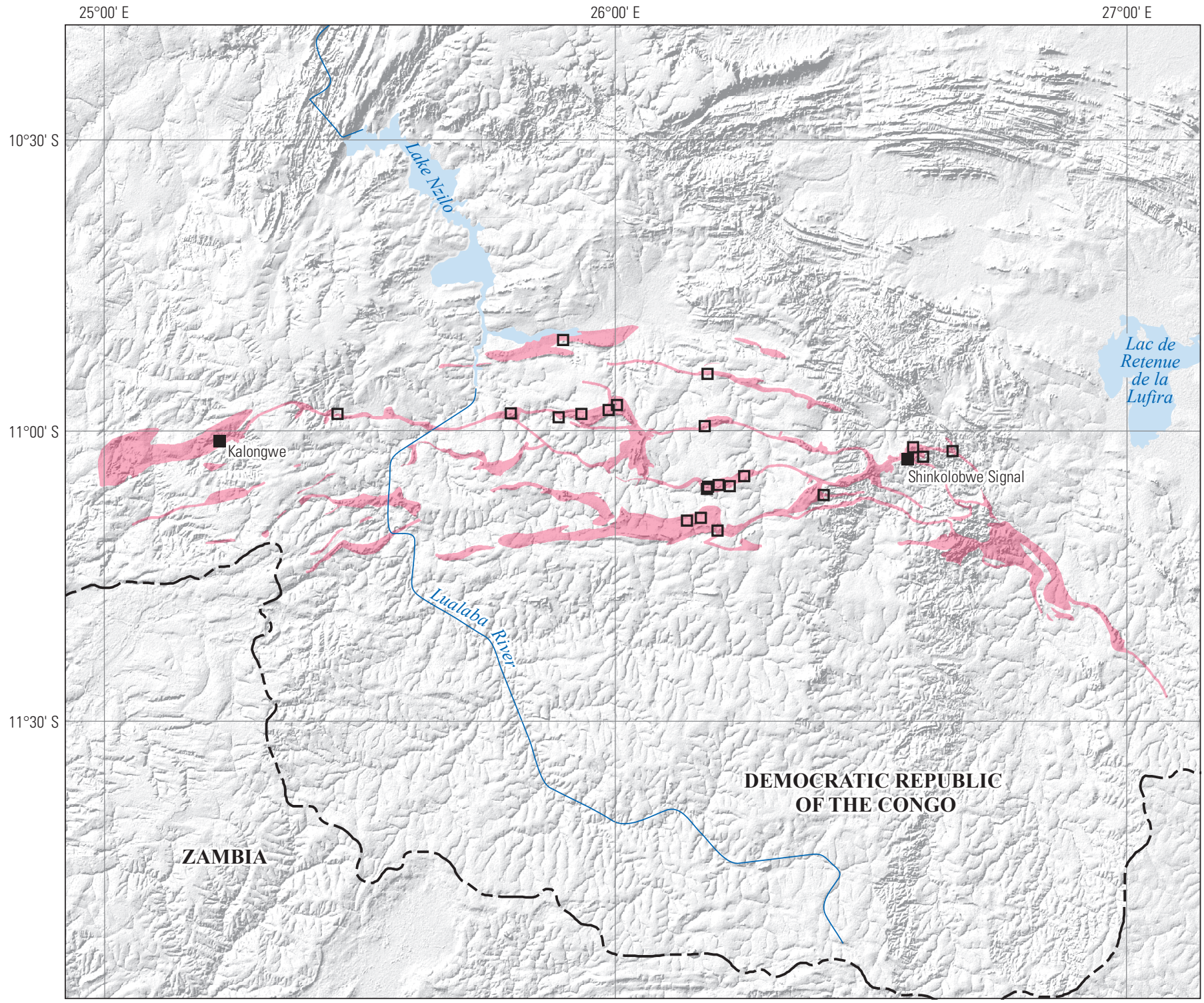

Political boundaries from U.S. Department of State (2009)

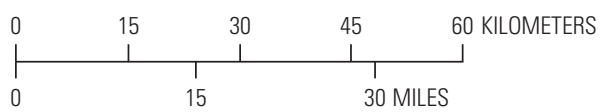

Africa Albers Equal-Area Conic projection

Central meridian $26^{\circ}$ E.; latitude of origin $0^{\circ}$

EXPLANATION

Assessed sediment-hosted copper tract 002rfceCu1000a

Sediment-hosted copper deposit

ㅁ Sediment-hosted copper prospect

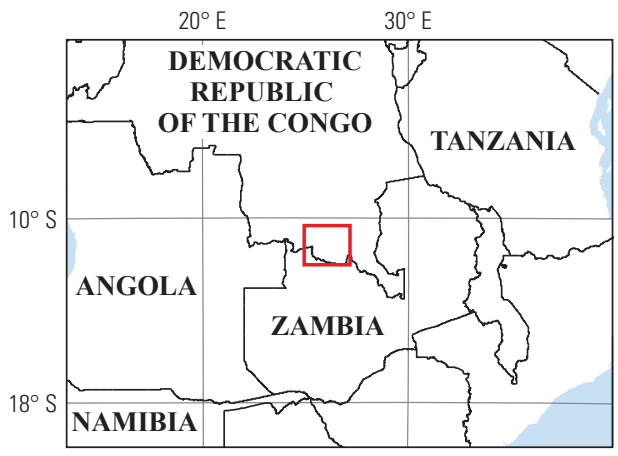




\title{
Plate 231. Sediment-Hosted Stratabound Copper Assessment for Tract 002rfceCu1000b, Central Carbonate Écaille, Katanga Basin-Democratic Republic of the Congo and Zambia
}

\author{
Descriptive model: \\ Grade and tonnage model: \\ Geologic feature assessed: \\ Number of known deposits:
}

Sediment-hosted stratabound copper-Reduced-facies-carbonate-écaille copper subtype model (Cox and others, 2007; Zientek, Hayes, and Hammarstrom, 2013)

Sediment-hosted stratabound copper-Reduced-facies-carbonate-écaille copper subtype model (Zientek, Hayes, and Taylor, 2013)

Marine carbonaceous rocks of the Neoproterozoic Mines Subgroup that overlie Neoproterozoic continental clastic rocks of the Roches Argilo-Talqueuses (R.A.T.) Subgroup, Katanga Basin 52

\section{Selected Resource Assessment Results for Sediment-Hosted Stratabound Copper}

[Assessment depth, 2 kilometers $(\mathrm{km}) ; \mathrm{km}^{2}$, square kilometer; Mt, millions of metric tons]

\begin{tabular}{ccccccc}
\hline $\begin{array}{c}\text { Date of } \\
\text { assessment }\end{array}$ & $\begin{array}{c}\text { Tract area } \\
\left(\mathbf{k m}^{2}\right)\end{array}$ & $\begin{array}{c}\text { Identified } \\
\text { copper } \\
\text { resources } \\
(\mathbf{M t})\end{array}$ & $\begin{array}{c}\text { Median estimate of } \\
\text { in-place resources } \\
(\mathbf{M t})\end{array}$ & $\begin{array}{c}\text { Mean estimate of } \\
\text { in-place resources } \\
\text { (Mt) }\end{array}$ & $\begin{array}{c}\text { Probability of mean } \\
\text { or greater } \\
\text { (percent) }\end{array}$ & $\begin{array}{c}\text { Probability of } \mathbf{0} \\
\text { in-place resources } \\
\text { (percent) }\end{array}$ \\
\hline 2010 & 3,538 & 61 & 120 & 130 & 45 \\
\hline
\end{tabular}

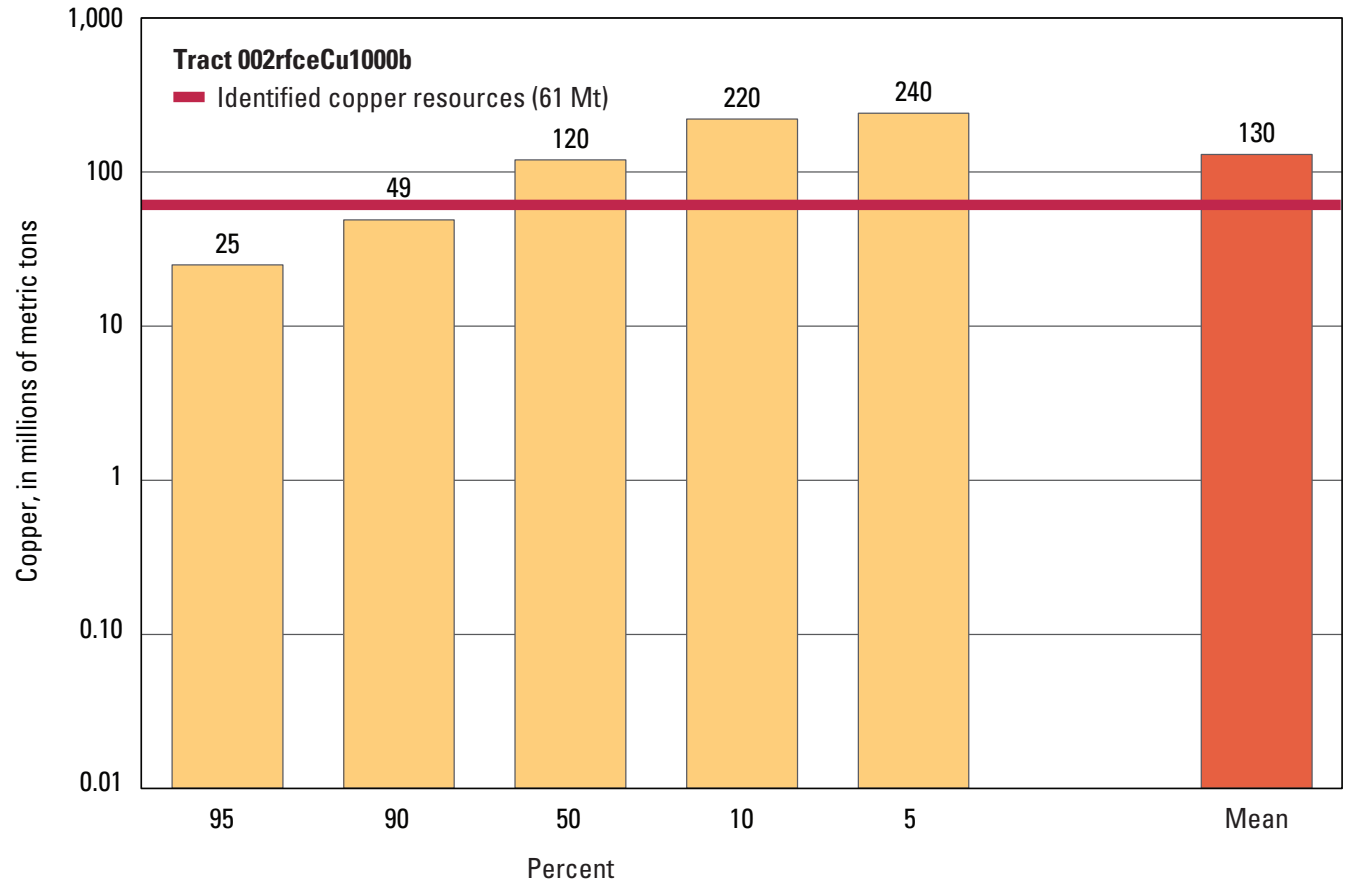

Graph showing the estimated probability distribution of undiscovered copper resources, where each bar represents the minimum amount estimated at the indicated percentage.

\section{Source}

Zientek, Bliss, and others, 2014, Sediment-hosted stratabound copper assessment of the Neoproterozoic Roan Group, Central African Copperbelt, Katanga Basin, Democratic Republic of the Congo and Zambia: U.S. Geological Survey Scientific Investigations Report 2010-5090-T, http://dx.doi.org/10.3133/sir20105090T. 


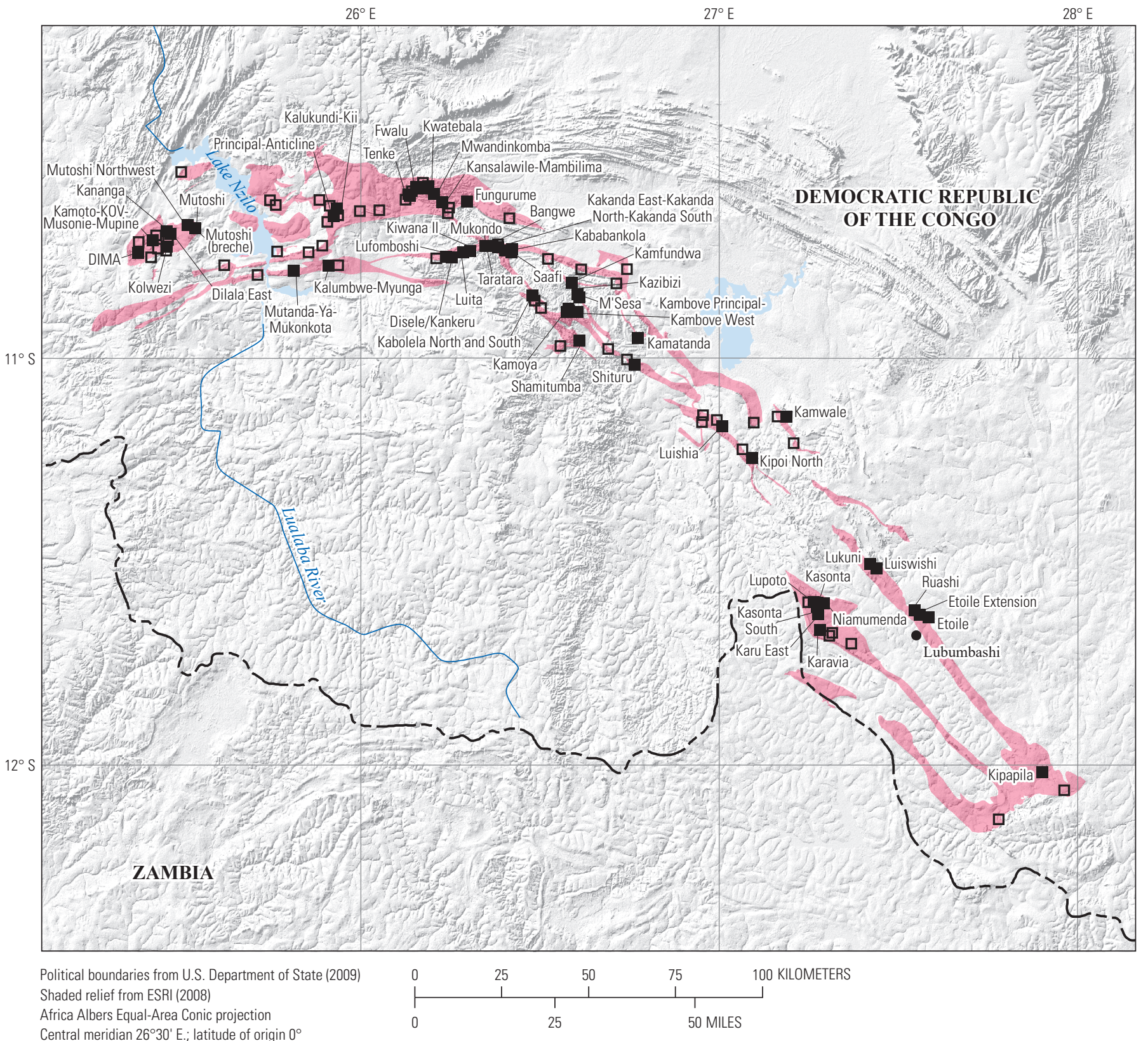

Central meridian $26^{\circ} 30^{\prime}$ E.; latitude of origin $0^{\circ}$

EXPLANATION

Assessed sediment-hosted copper tract 002rfceCu1000b

Sediment-hosted copper deposit

$\square \quad$ Sediment-hosted copper prospect

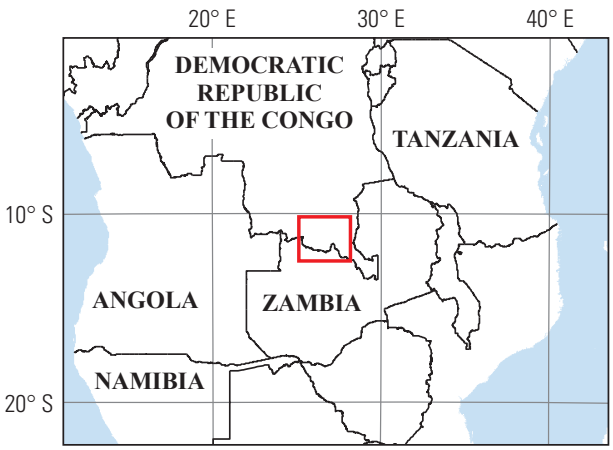




\title{
Plate 232. Sediment-Hosted Stratabound Copper Assessment for Tract 002rfceCu1000c, Northern Carbonate Écaille, Katanga Basin-Democratic Republic of the Congo
}

\author{
Descriptive model: \\ Grade and tonnage model: \\ Geologic feature assessed: \\ Number of known deposits:
}

Sediment-hosted stratabound copper-Reduced-facies-carbonate-écaille copper subtype model (Cox and others, 2007; Zientek, Hayes, and Hammarstrom, 2013)

Sediment-hosted stratabound copper-Reduced-facies-carbonate-écaille copper subtype model (Zientek, Hayes, and Taylor, 2013)

Marine carbonaceous rocks of the Neoproterozoic Mines Subgroup that overlie Neoproterozoic continental clastic rocks of the Roches Argilo-Talqueuses (R.A.T.) Subgroup, Katanga Basin

2

\section{Selected Resource Assessment Results for Sediment-Hosted Stratabound Copper}

[Assessment depth, 2 kilometers ( $\mathrm{km}) ; \mathrm{km}^{2}$, square kilometer; Mt, millions of metric tons]

\begin{tabular}{ccccccc}
\hline $\begin{array}{c}\text { Date of } \\
\text { assessment }\end{array}$ & $\begin{array}{c}\text { Tract area } \\
\left(\mathbf{k m}^{2}\right)\end{array}$ & $\begin{array}{c}\text { Identified } \\
\text { copper } \\
\text { resources } \\
(\mathbf{M t})\end{array}$ & $\begin{array}{c}\text { Median estimate of } \\
\text { in-place resources } \\
(\mathbf{M t})\end{array}$ & $\begin{array}{c}\text { Mean estimate of } \\
\text { in-place resources } \\
\text { (Mt) }\end{array}$ & $\begin{array}{c}\text { Probability of mean } \\
\text { or greater } \\
\text { (percent) }\end{array}$ & $\begin{array}{c}\text { Probability of } \mathbf{0} \\
\text { in-place resources } \\
\text { (percent) }\end{array}$ \\
\hline 2010 & 4,311 & 4.1 & 9.6 & 12 & 42 \\
\hline
\end{tabular}

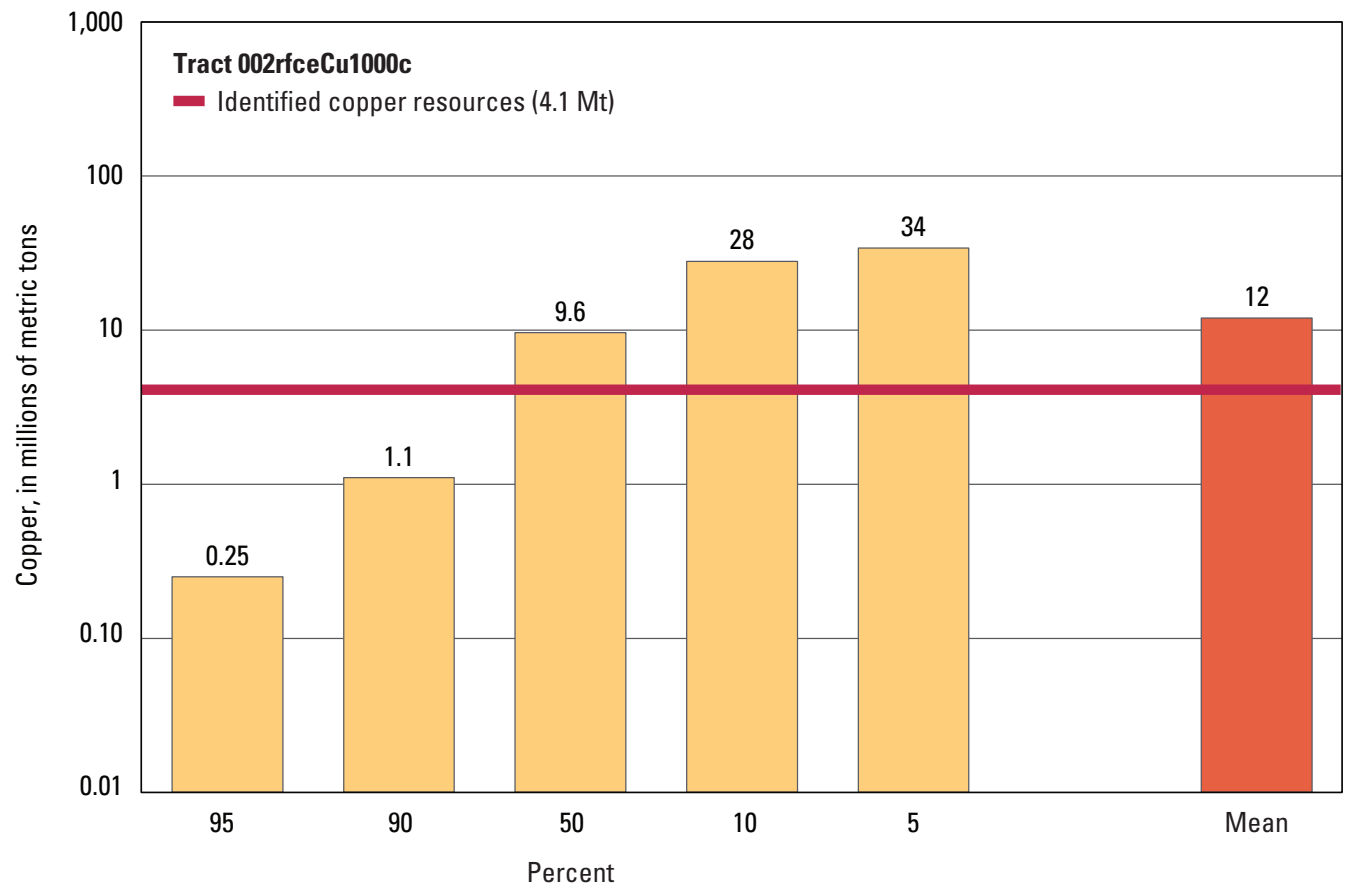

Graph showing the estimated probability distribution of undiscovered copper resources, where each bar represents the minimum amount estimated at the indicated percentage.

\section{Source}

Zientek, Bliss, and others, 2014, Sediment-hosted stratabound copper assessment of the Neoproterozoic Roan Group, Central African Copperbelt, Katanga Basin, Democratic Republic of the Congo and Zambia: U.S. Geological Survey Scientific Investigations Report 2010-5090-T, http://dx.doi.org/10.3133/sir20105090T. 


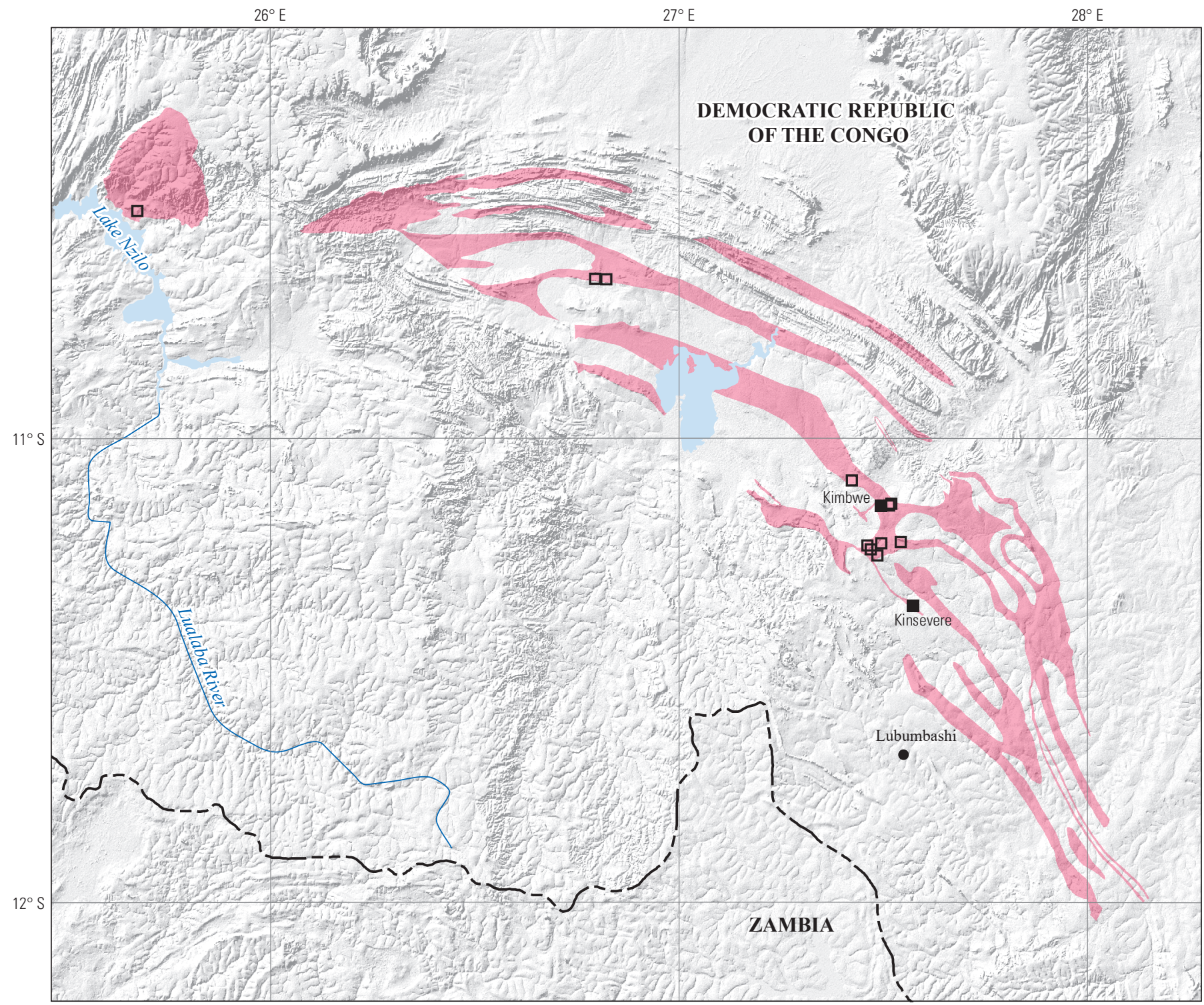

Political boundaries from U.S. Department of State (2009)

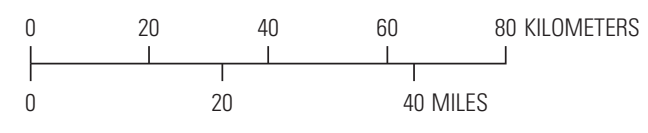

Africa Albers Equal-Area Conic projection

Central meridian $27^{\circ} \mathrm{E}$.; latitude of origin $0^{\circ}$

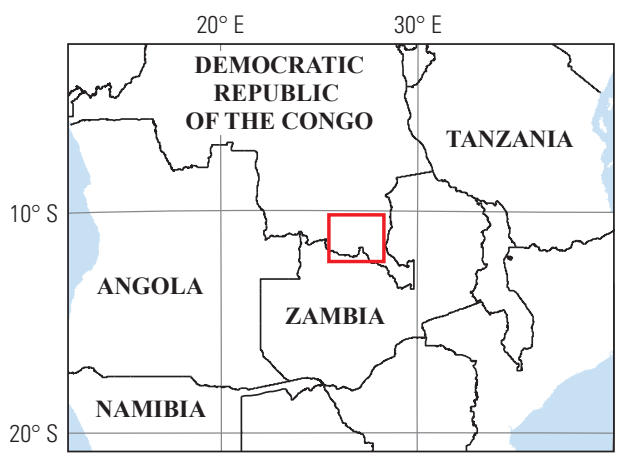




\title{
Plate 233. Sediment-Hosted Stratabound Copper Assessment for Tract 002rfnbCu1001, Ore Shale, Katanga Basin-Democratic Republic of the Congo and Zambia
}

\author{
Descriptive model: \\ Grade and tonnage model: \\ Geologic feature assessed: \\ Number of known deposits:
}

Sediment-hosted stratabound copper-Reduced-facies-nonbrecciated copper subtype model (Cox and others, 2007; Zientek, Hayes, and Hammarstrom, 2013)

Sediment-hosted stratabound copper-Reduced-facies-nonbrecciated copper subtype model (Zientek, Hayes, and Taylor, 2013)

Marine carbonaceous rocks of the Neoproterozoic Ore Shale member of the Kitwe Formation that overlie Neoproterozoic continental clastic rocks of the Mindola Formation, Katanga Basin

9

\section{Selected Resource Assessment Results for Sediment-Hosted Stratabound Copper}

[Assessment depth, 2 kilometers ( $\mathrm{km}) ; \mathrm{km}^{2}$, square kilometer; Mt, millions of metric tons]

\begin{tabular}{ccccccc}
\hline $\begin{array}{c}\text { Date of } \\
\text { assessment }\end{array}$ & $\begin{array}{c}\text { Tract area } \\
\left(\mathbf{k m}^{2}\right)\end{array}$ & $\begin{array}{c}\text { Identified } \\
\text { copper } \\
\text { resources } \\
(\mathbf{M t})\end{array}$ & $\begin{array}{c}\text { Median estimate of } \\
\text { in-place resources } \\
(\mathbf{M t})\end{array}$ & $\begin{array}{c}\text { Mean estimate of } \\
\text { in-place resources } \\
\text { (Mt) }\end{array}$ & $\begin{array}{c}\text { Probability of mean } \\
\text { or greater } \\
\text { (percent) }\end{array}$ & $\begin{array}{c}\text { Probability of } \mathbf{0} \\
\text { in-place resources } \\
\text { (percent) }\end{array}$ \\
\hline 2010 & 890 & 71 & 0.88 & 5.1 & 23 \\
\hline
\end{tabular}

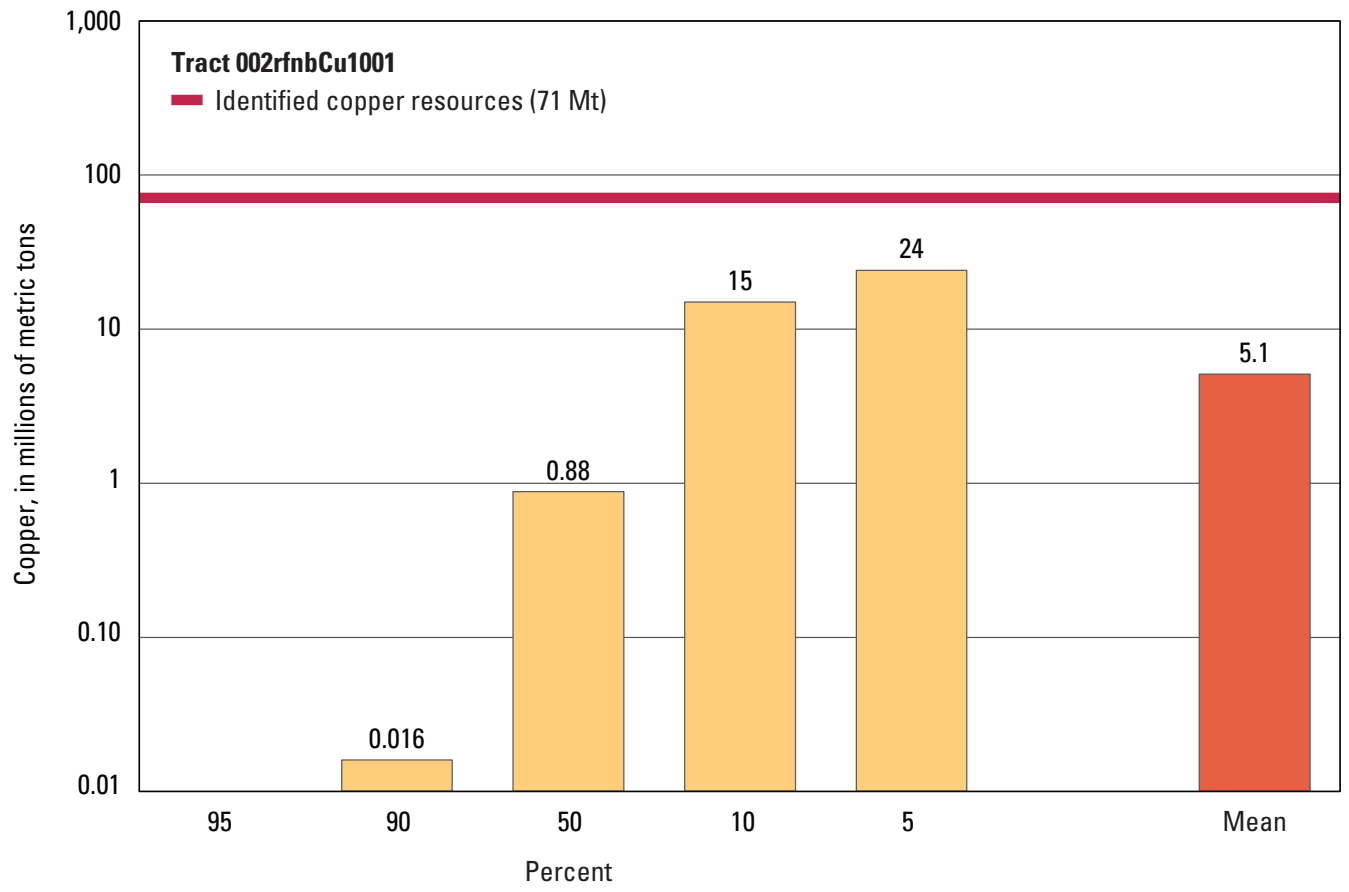

Graph showing the estimated probability distribution of undiscovered copper resources, where each bar represents the minimum amount estimated at the indicated percentage.

\section{Source}

Zientek, Bliss, and others, 2014, Sediment-hosted stratabound copper assessment of the Neoproterozoic Roan Group, Central African Copperbelt, Katanga Basin, Democratic Republic of the Congo and Zambia: U.S. Geological Survey Scientific Investigations Report 2010-5090-T, http://dx.doi.org/10.3133/sir20105090T. 


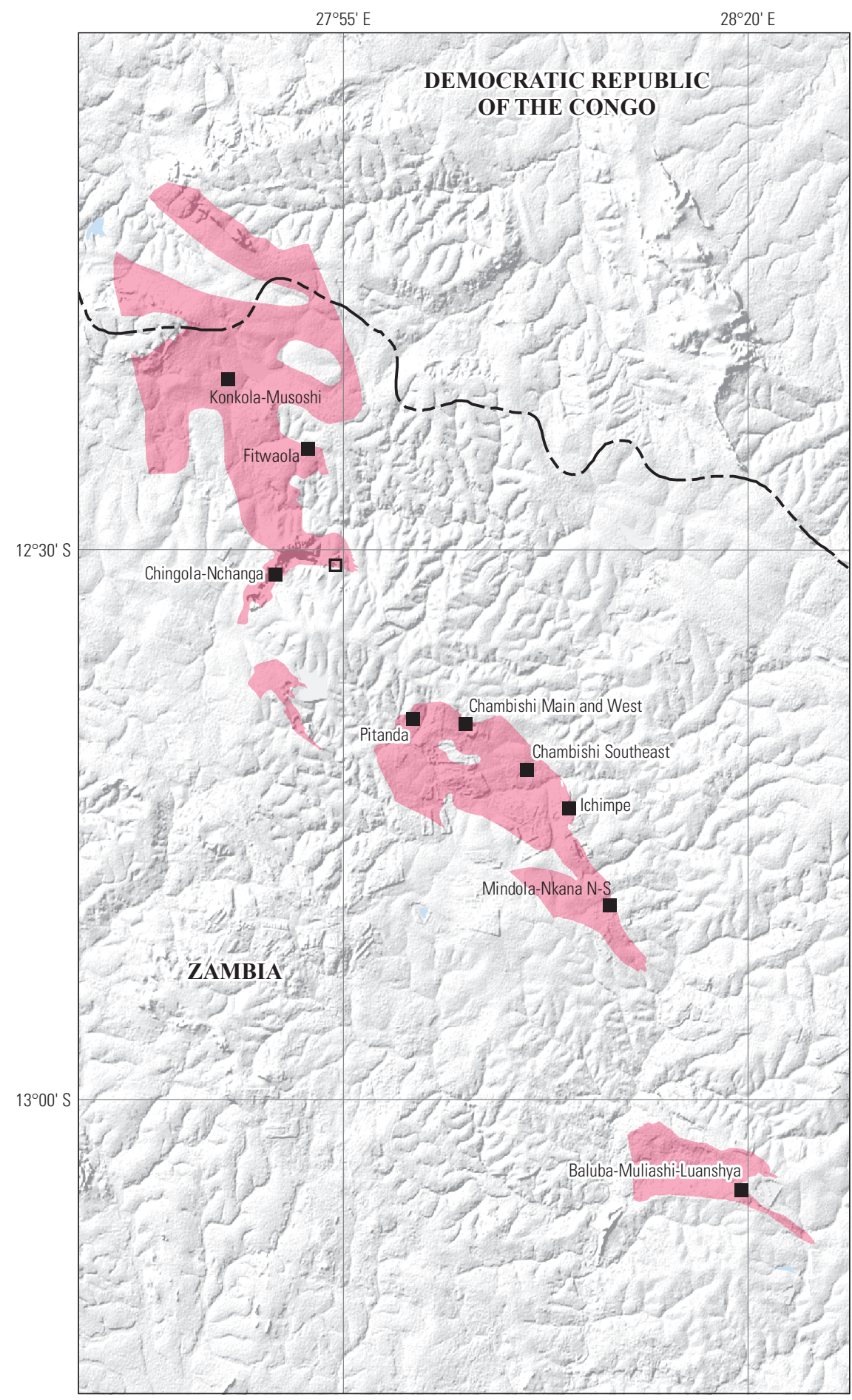

Political boundaries from U.S. Department of State (2009) Shaded relief from ESRI (2008)

Africa Albers Equal-Area Conic projection

Central meridian $28^{\circ}$ E.; latitude of origin $0^{\circ}$

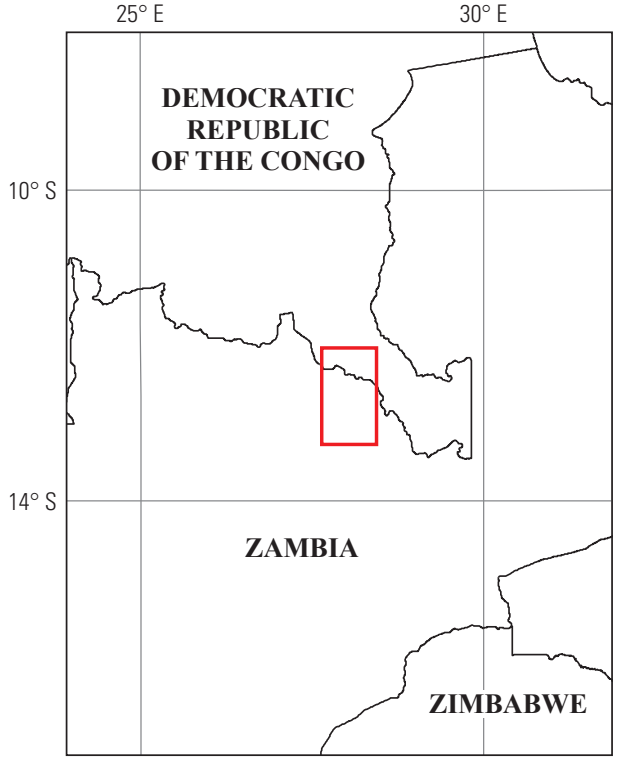

\section{EXPLANATION}

Assessed sediment-hosted copper tract 002 rfnbCu1001

- Sediment-hosted copper deposit

$\square \quad$ Sediment-hosted copper prospect 


\title{
Plate 234. Sediment-Hosted Stratabound Copper Assessment for Tract 002ssCu1002, Roan Arenite, Katanga Basin-Democratic Republic of the Congo and Zambia
}

\author{
Descriptive model: \\ Grade and tonnage model: \\ Geologic feature assessed: \\ Number of known deposits:
}

\begin{abstract}
Sediment-hosted stratabound copper-Sandstone copper subtype model (Cox and others, 2007; Zientek, Hayes, and Hammarstrom, 2013)

Sediment-hosted stratabound copper-Sandstone copper subtype, Roan arenite model (Zientek, Hayes, and Taylor, 2013)

Neoproterozoic coarse-grained siliciclastic rocks in the lower Roan Subgroup near the Kafue Anticline and adjacent basement-cored domes, Katanga Basin
\end{abstract}

20

\section{Selected Resource Assessment Results for Sediment-Hosted Stratabound Copper}

[Assessment depth, 2 kilometers ( $\mathrm{km}) ; \mathrm{km}^{2}$, square kilometer; Mt, millions of metric tons]

\begin{tabular}{ccccccc}
\hline $\begin{array}{c}\text { Date of } \\
\text { assessment }\end{array}$ & $\begin{array}{c}\text { Tract area } \\
\left(\mathbf{k m}^{2}\right)\end{array}$ & $\begin{array}{c}\text { Identified } \\
\text { copper } \\
\text { resources } \\
(\mathbf{M t})\end{array}$ & $\begin{array}{c}\text { Median estimate of } \\
\text { in-place resources } \\
(\mathbf{M t})\end{array}$ & $\begin{array}{c}\text { Mean estimate of } \\
\text { in-place resources } \\
\text { (Mt) }\end{array}$ & $\begin{array}{c}\text { Probability of mean } \\
\text { or greater } \\
\text { (percent) }\end{array}$ & $\begin{array}{c}\text { Probability of } \mathbf{0} \\
\text { in-place resources } \\
\text { (percent) }\end{array}$ \\
\hline 2010 & 13,060 & 16 & 6.4 & 8.4 & 39 \\
\hline
\end{tabular}

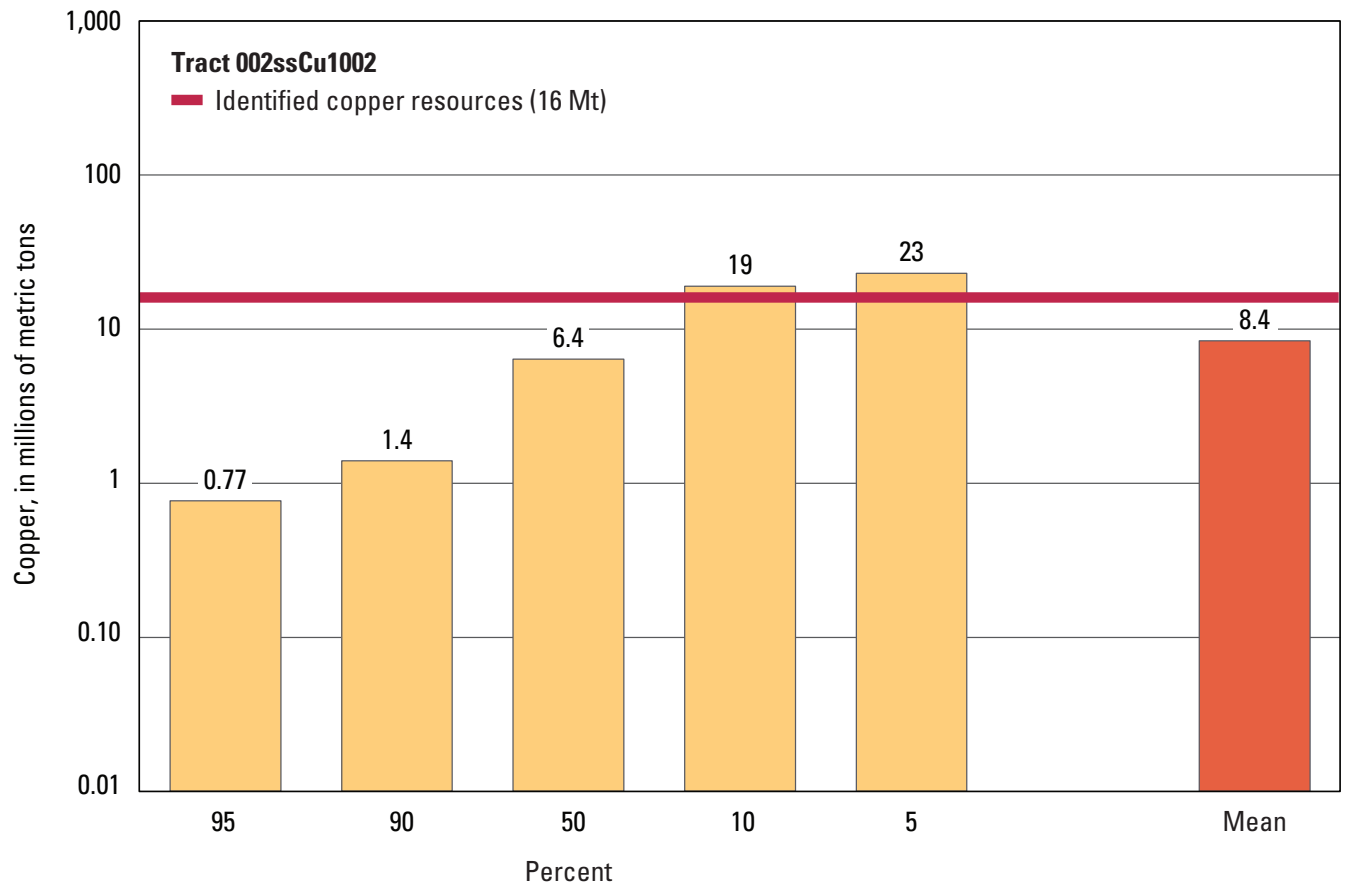

Graph showing the estimated probability distribution of undiscovered copper resources, where each bar represents the minimum amount estimated at the indicated percentage.

\section{Source}

Zientek, Bliss, and others, 2014, Sediment-hosted stratabound copper assessment of the Neoproterozoic Roan Group, Central African Copperbelt, Katanga Basin, Democratic Republic of the Congo and Zambia: U.S. Geological Survey Scientific Investigations Report 2010-5090-T, http://dx.doi.org/10.3133/sir20105090T. 


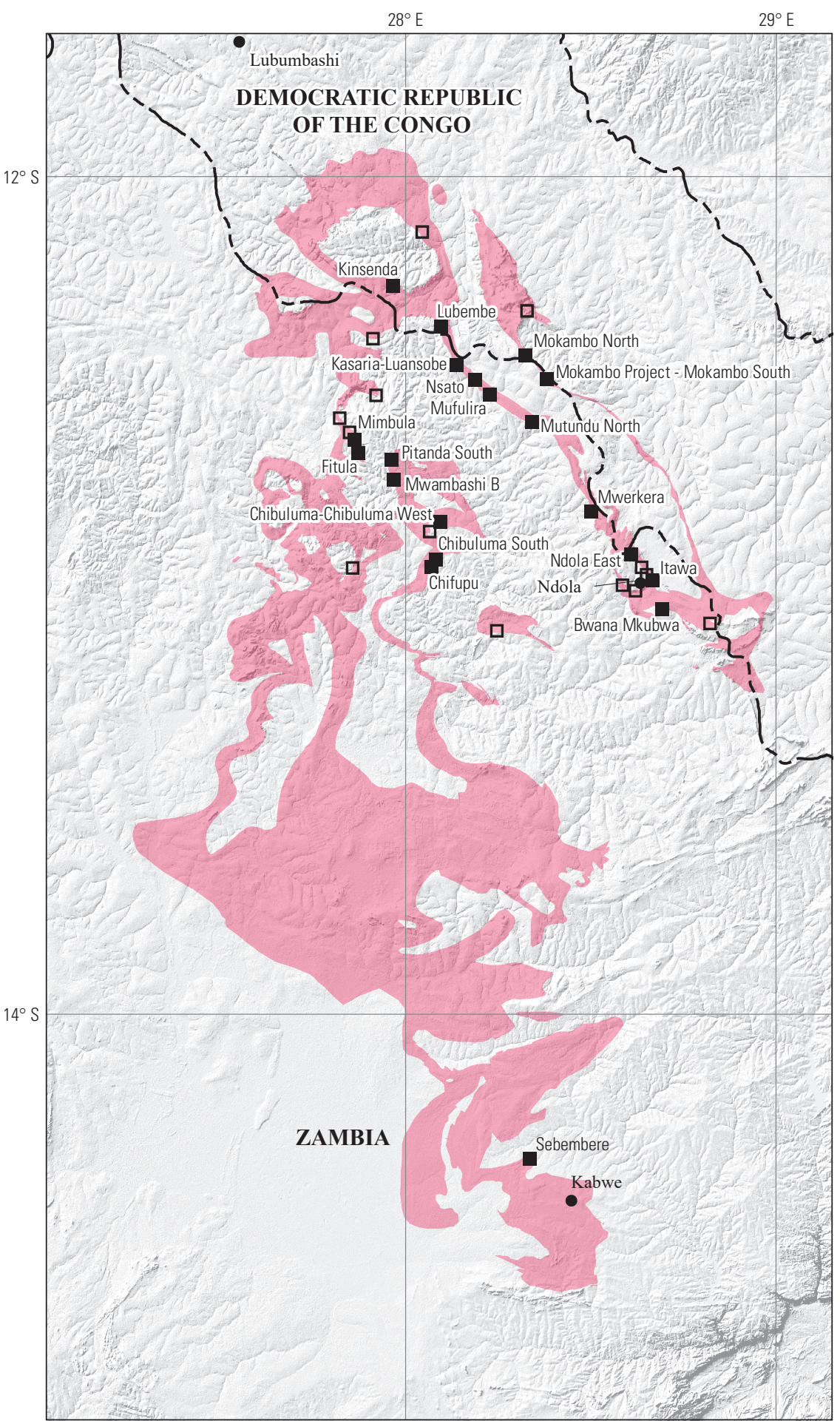

Political boundaries from U.S. Department of State (2009) Shaded relief from ESRI (2008)

Africa Albers Equal-Area Conic projection

Central meridian $28^{\circ} \mathrm{E}$.; latitude of origin $0^{\circ}$

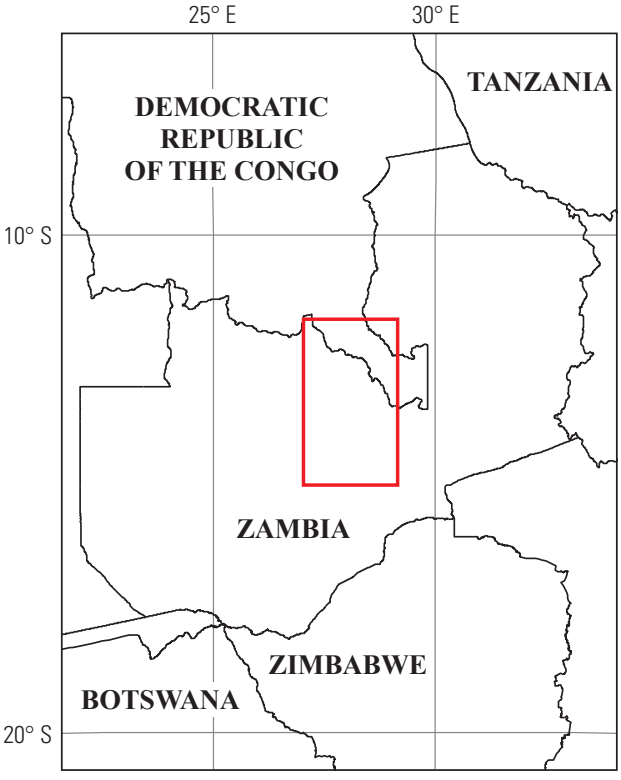

\section{EXPLANATION}

Assessed sediment-hosted copper tract 002 ssCu1002

Sediment-hosted copper deposit

$\square \quad$ Sediment-hosted copper prospect 


\section{Plate 235. Sediment-Hosted Stratabound Copper Assessment for Tract 002rfCu2002, Northwest Botswana Rift—Botswana and Namibia}

Descriptive model:

Geologic feature assessed:

Number of known deposits:
Sediment-hosted stratabound copper-Reduced-facies copper subtype model (Cox and others, 2007; Zientek, Hayes, and Hammarstrom, 2013)

Marine carbonaceous rocks of the Neoproterozoic Klein Aub and D'Kar Formations, Northwest Botswana Rift, which includes the Kalahari Copperbelt

18

\section{Selected Resource Assessment Results for Sediment-Hosted Stratabound Copper}

[Assessment depth, 0 kilometer $(\mathrm{km}) ; \mathrm{km}^{2}$, square kilometer; Mt, millions of metric tons]

\begin{tabular}{|c|c|c|c|c|}
\hline \multirow[b]{2}{*}{$\begin{array}{c}\text { Date of } \\
\text { assessment }\end{array}$} & \multirow[b]{2}{*}{$\begin{array}{c}\text { Tract area } \\
\quad\left(\mathbf{k m}^{2}\right)\end{array}$} & \multirow{2}{*}{$\begin{array}{l}\text { Identified } \\
\text { copper } \\
\text { resources } \\
\text { (Mt) }\end{array}$} & \multicolumn{2}{|c|}{ Qualitative assessment ranking } \\
\hline & & & $\begin{array}{c}\text { Analytic hierarchy process- } \\
\text { Alternative utility* } \\
\text { (percent) }\end{array}$ & Overall rank \\
\hline 2012 & 135,005 & 4.2 & 14.7 & 1 st of 10 areas \\
\hline
\end{tabular}

"Alternative utility is a numerical weight derived from evaluation of three assessment criteria.

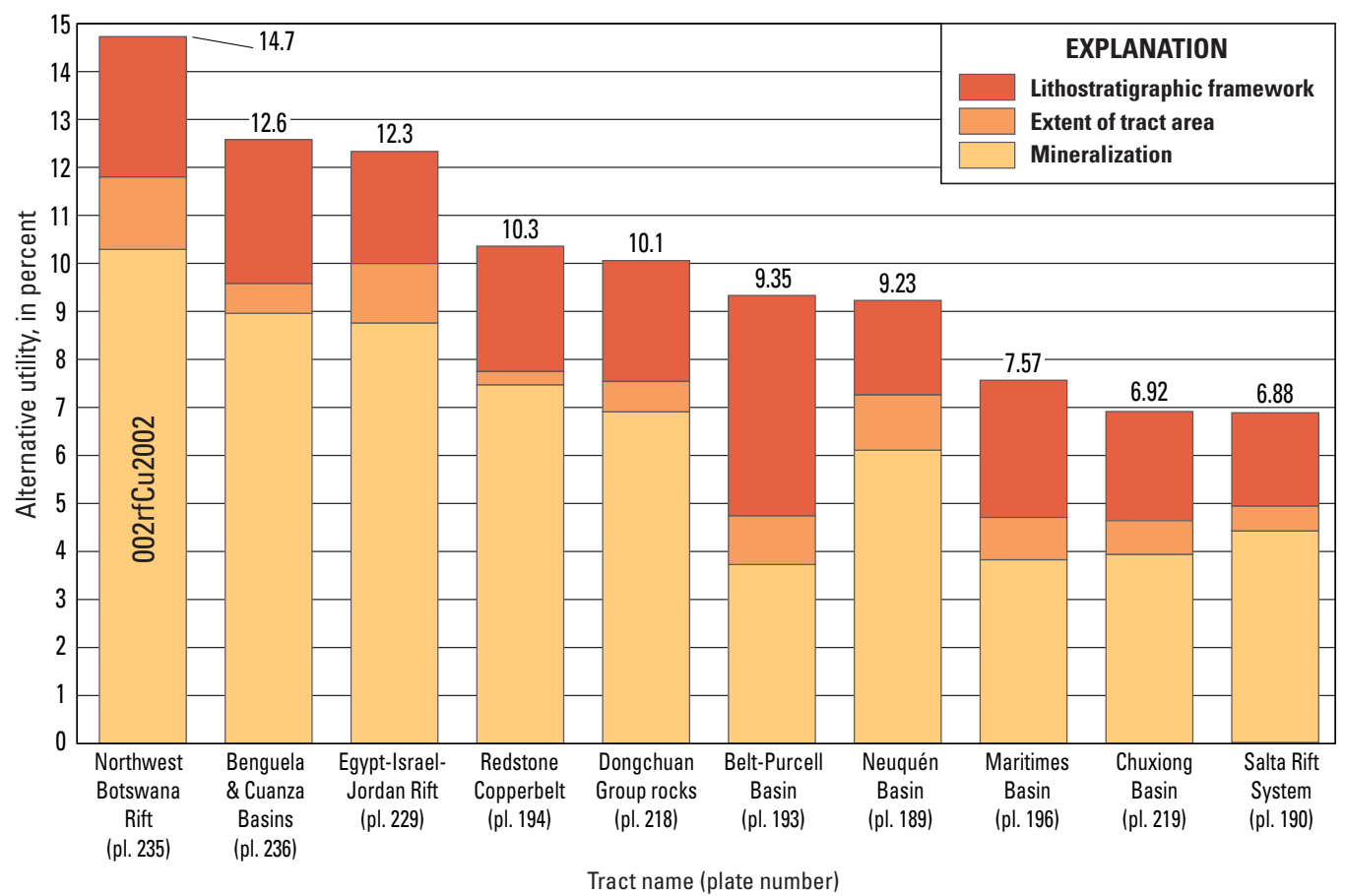

Graph showing qualitative ranking of basins determined by the analytic hierarchy process (AHP). Alternative utility is the overall score derived from the AHP method.

\section{Source}

Zientek, Wintzer, and others, 2015, Qualitative assessment of selected areas of the world for undiscovered sediment-hosted stratabound copper deposits: U.S. Geological Survey Scientific Investigations Report 2010-5090-Y, http://dx.doi.org/10.3133/sir20105090Y. 


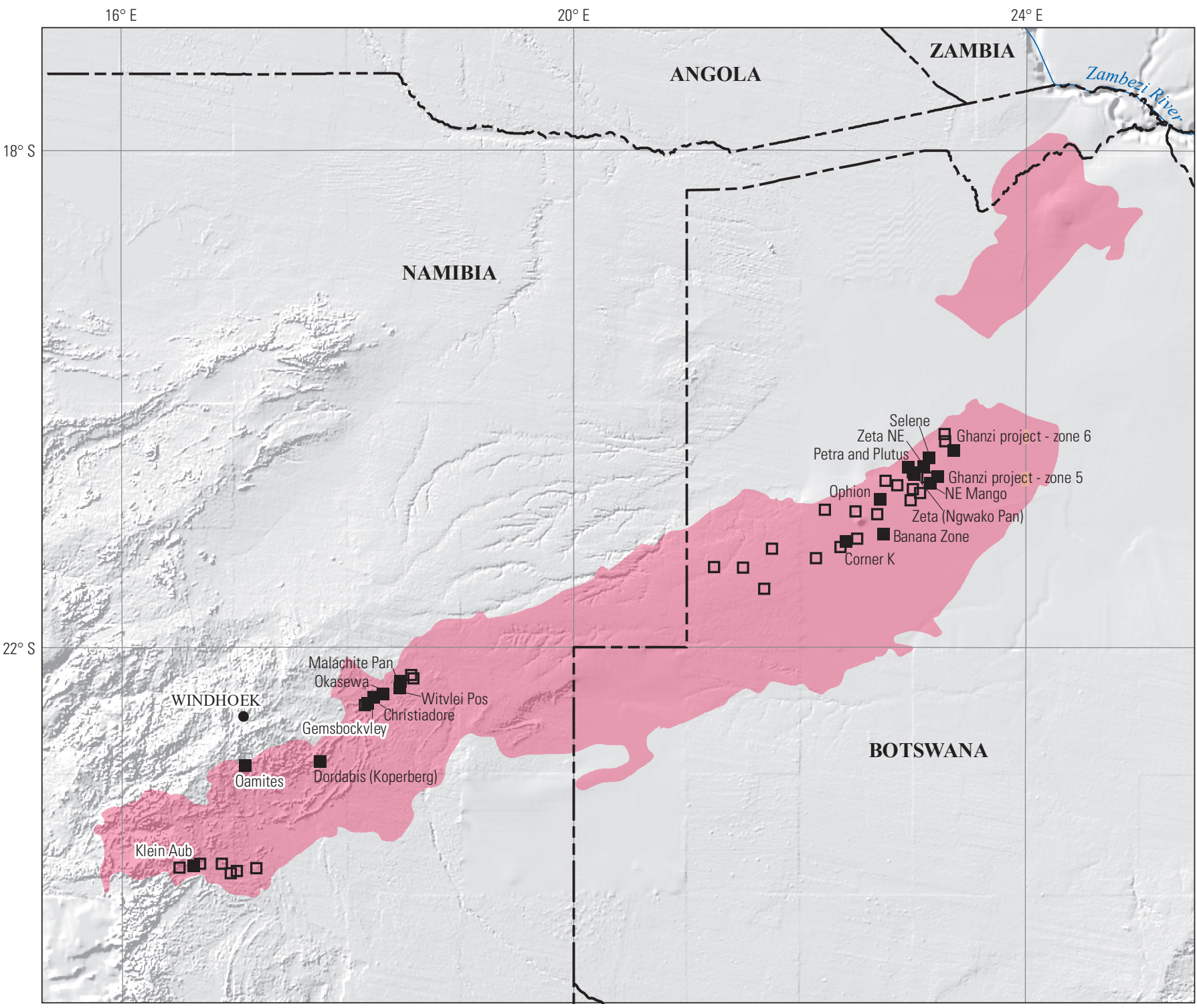

Political boundaries from U.S. Department of State (2009)

Shaded relief from Earth Resources Observation and Science (EROS) Center (2011)

Africa Albers Equal-Area Conic projection

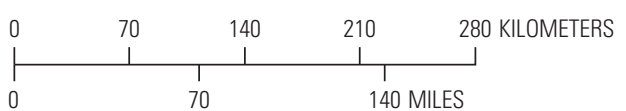

Central meridian $20^{\circ}$ E.; latitude of origin $0^{\circ}$

\section{EXPLANATION}

Assessed sediment-hosted copper tract 002rfCu2002

Sediment-hosted copper deposit

ㅁ Sediment-hosted copper prospect

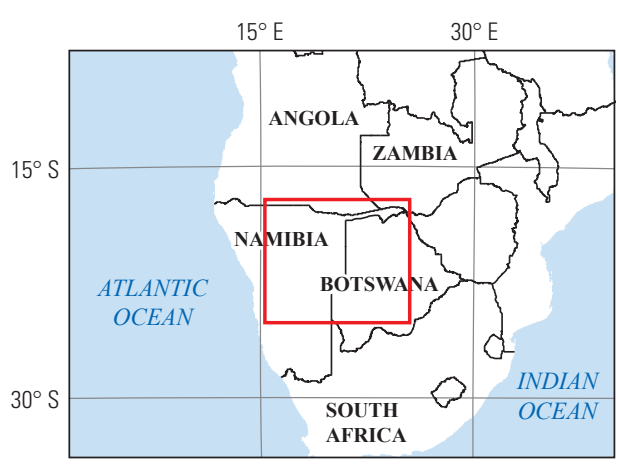




\title{
Plate 236. Sediment-Hosted Stratabound Copper Assessment for Tract 002rfCu2000, Benguela and Cuanza Basins-Angola
}

\author{
Descriptive model: \\ Geologic feature assessed: \\ Number of known deposits:
}

Sediment-hosted stratabound copper-Reduced-facies copper subtype model (Cox and others, 2007; Zientek, Hayes, and Hammarstrom, 2013)

Lower Cretaceous Cuvo Formation of the Benguela and Cuanza Basins

2

\section{Selected Resource Assessment Results for Sediment-Hosted Stratabound Copper}

[Assessment depth, 0 kilometer ( $\mathrm{km}) ; \mathrm{km}^{2}$, square kilometer; Mt, millions of metric tons]

\begin{tabular}{ccccc}
\hline $\begin{array}{c}\text { Date of } \\
\text { assessment }\end{array}$ & $\begin{array}{c}\text { Tract area } \\
\left.\mathbf{( k m}^{2}\right)\end{array}$ & $\begin{array}{c}\text { Identified } \\
\text { copper } \\
\text { resources } \\
(\mathbf{M t})\end{array}$ & $\begin{array}{c}\text { Analytic hierarchy process- } \\
\text { Alternative utility* } \\
\text { (percent) }\end{array}$ & Overall rank \\
\hline 2012 & 7,626 & 0.15 & 12.6 & 2d of 10 areas \\
\hline
\end{tabular}

*Alternative utility is a numerical weight derived from evaluation of three assessment criteria.

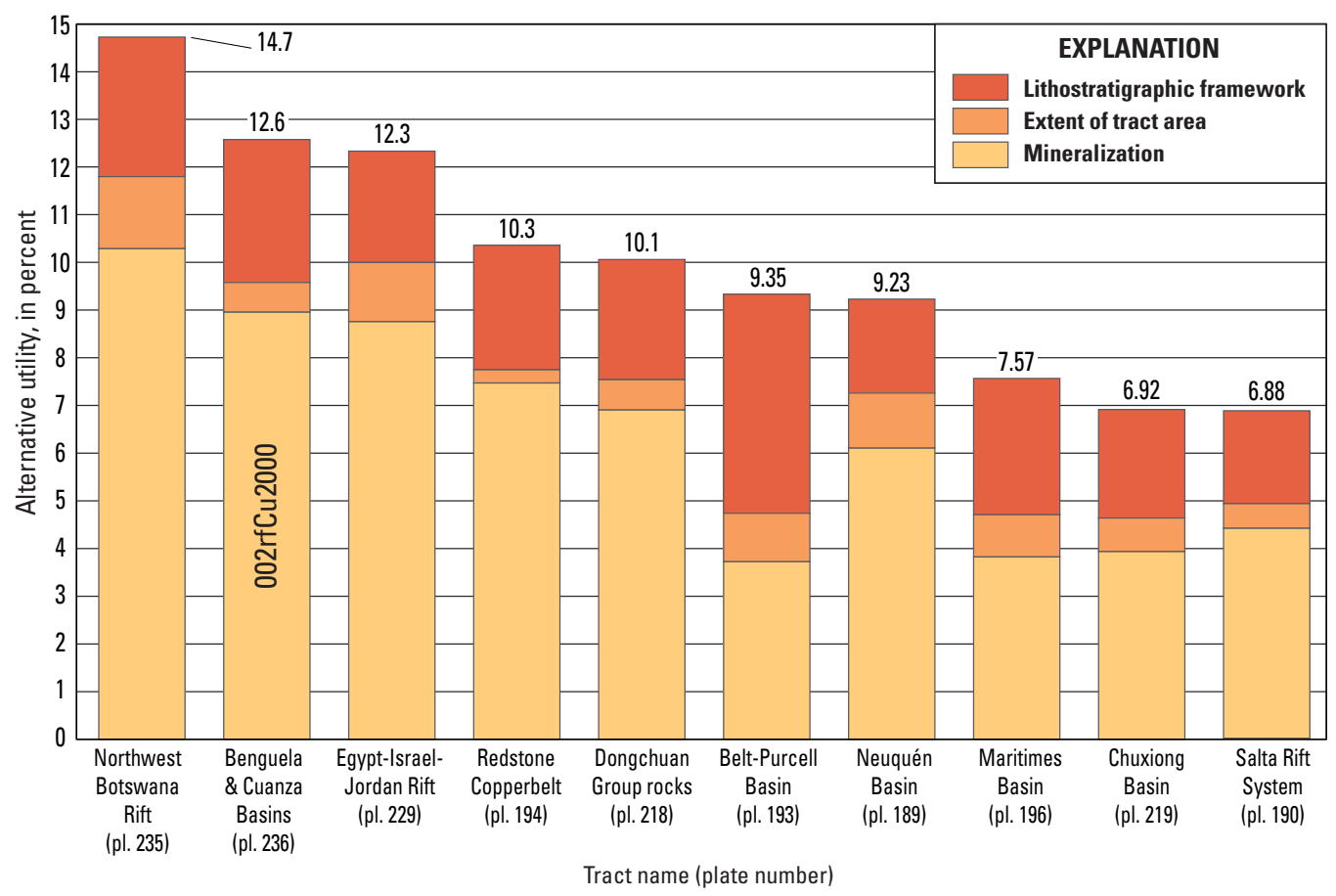

Graph showing qualitative ranking of basins determined by the analytic hierarchy process (AHP). Alternative utility is the overall score derived from the AHP method.

\section{Source}

Zientek, Wintzer, and others, 2015, Qualitative assessment of selected areas of the world for undiscovered sediment-hosted stratabound copper deposits: U.S. Geological Survey Scientific Investigations Report 2010-5090-Y, http://dx.doi.org/10.3133/sir20105090Y. 

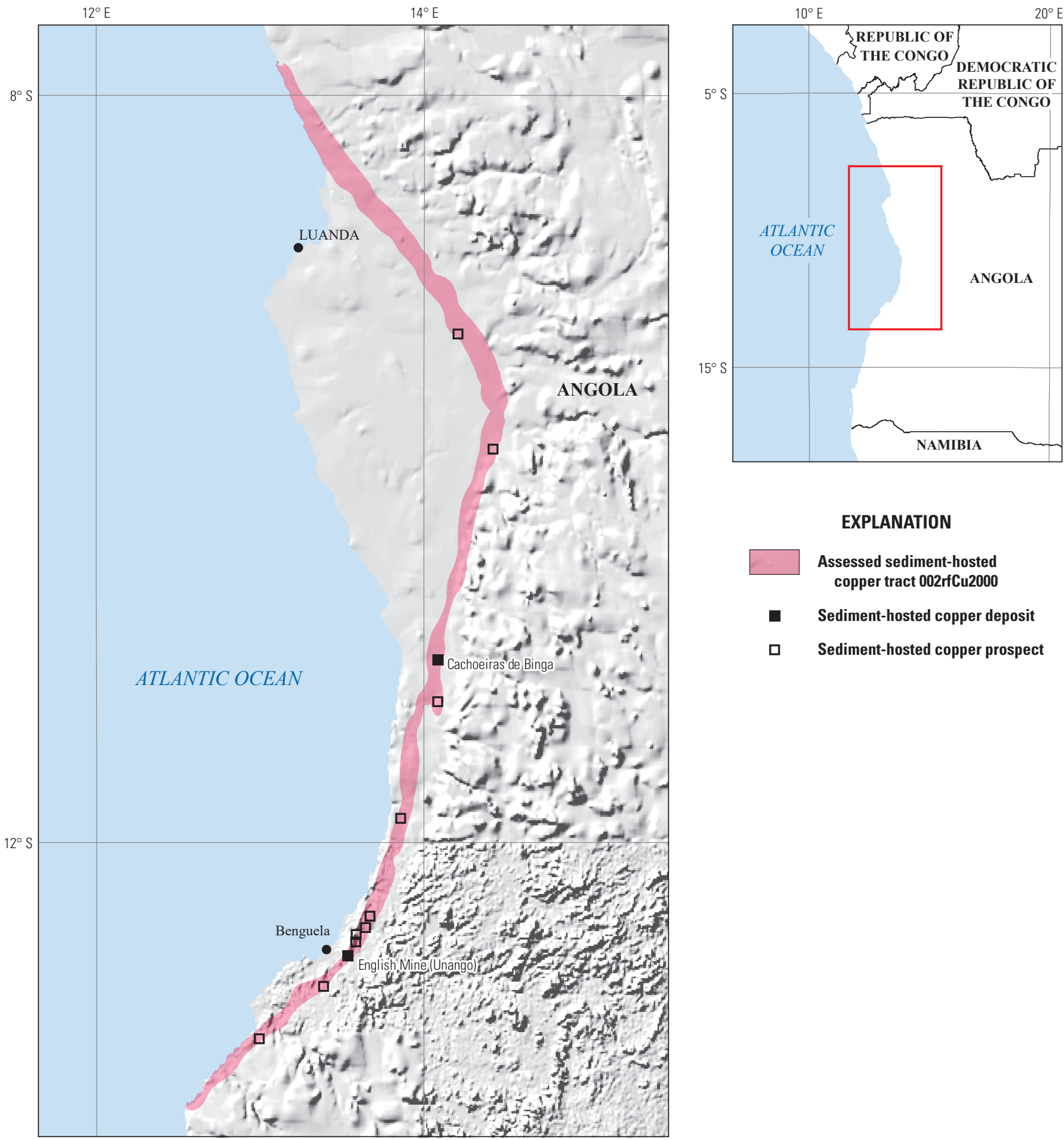

\section{EXPLANATION}

\section{Assessed sediment-hosted} copper tract $002 \mathrm{rfCu} 2000$

- Sediment-hosted copper deposit

ㅁ Sediment-hosted copper prospect

Political boundaries from U.S. Department of State (2009) Shaded relief from Earth Resources Observation and Science (EROS) Center (2011)

Africa Albers Equal-Area Conic projection Central meridian $13^{\circ} \mathrm{E}$.; latitude of origin $0^{\circ}$

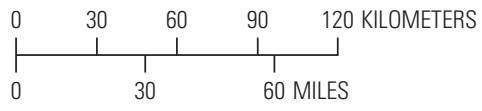




